

\section{Qx

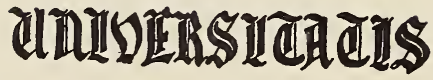

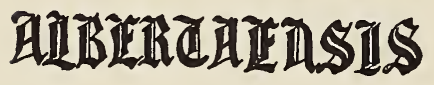

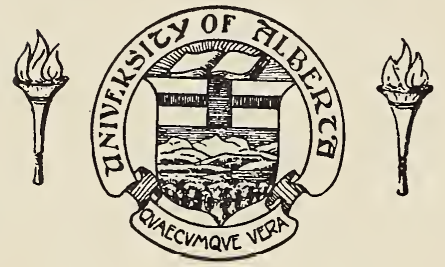


.L COMSTOCK, B. S.

niversity; Author of How to Keep Bees, and ator and Engraver for Manual for the sects and for Insect Life

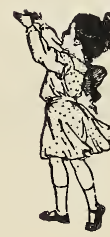

Whe

NTH EDITION

WART, LTD.

CANADA 


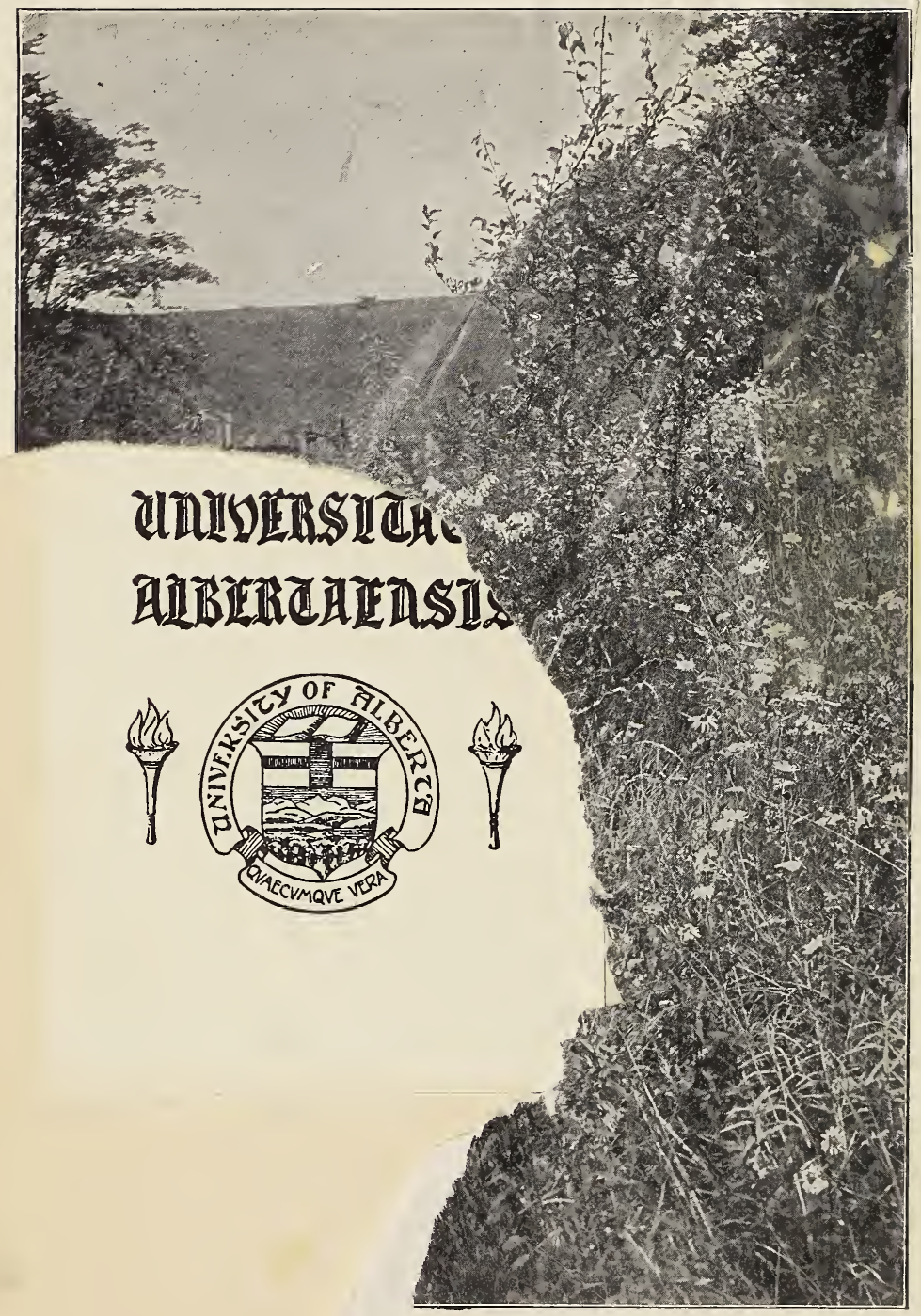




\section{HANDBOOK OF}

\section{NATURE-ST UDY}

For Teachers and Parents

Based on the Cornell Nature-Study Leaflets, with Much Additional Material and Many New Illustrations

By ANNA BOTSFORD COMSTOCK, B. S. Professor in Nature-Study in Cornell University; Author of How to Keep Bees, and Ways of the Six-Footed; Illustrator and Engraver for Manual for the Study of Insects and for Insect Life

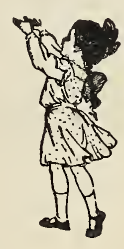

FIFTEENTH EDITION

MCCLELLAND AND STEWART, LTD. TORONTO

CANADA 
COPYRIGHT, IỌII

BY ANNA BOTSFORD COMSTOCE

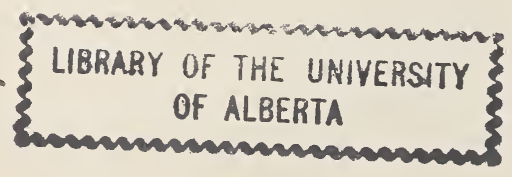

Printed in the U.S. A. 


\section{LIBERTY HYDE BAILEY}

UNDER WHOSE WISE, STAUNCH AND INSPIRING LEADERSHIP THE NATURE-STUDY WORK AT CORNELL UNIVERSITY

HAS BEEN ACCOMPLISHED

AND TO MY CO-WORKER

\section{JOHN WALTON SPENCER}

WHOSE COURAGE, RESOURCEFULNESS AND UNTIRTXY ZEAL WERE POTENT FACTORS IN THE SUCCESS

OF THE CAUSE " :

THIS BOØK 1S, OEDICATED 
Digitized by the Internet Archive in 2016 


\section{PREFACE}

The Cornell University Nature-Study propaganda was essentially an agricultural movement in its inception and its aims; it was inaugurated as a direct aid to better methods of agriculture in New York State. During the years of agricultural depression $189 \mathrm{I}-1893$, the Charities of New York City found it necessary to help many people who had come from the rural districts-a condition hitherto unknown. The philanthropists managing the Association for Improving the Condition of the Poor asked, "What is the matter with the land of New York State that it cannot support its own population?" A conference was called to consider the situation to which many people from different parts of the State were invited; among them was the author of this book, who little realized that in attending that meeting the whole trend of her activities would be thereby changed. Mr. George T. Powell, who had been a most efficient Director of Farmers' Institutes of New York State was invited to the conference as an expert to explain conditions and give advice as to remedies. The situation seemed so serious that a Committee for the Promotion of Agriculture in New York State was appointed. Of this committee the Honorable Abram S. Hewitt was Chairman, Mr. R. Fulton Cutting, Treasurer, Mr. Wm. H. Tolman, Secretary. The other members were Walter L. Suydam, Wm. E. Dodge, Jacob H. Schiff, George T. Powell, G. Howard Davidson, Howard Townsend, Professor I. P. Roberts, C. MicNamee, Mrs. J. R. Lowell, and Mrs. A. B. Comstock. Mr. George T. Powell was made Director of the Department of Agricultural Education.

At the first meeting of this committee Mr. Powell made a strong plea for interesting the children of the country in farming as a remedial measure, and maintained that the first step toward agriculture was nature-study. It had been Mr. Powell's custom to give simple agricultural and naturestudy instruction to the school children of every town where he was conducting a farmers' institute, and his opinion was, therefore, based upon experience. The committee desired to see for itself the value of this idea, and experimental work was suggested, using the schools of Westchester County as a laboratory. Mr. R. Fulton Cutting generously furnished the funds for this experiment, and work was done that year in the Westchester schools, which satisfied the committee of the soundness of the project.

The committee naturally concluded that such a fundamental movement must be a public rather than a private enterprise; and Mr. Frederick Nixon then Chairman of the Ways and Means Committee of the Assembly, was invited to meet with the committee at Mr. Hewitt's home. Mr. Nixon had been from the beginning of his public career deeply interested in improving the farming conditions of the State. In $x 894$, it was through 
his influence and the support given him by the Chautauqua Horticultural Society under the leadership of Mr. John W. Spencer, that an appropriation had been given to Cornell University for promoting the horticultural interests of the western counties of the State. In addition to other work done through this appropriation, horticultural schools were conducted under the direction of Professor L. H. Bailey with the aid of other Cornell instructors and especially of Mr. E. G. Lodeman; these schools had proved to be most useful and were well attended. Therefore, Mr. Nixon was openminded toward an educational movement. He listened to the plan of the committee and after due consideration declared that if this new measure would surely help the farmers of the State, the money would be forthcoming. The committee unanimously decided that if an appropriation were made for this purpose it should be given to the Cornell College of Agriculture; and that year eight thousand dollars was added to the Cornell University Fund, for Extension Teaching and inaugurating this work. The work was begun under Professor I. P. Roberts; after one year Professor Roberts placed it under the supervision of Professor L. H. Bailey, who for the fifteen years since has been the inspiring leader of the movement, as well as the official head.

In I896, Mr. John W. Spencer, a fruit grower in Chautauqua County, became identified with the enterprise; he had lived in rural communities and he knew their needs. He it was who first saw clearly that the first step in the great work was to help the teacher through simply written leaflets; and later he originated the great plan of organizing the children in the schools of the State into Junior Naturalists Clubs, which developed a remarkable phase of the movement. The members of these clubs paid their dues by writing letters about their nature observations to Mr. Spencer, who speedily became their beloved "Uncle John;" a button and charter were given for continued and earnest work. Some years, 30,000 children were thus brought into direct communication with Cornell University through Mr. Spencer. A monthly leaflet for Junior Naturalists followed; and it was to help in this enterprise that Miss Alice G. McCloskey, the able Editor of the present Rural School Leaflet, was brought into the work. Later, Mr. Spencer organized the children's garden movement by forming the children of the State into junior gardeners; at one time he had 25,000 school pupils working in gardens and reporting to him.

In I899, Mrs. Mary Rogers Miller, who had proven a most efficient teacher when representing Cornell nature-study in the State Teachers' Institutes, planned and started the Home Nature-Study Course Leaflets for the purpose of helping the teachers by correspondence, a work which fell to the author in 1903 when Mrs. Miller was called to other fields.

For the many years during which New York State has intrusted this important work to Cornell University, the teaching of nature-study has 
gone steadily on in the University, in teachers' institutes, in State summer schools, through various publications and in correspondence courses. Many have assisted in this work, notably Dr. W. C. Thro, Dr. A. A. Allen, and Miss Ada Georgia. The New York Education Department with Charles R. Skinner as Commissioner of Education and Dr. Isaac Stout as the Director of Teachers' Institutes co-operated heartily with the movement from the first. Later with the co-operation of Dr. Andrew Draper, as Commissioner of Education, many of the Cornell leaflets have been written with the special purpose of aiding in carrying out the New York State Syllabus in Nature-Study and Agriculture.

The leaflets upon which this volume is based were published in the Home Nature-Study Course during the years I903-I9 I I, in limited editions and were soon out of print. It is to make these lessons available to the general public that this volume has been compiled. While the subject matter of the lessons herein given is essentially the same as in the leaflets, the lessons have all been rewritten for the sake of consistency, and many new lessons have been added to bridge gaps and make a coherent whole.

Because the lessons were written during a period of so many years, each lesson has been prepared as if it were the only one, and without reference to others. If there is any uniformity of plan in the lessons, it is due to the inherent qualities of the subjects, and not to a type plan in the mind of the writer; for, in her opinion, each subject should be treated individually in nature-study; and in her long experience as a nature-study teacher she has never been able to give a lesson twice alike on a certain topic or secure exactly the same results twice in succession. It should also be stated that it is not because the author undervalues physics nature-study that it has been left out of these lessons, but because her own work has been always along biological lines.

The reason why nature-study has not yet accomplished its mission, as thought-core for much of the required work in our public schools, is that the teachers are as a whole untrained in the subject. The children are eager for it, unless it is spoiled in the teaching; and whenever we find a teacher with an understanding of out-of-door life and a love for it, there we find nature-study in the school is an inspiration and a joy to pupils and teacher. It is because of the author's sympathy with the untrained teacher and her full comprehension of her difficulties and helplessness that this book has been written. These difficulties are chiefly three-fold: The teacher does not know what there is to see in studying a plant or animal; she knows little of the literature that might help her; and because she knows so little of the subject, she has no interest in giving a lesson about it. As a matter of fact, the literature concerning our common animals and plants is so scattered that a teacher would need a large library and almost unlimiter time to prepare lessons for an extended nature-study course. 
The writer's special work for fifteen years in Extension teaching has been the helping of the untrained teacher through personal instruction and through leaflets. Many methods were tried and finally there was evolved the method followed in this volume: All the facts available and pertinent concerning each topic have been assembled in the "Teacher's story" to make her acquainted with the subject; this is followed by an outline for observation on the part of the pupils while studying the object. It would seem that with the teacher's story before the eyes of the teacher, and the subject of the lesson before the eyes of the pupils with a number of questions leading them to see the essential characteristics of the object, there should result a wider knowledge of nature than is given in this or any other book.

That the lessons are given in a very informal manner, and that the style of writing is often colloquial, result from the fact that the leaflets upon which the book is based were written for a correspondence course in which the communications were naturally informal and chatty. That the book is meant for those untrained in science accounts for the rather loose terminology employed; as, for instance, the use of the word seed in the popular sense whether it be a drupe, an akene, or other form of fruit; or the use of the word pod for almost any seed envelope, and many like instances. Also, it is very likely, that in teaching quite incidentally the rudiments of the principles of evolution, the results may often seem to be confused with an idea of purpose, which is quite unscientific. But let the critic labor for fifteen years to interest the untrained adult mind in nature's ways, before he casts any stones! And it should be always borne in mind that if the author has not dipped deep in the wells of science, she has used only a child's cup.

For many years requests have been frequent from parents who have wished to give their children nature interests during vacations in the country. They have been borne in mind in planning this volume; the lessons are especially fitted for field work, even though schoolroom methods are so often suggested.

The author feels apologetic that the book is so large. However, it does not contain more than any intelligent country child of twelve should know of his environment; things that he should know naturally and without effort, although it might take him half his life-time to learn so much if he should not begin before the age of twenty. That there are inconsistencies, inaccuracies, and even blunders in the volume is quite inevitable. The only excuse to be offered is that, if through its use, the children of our land learn early to read nature's truths with their own eyes, it will matter little to them what is written in books.

The author wishes to make grateful acknowledgment to the following people: To Professor Wilford M. Wilson for his chapter on the weather; to Miss Mary E. Hill for the lessons on mould, bacteria, the minerals, and reading the weather maps; to Miss Catherine Straith for the lessons on 
the earthworm and the soil; to Miss Ada Georgia for much valuable assistance in preparing the original leaflets on which these lessons are based; to Dean L. H. Bailey and to Dr. David S. Jordan for permission to quote their writings; to Mr. John W. Spencer for the use of his story on the movements of the sun; to Dr. Grove Karl Gilbert, Dr. A. C. Gill, Dr. Benjamin Duggar, Professor S. H. Gage and Dr. J. G. Needham for reading and criticizing parts of the manuscript; to Miss Eliza Tonks for reading the proof; to the Director of the College of Agriculture for use of the engravings made for the original leaflets; to Miss Martha Van Rensselaer for the use of many pictures from Boys and Girls; to Professor Cyrus Crosby, and to Messrs. J. T. Lloyd, A. A. Allen and R. Matheson for the use of their personal photographs; to the U. S. Geological Survey and the U. S. Forest Service for the use of photographs; to Louis A. Fuertes for drawings of birds; to Houghton, Mifflin \& Company for the use of the poems of Lowell, Harte and Larcom, and various extracts from Burroughs and Thoreau; to Small, Maynard \& Company and to John Lane \& Company for the use of poems of John T. Babb; to Doubleday, Page \& Company for the use of pictures of birds and flowers; and to the American Book Company for the use of electrotypes of dragon-flies and astronomy. Especially thanks are extended to Miss Anna C. Stryke for numerous drawings, including most of the initials 


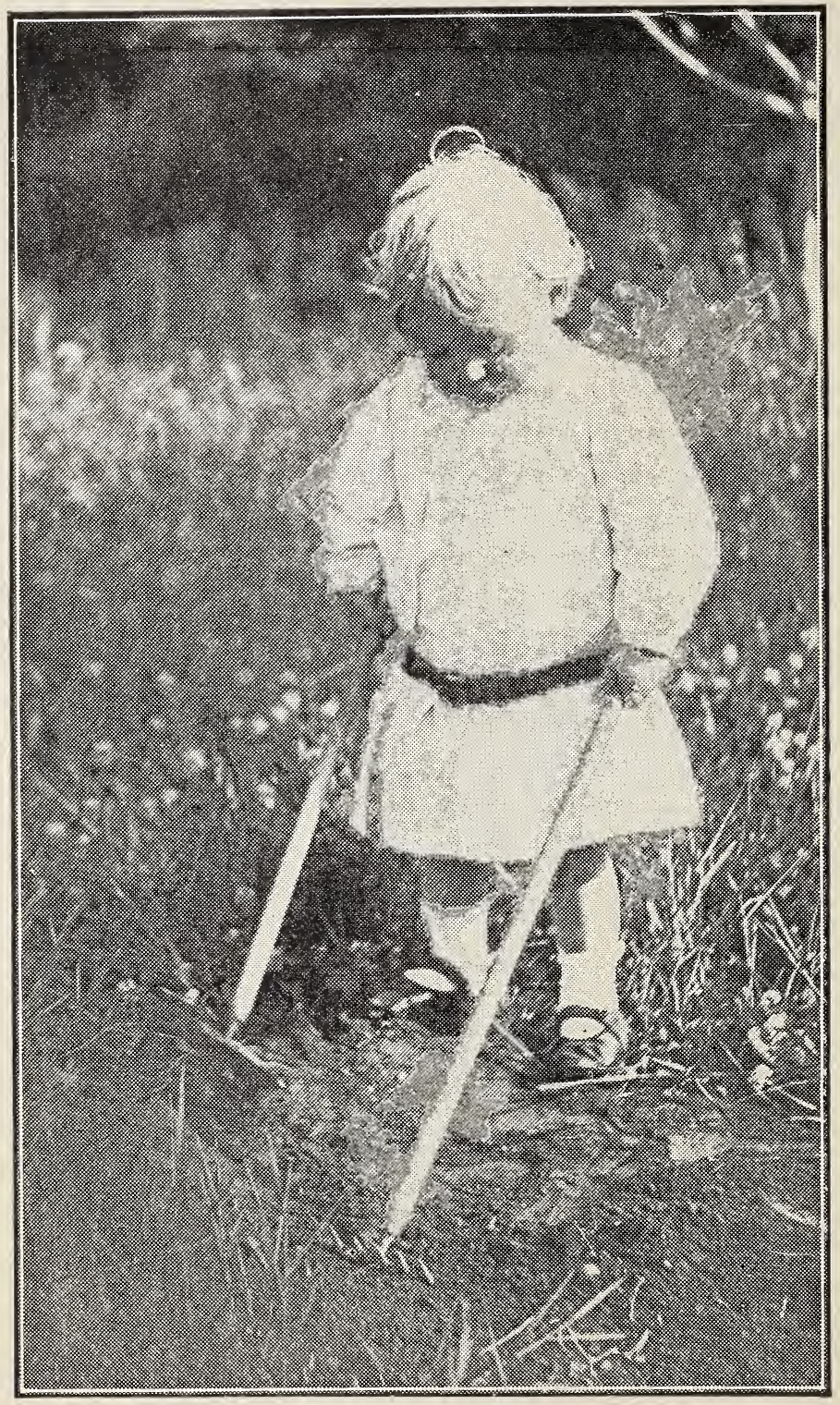




\title{
TABLE OF CONTENTS
}

\author{
PART I \\ The Teaching of Nature-Study
}

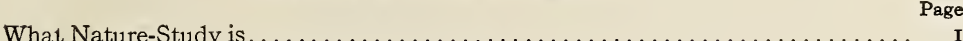

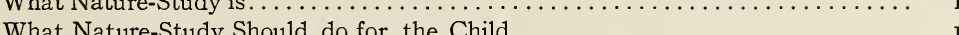

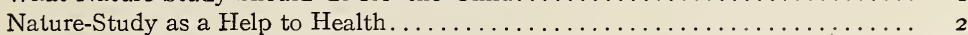

What Nature-Study Should do for the Teacher..................... 2

When and Why the Teacher Should say "I do not know!"'............... 3

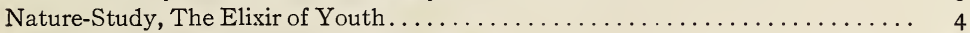

Nature-Study as a Help in School Disci $r$ ine....................... 4

The Relation of Nature-Study to Science.......................... 5

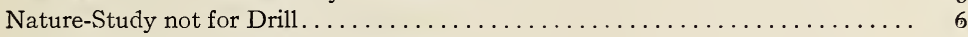

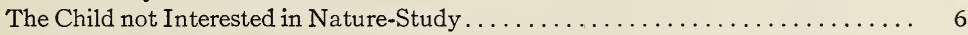

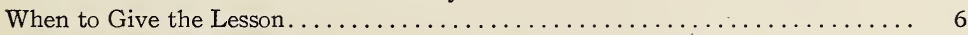

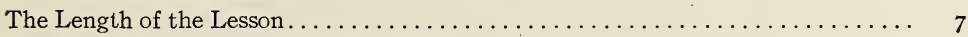

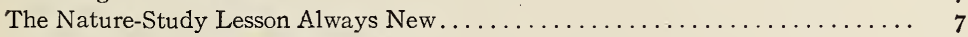

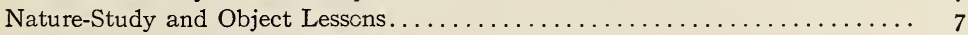

Nature-Study in the Schoolroom $\ldots \ldots \ldots \ldots \ldots \ldots \ldots \ldots \ldots \ldots \ldots \ldots \ldots, 8$

Nature-Study and Museum Specimens .......................... 8

The Lens, Microscope and Field-glass as Felps..................... 9

Use of Pictures, Charts and Blackboard Drawings.................... Iо

The Use of Scientific Names................................ Io

The Story as a Supplement to the Nature-Study Lesson ................. Io

The Nature-Study Attitude toward Life and Death $\ldots \ldots \ldots \ldots \ldots \ldots \ldots \ldots$ I I

Should the Nature-Study Teacher Teach How to Destroy Life? .............. I3

The Field Note-book $\ldots \ldots \ldots \ldots \ldots \ldots \ldots \ldots \ldots \ldots \ldots \ldots \ldots \ldots \ldots \ldots \ldots \ldots \ldots, \ldots \ldots$

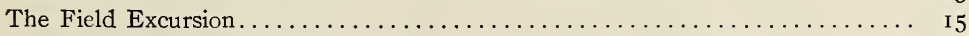

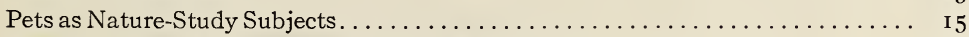

The Correlation of Nature-Study with Language Work ................. I6

The Correlation of Nature-Study with Drawing................... I7

The Correlation of Nature-Study with Geography $\ldots \ldots \ldots \ldots \ldots \ldots \ldots \ldots$ I 8

The Correlation of Nature-Study with History $\ldots \ldots \ldots \ldots \ldots \ldots \ldots \ldots \ldots \ldots \ldots \ldots \ldots \ldots$

The Correlation of Nature-Study with Arithmetic.................... I9

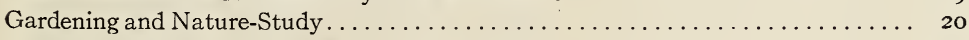

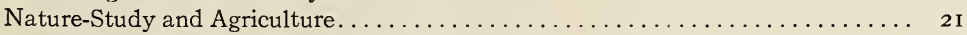

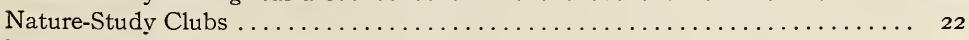

How to Use this Book.................................. 24

\section{PART II}

ANIMAL LifE

\section{Bird Study}

Beginning Bird Study in the Primary Grades $\ldots \ldots \ldots \ldots \ldots \ldots \ldots \ldots \ldots \ldots .25$

Feathers as Clothing $\ldots \ldots \ldots \ldots \ldots \ldots \ldots \ldots \ldots \ldots \ldots \ldots \ldots \ldots \ldots \ldots \ldots \ldots \ldots \ldots \ldots \ldots, 27$

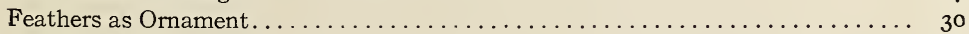

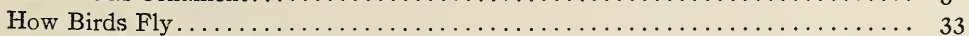

Eyes and Ears of Birds....................................... 36 
The Form and Use of Beaks. . . . . . . . . . . . . . . . . . . . . . . .

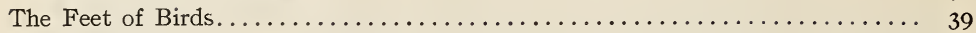

Chicken Ways...................................... ${ }_{4} \mathbf{I}$

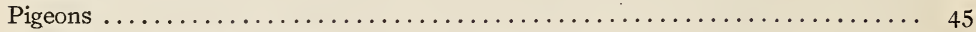

The Canary and the Goldfinch . . . . . . . . . . . . . . . . . . . 49

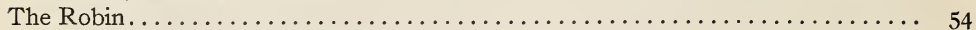

The Bluebird . . . . . . . . . . . . . . . . . . . . . . . . . . . . .

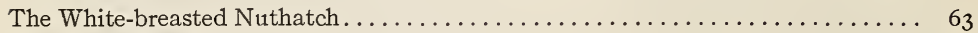

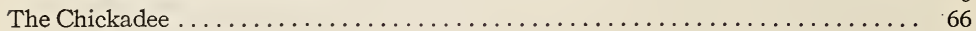

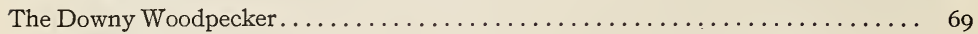

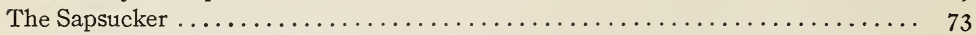

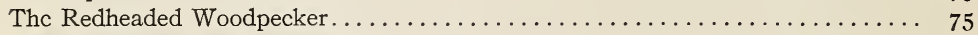

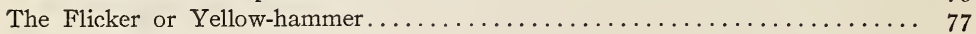

The Meadowlark ..................................... 80

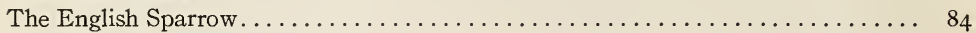

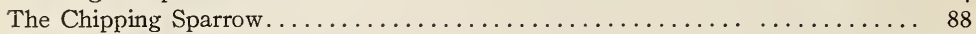

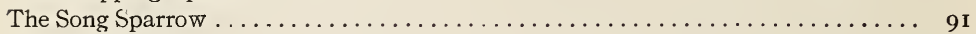

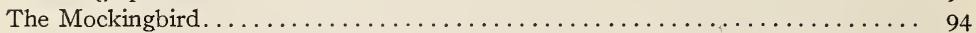

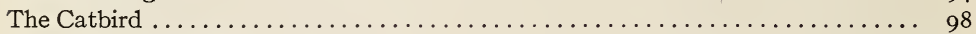

The Belted Kingfisher. . . . . . . . . . . . . . . . . . . . . . . .

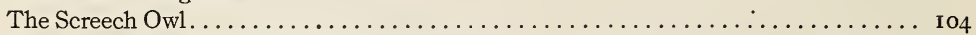

The Red Shouldered and Red Tailed Hawks. . . . . . . . . . . . . . . . . . 108

The Swallows and the Chimney Swift $\ldots \ldots \ldots \ldots \ldots \ldots \ldots \ldots \ldots \ldots \ldots \ldots \ldots \ldots \ldots \ldots$ I 2

The Hummingbird . . . . . . . . . . . . . . . . . . . . . . 20

The Red-winged Blackbird ............................. 22

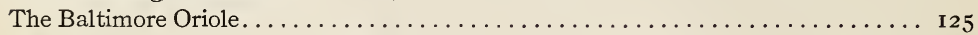

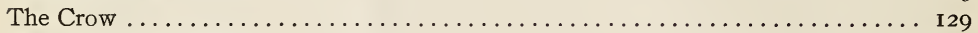

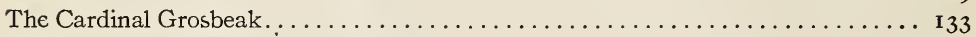

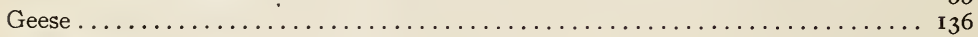

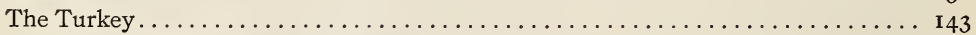

The Study of Birds' Nests in Winter....................... $\mathbf{I}_{47}$

II Fish Study

The Goldfish $\ldots \ldots \ldots \ldots \ldots \ldots \ldots \ldots \ldots \ldots \ldots \ldots \ldots \ldots \ldots \ldots \ldots \ldots \ldots \ldots \ldots \ldots$

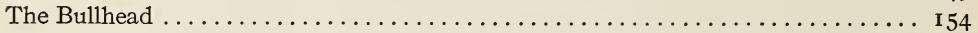

The Common Sucker............................. I 58

The Shiner............................

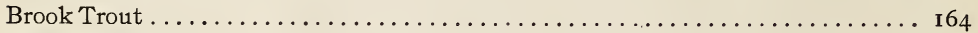

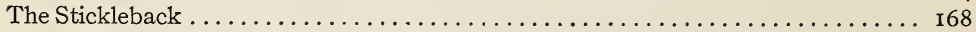

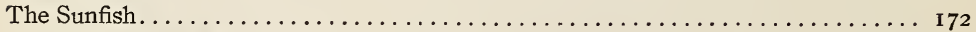

The Johnny Darter $\ldots \ldots \ldots \ldots \ldots \ldots \ldots \ldots \ldots \ldots \ldots \ldots \ldots \ldots \ldots \ldots \ldots \ldots$

\section{Batrachian Study}

The Common Toad $\ldots \ldots \ldots \ldots \ldots \ldots \ldots \ldots \ldots \ldots \ldots \ldots \ldots \ldots \ldots \ldots$ I 8 I

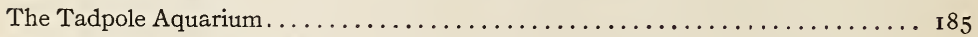

The Tree-frog or Tree-toad ................................ I90

The Frog . . . . . . . . . . . . . . . . . . . . . . . . . . . . . . 93

The Newt, Eft or Salamander. ........................ 197

\section{Reptile Study}

The Garter or Garden Snake. . . . . . . . . . . . . . . . . . . . . . . . 20 I

The Milk Snake, or Spotted Adder. . . . . . . . . . . . . . . . . . . 204 


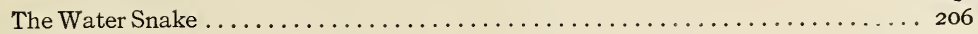

The Turtle........................................ 208

\section{Mammal Study}

The Cotton-tail Rabbit. ............................. 2 I 3

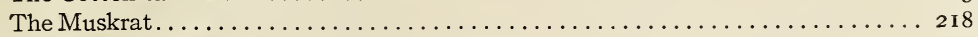

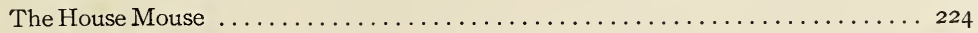

The Woodchuck...................................... 229

The Red Squirrel or Chickaree. . . . . . . . . . . . . . . . . . . . . 233

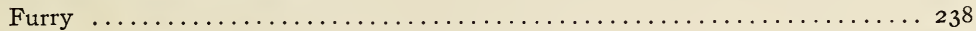

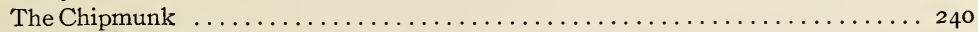

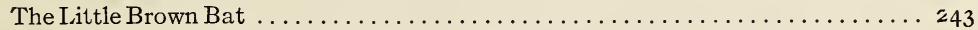

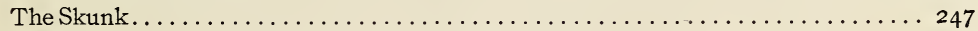

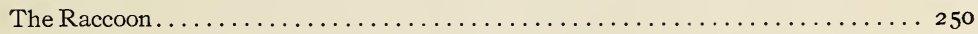

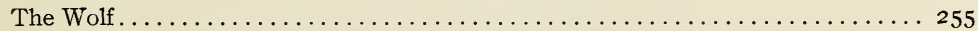

The Fox. . . . . . . . . . . . . . . . . . 257

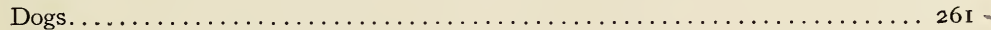

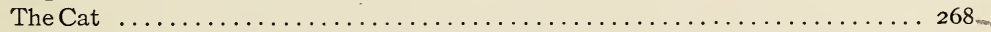

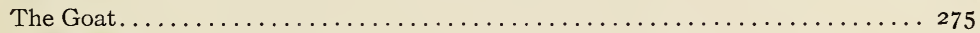

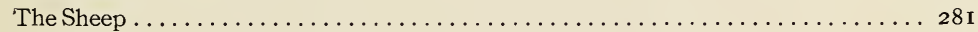

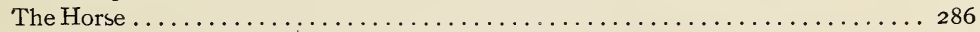

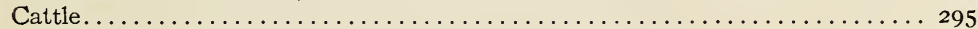

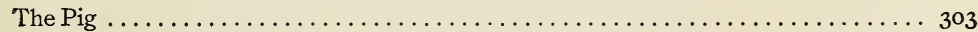

\section{Insect Study}

The Life History of Insects. . . . . . . . . . . . . . . 308

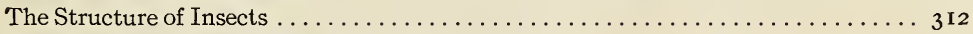

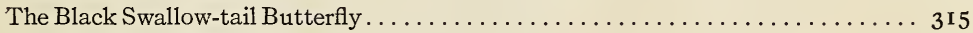

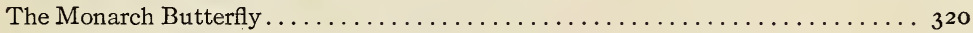

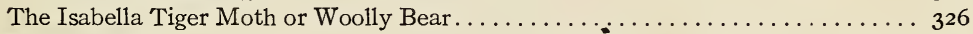

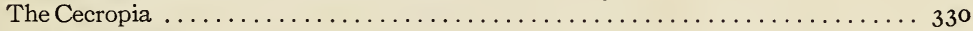

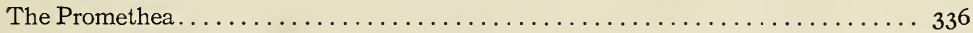

The Hummingbird, or Sphinx, Moths. . . . . . . . . . . . . . . 340

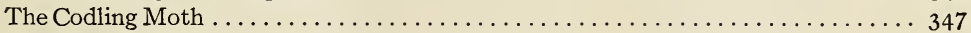

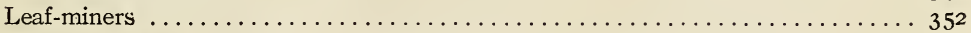

The Leaf-rollers . . . . . . . . . . . . . . . . . . . . . . . . . . . 357

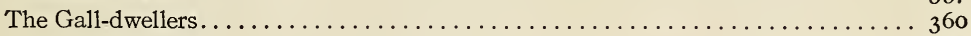

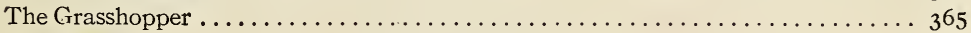

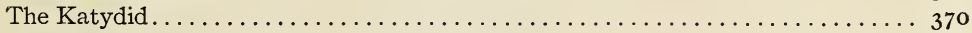

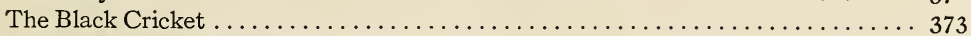

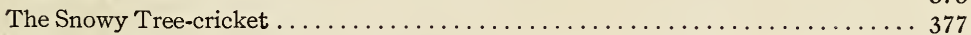

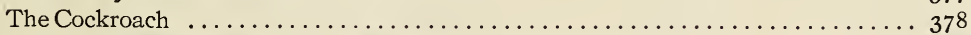

How to Make an Aquarium for Insects... . . . . . . . . . . . . . . . . . 380

The Dragon-flies and Damsel-flies. . . . . . . . . . . . . . . . . . . . 382

The Caddis-worms and the Caddis-flies. . . . . . . . . . . . . . . . . 387

The Aphids or Plant Lice . . . . . . . . . . . . . . . . . . . . . . . 392

The Ant-lion . . . . . . . . . . . . . . . . . . . . . . . . . . . 395

Mother Lace-wing and the Aphis-lion. . . . . . . . . . . . . . . . . . 397

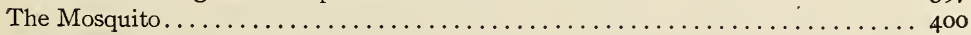

The House-fly ............................................ 405

The Colorado Potato-beetle $\ldots \ldots \ldots \ldots \ldots \ldots \ldots \ldots \ldots \ldots \ldots \ldots \ldots \ldots \ldots \ldots \ldots . \ldots \ldots$

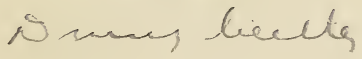




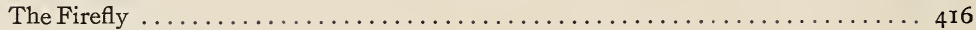

The Ways of the Ant .................................... 4 I9

How to Make a Lubbock Ant-Nest . . . . . . . . . . . . . . . . . 423

The Ant-Nest and What May be Seen Within it.................... 425

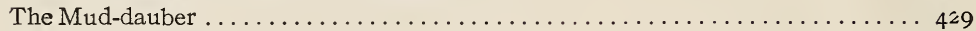

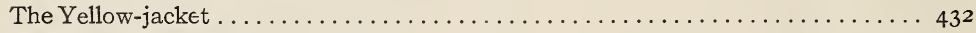

The Leaf-cutter Bee. . . . . . . . . . . . . . . . . . . . . . . . . 436

The Little Carpenter Bee. . . . . . . . . . . . . . . . . . . . . . . 439

The Bumblebee . . . . . . . . . . . . . . . . . . . . . . . . . . $44^{2}$

The Honey-bee. . . . . . . . . . . . . . . . . . . . . . . . . . . 445

The Honey-comb........................................ $45^{\mathrm{I}}$

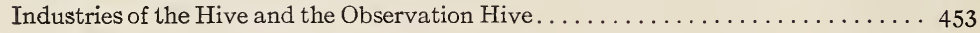

VII Other Inveriebrate-Animal Study

The Garden Snail. . . . . . . . . . . . . . . . . . . . . . . . $44^{8}$

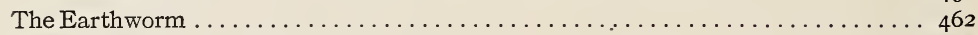

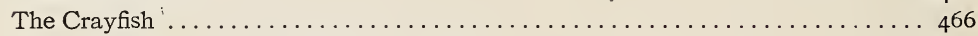

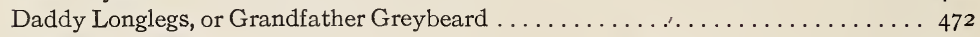

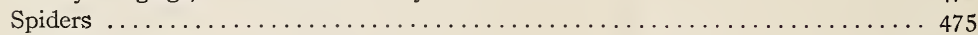

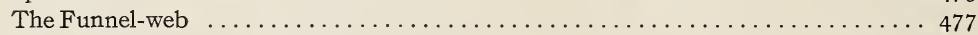

The Orb-web . . . . . . . . . . . . . . . . . . . . . . . . . . 478

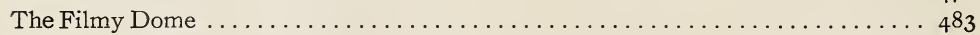

Ballooning Spiders. . . . . . . . . . . . . . . . . . . . . . . . . 484

The White Crab-Spider . . . . . . . . . . . . . . . . . . . . . 485

How the Spider Mothers Take Care of their Young.................. 487

\section{PART III}

\section{Plant Life}

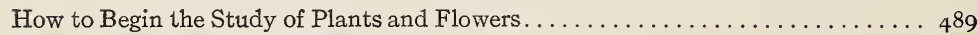

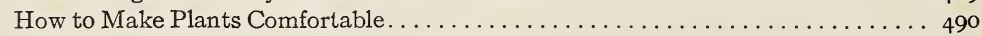

How to Teach the Names of the Parts of a Flower. . . . . . . . . . . . . . 492

Teach the Use of a Flower. . . . . . . . . . . . . . . . . . . . . . . . 493

Flowers and Insect Partners. . . . . . . . . . . . . . . . . . . . . . 494

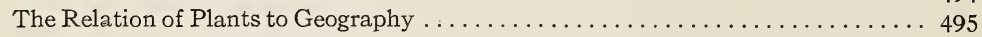

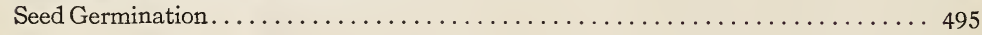

\section{Wild-flower Study}

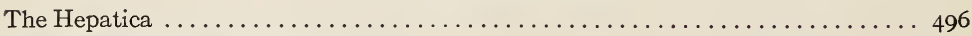

The Yellow Adder's Tongue . . . . . . . . . . . . . . . . . . . . . . . . 499

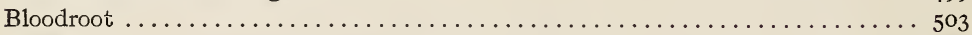

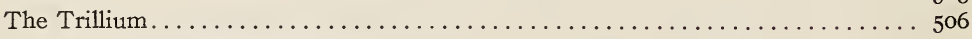

Dutchman's Breeches and Squirrel Corn. . . . . . . . . . . . . . . . . 509

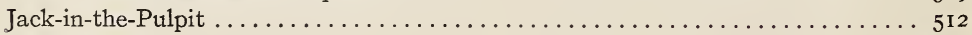

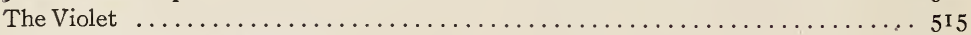

The May Apple or Mandrake. . . . . . . . . . . . . . . . . . . 5 I9

The Bluets. . . . . . . . . . . . . . . . . . . . . . . . . . . $55^{23}$

The Yellow Lady's Slipper, or Moccasin Flower . . . . . . . . . . . . . 525

The Common Buttercup. . . . . . . . . . . . . . . . . . . . . . 528

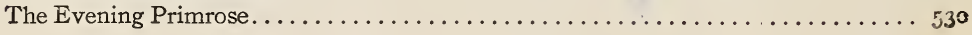


The Hedge Bindweed. . . . . . . . . . . . . . . . . . . . . . . . . . . . 535

The Dodder. . . . . . . . . . . . . . . . . . . . . . . . . . . . . . 538

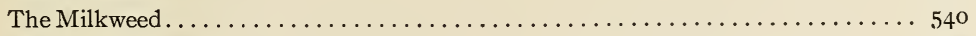

The White Water Lily . . . . . . . . . . . . . . . . . . . . . . . . . . 545

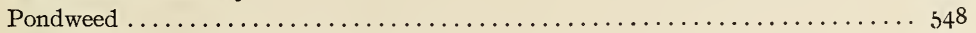

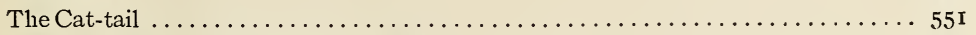

A Type Lesson for a Composite Flower. . . . . . . . . . . . . . . . . . . . . . . . . . 554

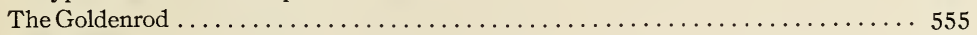

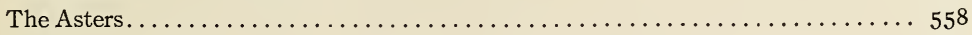

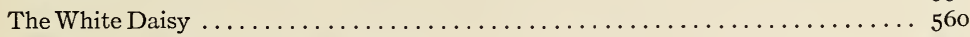

The Yellow Daisy or Black-eyed Susan. . . . . . . . . . . . . . . . . . 562

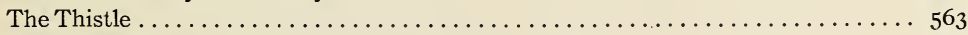

The Burdock. . . . . . . . . . . . . . . . . . . . . . . . . . . . 566

Prickly Lettuce, A Compass Plant. . . . . . . . . . . . . . . . . . . . 570

The Dandelion . . . . . . . . . . . . . . . . . . . . . . . . . . . . 572

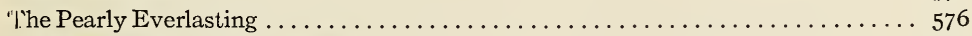

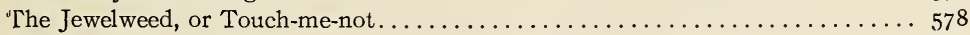

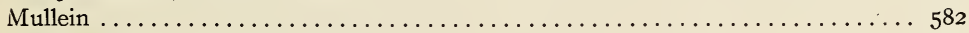

The Teasel. ..................................... $55^{86}$

Queen Anne's Lace, or Wild Carrot . . . . . . . . . . . . . . . . . . . . . $5^{89}$

Weeds ... . . . . . . . . . . . . . . . . . . . . . . . . . . . . . . . . . . 594

Outline for the Study of a Weed . . . . . . . . . . . . . . . . . . . . 595

\section{Cultivated-Plant Study}

The Crocus . . . . . . . . . . . . . . . . . . . . . . . . . . . . . 596

Daffodils and their Relatives . . . . . . . . . . . . . . . . . . . . . . . 599

The Tulip $\ldots \ldots \ldots \ldots \ldots \ldots \ldots \ldots \ldots \ldots \ldots \ldots \ldots \ldots \ldots \ldots \ldots \ldots \ldots \ldots \ldots \ldots$

The Pansy . . . . . . . . . . . . . . . . . . . . . . . . . . . . . 607

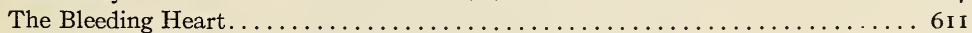

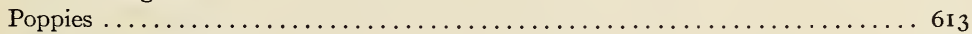

The California Poppy $\ldots \ldots \ldots \ldots \ldots \ldots \ldots \ldots \ldots \ldots \ldots \ldots \ldots \ldots \ldots \ldots \ldots \ldots \ldots \ldots$

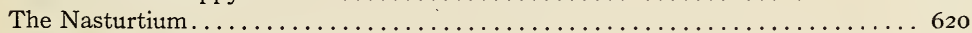

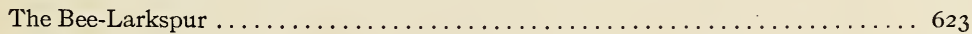

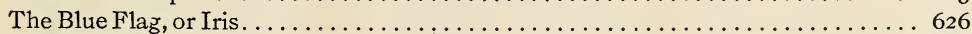

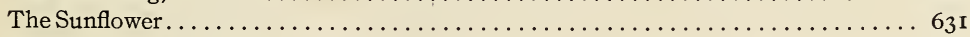

The Bachelor's Button $\ldots \ldots \ldots \ldots \ldots \ldots \ldots \ldots \ldots \ldots \ldots \ldots \ldots \ldots \ldots \ldots \ldots \ldots \ldots \ldots . \ldots \ldots 6$

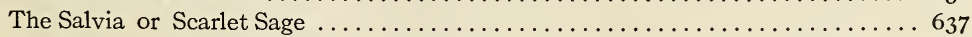

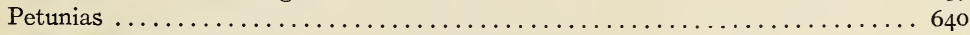

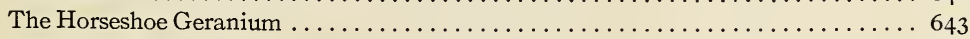

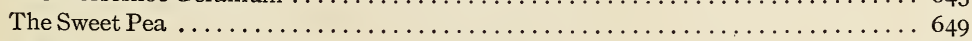

The Clovers . . . . . . . . . . . . . . . . . . . . . . . . . . . . . . . . . 652

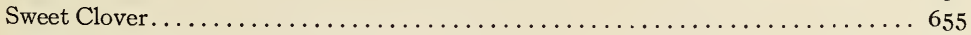

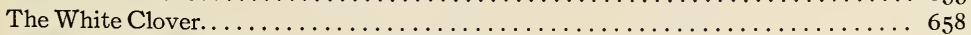

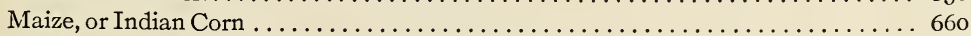

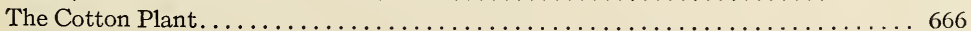

The Strawberry $\ldots \ldots \ldots \ldots \ldots \ldots \ldots \ldots \ldots \ldots \ldots \ldots \ldots \ldots \ldots \ldots \ldots \ldots \ldots \ldots \ldots \ldots \ldots$

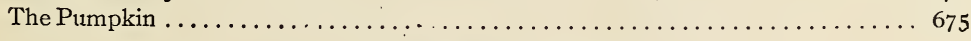

The Christmas Fern . . . . . . . . . . . . . . . . . . . . . . . . . 684

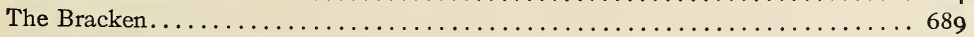

How a Fern Bud Unfolds. . . . . . . . . . . . . . . . . . . 


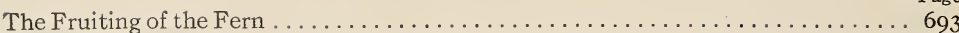

The Field Horsetail $\ldots \ldots \ldots \ldots \ldots \ldots \ldots \ldots \ldots \ldots \ldots \ldots \ldots \ldots \ldots \ldots \ldots . \ldots \ldots$

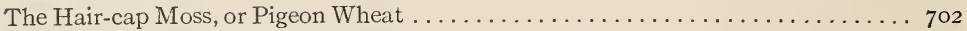

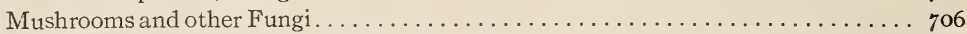

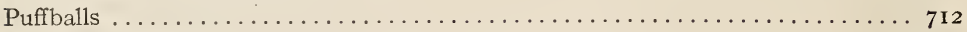

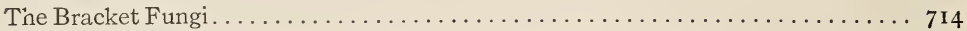

Hedgehog Fungi ................................. 7 17

The Scarlet Saucer. . . . . . . . . . . . . . . . . . . . . . . . 718

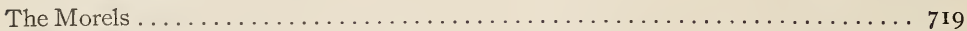

The Stinkhorns. . . . . . . . . . . . . . . . . . . .

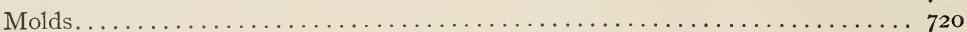

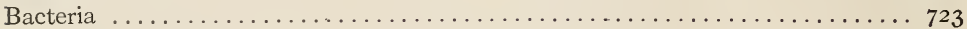

\section{Tree Study}

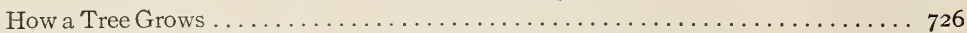

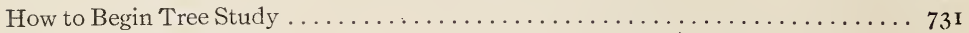

How to Make Leaf Prints . . . . . . . . . . . . . . . . . . . . 734

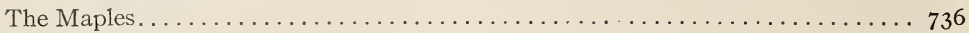

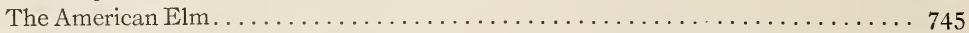

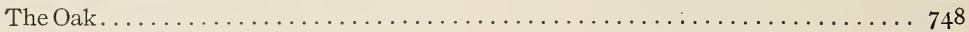

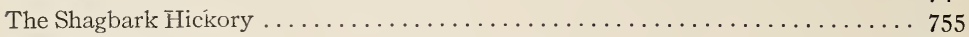

The Chestnut . . . . . . . . . . . . . . . . . . . . . . . . 757

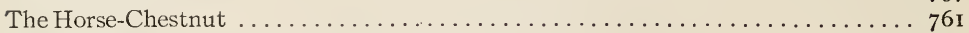

The Willows . . . . . . . . . . . . . . . . . . . . . . . . . . . . . 765

The Cottonwood or Carolina Poplar $\ldots \ldots \ldots \ldots \ldots \ldots \ldots \ldots \ldots \ldots \ldots \ldots \ldots \ldots \ldots$

The White Ash . . . . . . . . . . . . . . . . . . . . . . . . . . . . . . . 774

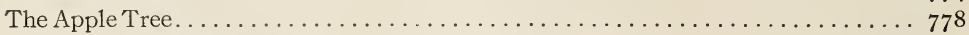

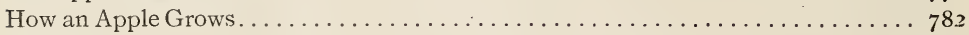

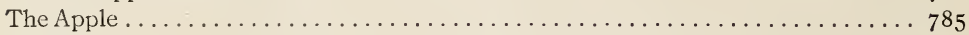

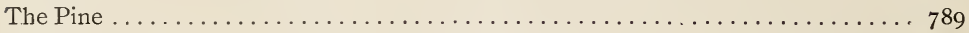

The Norway Spruce. . . . . . . . . . . . . . . . . . . . . . . 796

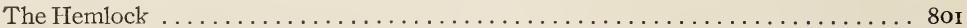

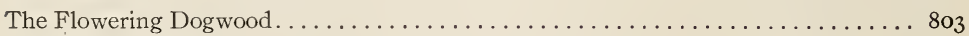

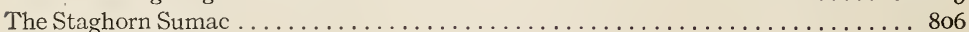

The Witch-Hazel . . . . . . . . . . . . . . . . . . . . . . . . . . 8

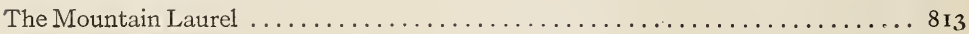

PART IV

EARTh AND Sky

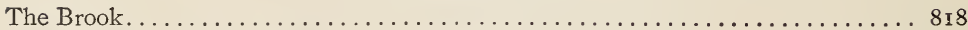

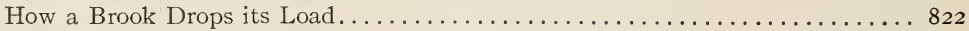

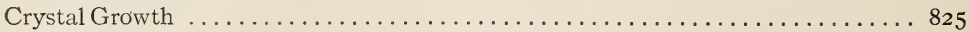

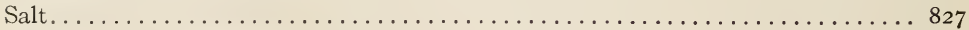

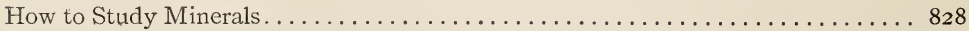

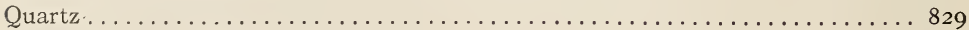

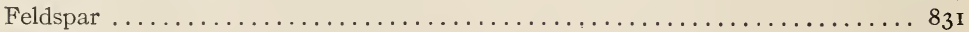

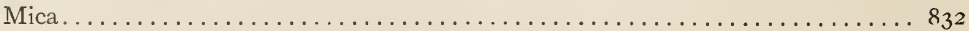

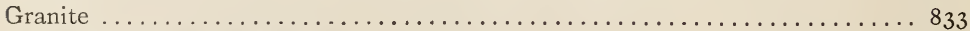

Calcite, marble and Limestone . . . . . . . . . . . . . . . . . . 835

The Magnet . . . . . . . . . . . . . . . . . . . . . . . . . . 838

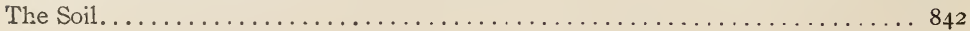


Water Forms.

The Weather.

Experiments to

The Barometer.

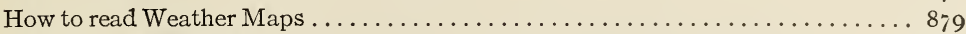

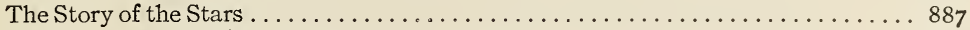

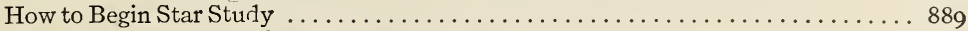

Cassiopeia's Chair, Cepheus and the Dragon..................... 893

The Winter Stars . . . . . . . . . . . . . . . . . . . . . . . . . . 895

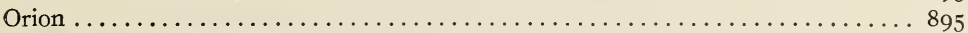

Aldebaran and the Pleiades.................................. 897

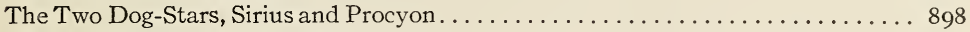

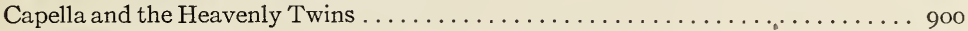

The Stars of Summer.................................. 901

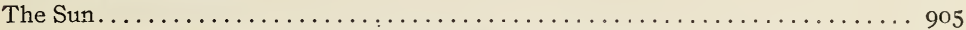

The Relation between the Tropic of Cancer and the Planting of the Garden ...... 909

The Zodiac and its Signs . . . . . . . . . . . . . . . . . .

The Relations of the Sun to the Earth ........................ 9 3

How to Make a Sun-dial ............................... 9 I 5

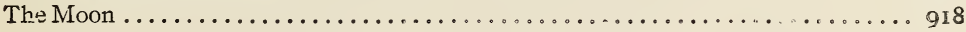


In Nature's infinite book of secrecy A little can I read.

- SHAKESPEARE 


\section{THE TEACHING OF NATURE-STUDY}

\section{WHAT NATURE-STUDY IS}

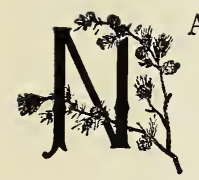

ATURE-STUDY is, despite all discussions and perversions, a study of nature; it consists of simple, truthful observations that may, like beads on a string, finally be threaded upon the understanding and thus held together as a logical and harnonious whole. Therefore, the object of the nature-study teacher should be to cultivate in the children powers of accurate observation and to build up within them, understanding.

\section{WHAT NATURE-STUDY SHOULD DO FOR THE CHILD}

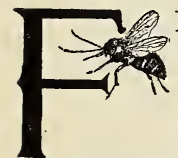

IRST, but not most important, nature-study gives the child practical and helpful knowledge. It makes him familiar with nature's ways and forces, so that he is not so helpless in the presence of natural misfortune and disasters.

Nature-study cultivates the child's imagination since there are so many wonderful and true stories that he may read with his own eyes, which affect his imagination as much as does fairy lore; at the same time nature-study cultivates in him a perception and a regard for what is true, and the power to express it. All things seem possible in nature; yet this seeming is always guarded by the eager quest of what is true. Perhaps, half the falsehood in the world is due to lack of power to detect the truth and to express it. Nature-study aids both in discernment and expression of things as they are.

Nature-study cultivates in the child a love of the beautiful; it brings to him early a perception of color, form and music. He sees whatever there is in his environment, whether it be the thunder-head piled up in the western sky, or the golden flash of the oriole in the elm; whether it be the purple of the shadows on the snow, or the azure glint on the wing of the little butterfly. Also, what there is of sound, he hears; he reads the music score of the bird orchestra, separating each part and knowing which bird sings it. And the patter of the rain, the gurgle of the brook, the sighing of the wind in the pine, he notes and loves and becomes enriched thereby.

But, more than all, nature-study gives the child a sense of companionship with life out of doors and an abiding love of nature. Let this latter be the teacher's criterion for judging his or her work. If nature-study as taught does not make the child love nature and the out-of-doors, then it should cease. Let us not inflict permanent injury on the child by turning him away from nature instead of toward it. However, if the love of nature is in the teacher's heart, there is no danger; such a teacher, no 
matter by what method, takes the child gently by the hand and walks with him in paths that lead to the seeing and comprehending of what he may find beneath his feet or above his head. And these paths whether they lead among the lowliest plants, or whether to the stars, finally converge and bring the wanderer to that serene peace and hopeful faith that is the sure inheritance of all those who realize fully that they are working units of this wonderful universe.

\section{NATURE-STUDY AS A HELP TO HEALTH}

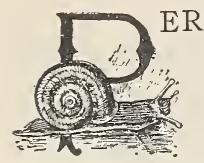

RHAPS the most valuable practical lesson the child gets from nature-study is a personal knowledye that nature's laws are not to be evaded. Wherever he looks, he discovers that attempts at such evasion result in suffering and death. A knowledge thus naturally attained of the immutability of nature's "must" and "shall not" is in itself a moral education. That the fool as well as the transgressor fares ill in breaking natural laws, makes for wisdom in morals as well as in hygiene.

Out-of-door life takes the child afield and keeps him in the open air, which not only helps him physically and occupies his mind with sane subjects, but keeps him out of mischief. It is not only during childhood that this is true, for love of nature counts much for sanity in later life. This is an age of nerve tension, and the relaxation which comes from the comforting companionship found in woods and fields is, without doubt, the best remedy for this condition. Too nuany men who seek the out-ofdoors for rest at the present time, can only find it with a gun in hand. To rest and heal their nerves they must go out and try to kill some unfortunate creature,- - the old, old story of sacrificial blood. Far better will it be when, through properly training the child, the man shall be enabled to enjoy nature through seeing how creatures live rather than watching them die. It is the sacred privilege of nature-study to do this for future generations and for him thus trained, shall the words of Longfellow's poem to Agassiz apply:

\footnotetext{
"And he wandered away and away, with Nature the dear old nurse,

Who sang to him night and day, the rhymes of the universe.

And when the way seemed long, and his heart began to fail,

She sang a more wonderful song, or told a more wonderful tale."
}

\section{WHAT NATURE-STUDY SHOULD DO FOR THE TEACHER}

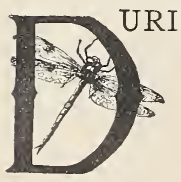

NG many years, I have been watching teachers in our public schools in their conscientious and ceaseless work; and so far as I can foretell, the fate that awaits them finally is either nerve exhaustion or nerve atrophy. The teacher must, become either a neurasthenic or a "clam."

I have had conversations with hundreds of teachers in the public schools of New York State concerning the introduction of nature-study into the curriculum, and most of them declared, "Oh, we have not time for it. Every moment is full now!" Their nerves were at such a tension that with one more thing to do they must fall apart. The question in my own mind during these conversations was always, how long can she 
stand it! I asked some of them "Did you ever try a vigorous walk in the open air in the open country every Saturday or every Sunday of your teaching year?" "Oh no!" they exclaimed in despair of making me understand. "On Sunday we must go to church or see our friends and on Saturday we must do our shopping or our sewing. We must go to the dressmaker's lest we go unclad, we must mend, and darn stockings; we need Saturday to catch up."

Yes, catch up with more cares, more worries, more fatigue, but not with more growth, more strength, more vigor and more courage for work. In my belief, there are two and only two occupations for Saturday afternoon or forenoon for a teacher. One is to be out of doors and the other is to lie in bed, and the first is best. Out in this, God's beautiful world, there is everything waiting to heal lacerated nerves, to strengthen tired muscles, to please and content the soul that is torn to shreds with duty and care. To the teacher who turns to nature's healing, nature-study in the schoolroom is not a trouble; it is a sweet, fresh breath of air blown across the heat of radiators and the noisome odor of over-crowded small humanity. She, who opens her eyes and her heart nature-ward even once a week, finds nature-study in the schoolroom a delight and an abiding joy. What does such a one find in her schoolroom instead of the terrors of discipline, the eternal watching and eternal nagging to keep the pupils quiet and at work? She finds, first of all, companionship with her children; and second, she finds that without planning or going on a far voyage, she has found health and strength.

\section{WHEN AND WHY THE TEACHER SHOULD SAY "I DO NOT KNOW"}

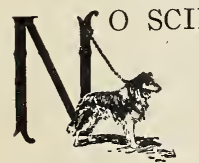

NCE professor in any university, if he be a man of high attainment, hesitates to say to his pupils "I do not know," if they ask for information beyond his knowledge. The greater his scientific reputation and erudition, the more readily, simply and without apology he says this. He, better than others, comprehends how vast is the region that lies beyond man's present knowledge. It is only the teacher in the elementary schools who has never received enough scientific training to reveal to her how little she does know, who feels that she must appear to know everything or her pupils will lose confidence in her. But how useless is this pretence, in nature-study! The pupils, whose younger eyes are much keener for details than hers, will soon discover her limitations and then their distrust of her will be real.

In nature-study any teacher can with honor say, "I do not know;" for perhaps, the question asked is as yet unanswered by the great scientists. But she should not let her lack of knowledge be a wet blanket thrown over her pupils' interest. She should say frankly, "I do not know; let us see if we cannot together find out this mysterious thing. Maybe no one knows it as yet, and I wonder if you will discover it before I do." She thus conveys the right impression, that only a little about the intricate life of plants and animals is yet known; and at the same time she makes her pupils feel the thrill and zest of investigation. Nor will she lose their respect by doing this, if she does it in the right spirit. For three years, I had for comrades in my walks afield, two little children and they kept me 
busy saying, "I do not know". But they never lost confidence in me or in my knowledge; they simply gained respect for the vastness of the unknown.

The chief charm of nature-study would be taken away if it did not lead us through the border-land of knowledge in to the realm of the undiscovered. Moreover, the teacher, in confessing her ignorance and at the same time her interest in a subject, establishes between herself and her pupils a sense of companionship which relieves the strain of discipline, and gives her a new and intimate relation with her pupils which will surely prove a potent element in her success. The best teacher is always one who is the good comrade of her pupils.

\section{NATURE-STUDY, THE ELIXIR OF YOUTH}

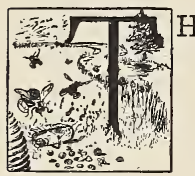

$\mathrm{HE}$ old teacher is too likely to become didactic, dogmatic and "bossy" if she does not constantly strive with herself. Why? She has to be thus five days in the week and, therefore, she is likely to be so seven. She knows arithmetic, grammar and geography to their uttermost and she is never allowed to forget that she knows them, and finally her interests become limited to what she knows.

After all, what is the chief sign of growing old? Is it not the feeling that we know all there is to be known? It is not years which make people old; it is ruts, and a limitation of interests. When we no longer care about anything except our own interests, we are then old, it matters not whether our years be twenty or eighty. It is rejuvenation for the teacher, thus growing old, to stand ignorant as a child in the presence of one of the simplest of nature's miracles-the formation of a crystal, the evolution of the butterfly from the caterpillar, the exquisite adjustment of the silken lines in the spider's orb-web. I know how to "make magic" for the teacher who is growing old. Let her go out with her youngest pupil and fall on her knees before the miracle of the blossoming violet and say: "Dear Nature, I know naught of the wondrous life of these, your smallest creatures. Teach me!" and she will suddenly find herself young.

\section{NATURE-STUDY AS A HELP IN SCHOOL DISCIPLINE}

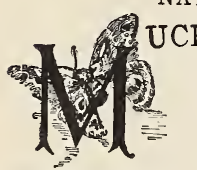
lack of interest in his work, augmented by the physical inaction that results from an attempt to sit quietly. The best teachers try to obviate both of these rather than to punish because of them. Nature-study is an aid in both respects, since it keeps the child interested and also gives him something to do.

In the nearest approach to an ideal school that I have ever seen, for children of second grade, the pupils were allowed, as a reward of merit, to visit the aquaria or the terrarium for periods of five minutes, which time was given to the blissful observation of the fascinating prisoners. The teacher also allowed the reading of stories about the plants and animals under observation to be regarded as a reward of merit. As I entered the schoolroom, there were eight or ten of the children at the windows watching eagerly what was happening to the creatures confined there in the various cages. There was a mud aquarium for the frogs and salamanders, 
an aquarium for fish, many small aquaria for insects and each had one or two absorbingly interested spectators who were quiet, well behaved and were getting their nature-study lessons in an ideal manner. The teacher told me that the problem of discipline was solved by this method, and that she was rarely obliged to rebuke or punish. In many other schools, watching the living creatures in the aquaria, or terrarium has been used as a reward for other work well done.

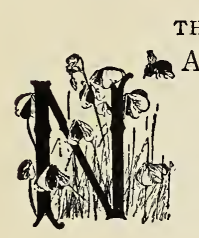

THE RELATION OF NATURE-STUDY TO SCIENCE

ATURE-STUDY is not elementary science as so taught, because its point of attack is not the same; error in this respect has caused many a teacher to abandon naturestudy and many a pupil to hate it. In elementary science the work begins with the simplest animals and plants and progresses logically through to the highest forms; at least this is the method pursued in most universities and schools. The object of the study is to give the pupils an outlook over all the forms of life and their relation one to another. In nature-study the work begins with any plant or creature which chances to interest the pupil. It begins with the robin when it comes back to us in March, promising spring; or it begins with the maple leaf which flutters to the ground in all the beauty of its autumnal tints. A course in biological science leads to the comprehension of all kinds of life upon our globe. Nature-study is for the compreheision of the individual life of the bird, insect or plant that is nearest at hand.

Nature-study is perfectly good science within its limits, but it is not meant to be more profound or comprehensive than the capabilities of the child's mind. More than all, nature-study is not science belittled as if it were to be looked at through the reversed opera glass in order to bring it down small enough for the child to play with. Nature-study, as far as it goes, is just as large as is science for "grown-ups" and may deal with the same subject matter and should be characterized by the same accuracy. It simply does not go so far.

To illustrate: If we are teaching the science of ornithology, we take first the Archaeopteryx, then the swimming and the scratching birds and finally reach the song birds, studying each as a part of the whole. Naturestudy begins with the robin because the child sees it and is interested in it and he notes the things about the habits and appearance of the robin that may be perceived by intimate observation. In fact, he discovers for himself all that the most advanced book of ornithology would give concerning the ordinary habits of this one bird; the next bird studied may be the turkey in the barnyard, or the duck on the pond, or the screech-owl in the spruces, if any of these happen to impinge upon his notice and interest. However, such nature-study makes for the best of scientific ornithology, because by studying the individual birds thus thoroughly, the pupil finally studies a sufficient number of forms so that his knowledge, thus assembled, gives him a better comprehension of birds as a whole than could be obtained by the routine study of the same. Nature-study does not start out with the classification given in books, but in the end it builds up a classification in the child's mind which is based on fundamental knowledge; it is a classification like that evolved by the first naturalists, it is built on careful personal observations of both form and life. 


\section{NATURE-STUDY NOT FOR DRILL}

If nature-study is made a drill, its pedagogic value is lost. When it is properly taught, the child is unconscious of mental effort or that he is suffering the act of teaching. As soon as nature-study becomes a task, it should be dropped; but how could it ever be a task to see that the sky is blue, or the dandelion golden, or to listen to the oriole in the elm!

\section{THE CHILD NOT INTERESTED IN NATURE-STUDY}

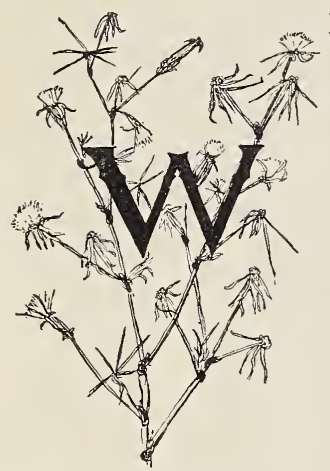

HAT to do with the pupil not interested in nature-study subjects is a problem that confronts many earnest teachers. Usually the reason for this lack of interest, is the limited range of subjects used for nature-study lessons. Often the teacher insists upon flowers as the lesson subject, when toads or snakes would prove the key to the door of the child's interest. But whatever the cause may be, there is only one right way out of this difficulty: The child not interested should be kept at his regular school work and not admitted as a member of th: nature-study class, where his influence is always demoralizing. He had much better be learning his spelling lesson than learning to hate nature through being obliged to study subjects in which he is not interested. In general, it is safe to assume that the pupil's lack of interest in nature-study is owing to a fault in the teacher's method. She may be trying to fill the child's mind with facts when she should be leading him to observe these for himself, which is a most entertaining occupation for the child. It should always be borne in mind that mere curiosity is always impertinent, and that it is never more so than when exercised in the realm of nature. A genuine interest should be the basis of the study of the lives of plants and lower animals. Curiosity may elicit facts, but only real interest may mold these facts into wisdom.

\section{WHEN TO GIVE THE LESSON}

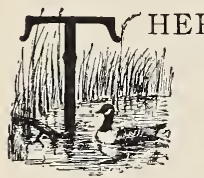

$\mathrm{RE}$ are two theories concerning the time when a naturestudy lesson should be given. Some teachers believe that it should be a part of the regular routine; others have found it of greatest value if reserved for that period of the school day when the pupils are weary and restless, and the teacher's nerves strained to the snapping point. The lesson on a tree, insect or flower at such a moment affords immediate relief to everyone; it is a mental excursion, from which all return refreshed and ready to finish the duties of the day.

While I am convinced that the use of the nature-study lesson for mental refreshment makes it of greatest value, yet I realize fully that if it is relegated to such periods, it may not be given at all. It might be better to give it a regular period late in the day, for there is strength and sureness in regularity. The teacher is much more likely to prepare herself for the lesson, if she knows that it is required at a certain time. 
THE LENGTH OF THE LESSON

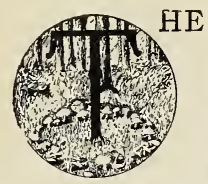

nature-study lesson should be short and sharp and may vary from ten minutes to a half hour in length. There should be no dawdling; if it is an observation lesson, only a few points should be noted and the meaning for the observations made clear. If an outline be suggested for field observation, it should be given in an inspiring manner which shall make each pupil anxious to see and read the truth for himself. The nature story when properly read is never finished; it is always at an interesting point, "continued in our next."

The teacher may judge as to her own progress in nature-study by the length of time she is glad to spend in reading from nature's book what is therein written. As she progresses, she finds those hours spent in studying nature speed faster, until a day thus spent seems but an hour. The author can think of nothing she would so gladly do as to spend days and months with the birds, bees and flowers with no obligation for telling what she should see. There is more than mere information in hours thus spent. Lowell describes them well when he says:

"Those old days when the balancing of a yellow butterfly o'er a thistle bloom

Was spiritual food and lodging for the whole afternoon."

\section{THE NATURE-STUdy LESSON ALWAYS NEW}

A nature-study lesson should not be repeated unless the pupils demand it. It should be done so well the first time that there is no need of repetition, because it has thus become a part of the child's consciousness. The repetition of the same lesson in different grades was, to begin with, a hopeless incubus upon nature-study. One disgusted boy deciared, "Darn germination! I had it in the primary and last year and now I am having it again. I know all about germination." The boy's attitude was a just one; but if there had been revealed to him the meaning of germination, instead of the mere process, he would have realized that until he had planted and observed every plant in the world he would not know all about germination, because each seedling has its own interesting story. The nnly excuse for repeating a nature-study lesson is in recalling it for comparison and contrast with other lessons. The study of the violet will naturally bring about a review of the pansy; the dandelion, of the sunflower; the horse, of the donkey; the butterfly, of the moth.

\section{NATURE-STUDY AND OBJECT LESSONS}

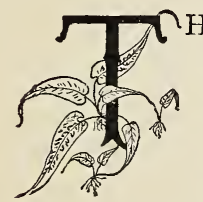

HE object lesson method was introduced to drill the child to see a thing accurately, not only as a whole, but in detail and to describe accurately what he saw. A book or a vase or some other object was held up before the class for a moment and then removed; afterwards the pupils described it as perfectly as possible. This is an excellent exercise and the children usually enjoy it as if it were a game. But if the teacher has in mind the same thought when she is giving the nature-study lesson, she has little comprehension of the meaning of the latter and the pupils will have less. In nature-study, it is not desirable that the child see all the detaiis, but rather those details that have something to do with the life of the creature studied; if he sees that the 
grasshopper has the hind legs much longer than the others, he will inevitably note that there are two other pairs of legs and he will in the meantime have come into an illuminating comprehension of the reason the insect is called "grasshopper." The child should see definitely and accurately all that is necessary for the recognition of a plant or animal; but in nature-study, the observation of form is for the purpose of better understanding life. In fact, it is form linked with life, the relation of "being" to "doing."

\section{NATURE-STUDY IN THE SCHOOLROOM}

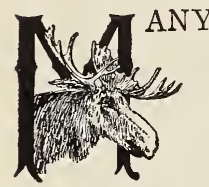

subjects for nature-study lessons may be brought into the schoolroom. Whenever it is possible, the pupils should themselves bring the material, as the collecting of it is an important part of the lesson. There should be in the schoolroom conveniences for caring for the little prisoners brought in from thefield. The terrarium and breeding cages, of different kinds should be provided for the insects, toads and little mammals. Here they may live in comfort, when given their natural food, while the children observe their interesting ways. The ants' nest, and the observation hive yield fascinating views of the marvelous lives of the insect socialists, while the cheerful prisoner in the bird cage may be made a constant illustration of the adaptations and habits of all birds. The aquaria for fishes, tadpoles and insects afford the opportunity for continuous study of these water creatures and are a never-failing source of interest to the pupils, while the window garden may be made not only an ornament and an æsthetic delight, but a basis for interesting study of plant growth and development.

A schoolroom thus equipped is a place of delight as well as enlightenment to the children. Once, a boy whose luxurious home was filled with all that money could buy and educated tastes select, said of a little naturestudy laboratory which was in the unfinished attic of a school building, but which was teeming with life: "I think this is the most beautiful room in the world."

\section{NATURE-STUDY AND MUSEUM SPECIMENS}

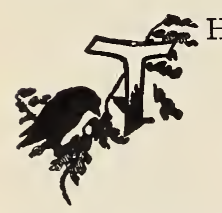

$\mathrm{HE}$ matter of museum specimens is another question for the nature-study teacher to solve, and has a direct bearing on an attitude toward taking life. There are many who believe the stuffed bird or the case of pinned insects have no place in nature-study; and certainly these should not be the chief material. But let us use our common sense; the boy sees a bird in the woods or field and does not lnow its name; he seeks the bird in the museum and thus is able to place it and read about it and is stimulated to make other observations concerning it. Wherever the museum is a help to the study of life in the field, it is well and good. Some teachers may give a live lesson from a stuffed specimen, and other teachers may stuff their pupils with facts about a live specimen; of the two, the former is preferable.

There is no question that making a collection of insects is an efficient way of developing the child's powers of close observation, as well as of giving him manual dexterity in handling fragile things. Also it is a false sentiment which attributes to an insect the same agony at being 
impaled on a pin that we might suffer at being thrust through by a stake. The insect nervous system is far more conveniently arranged for such an ordeal than ours; and, too, the cyanide bottle brings immediate and painless death to the insects placed within it; moreover, the insects usually collected have short lives anyway. So far as the child is concerned, he is thinking of his collection of moths or butterflies and not at all of taking life; so it is not teaching him to wantonly destroy living creatures. However, an indiscriminate encouragement of the making of insect collections cannot be advised. There are some children who will profit by it and some who will not, and unquestionably the best kind of study of insects is watching their interesting ways while they live.

To kill a creature in order to prepare it for a nature-study lesson is not only wrong but absurd, for nature-study has to do with life rather than death, and the form of any creature is interesting only when its adaptations for life are studied. But again, a nature-study teacher may be an opportunist; if without any volition on her part or the pupils', a freshly killed specimen comes to hand, she should make the most of it. The writer remembers most illuminating lessons from a partridge that broke a window and its neck simultaneously during its flight one winter night, a yellow hammer that killed itself against an electric wire, and a muskrat that turned its toes to the skies for no understandable reason. In each of these cases the creature's special physical adaptations for living its own peculiar life were studied, and the effect was not the study of a dead thing, but of a successful and wonderful life.

\section{THE LENS, MICROSCOPE AND FIELD GLASS AS HELPS IN NATURE-STUDY}

elementary grades, nature-study deals with objects which the children can see with the naked eye. However, a lens is a help in almost all of this work because it is such a joy to the child to gaze at the wonders it reveals. There is no lesson given in this book which requires more than a simple lens for seeing the most minute parts discussed. An excellent lens may be bought for a dollar, and a fairly good one for fifty cents or even twenty-five cents. The lens should be chained to a table or desk where it may be used by the pupils at recess. This gives each an opportunity for using it and obviates the danger of losing it. If the pupils themselves own lenses, they should be fastened by a string or chain to the pocket.

A microscope has no legitimate part in nature-study. But if there is one available, it reveals so many wonders in the commonest objects, that it can be made a source of added interest ofttimes. For instance, to thus see the scales on the butterfly's wing affords the child pleasure as well as edification. Field or opera glasses, while indispensible for bird study, are by no means necessary in nature-study. However, the pupils will show greater interest in noting the birds' colors if they are allowed to make the observations with the help of a glass. 


\section{USES OF PICTURES, CHARTS AND BLACKBOARD DRAWINGS}

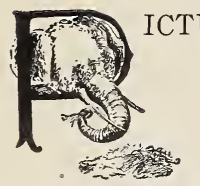

RES alone should never be used as the subjects for nature-study lessons, but they may be of great use in illustrating and illuminating a lesson. Books well illustrated are more readily comprehended by the child and are often very helpful to him, especially after his interest in the subject is thoroughly aroused. If charts are used to illustrate the lesson, the child is likely to be misled by the size of the drawing, which is also the case in blackboard pictures. However, this error may be avoided by fixing the attention of the pupil on the object first. If the pupils are studying the ladybird and have it in their hands, the teacher may use a diagram representing the beetle as a foot long and it will still convey the idea accurately; but if she begins with the picture, she probably can never convince the children that the picture has anything to do with the insect.

In making blackboard drawings illustrative of the lesson, it is best, if possible, to have one of the pupils do the drawing in the presence of the class; or, if the teacher does the drawing, she should hold the object in her hand while doing it and look at it often so that the children may see that she is trying to represent it accurately. Taking everything into consideration, however, nature-study charts and blackboard drawings are of little use to the nature-study teacher.

\section{THE USES OF SCIENTIFIC NAMES}

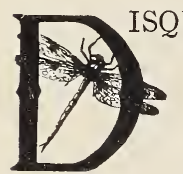

UIETING problems relative to scientific nomenclature always confront the teacher of nature-study. My own practice has been to use the popular names of species, except in cases where confusion might ensue, and to use the scientific names for anatomical parts. However, this matter is of little importance if the teacher bears in mind that the purpose of nature-study is to know the subject under observation and to learn the name incidentaliy.

If the teacher says: "I have a pink hepatica. Can anyone find me a blue one?" the children, who naturally like grown-up words, will soon be calling these flowers hepaticas. But if the teacher says, "These flowers are called hepaticas. Now please everyone remember the name. Write it in your books as I write it on the blackboard, and in half an hour I shall ask you again what it is," the pupils naturally look upon the exercise as a word lesson and its real significance is lost. This sort of nature-study is dust and ashes and there has been too much of it. The child should never be required to learn the name of anything in the nature-study work; but the name should be used so often and so naturally in his presence, that he will learn it without being conscious of the process.

\section{THE STORY AS A SUPPLEMENT TO THE NATURE-STUDY LESSON}

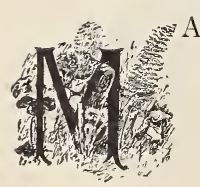

ANY of the subjects for nature lessons can be studied only in part, since but one phase may be available at the time. Often, especially if there is little probability that the pupils will find opportunity to complete the study, it is best to round out their knowledge by reading or telling the story to supplement the facts which they have discor- 
ered for themselves. This story should not be told as a finality or as a complete picture but as a guide and inspiration for further study. Always leave at the end of the story an interrogation mark that will remain aggressive and insistent in the child's mind. To illustrate: Once a club of junior naturalists brought me rose leaves injured by the leaf-cutter bee and asked me why the leaves were cut out so regularly. I told them the story of the use made by the mother bee of these oval and circular bits of leaves and made the account as vital as I was able; but at the end I said, "I do not know which species of bee cut these leaves. She is living here among us and building her nest with your rose leaves which she is cutting every day almost under your very eyes. Is she then so much more clever than you that you cannot see her nor find her nest?" For two years following this lesson I received letters from members of this club. Two carpenter bees and their nests were discovered by them and studied before the mysterious leaf-cutter was finally ferreted out. My story had left something interesting for the young naturalists to discover. The children should be impressed with the fact that the nature story is never finished. There is not a weed nor an insect nor a tree so common that the child, by observing carefully, may not see things never yet recorded in scientific books; therefore the supplementary story should be made an inspiration for keener interest and further investigation on the part of the pupil. The supplementary story simply thrusts aside some of the obscuring underbrush thus revealing more plainly the path to further knowledge.

THE NATURE-STUDY ATTITUDE TOWARD LIFE AND DEATH

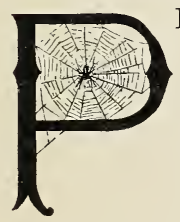

ERHAPS no greater danger besets the pathway of the nature-study teacher than the question involved in her pupils' attitude toward life and death. To inculcate in the child a reverence for life and yet to keep him from becoming mawkish and morbid is truly a problem. It is almost inevitable that the child should become sympathetic with the life of the animal or plant studied, since a true understanding of the life of any creature creates an interest which stimulates a desire to protect this particular creature and make its life less hard. Many times, within my own experience, have I known boys, who began by robbing birds' nests for egg collections, to end by becoming most zealous protectors of the birds. The humane qualities within these boys budded and blossomed in the growing knowledge of the lives of the birds. At Cornell University, it is a well known fact that those students who turn aside so as not to crush the ant, caterpillar or cricket on the pavement are almost invariably those that are studying entomology; and in America it is the botanists themselves who are leading the crusade for flower protection.

Thus, the nature-study teacher, if she does her work well, is a sure aid in inculcating a respect for the rights of all living beings to their own lives; and she needs only to lend her influence gently in this direction to change carelessness to thoughtfulness and cruelty to kindness. But with this impetus toward a reverence for life, the teacher soon finds herself in a dilemma from which there is no logical way out, so long as she lives in a world where lamb chop, beefsteak and roast chicken are articles of ordi- 
nary diet; a world in fact, where every meal is based upon the death of some creature. For if she places much emphasis upon the sacredness of life, the children soon begin to question whether it be right to slay the lamb or the chicken for their own food. It would seem that there is nothing for the consistent nature-study teacher to do but become a vegetarian, and even then there might arise refinements in this question of taking life, she might have to consider the cruelty to asparagus in cutting it off in plump infancy, or the ethics of devouring in the turnip the food laid up by the mother plant to perfect her seed. In fact, a most rigorous diet would be forced upon the teacher who should refuse to sustain her own existence at the cost of life; and if she should attempt to teach the righteousness of such a diet she would undoubtedly forfeit her position; and yet what is she to do! She will soon find herself in the position of a certain lady who placed sheets of sticky fly-paper around her kitchen to rid her house of flies, and then in mental anguish picked off the buzzing, struggling victims and sought to clean their too adhesive wings and legs.

In fact, drawing the line between what to kill and what to let live, requires the use of common sense rather than logic. First of all, the nature-study teacher, while exemplifying and encouraging the humane attitude toward the lower creatures, and repressing cruelty which wantonly causes suffering, should never magnify the terrors of death. Death is as natural as life and the inevitable end of physical life on our globe. Therefore, every story and every sentiment expressed which makes the child feel that death is terrible, is wholly wrong. The one right way to teach about death is not to emphasize it one way or another, but to deal with it as a circumstance common to all; it should be no more emphasized than the fact that creatures eat or fall asleep.

Another thing for the nature-study teacher to do is to direct the interest of the child so that it shall center upon the hungry creature rather than upon the one which is made into the meal. It is well to emphasize the fact that one of the conditions imposed upon every living being in the woods and fields, is that it is entitled to a meal when it is hungry, if it is clever enough to get it. The child naturally takes this view of it. I remember well as a child I never thought particularly about the mouse which my cat was eating; in fact, the process of transmuting mouse into cat seemed altogether proper, but when the cat played with the mouse, that was quite another thing, and was never permitted. Although no one appreciates more deeply than I the debt which we owe to Thompson-Seton and writers of his kind, who have placed before the public the animal story from the animal point of view and thus set us all to thinking, yet it is certainly wrong to impress this view too strongly upon the young and sensitive child. In fact, this process should not begin until the judgment and the understanding is well developed, for we all know that although seeing the other fellow's standpoint is a snurce of strength and breadth of mind, yet living the other fellow's life is, at best, an enfeebling process and a futile waste of energy. 
SHOULD THE NATURE-STUDY TEACHER TEACH HOW TO DESTROY LIFE ?

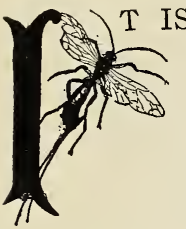

IS probably within the proper scope of the nature-study teacher to place emphasis upon the domain of man, who being the most powerful of all animals, asserts his will as to which ones shall live in his midst. From a standpoint of abstract justice, the stray cat has just as much right to kill and eat the robin which builds in the vine of my porch as the robin has to pull and eat the earthworms from my lawn; but the place is mine, and I choose to kill the cat and preserve the robin.

When emphasizing the domain of man, we may have to deal with the killing of creatures which are injurious to his interests. Nature-study may be tributary to this, in a measure, and indirectly, but it is surely not nature-study. For example, the child studies the cabbage butterfly in all its stages, the exquisitely sculptured yellow egg, the velvety green caterpillar, the chrysalis with its protecting colors, the white-winged butterfly, and becomes interested in the life of the insect. Not under any consideration, when the attention of the child is focused on the insect, should we suggest a remedy for it when a pest. Let the life-story of the butterfly stand as a fascinating page of nature's book. But later, when the child enters on his career as a gardener, when he sets out his row of cabbage plants and waters and cultivates them, and does his best to bring them to maturity, along comes the butterfly, now an arch enemy, and begins to rear her progeny on the product of his toil. Now the child's interest is focused on the cabbage, and the question is not one of killing insects so much as of saving plants. In fact, there is nothing in spraying the plants with Paris green which suggests cruelty to innocent caterpillars, nor is the process likely to harden the child's sensibilities.

To gain knowledge of the life-story of insects or other creatures is nature-study. To destroy them as pests is a part of Agriculture or Horticulture. The one may be of fundamental assistance to the other, but the two are quite separate and should never be confused.

\section{THE FIELD NOTE-BOOK}

A field note-book may be made a joy to the pupil and a help to the teacher. Any kind of a blank book will do for this, except that it should not be too large to be carried in the pocket, and it should always have the pencil attached. To make the note-book a success the following rules should be observed:

(a) The book should be considered the personal property of the child and should never be criticized by the teacher except as a matter of encouragement; for the spirit in which the notes are made, is more important than the information they cover.

(b) The making of drawings should be encouraged for illustrating what is observed. A graphic drawing is far better than a long description of a natural object.

(c) The note-book should not be regarded as a part of the work in English. The spelling, language and writing of the notes should all be exempt from criticism.

(d) As occasion offers, outlines for observing certain plants or animals may be placed in the note-book previous to the field excursion so as to give definite points for the work. 
(e) No child should be compelled to have a note-book.

The field note-book is a veritable gold mine for the nature-study teacher to work, in securing voluntary and happy observations from the pupils concerning their out-of-door interests. It is a friendly gate which admits the teacher to a knowledge of what the child sees and cares for. Through it she may discover where the child's attention impinges upon the realm of nature and thus may know where to find the starting point for cultivating larger intelligence and a wider interest.

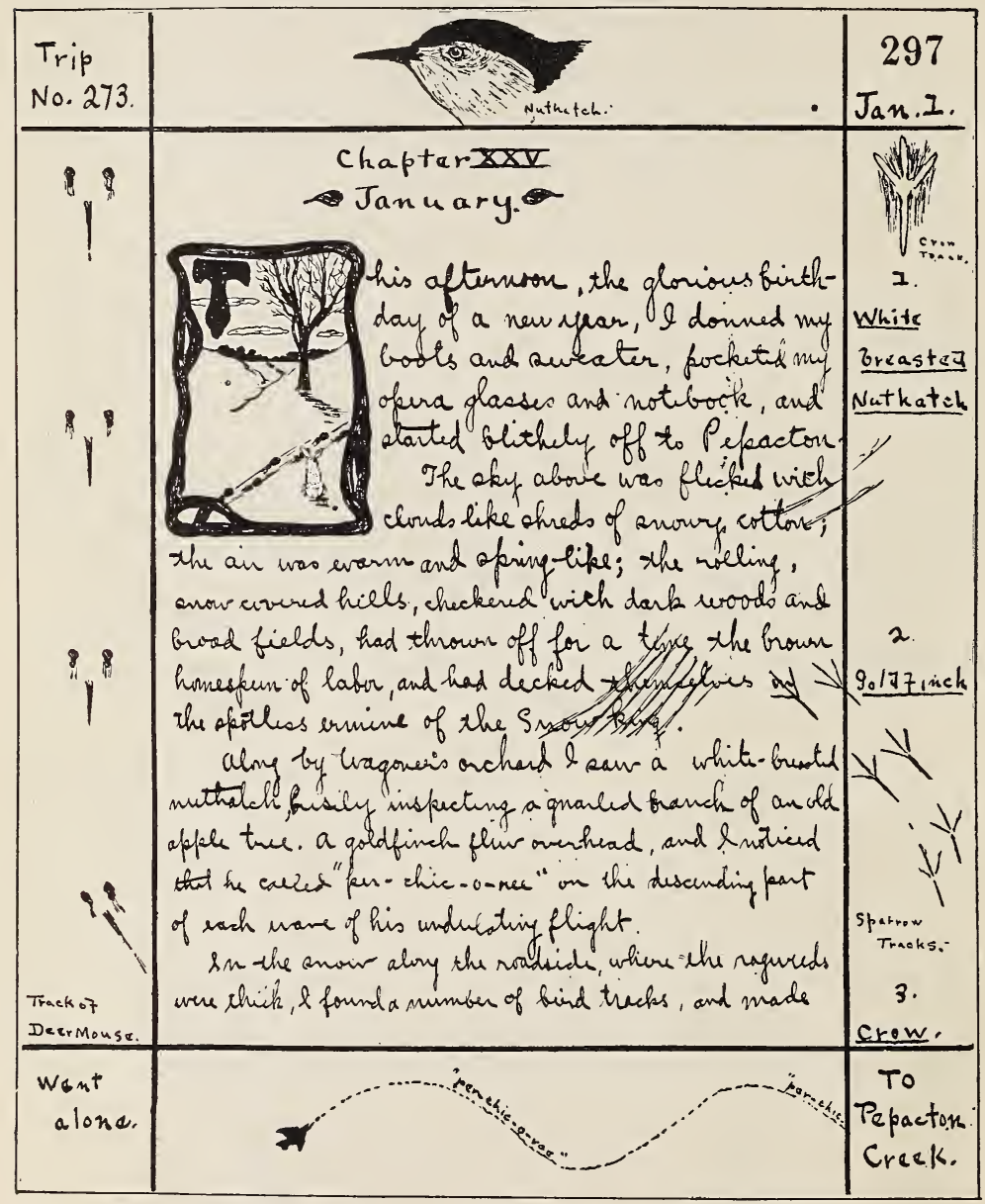

A page from the field note-book of a lad of fourteen who read Thorean and admired the books of Thompson-Seton. 
I have examined many field note-books kept by pupils in the intermediate grades and have been surprised at their plenitude of accurate observation and graphic illustration. These books ranged from blank account books furnished by the family grocer up to a quarto, the pages of which were adorned with many marginal illustrations made in passionate admiration of Thompson-Seton's books and filled with carefully transcribed text, that showed the direct influence of Thoreau. These books, of whatever quality, are precious beyond price to their owners. And why not? For they represent what cannot be bought or sold, personal experience in the happy world of out-of-doors.

THE FIELD EXCURSION

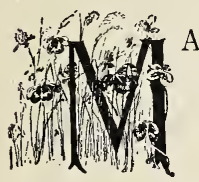

ANY teachers look upon the field excursion as a precar ious voyage, steered between the Scylla of hilarious seeing too much and the Charybdis of seeing nothing at all because of the zest which comes from freedom in the fields and wood. This danger can be obviated if the teacher plans the work definitely before starting, and demands certain results.

It is a mistake to think that a half day is necessary for a field lesson, since a very efficient field trip may be made during the ten or fifteen minutes at recess, if it is well planned. Certain questions and lines of investigation should be given the pupils before starting and given in such a manner as to make them thoroughly interested in discovering the facts. A certain teacher in New York State has studied all the common plants and trees in the vicinity of her school with these recess excursions and the pupils have been enthusiastic about the work.

The half hour excursion should be preceded by a talk concerning the purposes of the outing and the pupils must know that certain observations are to be made or they will not be permitted to go again. This should not be emphasized as a punishment; but they should be made to understand that a field excursion is only, naturally enough, for those who wish to see and understand outdoor life. For all field work, the teacher should make use of the field notebook which should be a part of the pupils' equipment.

\section{PETS AS NATURE-STUDY SUBJECTS}

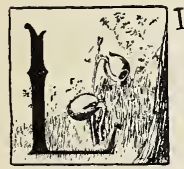

ITTLE attention has been given to making the child understand what would be the lives of his pets if they were in their native environment; or to relating their habits and lives as wild animals. Almost any pet, if properly observed, affords an admirable opportunity for understanding the reasons why its structure and peculiar habits may have made it successful among other creatures and in other lands.

Moreover the actions and the daily life of the pet make interesting subject matter for a note-book. The lessons on the dog, rabbit and horse as given in this volume may suggest methods for such study, and with apologies that it is not better and more interesting, I have placed with the story of the squirrel a few pages from one of my own note-books regarding my experiences with "Furry." I include this record as a suggestion for the children that they should keep note-books of their pets. It will leat 
them to closer observation and to a better and more natural expression of their experiences.

\section{THE CORRELATION OF NATURE-STUDY WITH LANGUAGE WORK}

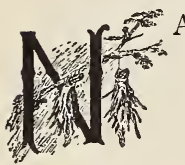

ATURE-STUDY should be so much a part of the child's thought and interest that it will naturally form a thought core for other subjects quite unconsciously on his part. In fact, there is one safe rule for correlation in this case, it is legitimate and excellent training as long as the pupil does not discover that he is correlating. But there is something in human nature which revolts against doing one thing to accomplish quite another. A boy once said to me, "I'd rather never go on a field excursion than to have to write it up for English," a sentiment I sympathized with keenly; ulterior motive is sickening to the honest spirit. But if that same boy had been a member of a field class and had enjoyed all the new experiences and had witnessed the interesting things discovered on this excursion, and if later his teacher had asked him to write for her an account of some part of it, because she wished to know what he had discovered, the chances are that he would have written his story joyfully and with a certain pride that would have counted much for achievement in word expression.

When Mr. John Spencer, known to so many children in New York State as "Uncle John," was conducting the Junior Naturalist Clubs, the teachers allowed letters to him to count for language exercises; and the eagerness with which these letters were written should have given the teachers the key to the proper method of teaching English. Mr. Spencer requested the teachers not to correct the letters, because he wished the children to be thinking about the subject matter rather than the form of expression. But so anxious were many of the pupils to make their letters perfect, that they earnestly requested their teachers to help them write correctly, which was an ideal condition for teaching them English. Writing letters to Uncle John was such a joy to the pupils that it was used as a privilege and a reward of merit in many schools. One rural teacher reduced the percentage of tardiness to a mininium by giving the first period in the morning to the work in English which consisted of letters to Uncle John.

Why do pupils dislike writing English exercises? Simply because they are not interested in the subject they are asked to write about, and they know that the teacher is not interested in the information contained in the essay. But when they are interested in the subject and write about it to a person who is interested, the conditions are entirely changed. If the teacher, overwhelmed as she is by work and perplexities, could only keep in mind that the purpose of a language is, after all, merely to convey ideas, some of her perplexities would fade away. A conveyance naturally should be fitted for the load it is to carry, and if the pupil acquires the load first he is very likely to construct a conveyance that will be adequate. How often the conveyance is made perfect through much effort and polisher through agony of spirit and the load entirely forgotten!

Nature-study lessons give much excellent subject matter for stories and essays, but these essays should never be criticized or defaced with the blue pencil. They should be read with interest by the teacher; the mis- 
takes made in them, so transformed as to be unrecognizable, may be used for drill exercises in grammatical construction. After all, grammar and spelling are only gained by practice and there is no royal road leading to their acquirement.

\section{THE CORRELATION OF NATURE-STUDY AND DRAWING}

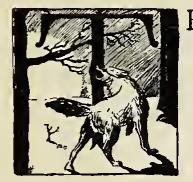

HE correlation of nature-study and drawing is so natural and inevitable that it needs never be revealed to the pupil. When the child is interested in studying any object, he enjoys illustrating his observations with drawings; the happy absorption of children thus engaged is a delight to witness. At its best, drawing is a perfectly natural method of self-expression. The savage and the young child, both untutored, seek to express themselves and their experiences by this means. It is only when the object to be drawn is foreign to the interest of the child that drawing is a task.

Nature-study offers the best means for bridging the gap that lies between the kindergarten child who makes drawings because he loves to and is impelled to from within, and the pupil in the grades who is obliged to draw what the teacher places before him. From making crude and often meaningless pencil strokes, which is the entertainment of the young child, the outlining of a leaf or some other simple and interesting natural object, is a normal step full of interest for the child because it is still selfexpression.

Miss Mary E. Hill gives every year in the Goodyear School of Syracuse an exhibition of the drawings made by the children in the nature-study classes; and these are universally so excellent that most people regard them as an exhibition from the Art Department; and yet many of these pupils have never had lessons in drawing. They have learned to draw because they like to make pictures of the living objects which they have studied. One year there were many pictures of toads in various stages in this exhibit, and although their anatomy was sometimes awry in the pictures, yet there was a certain vivid expression of life in their representation; one felt that the toads could jump. Miss Hill allows the pupils to choose their own medium, pencil, crayon, or water-color, and says that they seem to feel which is best. For instance, when drawing the outline of trees in winter they choose pencil, but when representing the trillium or iris they prefer the water-color, while for bitter-sweet and crocuses they choose the colored crayons.

It is through this method of drawing that which interests him, that the child retains and keeps as his own, what should be an inalienable right, a graphic method of expressing his own impressions. Too much have we emphasized drawing as an art; it may be an art, if the one who draws is an artist; but if he is not an artist he still has a right to draw if it pleases him to do so. We might as well declare that a child should not speak unless he put his words into poetry, as to declare that he should not draw because his drawings are not artistic. 


\section{THE CORRELATION OF NATURE-STUDY WITH GEOGRAPHY}

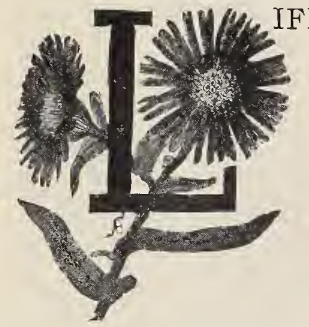

depends upon its environment. Geographical conditions and limitations have shaped the mold into which plastic life has been poured and by which its form has been modified. It may be easy for the untrained mind to see how the deserts and oceans affect life. Cattle may not roam in the former because there is nothing there for them to eat, nor may they occupy the latter because they are not fitted for breathing air in the water. And yet the camel can endure thirst and live on the scant food of the desert; and the whale is a mammal fitted to live in the sea. The question is, how are we to impress the child with the "have to " which lies behind all these geographical facts. If animals live in the desert they have to subsist on scant and peculiar food which grows there; they have to get along with little water; they have to endure heat and sand storms; they have to have eyes that will not become blinded by the vivid reflection of the sunlight on the sand; they have to be of sand color so that they may escape the eyes of their enemies or creep upon their prey unperceived.

All these have to's are not mere chance, but they have existed so long that the animal, by constantly coming in contact with them, has attained its present form and habits.

There are just as many have to's in the stream or the pond back of the school-house, on the dry hillside behind it or in the woods beyond the creek as there are in desert or ocean; and when the child gets an inkling of this fact, he has made a great step into the realm of geography. When he realizes why water lilies can grow only in still water that is not too deep and which has a silt bottom, and why the cat-tails grow in swamps where there is not too much water, and why the mullen grows in the dry pasture, and why the hepatica thrives in the rich, damp woods, and why the daisies grow in the meadows, he will understand that this partnership of nature and geography illustrates the laws which govern life. Many phases of physical geography belong to the realm of nature-study; the brook, its course, its work or erosion and sedimentation; the rocks of many kinds, the soil, the climate, the weather, are all legitimate subjects for naturestudy lessons.

\section{THE CORRELATION OF NATURE-STUDY WITH HISTORY}

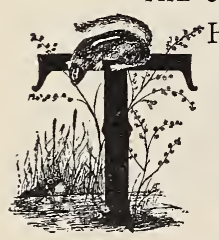

HERE are many points where nature-study impinges upon history in a way that may prove the basis for an inspiring lesson. Many of our weeds, cultivated plants and domestic animals have been introduced from Europe and are a part of our colonial history; while there are many of the most commonly seen creatures which have played their part in the history of ancient times. For instance, the bees which gave to man the only means available to him for sweetening his food until the I 7 th century, were closely allied to the home life of ancient peoples. The buffalo which ranged our western plains had much to do with the life of the red man. The study of the grasshopper brings to the child's attention stories 
of the locusts' invasion mentioned in the Bible, and the stars which witnessed our creation and of which Job sang and the ancients wrote, shine over our heads every night.

But the trees, through the lengthy span of their lives, cover more history individually, than do other organisms. In glancing across the wood-covered hills of New York one often sees there, far above the other trees, the gaunt crowns of old white pines. Such trees belonged to the forest primeval and may have attained the age of two centuries; they stand there looking out over the world, relics of another age when America belonged to the red man, and the bear and the panther played or fought beneath them. The cedars live longer than do the pines and the great scarlet oak may have attained the age of four centuries before it yields to fate.

Perhaps in no other way may the attention of the pupil be turned so naturally to past events, as through the thought that the life of such a tree has spanned so much of human history. The life history of one of these ancient trees should be made the center of local history; let the pupils find when the town was first settled by the whites and where they came from and how large the tree was then. What Indian tribes roamed the woods before that and what animals were common in the forest when this tree was a sapling? Thus may be brought out the chief events in the history of the county and township, when they were established and for ' whom or what they were named; and a comparison of the present

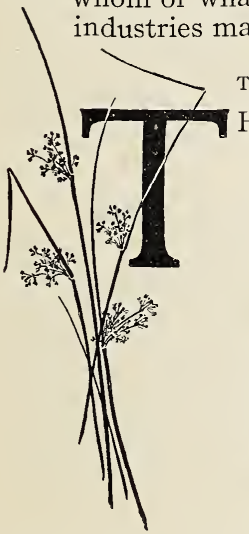

THE CORRELATION OF NATURE-STUDY WITH ARITHMETIC

$\mathrm{HE}$ arithmetical problems presented by nature-study are many; some of them are simple and some of them are complicated, and all of them are illumining. Seed distribution especially lends itself to computation; a milkweed pod contains I 40 seeds; there are five such pods on one plant, each milikweed plant requires at least one square foot of ground to grow on; how much ground would be required to grow all of the seeds from this one plant? Or, count the seeds in one dandelion head, multiply by the number of flower heads on the plant and estimate how many plants can grow on a square foot, then ask a boy how long it would take for one dandelion plant to cover his father's farm with its progeny; or count the blossoms on one branch of an apple tree, later count the ripened fruit; what percentage of blossoms matured into fruit? Measuring trees, their height and thickness and computing the lumber they will make combines arithmetic and geometry, and so on ad infinitum.

As a matter of fact, the teacher will find in almost every nature lesson an arithmetic lesson; and when arithmetic is used in this work, it should be vital and inherent and not "tacked on;" the pupils should be really interested in the answers to their problems; and as with all correlation, the success of it depends upon the genius of the teacher. 
GARDENING AND NATURE-STUDY

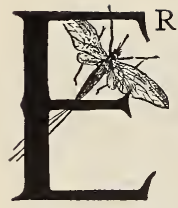
cultivate them. They are taught how to prepare the soil, but the reason for this from the plant's standpoint is never revealed; and if the child becomes acquainted with the plants in his garden, he makes the discovery by himself. All this is nothing against gardening! It is a wholesome and valuable experience for a child to learn how to make a garden even if he remains ignorant of the interesting facts concerning the plants which he there cultivates. But if the teachers are so inclined, they may find in the garden and its products, the most interesting material for the best of nature lessons. Every plant the child grows is an individual with its own peculiarities as well as those of its species in manner of growth. Its roots, stems and leaves are of certain form and structure; and often the special uses to the plant of its own kind of leaves, stems and roots are obvious. Each plant has its own form of flower and even its own tricks for securing pollination; and its own manner of developing and scattering its seeds. Every weed of the garden has developed some special method of winning and holding its place among the cultivated plants; and in no other way may the child so fully and naturally come into a comprehension of that term "the survival of the fittest" as by studying the ways of the fit as exemplified in the triumphant weeds of his garden.

Every earthworm working below the soil is doing something for the garden. Every bee that visits the flowers there is on an errand for the garden as well as for herself. Every insect feeding on leaf or root is doing something to the garden. Every bird that nests near by or that ever visits it, is doing something which affects the life and the growth of the garden. What all of these uninvited guests are doing is one field of garden nature-study. Aside from all this study of individual life in the garden which even the youngest child may take part in, there are the more advanced lessons on the soil. What kind of soil is it? From what sort of rock was it formed? What renders it mellow and fit for the growing of plants? Moreover, what do the plants get from it? How do they get it? What do they do with what they get?

This leads to the subject of plant physiology, the elements of which may be taught simply by experiments carried on by the children themselves, experiments which should demonstrate the sap currents in the plant; the use of water to carry food and in making the plant rigid; the use of sunshine in making the plant food in the leaf laboratories; the nourishment provided for the seed and its germination, and many other similar lessons.

A child who makes a garden, and thus becomes intimate with the plants he cultivates, and comes to understand the interrelation of the various forms of life which he finds in his garden, has progressed far in the fundamental knowledge of nature's ways as well as in a practical knowledge of agriculture. 


\section{NATURE-STUDY AND AGRICULTURE}

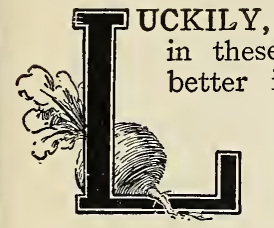

thumb-rule agriculture is being pushed to the wall in these enlightened days. Thumb rules would work much better if nature did not vary her performances in such a confusing way. Government experiment stations were established because thumb rules for farming were unreliable and disappointing; and all the work of all the experiment stations has been simply advanced nature-study and its application to the practice of agriculture. Both nature-study and agriculture are based upon the study of life and the physical conditions which encourage or limit life; this is known to the world as the study of the natural sciences; and if we see clearly the relation of nature-study to science, we may understand better the relation of nature-study to agriculture, which is based upon the sciences.

Nature-study is science brought home. It is a knowledge of botany, zoology and geology as illustrated in the dooryard, the corn-field or the woods back of the house. Some people have an idea that to know these sciences one must go to college; they do not understand that nature has furnished the material and laboratories on every farm in the land. Thus, by beginning with the child in nature-study we take him to the laboratory of the wood or garden, the roadside or the field, and his materials are the wild flowers or the weeds, or the insects that visit the golden-rod or the bird that sings in the maple tree, or the woodchuck whistling in the pasture. The child begins to study living things anywhere or everywhere, and his progress is always along the various tracks laid down by the laws of life, along which his work as an agriculturist must always progress if it is to be successful.

The child through nature-study learns the way a plant grows, whether it be an oak, a turnip or a pigweed; he learns how the roots of each is adapted to its needs; how the leaves place themselves to get the sunshine and why they need it; and how the flowers get their pollen carried by the bee or wind; and how the seeds are finally scattered and planted. Or he learns about the life of the bird, whether it be a chicken, an owl or a bobolink; he knows how each bird gets its food and what its food is, where it lives, where it nests and its relation to other living things. He studies the bumblebee and discovers its great mission of pollen carrying for many flowers, and in the end would no sooner strike it dead than he would voluntarily destroy his clover patch. This is the kind of learning we call nature-study and not science or agriculture. But the country child can never learn anything in nature-study that has not something to do with science; and that has not its own practical lesson for him, when he shall become a farmer.

Some have argued, "Why not make nature-study along the lines of agriculture solely? Why should not the child begin nature-study with the cabbage rather than the wild flowers?" This argument carried out iogically provides recreation for a boy in hoeing corn rather than in playing ball. Many parents in the past have argued thus and have, in consequence, driven thousands of splendid boys from the country to the city with a loathing in their souls for the drudgery which seemed all there was to farm life. The reason why the wild flowers may be selected for begin- 
ning the nature-study of plants, is because every child loves these woodland posies, and his happiest hours are spent in gathering them. Never yet have we known of a case where a child having gained his knowledge of the way a plant lives through studying the plants he loves, has failed to be interested and delighted to find that the wonderful things he discovered about his wild flower may be true of the vegetable in the garden, or the purslane which fights with it for ground to stand upon.

Some have said, "We, as farmers, care only to know what concerns our pocket-books; we wish only to study those things which we must, as farmers, cultivate or destroy. We do not care for the butterfly, but we wish to know the plum weevil; we do not care for the trillium but we are interested in the onion; we do not care for the meadow-lark but we cherish the gosling." This is an absurd argument since it is a mental impossibility for any human being to discriminate between two things when he knows or sees only one. In order to understand the important economic relations to the world of one plant or animal, it is absolutely necessary to have a wide knowledge of other plants and animals. One might as well say, "I will see the approaching cyclone, but never look at the sky; I will look at the clover but not see the dandelion; I will look for the sheriff when he comes over the hill but will not see any other team on the road."

Nature-study is an effort to make the individual use his senses instead of losing them; to train him to keep his eyes open to all things so that his powers of discrimination shall be based on wisdom. The ideal farmer is not the man who by hazard and chance succeeds; he is the man who loves his farm and all that surrounds it because he is a wake to the beauty as well as to the wonders which are there; he is the man who understands as far as may be the great forces of nature which are at work around him, and therefore, he is able to nake them work for him. For what is agriculture save a diversion of natural forces for the benefit of man! The farmer who knows these forces only when restricted to his paltry crops, and has no idea of their larger application, is no more efficient as a farmer than would a man be as an engineer who knew nothing of his engine except how to start and stop it.

In order to appreciate truly his farm, the farmer must needs begin as a child with nature-study; in order to be successful and make the farm pay, he must needs continue in nature-study; and to make his declining years happy, content, full of wide sympathies and profitable thought, he must needs conclude with nature-study; for nature-study is the alphabet of agriculture and no word in that great vocation may be spelled without it.

\section{NATURE-STUDY CLUBS}

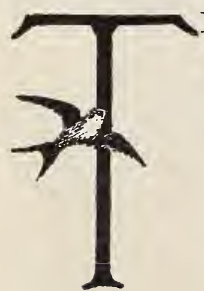

$\mathrm{HE}$ organizing of a club by the pupils for the purpose of studying out-of-door life, is a great help and inspiration to the work in nature-study in the classroom. The essays and the talks before the club, prove efficient aid in English composition; and the varied interests of the members of the club, furnish new and vital material for study. A button or a badge may be designed for the club and, of course, it must have constitution and by-laws. The proceedings of the club meetings should be conducted according to parliamentary rules; but the field excursions

should be entirely informal. 
The meetings of the Junior Naturalists Clubs, as organized in the schools of New York State by Mr. John W. Spencer, were most impressive. The school session would be brought to a close, the teacher stepping down and taking a seat with the pupils. The president of the club, some bashful boy or slender slip of a girl would take the chair and conduct the meeting with a dignity and efficiency worthy of a statesman. The order was perfect, the discussion much to the point. I confess to a feeling of awe when I attended these meetings, conducted so seriously and so formally, by such youngsters. Undoubtedly, the parliamentary training and experience in speaking impromptu, are among the chief benefits of such a club.

These clubs may be organized for special study. In ore bird club of which I know there have been contests. Sides were chosen and the number of birds seen from May ist to 3 Ist inclusive was the test of supremacy. Notes on the birds were taken in the field with such care, that when at the end of the month each member handed in his notes, they could be used as evidence of accurate identification. An umpire with the help of bird manuals decided the doubtful points. This year the score stood 79 to $8 \mathrm{r}$.

The programs of the nature club should be varied so as to be continually interesting. Poems and stories, concerning the objects studied, help make the program attractive.

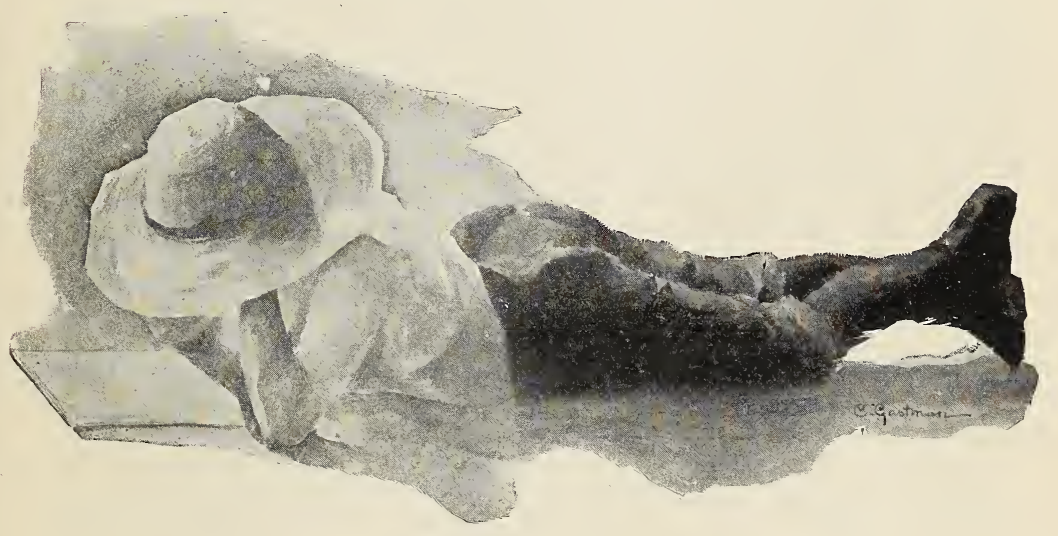




\section{HOW TO USE THIS BOOK}

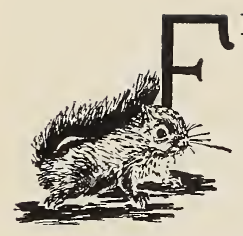

ing the story.

IRST and indispensably, the teacher should have at hand the subject of the lesson. She should make herself familiar with the points covered by the questions and read the story before giving the lesson. If she does not have the time to go over the observations suggested, before giving the lesson, she should take up the questions with the pupils as a joint investigation, and be boon companion in discover-

The story should not be read to the pupils. It is given as an assistance to the teacher, and is not meant for direct information to the pupils. If the teacher knows a fact in nature's realm, she is then in a position to lead her pupils to discover this fact for themselves.

Make the lesson an investigation and make the pupils feel that they are investigators. To tell the story to begin with, inevitably spoils this attitude and quenches interest.

The "leading thought" embodies some of the points which should be in the teacher's mind while giving the lesson; it should not be read or declared to the pupils.

The outlines for observations herein given, by no means cover all of the observations possible; they are meant to suggest to the teacher observations of her own, rather than to be followed slavishly.

The suggestions for observations have been given in the form of questions, merely for the sake of saving space. The direct questioning method, if not employed with discretion, becomes tiresome to both pupil and teacher. If the questions do not inspire the child to in vestigate, they are useless. To grind out answers to questions about any natural object is not nature-study, it is simply "grind," a form of mental activity which is of much greater use when applied to spelling or the multiplication table than to the study of nature. The best teacher will cover the points suggested for observations with few direct questions. To those who find the questions inadequate I will say that, although I have used these outlines once, I am sure I should never be able to use them again without making changes.

The topics chosen for these lessons may not be the most practical nor the most interesting nor the most enlightening that are to be found; they are simply those subjects which I have used in my classes, because we happened to find them at hand the mornings the lessons were given.

While an earnest attempt has been made to make the information in this book accurate, it is to be expected and to be hoped that many discrepancies will be found by those who follow the lessons. No two animals or plants are just alike, and no two people see things exactly the same way. The chief aim of this volume is to encourage investigation rather than to give information. Therefore, if mistakes are found, the object of the book will have been accomplished, and the author will feel deeply gratified. If the teacher finds that the observations made by her and her pupils, do not agree with the statements in the book, I earnestly enjoin upon her to trust to her own eyes rather than to any book.

No teacher is expected to teach all the lessons in this book. A wide range of subjects is given, so that congenial choice may be made. 


\section{PART II.}

\section{ANIMAL LIFE}

\section{BIRD STUDY}

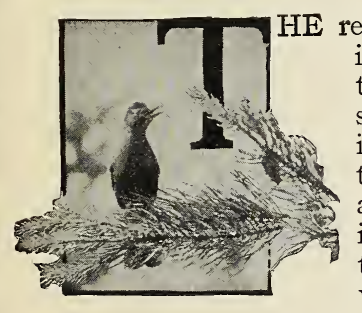

reason for studying any bird is to ascertain what it does; in order to accomplish this, it is necessary to know what the bird is, learning what it is, being simply a step that leads to a knowledge of what it does. But, to hear some of our bird devotees talk, one would think that to be able to identify a bird is all of bird study. On the contrary, the identification of birds is simply the alphabet to the real study, the alphabet by means of which we may spell out the life habits of the bird. To know these habits is the ambition of the true ornithologist, and should likewise be the ambition of the beginner, even though the beginner be a young child.

Several of the most common birds have been selected as subjects for lessons in this book; other common birds, like the phobe and wrens, have been omitted purposely; after the children have studied the birds, as indicated in the lessons, they will enjoy working out lessons for themselves with other birds. Naturally, the sequence of these lessons does not follow scientific classification; in the first ten lessons, an attempt has been made to lead the child gradually into a knowledge of bird life. Beginning with the chicken there follow naturally the lessons with pigeons and the canary; then there follows the careful and detailed study of the robins and constant comparison of them with the blue birds. This is enough for the first year in the primary grades. The next year the work begins with the birds that remain in the North during the winter, the chickadee, nuthatch and downy woodpecker. After these have been studied carefully, the teacher may be an opportunist when spring comes and select any of the lessons when the bird subjects are at hand. The classification suggested for the woodpeckers and the swallows is for more advanced pupils, as are the lessons on the geese and turkeys. It is to be hoped that these lessons will lead the child directly to the use of the bird manuals, of which there are several excellent ones.

\section{BEGINNING BIRD STUDY IN THE PRIMARY GRADES}

The hen is especially adapted as an object lesson for the young beginner of bird study. First of all, she is a bird, notwithstanding the adverse opinions of two of my small pupils who stoutly maintained that "a robin is a bird, but a hen is a hen." Moreover, the hen is a bird always available for nature-study; she looks askance at us from the crates of the world's marts; she comes to meet us in the country barnyard, steppiny toward us sedately; looking at us earnestly, with one eye, then turning her 
head so as to check up her observations with the other; meantime she asks us a little question in a wheedling, soft tone, which we understand perfectly to mean "have you perchance brought me something to eat?" Not only is the hen an interesting bird in herself, but she is a bird with problems; and by studying her carefully we may be introduced into the very heart and center of bird life.

This lesson may be presented in two ways: First, if the pupils live in the country where they have poultry at home, the whole series of lessons may best be accomplished through interested talks on the part of the teacher, which should be followed on the part of the children, by observations, which should be made at home and the results given in school in oral or written lessons. Second, if the pupils are not familiar with fowls, a hen and a chick, if possible, should be kept in a cage in the schoolroom for a few days, and a duck or gosling should be brought in one day for observation. The crates in which fowls are sent to market make very good cages. One of the teachers of the Elmira, N. Y. Schools introduced into the basement of the schoolhouse a hen, which there hatched her brood of chicks, much to the children's delight and edification. After the pupils have become thoroughly interested in the hen and are familiar with her ways, after they have fed her and watched her, and have for her a sense of ownership, the following lessons may be given in an informal manner, as if they were naturally suggested to the teacher's mind through watching the fowl.

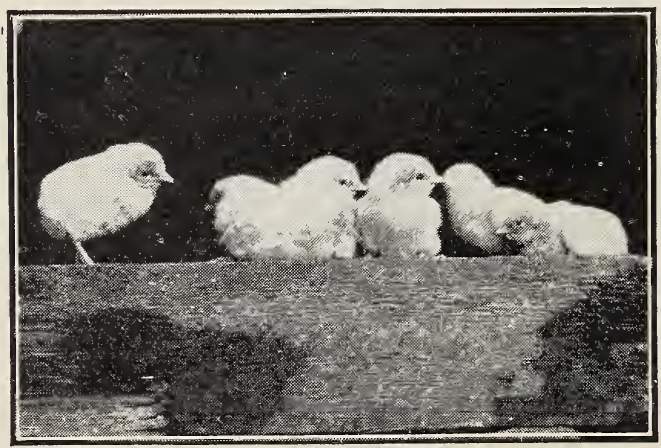




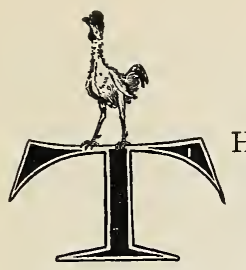

\section{FEATHERS AS CLOTHING}

\section{Teacher's Story}

$\mathrm{HE}$ bird's clothing affords a natural beginning for bird study because the wearing of feathers is a most striking character distinguishing birds from other creatures; also, feathers and flying are the first things the young child notices about birds.

The purpose of all of these lessons on the hen are: (a) To induce the child to make continued and sympathetic observations on the habits of the domestic birds. (b) To cause him involuntarily to compare the domestic with the wild birds. (c) To induce him to think for himself why the shape of the body, wings, head, beak, feet, legs and feathers are adapted in each species to protect the bird and assist it in getting its living.

The overlapping of the feathers on a hen's back and breast is a pretty illustration of nature's method of shingling, so that the rain, finding no place to enter, drips off, leaving the bird's underclothing quite dry. It is interesting to note how a hen behaves in the rain; she droops her tail and holds herself so that the water finds upon her no resting place, but simply a steep surface down which to flow to the ground.

Each feather consists of three parts, the shaft or quill, which is the central stiff stem of the feather, giving it strength. From this quill come off the barbs which, toward the outer end, join together in a smooth web, making the thin, fan-like portion of the feather; at the base is the fluff, which is soft and downy and near to the body of the fow 1 . The teacher should put on the blackboard this figure so that incidentally the pupils may learn the parts of a feather and their structure. If a microscope is available, show both the web

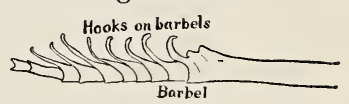
and the fluff of a feather under a three-fourths objective.

The feathers on the back of a hen are longer and narrower in proportion than those on the breast and are especially fitted to protect the back from rain; the breast feathers are shorter and have more of the fluff, thus protecting the breast from the cold as well as the rain. It is plain to any child that the soft fluff is comparable to our woolen underclothing while the smooth, overlapping web forms a rain and wind-proof outer coat. Down is a feather with no quill; young chicks are covered with down. A pin-feather is simply a young feather rolled up in a sheath, which bursts later and is shed, leaving the feather free to assume its form. Take a large pin-feather and cut the sheath open and show the pupils the young feather lying within. 
When a hen oils her feathers it is a process well worth observing. The oil gland is on her back just at the base of the tail feathers; she squeezes the gland with her beak to get the oil and then rubs the beak over the surface of her feathers and passes them through it; she spends more time oiling the feathers on her back and breast than those on the other parts, so that they will surely shed water. Country people say when the hen oils her feathers, it is a sure sign of rain. The hen sheds her feathers once a year and is a most untidy looking bird meanwhile, a fact that she seems to realize, and is as shy and cross as a young lady caught in company in curl papers; but she seems very pleased with herself when she finally gains her new feathers.

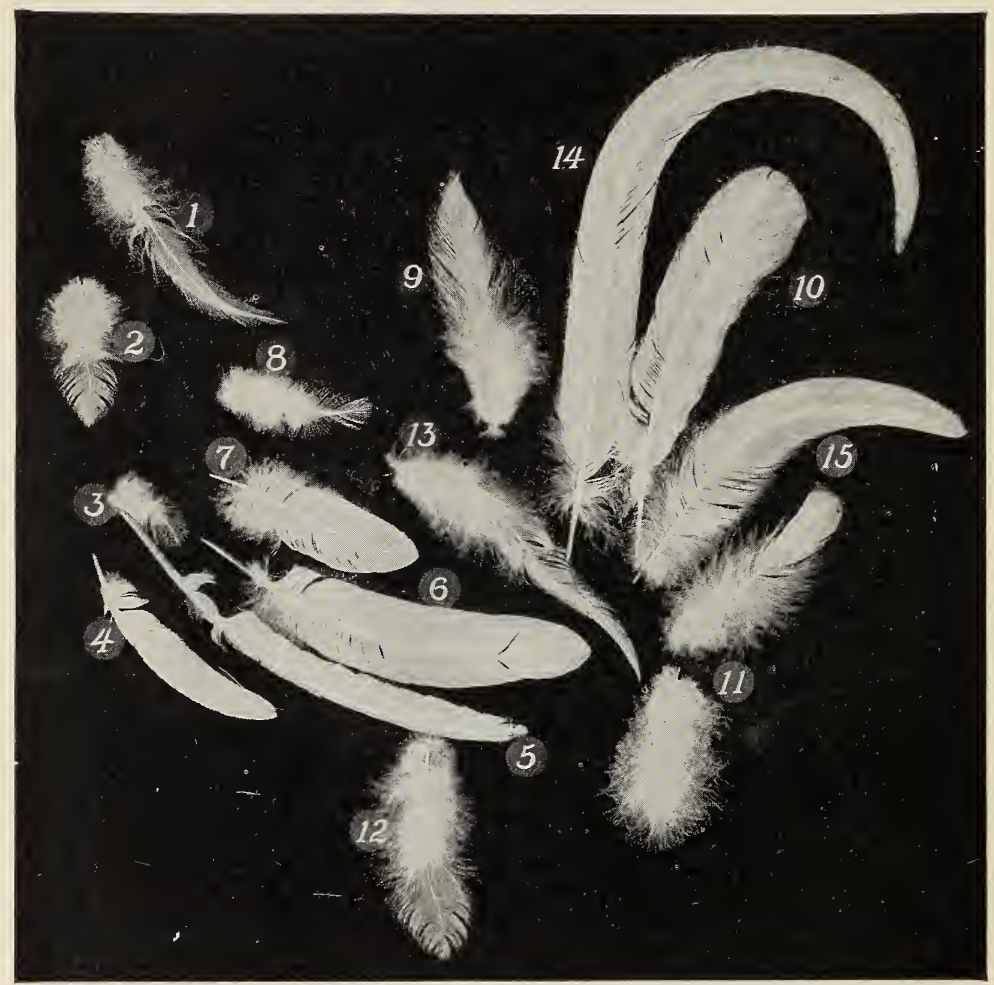

Feathers of a rooster, showing their relative size, shape and position I, neck hackle; 2 , breast; 3 , wing shoulder covert; 4 , wing flight covert; 5 , wing primary; 6 , wing secondary; 7 , wing covert; 8 , back; 9 , tail covert; IO, 'main tail; II, fluff; I2, thigh; I3, saddle hackle; I4, the sickle or feather of beauty: I5, lesser sickle. Prof. J. E. Rice in Rural School Leaflet. 


\section{LESSON I}

\section{Feathers as Clothing}

Leading thought-Feathers grow from the skin of a bird and protect the bird from rain, snow, wind and cold. Some of the feathers act as cloaks or mackintoshes and others as underclothing.

Method-The hen should be at close range for this lesson where the children may observe how and where the different kinds of feathers grow. The pupils should also study separately the form of a feather from the back, from the breast, from the under side of the body, and a pin-feather.

Observations for pupils- - . How are the feathers arranged on the back of the hen? Are they like shingles on the roof? If so, what for?

2. How does a hen look when standing in the rain?

3. How are the feathers arranged on the breast?

4. Compare a feather from the back and one from the breast and note the difference.

5. Are both ends of these feathers alike? If not, what is the difference?

6. Is the fluffy part of the feather on the outside or next to the bird's skin? What is its use?

7. Why is the smooth part of the feather (the web) on the outside?

8. Some feathers are all fluff and are called "down." At what age was the fowl all covered with down?

9. What is a pin-feather? What makes you think so?

I0. How do hens keep their feathers oily and glossy so they will shed water?

I r. Where does the hen get the oil? Describe how she oils her feathers and which ones does she oil most? Does she oil her feathers before a rain?

"How beautiful your feathers be!"

The Redbird sang to the Tulip-tree New garbed in autumn gold.

"Alas!" the bending branches sighed,

"They cannot like your leaves abide To keep us from the cold!"

- John B. TABB.

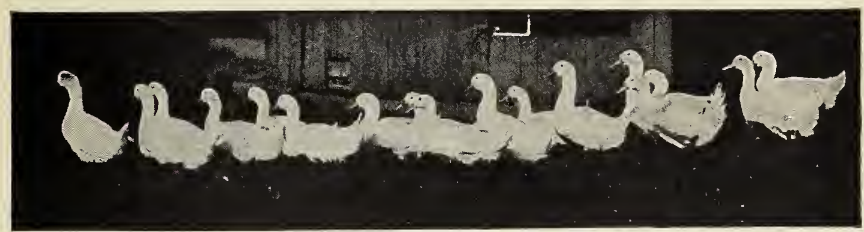




\section{FEATHERS AS ORNAMENT}

\section{Teacher's Story}

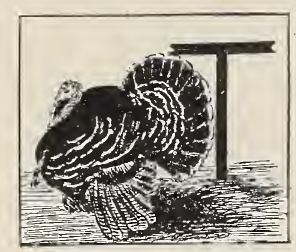

HE ornamental plumage of birds is one of the principal illestrations of a great principle of evolution. The theory is that the male birds win their mates because of their beauty, those that are not beautiful being doomed to live single and leave no progeny to inherit their dullness. On the other hand, the successful wooer hands down his beauty to his sons. However, another quite different principle acts upon the coloring of the plumage of the mother birds; for if they should develop bright colors themselves, they would attract the eyes of the enemy to their precious hidden nests; only by being inconspicuous, are they able to protect their eggs and nestlings from discovery and death. The mother partridge, for instance, is so nearly the color of the dead leaves on the ground about her, that we may almost step upon her before we discover her; if she were the color of the oriole or tanager she would very soon be the center of attraction to every prowler. Thus, it has come about that among the birds the feminine love of beauty has developed the gorgeous colors of the males, while the need for protection of the home has kept the female plumage modest and unnoticeable.

The curved feathers of the rooster's tail are weak and mobile and could not possibly be of any use as a rudder; but they give grace and beauty to the fowl and cover the useful rudder feathers underneath by a feather fountain of iridescence. The neck plumage of the cock is also often luxurious and beautiful in color and quite different from that of the hen. Among the ducks the brilliant blue-green iridescent head of the drake and his wing bars are beautiful, and make his wife seem Quaker-like in contrast.

As an object lesson to instil the idea that the male bird is proud of his beautiful feathers, I know of none better than that presented by the turkey gobbler, for he is a living expression of self-conscious vanity. $\mathrm{He}$ spreads his tail to the fullest extent and shifts it this way and that to show the exquisite play of colors over the feathers in the sunlight, meanwhile throwing out his chest to call particular attention to his blue and red wattles; and to keep from bursting with pride he bubbles over in vainglorious "gobbles."

The hen with her chicks and the turkey hen with her brood, if they follow their own natures, must wander in the fields for food. If they were bright in color, the hawks would soon detect them and their chances of escape would be small; this is another instance of the advantage to the young of adopting the colors of the mother rather than of the father; a fact equally true of the song birds in cases where the males are brilliant in color at maturity. The Baltimore oriole does not assist his mate in brooding, but he sits somewhere on the home tree and cheers her by his glorious song and by glimpses of his gleaming orange coat. Some have accused him of being lazy; on the contrary, he is a wise householder for, instead of attracting the attention of crow or squirrel to his nest, he distracts their attention from it by both color and song.

A peacock's feather should really be a lesson by itself, it is so much a thing of beauty. The brilliant color of the purple eye-spot, and the grace- 
ful flowing barbs that form the setting to the central gem, are all a training in rsthetics as well as in nature-study. After the children have studied such a feather let them see the peacock either in reality or in picture and give them stories about this bird of Juno; a bird so inconspicuous if it were not for his great spread of tail, that a child seeing it first cried, "Oh, oh, see this old hen all in bloom!"

The whole question of sexual selection may be made as plain as need be for the little folks, by simply telling them that the

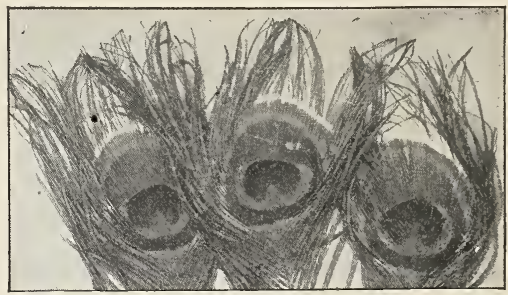

Peacock feathers. Is beauty useful? mother bird chooses for her mate the one which is most brightly and beautifully dressed, and make much of the comb and wattles of the rooster and gobbler as additions to the brilliancy of their appearance.

\section{LESSON II}

\section{Feathers as Ornament}

Leading thought-The color of feathers and often their shape are for the purpose of making birds more beautiful; while in others, the color of the feathers protects them from the observation of their enemies.

Methods-While parts of this lesson relating to fowls, may be given in primary grades, it is equally fitted for pupils who have a wider knowledge of birds. Begin with a comparison of the plumage of the hen and the rooster. Then, if possible, study the turkey gobbler and a peacock in life or in pictures. Also the plumage of a Rouen duck and drake, and if possible, the Baltimore oriole, the goldfinch, the scarlet tanager and the cardinal.

Observations-I. Note difference in shape and color of the tail feathers of hen and rooster.

2. Do the graceful curved tail feathers of the rooster help him in flying? Are they stiff enough to act as a rudder?

3. If not of use in flying what are they for? Which do you think the more beautiful the hen or the rooster?

4. In what respects is the rooster a more beautiful fowl?

5. What other parts of the rooster's plumage is more beautiful than that of the hen?

6. If a turkey gobbler sees you looking at him he begins to strut. Do you think he does this to show off his tail feathers? Note how he turns his spread tail this way and that so the sunshine will bring out the beautiful changeable colors. Do you think he does this so you can see and admire him?

7. Describe the difference in plumage between the hen turkey and the gobbler? Does the hen turkey strut?

8. Note the beautiful blue-green iridescent head and wing patches 
on the wings of the Rouen ducks? Is the drake more beautiful than the duck?

9. What advantage is it for these fowls to have the father bird more beautiful and bright in color than the mother bird?

Io. In case of the Baltimore oriole is the mother bird as bright in color as the father bird? Why?

I I. Study a peacock's feather. What color is the eye-spot? What color around that? What color around that? What color and shape are the outside barbs of the feather? Do you blame a peacock for being proud when he can spread a tail of a hundred eyes? Does the peahen have such beautiful tail feathers as the peacock?

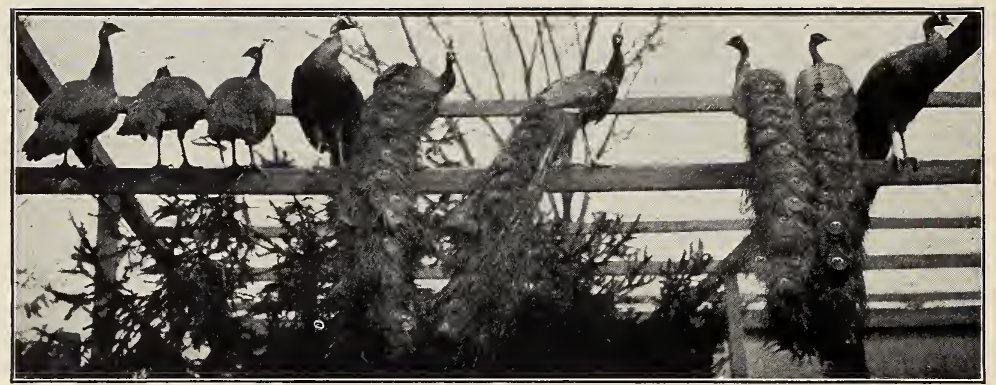

Peahens and peacocks

The bird of Juno glories in his plumes;

Pride makes the fowl to preene his feathers so.

His spotted train fetched from old Argus' head,

With golden rays like to the brighest sun,

Inserteth self-love in the silly bird;

- Till midst its hot and glorious fumes

He spies his feet and then lets fall his plumes.

-The Peacock, Robert Greene, (i560). 


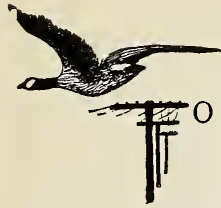

\section{HOW BIRDS FLY}

\section{Teacher's Story}

convince the children that a bird's wings correspond to our arms, they should see a fowl with its feathers off, prepared for market or oven, and they will infer the fact at once.

The bird flies by lifting itself through pressing down upon the air with its wings. There are several experiments which are needed to make the child understand this. It is difficult for children to conceive that the air is really anything, because they cannot see it; so the first experiment should be to show that the air is something we can push against or that pushes against us. Strike the air with a fan and we feel there is something which the fan pushes; we feel the wind when it is blowing and it is very difficult for us to walk against a hard wind. If we hold an open umbrella in the hand while we jump from a step we feel buoyed up because the umbrella presses down upon the air. The bird presses down upon the air with the wings, just as the open umbrella does. The bird flies by pressing down upon the air with its wings just as a boy jumps high by pressing down with his hands on his vaulting pole.

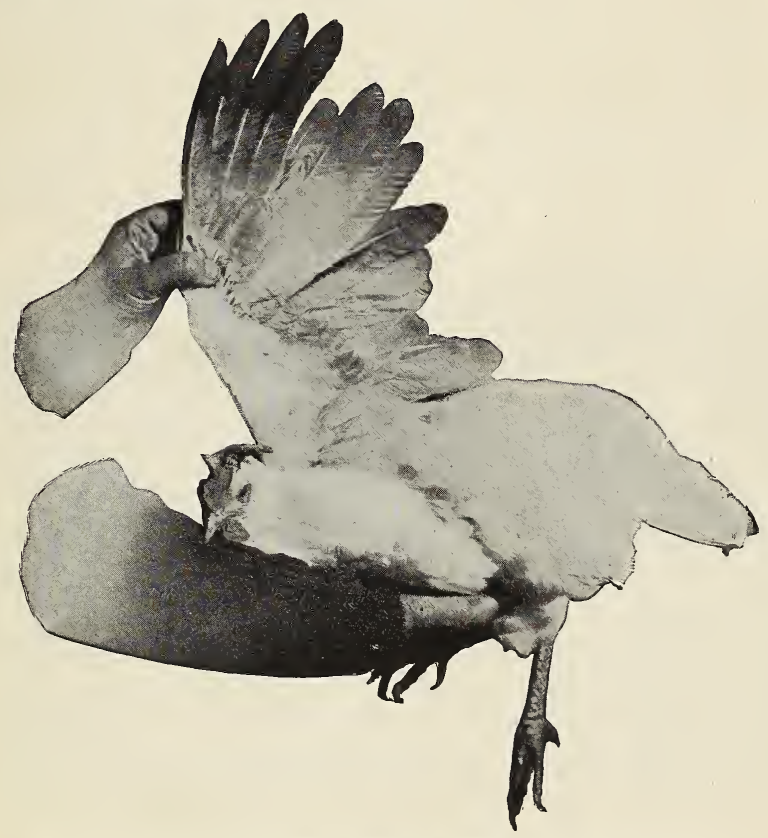

Hen with wing outstretched showing primaries and secondaries of the wing and the overlapping of the feathers.

From practical exercise on feathers by Prof. J. E. Rice in Rural School Leaflet. 
Study wing and note: (a) That the wings open and close at the will of the bird. (b) That the feathers open and shut on each other like a fan. (c) When the wing is open the wing quills overlap, so that the air cannot pass through them. (d) When the wing is open it is curved so that it is more efficient, for the same reason that an umbrella presses harder against the atmosphere when it is open than when it is broken by the wind and turned wrong side out.

A wing feather has the barbs on the front edge lying almost parallel to the quill while those on the hind edge come off at a wide angle. The reason for this is easy to see, for this feather has to cut the air as the bird flies; and if the barbs on the front side were like those of the other side they would be torn apart by the wind. The barbs on the hind side of the feather form a strong, close web so as to press down on the air and not let it through. The wing quill is curved; the convex side is up and the concave side below during flight. The concave side, like the umbrella, catches more air than the upper side; the down stroke of the wing is forward and down; while on the up stroke, as the wing is lifted, it bends at the joint like a fan turned sidewise, and offers less surface to resist the air. Thus, the up stroke does not push the bird down.

Observations should be made on the use of the bird's tail in flight. The hen spreads her tail like a fan when she flies to the top of the fence; the robin does likewise when in flight. The fact that the tail is used as a. rudder to guide the bird in flight, as well as to give more surface for pressing down upon the air, is hard for the younger pupils to understand, and perhaps can be best taught by watching the erratic unbalanced flight of young birds whose tail feathers are not yet grown.

The tail feather differs from the wing feather in that the quill is not curved, and the barbs on each side are of about equal length and lie at about the same angle on each side the quill. See Fig. p. 28.

References-The Bird Book, Eckstorm, pp. 75-92; Story of the Birds, Baskett, pp. I7I-I76; Bird Life, Chapman, p. I8; The Bird, Beebe, Ch. XIII; First Book of Birds, Miller.

\section{LESSON III.}

\section{How Birds FLY}

Leading thought-A bird flies by pressing down upon the air with its wings, which are made especially for this purpose. The bird's tail acts as a rudder during flight.

Method-The hen, it is hoped will by this time be tame enough so that the teacher may spread open her wings for the children to see. In addition, have a detached wing of a fowl such as are used in farm houses instead of a whisk-broom.

Observations-r. Do you think a bird's wings correspond to our arms? If so why?

2. Why do birds flap their wings when they start to fly?

3. Can you press against the air with a fan?

4. Why do you jump so high with a vaulting pole? Do you think the bird uses the air as you use the pole?

5. How are the feathers arranged on the wing so that the bird can use it to press down on the air? 
6. If you carry an umbrella on a windy morning, which catches more wind, the under or the top side? Why is this? Does the curved surface of the wing act in the same way?

7. Take a wing feather. Are the barbs as long on one side of the quill as on the other? Do they lie at the same angle from the quill on both sides? If not why?

8. Which side of the quill lies on the outer side and which on the inner side of the wing?

9. Is the quill of the feather curved?

Io. Which side is uppermost in the wing, the convex or the concave side? Take a quill in one hand and press the tip against the other. Which way does it bend easiest, toward the convex or the concave side? What had this to do with the flight of the bird?

II. If the bird flies by pressing the wings against the air on the down stroke, why does it not push itself downward with its wings on the up stroke?

I2. What is the shape and arrangement of the feathers so as to avoid pushing the bird back to earth when it lifts its wings?

13. Why do you have a rudder to a boat?

I 4. Do you think a bird could sail through the air without something to steer with? What is the bird's rudder?

I5. Have you ever seen a young bird whose tail is not yet grown, try to fly? If so, how did it act?

I6. Does the hen when she flies keep the tail closed or open like a fan?

I7. Compare a tail feather with a wing feather and describe the difference.

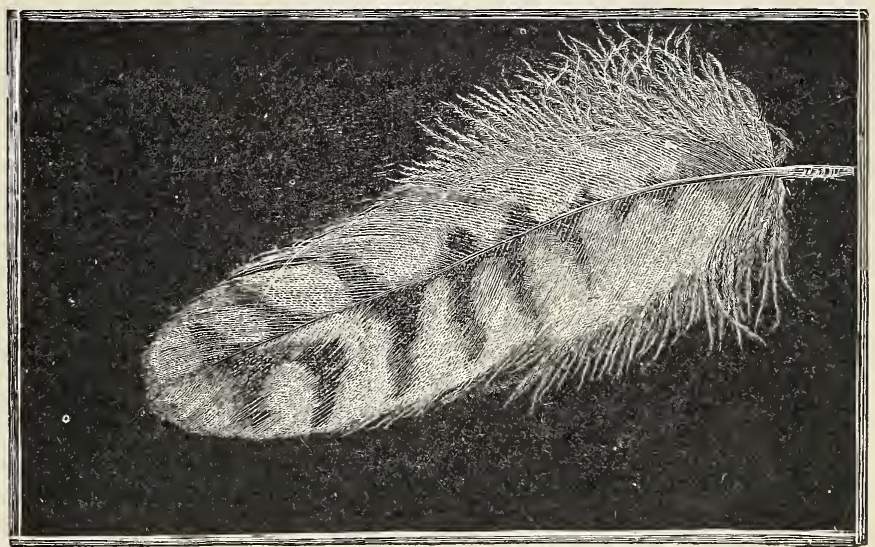

Engraved by Elsa L. Ames. 


\section{EYES AND EARS OF BIRDS}

\section{Teacher's Story}

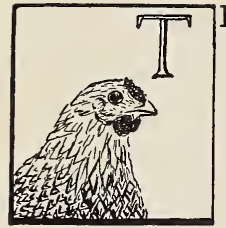

$\mathrm{HE}$ hen's eyes are placed at the side of the head so that she cannot see the same object with both eyes at the same time, and thus she has the habit of looking at us first with one eye and then the other to be sure she sees correctly; also the position of the hen's eyes give her a command of her entire environment. All birds have much keener eyes than have we; and they can adjust their eyes for either near or far vision much more effectively than we can; the hawk, flying high in the air, can see the mouse on the ground.

There is a wide range of colors found in the eyes of birds; white, red blue, yellow, brown, gray, pink, purple and green are found in the iris of different species. The hen's eye consists of a black pupil at the center, which must always be black in any eye, since it is a hole through which enters the image of the object. The iris of the hen's eye is yellow; there is apparently no upper lid but the lower lid comes up during the process of sleeping. When the bird is drowsy the little film lid comes out from the corner of the eye and spreads over it like a veil; just at the corner of our own eye, next the nose, is the remains of this film lid, although we cannot move it as the hen does.

The hearing of birds is very acute, although the ear is simply a hole in the side of the head in most cases, and is more or less covered with feathers. The hen's ear is like this in many varieties; but in others and in the roosters there are ornamental ear lobes.

\section{LESSON IV}

\section{Eyes AND EARS OF BiRds} efficient.

Leading thought-The eyes and ears of birds are peculiar and very

Methods-The hen or chicken and the rooster should be observed for this lesson; notes may be made in the poultry yard or in the schoolroom when the birds are brought there for study.

Observations-I. Why does the hen turn her head first this side and that as she looks at you? Can she see an object with both eyes at once? Can she see well?

2. How many colors are there in a hen's eye? Describe the pupil and the iris.

3. Does the hen wink as we do? Has she any eyelids?

4. Can you see the film lid? Does it come from above or below or the inner or outer corner? When do you see this film lid?

5. Where are the hen's ears? How do they look? How can you tell where the rooster's ears are?

6. Do you think the hen can see and hear well? 


\section{THE FORM AND USE OF BEAKS}

\section{Teacher's Story}

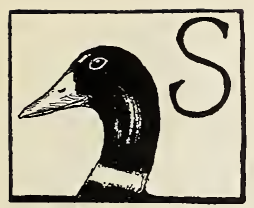

INCE the bird uses its arms and hands for flying, it has been obliged to develop other organs to take their place, and of their work the beak does its full share. It is well to emphasize this point by letting the children at recess play the game of trying to eat an apple or to put up their books and pencils with their arms tied behind them; such an experiment will show how naturally the teeth and feet come to the aid when the hands are useless.

The hen feeds upon seeds and insects which she finds on or in the ground; her beak is horny and sharp and acts not only as a pair of nippers, but also as a pick as she strikes it into the soil to get the seed or insect, having already made bare the place by scratching away the grass or surface of the soil with her strong, stubby toes. The hen does not have any teeth, nor does she need any, for her sharp beak enables her to seize her food; and she does not need to chew it, since her gizzard does this for her after the food is swallowed.

The duck's bill is broad, flat, and much softer than the hen's beak. The duck feeds upon water insects and plants; it attains these by thrusting its head down into the water, seizing the food and holding it fast while the water is strained out through the sieve at the edges of the beak; for this use, a wide, flat beak is necessary. It would be quite as impossible for a duck to pick up hard seeds with its broad, soft bill as it would for the hen to get the duck's food out of the water with her narrow, horny bill.

Both the duck and hen use their bills for cleaning and oiling their feathers and for fighting also; the hen strikes a sharp blow with her beak making a wound like a dagger, while the duck seizes the enemy and simply pinches hard. Both fowls also use their beaks for turning over the eggs when incubating, and also as an aid to the feet when they make nests for themselves.

The nostrils are very noticeable and are situated in the beak near the base. However, we do not believe that birds have a keen sense of smell since their nostrils are not surrounded by a damp, sensitive, soft surface as are the nostrils of the deer and dog, this arrangement aiding these animals to detect odor in a marvelous manner.

\section{LESSON V}

\section{The Beak of a Bird}

Leading thought-Each kind of bird has a beak especially adapted for getting its food. The beak and feet of a bird are its chief weapons and implements.

Methods-Study first the beak of the hen or chick and then that of the duckling or gosling.

Observations- - . What kind of food does the hen eat and where and how does she find it in the field or gat den? How is her beak adapted to get this food? If her beak were soft like that of a duck could she peck so hard for seeds and worms? Has the hen any teeth? Does she need any? 
2. Compare the bill of the hen with that of the duck? What are the differences in shape? Which is the harder?

3. Note the saw teeth along the edge of the duck's bill. Are these for chewing? Do they act as a strainer? Why does the duck need to strain its food?

4. Could a duck pick up a hen's food from the earth or the hen strain out a duck's food from the water? For what other things than getting food do these fowls use their bills?

5. Can you see the nostrils in the bill of a hen? Do they show painer in the duck? Do you think the hen can smell as keenly as the duck?

Supplementary reading-The Bird Book, p. 99; The First Book of Birds, pp. 95-7; Mother Nature's Children, Chapter VIII.

"It is said that nature-study teaching should be accurate, a statement that every good teacher will admit without debate; but accuracy is often interpreted to mean completeness, and then the statement cannot pass unchallenged. To study 'the dandelion,' 'the robin,' with-emphasis on the particle 'the', working out the complete structure, may be good laboratory work in botany or zoology for advanced pupils, but it is not an elementary educational process. It contributes nothing more to accuracy than does the natural order of leaving untouched all those phases of the subject that are out of the child's reach; while it may take out the life and spirit of the work, and the spiritual quality may be the very part that is most worth the while. Other work may provide the formal 'drill'; this should supply the quality and vivacity. Teachers often say to me that their children have done excellent work with these complete methods, and they show me the essays and drawings; but this is no proof that the work is commendable. Children can be made to do many things that they ought not to do and that lie beyond them. We all need to go to school to children." - "The Outlook to Nature," L. H. BAILEy.

"Weather and wind and waning moon, Plain and hilltop under the sky,

Ev'ning, morning and blazing noon, Brother of all the world am I.

The pine-tree, linden and the maize, The insect, squirrel and the kine,

All-natively they live their daysAs they live theirs, so I live mine,

I know not where, I know not what:Believing none and doubting none

What'er befalls it counteth not,Nature and Time and I are one." 


\section{THE FEET OF BIRDS}

\section{Teacher's Story}

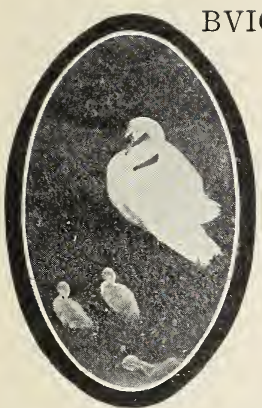

USLY, the hen is a digger of the soil; her claws are long, strong and slightly hooked, and her feet and legs are covered with horny scales as a protection from injury when used in scratching the hard earth, in order to lay bare the seeds and insects hiding there. The hen is a very good runner indeed. She lifts her wings a little to help, much as an athletic runner uses his arms, and so can cover ground with amazing rapidity, her strong toes giving her a firm foothold. The track she makes is very characteristic; it consists of three toe-marks projecting forward and one backward. A bird's toes are numbered thus:

A $\mathrm{duck}$

has the same number of toes as the hen, but there is a membrane, called the web, which joins the second, third and fourth toes, making a fan-shaped foot; the first or the hind toe has a little web of its own. A webbed foot is first of all a paddle for propelling its owner
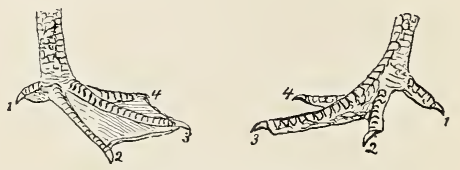

Duck's foot and hen's foot with toes numbered. through the water; it is also a very useful foot on the shores of ponds and streams, since its breadth and flatness prevent it from sinking into the soft mud.

The duck's legs are shorter than those of the hen and are placed farther back and wider apart. The reason for this is, they are essentially swimming organs and are not fitted for scratching nor for running. They are placed at the sides of the bird's body so that they may act as paddles, and are farther back so that they may act like the wheel of a prcpeller in

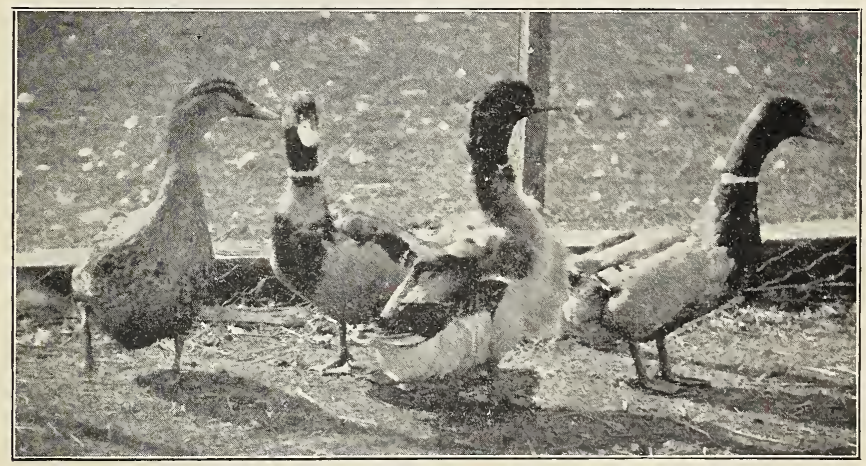

Rouen ducks. The Rowens are colored like the Wild Mallards. 
pushing the bird along. We often laugh at a duck on land, since its short legs are so far apart and so far back that its walk is necessarily an awkward waddle; but we must always remember that the duck is naturally a water bird, and on the water its movements are graceful. Think once, how a hen would appear if she attempted to swim! The duck's body is so illy balanced on its short legs that it cannot run rapidly; and if chased even a short distance, will fall dead from the effort, as many a country child has discovered to his sorrow when he tried to drive the ducks home from the creek or pond to coop. The long, hind claw of the hen enables her to clasp a roost firmly during the night; a duck's foot could not do this and the duck sleeps squatting on the ground. However, the Muscovy ducks, which are not good swimmers, have been known to perch.

\section{LESSON VI}

\section{The Feet of Birds}

Leading thought-The feet of birds are shaped so as to assist the bird in getting its food as well as for locomotion.

Methods-The pupils should have opportunity to observe the chicken or hen and a duck as they move about; they should also observe the duck swimming.

Observations- $-\mathrm{I}$. Are the toes of the hen long and strong? Have they long, sharp claws at their tips?

2. How are the legs and feet of the hen covered and protected?

3. How are the hen's feet and legs fitted for scratching the earth, and why does she wish to scratch the earth?

4. Can a hen run rapidly? What sort of a track does she make?

5. You number your fingers with the thumb as number one and the little finger as five. How do you think the hen's toes are numbered?

6. Has the duck as many toes as the hen? What is the chief difference between the feet of the duck and the hen?

7. Which of the duck's toes are connected by a web? Does the web extend to the tips of the toes? What is the web for and how does it help the duck?

8. Are the duck's legs as long as the hen's? Are they placed farther forward or farther back than those of the hen? Are they farther apart?

9. Can a duck run as well as a hen? Can the hen swim at all?

Io. Where does the hen sleep and how does she hold on to her perch? Could the duck hold on to a perch? Does the duck need to perch while sleeping? 


\section{CHICKEN WAYS}

\section{Teacher's Story}

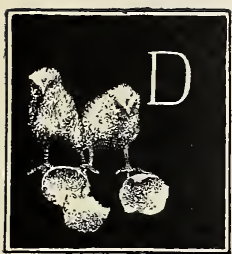

AME Nature certainly pays close attention to details, and an instance of this is the little tooth on the tip of the upper mandible of the young chick to aid it in breaking out of its egg-shell prison; and since a tooth in this particular place is of no use later, it disappears. The children are delighted with the beauty of a fluffy, little chick with its bright, questioning eyes and its life of activity as soon as it is freed from the shell. What a contrast to the blind, bare, scrawny young robin, which seems to be all mouth! The difference between the two is fundamental since it gives a character for separating ground birds from perching birds. The young partridge, quail, turkey and chick are clothed and active and ready to go with the mother in search of food as soon as they are hatched; while the young of the perching birds are naked and blind, being kept warm by the brooding mother, and fed and nourished by food brought by their parents, until they are large enough to leave the nest. The down which covers the young chick differs from the feathers which come later; the down has no quill but consists of several flossy threads coming from the same root; later on, this down is pushed out and off by the true feathers which grow from the same sockets. The

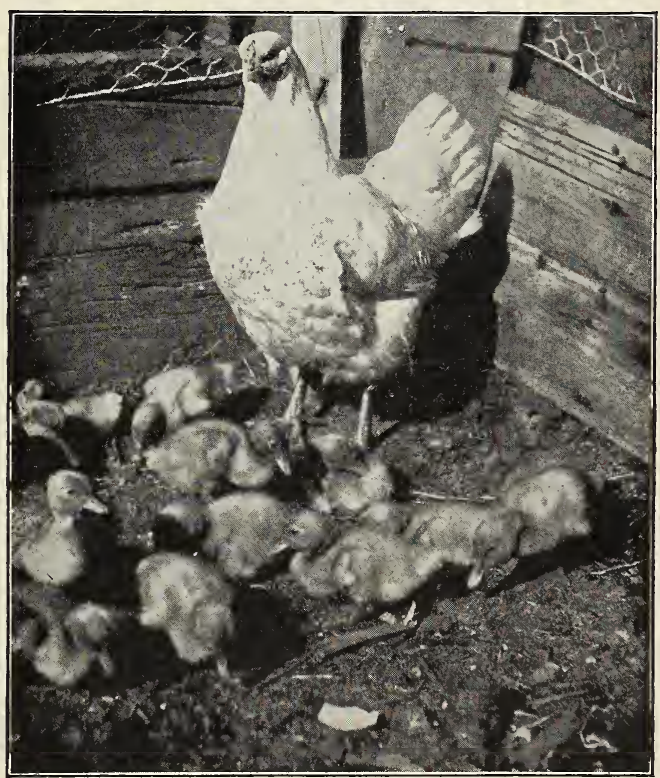

An anxious stepmother. 
pupils should see that the down is so soft that the little, fluffy wings of the chick are useless until the real wing feathers appear.

We chew food until it is soft and fine, then swallow it, but the chick swallows it whole and after being softened by juices from the stomach it passes into a little mill, in which is gravel that the chicken has swallowed, which helps to grind the food. This mill is called the gizzard and the pupils should be taught to look carefully at this organ the next time they have chicken for dinner. A chicken has no muscles in the throat, like ours, to enable it to swallow water as we do. Thus, it has first to fill its

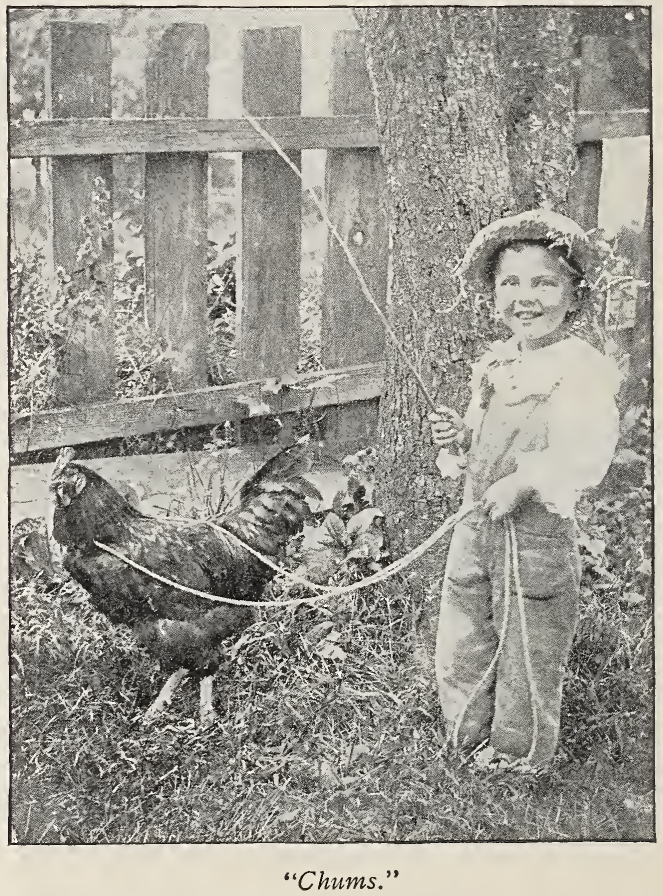

beak with water, then hold it up so the water will flow down the throat of itself. As long as the little chick has its mother's wings to sleep under, it does not need to put its head under its own wing; but when it grows up and spends the night upon a roost, it always tucks its head under its wing while sleeping.

The conversation of the barnyard fowl covers many elemental emotions and is easily comprehended. It is well for the children to understand from the first that the notes of birds mean something definite. The hen clucks when she is leading her chicks afield so that they will know where she is in the tall grass; the chicks follow "cheeping" or "peeping," as the children say, so that she will know where they are; but if a chick 
feels itself lost its "peep" becomes loud and disconsolate; on the other hand, there is no sound in the world so full of cosy contentment as the low notes of the chick as it cuddles under the mother's wing. When a hen finds a bit of food she utters rapid notes which call the chicks in a hurry, and when she sees a hawk she gives a warning "q-r-r" which makes every chick run for cover and keep quiet. When hens are taking their sun and dust baths together, they evidently gossip and we can almost hear them saying, "Did you not think Madam Dorking made a great fuss over her egg to-day?" Or, "that overgrown young rooster has got a crow to match his legs, has he not?" Contrast these low tones to the song of the hen as she issues forth in the first warm days of spring and gives to the world one of the most joyous songs of all nature. There is quite a different quality in the triumphant cackle of a hen telling to the world that she has laid an egg and the cackle which comes from being startled. When a hen is sitting or is not allowed to sit, she is nervous and irritable and voices her mental state by scolding. When she is really afraid, she squalls and when seized by an enemy, she utters long, horrible squawks. The rooster crows to assure his flock that all is well; he also crows to show other roosters what he thinks of himself and of them. The rooster also has other notes; he will question you as you approach him and his flock, and he will give a warning note when he sees a hawk; when he finds some dainty tidbit he calls his flock of hens to him and they usually arrive just in time to see him swallow the morsel.

When roosters fight, they confront each other with their heads lowered and then try to seize each other by the back of the neck with their beaks, or strike each other with the wing spurs, or tear with the leg spurs. Weasels, skunks, rats, hawks and crows are the most common enemies of the fowls, and often a rooster will attack one of these invaders and fight valiantly; the hen will also fight if her brood is disturbed.

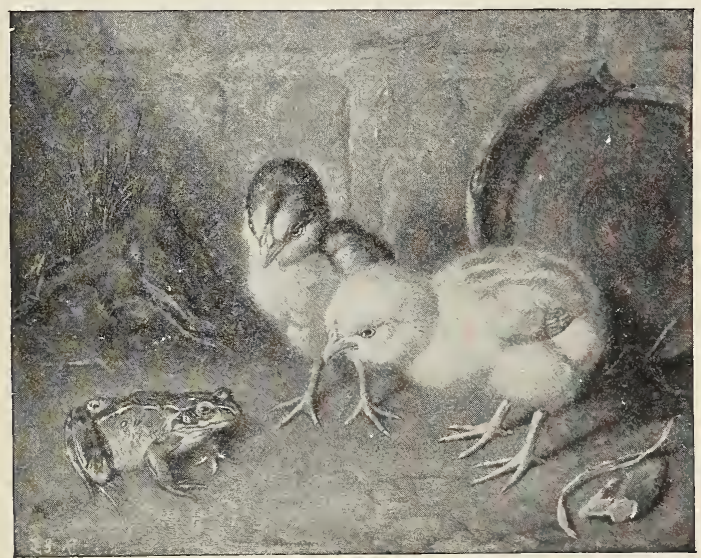

"Well, who are you?" 


\section{LESSON VII}

\section{Chicken Ways}

Leading thought-Chickens have interesting habits of life and extensive conversational powers.

Method-For this lesson it is necessary that the pupils observe the inhabitants of the poultry yard and answer these questions a few at a time.

Observations-I. Did the chick get out of the egg by its own efforts? For what use is the little tooth which is on the tip of the upper part of a young chicken's beak? Does this remain?

2. What is the difference between the down of the chick and the feathers of the hen? The little chick has wings; why can it not fly?

3. Why is the chick just hatched so pretty and downy, while the young robin is so bare and ugly? Why is the young chick able to see while the young robin is blind?

4. How does the young chick get its food?

5. Does the chick chew its food before swallowing? If not, why?

6. How does the chick drink? Why does it drink this way?

7. Where does the chick sleep at night? Where will it sleep when it is grown up?

8. Where does the hen put her head when she is sleeping? field?

9. How does the hen call her chicks when she is with them in the

ro. How does she call them to food?

I I. How does she tell them that there is a hawk in sight?

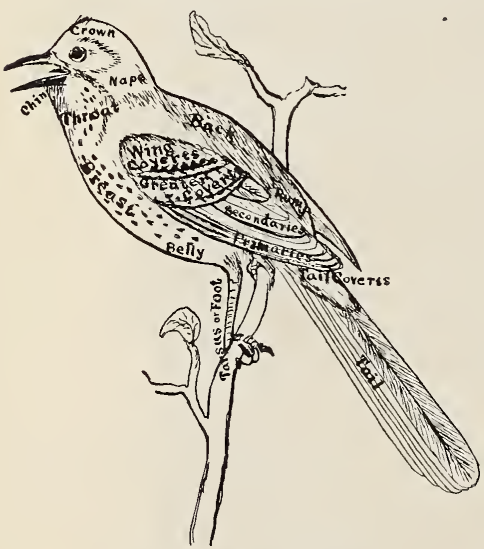

Parts of the bird labeled.

This figure shotild be placed on the blackboard where pupils may consult it when studying colors antid markings of birds.

I 2. What notes does the chick make when it is following its mother? When it gets lost? When it cuddles under her wing?

I3. What does the hen say when she has laid an egg? When she is frightened? When she is disturbed while sitting on eggs? When she is grasped by an enemy? How do hens talk together? Describe a hen's song.

I4. When does the rooster crow? What other sounds does he make?

I5. With what weapons does the rooster fight his rivals and his enemies?

I6. What are the natural enemies of the barnyard fowls and how do they escape them?

Supplementary reading-True Bird Stories, Miller p. Iо2. 


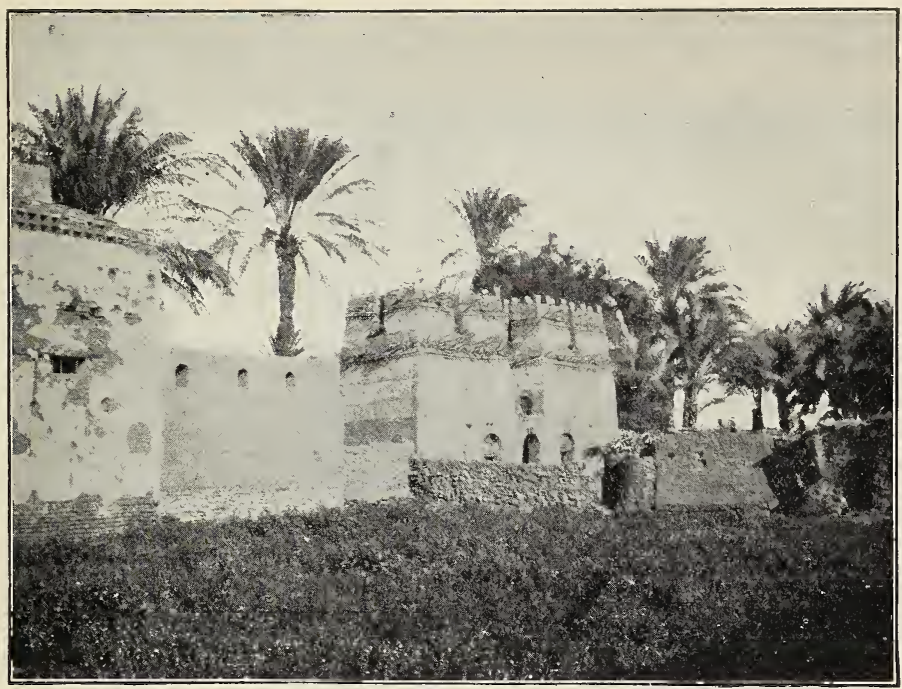

Pigeon houses of the upper Nile.

Photo by J. H. Comstock.

\section{PIGEONS}

\section{Teacher's Story}

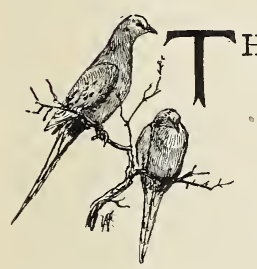

HERE is a mention of domesticated pigeons by writers three thousand years ago; and Pliny relates that the Romans were fervent pigeon fanciers at the beginning of the Christian era. All of our domestic varieties of pigeons have been developed from the Rock pigeon, a wild species common in Europe and Asia. The carrier pigeon was probably the first to be specially developed because of its usefulness; its love and devotion to mate and young and its homesickness when separated from them were used by man for his own interests. When a knight of old started off on a Crusade or to other wars, he took with him several pigeons from the home cote; and after riding many days he wrote a letter and tied it to the neck or under the wing of one of his birds, which he then set free, and it flew home with its message; later he would set free another in like manner. The drawback to this correspondence was that it went only in one direction; no bird from home brought message of cheer to the wandering knight. Now-a-days mail routes, telegraph wires and wireless currents enmesh our globe and the pigeon as a carrier is out-of-date; but fanciers still perfect the homer breed and train pigeons for very difficult flight competitions, some of them a distance of hundreds of miles. Recently. a homer made one thousand miles in two days, five hours and fifty minutes. Read to the pupils "Arnaux" in Animal Heroes by Thompson Seton to give them an idea of the life of a homing pigeon. 
The natural food of pigeons is grain; we feed them cracked corn, wheat, peas, Kafir corn, millet and occasionally hemp seed; it

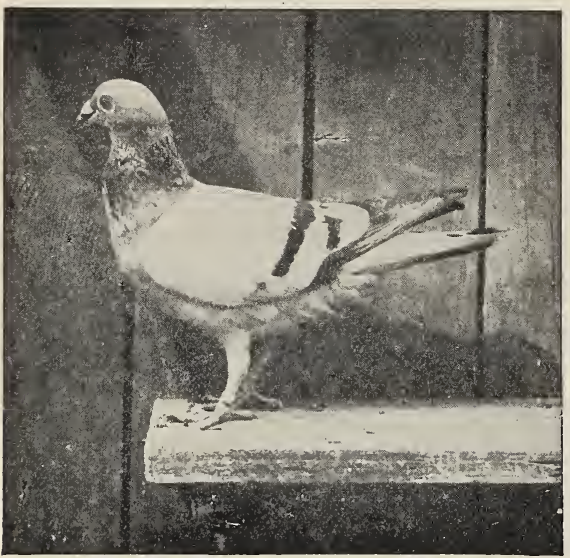

"Game Leg" a homer pigeon of notable achievement (Courtesy of Country Life in America.) is best to feed mixed rations as the birds tire of the monotonous diet. Pigeons should be fed twice a day; the pigeon is the only bird which call drink like a horse, that is, with the head lowered. The walk of a pigeon is accompanied by a peculiar nodding as if the head were in some way attached to the feet, and this movement sends waves of iridescent colors over the bird's plumage. The flight of the pigeon is direct without soaring, the wings move rapidly and steadily, the birds circling and sailing as they start or alight. The crow flaps hard and then sails for a distance when it is inspecting the ground, while the hawk soars on motionless wings. It requires closer attention to understand the language of the pigeon than that of the hen, nor has it so wide a range of expression as the latter; however, some emotions are voiced in the cooing, which the children will understand.

The nest is built of grass and twigs; the mother pigeon lays two eggs for a sitting; but in some breeds a pair will raise from seven to twelve broods per year. The eggs hatch in from sixteen to eighteen days, and both parents share the labors of incubating. In the case of the homer the father bird sits from Io A. M. to 4 P. M. and the mother the remainder of the day and night. The devotion of pigeons to their mates and to their young is great, and has been sung by the poets and praised by the philosophers during many ages; some breeds mate for life. The young pigeons or squabs are fed in a peculiar manner; in the crops of both parents is secreted a cheesy substance, known as pigeon milk. The parent seizes the beak of the squab in its own and pumps the food from its own crop into the stomach of the young. This nutritious food is given to the squab for about five days and then replaced by grain which is softened in the parents' stomachs, until the squabs are old enough to feed themselves. Rats, mice, weasels, and hawks are the chief enemies of the pigeons; since pigeons cannot fight, their only safety lies in flight.

As the original Rock pigeon built in caves, our domesticated varieties naturally build in the houses we provide for them. A pigeon house should not be built for more than fifty pairs; it should be well ventilated and kept clean; it should face the south or east and be near a shallow, running stream if possible. The nest boxes should be twelve inches square and nine inches in height with a door at one side, so 
that the nest may remain hidden. In front of each door there should be a little shelf to act as a balcony on which the resting parent bird may sit and coo to relieve the monotony of the sitter. Some breeders make a double compartment instead of providing a balcony, while in Egypt branches are inserted in the wall just below the doors of the very ornamental pigeon houses. The houses should be kept clean and whitewashed with lime to which carbolic acid is added in the proportion of one teaspoonful of acid to two

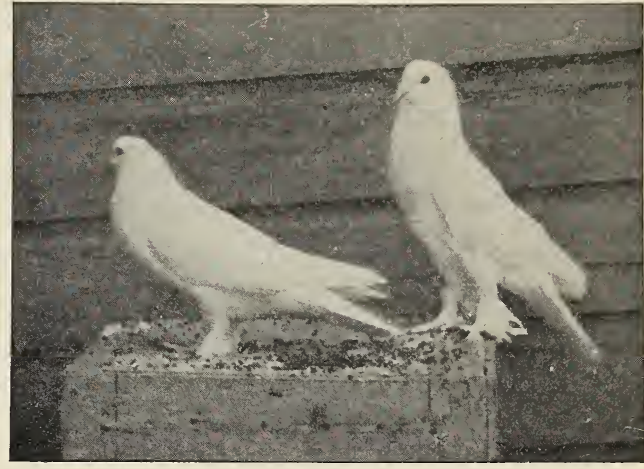

Pouter pigeons

Photo by J. Demary

gallons of the wash; the leaf stems of tobacco should be given to the pigeons as material for building their nests, so as to help keep in check the bird lice. There should be near the pigeon house plenty of fresh water for drinking and bathing; also a box of table salt, and another of cracked oyster shell and another of charcoal as fine as ground coffee. Salt is very essential to the health of pigeons. The house should be high enough from the ground to keep the inmates safe from rats and weasels.

\section{LESSON VIII}

\section{Pigeons}

Leading thought-The pigeons differ in appearance from other birds and also in their actions. Their nesting habits are very interesting and there are many things that may be done to make the pigeons comfortable. They were, in ancient days, used as letter carriers.

Methods-If there are pigeons kept in the neighborhood, it is best to encourage the pupils to observe these birds out-of-doors. Begin the work with an interesting story and with a few questions which will arouse the pupils' interest in the birds. A pigeon in a cage in the schoolroom for a special lesson on the bird's appearance, is desirable but not necessary.

Observations-r. For an out-of-door exercise during recess let the pupils observe the pigeon and tell the colors of the beak, eyes, top of the head, back, breast, wings, tail, feet and claws. This exercise is excellent training to fit the pupils to note quickly the colors of the wild birds.

2. On what do pigeons feed? Are they fond of salt?

3. Describe how a pigeon drinks. How does it differ in this respect from other birds?

4. Describe the peculiar movement of the pigeon when walking.

5. Describe the pigeon's flight. Is it rapid, high in the air, do the wings flap constantly, etc? What is the chief difference between the flight of pigeons, crows or hawks? 
6. Listen to the cooing of a pigeon and see if you can understand the different notes.

7. Describe the pigeon's nest. How many eggs are laid at a time?

8. Describe how the parents share the labors in hatching the eggs. and how long after the eggs are laid before the young hatch?

9. How do the parents feed their young and on what material?

Io. What are the enemies of pigeons and how do they escape from them? How can we protect them?

rr. Describe how a pigeon house should be built.

r 2. What must you do for pigeons to keep them healthy and comfortable?

I3. How many breeds of pigeons do you know? Describe them.

Supplementary reading- "Arnaux" in Animal Heroes, Thompson Seton; Audubon Leaflet, Nos. 2 and 6; Neighbors with Wings and Fins Ch. XV; Noah and the Dove, The Bible; Daddy Darwin's Dove Cote, Mrs. Ewing; Squab Raising, Bul. of U. S. Dept. Agr.

For my own part I readily concur with you in supposing that housedoves are derived from the small blue rock-pigeon, Columba livia, for many reasons. * * * But what is worth a hundred arguments is, the instance you give in Sir Roger Mostyn's housedoves in Carnarvonshire; which, though tempted by plenty of food and gentle treatment, can never be prevailed on to inhabit their cote for any time; but as soon as they begin to breed, betake themselves to the fastnesses of Ormshead, and deposit their young in safety amidst the inaccessible caverns and precipices of that stupendous promontory. "You may drive nature out with a pitchfork, but she will always return:"

"Naturam expellas furca * * * tamen usque recurret."

Virgil, as a familiar occurrence, by way of simile, describes a dove haunting the cavern of a rock in such engaging numbers, that I cannot refrain from quoting the passage.

"Qualis spelunca subito commota Columba, Cui domus, et dulces latebroso in pumice nidi,

Fertul in arva volans, plausumque exterrita pennis

Dat tecto ingentem, mox aere lapsa quieto,

Radit iter liquidum, celeres neque commovet alas."

(Virg. Aen. v. 2I $3^{-2}$ I 7 ).

"As when a dove her rocky hold forsakes,

Roused, in a fright her sounding wings she shakes;

The cavern rings with clattering:-out she flies,

And leaves her callow care, and cleaves the skies;

At first she flutters:-but at length she springs

Io smoother flight, and shoots upon her wings."

(Dryden's Translation).

White of Selbourne. 


\section{THE CANARY AND THE GOLDFINCH}

\section{Teacher's Story}

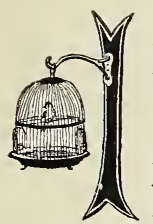

$\mathrm{N}$ childhood the language of birds and animals is learned unconsciously. What child, who cares for a canary, does not understand its notes which mean loneliness, hunger, eagerness, joy, scolding, fright, love and song!

The pair of canaries found in most cages are not natural mates. The union is one de convenance, forced upon them by people who know little of bird affinities. We could hardly expect that such a mating would be always happy. The singer, as the male is called, is usually arbitrary and tyrannical and does not hesitate to lay chastising beak upon his spouse. The expression of affection of the two is usually very practical, consisting of feeding each other with many beguiling notes and much fluttering of wings. The singer may have several songs; whether he has many or few depends upon his education; he usually shows exultation when singing by throwing the head back like a prima-donna, to let the music well forth. He is usually brighter yellow in color with more brilliantly black markings than his mate; she usually has much gray in her plumage. But there are about fifty varieties of canaries and each has distinct color and markings.

Canaries should be given a more varied diet than most people think. The seeds we buy or that we gather from the plantain or wild grasses, they eat eagerly. They like fresh, green leaves of lettuce and chickweed and other tender herbage; they enjoy bread and milk occasionally. There should always be a piece of cuttle-fish bone or sand and gravel where they can get it, as they need grit for digestion. Above all, they should have fresh water. Hard-boiled egg is given them while nesting. The canary seed which we buy for them is the product of a grass in the Canary Islands. Hemp and rape seed are also sold for canary food.

The canary's beak is wide and sharp and fitted for shelling seeds; it is not a beak fitted for capturing insects. The canary, when drinking, does not have to lift the beak so high in the air in order to swallow the water as do some birds. The nostrils are in the beak and are easily seen; the ear is hidden by the feathors. The canary is a fascinating little creature when it shows interest in an object; it has such a knowing look, and its perfectly round, black eyes arc so intelligent and cunning. If the canary winks, the act is so rapid as to be seen with difficulty, but when drowsy, the little inner lid appears at the inner corner of its eye and the outer lids close so that we may be sure that they are there; the lower lid covers more of the cye than the upper.

The legs and toes are covered with scale armor; the toes have long, curved claws that are neither strong nor sharp but are especially fitted for holding to the perch; the long hind toe with its stronger claw makes complete the grasp on the twig. When the canary is hopping about on the bottom of the cage we can see that its toes are more fitted for holding to the perch than for walking.

When the canary bathes, it ducks its head and makes a great splashing with its wings and likes to get thoroughly wet. Afterward, it sits all bedraggled and "humped up" for a time and then usually preens its feathers as they dry. When going to sleep, it at first fluffs out its feathers and squats on the perch, draws back its head and looks very drowsy. 
Later it tucks its head under its wing for the night and then looks like a little ball of feathers on the perch.

Canaries make a great fuss when building their nest. A pasteboard box is usually given them with cotton and string for lining; usually one pulls out what the other puts in; and they both industriously tear the paper from the bottom of the cage to add to their building material. Finally, a make-shift of a nest is completed and the eggs are laid. If the singer is a good husband, he helps incubate the eggs and feeds his mate and sings to her frequently; but often he is quite the reverse and abuses her abominably. The nest of the caged bird is very different in appearance from the neat nests of grass, plant down, and moss which the wild. ancestors of these birds made in some safe retreat in the shrubs or evergreens of the Canary Islands. The canary eggs are pale blue, marked with reddish-brown. The incubation period is I 3 to 14 days. The young are as scrawny and ugly as most little birds and are fed upon food partially digested in the parents' stomachs. Their first plumage resembles that of the mother usually.

In their wild state in the Canary and Azore Islands, the canaries are olive green above with golden yellow breasts. When the heat of spring begins, they move up the mountains to cooler levels and come down again in the winter. They may rear three or four broods on their way up the mountains, stopping at successive heights as the season advances, until finally they reach the high peaks.

\section{THE GOLDFINCH OR THISTLE BIRD}

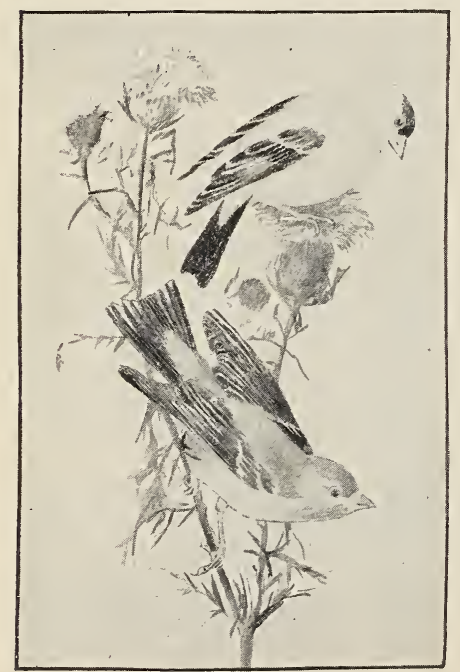

A pair of goldfinches.

(Courtesy of Audubon Educational Leaflet No. 17).
The goldfinches are bird midgets but their songs are so sweet and reedy that they seem to fill the world with music more effectually than many larger birds. They are fond of the seeds of wild grass, and especially so of thistle seed; and they throng the pastures and fence corners where the thistles hold sway. In summer, the male has bright yellow plumage with a little black cap "pulled down over his nose" $1 \mathrm{ike}$ that of a grenadier. He has also a black tail and wings with white-tipped coverts and primaries. The tail feathers have white on their inner webs also, which does not show when the tail is closed. The female has the head and back Drown and the under parts yellowish white, with wings and tail resembling those of the maie except that they are not so vividly black. In winter the male dons a dress more like that of his mate; he loses his

black cap but keeps his black wings and tail. 
The song of the goldfinch is exquisite and he sings during the entire period of his golden dress; he sings while flying as well as when at rest. The flight is in itself beautiful, being wave-like up and down, in graceful curves. Mr. Chapman says when on the down half of the curve the male sings "Per-chick or-ree." The goldfinch's call notes and alarm notcs are very much like those of the canary.

Since the goldfinches live so largely upon seeds of grasses, they stay with us in small numbers during the winter. During this period both parents and young are dressed in olive green, and their sweet call notes are a surprise to us of a cold, snowy morning, for they are associated in our memory with summer. The male dons his winter suit in October.

The goldfinch nest is a mass of fluffiness. These are the only birds that make feather beds for their young. But, perhaps, we should say beds of down, since it is the thistle down which is used for this mattress. The outside of the nest consists of fine shreds of bark or fine grass closely woven; but the inner portion is a mat of thistle down-an inch and a half thick of cushion for a nest which has an opening of scarcely three inches; sometimes the outside is ornamented with lichens. The nest is usually placed in some bush or tree, often in an evergreen, and not more than 5 or 6 feet from the ground; but sometimes it is placed 30 feet high. The eggs are from four to six in number and bluish white in color. The female builds the nest, her mate cheering her with song meanwhile; he feeds her while she is incubating and helps feed the young. A strange thing about the nesting habits of the goldfinches is that the nest is not built until August. It has been surmised that this nesting season is delayed until there is an abundance of thistle down for building material. Audubon Leaflet No. I7 gives special information about these birds and also furnishes an outline of the birds for the pupils to color.

\section{LESSON IX}

\section{The Canary and the Goldfinch}

Leading thought-The canary is a very close relative of the common wild goldfinch. If we compare the habits of the two we can understand how a canary might live if it were free.

Method-Bring a canary to the schoolroom and ask for observations. Request the pupils to compare the canary with the goldfinches which are common in the summer. The canary offers opportunity for very close observation which will prove excellent training for the pupils for beginning bird study.

Observations- - I. If there are two canaries in the cage are they always pleasant to each other? Which one is the "boss?" How do they show displeasure or bad temper? How do they show affection for each other?

2. Which one is the singer? Does the other one ever attempt to sing? What other notes do the canaries make besides singing? How do they greet you when you bring their food? What do they say when they are lonesome and hungry?

3. Does the singer have more than one song? How does he act while singing? Why does he throw back his head like an opera singer when singing? 
4. Are the canaries all the same color? What is the difference in color between the singer and the mother bird? Describe the colors of each in your note book as follows: Top and sides of head, back, tail, wings, throat, breast and under parts?

5. What does the canary eat? What sort of seeds do we buy for it? What seeds do we gather for it in our garden? Do the goldfinches live on the same seeds? What does the canary do to the seeds before eating them? What tools does he use to take off the shells?

6. Notice the shape of the canary's beak. Is it long and strong like a robin's? Is it wide and sharp so that it can shell seeds? If you should put an insect in the cage would the canary eat it?

7. Why do we give the canary cuttlebone? Note how it takes off pieces of the bone. Could it do this if its beak were not sharp?

8. Note the actions of the birds when they drink. Why do they do this?

9. Can you see the nostrils? Where are they situated? Why can you not see the ear?

Io. When the canary is interested in looking at a thing how does it act? Look closely at its eyes? Does it wink? How does it close its eyes? When it is drowsy can you see the little inner lid come from the corner of the eye nearest the beak? Is this the only lid?

II. How are the legs and feet covered? Describe the toes. Compare the length of the claw with the length of the toe. What is the shape of the claw? Do you think that such shaped claws and feet are better fitted for holding to a branch than for walking? Note the arrangement of the toes when the bird is on its perch. Is the hind toe longer and stronger? If so, why? Do the canaries hop or walk about the bottom of the cage?

I 2. What is the attitude of the canary when it goes to sleep at night? How does it act when it takes a bath? How does it get the water over its head? Over its back? What does it do after the bath? If we forget to put in the bath dish how does the bird get its bath?

\section{NESTING HABITS TO BE OBSERVED IN THE SPRING}

I3. When the canaries are ready to build a nest what material do we furnish them for it? Does the father bird help the mother to build the nest? Do they strip off the paper on the bottom of the cage for nest material? Describe the nest when it is finished.

I 4. Describe the eggs carefully. Does the father bird assist in sitting on the eggs? Does he feed the mother bird when she is sitting?

I5. How long after the eggs are laid before the young ones hatch? Do both parents feed the young? Do they swallow the food first and partially digest it before giving it to the young?

I6. How do the very young birds look? What is their appearance when they leave the nest? Does the color of their plumage resemble that of the father or the mother?

I 7 . Where did the canaries originally come from? Find the place on the map.

Supplementary reading- "A Caged Bird," Sarah Orne Jewett in Songs of Nature, p. 75; True Bird Stories, Miller. 


\section{The Goldfinch}

Leading thought-Goldfinches are seen at their best in late summer or September when they appear in flocks wherever the thistle seeds are found in abundance. Goldfinches so resemble the canaries in form, color, song and habits that they are called wild canaries.

Method-The questions for this lesson should be given to the pupils before the end of school in June. The answers to the questions should be put in their field note-books and the results be reported to the teacher in class when the school begins in the autumn.

Observations - $\mathrm{r}$. Where do you find the goldfinches feeding? How can you distinguish the father from the mother birds and from the young ones in color?

2. Describe the colors of the male goldfinch and also of the female as follows: Crown, back of head, back, tail, wings, throat, breast and lower parts. Describe in particular the black cap of the male.

3. Do you know the song of the goldfinch? Is it like the song of the canary? What other notes has the goldfinch?

4. Describe the peculiar flight of the goldfinches. Do they fly high in the air? Do you see them singly or in flocks usually?

5. Where do the goldfinches stay during the winter? What change takes place in the coat of the male during the winter? Why? What do they live upon during the winter?

6. At what time of year do the goldfinches build their nests? Why do they build these so much later than other birds? Describe the nest. Where is it placed? How far above the ground? How far from a stream or other water? Of what is the outside made? The lining? What is the general appearance of the nest? Do you think the goldfinches wait until the thistles are ripe in order to gather plenty of food for their young, or to get the thistle down for their nests? What is the color of the eggs?

Supplementary reading-True Bird Stories, Miller, pp. 6, 9, 26, 45. The Second Book of Birds, Miller, p. 82; Our Birds and Their Nestlings, Walker, pp. I8ô, 200.

Sometimes goldfinches one by one will drop

From low-hung branches; little space they stop,

But sip, and twitter, and their feathers sleek,

Then off at once, as in a wanton freak;

Or perhaps, to show their black and golden wings;

Pausing upon their yellow flutterings.

-JoHn KeAts. 


\section{THE ROBIN}

\section{Teacher's Story}

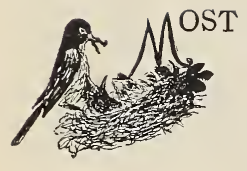

of us think we know the robin well, but very few of us know definitely the habits of this, our comrionest bird. The object of this lesson is to form in the pupils a habit of careful observation, and enable them to read for themselves the interesting story of this little life which is lived every year before their eyes. Moreover, a robin note-book, if well kept, is a treasure for any child; and the close observation necessary for this lesson trains the pupils to note in a comprehending way the habits of other birds. It is the very best preparation for bird study of the right sort.

A few robins occasionally find a swamp where they can obtain food to nourish them during the northern winter, but for the most part, they go in flocks to our Southern States where they settle in swamps and cedar forests and live upon berries. They are killed in great numbers by the native hunters who eat them or sell them for table use, a performance not understandable to the northerner. The robins do not nest nor sing while in Southland, and no wonder! When the robins first come to us in the spring they feed on wild berries, beirig especially fond of those of the Virginia creeper. As soon as the frost is out of the ground they begin feeding on earthworms, cutworms, white grubs, and other insects. The male robins come first, but do not sing until their mates arrive.

The robin is ten inches long and the English sparrow is only six and one-third inches long; the pupils should get the sizes of these two birds fixed in their minds for comparison in measuring othicr birds. The father robin is much more decided in color than his mate; his beak is yellow, there is a yellow ring about the eye and a white spot above it. The head is black and the back slaty-brown; the breast is brilliant reddish brown or bay and the throat is white, streaked with black. The mother bird has paler back and breast and has no black upon the head. The wings of both are a little darker than the back, the tail is black with the two outer feathers tipped with white. These white spots do not show except when the bird is flying and are "call colors," that is, they enable the birds to see each other and thus keep together when flying in flocks during the night. The white patch made by the under tail-coverts serves a similar purpose. The feet and legs are strong and dark in color.

The robin has many sweet songs and he may be heard in the earliest dawn and also in the evenings; if he wishes to cheer his mate he may burst into song at any time. He feels especially songful before the summer showers when he seems to sing, "I have a theory, a theory, its going to rain." And he might well say that he also has a theory, based on experience, that a soaking shower will drive many of the worms and larvæ in the soil up to the surface where he can get them. Besides these songs the robins have a great variety of notes which the female shares, although she is not a singer. The agonizing, angry cries they utter when they see a cat or squirrel must express their feelings fully; while they give a very different warning note when they see crow or hawk, a note hard to describe, but which is a long, not very loud squeak.

A robin can run or hop as pleases him best, and it is interesting to see one, while hunting earthworms run a little distance, then stop to bend the 
head and listen for his prey, and when he finally seizes the earthworm he braces himself on his strong legs and tugs manfully until he sometimes almost falls over backward as the worm lets go its hold. The robins, especially at nesting time, eat many insects as well as earthworms.

The beginning of a robin's nest is very interesting; much strong grass, fine straw, leaves and rootlets are brought and placed on a secure support. When enough of this material is collected and arranged, the bird goes to the nearest mud puddle or stream margin and fills its beak with soft mud and going back "peppers" it into the nest material, and after the latter is soaked the bird gets into it and molds it to the body by nestling and turning around and around. In one case which the author watched the mother bird did this part of the building, although the father worked industriously in bringing the other materials. After the nest is molded but not yet hardened, it is lined with fine grass or rootlets. If the season is very dry and there is no soft mud at hand, the robins can build without the aid of this plaster. There are usually four eggs laid which are exquisite greenish blue in color.

Both parents share the monotonous business of incubating, and in the instance under the eyes of the author the mother bird was on the nest at night; the period of incubating is from eleven to fourteen days. The most noticeable thing about à very young robin is its wide, yellowmargined mouth, which it opens like a satchel every time the nest is jarred. This wide mouth cannot but suggest to anyone that it is meant

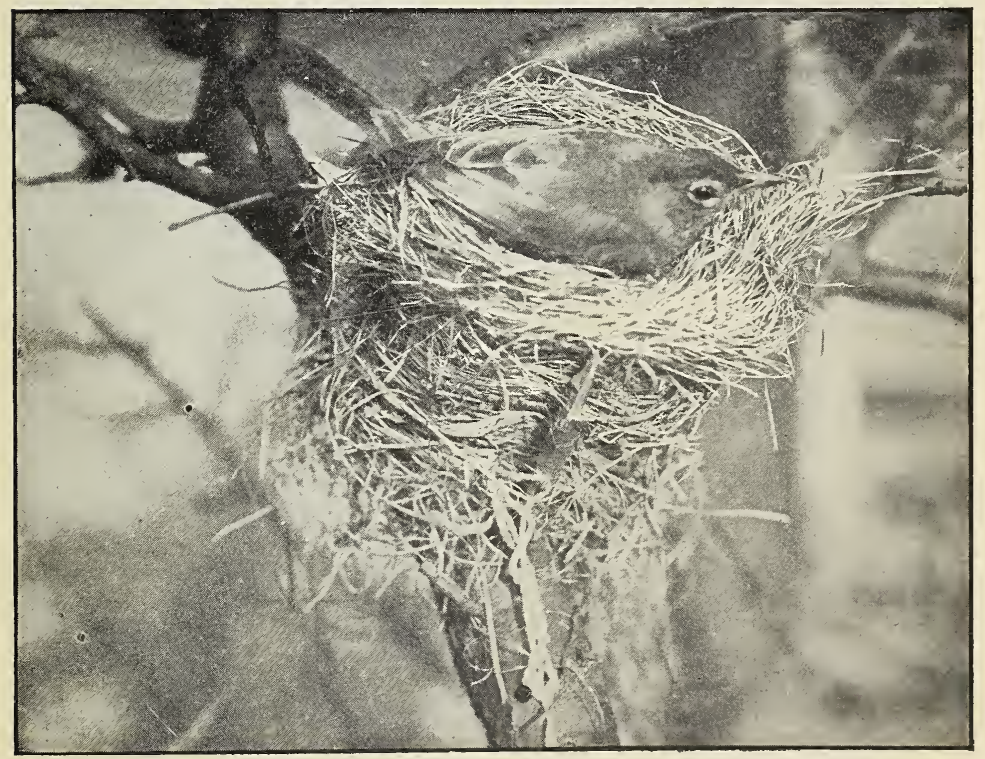

Robin on nest. 
to be stuffed, and the two parents work very hard to fill it. Both parents feed the young and often the father feeds the mother bird while she is brooding. Professor Treadwell experimented with young robins and found that each would take 68 earthworms daily; these worms if laid end to end would measure about i 4 feet. Think of i 4 feet of earthworm being wound into the little being in the nest, no wonder that it grows so fast! I am convinced that each pair of robins about our house has its own special territory for hunting worms, and that any trespasser is quickly driven off. The young bird's eyes are unsealed when they are from six to eight days old, and by that time the feather tracts, that is, the place where the feathers are to grow, are covered by the spine-like pin-feathers; these feathers push the down out and it often clings to their tips. In eleven days the birds are pretty well feathered; their wing feathers are fairly developed but alas, they have no tail feathers! When a young robin flies from the nest he is a very uncertain and tippy youngster not having any tail to steer him while flying, nor to balance him when alighting.

It is an anxious time for the old robins when the young ones leave the nest, and they flutter about and scold at any one who comes in sight, so afraid are they that injury will come to their inexperienced young ones; for some time the parents care for the fledglings, solicitously feeding them and giving them warnings of danger. The young robin shows in its plumage its relation to the thrush family, for it is yellowish and very spotted and speckled, especially the breast. The parents may raise several broods, but they never use the same nest for two consecutive broods, both because it may be infested with parasites and because it is more or less soiled; although the mother robin works hard to keep it clean, carrying away all waste matter in her beak and dropping it. Robins do not sing much after the breeding season is over until after they have molted. They are fond of cherries and other pulp fruits and often do much damage to such crops. The wise orchardist will plant a few Russian mulberry trees at a reasonable distance from his cherry trees, and thus, by giving the robins a fruit which they like better, and which ripens a little earlier, he may save his cherries. It has been proven conclusively that the robins are far more beneficial than damaging to the farmer; they destroy many noxious insects, two-thirds of their food the entire year consisting of insects; during April and May they do a great work in destroying cutworms.

The robins stay with us later than most migrating birds, not leaving us entirely before November. Their chief enemies in northern climates are cats, crows and squirrels. Cats should be taught to let birds alone (see lesson on cat) or should be killed. The crows have driven the robins into villages where they can build their nests under the protection of man. If crows venture near a house to attack the robins, firing a gun at them once or twice will give them a hint which they are not slow to take. The robins of an entire neighborhood will attack a nest-robbing crow, but usually too late to save the nestlings. The robins can defend themselves fairly well against the red squirrel unless he steals the contents of the nest while the owners are away. There can be no doubt that the same pair of robins return to the same nesting place year after year. On the Cornell Campus a robin lacking the white tip on one side of his tail was noted to have returned to the same particular feeding ground for several years; 
and we are very certain that the same female bird built in the vines of our piazza for seven consecutive years; it took two years to win her confidence; but after that, she seemed to feel as if she were a part of the family and regarded us all as friends. We were sure that during her fifth year she brought a new young husband to the old nesting site; probably her faithful old husband had been served for a dinner in some Tennessee hotel during the previous winter.

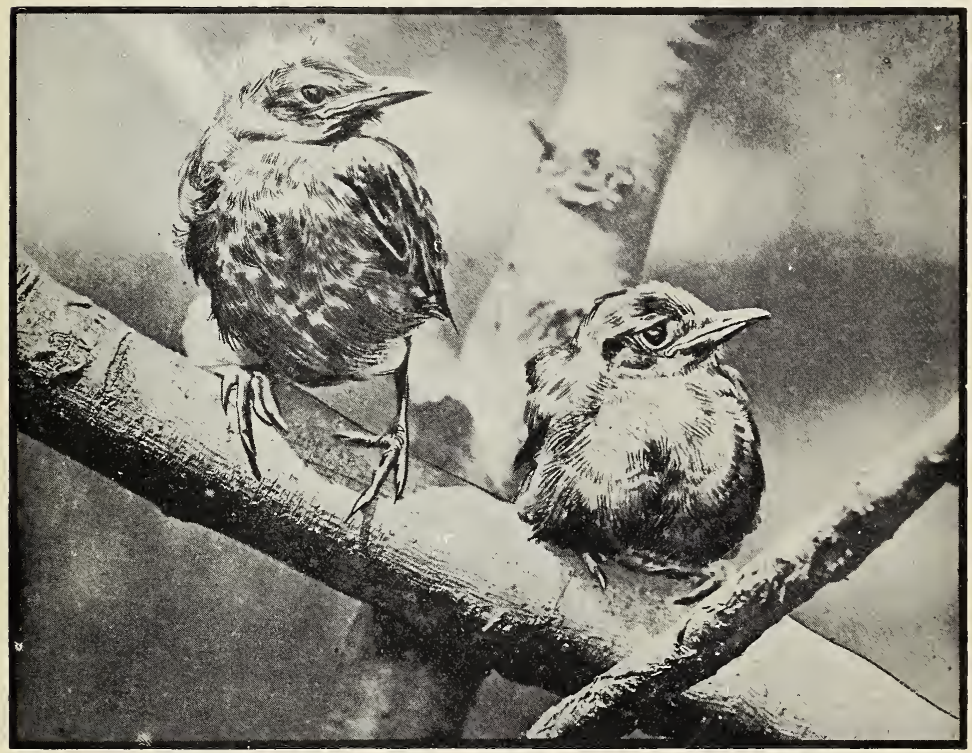

Young robins. Their spotted breasts show their relationship to the thrushes.

(Photo by Silas Lottridge).

\section{LESSON $\mathrm{X}$}

\section{The Robin}

Leading thought-To understand all we can about the life and ways of the robin.

Methods-For first and second grades this work may be done by means of an extra blackboard, or what is far better, sheets of ordinary, buff, manilla wrapping paper fastened together at the upper end, so that they may be hung and turned over like a calendar. On the outside page make a picture of a robin in colored chalk or crayons, coloring according to the children's answers to questions of series " $b$ ". Devote each page to one series of questions, as given below. Do not show these questions to the pupils until the time is ripe for the observations. Those pupils giving accurate answers to these questions should have their names on a roll of honor on the last page of the chart. 
For third or higher grades the pupils should have individual notebooks in which each one may write his own answers to the questions of the successive series, which should be written on the blackboard at proper time for the observations. This note-book should have a page about $6 \times 8$ inches and may be made of any blank paper. The cover or first page should show the picture of the robin colored by the pupil, and may contain other illustrative drawings, and any poems or other literature pertinent to the subject. If prizes are awarded in the school, a bird book should be given as award for the best note-book in the class.

Observations by pupils-Series a (To be given in March). I. At what date did you see the first robin this year?

2. Where did the robin spend the winter; did it build a nest or sing when in its winter quarters?

3. What does it find to eat when it first comes in the spring? How does this differ from its ordinary food?

4. Does the robin begin to sing as soon as it comes North?

Series $b$ (To be given the first week of April). I. How large is the robin compared with the English sparrow?

2. What is the color of the beak? The eye? Around and above the eye?

3. The color of the top of the head? The back? The throat? The breast?

4. Do all the robins have equally bright colors on head, back and breast?

5. What is the color of the wing feathers?

6. What is the color of the tail feathers? Where is the white on them? Can the white spots be seen except during flight of the bird? Of what use to the robin are these spots?

7. Is there white on the underside of the robin as it flies over you? Where?

8. What is the color of the feet and legs?

Series c (To be given the second week of April).

I. At what time of day does the robin sing? Is it likely to sing before a rain? How many different songs does a robin sing?

2. What note does a robin give when it sees a cat?

3. What sounds do the robins make when they see a crow or a hawk?

4. Does a robin run or walk or hop?

5. Do you think it finds the hidden earthworm by listening? If so describe the act.

6. Describe how a robin acts as it pulls a big earthworm out of the ground.

7. Do robins eat other food than earthworms?

Series $d$ (To be given by the middle of April). I. At what date did your pair of robins begin to build their nest?

2. Where was the nest placed and with what material was it begun?

3. Can you tell the difference in colors between the father and mother birds? Do both parents help in making the nest?

4. How and with what material is the plastering done? How is the nest molded into shape? Do both birds do this part of the work? 
5. Where is the mud obtained and how carried to the nest?

6. How is the nest lined?

Series e (To be given a week after series $d$ ). I. What is the number and color of the eggs in the nest?

2. Do both parents do the sitting? Which sits on the nest during the night?

3. Give the date when the first nestling hatches.

4. How does the young robin look? The color and size of its beak? Why is its beak so large? Can it see? Is it covered with down? Compare it to a young chick and describe the difference between the two.

5. What does the young robin do if it feels any jar against the nest? Why does it do this?

6. Do the young robins make any noise?

7. What do the parents feed their young? Do both parents feed them? Are the young fed in turns?

8. Does each pair of robins have a certain territory for hunting worms which is not trespassed upon by other robins?

Series $f$ (To be given three days after series $e$ ). I. How long after hatching before the young robin's eyes are open? Can you see where the feathers are going to grow? How do the young feathers look?

2. How long after hatching before the young birds are covered with feathers?

3. Do their wing or tail feathers come first?

4. How is the nest kept clean?

5. Give the date when the young robins leave the nest? How do the old robins act at this important crisis?

6. Describe the young robin's flight? Why is it so unsteady?

7. How do the young robins differ in colors of breast from the parents?

8. Do the parents stay with the young for a time? What care do they give them?

9. If the parents raise a second brood do they use the same nest?

Series $g$ (To be given for summer reading and observations). I. Do the robins sing all summer? Why?

2. Do the robins take your berries and cherries? How can you prevent them from doing this?

3. How does the robin help us?

4. How long does it stay with us in the fall?

5. What are the chief enemies of the robin and how does it fight or escape them? How can we help protect it?

6. Do you think the same robins come back to us each year?

Supplementary reading-Nestlings of Forest and Marsh, Wheelock p. 62; Our Birds and their Nestlings, Walker, pp. 26, 37, 4I, 42; True Bird Stories, Miller, pp. 37, I38; The Bird Book, Eckstrom, p. 248; Familiar Wild Animals, Lottridge; The History of the Robins, Trimmer; Field Book of Wild Birds and their Music, Mathews, p. 246; Birds in Their Relation to Man, Weed and Dearborn, p. 90; Songs of Nature, Burroughs, p. 94; Wake Robin, Burroughs; Audubon Leaflet No. 4 . 


\section{THE BLUEBIRD}

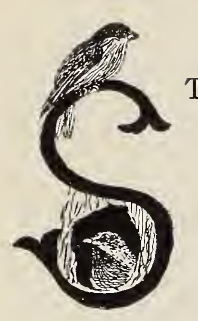

\section{Teacher's Story}

TERN as were our Pilgrim Fathers, they could not fail to welcome certain birds with plumage the color of June skies, whose sweet voices brought hope and cheer to their homesick hearts at the close of that first, long, hard winter of $162 \mathrm{I}$. The red breasts of these birds brought to memory the robins of old England and so they were called "Blue robins"; and this name expresses well the relationship implied, because the bluebirds and robins of America are both members of the thrush family, a family noted for exquisite song.

The bluebirds are usually ahead of the robins in the northward journey and arrive in New York often amid the blizzards of early March, their soft, rich "curly" notes bringing, even to the doubting mind, glad convictions of coming spring. There is a family resemblance between voices of bluebird and robin, a certain rich quality of tone, but the robin's song is far more assertive and complex than is the soft, "purling" song of the bluebird, which has been vocalized as "tru-al-ly, tru-al-ly." These love songs cease with the hard work of feeding the nestlings in April, but may be heard again as a prelude to the second brood in June. The red breast of the bluebird is its only color resemblance to the robin, although the young bluebirds and robins are both spotted, showing the thrush colors. The robin is so much larger than the bluebird that commonly the relationship is not noticed. This is easily explained because there is nothing to suggest a robin in the exquisite cerulean blue of the bluebird's head, back, tail and wings. This color is most brilliant when the bird is on the wing, in the sunshine. However, there is a certain mirror-like quality in these blue feathers; and among leaf shadows or even among bare branches they in a measure, reflect the surroundings and render the bird less noticeable. The female is paler, being grayish blue above and with only a tinge of redbrown on the breast; both birds are white beneath.

The bluebirds haunt open woods, fields of second growth and especially old orchards. They flit about in companies of three or four until they mate for nesting. While feeding, the bluebird usually sits on a low branch keeping a keen eye on the ground below, now and then dropping suddenly on an unsuspecting insect and then returning to its perch; it does not remain on the ground hunting food as does the robin. The nest is usually built in a hole in a tree or post and is made of soft grass. A hollow apple tree is a favorite nesting site.

In building birdhouses we should bear in mind that a cavity about ten inches deep and six inches in height and width will give a pair of bluebirds room for building a nest. The opening should not be more than two or two and one-half inches in diameter and there should be no threshold; this latter is a very particular point. If there is a threshold or place to alight upon, the sparrows are likely to dispute with the bluebirds and drive them away, but the sparrow does not care for a place which has no threshold. The box for the bluebird may be made out of old boards or may be a section of an old tree trunk; it should be fastened from six to fifteen feet above the ground, and should be in nowise noticeable in color from its surroundings. To protect the nest from cats, barbed wire should 
be wound around the tree or post below the box. If the box for the nest is placed upon a post the barbed wire will also protect it from the squirrels. The eggs are bluish white; the young birds, in their first feathers, are spotted on the back and have whitish breasts mottled with brown. The food of the nestlings is almost entirely insects. In fact, this bird during its entire life is a great friend to man. The food of the adult is more than three-fourths insects and the remainder is wild berries and fruits, the winter food being largely mistletoe berries. It makes a specialty of injurious beetles, caterpillars and grasshoppers, and never touches any of

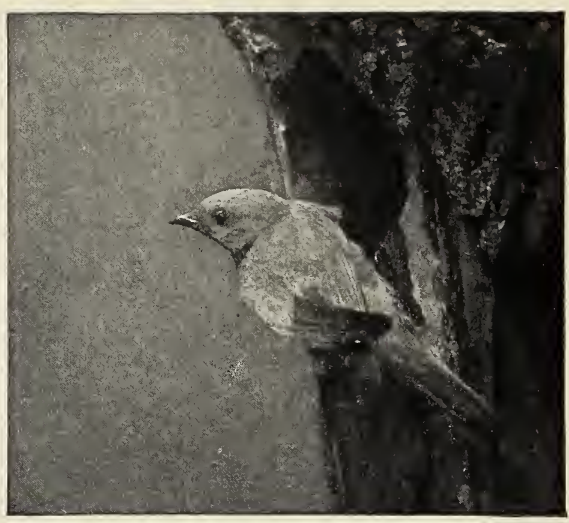

Bluebird at the entrance of its nest. From Country Life in America. our cultivated fruits. We should do everything in our power to encourage and protect these birds from their enemies, which are chiefly cats, squirrels and English sparrows.

The migration takes place in flocks during autumn, but it is done in a most leisurely manner with frequent stops where food is plenty. The bluebirds we see in September are probably not the ones we have had with us during the summer, but are those which have come from farther north.

They winter largely in the Gulf States; the writer has often heard them singing in midwinter in Southern Mississippi. The bluebirds seem to be the only ones that sing while at their winter resorts. They live the year round in the Bermudas, contrasting their heavenly blue plumage with the vivid red of the cardinals. The bluebird should not be confused with the indigo bunting; the latter is darker blue and has a blue breast.

References-Bulletin, Some Common Birds in Their Relation to Man, U. S. Dept. of Agr.; Bulletin, The Food of Nestling Birds, U. S. Dept. of Agr.; Birds in Their Relation to Man, Weed \& Dearborn, pp. 86-88; Nature-Study and Life, Hodge, chapters I8-21; Junior Audubon Leaflets; Birds of Eastern North America, Chapman, 9. 403; Field Book of Wild Birds and Their Music, Mathews, pp. 25I-254; Nature-Study in Elementary Schools, Wilson, p. I88.

"Winged lute that we call a bluebird, $Y$ ou blend in a silver strain

The sound of the laughing waters, The patter of spring's sweet rain, The voice of the winds, the sunshine, And fragrance of blossoming things.

Ah! You are an April poem,

That God has dowered with wings."

-The Bluebird, Rexford. 


\section{LESSON XI}

\section{The Bluebird}

Leading thought-The bluebird is related to the robins and thrushes and is as beneficial as it is beautiful. We should study its habits and learn how to make nesting boxes for it, and protect it in all ways.

Methods-The observations of this lesson must be made in the field and by the pupils individually. Give to each an outline of questions to answer through seeing. There should follow reading lessons on the bluebird's value to us and its winter migrations, and the lesson should end in discussions of best way to build boxes for its use in nesting season, its protection from cats and other enemies.

Observations-I. Which comes North earlier in spring the robin or the bluebird?

2. How do the two resemble each other and differ from each other?

3. Describe the bluebirds' song. Do they sing all summer?

4. Describe the colors of the bluebird as follows: The head, back, breast, under parts, wings, tail. How does the male bluebird differ from his mate in colors?

5. Where were the bluebirds you saw? What were they doing? If feeding, how did they act?

6. Can you see the color of the bluebird as plainly when it is in a tree as when it is flying? If not, why?

7. Where do the bluebirds build their nests? Of what material are the nests made? Do both parents work at the nest building?

8. What is the color of the eggs? How do the young birds look, when old enough to leave the nest, as compared with their parents?

9. What do the bluebirds eat? How do they benefit us? Do they do our fruit any injury?

Io. What can we do to induce the bluebirds to live near our houses? How can we protect them?

II. Where do the bluebirds spend the winter?

I 2. Make a colored picture of a bluebird. How can we tell the bluebird from the indigo bunting?

I3. What are the bluebirds' chief enemies?

Supplementary reading-Nestlings of Forest and Marsh, Wheelock, p. 62; True Bird Stories, Miller, p. I2; How to Attract the Birds, Blanchan; Bird Neighbors, Blanchan; Our Birds and their Nestlings, Walker, p. I7; Familiar Wild Animals, Lottridge; Audubon Leaflet, No. 24 .

Hark! 'tis the bluebird's venturous strain

High on the old fringed elm at the gate-

Sweet-voiced, valiant on the swaying bough, Alert, elate,

Dodging the fitful spits of snow, New England's poet-laureate

Telling us Spring has come cgain!-Thomas BaILEy Aldrich. 


\title{
THE WHITE-BREASTED NUTHATCH
}

\author{
Teacher's Story \\ "The busy nuthatch climbs his tree \\ Around the great bole spirally, \\ Peeping into wrinkles gray, \\ Under ruffled lichens gay, \\ Lazily piping one sharp note \\ From his silver mailed throat." \\ -Maurice Thompson.
}

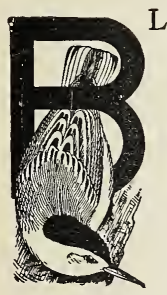

LIHTE and mellow is the ringing "ank, ank" note of the nuthatch, and why need we allude to its nasal timbre! While it is not a strictly musical note, it has a most enticing quality and translates into sound the picture of barebranched trees and the feeling of enchantment which permeates the forest in winter; it is one of the most "woodsy" notes in the bird repertoire. And while the singer of this note is not so bewitching as his constant chum the chickadee, yet it has many interesting ways quite its own. Nor is this "ank, ank," its only note. I have often heard a pair talking to each other in sweet confidential syllables, "wit, wit, wit" very different from the loud note meant for the world at large. The nuthatches and chickadees hunt together all winter; it is no mere business partnership but a matter of congenial tastes. The chickadees hunt over the twigs and smaller branches, while the nuthatches usually prefer the tree trunks and the bases of the branches; both birds like the looks of the world upside down, and while the chickadee hangs head down from a twig, the nuthatch is quite likely to alight head down on a tree bole, holding itself safely in this position by thrusting its toes out at right angles to the body, thus getting a firm hold upon the bark. Sometimes its foot will be twisted completely around, the front toes pointed up the tree. The foot is well adapted for clinging to the bark as the front toes are strong and the hind toe is very long and is armed with a strong claw. Thus equipped, this bird runs about on the tree so rapidly, it has earned the name of "tree mouse". It often ascends a tree trunk spirally but is not so hidebound in this habit as is the brown creeper. It runs up or down freely head first and never flops down backwards like a woodpecker.

In color the nuthatch is bluish gray above with white throat and breast and reddish underparts. The sides of the head are white; the black cap extends back upon the neck but is not "pulled down" to the eyes like the chickadees. The wing feathers are సark brown edged with pale gray. The upper middle tail feathers are biuish like the back; the others are dark brown and tipped with white in such a manner that the tail when spread shows a broad white border on both sides. The most striking contrast between the chickadee and nuthatch in markings is that the latter lacks the black bib. However, its entire shape is very different from that of the chickadee and its beak is long and slender, being as long or longer than its head, whiie the beak of the chickadee is a short, sharp, little pick. The bill of the nuthatch is exactly fitted to reach in crevices of the bark and pull out hiding insects, or to hammer open the shell of nut or acorn and get both the 
meat of the nut and the grub feeding upon it. It will wedge an acorn into a seam in the bark and then throw back its head, woodpecker fashion, and drive home.its chisel beak. But it does not always use common

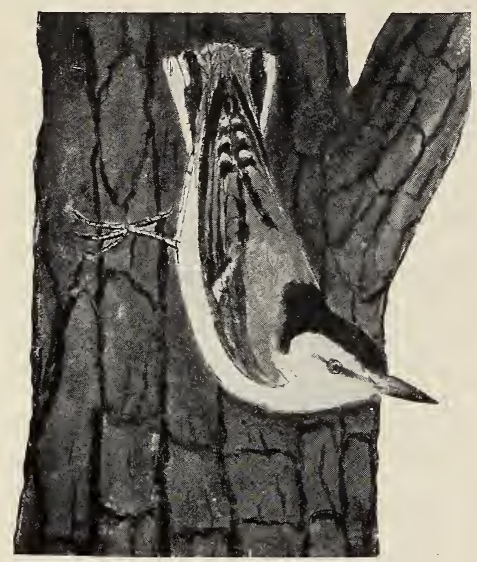

The white breasted nuthatch. sense in this habit. I have often seen one cut off a piece of suet, fly off and thrust it into some crevice and hammer it as hard as if it were encased in a walnut shell. This always seems bad manners, like carrying off fruit from table d'hote; but the nuthatch is polite enough in using a napkin, for after eating the suet, it invariably wipes its bill on a branch, first one side then the other most assiduously until it is perfectly clean.

The nuthatches are a great benefit to our trees in winter, for then is when they hunt for hiding pests on their trunks. Their food consists of beetles, caterpillars, pupæ of various insects, also seeds of ragweed, sunflowers, acorns, etc. While the nuthatch finds much of its food on trees, yet Mr. Torrey has seen it awkwardly turning over fallen leaves hunting for insects, and Mr. Baskett says it sometimes catches insects on the wing and gets quite out of breath from this unusual exercise.

It is only during the winter that we commonly see the nuthatches, for during the nesting season, they usually retire to the deep woods where they may occupy a cavity in a tree used by a woodpecker last year, or may make a hole for themselves with their sharp beaks. The nest is lined with leaves, feathers and hair; from five to nine creamy, speckled eggs are the treasure of this cave.

\section{LESSON XII}

\section{The Nuthatch}

Leading thought-The nuthatch is often a companion of the chickadees and woodpeckers. It has no black bib, like the chickadee, and it alights on a tree trunk head downward, which distinguishes it from woodpeckers.

Methods-This bird, like the chickadee and downy, gladly shares the suet banquet we prepare for them and may be observed at leisure while "at table." The contrast between the habits of the nuthatch and those of its companions make it a most valuable aid in stimulating close and keen observation on the part of the pupils.

Observations-r. Where have you seen the nuthatches? Were they with other birds? What other birds?

2. Does a nuthatch usually alight on the ends of the branches of a tree or on the trunk and larger limbs? Does it usually alight head down or up? When it runs down the tree, does it go head first or does it back 
down? When it ascends the tree does it follow a spiral path? Does it use its tail for a brace when climbing, as does the downy?

3. How are the nuthatch's toes arranged to assist it in climbing? Are the three front toes of each foot directed downward when the bird alights head downward? How does it manage its feet when in this position?

4. What is the general color of the nuthatch above and below? The color of the top and sides of head? Color of Back? Wings? Tail? Throat? Breast?

5. Does the black cap come down to the eyes on the nuthatch as on the chickadee? Has the nuthatch a black bib?

6. What is the shape of the beak of the nuthatch? For what is it adapted? How does it differ from the beak of the chickadee?

7. What is the food of the nuthatch? Where is it found? Does it open nuts for the grubs or the nut meat? Observe the way it strikes its beak into the suet, why does it strike so hard?

8. How would you spell this bird's note? Have you heard it give more than one note?

9. How does the nuthatch benefit our trees? At what season does it benefit them most? Why?

Io. Where do the nuthatches build their nests? Why do we see the nuthatches oftener in winter than in summer?

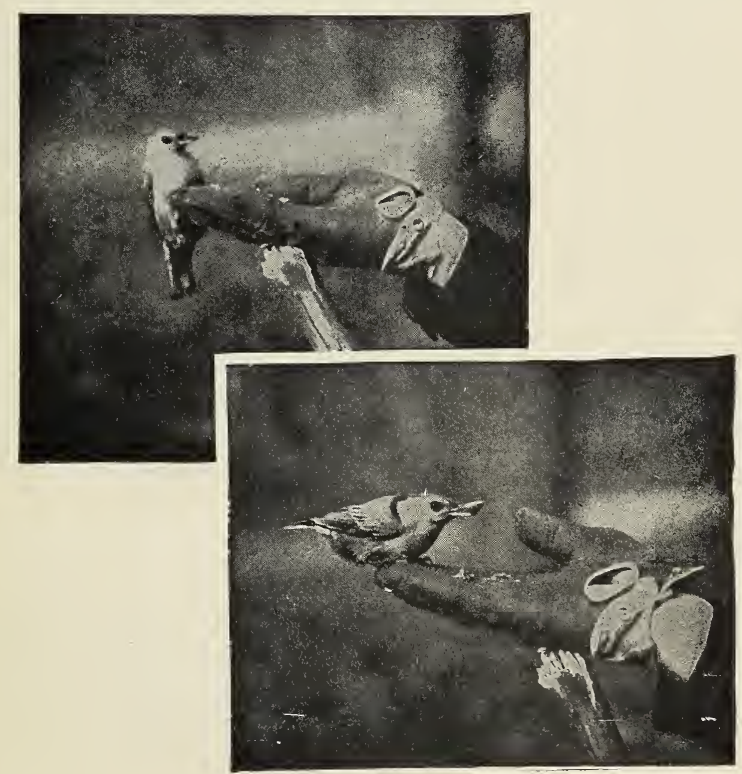




\section{THE CHICKADEE}

\section{Teacher's Story}

"He is the hero of the woods; there are courage and good nature enough in that compact little body, which you may hide in your fist, to supply a whole groveful of May songsters. He has the Spartan virtue of an eagle, the cheerfulness of a thrush, the nimbleness of Cock Sparrow, the endurance of the sea-birds condensed into his tiny frame, and there have been added a pertness and ingenuity all his own. His curiosity is immense, and his audacity equal to it; I have even had one alight upon the barrel of

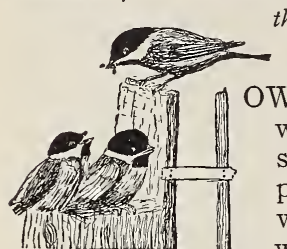
the gun over my shoulders as I sat quietly under his tree."

-ERnest INGERSOLl.

OWEVER careless we may be of our bird friends when we are in the midst of the luxurious life of summer, even the most careless among us give pleased attention to the birds that bravely endure with us the rigors of winter. And when this winged companion of winter proves to be the most fascinating little ball of feathers ever created, constantly overflowing with cheerful song, our pleased attention changes to active delight. Thus it is, that in all the lands of snowy winters the chickadee is a loved comrade of the country wayfarer; that happy song "chick-a-dee-dee-dee" finds its way to the dullest consciousness and the most callous heart.

The chickadees appear in small flocks in the winter and often in company with the nuthatches. The chickadees work on the twigs and ends of branches, while the nuthatches usually mine the bark of the trunk and larger branches, the former hunting insect eggs and the latter, insects tucked away in winter quarters. When the chickadee is prospecting for eggs, it looks the twig over, first above and then hangs head down and inspects it from below; it is a thorough worker and doesn't intend to overlook anything whatever; and however busily it is hunting, it always finds time for singing; whether on the wing or perched upon a twig or hanging from it like an acrobat, head down, it sends forth its happy "chickadeedee" to assure us that this world is all right and good enough for anybody. Besides this song, it begins in February to sing a most seductive "fee-bee," giving a rising

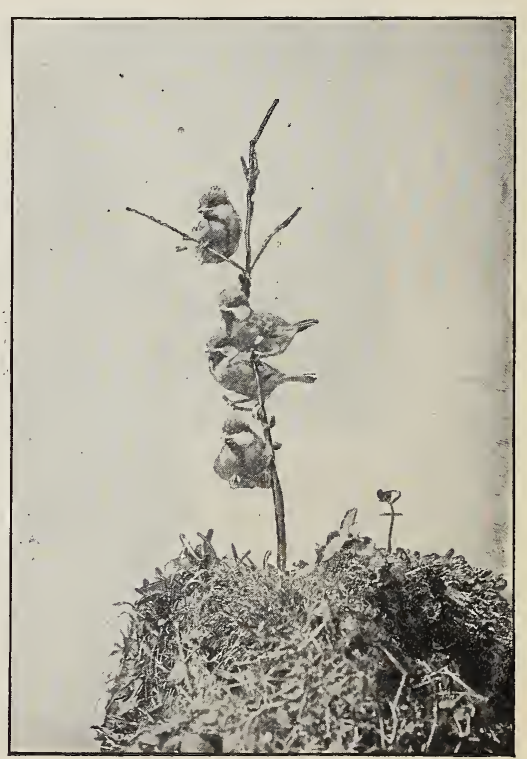

Chick-a-dee-dee-dee 
inflection to the first syllable and a long, falling inflection to the last, which makes it a very different song from the short, jerky notes of the

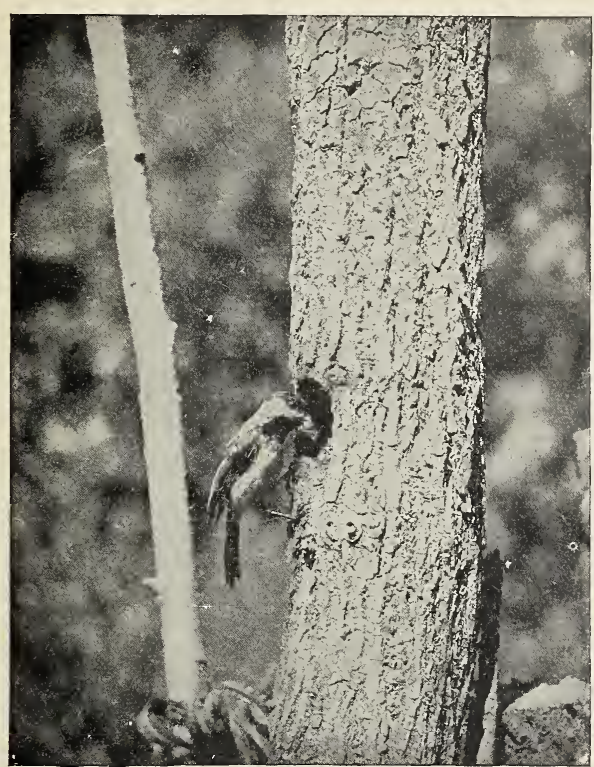

Chickadee entering her nest. phobe-bird, which cuts the last syllable short and gives it a rising inflection. More than this, the chickadee has some chatty conversational notes, and now and then performs a bewitching little yodle, which is a fit expression of its own delicious personality.

The general effect of the colors of the chickadee is grayish brown above and grayish white below. The top of the head is black, the sides white, and it has a seductive little black bib under its chin. The back is grayish, the wings and tail are dark gray, the feathers having white margins. The breast is grayish white changing to $\mathrm{buff}$ or brownish at the sides and below. It is often salled the "Black-capped Titmouse," and it may always be distinguished by black cap and black bib. It is smaller than the English sparrow; its beak is a sharp little pick just fitted for taking insect eggs off twigs and from under bark. Insects are obliged to pass the winter in some stage of their existence, and many of them wisely remain in the egg until there is something worth doing in the way of eating. These eggs are glued fast to the food trees by the mother insect and thus provides abundant food for the chickadees. It has been estimated that one chickadee will destroy several hundred insect eggs in one day, and it has been proven that orchards frequented by these birds are much more free from insect pests than other orchards in the same locality. They can be enticed into orchards by putting up beef fat or bones and thus we can secure their valuable service. In summer these birds attack caterpillars and other insects.

When it comes to nest building, if the chickadees cannot find a house to rent they proceed to dig out a proper hole from some decaying tree, which they line with moss, feathers, fur or some other soft material. The nest is often rot higher than six to ten feet from the ground. One which I studied was in a decaying fence post. The eggs are white, sparsely speckled and spotted with lilac or rufous. The young birds are often eight in number and how these fubsy birdlings manage to pack themselves in such a small hole is a wonder, and probably gives them good discipline in bearing hardships cheerfully. 
Reference-Useful Birds and Their Protection, Forbush, p. I6 3 ; Birds of Village and Field, Merriams; Bird Neighbors, Blancham.

\section{LESSON XIII \\ The Chickadee}

Ieading thought-The chickadee is as useful as it is delightful; it remains in the North during winter, working hard to clear our trees of insect eggs and singing cheerily all day. It is so friendly that we can induce it to come even to the window sill, by putting out suet to show our friendly interest.

Methods-Put beef fat on the trees near the schoolhouse in December and replenish it afresh about every two or three weeks. The chickadees will come to the feast and may be observed all winter. Give the questions a few at a time and let the children read in the bird books a record of the benefits derived from this bird.

Observations-I. Where have you seen the chickadees? What were they doing? Were there several together?

2. What is the common song of the chickadee? What other notes has it? Have you heard it yodle? Have you heard it sing "fe-bee, feebee." How does this song differ from that of the phœbe-bird? Does it sing on the wing or when at rest?

3. What is the color of the chickadee: Top and sides of head, back, wings, tail, throat, breast, under parts?

Compare size of chickadee with that of English sparrow.

4. What is the shape of the chickadee's bill and for what is it adapted? What is the food in winter? Where does the bird find it? How does it act when feeding and hunting for food?

5. Does the chickadee usually alight on the ends of the branches or on the larger portions near the trunk of the tree?

6. How can you distinguish the chickadees from their companions, the nuthatches?

7. Does the chickadee ever seem discouraged by the snow and cold weather? Do you know another name for the chickadee?

8. Where does it build its nest? Of what material? Have you ever watched one of these nests? If so, tell about it.

9. How does the chickadee benefit our orchards and shade trees? How can we induce it to feel at home with us and work for us?

Supplementary reading - "Foster Baby," Nestlings of Forest and Marsh; "Ch'-geegee-lokh-sis," Ways of Wood Folk; "Why a Chickadee Goes Crazy," Animal Heroes, Seton; "The Titmouse," a poem, by Emerson.

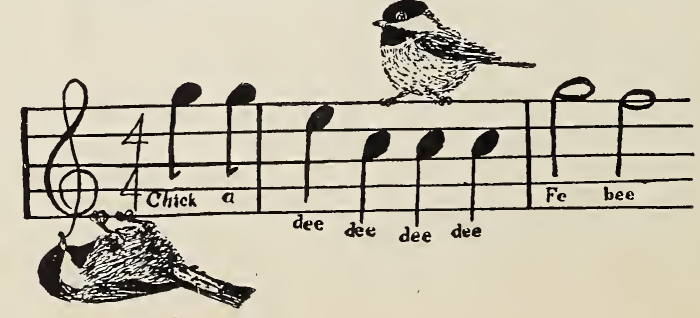




\section{THE DOWNY WOODPECKER}

\section{Teacher's Story}

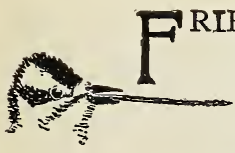

END Downy is the name this attractive little neighbor has earned, because it is so friendly to those of us who love trees. Watch it as it hunts each crack and crevice of the bark of your favorite apple or shade tree, seeking assiduously for cocoons and insects hiding there, and you will soon, of your own accord, call it friend; you will soon love its black and white uniform, which consists of a black coat speckled and barred with white and whitish gray vest and trousers. The front of the head is black and there is a black streak extending backward from the eye with a white streak above and also below it. The male has a vivid red patch on the back of the head, but his wife shows no such giddiness; plain black and white are good enough for her. In both sexes the throat and breast are white, the middle tail feathers black, while the side tail feathers are white, barred with black at their tips.

The downy has a way of alighting low down on a tree trunk or at the base of a larger branch and climbing upward in a jerky fashion; it never runs about over the tree nor does it turn around and go down head first, like the nuthatch; if it wishes to go down a short distance it accomplishes this by a few awkward, backward hops; but when it really wishes to descend, it flies off and down. The downy, as other woodpeckers, has a special arrangement of its physical machinery to enable it to climb trees in its own manner. In order to grasp the bark on the side of the tree more firmly, its fourth toe is turned backward to work as companion with the thumb. Thus it is able to clutch the bark as with a pair of nippers, two claws in front and two claws behind; and as another aid, the tail is arranged to prop the bird, like a bracket. The tail is rounded in shape and the middle feathers have rather strong quills; but the secret of the adhesion of the tail

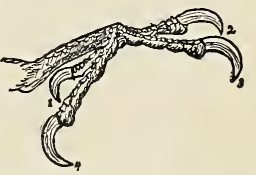

Friend Downy's foot. to the bark lies in the great profusion of barbs which, at the edge of the feathers, offer bristling tips, and when applied to the side of the tree act like a wire brush with all the wires pushing downward. This explains why the woodpecker cannot go backward without lifting the tail.

But even more wonderful than this, is the mechanism by which the downy and hairy woodpeckers get their food, which consists largely of wood-borers or larvæ working under the bark. When the woodpecker wishes to get a grub in the wood, it seizes the bark firmly with its feet, uses its tail as a brace, throws its head and upper part of the body as far back as possible, and then drives a powerful blow with its strong beak. The beak is adapted for just this purpose, as it is wedge-shaped at the end, and is used like a mason's drill sometimes, and sometimes like a pick. When the bird uses its beak as a pick, it strikes hard, deliberate blows and the chips fly; but when it is drilling, it strikes rapidly and not so hard and quickly drills a small, deep hole leading directly to the burrow of the grub. When finally the grub is reached, it would seem well nigh impossible to pull it out through a hole which is too small and deep to admit of the beak 
being used as pincers. This is another story and a very interesting one; the downy and hairy can both extend their tongues far beyond the point of the beak, and the tip of the tongue is hard and horny and covered with short backward-slanting hooks acting like a spear or harpoon, and when thrust into the grub pulls it out easily (see initial). The bones of the tongue have a spring arrangement; when not in use, the tongue lies soft in the mouth, like a wrinkled earthworm, but when in use, the bones spring out, stretching it to its full length and it is then slim and small. The process is like fastening a pencil to the tip of a glove finger; when drawn back the finger is wrinkled together, but when thrust out, straightens. This spring arrangement of the bones of the woodpecker's tongue is a marvellous mechanism and should be studied through pictures; see Birds, Eckstrom, Chapter XIV; The Bird, Beebe, p. I22; "The Tongues of Woodpeckers," Lucas, U. S. Department of Agriculture.

Since the food of the downy and

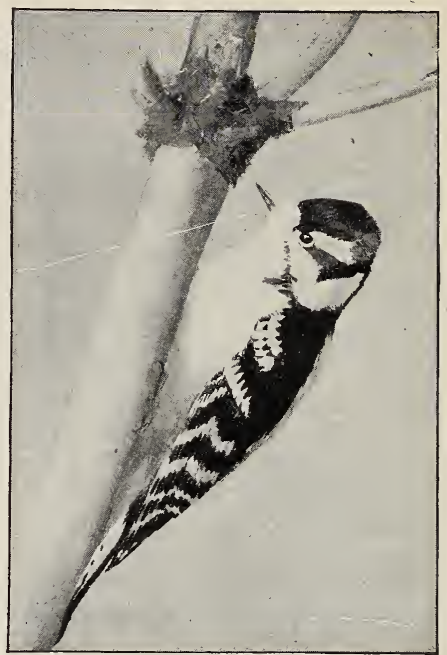

Friend Downy.

Drawing by A. L. Fuertes. the hairy is where they can get it all winter, there is no need for them to go South; thus they stay with us and work for us the entire year. We should try to make them feel at home with us in our orchards and shade trees by putting up pieces of beef fat, to convince them of their welcome. No amount of free food will pauperize these birds, for as soon as they have eaten of the fat, they commence to hunt for grubs on the tree and thus earn their feast. They never injure live wood.

James Whitcomb Riley describes the drumming of the woodpecker as "weeding out the lonesomeness" and that is exactly what the drumming of the woodpecker means. The male selects some dried limb of hard wood and there beats out his well-known signal which advertises far and near, "Wanted, a wife." And after he wins her, he still drums on for a time to cheer her while she is busy with her family cares. The woodpecker has no voice for singing, like the robin or thrush; and luckily, he does not insist on singing, like the peacock whether he can or not. He chooses rather to devote his voice to terse and business-like conversation; and when he is musically inclined, he turns drummer. He is rather particular about his instrument and having found one that is sufficiently resonant he returns to it day after day. While it is ordinarily the male that drums I once observed a female drumming. I told her that she was a bold minx and ought to be ashamed of herself; but within twenty minutes she had drummed up two red-capped suitors who chased each other about with great animosity, so her performance was evidently not considered improper in woodpecker society. I have watched a rival pair 
of male downies fight for hours at a time, but their duel was of the French brand,-much fuss and no bloodshed. They advanced upon each other with much haughty glaring and scornful bobs of the head, but when they were sufficiently near to stab each other they beat a mutual and circumspect retreat. Although we hear the male downies drumming every spring, I doubt if they are calling for new wives; I believe they are, instead, calling the attention of their lawful spouses to the fact that it is time for nest building to begin. I have come to this conclusion because the downies and hairies which I have watched for years have always come in pairs to partake of suet during the entire winter; and while only one at a time sits at meat and the lord and master is somewhat bossy, yet they seem to get along as well as most married pairs.

The downy's nest is a hole, usually in a partly decayed tree; an old apple tree is a favorite site and a fresh excavation is made each year. There are from four to six white eggs, which are laid on a nice bed of chips as fine almost as sawdust. The door to the nest is a perfect circle and about an inch and a quarter across.

The hairy woodpecker is fully one-third larger than the downy, measuring nine inches from tip of beak to tip of tail, while the downy measures only about six inches. The tail feathers at the side are white for the entire length, while they are barred at the tips in the downy. There is a black "parting" through the middle of the red patch on the back of the hairy's head. The two species are so much alike that it is difficult for the beginner to tell them apart. Their habits are very similar, except that the hairy lives in the woods and is not so commonly seen in orchards or on shade trees. The food of the hairy is much like that of the downy and it is, therefore, a beneficial bird and should be protected.

\section{LESSON XIV}

\section{The Downy Woodpecker}

Leading thought-The downy woodpecker remains with us all winter, feeding upon insects that are wintering in crevices and beneath the bark of our trees. It is fitted especially by shape of beak, tongue, feet and tail to get such food and it is a "friend in need" to our forest, shade and orchard trees.

Methods-If a piece of beef fat be fastened upon the trunk or branch of a tree, which can be seen from the schoolroom windows, there will be no lack of interest in this friendly little bird; for the downy will sooner or later find this feast spread for it and will come every day to partake. Give out the questions, a few at a time, and discuss the answers with the pupils.

Observations-r. What is the general color of the downy above and below? The color of the top of the head? Sides of the head? The throat and breast? The color and markings of the wings? Color and markings of the middle and side tail-feathers?

2. Do all downy woodpeckers have the red patch at the back of the head? If not, why?

3. What is the note of the downy? Does it make any other sound? Have you ever seen one drumming? At what time of the year? On what did it drum? What did it use for a drumstick? What do you suppose was the purpose of this music? 
4. How does the downy climb a tree trunk? how does it descend? How do its actions differ from those of the nuthatch?

5. How are the woodpecker's toes arranged to help it climb a tree trunk? How does this arrangement of toes differ from that of other birds?

6. How does the downy use its tail to assist it in climbing? What is the shape of the tail and how is it adapted to assist?

7. What does the downy eat and where does it find its food? Describe how it gets at its food. What is the shape of its bill and how is it fitted for getting the food? Tell how the downy's tongue is used to spear the grub.

8. Why does the downy not go South in winter?

9. Of what use is this bird to us? How should we protect it and entice it into our orchards?

ro. Write an English theme on the subject "How the downy builds its nest and rears its young".

Supplementary reading - The Woodpeckers, Eckstorm· Bird Neighbors, Blanchan. Winter Neighbors Burroughs.

A few seasons ago a downy woodpecker, probably the individual one who is now my winter neighbor, began to drum early in March in a partly decayed apple-tree that stands in the edge of a narrow strip of woodland near me. When the morning was still and mild I would often hear him through my window before I was up, or by half-past six o'clock, and he would keep it up pretty briskly till nine or ten o'clock, in this respect resembling the grouse, which do most of their drumming in the forenoon. His drum was the stub of a dry limb about the size of one's wrist. The heart was decayed and gone, but the outer shell was loud and resonant. The bird would keep his position there for an hour at a time. Between his drummings he would preen his plumage and listen as if for the response of the female, or for the drum of some rival. How swift his head would go when he was delivering his blows upon the limb! His beak wore the surface perceptibly. When he wished to change the key, which was quite often, he would shift his position an inch or two to a knot which gave out a higher, shriller note. When I climbed up to examine his drum he was much disturbed. I did not know he was in the vicinity, but it seems he saw me from a near tree, and came in haste to the neighboring branches, and with spread plumage and a sharp note demanded plainly enough what my business was with his drum. I was invading his privacy, desecrating his shrine, and the bird was much put out. After some weeks the female appeared; he had literally drummed up a mate; his urgent and oft-repeated advertisement was answered. Still the drumming did not cease, but was quite as fervent as before. If a mate could be won by drumming she could be kept and entertained by more drumming; courtship should not end with marriage. If the bird felt musical before, of course he felt much more so now. Besides that, the gentle deities needed propitiating in behalf of the nest and young as well as in behalf of the mate. After a time a second female came, when there was war between the two. I did not see them come to blows, but I saw one female pursuing the other about the place, and giving her no rest for several days. She was evidently trying to run her out of the neighborhood. Now and then she, too, would drum briefly as if sending a triumphant message to her mate.-Winter Neighbors, John BuRroughs. 


\section{THE SAPSUCKER}

\section{Teacher's Story}

The sapsucker is a woodpecker that has strayed from the paths of virtue; he has fallen into temptation by the wayside, and instead of drilling a hole for the sake of the grubat the end of it, he drills for drink. He is a tippler, and sap is his beverage; and he is also fond of the soft, inner bark. He often drills his holes in regular rows and thus girdles a limb or a tree, and for this is pronounced a rascal by men who have themselves ruthlessly cut from our land millions of trees that should now be standing. It is amusing to see a sapsucker take his tipple, unless his saloon happens to be one of our prized young trees. He uses his bill as a pick and makes the chips fly as he taps the tree; then he goes away and taps another tree. After a time he comes back and holding his beak close to the hole for a long time seems to be sucking up the sap; he then throws back his head and "swigs" it down

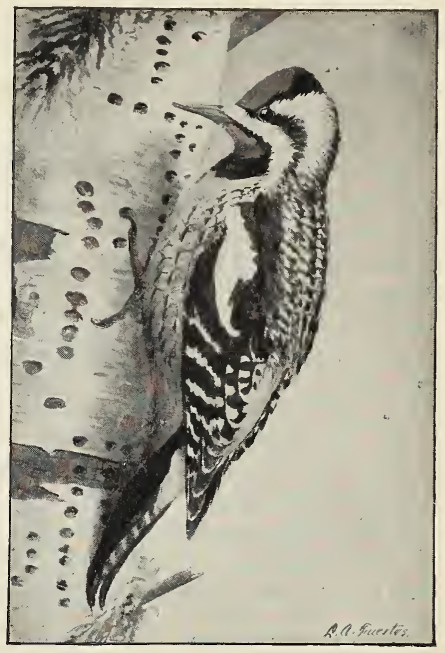

The yellow bellied sapsucker. Drawing by L. A. Fuertes. with every sign of delirious enjoyment. The avidity with which these birds come to the bleeding wells which they have made, has in it all the fierceness of a toper crazy for drink; they are particularly fond of the sap of the mountain ash, apple, thorn apple, canoe birch, cut-leaf birch, red maple, red oak, white ash and young pines. However, the sapsucker does not live solely on sap, he also feeds upon insects whenever he can find them. When feeding their young, the sapsuckers are true flycatchers snatching insects while on the wing. The male has the crown and throat crimson, edged with black with a black line extending back of the eye, bordered with white above and below. There is a large, black circular patch on the breast which is bordered at the sides and below with lemon yellow. The female is similar to the male and has a red forehead, but she has a white bib instead of a red one beneath the chin. The distinguishing marks of the sapsucker should be learned by the pupils. The red is on the front of the head instead of on the crown, as is the case with the downy and hairy; when it is flying the broad, white stripes extending from the shoulders backward, form a long, oval figure, which is very characteristic.

The sapsuckers spend the winter in the Southern States where they drill wells in the white oak and other trees. From Virginia to Northern New York and New England, where they breed, they are seen only during migration, which occurs in April; then the birds appear two and three together and are very bold in attacking shade trees, especially the white 
birch. They nest only in the Northern United States and northward. The nest is usually a hole in a tree about forty feet from the ground, and is likely to be in a dead birch.

\section{LESSON XV}

\section{The Sapsucker}

Leading thought-The sapsucker has a red cap, a red bib and a yellow breast; it is our only woodpecker that does injury to trees. We should learn to distinguish it from the downy and hairy, as the latter are among the best bird friends of the trees.

Methods - Let the observations begin with the study of the trees which have been attacked by the sapsucker, which are almost everywhere common, and thus lead to an interest in the culprit.

Observations-I. Have you seen the work of the sapsucker? Are the holes drilled in rows completely around the tree? If there are two rows or more, are the holes set evenly one below another?

2. Do the holes sink into the wood, or are they simply through the bark? Why does it injure or kill a tree to be girdled with these holes? Have you ever seen the sapsuckers making these holes? If so, how did they act?

3. How many kinds of trees can you find punctured by these holes? Are they likely to be young trees?

4. How can you distinguish the sapsucker from the other woodpeckers? How have the hairy and downy which are such good friends of the trees been made to suffer for the sapsucker's sins?

5. What is the color of the sapsucker as follows: Forehead, sides of head, back, wings, throat, upper and lower breast? What is the difference in color between the male and female?

6. In what part of the country do the sapsuckers build their nests? Where do they make their nests and how?

Supplementary reading-Bird Neighbors, Blanchan; Birds, Bees and Sharp Eyes, John Burroughs.

In the following winter the same bird (a sapsucker) tapped a maple-tree in front of my window in fifty-six places; and, when the day was sunny and the sapoozed out he spent most of his time there. He knew the good sap-days, and was on hand promptly for his tipple; cold and cloudy days he did not appear. He knew which side of the tree to tap, too, ana cooided the sunless northern exposure. When one series of wellholes failed to supply him, he would sink another, drilling through the bark with greut ease and quickness. Then, when the day was warm, and the sap ran freely, he would have a regular sugar-maple debauch, sitting there by his wells hour after hour, and as fast as they became filled sipping out the sap. This he did in a gentle, carressing manner that was very suggestive. He made a row of wells near the foot of the tree, and other rows higher up, and he would hop up and down the trunk as they became filled.Winter Neighbors, John Burroughs. 


\section{THE RED-HEADED WOODPECKER}

\section{Teacher's Story}

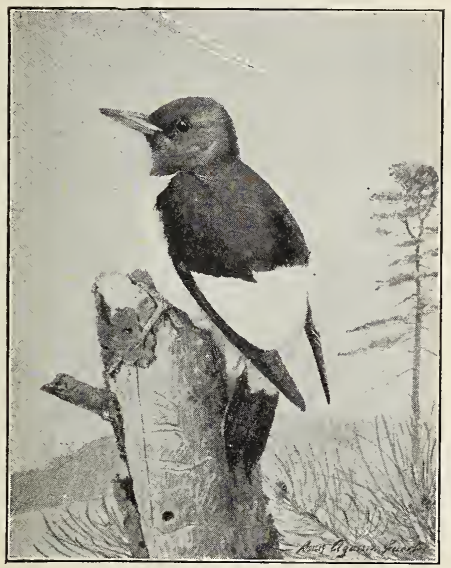

The red-headed wood pecker. Drawing by L. A. Fuertes.

The red-head is well named, for his helmet and visor show a vivid glowing crimson that stirs the sensibilities of the color lover. It is readily distinguished from the other woodpeckers because its entire head and $\mathrm{bib}$ are red. For the rest, it is a beautiful dark metallic blue with the lower back, a band across the wing, and the under parts white; its outer tail feathers are tipped with white. The female is colored like the male, but the young have the head and breast gray, streaked with black and white, and the wings barred with black. It may make its nest by excavating a hole in a tree or a stump or even in a telegraph pole; the eggs are glossy white. This woodpecker is quite different in habits from the hairy and downy, as it likes to flit along from stump to fence-post and catch insects on the wing, like a fly-catcher. The only time that it pecks wood is when it is making a hole for its nest.

As a drummer, the red-head is most adept and his roll is a long one. $\mathrm{He}$ is an adaptable fellow, and if there is no resonant dead limb at hand, he has been known to drum on tin roofs and lightning rods; and once we also observed him executing a most brilliant solo on the wire of a barbed fence. He is especially fond of beechnuts and acorns, and being a thrifty fellow as well as musical, in time of plenty he stores up food against time of need. He places his nuts in crevices and forks of the branches or in holes in trees or any other hiding place. He can shell a beechnut quite as cleverly as can the deer mouse; and he is own cousin to the Carpenter Woodpecker of the Pacific Coast, which is also red-headed and which drills holes in the oak trees wherein he drives acorns like pegs for later use.

\section{LESSON XVI}

\section{The Red-headed Woodpecker}

Leading thought-The red-headed woodpecker has very different habits from the downy and is not so useful to us. It lives upon nuts and fruit and such insects as it can catch upon the wing.

Methods-If there is a red-head in the vicinity of your school the children will be sure to see it. Write the following questions upon the blackboard and offer a prize to the first one who will make a note on where the red-head stores his winter food. 
Observations-I. Can you tell the red-head from the other woodpeckers? What colors especially mark his plumage?

2. Where does the red-head nest? Describe eggs and nest?

3. What have you observed the red-head eating? Have you noticed it storing nuts and acorns for the winter? Have you noticed it flying off with cherries or other fruit?

4. What is the note of the red-head? Have you ever seen one drumming? What did he use for a drum? Did he come back often to this place to make his music?

Supplementary reading - "The House That Fell" in Nestlings of Forest and Marsh; Our Birds and their Nestlings, p. 9o; Birds, Bees and Sharp Eyes, John Burroughs.

Another trait our woodpeckers have that endears them to me, and that has never been pointedly noticed by our ornithologists, is their habit of drumming in the spring. They are songless birds, and yet all are musicians; they make the dry limbs eloquent of the coming change. Did you think that loud, sonorous hammering which proceeded from the orchard or from the near woods on that still March or A pril morning was only some bird getting its breakfast? It is downy, but he is not rapping at the door of a grub; he is rapping at the door of spring, and the dry limb thrills beneath the ardor of his blows. Or, later in the season, in the dense forest or by some remote mountain lake, does that measured rhythmic beat that breaks upon the silence, first three strokes following each other rapidly, succeeded by two louder ones with longer intervals between them, and that has an effect upon the alert ear as if the solitude itself had at least found a voice-does that suggest anything less than a deliberate musical performance? In fact, our woodpeckers are just as characteristically drummers as is the ruffed grouse, and they have their particular limbs and stubs to which they resort for that purpose. Their need of expression is apparently just as great as that of the song-birds, and it is not surprising that they should have found out that there is music in a dry, seasoned limb which can be evoked beneath their beaks.

The woodpeckers do noi each have a particular dry limb to which they resort at all times to drum, like the one I have described. The woods are full of suitable branches, and they drum more or less here and there as they are in quest of food; yet I am convinced each one has its favorite spot, like the grouse, to which it resorts, especially in the morning. The sugar-maker in the maple woods may notice that this sound proceeds from the same tree or trees about his camp with great regularity. A woodpecker in my vicinity has drummed for two seasons on a telegraph-pole, and he makes the wires and glass insulators ring. Another drums on a thin board on the end of a long grapearbor, and on still mornings can be heard a long distance.

A friend of mine in a Southern city tells me of a red-headed woodpecker that drums upon a lightning-rod on his neighbor's house. Nearly every clear, still morning at certain seasons, he says, this musical rapping may be heard. "He alternates his tapping with his stridulous call, and the effect on a cool, autumn-like morning is very pleasing." - JoHn BuRroughs, in Birds, Bees and Sharp Eyes. 


\section{THE FLICKER OR YELIOW-HAMMER}

\section{Teacher's Story}

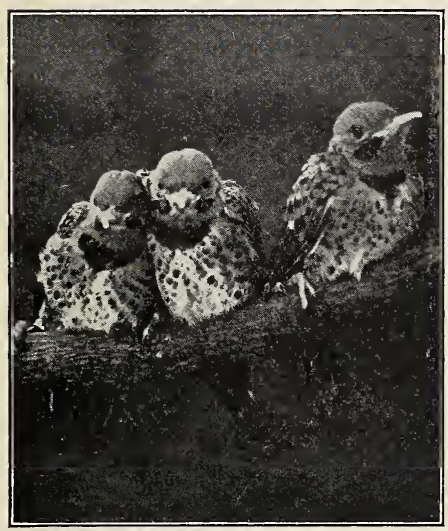

Young fickers "Two is company, three is a crowd."

Photo by J. M. Schreck.

The first time I ever saw a flicker I said, "What a wonderful meadowlark and what is it doing on that ant hill?" But, another glance revealed to me a red spot on the back of the bird's neck, and as soon as I was sure that it was not a bloody gash, I knew that it marked no meadow-lark. The top of the flicker's head and its back are slatygray, which is much enlivened by a bright red band across the nape of the neck. The tail is black above and yellow tipped with black below; the wings are black, but have a beautiful luminous yellow beneath, which is very noticeable during flight. There is a locket adorning the breast which is a thin, black crescent, much narrower than that of the meadow-lark. Below the locket, the breast is yellowish white thickly marked with circular, black spots. The throat and sides of the head are pinkish brown, and the male has a black mustache extending backward from the beak with a very fashionable droop. Naturally enough the female, although she resembles her spouse, lacks his mustache. The beak is long, strong, somewhat curved and dark colored. This bird is distinctly larger than the robin. The white patch on the rump shows little or none when the bird is at rest, for this white mark is a "color call," it being a rear signal by means of which the flock of migrating birds are able to keep together in the night. The yellowhammer's flight is wave-like and jerky and quite different from that of the meadow-lark; nor does it stay so constantly in the meadows but often frequents woods and orchards.

The flicker has many names, such as golden-winged woodpecker, yellow-hammer, high-hole, yarup, wake-up, clape and many others. It earned the name of high-hole because of its habit of excavating its nest high up in trees, usually between ten and twenty-five feet from the ground. It especially loves an old apple tree as a site for a nest, and most of our large old orchards can boast of a pair of these handsome birds during the nesting season of May and June. The flicker is not above renting any house he finds vacant, excavated by some other birds last year. He earned his name of yarup or wake-up from his spring song, which is a rollicking, jolly "wick-a, wick-a, wick-a-wick" a song commonly heard the last of March or early April. The chief food of the flicker is ants, although it also eats beetles, flies and wild fruit, but does little or no damage to planted crops. So long has it fed upon ants, that its tongue has become modified, like that of the ant-eater; it is covered with a sticky substance; and when it is thrust into an ant hill, all of the little 
citizens, disturbed in their communal labors, at once bravely attack the intruder and become glued fast to it, and are thus withdrawn and transferred to the capacious stomach of the bird. It has been known to eat three thousand ants at a single meal.

Those who have observed the flicker during the courting season declare him to be the most silly and vain of all bird wooers. Mr. Baskett says: "When he wishes to charm his sweetheart he mounts a small twig near her, and lifts his wings, spreads his tail, and begins to nod right and left as he exhibits his mustache to his charmer. He sets his jet locket first on one side of the twig and then on the other. He may even go so far as to turn his head half around to show her the pretty spot on his back hair. In doing all this he performs the most ludicrous antics and has the silliest expression of face and voice as if in losing his heart, as some one phrases it, he had lost his head also."

The nest hole is quite deep and the white eggs are from four to ten in number. The feeding of the young flickers is a painful process to watch. The parent takes the food into its own stomach and partially digests it, then thrusting its own bill down the throat of the young one it pumps the soft food into it "kerchug, kerchug." until it seems as if the young one must be shaken to its foundations. The young flickers as soon as they leave the nest climb around freely on the home tree in a delightful, playful manner.

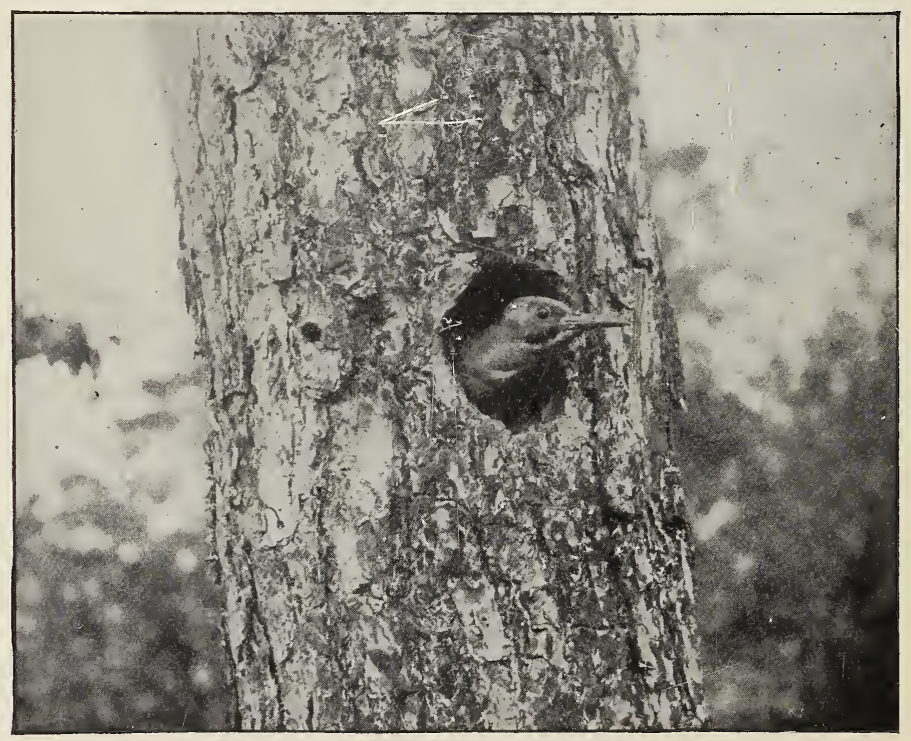

Flicker coming from the nest.

Photo by George Fiske, Jr. 


\section{LESSON XVII}

\section{The Flicker}

Leading thought-The flicker is a true woodpecker but has changed its habits and spends much of its time in meadows hunting for ants and other insects; it makes its nest in trees, like its relatives. It can be distinguished from the meadow-lark by the white patch above the tail which shows during flight.

Methods-This is one of the most important of birds of the meadow and the work may be done in September when there are plenty of young flickers, which have not learned to be wary. The observations may be made in the field, a few questions given at a time.

Observations-r. Where do you find the flicker in the summer and early autumn? How can you tell it from the meadow-lark in color and in flight? ants?

2. What is it doing in the meadows? How does it manage to trap

3. What is the size of the flicker as compared to the robin? What is its general color as compared to the meadow-lark?

4. Describe the colors of the flicker as follows: Top and sides of the head, back of the neck, lower back, tail, wings, throat and breast. The color and shape of the beak. Is there a difference in markings between the males and females?

5. Does the patch of white above the tail show, except when the bird is flying? Of what use is this to the bird?

6. What is the flicker's note? At what time of spring do you hear it first?

7. Where does the flicker build its nest and how? What is the color of the eggs? How many are there?

8. How does it feed its young? How do the young flickers act?

9. How many names do you know for the flicker?

Supplementary reading- "The Bird of Many Names," Nestlings of Forest and Marsh; A Fellow of Expedients, Long; Our Birds and Their Nestlings, p. I87; Audubon Leaflet No. 5 .

The high-hole appears to drum more promiscuously than does the downy. He utters his long, loud spring call, whick-whick-whick, and then begins to rap with his beak upon his perch before the last note has reached your ear. I have seen him drum sitting upon the ridge of the barn. The log-cock, or pileated woodpecker, the largest and wildest of our Northern species, I have never heard drum. His blows should wake the echoes.

When the woodpecker is searching for food, or laying siege to some hidden grub, the sound of his hammering is dead or muffled, and is heard but a few yards. It is only upon dry, seasoned timber, treed of its bark, that he beats his reveille to spring and woos his mate.-John BURROUGHs, in Birds, Bees and Sharp Eyes. 


\section{THE MEADOW-LARK}

\section{Teacher's Story}

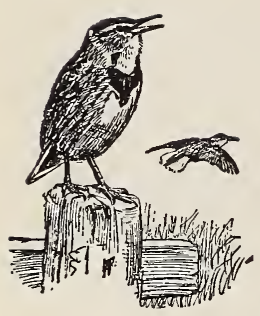

The first intimation we have in early spring, that the meadow-lark is again with us, comes to us through his soft, sweet, sad note which Van Dyke describes so graphically when he says it, "leaks slowly upward from the ground." One wonders how a bird can express happiness in these melancholy, sweet, slurred notes and yet undoubtedly it is a song expressing joy, the joy of returning home, the happiness of love and of nest building. But after one has spent a winter in the Gulf States, and has witnessed the slaughter there of this most valuable bird; and after the northern stomach and heart have turned sick at the sight of breasts once so full of song done brown on the luncheon table, one nolonger wonders that the meadowlark's song of joy is fraught with sadness. There should be national laws to protect the birds that are of value to one part of the United States from being slaughtered in their winter haunts, unless they are there a nuisance and injurious to crops, which is not the case with the meadow-lark.

The meadow-lark, as is indicated by its name, is a bird of the meadow. It is often confused with another bird of the meadow which has very different habits, the flicker. The two are approximately of the same size and color and each has a black crescent or locket on the breast and each shows the "white feather" during flight. The latter is the chief distinguishing character; the outer tail feathers of the meadow-lark are white, while the tail feathers of the flicker are not white at all, but it has a single patch of white on the rump. The flight of the two is quite different. The lark lifts itself by several sharp movements and then soars smoothly over the course, while the flicker makes a continuous up and down, wave-like flight. The songs of the two would surely never be confused, for the meadow-lark is among our sweetest singers, to which class the flicker with his "flick a flick" hardly belongs.

The colors of the meadow-lark are most harmonious shades of brown and yellow, well set off by the black locket on its breast. Its wings are light brown, each feather being streaked with black and brown; the line above the eye is yellow, bordered with black above and below; a buff line extends from the beak backward over the crown. The wings are light brown and have a mere suggestion of white bars; portions of the outer feathers on each side of the tail are white, but this white does not show except during flight. The sides of the throat are greenish, the middle part and breast are lemon-yellow, with the large, black crescent just below the throat. The beak is long, strong and black, and the meadow-lark is decidedly a low-browed bird, the forehead being only slightly higher than the upper part of the beak. It is a little larger than the robin which it rivals in plumpness.

The meadow-lark has a particular liking for meadows which border streams. It sings when on the ground, on the bush or fence and while on the wing; and it sings during the entire period of its northern stay, from April to November, except while it is moulting in late summer. Mr. Mathews, who is an eminent authority on bird songs, says that the 
meadow-larks of New York have a different song from those of Vermont or Nantucket, although the music has always the same general characteristics. The western species has a longer and more complex song than ours of the East. It is one of the few California birds that is a genuine joy to the eastern visitor; during February and March its heavenly music isas pervasive as the California sunshine.

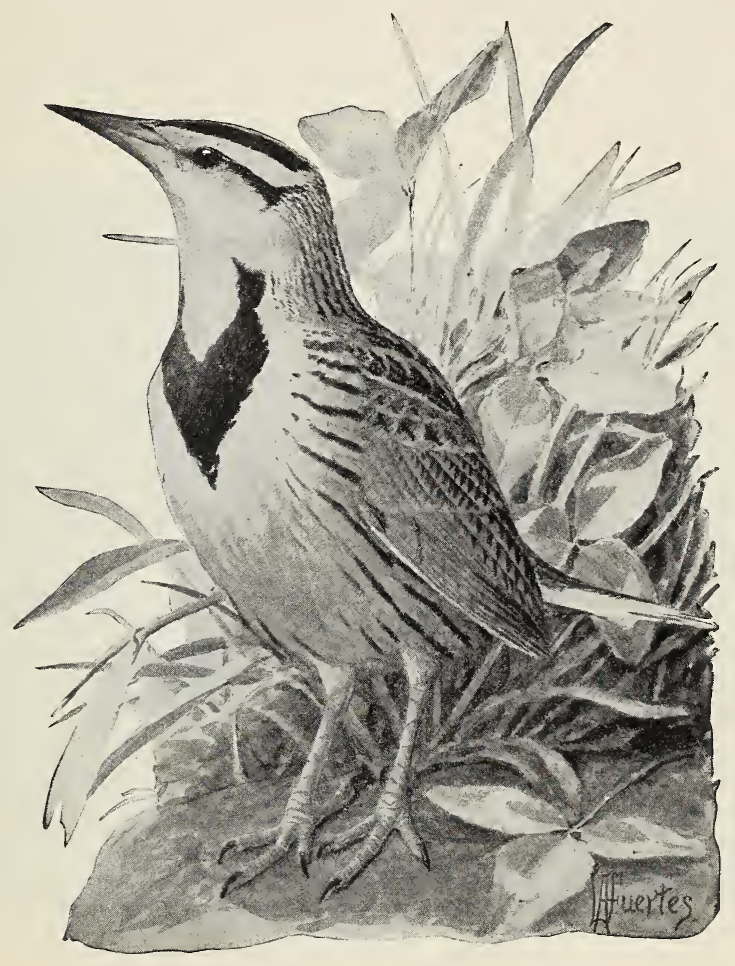

The meadow-lark.

Drawing by L. A. Fuertes.

The nest is built in a depression in the ground near a tuft of grass; it is constructed of coarse grass and sticks and is lined with finer grass; there is usually a dome of grass blades woven above the nest; and often a long, covered vestibule leading to the nest is made in a similar fashion. This is evidently for protection from the keen eyes of hawks and crows. The eggs are laid about the last of May and are usually from five to seven in number; they are white, speckled with brown and purple. The young larks are usually large enough to be out of the way before haying time in July. 
The food of the meadow-lark during the entire year, consists almost exclusively of insects which destroy the grass of our meadows. It eats great quantities of grasshoppers, cut worms, chinch bugs, army worms, wire worms, weevils, and also destroys some weed seeds. Each pupil should make a diagram in his note-book showing the proportions of the meadow-lark's different kinds of food. This may be copied from Audubon Leaflet No. 3. The killing of the meadow-lark in New York State is a punishable offence, as it should be in every state of the Union. Everyone who owns a meadow should use his influence to the uttermost to protect this valuable bird. It has been estimated that the meadow-larks save to every township where hay is produced, twenty-five dollars each year on this crop alone.

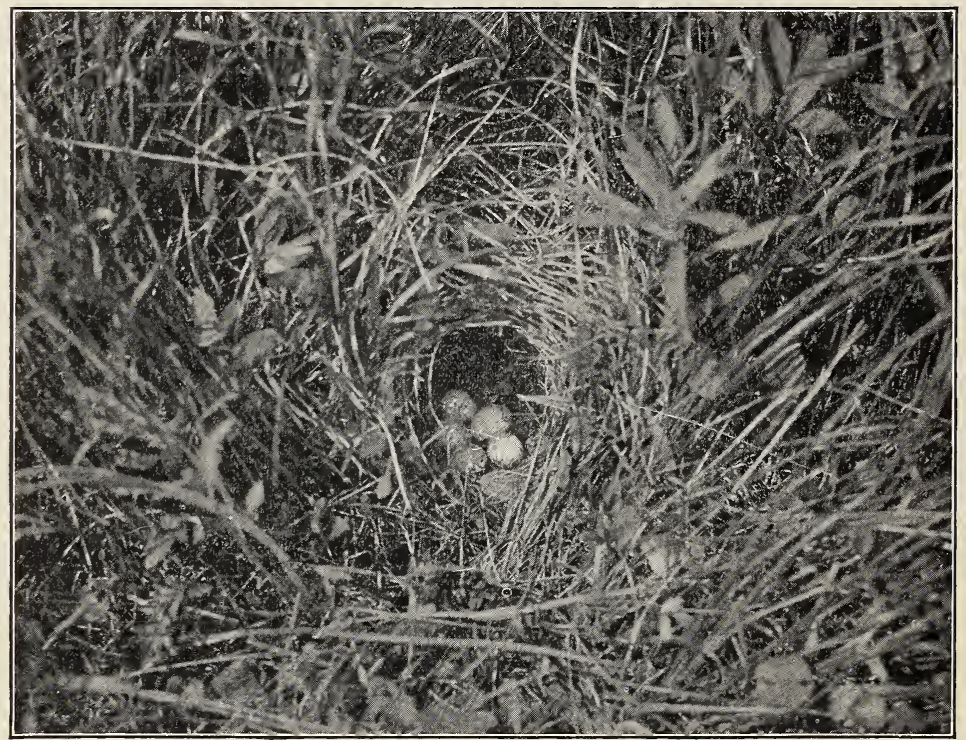

The meadow-lark's covered nest. Photo by Robert Matheson

\section{LESSON XVIII}

\section{The Meadow-Lark}

Leading thought-The meadow-lark is of great value in delivering the grass of our meadows from insect destroyers. It has a song which we all know; it can be identified by color as a large, light brown bird with white feathers on each side of the tail, and in flight, by its quick up and down movements finishing with long, low, smooth sailing.

Method-September and October are good months for observations on the flight, song and appearance of the meadow-lark, and also for learning 
how to distinguish it from the flicker. The notes must be made by the pupils in the field, and after they know the bird and its song let them, if they have opportunity, study the bird books and bulletins, and prepare written accounts of the way the meadow-lark builds its nest and of its economic value.

Observations-r. Where have you seen the meadow-lark? Did you ever see it in the woods? Describe its flight. How can you identify it by color when it is flying? How do its white patches and its flight differ from those of the flicker?

2. Try and imitate the meadow-lark's notes by song or whistle. Does it sing while on the ground, or on a bush or fence, or during flight?

3. Note the day when you hear its last song in the fall and also its first song in the spring. Does it sing during August and September? Why? Where does it spend the winter? On what does it feed while in the South? How are our meadow-larks treated when on their southern sojourn?

4. Is the meadow-lark larger or smaller than the robin? Describe from your own observation, as far as possible, the colors of the meadowlark as follows: Top of head; line above the eye; back; wings; tail; throat; breast; locket; color and shape of beak. Make a sketch of your own or a copy from Louis Fuertes' excellent picture of the meadow-lark in the Audubon Leaflet, and color it accurately.

5. When is the nest built; where is it placed; of what material is it built? How is it protected from sight from above? Why this protection, How many eggs? What are their colors and markings?

6. What is the food of the meadow-lark? Copy the diagram from the Audubon leaflet, showing the proportions of the different kinds of insects which it destroys. Why should the farmers of the South also protect the meadow-lark by law?

Supplementary reading--Audubon Education Leaflet No. 3; Farmers' Bulletin No. 54, U. S. Dept. of Agr.; "A Pioneer," in Nestlings of Forest and Marsh, Wheelock.

Sweet, sweet, sweet! O happy that I am!

(Listen to the meadow-larks, across the fields that sing!)

Sweet, sweet, sweet! O subtle breath of balm,

$O$ winds that blow, O buds that grow, O rapture of the spring!

Sweet, sweet, sweet! O happy world that is!

Dear heart, I hear across the fields my mateling pipe and call.

Sweet, sweet, sweet! O world so full of bliss,

For life is love. the world is love, and love is over all!

-Ina Coolbrith. 


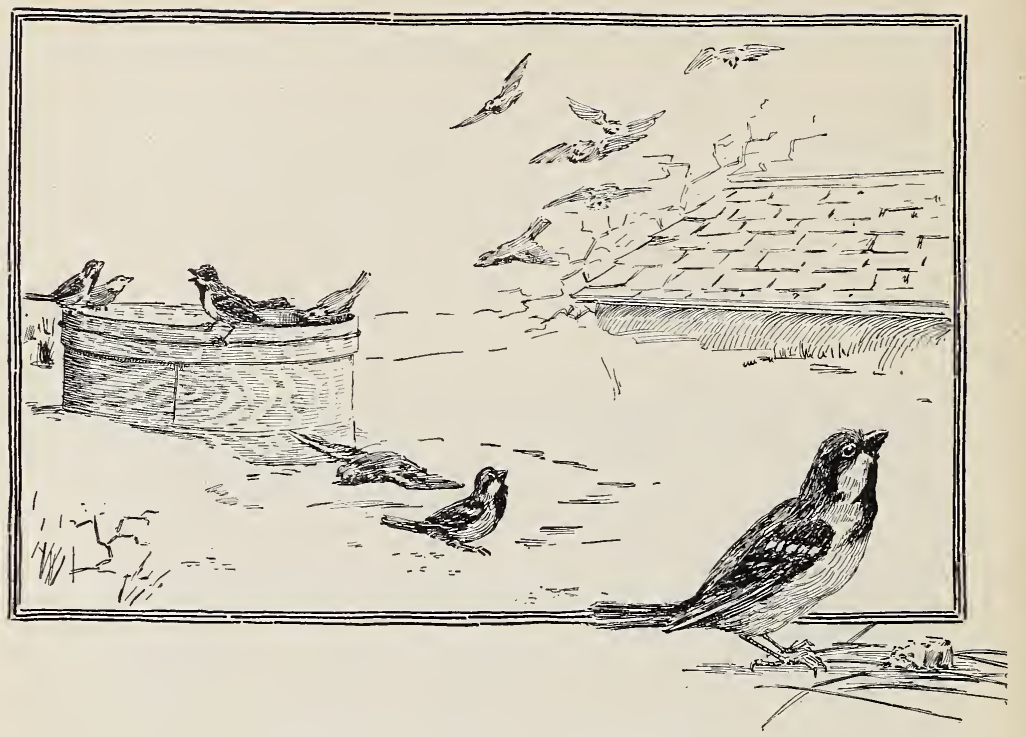

\section{THE ENGLISH SPARROW}

\section{Teacher's Story}

So dainty in plumage and hue, A study in grey and in brown,

How little, how little we knew

The pest he would prove to the town!

From dawn until daylight grows dim,

Perpetual chatter and scold.

No winter migration for him.

Not even afraid of the cold!

Scarce a song-bird he fails to molest,

Belligerent, meddlesome thing!

Wherever he goes as a guest

$\mathrm{He}$ is sure to remain as a King.

- Mary isabella Forsyth.

The English sparrow, like the poor and the house-fly, is always with us; and since he is here to stay, let us make him useful if we can devise any means of doing so. There is no bird that gives the pupils a more difficult exercise in describing colors and markings than does he; and his wife is almost equally difficult. I have known fairly skilled ornithologists to be misled by some variation in color of the hen sparrow, and it is safe to assert that the majority of people "do not know her from Adam." The male has the top of the head gray with a patch of reddish brown on either side; the middle of the throat and upper breast is black; the sides of the throat white; the lower breast and under parts grayish white; the 
back is brown streaked with black; the tail is brown, rather short, and not notched at the tip; the wings are brown with two white bars and a jaunty dash of reddish brown. The female has the head grayish brown, the breast, throat and under parts grayish white; the back is brown streaked with black and dirty yellow, and she is, on the whole, a "washed out" looking lady bird. The differences in color and size between the English sparrow and the chippy are quite noticeable, as the chippy is an inch shorter and far more slender in appearance, and is especially marked by the reddish brown crown.

When feeding, the English sparrows are aggressive, and their lack of table manners make them the "goops" among all birds; in the winter they settle in noisy flocks on the street to pick up the grain undigested by the horses, or in barnyards where the grain has been scattered by the cattle. They only eat weed seeds when other food fails them in the winter, for they are a civilized bird even if they do not act so, and they much prefer the cultivated grains. It is only during the nesting season that they destroy insects to any extent; over one-half the food of nestlings is insects, such as, weevils, grasshoppers, cutworms, etc.; but this good work is largely offset by the fact that these same nestlings will soon give their grown-up energies to attacking grain fields, taking the seed after sowing, later the new grain in the milk, and later still the ripened grain in the sheaf. Wheat, oats, rye, barley, corn, sorghum and rice are thus attacked. Once I saw on the upper Nile a native boat loaded with millet which was attacked by thousands of sparrows; when driven off by the sailors they would perch on the rigging, like flies, and as soon as the men turned their backs they would drop like bullets to the deck and gobble the grain before they were again driven off. English sparrows also destroy for us the buds and blossoms of fruit trees and often attack the ripening fruit.

The introduction of the English sparrow into America is one of the greatest arguments possible in favor of nature-study; for, ignorance of nature-study methods in this single instance, costs the United States millions of dollars every year. The English sparrow is the European house sparrow and people had a theory that it was an insect eater, but never took the pains to ascertain if this theory were a fact. About I $85^{\circ}$, some people with more zeal than wisdom introduced these birds into New York, and for twenty years afterwards there were other importations of the sparrows. In twenty years more, people discovered that they had taken great pains to establish in our country one of the worst nuisances in all Europe. In addition to all the direct damage which the English sparrows do, they are so quarrelsome that they have driven away many of our native beneficial birds from our premises, and now vociferously acclaim their presence in places which were once the haunts of birds with sweet songs. After they drive off the other birds they quarrel among themselves, and there is no rest for tired ears in their vicinity. There are various noises made by these birds which we can understand if we are willing to take the pains: The harassing chirping is their song; they squall when frightened and peep plaintively when lonesome, and make a disagreeable racket when fighting.

But to "give the devil his due" we must admit that the house sparrow is as clever as it is obnoxious, and its success is doubtless partly due to its superior cleverness and keenness. It is quick to take a hint, if sufficiently 
pointed; firing a shotgun twice into a flock of these birds has driven them from our premises; and tearing down their nests assiduously for a month seems to convey to them the idea that they are not welcome. Another instance of their cleverness I witnessed one day; I was watching a robin, worn and nervous with her second brood, fervently hunting earthworms in the lawn to fill the gaping mouths in the nest in the Virginia creeper shading the piazza. She finally pulled up a large, pink worm and a hen sparrow flew at her viciously; the robin dropped the worm to protect herself, and the sparrow snatched it and carried it off triumphantly to the grape arbor where she had a nest of her own full of gaping mouths. She soon came back, and at a safe distance watched the robin pull out another worm, and by the same tactics again gained the squirming prize. Three times was this repeated in an hour, and then the robin, discouraged, flew up into a Norway spruce and in a monologue of sullen cluckings tried to reason out what had happened.

The English sparrow's nest is quite in keeping with the bird's other qualities; it is usually built in a hole or box or in some protected corner beneath the eaves; it is also often built in vines on buildings and occasionally in trees. It is a good example of "fuss and feathers"; coarse straw, or any other kind of material, and feathers of hens or of other birds, mixed together without fashion or form, constitute the nest. In these sprawling nests the whitish, brown or gray-flecked eggs are laid and the young reared; and so far as I can ascertain, no one has ever counted the number of broods reared in one season. The nesting begins almost as soon as the snow is off the ground and lasts until late fall.

During the winter, the sparrows gather in flocks in villages and cities, but in the spring they scatter out through the country where they can find more grain. The only place where this bird is welcome is possibly in the heart of a great city, where no other bird could pick up a livelihood. It is a true cosmopolite and is the first bird to greet the traveler in Europe or northern Africa. These sparrows will not build in boxes suspended by a wire; and they do not like a box where there is no resting place in front of the door leading to the nest.

After the pupils have made observations upon the habits of the house sparrow, they may find, in the following books and bulletins, facts which will teach further the economic importance of this bird: Birds in Their Relation to Man, by Weed and Dearborn, p. r44. The following bulletins of the U. S. Department of Agriculture: "English Sparrow in North America;" "Relation of Sparrows to Agriculture," S. D. Judd, Bulletin I5; "The Food of Nestlings," Yearbook I9oo.

\section{LESSON XIX}

\section{The English Sparrow}

Leading thought-The English sparrow was introduced into America by people who knew nothing of its habits. It has finally over-run our whole country and, to a great extent, has driven out, from towns and villages our useful American song birds and it should be discouraged and not allowed to nest around our houses and grounds. As a sparrow it has interesting habits which we should observe.

Methods-Let the pupils make their observations in the street or wherever they find the birds. The greatest value of this lesson is to teach 
the pupils to observe the coloring and markings of a bird accurately and describe them clearly. This is the best of training for later work with the wild birds.

Observations- - . How many kinds of birds do you find in a flock of English sparrows?

2 . The ones with the black cravat are naturally the men of the family, while their sisters, wives and mothers are less ornamented. Describe in your note-book or from memory the colors of the cock sparrow as follows: Top of head; sides of the head; the back; the tail; the wings; wing bars; throat and upper breast; lower breast and under parts.

3. Describe the hen sparrow in the same manner and note the difference in markings between the two. Are the young birds, when they first fly, like the father or the mother?

4. Compare the English sparrow with the chippy and describe the differences in size and color.

5. Is the tail when the bird is not flying, square across the end or notched?

6. What is the shape of the beak? For what sort of food is this shaped beak meant?

7. What is the food of the English sparrows and where do they find it? Describe the actions of a flock feeding in the yard or street. Are the English sparrows kindly or quarrelsome in disposition?

8. Why do the English sparrows stay in the North during the coldest of winters? Do they winter out in the country or in villages?

9. Describe by observation how they try to drive away the robins or other native birds.

Io. Describe the nest of this sparrow. Of what material is it made? How is it supported? How sheltered? Is it a well-built nest?

I I. Describe the eggs? How many broods are raised a year? What kind of food do the parents give the nestlings?

I 2. If you have ever seen these sparrows do anything interesting describe the circumstance?

I3. In what ways are these birds a nuisance to us?

I 4. How much of English sparrow talk do you understand?

I 5. How can we build bird-boxes so that the English sparrows will not try to take possession of them?

Supplementary reading-"A Street Troubadour," in Lives of the Hunted, Thompson Seton. First Book of Birds, Miller, p. 8I. "Blizzard" and "Three Sparrows that live in the House," from True Bird Stories, Miller.

Do not tire the child with questions; lead him to question you, instead. Be sure, in any case, that he is more interested in the subject than in the questions about the subject. 


\section{THE CHIPPING SPARROW}

\section{Teacher's Story}

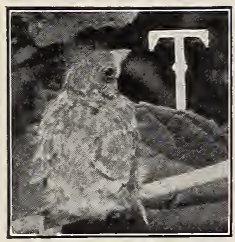

HIS midget lives in our midst, and yet, not among all bird kind, is there one which so ignores us as does the chippy. It builds its nest about our houses, it hunts for food all over our premises, it sings like a tuneful grasshopper in our ears, it brings up its young to disregard us, and every hour of the day it "tsip-tsips" us to scorn. And, although it has well earned the name of "doorstep sparrow," since it frugally gathers the crumbs about our kitchen doors, yet it rarely becomes tame or can be induced to eat from the hand, unless it is trained so to do as a nestling.

Its cinnamon-brown cap and tiny black forehead, the gray streak over the eye and the black through it, the gray cheeks and the pale gray, unspotted breast distinguish it from the other sparrows, although its brown back streaked with darker, and brown wings and blackish tail have a very sparrowish look; the two whitish wing bars are not striking; it has a bill fitted for shelling seeds, a characteristic of all the sparrows. Despite its seed-eating bill, the chippy's food is thirty-eight per-cent insects, and everyone should read what Mr. Forbush says about the good work this little bird does in our gardens and to our trees. It takes in large numbers cabbage caterpillars, the pea louse, the beet leaf-miners, leaf hoppers, grasshoppers, cutworms, and does its best to annihilate the caterpillars of the terrible gypsy and browntail moths. In fact, it works for our benefit even in its vegetable food, as this consists largely of the seeds of weeds and undesirable grasses. It will often fly up from its perch after flies or moths, like a flycatcher; and the next time we note it, it will be hopping around hunting for the crumbs we have scattered for it on the piazza floor. The song of the chippy is more interesting to it than to us; it is a continuous performance of high, shrill, rapid notes, all alike so far as I can detect; when it utters many of these in rapid succession it is singing, but when it gives them singly they are call notes or mere conversation.

One peculiarity of the nest has given this sparrow the common name of hair-bird, for the lining is almost always of long, coarse hair, usually treasure trove from the tails of horses or cattle switched off against boards, burs or other obstacles. Of the many nests I have examined, black horsehair was the usual lining; but two nests in our yard show the chippy to be a resourceful bird; evidently the hair market was exhausted and the soft, dead needles of the white pine were used instead and made a most satisfactory lining. The nest is tiny and shallow; the outside is of fine grass or rootlets carefully but not closely woven together; it is placed in vine or tree, usually not more than ten or fifteen feet from the ground; a vine of a piazza is a favorite nesting site. Once a bold pair built directly above the entrance to our front door and mingled cheerfully with other visitors. Usually, however, the nest is so hidden that it is not discovered until after the leaves have fallen. The eggs are light blue tinged with green, with fine, purplish brown specks or markings scrawled about the larger end. 
The chippy comes to us in April and usually raises two broods of from three to five "piggish" youngsters, which even after they are fully grown follow pertinaciously their tired and "frazzled out" parents and beg to be fed; the chippy parents evidently have no idea of discipline but indulge their teasing progeny until our patience, at least, is exhausted. The

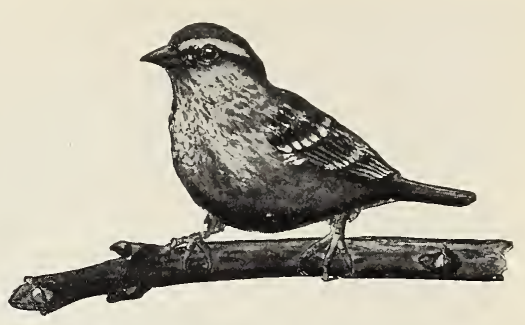

The chipping sparrow. young differ from the parents in having streaked breasts and lacking the reddish crown. In the fall the chippy parents lose their red-brown caps and have streaked ones instead; and then they fare forth in flocks for a seed-harvest in the fields. Thereafter our chippy is a stranger to us; we do not know it in its new garb, and it dodges into the bushes as we pass, as if it had not tested our harmlessness on our own door-stone. Reference-Wild Life, Ingersol, p. I 32.

\section{LESSON XX}

Leading thought-The chipping sparrow is a cheerful and useful little neighbor. It builds a nest, lined with horsehair, in the shrubbery and vines about our homes and works hard in ridding our gardens of insect pests and seeds of weeds.

Methods-Begin this lesson with a nest of the chippy, which is so unmistakable that it may be identified when found in the winter. Make the study of this nest so interesting that the pupils will wait anxiously to watch for the birds which made it. As soon as the chippies appear, the questions should be asked, a few at a time, giving the children several weeks for the study.

\section{The Nest}

Observations-r. Where was this nest found? How high from the ground?

2. Was it under shelter? How was it supported?

3. Of what material is the outside of the nest? How is it fastened together? How do you suppose the bird wove this material together?

4. Of what material is the lining? Why is the bird that built this nest called the "hair bird?" From what animal do you think the lining of the nest came? How do you suppose the bird got it?

5. Do you think the nest was well hidden when the leaves were about it? Measure the nest across and also its depth; do you think the bird that made it is as large as the English sparrow?

\section{The Bird}

6. How can you tell the chippy from the English sparrow?

7. Describe in your note-book or orally the colors of the chippy as follows: beak, forehead, crown, marks above and through the eyes, 
cheeks, throat, breast, wings and tail. Note if the wings have whitish bars and how many.

8. Describe the shape of the beak as compared with that of the robin. What is this shaped bill meant for?

9. What is the food of the chippy? Why has it been called the doorstep-sparrow?

Io. Note if the chippy catches flies or moths on the wing like the phœbe-bird.

I I. Why should we protect the chippy and try to induce it to live near our gardens?

I 2. Does it run or hop when seeking food on the ground?

I3. How early in the season does the chippy appear and where does it spend the winter?

I 4. Can you describe the chippy's song? How do you think it won the name of chipping sparrow?

I 5. If you have the luck to find a pair of chippies nesting, keep a diary of your observations in your note-book covering the following points: Do both parents build the nest? How is the frame-work laid? How is the finishing done? The number and color of the eggs? Do both parents feed the young? How do young chippies act when they first leave the nest? How large are the young birds before the parents stop feeding them? What are the differences in color and markings between parents and young?

\section{THE FIELD-SPARROW}

A bubble of music floats, the slope of the hillside over;

A little wandering sparrow's notes; and the bloom of yarrow and clover, And the smell of sweet-fern and the bayberry leaf, on his ripple of song are stealing, For he is a cheerful thief, the wealth of the fields revealing.

One syllable, clear and soft cis 0 ro indrop's silvery patter,

Or a tinkling fairy-bell; hecra aloft, in the midst of the merry chatter

Of robin and linnet and wren and jay, one syllable, oft repeated;

He has but a word to say, and of that he will not be cheated.

The singer I have not seen; but the song I arise and follow The brown hills over, the pastures green, and into the sunlit hollow. With a joy that his life unto mine has lent, I can feel my glad eyes glisten, Though he hides in his happy tent, while I stand outside, and listen.

This way would I also sing, my dear little hillside neighbor! A tender carol of peace to bring to the sunburnt fields of labor Is better than making a loud ado; trill on, amid clover and yarrow! Thore's a heart-beat echoing you, and blessing you, blithe little sparrow! 


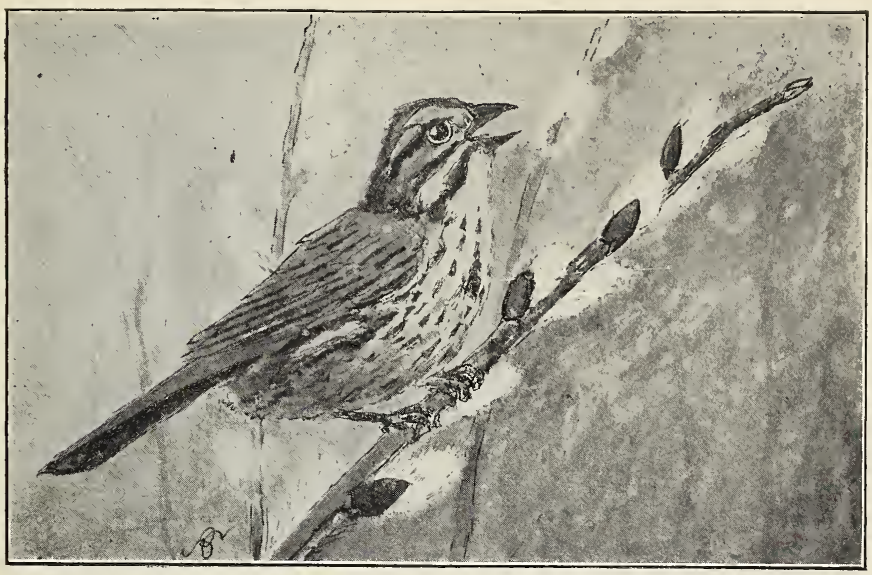

\section{THE SONG SPARROW}

\section{Teachers' Story}

"He does not wear a Joseph's coat of many colors, smart and gay

His suit is Quaker brown and gray, with darker patches at his throat.

And yet of all the well-dressed throng, not one can sing so brave a song.

It makes the pride of looks appear a vain and foolish thing to hear

His "Sweet, sweet, sweet, very merry cheer."

A lofty place he does not love, he sits by choice and well at ease In hedges and in little trees, that stretch their slender arns above

The meadow brook; and then he sings till all the field with pleasure rings; And so he tells in every ear, that lowly home's to heaven are near

In 'Sweet, sweet, sweet, very merry cheer.' "

- Henry Van Dyke.

Children should commit to memory the poem from which the above stanzas were taken; seldom in literature, have detailed accurate observation and poetry been so happily combined as in these verses. The lesson might begin in March when we are all listening eagerly for bird voices, and the children should be asked to look out for a little, brown bird which sings, "Sweet, sweet, sweet, very merry cheer," or, as Thoreau interprets it, "Maids! Maids! Maids! Hang on the teakettle, teakettle-ettleettle." In early childhood I learned to distinguish this sparrow by its "Teakettle" song. Besides this song, it has others quite as sweet; and when alarmed it utters a sharp "T'chink, t'chink."

The song sparrow prefers the neighborhood of brooks and ponds which are bordered with bushes, and also the hedges planted by nature along rail or other field fences, and it has a special liking for the shrubbery about gardens. Its movements and flight are very characteristic; it usually sits on the tip-top of a shrub or low tree when it sings, but when disturbed 
never rises in the air but drops into a low flight and plunges into a thicket with a defiant twitch of the tail which says plainly, "find me if you can."

The color and markings of this bird are typical of the sparrows. The head is a warm brown with a gray streak along the center of the crown and one above each eye, with a dark line through the eye. The back is brown with darker streaks. The throat is white with a dark spot on either side; the breast is white spotted with brown with a large, dark blotch at its very center; this breast blotch distinguishes this bird from all other sparrows. The tail and wings are brown and without buff or white bars or other markings. The tail is long, rounded and very expressive of emotions, and makes the bird look more slender than the English sparrow.

The nest is usually placed on the ground or in low bushes not more than five feet from the ground; it varies much in both size and material; it is sometimes constructed of coarse weeds and grasses; and sometimes only fine grass is used. Sometimes it is lined with hair, and again, with fine grass; sometimes it is deep, but occasionally is shallow. The eggs have a whitish ground-color tinged with blue or green, but are so blotched and marked with brown that they are safe from observation of enemies. The nesting season begins in May, and there are usually three and sometimes four broods; but so far as I have observed, a nest is never used for two consecutive broods. The song sparrow stays with us in NewYork State very late in the fall, and a few stay in sheltered places all winter. The quality in this bird which endears him to us all is the spirit of song which stays with him; his sweet trill may be heard almost any month of the year, and he has a charming habit of singing in his dreams, if sudden noise disturbs his slumber.

The song sparrow is not only the dearest of little neighbors, but it also works lustily for our good and for its own food at the same time. It destroys cutworms, plant-lice, caterpillars, canker-worms, ground beetles, grasshoppers and flies; in winter it destroys thousands of weed seeds, which otherwise would surely plant themselves to our undoing. Every boy and girl should take great pains to drive away stray cats and to teach the family puss not to meddle with birds; for cats are the worst of all the song sparrow's enemies, destroying thousands of its nestlings every year.

\section{LESSON XXI}

\section{The Song Sparrow}

Leading thought-The beautiful song of this sparrow is heard earlier in the spring than the notes of bluebird or robin. The dark blotch in the center of its speckled breast distinguishes this sparrow from all others; it is very beneficial and should be protected from cats.

Methods-All the observations of the song sparrow must be made in the field, and they are easily made because the bird builds near houses, in gardens, and in the shrubbery. Poetry and other literature about the song sparrow should be given to the pupils to read or to memorize.

Observations-r. Have you noticed a little brown bird singing a very sweet song in the early spring? Did the song sound as if set to the words "Little Maid! Little Maid! Little Maid! Put on the teakettle, teakettle-ettle ettle?" 
2. Where was this bird when you heard him singing? How high was he perched above the ground? What other notes did you hear him utter?

3. Describe the colors and markings of the song sparrow on head, back, throat, breast, wings and tail. Is this bird as large as the English sparrow? What makes it look more slim?

4. How can you distinguish the song sparrow from the other sparrows? When disturbed does it fly up or down? How does it gesture with its tail as it disappears in the bushes?

5. Where and of what material does the song sparrow build its nest?

6. What colors and markings are on the eggs? Do you think these colors and markings are useful in concealing the eggs when the mother bird leaves the nest?

7. How late in the season do you see the song sparrows and hear their songs? Does this bird, when disturbed, fly up or down?

8. How can we protect these charming little birds and induce them to build near our houses?

9. What is the food of the song sparrows and how do they benefit our fields and gardens?

Supplementary reading-Our Birds and Their Nestlings, Walker, pp. $43,49,50,52$; Second Book of Birds, Miller, p. 80; Birds of Song and Story, Grinnell, p. 73; The Song Sparrow, Van Dyke; Birds Through an Opera Glass, Merriam, p. 66; Field Book of Wild Birds, Mathews, p. Iо9; Wild Life, Ingersoll, p. I 44; Audubon Leaflet No. 3 I.

\section{THE SING-AWAY BIRD}

Have you ever heard of the Sing-away bird,

That sings where the Runaway River

Runs down with its rills from the bald-headed hills

That stand in the sunshine and shiver?

"Oh, sing! sing-away! sing-away!"

How the pines and the birches are stirred

By the trill of the Sing-away bird!

And the bald-headed hills, with their rocks and their rills,

To the tune of his rapture are ringing;

And their faces grow young, all the gray mists among,

While the forests break forth into singing.

"Oh sing! sing-away! sing-away!"

And the river runs singing along;

And the flying winds catch up the song.

' $T$ was a white-throated sparrow, that sped a light arrow

Of song from his musical quiver,

And it pierced with its spell every valley and dell

On the banks of the Runaway River.

"Oh, sing! sing-away! sing-away!"

The song of the wild singer had

The sound of a soul that is glad.-LUCy LARCom. 


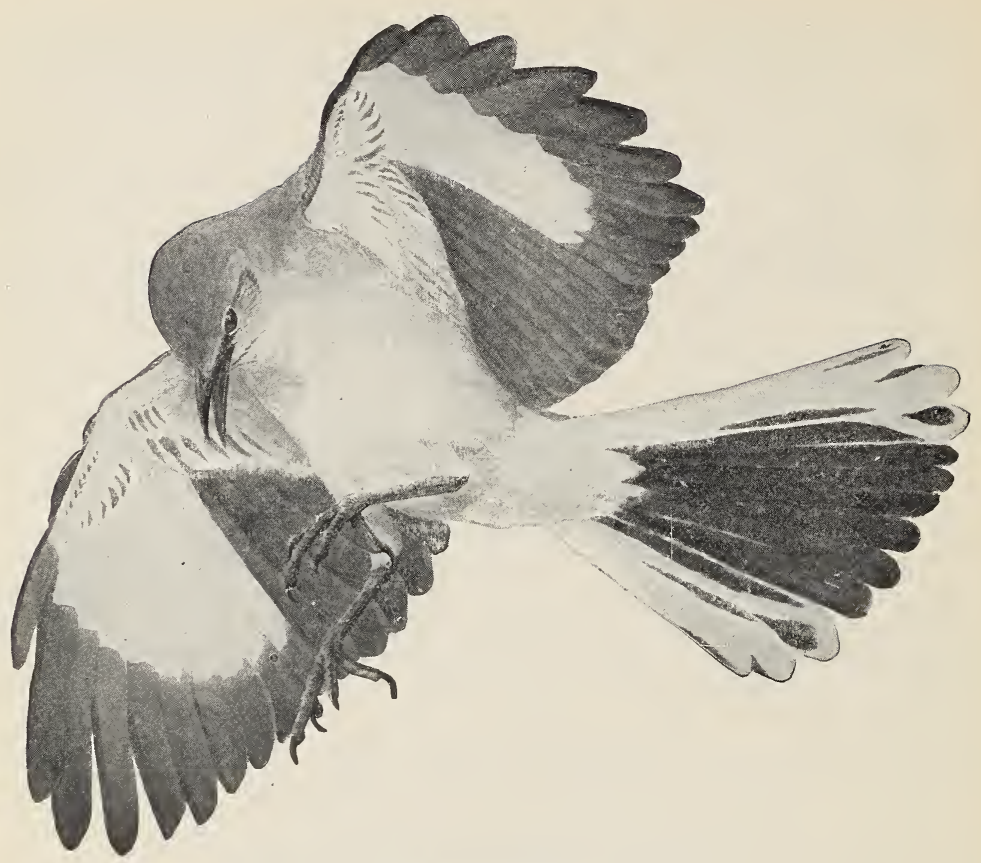

The mockingbird.

Drawing by L. A. Fuertes.

\section{THE MOCKINGBIRD}

\section{Teacher's Story}

Aınong all the vocalists in the bird world, the mockingbird is unrivaled in the variety and richness of his repertoire; and he has thus won his place anıong men, convincing many ignorant people by the means of his voice that a bird is good for something besides "victuals." The mockingbirds go as far north as southern New England, but they are found at their best in the Southern States and in California. On the Gulf Coast the mockers begin singing in February; in warmer climates they sing almost the year through. During the nesting season, the father mocker is so busy with his cares and duties during the day, that he does not have time to sing and so devotes the nights to serenading; he may sing almost ali night long if there is moonlight, but even on dark nights he gives now and then a happy, sleepy song. Not all mockingbirds are mockers; some sing their own song which is rich and beautiful; while others learn in addition, not only the songs of other birds, but their call notes as well. One authority noted a mocker which imitated the songs of twenty species of birds during a ten-minute performance. When singing, the mocker shows his relationship to the brown thrasher by lifting the head 
and depressing and jerking the tail. A good mocker will learn a tune, or parts of it, if it is 'whistled often enough in his hearing; he will also imitate other sounds and will often improve on a song he has learned from another bird by introducing frills of his own; when learning a song, he sits silent and listens intently, but will not try to sing it until it is learned.

Although the mockingbirds live in wild places, they prefer the haunts of men, taking up their home sites in gardens and cultivated grounds. Their flight is rarely higher than the tree tops and is decidedly jerky in character with much twitching of the long tail. For nesting sites, they choose thickets or the lower branches of trees, being especially fond of orange trees; the nest is usually from four to twenty feet from the ground. The foundation of the nest is made of sticks, grasses and weed stalks interlaced and crisscrossed; on these is built the nest of softer materials, such as, rootlets, horsehair, cotton, or in fact, anything suitable which is at hand. The nest is often in plain sight, since the mocker trusts to his strength as a fighter to protect it. He will attack cats with great ferocity and vanquish them; he will kill snakes; often good-sized black snakes have been known to end thus. The mocker, in making his attack, hovers above his enemy and strikes it at the hack of the head or neck; he will also drive away birds much larger than himself.

The female lays from four to six pale greenish or bluish eggs blotched with brown and which hatch in about two weeks; then comes a period of hard work for the parents, as both are indefatigable in catching insects to feed the young. The mocker, by the way, is a funny sight when he is chasing a beetle on the ground, lifting his wings in . 2 pugnacious fashion. The nockers often raise three broods a season; the young birds have spotted breasts, showing their relationship to the thrasher.

As a wooer, the mocker is a bird of nuch ceremony and dances into his lady's graces. Mrs. F. W. Rowe, in describing this, says that the birds stand facing each other with heads and tails erect and wings drooping; "then the dance would begin, and this consisted of the two hopping sideways in the same direction and in rather a straight line a few inches at a time, always keeping directly opposite each other and about the same distance apart. They would chassez this way four or five feet, then go back over the same line in the same manner." Mrs. Rowe also observed that the male mockers have hunting preserves of their own, not allowing any other males of their species in these precincts. The boundary was sustained by tactics of both offense and defense; but certain other species of birds were allowed to trespass without reproof.

Maurice Thompson describes in a delightful manner the "mounting" and "dropping" songs of the mocker which occur during the wooing season. The singer flits up from branch to branch of a tree, singing as he goes, and finally on the topmost bough gives his song of triumph to the world; then, reversing the process, he falls backward from spray to spray, as if drunk with the ecstasy of his own song, which is an exquisitely soft "gurgling series of notes, liquid and sweet, that seem to express utter rapture."

The mockingbirds have the same colors in both sexes; the head is black, the back is ashy-gray; the tail and wings are so dark brown that they look black; the tail is very long and has the outer tail feathers entirely white and the two next inner ones are white for more than half their length; the wings have a strikingly broad, white bar. which is very 
noticeable when the bird is flying. The under parts and breast are grayish white; the beak and legs are blackish. The food of the mockingbirds is about half insects and half fruit. They live largely on the berries of the red cedar, myrtle and holly, and we must confess are often too devoted to the fruits in our orchards and gardens; but let us put down to their credit that they do their best to exterminate the cotton boll caterpillars and moths, and also many other insects injurious to crops.

The mocker is full of tricks and is distinctly a bird of humor. He will frighten other birds by screaming like a hawk and then seem to chuckle over the joke.

Sidney Lanier describes him well.

Whate'er birds did or dreamed, this bird could say.

Then down he shot, bounced airily along

The sward, twitched in a grasshopper, made song

Midflight, perched, prinked, and to his art again.

\section{LESSON XXII}

\section{The Mocking Bird}

Leading thought-The mockingbird is the only one of our common birds that sings regularly at night. It imitates the songs of other birds and has also a beautiful song of its own. When feeding their nestlings, the mockers do us great service by destroying insect pests.

Method-Studies of this bird are best made individually by the pupils through watching the mockers which haunt the houses and shrubbery. If there are mockingbirds near the schoolhouse the work can be done in the most ideal way by keeping records in the school of all the observations made by the pupils, thus bringing out an interesting mockingbird story. The experiment in teaching songs to the birds may best be made with pet mockers.

Observations- $\mathrm{r}$. At what months of the year and for how many months does the mockingbird sing in this locality?

2. Does he sing only on moonlight nights? Does he sing all night?

3. Can you distinguish the true mockingbird song from the songs which he has learned from other birds? Describe the actions of a mocker when he is singing.

4. How many songs of other birds have you heard a mocker give and what are the names of these birds?

5. Have you ever taught a mocker a tune by whistling it in his presence? If so, tell how long before he learned it and how he acted while learning.

Describe the flight of the mockingbirds. Do they fly high in the air like crows?

7. Do these birds like best to live in wild places or about houses and gardens?

8. Where do they choose sites for their nests? Do they make an effort to hide the nest? If not, why?

9. Of what material is the nest made? How is it lined? How far from the ground is it placed?

Io. What are the colors of the eggs? How many are usually laid? How long before they hatch? 
II. Give instances of the parents' devotion to the young birds.

I 2. Have you seen two mockingbirds dancing before each other just before the nesting season?

I3. In the spring have you heard a mocker sing while mounting from the lower to the upper branches of a tree and then after pouring forth his best song fall backward with a sweet, gurgling song as if intoxicated with his music?

I4. How many broods does a pair of nıockers raise during one season? How does the color of the breast of the young differ from that of the parent?

I 5. How does the father bird protect the nestlings from other birds, cats and snakes?

I6. Does the mocker select certain places for his own hunting grounds and drive off other mockers which trespass?

I 7. Describe the colors of the mockingbird as follows: Beak, head, back, tail, wings, throat, breast, under parts and feet.

I8. What is the natural food of the mockingbirds and how do they benefit the farmer? How does the mocker act when attacking a ground beetle?

I9. Have you seen mockingbirds frighten other birds by imitating the cry of a hawk? Have you seen them play other kinis of tricks?

20. Write a little story which shall include your own observations on the ways of pet mockingbirds which you have known.

Supplementary reading-True Bird Stories, Miller, p. I42; Bob, by Sidney Lanier; Second Book of Birds, Miller, p. 34; Birds of Song and Story, Grinnell, p. 29; Stories About Birds, Kirby, p. 94.

"Soft and low the song began: I scarcely caught it as it ran

Through the melancholy trill of the plaintive whip-poor-will,

Through the ringdove's gentle wail, chattering jay and whistling quail,

Sparrow's twitter, catbird's cry, redbird's whistle, robin's sigh;

Blackbird, bluebird, swallow, lark, each his native note might mark.

Oft he tried the lesson o'er, each time louder than before;

Burst at length the finished song, loud and clear it poured along;

All the choir in silence heard, hushed before this wondrous bird.

All transported and amazed, scarcely breathing, long I gazed.

Now it reached the loudest swell; lower, lower, now it fell,-

Lower, lower, lower still, scurce it sounded o'er the rill."

- Joseph Rodman Drake. 


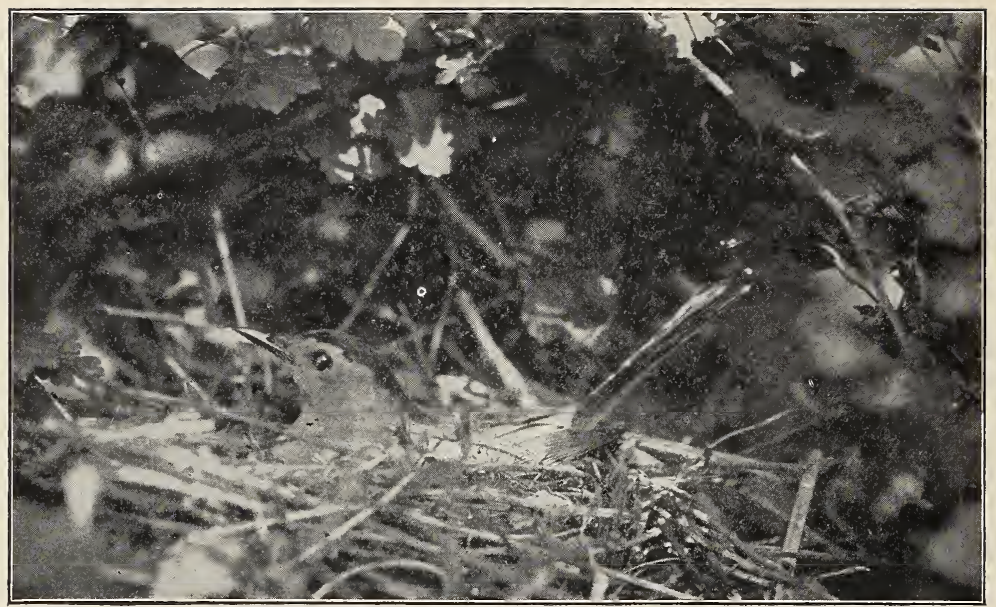

Catbird on nest.

Photo by Robert Matheson.

\section{THE CATBIRD}

\section{Teacher's Story}

"The Catbird sings a crooked song, in minors that are flat, And, when he can't control his voice he mews just like a cat, Then nods his head and whisks his tail and lets it go at that."

-Oliver Davie.

As a performer, the catbird distinctly belongs to the vaudeville, even going so far as to appear in slate-colored tights. His specialties range from the most exquisite song to the most strident of scolding notes; his nasal "n-y-a-a-h, n-y-a-a-h" is not so very much like the cat's mew after all, but when addressed to the intruder it means "get out;" and not in the whole gamut of bird notes is there another which so quickly inspires the listener with this desire. I once trespassed upon the territory of a wellgrown catbird family and the squalling that ensued was ear-splitting; as I retreated, the triumphant youngsters followed me for a few rods with every sign of triumph in their actions and voices; they obviously enjoyed my apparent fright. The catbirds have rather a pleasant "cluck, cltick" when talking to each other, hidden in the bushes, and they also have a variety of other notes. The true song of the catbird, usually given in the early morning, is very beautiful. Mr. Mathews thinks it is a medley gathered from other birds, but it seems to me very individual. However, true to his vaudeville training, this bird is likely to introduce into the middle or at the end of his exquisite song some phrase that suggests his cat call. He is, without doubt, a true mocker and will often imitate the robin's song, and also if opportunity offers learns to converse fluently in chicken language. One spring morning, I heard outside my window 
the mellow song of the cardinal, which is a rare visitor in New York, but there was no mistaking the "tor-re-do, tor-re-do." I sprang from my bed and rushed to the window only to see a catbird singing the cardinal song, and thus telling me that he had come from the sunny South and the happy companionship of these brilliant birds. Often when the catbird is singing, he sits on the topmost spray of some shrub lifting his head and depressing his tail, like a brown thrasher; and again, he sings completely hidden in the thicket.

In appearance the catbird is tailor-made, belonging to the same social class as the cedar-bird and the barn swallow. However, it affects quiet colors, and its well-fitting costume is all slate-gray except the top of the head and the tail which are black; the feathers beneath the base of the tail are brownish. The catbird is not so large as the robin, and is of very different shape; it is far more slender and has a long, emotional tail. The way the catbird twitches and tilts its tail, as it hops along the ground or alights in a bush, is very characteristic. It is a particularly alert and nervous bird, always on the watch for intruders, and the first to give warning to all other birds of their approach. It is a good fighter in defending its nest, and there are several observed instances where it has fought to defend the nest of other species of birds; and it has gone even further in its philanthropy, by feeding their orphaned nestlings.

The catbird chooses a nesting site in a low tree or shrub or brier, where the nest is built usually about four feet from the ground. The nest looks untidy, but is strongly made of sticks, coarse grass, weeds, bark strips and occasionally paper; it is lined with soft roots and is almost always well hidden in dense foliage. The eggs are from three to five in number and are dark greenish blue. Both parents work hard feeding the young and for this purpose destroy many insects which we can well spare. Sixty-two per cent. of the food of the young has been found in one instance to be cutworms, showing what a splendid work the parents do in our gardens. In fact, during a large part of the summer, while these birds are rearing their two broods, they benefit us greatly by destroying the insect pests; and although later they may attack our fruits and berries, it almost seems as if they had earned the right to their share. If we only had the wisdom to plant along the fences some elderberries or Russian mulberries, the catbirds as well as the robins would feed upon them instead of the cultivated fruits.

The catbirds afford a striking example for impressing upon children that each species of birds haunts certain kinds of places. The catbirds are never found in deep woods nor in open fields, but always near low thickets along streams, and in shrubbery along fences, in tangles of vines, and especially do they like to build about our gardens, if we protect them. They are very fond of bathing, and if fresh water is given them for this purpose, we may have opportunity to witness the most thorough bath a bird can take. A catbird takes a long time to bathe and preen its feathers and indulges in most luxurious sun baths and thus deservedly earns the epithet of "well-groomed;" it is one of the most intelligent of all our birds and soon learns "what is what," and repays in the nost surprising way the trouble of careful observation. 


\section{LESSON XXIII}

\section{The CATBird}

Leading thought-The catbird has a beautiful song as well as the harsh "miou," and can imitate other birds, although not so well as the mockingbird. It builds in low thickets and shrubbery and during the nesting season is of great benefit to our gardens.

Methods-First, let the pupils study and report upon the songs, scoldings and other notes of this our northern mockingbird; then let them describe its appearance and habits. Of course, the study must be made outside of school hours in the field.

Observations-I. Do you think the squall of the catbird sounds like the mew of a cat? When does the bird use this note and what for? What other notes have you heard it utter?

2. Describe as well as you can the catbird's true song. Are there any harsh notes in it? Where does he sit while singing? Describe his actions while singing.

3. Have you ever heard the catbird imitate the songs of other birds or other noises?

4. Describe the catbird as follows: its size and shape compared to the robin; the color and shape of head, beak, wings, tail, breast and under parts.

5. Describe its peculiar actions and its characteristic movements.

6. Where do catbirds build their nests? How high from the ground? What material is used? Is the nest compact and carefully finished? Is it hidden?

7. What is the color of the eggs? Do both parents care for the young?

8. What is the food of the catbird? Why is it an advantage to us to have catbirds build in our gardens?

9. Do you ever find catbirds in the deep woods or out in the open meadows? Where do you find them?

Io. Put out a pan of water where the catbirds can use it and then watch them make their toilets and describe the process. Describe how they take sun baths.

Supplcmentary reading-“"Monsieur Mischief," Nestlings of Forest and Marsh, Wheelock; Our Birds and Their Nestlings, Walker, pp. I67, I 74; Second Book of Birds, Miller, p. 37; Songs of Nature, Burroughs, p. I 72 ; Birds of Song and Story, Grinnell, p. 36.

\footnotetext{
"He sits on c. branch of yon blossoming bush, This madcap cousin of robin and thrush, And sings without ceasing the whole morning long;

Now wild, now tender, the wayward song

That flows from his soft, gray, fluttering throat;

But often he stops in his sweetest note,

And, shaking a flower from the blossoming bough,

Drawls out, "Mi-eu, mi-ow!"
} 


\section{THE BELTED KINGFISHER}

\section{Teacher's Story}

HIS patrol of our streams and lake shores, in his cadet uniform, is indeed a military figure as well as a militant personality. As he sits upon his chosen branch overhanging some stream or lake shore, his crest abristle, his keen eye fixed on the water below, his whole bearing alert, one must acknowledge that this fellow puts "ginger" into his environment, and that the spirit which animates him is very far from the "dolce far niente" which permeates the ordinary fisherman. However, he does not fish for fun but for business; his keen eye catches the gleam of a moving fin and he darts from his perch, holds hinself for a moment on steady wings above the surface of the water, to be sure of his quarry, and then there is a dash and a splash and he returns to his perch with the wriggling fish in his strong beak; he at once proceeds to beat its life out against a branch and then to swallow it sensibly, head first, so that the fins will not prick his throat nor the scales rasp it. He swallows the entire fish, trusting to his internal organs to select the nourishing part; and later he gulps up a ball of the indigestible scales and bones.

The kingfisher is very different in forn from an ordinary bird; he is larger than a robin, and his head and fore parts are much larger in proportion; this is the more noticeable because of the long feathers of the head which he lifts into a crest, and because of the shortness of the tail. The beak is very long and strong in order to seize the fish and hold it fast; but the legs are short and weak; the third and fourth toes are grown together for a part of their length; perhaps this is of use to the bird in pushing earth froni the burrow, when excavating. The kingfisher has no need for running and hopping, like the robin and, therefore, dces not need the robin's strong legs and feet. His colors are beautiful and harmonious; the upper parts are grayish blue, the throat and collar white, as is also the breast, which has a bluish gray band across the upper part, this giving the name of

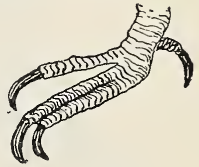

Kingfisher's foot.

This shows the weak toes; the third and fourth are joined together, which undoubtedly assists the bird in pushing out soil when excavating. the Belted Kingfisher to the bird. The feathers of the wings are tipped with white and the tail feathers narrowly barred with white. The under side of the body is white in the males, while in the fenales it is somewhat chestnut in color. There is a striking white spot just in front of the eye.

The kingfisher parents build their nest in a burrow which they tunnel horizontally in a bank; sometimes there is a vestibule of several feet before the nest is reached, and at other times it is built very close to the opening. Both parents are industrious in catching fish for their nestlings, but the burden of this duty falls heaviest upon the male. Many fish bones are found in the nest, and they seen so clean and white that they have been regarded as nest lining. Wonderful tales are told of the way the English kingfishers use fish bones to support the earth above their nests, and tributes have been paid to their architectural skill. But it is generally conceded that the lining of fish bones in nests of our kingfisher is incidental, since the food of the young is largely fish, although frogs, 
insects and other creatures are often eaten with relish. It is interesting to note the process by which the young kingfisher gets its skill in fishing. I have often seen one dive horizontally for a yard or two beneath the water and come up indignant and sputtering because the fish had escaped. It was fully two weeks after this before this one learned to drop like a bullet on its quarry.

The note of the kingfisher is a loud rattle, not especially pleasant close at hand, but not unmusical at a little distance. It is a curious coincidence that it sounds very much like the clicking of the fisherman's reel; it is a sound that conjures visions of shade-dappled streams and the dancing, blue waters of tree-fringed lakes and ponds.

There seems to be a division of fishing ground among the kingfishers, one bird never trespassing upon its neighbor's preserves. Unless it be the parent pair working near each other for the nestlings, or the nestlings still under their care, we never see two kingfishers in the same immediate locality.

References-The Bird, p. 97; The Bird Book, pp. I54, 444.

\section{LESSON XXIV}

\section{The Kingfisher}

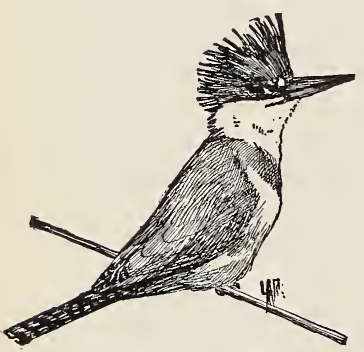

The belted kingfisher

Drawn by L. A. Fuertes.

Leading thought-The kingfisher is fitted by form of body and beak to be a fisherman.

Methods-If the school be near a stream or pond the following observations may be made by the pupils; otherwise let the boys who go fishing make a study of the bird and report to the school.

Observations- $\mathrm{I}$. Where have you seen the kingfisher? Have you often seen it on a certain branch which is its favorite perch? Is this perch near the water? What is the advantage of this position to the bird?

2. What does the kingfisher feed upon? How does it obtain its food? Describe the actions of one of these birds while fishing.

3. With what weapons does the kingfisher secure the fish? How long is its beak compared with the rest of its body? How does it kill the fish? Does it swallow the fish head or tail first? Why? Does it tear off the scales or fins before swallowing it? How does it get rid of these and the bones of the fish?

4. Which is the larger, the kingfisher or the robin? Describe the difference in shape of the bodies of these two birds; also in the size and shape of feet and beaks and explain why they are so different in form. What is there peculiar about the kingfisher's feet? Do you know which two toes are grown together?

5. What are the colors of the kingfisher in general? The colors of head, sides of head, collar, back, tail, wings, throat, breast and under parts? Is there a white spot near the eye? If so, where? Do you know the difference in colors between the parent birds?

6. Where is the nest built? How is it lined? 
7. What is the note of the kingfisher? Does it give it while perching or while on the wing? Do you ever find more than one kingfisher on the same fishing grounds?

Supplementary reading-The Second Book of Birds, Chapter XXX; "The Halycon Birds," Child's Study of the Classics; Audubon Leaflet No. I9; "Kooskosemus," Long; American Birds, Finley.

\section{THE KINGFISHER (OF ENGLAND)}

For the handsome Kingfisher, go not to the tree,

No bird of the field or the forest is he;

In the dry river rock he did never abide,

And not on the brown heath all barren and wide.

He lives where the fresh, sparkling waters are flowing,

Where the tall heavy Typha and Loosestrife are growing;

$B y$ the bright little streams that all joyfully run

Awhile in the shadow, and then in the sun.

He lives in a hole that is quite to his mind,

With the green mossy Hazel roots firmly entwined;

Where the dark Alder-bough waves gracefully o'er,

And the Sword-flag and Arrow-head grow at his door.

There busily, busily, all the day long,

He seeks for small fishes the shallows among;

For he builds his nest of the pearly fish-bone,

Deep, deep, in the bank, far retired, and alone.

Then the brown Water-Rat from his burrow looks oun,

To see what his neighbor Kingfisher's about;

And the green Dragon-fly, flitting slowly away,

Just pauses one moment to bid him good-day.

O happy Kingfisher! What care should he know,

By the clear, pleasant streams, as he skims to and fro,

Now lost in the shadow, now bright in the sheen

Of the hot summer sun, glancing scarlet and green!

-Mary Howitt. 


\section{'THE SCREECH OWI}

\section{Teacher's Story}

"Disquiet yourselves not: 'Tis nothing but a little, downy owl."-SHELLEy.

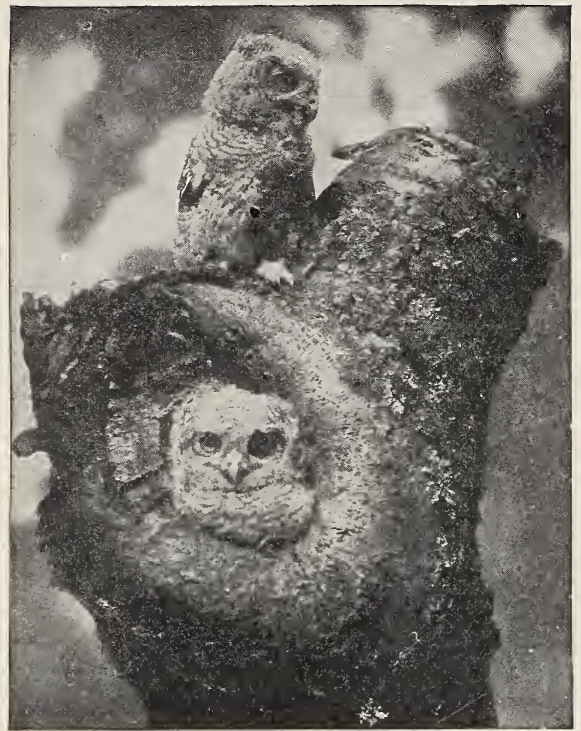

Screech owls.

From Country Life in America.

Of all the fascinating sounds to be heard at night in the woods, the screech owl's song is surely the most so; its fascination does not depend on music but upon the chills which it sends up and down the spine of the listener, thus attacking a quite different set of nerves than do other bird songs. The weird wail, tremulous and long drawn out, although so bloodcurdling, is from the standpoint of the owlet the most beautiful music in the world; by means of it he calls to his mate, cheering her with the assurance of his presence in the world; evidently she is not a nervous creature. The screech owls are likely to sing at night during any part of the year; nor should we infer that when they are singing they are not hunting, for perchance their music frightens their victims into fatal activity. Although the note is so unmistakable, yet there is great variation in the songs of individuals; the great variety of quavers in the song offering ample opportunity for the expression of individuality. Moreover, these owls often give themselves over to tremulous whispering and they emphasize excitement by snapping their beaks in an alarming manner.

Any bird that is flying about and singing in the night time must be able to see where it is going, and the owls have special adaptations for this. The eyes are very large and the yellow iris opens and closes about the pupil quite similar to the arrangement in the cat's eye, except that the pupil in the owl's eye is round when contracted instead of elongated; in the night this pupil is expanded until it covers most of the eye. The owl does not need to see behind and at the sides, since it does not belong to the birds which are the victims of other birds and animals of prey. The owl is a bird that hunts instead of being hunted, and it needs only to focus its eyes on the creature it is chasing. Thus, its eyes are in the front of the head like our own; but it can see behind, in case of need, for the head turns upon the neck as if it were fitted on a ball-bearing joint. I have often 
amused myself by walking around a captive screech owl, which would follow me with its eyes by turning the head until it almost made the circle, then the head would twist back with such lightning rapidity that I could hardly detect the movement; it seemed almost as if the head was on a pivot and could be moved around and around indefinitely. A1though the owl, like the cat, has eyes fitted for night hunting, it can also see fairly well during the daytime.

A beak with the upper mandible ending in a sharp hook signifies that its owner lives upon other animals and needs to rend and tear flesh. The owl's beak thus formed is somewhat buried in the feathers of the face, which gives it a striking resemblance to a Roman nose. This, with the great, staring, round eyes, bestows upon the owl an appearance of great wisdom. But it is not the beak which the owl uses for a weapon of attack; its strong feet and sharp, curved claws are its weapons for striking the enemy and also for grappling with its prey. The outer toe can be moved back at will, so that in grasping its prey or its perch, two toes may be directed forward and two backward, thus giving a stronger hold.

The ear is very different in form from the ear of other birds; instead of being a mere hole opening into the internal ear, it consists of a fold of skin forming a channel which extends from above the eye around to the side of the throat. (See The Bird, Beebe, p. 2I7). Thus equipped, while hunting in the dark the owl is able to hear any least rustle of mouse or bird and to know in which direction to descend upon it. There has been no relation established between the ear tufts of the screech owl and its ears, so far as I know, but the way the bird lifts the tufts when it is alert, always suggests that this movement in some way opens up the ear

In color there are two types among the screech owls, one reddish brown, the other gray. The back is streaked with black, the breast is marked with many shaft-lines of black. The whole effect of the owl's plumage makes it resemble a branch of a tree or a part of the bark, and thus it is protected from prying eyes, during the daytime when it is sleeping. Its plumage is very fluffy and its wing feathers, instead of being stiff to the very edge, have soft fringes which cushion the stroke upon the air. The owl's flight is, therefore, absolutely noiseless and the bird is thus able to swoop down upon its prey without giving warning of its approach.

The screech owls are partial to old apple orchards for nesting sites. They will often use an abandoned nest of a woodpecker; the eggs are almost as round as marbles and as white as chalk, showing very clearly that they are laid within a dark hole, otherwise their color would attract the eyes of enemies. There are usually four eggs; the fubsy little owlets climb out of their home cave by the end of May and are the funniest little creatures imaginable. They make interesting but decidedly snappy pets; they can be fed on insects and raw beef. It is most interesting to see one wake up late in the afternoon after its daytime sleep. All day it has sat motionless upon its perch with its toes completely covered with its fluffy feather skirt. Suddenly its eyes open, the round pupils enlarging or contracting with great rapidity as if adjusting themselves to the amount of light. When the owl winks it is like a moon in eclipse, so large are the eyes, and so entirely are they obscured by the lids which seem like circular curtains. When it yawns, its wide bill absurdly resembles a hunan mouth, and the yawn is very human in its expression. It then stretches its wings and it is astonishing how long this wing can be extended below the feet. 
It then begins its toilet. It dresses its feathers with its short beak, nibbling industriously in the fluff; it scratches its under parts and breast with its bill, then cleans the bill with its foot, meanwhile noving the head up and down as if in an attempt to see better its surroundings.

The owls are loyal lovers and are said to remain niated through life, the twain being very devoted to their nests and nestlings. Sometimes the two wise-looking little parents sit together on the eggs, a most happy way to pass the wearisome incubation period.

The screech owls winter in the north and they are distinctly foresighted in preparing for winter. They have often been observed catching mice, diring the late fall, and placing them in some hollow tree for cold storage, whence they may be taken in tine of need. Their food consists to some extent of insects, esfecially night-flying moths and beetles, also caterpillars and grasshoppers. However, the larger part of their food is mice; sometimes small birds are caught and the English sparrow is a frequent victim. Chickens are rarely taken, except when small, since this owlet is not as long as a robin. It swallows its quarry as whole as possible, trusting to its inner organs to do the sifting and selecting. Later it throws up pellets of the indigestible bones, hair, etc. By the study of these pellets, found under owl roosts, the scientists have been able to deternine the natural food of the bird, and they all unite in assuring us that the screech owl does the farmer much more good than harm, since it. feeds so largely upon creatures which destroy his crops.

\section{LESSON XXV}

\section{The Screech Owl}

Leading thought-This owl is especially adapted to get its prey at night. It feeds largely on field mice, grasshoppers, caterpillars and other injurious insects and is therefore the friend of the farmer.

Method-This lesson should begin when the children first hear the cry of this owl; and an owlet in captivity is a fascinating object for the children to observe. However, it is so important that the children learn the habits of this owl that the teacher is advised to hinge the lesson on any observation whatever made by the pupils, and illustrate it with pictures and stories.

Observations-I. Have you ever heard the screech owl? At what time of the day or night? Why was this? Why does the owl screech? How did you feel when listening to the owl's song?

2. Describe the owl's eyes. Are they adapted to see by night? What changes take place in them to enable the owl to see by daytime also? In what way are the owl's eyes similar to the cat's? Why is it necessary for an owl to see at night? Are the owl's eyes placed so that they can see at the sides like other birds. How does it see an object at the sides or behind it?

3. Note the owl's beak. For what purpose is a hooked beak? How does the owl use its beak? Why do we think that the owl looks wise?

4. Describe the feet and claws of the screech owl. What are such sharp hooked claws meant for? Does an owl cn a perch always have three toes directed forward and one backward? 
5. Describe the colors of the screech owl. Are all these owls of the same color? How do these colors protect the bird from its enenies?

6. How is the owl's plumage adapted to silent flight? Why is silent light advantageous to this bird?

7. How does the owl's ear differ from the ears of other birds? Of what special advantage is this? As the owl hunts during the night, what does it do in the daytime? How and by what means does it hide itself?

8. Where does the screech owl make its nest? Do you know anything about the devotion of the parent owls to each other and to their young? How many eggs are laid? What is their color? At what time of year do the little owls appear?

9 Where does the screech owl spend the winter? What do the screech owls feed upon? Do they chew their food? How do they get rid of the indigestible portion of their food? How does this habit help the scientists to know the food of the owls?

Io. How does the screech owl work injury to the farmers? How does it benefit them? Does not the benefit outweigh the injury?

II. How many other kinds of owls do you know? What do you know of their habits?

Supplementary reading-Audubon Educational Leaflets, Nos. 22, I2, I4; Second Book of Birds, Miller, Chap. 32-3; Familiar Wild Animals, Lottridge; "The Boy and Hushwing," Kindred of the Wild; "Koos, Koos, Koo" in Wilderness Ways; Wings and Fins, chap. I9; Heart of Oak Books, Vol. 4, P. 5 I; The Aziola, Shelley; American Birds, Finley.

\section{TWO WISE OWLS}

We are two dusky owls, and we live in a tree;

Look at her,-look at me!

Look at her, -she's my mate, and the mother of three

Pretty owlets, and we

Have a warm cosy nest, just as snug as can be.

We are both very wise; for our heads, as you see,

(Look at her-look at me!)

Are as large as the heads of four birds ought to be;

And our horns, you'll agree,

Make us look wiser still, sitting here on the tree.

And we care not how gloomy the night-time may be;

We can see, -we can see

Through the forest to roam, it suits her, it suits me;

And we're free,-we are free

To bring back what we find, to our nest in the tree.

-Anonymous. 


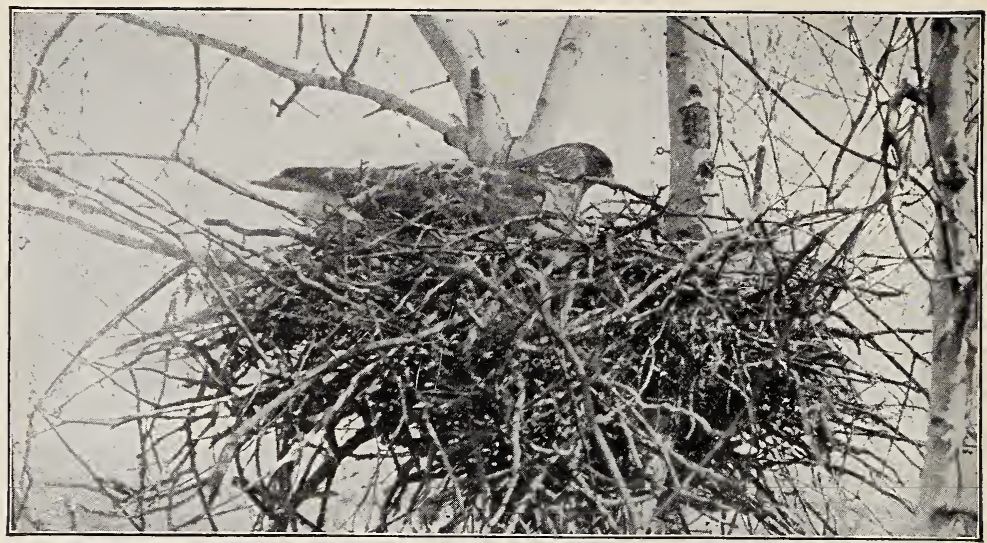

Red-tailed hawk on nest.

Photo by R. W. Hegner.

\section{THE HEN HAWKS}

\section{Teacher's Story}

"Above the tumult of the cañon lifted, the gray hawk breathless hung, Or on the hill a winged shadow drifted where furze and thornbush clung.".

\section{-BREt HaRTe.}

It is the teacher's duty and privilege to try to revolutionize some popular nisconceptions about birds, and two birds, in great need in this respect, are the so-called hen hawks. They are most unjustly treated, largely because most farmers consider that a "hawk is a hawk," and should always be shot to save the poultry, although there is as much difference in the habits of hawks as there is in those of men. The so-called hen hawks are the red-shouldered and the red-tailed species, the latter being somewhat the larger and rarer of the two; both are very large birds; the red-shouldered has cinnamon brown epaulets, the tail blackish, crossed by five or six narrow white bars, and the wing feathers are also barred. The red-tailed species has dark brown wings, the feathers not barred, and is distinguished by its tail which is brilliant cinnamon color with a black bar across it near the end; it is silvery white beneath. When the hawk is soaring, its tail shows reddish as it wheels in the air. Both birds are brown above and whitish below, streaked with brown.

The flight of these hawks is alike and is very beautiful; it consists of soaring on outstretched wings in wide circles high in the air, and is the ideal of graceful aerial motion. In rising, the bird faces the wind and drops a little in the circle as its back turns to the leeward, and thus it climbs an invisible wirding stair until it is a mere speck in the sky. This wonderful flight, on motionless wings, is what has driven to despair our inventors of airships who have not been able to fathom the mystery of it from a practical standpoint. When the bird wishes to drop, it lifts and 
holds its wings above its back, and comes down like a lump of lead, only to catch itself whenever it chooses to begin again to climb the invisible spiral. And all this is done without fatigue, for these birds have been observed to soar thus for hours together without coning to earth. When thus soaring the two species may be distinguished from each other by their cries; the red-tailed gives a high sputtering scream, which Chapman likens to the sound of escaping steain; while the red-shouldered calls in a high not unmusical note "kee-you, kee-you" or "tee-ur, tee-ur."

The popular fallacy for the teacher to correct about these birds, is that they are enemies of the farmers. Not until one has actually been seen to catch the chickens should it be shot, for very few of them are guilty of this sin. Sixty-six per cent. of the food of the red-tailed species consists of injurious animals, i. e., mice and gophers, etc., and only 7 per cent. consists of poultry; the victims are probably old or disabled fowls, and fall an easy prey; this bird much prefers nice and reptiles to poultry. The more common red-shouldered hawk feeds generally on mice, snakes, frogs, fish and is very fond of grasshoppers. Ninety per cent. of its food consists of creatures which injure our crops or pastures and scarcely $\mathrm{I} / 2$ per cent. is made up of poultry and game. These facts have been ascertained by the experts in the department of Agriculture at Washington who have examined the stomachs of hundreds of these hawks taken from different localities. Furthermore, Dr. Fisher states that a pair of the redshouldered hawks bred for successive years within a few hundred yards of a poultry farm, containing 800 young chickens and 400 ducks, and the owner never saw them attempt to catch a fowl.

However, there are certain species of hawks which are to be feared; these are the Cooper's hawk and the sharp-shinner hawk, the first being very destructive to poultry and the latter killing many wild birds. These are both somewhat smaller than the species we are studying. They are dark gray above and have very long tails, and when flying, they flap their wings for a time and then glide a distance. They do not soar on motionless outspread pinions by the hour.

When hawks are seen soaring, they are likely to be hunting for mice in the meadows below them; their eyes are remarkably keen; they can see a moving creature from a great height, and can suddenly drop upon it like a thunder bolt out of a clear sliy. Their wonderful eyes are farsighted when they are circling in the sky, but as they drop, 'the

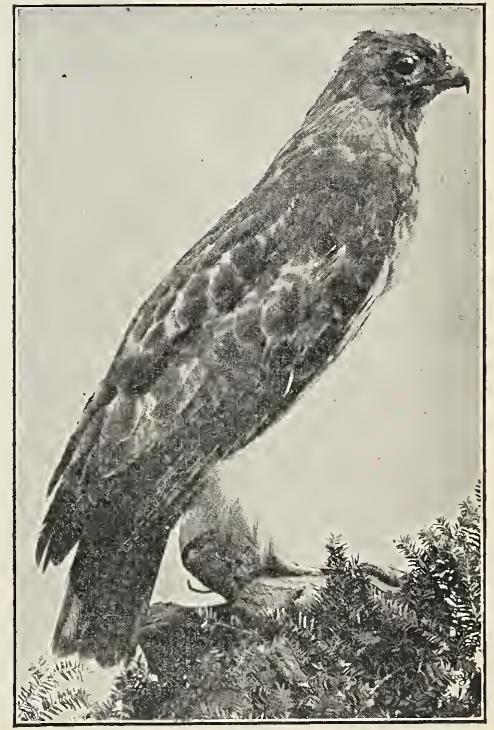

The red-tailed hawk. 
focus of the eyes changes automatically with great rapidity, so that by the time they reach the earth they are near-sighted, a feat quite impossible for our eyes unless aided by glasses or telescope.

These so-called hen hawks will often sit motionless, for hours at a time, on some dead branch or dead tree; they are probably watching for something eatable to stir within the range of their keen vision. When seizing its prey, a hawk uses its strong feet and sharp, curved talons. All hawks keep their claws sharp and polished, even as the warrior keeps his sword bright, so as to be ready for use; the legs are covered by a growth of feathers extending down from above, looking like feather trousers. The beak is hooked and very sharp and is used for tearing apart the flesh of the quarry. When a hawk fights some larger animal or man, it throws itself over upon its back and strikes its assailant with its strong claws as well as with its beak; but the talons are its chief weapons.

Both species build a large, shallow nest of coarse sticks and grass, lined with moss, feathers, etc.; it is a rude, rough structure, and is placed in tall trees from fifty to seventy-five feet from the ground. Only two to four eggs are laid; these are whitish spotted with brown. These hawks are said to remain mated for life and are devoted to each other and their young. Hawks and eagles are very similar in form and habits, and if the eagle is a noble bird so is the hawk.

\section{LESSON XXVI}

\section{The Red-shouldered and Red-tailed Hawks}

Leading thought-Ignorant people consider all hawks dangerous neighbors because they are supposed to feed exclusively on poultry. This idea is false and we should study carefully the habits of hawks before we shoot them. The ordinary large reddish "hen-hawks," which circle high above meadows, are doing great good to the farmer by feeding upon the mice and other creatures which steal his grain and girdle his trees.

Methods-Begin by observations on the flight of one of these hawks and supplement this with such observations as the pupils are able to make, or facts which they can discover by talking with hunters or others and by reading.

Observations- - . How can you tell a hawk, when flying, from a crow or other large bird? Describe how it soars? Does it move off in any direction; if so, does it move off in circles? How often does it make strokes with its wings? Does it rise when it is facing the wind and fall as it turns its back to the wind?

2. Have you seen a hawk flap its wings many times and then soar for a time? If so, what hawk do you think it was? How does it differ in habits from the "hen-hawks?"

3. Have you noticed a hawk when soaring drop suddenly to earth? If so, why did it do this?

4. How does a hawk hunt? How can it see a mouse in a meadow when it is so high in the air that it looks like a circling speck in the sky? If it is so far-sighted as this, how can it be near-sighted enough to catch the mouse when it is close to it? Would you not have to use field glasses or telescope to do this? 
5. When a hawk alights what sort of a place does it choose? How does it act?

6. Do hawks seize their prey with their claws or their beaks? What sort of feet and claws has the hawk? Describe the beak? What do you think this shaped beak is meant for?

7. Why do people shoot hawks? Why is it a sign of ignorance in people to wish to shoot all hawks?

8. What is the food of the red-shouldered hawk as shown by the bulletin of the U. S. Department of Agriculture or by the Audubon leaflets?

9. Where does the hawk place its nest? Of what does it build its nest?

ro. Compare the food and the nesting habits of the red-shouldered and red-tailed hawks?

II. How devoted are the hawks to their mates and their young? Does a hawk, losing its mate, live alone ever after?

I 2. Describe the colors of the hen hawks and describe how you can tell the two species apart by the colors and markings of the tail.

I3. What is the cry of the hawk? How can you tell the two species apart by this cry? Does the hawk give its cry only when on the wing?

I4. Why should an eagle be considered so noble a bird and the hawk be so scorned? What difference is there between them in habits?

Supplementary reading-Audubon Educational Leaflets Nos. 8, 9 and ro; "The Sparrow Hawk," Familiar Wild Animals, Lottridge; "Eyes as Cameras," also pp. IoI-IO2 The Bird Book, Eckstorm; pp. 3 I 7-3 I9, 326, Birds that Hunt and are Hunted; "Cloud Wings, The Eagle," in Wilderness Ways; "The Sky King and His Family," "Hannah Lomond's Bairn," in Neighbors with Wings and Fins, American Birds, Finley.

Reference books-The Bird, Beebe, pp. 389, 376, 208-2I I; Hawks and Owls from the Standpoint of the Farmer, Fisher, U. S. Department of Agriculture.

Yet, ere the noon, as brass the heaven turns,

The cruel sun smites with unerring aim,

The sight and touch of all things blinds and burns,

And bare, hot hills seem shimmering into flame!

On outspread wings a hawk, far poised on high,

Quick swooping screams, and then is heard no more:

The strident shrilling of a locust nigh

Breaks forth, and dies in silence as before.

-.-"Summer Drought," by J. P. Irvine。 


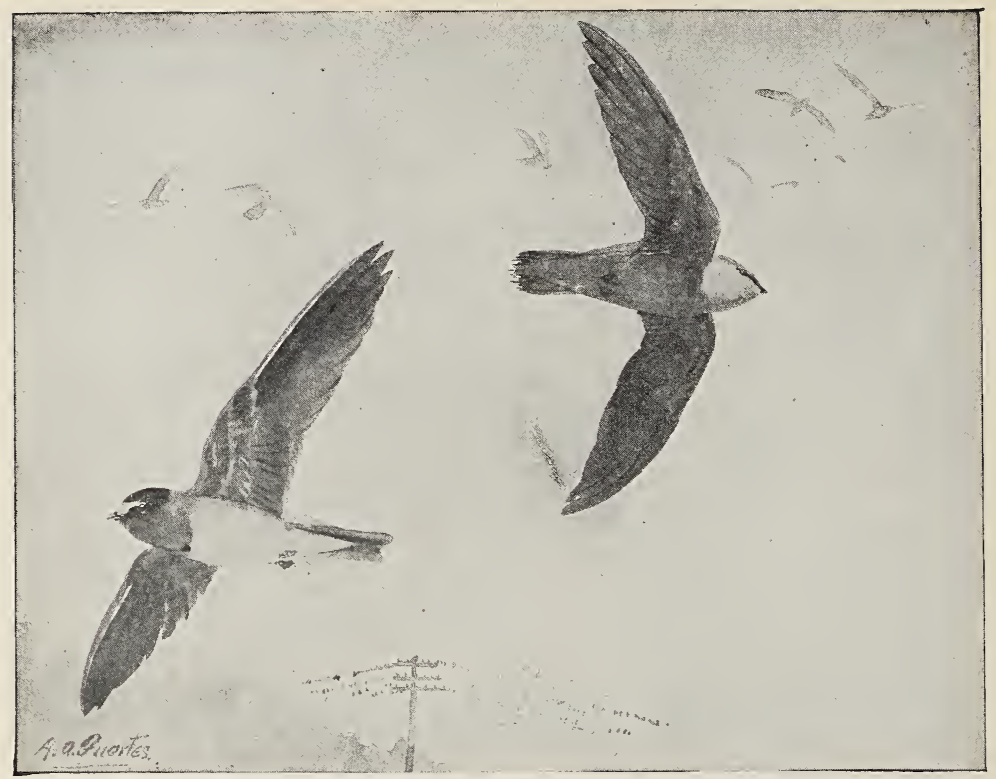

Swallows and swifts.

Drawn by L. A. Fuertes for General Biology by J. G. Needham.

\section{THE SWALLOWS AND THE CHIMNEY SWIFT}

\section{Teacher's Story}

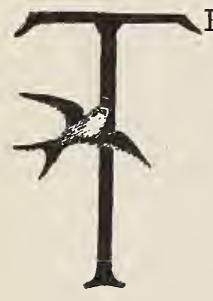

HESE friendly little birds spend their time darting through the air on swift wings, seeking and destroying insects which are foes to us and our various crops. However, it is safe to assume that they are not thinking of us as they skim above our meadows and ponds, hawking our tiny foes; for like most of us, they are simply intent upon getting a living. Would that we might perform this necessary duty as gracefully as they.

In general, the swallows have a long, slender, graceful body, with a long tail which is forked or notched, except in the case of the eave swallow. The beak is short but wide where it joins the head; this enables the bird to open its mouth wide and gives it more scope in the matter of catching insects; the swift flight of the swallows enables them to catch insects on the wing; their legs are short, the feet are weak and fitted for perching; it would be quite impossible for a swallow to walk or hop like a robin or blackbird.

The eave, or cliff, swallows-These swallows build under the eaves of barns or in similar locations. In early times they built against the sides of cliffs; but when man came and built barns, they chose them for their dwelling sites. The nest is made of mud pellets and is somewhat globular 
in shape, with an entrance at one side. When building on the sides of cliffs or in unprotected portions of a barn, a covered passage is built around the door, which gives the nest the shape of a gourd or retort; but when protected beneath the eaves the birds seem to think this vestibule is unnecessary. The mud nest is warmly lined with feathers and soft materials, and there are often many nests built so closely together that they touch. The eave swallow comes north about May ist, and soon after that, may be seen along streams or other damp places gathering mud for the nests. It seems necessary for the bird to find clay mud in order to render the nest strong enough to support the eggs and nestlings. The eggs are white, blotched with reddish brown. The parents cling to

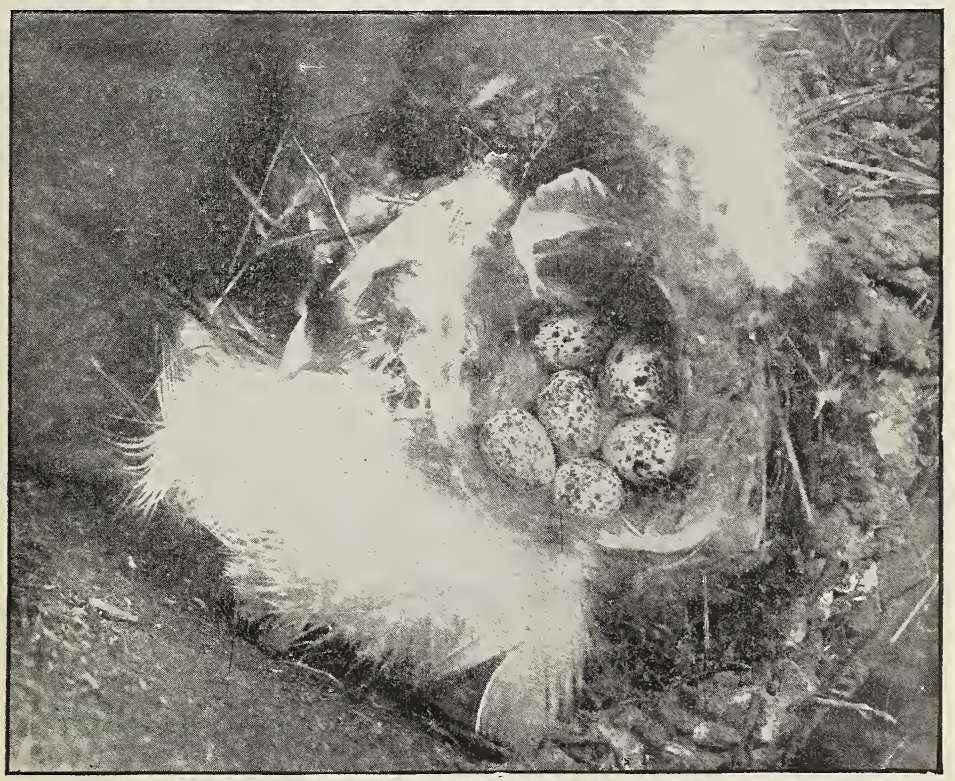

The barn swallow's feather bed.

the edge of the nest when feeding the young. Both the barn and eave swallows are blue above but the eave swallow has the forehead cream white and the rump of pale brick-red, and its tail is square across the end as seen in flight. The barn swallow has a chestnut forehead and its outer tail feathers are long, making a distinct fork during flight, and it is not red upon the rump.

The barn swallows-These birds choose a barn where there is a hole in the gable or where the doors are kept open all the time. They build upon beams or rafters, making a cup-shaped nest of layers of pellets of mud, with grass between; it is well lined with feathers. The nest is usually the shape of half of a shallow cup which has been cut in two lengthwise, the cut side being plastered against the side of the rafter. Sometimes the 
nests are more or less supported upon a beam or rafter; the eggs are white and dotted with reddish brown. The barn swallows, aside from

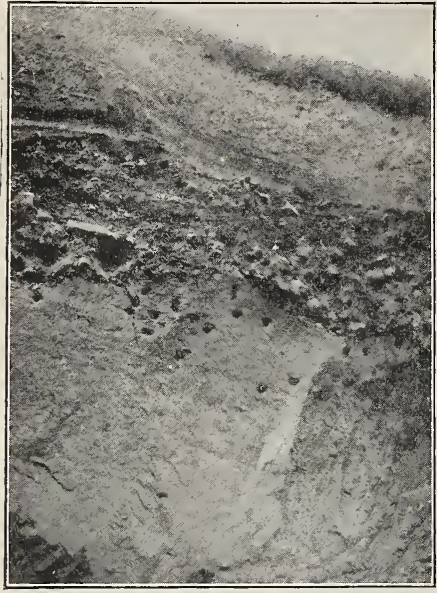

A bank swallow tenement. Photo by J. T. Lloyd. their constant twittering, have also a pretty song. Both parents work at building the nest and feeding the young; there are likely to be several pairs nesting in the same building. The parents continue to feed the young long after they have left the nest; often a whole family may be seen sitting on a telegraph wire or wire fence, the parents still feeding the wellgrown youngsters. This species comes north in the latter part of April and leaves early in September. It winters as far south as Brazil.

The barn swallow has a distinctly tailor-made appearance; its red-brown vest and iridescent blue coat, with deeply forked "coat tails" give it an elegance of style which no other bird, not even the chic cedar waxwing can emulate.

The Bank Swallow-When we see a sandy bank apparently shot full of holes as by small cannon balis, we may know that we have found a tenement of bank swallows. These birds always choose the perpendicular banks of creeks or of railroad cuts or of sand pits for their nesting sites; they require a soil sufficiently soft to be tunneled by their weak feet, and yet not so loose as to cave in upon the nest. The tunnel may extend from one to four feet horizontally in the bank with just enough diameter to admit the body of the rather small bird. The nest is situated at the extreme end of the tunnel and is lined with soft feathers and grasses.

The bank swallows arrive late in April and leave early in September. They may be distinguished from the other species by their grayish color above; the throat and breast are white with a broad, brownish band across the breast; the tail is slightly forked. The rough-winged swallow, which is similar in habits to the bank swallow, may be distinguished from it by its gray breast

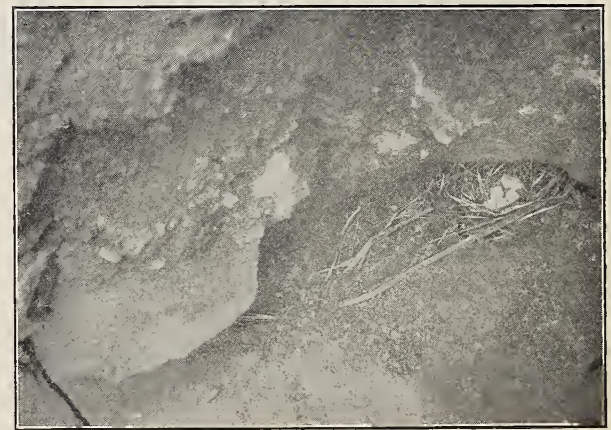

Bank swallow's nest with earth removed showing the upward direction of the tunnel. Photo by J T. Lloyd. which has no dark band. 


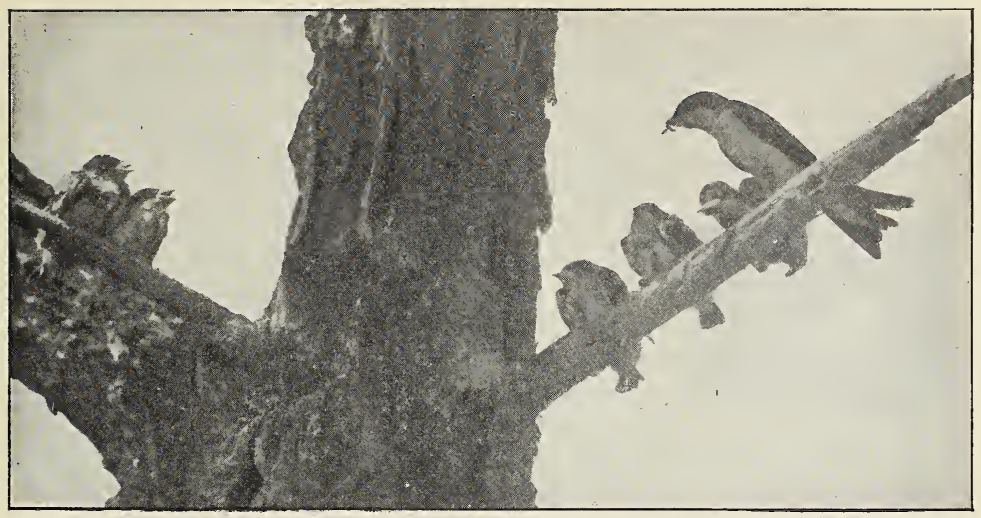

Tree swallows.

Photo by A. A. Allen.

The Tree Swallow-This graceful little bird builds naturally in holes in trees, but readily accepts a box if it is provided. It begins to build soon after it comes north in late April and it is well for us to encourage the tree swallows to live near our houses by building houses for them and driving away the English sparrows. The tree swallows live upon many insects which annoy us and injure our gardens and damage our orchards; they are, therefore, much more desirable neighbors than the English sparrows. The tree swallows congregate in great numbers for the southern migration very early in the season, often in early August. They are likely to congregate in marshes, as are also the other swallows. In color the tree swallow has a green metallic back and head, a pure white breast with no band across it, and these peculiarities distinguish it from all other species.

The Purple Martin-The martin is a larger bird than the largest swallow, being eight inches in length, while the barn swallow does not measure quite seven. The male is shining, steelblue above and below; the female is brownish above, has a gray throat, brownish breast and is white beneath. The martins originally nested in hollow trees but for centuries have been cared for by man. The Indians were wont to put out empty gourds for them to nest in; and as soon as America was settled by Europeans, martin boxes were built extensively. But when the English sparrows came, they took possession of the boxes, and the martins have to a large extent

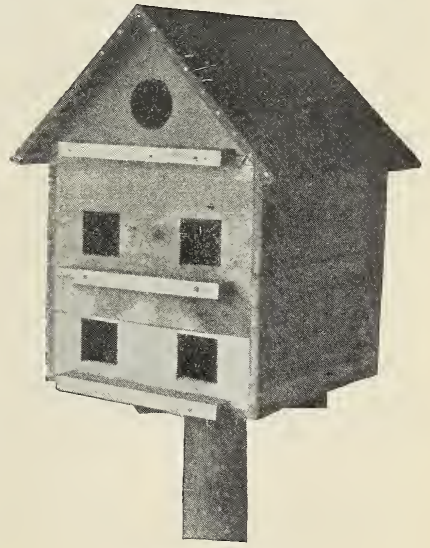

A martin house. 
disappeared, this is a pity since they are beneficial birds, feeding upon insects which are injurious to our farms and gardens. They are also delightful birds to have around, and we may possibly induce them to come back to us by building houses for them and driving away the sparrows.

\section{The Chimney Swift}

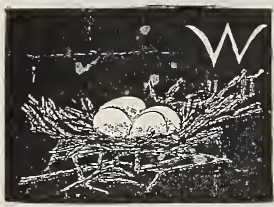

HEN the old-fashioned fire-places went out of use and were walled up, leaving the great old chimneys useless, these sociable birds took possession of them. Here they built their nests and reared their young, and twittered and scrambled about, awakening all sleepers in the neighborhood at earliest dawn, and in many ways made themselves a distinct part of family life. With the disappearance of these old chimneys and the growing use of the smaller chimney, the swifts have been more or less driven from their close association with people; and now their nests are often found in hay barns or other secluded buildings, although they still gather in chimneys when opportunity offers.

The chimney swifts originally built nests in hollow trees and caves; but with the coming of civilization they took possession of the chimneys disused during the summer, and here is where we know them best. The nests are shaped like little wall pockets; they are made of small sticks of nearly uniform size which are glued together and glued fast to the chimney wall by means of the saliva secreted in the mouth of the bird. After the nesting season, the swifts often gather in great flocks and live together in some large chimney; toward night-fall they may be seen circling about in great numbers and dropping into the mouth of the chimney, one by one, as if they were being poured into a funnel. In the morning they leave in reverse manner, each swift flying about in widening circles as it leaves the chimney. The swifts are never seen to alight anywhere except in hollow trees or chimneys or similar places; their tiny feet have sharp claws for clinging to the slightest roughness of the upright wall; the tail acts as a prop, each tail feather ending in a spine which is pressed against the chimney side when the bird alights and thus enables it to cling more firmly. In this fashion the swifts roost, practically hung up against a wall.

The swift has a short beak and wide mouth which it opens broadly to engulf insects as it darts through the air. Chimney swifts have been known to travel at the rate of I Io miles an hour.

This bird should never be confused with the swallows, for when flying, its tail seems simply a sharp point, making the whole body cigar-shaped. This character alone distinguishes it from the long tailed swallows. In color it is sooty brown, with a gray throat and breast: the wings are long and narrow and apparently curved. The manner of flight and appearance in the air make it resemble the bat more than it does the swallow. 


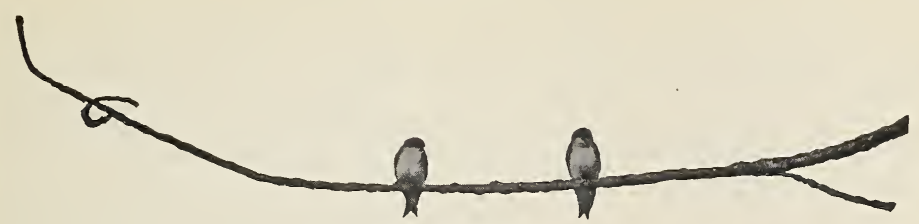

Tree swallows.

Photo by A. A. Allen.

\section{LESSON XXVII}

\section{The Swallows and Swifts}

Leading thought-The swallows are very graceful birds and are exceedingly swift fliers. They feed upon insects which they catch upon the wing. There are five native swallows which are common-the eave, or cliff, the barn, the bank, the tree swallow and the purple martin. The chimney swift, although often called so, is not a swallow; it is more nearly related to the hummingbird than to the swallows.

Method-The questions should be given as an outline for observation, and may be written on the blackboard or placed in the field notebook. The pupils should answer them individually and from field observation. We study the swifts and swallows together to teach the pupils to distinguish them apart.

Observations-I. What is the general shape of the swallow? What is the color of the forehead, throat, upper breast, neck, rump and tail?

2. Is the tail noticeably forked especially during flight?

3. Describe the flight of the swallow. What is the purpose of its long, swift flight? How are the swallow's wings fitted for carrying the bird swiftly?

4. Describe the form of the beak of the swallow. How does it get its food? What is its food?

5. In what particular locations do you see the swallows darting about? At what time of day do they seem most active?

6. Describe the swallow's legs and feet and explain why they look so different from those of the robin and blackbird.

\section{The Eave, or Cliff Swallow}

7. Where do the eave swallows build their nests? Of what material is the outside? The lining? Describe the shape of the nest and how it is supported.

8. How early in the spring do the eave swallows begin to make their nests? Where and by what means do they get the material for nest building? Are there a number of nests usually grouped together?

9. Describe the eave swallow's egg. Where do the parents sit when feeding the young? What is the note of the eave swallow?

ro. What are the differences between the barn and the eave swallow in color and shape of tail?

\section{The Barn Swallow}

II. Where does the barn swallow place its nest? What is the shape of the nest? Of what material is it made? 
I2. What is the color of the eggs? Describe the feeding of the young and the sounds made by them and their parents. Do both parents work together to build the nesi and feed the young?

I3. Is there usually more than one nest in the same locality? When the young swallows are large enough to leave the nest, describe how the parents continue to care for them.

I4. Have you ever heard the barn swallows sing? Describe their conversational notes.

I 5. When do the barn swallows migrate and where do they go during the winter? How can you distinguish the barn swallow from the eave swallow?

\section{The Bank Swallow}

I6. Where do the bank swallows build? What sort of soil do they choose?

I7. How does a bank look which is tenanted by these birds?

I8. How far do the bank swallows tunnel into the earth? What is the diameter of one of these tunnels? Do they extend straight or do they rise or deflect?

I9. With what tools is the tunnel excavated? Where is the nest situated in the tunnel and how is it lined?

20. How can you distinguish this species from the barn and eave and tree swallows? At what time do the bank swallows leave us for migration south?

\section{The Tree Swallow}

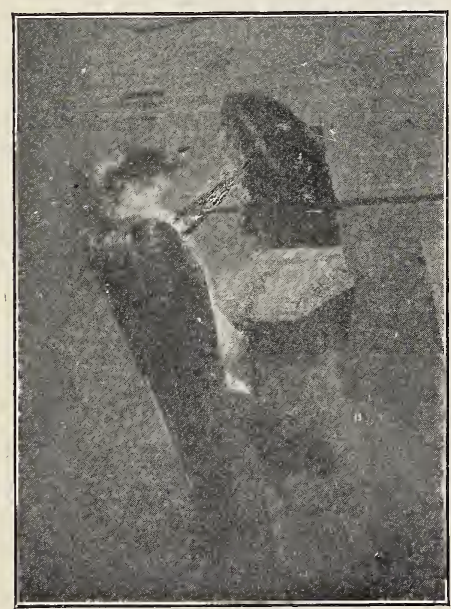

A tree swallow.

Photo by Geo. Fiske, Jr.

$2 \mathrm{I}$. Where doos the tree swallow make its nest? How does its nest differ from that of the barn, eave, or bank swallow? When does it begin to build?

22. How can we encourage the tree swallow to build near our houses? Why is the tree swallow a much more desirable bird to have in bird houses than the English sparrow?

23. Describe the peculiar migrating habits of the tree swallow. How can you tell this species from the barn, the eave and the bank swallows?

\section{The Purple Martin}

24. Compare the purple martin with the swallows and describe how it differs in size and color.

25. Where did the martins build their nests before America was civilized? Where do they like to nest now? How do the purple martins benefit us and how can we induce them to come to us? 


\section{The Chimney Swift}

26. Where do the chimney swifts build their nests? Of what materials is the nest made? What is its shape and how is it supported? Where does the chimney swift get its glue for nest bulding?

27. Describe how the chimney swifts enter their nesting place at night. Where and how do they perch? Describe the shape of the swift's tail and its use to the bird when roosting.

28. On what does the chimney swift feed and how does it procure this food? Describe how its beak is especially fitted for this?

29. How can you distinguish the chimney swift from the swallows? In what respect does the chimney swift resemble the swallows? In what respects does it differ from them?

Supplementary reading-"Chimney Swifts," Familiar Wild Animals, Lottridge; The Chimney Swifts, Washington Irving; Nestlings of Forest and Marsh, Wheelock, p. I9r; "The Eave Swallow" and "The Purple Martin" in The Bird Book, Eckstorm; The Second Bird Book, Miller; True Bird Stories, Miller, p. I 8 ; Our Birds and Their Nestlings, p. I 55: A Watcher in the Woods, Sharp, p. I63.
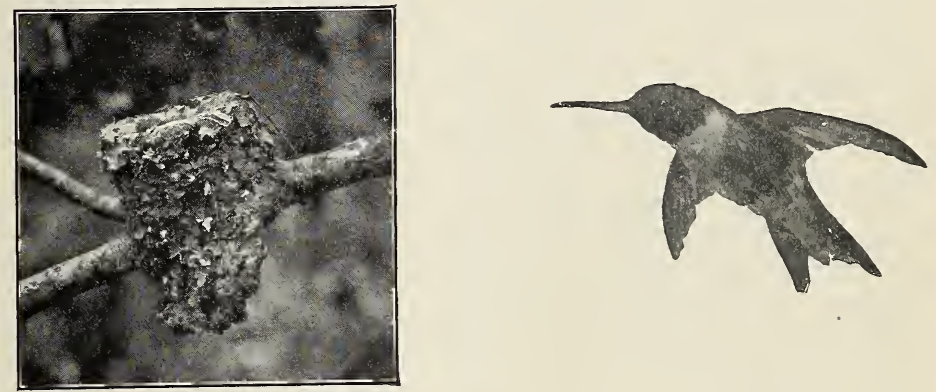

Nest of the ruby-throat hummingbird.

Photo by Geo. Fiske, J $J$ 。 


\section{THE HUMMINGBIRD}

\section{Teacher's Story}

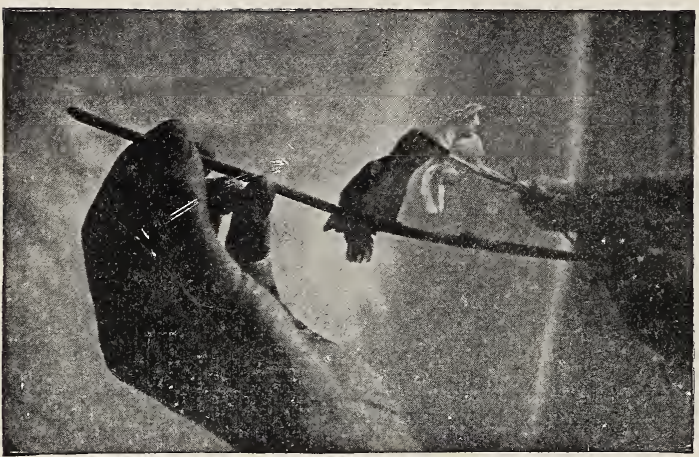

A hummingbird taking sweetened water from a flower. Photo by Mary Pierson Allen. Courtesy of Bird Lore.
Formerly it was believed that this daintiest of birds found the nectar of flowers ample support for its active life; but the later methods of discovering what birds eat by examining the contents of their stomachs, show that the hummingbird is an insect eater of most ravenous appetite. Not

only does it catch insects in mid air, but undoubtedly takes them while they are feasting on the nectar of the tubular flowers which the hummingbird loves to visit. Incidentally, the hummingbird carries the pollen for these flowers and may be counted as a friend in every respect, since usually the insects in the nectaries of the flowers with long tubular corollas, are stealing nectar without giving in return compensation to the flower by carrying its pollen. Such insects may be the smaller beetles, ants and flies. The adaptations of the hummingbird's beak and long, doubletubed tongue, are especially for securing this mingled diet of insects and nectar. It is interesting to note that the young hummingbirds have the beak much shorter than when mature. Its beak is exactly fitted to probe those flowers where the hummingbird finds its food. The tongue has the outer edges curved over making a tube on each side. These tubes are provided with minute brushes at the tips and thus are fitted both for sucking nectar and for sweeping up the insects.

The natural home of the hummingbird seems to have been in the Ameri

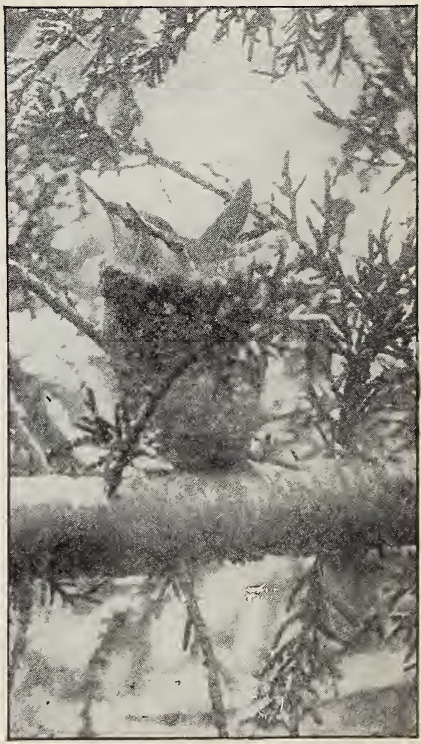

Two young hummingbirds in nest. Half natural size. 
can tropics. Our one species east of the Rocky Mountains with which we are all familiar has a ruby throat. This comes to us after a very long journey each year. One species on the Pacific Coast is known to travel three thousand miles to the north for the summer and back again in winter.

Hummingbirds are not supposed to sing, but to use their voices for squeaking when angry or frightened. However, I once had the privilege of listening to a true song by a hummingbird on the Pacific Coast. The midget was perched upon a twig and lifted up his voice with every appearance of ecstasy in pouring forth his lay. To my uncultured ear this song was a fine, shrill, erratic succession of squeaks, "as fine as a cambric needle," said my companion.

The nest of the hummingbird is a most exquisite structure; it is about three-fourths of an inch in diameter on the inside and about half an inch deep. It is, in shape, a symmetrical cup; the outside is covered with lichens to make it exactly resemble the branch on which it rests; the inside is iined with the down of plant seeds and plant fibres. The lichens are often fastened to the outside with the silk web of spiders or caterpillars. The nest is usually saddled on a branch of a tree from to to 50 feet above the ground. The eggs are two in number and white; they look like tiny beans. The young are black and look, at first glance, more like insects than like birds.

\section{LESSON XXVIII}

\section{The Hummingbird}

Leading thought-The hummingbird in

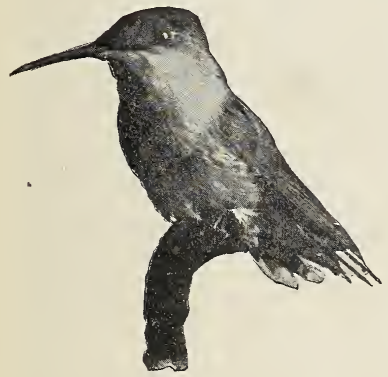
flight moves its wings so rapidly that we cannot see them. It can hold itself poised above flowers while it thrusts its long beak into them for nectar and insects.

Method-Give the questions to the pupils and let them make the observations when they have the opportunity.

Observations- $\mathrm{I}$. Where do you find the hummingbird? What flowers was it visiting? At what time of day? Can you tell whether it is a hummingbird or a hawkmoth which is visiting the flowers? At what time of day do the hawk-moths appear?

2. Does the hummingbird ever come to rest? Describe its actions while resting.

3. What are the colors of the back, throat, breast and under parts? How do you distinguish the mother hummingbird from her mate?

4. How does the hummingbird act when extracting the nectar? How does it balance itself in front of a flower? Have you ever seen hummingbirds catch insects in the air? If so, describe how they did it.

5. Describe the hummingbird's nest. How large is it in diameter? What is the covering outside? With what is it lined? 


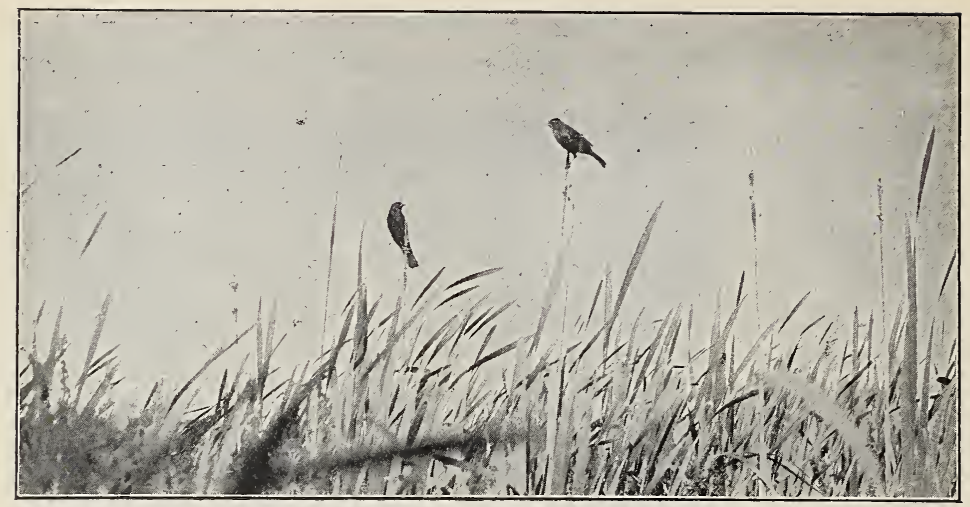

Photo by A. A. Allen.

\section{THE RED-WINGED BLACKBIRD}

\section{Teacher's Story}

The blackbirds are among our earliest visitors in the spring; they cume in flocks and beset our leafless trees like punctuation marks, meanwhile squeaking like musical wheelbarrows. What they are, where they come from, where they are going and what they are going to do, are the questions that naturally arise at the sight of these sable flocks. It is not easy to distinguish grackles, cowbirds and rusty blackbirds at a glance, but the red-wing proclaims his identity from afar. The bright red epaulets, margined behind with pale yellow, is a uniform to catch the admiring eye. The bird's glossy black plumage brings into greater contrast his bright decorations. That he is fully aware of his beauty, who can doubt who has seen him come sailing down at the end of his strong, swift flight, and balancing himself on some bending reed, drop his long tail as if it were the crank of his music box, and holding both wings lifted to show his scarlet decorations, sing his "quong quer ee-ee." Little wonder that such a handsome, military looking fellow should be able now and then to win more than his share of feminine admiration. But what though he become an entirely successful bigamist or even trigamist, he has proven himself to be a good protector of each and all of his wives and nestlings; however, he often has but one mate.

"The red-wing flutes his O-ka-lee" is Emerson's graphic description of the sweet song of the red-wing; he also has many other notes. He clucks to his mates and clucks more sharply when suspicious, and has one alarm note that is truly alarming. The male red-wings come from the South in March; they appear in flocks, often three weeks before their mates arrive. The female looks as though she belonged to quite a different species. Although her head and back are black, the black is decidedly rusty; it is quite impossible to describe her, she is so inconspicuously speckled with brown, black, whitish buff and orange. Most of us never recognize her unless we see her with her spouse. As she probably does most of the nest 
building, her suit of salt, pepper and mustard renders her invisible to the keen eyes of birds of prey. Only when she is flying, does she show her blackbird characteristics,- - her tail being long and of obvious use as a steering organ; and she walks with long, stiff strides. The red-wings are ever to be found in and about swamps and marshes. The nest is built usually in May; it is made of grasses, stalks of weeds and is lined with finer grass or reeds. It is bulky and is placed in low bushes or among the reeds. The eggs are pale blue, streaked and spotted with purple or black. The young resemble the mother in color, the males being obliged to wait a year for their epaulets. As to the food of the red-wings here in the North, Mr. Forbush says:

"Although the red-wings almost invariably breed in the swamp or marsh, they have a partiality for open fields and plowed lands; however, most of the blackbirds that nest in the smaller swamps adjacent to farm lands get a large share of their food from the farmer's fields. They forage about the fields and meadows when they first come north in the spring. Later, they follow the plow, picking up grubs, worms and caterpillars; and should there be an outbreak of cankerworms in the orchard, the blackbirds will fly at least half a mile to get canker-worms for their young. Wilson estimated that the redwings of the United States would in four months destroy sixteen thousand two hundred million larvæ. They eat the caterpillars

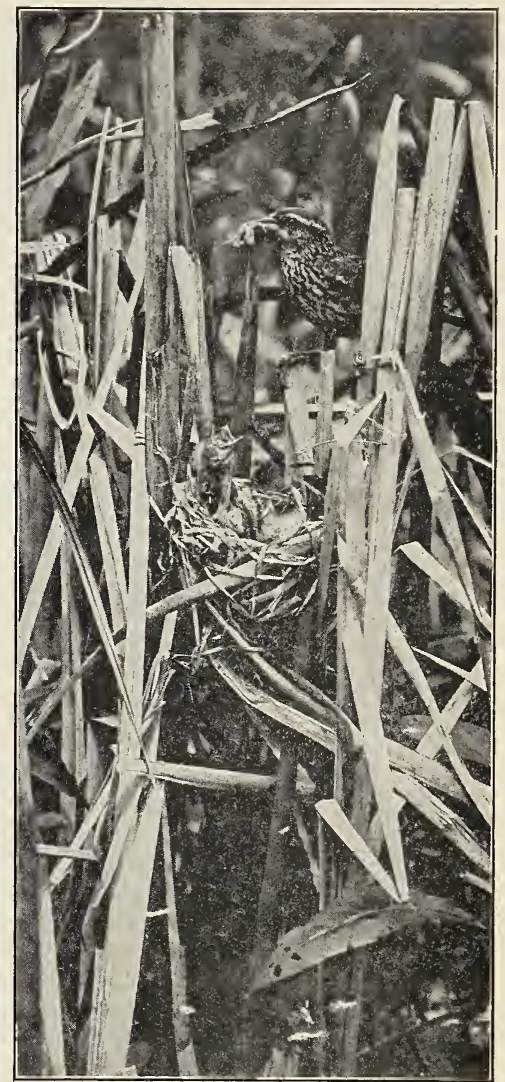

The mother red-wing, her nest and nestlings. Photo by A. A. Allen. of the gypsy moth, the forest tent-caterpillar, and other hairy larvæ. They are among the most destructive birds to weevils, click beetles, and wireworms. Grasshoppers, ants, bugs, and flies form a portion of the redwing's food. They eat comparatively little grain in Massachusetts although they get some from newly sown fields in spring, as well as from the autumn harvest; but they feed very largely on the seeds of weeds and wild rice in the fall. In the South they join with the bobolink in devastating the rice fields, and in the West they are often so numerous as to destroy the grain in the fields; but here the good they do far outweighs the injury, and for this reason they are protected by law." 


\section{LESSON XXIX}

\section{The Red-winged Blackbird}

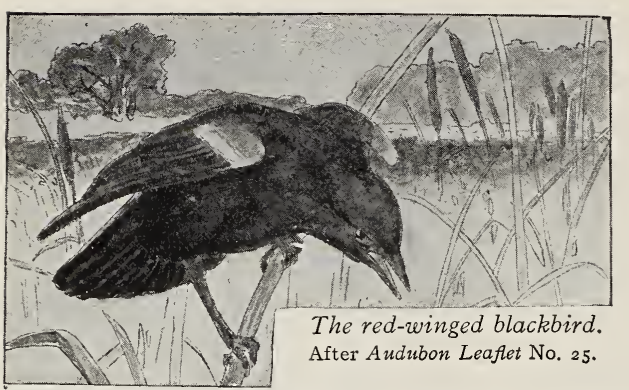

Leading thought-The red-winged blackbird lives in the marshes where it builds its nest However, it comes over to our plowed lands and pastures and $\mathrm{h}$ lps the farmer by destroying many insects which injure the meadows, crops and trees.

Method-The observations should be made by the pupils individually in the field. These birds may be looked for in flocks early in the spring, but the study should be made in May or June when they will be found in numbers in almost any swamp. The questions may be given to the pupils a few at a time or written in their field notebooks and the answers discussed when discovered.

Observations- $\mathrm{r}$. How can you distinguish the red-winged blackbird from all other blackbirds? Where is the red on his wings? Is there any other color besides black on the wings? Where? What is the color of the rest of the plumage?

2. What is there peculiar in the flight of the red-wing? Is its tail long or short? How does it use its tail in flight? What is its position when the bird alights on a reed?

3. What is the song of the red-wing? Describe the way he holds his wings and tail when singing, balanced on a reed or some other swamp grass. Does he show off his epaulets when singing? Why? What note does he give when he is surprised or suspicious? When frightened?

4. When does the red-wing first appear in the spring? Does he come alone or in flocks? Does his mate come with him? Where do the redwings winter? In what localities do the red-wing blackbirds live? Why do they live there? What is the color of the mother red-wing? Would you know by her looks that she was a blackbird? What advantage is it to the pair that the female is so dull in color?

5. At what time do these birds nest? Where is the nest built? Of what material? How is it concealed? What is the color of the eggs?

6. Do the young birds resemble in color their father or their mother? Why is this an advantage?

7. Is the red-wing ever seen in fields adjoining the marshes? What is he doing there? Does he walk or hop when looking for food? What is the food of the red-wings? Do they ever damage grain? Do they not protect grain more than they damage it?

8. What great good do the red-wings do for forest trees? For orchards?

9. At what time in the summer do the red-wings disappear from the swamps? Where do they gather in flocks? Where is their special feeding ground on the way south for the winter? 


\title{
THE BALTIMORE ORIOLE
}

\author{
Teacher's Story \\ "I know his name, I know his note, \\ That so with rapture takes my soul; \\ Like flame the gold beneath his throat, \\ His glossy cope is black as coal. \\ $O$ Oriole, it is the song \\ You sang me from the cottonwood, \\ Too young to feel that I was young, \\ Too glad to guess if life were good."
}

-William Dean Howells.

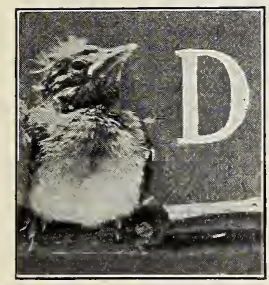
about seven inches long, and four and a half inches wide at the largest part, which is the bottom. The top is attached to forked twigs at the $\mathrm{Y}$ so that the mouth or door will be kept open to allow the bird to pass in and out; when within, the weight of the bird causes the opening to contract somewhat and protects the inmate from prying eyes. Often the pocket hangs free so that the breezes may rock it, but in one case we found a nest with the bottom stayed to a twig by guy lines. The bottom is much more closely woven than the upper part for a very good reason, since the open meshes admit air to the sitting bird. The nest is lined with hair $\wedge$ r other soft material, and although this is added last, the inside of the nest is woven first. The orioles like to build the framework of twine, and it is marvellous how they will loop this around a twig almost as evenly knotted as if crocheted; in and ou; of this net the mother bird with her long, sharp beak weaves bits of wood fibre, strong, fine grass and scraps of weeds. The favorite lining is horse hair, which simply cushions the bottom of the pocket. Dr. Detwiler had a pet oriole which built her nest of his hair which she pulled from his head; is it possible that orioles get their supply of horse hair in a similar way? If we put in convenient places, bright colored twine or narrow ribbons the orioles will weave them into the nest, but the strings should not be long, lest the birds become entangled. If the nest is strong the birds will use it a second year.

That Lord Baltimore founa in new America a bird wearing his colors, must have cheered him greatly; and it is well for us that this brilliant bird brings to our minds kindly thoughts of that tolerant, highminded English nobleman. The oriole's head, neck, throat and part of the back are black; the wings are black but the feathers are margined with white; the tail is black except that the ends of the outer feathers are yeliow; all the rest of the bird is golden orange, a luminous 
color which makes him seem a splash of brilliant sunshine. The female, although marked much the same, has the back so dull and mottled that

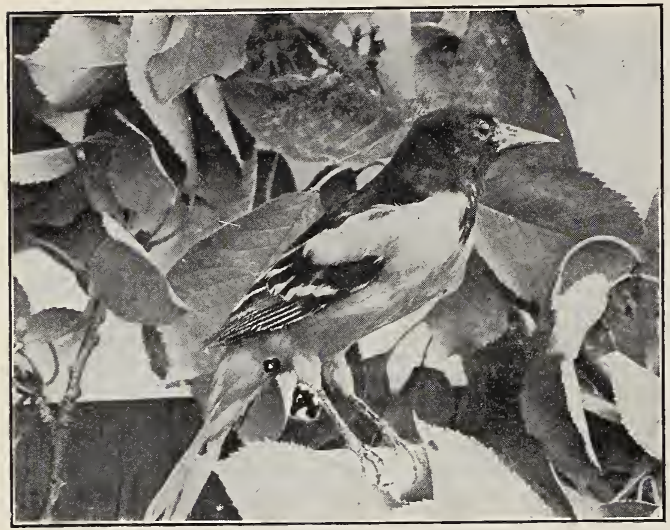

The Baltimore oriole.

it looks olive-brown; the rump, breast, and under parts are yellow but by no means showy. The advantage of these quiet colors to the mother bird is obvious since it is she that makes the nest and sits in it without attracting attention to its location. In fac:, when she is sitting, her brilliant mate places himself far enough away to distract the attention of meddlers, yet near enough for her to see the flash of his breast in the sunshine and to hear his rich and cheering song. He is a good spouse and brings her the materials for the nest which she weaves in, hanging head downward from a twig and using her long sharp beak for a shuttle. And his glorious song is for her alone; some hold that no two orioles have the same song; I know of two individuals at least whose songs were sung by no other birds; one gave a phrase from the Waldvogel's song in Sigfried; the other whistled over and over, "Sweet birdie, hello, hello." The orioles can chatter and scold as well as sing.

The oriole is a brave defender of his nest and a most devoted father, working hard to feed his ever hungry nestlings; we can hear these hollow mites peeping for more tood, "Tee dee dee, Tee dee dee", shrill and constant, if we stop for a moment under the nest in June. The young birds dress in the safe colors of the mother, the males not donning their bright plumage until the second year. A brilliant colored fledgling would not live long in a world where sharp eyes are in constant quest for little birds to fill empty stomachs.

The food of the oriole places it among our most beneficial birds, since it is always ready to cope with the hairy caterpillars avoided by most birds; it has learned to abstract the caterpillar from his spines and is thus able to swallow him minus his "whiskers." The orioles are waging a great war against the terrible brown-tail and gipsy moths in New England; they also eat click beetles and many other noxious insects. Once when we were breeding big caterpillars in the Cornell insectary, an oriole came in through the open windows of the greenhouse, and thinking he had found a bonanza proceeded to work it, carrying off our precious crawlers before we discovered what he was at.

The orioles winter in Central America and give us scarcely four months of their company. They do not usually appear before May and leave in early September. 


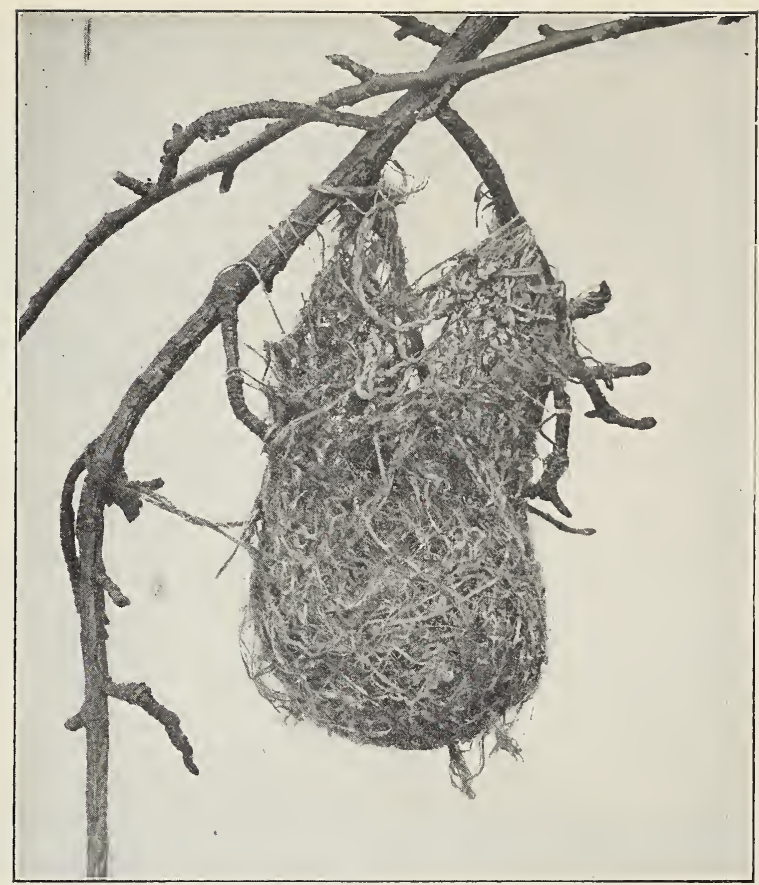

An oriole nest. An anchor to the windward.

Photo by C. R. Crosby.

\section{LESSON XXX}

\section{The ORIOLE}

Leading thought-The oriole is the most skillful of all our bird architects. It is also one of our prized song birds and is very beneficial to the farmer and fruit grower because of the insect pests which it destroys.

Method-Begin during winter or early spring with a study of the nest, which may be obtained from the elms of the roadsides. During the first week in May, give the questions concerning the birds and their habits. Let the pupils keep the questions in their note-books and answer them when they have opportunity. The observations should be summed up once a week.

Observations by pupils-I. Where did you find the nest? On what species of tree? Was it near the trunk of the tree or the tip of the branch?

2. What is the shape of the nest? How long is it? How wide? Is the opening as large as the bottom of the nest? How is it hung to the twigs so that the opening remains open and does not pull together with the weight of the bird at the bottom? Is the bottom of the nest stayed to a twig or does it hang loose? 
3. With what material and how is the nest fastened to the branches? Of what material is the outside made? How is it woven together? Is it more loosely woven at the top than at the bottom? How many kinds of material can you find in the outside of the nest?

4. With what is the nest lined? How far up is it lined? With what tool was the nest woven? If you put out bright colored bits of ribbon and string do you think the orioles will use them? Why should you not put out long strings?

5. At what date did you first see the Baltimore oriole? Why is it called the Baltimore oriole? How many other names has it? Describe in the following way the colors of the male oriole: top of head, back, wings, tail, throat, breast, under parts. What are the colors of his mate? How would it endanger the nest and nestlings if the mother bird were as bright colored as the father bird?

6. Which weaves the nest, the father or the mother bird? Does the former assist in any way in nest building?

7. Where does the father bird stay and what does he do while the mother bird is sitting on the eggs?

8. What is the oriole's song? Has he more than one song? What other notes has he? After the young birds hatch does the father bird help take care of them?

9. By the middle of June the young birds are usually hatched and if you know where an oriole nest is hung, listen and describe the call of the nestlings for food.

Io. Which parent do the young birds resemble in their colors? Why is this a benefit?

I I. What is the oriole's food? How is the oriole of benefit to us in ways which other birds are not?

I 2. Do the orioles use the same nest two years in succession? How long does the oriole stay in the North? Where does it spend its winters?

"Hush! 'tis he!
My oriole, my glance of summer fire,
Is come at last, and, ever on the watch,
Twitches the packthread I had lightly wound
About the bough to help his housekeeping,-
Twitches and scouts by turns, blessing his luck,
Yet fearing me who laid it in his way,
Nor, more than wiser we in our affairs.
Divines the Providence that hides and helps.
Heave, ho! Heave, ho! he whistles as the twine
Slackens its hold; once more, now! and a flash
Lightens across the sunlight to the elm
Where his mate dangles at her cup of felt."

- "UNDER the Willows"; LOWELL. 


\section{THE CROW}

\section{Teacher's Story}

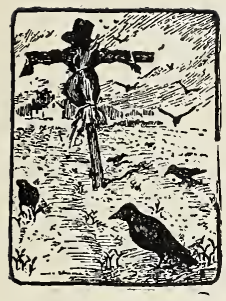

HOREAU says: "What a perfectly New England sound is this voice of the crow! If you stand still anywhere in the outskirts of the town and listen, this is perhaps the sound which you will be most sure to hear, rising above all sounds of human industry and leading your thoughts to some far-away bay in the woods. The bird sees the white man come and the Indian withdraw, but it withdraws not. Its untamed voice is still heard above the tinkling of the forge. It sees a race pass away, but it passes not away. It remains to remind us of aboriginal nature."

The crow is probably the most intelligent of all our native birds. it is quick to learn and clever in action, as many a farmer will testify who has tried to keep it out of corn fields with various devices, the harmless character of which the crow soon understood perfectly. Of all our birds, this one has the longest list of virtues and of sins, as judged from our standpoint; but we should listen to both sides of the case before we pass judgment. I find with crows, as with people, I like some more than I do others. I do not like at all the cunning old crow which steals the suet I put on the trees in winter for the chickadees and nuthatches; and I have hired a boy with a shotgun to protect the eggs and nestlings of the robins and other birds in my neighborhood from the ravages of one or two cruel

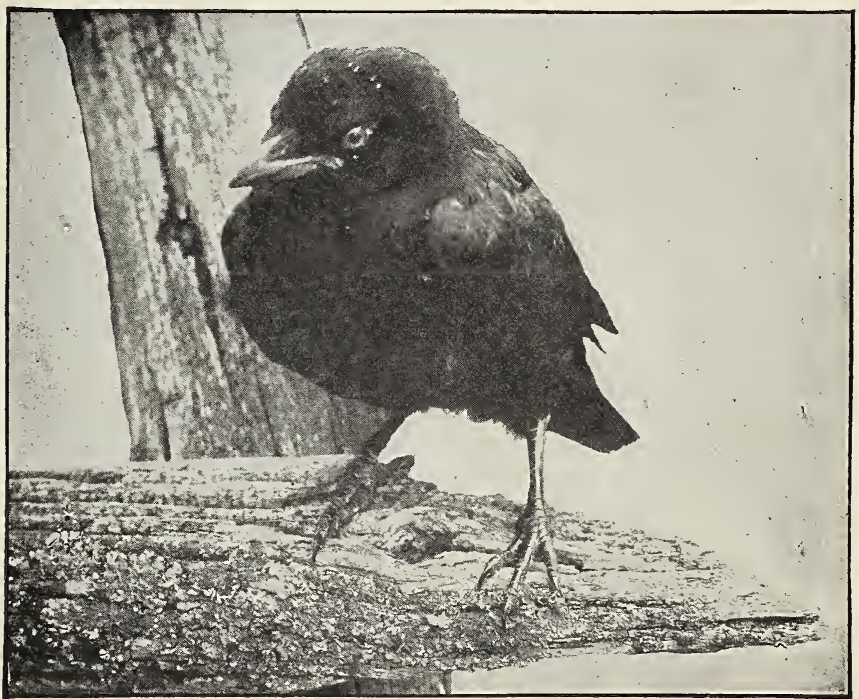

$A$ pet crow.

Photo by S A. Lottride. 
old crows that have developed the nest-hunting habit. On the other hand, I became a sincere admirer of a crow flock which worked in a field close to my country home, and I have been the chosen friend of several tame crows who were even more interesting than they were mischievous.

The crow is larger than any other of our common blackbirds; the northern raven is still larger, but is very rarely seen. Although the crow's feathers are black, yet in the sunlight a beautiful purple iridescence plays over the plumage, especially about the neck and back; it has a compact but not ungraceful body, and long, powerful wings; its tail is medium sized and is not notched at the end; its feet are long and strong; the track shows three toes directed forward and one long one directed backward. The crow does not sail through the air as does the hawk, but progresses with an almost constant flapping of the wings. Its beak is very strong and is used for tearing the flesh of its prey and for defense, and in fact, for almost anything that a beak could be used for; its eye is all black and is very keen and intelligent. When hunting for food in the field, it usually walks, but sometimes hops. The raven and the fish crows are the nearest relatives of the American crow, and next to them the jays. We should hardly think that the bluejay and the crow were related to look at them, but when we come to study their habits, much is to be found in common.

The crow's nest is usually very large; it is made of sticks, of grape vines and bark, sod, horse-hair, moss and grasses. It is placed in trees or in tall bushes rarely less than twenty feet from the ground. The eggs are pale bluish green or nearly white with brownish markings. The young crows hatch in April or May. Both parents are devoted to the care of the young, and remain with them during most of the summer. I have often seen a mother crow feeding her young ones which were following her with obstreperous caws, although they were as large as she.

While the note of the crow is harsh when close at hand, it has a musical quality in the distance. Mr. Mathews says: "The crow when he sings is nothing short of a clown; he ruffles his feathers, stretches his neck, like a cat with a fish bone in her throat, and with a most tremendous effort delivers a series of hen-like squawks." But aside from his caw, the crow has some very seductive soft notes. I have held long conversations with two pet crows, talking with them in a high, soft tone and finding that they answered readily in a like tone in a most responsive way. I have also heard these same tones among the wild crows when they were talking together; one note is a gutteral tremolo, most grotesque.

Crows gather in flocks for the winter; these flocks number from fifty to several hundred individuals, all having a common roosting place, usually in pine or hemlock forests or among other evergreens. They go out from these roosts during the day to get food, often making a journey of many miles. During the nesting season they scatter in pairs and do not gather again in flocks until the young are fully grown.

When crows are feeding in the fields there is usually, if not always, a sentinel posted on some high point so that he can give warning of danger. This sentinel is always an experienced bird and is keen to detect a dangerous from a harmless intruder. I once made many experiments with these sentinels; I finally became known to those of a particular flock and I was allowed to approach within a few yards of where the birds were feeding, a privilege not accorded to any other person in the neighborhood. 
The crow is a general feeder and will eat almost any food; generally, however, it finds its food upon the ground. The food given to nestlings is very largely insects, and many pests are thus destroyed. The crows damage the farmer by pulling the sprouting corn and by destroying the eggs and young of poultry. They also do much harm by destroying the eggs and nestlings of our native birds which are beneficial to the farmer; they also do some harm by distributing the seeds of poison ivy and other noxious plants. All these must be set down in the account against the crow, but on the credit side must be placed the fact that it does a tremendous amount of good work for the farmer by eating injurious insects, especially the grubs and cut-worms which work in the ground, destroying the roots of grasses and grains. It also kills many mice and other rodents which are destructive to crops.

The best method of preventing crows from taking sprouting corn is to tar the seed corn, which is planted around the edge of the field.

If any of the pupils in your school have had any experience with tame crows they will relate interesting incidents of the love of the crow for glittering objects. I once knew a tame crow which stole all of the thimbles in the house and buried them in the garden; he would watch to see when a thimble was laid aside when the sewing was dropped, and would seize it almost immediately. This same crow persisted in taking the clothes-pins off the line and burying them, so that he was finally imprisoned on washdays. He was fond of playing marbles with a little boy of the family. The boy would shoot a marble into a hole and then Billy, the crow, would take a marble in his beak and drop it into the hole. The bird understood the game perfectly and was highly indignant if the boy took his turn and made shots twice in succession.

References-The American Crow, Barrows \& Schwartz, Bulletin No. 6, Division of Ornithology, U. S. Department of Agriculture; Birds in Relation to Man, Weed \& Dearborn; Bird Neighbors, Blanchan; Birds of Villages and Field, Merriam; Outdoor Studies, Needham.

\section{LESSON XXXI}

\section{The Crow}

Leading thought-The crow has the keenest intelligence of any of our common birds. It does good work for us and also does damage. We should study its ways before we pronounce judgment, for in some localities it may be a true friend and in others an enemy.

Methods-This work should begin in winter with an effort on the part of the boys to discover the food of the crows while snow is on the ground. This is a good time to study their habits and their roosts. The nests are also often found in winter, although usually built in evergreens. The nesting season is in early April, and the questions about the nests should be given then. Let the other questions be given when convenient. The flight, the notes, the sentinels, the food, the benefit and damage may all be taken as separate topics.

The following topics for essays should be given to correlate with work in English: "What a pet crow of my acquaintance did;" "Evidences of crow intelligence;" "A plea a crow might make in self-defence to the farmer who wished to shoot him;" "The best methods of preventing crows from stealing planted corn." 
Observations-r. How large is the crow compared with other blackbirds?

2. Describe its colors when seen in the sunlight?

3. Describe the general shape of the crow.

4. Are its wings long and slender or short and stout?

5. Is the tail long or short? Is it notched or straight across the end?

6. Describe the crow's feet. Are they large and strong or slender? How many toes does the track show in the snow or mud? How many are directed forward and how many backward?

7. Describe a crow's flight compared with that of the hawk.

8. Describe its beak and what it is used for.

9. What is the color of the crow's eye?

ro. When hunting for food does the crow hop or walk?

Ir. Which are the crow's nearest relatives?

I2. Where and of what material do the crows build their nests?

r3. Describe the eggs. At what time of the year do the young crows hatch? Do both parents take care of and feed the young? How long do the parents care for the young after they leave the nest?

r. What are the notes of the crow? If you have heard one give any note except "caw," describe it.

r 5. Where and how do crows live in winter? Where do they live in summer?

r6. Do they post sentinels if they are feeding in the fields? If so, describe the action of the sentinel on the approach of people.

r7. Upon what do the crows feed? What is fed to the nestlings?

r8. How do the crows work injury to the farmer? How do they benefit the farmer? Do you think they do more benefit than harm to the farmer and fruit-grower?

r. Have you known of instances of the crow's fondness for shining or glittering articles, like pieces of crockery or tin?

Supplementary reading - "The Story of Silver Spot" in Wild Animals I have Known, Seton; Second Book of Birds, p. Ir7; “Jim's Babies" in Nestlings of Forest and Marsh; "How the Crow Baby was Punished," True Bird Stories; "The Children of a Crow," and "The Scare Crow" by Celia Thaxter; Our Birds and their Nestlings; "Crow Ways," Ways of Wood Folk, Long; "Not so Black as he is Painted," Outdoor Studies, Needham; The Crows, John Hay; "Jack Crow," American Birds, Finley.

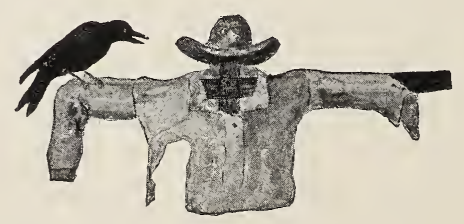




\section{THE CARDINAL GROSBEAK}

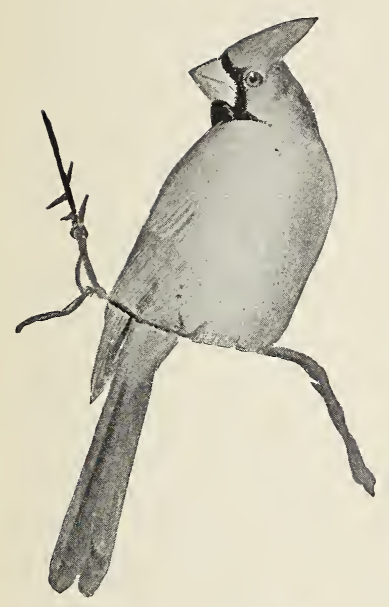

The cardinal grosbeak. After Audubon Leafler No. I8.

\section{Teacher's Story}

There never lived a Lord Cardinal who possessed robes of state more brilliant in color than the plumage of this bird. By the way, I wonder how many of us ever think when we see the peculiar red, called cardinal, that it gained its name from the dress of this high tunctionaryof the church? The cardinal grosbeak is the best name for the redbird because that describes it exactly, both as to its color and its chief characteristic, since its beak is thick and large; the beak is also red, which is a rare color in beaks, and in order to make its redness more emphatic it is set in a frame of black feathers. The use of such a large beak is unmistakable, for it is strong enough to crush the hardest of seed shells or to crack the hardest and driest of grains.

\section{"What cheer! What cheer!}

That is the grosbeak's way,

With his sooty tace and his coat of red"

sings Maurice Thompson. But besides the name given above, this bird has been called in different localities the redbird, Virginia redbird, crested redbird, winter redbird, Virginia nightingale, the red corn-cracker; but it remained for James Lane Allen to give it another name in his masterpiece, "The Kentucky Cardinal.':

The cardinal is a trifle smaller than the robin and is by no means slim and graceful, like the catbird or the scarlet tanager, but is quite stout and is a veritable chunk of brilliant color and bird dignity. The only other bird that rivals him in redness is the scarlet tanager which has black wings; the summer tanager is also a red bird, but is not so vermilion and is more slender and lacks the crest. The cardinal surely finds his crest useful in expressing his emotions; when all is serene, it lies back flat on the head, but with any excitement, whether of joy or surprise or anger, it lifts until it is as peaked as an old-fashioned nightcap. The cardinal's mate is of quiet color; her back is greenish gray and breast buffy, while her crest, wings and tail reflect in faint ways the brilliancy of his costume.

The redbird's song is a stirring succession of syllables uttered in a rich, ringing tone, and may be translated in a variety of ways. I have heard him sing a thousand times "tor-re'-do, tor-re'-do, tor-re'-do," but Dr. Dawson has heard him sing "che'-pew, che'-pew, we'-woo, we'-woo;" "bird-ie, bird-ie, bird-ie; tschew, tschew, tschew;" and "chit-e-kew, chit-e-kew; he-weet- he-weet." His mate breaks the custom of other birds of her sex and sings a sweet song, somewhat softer thar his. Both birds utter a sharp note "tsip, tsip."

The nest is built in bushes, vines or low trees, often in holly, laurel or other low evergreens, and is rarely more than six or eight feet above the 
ground. It is made of twigs, weed stems, tendrils, the bark of the grape vine and coarse grass; it is lined with fine grass and rootlets; it is rather loosely constructed but firm and is well hidden, for it causes these birds great anguish to have their nest discovered. Three or four eggs are laid, which are bluish white or grayish, dully marked with brown. The father cardinal is an exemplary husband and father; he cares for and feeds his mate tenderly and sings to her gloriously while she is sitting; and he works hard catching insects for the nestlings. He is also a brave defender of his nest and will attack any intruder, however large, with undaunted courage. The fledglings all have the dull color of the mother and have dark-colored bills. Their dull color protects the young birds from the keen eyes of their enemies while they are not yet able to take care of themselves. If the male fledglings were the color of their father, probably not one would escape a tragic death. While the mother bird is hatching the second brood the father keeps the first brood with him and cares for them; often the whole family remains together during the winter, making a small flock. However, the flocking habit is not characteristic of these birds, and we only see them in considerable numbers when the exigencies of seeking food in the winter naturally bring them together.

The car dinals are fond of the shrubbery and thickets of river bottoms, near grain fields, or where there is plenty of wild grass, and they only visit our premises when driven to us by winter hunger. Their food consists of the seeds of rank weeds, corn, wheat, rye, oats, beetles, grasshoppers, flies, and to some extent, wild and garden berries; but they never occur in sufficient numbers to be a menace to our crops. The cardinals may often be seen in the corn fields after the harvest, and will husk an overlooked ear of corn and crack the kernels with their beaks in a most dexterous manner. During the winter we may coax them to our grounds by scattering corn in some place not frequented by cats; thus, we may induce them to nest near us, since the cardinal is not naturally a migrant but likes to stay in one locality summer and winter. It has been known to come as far north as Boston and southern New York, but it is found in greatest numbers in our Southern States. Many nestlings were formerly taken, to ship in cages to Europe, but the National Association for Bird Protection has put a stop to this. In Ohio, no cardinal is allowed to be caged, and this same law should protect this beautiful bird in every Southern state, since it does not live long or happily in confinement. The cardinal's song is not at its best in a cage, but as the poet Naylor says:

\footnotetext{
"Alung the dust-white river road. The saucy redbird chirps and trills; His liquid notes resound and rise Until they meet the cloudless skies, And echo o'er the distant hills."
}

\section{LESSON XXXII}

\section{The Cardinal Grosbeak}

Leading thought-The cardinal is the most brilliantly colored of all our birds and because of its color and song, it has been destroyed by thousands as cage birds. We should seek to preserve it as a beautiful ornament to our groves and grounds. 
Methods-This work must be done by personal observation ^n the field. The field notes should be discussed in school. The effect of the whole lesson should be to stimulate an interest in protecting these beautiful birds. If possible, send for outline figures of the cardinal for the children to color; these outlines may be had at the cost of fifteen cents per dozen from the Audubon Society, I 4I Broadway, New York City.

Observations-I. Do you know the cardinal? Why is it so called?

2. How many names do you know for this bird?

3. Is the cardinal as large as the robin? Is it graceful in shape or stout?

4. Is there any culor except red upon it? If so, where?

5. What other vividly red birds have we and how can we distinguish them from the cardinal?

6. Describe the cardinal's crest and how it looks when lifted. Why do you think it lifts it?

7. Describe its beak as to color, shape and size. What work is such a heavy beak made for?

8. Is the cardinal's mate the same color as he? Describe the color of her head, back, wings, tail, breast.

9. Can you imitate the cardinal's song? What words do you think he seems to sing? Does his mate sing also? Is it usual for mother birds to sing? What other notes besides songs do you hear him utter?

Io. Where does the cardinal usually build its nest? How high from the ground? Of what materials? Is it compact or bulky? How many eggs and what are their colors?

I I. How does the father bird act while his mate is brooding? How does he help take care of the young in the nest?

I 2. How do the fledglings differ in color from their father? From their mother? Of what use to the young birds is their sober color?

I 3. What happens to the fledglings of the first brood while the mother is hatching the eggs of the second brood?

I 4. In what localities do you most often see the cardinals? Do you ever see them in flocks?

I5. What is the food of the cardinals? What do they feed their nestlings?

I6. How can you induce the cardinals to build near your home?

I7. What do you know about the laws protecting the redbirds?

Supplementary reading-The Second Book of Birds, Miller, p. 83; True Bird Stories, Miller, p. 86; The Song of the Cardinal, Porter; Audubon Educational Leaflet No. I8.

\footnotetext{
"Upon the gray old forest's rim

I snuffed the crab-tree's sweet perfume;

And farther, where the light was dim, I saw the bloom

Of May apples, beneath the tent

Of umbrel leaves above them bent,

Where oft was shifting light and shade

The blue-eyed ivy wildly strayed;

The Solomon's seal, in graceful play,

Swung where the straggling sunlight lay

The same as when I earliest heard

The Cardinal bird."
}

-W. S. Gallagher. 


\section{GEESE}

\section{Teacher's Story}

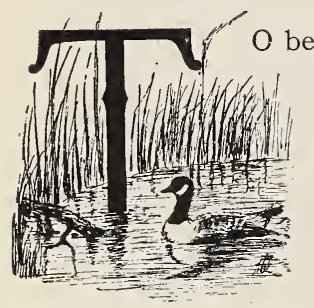

be called a goose should be considered most complimentary, for of all the birds the goose is probably the most intelligent. An observant lady who keeps geese on her farm assures me that no animal, not even dog or horse, has the intelligence of the goose. She says that these birds learn a lesson after a few repetitions, and surely her geese were patterns of obedience. While I was watching them one morning, they started for the brook via the corn field; she called to them sharply, "No, no, you mustn't go that way!" They stopped and conferred; she spoke again and they waited, looking at her as if to make up their minds to this exercise of self-sacrifice; but when she spoke the third time they left the corn field and took the other path to the brook. She could bring her geese into their house at any time of day by calling to them, "Home, home!" As soon as they heard these words, they would start and not stop until the last one was housed.

In ancient Greece maidens made pets of geese; and often there was such a devotion between the bird and girl that when the latter died her statue with that of the goose was carved on her burial tablet. The loyalty of a pet goose came under the observation of Miss Ada Georgia. A lone gander was the special pet of a small boy in Elmira, N. Y., who took sole care of him. The bird obeyed commands like a dog but would never let his little master out of his sight if he could avoid it; occasionally he would appear in the school yard, where the pupils would tease him by pretending to attack his master at the risk of being whipped with his wings so severely that it was a test of bravery among the boys to so challenge him. His fidelity to his master was extreme; once when the boy

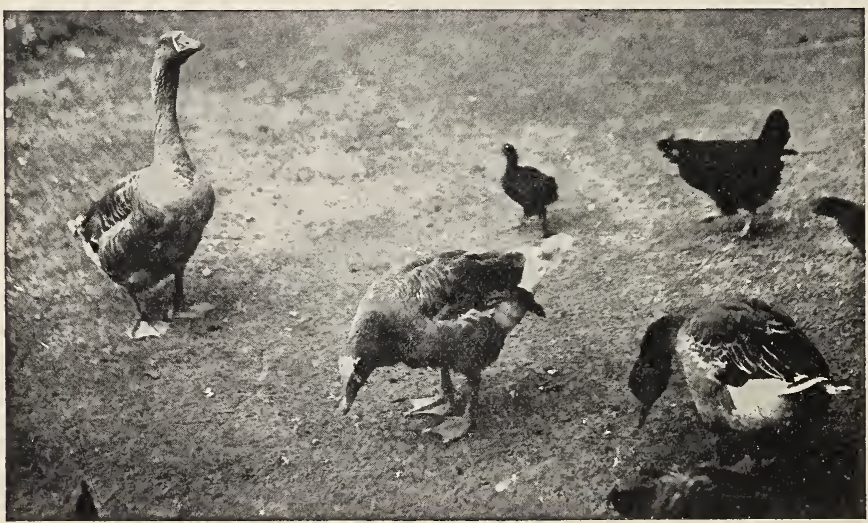


was ill in bed, the bird wandered about the yard honking disconsolately and refused to eat; he was driven to the side of the house where his master could look from the window and he immediately cheered up, took his food and refused to leave his post beneath the window while the illness. lasted.

The goose is a stately bird whether on land or water; its long legs give it good proportions when walking, and the neck being so much longer than that of the duck gives an appearance of grace and dignity. The duck on the other hand is beautiful only when on the water or on the wing; its short legs, placed far back and far out at the sides, make it a most ungraceful walker. The beak of the goose is harder in texture and is not flat like the duck's; no wonder the bird was a favorite with the ancient Greeks for the high ridge from the beak to the forehead resembles much the famous Grecian nose. The plumage of geese is very beautiful and abundant and for this reason they are profitable domestic birds. The "picking" occurs late in summer when the feathers are nearly ready to be molted; at this time the geese flap their wings often and set showers of loose feathers flying. A stocking or a bag is slipped over the bird's head and she is turned breast side up, with her head firmly between the knees or under the arm of the picker. The tips of the feathers are seized with the fingers and come out easily; only the breast, the under parts and the feathers beneath the wings are plucked. Geese do not seem to suffer while being plucked except through the temporary inconvenience and ignominy of having their heads thrust into a bag; it hurts their dignity more than their bodies.

The wings of geese are very large and beautiful; although our domestic geese have lost their powers of flight to a great extent, yet they often stretch their wings and take little flying hops, teetering along as if they can scarcely keep to earth; this must surely be reminiscent of the old instinct for traveling in the skies. The tail of the goose is a half circle and is spread when flying; although it is short, it seems to be sufficiently long to act as a rudder. The legs of the goose are much longer than those of the duck; they are not set so far back toward the rear of the body, and, therefore, the goose is the much better runner of the two. The track made by the goose's foot is a triangle with two scallops on one side made by the webs between the three front toes; the hind toe is placed high up; the foot and the unfeathered portion of the leg, protected by scales, are used as oars when the bird is swimming. When she swims forward rapidly, her feet extend out behind her and act on the principle of a propeller; but when swimming around in the pond she uses them at almost right angles to the body. Although they are such excellent oars they are also efficient on land; although when running, her body may waddle somewhat, her head and neck are held aloft in stately dignity.

The Toulouse are our common gray geese; the Embdens are pure white with orange bill and bright blue eyes. The African geese $\mathrm{h}$ ave a black head with a large black knob on the base of the black bill; the neck is long, snakelike, light gray, with a dark stripe down the back; the wings and tail are dark gray; there is a dewlap at the throat. The brown Chinese geese have also a black beak and a black knob at the base of the bill. The neck is light brown with a dull yellowish stripe down the neck. The back is dark brown, breast, wings and tail grayish brown. The white Chinese are shaped like the brown Chinese but the knob and bill are orange and the eyes light blue. 


\section{The Habits of Geese}

Geese are monogamous and are loyal to their mates. Old-fashioned people declare that they choose their mates on Saint Valentine's Day, but this is probably a pretty myth; when once mated, the pair live together year after year until one dies; an interesting instance of this is one of the traditions in my own family. A fine pair of geese belonging to my pioneer grandfather had been mated for several years and had reared handsome families; but one spring a conceited young gander fell in love with the old goose, and as he was young and lusty, he whipped her legitimate lord and master and triumphantly carried her away, although she was manifestly disgusted with this change in her domestic fortunes. The old gander sulked and refused to be comforted by the blandishments of any young goose whatever. Later the old pair disappeared from the farmyard and the upstart gander was left wifeless. It was inferred that the old couple had run away with each other into the encompassing wilderness and much sympathy was felt for them because of this sacrifice of their lives for loyalty. However, this was misplaced sentiment, for later in the summer the happy pair was discovered in a distant "slashing" with a fine family of goslings and were all brought home in triumph. The old gander, while not able to cope with his rival, was still able to trounce any of the animal marauders which approached his home and family.

The goose lines her nest with down and the soft feathers which she plucks from her breast. The gander is very devoted to his goose while she is sitting; he talks to her in gentle tones and is fierce in her defence. The eggs are about twice as large as those of the hen and have the ends more rounded. The period of incubation is four weeks. The goslings are beautiful little creatures, covered with soft down, and have large, bright eyes. The parents give them most careful attention from the first. One family which I studied consisted of the parents and eighteen goslings. The mother was a splendid African bird; she walked with dignified step, her graceful neck assuming serpentine curves; and she always carried her beak "lifted," which gave her an appearance of majestic haughtiness. The father was just a plebeian white gander, probably of Embden descent but he was a most efficient protector. The family always formed a procession in going to the creek, the majestic mother at the head, the goslings following her and the gander bringing up the rear to be sure there were no stragglers; if a gosling strayed away or fell behind, the male went after it, pushing it back into the family circle. When entering the coop at night he pushed the little ones in gently with his bill; when the goslings took their first swim both parents gently pushed them into the water, "rooted them in," as the farmer said. Any attempt to take liberties with the brood was met with bristling anger and defiance on the part of the gander; the mistress of the farm told me that he had whipped her black and blue when she tried to interfere with the goslings.

The gander and goose always show suspicion and resentment by opening the mouth wide, making a hissing noise, showing the whole round tongue in mocking defiance. When the gander attacks, he thrusts his head forward, even with or below the level of his back, and seizes his victim firmly with his hard, toothed bill so that it cannot get away, and then with bis strong wings beats the life out of it. I remember vividly a whipping 
which a gander gave me when I was a child, holding me fast by the blouse while he laid on the blows.

Geese feed much more largely upon land vegetation than do ducks; a good growth of clover and grass make excellent pasture for them; in the water, they feed upon water plants but do not eat insects and animals to any extent.

Undoubtedly goose language is varied and expresses many things. Geese talk to each other and call from afar; they shriek in warning and in general make such a turmoil that people do not enjoy it. The goslings, even when almost grown, keep up a constant "pee wee, pee wee," which is nerve-racking. There is a good opportunity for some interesting investigations in studying out just what the different notes of the geese mean.

The goose is tery particular about her toilet; she cleans her breast and back and beneath her wings with her bill; and she cleans her bill with her foot; she also cleans the top of her head with her foot and the under side of her wing with the foot of that side. When oiling her feathers, she starts the oil gland flowing with her beak, then rubs her head over the gland until it is well oiled; she then uses her head as a "dauber" to apply the oil to the feathers of her back and breast. When thus polishing her feathers, she twists the head over and over and back and forth to add to its efficiency.

\section{WILD GEESE}

HERE is a sound, that, to the weather-wise farmer, means cold and snow, even though it is heard through the hazy atmosphere of an Indian summer day; and that is the honking of wild geese as they pass on their southward journey. And there is not a more interesting sight anywhere in the autumn landscape than the wedge-shaped flock of these long-necked birds with their leader at the front apex. "The wild goose trails his harrow," sings the poet; but only the aged can remember the old-fashioned harrow which makes this simile graphic. The honking which reveals to us the passing flock, before our eyes can discern the birds against the sky, is the call of the wise old gander who is the leader, to those following him, and their return salute. He knows the way on this long thousand-mile journey, and knows it by the topography of the country. If ever fog or storm hides the earth from his view, he is likely to become confused, to the dismay of his flock, which follows him to the earth with many lonely and distressful cries.

The northern migration takes place in April and May, and the southern from October to December. The journey is made with stops for rest and refreshment at certain selected places, usually some secluded pond or lake. The food of wild geese consists of water plants, seeds and corn, and some of the smaller animals living in water. Although the geese come to rest on the water, they go to the shore to feed. In California, the wild geese are dreaded visitors of the cornfields, andmen with guns are employed regularly to keep them off.

The nests are made of sticks lined with down, usually along the shores of streams, sometimes on tree stumps and sometimes in deserted nests of the osprey. There are only four or five eggs laid and both parents are 
devoted to the young, the gander bravely defending his nest and family from the attacks of any enemies.

Although there are several species of wild geese on the Atlantic Coast, the one called by this name is usually the Canada goose. This

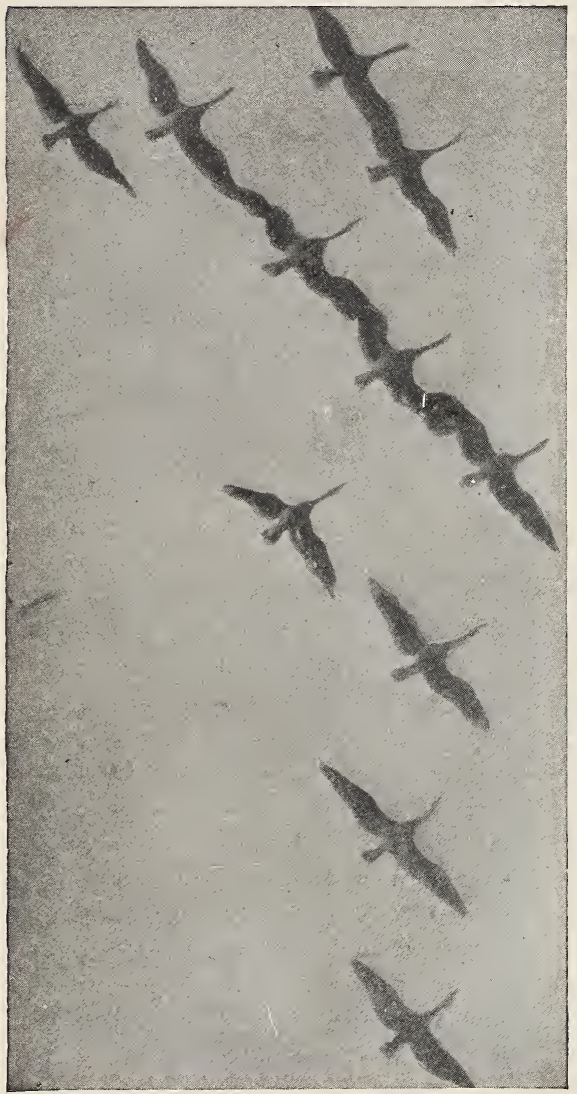

Wild geese flying in even ranks.

Photographed directly underneath by A. R. Dugmore.

Courtesy of Country Life in America. bird is a superb creature, brown above and gray beneath, with head, neck, tail, bill and feet of black. These black trimmings are highly ornamental and, as if to emphasize them, there is a whtte crescent-shaped "bib" extending from just back of the eyes underneath the head. This white patch is very striking, and gives one the impression of a bandage for sore throat. It is regarded as a callcolor, and is supposed to help keep the flock together; the side tail-coverts are also white and make another guide to follow.

Often some wounded or wearied bird of the migrating flock spends the winter in farmyards with domestic geese. One morning a neighbor of mine found that during the night a wild gander, injured in some way, had joined his flock. The stranger was treated with much courtesy by its new companions as well as by the farmer's family and soon seemed perfectly at home. The next spring he mated with one of the domestic geese. In the late summer, my neighbor, mindful of wild gesse habits, clipped the wings of the gander so that he would be unable to join any passing flock of his wild relatives. As the migrating season approached, the gander became very uneasy; not only was he uneasy and unhappy always but he insisted that $h$ is wife share his misery of unrest. He spent days in earnest remonstrance with her and, li :ting himself by his cropped wings to the top of the barnyard fence, he insisted that she keep him company on this, for web feet, uneasy resting place. Finally, after many days of tribulation. 
the two valiantly started south on foot. News was received of their progress for some distance and then they were lost to us. During the winter our neighbor visited a friend living eighteen miles to the southward and found in his barnyard the errant pair. They had become tired of migrating by tramping and had joined the farmer's flock; but we were never able to determine the length of time required for this journey.

\section{LESSON XXXIII}

\section{Geese}

Leading thought-Geese are the most intelligent of the domesticated birds, and they have many interesting habits.

Method-This lesson should not be given unless there are geese where the pupils may observe them. The questions should be given a few at a time and answered individually by the pupils after the observations are made.

Observations-I. What is the chief difference between the appearance of a goose and a duck? How does the beak of the goose differ from that of the duck in shape and in texture? Describe the nostrils and their situation.

2. What is the difference in shape between the neck of the goose and that of the duck?

3. What can you say about the plumage of geese? How are geese "picked?" At what time of year? From what parts of the body are the the feathers plucked?

4. Are the wings of the goose large compared with the body? How do geese exercise their wings? Describe the tail of the goose and how it is used.

5. How do the legs and feet of the goose differ from those of the duck? Describe the goose's foot. How many toes are webbed? Where is the other toe? What is the shape of the track made by the goose's foot? Which portions of the legs are used for oars? When the goose is swimming forward where are her feet? When turning around how does she use them? Does the goose waddle when walking or running as a duck does? Why? Does a goose toe-in when walking? Why?

6. Describe the shape and color of the following breeds of domestic geese: The Toulouse, the Embden, the African, and Chinese.

\section{Habits of Geese}

I. What is the chief food of geese? What do they find in the water to eat? How does their food differ from that of ducks?

2. How do geese differ from hens in the matter of mating and nesting? At what time of year do geese mate? Does a pair usually remain mated for life?

3. Describe the nest and compare the eggs with those of hens. Describe the young goslings in general appearance. With what are they covered? What care do the parents give to their goslings? Describe how the parents take their family afield. How do they induce their goslings to go into the water for the first time? How do they protect them from enemies? 
4. How does the gander or goose fight? What are the chief weapons? How is the head held when the attack is made?

5. How does the goose clean her feathers, wings and feet? How does she oil her feathers? Where does she get the oil and with what does she apply it?

6. How much of goose language do you understand? What is the note of alarm? How is defiance and distrust expressed? How does a goose look when hissing? What is the constant note of the gosling?

7. Give such instances as you may know illustrating the intelligence of geese, their loyalty and bravery.

8. Write an English Theme on "The Canada Goose, its appearance, nesting habits, and migrations."

Supplementary reading-Birds that Hunt and are Hunted, Blanchan; "In Quest of Waptonk The Wild," Northern Trails, Long; "The Homesickness of Kehonka," Kindred of the Wild, Roberts; Wild Geese, Celia Thaxter.

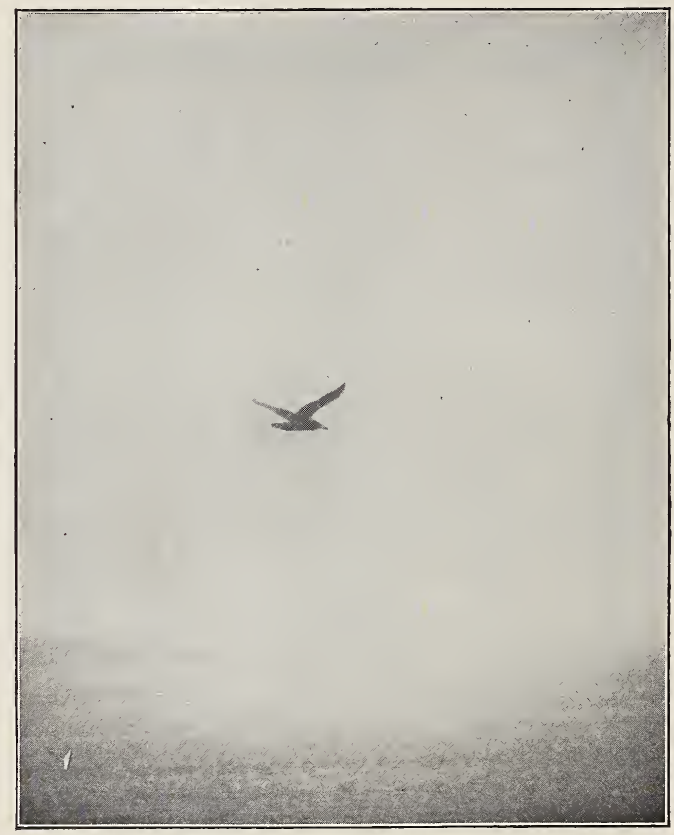

A sea-gull.

Photo by G. K. Gilbert. 


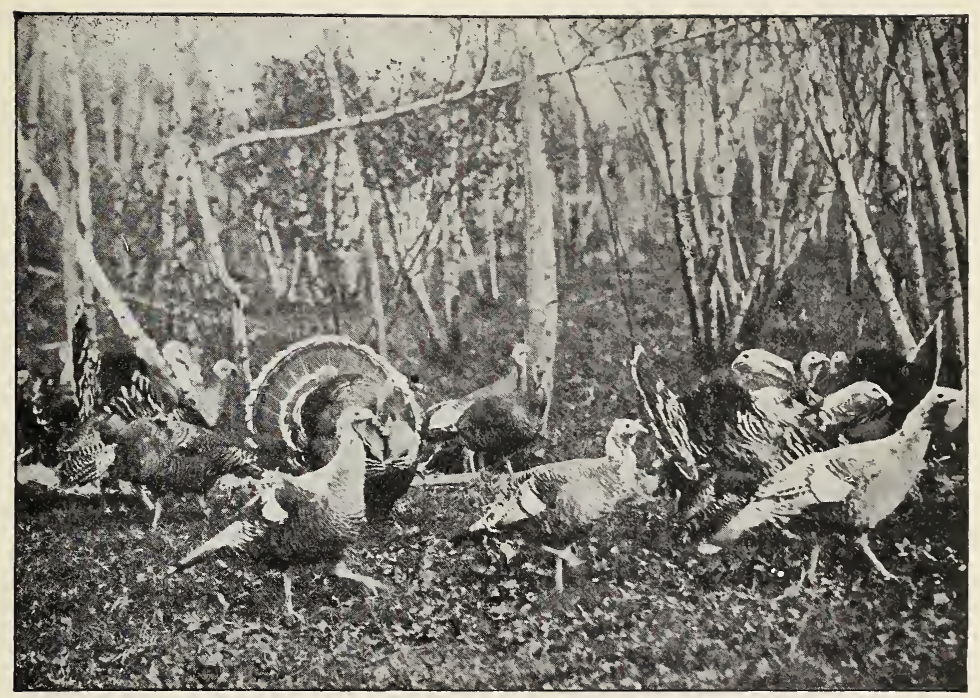

THE TURKEY

\section{Teacher's Story}

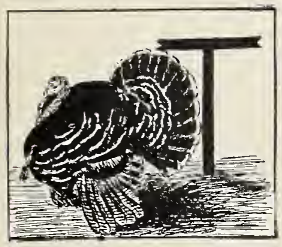

HAT the turkey and not the eagle should have been chosen for our national bird, was the conviction of Benjamin Franklin. It is a native of our country, it is beautiful as to plumage, and like the American Indian, it has never yielded entirely to the influences of civilization. Through the hundreds of years of domestication it still retains many of its wild habits. In fact, it has many qualities in common with the red man. Take for instance its sun dance, which any one can witness who is willing to get up early enough in the morning and who has a flock of turkeys at hand. Miss Ada Georgia made a pilgrimage to witness this dance and she describes it thus: "While the dawn was still faint and gray, the long row of birds on the ridge-pole stood up, stretched legs and wings and flew down into the orchard beside the barnyard and began a curious, high-stepping, 'flip-flop' dance on the frosty grass. It consisted of little, awkward, up-and-down jumps, varied by forward springs of about a foot, with lifted wings. Both hens and males danced, the latter alternately strutting and hopping and all 'singing,' the hens calling 'Quit, quit,' the males accompanying with a high-keyed rattle, sounding like a hard wood stick drawn rapidly along a picket fence. As the sun came up and the sky brightened, the exhibition ended suddenly when 'The Captain,' a great thirty pound gobbler and leader of the flock, made a rush at one of his younger brethren who had dared to be spreading a tail too near to his majesty." 
The bronze breed resembles most closely our native wild turkey and is therefore chosen for this lesson. The colors and markings of the plumage form the bronze turkey's chief beauty. From the skin of the neck, reaching half way to the middle of the back is a collar of glittering bronze with greenish and purple iridescence, each feather tipped with a narrow jet band. The remainder of the back is black except that each feather is edged with bronze. The breast is like the collar and at its center is a tassel of black bristles called the beard which hangs limply downward when the birds are feeding; but when the gobbler stiffens his muscles to strut, this beard is thrust proudly forth. Occasionally the hen turkeys have a beard. The long quills, or primaries, of the wings are barred across with bands of black and white; the secondaries are very dark, luminous brown, with narrower bars of white. Each feather of the fanshaped tail is banded with black and brown and ends with a black bar tip ped with white; the tail coverts are lighter brown but also have the black margin edged with white. The colors of the hen are like those of the gobbler except that the bronze brilliance of breast, neck and wings is dimmed by the faint line of white which tips each feather.

The heads of all are covered with a warty wrinkled skin, bluish white on the crown, grayish blue about the eyes, and the other parts red. Beneath the throat is a hanging fold called the wattle, and above the beak a fleshy pointed knob called the caruncle, which on the gobbler is prolonged so that it hangs over and below the beak. When the bird is angry these carunculated parts swell and grow more vivid in color, seeming to be gorged with blood. The color of the skin about the head is more extensive and brilliant in the gobblers than in the hens. The beak is slightly curved, short, stout, and sharp-pointed, yellowish at the tip and dark at the base.

The eyes are bright, dark hazel with a thin red line of iris. Just back of the eye is the ear, seemingly a mere hole, and yet it leads to a very efficient ear, upon which every smallest sound impinges.

The legs of the young turkeys are nearly black, fading to a brownish gray when mature. The legs and feet are large and stout, the middle toe of the three front ones being nearly twice the length of the one on either side; the hind toe is the shortest of the four. On the inner side of the gobbler's legs, about one-third the bare space above the foot, is a wicked looking spur which is a most effective weapon. The wings are large and powerful; the turkey flies well for such a large bird and usually roosts high, choosing trees or the ridge-pole of the barn for this purpose.

In many ways the turkeys are not more than half domesticated. They insistently prefer to spend their nights out of doors instead of under a roof. They are also great wanderers and thrive best when allowed to forage in the fields and woods for a part of their food.

The gobbler is the most vainglorious bird known to us; when he struts to show his flock of admiring hens how beautiful he is, he lowers his wings and spreads the stiff primary quills until their tips scrape the ground, lifting meanwhile into a semi-circular fan his beautiful tail feathers; he protrudes his chest, raises the iridescent plumage of his neck like a ruff to make a background against which he throws back his red, white and blue decorated head. He moves forward with slow and mincing steps and calls attention to his grandeur by a series of most aggressive "gobbles." But we must say for the gobbler that although he is vain he is also a brave 
fighter. When beginning a fight he advances with wings lowered and sidewise as if guarding his body with the spread wing. The neck and the sharp beak are outstretched and he makes the attack so suddenly, that it is impossible to see whether he strikes with both wing and beak or only with the latter, as with fury he pounces upon his adversary apparently striving to rip his neck open with his spurs.

Turkey hens usually begin to lay in April in this latitude and much earlier in more southern states. At nesting time each turkey hen strays off alone, seeking the most secluded spot she can find to lay the large, oval, brown-speckled eggs. Silent and sly, she slips away to the place daily, by the most round-about ways, and never moving in the direction of the nest when she thinks herself observed. Sometimes the sight of any person near her nest will cause her to desert it. The writer has spent many hours when a child, sneaking in fence corners and behind stumps and tree trunks, stalking turkeys' nests. Incubation takes four weeks. The female is a most persistent sitter and care should be taken to see that she gets a good supply of food and water at this time. Good sound corn or wheat is the best food for her at this period. When sitting she is very cross and will fight most courageously when molested on her nest.

Turkey nestlings are rather large, with long, bare legs and scrawny thin necks, and they are very delicate during the first six weeks of their lives. Their call is a plaintive "peep, weep," and when a little turkey feels lost its cry is expressive of great fear and misery. But if the mother is freely ranging she does not seem to be much affected by the needs of her brood; she will fight savagely for them if they are near her, but if they stray, and they usually do, she does not seem to miss or hunt for them, but strides serenely on her way, keeping up a constant crooning " $\mathrm{kr}$-rit, kr-rit," to encourage them to follow. As a consequence, the chicks are lost or get draggled and chilled by struggling through wet grass and leaves, that are no obstacle to the mother's strong legs, and thus many die. If the mother is confined in a coop it should be so large and roomy that she can move about without trampling on the chicks, and it should have a dry floor since dampness is fatal to the little ones.

For the first week the chicks should be fed five times a day, and for the next five weeks they should have three meals a day. They should be given only just about enough to fill each little crop and none left over to be trodden under their awkward little feet. Their quarters should be kept clean and free from vermin.

\section{LESSON XXXIV}

\section{TURKEYS}

Leading thought-The turkey is a native of America. It was introduced into Spain from Mexico in about 1.518 , and since then has been domesticated. However, there are still in some parts of the country flocks of wild turkeys. It is a beautiful bird and has interesting habits.

Method-If the pupils could visit a flock of turkeys the lesson would be given to a better advantage. If this is impossibIe, ask the questions a few at a time and let those pupils who have opportunities for observing the turkeys give their answers before the class.

Observations - I. Of what breed are the turkeys you are studying, Bronze, Black, Buff, White Holland or Narragansett? 
2. What is the general shape and size of the turkey? Describe its plumage, noting every color which you can see in it? Does the plumage of the hen turkey differ from that of the gobbler?

3. What is the covering of the head of the turkey, what is its color and how far does it extend down the neck of the bird? Is it always the same color, and if not, what causes the change? Is the head covering alike in shape and size on the male and the female? What is the part called that hangs from the front of the throat below the beak? From above the beak?

4. What is the color of the beak? Is it short or long, straight or curved? Where are the nostrils situated?

5. What is the color of the turkey's eyes? Do you think it is a keensighted bird?

6. Where are the ears? Do they show as plainly as a chicken's ears do? Are turkeys quick of hearing?

7. Do turkeys scratch like hens? Are they good runners? Describe the feet and legs as to shape, size and color. Has the male a spur on his legs, and if so, where is it situated.? For what is it used?

8. Can turkeys fly well? Are the wings small or comparatively large and strong for the weight of the body? Do turkeys prefer high or low places for perching when they sleep? Is it well to house and confine them in small buildings and parks as is done with other fowls?

9. Tell, as nearly as you can discover by close observation, how the gobbler sets each part of his plumage when he is "showing off" or strutting? What do you think is the bird's purpose in thus exhibiting his fine feathers? Does the "King of the flock" permit any such action by other "gobblers" in his company?

Io. Are turkeys timid and cowardly or independent and brave, ready to meet and fight anything which they think is threatening to their comfort and safety?

I I. When turkeys fight, what parts of their bodies seem to be used as weapons? Does the male "gobble" during a fight, or only as a challenge or in triumph when victorious? Do the hen turkeys ever fight, or only the males?

I 2. How early in the spring does the turkey hen begin to lay? Does she nest about the poultry yard and the barns or is she likely to seek some secret and distant spot where she may hide her eggs? Describe the turkey's egg, as well as you can, as to color, shape and size. Can one tell it by the taste from an ordinary hen's egg? About how many eggs does the turkey hen lay in her nest before she begins to "get broody" and want to sit?

I3. How many days of incubation are required to hatch the turkey chick? Is it as downy and pretty as other little chicks? How often should the young chicks be fed, and what food do you think is best for them? Are turkey chicks as hardy as other chicks?

I4. Is the turkey hen generally a good mother? Is she cross or gentle when sitting and when brooding her young? Is it possible to keep the mother turkey as closely confined with her brood as it is with the mother hen? What supplies should be given to her in the way of food, grits, dust-baths, etc.?

Supplementary reading-Birds that Hunt and are Hunted, Blanchan. 


\section{LESSON XXXV}

\section{The Study of Birds' Nests in Winter}

There are very good reasons for not studying birds' nests in summer, since too much familiarity on the part of eager children is something the birds do not understand and are likely, in consequence, to abandon both nest and locality. But after the birds have gone to sunnier climes and the empty nests are the only mementos we have of them, then we may study these habitations carefully and learn how to properly appreciate the small architects which made them. I think that every one of us who carefully examines the way that a nest is made must have a feeling of respect for its clever little builder.

I know of certain schools where the children make large collections of these winter nests, properly labelling each, and thus gaining a new interest in the bird life of their locality. A nest when collected should be labelled in the following manner?

Name of the bird which built the nest.

Where the nest was found.

If in a tree, what kind?

How high from the ground?

Bird Homes, by A. R. Dugmore is a book which affords practical help in determining the species of birds which made the nests.

After a collection of nests has been made let the pupils study them according to the following outline:

I. Where was the nest found?

a. If on the ground, describe the locality.

b. If on a plant, tree or shrub, tell the species, if possible.

c. If on a tree, tell where it was on a branch, in a fork, or hanging by the end of the twigs.

d. How high from the ground, and what was the locality?

e. If on or in a building, how situated?

2. Did the nest have any arrangement to protect it from rain?

3. Give the size of the nest, the diameter of the inside and the outside; also the depth of the inside.

4. What is the form of the nest? Are its sides flaring or straight? Is the nest shaped like a cup, basket or pocket?

5. What materials compose the outside of the nest and how are they arranged?

6. Of what materials is the lining made, and how are they arranged? If hair or feathers are used, on what creature did they grow?

7. How are the materials of the nest held together, that is, are they woven, plastered, or held in place by environment?

8. Had the nest anything peculiar about it either in situation, construction or material that would tend to render it invisible to the casual glance? 


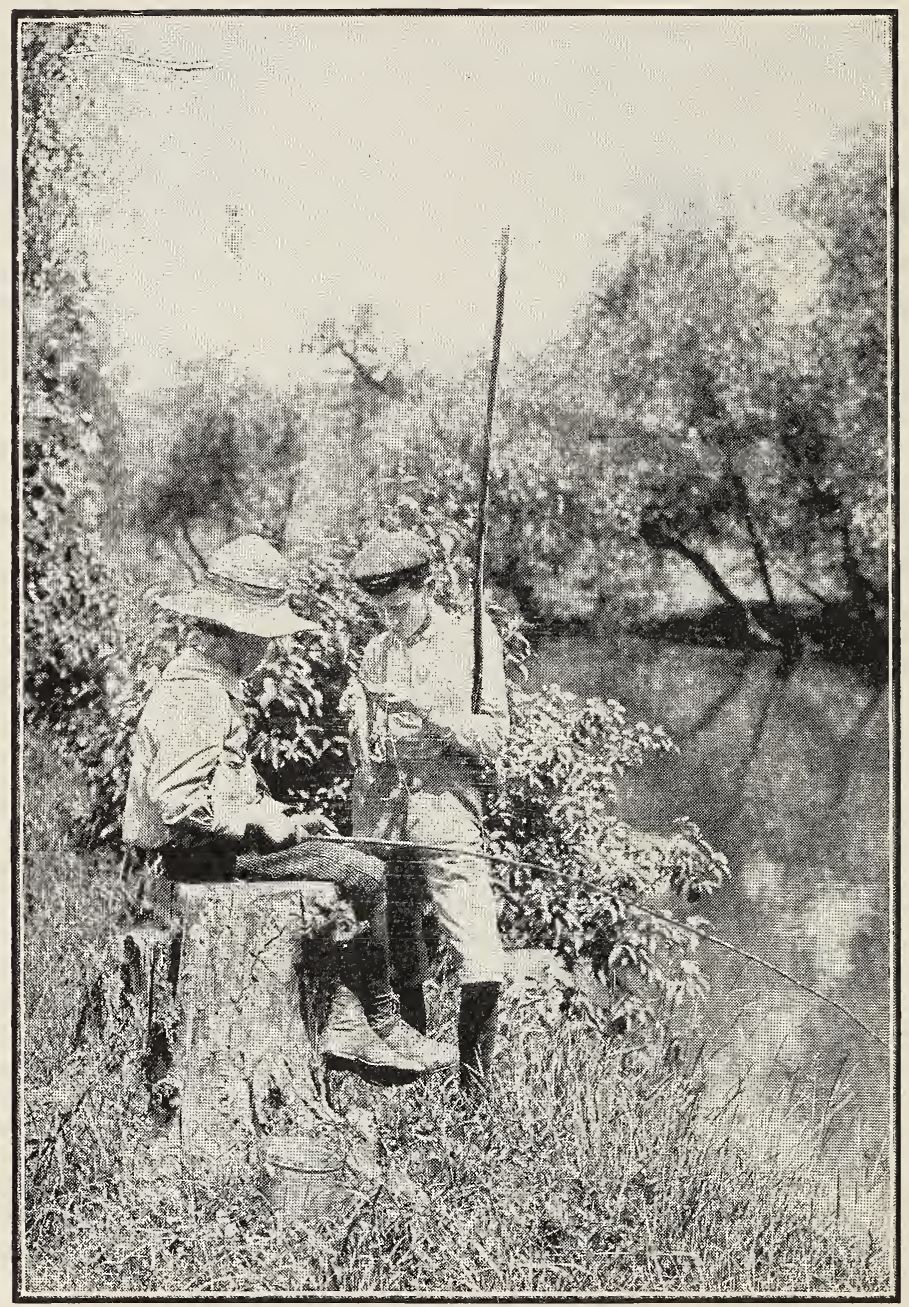

"Noon time and June time down around the river." 


\section{FISH STUDY}

"It remains yet unresolved whether the happiness of a man in this world doth consist more in contemplation or action. Concerning which two opinions I shall forebear to add a third by deciaring my own, and rest myself contented in telling you that both of these meet together, and do most properly belong to the most honest, ingenions, quiet and harmless art of angling. And first I tell you what some have observed, and I have found to be a real truth, that the very sitting by the riverside is not only the quietest and the fittest place for contemplation, but rill invite an angler to it."-ISAAK WALTON.

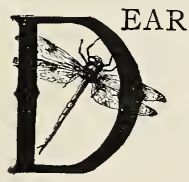

human, old Isaak Walton discovered that naturestudy, fishing, and philosophy were akin and as inevitabiy related as the three angles of a triangle. And yet it is surprising how little the fish have been used as subjects for nature lessons. Every brook and pond is a treasure to the teacher who will find what there is in it and who knows what may be gotten out of it.

Luckily there are some very good books on fishes which will assist materially in making the fish lessons interesting: Fishes, by David Starr Jordan, is a magnificent popular work in two volumes; American Food and Game Fishes, by Jordan and Evermann, is one of the volumes of the valuable Nature Library. While for supplementary reading the following will prove instructive and entertaining: The Story of the Fishes, Baskett; Fish Stories, by Holder and Jordan; "The Story of a Salmon," in Science Sketches, by Jordan; Neighbors with Wings and Fins, Johonnot; Half Hours with Fishes, Reptiles and Birds, Holder.

Almost any of the fishes found in brook or pond may be kept in an aquarium for a few days of observation in the schoolroom. A water pail or bucket does very well if there is no glass aquarium. The water should be changed every day and at least once a day it should be aerated by dipping it up and pouring it back from some distance above. The practice should be established, once for all, of putting these finny prisoners back into the brook after they have been studied.

\section{THE GOLDFISH}

\section{Teacher's Story}

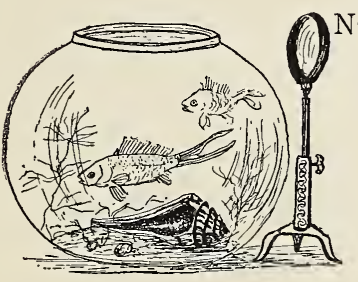

NCE upon a time, if stories are true, there lived a king called Midas, whose touch turned everything to gold. Whenever I see goldfish, I wonder if, perhaps, King Midas were not a Chinese and if he perchance did not handle some of the little fish in Orient streams. But common man has learned a magic as wonderful as that of King Midas, although it does not act so immediately, for it is through his agency in selecting and breeding that we have gained these exquisite fish for our aquaria. In the streams of China the goldfish, which were the ancestors of these effulgent creatures, wore safe green colors like the shiners in our brooks; and if any goldfish escape from our fountains and run wild, their progeny return to their native olive-green color. There are many 
such dull-colored goldfish in the Delaware and Potomac and other eastern rivers. It is almost inconceivable that one of the brilliant colored fishes, if it chanced to escape into our ponds, should escape the fate of being eaten by some larger fish attracted by such glittering bait.

The goldfish, as we see it in the aquarium, is brilliant orange above and pale lemon-yellow below; there are many specimens that are adorned with black patches. And as if this fish were bound to imitate the precious metals, there are individuals which are silver instead of gold: they are oxydized silver above and polished silver below. The gc'dfish are closely related to the carp and can live in waters that are stale. However, the water in the aquarium should be changed at least twice a week to keep it clear. Goldfish should not be fed too lavishly. An inch square of one of the sheets of prepared fish food, we have found a fair daily ration for five medium sized fish; these fish are more likely to die from overfeeding than from starving. Goldfish are naturally long-lived; Miss Ada Georgia has kept them until seven years old in a school aquarium; and there is on record one goldfish that lived nine years.

Too often the wonderful common things are never noticed because of their commonness; and there is no better instance of this than the form and movements of a fish. It is an animal in many ways similar to animals that live on land; but its form and structure are such that it is perfectly adapted to live in water all its life; there are none of the true fishes which live portions of their lives on land as do the frogs. The first peculiarity of the fish is its shape. Looked at from above, the broader part of the body is near the front end which is rounded or pointed so as to cut the water readily. The long, narrow, hind portion of the body with the tail acts as a propeller. Seen from the side, the body is a smooth, graceful oval and this form is especially adapted to move through the water swiftly, as can be demonstrated to the pupil by cutting a model of the fish from wood and trying to move it through the water sidewise.

Normally, the fish has seven fins, one along the back called the dorsal, one at the end of the tail called the tail or caudal fin, one beneath the rear end of the body called the anal, a pair on the lower side of the body called the ventrals, and a pair just back of the gill openings called the pectorals. All these fins play their own parts in the movements of the fish. The dor-

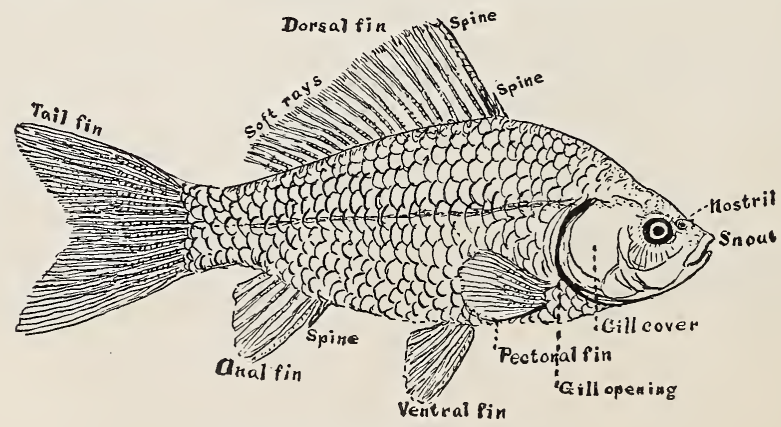

Goldfish with the parts named.

This figure should be copied on the blackboard for reference. 
sal fin is usually higher in front than behind and can be lifted or shut down like a fan. This fin when it is lifted gives the fish greater height and it can be twisted to one side or the other and thus be made a factor in steering. The anal fin on the lower side acts in a similar manner. The tail fin is the propeller and sends the body forward by pressing backward on the water, first on one side and then on the other, being used like a scull. The tail fin varies in shape very much in different species. In the goldfish it is fanlike, with a deeply notched hind edge, but in some it is rounded or square.

The paired fins correspond anatomically to our arms and legs, the pectorals representing the arms, the ventrals the legs. Fins are made up of rays, as the bony rods are called which support the membrane; these rays are of two kinds, those which are soft, flexible, many jointed and usually branched at the tip; and those which are bony, not jointed and which are usually stiff spines. When the spines are present in a fin they precede the soft rays.

Fishes' eyes have no eyelid but the eyeball is movable, and this often gives the impression that the fish winks. Fishes are necessarily nearsighted since the lens of the eye has to be spherical in order to see in the water. The sense of smell is located in a little sac to which the nostril leads; the nostrils are small and often partitioned and may be seen on either side of the snout. The nostrils have no connection whatever with breathing, in the fish.

The tongue of the fish is very bony or bristly and immovable. There is very little sense of taste developed in it. The shape, number and position of the teeth vary according to the food habits of the fish. The commonest type of teeth are fine, sharp and short and are arranged in pads, as seen in the bullhead. Some fish have blunt teeth suitable for crushing shells. Herbivorous fishes have sharp teeth with serrated edges, while those living upon crabs and snails have incisor-like teeth. In some specimens we find several types of teeth, in others the teeth may be entirely absent. The teeth are borne not only on the jaws but also in the roof of the mouth, on the tongue and in the throat.

The ear of the fish has neither outside form nor opening and is very imperfect in comparison with that of man. Extending along the sides of the body from head to tail is a line of modified scales containing small tubes connecting with nerves; this is called the lateral line and it is believed that it is in some way connected with the fish's senses, perhaps with the sense of hearing.

Since fishes must push through water, which is more difficult than moving through air, they need to have the body well protected. This protection is, in most fishes, in the form of an armor of scales which are smooth and allow the body to pass through the water with little friction. These scales overlap like shingles in a roof and are all directed backward. The study of the fish scale shows that it grows in layers.

In order to understand how the fish breathes we must examine its gills. In front, just above the entrance to the gullet are several bony ridges which bear two rows of pinkish fringes; these are the gill arches and the fringes are the gills. The gills are filled with tiny bloodvessels, and as the water passes over them, the impurities of the blood pass out through the thin skin of the gills and the life-giving oxygen passes in. Since fish cannot make use of air unless it is dissolved in water, it is very important 
that the water in the aquarium jar should often be replenished. The gill arches also bear a series of bony processes called gill-rakers. Their function is to prevent the escape of food through the gills while it is being swallowed, and they vary in size according to the food habits of the fish. We note that the fish in the aquarium constantly opens and closes the mouth; this action draws the water in to the throat and forces it out over the gills and through the gill openings; this then, is the act of breathing.

\section{LESSON XXXVI}

\section{A Study of the Fish}

Leading thought-A fish lives in the water where it must breathe, move and find its food. The water world is quite different from the air world and the fish have developed forms, senses and habits which fit them for life in the water.

Method-The goldfish is used as a subject for this lesson because it is so conveniently kept where the children may see it. However, a shiner or minnow would do as well.

Before the pupils begin the study, place the diagram shown on p. I 50 on the blackboard, with all the parts labelled; thus the pupils will be able to learn the parts of the fish by consulting it, and not be compelled to commit them to memory arbitrarily. It would be well to associate the goldfish with a geography lesson on China.

Observations - $\mathrm{I}$. Where do fishes live? Do any fishes ever live any part of their lives on land like the frogs? Could a salt-water fish live in fresh water, or vice versa?

2. What is the shape of a fish when seen from above? Where is the widest part? What is its shape seen from the side? Think if you can in how many ways the shape of the fish is adapted for movirig swiftly through the water.

3. How many fins has the fish? Make a sketch of the goldfish with all its fins and name them from the diagram on the blackboard.

4. How many fins are there in all? Four of these fins are in pairs; where are they situated? What are they called? Which pair corresponds to our arms? Which to our legs?

5. Describe the pectoral fins. How are they used? Are they kept constantly moving? Do they move together or alternately? How are they used when the fish swims backwards?

6. How are the ventral fins used? How do they assist the fish when swimming?

7. Sketch a dorsal fin. How many spines has it? How many soft rays are there in it? What is the difference in structure between the stiff spines in the front of the dorsal fin and the rays in the hind portion? Of what use to the fish are these two different kinds of fin supports?

8. Sketch the anal fin. Has it any spines in front? How many rays has it? How is this fin used when the fish is swimning?

9. With what fin does the fish push itself through the water? Make a sketch of the tail. Note if it is square, rounded, or notched at the end. Are the rays of the tail fin spiny or soft in character?

ro. Watch the goldfish swim and describe the action of all the fins while it is in motion. In what position are the fins when the fish is at rest? 
I I. What is the nature of the covering of the fish? Are the scales large or small? In which direction do they seem to overlap? Of what use to the fish is this scaly covering?

I 2. Can you see a line which extends from the upper part of the gill opening, along the side to the tail? This is called the lateral line. Do you think it is of any use to the fish?

I3. Note carefully the eyes of the fish. Describe the pupil and the iris. Are the eyes placed so that the fish can see in all directions? Can they be moved so as to see better in any direction? Does the fish wink? Has it any eyelids? Do you know why fish are near-sighted?

I4. Can you see the nostrils? Is there a little wartlike projection connected with the nostril? Do you think fishes breathe through their nostrils?

I5. Describe the mouth of the fish. Does it open upward, downward, or directly in front? What sort of teeth have fish? How does the fish catch its prey? Does the lower or upper jaw move in the process of eating?

r6. Is the mouth kept always in motion? Do you think the fish is swallowing water all the time? Do you know why it does this? Can you see a wide opening along the sides of the head behind the gill cover? Does the gill cover move with the movement of the mouth? How does a fish breathe?

I7. What are the colors of the goldfish above and below? What would happen to our beautiful goldfish if they were put in a brook with other fish? Why could they not hide? Do you know what happens to the colors of the goldfish when they run wild in our streams and ponds?

I8. Can you find in books or cyclopedias where the goldfish came from? Are they gold and silver in color in the streams where they are native? Do you think that they had originally the long, slender, swallow tails which we see sometimes in goldfish? How have the beautiful colors and graceful forms of the gold and silver fishes been developed?

"I have my world, and so have you,

A tiny universe for two,

A bubble by the artist blown,

Scarcely more fragile than our own,

Where you have all a whale could wish,

Happy as Eden's primal fish.

Manna is dropt you thrice a day

From some kind heaven not far away,

And still you snatch its softening crumbs,

Nor, more than we, think whence it comes.

No toil seems yours but to explore

Your cloistered realm from shore to shore;

Sometimes you trace its limits round,

Sometimes its limpid depths you sound, Or hover motionless midway,

Like gold-red clouds at set of day;

Erelong you whirl with sudden whim
Off to your globe's most distant rim, Where, greatened by the watery lens, Methinks no dragon of the fens

Flashed huger scales against the sky,

Roused by Sir Bevis or Sir Guy;

And the one eye that meets my view,

Lidless and strangely largening, too,

Like that of conscience in the dark,

Seems to make me its single mark.

What a benignant lot is yours

That have an own All-out-of-doors,

No words to spell, no sums to do,

No Nepos and no parlyvoo!

How happy you, without a thought

Of such cross things as Must and Ought-

I too the happiest of boys

To see and share your golden joys!" 


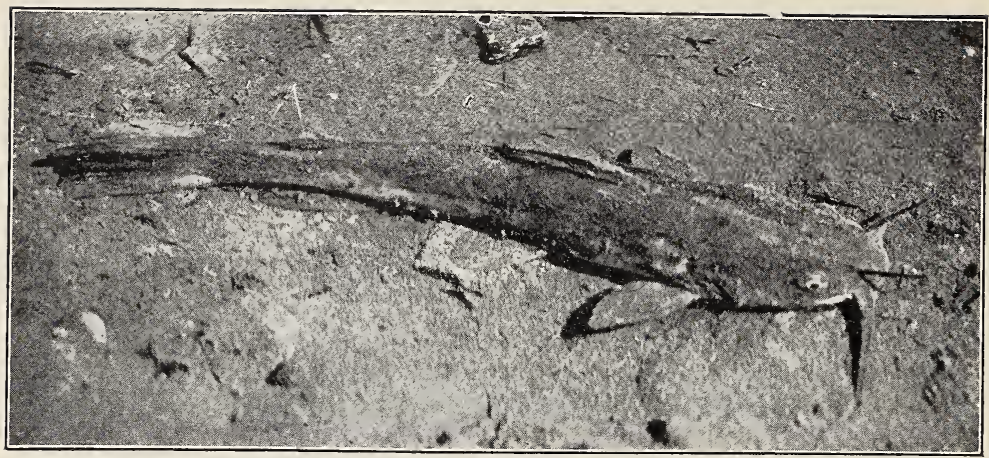

Bullhead at bottom of a pond.

Photo by Verne Morton.

\section{THE BULLHEAD}

\section{Teacher's Story}

"The bull-head does usually dwell and hide himself in holes or amongst stones in clear water; and in very hot days will lie a long time very still and sun himseif and will be easy to be seen on any flat stone or gravel; at which time he will suffer an angler to put a hock baited with a small worm very near into his mouth; and he never refuses to bite, nor indeed, to be caught with the worst of anglers." -ISAAK WALTON.

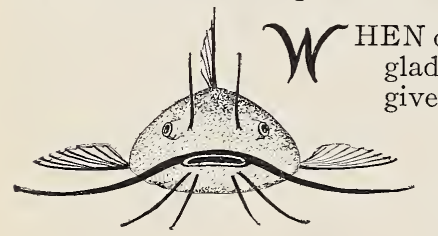

glad that it is not a ral bull for its bacbe

give that it is not a real bull for its barbels it an appearance quite fit for the making of a nightmare; and yet from the standpoint of the bullhead, how truly beautiful those fleshy feelers are! For without them how could it feel its way about searching for food in the mud where it lives? Two of these barbels stand straight up; the two largest ones stand out on each side of the mouth, and two pairs of short ones adorn the lower lip, the smallest pair at the middle.

As the fish moves about, it is easy to see that the large barbels at the side of the mouth are of the greatest use; it keeps them in a constantly advancing movement, feeling of everything it meets. The upper ones stand straight up, keeping watch for whatever news there may be from above; the two lower ones spread apart and follow rather than precede the fish, seeming io test what lies below. The upper and lower pairs seem to test things as they are, while the large side pair deal with what is going to be. The broad mouth seems to be formed for taking in all things eatable, for the bullhead lives on almost anything alive or dead that it discovers as it noses about in the mud. Nevertheless, it has its notions about its food for I have repeatedly seen one draw material into its mouth through its breathing motion and then spew it out with a vehemence one would hardly expect from such a phlegmatic fish. 
Although it has feelers which are very efficient, it also has perfectly good eyes which it uses to excellent purpose; note how promptly it moves to the other side of the aquarium when we are trying to study it. The eyes are not large; the pupils are black and oval and are rimmed with a narrow band of shiny pale yellow. The eyes are prominent so that when moved backward and forward they gain a view of the enemy in the rear or at the front while the head is motionless. It seems strange to see such a pair of pale yellow, almost white eyes in such a dark body.

The general shape of the front part of the body is flat, in fact, it is decidedly polywogy; this shape is especially fitted for groping about muddy bottoms. The flat effect of the body is emphasized by the gill. covers opening below rather than at the sides, every pulsation widening the broad neck. The pectoral fins also open out on the same plane as the body although they can be turned at an angle if necessary; they are thick and fleshy and the sharp tips of their spines offer punishment to whomsoever touches them. The dorsal fin is far forward and not large; it is usually raised at a threatening angle.

There is a little fleshy dorsal fin near the tail which stands in line with the body and one wonders what is its special use. The ventral fins are small. The anal fin is far back and rather strong, and this with the long, strong tail gives the fish good motor power and it can swim very rapidly if occasion requires.

The bullhead is mud-colored and has no scales; and since it lives in the mud, it does not need scales to protect it; but because of its scaleless condition it is a constant victim of the lampreys, and it would do well, :ndeed, if it could develop an armor of scales against this parasite. The

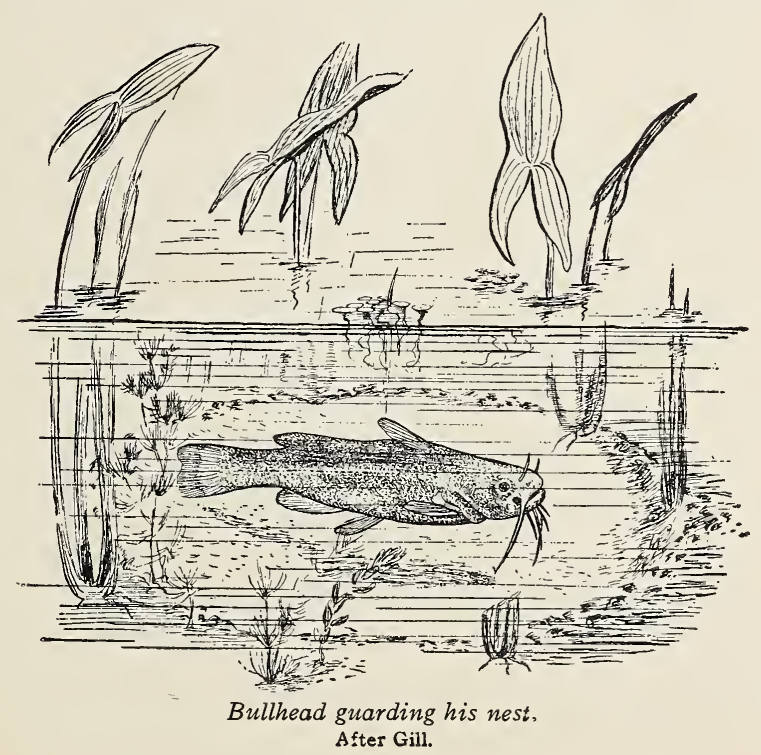


skin is very thick and leathery so that it is always removed before the fish is cooked. The bullhead is the earliest fish of the spring. This is probably because it burrows deep into the mud in the fall and remains there all winter; when the spring freshets come, it emerges and is hungry for fresh meat.

The family life of the bullheads and other catfishes seems to be quite ideal. Dr. Theodore Gill tells us that bullheads make their nests by removing stones and gravel from a more or less irregularly circular area in shallow water, and on sandy or gravelly ground. The nest is somewhat excavated, both parents removing the pebbles by sucking them into the mouth and carrying them off for some distance. After the eggs are laid, the male watches over and guards the nest and seems to have great family responsibilities. He is the more active of the two in stirring and mixing the young fry after they are hatched. Smith and Harron describe the process thus: "With their chins on the bottom, the old fish brush the corners where the fry were banked, and with the barbels all directed forward, and flexed where they touch the bottom, thoroughly agitate the mass of fry, bringing the deepest individuals to the surface. This act is usually repeated several times in quick succession."

"The nests are usually made beneath logs or other protecting objects and in shallow water. The paternal care is continued for many days after the birth of the young. At first these may be crowded together in a dense mass, but as time passes they disperse more and more and spread around the father. Frequently, especially when the old one is feeding, some-one or more- of the young are taken into the mouth, but they are instinctively separated from the food and spit out. At last the young swarm venture farther from their birthplace, or perhaps they are led away by their parents."

\section{LESSON XXXVII}

\section{The Bullhead, or Horned Pout}

Leading thought-The bullhead lives in mud bottoms of streams and ponds and is particularly adapted for life in such locations.

Method-A small bullhead may be placed in a small aquarium jar. At first let the water be clear and add a little pond weed so as to observe the natural tendency of the fish to hide. Later add mud and gravel to the aquarium and note the behavior of the fish.

Observations-I. What at the first glance distinguishes the bullhead from other fish? Describe these strange "whiskers" growing about the mouth; how many are there and where are they situated? Which are the longest pair? Can the fish move them in any direction at will?

2. Where do we find bullheads? On what do they feed? Would their eyes help them to find their food in the mud? How do they find it?

3. Explain, if you can, why the bulthead has barbels, or feelers, while the trout and bass have none.

4. What is the shape of the bullhead's mouth?

5. What is the general shape of the body? What is its color? Has it any scales?

6. Why should the bullhead be so flat horizontally while the sunfish is so flat in the opposite direction? 
7. Describe the bullhead's eyes. Are they large? What is their color? Where are they placed?

8. Describe the dorsal fin, giving its comparative size and position. Do you see another dorsal fin? Where is this peculiar fin and how does it differ from the others?

9. Describe the tail fin. Does it seem long and strong? Is the bullhead a good swimmer? fish?

Io. Is the anal fin large or small as compared with that of the gold-

II. How do the pectoral fins move as compared with those of the sunfish? Why is the position of the pectoral and dorsal fins of benefit to this fish?

I 2. How does the bullhead inflict wounds when it is handled? Tell how these spines protect it from its natural enemies.

I3. When is the best season for fishing for bullheads? Does the place where they are found affect the flavor of their flesh? Why?

I4. What is the spawning season? Do you know about the nests the bullheads build and the care they give their young?

I5. Write an essay on the nest-making habits of the bullheads and the care given the young by. the parents.

\begin{abstract}
"And what fish will the natural boy naturally take? In America, there is but one fish which enters fully into the spirit of the occasion. It is a fish of many species according to the part of the country, and of as many sizes as there are sizes of boys. This fish is the horned pout, and all the rest of the species of Ameiurus. Horned pout is its Boston name. Bullhead is good enough for New York; and for the rest of the country, big and little, all the fishes of this tribe are called catfish. A catfish is a jolly blundering sort of a fish, a regular Falstaff of the ponds. It has a fat jowl, and a fat belly, which it is always trying to fill. Smooth and sleek, its skin is almost human in its delicacy. It wears a long mustache, with scattering whiskers of other sort. Meanwhile it always goes armed with a sword, three swords, and these it has always on hand, always reaciy for a struggle on land as well as in the water. The small boy often gets badly stuck on these poisoned daggers, but, as the fish knows how to set them by a muscular twist, the small boy learns how, by a like untwist, he may unset and leave them harmless.

The catfish lives in sluggish waters. It loves the millpond best of all, and it has no foolish dread of hooks when it goes forth to bite. Its mouth is wide. It swallows the hook, and very soon it is in the air, its white throat gasping in the untried element. Soon it joins its fellows on the forked stick, and even then, uncomfortable as it may find its new relations, it never loses sight of the humor of the occasion. Its large head and expansive forehead betoken a large mind. It is the only fish whose brain contains a Sylvian fissure, a piling up of tissue consequent on the abundance of gray matter. So it understands and makes no complaint. After it has dried in the sun for an hour, pour a little water over its gills, and it will wag its tail, and squeak with gratitude. And the best of all is, there are horned pouts enough to go around."

"The female horned pout lays thousands of eggs, and when these hatch, she goes about near the shore with her school of little fishes, like a hen with myriad chicks. She should be respected and let alone, for on her success in rearing this breed of "bullying little rangers" depends ine sport of the small boy of the future."
\end{abstract}




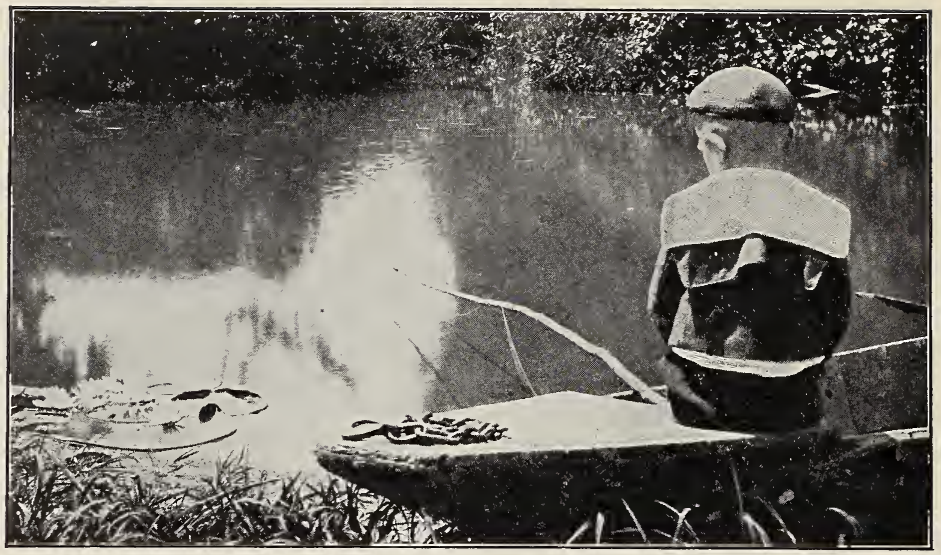

Fishing for suckers.

Photo by Verne Morton.

\section{THE COMMON SUCKER}

\section{Teacher's Story}

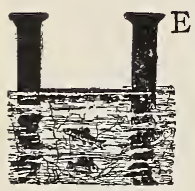

$\mathrm{E}$ who loves to peer down into the depths of still waters, often sees upon the sandy, muddy or rocky bottom several long, wedge-shaped sticks lying at various angles one to another. But if he thrust down a real stick, behold, these inert, water-logged sticks move off deftly! And then he knows that they are suckers. He may drop a hook baited with a worm in front of the nose of one, and if he waits long enough before he pulls up he may catch this fish, not by its gills but by the pit of its stomach; for it not only swallows" the hook completely but tries to digest it along with the worm. Its food is made up of soft-bodied insects and other small water creatures; it is also a mud eater and manages to make a digestive selection from the organic material of silt. For this latter reason, it is not a desirable food fish aithough its flesh varies in flavor with the locality where it is found. The suckers taken along the rocky shores of Cayuga Lake are fairly palatable, while those taken in the mud of the Cayuga Inlet are very inferior in flavor and often uneatable.

Seen from above, the sucker is wedge-shaped, being widest at the eyes; seen from the side it has a flat lower surface and an ungracefully rounded contour above which tapers only slightly toward the tail. The profile of the face gives the impression of a Roman nose. The young specimens have an irregular scale-mosaic pattern of olive-green blotches on a paler ground color, while the old ones are quite brown above and on the sides. The suckers differ from most other fishes in having the markings of the back extend down the sides almost to the belly. This is a help in concealing the fish, since its sides show from above quite as distinctly as its back 
because of its peculiar form. The scales are rather large and are noticeably larger behind than in the region of the head. Like other fish it is white below.

The dorsal fin is placed about midway the length of the fish as measured from nose to tail. It is not large and appears to have twelve rays; but there is a short spine in front and a delicate soft ray behind so that it really has fourteen. The tail is long and strong and deeply notched: the anal fin extends back to where the tail begins. The ventrai fins are small and are directly opposite the hind half of the dorsal fin. The pectorals are not large but are strong and are placed low down. The sucker has not a lavish equipment of fins but its tail is strong and it can swim swiftly; it is also a tremendous jumper; it will jump from the aquarium more successfully than any other fish. When resting on the bottom, it is supported by its extended pectoral and ventral fins, which are strong although not large.

The eyes are fairly large but the iris is not shiny; they are placed so that the fish can easily see above it as well as at the sidcs; the eyes move so as to look up or down and are very well adapted to serve a fish that lives upon the bottom. The nostrils are divided, the partition projecting until it seems a tubercle on the face. The mouth opens below and looks like the puckered opening of a bag. The lips are thick but are very sensitive; it is by projecting these lips, in a way that reminds one of a very short elephant's trunk, that it is enabled to reach and find its food in the mud or gravel; so although the sucker's mouth is not a beautiful feature, it is doubly useful. The sucker has the habit of remaining motionless for long periods of time. It breathes very slowly and appears sluggish; it never seizes its food with any spirit but simply slowly engulfs it; and for this reason it is considered poor game. It is only in the spring when they may be speared through the.ice that there is any fun in catching suckers; it is at this season of the year that they move to shallow water to spawn; those in the lakes move to the rivers, those in the rivers to the creeks, those in the creeks to the brooks. Even so lowly a creature as the sucker seems to respond to influences of the springtime, for at that period the male has a faint rosy stripe along his sides. In the winter these Îsh burrow in the mud of the river or pond bottoms; they may be frozen and thawed without harming them.

There are many species of suckers and they vary in size from six inches to three feet in length. They inhabit all sorts of waters, but they do not like a strong current and are, therefore, found in still pools. The common sucker (Catostomus commersoni), which is the subject of this lesson, sometimes attains the length of twenty-two inches and the weight of five pounds. The ones under observation were about eight inches long, and proved to be the acrobats of the aquarium, since they were likely at any moment to jump out; several times I found one languishing on the floor. 


\section{LESSON XXXVIII}

\section{The Common Sucker}

Leading thought-The sucker is especially adapted by shape for lying on the bottom of ponds under still water where its food is abundant.

Method-If still water pools along river or lakesides are accessible, it is far more interesting to study a sucker in its native haunts, as an introduction to the study of its form and colors when it is in the aquarium.

Observations - I. Where do you find suckers? How do you catch them? Do they take the hook quickly? What is the natural food of the sucker?

2. What is the shape of this fish's body when seen from above? From the side? What is the color above? On the sides? Below? Does the sucker differ from most other fishes in the coloring along its sides? What is the reason for this? What do suckers look like on the bottom of the pond? Are they easily seen?

3. Describe or sketch a sucker, showing the position, size and shape of the fins and tail. Are its scales large or small? How does it use its fins when at rest? When moving? Is it a strong swimmer? Is it a high jumper?

4. Describe the eyes; how are they especially adapted in position and in movement to the needs of a fish that lives on the bottom of streams and ponds?

5. Note the nostrils; what is there peculiar about them?

6. Where is the mouth of the sucker situated? What is its form? How is it adapted to get the food which the sucker likes best?

7. Tell all you know about the habits of the suckers. When do you see them first in the spring? Where do they spend the winter? Where do they go to spawn? How large is the largest one you have ever seen? Why is their flesh usually considered poor in quality as food? Is there a difference in the flavor of its flesh depending upon the locality in which the fish lives? Why?

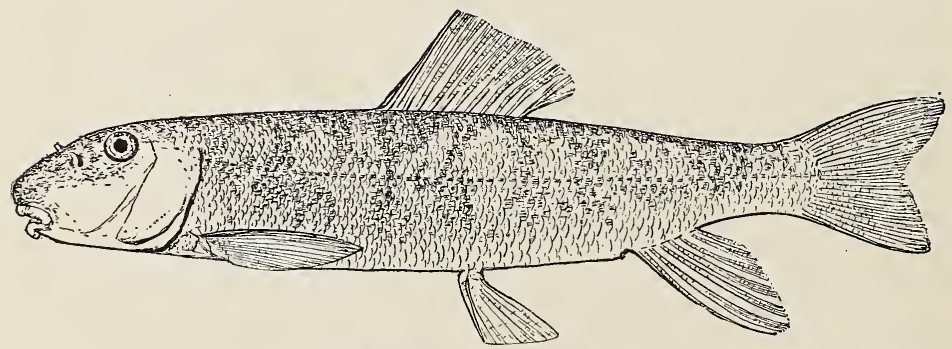

The common sucker. 


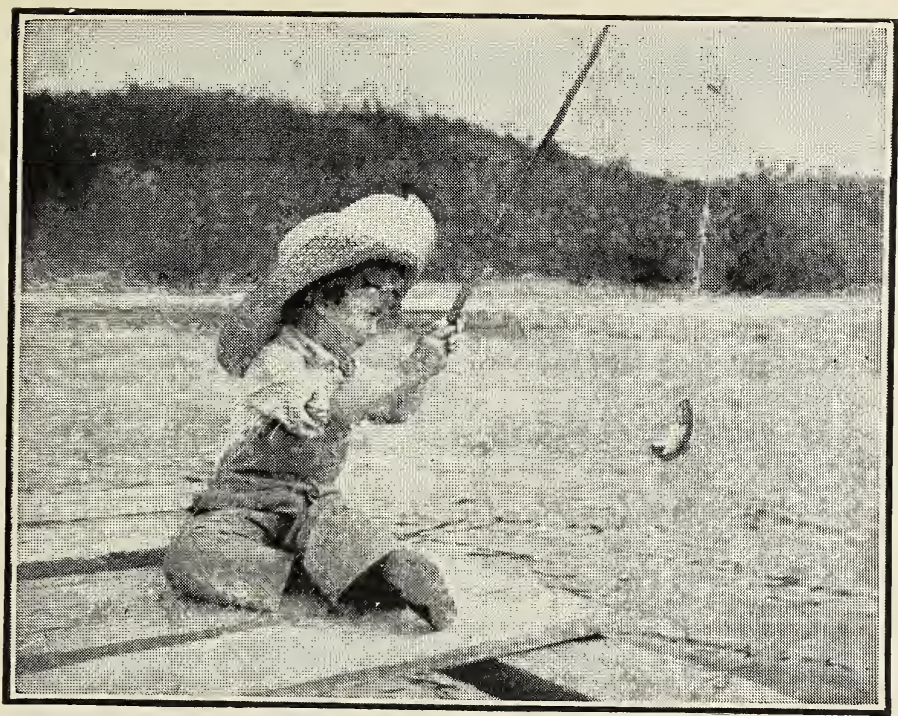

"I'm only wishing to go a fishing.",

\section{THE SHINER}

\section{Teacher's Story}

"This is a noteworthy and characteristic lineament, or cipher, or hieroglyphic, or type of spring. You look into some clear, sandy bottomed brook where it spreads into a deeper bay, yet flowing cold from ice and snow not far off, and see indistinctly poised over the sand on invisible fins, the outlines of the shiner, scarcely to be distinguished from the sands behind it as if it were transparent."-THOREAU.

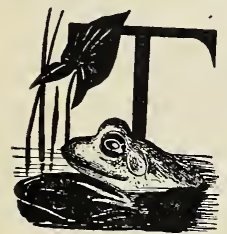

HERE are many species of shiners and it is by no means easy to recognize them nor to distinguish them from chub, dace and minnows since all these belong to one family; they all have the same arrangement of fins and live in the same water; and the plan of this lesson can with few changes be applied to any of them.

Never were seen more exquisite colors than shim mer along the sides of the common shiner (Notropis cornutus). It is pale olive-green above, just a sunny brook-color; this is bordered at the sides by a line of iridescent blue-purple, while the shining silver scales on the sides below, flash and glimmer with the changing hues of the rainbow. The minnows are darker than the shiners; the horned dace develops little tubercles on the head during the breeding season, which are lost later.

The body of the shiner is ideal for slipping through the water. Seen from above it is a narrow wedge, rounded in front and tapering to a point behind; from the side, it is long, oval, lance-shaped. The scales are large 
and beautiful, the lateral line looks like a series of dots embroidered at the center of the diamond-shaped scales.

The dorsal fin is placed just back of the center of the body and is not very large; it is composed of soft rays, the first two being stiff and unbranched. The tail is long, large, graceful and deeply notched. The anal fin is almost as large as the dorsal. The ventral pair is placed on the lower side, opposite the dorsal fin; the pectorals are set at the lower margin of the body, just behind the gill openings. The shiner and its relatives use the pectoral fins to aid in swimming, and keep them constantly in motion when moving through the water. The ventrals are moved only now and then and evidently help in keeping the balance. When the fish moves rapidly forward, the dorsal fin is raised so that its front edge stands at right angles to the body and the ventral and anal fins are expanded to their fullest extent. But when the fish is lounging, the dorsal, anal and ventral fins are more or less closed, although the tip of the dorsal fin swings with every movement of the fish.

The eyes are large, the pupils being very large and black; the iris is pale yellow and shining; the whole eye is capable of much movement forward and back. The nostril is divided by a little projecting partition which looks like a tubercle. The mouth is at the front of the head; to see the capabilities of this mouth, watch the shiner yawn, if the water of the aquarium becomes stale. Poor fellow! He yawns just as we do in the effort to get more oxygen.

The shiners are essentially brook fish although they may be found in larger bodies of water. They lead a precarious existence, for the larger fish eat them in all their stages. They only hold their own by laying countless numbers of eggs. They feed on water insects and get even with their big fish enemies by eating their eggs. They are pretty and graceful little creatures and may be seen swimming up the current in the middle of the brook. They often occur in schools or flocks, especially when young.

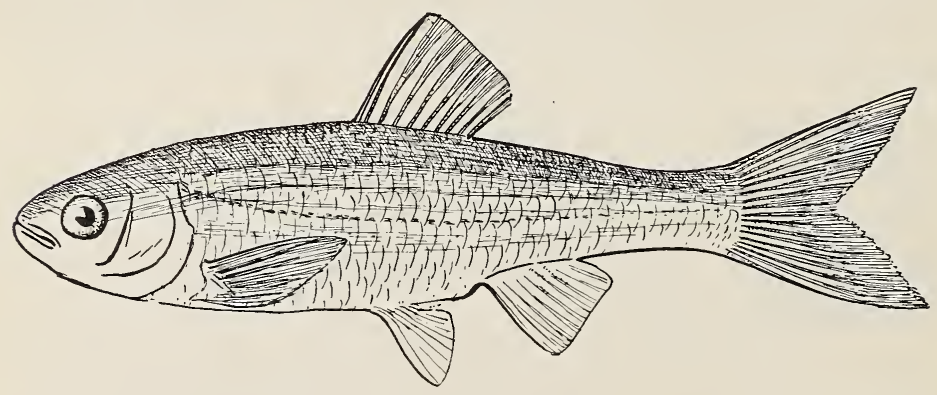

The common shiner. 


\section{LESSON XXXIX}

\section{The Shiner}

Leading thought-The shiners are among the most common of the little fish in our small streams. They are beautiful in form and play an important part in the life of our streams.

Method-Place in the aquarium shiners and as many as possible of the other species of small fish found in our creeks and brooks. The aquarium should stand where the pupil may see it often. The following questions may be asked, giving the children plenty of time for the work of observation:

Observations-I. Do you know how the shiner differs in appearance from the minnow and chub and dace?

2. What is the shape of the shiner's body when seen from above? When seen from the side? Do you think that its shape fits it for moving rapidly through the water?

3. What is the coloring above? On the sides? Below?

4. Are the scales large and distinct, or very small? Can you see the lateral line? Where are the tiny holes, which make this line, placed in the scales?

5. Describe or sketch the fish, showing position, relative size and shape of all the fins and the tail.

6. Describe the use and movements of each of the fins when the fish is swimming.

7. Describe the eyes. Do they move?

8. Describe the nostrils. Do you think each one is double?

9. Does the mouth open upwards, downwards or forwards? Have you ever seen the shiner yawn? Why does it yawn? Why do you yawn?

ro. Where do you find the shiners living? Do they haunt the middle of the stream or the edges? Do you ever see them in flocks or schools?

\section{MINNOWS}

How silent comes the water round that bend;

Not the minutest whisper does it send

To the o'er hanging sallows; blades of grass

Slowly across the chequer'd shadows pass,

Why, you might read two sonnets, ere they reach

To where the hurrying freshnesses aye preach

A natural sermon o'er their pebbly beds;

Where swarms of minnows show their little heads,

Staying their wavy bodies 'gainst the streams,

To taste the luxury of sunny beams

Tempered with coolness. How they ever wrestle

With their own sweet delight, and ever nestle

Their silver bellies on the pebbly sand!

If you but scantily hold out the hand,

That very instant not one will remain;

But turn your eye, and there they are again.

The ripples seem right glad to reach those cresses,

And cool themselves among the em'rald tresses;

The while they cool themselves, they freshness give,

And moisture, that the bowery green may live. 


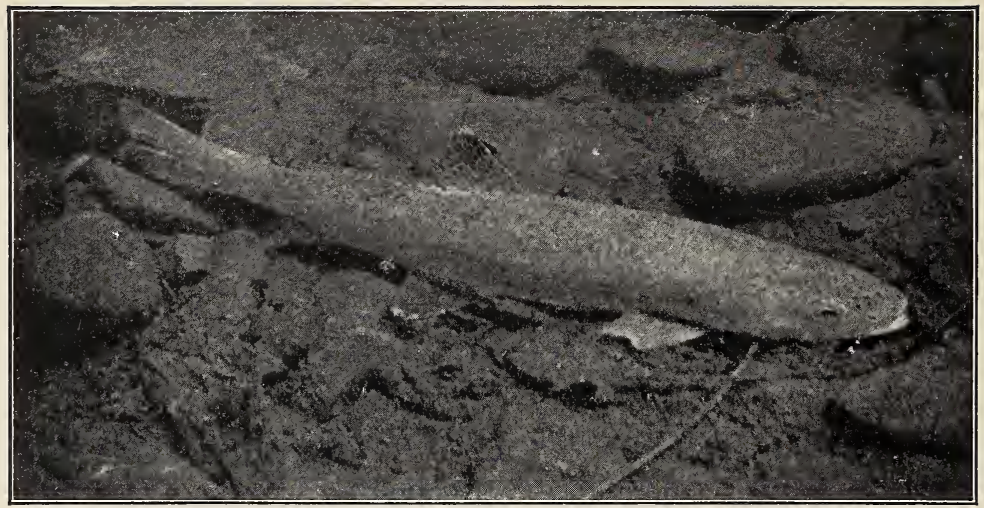

A speciled trout on a brook bottom.

Photo by Verne Morton.

\section{THE BROOK TROUT}

\section{Teacher's Story}

"Up and down the brook I ran, where beneath the banks so steep, Lie the spotted trout asleep."-WHitTIER.

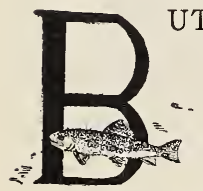

UT they were probably not asleep as Mr. Whittier might have observed if he had cast a fly near one of them. There is in the very haunts of the trout, a suggestion of where it gets its vigor and wariness: The cold, clear streams where the water is pure; brooks that wind in and out over rocky and pebbly beds, here shaded by trees and there dashing through the open, - it makes us feel vigorous even to think of such streams. Under the overhanging bank or in the shade of some fallen log or shelving rock, the brook trout hides where he may see all that goes on in the world above and around him without being himself seen. Woe to the unfortunate insect that falls upon the surface of the water in his vicinity or even that flies low over the surface for the trout will jump easily far out of the water to seize its prey! It is this habit of taking the insect upon and above the water's surface which has made trout fly-fishing the sport that it is. Man's ingenuity is fairly matched against the trout's cunning in this contest. I know of ore old trout that has kept fishermen in the region around on the qui vive for years; and up to date he is still alive, making a dash now and then at a tempting bait, showing himself enough to tantalize his would-be captors with his splendid size, but always retiring at the sight of the line.

The brook trout varies much in color, depending upon the soil and the rocks of the streams in which it lives. Its back is marbled with dark olive or black, making it just the color of shaded water. This marbled coloration also marks the dorsal and the tail fins. The sides, which vary much in color, are marked with beautiful vermilion spots, each placed in the center of a larger, brownish spot. In some instances the lower surface 
is reddish, in others whitish. All the fins on the lower side of the body have the front edges creamy or yellowish white, with a darker streak behind.

The trout's head is quite large and somewhat blunt. The large eye is a little in front of the middle of the head. The dorsal fin is at about the middle of the body, and when raised is squarish in outline. Behind the dorsal fin, and near to the tail is the little, fleshy adipose fin, so called because it has no rays. The tail is fan-shaped, slightly notched at the end and is large and strong. The anal fin is rather large, being shaped much like the dorsal fin, only slightly smaller. The ventral fins are directly below the dorsal fin and a little behind its middle. The pectorals are low down, being below and just behind the gill arches.

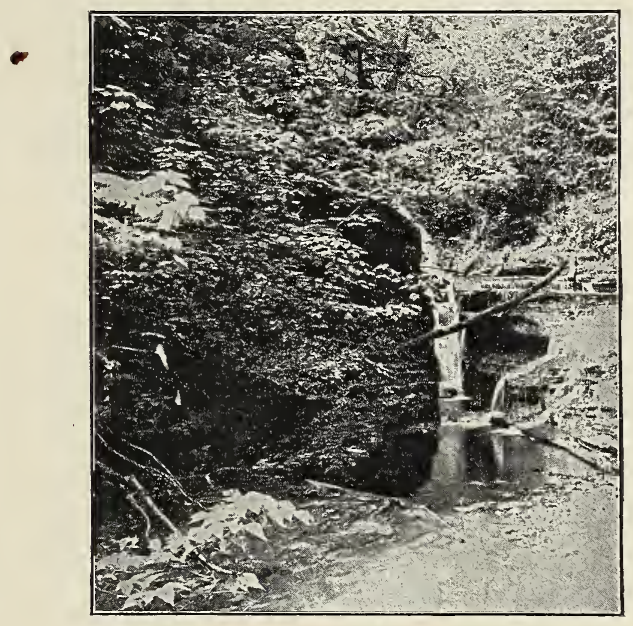

Where the trout hide.

In size the brook trout seldom is longer than seven or eight inches, but in the rivers of the Northeastern United States specimens weighing from six to eleven pounds are sometimes taken. It does not flourish in water which is warmer than $68^{\circ}$, but prefers a temperature of about $50^{\circ}$. It must have the pure water of mountain streams and cannot endure water of rivers which is polluted by mills or the refuse of cities. Where it has access to streams that flow into the ocean, it forms the salt water habit, going out to sea and remaining there during the winter. Such specimens become very large.

The trout can lay eggs when about six inches in length. The eggs are laid from September until late November, although, as Mr. Bream says, the brook trout are spawned at some locality in almost every month of the year except mid-summer. One mother trout lays from 400 to 600 eggs, but the large-sized ones lay more. The period of hatching depends upon the temperature of the water. In depositing their eggs the trout seek water with gravelly bottom, often where some mountain brook opens into 
a larger stream. The nest is shaped by the tail of the fish, the larger stones being carried away in the mouth. To make the precious eggs secure they are covered with gravel.

There have been strict laws enacted by almost all of our states with a view to protecting the brook trout and preserving it in our streams. The open season in New York is from the r 5 th of April to the Ist of September, and it is illegal to take from a stream a fish that is less than five inches in length. It is the duty of every decent citizen to abide by these laws and to see to it that his neighbors observe them. The teacher cannot emphasize enough upon the child the moral value of being law-abiding. There should be in every school in the Union children's clubs which should have for their purpose civic honesty and the enforcement of laws which affect the city, village or township.

Almost any stream with suitable water may be stocked with trout from the national or the state hatcheries, but what is the use of this expense if the game laws are not observed and these fish are caught before they reach maturity, as is so often the case?

References-American Food and Game Fishes, Jordan \& Everman; Guide to American Fishes, Jordan.

\section{LESSON XL \\ The Brook Trout}

Leading thought-The brook trout have been exterminated in our streams largely because the game laws have not been observed. The trout is the most cunning and beautiful of our common fishes and the most valuable for food. If properly guarded, every pure mountain stream in our country, could be well stocked with the brook trout.

Method-A trout may be kept in an aquarium of flowing water indefinitely and should be fed upon liver and hard clams chopped. If there is no aquarium with running water, the trout may be kept in an ordinary jar long enough for this lesson. The object of this lesson should be not only the study of the habits of the fish, but also a lesson in its preservation.

Observations-r. In what streams are the brook trout found? Must the water be warm or cold? Can the trout live in impure water? Can it live in salt water?

2. Do the trout swim about in schools or do they live solitary? Where do they like to hide?

3. With what kind of bait is trout caught? Why does it afford such excellent sport for fly-fishing? Can you tell what the food of the trout is?

4. What is the color of the trout above? What colors along its sides? What markings make the fish so beautiful? What is its color below? Has the trout scales? Do you see the lateral line?

5. What is the general shape of the brook trout? Describe the shape, position and color of the dorsal fin. Describe the little fin behind the dorsal. Why is it unlike the other fins? What is the shape of the tail fin? Is it rounded, square or crescent-shaped across the end? What is the position and size of the anal fin compared with the dorsal? What colors on the ventral fins and where are they placed in relation to the 
dorsal fin? What color are the pectoral fins and how are they placed in relation to the gill arches?

6. Describe the trout's eyes. Are they large and alert? Do you think the trout is keen-sighted?

7. When and where are the eggs laid? Describe how the nest is made. How are the eggs covered and protected?

8. Why are there no trout in the streams of your neighborhood? Could a trout live in these streams? Can you get state aid in stocking the streams?

9. What are the game laws concerning trout fishing? When is the open season? How long must the trout be to be taken legally? If you are a good citizen what do you do about the game laws?

Io. Write a story telling all you know about the wariness, cunning and strength of the brook trout.

Supplementary reading-The following from Fish Stories by Holder and Jordan: "The Trout of Los Laurelles;" "The Golden Trout of the High Sierras;" "The Lure of the Rainbow." "The Story of the Salmon" in Science Sketches, "The Master of the Golden Pool" in Watchers of the Trails; The Story of the Fishes, Baskett; Neighbors with Wings and Fins, Johonnet.

\section{TROUT}

"It is well for anglers not to make trout, of all fishes, the prime objective of a day's sport, as no more uncertain game loves the sunlight. Today he is yours for the very asking, tomorrow, the most luscious lure will not tempt him. One hour he defies you, the next, gazes at you from some ensconcement of the fishes, and knows you not, as you pass him, casting, by.

$I$ believe I accumulated some of this angling wisdom years ago, in a certain trout domain in New England, where there were streams and pools, ripples, cascades and drooping trees; where everything was fair and promising to the eyes for trout; but it required superhuman patience to lure them, and many a day I scored a blank. Yet on these very days when lures were unavailing, the creel empty save for fern leaves, I found they were not for naught; that the real fishing day was a composite of the weather, the wind, even if it was from the east, the splendid colors of forest trees, the blue tourmaline of the sky that topped the stream amid the trees, the flecks of clond mirrored on the surface. The delight of anticipation, the casting, the play of the rod, the exercise of skill, the quick turns in the steam opening up new vistas, the little openings in the forest. thirough which were seen distant meadows and nodding flowers - all these went to make up the real trout fishing, the actual catch being but an incident among many delights.

Just how long one could be content with mere scenery in lieu of trout, I am not prepared to say: if pushed to the wall, I confess that when fishing I prefer trout to scenic effects. Still, it is a very impracticable and delightful sentiment with some truth to it, the moral being that the angler should be resourceful, and not br entirely cast down on the days when the wind is in the east

I am aware that this method of angling is not in vogue with some, and would be deemed fanciful, indeed inane, by many more; yet it is based upon a true and homely philosophy, not of today, the philosophy of patience and contentment. "How poor are they that have not patience," said Othello. It is well to be content with things as we find them, and it is well to go a-fishing, not to catch fish alone, but every offering the day has to give. This should be an easy matter for the angler, as Walton tells us that Angling is somewhat like poetry; men are to be born so." 


\section{THE STICKLEBACK}

\section{Teacher's Story}

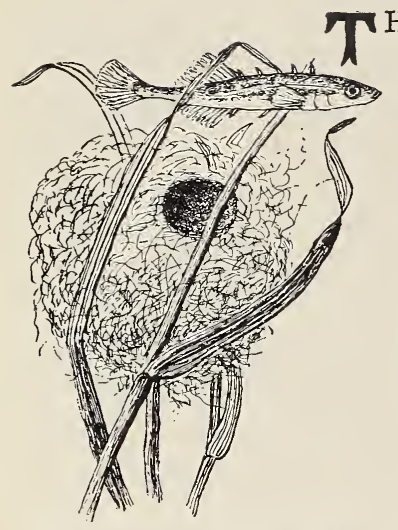

Stickleback guarding his nest. Drawn from nature.

HIS is certainly the most sagacious of the Lilliputian vertebrates; scarcely more than an inch in length when full-grown, it gazes at you with large, keen, shiningrimmed eyes, takes your measure and darts off with a flirt of the tail that says plainly, "Catch me if you can." The sticklebacks are delightful aquarium pets because their natural home is in still water sufficiently stagnant for algæ to grow luxuriously; thus we but seldom need to change the water in the aquarium, which, however, should be well stocked with water plants and have gravel at the bottom.

When the stickleback is not resting he is always going somewhere and he knows just where he is going and what he is going to do, and earthquakes shall not deter him. He is the most dynamic creature in all creation, I think, except perhaps the dragon fly, and he is so ferocious that if he were as large as a shark he would destroy all other fishes. Place an earthworm, cut into small sections, in the aquarium and while each section is wriggingly considering whether it may be able to grow both ends into another worm, the stickleback takes hold with a will and settles the matter in the negative. His ferocity is frightful to behold as he seizes his prey and shakes it as a terrier does a rat.

Well is this fish named stickleback, for along the ridge of its back are sharp, strong spines-five of them in our tiny, brook species. These spines may be laid back flat or they may be erected stiffly, making an efficient saw which does great damage to fish many times larger than the stickleback. When we find the minnows in the aquarium losing their scales we may be sure they are being raked off by this saw-back; and if the shiner or sunfish undertakes to make a stickleback meal, there is only one way to do it, and that is to catch the quarry by the tail, since he is too alert to be caught in any other way. But swallowing a stickleback tail first is a dangerous performance, for the sharp spines rip open the throat or stomach of the captor. Dr. Jordan says that the sticklebacks of the Puget Sound region are called "salmon killers" and that they well earn the name; these fierce midgets unhesitatingly attack the salmon, biting off pieces of their fins and also destroying their spawn.

As seen from the side, the stickleback is slender and graceful, pointed like an arrow at the front end, and with the body behind the dorsal fin forming a long and slender pedicel to support the beautifully rounded tail fin. The dorsal fin is placed well back and is triangular in shape; the anal fin makes a similar triangle opposite it below and has a sharp spine at its front edge. The color of the body varies with the light; when floating among the water weed the back is greenish mottled with paler green, but when the fish is down on the gravel it is much darker. The lateral line is marked by a rather broad silver stripe. 
If targe eyes count for beauty, then the stickleback deserves "the apple," for its eyes are not only large but gemlike, with a broad iris of golden brown around the black pupil. I am convinced that the stickleback has a keener vision than most fish; it can move its eyes backward and forward rapidly and alertly. The mouth opens almost upward and is a wicked little mouth, both in appearance and action.

When swimming, the stickleback darts about rapidly, its dorsal and anal fins extended, its spines all abristle, its tail lashing the water with strong strokes and the pectorals flying so fast that they make a blur; the ventral fins are rarely extended, in fact they are nothing but two little spines. When the fish wishes to lift itself through the water it seems to depend entirely upon its pectoral fins and these are also used for balancing. Its favorite position is hanging motionless among the pond weeds, with the tail, the dorsal and ventral fins partially closed; it usually rests upon the pectoral fins which are braced against some stem; in one case I saw the ventrals and pectorals used together to clasp a stem and hold the fish in place. In moving backward the pectorals do the work, with a little beckoning motion of the tail occasionally. When resting upon the bottom of the aquarium, it closes its fins and makes itself quite inconspicuous. It can dig with much power accomplishing this by a comical augerlike motion; it plunges head first into the gravel and then by twisting the body and tail around and around, it soon forms a hiding place.

But it is as a house builder and father and home protector that the stickleback shires. In the early spring he builds him a nest made from the fine green algæ called frog-spittle. This would seem a too delicate material for the house construction, but he is a clever builder. He fastens his filmy walls to some stems of reed or grass, using as a platform a supporting stem; the ones which I have especially studied were fastened to grass stems. The stickleback has a little cement plant of his own, supposed to be situated in the kidneys, which at this time of year secrete the glue for building purposes. The glue is waterproof. It is spun out in fine threads or in filmy masses through an opening near the anal fin. One species weights his platform with sand which he scoops up from the bottom, but I cannot detect that our brook stickleback does this. In his case, home is his sphere literally, for he builds a spherical house about the size of a glass marble, three-quarters of an inch in diameter; it is a hollow sphere and he cements the inside walls so as to hold them back and give room, and he finishes his pretty structure with a circular door at the side. When finished, the nest is like a bubble, made of threads of down and yet it holds together strongly.

In the case of the best known species, the male, as soon as he has finished his bower to his satisfaction, goes a-wooing; he selects some lady stickleback, and in his own way tells her of the beautiful nest he has made and convinces her of his ability to take care of a family. He certainly has fetching ways for he soon conducts her to his home. She enters the nest through the little circular door, lays her eggs within it, and then being a flighty creature, she sheds responsibilities and flits off care free. $\mathrm{He}$ follows her into the nest, scatters the fertilizing milt over the eggs and then starts off again and rolls his golden eyes on some other lady stickleback and invites her also to his home; she comes without any jealousy because she was not first choice, and she also enters the nest and lays her 
eggs and then swims off unconcernedly. Again he enters the nest and drops more milt upon the eggs and then fares forth again, a still energetic wooer. If there was ever a justified polygamist, he is one, since it is only the cares and responsibilities of the home that he desires. He only stops wooing when his nest holds as many eggs as he feels equal to caring for. He now stands on guard by the door, and with his winnowing pectoral fins, sets up a current of water over the eggs; he drives off all intruders with the most vicious attacks, and keeps off many an enemy simply by a display of reckless fury; thus he stands guard until the eggs hatch and the tiny little sticklebacks come out of the nest and float off, attaching themselves by their mouths to the pond weeds until they become strong enough to scurry around in the water.

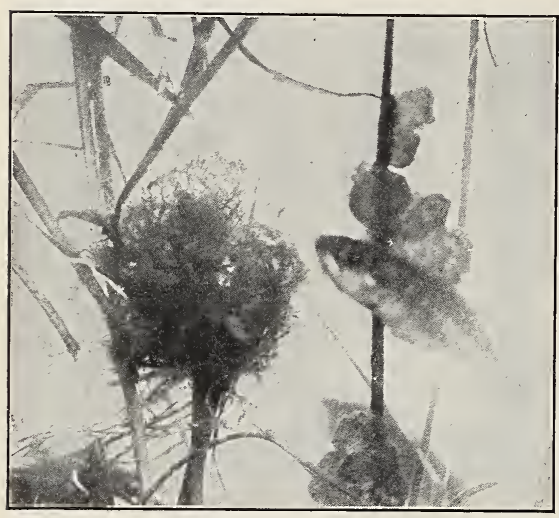

The five-spined stickleback and his nest. Photo by Eugene Barker.

Some species arrange two doors in this spherical nest so that a current of water can flow through and over the eggs. Mr. Eugene Barker, who has made a special study of the little fivespined sticklebacks of the Cayuga Basin, has failed to find more than one door to their nests. Mr. Barker made a most interesting observation on this stickleback's obsession for fatherhood. He placed in the aquarium two nests, one of which was guarded by its loyal builder, which allowed himself to be caught rather than desert his post; the little guardian soon discovered the unprotected nest and began to move the eggs from it to his own, carrying them carefully in his mouth. This addition made his own nest so full that the eggs persistently crowded out of the door, and he spent much of his time nudging them back with his snout. We saw this stickleback fill his mouth with algæ from the bottom of the aquarium, and holding himself steady a short distance away, apparently blow the algæ at the nest from a distance of half an inch, and we wondered if this was his method of laying on his building materials before he cemented thern.

The eggs of this species are white and shining like minute pearls, and seem to be fastened together in small packages with gelatinous matter. The mating habits of this species have not been thoroughly studied; therefore, here is an opportunity for investigation on the part of the buys and girls. 


\section{LESSON XLI}

\section{The Stickleback}

Leading thought-The stickleback is the smallest of our common fish. It lives in stagnant water. The father stickleback builds his pretty nest of frog-spittle which he watches very carefully.

Method-To find sticklebacks go to a pond of stagnant water which does not dry up during the year. If it is partly shaded by bushes so much the better. Take a dip net and dip deeply; carefully examine all the little fish in the net by putting them in a Mason jar of water so that you can see what they are like. The stickleback is easily distinguished by the five spines along its back. If you collect these fish as early as the first of May and place several of them in the aquarium with plenty of the algæ known as frog-spittle and other water plants they may perhaps build a nest for you. They may be fed upon bits of meat or liver chopped very fine or upon earthworms cut into small sections.

Observations-r. How did the stickleback get its name? How many spines has it? Where are they situated? Are they always carried erect? How are these spines used as weapons? How do they act as a means of safety to the stickleback?

2. Describe or make a sketch showing the shape and position of the dorsal, the anal, the ventral and the pectoral fins. What is the shape of the tail? What is the general shape of the fish?

3. What is the color of the sticklebacks? Is the color always the same? What is the color and position of the lateral line?

4. Describe the eyes. Are they large or small? Can they be moved? Do you think they can see far?

5. Describe the mouth. Does it open upward, straight ahead or downward?

6. When the stickleback is swimming what are the positions and motions of the dorsal, anal, tail and pectoral fins? Can you see the ventral pair? Are they extended when the fish is swimming?

7. When resting among the pond weed of the aquarium what fins does the stickleback use for keeping afloat? How are the other fins held? What fins does it use to move backward? Which ones are used when it lifts itself from the bottom to the top of the aquarium? How are its fins placed when it is at rest on the bottom?

8. Drop a piece of earthworm or some liver or fresh meat cut finely into the aquarium and describe the action of the sticklebacks as they eat it. How large is a full-grown stickleback?

9. In what kind of ponds do we find sticklebacks? Do you know how the stickleback nest looks? Of what is it built? How is it supported? Is there one door or two? Does the father or mother stickleback build the nest? Are the young in the nest cared for? At what time is the nest built? Holder.

Supplementary reading-Fish-stories, Chap. XXXVI, Jordan and 

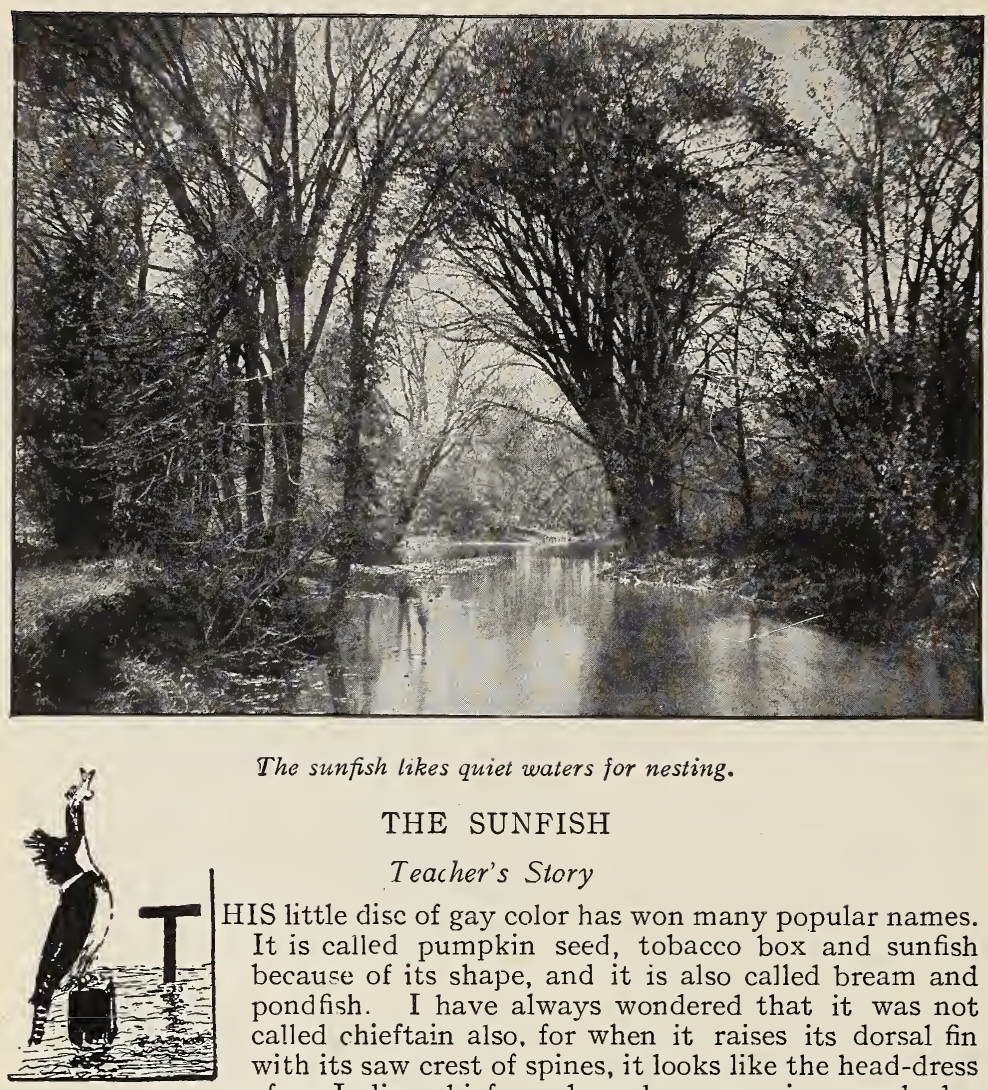

The sunfish likes quiet waters for nesting.

\section{THE SUNFISH}

\section{Teacher's Story}

HIS little disc of gay color has won many popular names. It is called pumpkin seed, tobacco box and sunfish because of its shape, and it is also called bream and pondfish. I have always wondered that it was not called chieftain also, for when it raises its dorsal fin with its saw crest of spines, it looks like the head-dress of an Indian chief; and surely no warrior ever had a greater enjoyment in a battle than does this indom-

itable little fish.

The sunfish lives in the eddies of our clear brooks and ponds. It is a near relative to the rock bass and also of the black bass and it has, according to its size, just as gamey qualities as the latter. I once had a sunfish on my line which made me think I had caught a bass and I do not know whether I or the mad little pumpkin seed was the most disgusted when I discovered the truth. I threw him back in the water but his fighting spirit was up, and he grabbed my hook again within five minutes, which showed that he had more courage than wisdom; it would have served him right if I had fried him in a pan, but I never could make up my mind to kill a fish for the sake of one mouthful of food.

Perhaps of all its names, "pumpkin seed" is the most graphic, for it resembles this seed in the outlines of its body when seen from the side. Looked at from above, it has the shape of a powerful craft with smooth. 
rounded nose and gently swelling and tapering sides; it is widest at the eyes and this is a canny arrangement, for these great eyes turn alertly in every direction; and thus placed they are able to discern the enemy or the dinner coming from any quarter.

The dorsal fin is a most militant looking organ. It consists of ten spines, the hind one closely joined to the hind dorsal fin, which is supported by the soft rays. The three front spines rise successively, one above another and all are united by the membrane, the upper edge of which is deeply toothed. The hind dorsal fin is gracefully rounded and the front and hind fin wo $\mathrm{k}$ independently of each other, the latter often winnowing the water when the former is laid flat. The tail is strong and has a notch in the end; the anal fin has three spines on its front edge and

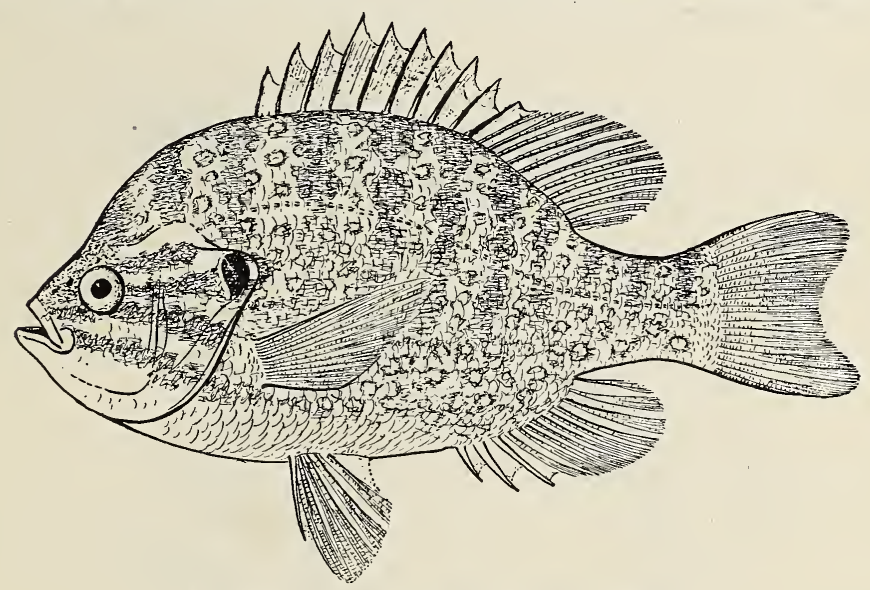

The pumpkin seed, the most common sunfish.

ten soft rays. Each ventral fin also has a spine at the front edge and is placed below and slightly behind the pectorals. The pectoral fins, I have often thought, were the most exquisite and gauzelike in texture of any fins I have ever seen; they are kept almost constantly in motion and move in such graceful flowing undulations that it is a joy to look at them.

The eye of the sunfish is very large and quite prominent; the large black pupil is surrounded by an iris that has shining lavender and bronze in it, but is more or less clouded above; the young ones have a pale silver iris. The eyes move in every direction and are eager and alert in their expression. The mouth is at the front of the body but it opens upward. The gill opening is prolonged backward at the upper corner, making an earlike flap; this, of course, has nothing to do with the fish's ears, but it is highly ornamental as it is greenish-black in color, bordered by iridescent, pale green, with a brilliant orange spot on its hind edge. The colors of the sunfish are too varied for description and too beautiful to reduce to mere words. There are dark, dull, greenish or purplish cross-bands worked out in patterns of scale-mosaic, and between them are bands of pale iridescent-green, set with black-edged orange spots. But just as we 
have described his colors our sunfish darts off and all sorts of shimmering, shining blue, green and purple tints play over his body and he settles down into another corner of the aquarium and his colors seem much paler and we have to describe him over again. The body below is brassy-yellow.

The beautiful colors which the male sunfish dons in spring, he puts at once to practical use. Professor Reighard says that when courting and trying to persuade his chosen one to come to his nest and there deposit her eggs, he faces her, with his gill covers puffed out, the scarlet or orange spot on the ear-flap standing out bravely, and his black ventral fins spread wide to show off their patent-leather finish. Thus, does he display himself before her and persuade her; but he is rarely allowed to do this in peace. Other males as brilliant as he arrive on the scene and he must forsooth stop parading before his lady love in order to fight his rival, and

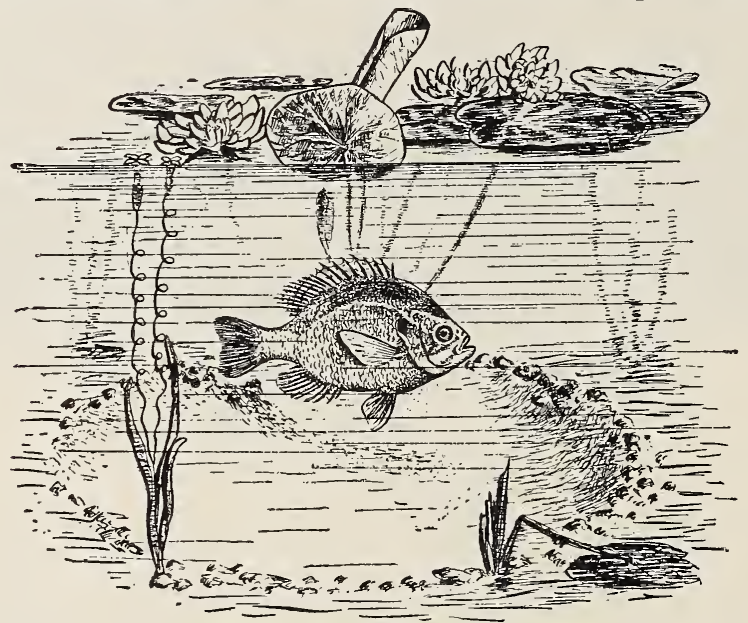

Male of the sunfish guarding his nest. After Gill

he fights with as much display of color as he courts. But in the sunfish duel the participants do not seek to destroy each other but to mutilate spitefully each other's fins. The vanquished one with his fins all torn retires from the field. Professor Gill says: "Meanwhile the male has selected a spot in very shallow water near the shore, and generally in a mass of aquatic vegetation, not too large or close together to entirely exclude the light and heat of the sun, and mostly under an over-hanging plant. The choice is apt to be in some general strip of shallow water close by the shore which is favored by many others so that a number of similar nests may be found close together, although never encroaching on each other. Each fish slightly excavates and makes a saucer-like basin in the chosen area which is carefully cleared of all pebbles. Such are removed by violent jerks of the caudal fin or are taken up by the mouth and carried to the circular boundary of the nest. An area of fine, clean sand or gravel is generally the result, but not infrequently, according to Dr. Reighard, the 
nest bottom is composed of the rootlets of water plants. The nest has a diameter of about twice the length of the fish."

On the nest thus formed, the sunfish belle is invited to deposit her eggs, which as soon as laid fall to the bottom and become attached to the gravel at the bottom of the nest by the viscid substance which surrounds them. Her duty is then done and she departs, leaving the master in charge of his home and the eggs. If truth be told, he is not a strict monogamist. Professor Reighard noticed one of these males which reared in one nest two broods laid at quite different times by two females. For about a week, depending upon the temperature, the male is absorbed in his care of the eggs and defends his nest with much ferocity, but after the eggs have hatched he considers his duty done and lets his progeny take care of themselves as best they may.

Sunfish are easily taken care of in an aquarium, but each should be kept by himself as they are likely to attack any smaller fish and are most uncomfortable neighbors. I have kept one of these beautiful, shimmering pumpkin seeds for nearly a year, by feeding him every alternate day with an earthworm; these unfortunate creatures are kept stored in damp soil in an iron kettle during the winter. When I threw one of them into the aquarium he would seize it and shake it as a terrier shakes a rat; but this was perhaps to make sure of his hold. Once he attempted to take the second worm directly after the first; but it was a doubtful proceeding, and the worm reappeared as often as a prima donna, waving each time a frenzied farewell to the world.

\section{LESSON XLI}

\section{The Sunfish}

Leading thought-The pumpkin seeds are very gamey little fishes which seize the hook with much fierceness. They live in the still waters of our streams or in poncs and build nests in the spring, in which the eggs are laid and which they defend valiantly.

Method-The common pumpkin seed in the jar aquarium is all that is necessary for this lesson. However, it will add much to the interest of the lesson if the boys who have fished for pumpkin seeds will tell of their experiences. The children should be stimulated by this lesson to a keeri interest in the nesting habits of the sunfishes.

Observations-I. Where are the sunfish found? How do they act when they take the hook?

2. What is the general shape of the sunfish's body as seen from above? As seen from the side? Why is it called pumpkin seed?

3. Describe the dorsal fin. How many spines has it? How many soft rays? What is the difference in appearance between the front and hind dorsal fin? Do the two act together or separately? Describe the tail fin. Describe the anal fin. Has it any spines? If so, where are they! Where are the ventral fins in relation to the pectorals? What is there peculiar about the appearance and movements of the pectoral fins?

4. Describe the eye of the sunfish. Is it large or small? Is it placed so that the fish can see on each side? Does the eye move in all directions?

5. Describe the position of the mouth. In which direction does it open? 
6. What is the color of the upper portion of the gill opening or operculum? What is the general color of the sunfish? Above? Below? Along the sides? What markings do you see?

7. Where does the sunfish make its nest? Does the father or mother sunfish make the nest? Do one or both protect it? Describe the nest.

8. How many names do you know for the sunfish? Describe the actions of your sunfish in the aquarium. How does he act when eating an earthworm?

Supplementary reading-Chapters XXX, XXXVI, in Fish Stories, Jordan and Holder.

"The lamprey is not a fish at all, only a wicked imitation of one which can deceivo nobody. But there are fishes which are unquestionably fish-fish from gills to tail, from head to fin, and of these the little sunfish may stand first. He comes up the brook in the spring, fresh as "coin just from the mint," finny arms and legs wide spread, his gills moving, his mouth opening and shutting rhythmically, his tail wide spread, and ready for any sudden motion for which his erratic little brain may give the order. The scales of the sunfish shine with all sorts of scarlet, blue, green and purple and golden colors. There is a black spot on his head which looks like an ear, and sometimes grows out in a long black flap, which makes the imitation still closer. There are many species of the sunfish, and there may be half a dozen of them in the same brook, but that makes no difference; for our purposes they are all one.

They. lie poised in the water, with all fins spread, strutting like turkey-cocks, snapping at worms and little crustaceans and insects whose only business in the brook is that the fishes may eat them. When the time comes, the sunfish makes its nest in the fine gravel, building it with some care-for a fish. When the female has laid her eggs the male stands guard until the eggs are hatched. His sharp teeth and snappish ways, and the bigness of his appearance when the fins are all displayed, keep the little fishes away. Sometimes, in his zeal, he snaps at a hook baited with a worm. He then makes a fierce fight, and the boy who holds the rod is sure that he has a real fish this time. But when the sunfish is out of the water, strung on a willow rod, and dried in the sun, the boy sees that a very little fish can make a good deal of a fuss."

-David Starr Jordan. 


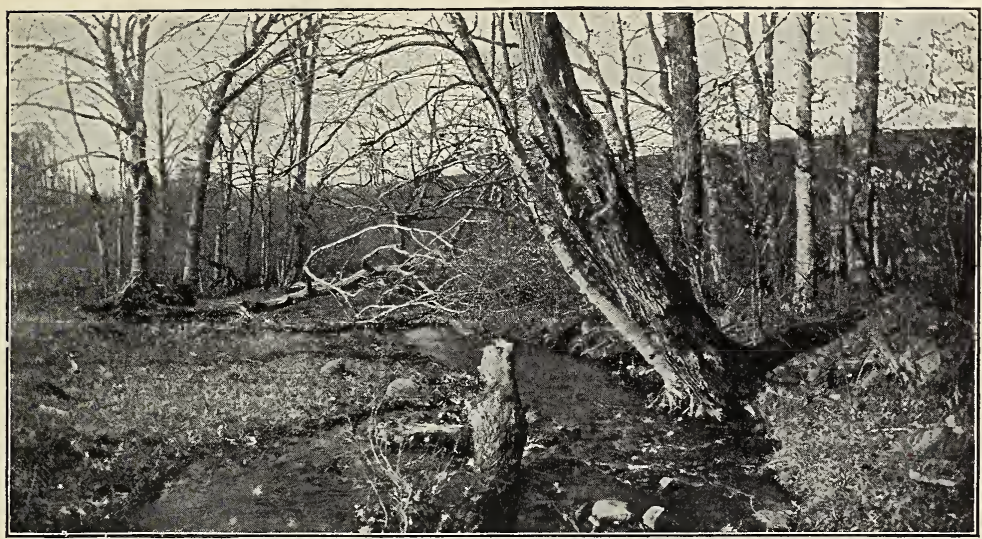

The johnny darter likes a swift-flowing brook

\section{THE JOHNNY DARTER}

\section{Teacher's Story}

"We never tired of watching the little Johnny, or Tessellated darter (Boleosoma nigrum), although our earliest aquarium friend, (and the very first specimens showed us by a rapid ascent of the river weed how 'a Johnny could climb trees,') he has still many resources which we have never learned. Whenever we try to catch him with the hand we begin with all the uncertainty that characterized our first attempts, even if we have him in a two-quart pail. We may know him by his short fins, his first dorsal having but nine spines, and by the absence of all color save a soft, yellowish brown, which is freckled with darker markings. The dark brown on the sides is arranged in seven or eight W-shaped marks, below which are a few flecks of the same color. Covering the sides of the back are the wavy markings and dark specks which have given the name of the "Tessellated Darter;" but Boleosoma is a preferred name, and we even prefer 'boly. for short. In the spring the males have the head jet black; and this dark color often extends on the back part of the body, so that the fish looks as if he had been taken by tho tail and dipped into a bottle of ink. But with the end of the nuptial season this cole. disappears and the fish regains his normul, strawy hue.

His actions are rather bird-like; for he will strike attitudes like a tufted titmous: and he flics rather than swims through the water. He will, with much perseverance push his body between a plant and the sides of the aquarium and balance himself on ." slender stem. Crouching catlike before a snail shell, he will snap off a horn which th.. unlucky owner pushes timudly out. But he is also less dainty and seizing the animur by the head, he dashes the shell against the glass or stones until he pulls the body out w breaks the shell."-DAvID STARR JORDAN.

The johnny darters are, with the sticklebacks, the most amusing little fish in the aquarium. They are well called darters since their movements are so rapid when they are frightened that the eye can scarcely follow them; and there is something so irresistibly comical in their bright, saucy 
eyes, placed almost on top of the head, that no one could help calling one of them "Johnny." A "johnny" will look at you from one side, and then as quick as a flash, will flounce around and study you with the other eye and then come toward you head-on so that he may take you in with both eyes; he seems just as interested in the Johnny out of the jar as is the latter, in the johnny within.

The johnny darter has a queer shaped body for a fish, for the head and shoulders are the larger part of him; not that he suddenly disappears into nothingness, by no means! His body is long and very slightly tapering to the tail; along his lateral line he has a row of olive-brown W's worked out in scale-mosaics; and he has some other scale-mosaics also following a pattern of angular lines and making blotches along his back. The whole upper part of his body is pale olive, which is a good imitation of the color of the brook.

The astonished and anxious look on the johnny darter's face comes from the peculiar position of the eyes which are set in the top of his forehead; they are big, alert eyes, with large black pupils, surrounded by a shining, pale yellow line at the inner edge of the green iris; and as the pupil is not set in the center of the eye, the iris above being wider than below, the result is an astonished look, as from raised eyebrows. The eyes move, often so swiftly that it gives the impression of winking. The eyes, the short snout, and the wide mouth give johnny a decidedly frog-

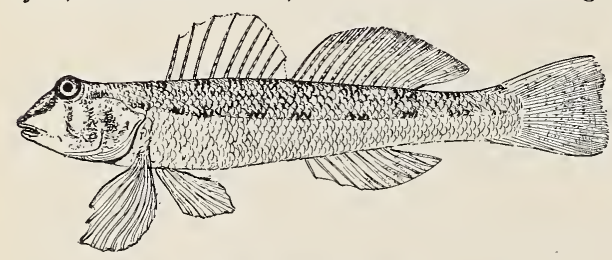

The johnny darter. like aspect.

Although he is no frog, yet johnny darter seems to be in a fair way to develop something to walk upon. His pectoral fins are large and strong and the ventral pair are situated very close to them; when he rests upon the gravel he supports himself upon one or both of these pairs of fins. He rests with the pectoral fins outspread, the sharp points of the rays taking hold of the gravel like toenails and thus give him the appearance of walking on his fins; if you poke him gently, you will find that he is very firmly planted on his fins so that you can turn him around as if he were on a pivot. He also uses the pectorals for swimming and jerks himself along with them in a way that makes one wonder if he could not swim well without any tail at all. The tail is large and almost straight across the end and is a most vigorous pusher. There are two dorsal fins; the front one has only nine rays; these are not branched and are therefore spines; when the fin is raised it appears almost semi-circular in shape. The hind dorsal fin is much longer and when lifted stands higher than the front one; its rays are all branched except the front one. As soon as the johnny stops swimming he shuts the front dorsal fin so that it can scarcely be detected; when frightened he shuts both the dorsal fins and closes the tail and the anal fin and spreads out his paired fins so that his body lies flat on the bottom; this act always reminds one of the "freezing" habit of the rabbit. But johnny does not stay scared very long; he lifts his head up inquisitively, stretching up as far as he is able on his front feet, that is, his pectorals, in such a comical way that one can hardly realize he is a fish. 
The tail and the dorsal fin of the johnny darter are marked with silver dots which give them an exquisite spun-glass look; they are as transparent as gauze.

The johnny darters live in clear, swift streams where they rest on the bottom, with the head up stream. Dr. Jordan has said they can climb up water weed with their paired fins. I have never observed them doing this but I have often seen one walk around the aquarium on his fins as if they were little fan-shaped feet; and when swimming he uses his fins as a bird uses its wings. There are many species of darters, some of them the most brilliantly colored of any of our fresh-water fishes. The darters are perch-like in form.

Dr. Jordan says of the breeding habits of the darters: "On the bottom, among the stones, the female casts her spawn. Neither she nor the male pays any further attention to it, but in the breeding season the male is painted in colors as beautiful as those of the wood warblers. When you go to the brook in the spring you will find him there, and if you catch him and turn him over on his side you will see the colors that he shows to his mate, and which observation shows are most useful in frightening away his younger rivals. But do not hurt him. Put him back in the brook and let him paint its bottom with colors of a rainbow, a sunset or a garden of roses. All that can be done with blue, crimson and green pigments, in fish ornamentation, you will find in some brook in which the darters live."

\section{LESSON XLIII}

\section{JOHNNY DARTER}

Leading thought-The johnny darter naturally rests upon the bottom of the stream where the current is swift. It uses its two pairs of paired fins somewhat as feet in a way interesting to observe.

Method-Johnny darters may be caught in nets with other small fry and placed in the aquarium. Place one or two of them in individual aquaria where the pupils may observe them at their leisure. They do best in running water.

Observations-I. Describe or sketch the johnny darter from above. From the side. Can you see the $\mathrm{W}$-shaped marks along its side? How is it colored above?

2. How are the pectoral fins placed? Are they large or small? How are they used in swimming? Where are the ventral fins placed? How are the ventrals and dorsals used together? When resting on the bottom how are the pectoral fins used?

3. What is there peculiar about the dorsal fins of the johnny darter? When he is resting, what is the attitude of the dorsal fins? What is the difference in shape of the rays of the front and hind dorsal fins?

4. When resting on the bottom of the aquarium how is the body held? On what does it rest? In moving about the bottom slowly why does it seem to walk? How does it climb up water weed?

5. When frightened how does it act? Why is it called a darter? What is the attitude of all the fins when the fish is moving swiftly?

6. What is the sliape of the tail? 
7. What is there peculiar about the eyes of the jchnny? Describe the eyes and their position. What reason is there in the life of the fish that makes this position of the eyes advantageous?

8. Where do we find the johnny darters? In what part of the stream do they live? Are they usually near the surface of the water or at the bottom?

"To my mind, the best of all subjects for nature-study is a brook. It affords studies of many kinds. It is near and dear to every child. It is an epitome of the nature in which we live. In miniature, it illustrates the forces which have shaped much of the earth's surface. It reflects the sky. It is kissed by the sun. It is rippled by the wind. The minnows play in the pools. The soft weeds grow in the shallows. The grass and the dandelions lie on its sunny banks. The moss and the fern are sheltered in the nooks. It comes from one knows not whence; it flows to one knows not whither. It awakens the desire to explore. It is fraught with mysteries. It typifies the flood of life. It goes on forever.

In other words, the reason why the brook is such a perfect nature-study subject is the fact that it is the central theme in a scene of life. Living things appeal to children."

"Nature-study not only educates, but it educates nature-ward; and nature is ever our companion. whether we will or no. Even though we are determined to shut ourselves ire an office, nature sends her messengers. The light, the dark, the moon, the cloud, the rain, the wind, the falling leaf, the fly, the bouquet, the bird, the cockroach-they are all ours.

If one is to be happy, he must be in sympathy with common things. He must live in harmony with his environment. One cannot be happy yonder nor tomorrow: he is happy here and now, or never. Our stock of knowledge of common things should be great. Few of us can travel. We must know the things at home.

Nature-love tends toward naturalness, and toward simplicity of living. It tends country-ward. One word from the fields is worth two from the city. "God made the country."

I expect, therefore, that much good will come from nature-study. It ought to revolutionize the school life, for it is capable of putting new force and enthusiasm into the school and the child. It is new, and therefore, is called a fad. A movement is a fad until it succeeds. We shall learn much, and shall outgrow some of our present notions, but nature-study has come to stay. It is in much the same stage of development that manual-training and kindergarten work were twenty-five years ago. We must take care that it does not crystalize into science-teaching on the one hand, nor fall into mere sentimentalism on the other.

$I$ would again emphasize the importance of obtaining our fact before we let loose the imagination, for on this point will largely turn the results-the failure or the success of the experiment. iVe must not allow our fancy to run away with us. If we hitch our wagon to a star, we must ride with mind and soul and body all alert. When we ride in such a wagon, we must not forget to put in the tail-board." 


\section{BATRACHIAN STUDY}

\section{THE COMMON TOAD}

\section{Teacher's Story}

"The toad hopped by us with jolting springs."-AKERs.

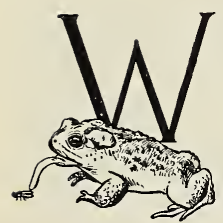

HOEVER has not had a pet toad has missed a most entertaining experience. Toad actions are surprisingly interesting; one of my safeguards against the blues is the memory of the thoughtful way one of my pet toads rubbed and patted its stomach with its little hands after it had swallowed a June-bug. Toads do not make warts upon attacking hands, neither do they rain down nor are they found in the bed-rock of quarries; but they do have a most interesting history of their own, which is not at all legendary, and which is very like a life with two incarnations.

The mother toad lays her eggs in May and June in ponds, or in the still pools, along streams; the eggs are laid in long strings of jellylike substance, and are dropped upon the pond bottom or attached to water weeds; when first deposited, the jelly is transparent and the little black eggs can be plainly seen; but after a day or two, bits of dirt accumulate upon the jelly, obscuring the eggs. At first the eggs are spherical, like tiny black pills, but as they begin to develop, they elongate and finally the tadpoles may be seen wriggling in the jelly mass, which affords them efficient protection. After four or five days, the tadpoles usually work their way out and swim away; at this stage, the only way to detect the head, is by the direction of the tadpole's progress, since it naturally goes head first. However, the head soon becomes decidedly larger, although at first it is not provided with a mouth; it has instead, a V-shaped elevation where the mouth should be, which forms a sucker secreting a sticky substance by means of which the tadpole attaches itself to water weeds, resting head up. When two or three days old, we can detect little tassels on either side of the throat, which are the gills by which the little creature breathes; the blood passes through these gills, and is purified by coming in contact with the air which is mixed in the water. About ten days later, these gills disappear beneath a membrane which grows down over them; but they are still used for breathing, simply having changed position from the outside to the inside of the throat. The water enters the nostrils to the mouth, passes through an opening in the throat and flows over the gills and out through a little opening at the left side of the body; this opening or breathing-pore, can be easily seen in the larger tadpoles; and when the left arm develops, it is pushed out through this convenient orifice.

When about ten days old, the tadpole has developed a small, round mouth which is constantly in search of something to eat, and at the same time constantly opening and shutting to take in air for the gills; the mouth is provided with horny jaws for biting off pieces of plants. As the 
tadpole develops, its mouth gets larger and wider and extends back beneath the eyes, with a truly toadlike expansiveness.

At first, the tadpole's eyes are even with the surface of the head and can scarcely be seen, but later they become more prominent and bulge like the eyes of the adult toad.

The tail of the tadpole is long and flat, surrounded by a fin, thus making an organ for swimming. It strikes the water, first this side and then that, making most graceful curves, which seem to originate near the

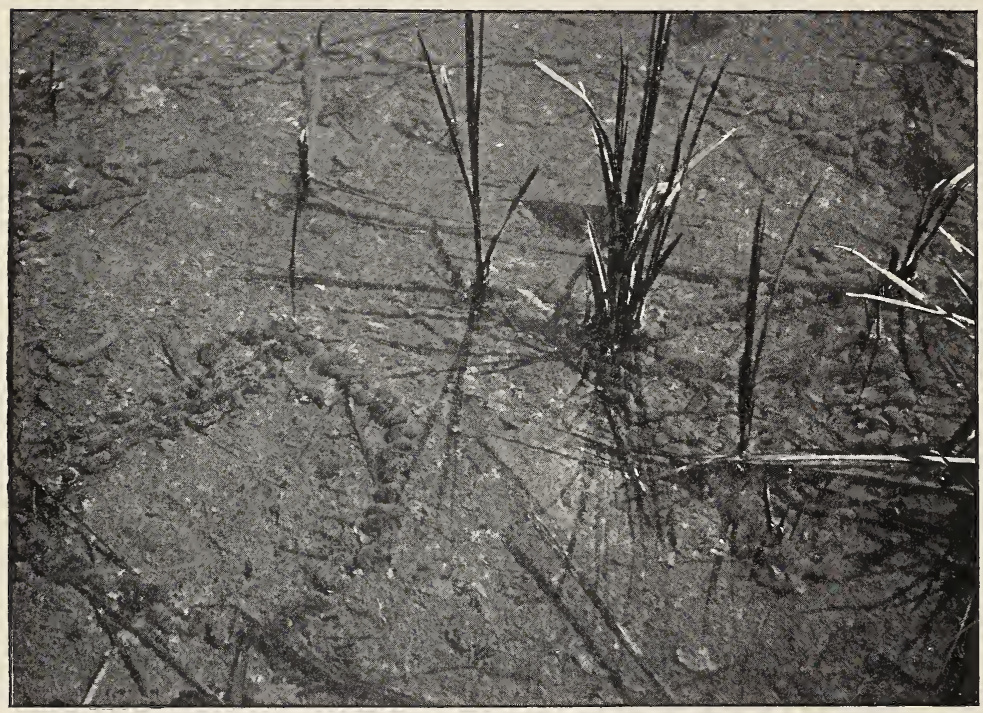

Toad's eggs.

Photo by Verne Morton.

body and multiply toward the tip of the tail. This movement propels the tadpole forward, or in any direction. The tail is very thin when seen from above; and it is amusing to look at a tadpole from above, and then at the side; it is like squaring a circle.

There is a superstition that tadpoles eat their tails; and in a sense this is true, because the material that is in the tail is absorbed into the growing body; but the last thing a right-minded tadpole would do, would be to bite off its own tail. However, if some other tadpole should bite off the tail or a growing leg, these organs conveniently grow anew.

When the tadpole is a month or two old, depending upon the species, its hind legs begin to show; they first appear as mere buds which finally push out completely. The feet are long and provided with five toes, of which the fourth is the longest; the toes are webbed so that they may be used to help in swimming. Two weeks later the arms begin to appear, the left one pushing out through the breathing-pore. The "hands" have four fingers and are not webbed; they are used in the water for balancing; while the hind legs are used for pushing, as the tail becomes smaller. 
As the tadpole grows older, not only does its tail become shorter but its actions change. It now comes often to the surface of the water in order to get more air for its gills, although it lacks the frog tadpole's nice adjustment of the growing lungs and the disappearing gills. At last some fine rainy day, the little creature feels that it is finally fitted to live the life of a land animal. It may not be a half inch in length, with big head, attenuated body and stumpy tail, but it swims to the shore, lifts itself on its front legs, which are scarcely larger than pins, and walks off, toeing in, with a very grown up air, and at this moment, the tadpole attains toadship. Numbers of them come out of the water together, hopping hither and thither with all of the eagerness and vim of untried youth. It is when issuing thus in hordes from the water and seen by the ignorant, that they gain the reputation of being rained down, when they really were rained up. It is quite impossible for a beginner to detect the difference between the toad and the frog tadpole; usually those of the toads are black, while those of the frogs are otherwise colored, though this is not an invariable distinction. The best way to distinguish the two is to get the eggs and develop the two families separately.

The general color of the common American toad is extremely variable. It may be yellowish-brown, with spots of lighter color, and with reddish or yellow warts. There are likely to be four irregular spots of dark color along each side of the middle of the back, and the under parts are light colored, often somewhat spotted. The throat of the male toad is slack and he is not so bright in color as is the female. The warts upon the back are glands, which secrete a substance disagreeable for the animal seeking toad dinners. This is especially true of the glands in the elongated swelling or wart, above and just back of the ear, which is called the parotid gland; these give forth a milky, poisonous substance when the toad is seized by an enemy, although the snakes do not seem to mind it. Some people have an idea that the toad is slimy, but this is not true; the skin is perfectly dry. The toad feels cold to the hand because it is a coldblooded animal, which means an animal with blood the temperature of the surrounding atmosphere; while the blood of the warm-blooded animal, has a temperature of its own, which it maintains whether the surrounding air is cold or hot.

The toad's face is well worth study; its eyes are elevated and very pretty, the pupil being oval and the surrounding iris shining like gold. The toad winks in a wholesale fashion, the eyes being pulled down into the head; the eyes are provided with nictitating lids, which rise from below, and are similar to those found in birds. When a toad is sleeping, its eyes do not bulge but are drawn in, so as to lie even with the surface of the head. The two tiny nostrils are black and are easily seen; the ear is a flat, oval spot behind the eye

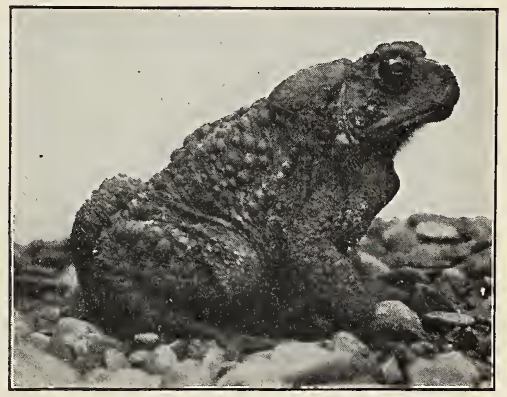

After a hard winter. Photo by Cyrus Crosby. 
and a little lower down; in the common species it is not quite so large as the eye; this is really the ear-drum, since there is no external ear like ours. The toad's mouth is wide and its jaws are horny; it does not need teeth since it swallows its prey whole.

The toad is a jumper, as may be seen from its long, strong hind legs, the feet of which are also long and strong and armed with five toes that are somewhat webbed. The "arms" are shorter and there are four "fingers" to each "hand;" when the toad is resting, its front feet toe-in, in a comical fashion. If a toad is removed from an earth or moss garden, and put into a white wash-bowl, in a few hours it will change to a lighter hue, and vice versa. This is part of its protective color, making it inconspicuous to the eyes of its enemy. It prefers to live in cool, damp places, beneath sidewalks or piazzas, etc., and its warty upper surface resembles the surrounding earth. If it is disturbed, it will seek to escape by long leaps and acts frightened; b ut if very much frightened, it flattens out on the ground, and looks so nearly like a clod of earth that it may escape even the keen eyes of its pursuer. When seized by the enemy, it will sometimes "play possum," acting as if it were dead; but when actually in the mouth of the foe, it emits terrified and heart-rending cries.

The toad's tongue is attached to the lower jaw, at the front edge of the mouth; it can thus be thrust far out, and since it secretes a sticky substance over its surface, any insects which it touches adhere, and are drawn back into the mouth and swallowed. It takes a quick eye to see this tongue fly out and make its catch. The tadpole feeds mostly upon vegetable matter, but the toad lives entirely upon small animals, usually insects; it is not particular as to what kind of insects; but because of the situations which it haunts, it usually feeds upon those which are injurious to grass and plants. Indeed, the toad is really the friend of the gardener and farmer, and has been most ungratefully treated by those whom it has befriended. If you doubt that a toad is an animal of judgment, watch it when it finds an earthworm and set your doubts at rest! It will walk around the squirming worm, until it can seize it by the head, apparently knowing well that the horny hooks extending backward from the segments of the worm, are likely to rasp the throat if swallowed the wrong way. If the worm prove a too large mouthful, the toad promptly uses its hands in an amusing fashion to stuff the wriggling morsel down its throat. When swallowing a large mouthful, it closes its eyes; but whether this aids the process, or is merely an expression of bliss, we have not determined. The toad never drinks by taking in water through the mouth, but absorbs it through the skin; when it wishes to drink, it stretches itself out in shallow water and thus satisfies its thirst; it will waste away and die in a short time, if kept in a dry atmosphere.

The toad burrows in the earth by a method of its own, hard to describe. It kicks backward with its strong hind legs, and in some mysterious way, the earth soon covers all excepting its head; then, if an enemy comes along, back goes the head, the earth caves in around it, and where is your toad! It remains in its burrow or hiding place usually during the day, and comes out at night to feed. This habit is an advantage, because snakes are then safely at home and, too, there are many more insects to be found at night. The sagacious toads have discovered that the vicinity of street lights is swarming with insects, and there they gather in 
numbers. In winter they burrow deeply in the ground and go to sleep, remaining dormant until the warmth of spring awakens them; then, they come out, and the mother toads seek their native ponds there to lay eggs for the coming generation. They are excellent swimmers; when swimming rapidly, the front legs are laid backward along the sides of the body, so as to offer no resistance to the water; but when moving slowly, the front legs are used for balancing and for keeping afloat.

The song of the toad is a pleasant, crooning sound, a sort of gutteral trill; it is made when the throat is puffed out almost globular, thus forming a vocal sac; the sound is made by the air drawn in at the nostrils and passed back and forth from the lungs to the mouth over the vocal chords, the puffed-out throat acting as a resonator.

The toad has no ribs by which to inflate the chest, and this draw air into the lungs, as we do when we breathe; it is obliged to swallow the air instead and thus force it into the lungs. This movement is shown in the constant pulsation, in and out, of the membrane of the throat.

As the toad grows, it sheds its horny skin, which it swallows; as this process is usually done strictly in private, the ordinary observer sees it but seldom. One of the toad's nice common qualities is its enjoyment in having its back scratched gently.

The toad has many enemies; chief among these is the snake and in only a lesser degree, crows and also birds of prey.

Reference-The Frog Book, Dickerson; Familiar Life in Field and Forest, Mathews; The Usefulness of the American Toad, U. S. Dept. Agr., Farmers Bulletin, No. 196.

\section{LESSON XLIV}

\section{The Tadpole Aquarium}

Leading thought-The children should understand how to make the tadpoles comfortable and thus be able to rear them.

Materials-A tin or agate pan or a deep earthenware washbowl.

Things to be done-I. Go to some pond where tadpoles live.

2. Take some of the small stones on the bottom and at the sides of the pond lifting them very gently so as not to disturb what is growing on their surface. Place these stones on the bottom of the pan, building up one side higher than the other, so that the water will be more shallow on one side than on the other; a stone or two should project above the water.

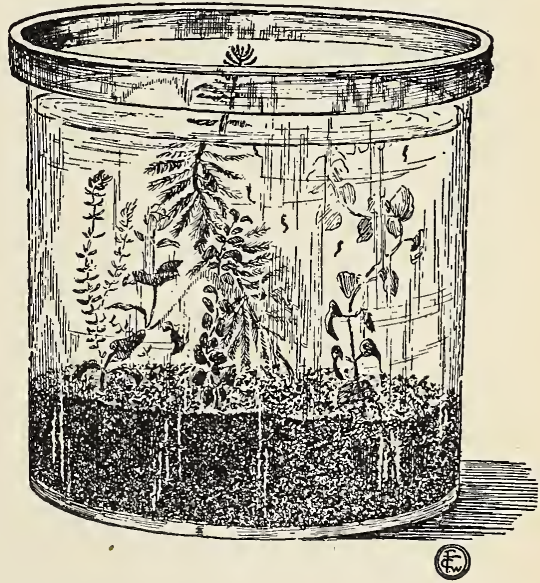

3. Take some of the mud and leaves from the bottom of the pond, being careful not to disturb them and place upon the stones. 
4. Take some of the plants found growing under water in the pond and plant them among the stones.

5. Carry the pan thus prepared back to the schoolhouse and place it where the sun will not shine directly upon it.

6. Bring a pail of water from the pond and pour it very gently in at one side of the pan, so as not to disarrange the plants; fill the pan nearly to the brim.

7. After the mud has settled and the water is perfectly clear, remove some of the tadpoles, which have hatched in the glass aquarium, and place in the "pond." Not more than a dozen should be put in a pan of this size, since the amount of food and microscopic plants which are on the stones in the mud, will afford food for only a few tadpoles.

8. Every week add a little more mud from the bottom of the pond or another stone covered with slime, which is probably some plant growth. More water from the pond should be added to replace that evaporated.

9. Care should be taken that the tadpole aquarium be kept where the sun will not shine directly upon it for any length of time, because if the water gets too warm the tadpoles will die.

ro. Remove the "skin" from one side of a tulip leaf, so as to expose the pulp of the leaf, and give to the tadpoles every day or two. Bits of hard-boiled egg should be given now and then.

\section{Toads' Eggs and TADPoles}

Leading thought-The toad's eggs are laid in strings of jelly in ponds. The eggs hatch into tadpoles which are creatures of the water, breathing by gills, and swimming with a long fin. The tadpoles gradually change to toads, which are air-breathing creatures, fitted for life on dry land.

Method-The eggs of toads may be found in almost any pond about the first of May and may be scraped up from the bottom in a scoop-net. They should be placed in the aquarium where the children can watch the stages of development. Soon after they are hatched, a dozen or so should be selected and placed in the tadpole aquarium and the others put back into the stream. The children should observe the tadpoles every day, watching carefully all the changes of structure and habit which take place. If properly fed, the tadpoles will be ready to leave the water in July, as tiny toads.

Observations-I. Where were the toads' eggs found and on what date? Were they attached to anything in the water or were they floating free? Are the eggs in long strings? Do you find any eggs laid in jellylike masses? If so, what are they? How can you tell the eggs of toads from those of frogs?

2. Is the jellylike substance in which the eggs are placed clear or discolored? What is the shape and the size of the eggs? A little later how do they look? Do the young tadpoles move about while they are still in the jelly mass?

3. Describe how the little tadpole works its way out from the jelly covering. Can you distinguish then which is head and which is tail? How does it act at first? Where and how does it rest?

4. Can you see with the aid of a lens the little fringes on each side of the neck? What are these? Do these fringes disappear a little later? Do they disappear on both sides of the neck at once? What becomes of 


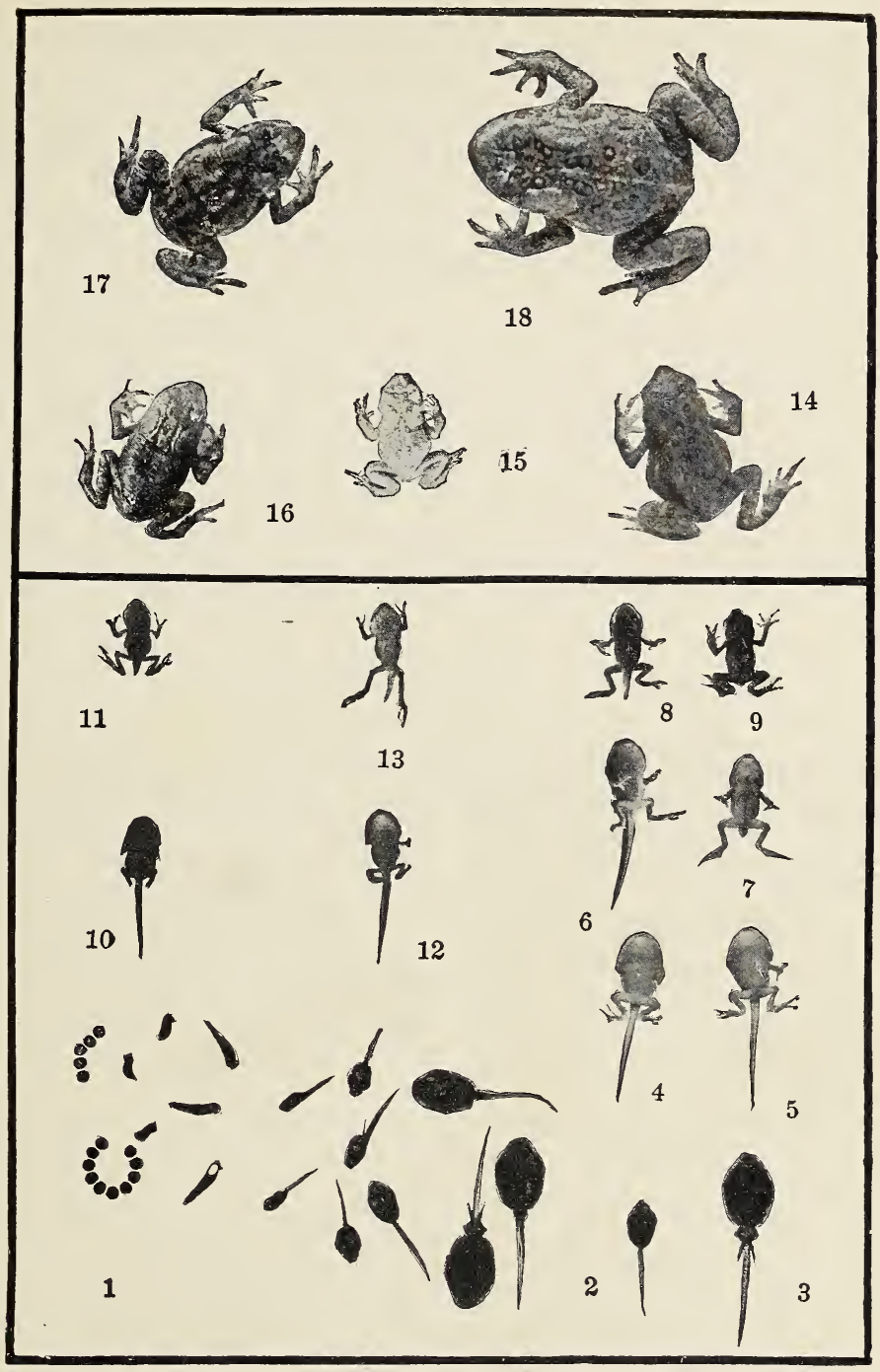

Toad development in a single season (I903).

1-18, Changes and growth from April to November 9-14, Different sizes, July 30, 1903 1-13 Development in 25 to 60 days 15-1.8 Different sizes, October 21, 1903 10,11 . The same tadpole, 11 is 47 hours older than 10

12,13 , The same tadpole, 13 is 47 hours older than 12 Photo by S. H. Gage. 
them? How does the tadpole breathe? Can you see the little hole on the left side, through which the water used for breathing passes?

5. How does the tail look and how is it used? How long is it in proportion to the body? Describe the act of swimming.

6. Which pair of legs appears first? How do they look? When they get a little larger are they used as a help in swimming? Describe the hind legs and feet.

7. How long after the hind legs appear before the front legs or arms appear? What happens to the breathing-pore when the left arm is pushed through?

8. After both pairs of legs are developed what happens to the tail? What becomes of it?

9. When the tadpole is very young can you see its eyes? How do they look as it grows older? Do they ever bulge out like toads' eyes?

Io. As the tadpole gains its legs and loses its tail how does it change in its actions? How does it swim now? Does it come oftener to the surface? Why?

II. Describe the difference between the front and the hind legs and the front and the hind feet on the fully grown tadpole. If the tail or a leg is bitten off by some other creature will it grow again?

\section{LESSON XLV}

\section{The Toad}

Leading thought-The toad is colored so that it resembles the soil and thus escapes the observation of its enemies. It lives in damp places and eats insects, usually hunting them at night. It has powerful hind legs and is a vigorous jumper.

Method-Make a moss garden in a glass aquarium jar thus: Place some stones or gravel in the bottom of the jar and cover with moss. Cover the jar with a wire screen. The moss should be deluged with water at least once a day and the jar should be placed where the direct sunlight will not reach it. In this jar, place the toad for study.

Observations-I. Describe the general color of the toad above and below. How does the toad's back look? Of what use are the warts on its back?

2. Where is the toad usually found? Does it feel warm or cold to the hand? Is it slimy or dry? The toad is a cold-blooded animal, what does this mean?

3. Describe the eyes and explain how their situation is of special advantage to the toad. Do you think it can see in front and behind and above all at the same time. Does the bulge of the eyes help in this? Note the shape and color of the pupil and iris. How does the toad wink?

4. Find and describe the nostrils. Find and describe the ear. Note the swelling above and just back of the ear. Do you know the use of this?

5. What is the shape of the toad's mouth? Has it any teeth? Is the toad's tongue attached to the front or the back part of the mouth? How is it used to catch insects?

6. Describe the "arms and hands." How many "fingers" on the "hand?" Which way do the fingers point when the toad is sitting down? 
7. Describe the legs and feet. How many toes are there? What is the relative length of the toes and how are they connected? What is this web between the toes for? Why are the hind legs so much larger than the front legs?

8. Will a toad change color if placed upon different colored objects? How long does it take it to do this? Of what advantage is this to the toad?

9. Where does the toad live? When it is disturbed how does it act? How far can it jump? If very frightened does it flatten out and lie still? Why is this?

Io. At what time does the toad come out to hunt insects? How does it catch the insect? Does it swallow an earthworm head or tail first? When swa1lowing an earthworm or large insect, how does it use its hands? How does it act when swallowing a large mouthful?

I I. How does the toad drink? Where does it remain during the day? Describe how it burrows into the earth.

I 2. What happens to the toad in the winter? What does it do in the spring? Is it a good swimmer? How does it use its legs in swimming?

I3. How does the toad look when croaking? What sort of a noise does it make?

I 4. Describe the action of the toad's throat when breathing. Did you ever see a toad shed its skin?

I5. What are the toad's enemies? How does it act when caught by a snake? Does it make any noise? Is it swallowed head or tail first? What means has it of escaping or defending itself from its enemies?

r6. How is the toad of great use to the farmer and gardener?

References - "The Life History of the Toad," by S. H. Gage, Cornell Nature-Study Volume; The Frog Book, Dickerson.

Supplementary reading - "K'dunk, the fat one," A Little Brother to the Bear, Long.

"In the early years we are not to teach nature as science, we are not to teach $i$ : primarily for method or for drill: we are to teach it for loving-and this is nature. study. On these points I make no compromise." 


\section{THE TREE-FROG, OR TREE-TOAD \\ Teacher's Story}

"Ere yet the earliest warbler wakes, of coming spring to tell,

From every marsh a chorus breaks, a choir invisible,

As if the blossoms underground, a breath of utterance had found."-TABB.

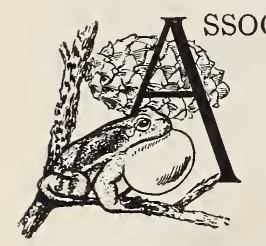

CIATED with the first songs of robin and bluebird, is the equally delightful chorus of the spring peepers, yet how infrequently do most of us see a member of this invisible choir! There are some creatures which are the quintessence of the slang word "cute" which, interpreted, means the pefection of Lilliputian proportions, permeated with undaunted spirit. The chickadee is one of these, and the tree-frog is another.

I confess to a thrill of delight when the Pickering's hyla lifts itself on its tiny front feet, twists its head knowingly, and turns on me the full gaze of its bronze-rimmed eyes. This is the tiniest froglet of them all, being little more than an inch long when fully grown; it wears the Greek cross in darker color upon its back, with some stripes across its long hind legs which join the pattern on the back when the frog is "shut up," as the boys say.

The reason we see so little of tree-frogs, is because they are protected from discovery by their color. They have the chameleon power of changing color to match their background. The Pickering's hyla will effect this change in twenty minutes; in this species, the darker lines forming the cross change first, giving a mottled appearance which is at once protective. I have taken three of these peepers, all of them pale yellowish brown with gray markings, and have placed one upon a fern, one on dark soil and one on the purple bud of a flower. Within half an hour, each matched its surroundings so closely, that the casual eye would not detect them. The song of the Pickering's hyla is a resonant chirp, very stirring when heard nearby; it sounds somewhat like the note of a water bird. How such a small creature can make such a loud noise, is a mystery. The process, however, may be watched at night by the light of a lamp, as none of the tree-frogs seem to pay any attention to an artificial light; the thin membrane beneath the throat swells out until it seems almost large enough to balloon the little chap off his perch. No wonder that, with such a sounding-sac, the note is stirring. There are several species of tree-frogs that trill in the branches

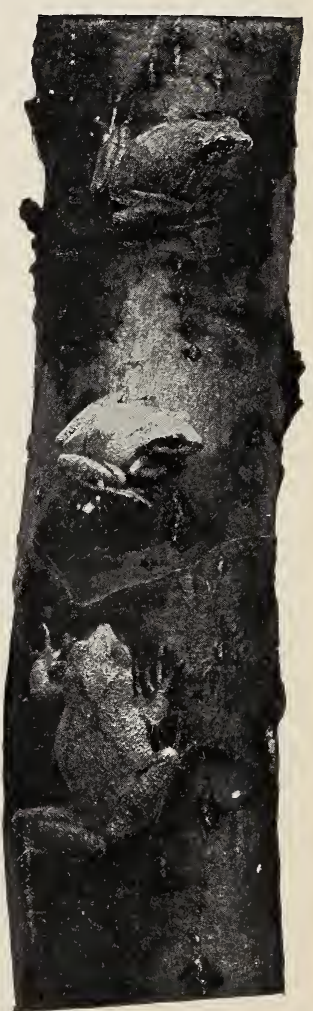

Sitting for their pictures. Pickering's Hyla. Photo by Cyrus Crosby. 
above our heads all summer, and their songs are sometimes mistaken for those of the cicada, which is far more shrill.

The tree-frogs have toes and fingers ending in little round discs which secrete at will a substance by means of which they can cling to vertical surfaces, even to glass. In fact, the way to study these wonderful feet is when the frog is climbing up the sides of the glass jar. The fingers are arranged, two short inside ones, a long one, and another short one outside. The hind feet have three shorter inside toes quite far apart, a long one at the tip of the foot and a shorter one outside. When climbing a smooth surface like glass, the toes are spread wide apart, and there are other little clinging discs on their lower sides, although not so large as those at the tips. It is by means of these sticky, disc-like toes that the tree-frogs hold themselves upon the tree trunks.

The whole body of the tree-frog is covered with little tubercles, which give it a roughened appearance. The eyes are black with the iris of reddish color. The tongue is like that of other frogs, hinged to the front of the lower jaw; it is sticky and can be thrust far out to capture insects, of which the tree-frcgs eat vast numbers.

The hylas breathe by the rapid pulsation of the membrane of the throat, which makes the whole body tremble. The nostrils are two tiny holes on either side of the tip of the snout. The ears are a little below and just behind the eyes, and are in the form of a circular slit.

The eggs of the spring peepers are laid in ponds during April; each egg has a little globe of jelly about it and is fastened to a stone or a water plant. The tadpoles are small and delicate; the under side of the body is reddish and shines with metallic lustre. These tadpoles differ from those of other frogs in that they often leave the water while yet the tail is still quite long. In summer, they may be found among the leaves and moss around the banks of ponds. They are indefatigable in hunting for gnats, mosquitoes and ants; their destruction of mosquitoes, as pollywogs and as grown up frogs, renders them of great use to us. The voice of this peeper may be heard among the shrubs and vines or in trees during late summer and until November. The little creatures sleep be neath moss and leaves during the winter, waking to give us the earliest news of spring.

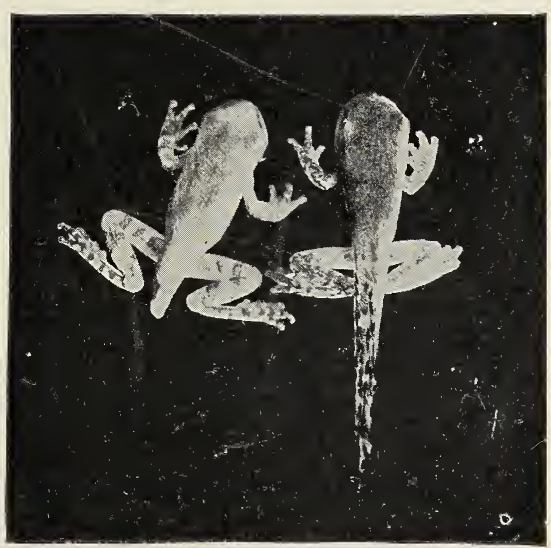

Iree-frog tadpoles. 


\section{LESSON XLVI}

\section{The Tree-frog or Tree-toad}

Leading thought-The prettiest part of the spring chorus of the irog ponds is sung by the tree-frogs. These little frogs have the tips of their toes specially fitted for climbing up the sides of trees.

Method-Make a moss garden in an aquarium jar or a two-quart can. Place stones in the bottom and moss at one side, leaving a place on the other side for a tiny pond of water. In this garden place a treefrog and cover the jar with mosquito netting and place in the shade. The frogs may be found by searching the banks of a pond at night with a lantern. However, this lesson is usually given when by accident the tree-frog is discovered. Any species of tree-frog will do; but the Pickering's hyla, known everywhere as the spring peeper, is the most interesting species to study.

Observations-I. How large is the tree-frog? What is its color? Describe the markings.

2. Place the tree-frog on some light-colored surface like a piece of white blotting paper. Note if it changes color after a half hour. Later place it upon some dark surface. Note if it changes color again. How does this power of changing color benefit the tree-frog? Place a tree-frog on a piece of bark. After a time is it noticeable?

3. Describe the eyes. Note how little the tree-frog turns its head to see anything behind it. Describe its actions if its attention is attracted to anything. What color is the pupil? The iris?

4. Note the movement of breathing. Where does this show the most? Examine the delicate membrane beneath the throat. What has this to do with the breathing?

5. What is the tree-frog's note? At what time of day does it peep? At what time of year? Describe how the frog looks when peeping.

6. How does the tree-frog climb? When it is climbing up a vertical surface study its toes. How many on the front foot? How are they arranged? How many toes on the hind foot? Sketch the front and hind feet. How do the toe-discs look when pressed against the glass? How does it manage to make the discs cling and then let go? Are there any more discs on the under side of the toes? Is there a web between the toes of the hind feet? Of the front feet?

7. Look at a tree-frog very closely and describe its nostrils and its ears.

8. Are the tree-frogs good jumpers? What is the size and length of the hind legs as compared with the body?

9. When and where are the eggs of the tree-frog laid? How do they look?

Io. How do the tree-frog tadpoles differ from other tadpoles? Describe them if you have ever seen them. In what situations do they live?

II. Of what use are the tree-frogs to us?

References - "The Life History of the Toad," Cornell Nature Study Volume, S. H. Gage; The Frog Book, Dickerson; Familiar Life of Field and Forest, Mathews; American Natural History, Hornaday: Elementary Zoology, V. L. Kellogg; From River Ooze to Tree-top, Sharp. 


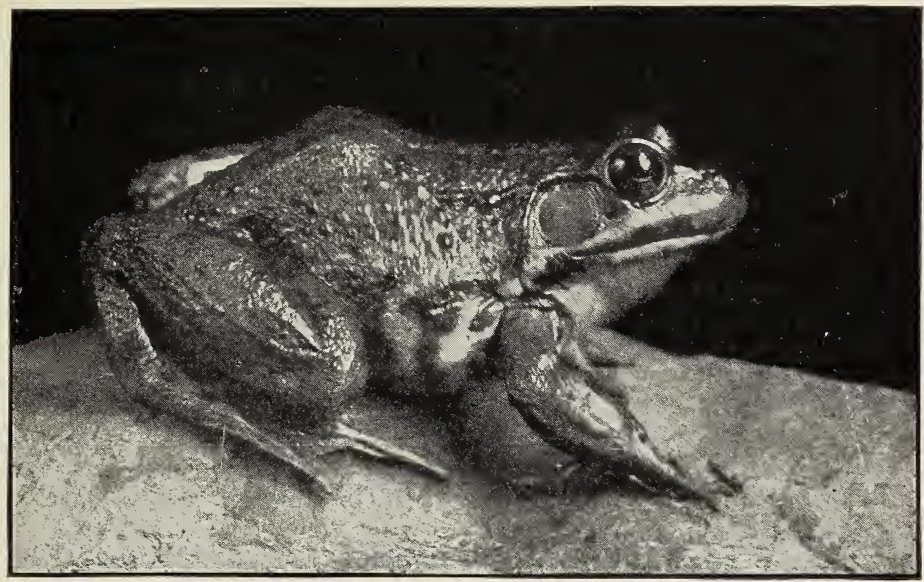

Bullfrog.

\section{THE FROG}

\section{Teacher's Story}

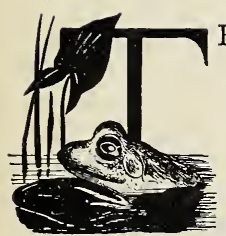

HE stroller along brooksides, is likely to be surprised some day, at seeing a bit of moss and earth suddenly make a high leap and a far one, without apparent provocation. An investigation resolves the clump of moss into a brilliantly green and yellow, striped frog, and then the stroller wonders how he could have overlooked such an obvious creature. But the leopard frog is only obvious when it is out of its environment. The common green frog is quite as well protected since its color is exactly that of green pools. Most frogs spend their lives in or about water, and if caught on land, they make great leaps to reach their native element; the leopard frog and a few other species sometimes wander far afield.

In form, the frog is more slim than the toad, and is not covered with great warts; it is cold and slippery to the touch. The frog's only chance of escaping its enemies, is through the slipperiness of its body and by making long, rapid leaps. As a jumper, the frog is much more powerful than the toad because its hind legs are so much larger and more muscular, in comparison with its size. The first toe in the front feet of the leopard frog is much swollen, making a fat thumb; the mechanics of the hind legs make it possible for the frog to feather the webbed feet as it swims. On the bottom of the toes are hardened places at the joints, and sometimes others besides, which give the foot a strong hold when pushing for the jump. The toe tips, when they are pressed against the glass, resemble slightly the tree-toads' discs. The hind foot is very long, while on the front foot the toes radiate almost in a circle. The foot and leg are colored like the back of the body above, and on the under side resemble the under parts. 
The frog is likely to be much more brightly colored than the toad, and usually has much of green and yellow in its dress. But the frog lives among green things, while it is to the toad's advantage to be the color of the soil. Frogs also have the chameleon power of changing color, to harmonize with their environment. I have seen a very green leopard frog change to a slate-gray when placed upon slate-colored rock. The change took place in the green portions. The common green frog will likewise change to slate-color, in a similar situation. A leopard frog changed quickly from dark green to pale olive, when it was placed in the water after having been on the soil.

The eyes of frogs are very prominent, and are beautiful when observed closely. The green frog has a dark bronze iris with a gleaming gold edge around the pupil, and around the outer margin. The eye of the leopard frog is darker; the iris seems to be black, with specks of ruddy gold scattered through it, and there is an outer band of red-gold around the margin. When the frog winks, the nictitating membrane rises from below and covers the whole eye; and when the frog makes a special effort of any sort, it has a comical way of drawing its eyes back into its head. When trying to hide at the bottom of the aquarium, the leopard species lets the eye-lids fall over the eyes, so that they do not shine up and attract pursuers.

The ear is in a similar position to that of the toad, and in the bullfrog, is larger than the eye. In the green frog, it is a dull grayish disc, almost as large as the eye. In the leopard frog, it is not so large as the eye, and has a giltish spot at the center.

The nostrils are small and are closed when below the water, as may be easily seen by a lens. The mouth opens widely, the corners extending back under the eye. The jaws are horny and are armed with teeth, which are for the purpose of biting off food rather than for chewing it. When above water, the throat keeps up a rythmic motion which is the process of breathing; but when below water this motion ceases. The food of frogs is largely composed of insects, that frequent damp places or that live in the water.

The sound-sacs of the frogs, instead of being beneath the throat, as is the case with toads and tree-frogs, are at the side of the throat; and when inflated, may extend from just back of the eyes, out above the front legs. The song is characteristic, and pleasant to listen to, if not too close by. Perhaps exception should be made to the lay of the bullfrog, which like the song of some noted opera singers, is more wonderful than musical; the boom of the bullfrog makes the earth fairly quake. If we seize the frog by the hind leg, it will usually croak and thus demonstrate for us, the position of its sound-sacs.

In addition to the snakes, the frogs have inveterate enemies in the herons which frequent shallow water, and eat them in great numbers. The frogs hibernate in mud and about ponds, burrowing deep enough to escape freezing. In the spring, they come up and sing their spring songs and the mother frogs lay their eggs in masses of jelly on the bottom of the pond, usually where the water is deeper than in the situations where the toads' eggs are laid. The eggs of the two can always be distinguished, since the toads' are laid in strings of jelly, while the frogs' are laid in masses.

It is amusing to watch with a lens, the frog tadpoles seeking for their microscopic food along the glass of the aquarium. There are horny 
upper and lower jaws, the latter being below and back of the former. The upper jaw moves back and forth slightly and rythmically, but the dropping of the lower jaw opens the mouth. There are three rows of tiny black teeth below the mouth and one row above; at the sides and below these teeth are little, finger-like fringes. Fringes, rows of teeth and jaws all work together, up and down, out and in, in the process of breathing. The nostrils, although minute, are present in the tadpole in its early stages. The pupil of the eye is almost circular and the iris is usually yellow or copper-bronze, with black mottling. The eyes do not wink nor withdraw. The breathing-pore on the left side, is a hole in a slight protuberance.

At first, the tadpoles of the frogs and toads are very much alike; but later, most of the frog tadpoles are lighter in color, usually being olivegreen, mottled with specks of black and white. The frog tadpoles usually remain much longer than the toads in the tadpole stage, and when finally they change to aduits, they are far larger in size than the toads are, when they attain their jumping legs.

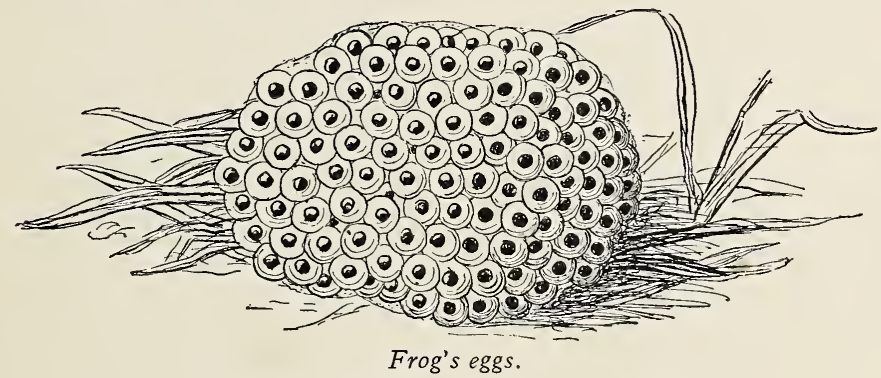

LESSON XLVII

\section{The Frog}

Leading thought-The frog lives near or in ponds or streams. It is a powerful jumper and has a slippery body. Its eggs are laid in masses of jelly at the bottom of ponds.

Method-The frog may be studied in its native situation by the pupils or it may be brought to the school and placed in an aquarium; however, to make a frog aquarium there needs to be a stick or stone projecting above the water, for the frog likes to spend part of the time entirely out of water or only partially submerged.

Observations-I. Where is the frog found? Does it live all its life in the water? When found on land how and where does it seek to escape?

2. Compare the form of the frog with that of the toad. Describe the skin; its color and texture. Compare the skin of the two.

3. Describe the colors and markings of the frog on the upper and on the under side. How do these protect it from observation from above? From below? How do we usually discover that we are in the vicinity of a frog?

4. Describe the frog's ears, eyes, nostrils and mouth.

5. Compare its "hands and feet" with those of the toad. Why the difference in the hind legs and feet? 
6. How does the frog feel to your hand? Is it easy to hold him? How does this slipperiness of the frog benefit it?

7. On what does the frog feed? What feeds on it? How does it escape its enemies?

8. What sounds does the frog make? Where are its sound sacs located? How do they look when they are inflated?

9. Is the frog a good swimmer? Is it a better jumper than the toad? Why?

Io. Where are the frog's eggs laid? How do they look?

I . Can you tell the frog tadpoles from those of the toad? Which remains longer in the tadpole stage? Study the frog tadpoles, following the questions given in Lesson XLIV.

I2. What happens to the frog in winter?

\section{FESTINA LENTE}

Once on a time there was a pool

Fringed all about with flag-leaves cool And spotted with cow-lilies garish,

Of frogs and pouts the ancient parish. Alders the creaking redwings sink on,

Tussocks that house blithe Bob o' Lincoln, Hedged round the unassailed seclusion, Where muskrats piled their cells Carthusian;

And many a moss-embroidered log,

The watering-place of summer frog,

Slept and decayed with patient skill,

As watering-places sometimes will.

Now in this Abbey of Theleme,

Which realized the fairest dream

That ever dozing bull-frog had,

Sunned, on a half-sunk lily pad,

There rose a party with a mission

To mend the polliwog's condition,

Who notified the selectmen

To call a meeting there and then.

"Some kind of steps," they said, "are needed;

They don't come on so fast as we did:

Let's dock their tails; if that don't make em

Frogs by brevet, the Old One take 'em!

That boy, that came the other day

To dig some flag-root down this way,

His jack-knife left, and 'tis a sign

That Heaven approves of our design:

' $T$ were wicked not to urge the step on,

When Providence has sent the weapon.".

Old croakers, deacons of the mire,

That led the deep batrachian choir,

"Ukl Uk! Caronk!" with bass that might

Have left Lablache's out of sight,

Shook nobby heads, and said "No, go!

You'd better let 'em try to grow:

Old Doctor Time is slow, but still

He does know how to make a pill."

But vain was all their hoarsest bass,

Their old experience out of place,

And spite of croaking and entreating
The vote was carried in marsh-meeting.

"Lord knows, "protest the polliwogs,

"We're anxious to be grown-up frogs;

But don't push in to do the work

Of Nature till she prove a shirk;

'Tis not by jumps that she advances, But wins her way by circumstances;

Pray, wait awhile, until you know

We're so contrived as not to grow;

Let Nature take her own direction,

And she'll absorb our imperfection;

You mightn't like 'em to appear with,

But we must have the things to steer with."

"No," piped the party of reform,

"All great results are ta'en by storm;

Fate holds her best gifts till we show

We've strength to make her let them go;

The Providence that works in history,

And seems to some folks such a mystery,

Does not creep slowly on, incog.,

But moves by jumps, a mighty frog;

No more reject the Age's chrism,

Your queues are an anachronism;

No more the future's promise mock,

But lay your tails upon the block,

Thankful that we the means have voted

To have you thus to frogs promoted."

The thing was done, the tails were cropped,

And home each philotadpole hopped,

In faith rewarded to exult,

And wait the beautiful result.

Too soon it came; our pool, so long

The theme of patriot bull-frog's song,

Next day was reeking, fit to smother,

With heads and tails that missed each other,-

Here snoutless tails, there tailless snouts;

The only gainers were the pouts.

\section{MORAL}

From lower to the higher next,

Not to the top is Nature's text;

And embryo Good, to reach full stature,

Absorbs the Evil in its nature.

-Lowell 
excited, evidently holding his breath since the pulsating throat would become rigid. There was a particularly alert attitude of the

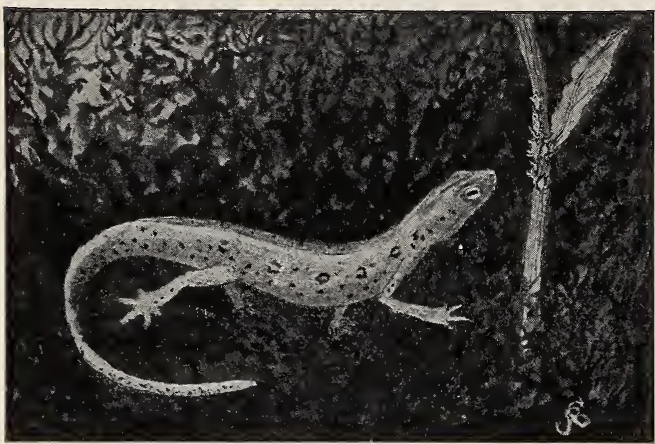

Red-spotted newt stalking plant-lice. whole front part of the body and especially of the eyes and the head; then the neck would stretch out long and thin, the orange snout approach stealthily within half an inch of the smug aphid, and then there was a flash as of lightning, something too swift to see coming out of the eft's mouth and swooping up the unsuspecting $10 \mathrm{use}$. Then there would be a gulp or two and all would be over. If the aphid happened to be a big one, the eft made visible effort to swallow it. Sometimes his eftship would become greatly excited when he first saw the plant-louse, and he would sneeze and snort in a very comical way, like a dog, when eager for game.

The following is the history of this species as summarized from Mrs. S. H. Gage's charming "Story of Little Red Spot." The egg was laid in some fresh water pond or the still borders of some stream where there is a growth of water weed. The egg, which is about the size of a small pea, is fastened to a water plant. It is covered with a tough but translucent envelope, and has at the center a little yellowish globule. In a little less than a month the eft hatches, but it looks very different from the form with which we are most familiar. It has gray stripes upon its sides and three tiny bunches of red gills on each side, just back of its broad head. The tail is long and very thin, surrounded by a fin; it is an expert swimmer and breathes water as does a fish. After a time, it becomes greenish above and buff below, and by the middle of August it develops legs and has changed its form so that it is able to live upon land; it no longer has gills or fin; soon the coat changes to the bright orange hue which makes the little creature so conspicuous.

The newt usually keeps hidden among moss, or under leaves, or in decaying wood, or other damp and shady places; but after a rain, when the whole world is damp, it feels confidence enough to go out in the open, and hunt for food. For two and a half years it lives upon land and then returns to the water. When this impulse comes upon it, it may be far from any stream; but it seems to know instinctively where to go. Soon after it enters the water, it is again transformed in color, becoming olivegreen above and buff below, although it still retains the red spots along the back, as mementos of its land life; and it also retains its pepper-like dots. Its tail develops a fin which extends along its back and is somewhat ruffled. In some mysterious way it develops the power to again breathe the air which is mixed with water. 
The male has the hind legs very large and flat; the female is lighter in color and has more delicate and smaller legs. It is here in the water that the efts find their mates and finish careers which must have surely been hazardous. During its long and varied life, the eft often sheds its skin like the snake; it has a strange habit of swallowing its cast-off coat.

\section{LESSON XLVIII}

\section{The Newt, Eft, or "Salamander"}

Leading thought-The newts change their form three times to fit different modes of life. They are born in the water and at first have fins and gills like fishes. They then live on land, and have lungs for breathing air and lose their fins; later they go back to the water and again develop the power of breathing the oxygen contained in water, and also a fin.

Method-The little, orange eft or red-spotted salamander may be kept in an aquarium which has in it an object, as a stone or a clump of moss which projects above the water. For food it should be given small earthworms or leaves covered with plant lice. In this way it may be studied at leisure.

Observations-I. Look at the eft closely. Is it all the same color? How many spots upon its back and what colors are they? Are there the same number of spots on both sides? Are there any spots or dots besides these

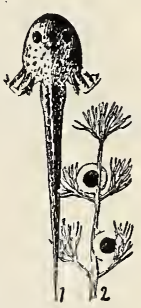

Early stage of vermilionspotted newt. Eggs of newt att ached to water plant. Drawn by Anna Stryke. larger ones? How does the eft resemble a toad?

2. Is the head the widest part of the body? Describe the eyes, the shape and color of the pupil and of the iris. How does the eft wink? Do you think it can see well?

3. Can you see the nostrils? How does the throat move and why?

4. Are both pairs of legs the same size? How many toes on the front feet? How many toes on the hind feet? Does the eft toe-in with its front feet like a toad?

5. Does it move more than one foot at a time when walking? Does it use the feet on the same side in two consecutive steps? After putting forward the right front foot what foot follows next? Can it move backward?

6. Is the tail as long as the head and body together? Is the tail round or flat at the sides? How is it used to help the eft when traveling? Does the tail drag or is it lifted, or does it push by squirming?

7. How does the eft act when startled? Does it examine its surroundings? Do you think it can see and is afraid of you?

8. Why do we find these creatures only during wet weather? Why do people think they rain down?

9. What does the eft eat? How does it catch its prey? Does it shed its skin? How many kinds of efts have you seen?

ro. From what kind of egg does the eft hatch? When is this egg laid? How does it look? On what is it fastened?

II. How many times during its life does the orange eft change color? What part of its life is spent upon land? What changes take place in its form when it leaves the water for life upon land, and what changes take place in its structure when it returns to the water? 


\section{REPTILE STUDY}

Yet when a child and barefoot; I more than once, at morn, Have passed, I thought, a whiflash unbraided in the sun, When, stooping to secure it, it wrinkled, and was gone.

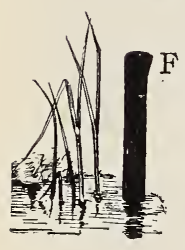

-Emily Dickinson.

F the teacher could bring herself to take as much interest as did Mother Eve in that "subtile animal," as the Bible calls the serpent, she might, through such interest, enter the paradise of the boyish heart instead of losing a paradise of her own. How many teachers, who have an aversion for snakes, are obliged to teach small boys whose pet diversion is capturing these living ribbons and bringing them into the schoolroom stowed away not too securely in pockets! In one of the suburban Brooklyn schools, boys of this ilk sought to frighten their teacher with their weird prisoners. But she was equal to the occasion, and surprised them by declaring that there were many interesting things to be studied about snakes, and forthwith sent to the library for books which discussed these reptiles; and this was the beginning of a nature-study club of rare efficiency and enterprise.

There are abroad in the land, many errors concerning snakes. Most people believe that they are all venomous, which is far from true. The rattlesnake still holds its own in rocky, mountainous places and the moccasin haunts the bayous of the southern coast; however, in most localities, snakes are not only harmless but are beneficial to the farmer. The superstition that if a snake is killed; its tail will live until sun-down, is general and has but slender foundation in the fact that snakes, being lower in their nerve-organization than mammals, the process of death is a slow one. Some people firmly believe that snakes spring or jump from the ground to seize their prey, which is quite false since no snake jumps clear of the ground as it strikes, nor does it spring from a perfect coil. Nor are snakes slimy, quite to the contrary, they are covered with perfectly dry scales. But the most general superstition of all is that, when a snake thrusts out its tongue, it is an act of animosity; the fact is, the tongue is a sense organ and is used as an insect uses its feelers or antennae, and the act is also supposed to aid the creature in hearing; thus when a snake thrusts out its tongue, it is simply trying to find out about its surroundings and what is going on.

Snakes are the only creatures able to swallow objects larger than themselves. This is rendered possible by the elasticity of the body walls, and the fact that snakes have an extra bone hinging the upper to the lower jaw, allowing them to spread widely; the lower jaw also separates at the middle of its front edge and spreads apart sidewise. In order to force a creature into a "bag" so manifestly too small, a special mechanism is needed; the teeth supply this by pointing backward, and thus assist in the swallowing. The snake moves by literally walking on the ends of its ribs, which are connected with the crosswise plates on its lower side; each of these crosswise plates has the hind edge projecting down so that it can hold to an object. Thus, the graceful, noiseless progress of the snake, is brought about by many of these crosswise plates worked by the movement of the ribs. 
Some species of snakes simply chase their prey, striking at it and catching it in the open mouth, while others, like the black snake, wind themselves about their victims crushing them to death. Snakes can live a long time without food; many instances on record show that they have been able to exist a year or more without anything to eat. In our northern climate they hibernate in winter, going to sleep as soon as the weather becomes cold and not waking up until spring. As snakes grow, they shed their skins; this occurs only two or three times a year. The crested fly-catcher adorns its nest with these phantom snakes.

References-The Reptile Book, by Ditmars, gives interesting accounts of our common snakes; Mathew's Familiar Life of Field and Forest is also valuable. To add interest to the snake lessons let the children read "Kaas Hunting" and "Rikki Tikki Tavi" from Kipling's Jungle Books.

\section{THE GARTER, OR GARDEN, SNAKE}

\section{Teacher's Story}

A chipmunk, or a sudden-whirring quail, Is startled by my step as on ${ }_{x}^{T}$ fare.

A gartersnake across the dusty trail, Glances and - is not there.-RILEY.

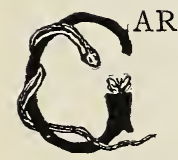

RTER snakes can be easily tamed, and are ready to meet friendly advances half way. A handsome yellow-striped, black garter lived for four years beneath our piazza and was very friendly and unafraid of the family. The children of the campus made it frequent visits, and never seemed to be weary of watching it; but the birds objected to it very much, although it never attempted to reach their nests in the vine above. The garter snakes are the most common of all, in our Northeastern States. They vary much in color; the ground color may be olive, brown or black, and down the center of the back is usually a yellow, green or whitish stripe, usually bordered by a darker band of ground-color. On each side is a similar stripe, but not so brightly colored; sometimes the middle stripe, and sometimes the side stripes are broken into spots or absent; the lower side is greenish white or yellow. When fully grown this snake is about three feet in length.

The garters are likely to congregate in numbers in places favorable for hibernation, like rocky ledges or stony side-hills. Here each snake finds a safe crevice, or makes a burrow which sometimes extends a yard or more under ground. During the warm days of Indian summer, these winter hermits crawl out in the middle of the day and sun themselves, retiring again to their hermitages when the air grows chilly toward night; and when the cold weather arrives, they go to sleep and do not awaken until the first warm days of spring; then, if the sun shines hot, they crawl out and bask in its welcome rays.

After the warm weather comes, the snakes scatter to other localities more favorable for finding food, and thus these hibernating places are deserted during the summer. The banks of streams, and the edges of woods are places which furnish snakes their food, which consists of earthworms, insects, toads, salamanders, frogs, etc. The young are born late 
in July and are about six inches long at birth; one mother may have in her brood from eleven to fifty snakelings; she stays with them during the fall to protect them, and there are many stories about the way the young ones run down the mother's throat in case of attack; but, as yet, no scientist has seen this act, or placed it on record. The little snakes shift for their own food, catching small toads, earthworms and insects. If it finds food in plenty, the garter snake will mature in one year. Hawks, crows, skunks, weasels and other predacious animals seem to find the garter snake attractive food.

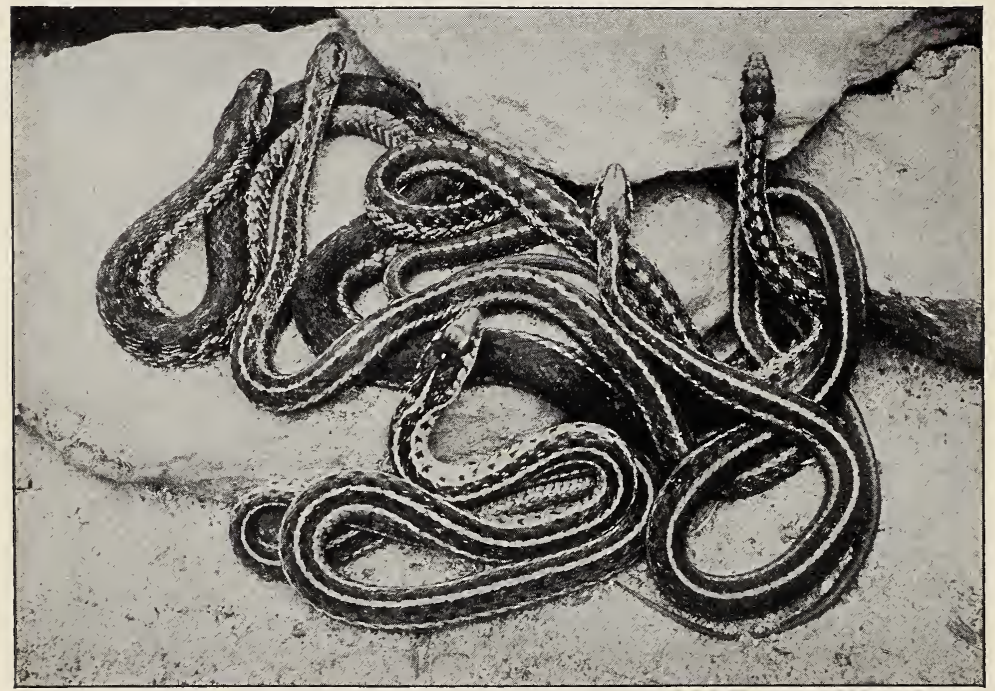

Garter snakes.

\section{LESSON XLIX}

The Garter, or Garden, Snake

Leading thought-The garter snake is a common and harmless little creature and has many interesting habits which are worth studying.

Method-A garter snake may be captured and placed in a box with a glass cover and thus studied in detail in the schoolroom, but the lesson should begin with observations made by the children on the snakes in their native haunts.

Observations- - . What are the colors and markings of your garter snake? Do the stripes extend along the head as well as the body? How long is it?

2. Describe its eyes, its ears, its nostrils and its mouth.

3. If you disturb it how does it act? Why does it thrust its tongue out? What shape is its tongue? 
4. In what position is the snake when it rests? Can you see how it moves? Look upon the lower side. Can you see the little plates extending crosswise? Do you think it moves by moving these plates? Let it crawl across your hand, and see if you can tell how it moves.

5. What does the garter snake eat? Did you ever see one swallow a toad? A frog? Did it take it head first or tail first?

6. Where does the garter spend the winter? How early does it appear in the spring?

7. At what time of year do you see the young snakes? Do the young ones run down the throat of the mother for safety when attacked? Does the mother snake defend her young?

8. What enemies has the garter snake?

"No life in earth or air or sky;

The sunbeams, broken silently,

On the bared rocks around me lie,-

Cold rocks with half-warmed lichens scarred,

And scales of moss; and scarce a yard

Away, one long strip, yellow-barred.

Lost in a cleft! 'Tis but a stride

To reach it, thrust its roots aside,

And lift it on thy stick astride!

Yet stay! That moment is thy grace!

For round thee, thrilling air and space,

$A$ chattering terror fills the place!

$A$ sound as of dry bones that stir,

In the dead valley! By yon fir

The locust stops its noon-day whir!

The wild bird hears; smote with the sound. As if by bullet brought to ground

On broken wing, dips, wheeling round!

The hare, transfixed, with trembling lip,

Halts breathless, on pulsating hip,

And palsied tread, and heels that slip.

Enough, old friend!-'tis thou. Forget

My heedless foot, nor longer fret

The peace with thy grim castanet!"

From "Crotalus" (The Rattlesnake), Bret Harte. 


\section{THE MILK SNAKE, OR SPOTTED ADDER}

\section{Teacher's Story}

The grass divides as with a comb, a spotted shaft is seen, And then it closes at your feet, and opens farther on.

-Emili Dickinson.

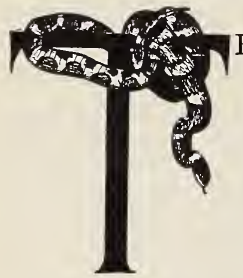

HIS is the snake which is said to milk cows, a most absurd belief; it would not milk a cow if it could, and it could not if it would. It has never yet been induced to drink milk when in captivity; and if it were very thirsty, it could not drink more than two teaspoonfuls of milk at most; thus in any case, its depredations upon the milk supply need not be feared. Its object, in frequenting milk houses and stables, is far other than the milking of cows, for it is an inveterate hunter of rats and mice and is thus of great benefit to the farmer. It is a constrictor, and squeezes its prey to death in its coils.

The ground color of the milk snake is pale gray, but it is covered with so many brown or dark gray saddle-shaped blotches, that they seem rather to form the ground-color; the lower side is white, marked with square black spots and blotches. The snake attains a length of about three feet when fully grown. Although it is called commonly the spotted adder, it does not belong to the adders at all, but to the family of the king snakes.

During July and August, the mother snake lays from seven to twenty eggs; they are deposited in loose soil, in moist rubbish, in compost heaps, etc. The egg is a symmetrical oval in shape and is about one and oneeighth inches long by a half inch in diameter. The shell is soft and white, like kid leather, and the egg resembles a puffball. The young hatch nearly two months after the eggs are laid, meanwhile the eggs have increased in size so that the snakelings are nearly eight inches long when they hatch. The saddle-shaped blotches on the young have much red in them. The milk snake is not venomous; it will sometimes, in defence, try to chew the hand of the captor, but the wounds it can inflict are very slight and heal quickly.

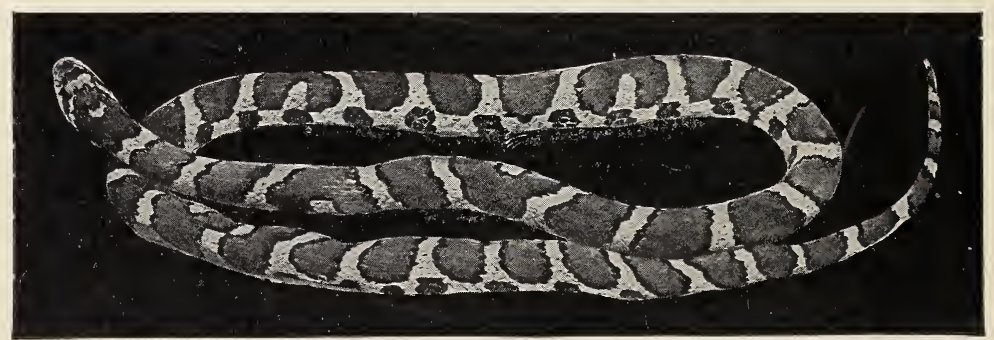

The milk snake, or spotted adder. 


\section{LESSON L.}

\section{The Milk Snake, or Spotted Adder}

Leading thought-The milk snake is found around stables where it hunts for rats and mice but never milks the cows.

Method-Although the snake acts fiercely, it is perfectly harmless and may be captured in the hands and placed in a glass-covered box for a study in the schoolroom.

Observations-I. Where is the milk snake found? Why is it called milk snake? Look at its mouth and see if you think it could possibly suck a cow. See if you can get the snake to drink milk.

2. What does it live upon? How does it kill its prey? Can the milk snake climb a tree?

3. Where does the mother snake lay her eggs? How do the eggs look? How large are they? How long are the little snakes when they hatch from the egg? Are they the same color as the old ones?

4. Describe carefully the colors and markings of the milk snake and explain how its colors protect it from observation. What are its colors on the under side?

5. Have you ever seen a snake shed its skin? Describe how it was done. How does the sloughed-off skin look? What bird always puts snake skins around its nest?

I have the same objection to killing a snake that I have to the killing of any other animal, yet the most humane man I know never omits to kill one.

Aug. 5, 1853 .

The mower on the river meadows, when he comes to open his hay these days, encounters some overgrown water adder, full of young (?) and bold in defense of its progeny, and tells a tale when he comes home at night which causes a shudder to run through the village - how it came at him and he ran, and it pursued and overtook him, and he transfixed it with a pitchfork and laid it on a cock of hay, but it revived and came at him again. This is the story he tells in the shops at evening. The big snake is a sort of fabulous animal. It is always as big as a man's arm and of indefinite length. Nobody knows exactly how deadly is its bite but nobody is known to have been bitten and recovered. Irishmen introduced into these meadows for the first time, on seeing a snake, a creature which they have seen only in pictures before, lay down their scythes and run as if it were the Evil One himself and cannot be induced to return to their work. They sigh for Ireland, where they say there is no venomous thing that can hurt you. 


\section{THE WATER SNAKE}

\section{Teacher's Story}

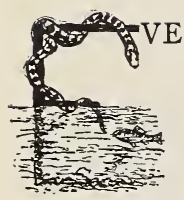

ERY boy that goes fishing, knows the snake found commonly about mill-dams and wharves or on rocks and bushes near the water. The teacher will have accomplished a great work, if these boys are made to realize that this snake is a more interesting creature for study, than as an object to pelt with stones.

The water snake is a dingy brown in color, with crossbands of brownish or reddish brown which spread out into blotches at the side. Its color is very protective as it lies on stones or logs in its favorite attitude of sunning itself. It is very local in its habits, and generally has a favorite place for basking and returns to it year after year on sunny days.

This snake lives mostly upon frogs and salamanders and fish; however, it preys usually upon fish of small value, so it is of little economic importance. It catches its victims by chasing, and seizing them in its jaws. It has a very keen sense of smell and probably traces its prey in this manner, something as a hound follows a fox. It is an expert swimmer, usually lifting the head a few inches above the water when swimming, although it is able to dive and remain below the water for a short time.

The water snake is a bluffer, and, when cornered, it flattens itself and strikes fiercely. But its teeth contain no poison and it can inflict only slight and harmless wounds. When acting as if it would "rather fight than eat," if given a slight chance to escape, it will flee to the water like a "streak of greased lightning," as any boy will assure you.

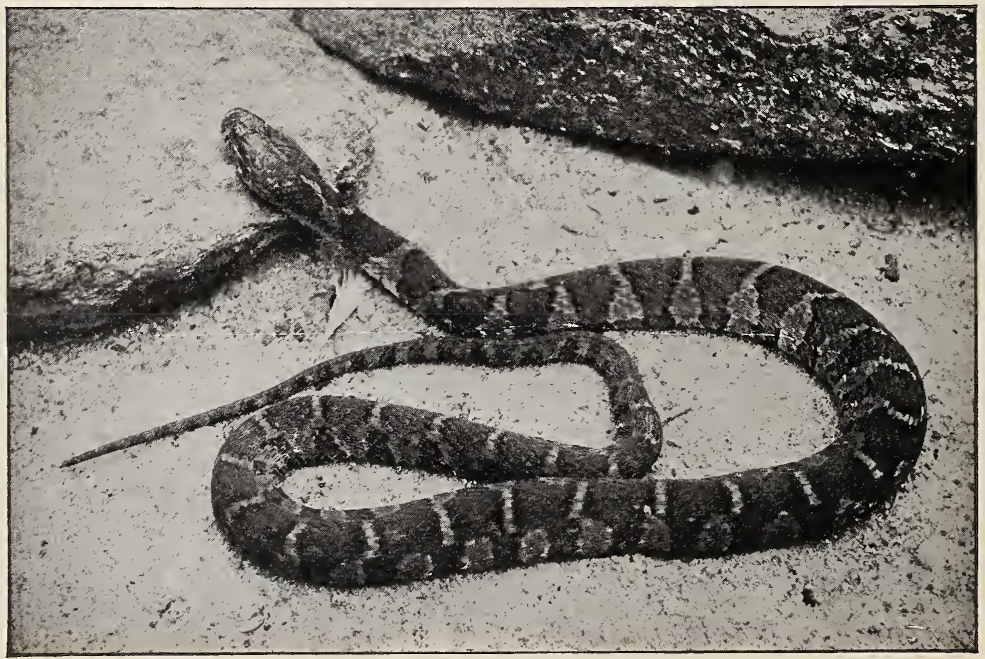

The water snake. 
The water snake attains a length of about four feet. The young do not hatch from eggs, but are born alive in August and September; they differ much in appearance from their parents as they are pale gray in color, with jet-black cross-bands.

\section{LESSON LI}

\section{The Water Snake}

Leading thought-The water snake haunts the banks of streams because its food consists of creatures that live in and about water.

Method-If water snakes are found in the locality, encourage the boys to capture one without harming it, and bring it to school for observation. However, as the water snake is very local in its habits, and haunts the same place year after year, it will be better nature-study to get the children to observe it in its native surroundings.

Observations-I. Where is the water snake found? How large is the largest one you ever saw?

2. Why does the water snake live near water? What is its food? How does it catch its prey?

3. Describe how the water snake swims. How far does its head project above the water when swimming? How long can it stay completely beneath the water?

4. Describe the markings and colors of the water snake. How do these colors protect it from observation? How do the young look?

5. Does each water snake have a favorite place for sunning itself?

6. Where do the water snakes spend the winter?

May I2, 1858 .

Found a large water adder by the edge of Farmer's large mudhole, which abounds with tadpoles and frogs, on which it was probably feeding. It was sunning on the bank and would face me and dart its head toward me when I tried to drive it from the water. It is barred above, but indistinctly when out of the water, so that it appears almost uniformly dark brown, but in the water, broad, reddish brown bars are seen. very distinctly alternating with very dark-brown ones. The head was very flat and suddenly broader than the neck behind. Beneath, it was whitish and reddish flesh-color. It was about two inches in diameter at the thickest part. The inside of its mouth and throat was pink. They are the biggest and most formidable-looking snakes that we have. It was awful to see it wind along the bottom of the ditch at last, raising wreaths of mud amid the tadpoles, to which it must be a very sea-serpent. I afterward saw another, running under Sam Barrett's grist-mill, the same afternoon. He said that he saw a water-snake, which he distinguished from a black snake, in an apple tree near by, last year, with a young robin in its mouth, having taken it from the nest. There was a cleft or fork in the tree which enabled it to ascend. 


\section{THE TURTLE \\ Teacher's Story}

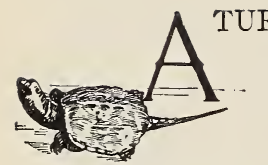

RTLE is at heart a misanthrope; its shell is in itself proof of its owner's distrust of this world. But we need not wonder at this misanthropy, if we think for a moment of the creatures that lived on this earth, at the time when turtles first appeared. Almost any of us would have been glad of a shell in which to retire, if we had been contemporaries of the smilodon and other monsters of earlier geologic times.

When the turtle feels safe and walks abroad for pleasure, ilis head projects far from the front end of his shell, and the legs, so wide, and soft that they look as if they had no bones in them, project out at the side, while the little, pointed tail brings up an undignified rear; but frighten him and at once head, legs and tail all disappear, and even if we turn him over, we see nothing but the tip of the nose, the claws of the feet and the tail turned deftly sidewise. When frightened, he hisses threateningly; the noise seems to be made while the mouth is shut, and the breath emitted through the nostrils.

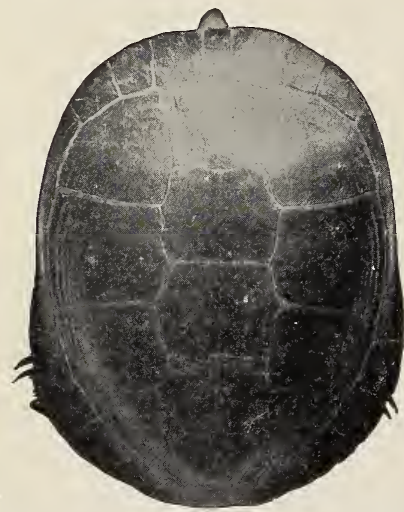

Carapace of painted terrapin in retirement.

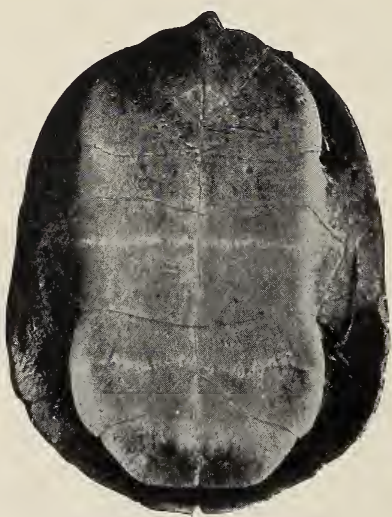

Plastron of same terrapin.

The upper shell of the turtle is called the carapace and the lower shell, the plastron. There is much difference in the different species of turtles in the shape of the upper shell and the size and shape of the lower one. In most species the carapace is sub-globular but in some it is quite flat. The upper shell is grown fast to the backbone of the animal, and the lower shell to the breast bone. The markings and colors of the shell offer excellent subjects for drawing. The painted terrapin has a red-mottled border to the shell, very ornamental; the wood turtle has a shell made up of plates each of which is ornamented with concentric ridges; and the boxturtle has a front and rear trap-door, hinged to the plastron, which can be pulled up against the carapace when the turtle wishes to retire, thus covering it entirely. 
The turtle's head is decidedly snakelike. Its color differs with different species. The wood turtle has a triangular, horny covering on the top of the head, in which the color and beautiful pattern of the shell are repeated; the underparts are brick-red with indistinct yellowish lines under the jaw. The eyes are black with a yellowish iris, which somehow gives them a look of intelligence. The turtle has no eyelids like our own, but has a nictitating membrane which comes up from below and completely covers the eye; if we seize the turtle by the head and attempt to touch its eyes, we can see the use of this eyelid. When the turtle winks, it seems to turn the eyeball down against the lower lid.

The sense of smell in turtles is not well developed, as may be guessed by the very small nostrils, which are mere pin-holes in the snout. The mouth is a more or less hooked beak, and is armed with cutting edges instead of teeth. The constant pulsation in the throat is caused by the turtle swallowing air for breathing.

The turtle's legs, although so large and soft, have bones within them, as the skeleton shows. The claws are long and strong; there are five claws on the front and four on the hind feet. Some species have a distinct web between the toes; in others, it is less marked, depending upon whether the species lives mostly in water or out of it. The color of the turtle's body varies with the species; the body is covered with coarse, rough skin made up of various-sized plates.

The enemies of turtles are the larger fishes and other turtles. Two turtles should never be kept in the same aquarium, since they eat each others' tails and legs with great relish. They feed upon insects, small fish, or almost anything softbodied which they can find in the water; they are especially fond of.

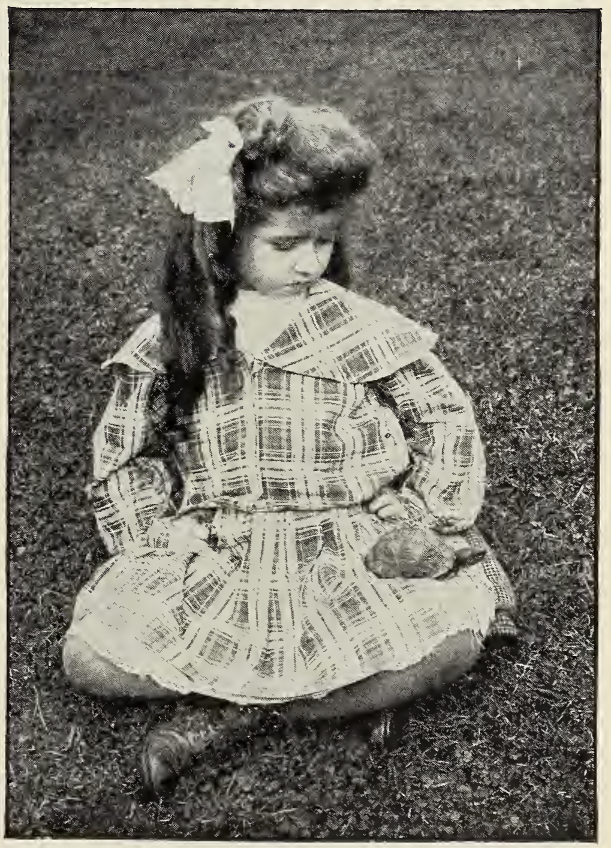

Boxy, a trained turtle. Photo by Silas Lottridge. earthworms. The species which frequent the land, feed upon tender vegetation and also eat berries. In an aquarium, a turtle should be fed earthworms, chopped fresh beef, lettuce leaves and berries. The wood turtle is especially fond of cherries. 
The aquarium should always have in it a stone or some other object projecting above the water, so that the turtle may climb out, if it chooses. In winter, iurtles bury themselves in the ooze at the bottom of ponds and streams. Their eggs have white leathery shells, are oblong or round, and are buried by the mother in the sand or soil near a stream or pond. The long life of turtles is a well authenticated fact, dates carved upon' their shells show them to have attained the age of thirty or forty years.

The following are, perhaps, the most common species of turtles:

(a) The Snapping Turtle-This sometimes attains a shell I4 inches long and a weight of forty pounds. It is a vicious creature and inflicts a severe wound with its sharp, hooked beak; it should not be used for a nature-study lesson unless the specimen is very young.

(b) The Mud Turtle-The musk turtle and the common mud turtle both inhabit slow streams and ponds; they are truly aquatic and only come to shore to deposit their eggs. They cannot eat, unless they are under water, and they seek their food in the muddy bottoms. The musk turtle when handled, emits a very strong odor; it has on each side of the head two broad yellow stripes. The mud turtle has no odor. Its head is ornamented with greenish yellow spots.

(c) The Painted Terrapin, or Pond Turtle-This can be determined by the red mottled border of its shell. It makes a good pet, if kept in an aquarium by itself, but will destroy other creatures. It will eat meat or chopped fish, and is fond of earthworms and soft insects.

(d) The Spotted Turtle-This has the upper shell black with numerous round yellow spots upon it. It is common in ponds and marshy streams and its favorite perch is, with many of its companions, upon a log. It feeds under water, eating insect larvæ, dead fish and vegetation. It likes fresh lettuce.

(e) The Wood Terrapin-This is our most common turtle; it is found in damp woods and wet places, since it lives largely upon the land. Its upper shell often reaches a length of six and one-half inches and is made up of many plates, ornamented with concentric ridges. This is the turtle upon whose shell people carve initials and dates and then set it free. All the fleshy parts of this turtle, except the top of the head and the limbs, are brick-red. It feeds on tender vegetables, berries and insects. It makes an interesting pet and will soon learn to eat from the fingers of its master.

(f) The Box-Turtle-This is easily distinguished from the others, because the front and rear portions of the lower shell are hinged so that they can be pulled up against the upper shell. When this turtle is attacked, it draws into the shell and closes both front and back doors, and is very safe from its enemies. It lives entirely upon land and feeds upon berries, tender vegetation and insects. It lives to a great age.

(g) The Soft-shelled Turtle-These are found in streams and canals. The upper shell looks as if it were of one piece of soft leather, and resembles a griddle-cake. Although soft-shelled, these turtles are far from softtempered, and must be handled with care. 


\section{LESSON LII}

\section{The Turtle}

\section{Leading thought-} The turtle's shell is for the purpose of protecting its owner from the attack of enemies. Some turtles live upon land and others in water. Method-A turtle of any kind, in the schoolroom, is all that is needed to make this lesson interesting.

ObservationsI. How much can you see of the turtle when it is walking? If you disturb it what does it do? How much of it can you see then? Can you see more of it from the

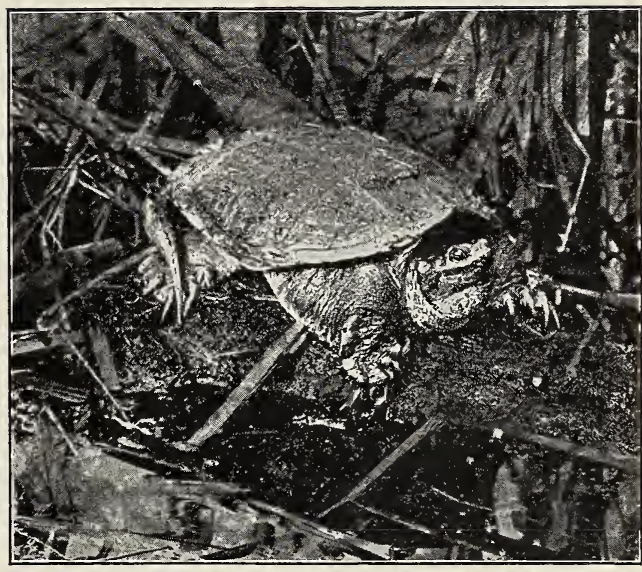

A snapping turtle.

Photo by J. T. Lloyd. lower side than the upper? What is the advantage to the turtle of having such a shell?

2. Compare the upper shell with the lower as follows: How are they shaped differently? What is their difference in color? Would it be a disadvantage to the turtle if the upper shell were as light colored as the lower? Why? Make a d:awing of the upper and the lower shell showing the shape of the plates of which they are composed. Where are the two grown together?

3. Is the border of the upper shell different from the central portion in color and markings? Is the edge smooth or scalloped?

4. How far does the turtle's head project from the front of the shell? What is the shape of the head? With what colors and pattern is it marked? Describe the eyes. How are they protected? How does the turtle wink? Can you discover the little eyelid which comes up from below to cover the eye?

5. Describe the nose and nostrils. Do you think it has a keen sense of smell?

6. Describe the mouth. Are there any teeth? With what does it bite off its food? Describe the movement of the throat. Why is this constant pulsation?

7. What is the shape of the leg? How is it marked? How many claws on the front feet? Are any of the toes webbed? Or. which fect are the webbed toes? Why should they be webbed? Describe the way a turtle swims. Which feet are used for oars?

8. Describe the tail. How much can be seen from above when the turtle is walking? What becomes of it, when the turtle withdraws into its shell? 
9. How much of the turtle's body can you see? What is its color? Is it rough or smooth?

ro. What are the turtle's enemies? How does it escape from them? What noise does the turtle make when frightened or angry?

II. Do all turtles live for part of the time in water? What is their food and where do they find it? Write an account of all the species of turtles that you know.

I 2. How do turtle eggs look? Where are they laid? How are they hidden?

Supplementary reading — “Turtle Eggs for Agassiz," Dalles Lore Sharp, Altantic Monthly, Feb., Igı。.

\section{MAMMAL STUDY}
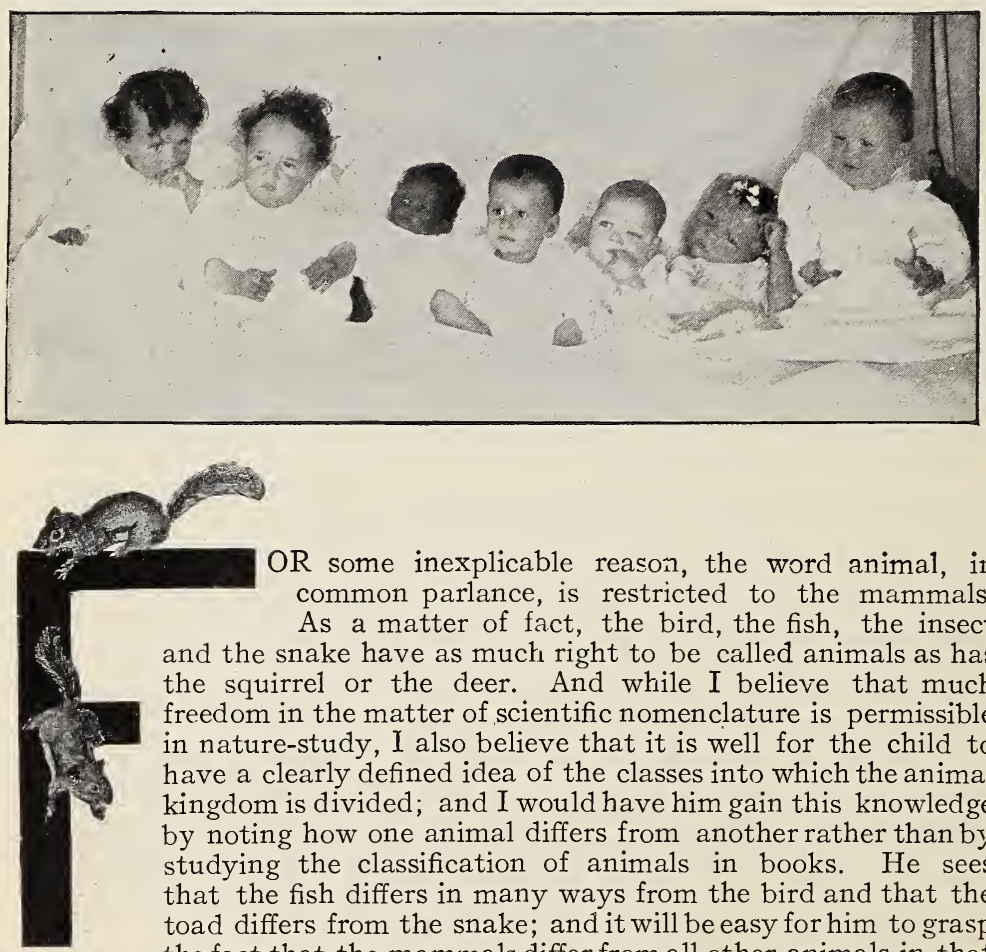

OR some inexplicable reason, the word animal, in common parlance, is restricted to the mammals. As a matter of fact, the bird, the fish, the insect and the snake have as much right to be called animals as has the squirrel or the deer. And while I believe that much freedom in the matter of scientific nomenclature is permissible in nature-study, I also believe that it is well for the child to have a clearly defined idea of the classes into which the animal kingdom is divided; and I would have him gain this knowledge by noting how one animal differs from another rather than by studying the classification of animals in books. He sees that the fish differs in many ways from the bird and that the toad differs from the snake; and it will be easy for him to grasp the fact that the mammals differ from all other animals in that the young are nourished by milk produced for this purpose in the breasts of the mother; when he understands this, he can comprehend how such diverse forms as the whale, the cow, the bat, and human beings are akin. 


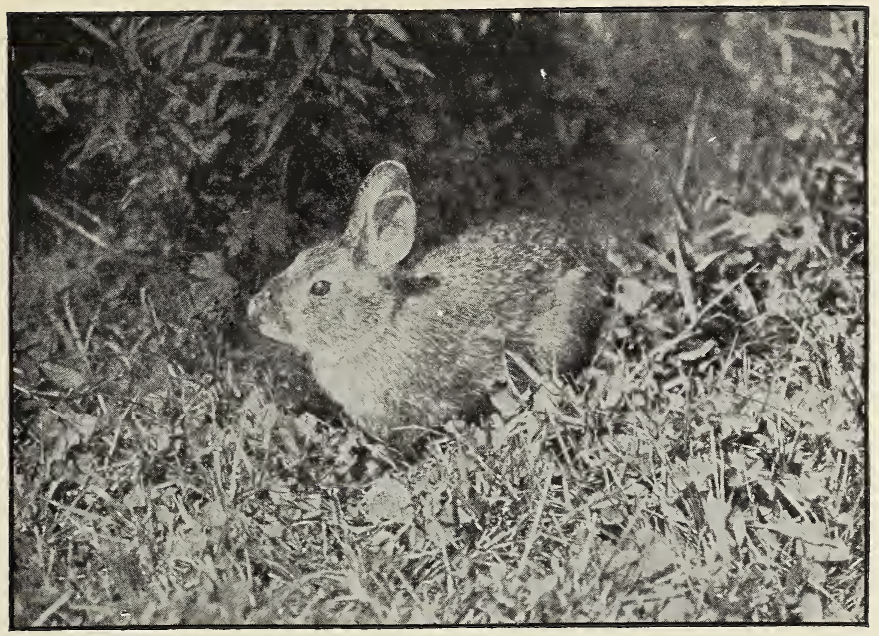

A cotton-tail rabbit.

\section{THE COTTON-TAIL RABBIT}

\section{Teacher's Story}

"The Bunnies are a jeeble folk whose weakness is their strength.

To shun a gun a Bun will run to almost any length."--Oliver Herford.

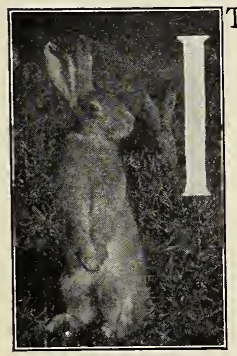

T IS well for Molly Cotton-tail and her family that they have learned to shun more than guns for almost every predatory animal and bird makes a dinner of them on every possible occasion. But despite these enemies, moreover, with the addition of guns, men and dogs, the cotton-tail lives and flourishes in our midst. A "Molly" raised two families last year in a briar-patch back of our garden on the Cornell Campus, where dogs of many breeds abound; and after each fresh fall of snow this winter we have been able to trace our bunny neighbors in their night wanderings around the house, beneath the spruces and in the orchard. The track consists of two long splashes, paired, and between and a little behind them, two smaller ones; the rabbit uses its front feet as a boy uses a vaulting pole and lands both hind feet on each side and ahead of them; owing to the fact that the bottoms of the feet are hairy the print is not clear-cut. When the rabbit is not in a hurry it has a peculiar lope, but when frightened it makes long jumps. The cotton-tails are night wanderers and usually remain hidden during the day. In summer, they feed on clover or grass or other juicy herbs and show a fondness for sweet apples and fresh cabbage; in our 
garden last summer Molly was very considerate. She carefully pulled all the grass out of the garden-cress bed, leaving the salad for our enjoyment. In winter, the long, gnawing teeth of the cotton-tail are sometimes used to the damage of fruit trees and nursery stock since the rabbits are obliged to feed upon bark in order to keep alive.

The long, strong hind legs and the long ears tell the whole bunny story. Ears to hear the approach of the enemy, and legs to propel the listener by long jumps to a safe retreat. The attitude of the ears is a good indication of the bunny's state of mind; if they are set back to back and directed backward, they indicate placidity, but a placidity that is always on guard; if lifted straight up they signify attention and anxiety; if one is bent forward and the other backward the meaning is: "Now just where did that sound come from?" When running or when resting in the form, the ears are laid back along the neck. When the cotton-tail stands up on its haunches with both ears erect, it looks very tall indeed.

Not only are the ears always alert, but also the nose; the nostrils are partially covered and in order to be always sure of getting every scent they wabble constantly, the split upper lip aiding in this performance; when the rabbit is trying to get a scent it moves its head up and down in a sagacious, apprehensive manner.

The rabbit has an upper and lower pair of incisors like other rodents, but on the upper jaw there is a short incisor on each side of the large teeth; these are of no use now but are inherited from some ancestor which found them useful. There are at the back of each side of the upper jaw six grinding teeth, and five on each side of the lower jaw. The split upper lip allows the free use of the upper incisors. The incisors are not only used for taking the bark from trees, but also for cutting grass and other food. The rabbit has a funny way of taking a stem of grass or clover at the end and with much wabbling of lips, finally taking it in, meanwhile chewing it with a sidewise motion of the jaws. The rabbits' whiskers are valuable as feelers, and are always kept on the qui vive for impressions; when two cotton-tails meet each other amicably, they rub whiskers together. The eyes are large and dark and placed on the bulge at the side of the head, so as to command the view both ways. Probably a cotton-tail winks, but I never caught one in the act.

The strong hind legs of the rabbit enable it to make prodigious jumps, of eight feet or more; this is a valuable asset to an animal that escapes its enemies by running. The front feet are short and cannot be turned inward like those of the squirrel, to hold food. There are five toes on the front feet, and four on the hind feet; the hair on the bottom of the feet is a protection, much needed by an animal which sits for long periods upon the snow. When sleeping, the front paws are folded under and the rabbit rests on the entire hind foot, with the knee bent, ready for a spring at the slightest alarm; when awake, it rests on the hind feet and front toes; and when it wishes to see if the coast is clear, it rises on its hind feet, with front paws drooping.

The cotton-tail has a color well calculated to protect it from observation; it is brownish-gray on the back and a little lighter along the sides, grayish under the chin and whitish below; the ears are edged with black, and the tail when raised shows a large, white fluff at the rear. The general color of the rabbit fits in with natural surroundings; since the cotton-tail often escapes its enemies by "freezing," this color makes the scheme work 
well. I once saw a marsh hare, on a stone in a brook, freezing r.ost successfully. I could hardly believe that a living thing could seen so much like a stone; only its bright eyes revealed it to us.

The rabbit cleans itself in amusing ways. It shakes its feet, one at a time, with great vigor and rapidity to get off the dirt and then licks them clean. It washes its face with both front paws at once. It scratches its ear with the hind foot, and pushes it forward so that it can be licked; it takes hold of its fur with its front feet to pull it around within reach of the tongue.

The cotton-tail does not dig a burrow, but sometimes occupies the deserted burrow

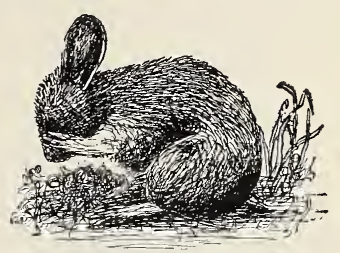

Washing up. of a woodchuck or skunk. Its nest is called a "form," which simply means a place beneath a cover of grass or briars, where the grass is beaten down or eaten out for a space large enough for the animal to sit. The mother makes a soft bed for the young, using grass and her own hair for the purpose; and she constructs a coarse felted coverlet, under which she tucks her babies with care, every time she leaves them. Young rabbits are blind at first, but when about three weeks old, are sufficiently grown to run quite rapidly. Although there may be five or six in a litter, yet there are so many enemies that only a few escape.

Fox, mink, weasel, hawk, owl and snake all relish the young cottontail if they can get it. Nothing but its runways through the briars can save it. These roads wind in and out and across, twisting and turning perplexingly; they are made by cutting off the grass stems, and are just wide enough for the rabbit's body. However, a rabbit has weapons and can fight if necessary; it leaps over its enemy, kicking it on the back fiercely with its great hind feet. Mr. Seton tells of this way of conquering the black snake, and Mr. Sharf saw a cat completely vanquished by the same method. The rabbit can also bite, and when two males are fighting, they bite each other savagely. Mr. E. W. Cleeves told me of a Belgian doe which showed her enmity to cats in a peculiar way. She would run after any cats that came in sight, butting them like a billy-goat. The cats soon learned her tricks, and would climb a tree as soon as they caught sight of her. The rabbit's sound of defiance, is thumping the ground with the strong hind foot. Some have declared that the front feet are used also for stamping; although I have heard this indignant thumping more than once, I could not see the process. The cotton-tail is a hare, while the common domestic rabbit is a true rabbit. The two differ chiefly in the habits of nesting; the hares rest and nest in forms, while the rabbit makes burrows, digging rapidly with the front feet.

Not the least of tributes to the rabbit's sagacity, are the negro folkstories told by Uncle Remus, wherein Bre'r Rabbit, although often in trouble, is really the most clever of all the animals. I have often thought

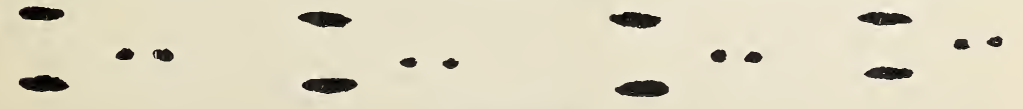

Rabbit tracks. 
when I have seen the tactics which rabbits have adopted to escape dogs, that we in the North have under-rated the cleverness of this timid animal. In one instance at least that came under our observation, a cotton-tail led a dog to the verge of a precipice, then doubled back to safety, while the dog went over, landing on the rocks nearly three hundred feet below.

\section{LESSON LIII}

\section{The Cotton-tail Rabit}

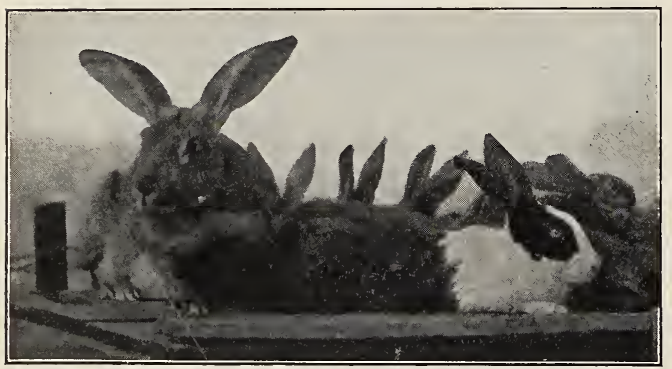

Belgian hares and Dutch rabbit.
Leading thoughtThe cotton-tail thrives amid civilization; its color protects it from sight; its long ears give it warning of the approach of danger; and its long legs enable it to run by swift, long leaps. It feeds upon grasses, clover, vegetables and other herbs.

Method-This study may be begun in the winter, when the rabbit tracks can be observed and the haunts of the cotton-tail discovered. If caught in a box trap, the cotton-tail will become tame if properly fed and cared for, and may thus be studied at close range. The cage I have used for rabbits as thus caught, is made of wire screen, nailed to a frame, making a wire-covered box, two feet high and two or three feet square, with a door at one side and no bottom. It should be placed upon oil-cloth or linoleum, and thus may be moved to another carpet when the floor needs cleaning. If it is impossible to study the cotton-tail, the domestic rabbit may be used instead.

Observations-r. What sort of tracks does the cotton-tail make in the snow? Describe and sketch them. Where do you find these tracks? How do you know which way the rabbit was going? Follow the track and see if you can find where the rabbit went. When were these tracks made, by night or by day? What does the rabbit do during the day? What does it find to eat during the winter? How are its feet protected so that they do not freeze in the snow?

2. What are the two most noticeable peculiarities of the rabbit? Of what use are such large ears? How are the ears held when the rabbit is resting? When startled? When not quite certain about the direction of the noise? Explain the reasons for these attitudes. When the rabbit wishes to make an observation to see if there is danger coming, what does it do? How does it hold its ears then? How are the ears held when the animal is running?

3. Do you think the rabbit has a keen sense of smell? Describe the movements of the nostrils and explain the reason. . How does it move its head to be sure of getting the scent? 
4. What peculiarity is there in the upper lip? How would this be an aid to the rabbit when gnawing? Describe the teeth; how do these differ from those of the mouse or squirrel? Of what advantage are the gnawing teeth to the rabbit? How does it eat a stem of grass? Note the rabbit's whiskers. What do you think they are used for?

5. Describe the eyes. How are they placed so that the rabbit can see forward and backward? Do you think that it sleeps with its eyes open? Does it wink?

6. Why is it advantageous to the rabbit to have such long, strong, hind legs? Compare them in size with the front legs. Compare the front and hind feet. How many toes on each? How are the bottoms of the feet protected? Are the front feet ever used for holding food like the squirrel's? In what position are the legs when the rabbit is resting? When it is standing? When lifted up for observation?

7. How does the cotton-tail escape being seen? Describe its coat. Of what use is the white fluff beneath the tail? Have you ever seen a wild rabbit "freeze"? What is meant by freezing and what is the use of it?

8. In making its toilet how does the rabbit clean its face, ears, feet, and fur?

9. What do the cotton-tails feed upon during the summer? During the winter? Do they ever do much damage?

Io. Describe the cotton-tail's nest. What is it called? Does it ever burrow in the ground? Does it ever use a second-hand burrow? Describe the nest made for the young by the mother. Of what is the bed composed? Of what is the coverlet made? What is the special use of the coverlet? How do the young cotton-tails look? How old are they before they are able to take care of themselves?

II. What are the cotton-tail's enemies? How does it escape them? Have you ever seen the rabbit roads in a briar patch? Do you think that a dog or fox could follow them? Do rabbits ever fight their enemies? If so, how? How do they show anger? Do they stamp with the front or the hind foot?

12. Tell how the cotton-tail differs in looks and habits from the common tame rabbit. How do the latter dig their burrows? How many breeds of tame rabbits do you know?

I3. Write or tell stories on the following topics: "A Cotton-tail's Story of its Own Life Until it is a Year Old;" "The Jack-rabbit of the West;" "The Habits of the White Rabbit or Varying Hare;" "The Rabbit in Uncle Remus' Tales."

Supplementary reading- "Raggylug" and "Little War Horse," Thompson-Seton; Squirrels and Other Fur Bearers, Burroughs; Watchers in the Woods, Sharp; American Animals, Stone \& Cram; Familiar Life in Field and Forest, Mathews; Sharp Eyes, Gibson; Neighbors with Claws and Hoofs, Johonnot; True Tales of Birds and Beasts, Jordan; Uncle Remus Stories, especially The Tar Baby, which emphasizes the fact that the rabbits' runways are in the protecting briar-patch. 


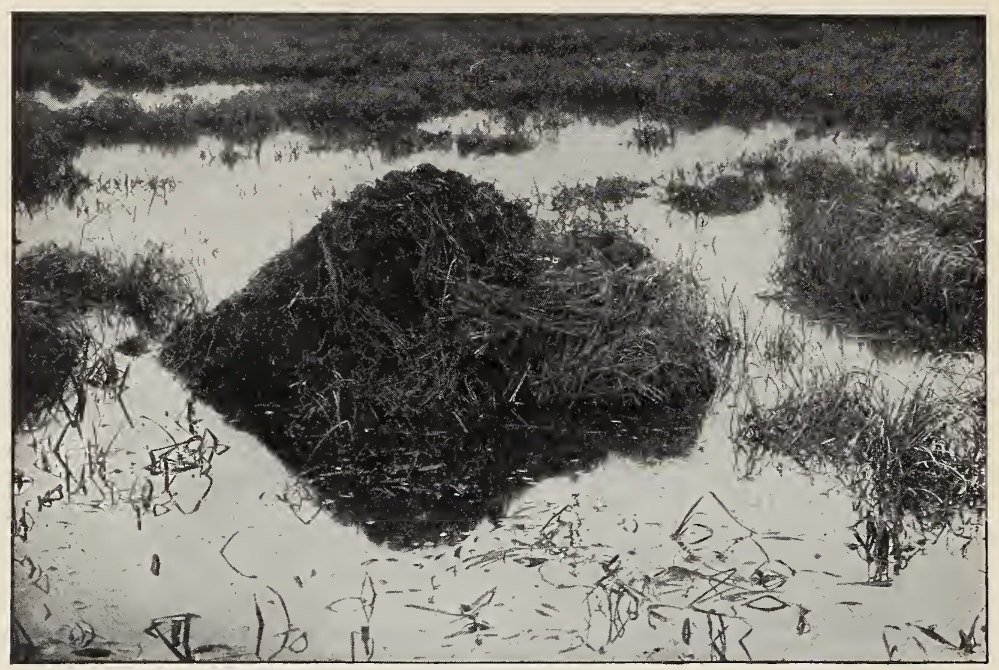

Winter lodge of muskrats.

Photo by Silas Lottridge.

\section{THE MUSKRAT}

\section{Teacher's Story}

"Having finished this first course of big-neck clams, they w'ere joined by a third muskrat, and, together, they filed over the bank and down into the meadow. Shortly two of them returned with great mouthfuls of the mud-bleached ends of calamus-blades. Then followed the washing.

They dropped their loads upon the plank, took up the stalks, pulled the blades apart, and soused them up and down in the water, rubbing them with their paws until they were as clean and white as the whitest celery one ever ate. What a dainty picture! Two little brown creatures, humped on the edge of a plank, washing calamus in moonlit water!"-Dallas Lore Sharp.

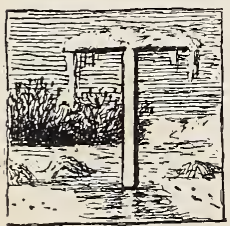

RACKING is a part of every boy's education who aspires to a knowledge of wood lore; and a boy with this accomplishment is sure to be looked upon with great admiration by other boys, less skilled in the interpretation of that writing made by small feet, on the soft snow or on the mud of stream margins. To such a boy, the track of the muskrat is well known, and very easily recognized.

The muskrat is essentially a water animal, and therefore its tracks are to be looked for along the edges of ponds, streams or in marshes. Whether the tracks are made by walking or jumping, depends upon the depth of the snow or mud; if it is deep, the animal jumps, but in shallow snow or mud, it simply runs along. The tracks show the front feet to be smaller 
than the hind ones. The muslzrat track is, however, characterized by the tail imprint. When the creature jumps through the snow, the mark of the tail follows the paired imprints of the feet; when it walks, there is a continuous line made by this strong, naked tail. This distinguishes the track of the muskrat from that of the mink, as the bushy tail of the latter does not make so distinct a mark. Measuring the track, is simply a device for making the pupils note its size and shape more carefully. The tracks may be looked for during the thaws of March or February, when the muskrats come out of the water to seek food.

In appearance the muskrat is peculiar. The body is usually about a foot in length and the tail about eight inches. The body is stout and thickset, the head is rounded and looks like that of a giant meadow mouse; the eyes are black and shining; the ears are short and close to the head; the teeth, like those of other rodents, consist of a pair of front teeth on each jaw, then a long, bare space and four grinders on each side. There are long sensitive hairs about the nose and mouth, like the whiskers of mice.

The muskrat's hind legs are much larger and stronger than the front ones; and too, the hind feet are much longer than the front feet and have a web between the toes; there are also stiff hairs which fill the space between the toes, outside the web, thus making this large hind foot an excellent swimming organ. The front toes are not webbed and are used for digging. The claws are long, stout and sharp. The tail is long, stout and flattened at the sides; it has little or no fur upon it but is covered with scales; it is used as a scull and also as a rudder when the muskrat is swimming.

The muskrat's outer coat consists of long, rather coarse hairs; its under coat is of fur, very thick and fine, and although short, it forms a waterproof protection for the body of the animal. In color, the fur is dark brown above with a darker streak along the middle of the back; beneath, the body is grayish changing to whitish on the throat and lips, with a brown spot on the chin. In preparing the pelts for commercial use, the long hairs are plucked out leaving the soft, fine under coat, which is dyed and sold under the name of "electric seal."

The muskrat is far better fitted by form, for life in the water than upon the land. Since it is heavy-bodied and short-legged, it cannot run rapidly but its strong, webbed hind feet are most efficient oars, and it swims rapidly and easily; for rudder and propeller the strong, flattened tail serves admirably, while the fine fur next the body is so perfectly waterproof that, however much the muskrat swims or dives, it is never wet. It is a skillful diver and can stay under water for several minutes; when swimming, its nose and sometimes the head and the tip of the tail appear on the surface of the water.

The food of muskrats is largely roots, especially those of the sweet flag and the yellow lily. They also feed on other aquatic plants and are fond of the fresh-water shell-fish. Mr. Sharp tells us, in one of his delightfui stories, how the muskrats wash their food by sousing it up and down in water many times before eating it. Often, a muskrat chooses some special place upon the shore which it uses for a dining-room, bringing there and eating pieces of lily root or fresh-water clams, and leaving the debris to show where it habitually dines. It does most of its hunting for food at night, although sometimes it may be seen thus employed during the day. 
The winter lodge of the muskrat is a most interesting structure. A foundation of tussocks of rushes, in a stream or shallow pond, is built upon with reeds plastered with mud, making a rather regular dome which may be nearly two or three feet high; or, if many-chambered, it may be a grand affair of four or five feet elevation; but it always looks so much like a natural hummock that the eye of the uninitiated never regards it as a habitation. Always beneath this dome and above the water line, is a snug, covered chamber carpeted with a soft bed of leaves and moss, which has a passage leading down into the water below, and also has an air-hole for ventilation. In these cabins, closely cuddled together, three or four in a chamber, the muskrats pass the winter. After the pond is frozen they are safe from their enemies and are always able to go down into the water and feed upon the roots of water plants. These cabins are sometimes built in the low, drooping branches of willows or on other objects.

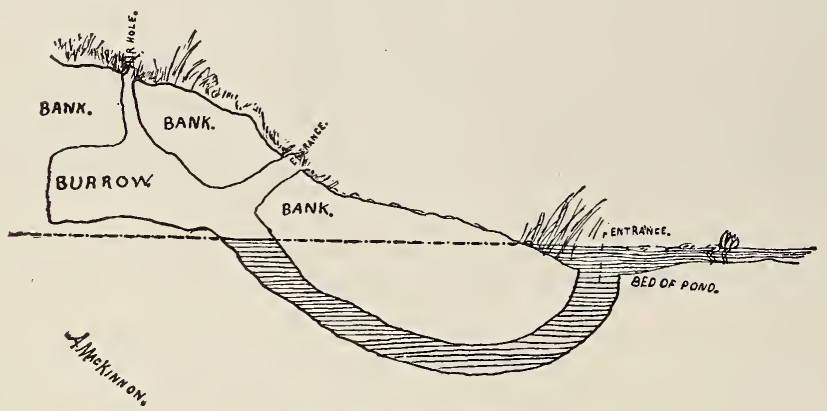

A muskrat's summer home.

Drawn by A. MacKinnon, a boy of 13 years.

Whether the muskrat builds itself a winter lodge or not, depends upon the nature of the shore which it inhabits; if it is a place particularly fitted for burrows, then a burrow will be used as a winter retreat; but if the banks are shallow, the muskrats unite in building cabins. The main entrance to the muskrat burrow is always below the surface of the water, the burrow slanting upward and leading to a nest well lined, which is above the reach of high water; there is always an air hole above, for ventilating this nest, and there is also often a passage, with a hidden entrance, leading out to dry land.

The flesh of the muskrat is delicious, and therefore the animal has many enemies; foxes, weasels, dogs, minks and also hawks and owls prey upon it. It escapes the sight of its enemies as does the mouse, by having the color of its fur not noticeable; when discovered, it escapes its enemies by swimming, although when cornered, it is courageous and fights fiercely, using its strong incisors as weapons. In winter, it dwells in safety when the friendly ice protects it from all its enemies except the mink; but it is exposed to great danger when the streams break up in spring, for it is then often driven from its cabin by floods, and preyed upon while thus helplessly exposed. The muskrat gives warning of danger to its fellows by splashing the water with its strong tail 


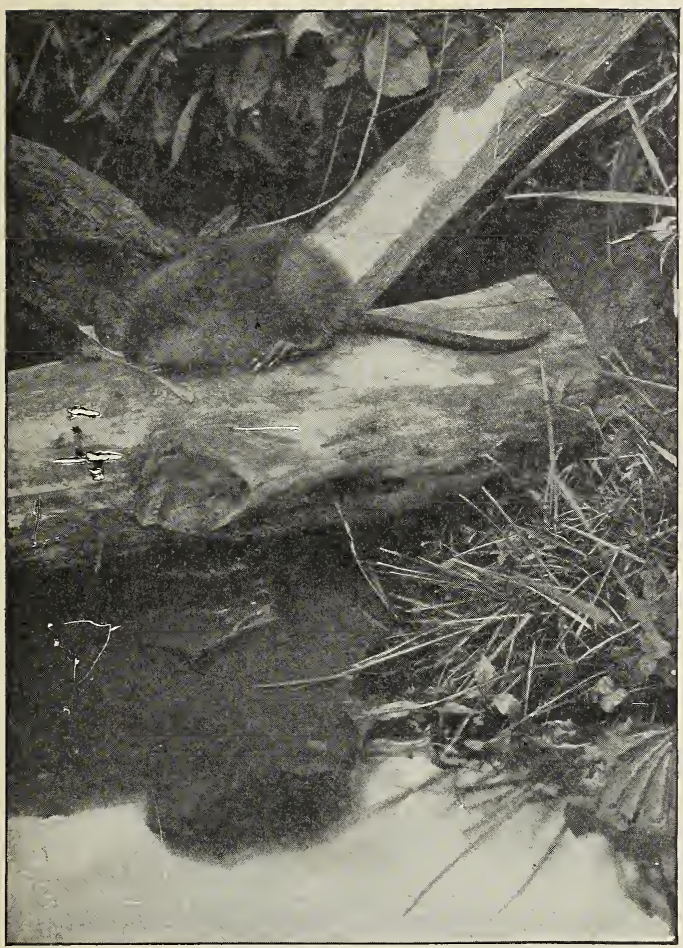

The muskrat.

Photo by Silas Lottridge.

It is called musk rat because of the odor, somewhat resembling $\mathrm{musk}$, which it exhales from two glands on the lower side of the body between the hind legs; these glands may be seen when the skin is removed, which is the too common plight of this poor creature, since it is hunted mercilessly for its pelt.

The little muskrats are born in April and there are usually from six to eight in a litter. Another litter may be produced in June or July and a third in August or September. It is only thus, by rearing large families often, that the muskrats are able to hold their own against the hunters and trappers and their natural enemies.

References-Wild Animals, Stone \& Cram; A Watcher in the Woods, Sharp; Wild Life, Ingersoll; Farmers' Bulletin No. 396, U. S. Dept. of Agriculture.

\section{LESSON LIV}

\section{The Muskrat}

Leading thought-The muskrat, while a true rodent, is fitted for life in the water more than for life upon the land. Its hind feet are webbed for use as oars and its tail is used as a rudder. It builds lodges of mud, cat-tails and rushes in which it spends the winter.

Method-It might be well to begin this work by asking for observations on the tracks of the muskrat which may be found about the edges of almost any creek, pond or marsh. If there are muskrat lodges in the region they should be visited and described. For studying the muskrat's form a live muskrat in captivity is almost necessary. If one is trapped 
with a "figure rour" it will not be injured and it may be made more or less tame by feeding it with sweet apples, carrots and parsnips. The pupils can thus stidy it at leisure although they should not be allowed to handle the creature as it inflicts very severe wounds and is never willing to be handled. If a live muskrat cannot be obtained perhaps some hunter in the neighborhood will supply a dead one for this observation lesson.

While studying the muskrat the children should read all the stories of beavers which are available as the two animals are very much alike in their habits.

Observations-r. In what locality have you discovered the tracks of the muskrat? Describe its general appearance. Measure the muskrat's track as follows: (a) Width and length of the print of one foot; (b) the width between the prints of the two hind feet; (c) the length between the prints made by the hind feet in several successive steps or jumps.

2. Was the muskrat's track made when the animal was jumping or walking? Can you see in it a difference in the size of the front and hind feet? Judging from the track, where do you think the muskrat came from? What do you think it was hunting for?

3. What mark does the tail make in the snow or mud? Judging by its imprint, should you think the muskrat's tail was long or short, bare or brushy, slender or strong?

4. How long is the largest muskrat you ever saw? How much of the whole length is tail? Is the general shape of the body short and heavy or long and slender?

5. Describe the muskrat's eyes, ears and teeth. For what are the teeth especially fitted? Has the muskrat whiskers like mice and rats?

6. Compare the front and hind legs as to size and shape. Is there a web between the toes of the hind feet? What does this indicate? Do you think that the muskrat is a good swimmer?

7. Describe the muskrat fur. Compare the outer and under coat. What is its color above and below? What is the name of muskrat fur in the shops?

8. Describe the tail. What is its covering? How is it flattened? What do you think this strong, flattened tail is used for?

9. Do you think the muskrat is better fitted to live in the water than on land? How is it fitted to live in the water in the following particulars: Feet? Tail? Fur?

ro. How much of the muskrat can you see when it is swimming? How long can it stay under water when diving?

II. What is the food of the muskrat? Where does it find it? How does it prepare the food for eating? Does it seek its food during the night or day? Have you ever observed the muskrat's dining room? If so, describe it.

I 2. Describe the structure of the miskrat's winter lodge, or cabin, in the following particulars: Its size. Where built? Of what material? How many rooms in it? Are these rooms above or below the water level? Of what is the bed made? How is the nest ventilated? How is it arranged so that the entrance is not closed by the ice? Is such a home built by one or more muskrats? How many live within it? Do the muskrats always build these winter cabins? What is the character of the shores where they are built? 
I3. Describe the muskrat's burrow in the bank in the following particulars: Is the entrance above or below water? Where and how is the nest made? Is it ventilated? Does it have a back door leading out upon the land?

I4. What are the muskrat's enemies? How does it escape them? How does it fight? Is it a courageous animal? How does the muskrat give warning to its fellows when it perceives danger? At what time of year is it comparatively safe? At what time is it exposed to greatest danger?

I5. Why is this animal called muskrat? Compare the habits of muskrats with those of beaver and write an English theme upon the similarity of the two.

I6. At what time of year do you find the young muskrats? How many in a litter?

17. Read Farmers' Bulletin No. 396 of the U. S. Dept. of Agriculture and write an English theme on the destructive habits of muskrats and the economic uses of these animals.

Supplementary reading-Familiar Wild Animals, Lottridge; Little Beasts of Field and Wood, Cram; Squirrels and other Fur-bearers, Burroughs; "The Builders" in Ways of Wood Folk, Long.

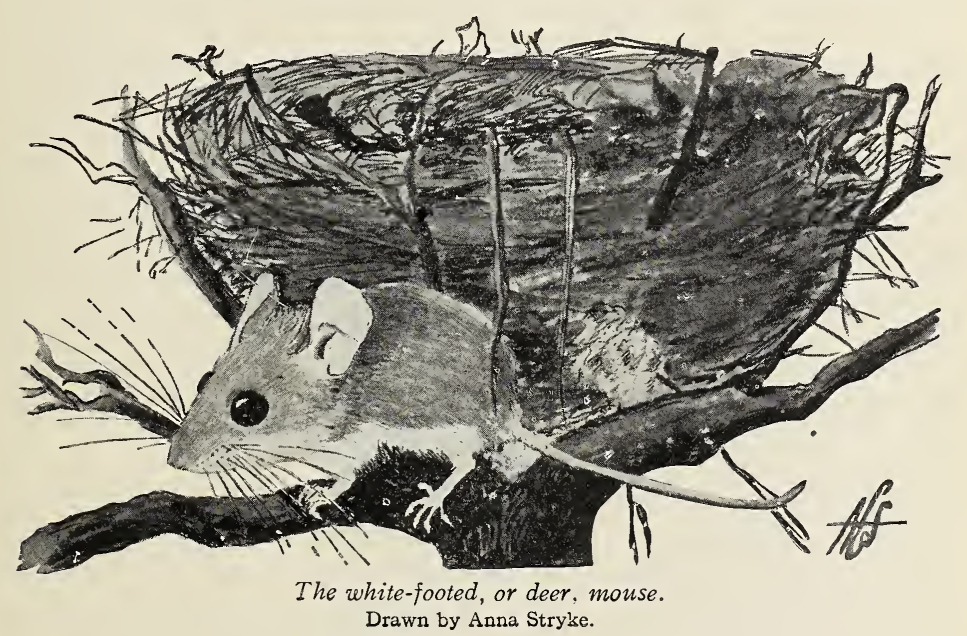




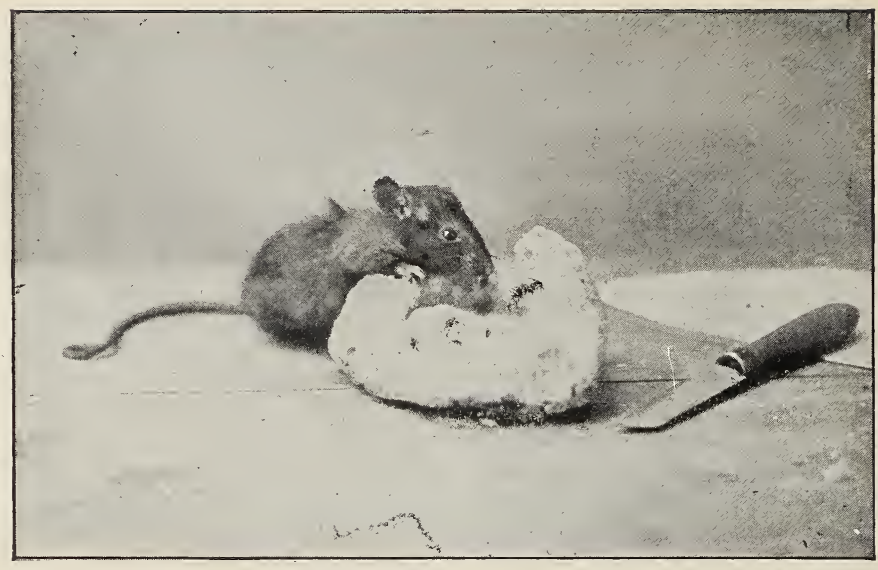

The house mouse feeds upon almost anything which people like to eat.

\section{THE HOUSE MOUSE}

\section{Teacher's Story}

Somewhere in the darkness a clock strikes two;

And there is no sound in the sad old house,

But the long veranda dripping with dew,

And in the wainscot-a mouse.-BRET HARTE.

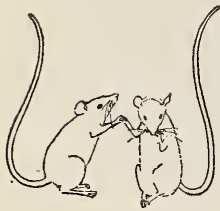

ERE mouse-gray a less inconspicuous color, there would be fewer mice; when a mouse is running along the floor, it is hardly discernible, it looks so like a flitting shadow; if it were black or white or any other color, it would be more often seen and destroyed. Undoubtedly, it is owing to the fact that its soft fur has this shadowy color, that this species has been able to spread over the world.

At first glance one wonders what possible use a mouse can make of a tail which is as long as its body, but a little careful observation will reveal the secret. The tail is covered with transverse ridges and is bare save for sparse hairs, except toward the tip. Dr. Ida Reveley first called my attention to the fact that the house mouse uses its tail in climbing. I verified this interesting observation, and found that my mouse used the tail for aid when climbing a string. He would go up the string, hand over hand, like a sailor, then in trying to stretch to the edge of his jar, he invariably wound his tail about the string two or three times, and hanging to the string with the hind feet and tail, would reach far out with his head and front feet. Also, when clinging to the edge of the cover of the jar, he invariably used his tail as a brace against the side of the glass, so that it pressed hard for more than half its length. Undoubtedly the tail is of great service when climbing up the sides of walls. 
The tail is also of some use, when the mouse jumps directly upwards. The hind legs are very much longer and stronger than the front legs. The hind feet are also much longer and larger than the front feet; and although the mouse, when it makes its remarkable jumps, depends upon its strong hind legs, I am sure that often the tail is used as a brace to guide and assist the leap. The feet are free from hairs but are downy; the hind foot has three front toes, a long toe behind on the outside and a short one on the inside. The claws are fairly long and very sharp so that they are able to cling to almost anything but glass. When exploring, a mouse stands on its hind feet, folding its little front paws under its chin while it reaches up ready to catch anything in sight; it can stretch up to an amazing height. It feeds upon almost anything which people like to eat and, when eating, holds its food in its front paws like a squirrel.

The thin, velvety ears are flaring cornucopias for taking in sound; the large, rounded outer ear can be moved forward or back to test the direction of the noise. The eyes are like shining, black beads; and if a mouse can wink, it does it so rapidly as not to be discernible. The nose is long, inquisitive, and always sniffing for new impressions. The whiskers are delicate and probably sensitive. The mouth is furnished with two long, curved gnawing teeth at the front of each jaw, then a bare space, and four grinding teeth on each side, above and below, like the teeth of woodchucks and other rodents. The gnawing teeth are very strong and enable the mouse to gnaw through board partitions and other obstacles.

The energy with which the mouse cleans itself is inspiring to behold. It nibbles its fur and licks it with fervor, reaching around so as to get at it from behind, and taking hold with its little hands to hold firm while it cleans. When washing its face and head, it uses both front feet, licking them clean and rubbing them both simultaneously from behind the ears down over the face. It takes its hind foot in both front feet and nibbles and licks it. It scratches the back of its head with its hind foot.

Young mice are small, downy, pink and blind when born. The mother makes for them a nice, soft nest of pieces of cloth, paper, grass, or whatever is at hand; the nest is round like

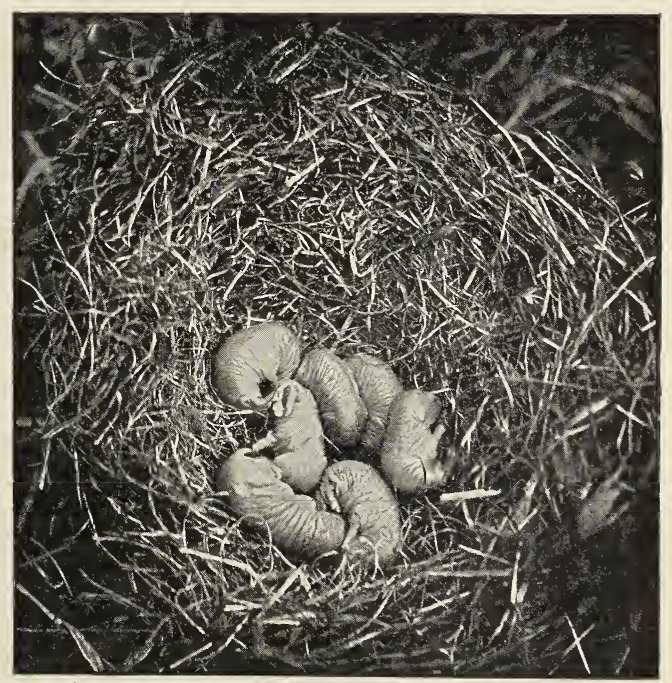

Young mice, blind, pink and hairless. 
a ball and at its center is nestled the family. Mice living in houses, have runways between the plaster and the outside, or between ceiling and floor. In winter they live on what food they can find, and upon flies or other insects hibernating in our houses. The house mice sometimes live under stacks of corn or grain in the fields, but usually confine themselves to houses or barns. They are thirsty little fellows and they like to make their nests within easy reach of water. Our house mice came from ancestors which lived in Asia originally; they have always been great travelers and they have followed men wherever they have gone, over the world. They came to America on ships with the first explorers and the Pilgrim fathers. They now travel back and forth, crossing the ocean in ships of all sorts. They also travel across the continent on trains. Wherever our food is carried they go; and the mouse, which you see in your room one day, may be a thousand miles away within a week. They are clever creatures, and learn quickly to connect cause and effect. For two years, I was in an office in Washington, and as soon as the bell rang for noon, the mice would appear instantly, hunting waste-baskets for scraps of lunch. They had learned to connect the sound of the bell with food.

Of all our wild mice, the white-footed or deer mouse is the most interesting and attractive. It is found almost exclusively in woods and is quite different in appearance from other mice. Its ears are very large; its fur is fine and beautiful and a most delicate gray color. It is white beneath the head and under the sides of the body. The feet are pinkish, the front paws have short thumbs, while the hind feet are very much longer and have a long thumb looking very much like an elfin hand in a gray-white silk glove. On the bottom of the feet are callous spots which are pink and serve as foot pads. It makes its nest in hollow trees and stores nuts for winter use. We once found two quarts of shelled beech nuts in such a nest. It also likes the hips of the wild rose and many kinds of berries; it sometimes makes its summer home in a bird's nest, which it roofs over to suit itself. The young mice are

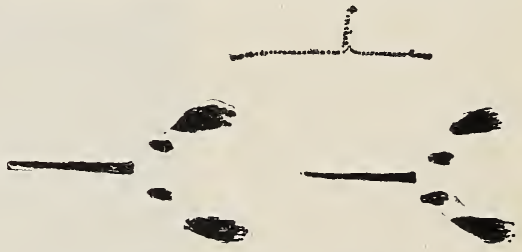

Track of white-footed mouse.

Notice tail-track. carried, hanging to the mother's breasts. As an inhabitant of summer cottages, white-foot is cunning and mischievous; it pulls cotton out of quilts takes covers off of jars, and as an explorer, is equal to the squirrel. I once tried to rear some young deer mice by feeding them warm milk with a pipette; although their eyes were not open, they invariably washed their faces after each meal, showing that neatness was bred in the bone. This mouse has a musical voice and often chirps as sweetly as a bird. Like the house mouse it is more active at night.

The meadow mouse is the one that makes its run-ways under the snow, making strange corrugated patterns over the ground which attract our attention in spring. It has a heavy body, short legs, short ears and short tail. It is brownish or blackish in color. It sometimes digs burrows straight into the ground, but more often makes its nest beneath sticks and 
stones or stacks of corn. It is the nest of this field mouse which the bumblebee so often takes possession of, after it is deserted. The meadow mouse is a good fighter, sitting up like a woodchuck and facing its enemy bravely. It needs to be courageous, for it is preyed upon by almost every creature that feeds upon small animals; the hawks and owls especially are its enemies. It is well for the farmer that these mice have so many enemies, for they multiply rapidly and would otherwise soon overrun and destroy the grain fields. This mouse is an excellent swimmer.

A part of winter work, is to make the pupils familiar with the tracks of the meadow mice and how to distinguish them from other tracks.

2

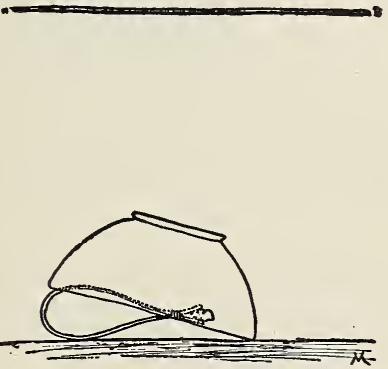

2

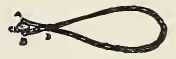

Mouse traps.

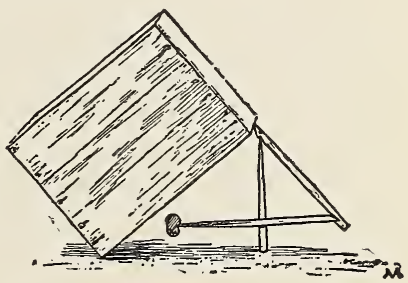

The bow trap. I. A smooth splint or a peeled twig.

2. Splint bowed and tied at $\mathrm{D}$, the bait inserted at $\mathrm{C}$.

Figure 4, trap.

3. The inverted bowl balanced on splint bow.

Trapping Field Mice-Probably wild animals have endured more cruelty through the agency of traps than through any other form of human persecution. The savage steel traps often catch the animal by the leg, holding it until it gnaws off the imprisoned foot, and thus escapes maimed and handicapped for its future struggle for food; or if the trap gets a strong hold, the poor creature may suffer tortures during a long period, before the owner of the trap appears to put an end to its sufferings by death. If box traps are used, they are often neglected and the poor creature imprisoned, is left to languish and starve. The teacher cannot enforce too strongly upon the child the ethics of trapping. Impress upon him that the box traps are far less cruel; but that if set, they must be examined regularly and not neglected. The study of mice affords a good opportunity for giving the children a lesson in humane trapping. Let them set a figure 4 or a bowl trap, which they must examine every morning. The little prisoners may be brought to school and studied; meanwhile, they should be treated kindly and fed bountifully. After a mouse has been studied, it should be set free, even though it be one of the quite pestiferous field mice. The moral effect of killing an animal, after a child has become thoroughly interested in it and its life, is always bad.

References-Claws and Hoofs, Johomot, American Animals, Stone \& Cram; Secrets of the Woods, Long; Wild Life, Ingersoll; Familiar Wild Animals, Lottridge. 


\section{LESSON LV \\ The House Mouse}

Leading thought-The mouse is fitted by color, form, agility and habits to thrive upon the food which it steals from man, and to live in the midst of civilized people.

Method-A mouse cage can be easily made of wire window-screen tacked upon a wooden frame. I have even used aquarium jars with wire screen covers, and by placing one jar upon another, opening to opening, and then laying them horizontal, the mouse can be transferred to a fresh cage without trouble, and thus the mousey odor can be obviated, while the little creature is being studied. A little water in a wide-necked bottle can be lowered into this glass house by a string, and the food can be given in like manner. Stripped paper should be put into the jar for the comfort of the prisoner; a stiff string hanging down from the middle of the cage will afford the prisoner a chance to show his feats as an acrobat.

Observations-r. Why is the color of the mouse of special benefit to it? Do you think it protects it from the sight of its enemies? Can you see a mouse easily as it runs across the room? What is the nature of the fur of a mouse?

2. How long is a mouse's tail as compared with its body? What is the covering of the tail? Of what use to the mouse is this long, ridged tail? Watch the mouse carefully and discover, if you can, the use of the tail in climbing.

3. Is the mouse a good jumper? Are the hind legs long and strong when compared with the front legs? How high do you think a mouse can jump? Do you think it uses its tail as an aid in jumping? How much of the legs are covered with hair? Compare the front and hind feet. What sort of claws have they? How does the mouse use its feet when climbing the string? How can it climb up the side of a wall?

4. Describe the eyes. Do you think the mouse can see very well? Does it wink? What is the shape of the ears? Do you think it can hear well? Can it move its ears forward or backward?

5. What is the shape of the snout? Of what advantage is this? Note the whiskers. What is their use? Describe the mouth. Do you know how the teeth are arranged? For what other use than to bite food does the mouse use its teeth? What other animals have their teeth arranged like those of the mouse? What food does the house mouse live upon? How does it get it?

6. How does the mouse act when it is reaching up to examine something? How does it hold its front feet? Describe how the mouse washes its face. Its back. Its feet.

7. Where does the house mouse build its nest? Of what material? How do the baby mice look? Can they see when they are first born?

8. House mice are great travelers. Can you tell how they manage to get from place to place? Write a story telling all you know of their habits.

9. How many kinds of mice do you know? Does the house mouse ever live in the field? What do you know of the habits of the white-footed mouse? Of the meadow mice? Of the jumping mice? 


\section{THE WOODCHUCK}

\section{Teacher's Story}

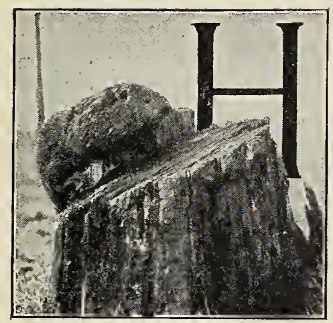

$\mathrm{E}$ who knows the ways of the woodchuck can readily guess where it is likely to be found; it loves meadows and pastures where grass or clover lushly grows. It is also fond of garden truck and has a special delectation for melons. The burrow is likely to be situated near a fence or stone heap, which gives easy access to the chosen food. The woodchuck makes its burrow by digging the earth loose with its front feet, and pushing it backward and out of the entrance with the hind feet. This method leaves the soil in a heap near the entrance, from which paths radiate into the grass in all directions. If one undertakes to dig out a woodchuck, one needs to be not only a husixy individual, but something of an engineer; the direction of the burrow extends downward for a little way, and then rises at an easy angle, so that the inmate may be in no danger of flood. The nest is mereiy an enlargement of the burrow, lined with soft grass, which the woodchucks bring in in their mouths. During the early part of the season, the father and mother and the litter of young may inhabit the same burrow, although there are likely to be at least two separate nests. There is usually more than one back door to the woodchuck's dwelling, through which it may escape, if pressed too closely by enemies; these back doors differ from the entrance, in that they are usually hidden and have no earth heaped near them.

The woodchuck usually feeds in the morning and again in the evening, and is likely to spend the middle of the day resting. It often goes some distance from its burrow to feed, and at short intervals, lifts itself upon its hind feet to see if the coast is clear; if assailed, it will seek to escape by running to its burrow; and when running, it has a peculiar gait well described as "pouring itself along." If it reaches its burrow, it at once begins to dig deeply and throw the earth out behind it, thus making a wall to keep out the enemy. When cornered, the woodchuck is a courageous and fierce fighter; its sharp incisors prove a powerful weapon and it will often whip a dog much larger than itself. Every boy knows how to find whether the woodchuck is in its den or not, by rolling a stone in to the burrow, and listening; if the animal is at home, the sound of its digging apprises the listener of the fact. In earlier times, the ground-hogs were much preyed upon by wolves, wildcats and foxes; now, only the fox remains and he is fast disappearing, so that at present, the farmer and his dog are about the only enemies this burrower has to contend with. It is an animal of resources and will climb a tree if attacked by a dog; it will also climb trees for fruit, like peaches. During the late summer, it is the ground-hog's business to feed very, constantly and become very fat. About the first of October, it retires to its den and sleeps until the end of March or April. During this dormant state, the beating of its heart is so faint as to be scarcely perceptible, and very little nourishment is required to keep it alive; this nourishment is supplied by the fat stored in its body, which it uses up by March, and comes out of its burrow in the spring, looking gaunt and lean. The old saying that the ground-hog comes out on 
Candlemas Day, and if it sees its shadow, goes back to sleep for six weeks more, may savor of meteorological truth, but it is certainly not true of the ground-hog.

The full-grown woodchuck ordinarily measures about two feet in length. Its color is grizzly or brownish, sometimes blackish in places; the under parts are reddish and the feet black. The fur is rather coarse, thick and brown, with longer hairs which are grayish. The skin is very thick and tough and seems to fit loosely, a condition which gives the peculiar "pouring along" appearance when it is running. The hind legs and feet are longer than those in front. Both pairs of feet are fitted for digging, the front ones being used for loosening the earth and the hind pair for kicking it out of the burrow.

The woodchuck's ears are roundish and not prominent, and by muscular contraction they are closed when the animal is digging, so that no

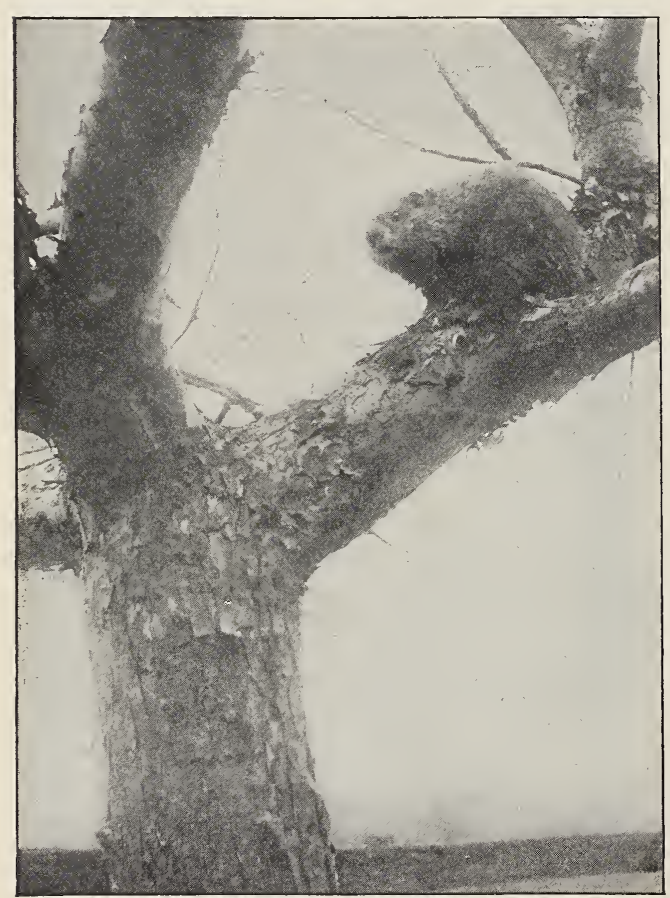

Treed!

Photo by Verne Morton. soil can enter; the sense of hearing is acute. The teeth consist of two large incisors at the front of each jaw, a bare space and four grinders on each side, above and below; the incisors are used for biting food and also for fighting. The eyes are full and bright. The tail is short and brushy, and it with the hind legs, form a tripod which supports the animal, as it sits with its forefeet lifted.

When feeding, the woodchuck often makes a contented grunting noise; when attacked and fighting, it growls; and when feeling happy and conversational, it sits up and whistles. I had a woodchuck acquaintance once which always gave a high, shrill, almost birdlike whistle when I came in view, a very jolly greeting. There are plenty of statements in books that woodchucks are fond of music, and Mr. Ingersoll states that at Wellesley College a woodchuck on the chapel lawn was wont to join the morning song exercises with a "clear soprano." The young woodchucks are born about the first of May and the litter usually numbers four or five. In June the "chucklings" may be seen following the mother in the field with much babyish grunting. If 
captured at this period, they make every interesting pets. By August or September the young woodchucks leave the home burrow and start burrows of their own.

References-Wild Animals, Stone \& Cram; Wild Neighbors, Ingersoll; Squirrels and Other Fur Bearers, Burroughs; Familiar Wild Animals, Lottridge.

\section{LESSON LVI}

\section{The Woodchuck or Ground-Hog}

Leading thought-The woodchuck has thriven with civilization, notwithstanding the farmer's dog, gun, traps and poison. It makes its nest in a burrow in the earth and lives upon vegetation; it hibernates in winter.

Method-Within convenient distance for observation by the pupils of every country schoolhouse and of most village schoolhouses, may be found a woodchuck and its dwelling. The pupils should be given the outline for observations which should be made individually througis watching the woodchuck for weeks or months.

Observations-I. Where is the woodchuck found? On what does it live? At what time of day does it feed? How does it act when startled?

2. Is the woodchuck a good fighter? With what weapons does it fight? What are its enemies? How does it escape its enemies when in or out of its burrow? How does it look when running?

3. What noises does the woodchuck make and what do they mean? Play a "mouth-organ" near the woodchuck's burrow and note if it likes music.

4. How does the woodchuck make its burrow? Where is it likely to be situated? Where is the earth placed which is taken from the burrow? How does the woodchuck bring it out? How is the burrow made so that the woodchuck is not drowned in case of heavy rains? In what direction do the underground galleries go? Where is the nest placed in relation to the galleries? Of what is the nest made? How is the bedding carried in? Of what special use is the nest?

5. Do you find paths leading to the entrances of the burrow? If so, describe them. How can you tell whether a woodchuck is at home or not if you do not see it enter? Where is the woodchuck likely to station itself when it sits up to look for intruders?

6. How many woodchucks inhabit the same burrow? Are there likely to be one or more back doors to the burrow? What for? How do the back doors differ from the front doors?

7. How long is the longest woodchuck that you have ever seen? What is the woodchuck's color? Is its fur long or short? Coarse or fine? Thick or sparse? Is the skin thick or thin? Does it seem loose or close fitting?

8. Compare the front and hind feet and describe difference in size and shape. Are either or both slightly webbed? Explain how both front and hind feet and legs are adapted by their shape to help the woodchuck. Is the tail long or short? How does it assist the animal in sitting up?

9. What is the shape of the woodchuck's ear? Can it hear well? Why are the ears not filled with soil when the animal is burrowing? Of what use are the long incisors? Describe the eyes. 
Io. How does the woodchuck prepare for winter? Where and how does it pass the winter? Did you ever know a woodchuck to come out on Candlemas Day to look for its shadow?

II. When does the woodchuck appear in the spring? Compare its general appearance in the fall and in the spring and explain the reason for the difference.

I2. When are the young woodchucks born? What do you know of the way the mother woodchuck cares for her young?

As I turned round the corner of Hubbard's Grove, saw a woodchuck, the first of the season, in the middle of the field six or seven rods from the fence which bounds the wood, and twenty rods distant. I ran along the fence and cut him off, or rather overtook him, though he started at the same time. When I was only a rod and a half off, he stopped, and I did the same; then he ran again, and I ran up within three feet of him, when he stopped again, the fence being between us. I squatted down and surveyed him at my leisure. His eyes were dull black and rather inobvious, with a faint chestnut iris, with but little expression and that more of resignation than of anger. The general aspect was a coarse grayish brown, a sort of grisel. A lighter brown next the skin, then black or very dark brown and tipped with whitish rather loosely. The head between $a$ squirrel and a bear, flat on the top and dark brown, and darker still or black on the tip of the nose. The whiskers black, two inches long. The ears very small and roundish, set far back and nearly buried in the fur. Black feet, with long and slender claws for digging. It appeared to tremble, or perchance shivered with cold. When I moved, it gritted its teeth quite loud, sometimes striking the under jaw against the other chatteringly, sometimes grinding one jaw on the other, yet as if more from instinct than anger. Whichever way I turned, that way it headed. I took a twig a foot long and touched its snout, at which it started forward and bit the stick, lessening the distance between us to two feet, and still it held all the ground it gained. I played with it tenderly awhile with the stick, trying to open its gritting jaws. Ever its long incisors, two above and two below, were presented. But I thought it would go to sleep if I stayed long enough. It did not sit upright as sometimes, but standing on its fore feet with its head down, i. e., half sitting, half standing. We sat looking at one another about half an hour, till we began to feel mesmeric infuences. When I was tired, I moved away, wishing to see him run, but I could not start him. He would not stir as long as I was looking at him or could see him. I walked around him; he turned as fast and fronted me still. I sat down by his side within a foot. I talked to him quasi forest lingo, baby-talk, at any rate in a concilatory tone, and thought that I had some influence on him. He gritted his teeth less. I chewed checkerberry leaves and presented them to his nose at last without a grit; though I saw that by so much gritting of the teeth he had worn them rapidly and they were covered with a fine white powder, which, if you measured it thus, would have made his anger terrible. He did not mind any noise I might make. With a little stick I lifted one of his paws to examine it, and held it up at pleasure. I turned him over to see what color he was beneath (darker or most pusely brown), though he turned himself back again sooner than I could have wished. His tail was also brown, though not very dark, rat-tail like, with loose hairs standing out on all sides like a caterpillar brush. He had a rather mild look. I spoke kindly to him. I reached checkerberry leaves to his mouth. I stretched my hands over him, though he turned up his head and still gritted a little. I laid my hand on him, but immediately took it off again, instinct not being whuily overcome. If I had had a few fresh bean leaves, thus in advance of the season, I am sure I should have tamed him completely. It was a frizzly tail. His is a humble, terrestrial color like the partridge's, well concealed where dead wiry grass rises above darker brown or chestnut dead leaves-a modest color. If I had had some food, I should have ended with stroking him at my leisure. Could easily have wrapped him in my handkerchief. He was not fat nor particularly lean. I finally had to leave him without seeing him move from the place. A large, clumsy, burrowing squirrel. Arctomys, bear-mouse. I respect him as one of the natives. He lies there, by his color and habits, ro naturalized amid the dry leaves, the withered grass, and the bushes. A sound nap, too, he has enjoyed in his native fields, the past winter. I think I might learn some wisdom of him. His ancestors have lived here longer than mine. He is more thoroughly acclimated and naturalized than I. Bean leaves the red man raised for him, but he can do without them.-THOREAU's JOURNAL. 


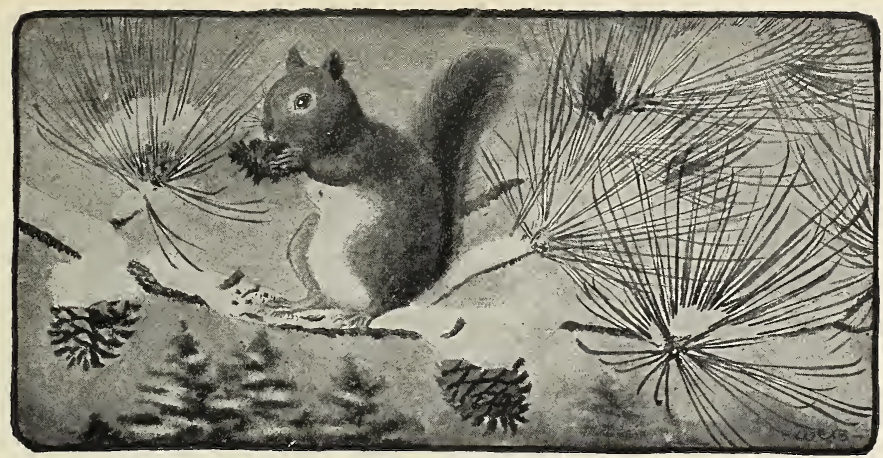

THE RED SQUIRREL OR CHICKAREE

\section{Teacher's Story}

Just a tawny glimmer, a dash of red and gray,

Was it a flitting shadow, or a sunbeam gone astray!

It glances up a tree trunk, and a pair of bright eyes glow

Where a little spy in ambush is measuring his foe.

I hear a mocking chuckle, then wrathful, he grows bold

And stays his pressing business to scold and scold and scold.

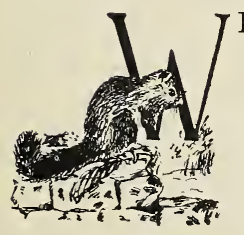

E ought to yield admiring tribute to those animals which have been able to flourish in our midst despite man and his gun, this weapon being the most cowardly and unfair invention of the human mind. The only time that man has been a fair fighter, in combating his fourfooted brethren, was when he fought them with a weapon which he wielded in his hand. There is nothing in animal comprehension which can take into account a projectile, and much less a shot from a gun; but though it does not understand, it experiences a deathly fear at the noise. It is pathetic to note the hush in a forest that follows the sound of a gun; every song, every voice, every movement is stilled and every little heart filled with nameless terror. How any man or boy can feel manly when, with this scientific instrument of death in his hands, he takes the life of a little squirrel, bird or rabbit, is beyond my comprehension. In pioneer days when it was a fight for existence, man against the wilderness, the matter was quite different; but now it seems to me that anyone who hunts what few wild creatures we have left, and which are in nowise injurious, is, whatever he may think of himself, no believer in fair play.

Within my own memory, the beautiful black squirrel was as common in our woods as was his red cousin; the shot-gun has exterminated this splendid species. Well may we rejoice that the red squirrel has, through its lesser size and greater cunning, escaped a like fate; and that pugracious and companionable and shy, it lives in our midst and climbs our very roofs to sit there and scold us for coming within its range of vision. 
It has succeeded not only in living despite of man, but because of man, for it rifles our grain bins and corn cribs and waxes opulent by levying tribute upon our stores.

Thoreau describes most graphically the movements of this squirrel. He says: "All day long the red squirrels came and went. One would approach at first warily, warily, through the shrub-oaks, running over the snow crust by fits and starts and like a leaf blown by the wind, now a few paces this way, with wonderful speed and waste of energy, making inconceivable haste with his "trotters," as if it were for a wager, and now as many paces that way, but never getting on more than half a rod at a time; and then suddenly pausing with a ludicrous expression and a gratuitous somersault, as if all the eyes of the universe were fixed on him, * * * and then suddenly, before you could say Jack Robinson he would be in the top of a young pitch pine, winding up his clock, and chiding all imaginary spectators, soliloquizing and talking to all the universe at the same time."

It is surely one of the most comical of sights to see a squirrel stop running and take observations; he lifts himself on his haunches, and with body bent forward, presses his little paws against his breast as if to say, "Be still, oh my beating heart!" which is all pure affectation because he knows he can scurry away in perfect safety. He is likely to take refuge on the far side of a tree, peeping out from this side and that, and whisking back like a flash as he catches our eye; we might never know he was there except as Riley puts it, "he lets his own tail tell on him." When climbing up or down a tree, he goes head first and spreads his legs apart to clasp as much of the trunk as possible; meanwhile his sharp little claws cling securely to the bark. He can climb out on

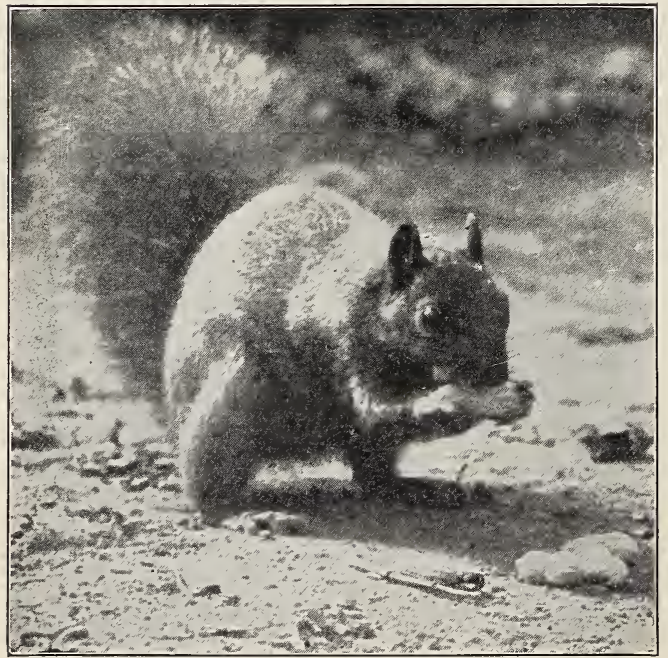

Red squirrel or Chickaree. the smallest twigs quite as well, when he needs to do so, in passing from tree to tree or when gathering acorns.

A squirrel always establishes certain roads to and from $h$ is abiding place and almost invariably follows them. Such a path may be entirely in the treetops, with air bridges from a certain branch of one tree to a certain branch of another, or it may be partially on the ground between trees. I have made notes of these paths in the vicinity of 
my own home, and have noted that if a squirrel leaves them for exploring, he goes warily; while, when following them, he is quite reckless in his haste. When making a jump from tree to tree, he flattens himself as widely as possible and his tail is held somewhat curved, but on a level with the body, as if its wide brush helped to buoy him up and perhaps to steer him also.

During the winter the chickaree is quite dingy in color and is an inconspicuous object, especially when he "humps himself up" so that he resembles a knot on a limb; but with the coming of spring, he dons a brighter coat of tawny-red and along his sides, where the red meets the grayish white of the under side, there is a dark line which is very ornamental; and now his tail is a shower of ruddiness. As the season advances, the colors seem to fade; they are probably a part of his wooing costume. When dashing up a tree trunk, his color is never very striking but looks like the glimmer of sunlight; this has probably saved many of his kind from the gunner, whose eyes being at the front of his head, cannot compare in efficiency with those of the squirrel, which being large and full and alert, are placed at the sides of the head so as to see equally well in all directions.

The squirrel's legs are short because he is essentially a climber rather than a runner; the hips are very strong which insures his power as a jumper and his leaps are truly remarkable. A squirrel uses his front paws for hands in a most human way; with them he washes his face and holds his food up to his mouth while eating, and it is interesting to note the skill of his claws when used as fingers. The track he makes in the snow is quite characteristic. The tracks are paired and those of the large five-toed hind feet are always in front.

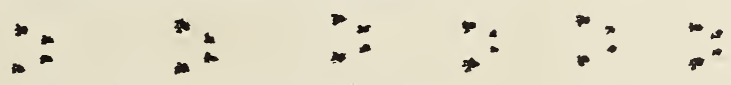

Squirrel tracks.

The squirrel has two pairs of gnawing teeth which are very long and strong, as in all rodents, and he needs to keep busy gnawing hard things with them, or they will grow so long that he cannot use them at all and will starve to death. He is very clever about opening nuts so as to get all the meats. He often opens a hickory nut with two holes which tap the places of the nut meats squarely; with walnuts or butternuts, which have much harder shells, he makes four small holes, one opposite each quarter of the kernel. He has no cheek-pouches like a chipmunk but he can carry corn and other grain. He often fills his mouth so full that his cheeks bulge out like those of a boy eating pop-corn; but anything as large as a nut he carries in his teeth. His food is far more varied than many suppose and he will eat almost anything eatable; he is a little pirate and enjoys stealing from others with keenest zest. In spring, he eats leaf buds and hunts our orchards for apple seeds. In winter, he feeds on nuts and cones; it is marvelous how he will take a cone apart, tearing off the scales and leaving them in a heap while searching for seeds; he is especially fond of the seeds of Norway spruce and hemlock. Of course, he is fond of nuts of all kinds and will cut the chestnut burs from the tree before they are ripe, so that he may get ahead of the other harvesters. $\mathrm{He}$ stores his food for winter in all sorts of odd places and often forgets 
where he puts it. We often find his winter stores untouched the next summer. He also likes birds' eggs and nestlings, and if it were not for the chastisement he gets from the parent robins, he would work much damage in this way.

The squirrel is likely to be a luxurious fellow and have a winter and a summer home. The former is in some hollow tree or other protected place; the summer home consists of a platform of twigs in some tree-top, often built upon an abandoned crow or hawk nest; but just how he uses these two homes, is as yet, a matter of guessing and is a good subject for young naturalists to investigate. During the winter, he does not remain at home except in coldest weather, when he lies cozily with his tail wrapped around him like a boa to keep him warm. He is too full of interest in the world to lie quietly long, but comes out, hunts up some of his stores, and finds life worth while despite the cold. One squirrel adopted a bird house in one of our trees, and he or his kin have lived there for years; in winter, he takes his share of the suet put on the trees for birds, and because of his greediness, we have been compelled to use picture wire for tying on the suet.

The young are born in a protected nest, usually in the hollow of a tree. There are four to six young in a litter and they appear in April. If necessary to move the young, the mother carries the squirrel baby clinging to her breast with its arms around her neck.

The squirrel has several ways of expressing his emotions; one is by various curves in his long beautiful, bushy tail. If the creatures of the wood had a stage, the squirrel would have to be their chief actor. Surprise, incredulousness, indignation, fear, anger and joy are all perfectly expressed by tail gestures and also by voice. As a vocalist he excels; he chatters with curiosity, "chips" with surprise, scolds by giving a gutteral trill, finishing with a falsetto squeal. He is the only singer I know who can carry two parts at a time. Notice him sometimes in the top of a hickory or chestnut tree when nuts are ripe, and you will hear him singing a duet all by himself, a high shrill chatter with a chuckling accompaniment. Long may. he abide with us as an uninvited guest at our cribs! For, though he be a freebooter and conscienceless, yet our world would lack its highest example of incarnate grace and activity, if he were not in it.

\section{LESSON LVII}

\section{The Red Souirrel or Chickaree}

Leading thought-The red squirrel by its agility and cleverness has lived on, despite its worst enemy-man. By form and color and activity it is fitted to elude the hunter.

Method-If a pet squirrel in a cage can be procured for observation at the school, the observations on the form and habits of the animal can be best studied thus; but a squirrel in a cage is an anomaly and it is far better to stimulate the pupils to observe the squirrels out of doors. Give the following questions, a few at a time, and ask the pupils to report the answers to the entire class. Much should be done with the supplementary reading, as there are many interesting squirrel stories illustrating its habits 
Observations-I. Where have you seen a squirrel? Does the squirrel trot along or leap when running on the ground? Does it run straight ahead or stop at intervals for observation? How does it look? How does it act when looking to see if the "coast is clear"?

2. When climbing a tree, does it go straight up, or move around the trunk? How does it hide itself behind a tree trunk and observe the passer-by? Describe how it manages to climb a tree? Does it go down the tree head first? Is it able to climb out on the smallest branches? Of what advantage is this to it?

3. Look closely and see if a squirrel follows the same route always when passing from one point to another. How does it pass from tree to tree? How does it act when preparing to jump? How does it hold its legs and tail when in the air during a jump from branch to branch?

4. Describe the colors of the red squirrel above and below. Is there a dark stripe along its side, if so, what color? How does the color of the squirrel protect it from its enemies? Is its color brighter in summer or in winter?

5. How are the squirrel's eyes placed? Do you think it can see behind as well as in front all the time? Are its eyes bright and alert, or soft and tender?

6. Are its legs long or short? Are its hind legs stronger and longer than the front legs? Why? Why does it not need long legs? Does its paws have claws? How does it use its paws when eating and in making its toilet?

7. Describe the squirrel's tail. Is it as long as the body? Is it used to express emotion? Of what use is it when the squirrel is jumping? Of what use is it in the winter in the nest?

8. What is the food of the squirrel during the autumn? Winter? Spring? Summer? Where does it store food for the winter? Does it steal food laid up by jays, chipmunks, mice or other squirrels? How does it carry nuts? Has it cheek-pouches like the chipmunk for carrying food? Does it stay in its nest all winter living on stored food like a chipmunk?

9. Where does the red squirrel make its winter home? Does it also have a summer home, if so, of what is it made and where built? In what sort of a nest are the young born and reared? At what time of the year are the young born? How does the mother squirrel carry her little ones if she wishes to move them?

Io. How much of squirrel language can you understand? How does it express surprise, excitement, anger, or joy during the nut harvest? Note how many different sounds it makes and try to discover what they mean.

I I. Describe or sketch the tracks made by the squirrel in the snow.

I 2. How does the squirrel get at the meats of the hickory nut and the walnut? How are its teeth arranged to gnaw holes in such hard substances as shells?

Supplementary reading-Squirrels and Other Fur Bearers, John Burroughs; American Animals, Stone \& Cram; Secrets of the Woods, Long; Familiar Life in Field and Forest, Mathews; Little Beasts of Field and Wood; Cram; Wild Neighbors, Ingersoll; Familiar Wild Animals, Lottridge. 


\section{FURRY}

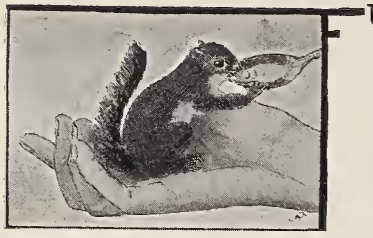

URRY was a baby red squirrel. One day in May his mother was moving him from one tree to another. He was clinging with his little arms around her neck and his body clasped tightly against her breast, when something frightened her and in her sudden movement, she dropped her heavy baby in the grass. Thus, I inherited him and entered upon the rather onerous duties of caring for a baby of whose needs I knew little; but I knew that every well cared for baby should have a book detailing all that happens to it, therefore, I made a book for Furry, writing in it each day the things he did. If the children who have pets keep similar books, they will find them most interesting reading afterward, and they will surely enjoy the writing very much.

\section{Extracts from Furry's Note-book}

May I8, I902-The baby squirrel is just large enough to cuddle in one hand. He cuddles all right when once he is captured; but he is a terrible fighter, and when I attempt to take him in my hand, he scratches and bites and growls so that I have been obliged to name him Fury. I told him, however, if he improved in temper I would change his name to Furry.

May I9-Fury greets me, when I open his box, with the most aweinspiring little growls, which he calculates will make me turn pale with fear. He has not cut his teeth yet, so he cannot bite very severely, but that isn't his fault, for he tries hard enough. The Naturalist said cold milk would kill him, so I warmed the milk and put it in a teaspoon and placed it in front of his nose; he batted the spoon with both forepaws and tried to bite it, and thus got a taste of the milk, which he drank eagerly lapping it up like a kitten. When I hold him in one hand and cover him with the other, he turns contented little somersaults over and over.

May 20-Fury bit me only once to-day, when I took him out to feed him. He is cutting his teeth on my devoted fingers. I tried giving him grape-nuts soaked in milk, but he spat it out in disgust. Evidently he does not believe he needs a food for brain and nerve. He always washes his face as soon as he is through eating.

May 2 I-Fury lies curled up under his blanket all day. Evidently good little squirrels stay quietly in the nest, when the mother is not at home to give them permission to run around. When Fury sleeps, he rolls himself up in a little ball with his tail wrapped closely around him. The squirrel's tail is his "furs," which he wraps around him to keep his back warm when he sleeps in winter.

May 23-Every time I meet Uncle John he asks, "Is his name Fury or Furry now?" Uncle John is much interested in the good behavior of even little squirrels. As Fury has not bitten me hard for two days, I think I will call him Furry after this. He ate some bread soaked in milk to-day, holding it in his hands in real squirrel fashion. I let him run around the room and he liked it.

May 25-Furry got away from me this morning and I did not find him for an hour. Then I discovered him in a pasteboard box of drawing paper with the cover on. How did he squeeze through? 
May $26-$ He holds the bowl of the spoon with both front paws while he drinks the milk. When I try to draw the spoon away, to fill it again after he has emptied it, he objects and hangs on to it with all his little might, and scolds as hard as ever he can. He is such a funny, unreasonable baby.

May 28-To-night I gave Furry a walnut meat. As soon as he smelled it he became greatly excited; he grasped the meat in his hands and ran off and hid under my elbow, growling like a kitten with its first mouse.

May 30-Since he tasted nuts he has lost interest in milk. The nut meats are too hard for his new teeth, so I mash them and soak them in water and now he eats them like a little piggy-wig with no manners at all. He loves to have me stroke his back while he is eating. He uses his thumbs and fingers in such a human way that I always call his front paws hands. When his piece of nut is very small he holds it in one hand and clasps the other hand behind the one which holds the dainty morsel, so as to keep it safe.

May $3 \mathrm{I}$-When he is sleepy he scolds if I disturb him and turning over on his back bats my hand with all of his soft little paws and pretends that he is going to bite.

June 4-Furry ranges around the room now to please himself. He is a little mischief; he tips over his cup of milk and has commenced gnawing off the wall paper behind the book-shelf to make him a nest. The paper is green and will probably make him sorry.

June 5-This morning Furry was hidden in a roll of paper. I put my hand over one end of the roll and then reached in with the other hand to get him; but he got me instead, because he ran up my sleeve and was much more contented to be there than I was to have him. I was glad enough when he left his hiding place and climbed to the top shelf of the bookcase, far beyond my reach.

June 6-I have not seen Furry for twenty-four hours, but he is here surely enough. Last night he tipped over the ink bottle and scattered nut shells over the floor. He prefers pecans to any other nuts.

June 7-I caught Furry to-day and he bit my finger so it bled. But afterwards, he cuddled in my hand for a long time, and then climbed my shoulder and went hunting around in my hair and wanted to stay there and make a nest. When I took him away, he pulled out his two hands full of my devoted tresses. I'll not employ him as a hairdresser.

June 9-Furry sleeps nights in the top drawer of my desk; he crawls in from behind. When I pull out the drawer he pops out and scares me nearly out of my wits; but he keeps his wits about him and gets away before I can catch him.

June 20-I keep the window open so Furry can run out and in and learn to take care of himself out-of-doors.

Furry soon learned to take care of himself, though he often returned for nuts, which I kept for him in a bowl. He does not come very near me out-of-doors, but he often speaks to me in a friendly manner from a certain pitch pine tree near the house.

There are many blank leaves in Furry's note-book. I wish that he could have written on these of the things that he thought about me and my performances. It would certainly have been the most interesting book concerning squirrels in the world. 


\section{THE CHIPMUNK}

\section{Teacher's Story}

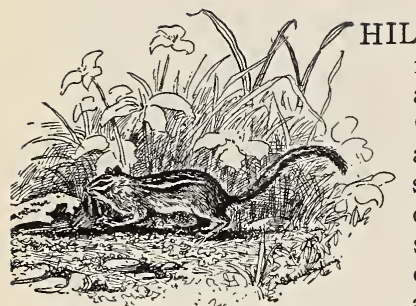

LE the chipmunk is a good runner and jumper, it is not so able a climber as is the red squirrel, and it naturally stays nearer the ground. One windy day I was struck by the peculiar attitude of what, I first thought, was a red squirrel gathering green acorns from a chestnut oak in front of my window. A second glance showed me that it was a chipmunk lying close to the branch, hanging on for "dear life" and with an attitude of extreme caution, quite foreign to the red squirrel in a similar situation. He would creep out, seize an acorn in its teeth, creep back to a larger limb, take off the shell, and with his little paws stuff the kernel into his cheek pouches; he took hold of one side of his mouth with one hand to stretch it out, as if opening a bag, and stuffed the acorn in with the other. I do not know whether this process was necessary or not at the beginning, for his cheeks were distended when I first saw him; and he kept on stuffing them until he looked as if he had a hopeless case of mumps. Then with obvious care he descended the tree and retreated to his den in the side hill, the door of which I had already discovered, although it was well hidden by a bunch of orchard grass.

Chipmunks are more easily tamed than red squirrels and soon learn that pockets may contain nuts and other things good to eat. The first tame chipmunk of my acquaintance belonged to a species found in the California mountains. He was a beautiful little creature and loved to play about his mistress' room; she being a naturalist as well as a poet, was able to understand her little companion, and the relations between them were full of mutual confidence. He was fond of English walnuts and would always hide away all that were placed in a dish on the table. One day his mistress, when taking off her bonnet after returning from church, discovered several of these nuts tucked safely in the velvet bows; they were invisible from the front but perfectly visible from the side. Even yet, she wonders what the people at church that day thought of her original ideas in millinery; and she wonders still more how "Chipsie" managed to get into the bonnet-box, the cover of which was always carefully closed.

The chipmunk is a good home builder and carries off, presumably in its cheek pouches, all of the soil which it removes in making its burrow. The burrow is made usually in a dry hillside, the

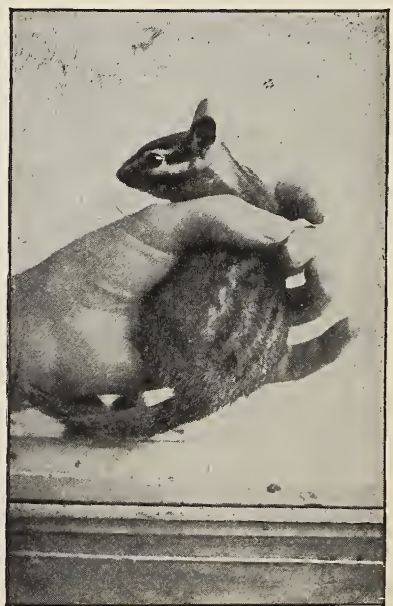

"Chipsie", a chipmunk of the Sierras. 
passageway just large enough for its own body, widening to a nest which is well bedded down. There is usually a back door also, so that in case of necessity, the inmate can escape. It retires to this nest in late November and does not appear again until March. In the nest, it stores nuts and other grains so that when it wakens, at long intervals, it can take refreshment.

If you really wish to know whether you see what you look at or not, test yourself by trying to describe the length, position and number of the chipmunk's stripes. These stripes, like those of the tiger in the jungle, make the creature less conspicuous; when on the ground, where its stripes fall in with the general shape and color of the grass and underbrush, it is quite invisible until it stirs. Its tail is not so long nor nearly so bushy as that of the squirrel; it does not need a tail to balance and steer with in the tree tops; and since it lives in the ground, a bushy tail would soon be loaded with earth and would be an incubus instead of a thing of beauty.

The chipmunk is not a vocalist like the red squirrel, but he can cluck like a cuckoo and chatter gayly or cogently; and he can make himself into a little bunch with his tail curved up his back, while he eats a nut from both his hands, and is even more amusing than the red squirrel in this attitude; probably because he is more innocent and not so much of a poseur. His food consists of all kinds of nuts, grain and fruit, but he does little or no damage, as a rule. He is pretty and distinctly companionable, and I can rejoice, in that I have had him and his whole family as my near neighbors for many years. I always feel especially proud when he shows his confidence, by scampering around our piazza floor and peeping in at our windows, as if taking a reciprocal interest in us.

\section{LESSON LVIII}

\section{The Chipmunk}

Leading thought-The chipmunk lives more on the ground than does the squirrel; its colors are protective and it has cheek pouches in which it carries food, and also soil when digging its burrow. It stores food for winter in its den.

Method-The field note-book should be the basis for this work. Give the pupils an outline of observations to be made, and ask for reports now and then. Meanwhile stimulate interest in the little creatures by reading aloud from some of the references given.

Observations-I. Do you see the chipmunk climbing around in trees like the red squirrel? How high in a tree have you ever seen a chipmunk?

2. What are the chipmunk's colors above and below? How many stripes has it? Where are they and what are their colors? Do you think that these stripes conceal the animal when among grasses and bushes?

3. Compare the tails of the chipmunk and the red squirrel. Which is the longer and bushier? Tell if you can the special advantage to the chipmunk in having this less bushy tail?

4. What does the chipmunk eat? How does it carry its food? How does it differ in this respect from the red squirrel? Does it store its food for winter use? How does it prepare its nuts? How does it hold its food while eating? 
5. Where does the chipmunk make its home? How does it carry away soil from its burrow? How many entrances are there? How is the den arranged inside? Does it live in the same den the year round? When does it retire to its den in the fall? When does it come out in the spring?

6. Does the chipmunk do any damage to crops? What seeds does it distribute? At what time do the little chipmunks appear in the spring?

7. Observe carefully the different tones of the chipmunk and compare its chattering with that of the squirrel.

Supplementary reading-Squirrels and Other Fur-Bearers, John Burroughs; American Animals, Stone and Cram.

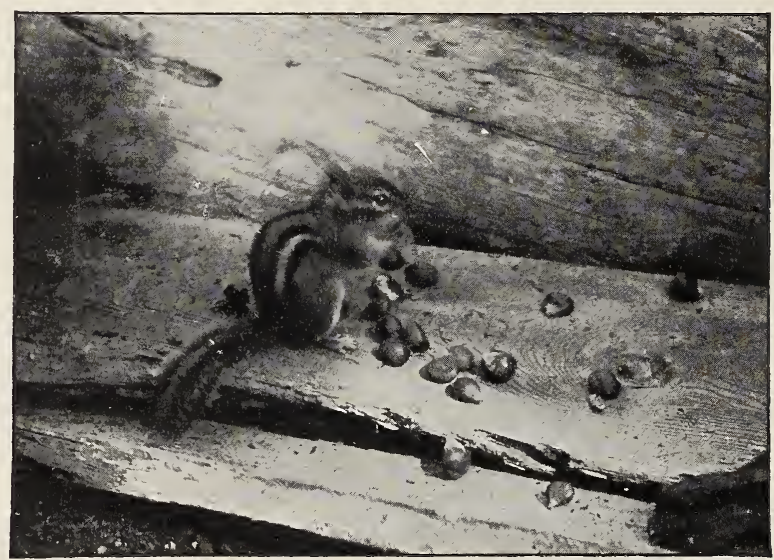

The Eastern Chipmunk.

Photo by Verne Morton

\section{TO A CAPTIVE CHIPMUNK OF THE SIERRAS}

Bright little comrade from the woods, come show

Thy antic cheer about my sunlit room

Of books, that stand in moods of gloom

Because thought's tide is out, heart's rhythm is low

With weariness. Friendly thou art and know

Good friend in me, who yet did dare presume

To take thee from thy home, thy little doom

To make for thee, and longer life bestow.

So, thou hast not been eaten by the snake;

Thy gentle blood no weasel drank at night;

Thou hast not starved 'mid winter's frozen wood,

Nor waited vainly for the sun to make

Sweet the wild nuts for thee. Yet, little sprite,

Thou still doth question if my deed were good?

- Irene Hardy. 


\section{THE LITTLE BROWN BAT}

\section{Teacher's Story}

His small umbrella, quaintly halved, Describing in the air an arc alike inscrutable,Elate shilosopher!-EMily Dickenson.

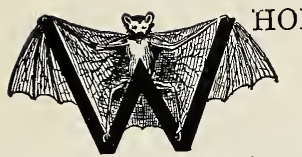

HOEVER first said "as blind as a bat," surely never looked a bat in the face, or he would not have said it. The deep-set, keen, observant eyes are quite in keeping with the alert attitude of the erect, pointed ears; while the pug-nose and the wide open, little, pink bag of a mouth, set with tiny, sharp teeth, give this anomalous little animal a deliciously impish look. Yet how have those old artists belied the bat, who fashioned their demons after his pattern, ears, eyes, nose, mouth, wings and all! Certain it is, if human beings ever get to be winged angels in this world, they are farmore likely to have their wings fashioned like those of the bat than like those of the bird. As a matter of fact, there are no other wings so wonderful as the bat's; the thin membrane is equipped with sensitive nerves which inform the flier of the objects in his path, so that he darts among the branches of trees at terrific speed and never touches a twig; a blinded bat was once set free in a room, across which threads were stretched, and he flew about without ever touching one. After we have tamed one of these little, silky flitter-mice we soon get reconciled to his wings for he proves the cunningest of pets; he soon learns who feeds him, and is a constant source of entertainment.

The flight of the bat is the highest ideal we may have, for the achievement of the aeroplane. It consists of darting hither and thither with incredible swiftness, and making sharp turns with no apparent effort. Swifts and swallows are the only birds that can compete with the bat in wing celerity and agility; it is interesting to note that these birds also catch insects on the wing, for food. The bat, like the swift, keeps his mouth open, scooping in all the insects in his way; more than this, he makes a collecting net of the wing membrane, stretched between the hind legs and tail, doubling it up like an apron on the unfortunate insects, and then reaching down and gobbling them up; and thus he is always doing good service to us on summer evenings by swallowing mosquitoes and gnats.

The short fur of the bat is as soft as silk, and covers the body but not the wings; the plan of the wing is something like that of the duck's foot; it consists of a web stretched between very much elongated fingers. If a boy's fingers were as long in proportion, as a bat's, they would measure four feet. Stretched between the long fingers is a thin, rubbery membrane, which extends back to the ankles and thence back to the tip of the bony tail; thus, the bat has a winged margin all around his body. Since fingers make the framework, it is the thumb that projects from the front angle of the wing, in the form of a very serviceable hook, resembling that used by a one-armed man to replace the lost member. These hooks the bat uses in many ways. He drags himself along the floor with their aid, or he scratches the back of his head with them, if occasion requires. He is essentially a creature of the air and is not at all fitted for walking; his 
knees bend backward in an opposite direction from ours. This renders him unable to walk, and when attempting to do so, he has the appeairance of "scrabbling" along on his feet and elbows. Wh en thus movng he keeps his wings fluttering rapidly, as if feeling his way in the dark, and his movements are trembly. He uses his teeth to aid in climbing.

The little brown bat's wings often measure nine inches from tip to tip, and yet he folds them so that they scarcely show; he does not fold them like a fan, but rather like a pocket knife. The hind legs merely act as a support for the side wing, and the little hip bones look pitifully sharp; the membrane reaches only to the ankle, the tiny emaciated foot projecting from it is armed with five, wirelike toes, tipped with sharp hooked claws. It is by these claws that he hangs when resting during the day, for he is upside-down-y in his sleeping habits, slumbering during the daytime, while hanging head downward, without any inconvenience from a rush of blood to the brain; when thus suspended, the tail is folded down. Sometimes he hangs by one hind foot and a front hook; and he is a wee thing when all folded together and hung up, with his nose tucked between his hooked thumbs, in a very babyish fashion.

The bat is very particular about his personal cleanliness. People who regard the bat as a dirty creature, had better look to it that they are even half as fastidious as he. He washes his face with the front part of his wing, and then licks his wash-cloth clean; he scratches the back of his head with his hind foot and then licks the foot; when hanging head down, he will reach one hind foot down and scratch behind his ear with an aplomb truly comical in such a mite; but it is most fun of all to see him clean his wings; he seizes the edges in his mouth and stretches and licks the membrane until we are sure it is made of silk elastic, for he pulls and hauls it in a way truly amazing.

The bat has a voice which sounds like the squeak of a toy wheelbarrow, and yet it is expressive of emotions. He squeaks in one tone when holding conversation with other bats, and squeaks quite differently when seized by the enemy.

The mother bat feeds her little ones from her breasts as a mouse does its young, only she cradles them in her soft wings while so doing; often she takes them with her when she goes out for insects in the evenings; they cling to her neck during these exciting rides; but when she wishes to work unencumbered, she hangs her tiny youngsters on some twig and goes back to them later. The little ones are born in July and usually occur as twins. During the winter, bats hibernate like woodchucks or chipmunks. They select for winter quarters some hollow tree or cave or other protected place. They go to sleep when the cold weather comes, and do not awake until the insects are flying; they then come forth in the evenings, or perhaps early in the morning, and do their best to rid the world of mosquitoes and other insect nuisances.

There are many senseless fears about the bat; for instance, that he likes to get tangled in a lady's tresses, a situation which would frighten him far more than the lady; or that he brings bedbugs into the house, when he enters on his quest for mosquitoes, which is an ungrateful slander. Some people believe that all bats are vampires, and only await an opportunity to suck blood from their victims. It is true that in South America there are two species which occasionally attack people who are careless enough to sleep with their toes uncovered, but feet thus injured seem to 
recover speedily; and these bats do little damage to people, although they sometimes pester animals; but there are no vampires in the United States. Our bats, on the contrary, are innocent and beneficial to man; and if we had more of them we should have less malaria. There a few species in our country, which have little, leaf-like growths on the end of the nose; and when scientists study the bat from a nature-study instead of an anatomical standpoint, we shall know what these leafy appendages are used for.

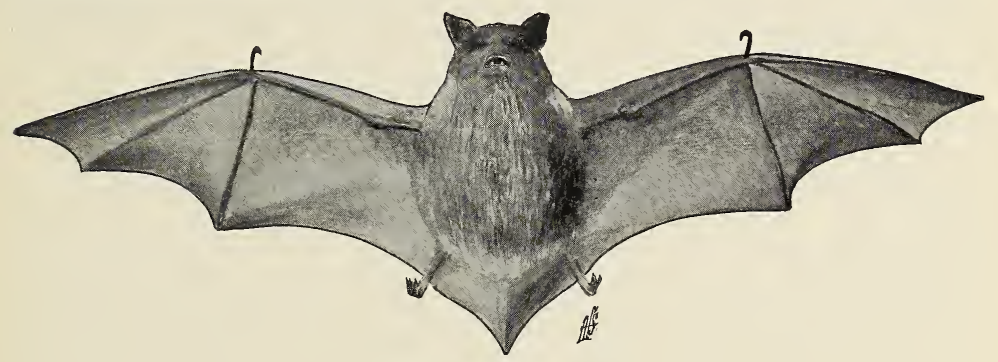

The little brown bat.

\section{LESSON LIX}

The Bat

Leading thought-Although the bat's wings are very different from those of the bird's yet it is a rapid and agile flier. It flies in the dusk and catches great numbers of mosquitoes and other troublesome insects, upon which it feeds.

Method-This lesson should not be given unless there is a live bat to illustrate it; the little creature can be cared for comfortably in a cage in the schoolroom, as it will soon learn to take flies or bits of raw meat when presented on the point of a pencil or toothpick. Any bat will do for this study, although the little brown bat is the one on which my observations were made.

Observations-r. At what time of day do we see bats flying? Describe how the bat's flight differs from that of birds. Why do bats dart about so rapidly?

2. Look at a captive bat and describe its wings. Can you see what makes the framework of the wings? Do you see the three finger bones extending out into the wings? How do the hind legs support the wing? The tail? Is the wing membrane covered with fur? Is it thick and leathery or thin and silky and elastic? How does the bat fold up its wings?

3. In what position does the bat rest? Does it ever hang by his thumb hooks?

4. Can you see whether the knees of the hind legs bend upward or downward? How does the bat act when trying to walk or crawl? How does it use its thumb hooks in doing this?

5. What does the bat do daytimes? Where does it stay during the day? Do many bats congregate together in their roosts? 
6. Describe the bat's head, including the ears, eyes, nose and mouth. What is its general expression? Do you think it can see and hear well? How is its mouth fitted for catching insects? Does it shut its mouth while chewing or keep it open? Do you think that bats can see by daylight?

7. What noises does a bat make? How does it act if you try to touch it? Can it bite severely? Can you understand why the Germans call it a flitter-mouse?

8. Do you know how the mother bat cares for her young? How does she carry them? At what time of year may we expect to find them?

9. When making its toilet, how does a bat clean its wings? Its face? Its back? Its feet? Do you know if it is very clean in his habits?

Io. How and where do the bats pass the winter? How are they beneficial to us? Are they ever harmful?

Supplementary reading-American Animals, Stone and Cram.

Nature-study should not be unrelated to the child's life and circumstances. It stands for directness and naturalness. It is astonishing when one comes to think of it, how indirect and how remote from the lives of pupils much of our education has been. Geography still often begins with the universe, and finally, perhaps, comes down to some concrete and familiar object or scene that the pupil can understand. Arithmetic has to do with brokerage and partnerships and partial payments and other things that mean nothing to the child. Botany begins with cells and protoplasm and cryptogams. History deals with political and military affairs, and only rarely comes down to physical facts and to those events that express the real lives of the people; and yet political and social affairs are only the results of expressions of the way in which people live. Readers begin with mere literature or with stories of scenes the child will never see. Of course these statements are meant to be only general, as illustrating what is even yet a great fault in educational methods. There are many exceptions, and these are becoming commoner. Surely, the best education is that which begins with the materials at hand. $A$ child knows a stone before it knows the earth. 


\section{THE SKUNK}

\section{Teacher's Story}

PDANGER HOSE who have had experience with this animal, surely are glad that it is small; and the wonder always is, that so little a creature can make such a large impression upon the atmosphere. A fully grown skunk is about two feet long: its body is covered with long, shining, rather coarse hair, and the tail which is carried like a flag in the air, is very large and bushy. In color, the fur is sometimes entirely black, but most often has a white patch on the back of the neck, with two stripes extending down the back and along the sides to the tail; the face, also, has a white stripe.

The skunk has a long head and a rather pointed snout; its front legs are very much shorter than its hind legs, which gives it a very peculiar gait. Its forefeet are armed with long, strong claws, with which it digs its burrow, which is usually made in light soil. It also often makes its home in some crevice in rocks, or even takes possession of an abandoned woodchuck's hole; or trusting to its immunity from danger, makes its home under the barn. In the fall, it becomes very fat, and during the early part of winter, hibernates within its den; it comes out during the thaws of winter and early spring.

The young skunks appear in May; they are born in an enlarged portion of the burrow, where a nice bed of grass and leaves is made for them; the skunk is scrupulously neat about its own nest. The young skunks are very active, and interesting to watch, when playing together like kittens.

The skunk belongs to the same family as the mink and weasel, which also give off a disagreeable odor when angry. The fetid material which is the skunk's defence, is contained in two capsules under the root of the tail. These little capsules are not larger than peas, and the quantity of liquid forced from them in a discharge is scarcely more than a large drop; yet it will permeate the atmosphere with its odor for a distance of a mile. The fact that this discharge is so disagreeable to all other animals, has had a retarding influence upon the skunk's intelligence. It has not been obliged to rely upon its cunning to escape its enemies, and has therefore never developed either fear or cleverness. It marches abroad without haste, confdent that every creature which sees it will give it plenty of room. It is a night prowler, although it is not averse to a daytime promenade. The white upon its fur gives warning at night, that here is an animal which had best be left alone. This immunity from attack makes the skunk careless in learning

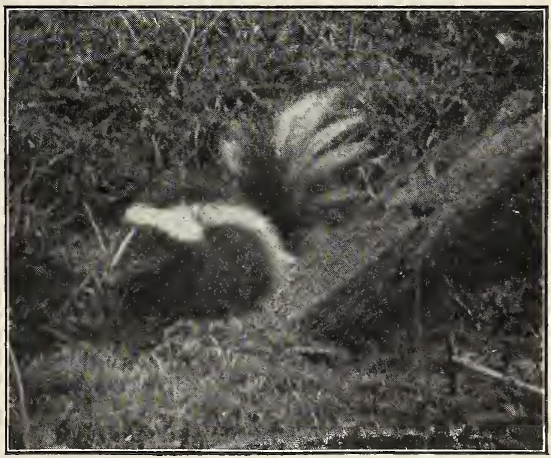
The skunk.
Photo by Verne Mortor. 
wisdom from experience; it never learns to avoid a trap or a railway or trolley track.

The skunk's food consists largely of insects, mice, snakes and other small animals. It also destroys the eggs and young of birds which nest upon the ground. It uses its strong forepaws in securing its prey. Dr. Merriam, who made pets of young skunks after removing their scent capsules, found them very interesting. He says of one which was named "Meph": "We used to walk through the woods to a large meadow that abounded in grasshoppers. Here, Meph would fairly revel in his favorite food, and it was rich sport to watch his manœuvres. When a grasshopper jumped, he jumped, and I have seen him with as many as three in his mouth and two under his fore-paws at the same time."

The only injury which the skunk is likely to do to the farmers, is the raiding of the hens' nests, and this can be obviated by properly housing the poultry. On the other hand, the skunk is of great use in destroying injurious insects and mice. Often when skunks burrow beneath barns, they completely rid the place of mice. Skunk fur is very valuable and is sold under the name of Alaskan sable. The skunk takes short steps, and goes so slowly that it makes a double track, the imprints being very close together. The foot makes a longer track than that of the cat, as the skunk is plantigrade; that is, it walks upon its palms and heels as well as its toes.
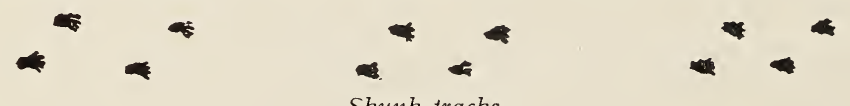

References-Wild Neighbors, Ingersoll; Familiar Life in Field and Forest, Mathews; American Animals, Stone and Cram; Squirrels and Other Fur Bearers, Burroughs.

\section{LESSON LX}

\section{The SKunk}

Leading thought-The skunk has depended so long upon protecting itself from its enemies by its disagreeable odor, that it has become stupid in this respect, and seems never to be able to learn to keep off of railroad tracks. It is a very beneficial animal to the farmer because its food consists so largely of injurious insects and rodents.

Method-The questions should be given the pupils and they should answer them from personal observations or inquiries.

Observations-r. How large is a skunk? Describe its fur. Where does the black and white occur in the fur? Of what use is the white to the skunk? Is the fur valuable? What is its commercial name?

2. What is the shape of the skunk's head? The general shape of the body? The tail? Are the front legs longer or shorter than the hind legs? Describe the front feet. For what are they used?

3. Where and how does the skunk make its nest? Does it sleep like a woodchuck during the winter? What is its food? How does it catch its prey? Does it hunt for its food during the day or the night? Does 
the skunk ever hurry? Is it afraid? How does it protect itself from its enemies? Do you think that the skunk's freedom from fear has rendered the animal less intelligent?

4. At what time do the skunk kittens appear? Have you ever seen little skunks playing? If so, describe their antics. How is the nest made soft for the young ones?

5. How does the skunk benefit farmers? Does it ever do them any injury? Do you think that it does more good than harm?

6. Describe the skunk's track as follows: How many toes show in the track? Does the palm or heel show? Are the tracks near together? Do they form a single or a double line?

Supplementary reading-Squirrels and Other Fur Bearers, Burroughs.

Saw a little skunk coming up the river bank in the woods at the white oak, a funny little fellow, about six inches long and nearly as broad. It faced me and actually compelled me to retreat before it for five minutes. Perhaps I was between it and its hole. Its broad black tail, tipped with white, was erect like a kitten's. It had what looked like a broad white band drawn tight across its forehand or top-head, from which two lines of white ran down, one on each side of its back, and there was a narrow white line down its snout. It raised its back, sometimes ran a few feet forward, sometimes backward, and repeatedly turned its tail to me, prepared to discharge its fluid, like the old ones. Such was its instinct, and all the while it kept up a fine grunting like a little pig or a red squirrcl.-HENRY THOREAU.

Few animals are so silent as the skunk. Zoological works contain no information as to its voice, and the essayists rarely mention it except by implication. Mr. Burroughs says: "The most silent creature known to me, he makes no sound, so far as I have observed, save a diff use, impatient noise, like that produced by beating your hand with a whisk-broom, when the farm-dog has discovered his retreat in the stone fence." Rowland Robinson tells us that: "The voiceless creature sometimes frightens the belated farm-boy, whom he curiously follows with a mysterious hollow beating of his feet upon the ground." Thoreau, as has been mentioned, heard one keep up a "fine grunting, like a little pig or a squirrel," but he seems to have misunderstood altogether a singular loud patting sound heard repeatedly on the frozen ground under the wall, which he also listened to, for he thought it "had to do with getting its food, patting the earth to get the insects or worms." Probably he would have omitted this guess if he could have edited his diary instead of leaving that to be done after his death. The patting is evidently merely a nervous sign of impatience or apprehension, similar to the well-known stamping with the hind feet indulged in by rabbits, in this case probably a menace like a doubling of the fists, as the hind legs, with which they kick, are their only weapons. The skunk, then, is not voiceless, but its voice is weak and querulous, and it is rarely if ever heard except in the expression of anger.

\section{-Ernest Ingersol in "Wild Neighbors."}




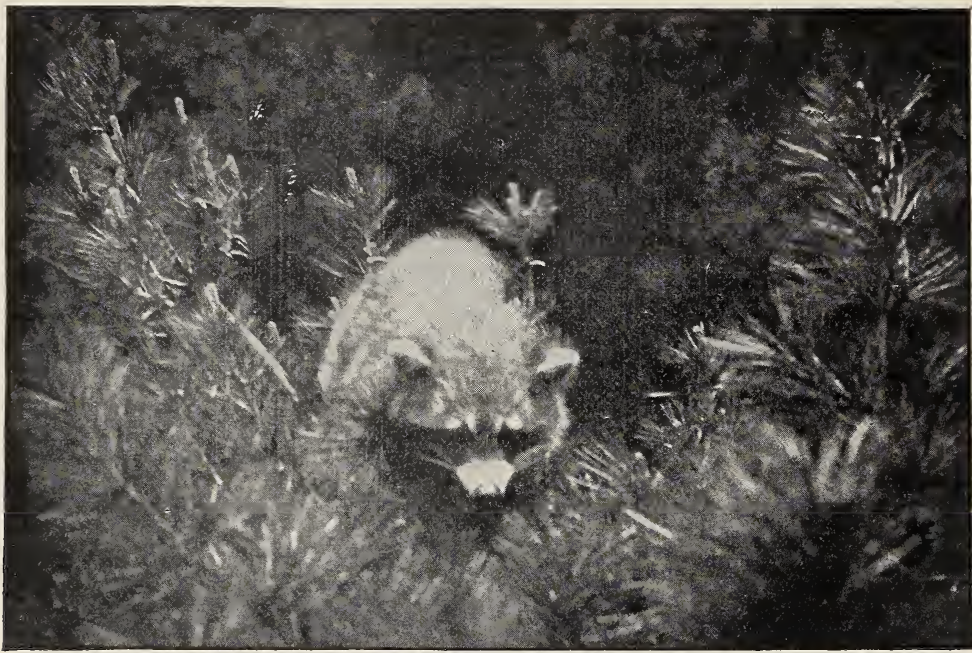

The raccoon.

Photo by George Fiske, Jr.

\section{THE RACCOON}

\section{Teacher's Story}

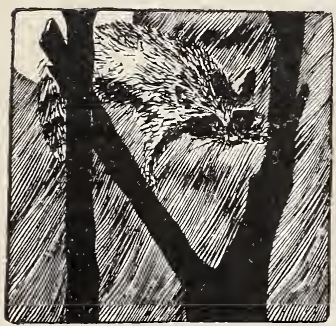

ONE other of our little brothers of the forest, has such a mischievous countenance as the coon. The black patch across the face and surrounding the eyes, like large goggles, and the black line extending from the long, inquisitive nose directly up the forehead give the coon's face an anxious expression; and the keenness of the big, beady, black eyes and the alert, "sassy" looking, broadly triangular ears, convince one that the anxiety depicted in the face is anxiety lest something that should not be done be left undone; and I am sure that anyone who has had experience with pet coons will aver that their acts do not belie their looks.

What country child, wandering by the brook and 1
watching its turbulence in early spring, has not viewed with awe, a footprint on the muddy banks looking as if it were made by the foot of a 2 very little baby. The first one I ever saw, I promptly concluded was made by the

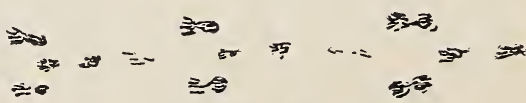

Coon tracks.

$\tau$ Walking 2 Jumping 
foot of a brook fairy. However, the coon is no fairy; it is a rather heavy, logy animal and, like the bear and skunk, is plantigrade, walking on the entire foot instead of on the toes, like a cat or dog. The hind foot is long, with a well-marked heel, and five comparatively short toes, giving it a remarkable resemblance to a human foot. The front foot is smaller and looks like a wide, little hand, with fourlong fingers and a rather short thumb. The claws are strong and sharp. The soles of the feet and the palms of the hands look as if they were covered with black kid, while the feet above and the backs of the hands are covered with short fur. Coon tracks are likely to be found during the first thawing days of winter, along some stream or the borders of swamps, often following the path made by cattle. The full-length tracik is about 2 inches long; as the coon puts the hind foot in the track made by the front foot on the same side, only the print of the hind feet is left, showing plainly five toe prints and the heel. The tracks may vary from one-half inch to one foot or more apart, depending on how fast the animal is going; when it runs it goes on its toes, but when walking sets the heel down; the tracks are not in so straight a line as those made by the cat. Sometimes it goes at a slow jump, when the prints of the hind feet are paired, and between and behind them are the prints of the two front feet.

The coon is covered with long, rather coarse hair, so long as to almost drag when the animal is walking; it really has two different kinds of hair, the long, coarse, gray hair, blackened at the tips, covering the fine, short, grayish or brownish under coat. The very handsome bushy tail is ringed with black and gray.

The raccoon feeds on almost anything eatable, except herbage. It has a special predilection for corn in the milk stage and, in attaining this sweet and toothsome luxury, it strips down the husks and often breaks the plant, doing much damage. It is also fond of poultry and often raids hen houses; it also destroys birds' nests and the young, thus damaging the farmer by killing both domestic and wild birds. It is especially fond of fish and is an adept at sitting on the shore and catching them with its hands; it likes turtle eggs, crayfish and snakes; it haunts the bayous of the Gulf Coast for the oysters which grow there; it is also a skillful frog catcher. Although fond of animal diet, it is also fond of fruit, especially of berries and wild grapes.

It usually chooses for a nest a hollow tree or a cavern in a ledge near a stream, because of its liking for water creatures; and also because of its strange habit of washing its meat before eating it. I have watched a pet coon performing this act; he would take a piece of meat in his hands, dump it into the pan of drinking water and souse it up and down a few times; then he would get into the pan with his splay feet and roll the meat beneath and between them, meanwhile looking quite unconcernedly at his surroundings, as if washing the meat were an act too mechanical to occupy his mind. After the meat had become soaked until white and flabby, he would take it in his hands and hang on to it with a tight grip while he pulled off pieces with his teeth; or sometimes he would hold it with his feet, and use hands as well as teeth in tearing it apart. The coon's teeth are very much like those of the cat, having long, sharp tushes or canines, and sharp, wedge-shaped grinding teeth, which cut as well as grind. After eating, the pet coon always washed his feet by splashing them in the pan. 
It is a funny sight to watch a coon arrange itself for a nap, on a branch or in the fork of a tree; it adapts its fat body to the unevenness of the bed with apparent comfort; it then tucks its nose down between its paws and curls its tail about itself, making a huge, furry ball. In all probability, the rings of gray and black on the tail, serve as protective color to the animal sleeping in a tree during the daytime, when sunshine and shadow glance down between the leaves with ever-changing light. The coon spends much of its days asleep in some such situation, and comes forth at night to seek its food.

In the fall, the coon lays on fat enough to last it during its winter sleep. Usually several inhabit the same nest in winter, lying curled up together in a hollow tree, and remaining dormant all winter except when awakened by the warmth of a thaw. They then may come forth to see what is happening, but return shortly to wait until March or April; then they issue to hunt for the scant food, and are so lean and weak that they fall easy prey to their enemies.

The young are born in April and May; there are from three to six in a litter; they are blind and helpless at first, and are cared for carefully by their parents, the family remaining together for a year, until the young are fully grown. If removed from their parents the young ones cry pitifully, almost like babies. The cry or whistle of the fully grown coon is anything but a happy sound, and is quite impossible to describe. I have been awakened by it many a night in camp, and it always sounded strange, taking on each time new quavers and whimperings. As a cry, it is first cousin to that of the screech-owl.

The stories of pet coons are many. I knew one which, chained in a yard, would lie curled up near its post looking like an innocent stone except for one eye kept watchfully open. Soon a hen, filled with curiosity would come warily near, looking longingly at remains of food in the pan; the coon made no move until the disarmed biddy came close to the pan. Then, there was a scramble and a squawk and with astonishing celerity he would wring her neck and strip off her feathers. Another pet coon was allowed to range over the house at will, and finally had to be sent away because he had learned to open every door in the house, including cupboard doors, and could also open boxes and drawers left unlocked; and I have always believed he could have learned to unlock drawers if he had been given the key. All coons are very curious, and one way of trapping them is to suspend above the trap a bit of bright tin; in solving this glittering mystery, traps are forgotten.

\section{LESSON LXI}

\section{The Raccoon}

Leading thought-The raccoon lives in hollow trees or caves along the banks of streams. It sleeps during the day and seeks its food at night. It sleeps during the winter.

Method-If there are raccoons in the vicinity, ask the older boys to look for their tracks rear the streams and to describe them very carefully to the class. The ideal method of studying the animal, is to have a pet coon where the children may watch at leisure its entertaining and funny performances. If this is impossible, then follow the 
less desirable method of having the pupils read about the habits of the coon and thus arouse their interest and open their eyes, so that they may make observations of their own when opportunity offers. I would suggest the following topics for oral or written work in English:

"How and Where Coons Live and What They Do;" "The Autobiography of a Coon One Year Old;" "The Queer Antics of Pet Coons;" "Stories of the Coon's Relative, the Bear."

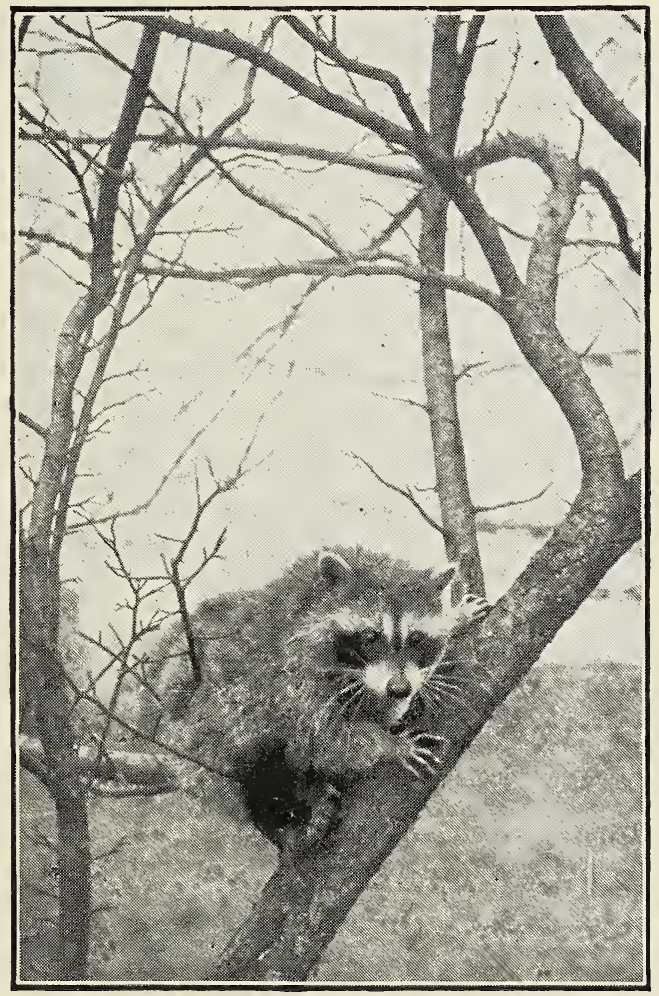

Treed.

Observations- - . Where have you found raccoon tracks? How do they differ from those of fox or dog? How far are the footprints apart? Can you see the heel and toe prints? Do you see the tracks of all four feet? Are the tracks in a straight line like those of the cat? What is the size of the track, the length, the breadth?

2. What do coons eat and how do they get their food? Which of our crops are they likely to damage? What other damage do they do? Have you ever heard coons cry or whistle during August nights in the cornfields? 
3. Why do raccoons like to live near the water? What do they find of interest there? How do they prepare their meat before eating it? How does a coon handle its meat while eating it?

4. What kind of fur has the coon? Why does it need such a heavy covering? Describe the color of the fur. Describe the tail. Of what use is such a large and bushy tail to this animal?

5. Describe the coon's face. How is it marked? What is its expression? Describe the eyes and ears. The nose. Has it teeth resembling those of the cat and dog?

6. Describe the coon's feet. How many toes on the front feet? How many on the hind feet? How does this differ from the cat and dog? How do the front and hind feet differ in appearance? Can both be used as hands?

7. How do coons arrange themselves for a nap in a tree? How do they cover the head? How is the tail used? Do you think this bushy tail used in this way would help to keep the animal warm in winter? Do coons sleep most daytimes or nights?

8. At what time of year are coons fattest? Leanest? Why? Do they ever come out of their nests in winter? Do they live together or singly in winter?

9. At what time of year are the young coons born? Do you know how they look when they are young? How are they cared for by their parents?

Io. Are the coon's movements slow or fast? What large animal is a near relative of the coon?

Supplementary reading-American Animals, Stone and Cram; Wild Neighbors, Ingersoll; Familiar Life of Field and Forest, Mathews; Little People of the Sycamore, Roberts; Life of Animals, Ingersoll; "Mux" in Roof and Meadow, Sharp; Little Brother of the Bear, Long.

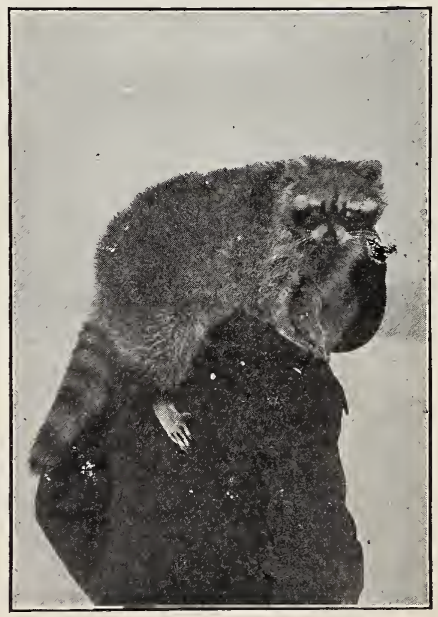

Professor Fred S. Charles and his pet coon, "Dick". 


\section{THE WOLF}

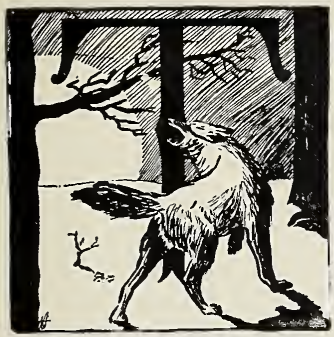

HE study of the wolf should precede the lessons on the fox and the dog. After becoming familiar with the habits of wolves, the pupils will be much better able to understand the nature of the dog and its life as a wild animal. In most localities, the study of the wolf must, of course, be a matter of reading, unless the pupils have an opportunity to study the animal in traveling manageries or in zoological gardens. However, in all the government preserves, the timber wolf has multiplied to such an extent, that it may become a factor in the lives of many people in the United States. This wolf ranged in packs over New York State a hundred years ago, but was finally practically exterminated in most of the eastern forests, except in remote and mountainous localities. A glance at Bulletin 72 by Vernon Bailey, published by the U. S. Department of Agriculture, Forest Service, is a revelation of the success of the timber wolf, in coming back to his own, as soon as the forest preserves furnished plenty of game, and forbade hunters. Timber wolves are returning of late years to Western Maine and Northern New Hampshire; Northern Michigan and Wisconsin have them in greater numbers; some have also been killed in the Apalachian Mountains of Tennessee, Virginia and West Virginia, but their stronghold is in the great Rocky Mountain Region and the Northwestern Sierras, from which they have never been driven.

It might be well to begin this lesson on the wolf with a talk about the gray wolves which our ancestors had to contend with, and also with stories of the coyote or prairie wolf which has learned to a dapt itself to civilization and flourishes in the regions west of the Rocky Mountains, despite men and dogs. Literature is rich in wolf stories. Although Kipling's famous Mowgli Stories belong to the realm of fiction, yet they contain interesting accounts of the habits of the wolves of India, and are based upon the hunter's and track-

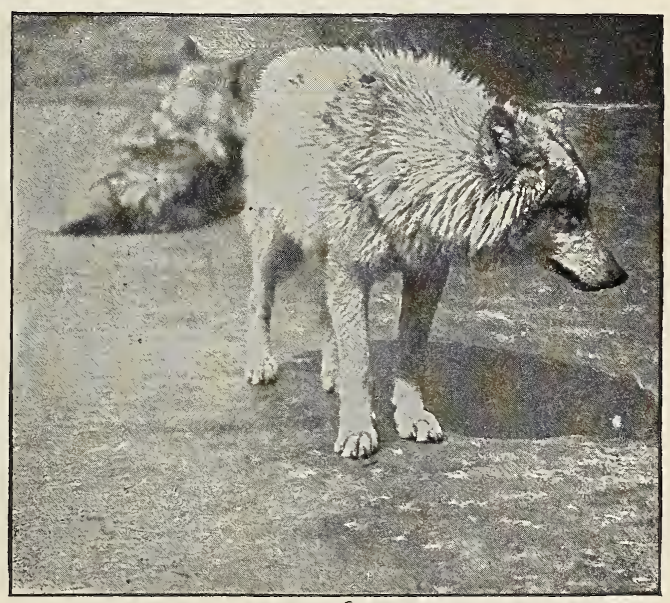

Gray Wolf 
er's knowledge of these animals. We have many thrillingly interesting stories in our own literature which deal with our native wolves. The following are among the best:

"Lobo" in Wild Animals I Have Known; "Tito" in Lives of the Hunted; "Bad Lands Billy and the Winnipeg Wolf" in Animal Heroes all by Thompson Seton; "The Passing of Black Whelps" in Watchers of the Trail by Roberts; Northern Trails by Long; "Pico, Coyote" by Coolidge in True Tales of Birds and Beasts.

For more serious accounts of the wolves see American Animals, p. 277; The "Hound of the Plains,"in Wild Neighbors, and page I88 in the Life of Animals, both by Ingersoll. "The Coyote" by Bret Harte and "The Law of the Pack" in the Second Jungle Book bring the wolf into poetry.

From some or all of these stories, the pupils should get information about the habits of the wolves. This information should be incorporated in an essay or an oral exercise and should cover the following points: Where do the wolves live? On what do they feed? How do they get their prey? Do they hunt alone or in packs? How do they call to each other? Description of the den where the young are reared. The wolf's cleverness in eluding hunters and traps.

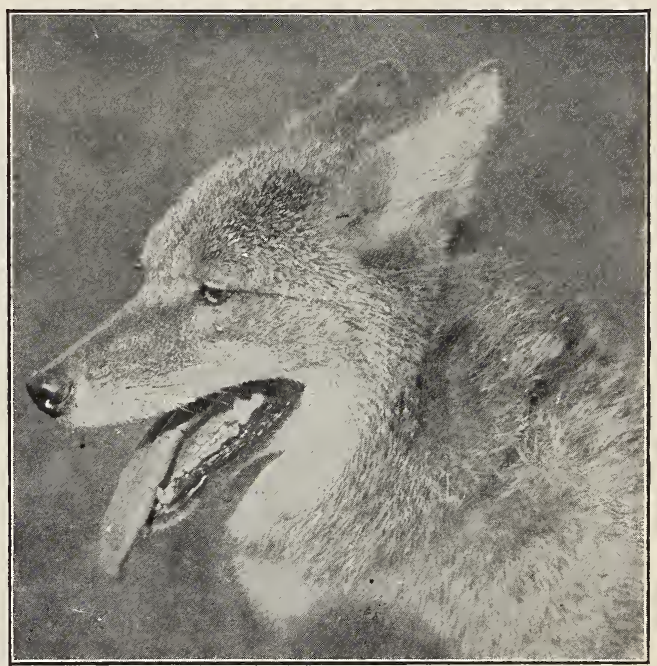

"Katrina Wolfchen", the pet coyote of Professor Fred S. Charles. 


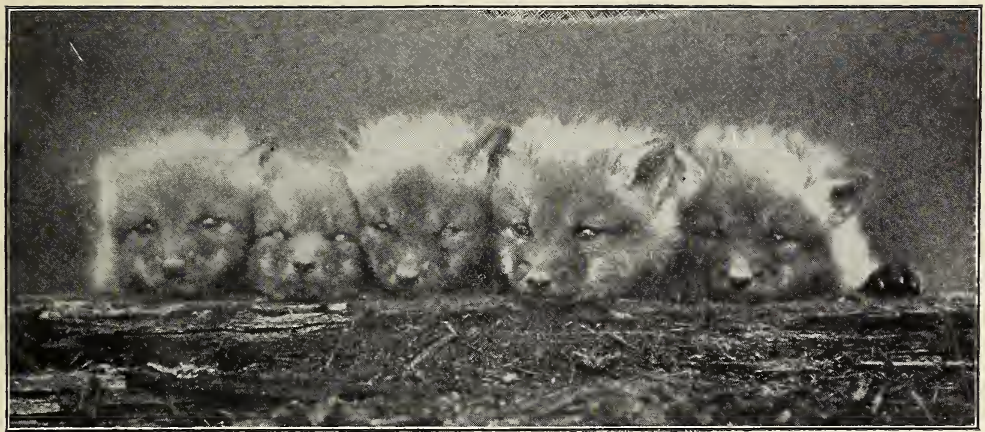

Fox cubs.

\section{THE FOX}

\section{Teacher's Story}

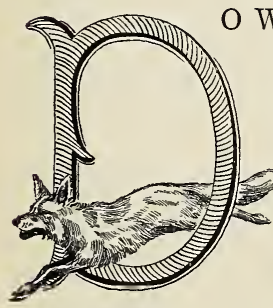

WE not always, on a clear morning of winter, feel a thrill that must have something primitive in its quality, at seeing certain tracks in the snow that somehow suggest wildness and freedom! Such is the track of the fox. Although it is somewhat like that of a small dog yet it is very different. The fox has longer legs than most dogs of his weight, and there is more of freedom in his track and more of strength and agility expressed in it. His gait is usually an easy lope; this places the imprint of three feet in a line, one ahead of another, but the fourth is off a little at one side, as if to keep the balance.

The fox lives in a den or burrow. The only fox home which I ever saw, was a rather deep cave beneath the roots of a stump, and there was no burrow or retreat beyond it. However, foxes often select woodchuck burrows, or make burrows of their own, and if they are caught within, they can dig rapidly, as many a hunter can attest. The mother usually selects an open place for a den for the young foxes; often an open field or side-hill is chosen for this. The den is carpeted with grass and is a very comfortable place for the fox puppies. The den of the father fox is usually not far away.

The face of the red fox shows plainly why he has been able to cope with man, and thrive despite and because of him. If ever a face showed cunning, it is his. Its pointed, slender nose gives it an expression of extreme cleverness, while the width of the head between the upstanding, triangular ears gives room for a brain of power. In color the fox is russetred, the hind quarters being grayish. The legs are black outside and white inside; the throat is white, and the broad, triangular ears are tipped with black. The glory of the fox is his "brush," as the beautiful, bushy tail is called. This is red, with black toward the end and white-tipped. This tail is not merely for beauty, for it affords the fox warmth during the winter, as any one may see who has observed the way it is wrapped 
around the sleeping animal. But this bushy tail is a disadvantage, if it becomes bedraggled and heavy with snow and sleet, when the hounds are giving close chase to its owner. The silver fox and the black fox are the same species as the red fox.

The fox is an inveterate hunter of the animals of the field; meadow mice, rabbits, woodchucks, frogs, snakes and grasshoppers, are all acceptable food; he is also destructive of birds. His fondness for the latter has given him a bad reputation with the farmer because of his attacks on poultry. Not only will he raid hen-roosts if he can force entrance, but he catches many fowls in the summer when they are wandering through the fields. The way he carries the heavy burden of his larger prey shows his cleverness: He slings a hen or a goose over his shoulders, keeping the head in his mouth to steady the burden. Mr. Cram says, in American Animals:

"Yet, although the farmer and the fox are such inveterate enemies, they manage to benefit each other in a great many ways quite unintentionally. The fox destroys numberless field mice and woodchucks for the farmer and in return the farmer supplies him with poultry, and builds convenient bridges over streams and wet places, which the fox crosses oftener than the farmer, for he is as sensitive as a cat about getting his feet wet. On the whole, I am inclined to believe that the fox gets the best part of the exchange, for, while the farmer shoots at him on every occasion, and hunts him with dogs in the winter, he has cleared the land of wolves and panthers, so that foxes are probably safer than before any land was ploughed."

The bark of the fox is a high, sharp yelp, more like the bark of the coyote than of the dog. There is no doubt a considerable range of meaning in the fox's language, of which we are ignorant. He growls when angry, and when pleased he smiles like a dog and wags his beautiful tail.

Many are the wiles of the fox to head off dogs following his track: he often retraces his own

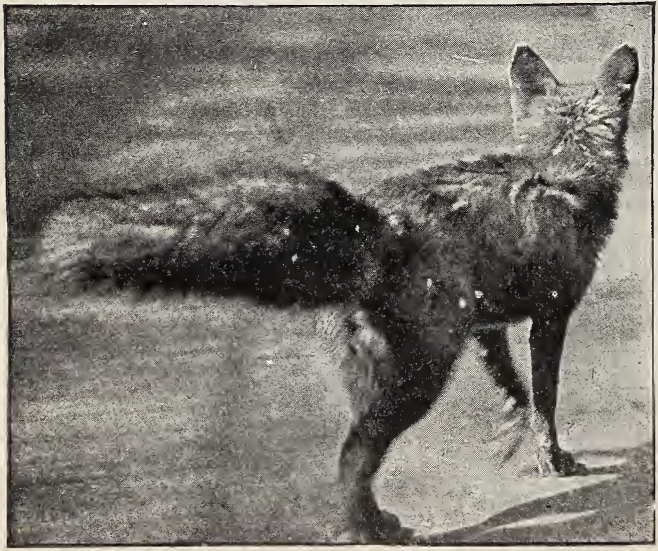

Red Fox。 steps for a few yards and then makes a long sidewise jump; the dogs go on, up to the end of the trail pocket, and try in vain to get the scent from that point. Sometimes he walks along the top rails of fences or takes the high and dry ridges where the scent will not remain; he often follows roads and beaten paths and also goes around and around in the midst of a herd of cattle, so that his scent is hidden; he crosses 
streams on logs and invents various other devices too numerous and intricate to describe. When chased by dogs, he naturally runs in a circle, probably so as not to be too far from home If there are young ones in the den, the father fox leads the hounds far away, in the next county, if possible. Perhaps one of the most clever tricks of the fox, is to make friends with the dogs. I have known of two instances where a dog and fox were daily companions and playfellows.

The young foxes are born in the spring. They are black at first and are fascinating little creatures, being exceedingly playful and active. Their parents are very devoted to them, and during all their puppyhood, the mother fox is a menace to the poultry of the region, because the necessity is upon her of feeding her rapidly growing litter.

In my opinion, the best story of animal fiction is "Red Fox" by Roberts. Like all good fiction, it is based upon facts and it presents a wholesome picture of the life of the successful fox. "The Silver Fox" by Thompson Seton is another interesting and delightful story. Although the Nights with Uncle Remus could scarcely be called nature stories, yet they are interesting in showing how the fox has become a part of folk-lore.

Fox tracks.

\section{LESSON LXII}

The Fox

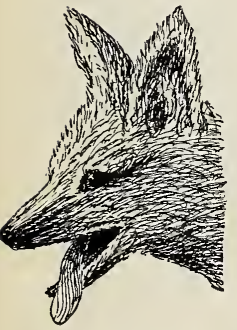

Leading thought-The red fox is so clever that it has been able, in many parts of our country, to maintain itself despite dogs and men.

Method-This lesson is likely to be given largely from hearsay or reading. However, if the school is in a rural district, there will be plenty of hunters' stories afloat, from which may be elicited facts concerning the cunning and cleverness of the red fox. In such places there is also the opportunity in winter to study fox tracks upon the snow. The lesson may well be given when there are fox tracks for observation. The close relationship between foxes and dogs should be emphasized.

Observations and reading- $\mathrm{I}$. Describe the fox's track. How does it differ from the track of a small dog?

2. Where does the fox make its home? Describe the den. Describe the den in which the young foxes live?

3. Describe the red fox, its color and form as completely as you can. What is the expression of its face? What is there peculiar about its tail? What is the use of this great bushy tail in the winter?

4. What is the food of the fox? How does it get its food? Is it a day or a night hunter? How does the fox benefit the farmer? How does it injure him? How does the fox carry home its heavy game, such as a goose or a hen? 
5. Have you ever heard the fox bark? Did it sound like the bark of a dog? How does the fox express anger? Pleasure?

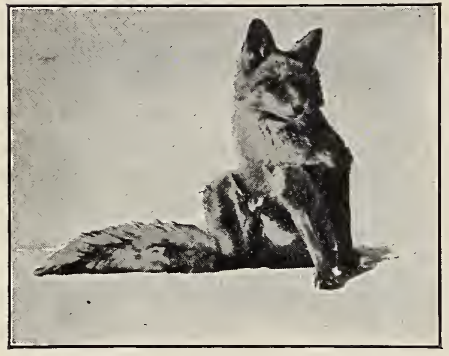

"Got a bite".

6. When chased by dogs, in what direction does the fox run? Describe all of the tricks which you know by which the fox throws the dog off the scent.

7. When are the young foxes born? How many in a litter? What color are they? How do they play with each other? How do they learn to hunt?

Supplementary reading-Red Fox by Roberts; Silver Fox by Thompson Seton; Little Beasts of Field and Wood, page 25; Squirrels and Other Fur Bearers, chapter 7 ; Fox Ways in Ways of Wood Folk; The Springfield Fox in Wild Animals I Have Known; Familiar Wild Animals; Familiar Life in Field and Forest, page 213; American Animals, page 264; Nights with Uncle Remus.

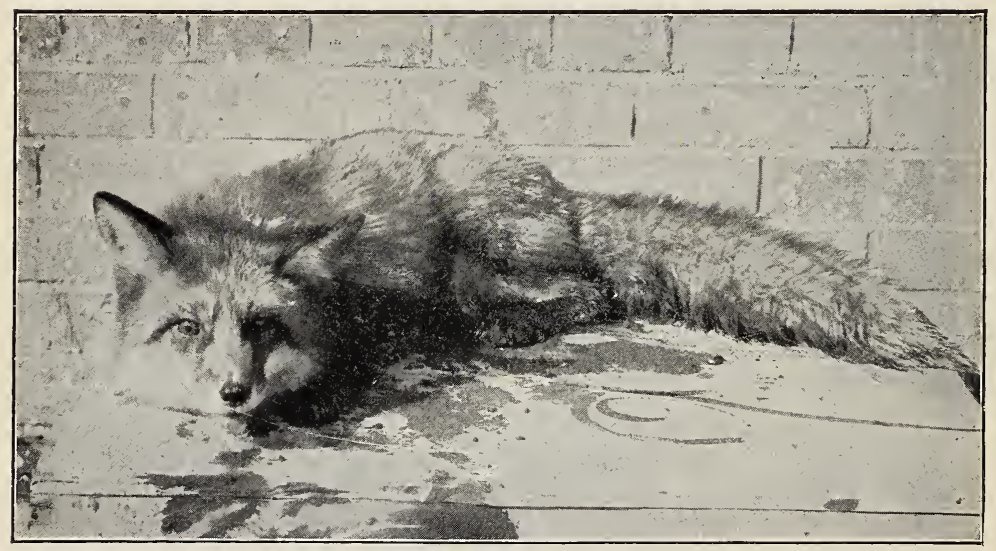

$A$ pet red fox.

Photo by Fred S. Charles. 


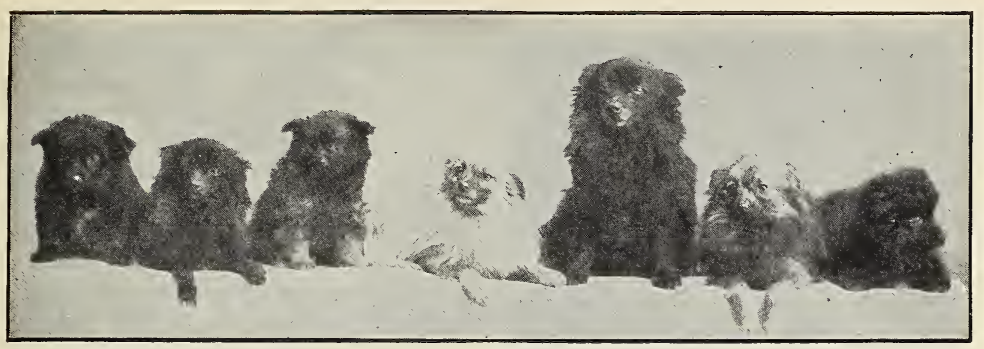

\section{DOGS}

\section{Teacher's Story}

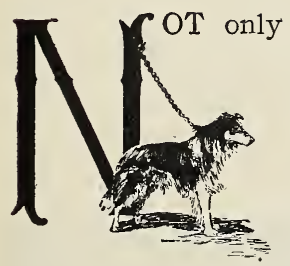

to-day but in ancient days, before the dawn of history, the dog was the companion of man. Whether the wild species from whence he sprang, was wolf or jackal or some other similar animal, we do not know, but we do know that many types of dogs have been tamed independently by savages, in the region where their untamed relatives run wild. As the whelps of wolves, jackals and foxes are all easily tamed, and are most interesting little creatures, we can understand how they became companions to the children of the savage and barbarous peoples who hunted them.

In the earliest records of cave dwellers, in the picture writing of the ancient Egyptians and of other ancient peoples, we find record of the presence and value of the dog. But man, in historical times, has been able to evolve breeds that vary more in form than do the wild species of the present. There are 200 distinct breeds of dogs known to-day, and many of these have been bred for special purposes. The paleontologists, moreover, assure us that there has been a decided advance in the size and quality of the dog's brain since the days of his savagery; thus, he has been the companion of man's civilization also. It is not, therefore, to be wondered at that the dog is now the most companionable, and has the most human qualities and intelligence of all our domesticated animals.

Dogs run down their prey; it is a necessity, therefore, that they be equipped with legs that are long, strong and muscular. The cat, which jumps for her prey, has much more delicate legs but has powerful hips to enable her to leap. The dog's feet are much more heavily padded than those of the cat, because in running, he must not stop to save his feet. Hounds often return from a chase with bleeding feet, despite the heavy pads, but the wounds are usually cuts between the toes. The claws are heavy and are not retractile; thus, they afford a protection to the feet when running, and they are also used for digging out game which burrows into the ground. They are not used for grasping prey like those of the cat and are used only incidentally in fighting, while the cat's claws are the most important weapons in her armory. It is an interesting fact that Newfoundland dogs, which are such famous swimmers, have their toes somewhat webbed. 


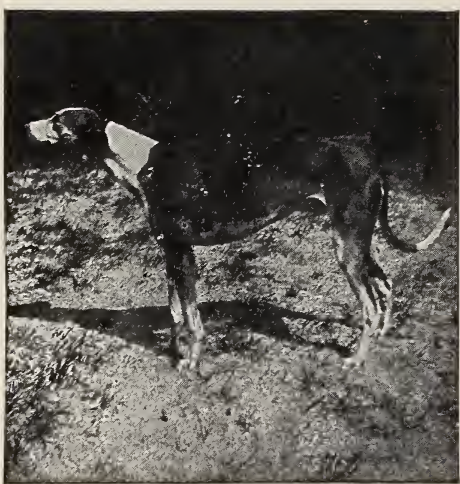

Greyhound.

The dog's body is long, lean, and very muscular, a fat dog being usually pampered and old. The coat is of hair and is not of fine fur like that of the cat. It is of interest to note that the Newfoundland dog has an inner coat of fine hair comparable to that of the mink or muskrat. When a dog is running, his body is extended to its fullest length; in fact, it seems to "lie flat," the outstretched legs heightening the effect of extreme muscular effort of forward movement. A dog is master of several gaits; he can run, walk, trot, bound and crawl.

The iris of the dog's eye is usually of a beautiful brown, although this varies with breeds; in puppres, the iris is usually blue. The pupil is round like our own; and dogs cannot see well in the dark like the cat, but in daylight they have keen sight. The nose is so much more efficient than the eyes, that it is on the sense of smell the dog depends for following his prey and for recognizing friend and foe. The damp, soft skin that covers the nose, has in its dampness the conditions for carrying the scent to the wide nostrils; these are situated at the most forward part of the face, and thus may be lifted in any direction to receive the marvelous impressions, so completely beyond our comprehension. Think of being able to scent the track of a fox made several hours previously. Not only to scent it, but to

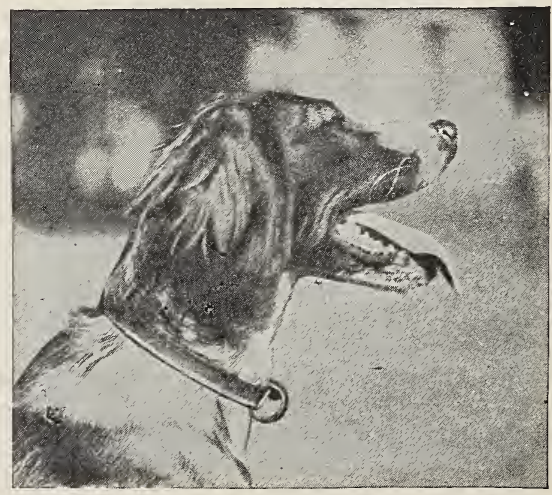

Bird dog. follow by scent for many miles without ever having a glimpse of the fleeing foe! In fact, while running, the dog's attention seems to be focused entirely upon the sense of smell, for I have seen hounds pass within a few rods to the windward of the fox they were chasing, without observing him at all. When the nose of any of the moist-nosed beasts, such as cattle and dogs, becomes dry it is a sign of illness.

A light fall of damp snow gives the dog the best conditions for following a track by scent and a hound, when on the trail, will run until exhausted. There are many authentic observations which show that hounds have followed a fox for twenty-four hours without food, and probably with little rest. 
The dog's weapons for battle, like those of the wolf, are his tushes: with these, he holds and tears his prey; with them, he seizes the woodchuck or other small animal through the back and shakes its life out. In fighting a larger animal, the dog leaps against it and often incidentally tears its flesh with his strong claws; but he does not strike a blow with his foot like the cat, nor can he hold his quarry with it.

Dog's teeth are especially fitted for their work. The incisors are small and sharp; the canine teeth or tushes are very long, but there are bare spaces on the jaws so that they are able to cross past each other; the molar teeth are not fitted for grinding, like the teeth of a cow, but are especially fitted for cutting, as may be noted if we watch the way a dog gnaws bones, first gnawing with the back teeth on one side and then on the other. In fact, a dog does not seem to need to chew anything, but simply needs to cut his meat in small enough pieces so that he can gulp them down without chewing. His powers of digesting unchewed food are something that the hustling American may well envy.

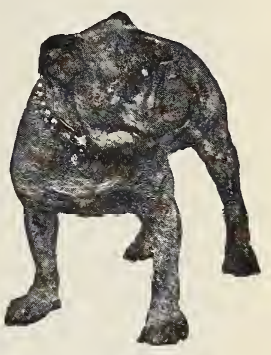

Bulldog.

Of all domestic animals, the dog is most humanly understandable in expressing emotions. If delighted, he leaps about giving ecstatic little barks and squeals, his tail in the air and his eyes full of happy an-

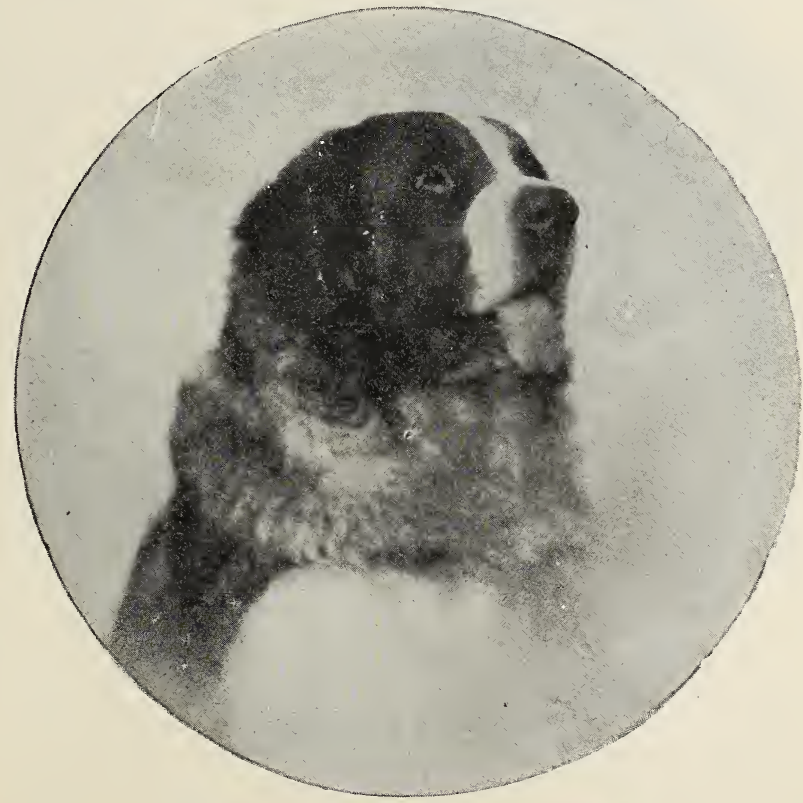

"Mateo", a St. Bernard of long pedigreє. . 
ticipation. If he wishes to be friendly, he looks at us interestedly, comes cver to smell of us in order to assure himself whether he has ever met us before, and then wags his tail as a sign of good faith. If he wishes to show affection, he leaps upon us and licks our face or hands with his soft, deft tongue and follows us jealously. When he stands at attention, he holds his tail stiff in the air, and looks up with one ear lifted as if to say, "Well, what's doing?" When angry, he growls and shows his teeth and the tail is held rigidly out behind, as if to convince us that it is really a continuation of his backbone. When afraid, he whines and lies flat upon his belly, often looking beseechingly up toward his master as if begging not to be punished; or he crawls away out of sight. When ashamed, he drops his tail between his legs and with drooping head and sidewise glance slinks away. When excited, he barks and every bark expresses high nervous tension.

Almost all dogs that chase their prey, bark when so doing, which would seem at first sight to be a foolish thing to do, in that it reveals their whereabouts to their victims and also adds an incentive to flight. But it must be borne in mind that dogs are descended from wolves, which

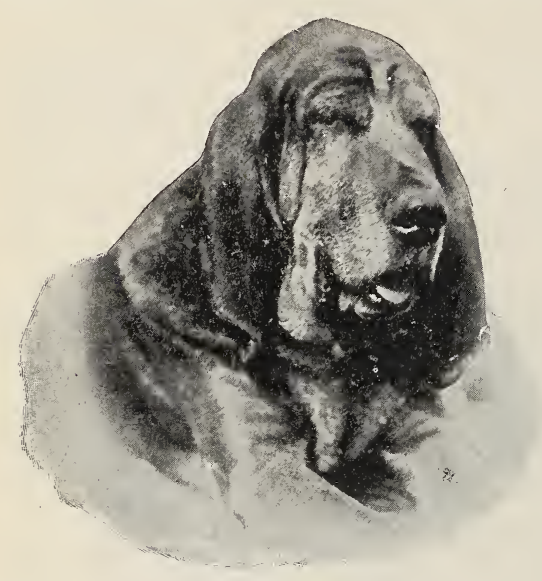

Bloodhound. naturally hunt in packs and do not stalk their prey. The baying of the hound is a most common example of the habit, and as we listen we can understand how, by following this sound, the pack is kept together. Almost all breeds of dogs have an acute sense of hearing. When a dog bays at the moon or howls when he hears music, it is simply a reversion to the wild havie of howling to call together the pack or in answer "to the music of the pack." It is interesting that our music, which is the flower of our civilization, should awaken the sleeping ancestral traits in the canine breast. But perhaps that, too, is why we

respond to music, because it awakens in us the strong, primitive emotions, and for the time, enables us to free ourselves from all conventional shackles and trammels. 


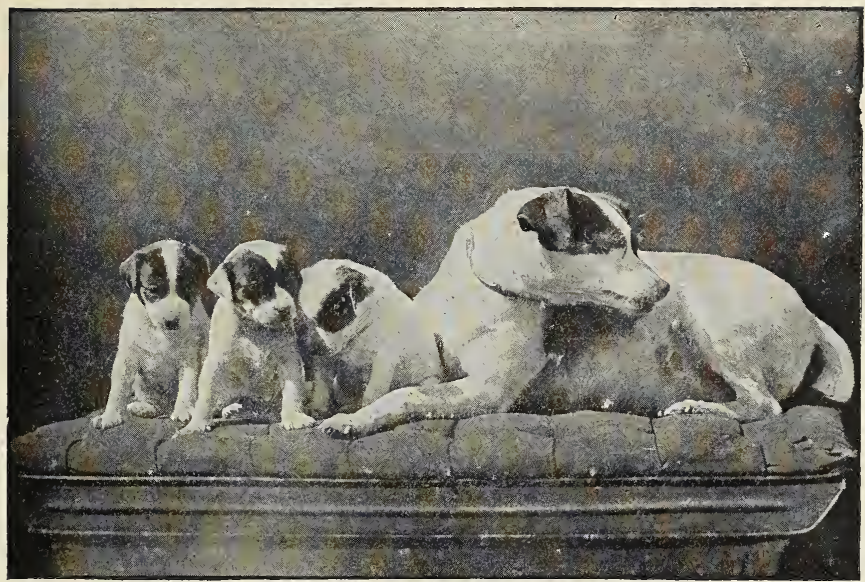

Fox terrier and pups.

\section{LESSON LXIII}

\section{DOGS}

Leading thought-The dog is a domesticated descendant of wolf-like animals and has retained certain of the habits and characteristics of his ancestors.

Method-For the observation lesson it would be well to have at hand, a well-disposed dog which would not object to being handled; a collie or a hound would be preferable. Many of the questions should be given to the pupils to answer from observations at home, and the lesson should be built upon the experience of the pupils with dogs.

Observations-I. Why are the legs of the dog long and strong in proportion to the body compared with those of the cat?

2. Compare the feet of the cat with those of the dog and note which has the heavier pads. Why is this of use to each?

3. Which has the stronger and heavier claws, the dog or the cat? Can the dog retract his claws so that they are not visible, as does the cat? Of what use is this arrangement to the dog? Are the front feet just like the hind feet? How many toe impressions show in the track of the dog?

4. What is the general characteristic of the body of the dog? Is it soft like that of the cat, or lean and muscular? What is the difference between the hair covering of the dog and cat? What is the attitude of the dog when running fast? How many kinds of gaits has he?

5. In general, how do the eyes of the dog differ from those of the cat? Does he rely as much upon his eyes for finding his prey as does the cat? Can a dog see in the dark? What is the color of the dog's eyes?

6. Study the ear of the dog; is it covered? Is this outer ear movable, is it a flap, or is it cornucopia shaped? How is this flap used when the dog is listening? Roll a sheet of paper into a flaring tube and place the 
small end upon your own ear, and note if it helps you to hear better the sounds in the direction toward which the tube opens? Note how the hound lifts his long earlaps, so as to make a tube for conveying sounds to his inner ear. Do you think that dogs can hear well?

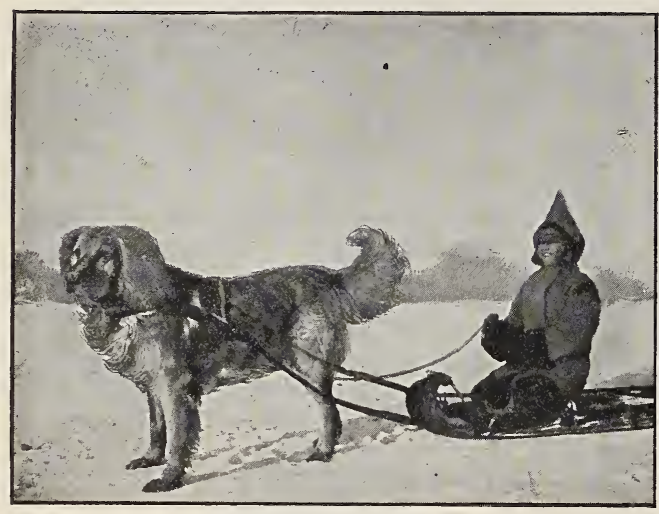

"Klondike Jack".

The dog that pulled four hundred fifty pounds five hundred miles through the White Horse Pass in the winter of the first gold excitement.

7. What is the position of the nose in the dog's face? Of what use is this? Describe the 'nostrils; are they placed on the foremost point of the face? What is the condition of the skin that surrounds them? How does this condition of the nose aid the dog? What other animals have it? Does the dog recognize his friends or become acquainted with stralngers by means of his sight or of his powers of smelling?

8. How long after a fox or rabbit has passed can a hound follow the track? Does he follow it by sight or by smell? What are the conditions most favorable for retaining the scent? The most unfavorable? How long will a hound follow a fox trail without stopping for rest or food? Do you think the dog is your superior in ability to smell?

9. How does a dog seize and kill his prey? How does he use his feet and claws when fighting? What are his especially strong weapons? Describe a dog's teeth and explain the reason for the bare spaces on the jaw next to the tushes. Does the dog use his tushes when chewing? What teeth does he use when gnawing a bone? Make a diagram of the arrangement of the dog's teeth.

ro. How by action, voice, and especially by the movement of the tail does the dog express the following emotions: Delight, friendliness, affection, attention, anger, fear, shame, excitement? How does he act when chasing his prey? Why do wolves and dogs bark when following the trail? Do you think of a reason why dogs often howl at night or when listening to music? What should we feed to our pet dogs? What should we do to make them comfortable in other ways?

Ir. Tell or write a story of some dog of which you know by experience or hearsay.

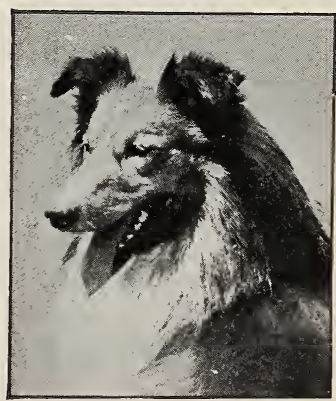

In pleasant mood. A collie. 
Of what use was the dog to the pioneer? How are dogs used in the Arctic regions? In Holland?

I2. How many breeds of dogs do you know? Describe characters of such as follows: The length of the legs as compared with the body; the general shape of the body, head, ears, nose; color and character of hair on head, body and tail.

I3. Find if you can the reasons which have led to the developing of the following breeds: Newfoundland, St. Bernard, mastiffs hounds, collies, spaniels, setters, pointers, bulldogs, terriers, and pugs.

Supplementary reading-"Stories of Brave Dogs" from St. Nicholas, the Century Co.; the following three stories from Thompson-Seton: "Chink" in Lives of the Hunted, "Snap" in Animal Heroes, "Wully" in Wild Animals I Have Known; Bob, Son of Battle; Mack, His Book, by Florence Leigh; Rab and his Friends; The Dog of Flanders; "Red Dog", in Kipling's Jungle Stories; Animals of the World, Knight and Jenks, p. 8o; Life of Animals, Ingersoll, p. I87.

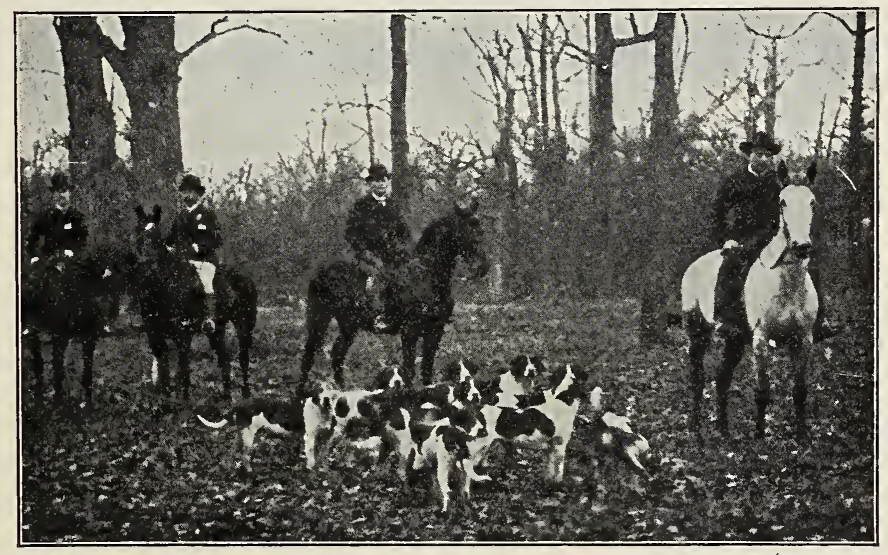

Fox hunting, in the Genesee Valley, N. Y. 


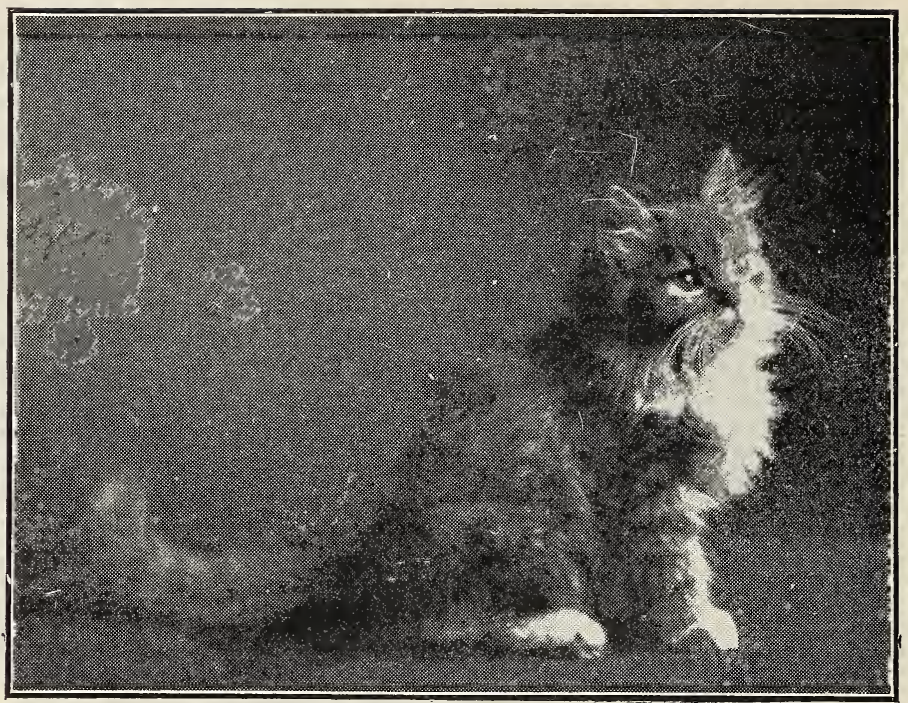

An aristocrat.

\section{THE CAT}

\section{Teacher's Story}

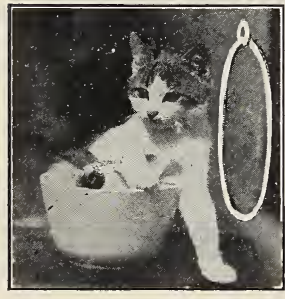

F all people, the writer should regard the cat sympathetically, for when she was a baby of five months she was adopted by a cat. My selfelected foster-mother was Jenny, a handsome black and white cat, which at that time lost her first litter of kittens, through the attack of a savage cat from the woods. She was as Rachel crying for her children, when she seemed suddenly to comprehend that I, although larger than she, was an infant. She haunted my cradle, trying to give me milk from her own breasts; and later she brought half-killed mice and placed them enticingly in my cradle, coaxing me to play with them, a performance which pleased me much more than it did my real mother. Jenny always came to comfort me when I cried, rubbing against me, purring loudly, and licking me with her tongue in a way to drive mad the modern mother, wise as to the sources of children's internal parasites. This maternal attitude toward me lasted as long as Jenny lived, which was until I was nine years old. Never during those years did I lift my voice in wailing, that she did not come to comfort me; and even to-day I can remember how great that comfort was, especially when my naughtiness was the cause of my weeping, and when, therefore, I felt that the whole world, except Jenny, was against me. 
Jenny was a cat of remarkable intelligence and was very obedient and useful. Coming down the kitchen stairs one day, she played with the latch and someone hearing her, opened the door. She did this several times, when one day she chanced to push down the latch, and thus opened the door herself. After that, she always opened it herself. A little later, she tried the trick on other doors, and soon succeeded in opening all the latched doors in the house, by thrusting one front leg through the handle, and thus supporting her weight and pressing down with the foot of the other on the thumb-piece of the latch. I remember, guests were greatly astonished to see her coming thus swinging into the sitting-room. Later she tried the latches from the other side, jumping up and trying to lift the hook; but now, her weight was thrown against the wrong side of the door for opening, and she soon ceased this futile waste of energy; but for several years, she let herself into all the rooms in this clever manner, and taught a few of her bright kittens to do the same.

A pet cat enjoys long conversations with favored members of the household. She will sit in front of her mistress and mew, with every appearance of answering the questions addressed her; and since the cat and the mistress each knows her own part of the conversation, it is perhaps more typical of society chatter than we might like to confess. Of our language, the cat learns to understand the call to food, its own name, "scat," and "No, No," probably inferring the meaning of the latter from the tone of voice. On the other hand, we understand when it asks to go out, and its polite recognition to the one who opens the door. I knew one cat which invariably thanked us when we let him in as well as out. When the cat is hungry, it mews pleadingly; when happy in front of the fire, it looks at us sleepily out of half-closed eyes and gives a short mew expressive of affection and content; or it purrs, a noise which we do not know how to imitate and which expresses perfectly the happiness of intimate companionship. When frightened the cat yowls, and when hurt squalls shrilly; when fighting, it is like a savage warrior in that it howls a war-song in blood-curdling strains, punctuated with a spitting expressive of fear and contempt; and unfortunately, its love song is scarcely less agonizing to the listener. The cat's whole body enters into the expression of its emotions. When feeling affectionate toward its mistress, it rubs against her gown, with tail erect, and vibrating with a purr which seems fundamental. When angry, it lays its ears back and lashes its tail back and forth, the latter being a sign of excitement; when frightened, its hair stands on end, especially the hair of the tail, making that expressive appendage twice its natural size; when caught in disobedience, the cat lets its tail droop, and when running lifts it in a curve.

While we feed cats milk and scraps from our own table, they have never become entirely civilized in their tastes. They always catch mice and other small animals and prove pestiferous in destroying birds. Jenny was wont to bring her quarry, as an offering, to the front steps of our home every night; one morning we found seven mice, a cotton-tail rabbit and two snakes, which represented her night's catch. The cat never chases its prey like the dog. It discovers the haunts of its victims,

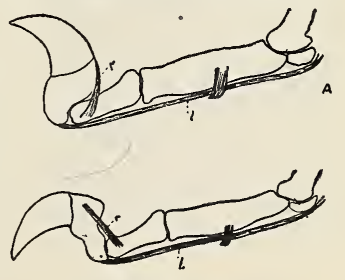

Bones and ligaments of cat's claw.

A Claw up. B Clar. thrust out. 
and then lies in ambush, flattened out as still as a statue and all its feet beneath it, ready to make the spring. The weight of the body is a factor which enters in the blow with which the cat strikes down its victim, and thus stuns and which it later kills by gripping the throat with the strong tushes. She carries her victims as she does her kittens, by the back.

The cat's legs are not long compared with the body, and it runs with a leaping gallop; the upper legs are armed with powerful muscles. It walks on the padded toes, five on the front feet and four of the hind feet. The cat needs its claws to be sharp and hooked, in order to seize and hold its prey, so they are kept safely sheathed when not thus used. If the claws struck the earth during walking, as do the dog's, they would soon become dulled. When sharpening its claws it reaches high up against a tree or post, and strikes them into the wood with a downward scratch; this act is probably more for exercising the muscles which control the claws than for sharpening them.

The cat's track is in a single line as if it had only two feet, one set directly ahead of the other. It accomplishes this by setting its hind feet exactly in the tracks made by the front feet. The cat can easily leap upward, landing on a window-sill five feet from the ground. The jump is made with the hind legs and the alighting is done silently on the front feet.

Cats' eyes are fitted for seeing in the dark; in the daytime the pupil is simply a narrow, up and down slit; under excitement, and at night, the pupil covers almost the entire eye. At the back of the eye is a reflecting surface, which catches such dim light as there is, and by reflecting it enables the cat to use it twice. It is this reflected light, which gives the peculiar green glare to the eyes of all the cats when seen in the dark. Some night-flying moths have a like arrangement for utilizing the light,

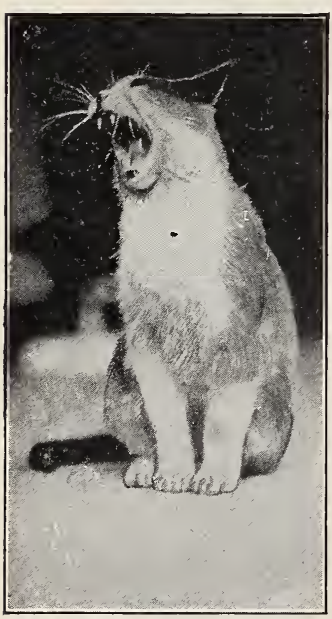

"Folks are so tiresome." and their eyes glow like living coals. Of course, since the cat is a night hunter, this power of multiplying the rays of light is of great use. The iris of the eye is usually yellow, but in kit,tens it may be blue or green.

The cat's teeth are pecularily fitted for its needs. The six doll-like incisors of the upper and lower jaw are merely for scraping meat from bones. The two great tushes, or canines, on each jaw, with a bare place behind so that they pass each other freely, are sharp and hooked, and are for seizing and carrying prey. The cat is able to open its mouth as wide as a right angle, in order to better hold and carry prey. The back teeth, or molars, are four on each side in the upper jaw and three, below. They are sharp-edged wedges made for cutting meat fine enough, so that it may be swallowed.

The tongue is covered with sharp papillæ directed backwards, also used for rasping juices from meat. The cat's nose is moist, and her sense of smell very keen, as is also her sense of hearing. The ears rise like two hollow half-cones on either 
side of the head and are filled with sensitive hairs; they ordinarily open forward, but are capable of movement. The cat's whiskers consist of from twenty-five to thirty long hairs set in four lines, above and at the sides of the mouth; they are connected with sensitive nerves and are therefore true feelers. The cat's fur is very fine and thick, and is also sensitive; as can readily be proved, by trying to stroke it the wrong way. While the wild cats have gray or tawny fur, variously mottled or shaded, the more striking colors we see in the domestic cats are the result of man's breeding.

Cats are very cleanly in their habits. Puss always washes her face directly after eating, using one paw for a wash-cloth and licking it clean after she rubs her face. She cleans her fur with her rough tongue and also by biting; and she promptly buries objectionable matter. The mother cat is very attentive to the cleanliness of her kittens, licking them clean from nose tip to tail tip. The ways of the mother cat with her kittens do much to sustain the assertions of Mr. Seton and $\mathrm{Mr}$. Long that young animals are trained and educated by their parents. The cat brings half-dazed mice to her kittens, that they may learn to follow and catch them with their own little claws. When she punishes them, she cuffs the ears by holding one side of the kitten's head firm with the claws of one foot, while she lays on the blows with the other. She carries her kittens by the nape of the neck,

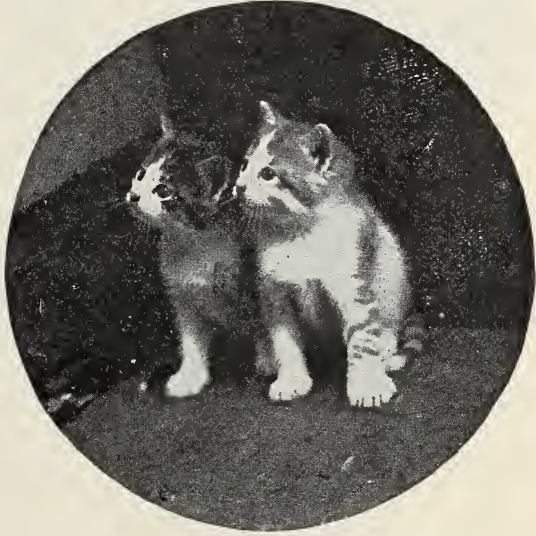

"Interested!" never hurting them. She takes them into the field when they are old snough, and shows them the haunts of mice, and does many things for their education and welfare. The kittens meantime train themselves to agility and dexterity, by playing rough and tumble with each other, and by chasing every small moving object, even to their own tails.

The cat loves warmth and finds her place beneath the stove or at the hearthside. She likes some people, and dislikes others, for no reason we can fetect. She can be educated to be friendly with dogs and with birds. In feeding her, we should give her plenty of sweet milk, some cooker meat and fish of which she is very fond; and we should keep a bundle of catnip to make her happy, for even the larger cats of the wilderness seem to have a passionate liking for this herb. The cat laps milk with her rough tongue, and when eating meat, she turns the head this way and that. to cut the tough muscle with her back teeth. 


\section{Cats Should be Trained to Leave Birds Alone}

Every owner of a cat owes it to the world to train puss to leave birds alone. If this training is begun during kittenhood, by switching the culprit every time it even looks at a bird, it will soon learn to leave them

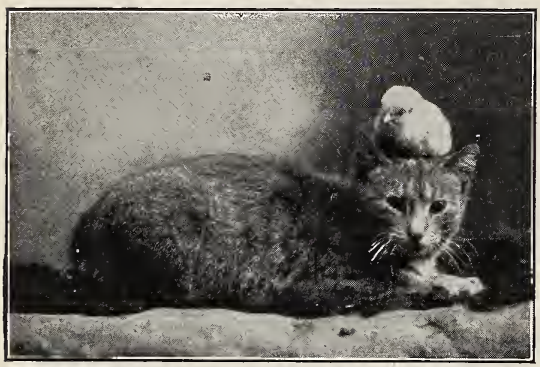

This cat has been trained to be friendly with birds.

severely alone. I have tried this many times, and I know it is efficacious, if the cat is intelligent. We have never had a cat whose early training we controlled, that could ever be induced to even watch birds. If a cat is not thus trained as a kitten, it is likely to be always treacherous in this respect. But in case any one has a valuable cat which is given to catching birds, I strongly advise the following treatment which has been proved practicable by a friend of mine. When a cat has made the catch, take the bird away and sprinkle it with red pepper, and then give it back. One such treatment as this resulted in making one cat, which was an inveterate bird hunter, run and hide every time he saw a bird thereafter. Any persons taking cats with them to their summer homes, and abandoning them there to prey upon the birds of the vicinity, and to become poor, halfstarved, wild creatures, ought to be arrested and fined. It is not only cruelty to the cats, but it is positive injury and damage to the community, because of the slaughter of beneficial birds which it entails.

\section{LESSON LXIV}

\section{The CAT}

Leading thought-The cat was made a domestic animal before man wrote histories. It gets prey by springing from ambush and is fitted by form of body and teeth to do this. It naturally hunts at night and has eyes fitted to see in the dark.

Method-This lesson may be used in primary grades by asking a few questions at a time and allowing the children to make their observations on their own kittens at home, or a kitten may be brought to school for this purpose. The upper grade work consists of reading and retelling or writing exciting stories of the great, wild, savage cats, like the tiger, lion, leopard, lynx and panther.

Observations-r. How much of Pussy's language do you understand? What does she say when she wishes you to open the door for her? How does she ask for something to eat? What does she say when she feels like conversing with you? How does she cry when hurt? When frightened? What noise does she make when fighting? When calling other cats? What are her feelings when she purrs? When she spits? How many things which you say does she understand? 
2. How else than by voice does she express affection, pleasure and anger? When she carries her tail straight up in the air is she in a pleasant mood? When her tail "bristles up" how does she feel? What is it a sign of, when she lashes her tail back and forth?

3. What do you feed to cats? What do they catch for themselves? What do the cats that are wild live upon? How does the cat help us? How does she injure us?

4. How does a cat catch her prey? Does she track mice by the scent? Does she catch them by running after them as a dog does? Describe how she lies in ambush. How does she hold the mouse as she pounces upon it? How does she carry it home to her kittens?

5. Study the cat's paws to see how she holds her prey. Where are the sharp claws? Are they always in sight like a dog's? Does she touch them to the ground when she walks? Which walks the more silently,

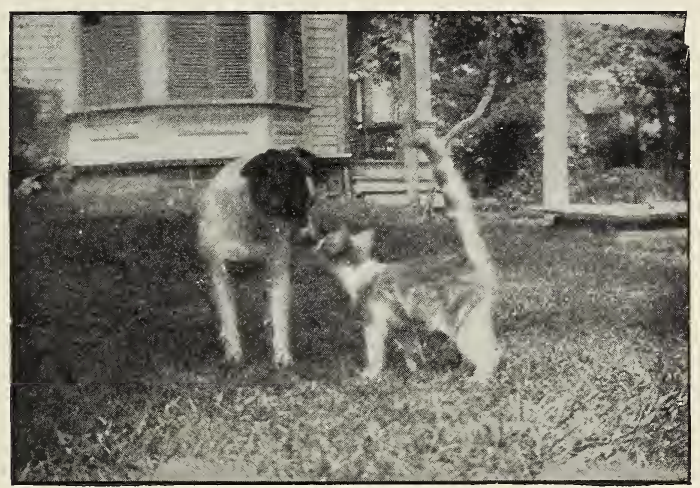

Amicable advances.

a dog or a cat? Why? Describe the cat's foot, including the toe-pads. Are there as many toes on the hind feet as on the front feet? What kind of a track does the cat make in the snow? How does she set her feet to make such a track? How does she sharpen her claws? How does she use her claws for climbing? How far have you ever seen a cat jump? Does she use her front or her hind feet in making the jump? On which feet does she alight? Does she make much noise when she alights?

6. What is there peculiar about a cat's eyes? What is their color? What is the color of kittens' eyes? What is the shape of the pupil in daylight? In the dark? Describe the inner lid which comes from the corner of the eye.

7. How many teeth has Puss? What is the use of the long tushes? Why is there a bare space behind these? What does she use her little front teeth for? Does she use her back teeth for chewing or for cutting meat?

8. How many whiskers has she? How long are they? What is their use? Do you think that puss has a keen sense of smell? Why do 
you think so? Do you think she has a keen sense of hearing? How do the shape and position of the ears help in listening? In what position are the ears when puss is angry?

9. How many colors do you find in our domestic cats. What is the color of wild cats? Why would it not be beneficial to the wild-cat to have as striking colors as our tame cats? Compare the fur of the cat with the hair of the dog. How do they differ? If a cat chased her prey like the dog do you think her fur would be a too warm covering?

I0. Describe how the cat washes her face. How does she clean her fur? How does her rough tongue help in this? How does the mother cat wash her kittens?

I I. How does a little kitten look when a day or two old? How long before its eyes open? How does the cat carry her kittens? How does a kitten act when it is being carried? How does the mother cat punish her kittens? How does she teach them to catch mice? How do kittens play? How does the exercise they get in playing fit them to become hunters?

I 2. How should cats be trained not to touch birds? When must this training begin? Why should a person be punished for injury to the public who takes cats to summer cottages and leaves them there to run wild?

I3. Where in the room does puss best like to lie? How does she sun herself? What herb does she like best? Does she like some people and not others? What strange companions have you known a cat to have? What is the cat's chief enemy? How should we care for and make her comfortable?

I 4. Write or tell stories on the following subjects: (I) The things which my pet cat does; (2) The Wild Cat; (3) The Lion; (4) The Tiger; (5) The Leopard; (6) The Panther and the Mountain Lion; (7) The Lynx; (8) The History of Domestic Cats; (9) The Different Races of Cats, describing the Manx, the Persian and the Angora Cats.

Supplementary reading-The Life of Animals, Ingersoll; American Animals, Stone and Cram; Our Domestic Animals, Burkett; The Fireside Sphinx, Repplier; Concerning Cats, Winslow; The following animal stories from St. Nicholas Magazine: Cat Stories, Lion and Tiger Stories, Panther Stories.

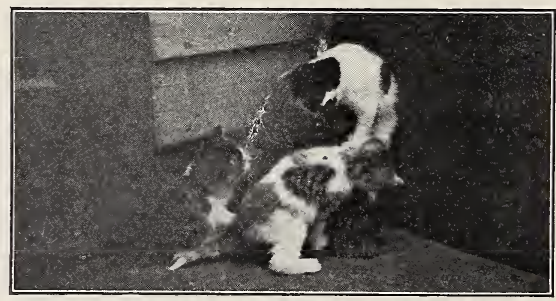

Photo by Verne Morton 


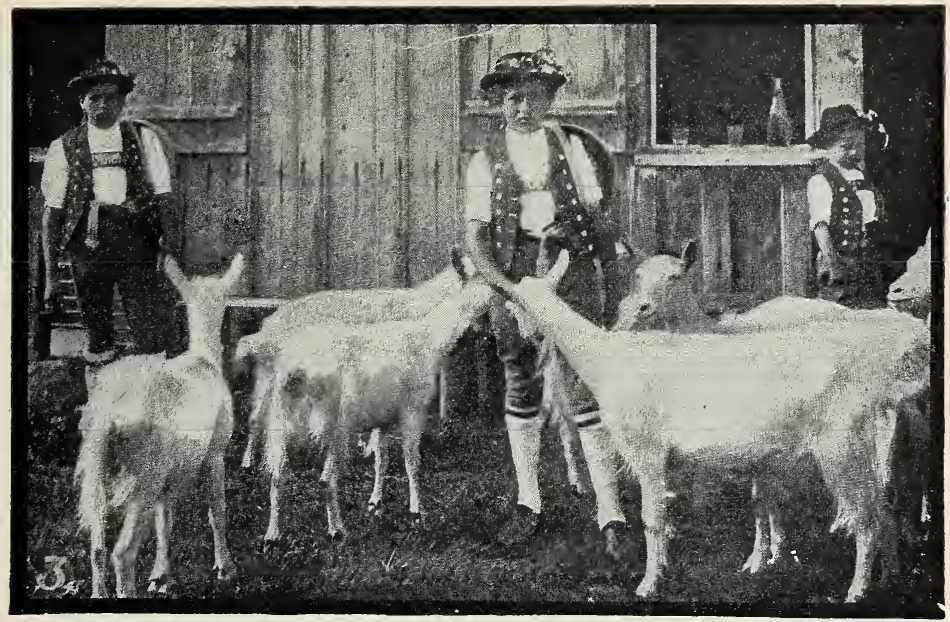

Saanen goats in Switzerland.

Peer, Twenty-first Annual Report Bureau of Animal Industry, U. S. Department of Agriculture.

\section{THE GOAT}

\section{Teacher's Story}

Little do we in America realize the close companionship that has existed in older countries, from time immemorial, between goats and people. This association began when man was a nomad, and took with him in his wanderings, his flocks, of which goats formed the larger part. He then drank their milk, ate their flesh, wove their hair into raiment, or made cloth of their pelts, and used their skins for water bags. Among peoples of the East all these uses continue to the present day. In the streets of Cairo, old Arabs may be seen with goat skins filled with water upon their backs; and in any city of Western Asia or Southern Europe, flocks of goats are driven along the streets to be milked in sight of the consumer.

In order to understand the goat's peculiarities of form and habit, we should consider it as a wild animal, living upon the mountain heights amid rocks and snow and scant vegetation. It is marvelously sure-footed and when on its native mountains, it can climb the sharpest crags and leap chasms. This peculiarity has been seized upon by showmen who often exhibit goats which walk on the tight rope with ease, and even turn themselves upon it without falling. The instinct for climbing still lingers in the domestic breeds, and in the country the goat may be seen on top of stone piles or other objects, while in city suburbs, its form may be discerned on the roofs of shanties and stables.

It is a common saying that a goat will eat anything, and much sport is made of this peculiarity. This fact has more meaning for us when we realize that wild goats live in high altitudes, where there is little plant life, and are therefore, obliged to find sustenance on lichens, moss and such scant vegetation as they can find. 
The goat is closely allied to the sheep, differing from it in only a few particulars; its horns rise from the forehead curving over backward and do not form a spiral like those of the ram; its covering is usually of hair, and the male has a beard from which we get the name goatee; the goat has no gland between the toes, and it does have a rank and disagreeable odor. In a wild state, it usually lives a little higher up the mountains than do the sheep, and it is a far more intelligent animal. Mary Austin says: "Goats lead naturally by reason of a quicker instinct, forage more freely and can find water on their own account, and give voice in case of alarm. Goat leaders exhibit jealousy of their rights to be first over the stepping-stones or to walk the teetering log bridges at the roaring creeks." On the great plains, it is a common usage to place a few goats in a flock of sheep, because of the greater sagacity of these animals as leaders, and also as defenders in case of attack.

Goats' teeth are arranged for cropping herbage and especially for

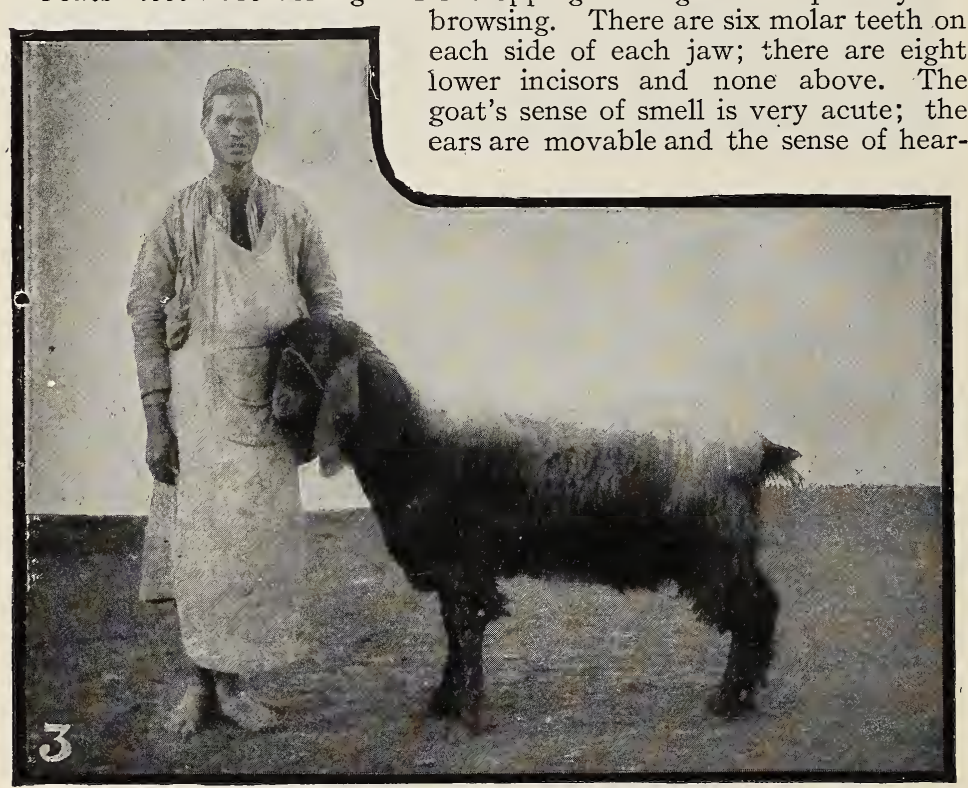

Zaraibi milch goats of Egypt.

Thompson. Twenty-first Annual Report Bureau of Animal Industry, U. S. Department of Agriculture.

ing is keen; the eyes are full and very intelligent; the horns are somewhat flattened and angular and often knobbed somewhat in front, and curve backward above the neck; they are, however, very efficient as weapons of defence. The legs are strong, though not large, and are well fitted for leaping and running. The feet have two hoofs, that is, the animal walks upon two toe-nails. There are two smaller toes behind 
and above the hoofs. The goat can run with great rapidity. The tail of the goat is short like that of the deer, and does not need to be amputated like that of the sheep. Although the normal covering of the goat is hair, there are some species which have a more or less woolly coat. When angry the goat shakes its head, and defends itself by butting with the head, also by striking with the horns, which are very sharp. Goats are very tractable and make affectionate pets when treated with kindness; they display far more affection for their owner than do sheep.

Our famous Rocky Mountain goat, although it belongs rather to the antelope family, is a large animal, and is the special prize of the hunter; however, it still holds its own in the high mountains of the Rocky and

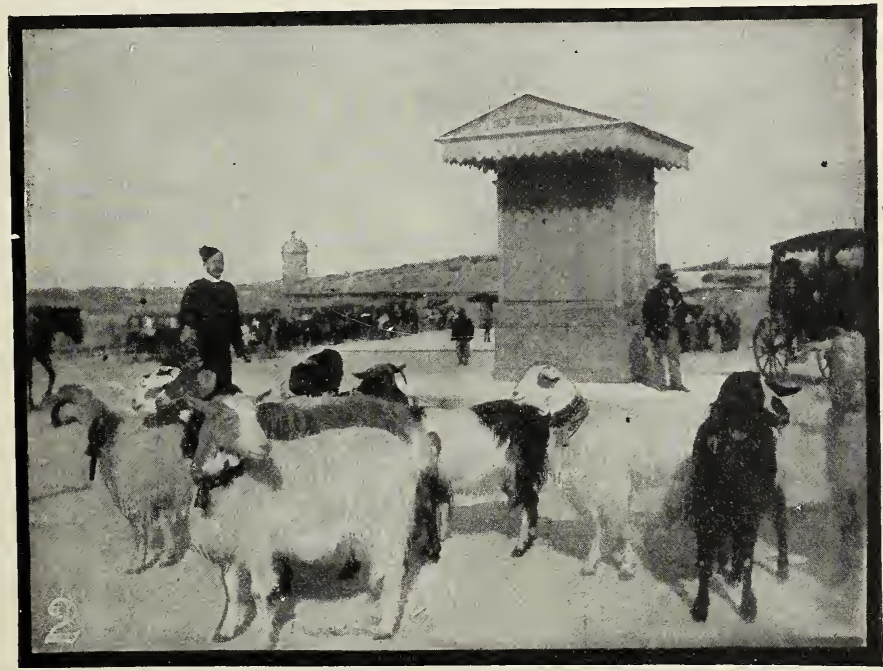

Milch goats in Malta.

Thompson. Twenty-first Annual Report Bureau of Animal Industry, Department of Agriculture.

Cascade Ranges. Both sexes have slender black horns, white hair, and black feet, eyes and nose. Owen Wister says of this animal: "He is white, all white, and shaggy, and twice as large as any goat you ever saw. His white hair hangs long all over him like a Spitz dog's or an Angora cat's; and against its shaggy white mass the blackness of his hoofs and horns, and nose looks particularly black. His legs are thick, his neck is thick, everything about him is thick, save only his thin black horns. They're generally about six (often more than nine) inches long, they spread very slightly, and they curve slightly backward. At their base they are a little rough, but as they rise they become cylindrically smooth and taper to an ugly point. His hoofs are heavy, broad and blunt. The female is lighter than the male, and with horns more slender, a trifle. And (to return to the question of diet) we visited the pasture where the herd (of thirty-five) had been, and found no signs of grass growing or grass eaten; there was no grass on that mountain. The only edible substance 
was a moss, tufted, stiff and dry to the touch. I also learned that the goat is safe from predatory animals. With his impenetrable hide and his disemboweling horns he is left by the wolves and mountain lions respectfully alone." (See American Animals, p. 57 ; Camp Fires of a Naturalist, chapters VIII and XIII).

Milch Goats-Many breeds of these have been developed, and the highest type is, perhaps, found in Switzerland. The Swiss farmers have found the goat particularly adapted to their high mountains and have used it extensively; thus, goats developed in the Saane and Toggenburg valleys have a world-wide reputation. Above these valleys the high mountains are covered with perpetual snow, and winter sets in about November Ist, lasting until the last of May. The goats are kept with the cows in barns and fed upon hay; but as soon as the snow is gone from the valleys and the lower foot-hills, the cattle and goats are sent with the herders and boy assistants, to the grazing grounds. A bell is put upon the cow that leads the herd so as to keep it together and the boys, in their gay

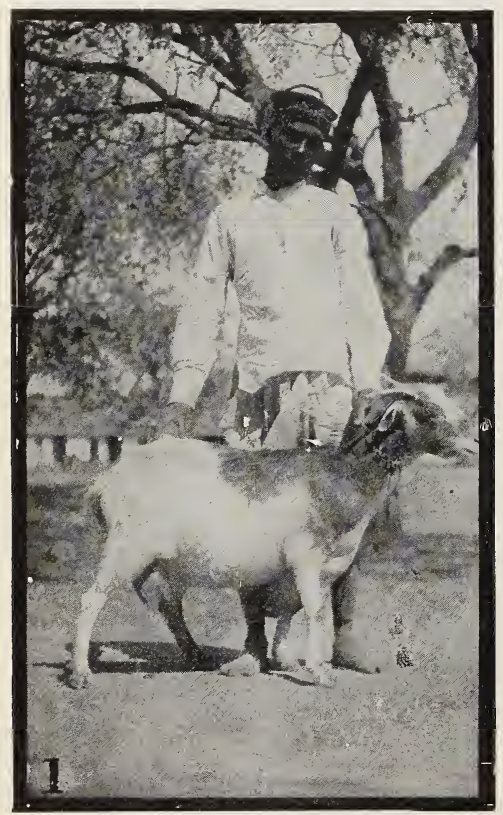

Poona (India) goat.

Thompson. Twenty-first Annual Report Bureau of Animal Industry, U. S. Deparcment of Agriculture. peasant dresses, are as happy as the playful calves and goats to get out in the spring sunshine. The herds follow the receding snows up the mountains until about midsummer, when they reach the high places of scanty vegetation; then they start on the downward journey, returning to the hume and stables about November ist. The milk from goats is mixed with that from cows to make cheese, and this cheese has a wide reputation; some of the varieties are: Roquefort, Schweitzer and Altenburger. Although the cheese is excellent, the butter made from goat's milk is quite inferior to that made from the cow's. The milk, when the animals are well taken care of, is exceedingly nourishing; it is thought to be the best milk in the world for children. Usually, the trouble with goat's milk is, that the animals are not kept clean nor is care taken in milking. Germany has produced many distinct and excellent breeds of milch goats; the Island of Malta, Spain, England, Ireland, Egypt and Nubia have each developed noted breeds. Of all these, the Nubias give the most milk, sometimes yielding from four to six quarts per day, while an ordinary goat is considered fairly good if it yields two quarts per day. 
The Mohair Goats-There are two noted breeds of goats whose hair is used extensively for weaving into fabrics; one of these is the Cashmere and the other the Angora. The Cashmere goat has long, straight, silky hair for an outside coat and has a winter under-coat of very delicate wool. There are not more than two or three ounces of this wool upon one goat, and this is made into the famous Cashmere shawls; ten goats furnish barely enough of this wool for one shawl. The Cashmere goats are grown most largely in Thibet, and the wool is shipped from the high tableland to the Valley of Cashmere, and is made into shawls. It requires the work of several people for a year to produce one of these famous shawls.

The Angora goat has a long, silky and very curly fleece. These goats were first discovered in Angora, a city of Asia Minor south of the Black Sea, and some 200 miles southeast from Constantinople. The Angora goat is a beautiful and delicate animal, and furnishes most of the mohair, which is made into the cloths known as mohair, alpaca, camel's hair and many other fabrics. The Angora goat has been introduced into America, in California, Texas, Arizona, and to some extent in the Middle West. It promises to be a very profitable industry. (See Farmers' Bulletin No. I37, "The Angora Goat," United States Department of Agriculture.)

The skins of goats are used extensively; morocco, gloves and many other articles are made from them. In the Orient, the skin of the goat is used as a bag in which to carry water and wine.

References-American Animals, p. 55; Neighbors with Claws and Hoofs, p. I90; Familiar Animals, pp. I69 and I83; Camp Fires of a Naturalist, chapters VIII and XIII; Lives of Animals.

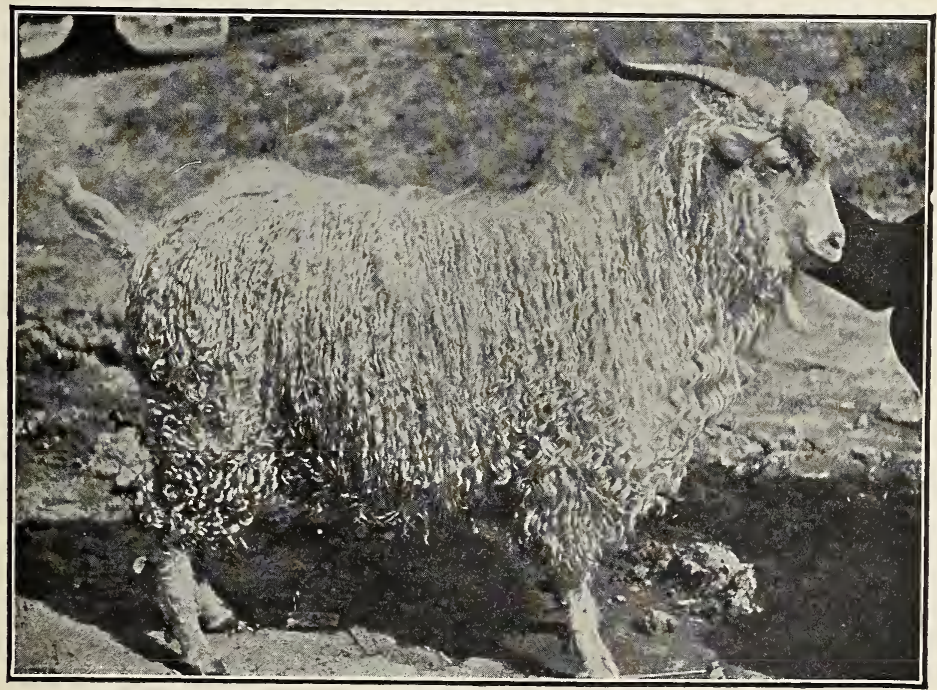

Angora goat.

Thompson, Twenty-first Annual Report Bureau of Animal Industry U. S. Department of Agriculture. 


\section{LESSON LXV}

\section{The Goat}

Leading thought-Goats are among our most interesting domesticated animals, and their history is closely interwoven with the history of the development of civilization. In Europe, their milk is made into cheese that has a world-wide fame; and from the hair of some of the species, beautiful fabrics are woven. The goat is naturally an animal of the high mountains.

Method-A span of goats harnessed to a cart is second only to ponies, in a child's estimation; therefore, the beginning of this lesson may well be a span of goats thus employed. The lesson should not be given unless the pupils have an opportunity for making direct observations on the animal's appearance and habits. There should be some oral and written work in English done with this lesson. Following are topics for such work: "The Milch Goat of Switzerland," "How Cashmere Shawls are Made," "The Angora Goat," "The Chamois."

Observations-I. Do you think that goats like to climb to high points? Are they fitted to climb steep, inaccessible places? Can they jump off steep places in safety? How does it happen the goat is sure-footed? How do its legs and feet compare with those of the sheep?

2. What does the goat eat? Where does it find its natural food on mountains? How are the teeth arranged for cutting its food? Does a goat chew its cud like a cow?

3. What is the covering of the goat? Describe a billy-goat's beard. Do you suppose this is for ornament? For what is goat's hair used?

4. Do you think the goat has a keen sense of sight, of hearing and of smell? Why? Why did it need to be alert and keen when it lived wild upon the mountains? Do you think the goat is intelligent? Give instances of this?

5. Describe the horns. Do they differ from the horns of the sheep? How does a goat fight? Does he strike head on, like the sheep, or sidewise? How does he show anger?

6. What noises does a goat make? Do you understand what they mean?

7. Describe the goat, its looks and actions. Is the goat's tail short at first or does it have to be cut off like the lamb's tail? Where and how is goat's milk used? What kinds of cheese are made from it? For what is its skin used? Is its flesh evər eaten?

Everyone knows the gayety of young kids, which prompts them to cut the most amusing and burlesque capers. The goat is naturally capricious and inquisitive, and one might say crazy for every species of adventure. It positively delights in perilous ascensions. At times it will rear and threaten you with its head and horns, apparently, with the worst intentions, whereas it is usually an invitation to play. The bucks, however, fight violently with each other; they seem to have no consciousness of the most terrible blows. The ewes themselves are not exempt from this vice.

They know very well whether or not they have deserved punishment. Drive them out of the garden, where they are forbidden to go, with a whip and they will flee without uttering a sound; but strike them without iust cause and they will send forth lamentable cries.

Charles William Burkett in "Our Domestic Animals." 


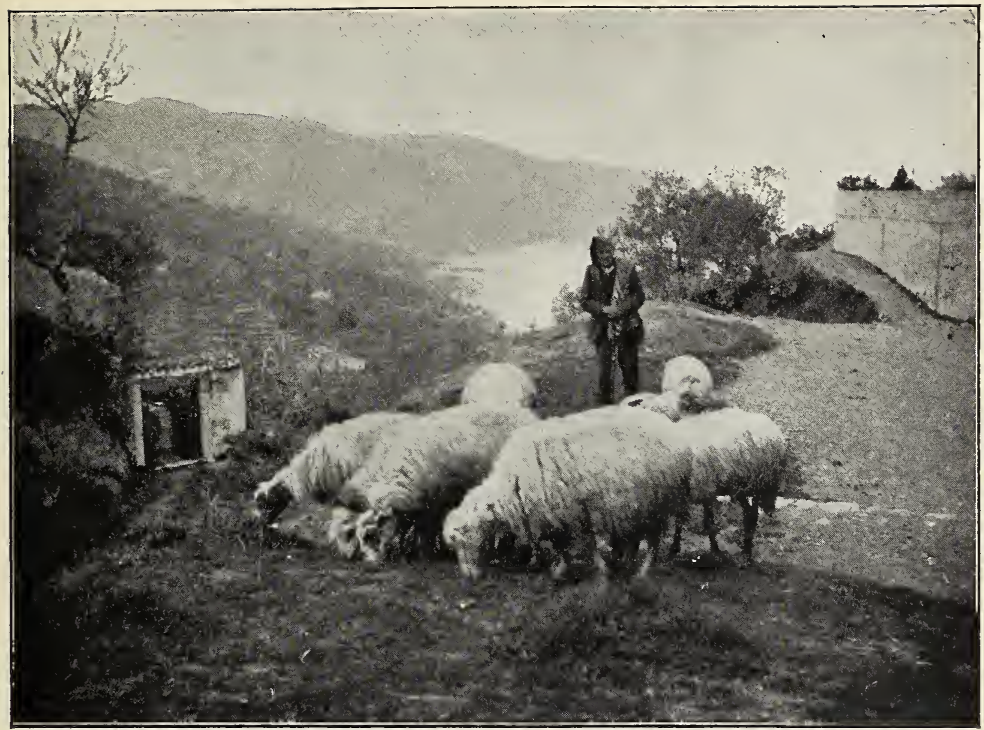

A Sicilian shepherd.

Photo by J. H. Comstock.

\section{THE SHEEP}

\section{Teacher's Story}

"The earliest important achievement of ovine intelligence is to know whether its own notion or another's is most worth while, and if the other's, which one?. Individual sheep have certain qualities, instincts, competences, but in the man-herded flocks these are superseded by something which I shall call the flock mind, though I cannot say very well what it is, except that it is less than the sum of all their intelligences. This is why there have never been any notable changes in the management of flocks since the first herder girt himself with a wallet of sheep-skin and went out of his cave-dwelling to the pastures."- "The Flock," by MARY Austin.

Both sheep and goats are at home on mountains, and sheep especially, thrive best in cool, dry locations. As wild animals, they were creatures of the mountain crag and chasm, although they frequented more open places than the mountain goats, and their wool was developed to protect them from the bitter cold of high altitudes. They naturally gathered in flocks, and sentinels were set to give warning of the approach of danger; as soon as the signal came, they made their escape, not in the straight away race like the deer, but in following the leader over rock, ledge and precipice to mountain fastnesses where wolf nor bear could follow. Thus, the instinct of following the leader blindly, came to be the salvation of the individual sheep.

The teeth of the sheep are like those of the goat, eight incisors below and none on the upper row, and six grinding teeth at the back of each side 
of each jaw. This arrangement of teeth on the small, delicate, pointed jaws enables the sheep to crop herbage where cattle would starve; it can cut the small grass off at its roots, and for this reason, where vast herds of sheep range, they leave a desert behind them. This fact brought about a bitter feud between the cattle and sheep men in the far West. In forests, flocks of sheep completely kill all underbrush, and now they are not permitted to run in government reserves.

The sheep's legs are short and delicate below the ankle. The upper portion is greatly developed to help the animal in leaping, a peculiarity to which we owe the "leg of lamb" as a table delicacy. The hoof is cloven, that is, the sheep walks upon two toes; it has two smaller toes above and behind these. There is a little gland between the front toes which secretes

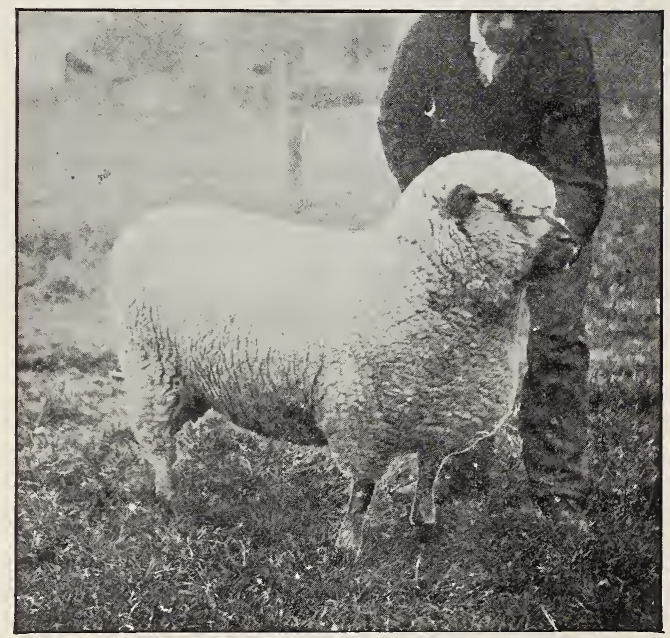

A sheep of pedigree, Shropshire ram.

an oily substance, which perhaps serves in preventing the hoof from becoming too dry. The ears are large and are moved to catch better the direction of sound. The eyes are peculiar; in the sunlight the pupil is a mere slit, while the iris is yellow or brownish, but in the dark, even of the stable, the pupils enlarge, almost covering the eye. The ewes either lack horns or have small ones, but the horns of wild rams are large, placed at the side of the head and curled outward in a spiral. These horns are perhaps not so much for fighting the enemy as for rival rams. The ram can strike a hard blow with head and horns, coming at the foe head on, while the goat always strikes sidewise. So fierce is the blow of the angry sheep, that an ancient instrument of war was fashioned like a ram's head and used to knock down walls, and was called a battering ram. A sheep shows anger by stamping the ground with the front feet. The habit of rumination enables the sheep to feed in a flock and then retire to some place to rest and chew the cud, a performance peculiarly funny in the sheep. 
Sheep under attack and danger are silent; ordinarily they keep up a constant, gentle bleating to keep each other informed of their whereabouts; they also give a peculiar call when water is discovered, and another to inform the flock that there is a stranger in the midst; they also give a peculiar bleat, when a snake or other enemy which they conquer, is observed. Their sense of smell is very acute. Mary Austin says, "Young lambs are principally legs, the connecting body being simply a contrivance for converting milk into more leg, so you understand how it is that they will follow the flock in two days and are able to take the trail in a fortnight, traveling four and five miles a day, falling asleep on their feet and tottering forward in the way."

The older lambs have games which they play untiringly, and which fit them to become active members of the flock; one, is the regular game of "Follow My Leader," each lamb striving to push ahead and attain the place of leader. In playing this the head lamb leads the chase over most difficult places, such as logs, stones and across brooks; thus is a training begun which later in life may save the flock. The other game is peculiar to stony pastures; a lamb climbs to the top of a boulder and its comrades gather around and try to butt it off; the one which succeeds in doing this, climbs the rock and is "it." This game leads to agility and sure-footedness. A lamb's tail is long and is most expressive of lambkin bliss, when feeding time comes; but, alas! it has to be cut off so that later it will not become matted with burrs and filth. In southern Russia there is a breed of sheep with large, flat, fat tails which are esteemed as a great table delicacy. This tail becomes so cumbersome that wheels are placed beneath it, so that it trundles along behind its owner.

We have a noble species of wild sheep in the Rocky Mountains which is likely to become extinct soon. The different breeds of domesticated sheep are supposed to have been derived from different wild species. Of the domesticated varieties, we have the Merinos which originated in Spain and which give beautiful, long, fine wool for our fabrics; but their flesh is not very attractive. The Merinos have wool on their faces and legs and have wrinkled skins. The English breeds of sheep have been especially developed for mutton, although their wool is valuable. Some of these like the Southdown, Shropshire, and Dorset, give a medium length of wool, while the Cotswold has very long wool, the ewes having long strings of wool over their eyes in the fashion of "bangs."

The dog, as descended from the wolf, is the ancient enemy of sheep; and even now after hundreds of years of domestication, some of our dogs will revert to savagery and chase and kill sheep. This, in fact, has been one of the great drawbacks to sheep raising in the 'Eastern United States. The collie, or sheep-dog, has been bred so many years as the special care-taker of sheep, that a beautiful relationship has been 
established between these dogs and their flocks. For instances of this, read the chapter on sheep-dogs in A Country Reader; "Wully" in Wild Animals I Have Known, and "Bob, Son of Battle."

\section{LESSON LXVI}

\section{The Sheep}

Leading thought-Sheep live naturally in high altitudes. When attacked by enemies, they follow their leader over difficult and dangerous mountain places.

Method-The questions of this lesson should be given to the pupils and the observations should be made upon the sheep in pasture or stable. Much written work may be done in connection with this lesson. The following topics are suggested for themes: "The Methods by which Wool is Made into Cloth," "The Rocky Mountain Sheep," "The Sheep-herders of California and their Flocks," "The True Story of a Cosset Lamb."

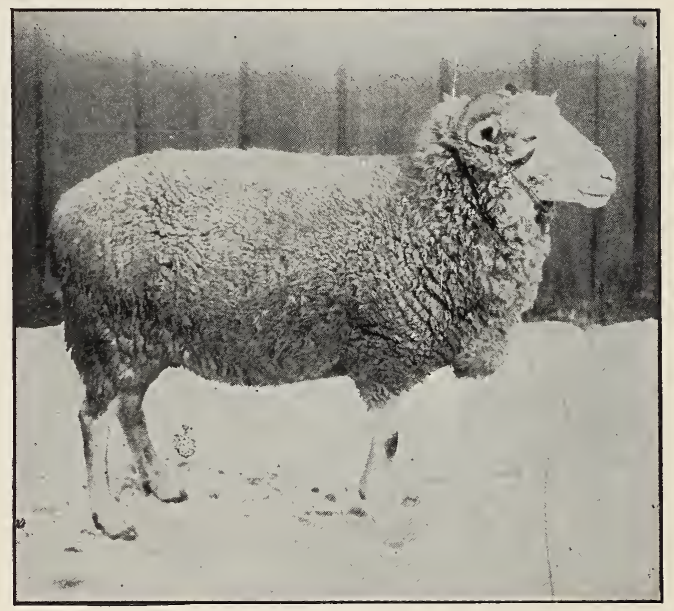

Horned Dorset ram.

Observations-r. What is the chief character that separates sheep from other animals? What is the difference between wool and hair? Why is wool of special use to sheep in their native haunts? Is there any hair on sheep?

2. Where do the wild sheep live? What is the climate in these places? Does wool serve them well on this account? What sort of pasturage do sheep find on mountains? Could cows live where sheep thrive? Describe the sheep's teeth and how they are arranged to enable it to crop vegetation closely? What happens to the vegetation on the range, when a great flock of sheep passes over it? Why are sheep not allowed in our forest preserves? 
3. What are the chief enemies of sheep in the wilderness? How do the sheep escape them? Describe the foot and leg of the sheep and explain how they help the animal to escape its enemies. We say of certain men that they "follow like a flock of sheep." Why do we make this comparison? What has this habit of following the leader to do with the escape of sheep from wolves and bears?

4. How do sheep fight? Do both rams and ewes have horns? Do they both fight? How does the sheep show anger? Give your experience with a cross cosset lamb.

5. Do you think that sheep can see and hear well? What is the position of the sheep's ears when it is peaceful? When there is danger? How do the sheep's eyes differ from those of the cow?

6. Does the sheep chew its cud like the cow? Describe the actionas performed by the sheep. How is this habit of cud chewing of use to the wild sheep?

7. Describe a young lamb. Why has it such long legs? How do es it use its tail to express joy? What happens to this tail later? What games have you seen lambs play? Tell all the stories of lambs that you know.

8. How much of sheep language do you understand? What is the use to the wild flock of the constant bleating?

9. For what purposes do we keep sheep? How many breeds of sheep do you know? What are the chief differences between the English breeds and the Merinos? Where and for what purposes is the milk of sheep used?

Io. Have you ever seen a collie looking after a herd of sheep? If so, describe his actions. Did you ever know of dogs killing sheep? At what time of day or night was this done? Did you ever know of one dog attacking a flock of sheep alone. What is there in the dog's ancestry which makes two or three dogs, when hunting, give chase and attack sheep?

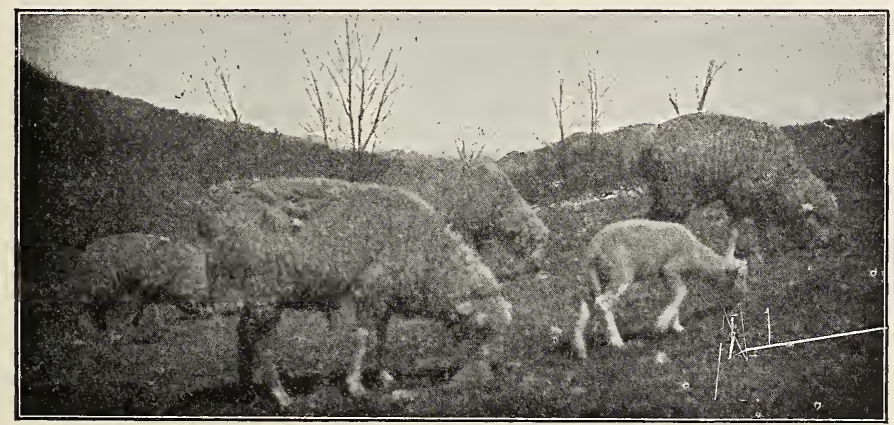

Photo by Gerrit Miller 


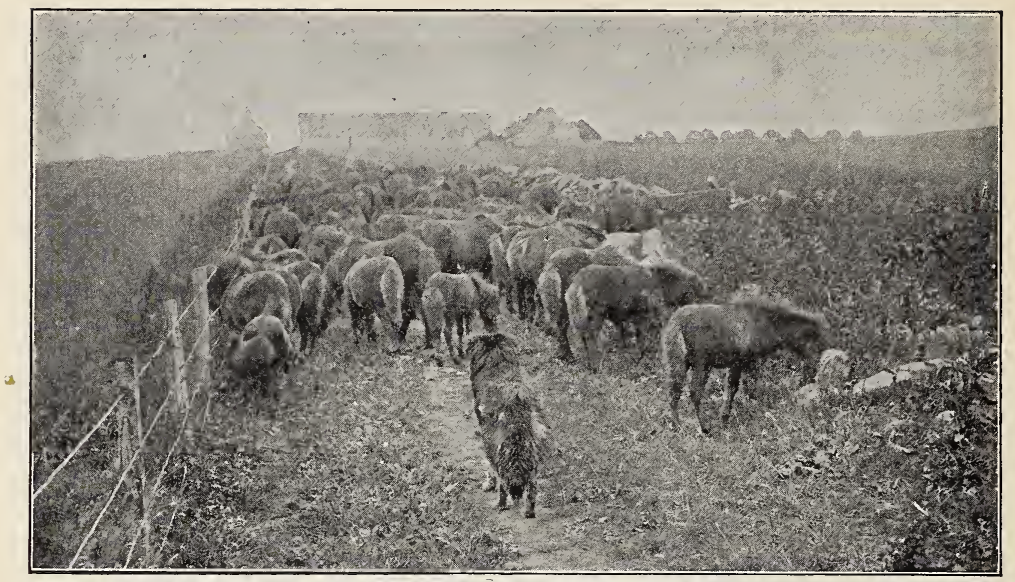

A herd of ponies in the Isle of Shetland guarded by a sheep-dog.

\section{THE HORSE}

\section{Teacher's Story}

"There was once a little animal no bigger than a fox. And on five toes he scrambled over Tertiary rocks.

They called him Eohippus, and they called him very small, And they thought hrm of no value when they thought of him at all.

Said the little Eohippus, I am going to be a horse! And on my middle finger nails to run my earthly course! I am going to have a flowing tail! I am going to have a mane! And I am going to stand fourteen hands high on the Psychozooic plain!" -Mrs. Stetson.

It was some millions of years ago, that Eohippus lived out in the Rocky Mountain Range; its fore feet had four toes and the splint of the fifth; the hind feet had three toes and the splint of the fourth. Eohippus was followed down the geologic ages by the Orohippus and the Mesohippus and various other hippuses, which showed in each age a successive enlargement and specialization of the middle toe and the minimizing and final loss of the others. This first little horse with many toes, lived when the earth was a damp, warm place and when animals needed toes to spread out to prevent them from miring in the mud. But as the ages went on, the earth grew colder and drier, and a long leg ending in a single hoof, was very serviceable in running swiftly over the dry plains; and according to the story read in the fossils of the rocks, our little American horses migrated to South America; and also trotted dry-shod over to Asia in the Mid-pleocine age, arriving there sufficiently early to become the companion of prehistoric man. In the meantime, horses were first hunted by 
savage man for their flesh, but were later ridden. At present, there are wild horses in herds on the plains of Tartary; and there are still sporadic herds of mustangs on the great plains of our own country, although for the most part, they are branded and belong to someone, even though they live like wild horses; these American wild horses are supposed to be descendents of those brought over centuries ago by the Spaniards. The Shetland ponies are also wild

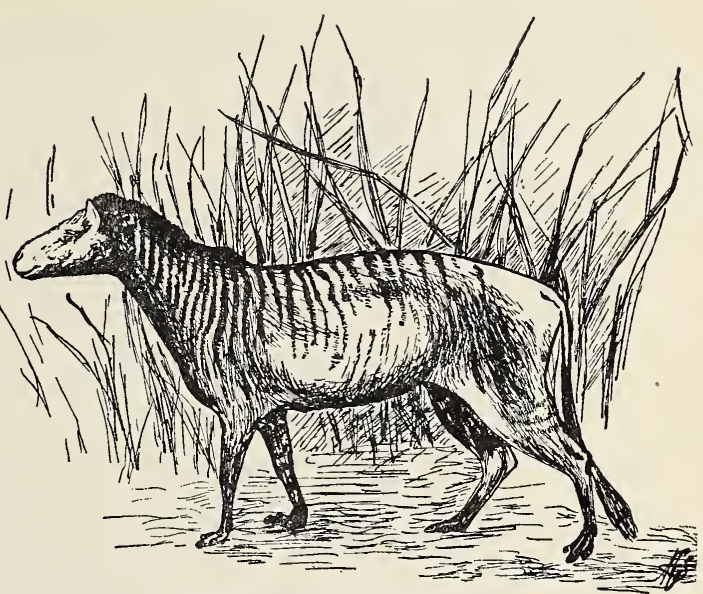

Four-toed horse of the Eocene period. After Charles R. Knight. in the islands north of Scotland, and the zebras roam the plains of Africa the most truly wild of all. In a state of wildness, there is always a stallion at the head of a herd of mares, and he has to win his position and keep it by superior strength and prowess. Fights between stallions are terrible to witness, and often result in the death of one of the participants. The horse is well armed for battle; his powerful teeth can inflict deep wounds and he can kick and strike hard with the front feet; still more efficient is the kick made with both hind feet while the weight of the body is borne on the front feet, and the head of the horse is turned so as to aim well the terrible blow. There are no wild beasts of prey which will not slink away to avoid a herd of horses. After attaining their growth in the herd with their mothers, the young males are forced by the leader to leave and go off by themselves; in turn, they must by their own strength and attractions, win their following of mares. However, there are times and places where many of these herds join, making large bands wandering together.

The length of the horse's leg was evidently evolved to meet the need for flight before fierce and swift enemies, on the great ancient plains. The one toe, with its strong, sharp hoof, makes a fit foot for such a long leg, since it strikes the ground with little waste of energy and is sharp enough not to slip, but it is not a good foot for marshy places; a horse will mire where a cow can pass in safety. The development of the middle toe into a hoof results in lifting the heel and wrist far up the leg, making them appear to be the knee and elbow, when compared with the human body.

The length of neck and head are necessary in order that an animal, with such length of leg as the horse, may be able to graze. The head of the horse tells much of its disposition; a perfect head should be not too iarge, broad between the eyes and high between the ears, while below the eyes, it should be narrow. The ears, if lopped or turned back, denote a treacherous disposition. They should point upward or forward; the ears laid back is always a sign that the horse is angry; sensitive, quick-moving 
ears indicate a high-strung, sensitive animal. The eyes are placed so that the horse can see in front, at the side and behind, the last being

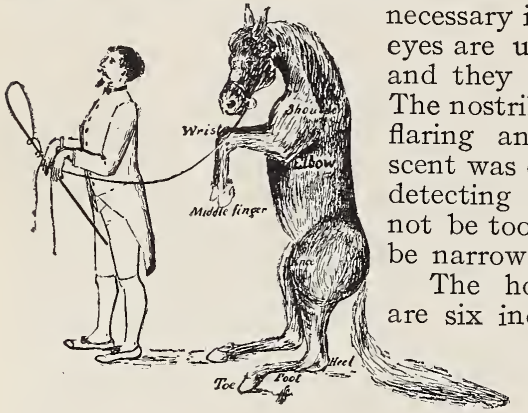
eyes are usually preferred to dark ones, and they should be bright and prominent. The nostrils should be thin-skinned, widethensitive; as a wild animal, one of the horse's chief aids in (he lips should not be too thick and the lower jaw should narrow where it joins the head.

The horse's teeth are peculiar; there isors on both jaws; behind them is a bare space called the bar, of which we have made use for placing the bit. Back of the bar, there are six molars or grinders on each side of each jaw. At the age of about three years, canine teeth or tushes appear behind the incisors; these are more noticeable in males, and never seem to be of much use. Thus, the horse has on each jaw, when full-grown, six incisors, two canines, and twelve molars, making forty teeth in all. The incisors are prominent and enable the horse to bite the grass more closely than can the cow. The horse when chewing, does not have the sidewise motion of the jaws peculiar to the cow and sheep.

The horse's coat is, when rightly cared for, glossy and beautiful; but if the horse is allowed to run out in the pasture all winter, the coat becomes very shaggy, thus reverting to the condition of wild horses which stand in need of a warmer coat for winter; the hair is shed every year. The mane and the forelock are useful in protecting the head and neck from flies; the tail is also an efficient fly-brush. Although the mane and tail
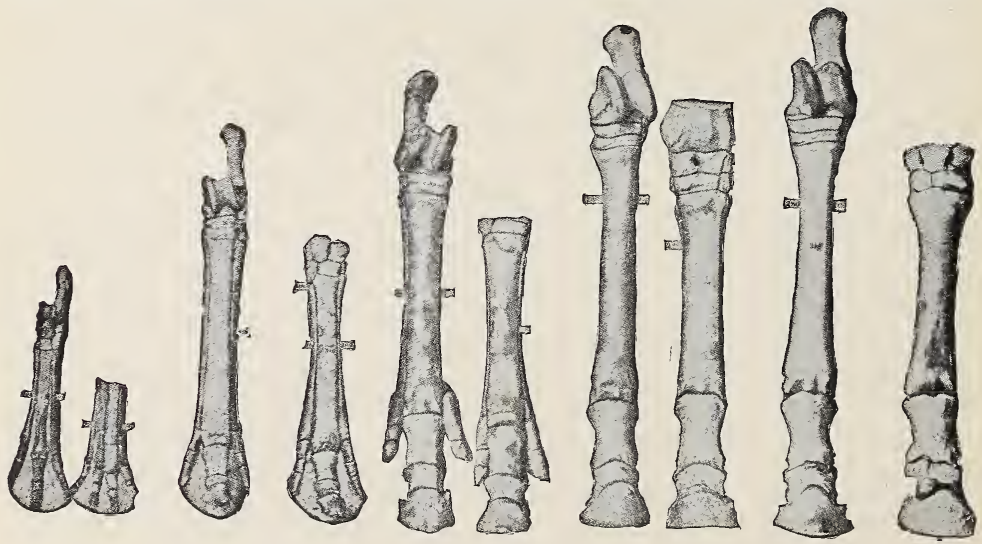

Hoofs of horses from earliest ages to the present time, arranged in pairs, hind and front. 
have thus a practical value, they add greatly to the animal's beauty. To dock a horse's tail as an ornament is as absurd as the sliced ears and welted cheeks of savages; and horses thus mutilated suffer greatly from the attacks of flies.

Owing to the fact that wild horses made swift flight from enemies, the colts could not be left behind at the mercy of wolves. Thus it is, the colt like the lamb, is equipped with long legs from the first, and can run very rapidly; as a runner, it could not be loaded with a big compound stomach full of food, like the calf, and therefore, must needs take its nourishment from the mother often. The colt's legs are so long that, in order to graze, it spreads the front legs wide apart in order that it may reach the grass with its mouth. When the colt or the horse lies down out of doors and in perfect freedom, it lies flat upon the side. In lying down, the hind quarters go first, and in rising, the front legs are thrust out first.

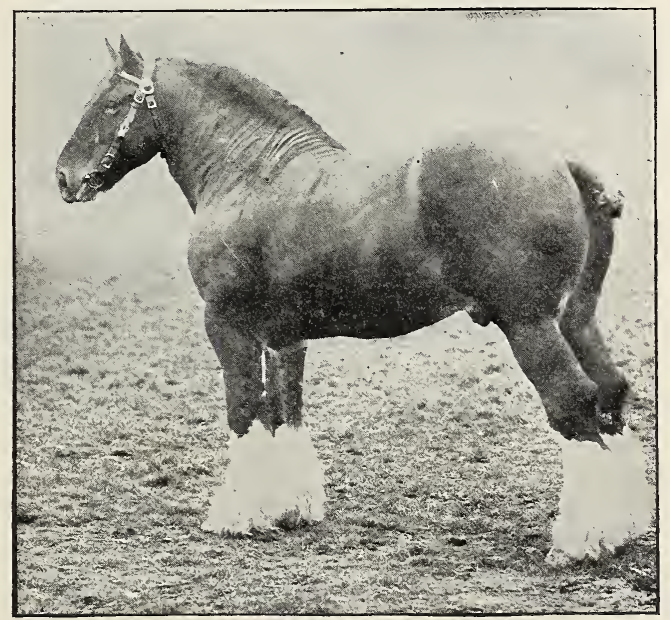

English draft-horse.

The horse has several natural gaits and some that are artificial. Its natural methods of progression are the walk, the trot, the amble, the gallop. When walking there are always two or more feet on the ground and the movement of the feet consists in placing successively the right hind foot, the right fore foot, left hind foot, left fore foot, right hind foot, etc. In trotting, each diagonal pair of legs is alternately lifted and thrust forward, the horse being unsupported twice during each stride. In ambling, the feet are moved as in the walk, only differing in that a hind foot or a fore foot is lifted from the ground, before its fellow fore foot or hind foot is set down. In a canter, the feet are landed on the ground in the same sequence as a walk but much more rapidly; and in the gallop, the spring is made from the fore foot and the landing is on the diagonal hind foot and just before landing, the body is in the air and the legs are all bent beneath it. 
An excellent horseman once said to me, "The whip may teach a horse to obey the voice, but the voice and hand control the well-broken horse," and this epitomizes the best horse training. He also said, "The horse knows a great deal, but he is too nervous to make use of his knowledge when he needs it most. It is the horse's feelings that I rely on. He always has the use of his feelings and the quick use of them." It is a well-known fact that those men who whip and scold and swear at their horses, are meantime showing to the world that they are fools in this particular business. Many of the qualities which we do not like in our domesticated horses, were most excellent and useful when the horses were wild, for instance, the habit of shying was the wild horse's method of escaping the crouching foe in the grass. This habit as well as many others

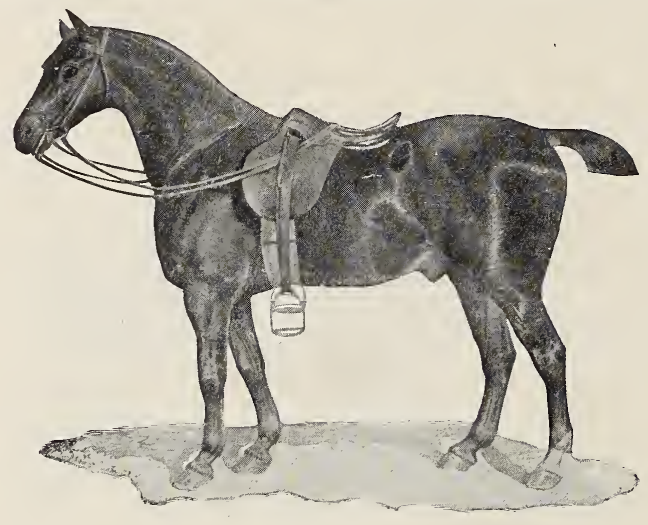

Saddle-horse.

is best controlled by the voice of the driver instead of a blow from the whip.

Timothy hay, or hay mixed with clover, form good, bulky food for the horse, and oats and corn are the best concentrated food. Oats are best for driving-horses and corn for the working team. Dusty hay should not be fed to a horse; but if unavoidable, it should always be dampened before feeding. A horse should be fed with regularity, and should not be used for a short time after having eaten. If the horse is not warm, it should be watered before feeding, and in the winter the water should have the chill taken off. The frozen bit should be warmed before being placed in the horse's mouth; if anyone doubts the wisdom of this, let him put a frozen piece of steel in his own mouth. The tight-drawn, cruel use of the over check-rein should not be permitted, although a moderate check is often needed and is not cruel. When the horse is sweating, it should be blanketed immediately if hitched outside in cold weather; but in the barn, the blanket should not be put on until the perspiration has stopped steaming. The grooming of a horse is a part of its rights, and its legs should receive more attention during this process than its body, a fact not always well understood.

The breeds of horses may always be classified more or less distinctly as follows: Racers or thoroughbreds; the saddle-horse, or hunter; the 
coach-horse; the draft-horse and the pony. For a description of breeds see dictionaries or cyclopedias. Of the draft-horses, the Percherons, Shires and Clydesdales are most common; of the carriage and coachhorses, the English hackney and the French and German coach-horses are famed examples. Of the roadster breeds, the American trotter, the American saddle-horse and the English thoroughbred are most famous.

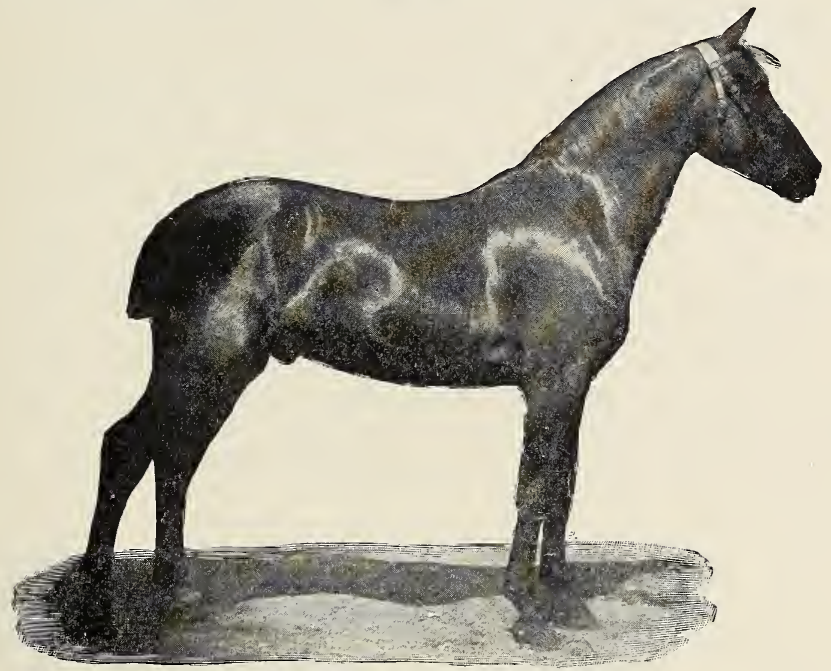

A good coacher.

\section{LESSON LXVII}

The Horse

Leading thought-The horse as a wild animal depended largely upon its strength and fleetness to escape its enemies, and these two qualities have made it of greatest use to man.

Method-Begin this study of the horse with the stories of wild horses. "The Pacing Mustang" in Wild Animals I Have Known, is an excellent story to show the habits of the herds of wild horses; Chapter first in A Country Reader and the story of horses in Life of Animals are excellent as a basis for study. Before beginning actual study of the domestic horses, ask for oral or written English exercises descriptive of the lives of the wild horses. Get Remington's pictures illustrating the wild horses of America. After the interest has been thus aroused the following observations may be suggested, a few at a time, to be made incidentally in the street or in the stable.

Observations-I. Compare the length of the legs of the horse with its height. Has any other domestic animal legs as long in proportion? What habits of the ancestral wild horses led to the development of such long legs? Do you think the length of the horse's neck and head correspond to the length of its legs? Why? 
2. Study the horse's leg and foot. The horse walks on one tce. Which toe do you think it is? What do we call the toe-nail of the horse? What adrantage is this sort of a foot to the horse? Is it best fitted for running on dry plains or for marshy land? Does the hoof grow as our nails do? Do you know whether there were ever any horses with three toes or four toes on each foot? Make a sketch of the horse's front and hind leg and label those places which correspond to our wrist, elbow, shoulder, hand, heel, knee and hip.

3. Where are the horse's ears placed on the head? How do they move? Do they flap back and forth like the cow's ears when they are moved, or do they turn as if on a pivot? What do the following different positions of the horse's ears indicate: When lifted and pointing forward? When thrown back? Can you tell by the action of the ears whether a horse is nervous and high-strung or not?

4. What is the color of the horse's eyes? The shape of the pupil? What advantage does the position of the eyes on the head give to the wild horse? Why do we put blinders on a horse? Can you tell by the expression of the eye the temper of the horse?

5. Look at the mouth and nose. Are the nostrils large and flaring? Has the horse a keen sense of smell? Are the lips thick or thin? When taking sugar from the hand, does the horse use teeth or lips?

6. Describe the horse's teeth. How many front teeth? How many back teeth? Describe the bar where the bit is placed. Are there any

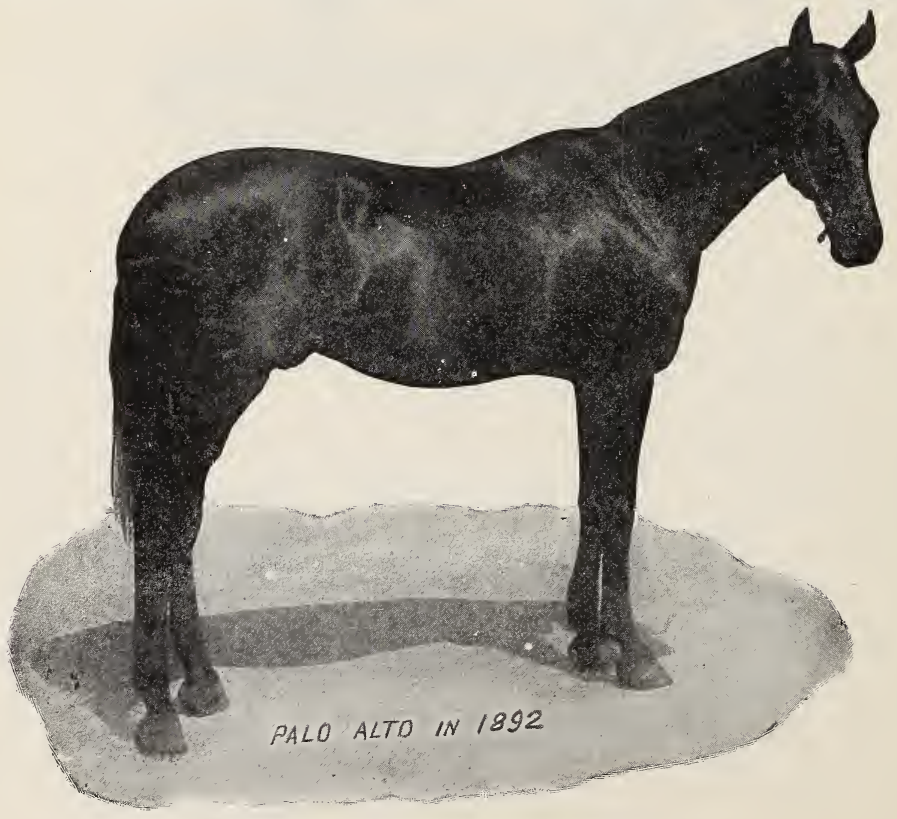

"Palo Aito", a famous running horse. 
canine teeth? If so, where? Do you know how to tell a horse's age by its teeth? (See Elements of Agriculture, Warren, page 304, and The Horse, Roberts, page 246.) Can a horse graze the grass more closely than a cow? Why? When it chews does it move the jaws sidewise like the cow? Why? Why did the wild horses not need to develop a cudchewing habit?

7. What is the nature of the horse's coat in summer? If the horse runs in the pasture all winter, how does its coat change? When does the horse shed its coat? What is the use of the horse's mane, forelock and tail? Do you think it is treating the horse well to dock its tail?

8. Why do colts need to be so long-legged? How does a colt have to place its front legs in order to reach down and eat the grass? Does the colt need to take its food from the mother often? How does it differ from the calf in this respect? How has this difference of habit resulted in a difference of form in the calf and colt?

9. When the horse lies down which part goes down first? When getting up which rises first? How does this differ from the method of the cow? When the horse lies down to sleep does it have its legs partially under it like the cow?

Io. In walking which leg moves first? Second? Third? Fourth? How many gaits has the horse? Describe as well as you can all of these gaits. (See pictures illustrating the word "movement" in the Standard Dictionary.)

II. Make a sketch of a horse showing the parts. (See Webster's Unabridged). When we say a horse is fourteen hands high what do we mean?

I 2. In fighting, what weapons does the horse use and how?

I3. In training a horse, should the voice or the whip be used the most? What qualities should a man have to be a good horse trainer? Why is shying a good quality in wild horses? How should it be dealt with in the domestic horse?

I4. What sort of feed is best for the horse? How and when should the horse be watered? Should the water be warmed in cold weather? Why? Should the bit be warmed in winter before putting it in a horse's mouth? Why? Should a tight over check-rein be used when driving? Why? When the horse has been driven until it is sweating what are the rules for blanketing it when hitched out of doors and when hitched in the barn? What is your opinion of a man who lets his horse stand waiting in the cold, unblanketed in the village street. If horses were kept out of doors all the time would this treatment be so cruel and dangerous? Why? Why should dusty hay be dampened before it is fed to a horse? Why should a horse be groomed? Which should receive the most attention, the legs or the body?

I 5. How many breeds of horses do you know? What is the use of each? Describe as well as you can the characteristics of the following breeds: The thoroughbred, the hackney, and other coach-horses; the American trotter, the Percheron, the Clydesdale.

I6. Write English themes on the following subjects: "The Prehistoric Horses of America," "The Arabian Horse and Its Life With Its Master," "The Bronchos and Mustangs of the West," "The Wild Horses of Tartary," "The Zebras of Africa," "The Shetland Ponies and the Islands on Which They Run Wild." 
Supplementary reading-The Horse, Roberts; Elements of Agriculture, Warren; Life of Animals, Cram; Neighbors with Claws and Hoofs; A Country Reader; Agriculture for Beginners; Black Beauty; John Brent, by Theodore Withrop; Half Hours with Mammals, Holder; Chapters on Animals, Hammerton; "Kaweah's Run" in Claws and Hoofs.

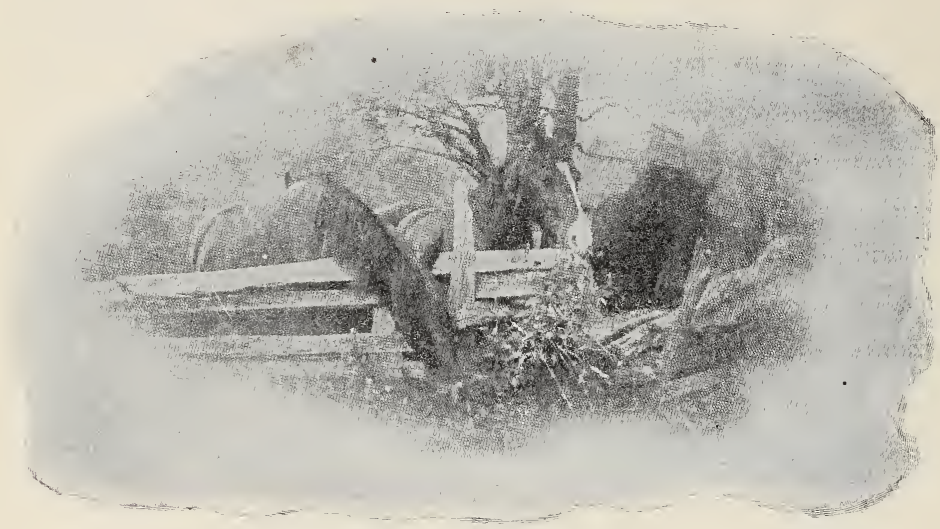

Many horses shy a good deal at objects they meet on the road. This mostly arises from nervousness, because the objects are not familiar to them. Therefore, to cure the habit, you must get your horse accustomed to what he sees, and so give him confidence. . . . Be careful never to stop a horse that is drawing a vehicle or load in the middle of a hill, except for a rest; and if for a rest, draw him across the hill and place a big stone behind the wheel, so that the strain on the shoulder may be eased. Unless absolutely necessary never stop a horse on a hill or in a rut, so that when he starts again it means a heavy tug. Many a horse has been made a jibber and his temper spoilt by not observing this rule. 


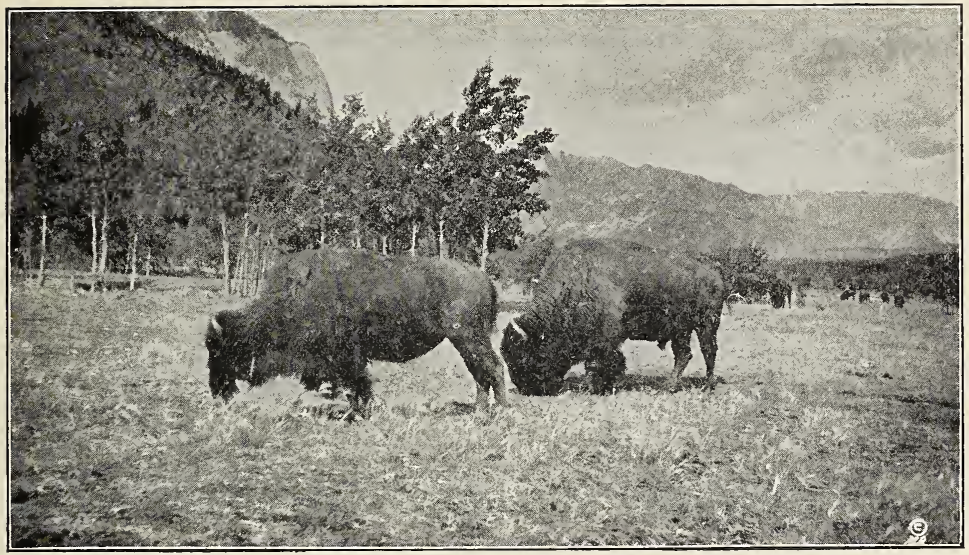

The original wild cattle of America.

Photo by John L. Rich.

\section{CATTLE}

\section{Teacher's Story}

That in numbers there is safety, is a basic principle in the lives of wild cattle, probably because their chief enemies, the wolves, hunted in packs. It has often been related that, when the herd is attacked by wolves, the calves are placed at the center of the circle made by the cattle, standing with heads out and horns ready for attack from every quarter. But when a single animal, like a bear or tiger, attacks any of the herd, they all gather around it in a narrowing circle of clashing horns, and many of these great beasts of prey have thus met their death. The cow is as formidable as the bull to the enemy, since her horns are strong and sharp and she tosses her victim, unless it is too large. The heavy head, neck and short massive horns of the bull, are not so much for defence against enemies as against rival bulls. The bull not only tosses and gores his victim, but kneels or tramples upon it. Both have effective weapons of defence in the hind feet, which kick powerfully. The buffalo bull of India will attack a tiger single handed, and usually successfully. It is a strange thing that all cattle are driven mad by the smell of blood, and weird stories are told of the stampeding of herds from this cause, on the plains of our great West.

Cattle are essentially grass and herbage eaters, and their teeth are peculiarly arranged for this. There are eight front teeth on the lower jaw, and a horny pad opposite them on the upper jaw. Back of these on each jaw there is a bare place and six grinding teeth on each side. As a cow crops the herbage, her head is moved up and down to aid in severing the leaves, and the peculiar sound of the tearing of the leaves thus made is not soon forgotten by those who have heard it. In the wild or domesticated state the habit of cud-chewing is this: The cattle graze in mornings and evenings, swallowing the food as fast as cropped, and storing it 


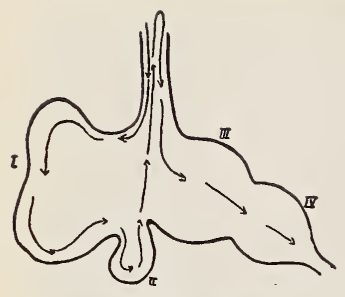

Course of food in a cow's stomach.

I, ruminant stomach; II, where the cud-balls are formed; III, IV, true stomachs,

mother; the young for a long journey; so the mother hides it, and there it stays "frozen" and will never stir unless actually touched. As the mother is obliged to be absent for some time grazing: with the herd, the calf is obliged to go without nourishment for a number of hours, and so it is provided with a large compound stomach which, if filled twice per day, suffices to insure health and growth. The cow, on the other hand, giving her milk out only twice per day, needs a large udder in which to store it. The size of the udder is what has made the cow useful to us as a milch animal.

A fine cow is a beautiful creature, her soft yellow skin beneath the sleek coat of short hair, the well proportioned body, the mild face, crowned with spreading, polished horns and illuminated with large gentle eyes, are all

in their ruminating stomachs. During the heat of the day, they move to the shade, preferably to the shady banks of streams, and there in quiet the food is brought up, a small portion at a time, and chewed with a peculiar sidewise movement of the jaws and then swallowed, passing to the true stomach. There is probably no more perfect picture of utter contentment, than a herd of cows chewing their cuds in the shade, or standing knee-deep in the cool stream on a summer's day. The cattle in a herd when grazing, keep abreast and move along, heads in the same direction.

Connected with the grazing habit, is that of the hiding of the new-born calf by its calf is a wabbly creature and ill-fitted

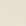

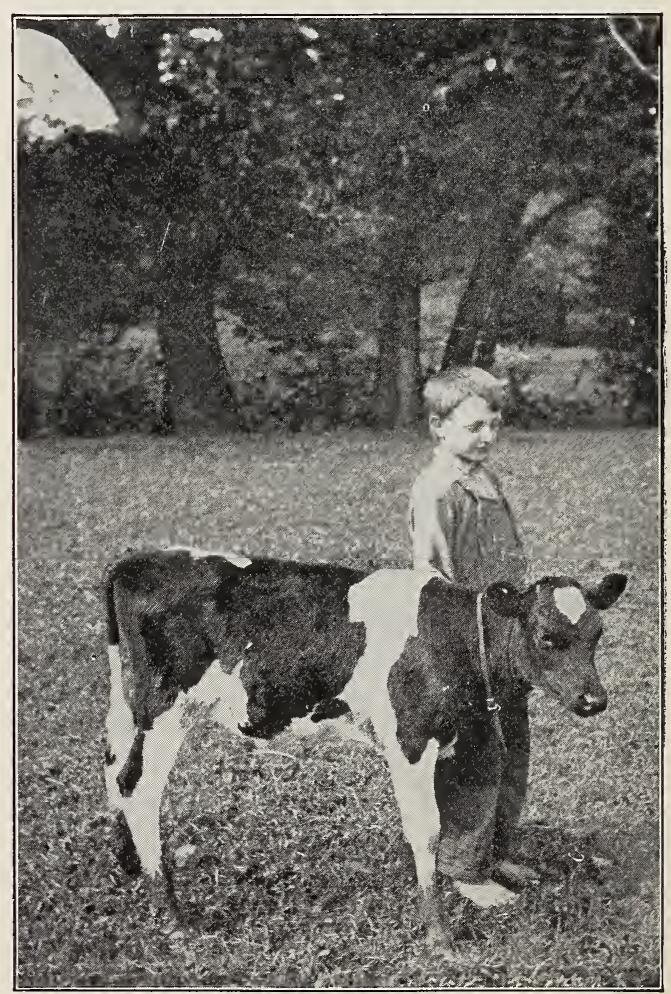

$A$ pet Holstein. 
elements of beauty which artists have recognized, especially those of the Dutch school. The ancients also admired bovine eyes, and called their most beautiful goddess the ox-eyed Juno.

The cow's ears can be turned in any direction, and her sense of hearing is keen; so is her sense of smell, aided by the moist, sensitive skin of the nose; she always sniffs danger and also thus tests her food. Although a cow if well kept has a sleek coat, when she is allowed to run out of doors during the winter, her hair grows long and shaggy as a protection. The cow walks on two toes, or as we say has a split hoof. She has two lesser toes above and behind the hoofs which we call dew-claws. The part of her leg which seems at first glance to be her knee, is really her wrist or ankle. Although short-legged, the cow is a good runner, as those who have chased her can bear witness. She can walk, gallop and has a pacing trot; she is a remarkable jumper, often taking a fence like a deer; she also has marvelous powers as a swimmer, a case being on record where a cow swam five miles. But a cow would be illy equipped for comfort if it were not for her peculiar tail, which is made after the most approved pattern of fly-brushes, and is thus used. Woe betide the fly she hits with it, if the blow is as efficient as that which she incidentally bestows on the head of the milker. It is to get rid of flies, that the cattle, and especially the buffaloes, wallow in the mud, and thus coat themselves with a fly. proof armor.

There is a fairly extensive range of emotions expressed in cattle language, from the sullen bellow of the angry animal to the lowing which is the call of the herd, and the mooing which is meant for the calf; and thexe are many other bellowings and mutterings which we can partially understand.

Every herd of cows has its leader, which has won the position by fair fight. Add a new cow to the herd, and there is at once a trial of strength, to adjust her to her proper place; and in a herd of cows, the leader leads; she goes first and no one may say her nay. In fact, each member of the herd has her place in it; and that is why it is so easy to teach cows each to take her own stanchion in the stable. In a herd of forty cows which I knew, each cow took her stanchion, no matter in what order she happened to enter the stable.

A cow at play is a funny sight; her tail is lifted aloft like a pennant and she kicks as lightly as if she were made of rubber. She is also a surefooted beast, as anyone can attest who has seen her running down the rocky mountain sides of the Alps, at a headlong pace and never making a mistake. In lying down, the cow first kneels with the front legs, or rather drops on her wrists, and then the hind quarters go down, and then the front follow. She does not lie flat on her side when resting, like the horse when at ease, but with her legs partially under her. In getting up, she rests upon her wrists and then lifts the hind quarters.

\section{The Usefulness of Cattle}

When man emerged from the savage state, his first step toward civilization was domesticating wild animals and training them for his own use. During the nomad stage, when tribes wandered over the face of the earth, they took their cattle along. From the first, these animals have been used in three capacities: First, for carrying burdens and as draught 
animals; second, as meat; third, as givers of milk. They were also used in the earlier ages as sacrifices to the various deities, and in Egypt, some were held as sacred.

As beasts of burden and draft animals, oxen are still used in many parts of the United States. For logging, especially in pioneer days, oxen were far more valuable than horses. They are patient and will pull a few inches at a time, if necessary, a tedious work which the nervous horse refuses to endure. Cows too, have been used as draft animals, and are so used in China today, where they do most of the plowing; in these oriental countries milk is not consumed to any extent, so the cow is kept for the work she can do. In ancient times in the East, white oxen formed a part of royal processions.

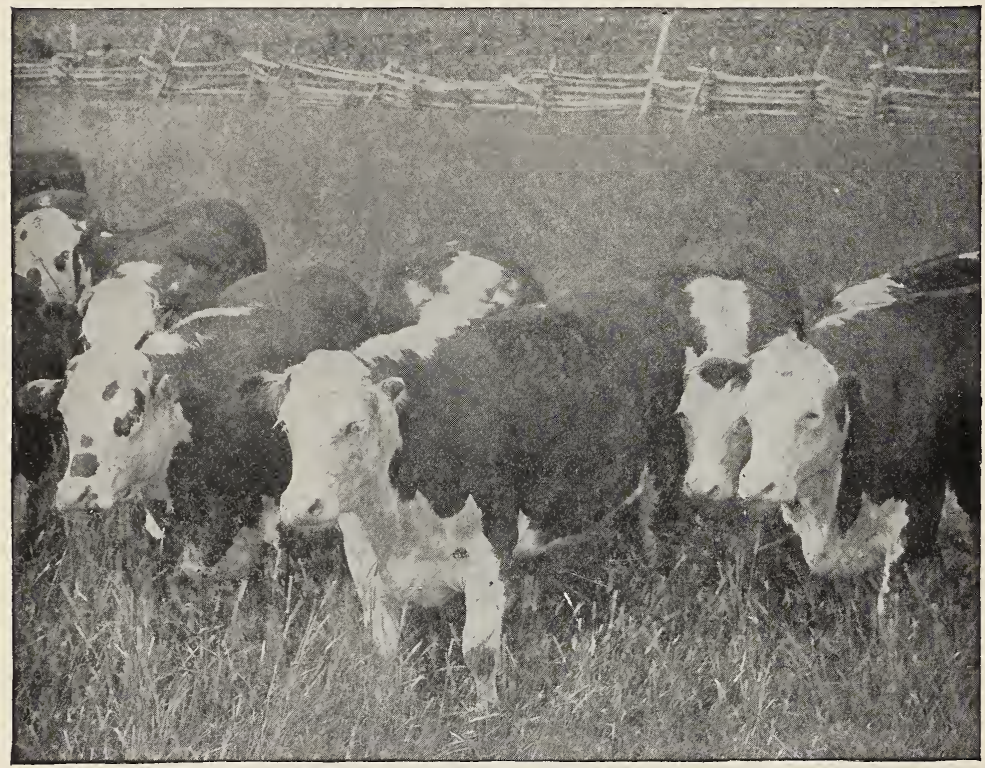

Beef cattle.

Because of two main uses of cattle by civilized man, he has bred them in two directions; one for producing beef, and one for milk. The beef cattle are chiefly Aberdeen-Angus, Galloway, Short-horn or Durham, and Hereford; the dairy breeds are the Jersey, Guernsey, Ayrshire, HolsteinFrisian and Brown Swiss. The beef animal is, in cross-section, approximately like a brick set sidewise. It should be big and full across the loins and back, the shoulders and hips covered heavily with flesh, the legs stout, the neck thick and short, and the face short; the line of the back is straight, and the stomach line parallel with it. Very different is the appearance of the milch cow. Her body is oval, instead of being approximately square in cross-section. The outline of her back is not straight, 
but sags in front of the hips, which are prominent and bony. The shoulders have little flesh on them; and if looked at from above, her body is wedge-shaped, widening from shoulders backward. The stomach line is not parallel with the back bone, but slants downward from the shoulder to the udder. The following are the points that indicate a good milch cow: Head high between the eyes, showing large air passages and indicating strong lungs. Eyes clear, large and placid, indicating good disposition. Mouth large, with a muscular lower jaw, showing ability to chew efficiently and rapidly. Neck, thin and fine, showing veins through the skin. Chest deep and wide, showing plenty of room for heart and lungs. Abdomen, large but well supported, and increasing in size toward the rear. Ribs, well spread, not meeting the spine like the peak of a roof, but the spine must be prominent, revealing to the touch the separate vertebræ. Hips, much broader than the shoulders. Udder, large, the four quarters of equal size, and not fat; the "milk veins" which carry the blood from the udder should be large and crooked, passing into the abdomen through large openings. Skin, soft, pliable and covered with fine, oily hair. She should have good digestion and great powers of assimilation. The milch cow is a milk-making machine, and the more fuel (food) she can use, the greater her production.

The physiological habits of the beef and milch cattle have been changed as much as their structure. The food given to the beef cow goes to make flesh; while that given to the milch cow goes to make milk, however abundant her food. Of course, there are all grades between the beef and the milch types, for many farmers use dual herds for both. However, if a farmer is producing milk it pays him well to get the best possible machine to make it, and that is always a cow of the right type.

\section{A Geography Lesson}

All the best breeds of cattle have been evolved in the British Isles and in Europe north of Italy and west of Russia. All our domesticated cattle were developed from wild cattle of Europe and Asia. The cattle which roam in our rapidly narrowing grazing lands of the far West are European cattle. America had no wild cattle except the bison. In geography supplementary readers, read about Scotland, England, the Channel Islands, the Netherlands, France and Switzerland and the different kinds of cattle developed in these countries; for example, "A Holland Dairy," in Northern Europe, Ginn \& Co.

\section{How to Produce Good Milk}

There are three main ingredients of milk-fat, curd and ash. The fat is for the purpose of supplying the animal with fat and we make it into butter; the curd supplies muscle, or the lean meat of the animal, and is the main ingredient of cheese, although cheese to be good should contain a full amount of butter fat; the ash which may be seen as residue when milk is evaporated, builds up the bone of the animal. The best butter cows are those which give a larger per cent. of fat and a small per cent. of curd, like the Jerseys; the best cheese cows are those which give a fair per cent. of fat and a larger yield of curd, like the Ayrshire and Holstein. 
A cow for producing cheese, is not profitable, unless she gives seven thousand pounds of milk per year; a butter cow, a Jersey for instance, should produce five thousand pounds of milk per year to be really profitable.

The stable where milch cows are kept should be thoroughly cleaned before each milking, and should be swept each day; the cows' udders should be brushed, and the milkers should wear clean aprons and should wash their hands before milking. Milk should never be strained in the barn, but in some place where the air is fresh. If milk is perfectly clean, it will keep sweet much longer; sterilized milk put in bottles will keep sweet for weeks and even months. Loud talking should not be permitted in the stables while the cows are being milked, and each cow should be milked by the same person for the entire season.

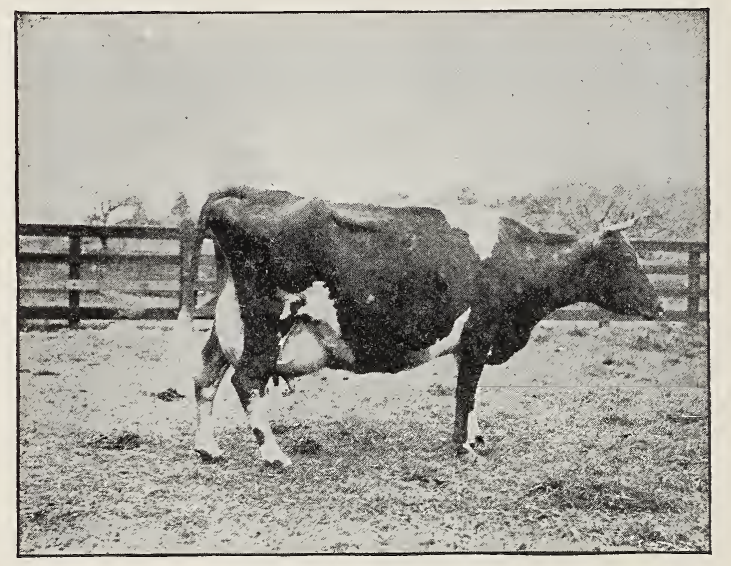

The perfect milch type.

Milk to be legally sold in New York State must possess three per cent. of butter fat. For upper grades or first year work in the high school, there could not be a more profitable exercise than teaching the pupils the use of the Babcock milk tester.

\section{The Care of the Milch Cow}

The importance cannot be over-estimated of teaching the pupils in rural districts, the proper care of milch cattle for the production of milk. The milch cow is a perfect machine, and should be regarded as such in producing milk. First, she should have plenty of food of the right kind, that is, a well-balanced ration. Second, she should have a warm, clean stable and be supplied with plenty of good, fresh air. A cold stable makes it necessary to provide much more food for the cow; a case on record shows that when a barn was opened up in cold weather for necessary repairing, the amount of milk from the cows stabled in it, decreased ten per cent. in twenty-four hours. There should be a protected place for 
drinking, if the cattle must be turned out of the barn for water in winter; it is far better to have the water piped into the barn, although the herd should be given a few hours each day in the open air. A dog should never be used for driving cows. To be profitable, a cow should give milk ten months of the year at least. Calves should be dehorned when they are a few days old by putting caustic potash on the budding horns, thus obviating the danger of damaging the cow by dehorning.

In a properly run dairy, a pair of scales stands near the can for receiving the milk; and as the milk from each cow is brought in, it is weighed and the amount set down opposite the cow's name on a "milk sheet," that is tacked on the wall, near by. At the end of each week, the figures on the milk sheet are added, and the farmer knows just how much milk each cow is giving him, and whether there are any in the herd which are not paying their board.

References-Elements of Agriculture, Warren; Agriculture for Beginners, Burkett, Stevens and Hill, p. 2 I6; First Principles of Agriculture, Vorhees, p. II7; Elements of Agriculture, Sever, p. 57; Elements of Agriculture, Shepperd, chapters I5 and 22; First Principles of Agriculture, Goff and Maine, p. I54; Agriculture Through the Laboratory, School and Garden, Jackson and Dougherty, chapter 8; The Dairy Herd, Farmers' Bulletin No. 55, U. S. Dept. of Agr.; Care of Milk on the Farm, Farmers' Bulletin No. 63, U. S. Dept. of Agr.

\section{LESSON LXVIII}

\section{The Cow}

Leading thought-Certain characteristics which enable the cow to live successfully as a wild animal, have rendered her of great use to us as a domestic animal.

Method-Begin the lesson with leading the pupils to understand the peculiar adaptation of cattle for success, as wild animals. This will have to be done largely by reading and asking for oral or written work on the following topics: "The Aurochs," "Wild Cattle of the Scottish Highlands," "The Buffaloes of the Orient," "The American Bison," "The Cow-boys of the West and their Work with their Herds," "The Breeds of Beef Cattle, Where they Came From, and Where Developed," "The Breeds of Milch Cattle, their Origin and Names." The following questions may be given out a few at a time and answered as the pupils have opportunity for observation.

Observations-I. What are the characteristics of a fine cow? Describe her horns, ears, eyes, nose and mouth. Do you think she can hear well? What is the attitude of her ears when she is listening? Do you think she has a keen sense of smell? Is her nose moist? Is her hair long or short? Smooth or rough?

2. The cow walks on two toes. Can you see any other toes which she does not walk on? Why is the cow's foot better adapted than that of the horse, to walk in mud and marshes? What do we call the two hind toes which she does not walk on? Can you point out on the cow's leg those parts which correspond with our elbow, wrist, knee and ankle? Is the cow a good runner? Is she a good jumper? Can she swim? 
3. For what use was the cow's tail evidently intended? How do the wild buffalos and bisons get rid of attacks of flies?

4. How much of cattle language do you understand? How does the cow express pleasure? Lonesomeness? Anger? How does the bull express anger? What does the calf express with the voice?

5. Is there always a leader in a herd of cows? Do certain cows of the herd always go first and others last? Do the cows readily learn to take each her own place in the stable? How is leadership of the herd attained? Describe cattle at play.

6. At what time of day do cattle feed in the pasture? When and where do they chew the cud? Do they stand or lie to do this? Describe how a cow lies down and gets up.

7. How do wild cattle defend themselves from wolves? From bears or other solitary animals?

8. For what purposes were cattle first domesticated? For how many purposes do we rear cattle today?

9. Name and give brief descriptions of the different breeds of cattle with which you are familiar. Which of these are beef and which milch types?

IO. What are the distinguishing points of a good milch cow? Of a good beef animal? What does the food do for each of these? Which part of the United States produces most beef cattle? Which the most milch cattle?

II. What do we mean by a balanced ration? Do you know how to compute one? What is the advantage of feeding cattle a balanced ration?

I 2. How many pounds of milk should a dairy cow produce in a year to be profitable if the product is cheese? If the product is butter? Why this discrepancy? What must be the percent. of butter fat in milk to make it legally salable in your state? How many months of the year should a good cow give milk?

I3. Why should a cow be milked always by the same person? Does the milker always sit on the same side? Why should loud talking and other noise at milking time be avoided? Should a dog be used in driving dairy cows? Why?

I 4. Why is a cool draughty barn an expensive place in which to keep cattle? Why is a barn not well-ventilated, a danger?

I5. Why and where is the dehorning of cattle practiced? When and how should a calf be dehorned?

I6. Why should milk not be strained in the barn? Why is it profitable for the dairy farmer to keep his stable clean and to be cleanly in the care of milk? How does the food of cows affect the flavor of the milk? Why should a farmer keep a record of the number of pounds of milk which each cow in his dairy gives each day?

I 7. For what are oxen used? Wherein are they superior to horses as draft animals? Do you know of any place where oxen are used as riding animals?

I8. How many industries are dependent upon cattle?

19. Give oral or written exercises on the following themes: "How the Best Butter is Made;" "The Use of Bacteria in Butter;" "How Dairy Cheese is Made;" "How Fancy Cheeses are Made." 


\section{THE PIG}

\section{Teacher's Story}

"I wander through the underbresh,

Where pig tracks pintin' to'rds the crick,

Is picked and printed in the fresh

Black bottom-lands, like wimmen prick

Their pie-crust with a fork."-RILEY.

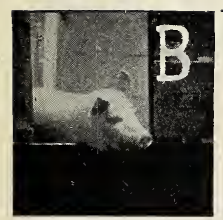

Y a forest law of William the First of England in the eleventh century, it was ordained that any that were found guilty of killing the stag or the roebuck or the wild boar, should have their eyes put out. This shows that the hunting of the wild boar in England was considered a sport of gentlemen in an age when nothing was considered sport unless it was dangerous. The wild hog of Europe is the ancestor of our common domesticated breeds; although independent of these, the Chinese domesticated their own wild species, even before the dawn of history.

The wild hog likes damp situations where it may wallow in the water and mud; but it also likes to have, close by, woods, thicket or underbrush, to which it can retire for rest and also when in danger. The stiff, bristling hairs which cover its thick skin, are a great protection when it is pushing through thorny thickets. When excited or angry, these bristles rise and add to the fury of its appearance. Even in our own country, the wild hogs of the South whose ancestors escaped from domestication, have reverted to their original savagery, and are dangerous when infuriated. The only recorded instance when our great national hunter, Theodore Roosevelt, was forced ignominiously to climb a tree, was after he

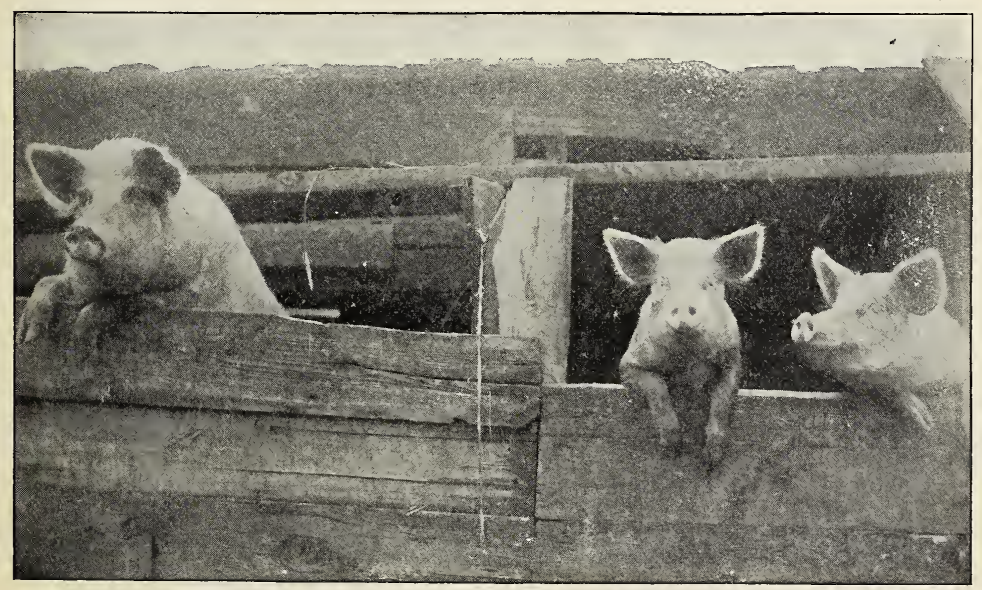

Anxious for dinner. 
had emptied his rifle into a herd of "javelins," as the wild pigs of Texas are called; the javelins are the peccaries, which are the American representatives of the wild hog.

That the hog has become synonymous with filth is the result of the influence of man upon this animal, for of all animals, the pig is naturally the neatest, keeping its bed clean, often in the most discouraging and illkept pens. The pig is sparsely clothed with bristles and hairs, which yield it no protection from the attacks of flies and other insects. Thus it is the pig, in order to rid itself of these pests, has learned to wallow in the mud. However, this is in the nature of a mud bath, and is for the purpose of keeping the body free from vermin. The wild hogs of India make for themselves grass huts, thatched above and with doors at the sides, which shows that the pig, if allowed to care for itself, understands well the art of nest-building.

One of the most interesting things about a pig, is its nose; this is a fleshy disc with nostrils in it and is a most sensitive organ of feeling; it can select grain from chaff, and yet is so strong that it can root up the ground in search for food. "Root" is a pig word, and was evidently coined to describe the act of the pig when digging for roots; the pig's nose is almost as remarkable as the elephant's trunk, and the pig's sense of smell is very keen; it will follow a track almost as well as a dog. There are more instances than one of a pig being trained as a pointer for hunting birds, and showing a keener sense of smell, and keener intelligence in this capacity, than do dogs. French pigs are taught to hunt for truffles, which are fungi growing on tree roots, a long way below the surface of the ground; the pig detects their presence through the sense of smell.

The pig has a full set of teeth, having six incisors, two canines and seven grinding teeth on each jaw; although in some cases there are only four incisors on the upper jaw. A strange thing about a pig's teeth, is the action of the upper canines, or tushes, which curve upward instead of downward; the lower canines grind up against them, and are thus sharpened. The females have no such development of upper tushes as do the males; these tushes, especially the upper ones, are used as weapons; with them, the wild boar slashes out and upward, inflicting terrible wounds, often disabling horses and killing men. Professor H. F. Button describes the fighting of hogs thus: "To oppose the terrible weapons of his rival, the boar has a shield of skin over his neck and shoulders, which may become two inches thick, and so hard as to defy a knife. When two of these animals fight, each tries to keep the tushes of his opponent against the shield, and to get his own tushes under the belly or flank of the other. Thus, each goes sidewise or in circles, which has given rise to the expression, 'to go sidewise like a hog to war.' "'

When, as a small girl, I essayed the difficult task of working buttonholes, I was told if I did not set my stitches more closely together, my buttonhole would look like a pig's eye, a remark which made me observant of that organ ever after. But though the pig's eyes are small, they certainly gleam with intelligence, and they take in all that is going on, which may in any way affect his pigship.

The pig is the most intelligent of all the farm animals, if it is only given a chance; it has excellent memory and can be taught tricks readily; it is affectionate and will follow its master around like a dog. Anyone who has seen a trained pig at a show picking out cards and counting, must 
grant that it has brains, although we stuff it so with fattening food, that it does not have a chance to use its brain, except now and then when it breaks out of the sty and we try to drive it back. Under these circumstances, we grant the pig all the sagacity usually imputed to the one who once possessed swine and drove them into the sea. Hunters of wild hogs proclaim that they are full of strategy and cunning, and are exceedingly fierce. We pay tribute to the pig's cleverness when free to outwit us, when we say of other uncertain undertakings, that they are like "buying a pig in a poke."

The head of the wild hog is wedge-shaped with pointed snout, and this form enables the animal to push in to the thick underbrush along the river banks, whenever it is attacked. But civilization has changed this bold profile of the head, so that now in many breeds, there is a hollow between the snout and eyes, giving the form which we call "dished." Some breeds have sharp, forward-opening ears, while others have ears that lop. The wild pig of Europe and Asia has large, open ears extending out wide and alert on each side of the head.

The covering of the pig is a thick skin beset with bristling hairs; when the hog is excited, the bristles rise and add to the fury of its appearance. The bristles aid in protecting the animal when it is pushing through thorny

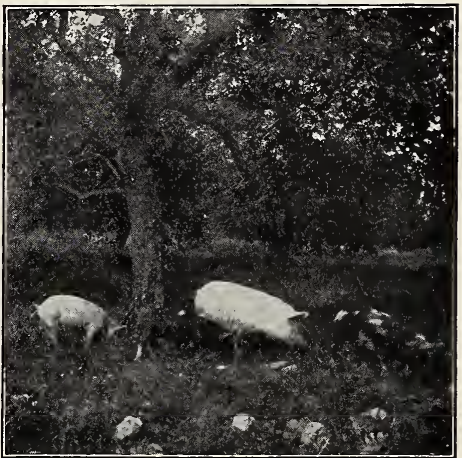

Good for the pigs and good for the orchard. thickets. The pig's querly tail is merely an ornament, although the tail of the wart hog of Africa, if pictures may be relied upon, might be used in a limited fashion as a fly-brush.

When the pig is allowed to roam in the woods, it lives on roots, nuts, and especially acorns and beech nuts; in the autumn it becomes very fat through feeding upon the latter. The mast-fed bacon of the semi-wild hogs of the Southern States is considered the best of all. But almost anything animal or vegetable, that comes in its way, is eaten by the hog, and it has been long noted that the hog has done good service on our frontier as a killer of rattlesnakes. The pig is well fitted for locomotion on either wet or dry soil, for the two large hoofed toes enable it to walk well on dry ground and the two hind toes, smaller and higher up, help to sustain it on marshy soil. Although the pig's legs are short, it is a swift runner unless it is too fat. The razor-backs of the South are noted for their fleetness.

We understand somewhat the pig's language; there is the constant grunting, which is a sound that keeps the pig herd together. We understand perfectly the complaining squeal of hunger, the satisfied grunt signifying enjoyment of food, the squeal of terror when seized, and the nasal growl when fighting. But there is much more to the pig's conversation than this; I know a certain lady, who is a lover of animals, and who once undertook to talk pig language as best she could imitate it, to two of 
her sows when they were engaged in eating. They stopped eating, looked at each other a moment and forthwith began fighting, each evidently attributing the lady's remark to the other, and obviously it was of an uncomplimentary character.

The pig's ability to take on fat was evidently a provision, in the wild state, for storing up fat from mast that should help sustain the animal during the hardships of winter; and this character is what makes swine useful for our own food. Pigs, to do best, should be allowed to have pasture and plenty of fresh green food. Their troughs should be kept clean and they should have access to ashes, and above all, they should have plenty of pure water; and as the pig does not perspire freely, access to water where it can take its natural mud-baths helps to keep the body cool and the pig healthy in hot weather.

The breeds of hogs most common in America are the Berkshires, which are black with white markings, and have ears extending erect; the Poland Chinas, which are black and white with drooping ears; the DurocJersey, which are red or chestnut with drooping ears; the Yorkshire and Cheshire, which are white with erect ears, while the Cheshire White is white with drooping ears. The Poland China and Duroc-Jersey are both pure American breeds.

References-Elementary Agriculture, Warren; Our Domestic Animals, Burkett; The Country Reader, Buchanan; Lives of Animals, Ingersoll; Types and Breeds of Farm Animals, Plumb; and the bulletins of the U. S. Department of Agriculture.

\section{LESSON LXIX}

\section{The PIG}

Leading thought-The pig is something more than a source of pork. It is a sagacious animal and naturally cleanly in its habits when not made prisoner by man.

Method-The questions in this lesson may be given to the pupils a few at a time, and those who have access to farms or other places where pigs are kept may make

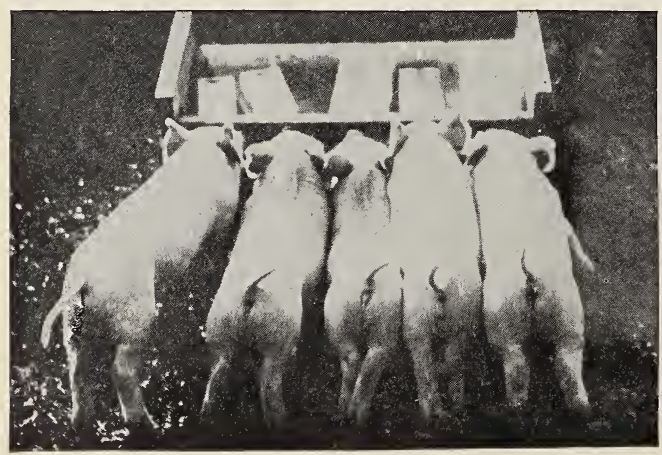
the observations and in giving them to the class they should be discussed. Supplementary reading should be given the pupils, which may inform them as to the habits and peculiarities of the wild hogs. Theodore Roosevelt's experience in hunting the wart-hog in Africa will prove interesting reading.

Observations - I. Bottle-fed babies. How does the pig's nose differ from that 
of other animals? What is it used for besides for smelling? Do you think the pig's sense of smell is very keen? Why do pigs root?

2. Describe the pig's teeth. For what are they fitted? What are the tushes for? Which way do the upper tushes turn? How do wild hogs use their tushes?

3. Do you think that a pig's eyes look intelligent? What color are they? Do you think the pig can see well?

4. Is the pig's head straight in front or is it dished? Is this dished appearance ever found in wild hogs? Do the ears stand out straight or are they lopped? What advantage is the wedge-shaped head to the wild hogs?

5. How is the pig covered? Do you think the hair is thick enough to keep off flies? Why does the pig wallow in the mud? Is it because the animal is dirty by nature or because it is trying to keep clean? Do the hog's bristles stand up if it is angry?

6. If the pig could have its natural food what would it be and where would it be found? Why and on what should pigs be pastured? What do pigs find in the forest to eat? What kind of bacon is considered the best?

7. On how many toes does the pig walk? Are there other toes on which it does not walk? If wading in the mud are the two hind toes of use? Do wild pigs run rapidly? Do tame pigs run rapidly if they are not too fat? Do you think the pig can swim? Do you think that the pig's tail is of any use or merely an ornament?

8. What cries and noises do the pigs make which we can understand?

9. How do hogs fight each other? When the boars fight, how do they attack or ward off the enemy? Where do we get the expression going "sidewise like a hog to war?"

ro. How many breeds of pigs do you know? Describe them.

Ir. What instances have you heard that show the hog's intelligence?

I2. Give an oral or written English exercise on one of the following topics: "The antiquity of swine; how they were regarded by the ancient Egyptians, Greeks and Romans;" (see encyclopedia). "The story of hunting wild hogs in India; "The razor-back hogs of the South;" "The wart-hog of Africa."

"The nice little pig with a querly tail, All soft as satin and pinky pale Is a very different thing by far

Than the lumps of iniquity, big pigs are."

-Nonsense Rhyme. 


\section{INSECT STUDY}

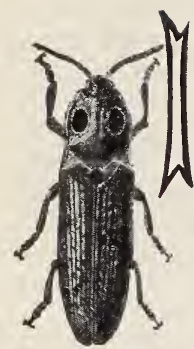

NSECTS are among the most interesting and available of all living creatures for nature-study. The lives of many of them afford more interesting stories than are found in fairy lore; many of them show exquisite colors and, more than all, they are small and are, therefore, easily confined for observation.

While the young pupils should not be drilled in insect anatomy, as if they were embryo zoologists, yet it is necessary for the teacher, who would teach intelligently, to know something of the life stories, habits and structure of the common insects. Generally speaking, all insects develop from eggs. To most of us the word egg brings before us the picture of the egg of the hen or of some other bird. But insect eggs are often far more beautiful than those of any bird; they are of widely differing forms, and are often exquisitely colored and the shells may be ornately ribbed and pitted, sometimes adorned with spines, and are as beautiful to look at through a microscope as the most artistic piece of mosaic.

From the eggs, larvæ (sing. larva) issue. These larvæ may be caterpillars, or the creatures commonly called worms, or may be maggots
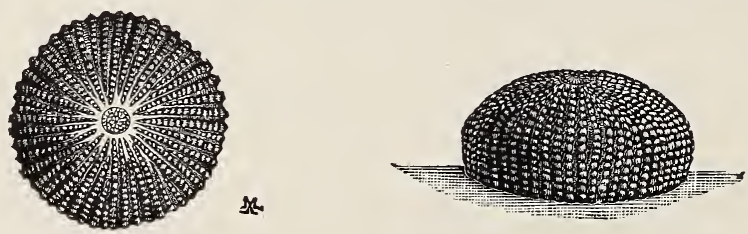

The egg of the cotton moth, greatly enlarged.

From Manual for the Study of Insects.

or grubs. The larval stage is always devoted to feeding and to growth. It is the chief business of the larva to eat diligently and to attain maturity as soon as possible; for often the length of the larval period depends more upon food than upon lapse of time. All insects have their skeletons on the outside of the body; that is, the outer covering of the body is chitinous, and the soft and inner parts are attached to it and supported

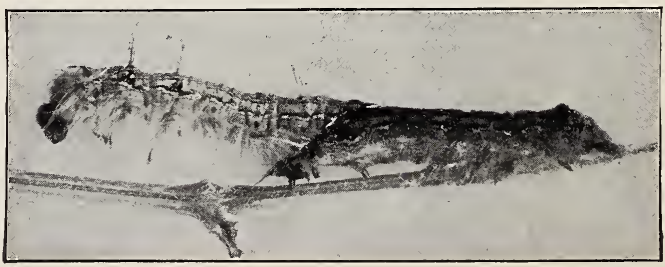

The forest tent-caterpillar shedding its skin. Photo by M. V. Slingerland. 


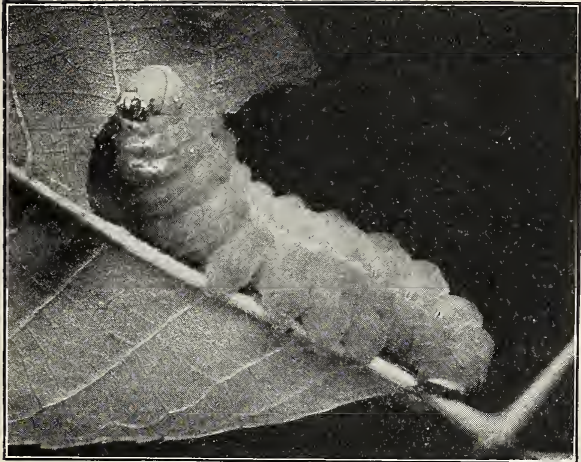

Full-grown caterpillar of the luna moth. Photo by M. V. Slingerland.

by it. This skin is so firm that it cannot stretch to accommodate the increasing size of the growing insect, thus from time to time it is shed. But before this is done, a new skin is formed beneath the old one. After the old skin bursts open and the insect c'rawls forth, the new skin is sufficiently soft and elastic to allow for the increase in the size of the insect. Soon, the new skin becomes hardened like the old one, and after a time, is shed. This shedding of the skin is called molting. Some insects shed their skins only four or five times during the period of attaining their growth, while other species may molt twenty times or more.

After the larva has attained its full growth, it changes its skin and its form, and becomes a pupa. The pupa stage is ordinarily one of inaction, except that very wonderful changes take place within the body itself. Usually the pupa has no power of moving around, but in many cases it can squirm somewhat, if disturbed. The pupa of the mosquito is active and is an exception to the rule. The pupa is usually an oblong object and seems to be without head, feet or wings; but if it is examined closely, especially in the case of butterflies and moths, the antennæ, wings and legs may be seen, folded down beneath the pupa skin.

Many larvæ, especially those of moths, weave about themselves a covering of silk which serves to protect them from their enemies and the weather, during the helpless pupa period. This silken covering is called a cocoon. The larvæ of butterflies do not make a silken cocoon, but the pupa is suspended to some object by a silken knob, and in some cases by a halter of

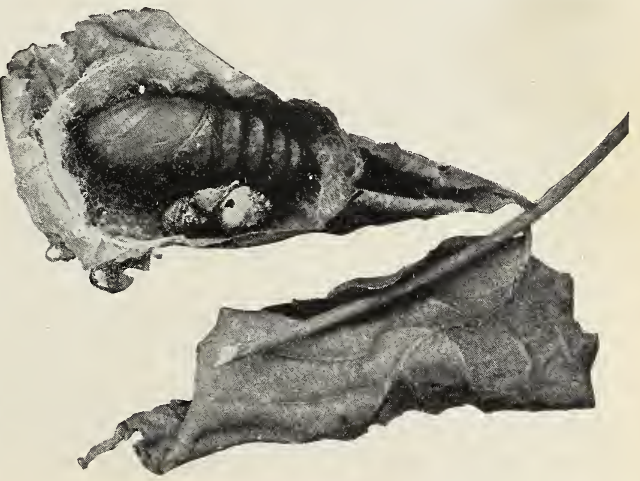

A luna cocoon cut open, showing the pupa. Photo by M. V. Slingerland.

silk, and remains entirely naked. The pupa of a butterfly is called a chrysalis. Care should be taken to have the children use the wordspupa, chrysalis and cocoon-understandingly. 
After a period varying from days to months, depending upon the species of insect and the climate, the pupa skin bursts open and from it

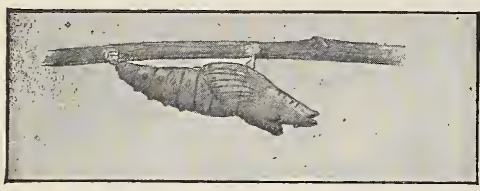

A butterfly chrysalis. emerges the adult insect, often equipped with large and beautiful wings and always provided with six legs and a far more complex structure of body than characterized it as a larva. The insect never grows after it reaches this adult stage and, therefore, never molts. Some people seem to believe that a small fly will grow into a large fly, and a small beetle into a large beetle; but after an insect attains its

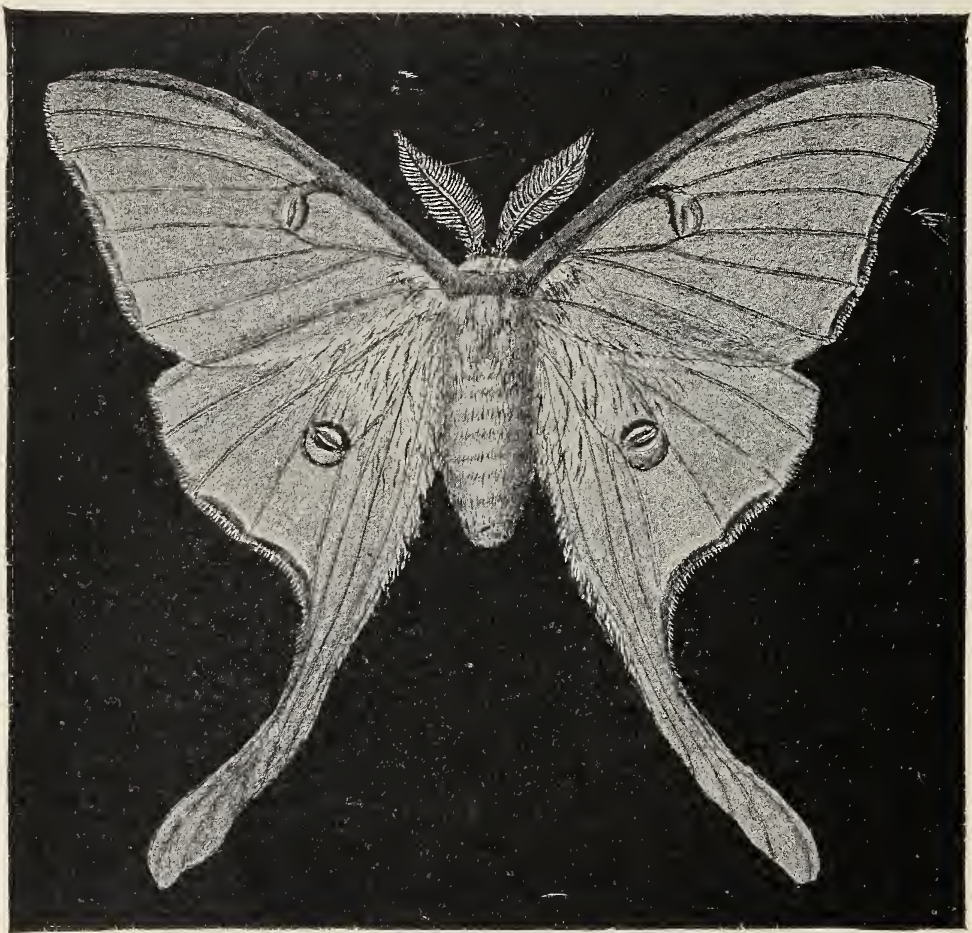

\section{A luna moth.}

The delicate, exquisite green of the luna's wings is set off by the rose-purple, velvet border of the front wings, and the white fur on the body and inner edge of the hind wings. Litrle wonder that it has been called the "Empress of the night". "The long swallow tail of the hind wings give the moth a most graceful shape, at the same time probably afford it protection from observation. During the daytime the moth hangs wings dotin beneath the green leaves, and these long projections of the hind wings folded together resemble a petiols, making the insect look very much like a large leaf. 
perfect wings, it does not grow larger. Many adult insects take very little food, although some continue to eat in order to support life. The adult stage is ordinarily shorter than the larval stage; it seems a part of nature's economic plan that the grown-up insects should live only long enough to lay eggs, and thus secure the continuation of the species. Insects having the four distinct stages in their growth, egg, larva, pupz and adult, are said to undergo complete metamorphosis.

But not all insects pass through an inactive pupa stage. With some insects, like the grasshoppers, the young, as soon as they are hatched, resemble the adult forms in appearance. These insects, like the larvæ, shed their skins to accommodate their growth, but they continue to feed and move about actively until the final molt when the perfect insect appears. Such insects are said to have incomplete metamorphosis, which simply means that the form of the body of the adult insect is not greatly different from that of the young; the dragon-flies, crickets, grasshoppers and bugs are of this type. The young of insects with an incomplete metamorphosis are called nymphs instead of larvæ.

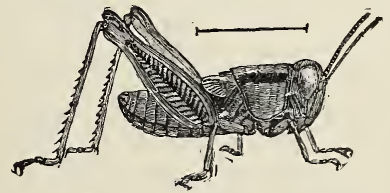

A young grasshopper, enlarged.

The line shows its actual length.

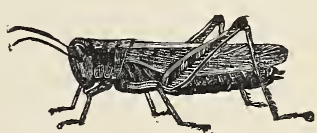

The adult of the same grasshopper, natural size.

\section{Summary of ihe Metamorphoses of Insects}

Kinds of Metamorphosis

I. Complete metamorphosis

II. Incomplete metamorphosis

\section{Names of Stages}

Egg.

Larva.

Pupa. (The pupa is sometimes enclosed in a cocoon.)

Adult or winged insect.

Egg.

Nymph (several stages).

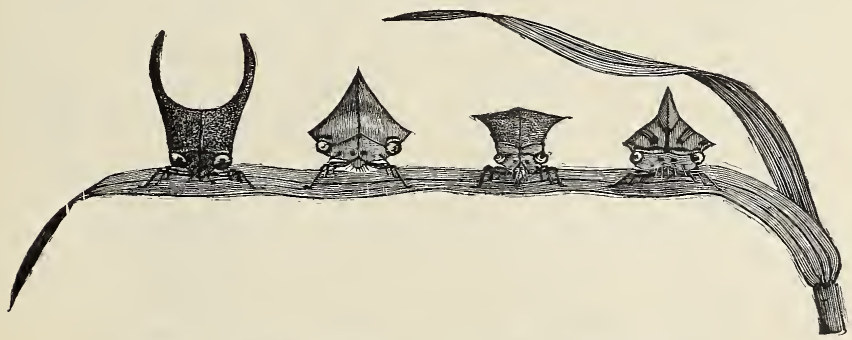

Insect brownies; tree-hoppers as seen through a lens. 


\section{The Structure of Insects}

The insect body is made up of ring-like segments which are grown together. These segments are divided into groups according to their use and the organs which they bear. Thus the segments of an insect's body are grouped into three regions, the head, the thorax and the abdomen. The head bears the eyes, the antennæ, and the mouth-parts. On each side of the head of the adult insect may be seen the compound eyes; these

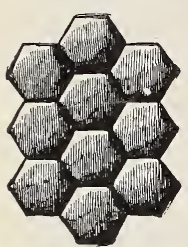

A part of the compound eye of an insect, enlarged. are so called, because they are made up of many small eyes set together, much like the cells of the honeycomb. These compound eyes are not found in larvæ. In addition to the compound eyes, many adult insects possess simple eyes; these are placed between the compound eyes and are usually three in number. Often they cannot be seen without the aid of a lens.

The antennæ or feelers are composed of many segments and are inserted in front of the eyes or between them. They vary greatly in form. In some insects they are mere threads; in others, like the silk-worm moths, they are large, feather-like organs.

The mouth-parts of insects vary greatly in structure and in form, being adapted to the life of the insect species to which they minister. Some insects have jaws fitted for seizing their prey, others for chewing

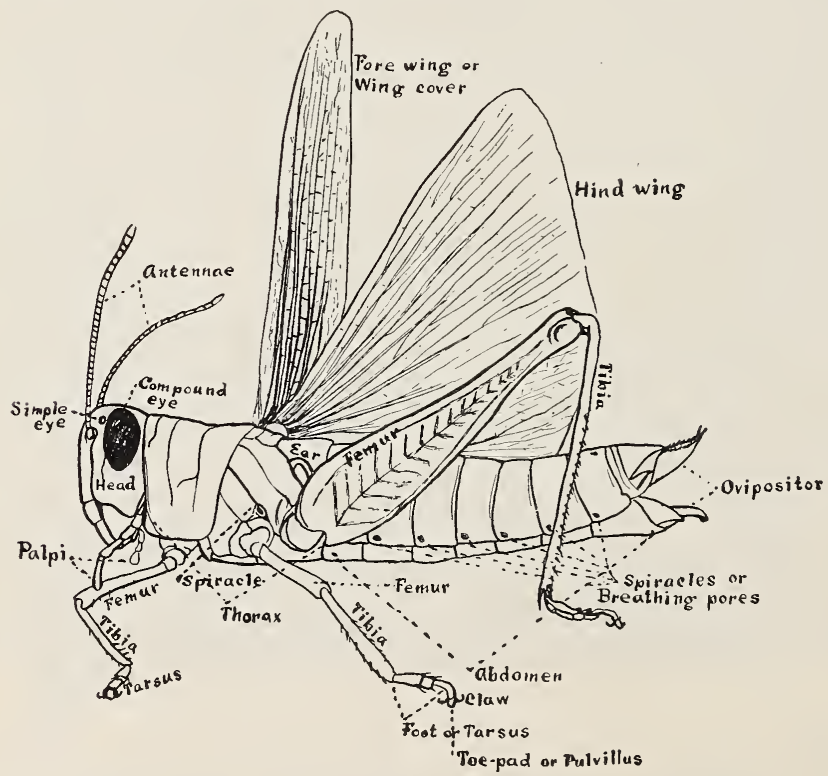

Grasshopper, with the parts of the external anatomy nawed. 


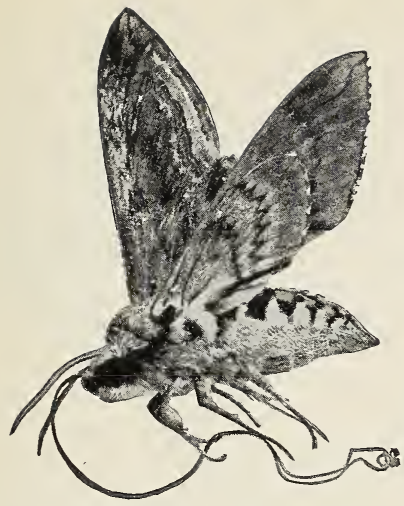

A sphinx moth with the sucking tongue unrolled.

Photo by M. V. Slingerland.

leaves, others have a sucking tube for getting the juices from plants or the blood from animals, and others long delicate tubes for sipping the nectar from flowers.

In the biting insects, the mouthparts consist of an upper lip, the labrum, and under lip, the labium, and two pairs of jaws between them. The upper pair of jaws is called the mandibles and the lower pair, the maxillæ (sing. maxilla). There may be also within the mouth, one or two tongue-like organs. Up.on the maxillæ and upon the lower lip there may also be feelers which are called palpi (sing. palpus). The jaws of insects, when working, do not move up and down, as do ours, but move sidewise like shears. In many of the insects, the children are able to observe the mandibles and the palpi without the aid of a lens.

The thorax is the middle region of the insect body. It is composed of three of the body segments more or less firmly joined together. The segment next the head is called the prothorax, the middle one, the mesothorax, and the hind one, the metathorax. Each of these segments bears a pair of legs and, in the winged insects, the second and third segments bear the wings. Each leg

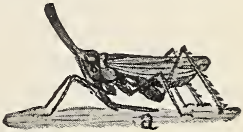

A tree-hopper, showing the mouth as a long, three-jointed sucking tube, at a.

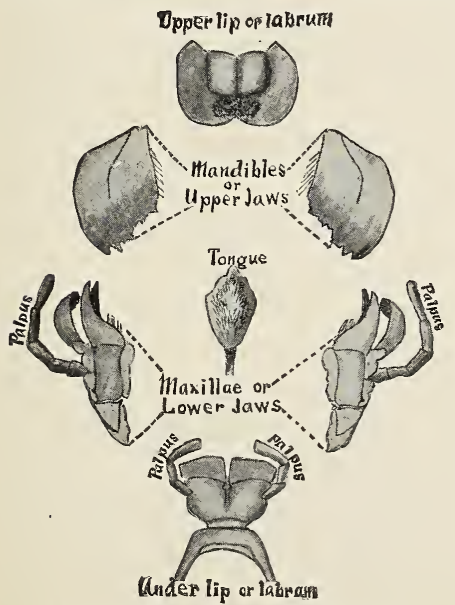

The mouth-parts of a grasshopper izisserted off, enlarged and named. consists of two small segments next to the body, next to them a longer segment, called the femur, beyond this a segment called the tibia, and beyond this the tarsus or foot. The tarsus is made up of a number of segments, varying from one to six, the most common number being five. The last segment of the tarsus usually bears one or two claws.

While we have little to do with the internal anatomy of insects in elementary nature-study, the children should be taught something of the way that insects breathe. The child naturally believes that the insect, like himself, breathes through the mouth, while as a matter of fact, insects breathe through their sides. If we examine almost any insect carefully, we can find along the sides of the body a series of openings. These are called the spiracles, and 
through them the air passes into the insect's body. The number of spiracles varies greatly in different insects. There is, however, never more than one pair on a single segment of the body, and they do not occur on the head. The spiracles, or breathing pores, lead into a system of air tubes which are called tracheæ $\left(\mathrm{tra}^{\prime}-\mathrm{ke}-\mathrm{ee}\right)$, which permeate the insect's body and thus carry the air to every smallest part of its anatomy. The blood of the insect bathes these thin-walled air tubes and thus becomes purified, just as our blood becomes purified by bathing the air tubes of our lungs. Thus, although the insects do not have localized breathing organs, like our lungs, they have, if the expression may be permitted, lungs in every part of their little bodies.

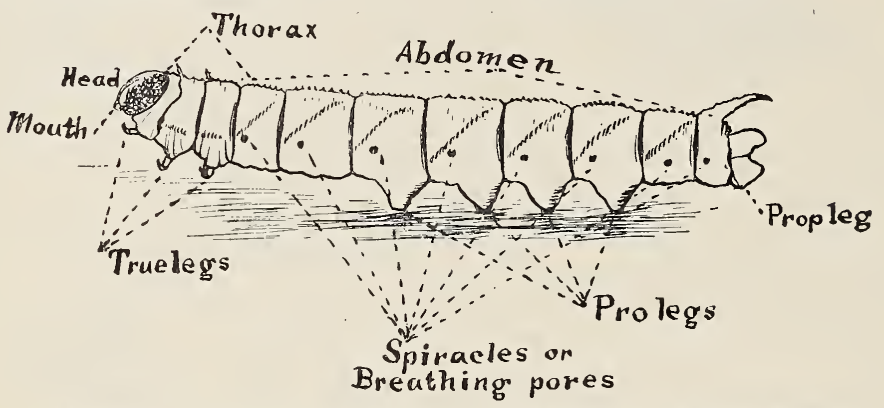

The sphinx caterpillar, with the parts of the external anatomy named.

\section{Summary of Structure of an Insect}

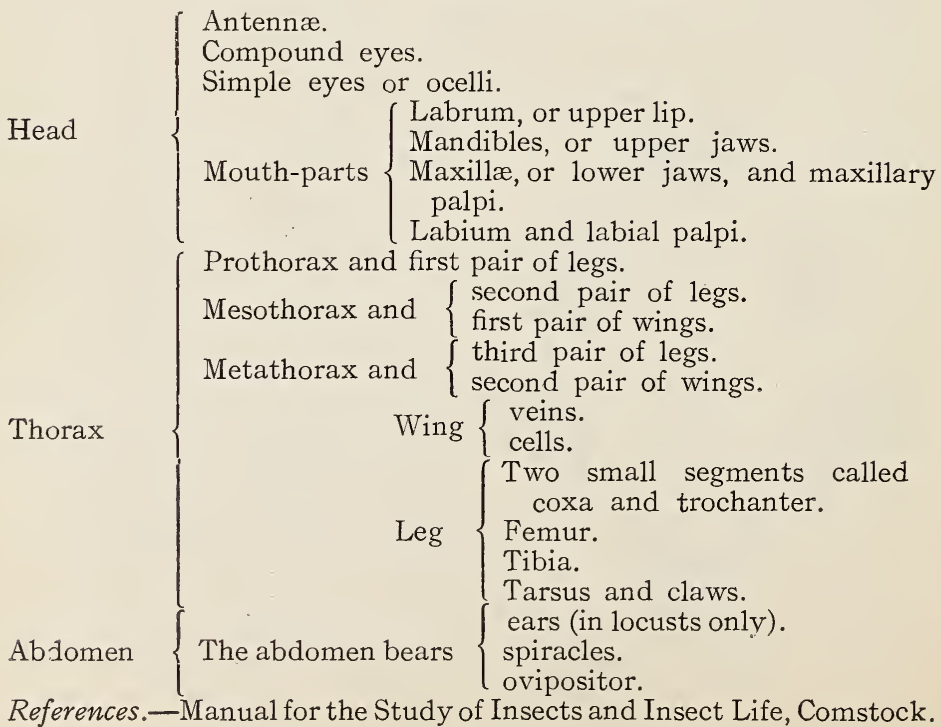




\section{THE BLACK SWALLOW-TAIL BUTTERFLY}

\section{Teacher's Story}

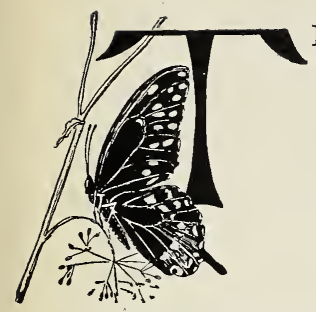

HIS graceful butterfly is a very good friend to the flowers, being a most efficient pollen carrier. It haunts the gardens and sips nectar from all the blossom cups held out for its refreshment; and it is found throughout almost all parts of the United States. The grace of its appearance is much enhanced by the "swallow-tails," two projections from the hind margins of the hind wings. The wings are velvety black with three rows of yellow spots across them, the outer row being little crescents set in the margin of the wing; and each triplet of yellow spots is in the same cell of the wing between the same two veins. The hind wings are more elaborate, for between the two inside rows of yellow spots, there are exquisite metallic blue splashes, more vivid and more sharply outlined toward the inside of the wing and shading off to black at the outside. And just above the inner angle of the hind wing is an orange eye-spot with a black center. On the lower surface of the wings, most of the yellow spots are replaced with orange.

The mother butterfly is larger than her mate and has more blue on her wings, while he has the yellow markings of the hind wings much more conspicuous. She lays her egg, just the color of a drop of honey, on the under surface of the leaf of the food plant. After about ten days there hatches from this egg a spiny little fellow, black and angular, with a saddle-shaped, whitish blotch in the middle of its back. But it would take an elfin rider to sit in this warty, spiny saddle. The caterpillar has six spines on each segment, making six rows of spines, the whole length of the body; the spines on the black portions are black and those on the saddle white, but they all have orange-colored bases.

When little, spiny saddle-back gets ready to change its skin to one more commodious for its increased size, it seeks some convenient spot on the leaf or stem and spins a little silken carpet from the silk gland opening in its under lip; on this carpet it rests quietly for some time, and then the old tight skin splits down the back, the head portion coming off separately. Swelling out to fill its new skin to the utmost, it leaves its cast-off clothes

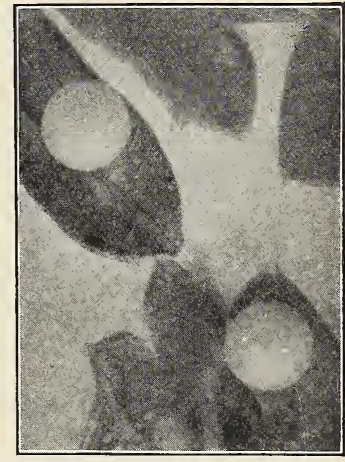

The eggs of the black swallowtail butterfly, enlarged.

Photo-micrograph by M. V. Slingerland. clinging to the silken carpet and marches back to its supper.

But after one of these changes of skin it becomes a very different looking caterpillar, for now it is as smooth as it was formerly spiny; it is now brilliant caraway green, ornamented with roundwise stripes of velvety black; and set in the front margin of each of these stripes are six yellow spots. In shape, the caterpillar is larger toward the head: its true feet have little, sharp claws and look very different from the 
four pairs of prolegs and the hind prop-leg, all of which enable him to hold fast to the stem or the leaf; these fat legs are green, each ornamented with a black, velvety polka-dot.

When we were children we spent hours poking these interesting creatures with straws to see them push forth their brilliant orange horns. We knew this was an act of resentment, but we did not realize that from these horns was exhaled the nauseating odor of caraway which greeted our nostrils. We incidentally discovered that they did not waste this odor upon each other, for once we saw two of the full-grown caterpillars meet on a caraway stem. Neither seemed to know that the other was there until they touched; then both drew back the head and butted each other like billy-goats, Whack! whack! Then both turned laboriously around and hurried off in a

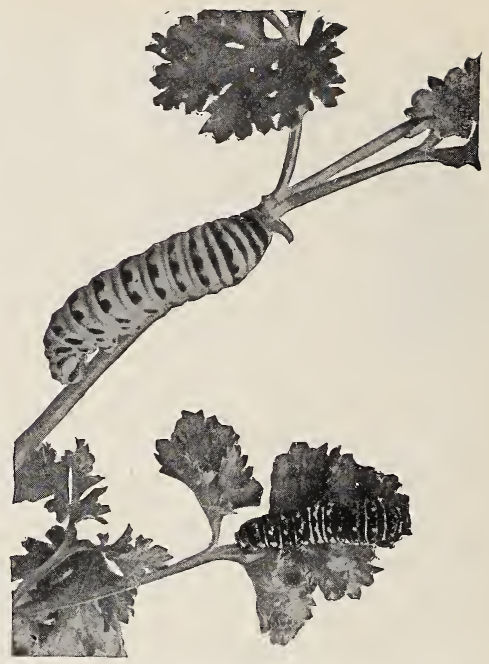

Black swallow-tail caterpillars, showing two stages of growth. The larger one has the scent organs protruded.

Photo by M. V. Slingerland. panic.

The scent organs of these caterpillars are really little Y-shaped pockets in the segment back of the head, pockets full of this peculiar caterpillar perfume. Under the stimulus of attack, the pocket is turned wrong side out and pushed far out making the "horns," and at the same time throwing the strong odor upon the air. This spoils the flavor of these caterpillars as bird food, so they live on in serene peace, never hiding under the leaves but trusting, like the skunk, to a peculiar power of repelling the enemy.

We must admire this caterpillar for the methodical way in which it eats the leaf: Beginning near the base, it does not burn its bridges behind it by eating through the midrib, but eats everything down to the midrib; after it arrives at the tip of the leaf it finishes midrib and all on its return journey, doing a clean job, and finishing everything as it moves along. (See Moths and Butterflies, Dickerson, p. 42.)

When the caterpillar has completed its growth, it is two inches long; it then seeks some sheltered spot, the lower edge of a clapboard or fence rail being a favorite place; it there spins a button of silk which it grasps firmly with its hind prop-leg, and then, with head up, or perhaps horizontal, it spins a strong loop or halter of silk, fastening each end of it firmly to the object on which it rests. It thrusts its head through, so that the halter acts as a sling holding the insect from falling. There it sheds its last caterpillar skin, which shrinks back around the button, revealing the chrysalis which is angular with ear-like projections in front. Then comes the critical moment, for the chrysalis lets go of the button with its caterpillar feet, and trusting to the sling for 
support, pushes off the shrunken skin just shed and inserts the hooks,

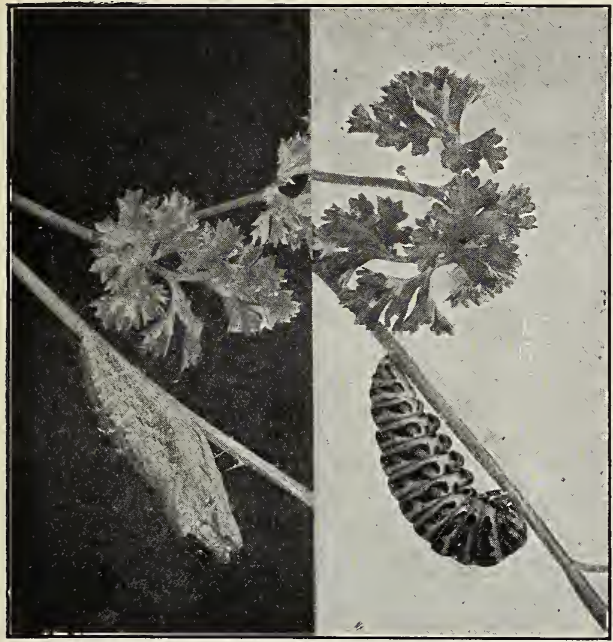

The chrysalis.

Photo by V. Slingerland he caterpillar of the to change to a chrysalis. with which it is furnished, firmly in the button of silk. Sometimes during this process, the chrysalis loses its hold entirely and falls to the ground, which is a fatal disaster. The chrysalis is yellowish brown and usually looks very much like the object to which it is attached, and is thus undoubtedly protected from sight of possible enemies. Then som e day it breaks open, and from it issues a crumpled mass of very damp insect velvet, which soon expands into a beautiful butterfly.

References.-Everyday Butterflies, Scudder; Moths and Butterflies, Dickerson; How to Know the Butterflies, Comstock; Moths and Butterflies, Ballard.

\section{LESSON LXX}

\section{The Black Swallow-Tail Butterfly}

Leading thought-The caterpillars of the swallow-tail butterflies have scent organs near the head which they thrust forth when attacked, thus giving off a disagreeable odor which is nauseating to birds.

Method-In September, bring into the schoolroom and place in the terrarium, or breeding cage, a caraway or parsley plant on which these caterpillars are feeding, giving them fresh food day by day, and allow the pupils to observe them at recess and thus complete the lesson.

\section{The Caterpillar and Chrysalis.}

Observations.- - . Touch the caterpillar on the head with a bit of grass. What does it do? What color are the horns? Where do they come from? Are there two separate horns or two branches of one horn? What odor comes from these horns? How does this protect the caterpillar? Does the caterpillar try to hide under the leaves when feeding? Is this evidence that it is not afraid of birds?

2. Describe the caterpillar as follows: What is its shape? Is it larger toward the head or the rear end? What is its ground color? How is it striped? How many black stripes? How many yellow spots in each 
black stripe? Are the yellow spots in the middle, or at each edge of the stripe?

3. How do the front three pairs of legs look? How do they compare with the prolegs? How many prop-legs are there? What is the color of whe prolegs? How are they marked? Describe the prop-leg. What is its use?

4. Observe the caterpillar eating a leaf. How does it manage so as not to waste any?

5. Have you found the egg from which the caterpillar came? What color is it? Where is it laid?

6. How does the young caterpillar look? What are its colors? How many fleshy spines has it on each segment? Are these white on the white segments and black on the black segments? What is the color of the spines at their base?

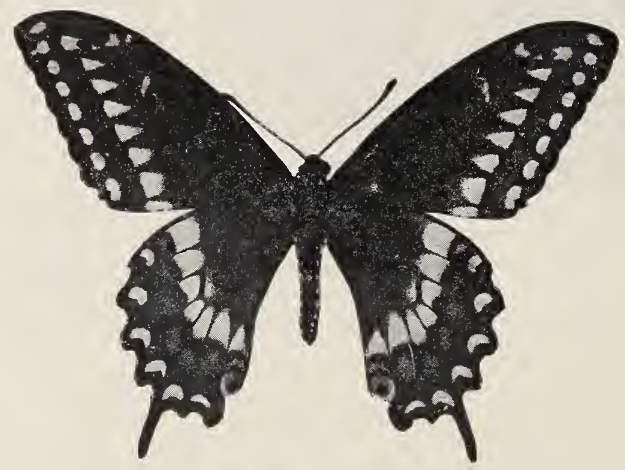

Black swallow-tail butterfly. Photo by M. V. Slingerland.

7. Watch one of these caterpillars shed its skin. How does it prepare for this? How does it spin its carpet? Where does the silk come from? Describe how it acts when shedding its skin?

8. When a caterpillar is full grown, how does it hang itself up to change to a chrysalis? How does it make the silk button? How does it weave the loop or halter? How does it fasten it? When the halter is woven what does the caterpillar do with it? Describe how the last caterpillar skin is shed. How does the insect use its loop or halter while getting free from the molted skin?

9. Describe the chrysalis. What is its general shape? What is its color? Is it easily seen? Can you see where the wings are, within the chrysalis? How is the chrysalis supported?

I0. How does the chrysalis look when the butterfly is about to emerge? Where does it break open? How does the butterfly look at first? 


\section{The Butterfly}

I. Why is this butterfly called the black swallow-tail? What is the ground color of the wings? How many rows of yellow spots on the front wings? Are they all the same shape? How are they arranged between each two veins? Describe the hind wings. What colors are on them that are not on the front wings? Describe where this color is placed. Describe the eye-spot on the hind wing. Where is it? How do the markings on the lower side of the wing differ from those above? How does the ground color differ from the upper side?

2. What is the color of the body of the butterfly? Has it any marks? Has it the same number of legs as the Monarch? Describe its antennæ. Watch the butterfly getting nectar from the petunia blossom and describe the tongue. Where is the tongue when not in use?

3. How does the butterfly pass the winter? How does the mother butterfly differ in size and in markings from her mate?

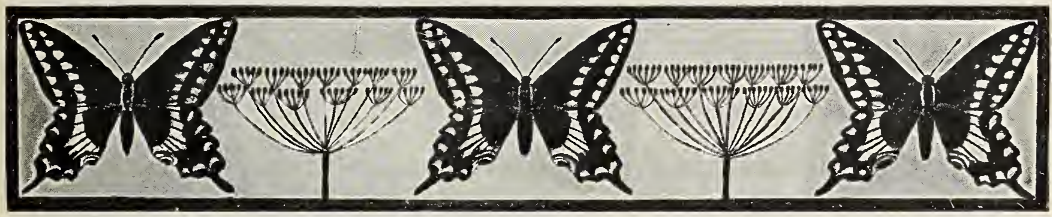

"The 'caraway worms' were the ones that revealed to us the mystery of the pupa and butterfly. We saw one climb up the side of a house, and watched it as with many slow, graceful movements of the head, it wove for itself the loop of silk which we called the 'swing' and which held it in place aftex it changed to a chrysalis. We wondered why such a brilliant caterpillar should change to such a dull-colored object, almost the color of the clapboard against which ii hung. Then, one day, we found a damp, crumpled, black butterfly hanging to the empty chrysalis skin, its wings 'all mussed' as we termed it; and we gazed at it pityingly; but even as we gazed, the crumpled wings expanded and then there came to our childish minds a dim realization of the miracle wrought within that little, dingy, empty shell." 


\section{'The Monarch Butterfly Teacher's Story}

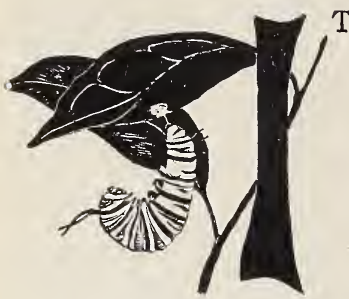

T IS a great advantage to an insect to have the bird problem eliminated, and the monarch butterfly enjoys this advantage to the utmost. Its method of flight proclaims it, for it drifts about in a lazy, leisurely manner, its glowing red making it like a gleaming jewel in the air, a very different flight indeed from the zigzag dodging movements of other butterflies. The monarch has an interesting race history. It is a native of tropic America, and has probably learned through some race instinct, that by following its food plant north with the opening season, it gains immunity from special enemies other than birds, which attack it in some stage in its native haunts. Each mother butterfly follows the spring northward as it advances, as far as she finds the milkweed sprouted. There she deposits her eggs, from which hatch individuals which carry on the migration as far to the north as possible. It usually arrives in New York State early in July. As cold weather approaches, the monarchs often gather in large flocks and move back to the South. How they find their way we cannot understand, since there are among them none of the individuals which pressed northward early in the season.

The very brilliant copperred color of the upper sides of the wings of the monarch is made even more brilliant by the contrasting black markings which outline the veins and border the wings, and also cover the tips of the front wings with a triangular patch; this latter seems to be an especially planned background for showing off the pale orange and

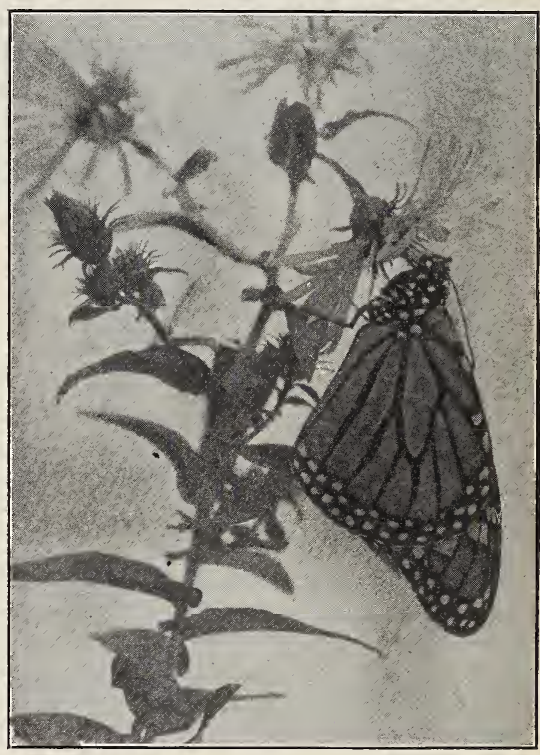

The monarch butterfly. white dots set within it. There are white dots set, two pairs in two rows, between each two veins in the black margin of the wings; and the fringe at the edge of the wings shows corresponding white markings. The hind wings and the front portions of the front wings have, on their lower sides, a ground color of pale yellow, which makes the insect less conspicuous when it alights and folds its wings above its back, upper surfaces together. 
The black veins, on the lower surface of the hind wings, are outlined with white, and the white spots are much larger than on the upper surface. The body is black, ornamented with a few pairs of white spots above and with many large white dots below. The chief distinguishing characteristic of insects, is the presence of six legs; but in this butterfly, the front legs are so small that they scarcely look like legs.

It is easy to observe the long, coiled tongue of the butterfly. If the act is done gently, the tongue may be uncoiled by lifting it out with a pin.

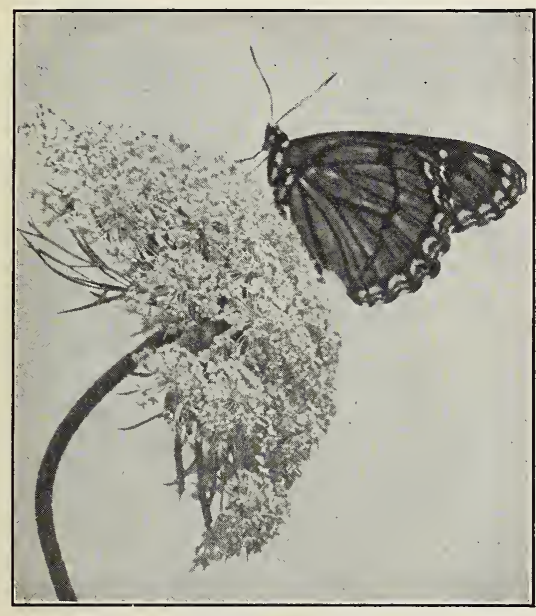

The viceroy butterfly.

Note the black band on the hind wings which distinguishes it from the monarch, which it imitates in color and markings. To see a butterfly feeding upon nectar, is a very interesting process and may be observed in the garden almost any day. I have also observed it indoors, by bringing in petunias and nasturtiums for my imprisoned butterflies, but they are not so likely to eat when in confinement. The antennæ are about twothirds as long as the body and each ends in a long knob; this knob, in some form, is what distinguishes the antennæ of the butterflies from those of moths. The male monarch has a black spot upon one of the veins of the hind wing; this is a perfume pocket and is filled with what are called scent scales; these are scales of peculiar shape which cover the wing at this place and give forth an odor, which we with our coarse sense of smell cannot perceive; but the lady monarch is attracted by this odor. The male monarch may be described to the children, as a dandy carrying a perfume pocket to attract his sweetheart.

It is very interesting to the pupils if they are able to see a bit of the butterfly's wing through a three-fourths objective; the covering of scales, arranged in such perfect rows, is very beautiful and also very wonderful. The children know that they get dust upon their fingers from butterflies' wings, and they should know that each grain of this dust is an exquisite scale with notched edges and a ribbed surface.

The monarch is, for some reason unknown to us, distasteful to birds, and its brilliant colors are an advertisement to all birds of discretion, that here is an insect

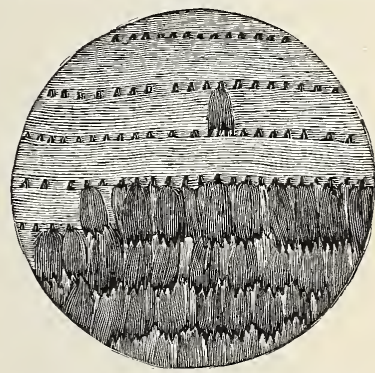

The scales on a butterfly's wing, as seen through a microscope. which tastes most disagreeably and that, therefore, should be left severely 
alone. There is another butterfly called the viceroy, which has taken advantage of this immunity from bird attack on the part of the monarch and has imitated its colors in a truly remarkable way, differing from it only in being smaller in size and having a black band across the middle of the hind wing. (See The Ways of the Six Footed, "A Sheep in Wolf's Clothing"').

The milkweed caterpillar, which is the young of the monarch butterfly, is a striking object, and when fully grown is about two inches long. The milkweed is a succulent food and the caterpillar may mature in eleven days; it is a gay creature, with ground color of green and cross stripes of yellow and black. On top of the second segment, back of the head, are two long, slender whiplash-like organs, and on the seventh segment of the abdomen is a similar pair. When the caterpillar is frightened, the whiplashes at the front of the body twitch excitedly; when it walks, they move back and forth. Those at the rear of the body are more quiet and not so expressive of caterpillar emotions. These filaments are undoubtedly of use in frightening away the little parasitic flies, that lay their eggs upon the backs of caterpillars; these eggs hatch into little grubs that feed upon the internal fatty portions of the caterpillar and bring about its death through weakness. I remember well when I was a child, the creepy feeling with which I beheld these black and yellow-ringed caterpillars waving and

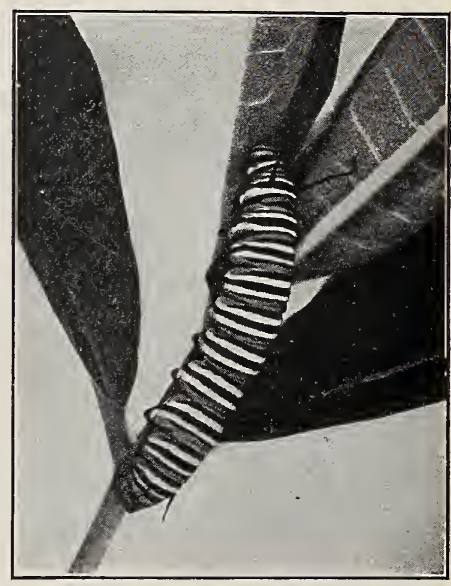

The monarch caterpillar.

Photo by M. V. Slingerland. lashing their whips back and forth after I had disturbed them; if the ichneumon flies were as frightened as I, the caterpillars were surely safe.

The caterpillar will feed upon no plant except milkweed; it feeds both day and night, with intervals of rest, and when resting, hides beneath the leaf. Its striking colors undoubtedly defend it from birds, because it is

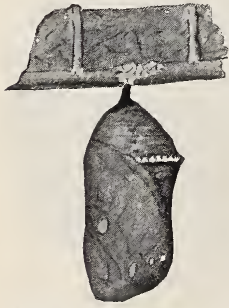

Monarch chrysalis. A jewel of living jade and gold. as distasteful to them as is the butterfly. However. when frightened, these caterpillars fall to the ground where their stripes make them very inconspicuous among the grass and thus perhaps save them from the attack of animals less fastidious than birds. These caterpillars, like all others, grow by shedding the skeleton skin as often as it becomes too tight.

The monarch chrysalis is, I maintain, the most beautiful gem in Nature's jewel casket; it is an chlong jewel of jade, darker at the upper end and shading to the most exquisite whitish green below; outlining this lower paler portion are shining flecks of gold. If we look at these gold flecks. with a lens, we cannot but believe that they are bits of polished gold-foil. There 


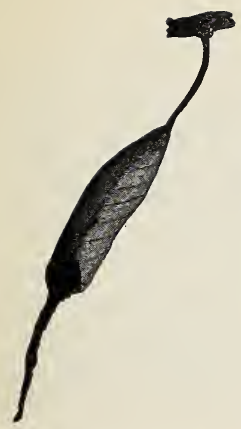

The winter home of the viceroy caterpillar.

may be other gold dots also, and outlining the apex of the jewel, is a band of gold with a dotted lower edge of jet; and the knob at the top, to which the silk which suspends the chrysalis is fastened, is also jet. The chrysalis changes to a darker blue-green after two days, and black dots appear in the gold garniture. As this chrysalis is usually hung to the under side of a fence rail or overhanging rock, or to a leaf, it is usually surrounded by green vegetation, so that its green color protects it from prying eyes. Yet it is hardly from birds that it hides; perhaps its little gilt buttons are a hint to birds that this jewel is not palatable. As it nears the time for the butterfly to emerge, the chrysalis changes to a duller and darker hue. The butterfly emerges about twelve days after the change to a chrysalis.

References-Every Day Butterflies, Scudder; How to Know the Butterflies, Comstock; Moths and Butterflies, Dickerson; Ways of the Six Footed, Comstock; Moths and Butterflies, Ballard.

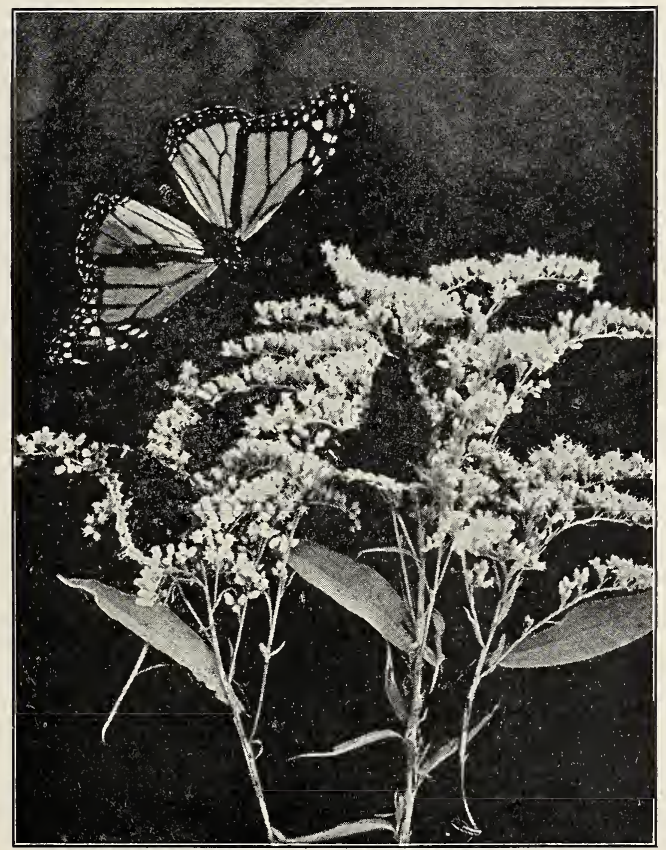

The male monarch butterfly, showing the scent pockets on the hind wings.

Photo by M. V. Slingerland. 


\section{LESSON LXXI}

\section{The Monarch Butterfly}

Leading thought-The monarch butterfly migrates northward, every spring and summer, moving up as fast as milkweed appears, so as to give food to its caterpillar; and it has often been noticed migrating back southward in the autumn in large swarms. This insect is distasteful to birds in all its stages. Its chrysalis is one of the most beautiful objects in all nature.

Method-This lesson should be given in September, while yet the caterpillars of the monarch may be found feeding upon milkweed, and while there are yet many specimens of this gorgeous butterfly to be seen. The caterpillars may be brought in, on the food plant, and their habits and performances studied in the schoolroom; but care should be taken not to have the atmosphere too dry.

\section{The Butterfly}

Observations-r. How can you tell the monarch butterfly from all others? What part of the wings is red? What portions are black? What portions are white? What are the colors and markings on the lower side of the wings? What is the color of the body and how is it ornamented?

2. Is the flight of the monarch rapid or slow and leisurely? Is it a very showy insect when flying? Are its colors more brilliant in the sunshine when it is flying than at any other time? Why is it not afraid of birds?

3. When the butterfly alights, how does it hold its wings? Do you think it is as conspicuous when its wings are folded as when they are open?

4. Can you see the butterfly's tongue? Describe the antennæ. How do they differ from the antennæ of moths? How many legs has this butterfly? How does this differ from other insects? Note if you can see any indications of front legs.

5. Is there on the butterfly you are studying, a black spot near one of the veins on each hind wing? Do you know what this is? What is it for?

6. Why are the striking colors of this butterfly a great advantage to it? Do you know of any other butterfly which imitates it and thus gains an advantage?

\section{The Monarch Caterpillar}

x. Where did you find the Monarch caterpillar? Was it feeding below or above on the leaves? Describe how it eats the milkweed leaf.

2. What are the colors and the markings of the caterpillar? Do you think these make it conspicuous?

3. How many whip-lash shaped filaments do you find on the caterpillar? On which segments are they situated? Do these move when the caterpillar walks or when it is disturbed? Of what use are they to the caterpillar?

4. Do you think this caterpillar would feed upon anything except milkweed? Does it rest, when not feeding, upon the upper or the lower surface of the leaves? Does it feed during the night as well as the day?

5. If disturbed, what does the caterpillar do? When it falls down among the grass how do its cross stripes protect it from observation? do.

6. Tell all the interesting things which you have seen this caterpillar 


\section{The Chrysalis}

I. When the caterpillar gets ready to change to a chrysalis what does it do? How does it hang up? Describe how it sheds its skin.

2. Describe the chrysalis. What is its color? How and where is it ornamented? Can you see, in the chrysalis, those parts which cover the wings of the future butterfly?

3. To what is the chrysalis attached? Is it in a position where it does not attract attention? How is it attached to the object?

4. After three or four days, how does the chrysalis change in color? Observe, if you can, the butterfly come out from the chrysalis, noting the following points: Where does the chrysalis skin open? How does the butterfly look when it first comes out? How does it act for the first two or three hours? How does the empty chrysalis skin look?

\section{A BUTTERFLY AT SEA}

Far out at sea-the sun was high,

While veered the wind and flapped the sail;

We saw a snow-white butterfly

Dancing before the fitful gale

Far out at sea.

The little wanderer, who had lost

His way, of danger nothing knew;

Settled a while upon the mast;

Then fluttered o'er the waters blue

Far out at sea.

Above, there gleamed the boundless sky;

Beneath, the boundless ocean sheen;

Between them danced the butterfly,

The spirit-life of this fair scene,

Far out at sea.

The tiny soul that soared away,

Seeking the clouds on fragile wings,

Lured by the brighter, purer ray

Which hope's ecstatic morning brings-

Far out at sea.

Away he sped, with shimmering glee,

Scarce seen, now lost, yet onward borne!

Night comes with wind and rain, and he

No more will dance before the morn,

Far out at sea.

He dies, unlike his mates, I ween, Perhaps not sooner or worse crossed;

And he hath felt and known and seen

A larger life and hope, though lost

Far out at sea.

-R. H. HORne. 


\section{THE ISABELLA TIGER MOTH OR WOOLLY BEAR}

\section{Teacher's. Story}

"Brown and furry, Caterpillar in a hurry, Take your walk

To the shady leaf or stalk, Or what not,
Which may be the chosen spot, No toad spy you, Hovering bird of prey pass by you: Spin and die,

To live again a butterfly."

-Christina Rosetti.

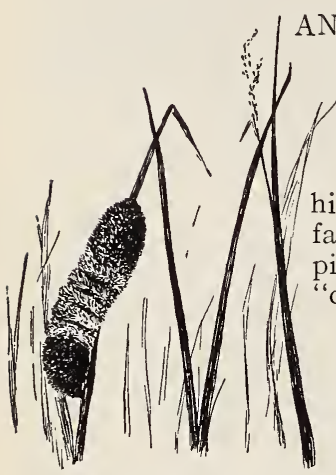

ANY times during autumn, the children find and bring in the very noticeable caterpillar which they call the "woolly bear." It seems to them a companion V of the road and the sunshine; it usually seems in a hurry, and if the children know that it is thus hastening to secure some safe place in which to hide during the season of cold and snow, they are far more interested in its future fate. If the caterpillar is already curled up for the winter, it will "come to" if warmed in the hand or in the sunshine.

The woolly bear is variable in appearance; sometimes there are five of the front segments black, four of the middle reddish brown, and three of the hind segments black. In others there are only four front segments black, six reddish ones, and two that are black at the end of the body; there are still other variations, so that each individual will tell its own story of color. There are really thirteen segments in this caterpillar, not counting the head; but the last two are so joined that probabiy the children will only count twelve. There are a regular number of tubercles on each side of each segment, and from eacii of these arises a little rosette of hairs; but the tubercles are packed so closely together, that it is difficult for the children to see how many rosettes there are on each side. While the body of the caterpillar looks as if it were covered with evenly clipped fur, there are usually a few longer hairs on the rear segment.

There is a pair of true legs on each of the three front segments which form the thorax, and there are four pairs of prolegs. All of the segments behind the front three, belong to the abdomen, and the prolegs are on the $3 \mathrm{~d}, 4$ th, 5 th and 6 th abdoninal segments; the prop-leg is at the rear end of the body. The true legs of this caterpillar have little claws, and are as shining as if encased in patent leather; but the prolegs and propleg are merely prolongations of the sides of the body to assist the insect in holding to the leaf. The yellow spot on either side of the first segment is a spiracle; this is an opening leading into the air tubes within the body, around which the blood flows and is thus purified. There are no spiracles on the second and third segments of the thorax, but eight of the abdominal segments have a spiracle on either side.

The woolly bear's head is polished black; its antennæ are two tiny, yellow projections which can easily be seen with the naked eye. The eyes are too small to be thus seen; because of its minute eyes, the woolly bear cannot see very far and, therefore, it is obliged to feel its way. It does this by stretching out the front end of the body and reaching in every 


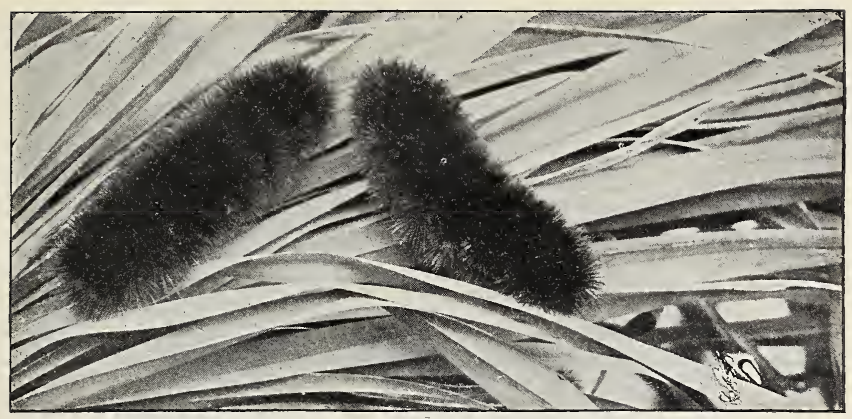

Woolly bears.

Photo by M. V. Slingerland.

direction, to observe if there is anything to cling to in its neighborhood. When we try to seize the woolly bear, it rolls up in a little ball, and the hairs are so elastic that we take it up with great difficulty. These hairs are a protection from the attacks of birds which do not like bristles for food; and when the caterpillar is safely rolled up, the bird sees only a little bundle of bristles and lets it alone. The woolly bear feeds upon many plants, grass, clover, dandelion and others. It does not eat very much after we find it in autumn, because its growth is completed. The woolly bear should be kept in a box which should be placed out of doors, so that it may be protected from storms but have the ordinary winter temperature. Keeping it in a warm room during the winter often proves fatal.

Normally, the woolly bear does not make its cocoon until April or May. It finds some secluded spot in the fall, and there curls up in safety for the long winter nap; when the warm weather comes in the spring, it makes its cocoon by spinning silk about itself; in this silk are woven the hairs which it sheds easily at that time, and the whole cocoon

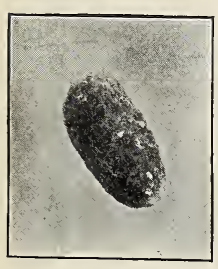

The cocoon of the woolly bear.

Photo by M. V. Slingerland. seems made of felt. It seems amazing that such a large caterpillar can spin about itself and squeeze itself into such a small cocoon; and it is quite as amazing to see the smooth little pupa within the cocoon, in which is condensed all that was essential of the caterpillar. Sometimes when the caterpillars are kept in a warm room, they make their cocoons in the fall, but this is not natural.

The issuing of the moth from the cocoon is an interesting lesson for the last of May. The size of the moth which comes from the cocoon is quite comparable as a miracle with the size of the caterpillar that went into it. The moth is in color dull, grayish, tawny yellow with a few black dots on the wings; sometimes the hind wings are tinted with dull orange-red. On the middle of the back of the moth's body there is a row of six black dots; and on each side of the body is a similar row. The legs are reddish above and tipped with black. The antennæ are small and inconspicuous. 
The moths are night fliers, and the mother moth seeks some plant on which to lay her eggs, that will be suitable food for the little caterpillar as soon as it is hatched.

References-Moths and Butterflies, Ballard.

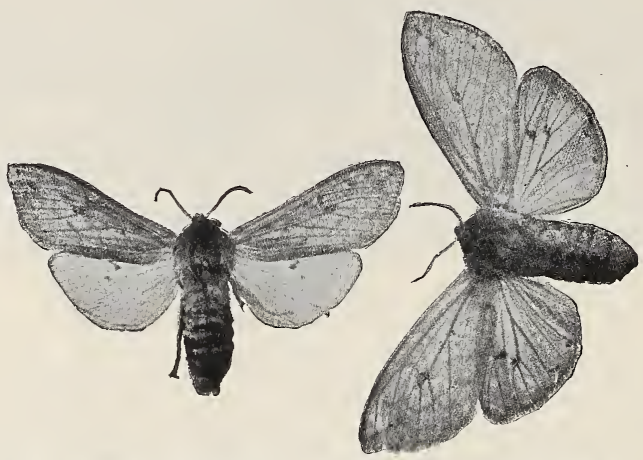

The Isabella tiger-moths, the adults of the woolly bear. The larger is the female.

Photo by M. V. Slingerland.

\section{LESSON LXXII}

\section{The Isabella Tiger-Moth, or Woolly Bear}

Leading thought-When we see the woolly bear hurrying along in the fall, it is hunting for some cozy place in which to pass the winter. It makes its cocoon of silk woven with its own hair. In May, it comes forth a yellowish moth with black dots on its wings.

Method-Have the children bring in woolly bears as they find them, place them in boxes or breeding jars which have grass or clover growing in them. The children can handle the caterpillars while they are studying them, and then they should be put back into the breeding jars and be set out of doors where they can have natural conditions; thus the entire history may be studied.

\section{The Caterpillar}

Observations-I. How can you tell the woolly bear from all other caterpillars? Are they all colored alike? How many segments of the body are black at the front end? How many are red? How many segments are black at the rear end of the body? How many segments does this make in all?

2. Look closely at the hairs of the woolly bear. Are they set separately or in rosettes? Are any of the hairs of the body longer than others or are they all even?

3. Can you see, just back of the head, the true legs with their little sharp claws? How many are there?

4. Can you see the fleshy legs along the sides of the body? How many are there of these? 
5. Can you see the prop-leg, or the hindmost leg of all? Of what use to the caterpillar are these fleshy legs?

6. Describe the woolly bear's head. How does it act when eating?

7. Can you see a small, bright yellow spot on each side of the segment just behind the head? What do you suppose this is? Can you see little openings along each side of all the segments of the body, except the second and third? What are they? Describe how the woolly bear breathes.

8. On what does the woolly bear feed? If you can find a little woolly bear, give it fresh grass to eat and see how it grows. Why does it shed its skin?

9. When the woolly bear is hurrying along, does it lift its head and the front end of its body now and then? Why does it do this? Do you think it can see far?

Io. What does the woolly bear do when you try to pick it up? Do you find you can pick it up easily? Do you think that these stiff hairs protect woolly bear from its enemies? What are its enemies?

II. Where should the woolly bear be kept in winter to make it comfortable?

\section{The Cocoon}

I. When does the woolly bear make its cocoon?

2. Of what material is it made? How does the woolly bear get into its cocoon?

3. What happens to it inside the cocoon?

4. Cut open a cocoon and describe how woolly bear looks now.

\section{The Moth}

I. Where did the moth come from?

2. How did it come out of the cocoon? See if you can find the empty pupa case in the cocoon.

3. What is the color of the moth and how is it marked? Are the front and hind wings the same color?

4. What are the markings and colors of the body? Of the legs?

5. What do you think that the Mother Isabella will do, if you give her liberty?

The mute insect, fix't upon the plant

On whose soft leaves it hangs, and from whose cup

Drains imperceptibly its nourishment,

Endear'd my wanderings.

-WORDSWORTH.

Before your sight,

Mounts on the breeze the butterfly, and soars,

Small creature as she is, from earth's bright flowers

Into the dewy clouds.

-WORDSWORTH. 


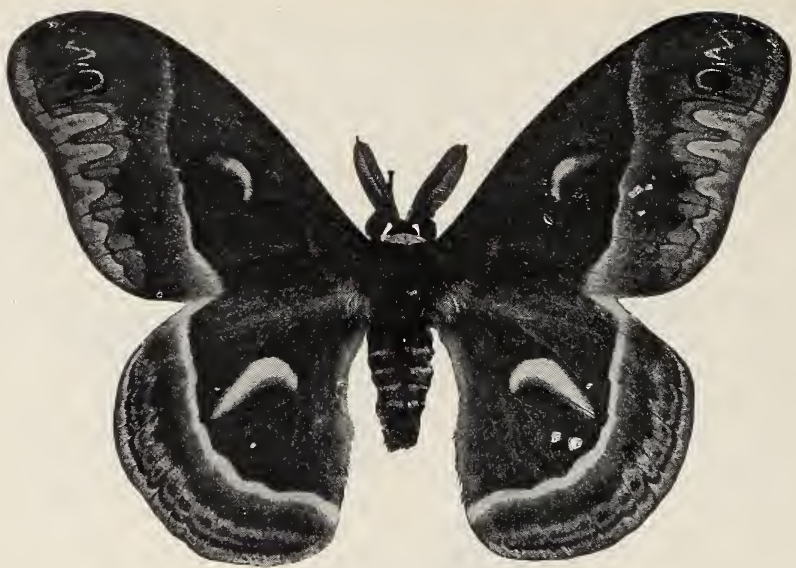

The cecropia moth.

Photo by M. V. Slingerland.

\section{THE CECROPIA}

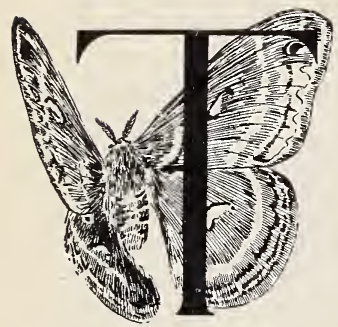

\section{Teacher's Story}

$\mathrm{HE}$ silk-worm which gives us the silk of com. merce, has been domesticated for centuries in China. Because of this domestication, it is willing to be handled and is reared successfully in captivity, and has thus come to be the source of most of our silken fabrics. However, we have in America native silk-worms which produce a silk that is stronger and makes a more lustrous cloth than does that made from the Chinese species. But we have never had the time and the patience, here in America, to domesticate these giant silk-worms of ours, and so they are, as yet, of no commercial importance.

The names of our common native silk-worms are: The cecropia, promethea, polyphemus, and luna. In all of these species the moths are large and beautiful, attracting the attention of everyone who sees them. The caterpillars are rarely found, since their varied green colors render them inconspicuous among leaves on which they feed. None of the caterpillars of the giant silk-worms occur in sufficient numbers to injure the foliage of our trees to any extent; they simply help nature tc do a little needful pruning. All of the moths are night flyers and are, therefore, seldom seen except by those who are interested in the visitors to our street lights.

The cecropia is the largest of our giant silk-worms, the wings of the moth expanding sometimes six and one-half inches. It occurs from the Atlantic Coast to the Rocky Mountains. 
The cecropia cocoon is found most abundantly on our orchard and shade trees; it is called by the children the "cradle cocoon," since it is shaped like a hammock and hung close below a branch, and it is a very

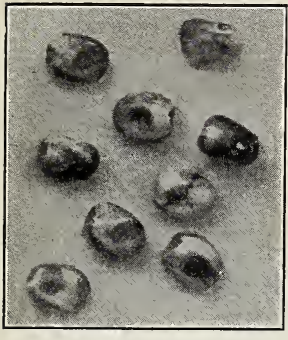

The eggs of the cecropia moth.

Photo by M. V. Slingerland. safe shelter for the helpless creacure within it. It is made of two walls of silk, the outer one being thick and paperlike and the inner one thin and firm; between these walls is a matting of loose silk, showing that the insect knows how to make a home that will protect it from winter weather. It is a clever builder in another respect, since at one end of the cocoon it spins the silk lengthwise instead of crosswise, thus making a valve through which the moth can push, when it issues in the spring. It is very interesting to watch one of these caterpillars spin its cocoon. It first makes a framework by stretching a few strands of silk, which it spins from a gland opening in the lower lip; it then makes a loose net-work upon the supporting strands, and then begins laying on the silk by moving its head back and forth, leaving the sticky thread in the shape of connecting M's or of figure 8's. Very industriously does it work, and after a short time it is so screened by the silk, that the rest of its performance remains to us a mystery. It is especially mysterious, since the inner wall

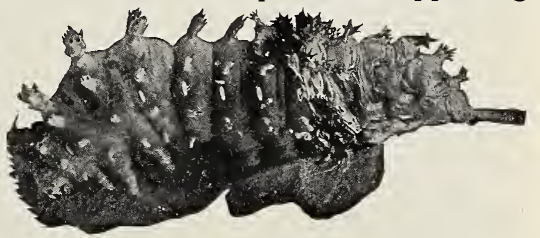

The cecropia caterpillar molting. Photo by M. V. Slingerland. of the cocoon encloses so small a cell that the caterpillar is obliged to compress itself in order to fit within it. This achievement would be something like that of a man who should build around

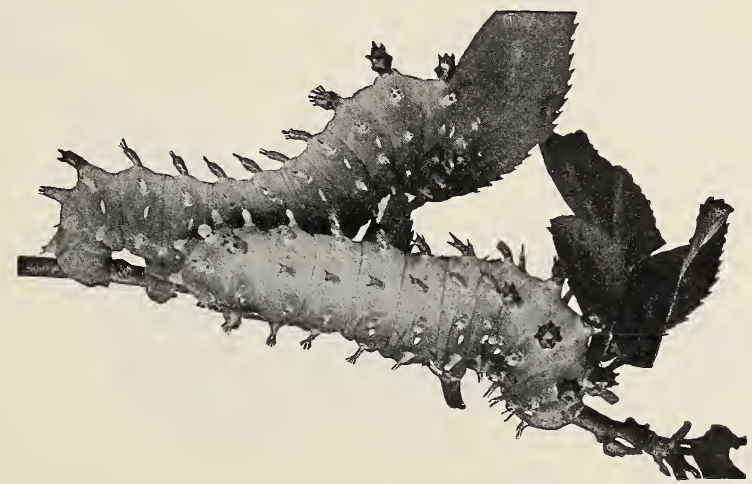

Full-grown cecropia caterpillars.

Photo by M. V. Slingerland. 
himself a box only a few inches longer, wider and thicker than himself. After the cocoon is entirely finished, the caterpillar sheds its skin for the last time and changes into a pupa.

Very different, indeed, does the pupa look from the brilliant colored, warty caterpillar. It is compact, brown, oval and smooth, with ability to move but very little when disturbed. The cases which contain the wings, which are later to be the objects of our admiration, are now folded down like a tight cape around the body; and the antennæ, like great feathers, are outlined just in front of the wing cases. There is nothing more wonderful in all nature than the changes which are worked within one of these little, brown pupa cases; for within it, processes go on which change the creature from a crawler among the leaves to a winged inhabi-

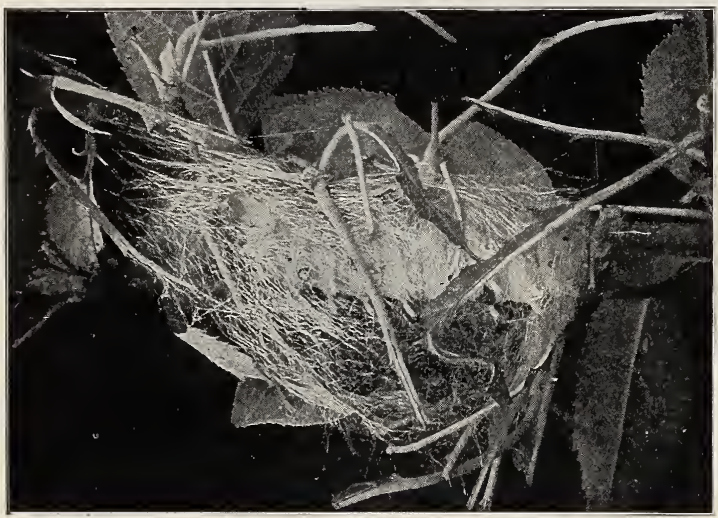

Cecropia caterpillar weaving its cocoon. Photo by M. V. Slingerland. tant of the air. When we see how helpless this pupa is, we can understand better how much the strong silken cocoon is needed for protection from enemies, as well as from inclement weather.

In spring, usually in May, after the leaves are well out on the trees, the pupa skin is shed in its turn, and out of it comes the wet and wrinkled moth, its wings all crumpled, its furry, soft body very untidy; but it is only because of this soft and crumpled state that it is able to push its way out through the narrow door into the outer world. It has, on each side of its body just back of the head, two little horny hooks that help it to work its way out. It is certainly a sorry object as it issues, looking as if it had been dipped in water and had been squeezed in an inconsiderate hand. But the wet wings soon spread, the bright antennæ stretch out, the furry body becomes dry and fluffy, and the large moth appears in all its perfection. The ground color of the wings is a dusky, grayish brown while the outer margins are clay colored; the wings are crossed, beyond the middle, by a white band which has a broad outside margin of red. There is a red spot near the apex of the front wing, just outside of the zigzag white line; each wing bears, near its center, a crescent-shaped white spot bordered with red. But though it is so large, it does not need to eat; the caterpillar did all the eating that was necessary for the whole life of the insect; the mouth of the moth is not sufficiently perfected to take food.

When the cecropia caterpillar hatches from the egg, it is about a quarter of an inch long and is black; each segment is ornamented 
with six spiny tubercles. Like all other caterpillars, it has to grow by shedding its horny, skeleton skin, the soft skin beneath stretching to give more room at first, then finally hardening and being shed in its turn. This first molt of the cecropia caterpillar occurs about four days after it is hatched, and the caterpillar which issues looks quite different than

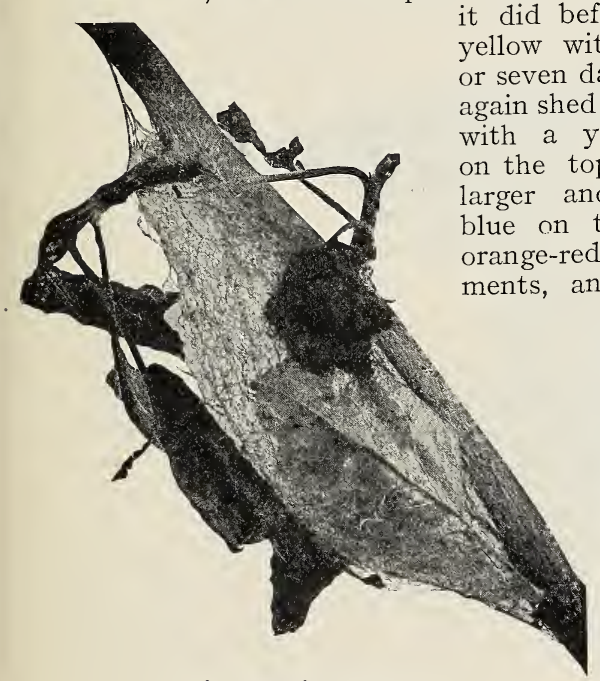

A cecropia cocoon.

Photo by M. V. Slingerland. it did before; it is now dull orange or yellow with black tubercles. After six or seven days more of feeding, the skin is again shed and now the caterpillar appears with a yellow body; the two tubercles on the top of each segment are now larger and more noticeable. They are blue on the first segment, large and orange-red on the second and third segments, and greenish blue with blackish spots and spines on all the other segnients except the eleventh, which has on top, instead of a pair of tubercles, one large, yellow tubercle, ringed with black. The tubercles along the side of the insect are blue during this stage. The next molt occurs five or six days later; this time the caterpillar is bluish green in color, the large tubercles on the second and third segments being deep orange, those on the upper part of the other segments yellow, except those on the first and last segments, which are blue. All the other tubercles along the sides are blue. After the fourth molt it appears as an enormous caterpillar, often attaining the length of three inches, and is as

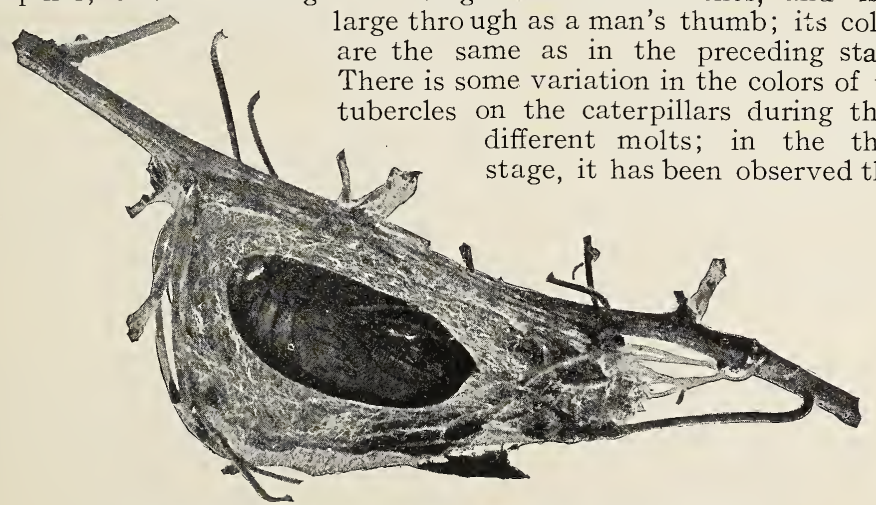

The cecropia cocoon cut open, showing the pupa within it.

Photo by M. V. Slingerland. 
the tubercles usually blue are sometimes black. After the last molt the caterpillar eats voraciously for perhaps two weeks or longer and then begins to spin its cocoon.

References-Moths and Butterflies, Ballard; Moths and Butterflies, Dickerson; Caterpillars and their Moths, Elliot and Soule.

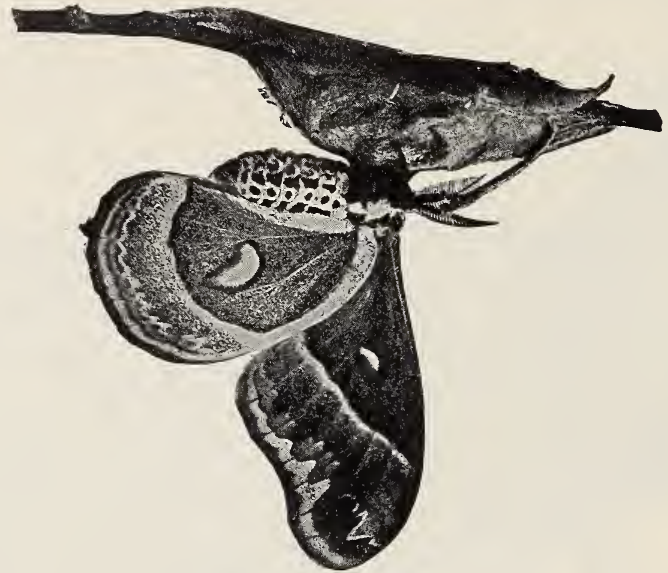

Just out of the cocoon.

Photo by M. V. Slingerland.

\section{LESSON LXXII}

\section{The Cecropia}

Leading thought-The cecropia moth passes the winter as a pupa in a cocoon which the caterpillar builds out of silk for the purpose. In the spring the moth issues and lays her eggs on some tree, the leaves of which the caterpillar relishes. The caterpillars are large and green with beautiful blue and orange tubercles.

Method-It is best to begin with the cocoons, for these are easily found after the leaves have fallen. These cocoons if kept in the schoolroom should be thoroughly wet at least once a week. However, it is better to keep them in a box out of doors where they can have the advantage of natural moisture and temperature; and from those that are kept outside the moths will not issue, until the leaves open upon the trees and provide food for the young caterpillars when the eggs hatch.

\section{The Cocoon}

Observations-I. How does the cocoon look on the outside? What is its general shape? To what is it fastened? Is it fastened to the lower or the upper side of a twig? Are there any dried leaves attached to it?

2. Where do you find cecropia cocoons? How do they look on the tree? Are they conspicuous?

3. Cut open the cocoon, being careful not to hurt the inmate. Can you see that it has an outer wall which is firm? What lies next to this? 
Describe the wall next to the pupa. How does this structure protect the pupa from changes of temperature and dampness?

4. Is the outside covering easy to tear? What birds are strong enough to tear this cocoon apart?

5. Are both ends of the cocoon alike? Do you find one end where the silk is not woven across but is placed lengthwise? Why is this so? Do you think that the moth can push out at this end better than at the other? Do you think the caterpillar, when it wove the cocoon, made it this way so that the moth could get out easily?

\section{The Pupa}

I. Take a pupa out of a cocoon carefully and place it on cotton in a wide-mouthed fruit jar where it may be observed. Can the pupa move at all? Is it unable to defend itself? Why does it not need to defend itself?

2. Can you see in the pupa the parts that will be the antennæ and the mouth?

3. Describe how the wing coverings look. Count the rings in the abdomen.

4. Why does the pupa need to be protected by a cocoon?

\section{The Moth}

I. What is the first sign which you discover that the moth is coming out of the cocoon? Can you hear the little scratching noise? What do you suppose makes it? How does the moth look when it first comes out? If it were not all soft and wet how could it come out from so small an opening?

2. Describe how the crumpled wings spread out and dry. How does the covering of the wings change in looks?

3. Make a water-color drawing or describe in detail the fully expanded moth, showing the color and markings of wings, body and antennæ.

4. Do the moths eat anything? Why do they not need to eat?

5. If one of the moths lays eggs, describe the eggs, noting color, size and the way they are placed.

\section{The Caterpillar}

I. On what do you find the cecropia caterpillar feeding? Describe its actions while feeding.

2. What is the color of the caterpillar? Describe how it is ornamented.

3. Can you see the breathing pores, or spiracles, along the sides of the body? How many of these on each segment? How do they help the caterpillar to breathe?

4. Describe the three pairs of true legs on the three segments just back of the head. Do these differ in form from the prolegs along the sides of the body? What is the special use of the prolegs? Describe the propleg which is the hindmost leg of all.

5. Do you know how many times the cecropia caterpillar sheds its skin while it is growing? Is it always the same color?

6. Watch the caterpillar spin its cocoon, describe how it begins and how it acts as long as you can see it. Where does the silk come from? 


\section{THE PROMETHEA}

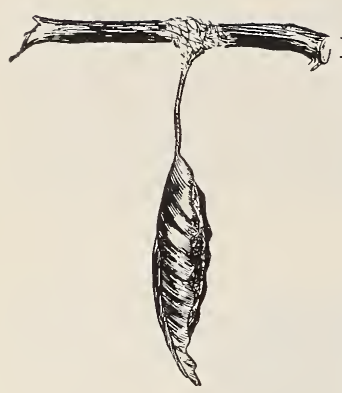

\section{Teacher's Story}

$\mathrm{HE}$ promethea is not so large as the cecropia, although the female resembles the latter somewhat. It is the most common of all our giant silk-worms. Its caterpillars feed upon wild cherry, lilac, ash, sassafras, buttonwood and many other forest trees.

During the winter, leaves may often be seen hanging straight down from the branches of wild cherry, lilac and ash. If these leaves are examined, they will be found to be wrapped around a silken case containing the pupa of the promethea. It is certainly a canny insect which hides itself during the winter in so good a disguise, that only the very wisest of birds ever suspect its presence. When the promethea caterpillar begins to spin, it selects a leaf and covers the upper side with silk, then it covers the petiole with silk, fastening it with a strong band to the twig, so that not even most violent winter winds will be able to tear it off. Then it draws the two edges of the leaf about itself like a cloak as far as it will reach, and inside this folded leaf it makes its cocoon, which always has an opening in the shape of a conical valve at the upper end, through which the moth

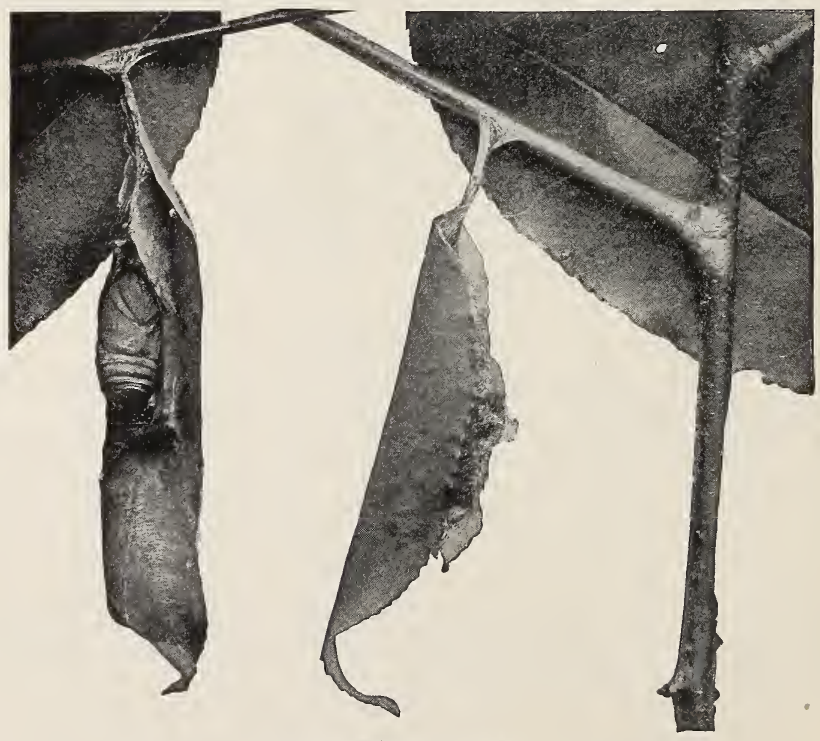

Promethea cocoons.

Note how the leaves are fastened by silk to the twigs. Photo by M. V. Slingerland. 
may emerge in the spring. This caterpillar knows more botany than some people do, for it makes no mistake in distinguishing a compound leaf from a simple one. When it uses a leaflet of hickory for its cocoon, it fastens the leaflet to the mid stem of the leaf and then fastens the stem to the twig. The male pupa is much more slender than that of the female. The moths do not issue until May or June.

The moth works its way out through the valve at the top of the cocoon. The female is a large, reddish brown moth with markings resembling somewhat those of the cecropia. The male is very different in appearance; its front wings have very graceful, prolonged tips, and both wings are almost black, bordered with ash color. The promethea moths differ somewhat in habit from the other silk-worms, in that they fly during the late afternoon as well as at night. The eggs are whitish with brown stain, and are laid in rows, a good many on the same leaf.

The caterpillars, as they hatch from the eggs, have bodies ringed with black and yellow. They are sociable little fellows and live together side by side amicably, not exactly "toeing the mark" like a spelling class, but all heads in a row at the edge of the leaf where each is eating as fast as

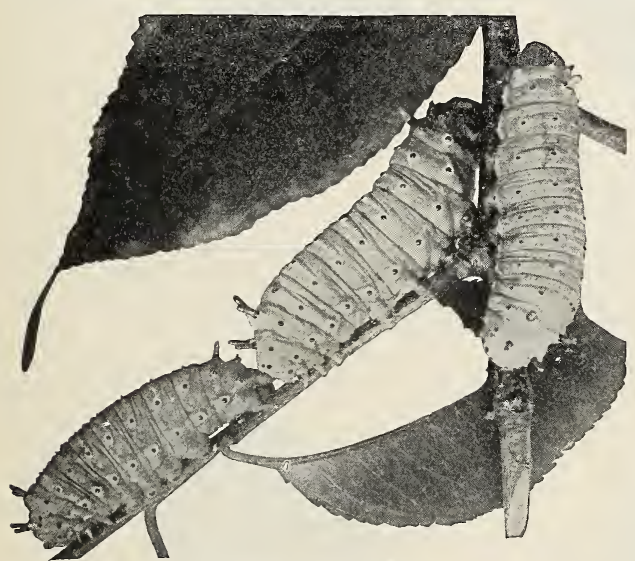

Promethea caterpillars.

Photo by M. V. Slingerland. possible. When they are small, the caterpillars remain on the under side of the leaves out of sight. In about five days, the first skin is shed and the color of the caterpillar remains about the same. Four or five days later, the second molt occurs, and then the caterpillar appears in a beautiful bluish green costume, with black tubercles, except four large ones on the second and third segments, and one large one on the eleventh segment, which are yellow. This caterpillar has an interesting habit of weaving a carpet of silk on which to change its skin; it seems to be better able to hold on while pushing off the old skin, if it has the silken rug to cling to. After the third molt, the color is a deeper greenish blue and the black tubercles are smaller, and the five big ones are larger and bright orange in color. After the fourth molt, which occurs after a period of about five or six days, the caterpillar appears in its last stage. It is now over two inches long, quite smooth and most prosperous looking. Its color is a beautiful, light, greenish blue, and its head is yellow. It has six rows of short, round, black tubercles. The four large tubercles at the front end of the body are red, and the large tubercle on the rear end of the body is yellow.

The cynthia is a beautiful moth which has come to us from Asia; it is very large with a ground color of olive-green, with lavender tints and 
white markings; there are white tufts of hairs on the abdomen. It builds its cocoon like the promethea, fastening the petiole to the twig,

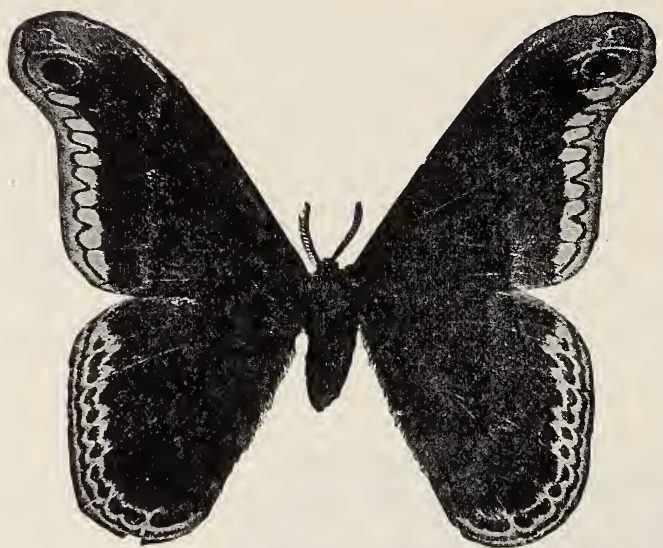

The male promethea.

Photo by M. V. Slingerland.

therefore the lesson indicated for the promethea will serve as well for the cynthia. The cynthia caterpillars live upon the ailanthus tree and are found only in the regions where this tree has been introduced.

References -Moths and Butterflies, Dickerson; Caterpillars and Their Moths, Elliot and Soule; Moths and Butterflies, Ballard,

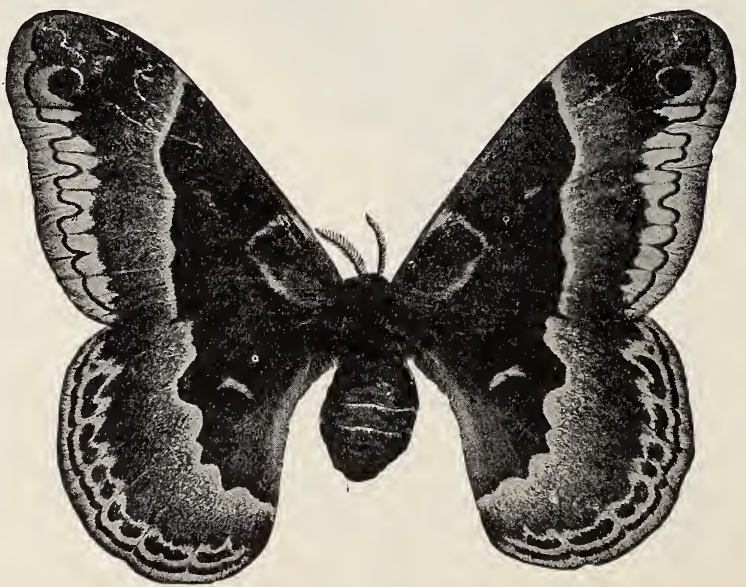

The female promethea.

Photo by M. V. Slingerland. 


\section{LESSON LXXIV}

\section{The Promethea}

Leading thought-The promethea caterpillar fastens a leaf to a twig with silk and then makes its cocoon within this leaf. The male and female moths are very different in appearance.

Method-This work should begin in the late fall, when the children bring in these cocoons which they find dangling on the lilac bushes or wild cherry trees. Much attention should be paid to the way the leaf is fastened to the twig so it will not fall. The cocoons should be kept out of doors, so that the moths will issue late in the spring when they can have natural conditions for laying their eggs, and the young caterpillars are upplied with plenty of food consisting of new and tender leaves.

\section{The Cocoon}

Observations-r. On what tree did you find it? Does it loòk like a cocoon? Does it not look like a dried leaf still clinging to the tree? Do you think that this disguise keeps the birds from attacking it? Do you know which birds are clever enough to see through this disguise?

2. How is the leaf fastened to the twig? Could you pull it off readily? What fastened the leaf to the twig?

3. Tear off the leaf and study the cocoon. Is there an opening to it? At which end? What is this for?

4. Cut open a cocoon. Is it as thick as that of the cecropia?

5. Study the pupa. Is it as large as that of the cecropia?

6. Can you see where the antennæ of the moth are? Can you see the wing covers? Can the pupa move?

\section{The Moth}

I. Are there two kinds of moths that come from the promethea cocoons? Does one of them look something like the cecropia? This is the mother promethea.

2. Are any of the moths almost black in color with wings bordered with gray and with graceful prolonged tips to the front wings? This is the father moth.

3. Make water color drawings of promethea moths, male and female.

4. If a promethea mother lays eggs, describe them.

\section{The Caterpillar}

I. How do the promethea caterpillars look when they first hatch from the eggs? Do they stay together when they are very young? How do they act? Where do they hide?

2. How do they change color as they grow older? Do they remain together or scatter? Do they continue to hide on the lower sides of leaves?

3. What preparation does a promethea caterpillar make before changing its skin? Why does it shed its skin? Does its colors change with every change of skin?

4. Describe the caterpillar when it is full-grown. What is its ground color? What are the colors of its ornamental tubercles? The color of its head?

5. Describe how a promethea caterpillar makes its cocoon. 


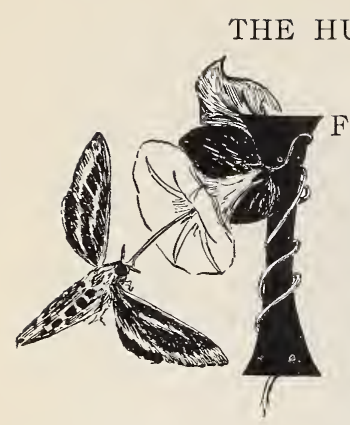

\section{Teacher's Story}

during the early evening, when all the swift humming birds are abed, we hear the whirr of rapidly moving wings and detect the blur of them in the twilight, as if the creature carried by them hung entranced before some deep-throated flower, and then whizzed away like a bullet, we know that it was a hummingbird, or sphinx, moth. And when we see a caterpillar with a horn on the wrong end of the body, a caterpillar which, when disturbed, rears threateningly, then we may know it is the sphinx larva. And when we find a strange, brown segmented shell, with a long jug handle at one side, buried in the earth as we spade up the garden in the spring, then we know we have the sphinx pupa.

The sphinx was a vaudeville person of ancient mythology who went about boring people by asking them riddles; and, if they could not give the right answers, very promptly ate them up. Although Linnæus gave the name of sphinx to these moths, because he fancied he saw a resemblance in the resting or threatening attitude of the larvæ to the Egyptian Sphinx, there are still other resemblances. These insects present three riddles: The first one is, "Am I a humming-bird?" the second, "Why do I wear a horn or an eye-spot on the rear end of my body where horns and eyes are surely useless?" and the third, "Why do I look like a jug with a handle and no spout?"

The sphinx moths are beautiful and elegant creatures. They have a distinctly tailor-made appearance, their colors are so genteel and "the cut" so perfect. They have long, rather narrow, strong wings which enable them to fly with extraordinary rapidity. The hind wings are shorter, but act as one with the front wings. The body is stout and spindle-shaped. The antennæ are thickened in the middle or toward the tip, and in many species have the tip recurved into a hook. Their colors show most harmonious combinations and most exquisite contrasts; the pattern, although often complex, shows perfect refinement. Olive, tan, brown and ochre, black and yellow, and the whole gamut of greys, with eyespots or bands athwart the hind wings of rose color or crimson, are some of the sphinx color schemes.

Most of the sphinx moths have remark-

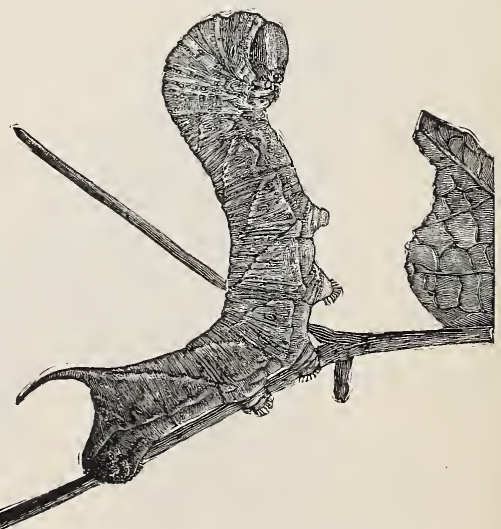

Sphinx larva in sphinx attitude. From Manual for the Study of Insects. 


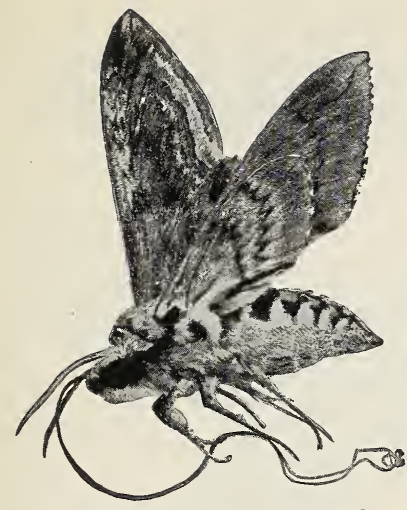

The tobacco sphinx moth with tongue extended.

Photo by M. V. Slingerland.

able long tongues, being sometimes twice the length of the body. When not in use, the tongue is curled like a watch spring in front and beneath the head; but of what possible use is such a long tongue! That is a story for certain flowers to tell, the flowers which have the nectar wells far down at the base of tubular corollas, like the petunia, the morning glory or the nasturtium; such flowers were evidently developed to match the long-tongued insects. Some of these flowers, like the jimson weed and nicotina, open late in the day so as to be ready for these evening visitors. In some cases, especially in the orchids, there is a special partnership established between one species of flower and one species of sphinx moths. The tobacco sphinx is an instance of such partnership; this moth visits tobacco flowers and helps develop the seeds by carrying pollen from flower to flower; and in turn it lays its eggs upon the leaves of this plant, on which its great caterpillar feeds and waxes fat, and in high dudgeon often disputes the smoker's sole right to the "weed." Tobacco probably receives enough benefit from the ministrations of the moth to compensate for the injury it suffers from the caterpillars; but the owner of the tobacco field, not being a plant, does

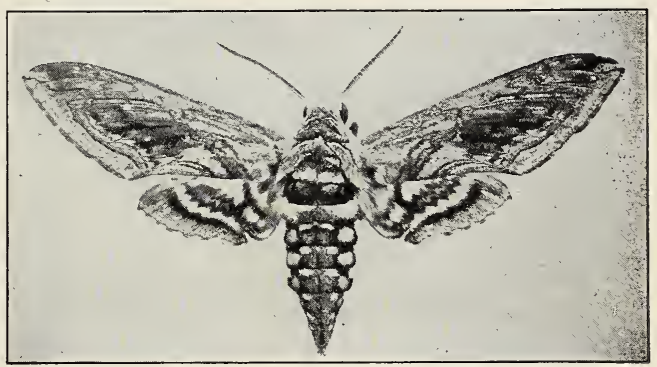

The moth of the sphinx caterpillar, which feeds on tomato.

Photo by M. V. Slingerland. not look at it in this equitable manner.

The sphinx caterpillars are leaf eaters and each species feeds upon a limited number of plants which are usually related; for instance, one feeds upon both the potato and tomato; another upon the Virginia creeper and grapes. In color these caterpillars so resemble the leaves that they are discovered with difficulty. Those on the Virginia creeper, which shades porches, may be located by the black pellets of waste material which fall from them to the ground; but even after this unmistakable hint I have searched a long time to find the caterpillar in the leaves above; its color serves to hide the insect from birds which feed upon it eagerly. In some species, the caterpillars are ornamented with oblique stripes along the sides, and in others the stripes are lengthwise. There is often a great variation in color between the saterpillars of 
the same species; the tomato worm is sometimes green and sometimes black.

The horn on the rear end is often in the young larva of different color than the body; in some species it stands straight up and in some it is curled toward the back. It is an absolutely harmless projection and does not sting nor is it poison-

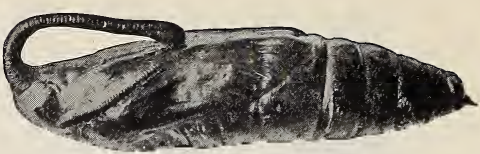

The pupa of the common tomato sphinx caterpillar.

Note that the part encasing the long tongue is free and looks like the handle of a jug. Photo by M. V. Slingerland.

ous. However, it looks awe-inspiring and perhaps protects its owner in that way. The Pandora sphinx has its horn curled over its back in the young stage but when fully grown the horn is shed; in its place is an eyespot which, if seen between the leaves, is enough to frighten away any cautious bird fearing the evil eye of serpents. The sphinx caterpillars have a habit, when disturbed or when resting, of rearing up the front part of the body, telescoping the head back into the thoracic segments, which in most species are enlarged, and assuming a most threatening and ferocious aspect. If attacked they will swing sidewise, this way and then that, making a fierce crackling sound meanwhile, well calculated to fill the trespasser with terror. When resting they often remain in this lifted

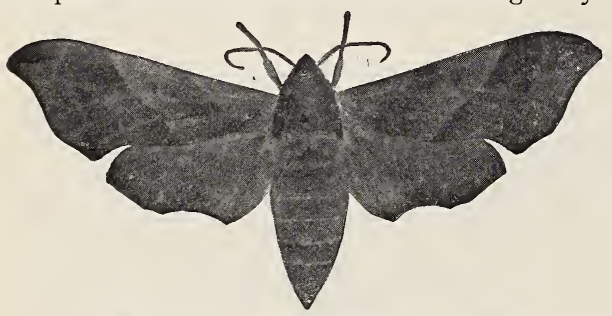

Tailor-made moth, the adult of the Myron sphinx. attitude for hours, absolutely rigid.

The six true legs are short with sharp, little claws. There are four pairs of fleshy prolegs, each foot being armed with hooks for holding on to leaf or twig; and the large, fleshy prop-leg on the rear segment is able to clasp a twig like a vise. All these fleshy legs are used for holding on, while the true legs are used for holding the edges of the leaf where the sidewise working jaws can cut it freely. These caterpillars do clean work, leaving only the harder and more woody ribs of the leaves. The myron caterpillar seems to go out of its way to cut off the stems of both the grape and Virginia creeper.

There are nine pairs of spiracles, a pair on each segment of the abdomen and on the first thoracic segment. The edges of these air openings are often strikingly colored. Through the spiracles the air is admitted into all the breathing tubes of the body around which the blood flows and is purified; no insect breathes through its mouth. These caterpillars, like all others, grow by shedding the skeleton skin, which splits down the back.

Often one of these caterpillars is seen covered with white objects which the ignorant,

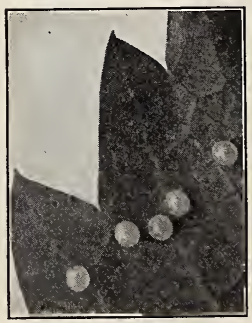

The eggs of the Myrin sphinx.

Photo by M. V. Slingerland 
who do not know that caterpillars never lay eggs, have called, eggs. But the sphinx moths at any stage would have horror of such eggs as these! They are not eggs but are little silken cocoons spun by the larvæ of a hymenopterous parasite. It is a tiny, four-winged "fly" which lays its eggs within the caterpillar. The little grubs which hatch from these eggs feed upon the fleshy portions of the caterpillar until they get their growth, at which time the poor caterpillar is almost exhausted; and then they have the impudence to come out and spin their

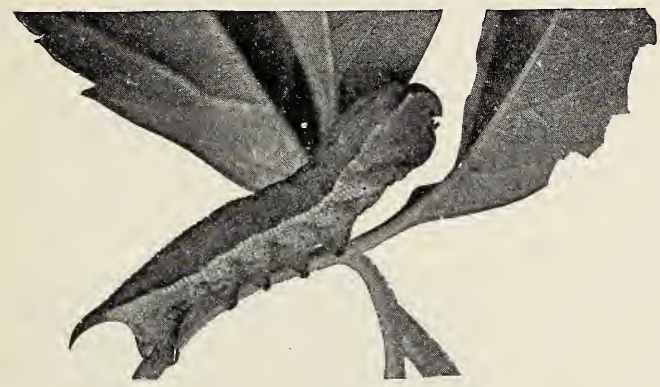

A full-grown caterpillar of the Myron sphinx. silken cocoons and fasten them to the back of their victim. Later, they cut a little lid to their silken cells which they lift up as they come out into the world to search for more caterpillars.

As soon as the sphinx larva has obtained its growth, it descends and burrows into the earth. It does not spin any cocoon but packs the

soil into a smooth-walled cell in which it changes to a pupa. In the spring the pupa works its way to the surface of the ground and the moth issues. In the case of the tomato and tobacco sphinx pupa, the enormously long tongue has its case separate from the body of the pupa, which makes the "jug handle." The wing cases and the antennre cases can be distinctly seen. In the case of the other species the pupæ have the tongue case fast to the body. The larva of the myron sphinx does not enter the ground, but draws a few leaves about it on the surface of the ground, fastens them with silk and there changes to a pupa.

References-Caterpillars and their Moths, Elliot and Soule; Moths and Butterflies, Dickerson; Moths and Butterflies, Ballard; Manual for the Study of Insects, Comstock.

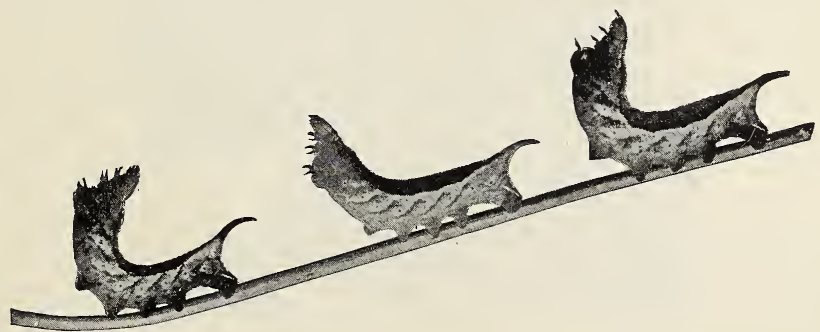

A "cake walk." The caterpillars of the Myron sphinx in attitude of defence.

Photo by M. V. Slingerland. 


\section{LESSON LXXV}

\section{The Humming-Bird, or Sphinx, Moths}

Leading thought-The sphinx caterpillars have a slender horn or eyespot on the last segment of the body. When disturbed or when resting they rear the front part of the body in a threatening atticude. They spin no cocoons but change to pupæ in the ground. The adults are called humming-bird moths, because of their swift and purring flight. Many flowers depend upon the sphinx moths for carrying their pollen.

Method-The sphinx caterpillar found on the potato or tobacco, or one of the species feeding upon the Virginia creeper is in September available in almost any locality for this lesson. The caterpillars should be placed in a breeding cage in the schoolroom. Fresh food should be given them every day and moist earth be placed in the bottom of the cages. It is useless for the amateur to try to rear the adults from the pupæ in breeding cages. The moths may be caught in nets during the even ng when they are hovering over the petunia beds. These may be placed on leaves in a tumbler or jar for observation.

\section{The Caterpillar}

Observations- $\mathrm{I}$. On what plant is it feeding? What is its general color? Is it striped? What colors in the stripes? Are they oblique or lengthwise stripes? Are all the caterpillars the same color?

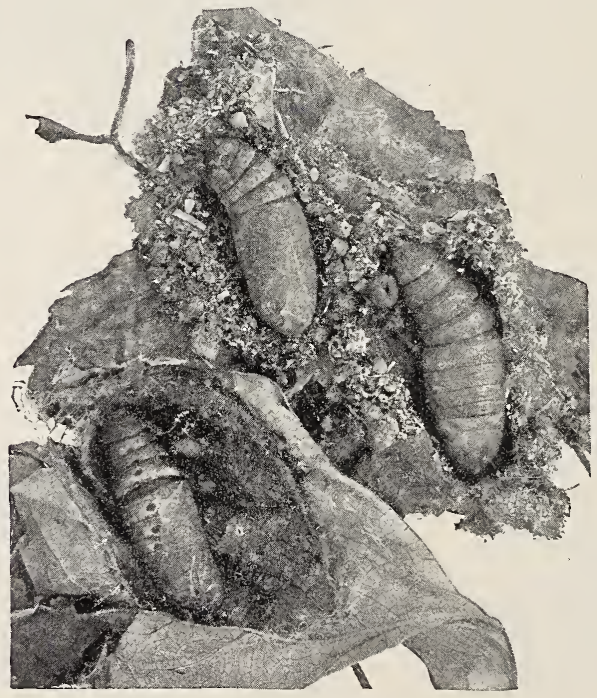

The pupue of the Myron sphinx within the cocoons.

Photo by M. V. Slingerland. 
2. Can you find the caterpillar easily when feeding? Why is it not conspicuous when on the plant? Of what use is this to the caterpillar?

3. Note the horn on the end of the caterpillar. Is it straight or curled? Is it on the head end? What color is it? Do you think it is of any use to the caterpillar? Do you think it is a sting? If there is no horn, is there an eye-spot on the last segment? What color is it? Can you think of any way in which this eye-spot protects the caterpillar?

4. Which segments of the caterpillar are the largest? When the creature is disturbed what position does it assume? How does it move? What noise does it make? Do you think this attitude scares away enemies? What position does it assume when resting? Do you think that it resembles the Egyptian Sphinx when resting?

5. How many true legs has this caterpillar? How does it use them when feeding? How many prolegs has it? How are these fleshy legs used? How are they armed to hold fast to the leaf or twig? Describe the hind or prop-leg. How is it used?

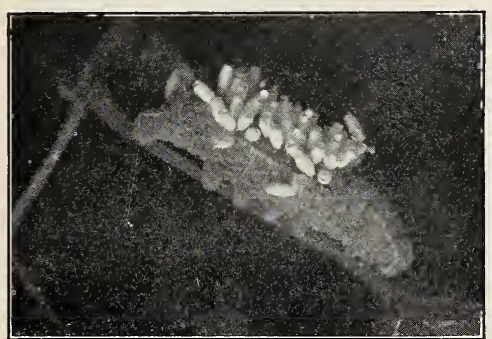

A Myron caterpillar that' has been parasitized. The white objects upon it are the cocoons of the little grubs which feed upon the fatty parts of the caterpillar.

Photo by M. V. Slingerland.

6. Do you see the breathing pores or spiracles along the sides of the body? How many are there? How are they colored? How does the caterpillar breathe? Do you think it can breathe through its mouth?

7. How does the sphinx caterpillar grow? Watch your cater. pillar and see it shed its skin. Where does the old skin break open? How does the new, soft skin look? Do the young caterpillars resemble the full-grown ones?

8. Describe how the caterpillar eats. Can you see the jaws move? Does it eat up the plant clean as it goes?

9. Have you ever found the sphinx caterpillar covered with whitish, oval objects? What are these? Does the caterpillar look plump or emaciated? Explain what these objects are and how they came to be there.

ro. Where does the caterpillar go to change to a pupa? Does it make cocoons? How does the pupa look? Can you see the long tongue case, the wing cases, the antennæ cases?

\section{The Moth}

r. Where did you find this moth? Was it flying by daylight or in the dusk? How did its swift moving wings sound? Was it visiting flowers? What flowers? Where is the nectar in these flowers?

2. What is the shape of the moth's body? Is it stout or slender? What colors has it? How is it marked?

3. The wings of which pair are longer? Sketch or describe the form of the front and the hind wings? Are the outer edges scalloped, 


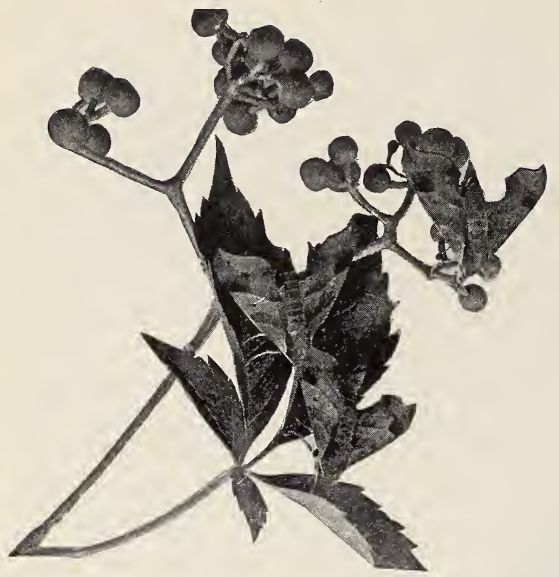

The moths of the Myron sphinx on Virginia creeper.

Photo by M. V: Slingerland.

Hurt no living thing:

Ladybird, nor butterfly,

Nor moth with dusty wing,

Nor cricket chirping cheerily,

Nor grasshopper so light of leap,

Nor dancing gnat, nor beetle fat,

Nor harmless worms that creep.

-Christina Rossetti. notched or even? What colors are on the front wing? On the hind one? Are these colors harmonious and beautiful? Make a sketch of the moth in water-color.

4. What is the shape of the antennæ? Describe the eyes. Can you see the coiled tongue? Uncoil it with a pin and note how long it is. Why does this moth need such a long tongue?

5. From what flowers do the sphinx moths get nectar? How does the moth support itself when probing for nectar? Do you know any flowers which are dependent on the sphinx moths for carrying their pollen? How many kinds of sphinx moths do you know?

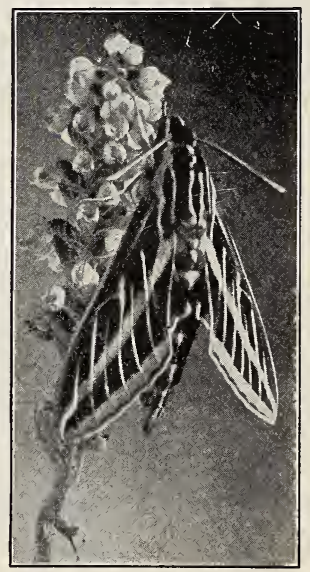

The white-lined sphinx moth. 


\section{THE CODLING MOTH \\ Teacher's Story}

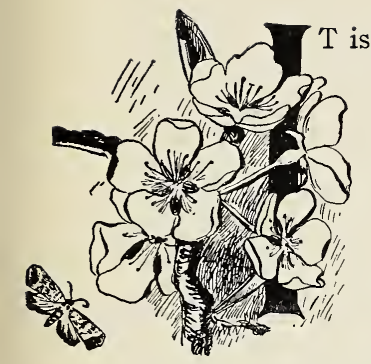

difficult to decide which seems the most disturbed, the person who bites into an apple and uncovers a worm, or the worm which is uncovered. From our standpoint, there is nothing attractive about the worm which destruys the beauty and appetizing qualities of our fruit, but from the insect standpoint the codling caterpillar (which is not a worm at al1), is not at all bad. When full-grown, it is about three-fourths of an inch long, and is likely to be flesh color, or even rose color, with brownish head; as a young larva, it has a number of darker rose spots on each seyment and is whitish in color; the shield on the first segment behind the head, and that on the last segment of the body, are black. When full-grown, the apple worm is plump and lively; and while jerking angrily at being disturbed, we can see its true legs, one pair to each of the three segnients of the body behind the head. These true legs have sharp, single claws. Behind these the third, fourth, fifth and sixth segments of the abdomen are each furnished with a pair of fleshy prolegs and the hind segment has a prop-leg. These fleshy legs are inere makeshifts on the part of the caterpillar for carrying the long body; since the three pairs of front legs are the ones froin which develop the legs of the moth. The noticing of the legs of the codling moth is an important observation on the part of the pupils, since, by their presence, this insect may be distinguished from the young of the plunı curculio, which is also found in apples but which is legless. The codling moth has twelve segments in the body, back of the head.

The codling larva usually enters the apple at the blossom end and tunnels down by the side of the core until it reaches the middle, before making its way out into the pulp. The larva weaves a web as it goes, but this is probably incidental, since many caterpillars spin silk as they go, "street yarn" our grandmothers night have called it. In this web are entangled the pellets of indigestible matter, making a very unsavory looking mass. The place of exit is usually circular, large enough to accommodate the body of the larva, and it leads out from a tunnel which may be a half inch or more in diameter beneath the rind. Often the larva makes the door sometime before it is ready to leave the apple, and plugs it with a mass of debris, fastened together with the silk. As it leaves the apple, the remnants of this plug may be seen streaming out of the opening. Often also, there is a mass of waste pellets pushed out by the young larva from its burrow, as it enters the apple; thus it injures the appearance of the apple, at both entrance and exit. If the apple has not received infection by lying next to another rotting apple, it first begins to rot ar ound the burrow of the worm, especially near the place of exit.

The codling caterpillar injures the fruit in the following ways: The apples are likely to be stunted and fall early; the apples rot about the injured places and thus cannot be stored successfully; the apples thus injured look unattractive and, therefore, their market value is lessened; wormy apples, packed in barrels with others, rot and contaminate all the 


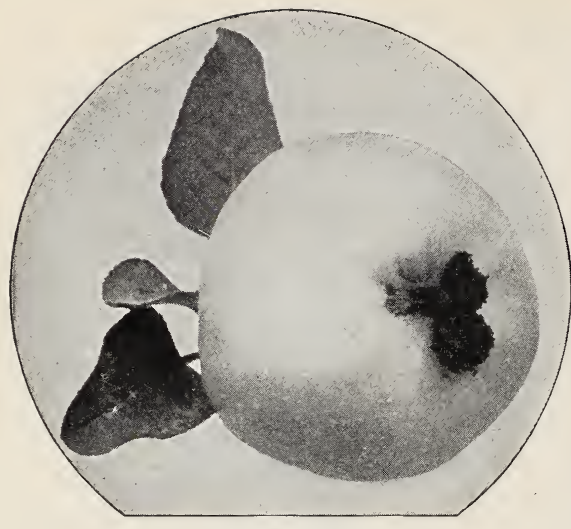

A wormy apple.

Photo by M. V. Slingerland.

neighboring apples. This insect also attacks pears and sometimes peaches. It has been carefully estimated that every year the codling moth does three million dollars worth of injury to the apple and pear crops in New York State. Think of paying three million dollars a year for the sake of having wormy apples!

The larvæ usually leave the apples before winter. If the apples have fallen, they crawl up the tree and there. make their cocoons beneath the loose bark; but if they leave the apples while they are on the trees, they spin silk and swing down. If carried into the storeroom or placed in barrels, they seels quarters in protected crevices. In fact, while they particularly like the loose bark of the apple trees, they are likely to build their cocoons on nearby fences or on brush, wherever they can find the needed protection. The cocoon is made of fine but rather rough silk which is spun from a gland opening near the mouth of the caterpillar; the cocoon is not beautiful although it is smooth inside. It is ustally spun between a loose bit of bark and the body of the tree; but after making it, the insect seems in no hurry to change its condition and remains a quite lively caterpillar until spring. It is while the codling larvæ are in their winter quarters that our bird friends of the winter, the nuthatches, woodpeckers and chickadees, destroy them in great numbers, hunting eagerly for them in every crevice of the trees. It is therefore good policy for us to coax these birds to our orchards by placing beef fat on the branches and thus entice these little caterpillar hunters to visit the trees every day.

It is an interesting fact that the codling caterpillars, which make cocoons before August first, change immediately to pupx which soon change to moths, and thus another generation gets in its work before the apples are harvested.

The codling moth is a beautiful little creature with delicate antennæ

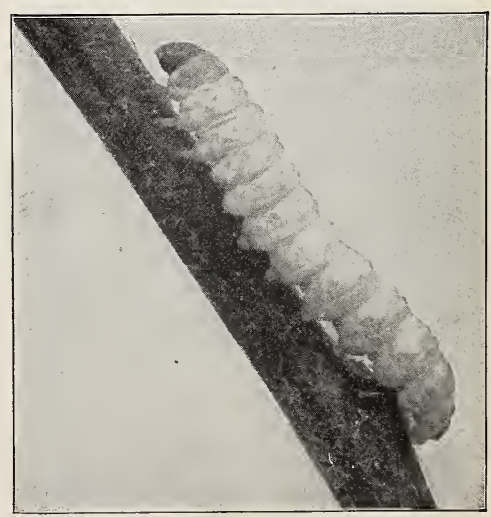

The larva of the codling moth, much enlarged.

Photomicrograph by M. V. Slingerland. 
and a brown, mottled and banded body; its wings are graced by wavy bands of ashy and brown lines, and the tips of the front wings are dark brown with a pattern of gold bronze wrought into them; the hind wings are shiny brown with darker edges and little fringes. The moths issue in the spring and lay their eggs on the young apples just after the petals fall. The egg looks like a minute drop of dried milk and is laid on the side of the bud; but the little larva, soon after it is hatched, crawls to the blosson and finds entrance there; and it is therefore important that its first lunch should include a bit of arsenic and thus end its career before it fairly begins. The trees should be sprayed with some arsenical poison directly after the petals fall, and before the five lobes of the calyx close up around the stamens. If the tiees are sprayed while blossoming, the pollen is washed away and the apples do not set; moreover, the bees which help us much in carrying pollen are killed.

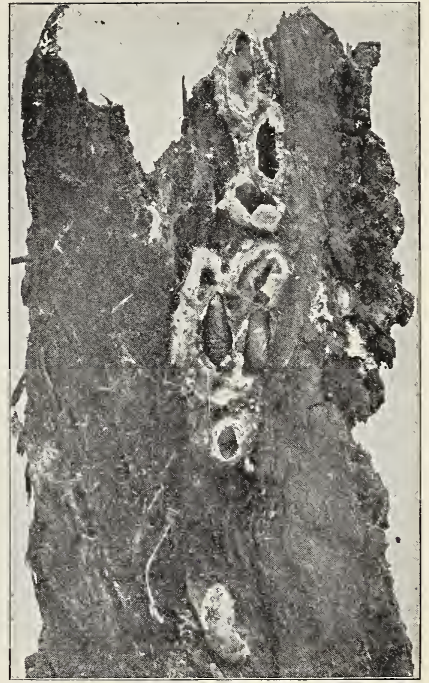

The pupae and cocoons of the codling moths.

Photo by M. V. Slingerland. If the trees are sprayed directly after the calyx closes up arount the stamens the poison does not lodge at the base of the stamens and the little rascals get into the apples without getting a dose. (See Lesson on the Apple).

\section{LESSON LXXVI \\ The Codling Moth}

Leading thought - The codling moth is a tiny brown moth with bronze

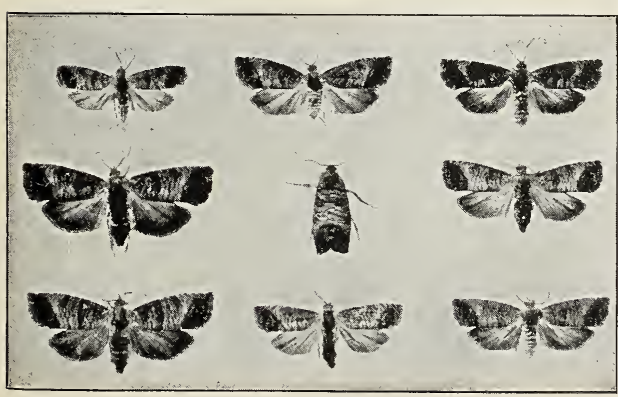

The adult of the codling moth, showing the variations of its markings. The two larger are twice natural size. markings which lays its egg on the apple. 'The larva hatching from the egg erters the blossom end and feeds upon the pulp of the appie, injuring it greatly. After attaining its growth it leaves the apple and hides beneath the bark of the tree or in other protected places, and in the spring makes the cocoon from which the moth issues in time to lay eggs upon the young apples. 


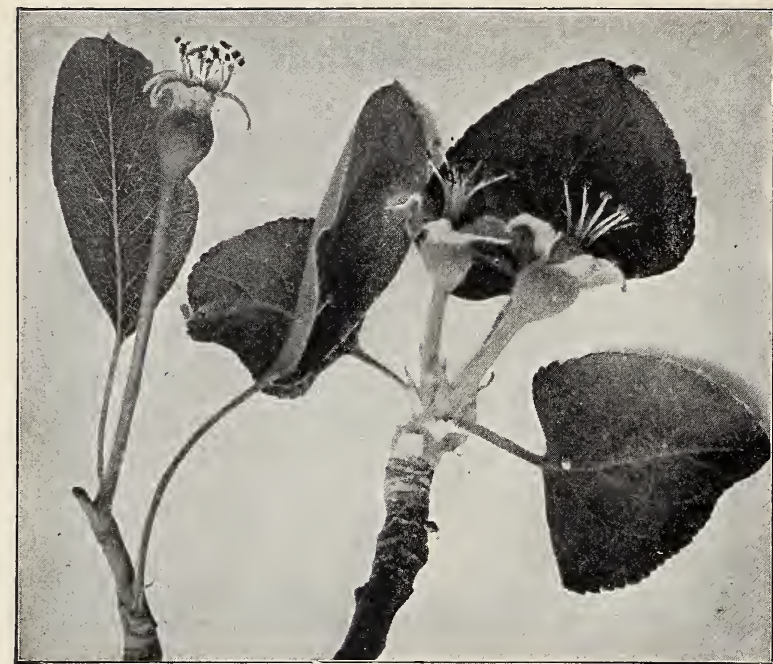

Just ready to spray. A pear and two apples from which the petals have recently fallen and with calyx lobes widely spread. Photo by M. V. Slingerland.
Method-
The lesson should begin with a study of wormy apples, preferably in the fall when the worms are still within their burrows. After the pupils become familiar with the appearance of the insect and its methods of work, a prize of some sort might be offered for the one who will bring to school the greatest num-

ber of hibernating larvæ found in their winter quarters. Place these larvæ in a box with cheese-cloth tacked over its open side; place this box out of doors in a protected position. Examine the cocoons to find the pupæ abo11t the last of April; after the pupæ appear, look for the moths in about five days.

It would be a very good idea for the pupils to prepare a Riker mount showing specimens of the moths, of the cocoons shcwing the cast pupa skin, and of the caterpillar in a homeopathic vial of alcohol; pictures illustrating the work of the insect may be added. The pictures should be drawn by the pupils, showing the wormy apple, both the outside and in section. The pupils can also sketch, from the pictures here given, the young apple when just in the right condition to spray, with a note explains ing why.

Observations-I. Find an apple with a codling moth larva in it. How large is the worm? How does it act when disturbed?

2. What is the color of the caterpillar's body? Its head?

3. How many segments are there in the body? How many of these bear legs? What is the difference in form between the three front pairs of legs and the others?

4. Look at a wormy apple. How can you tell it is wormy from the outside? Can you see where the worm entered the apple? Was the burrow large or small at first? Can you find an apple with a worm in it which has the door for exit made, but closed with waste matter? How is this matter fastened together? If the apple has no worm in it, can you see where it left the apple? Make a sketch or describe the evidence of the caterpillar's progress through the apple. Do you find a web of silk in 
the wormy part? Why is this? Does the worm eat the seeds as well as the pulp of the apple?

5. Take a dozen rotting apples, how many of them are wormy? Do the parts of the apple injured by the worm begin to rot first? In how many ways does the codling moth injure the apple? Does it injure other fruits than apples?

6. How late in the fall do you find the codling larvæ in the apple? Where do these larvæ go when they leave the apple?

Work to be done in March or early A pril-Visit an orchard and look under the loose bark on old trees, or along protected sections of fences or brush piles and bring in all the cocoons you can find. Do not injure the cocoons by tearing them from the places where they are woven, but bring them in on bits of the bark or other material to which they are attached.

I. How does the cocoon look outside and inside? What is in the cocoon? Why was the cocoon made? When was it made?

2. Place the cocoons in a box covered with cheese-cloth and place the box out of doors where the contents can be frequently observed and make the following notes:

3. When does the larva change to the pupa? Describe the pupa. How does the cocoon look after the moth issues from it?

4. Describe the moth, noting color of head, thorax, body, front and hind wings?

5. If these moths were free to fly around the orchard, when and where would they lay their eggs?

6. When should the trees be sprayed to kill the young codling moth? With what should they be sprayed? Why should they not be sprayed during the blossoming period? Why not after the calyx closes?

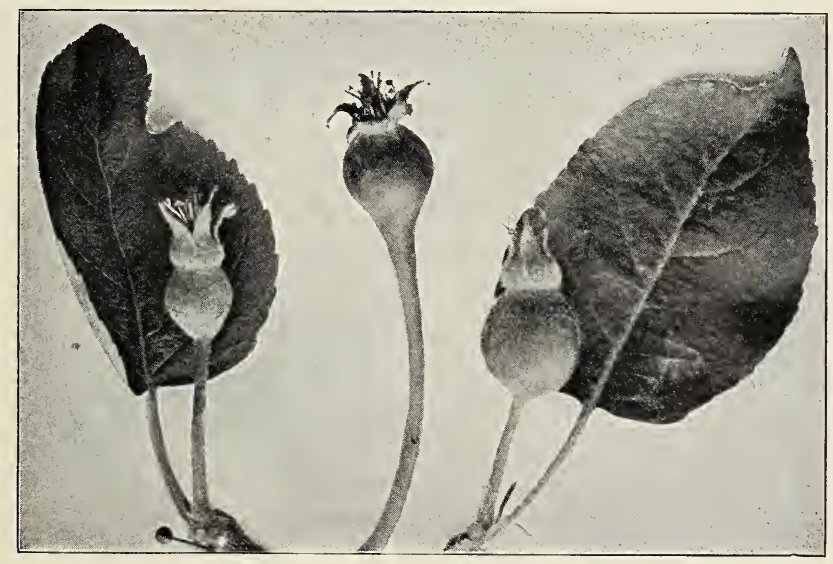

Almost too late to spray. The apples on each side have the calyx lobes nearly drawn together. The pear in the middle still has the calyx cavity open.

Photo by M. V. Slingerland. 
7. How do the nuthatches, downy woodpeckers and chickadees help us in getting rid of the codling moth?

8. Write an essay on the life history of the codling moth, the damage done by it, and the best methods of keeping it in check.

References-The following bulletins from the U. S. Dept. of Agriculture: Farmers' Bulletin 247, "The Control of the Codling Moth and Apple Scab;" Bulletin 35, New Series, Bureau of Entomology, "Report on the Codling Moth Investigations," price ro cents; Bulletin 4I, "The Codling Moth," I05 pages, I 5 cents, by Special Field Agent, C. B. Simpson; Bulletin 68, Part VII, "Demonstration Spraying for the Codling Moth," price 5 cents. The Spraying of Plants, Lodeman, Macmillan Company; Economic Entomology, Smith.

\section{LEAF-MINERS}

\section{Teacher's Story}

"And there's never a leaf nor a blade too mean To be some happy creature's palace".

\section{-Lowell.}

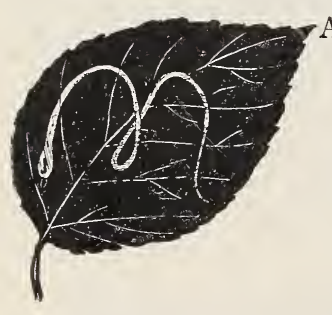

AY not Lowell have had in mind, when he wrote these lines, the canny little creatures which find sustenance for their complete growth between the upper and lower surfaces of a leaf, which seems to us as thin as a sheet of paper. To most children, it seems quite incredible that there is anything between the upper and lower surfaces of a leaf, and this lesson should hinge on the fact that in every leaf, however thin, there are rows of cells containing the living substance of the leaf, with a wall above and a wall below to protect them. Some of the smaller insects have discovered this hidden treasure, which they mine while safely protected from sight, and thus make strange figures upon the leaves.

Among the most familiar of these are the serpentine mines, so called because the figure formed by the eating out of the green pulp of the leaf, curves like a serpent. These mines are made by the caterpillars of tiny moths, which have long fringes upon the hind wings. The life story of such a moth is as follows: The little moth, whose expanded wings measure scarcely a quarter of an inch across, lays an egg on the leaf; from this, there hatches a tiny caterpillar that soon eats its way into the midst of the leaf. In shape, the caterpillar is somewhat "square built," being rather stocky and wide for its length; it feeds upon the juicy tissues of the leaf and divides, as it goes, the upper from the lower surface of the leaf; and it teaches us, if we choose to look, that these outer walls of the leaf are thin, colorless, and paper-like. We can trace the whole life history and wanderings of the little creatire, from the time when, as small as a pin point, it began to feed, until it w. tained its full growth. As it increased in size, its appetite grew larger also, and these two forces working together naturally enlarged its house. When finally the little niner gets its growth, it makes a rather larger and more ommodious room at the end of its mine, which to us looks like 
the head of the serpent; here it changes to a pupa, perhaps after nibbling a hole with its sharp little jaws, so that when it changes to a soft, fluffy little moth with mouth unfitted for biting, it is able to escape. In some species, the caterpillar comes out of the mine and goes into the ground to change to a pupa. By holding up to the light a leaf thus mined, we can see why this little chap was never obliged to clean house; it mined out a new room every day, and left the sweepings in the abandoned mine behind. Mines of this sort are often seen on the leaves of nasturtium, the smooth pigweed, columbine, and many other plants. There are mines of many shapes, each form being made by a different species of insect. Some flare suddenly from a point and are trumpet-shaped while some are mere blotches. The blotch mines are made, through the habits of the insect within them; it feeds around and around, instead of forging ahead,

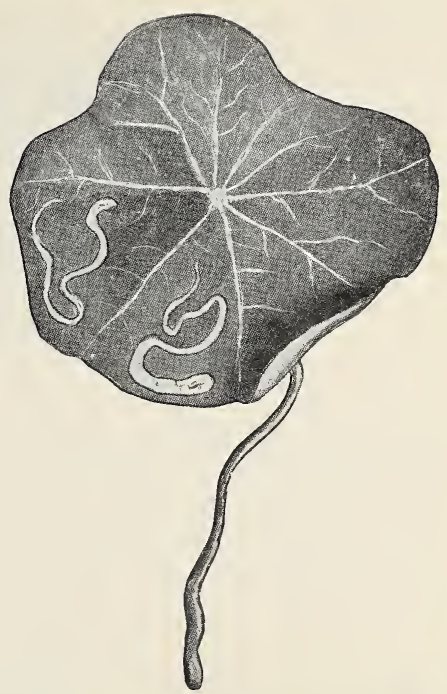

Serpentine mines in nasturtium leaf.

as is the case with the serpentine miners. The larvie of beetles, flies and moths may mine leaves, each species having its own special food plant. Most of the smaller leaf mines are made by the caterpillars of the moths, which are fitly called the Tineina or Tineids. Most of these barely have a wing expanse that will reach a quarter of an inch and many are much smaller; they all have narrow wings, the hind wings being mere threads bordered with beautiful fringes. The specific names of these moths usually end in

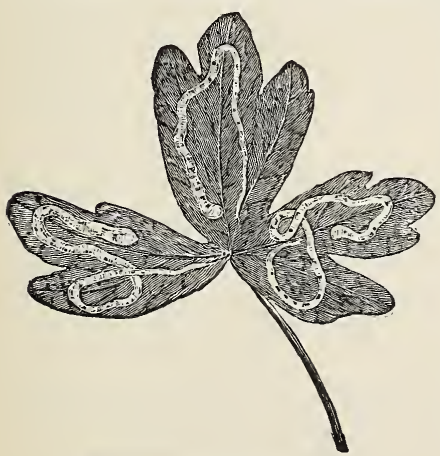

Serpentine mines in leaf of columbine.

Comstock's Manual. "ella;" thus, the one that mines in apple is malifoliella, the one in grain is granella. One of these little moths, Gelechia pinifoliella lives the whole of its growing life in half of a pine needle. The moth lays the egg at about the middle of the needle, and the little caterpillar that hatches from it, gnaws its way directly into the heart of the needle; and there, as snug as snug can be, it lives and feeds until it is almost a quarter of an inch long, think of it! Many a time I have held up to the light a pine needle thus inhabited, and have seen the little miner race up and down its abode as if it knew that something was happening. When it finally attains its 


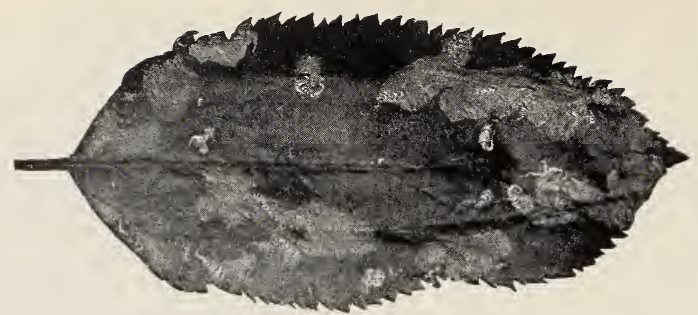

Trumpet mines in leaf of apple. Photo by M. V. Slingerland.

growth it makes wider the little door, through which it entered; it does this very neatly, the door is an even oval, and looks as if it were made with the use of dividers. After thus opening the door, the caterpillar changes to a little, long pupa, very close to its exit; and later it emerges, as an exquisite little moth with silvery bands on its narrow, brown wings,

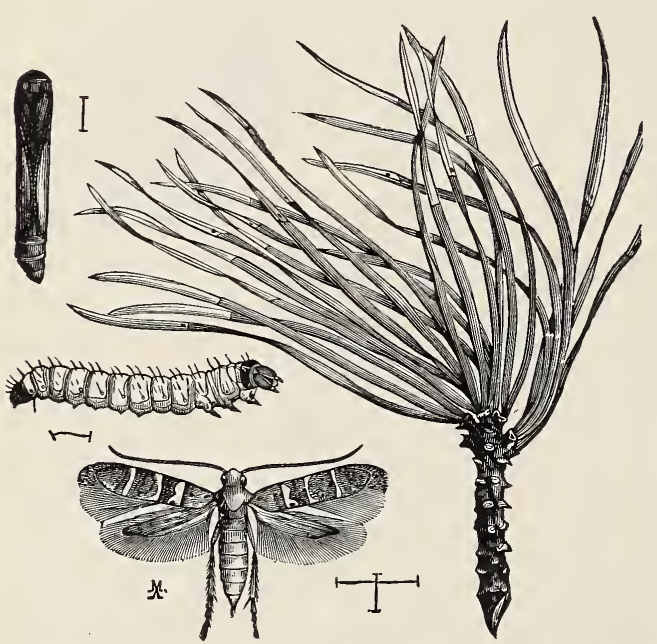

The pine-needle leaf-miner. The mined leaves of pine natural size. The caterpillar, pupa and moth of the leaf miner much enlarged. The lines show actuab size of insect.

\section{Comstock's Manual.} and a luxurious fringe on the edges of its narrow, hind wings and also on the outer hind edges of the front wings.

The gross mines in the leaves of dock and beet are not pretty. The poor leaves are slitted, sometimes for their whole length, and soon turn brown and lie prone on the ground, or dangle pathetically from the stalk. These mines are made by the larvæ of a fly, and a whole family live in the same habitation. If we hold a leaf thus mined up to the light, while it is still green, we can see several of the larvæ working, each making a bag in the life substance of the leaf, and yet all joining together to make a great blister. The flies that do this mischief belong to the family Anthomyine; and there are several species which have the perturbing habit of mining the leaves of beets and spinach. It behooves those of us who are fond of these "greens," as our New England ancestors called them, to hold every leaf 
up to the light before we put it into the skillet, lest we get more meat than vegetable in these viands. The flies, who this take our greens ahead of us, are perhaps a little larger than house-flies, and are generally gray in color with the front of the head silver-white. These insects ought to teach us the value of clean culture in our gardens, since they also mine in the smooth pigweed.

References-Manual for the Study of Insects, Comstock.

\section{LESSON LXXVII}

\section{LEAF-MINERS}

Leading thought-The serpent-like markings and the blister-like blotches which we often see on leaves are made by the larvæ of insects which complete their growth by feeding upon the inner living substance of the leaf.

Method-The nasturtium leaf-miner is perhaps the most available for this lesson since it may be found in its mine in early September. However, the pupils should bring to the schoolroom all the leaves with mines in them, that they can find and study the different forns.

Observations-r. Sketch the leaf with the mine in it, showing the shape of the mine. What is the name of the plant on which the leaf grew?

2. Hold the leaf up to the light, can you see the insect within the mine? What is it doing? Are there more than one insect in the mine? Open the mine and see how the miner looks.

3. There are three general types of mines: Those that are long, curving lines called serpentine mines; those that begin small and flare out, called trumpet mines; and those that are blister-like called blotch mines. Which of these is the mine you are studying?

4. Study a serpentine mine. Note that where the little insect began to eat, the mine is small. Why does it widen from this point? What happened in the part which we call the serpent's head?

5. Look closely with a lens and find if there is a break above the mine in the upper surface of the leaf or below the mine in the lower surface of the leaf? If the insect is no longer in the mine can you find where it escaped? Can you find a shed pupa-skin in the "serpent's head?"

6. Why does an insect mine in a leaf? What does it find to eat? How is it protected from the birds or insects of prey while it is getting its growth?

7. Look on leaves of nasturtium, columbine, lamb's quarters, dock and burdock, for serpentine mines. Are the mines on these different plants alike? Do you suppose they are made by the same insect?

8. Look on leaves of dock, burdock, beet and spinach for blotch mines. Are there more than one insect in these mines? If the insects are present, hold the leaf out to the light and watch them eat.

9. Look in the leaves of pitch or other thick leaved pines (not white pine), for pine needles which are yellow at the tip. Examine these for miners. If the miner is not within, can you find the little circular door 
by which it escaped? Would you think there was enough substance in a half a pine needle to support a little creature while it grew up?

ıо. If you find leaf-miners at work, do not pluck off the leaves being mined but cover each with a little bag of swiss muslin tied close about the petiole and thus capture the winged insect.

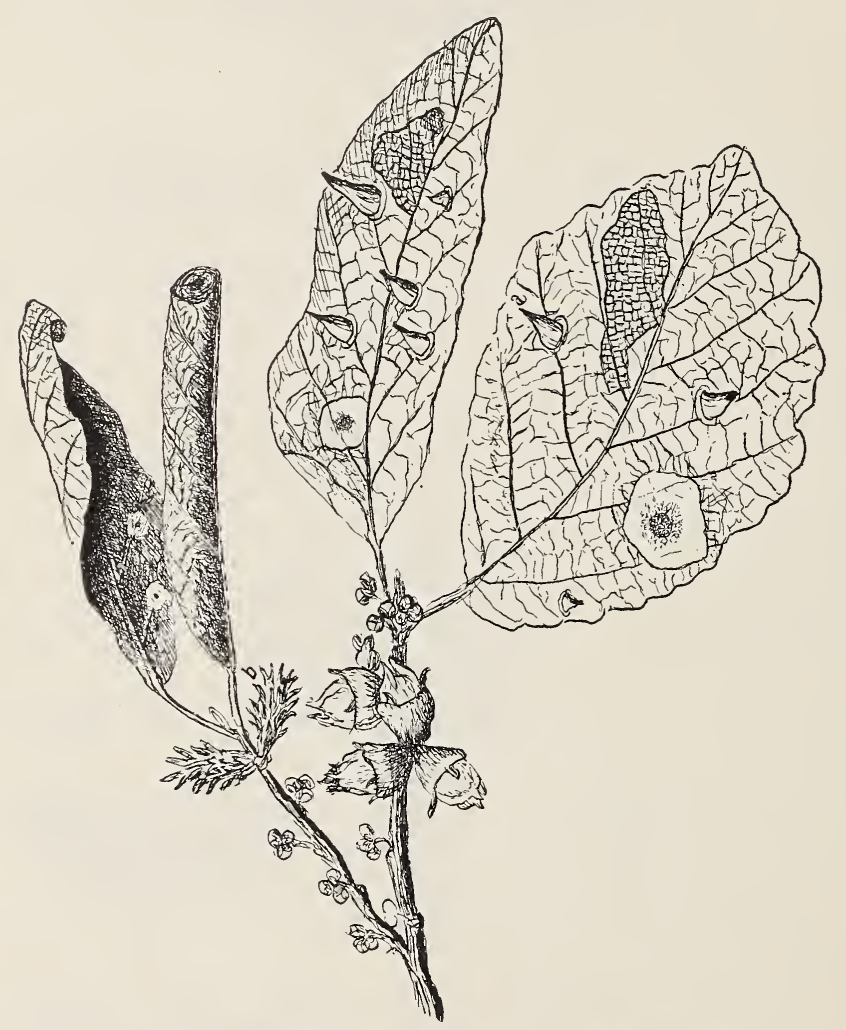

Witch-hazel, showing work of leaf-rollers, leaf-miners and gall-makers. 


\section{THE LEAF-ROLLERS}

\section{Teacher's Story}

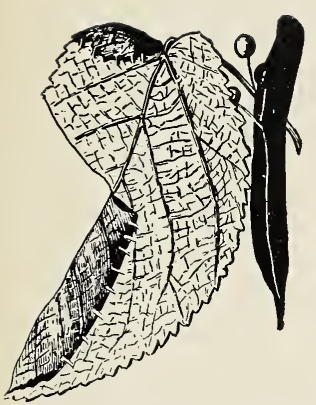

F we look closely at sumac leaves before they are aflame from autumn's torch, we find many of the leaflets rolled into little cornucopias fastened with silk. The silk is not in a web, like that of the spider, but the strands are twisted together, hundreds of threads combined in one strong cable, and these are fastened from roll to leaf, like tent ropes. If we look at the young basswoods, we find perhaps many of their leaves cut across, and the flap made into a roll and likewise fastened with silken ropes. The witch-hazel, which is a veritable insect tenement, also shows these rolls. In fact, we may find them upon the leaves of almost any species of tree or shrub, and each of these rolls has its own special maker or indweller. Each species of insect, which rolls the leaves, is limited to the species of plant on which it is found; and one of these caterpillars would sooner starve than take a mouthful from a leaf of any other plant. Some people think that insects will eat anything that comes in their way; but of all created animals, insects are the most fastidious as to their food.

Some species of leaf-rollers unite several leaflets together, while others use a single leaf. In the case of the sumac leafroller, it begins in a single leaf; but in its later stages, it fastens together two or three of the terminalleaflets in order to gain more pasturage. The little silken tent ropes which hold the folded leaves are well worth study with a lens. They are made of hundreds of threads of the finest silk, woven from a gland opening near the lower lip of the caterpillar. The rope is always larger where it is attached to the leaf than at the center, because the caterpillar crisscrosses the threads in order to make the attachment to the

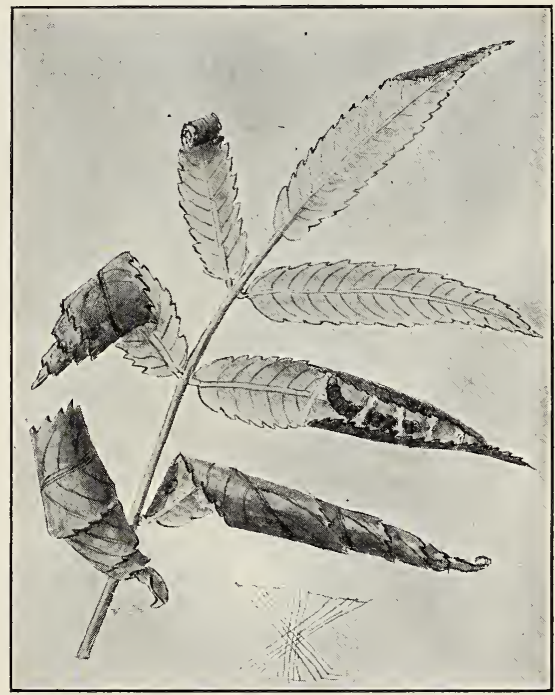

Leaf-rollers in sumac, with diagram showing the fastening of the silk-stay-ropes.

leaf larger and firmer. Unroll a tent carefully, and you may see the fastenings used in an earlier stage, and may even find the first turned-down edge of the leaf. However, the center of a leaf roller's habitation is usually very much eaten, for the whole reason for making its little house 
is that the soft-bodier caterpillar may eat its fill completely hidden trom the eyes of birds or other animals. When it first hatches from the egg, it feeds for a short time, usually on the under side of the leaf: but when still so small that we can barely see it with the naked eye, it somehow manages to fold over itself one edge of the leaf and peg it down. The problem of how so small a creature is able to pull over and fold down or to make in a roll a stiff leaf is hard to solve. I, myself, believe it is done by making many threads, each a little more taut than the last. I have watched several species working, and the leaf cones slowly together as the caterpillar stretches its head and sways back and forth hundreds of times, fastening the silk first to one side and then to the other. Some observers believe that the caterpillar throws its weight upon the silk, in order to pull the leaf together; but in the case of the sumac leaf-roller, I am sure

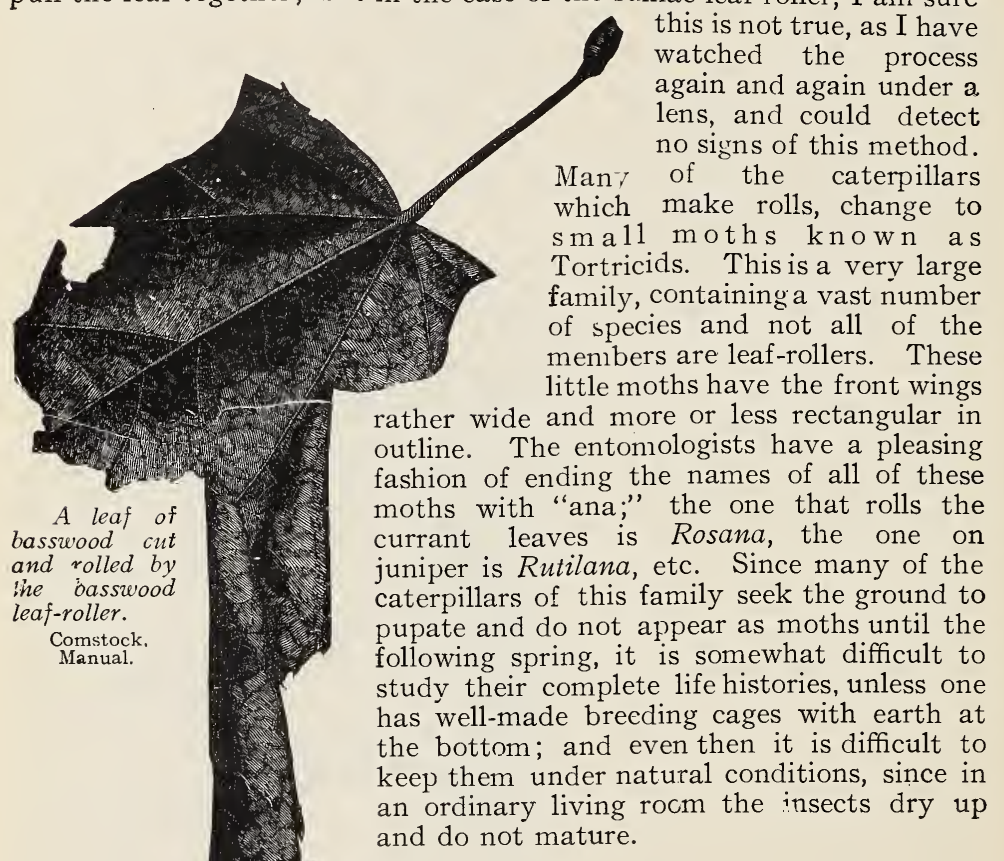




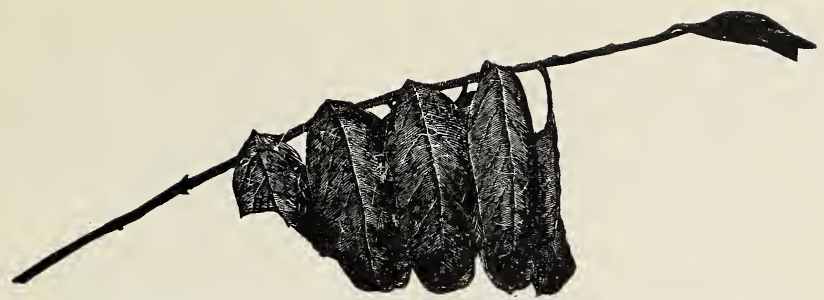

Leaflets of locust, fastened together to make a nest by the caterpillar of a butterfly.

\section{LESSON LXXVIII}

The Leaf-Rollers

Leading thought-There are many kinds of insects which roll the leaves of trees and plants into tents, in which they dwell and feed during their early stages.

Method-This is an excellent lesson for early autumn when the pupils may find many of these rolled leaves, which they may bring to the schoolroom, and which will give material for the lesson. The rolls are found plentifully on sumac, basswood and witch-hazel.

Observations- - . What is the name of the trees and shrubs from which these rolled leaves which you have collected were tären?

2. Are more than one leaf or leaflet used in making the roll?

3 . Is the leaf rolled crosswise or lengthwise? How large is the tube thus made?

4. Is the nest in the shape of a tube, or are several leaves fastened together, making a box-shaped nest??

5. How is the roll made fast? Examine the little silken ropes with a lens and describe one of them. Is it wider where it is attached to the leaf than at the middle? Why?

6. How many of these tent ropes are there which make fast the roll? Unroll a leaf carefully and see if you can find signs of the tent ropes that fastened the roll together when it was smaller. Can you find where it began?

7. As you unroll the leaves what do you see at the center? Has the leaf been eaten? Can you discover the reason why the caterpillar made this roll?

8. How do you think a caterpillar manages to roll a leaf so successfully? Where is the spinning gland of a caterpillar? How does the insect act when spinning threads back and forth when rolling the leaf? What sort of insect does the caterpillar which rolls the leaf change into? Do you suppose that the same kind of caterpillars makes the rolls on two different species of trees?

9. In July or early August get some of the rolls with the caterpillars in them, unroll a nest, take the caterpillar out and put it on a fresh leaf of the same kind of tree or shrub on which you found it, and watch it make its roll.

Supplementary reading - "A Dweller in Tents" and "A Little Nomad," in Ways of the Six-Footed. 


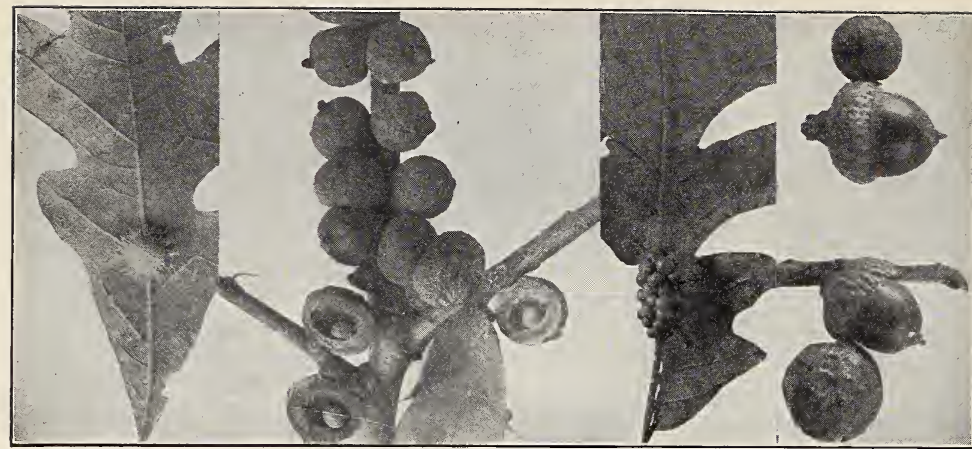

The spiny oak-gall. The pointed bullet-gall
on oak twigs.
A cluster of galls on midrib of oak leaf.
The acorn plum-gall.
Photo by

\section{THE GALL-DWELLERS}

He retired to his chamber, took his lamp, and summoned the genius as usual. "Genius," said he, "build me a palace near the sultan's, fit for the reception of my spouse, the princess; but instead of stone, let the walls be formed of massy gold and silver, laid in alternate rows; and let the interstices be enriched with diamonds and emeralds. The palace must have a delightful garden, planted with aromatic shrubs and plants, bearing the most delicious fruits and beautiful flowers. But, in particular, let there be an immense treasure of gold and silver coin. The palace, moreover, must be well provided with offices, storehouses, and stables full of the finest horses, and attended by equerries, grooms, and hunting equipage." By the dawn of the ensuing morning, the genius presented himself to Aladdin, and said, "Sir, your palace is finished; come and see if it accords with your wishes."-ARABIAN Nights EnTERTAINMENTs.

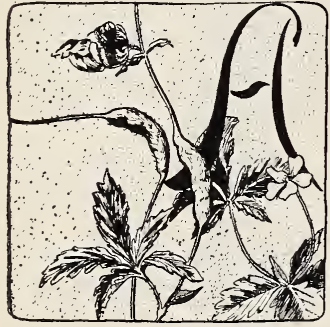

There are many forms of these gall-dwellings, and they may grow upon the root, branch, leaf, blossom, or fruit. The miraculous thing about them is that each kind of insect builds its magical house on a certain part of a certain species of tree or plant; and the house is always of a certain definite form on the outside and of a certain particular pattern within. Many widely differing species of insects are gall-makers; and he who is skilled in gall lore knows, when he looks at the outside of the house, just what insect dwells within it. 
We may take the history of the common oak apple, as an exaniple. A little, four-winged, fly-like creature lays its eggs, early in the season, on the leaf of the scarlet oak. As soon as the larva hatches, it begins to

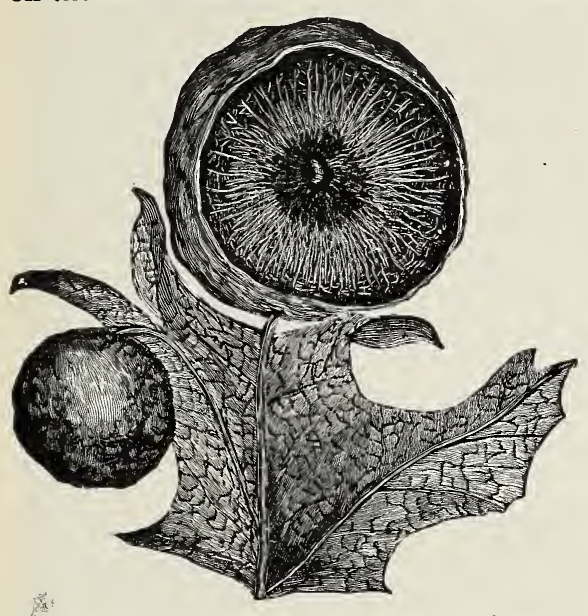

Oak apple, showing the larva of the gall insect. Comstock's Manual. eat into the substance of one of the leaf veins. As it eats, it discharges through its mouth into the tissues of the leaf, a substance which is secreted from glands within its body. Immediately the building of the house commences; out around the little creature grow radiating vegetable fibers, showing by their position plainly that the gri1b is the center of all of this new growth; meanwhile, a smooth, thin covering completely encloses the globular house; larger and larger yrows the house until we are accustomed to call it an oak apple, so large is it. The little chap inside is surely content and happy, for it is protected from the sight of all of its enemies, and it finds the walls of its house the best of food. It is comparable to a boy living in the middle of a giant sponge cake, and who when hungry would naturally eat out a larger cave in the heart of the cake. After the inmate of the oak apple completes its growth, it changes to a pupa and finally comes out into the world a tiny four-winged fly, scarcely a quarter of an inch in length.

The story of the willow cone-gall is quite different. A little gnat lays her eggs on the tip of the bud of a twig; as soon as the grub hatches and begins to eat, the growth of the twig is arrested, the leaves are stunted until they are mere scales and are obliged to overlap in rows around the little inma's, thus making for i's a cone-shaped house which is very thoroughly shingled. The inhabitant of this gall is a hospitable little fellow, and his houre shelters and feeds many other insect guests. $\mathrm{He}$ does not pay any attention to them, being a recluse in his own cell, but he civilly allows them to take care of themselves in his domain, and feed upon the walls of his house. He stays in his snug home all winter and comes out in the spring a tiny, two-winged fly.

There are two galls common on the stems of goldenrod. The more numerous is spherical in form and is made by a fat and prosperous looking little grub which later develops into a fly. But although it is a fly that makes the globular gall in the stem of goldenrod, the spindle-shaped gall often seen on the same stem has quite another story. A little brown and gray mottled moth, about three-fourths of an inch long, lays her egg on the stem of the young goldenrod. The caterpillar, when it hatches, lives inside the stem, which accommodatingly 


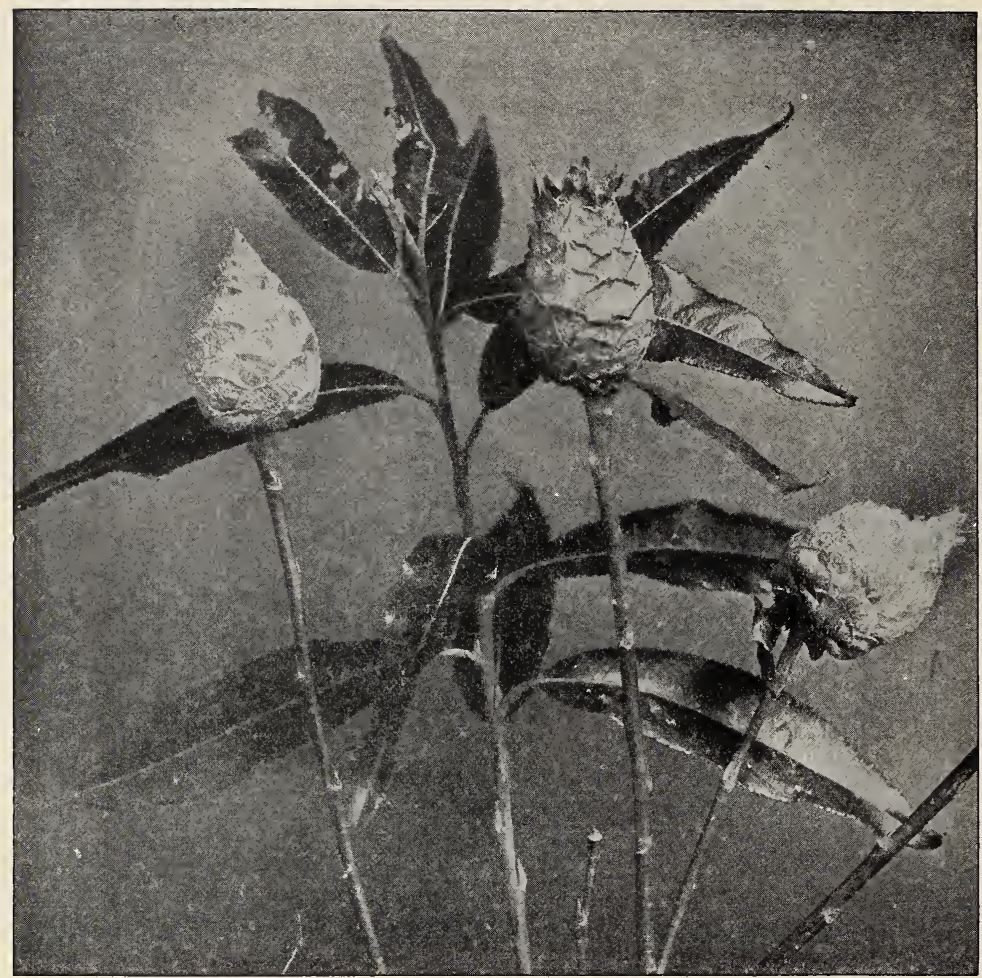

Willow cone-galls.

Photo by Verne Morton.

enlarges into an oblong room. The caterpillar feeds upon the substance of the stem until it attains its growth, and then seems to dimly realize something about its future needs. At least it cuts, with its sharp jaws, a little oval door at the upper end of its house and makes an even bevel by widening the opening toward the outside. It then makes a little plug of debris which completely fills the door; but because of the bevel, no intrusive beetle or ant can push it in. Thus the caterpillar changes to a helpless pupa in entire safety; and when the little moth issues from the pupa skin, all it has to do is to push its head against the door, and out it falls, and

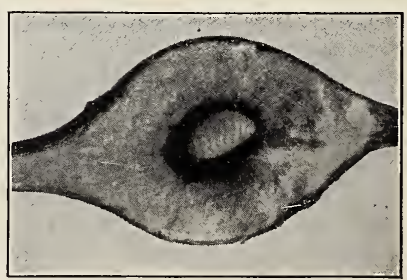

Spherical gall of goldenrod, opened, showing its pros perous looking owner.

Photo by M. V Slingerland. 
the recluse is now a creature of the outside world.

Many galls are compound, that is, they are made up of a community of larvæ, each in its own cell. The mossy rose-yall is an instance of this. The galls made by mites and aphids are open either below or above the surface of the leaf; the little conical galls on witch-hazel are examples of these. In fact, each gall has its own particular history, which proves a most interesting story if we seek to read it with our own eyes.

\section{LESSON LXXIX}

\section{The Gall-dwellers}

Leading thought-The galls are protective habitations for the little insects which dwell within them. Each kind of insect makes its own peculiar gall on a certain species of plant, and no one understands just how this is done or why it is so.

Method-Ask the pupils to bring in as many of these galls as possible. Note that some have open doors and some are entirely closed. Cut open a gall and see what sorts of insects are found within it. Place each

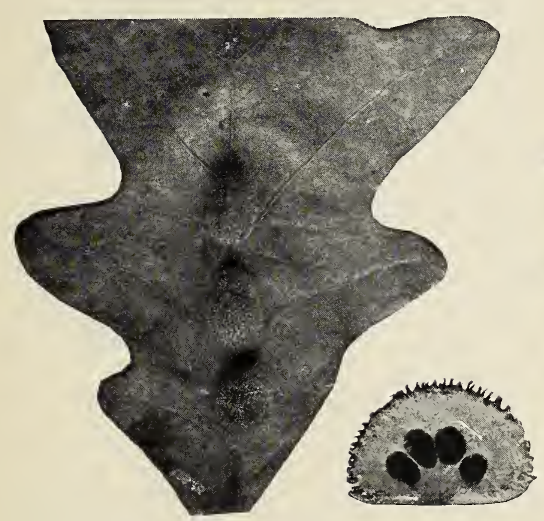

Porcupine gall on leaf of white oak.
Section of same showing cells.
Photo by C. J. Triggerson. kind of gall in a tumbler or jar covered with cheesecloth and place where they may be under observation for perhaps several months; note what sort of winged insect comes froin each.

Observations - I. On what plant or tree did this ga 11 grow? Were there many like it? Did they grow upon the root, stem, leaf, flower, or fruit? If on the leaf, did they Female gall- grow upon the pet-
fly laying iole or the blade? $\begin{array}{lll}\text { fly laying role or the } & \text { 2. What is the }\end{array}$ bud. shape of the little 
house? What is its color? Its size? Is it smooth or wrinkled on the outside? Is it covered with fuzz or with spines?

3. Open the gall; is there an insect within it? If so, where is it and how does it look? What is the appearance of the inside of the gall?

4. Is there a cell for the insect at the very center of the gall, or are there many such cells?

5. Has the house an open door? If so, does the door open above or below? Are there more than one insect in the galls with open doors? What sort of insect makes this kind of house?

6. Do you find any insects besides the original gall-maker within it? If so, what are they doing?

7. Of what use are these houses to their little inmates? How do they protect them from enemies? How do they furnish them with food?

8. Do the gall insects live all their lives within the galls or do they change to winged insects and come out into the world? If so, how do they get out?

9. How many kinds of galls can you find upon oaks? Upon goldenrod? Upon witch-hazel? Upon willow?

Supplementary reading-Outdoor Studies, Needham, pages 18 and 37; "Houses of Oak," in Insect Stories, Kellogg; Manual for the Study of Insects.

A green little world With me at its heart!

A house grown by magic, Of a green stem, a part.

My walls give me food And protect me from foes,

I eat at my leisure, In safety repose.

My house hath no window, 'Tis dark as the night!

But I make me a door And batten it tight.

And when my wings grow I throw wide my door; And to my green castle I return nevermore.

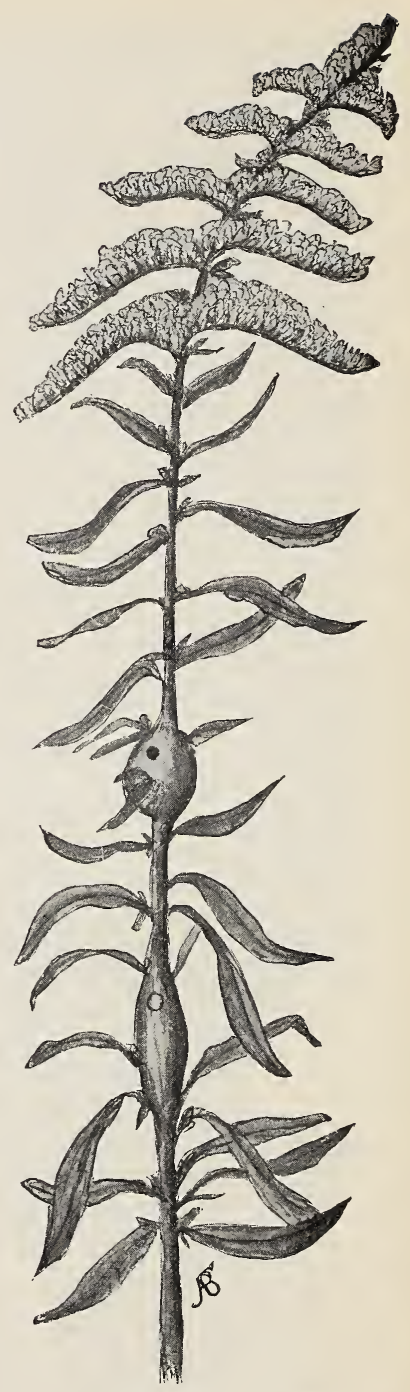

Stem of golden-rod, showing the spherical gall above, made by larva of a fly; and the spindleshaped gall below, made by the caterpillar of a moth. 


\section{THE GRASSHOPPER}

\section{Teacher's Story}

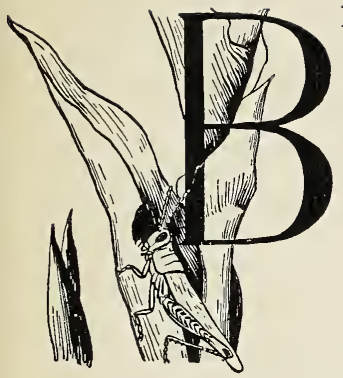

ECAUSE the grasshopper affords special facilities for the study of insect structure, it has indeed become a burden to the students in the laboratories of American universities. But in naturestudy we must not make anything a burden, least of all the grasshopper, which being such a famous jumper as well as flier, does not long voluntarily burden any object.

Since we naturally select the most salient characteristic of a creature to present first to young pupils, we naturally begin this lesson with the peculiarity which makes this insect a "grasshopper." When any creature has unusually strong hind legs, we may be sure it is a jumper, and the grasshopper shows this peculiarity at first glance. The front legs are short, the middle legs a trifle longer, but the femur of the hind leg is nearly as long as the entire body, and contains many powerful muscles which have the appearance of being braided, because of the way they are attached to the skeleton of the leg; the tibia of the hind leg is long and as stiff as if made of steel. When getting ready to jump the grasshopper lowers the great fenur below the level of the closed wings and until the tibia is parallel with it and the entire foot is pressed against the ground.

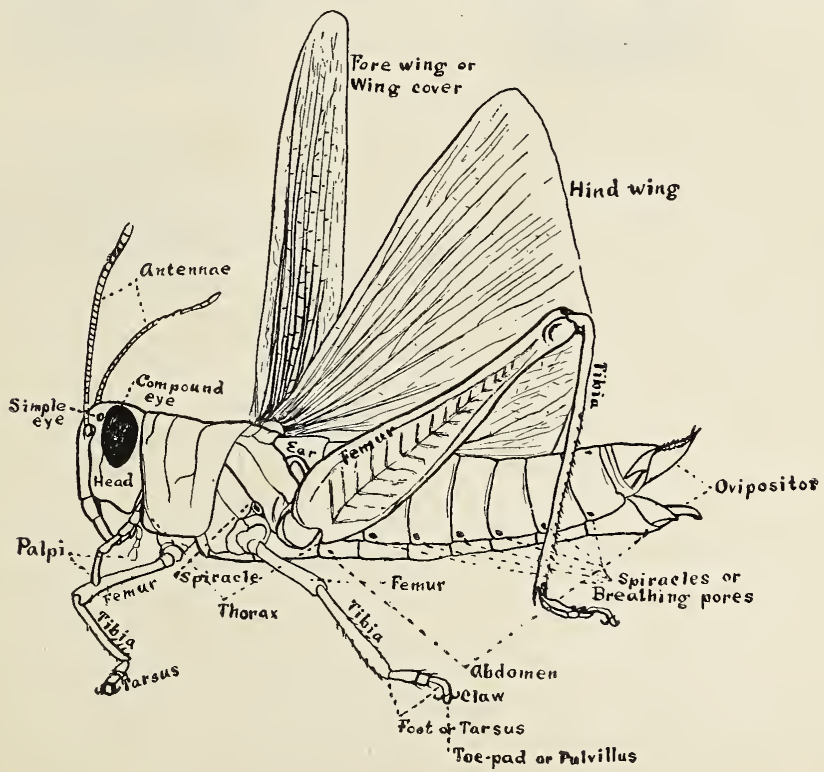

Grasshopper with parts of external anatomy named. 
The pair of double spines at the end of the tibia, just back of the foot, are pressed against the ground like a spiked heel, and the whole attitude of the insect is tense. Then, like a steel spring, the long legs straighten and the insect is propelled high into the air and far away. This is a remarkable example of insect dynamics; and since so many species of birds feed upon the grasshopper, its leaping power is much needed to escape them. However, when the grasshopper makes a journey it uses its wings.

As we watch a grasshopper crawling up the side of a vial or tumbler we can examine its feet with a lens. Between and in front of the claws is an oval pad which clings to the glass, not by air pressure as was once supposed, but by means of microscopic hairs, called tenent hairs, which secrete a sticky fluid. Each foot consists of three segments and a claw; when the insect is quiet, the entire foot rests upon the ground; but when climbing on glass, the toe pads are used.

The grasshopper's face has a droll expression; would that some caricaturist could analyze it! It is a long face, and the compound eyes placed high upon it, give a look of solemnity. The simple eyes can be made out. with a lens. There is one just in front of each big eye, and another, like the naughty little girl's curl, is "right in the middle of the forehead." The antennæ are short but alert. The two pairs of palpi connected with the mouth-parts are easily seen, likewise the two pairs of jaws, the notched mandibles looking like a pair of nippers. We can see these jaws much

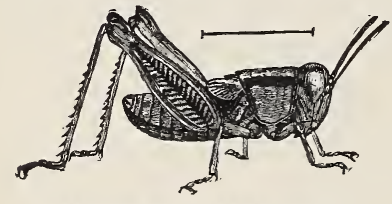

The nymph of the red-legged grasshopper, enlarged.

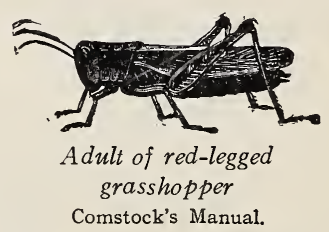

better when the insect is eating, which act is done methodically. First, it begins at one edge of a leaf, which it seizes between the front feet so as to hold it firm; it eats by reaching up and cutting downwards, making an even-edged, long hole on the leaf margin; the hole is made deeper by repeating the process. It sometimes makes a hole in the middle of a leaf and bites in any direction, but it prefers to move the jaws downward. While it is feeding, its palpi tap the leaf continually and its whole attitude is one of deep satisfaction. There is an uprolled expression to the compound eves which reminds us of the way a child looks over the upper edge of its cup while drinking milk. The grasshopper has a preference for tender herbage, but in time of drouth will eat alnost any living plant.

Back of the head is a sun-bonnet-shaped piece, bent down at the sides, forming a cover for the thorax. The grasshopper has excellent wings, as efficient as its legs; the upper pair are merely strong, thick, membranous covers, bending down at the sides so as to protect the under wings; these wing-covers are not meant for flying and are held stiff and straight up in the air, during flight. The true wings, when the grasshopper is at rest, are folded lengthwise like a fan beneath the wing-covers; they are strongly veined and circular in shape, giving much surface for beating the air. The grasshoppers' flight is usually swift and short; but in years of famine 
they fly high in the air and for long distances, a fact recorded in the Bible regarding the plague of locusts. When they thus appear in vast hordes, they destroy all the vegetation in the region where they settle.

The wings of grasshoppers vary in color, those of the red-legged species being gray, while those of the Carolina locusts are black with yellow edges. The abdomen is segmented, as in all insects, and along the lower side there are two lengthwise sutures or creases which open and shut bellows-like, when the grasshopper breathes. The spiracles or breathing pores can be seen on each segment, just above this suture.

The grasshopper has its ears well protected; to find them, we must lift the wings in order to see the two large sounding disks, one on each side of the first segment of the abdomen. These are larger and much more like ears than are the little ears in the elbows of the katydids.

The singing of the short-horned grasshoppers is a varied performance, each species doing it in its own way. One species makes a most seductive little note by placing the femur and tibia of the hind legs together, and with the hind feet completely off the ground, the legs are moved up and down with great rapidity, giving off a little purr. The wings in this case, do not lift at all. There are other species that make the sound by rubbing the legs against the wing-covers.

The grasshopper makes its toilet thus: It cleans first the hind feet by rubbing them together and also by reaching back and scrubbing them with the middle feet; the big hind femur it polishes with the bent elbow of the second pair of legs. It cleans the middle feet by nibbling and licking them, bending the head far beneath the body in order to do it. It polishes its eyes and face with the front feet, stopping to lick them clean

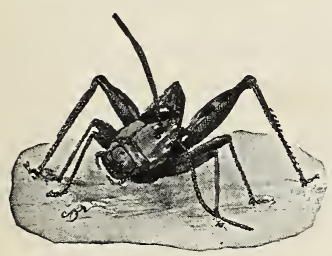

Grasshopper cleaning its antenna. between whiles, and it has a most comical manner of cleaning its antennæ; this is accomplished by tipping the head sidewise, and bending it down so that the antenna of one side rests upon the floor; it then plants the front foot of that side firmly upon the antenna and pulls it slowly backward between the foot and floor.

The grasshopper has some means of defence as well as of escape; it can give a painful nip with its mandibles; and when seized, it emits copiously from the mouth a brownish liquid which is acrid and ill-smelling. This performance interests children, who are wont to seize the insect by its jumping legs and hold it up, commanding it to "chew tobacco."

Grasshoppers are insects with incomplete metamorphosis, which merely means that the baby grasshopper, as soon as it emerges from the egg, is similar in form to its parent except that it has a very large head and a funny little body, and that it has no quiet stage during life. When immature, the under wings or true wings have a position outside of the wing-covers and look like little fans.

The short-horned grasshoppers lay their eggs in oval masses protected by a tough overcoat. The ovipositor of the mother grasshopper is a very efficient tool, and with it she makes a deep hole in the ground, or sometimes in fence rails or other decaying wood; after placing her eggs in such a cavity, she covers the hiding place with a gummy substance so that no 
intruders or robbers may work harm to her progeny. Most species of grasshoppers pass the winter in the egg stage; but sometimes we find in early spring the young ones which hatched in the fall, and they seem as spry as if they had not been frozen stiff.

\section{LESSON LXXX}

\section{The Red-LegGed GRASSHOPPER}

Leading thought-The grass hopper feeds upon grass and other herbage and is especially fitted for living in grassy fields Its color protects it from being seen by its enemies the birds. If attacked, it escapes by long jumps and by flight. It can make long journeys on the wing.

Method-The red-1egged grasshopper (M. femur-rubrum) has been selected for this lesson because it is the most common of all grasshoppers, though other species may be used as well. The red-legged locust, or grass-

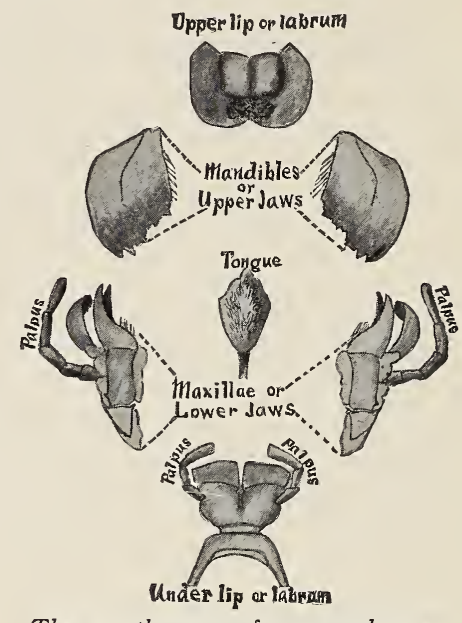

The mouth-parts of a grasshopper dissected off, enlarged and named. hopper has, as is indicated by its name, the large femur of the hind legs reddish in color. Place the grasshopper under a tunzbier anci uporı a spray of fresh herbage, and allow the pupils to observeit at leisure. It might be well to keep sonie of the grasshoppers in a cage similar to that described for crickets. When studying the feet, or other parts of the insect requiring close scrutiny, the grasshopper should be placed in a vial so that it may be passed around and observed with a lens. Give the questions a few at a time, and encourage the pupils to study these insects in the field.

Observations-I. Since a grasshopper is such a high jumper, discover if you can how he does this "event." Which pair of legs is the longest? Which the shortest? How long are the fenur and tibia of the hind leg compared with the body. What do vou think gives the braided appearance to the surface of the hind femur? What is there peculiar about the hind femur? Note the spines at the end of the tibia just behind the foot.

2. Watch the grasshopper prepare to jump and describe the process. How do you think it manages to throw itself so far? If a man were as good a jumper as a grasshopper in comparison to his size, he could jump 300 feet high or 500 feet in distance. Why do you think the grasshopper needs to jump so far?

3. As the grasshopper climbs up the side of a tumbler or vial, look at its feet through a lens and describe them. How many segnients are there? Describe the claws. How does it cling to the glass? Describe the little pad between the claws.

4. Look the grasshopper in the face. Where are the compound eyes situated? Can you see the tiny simple eyes like mere dots? How mar y 
are there? Where are they? How long are the antennæ? For what are they used?

5. How does a grasshopper eat? Do the jaws move up and down or sidewise? What does the grasshopper eat? How many pairs of palpi

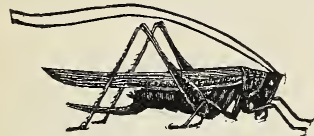

Long horned, or meadow grasshopper.
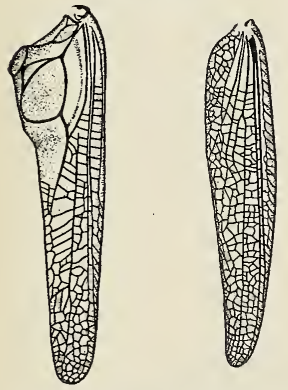

Wing of male and ff female meadow grasshoppers.

Comstock's Manual. can you see connected with the mouth-parts? How are these used when the insect is eating? When there are many grasshoppers, what happens to the crops?

6. What do you see just back of the grasshopper's head, when looked at from above?

7. Can the grasshopper fly as well as jump? How many pairs of wings has it? Does it use the first pair of wings to fly with? How does it hold them when flying? Where is the lower or hind pair of wings when the grass- Front leg of katydid, hopper is walking? How do they differ in shape

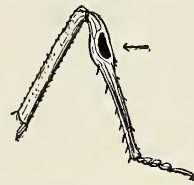

Front leg of katydid.
showing ear near elbow. Comstock's Manual. from the front wings?

8. Note the abdomen. It is made of many rings or segments. Are these rings continuous around the entire body? Where do their breaks occur? Describe the movement of the abdomen as the insect breathes. Can you see the spiracles or breathing pores? Lift the wings,

and find the ear on the first segment of the abdomen.

9. If you seize the grasshopper how does it show that it is offended?

Io. How does the grasshopper perform its toilet? Describe how it cleans its antennæ, face and legs.

I I. What becomes of the grasshoppers in the winter? Where are the eggs laid? How can you tell a young from a full-grown grasshopper?

I 2. Do all grasshoppers have antennæ shorter than half the length of their bodies? Do some have antennæ longer than their bodies? Where are the longhorned grasshoppers found? Describe how they resemble the katydids in the way they make music and in the position of their ears.

Supplementary reading $-\mathrm{Ch}$ a pters XVI-XVIII in Grasshopper Land, Morley.

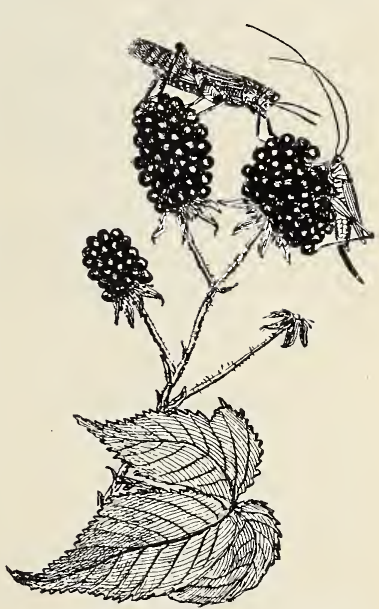

Short-horned and long-horned, or meador', grasshoppers. 


\section{THE KATYDID}

\section{Teacher's Story}

"I love to hear thine earnest voice

Wherever thou art hid,

Thou testy little dogmatist,

Thou pretty katydid,
Thou mindest me of gentle folks. Old gentle folks are they,

Thou say'st an undisputed thing In such a solemn way."

-Holmes.

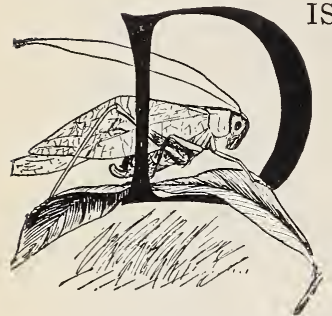

ISTANCE, however, lends enchantment to the song of the katydid, for it grates on our nerves as well as on our ears, when at close quarters. The katydid makes his music in a manner similar to that of the cricket but is not, however, so well equipped since he has only one file and only one scraper for playing. As with the meadow grasshoppers and crickets, only the males make the music, the wings of the females being delicate and normally veined at the base. The ears, too, are in the same position as those of the cricket, and may be seen as a black spot in the front elbow. The song is persistent and may last the night long: "Katy did, she didn't she did." James Whitcomb Riley says, "The katydid is rasping at the silence," and the word rasping well describes the note.

The katydids are beautiful insects, with green, finely veined, leaf-like wing-covers under which is a pair of well developed wings, folded like fans; they resemble in form the long-horned grasshoppers. The common northern species (Cyrtophyllus) is all green above except for the long, delicate, fawn-colored antennæ and the brownish fiddle of the male, which consists of a flat triangle just back of the thorax where the wingcovers overlap. Sometimes this region is pale brown and sometimes green, and with the unaided eye we can plainly see the strong cross-vein, bearing the file. The green eyes have darker centers and are not so large as the eyes of the grasshopper. The body is green with white lines below on either side. There is a suture the length of the abdomen in which are placed the spiracles. The insect breathes by sidewise expansion and contraction, and the sutures rhythmically open and shut; when they are open, the spiracles can be seen as black dots. The legs are slender and the hind pair, very long. The feet are provided with two little pads, one on each side of the base of the claw. In the grasshopper there is only one pad which is placed between the two hooks of the claw. The female has a green, sickle-shaped ovipositor at the end of the body. With . his she lays her flat, oval eggs, slightly over-lapping in a neat row.

The katydids are almost all dwellers in trees and shrubs; although I have often found our common species upon asters and similar high weeds. The leaf-like wings of these insects are, in form and color, so similar to the leaves that they are very completely hidden. The katydid is rarely discovered except by accident; although when one is singing, it may be approached and ferreted out with the aid of a lantern.

The katydid, when feeding, often holds the leaf or the flower firmly with the front feet, while biting it off like a grazing cow, and if it is tough, chews it industriously with the sidewise working jaws. A katydid will often remain quiet a long time with one long antenna directed forward and the other backward, as if on the lookout for news from the front and 
the rear. But when the katydid "cleans up," it does a thorough job. It

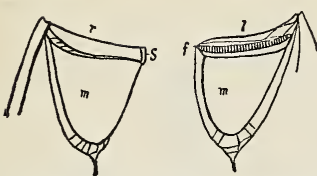

The front portions of the wings of a male katydid showing file on one wing and scraper on the other. nibbles its front feet, paying special attention to the pads, meanwhile holding the foot to its mandibles with the aid of the palpi. But once washing is not enough; I have seen a katydid go over the salne foot a dozen times in succession, beginning always with the hind spurs of the tibia and nibbling along the tarsus to the claws. It cleans its face with its front foot, Arawing it duwnward over the eye and then licking it clean. It cleans its antenna with its mandibles by beginning at the base and drawing it up in a loop as fast as finished. After watching the process of these lengthy ablutions, we niust conclude that the katydid is among the most fastidious members of the insect "four hundred."

References-Manual for Study of Insects, Comstock; American Insects, Kellogg; Ways of Six Fuoted, Comstock; Grasshopper Land, Morley.

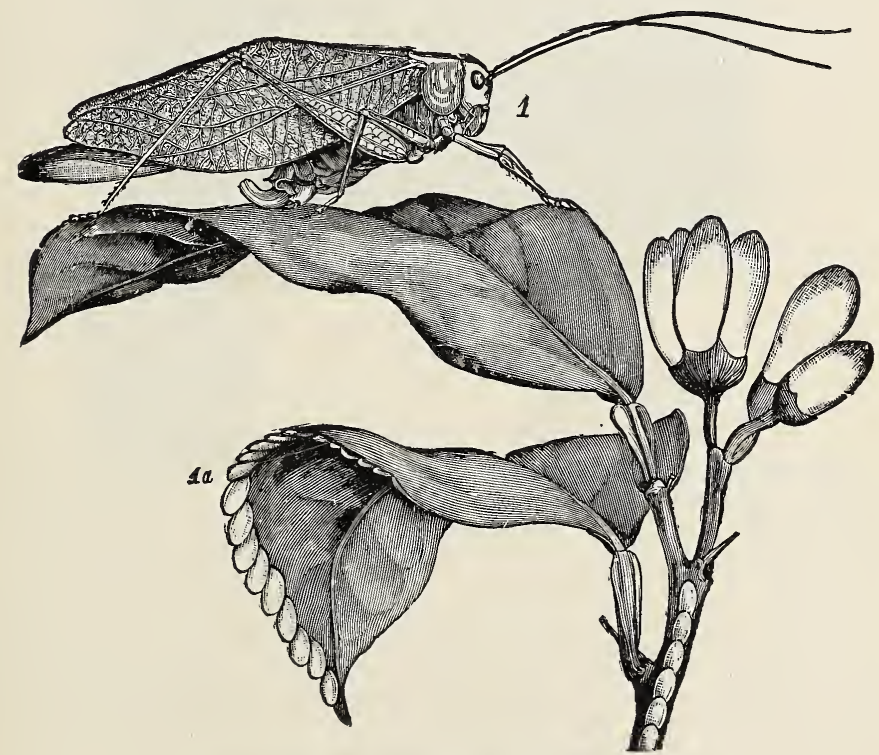

The angular-winged katydid and her eggs. Comstock's Manual. 


\section{LESSON LXXXI}

\section{The Katydid}

Leading thought-The katydids resemble the long-horned grasshoppers and the crickets. They live in trees, and the male sings "katy-did" by means of a musical instrument similar to that of the cricket.

Method-Place a katydid in a cricket cage in the schoolroom, giving it fresh leaves or flowers each day, and encouraging the pupils to watch it at recess. It may be placed in a vial and passed around, for close observation. In studying this insect, use the lesson on the red-legged grasshopper and also that on the cricket. These lessons will serve to call the attention of the pupils to the differences and resernblances between the katydid and these two allied insects.

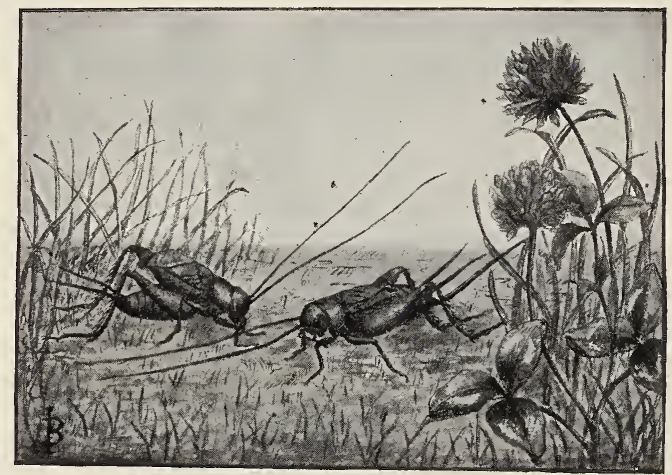

A pair of dusky lovers.

Drawing by Ida Baker.

\section{THE BLACK CRICKETS}

Of the insect musicians the cricket is easily the most popular. Long associated with man, as a companion of the hearth and the field, his song touches ever the chords of human experience. Although we, in America, do not have the housecricket which English poets praise, yet our field-crickets have a liking for warm corners, and will, if encouraged, take up their abode among our hearthstones. The greatest tribute to the music of the cricket is the wide range of human emotion which it expresses. "As merry as a cricket" is a very old saying and is evidence that the cricket's fiddling has ever chimed with the gay moods of dancers and merrymakers. Again, the cricket's song is made an emblem of peace; and again we hear that the cricket's "plaintive cry" is taken as the harbinger of the sere and dying year. From happiness to utter loneliness is the gamut covered by this sympathetic song. Leigh Hunt found him glad and thus addresses him:

"And you, little housekeeper who class

With those who think the candles come too soon,

Loving the fire, and with your tricksome tune

Nick the glad, silent moments as they pass."

WAYS OF THE SiX-Footed. 


\section{THE BLACK CRICKET}

\section{Teacher's Story}

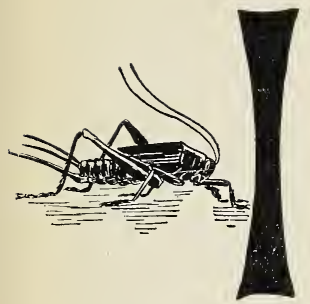

F we wish to become acquainted with these charming little troubadours of the field, we should have a cricket cage with a pair of them within it. Thcy are most companionable, and it is interesting to note how quickly thiey respond to a musical sound. I had a pair in my room at one time, when I lived very near a cathedral. Almost every tine that the bells rang during the night, my cricket would respond with a most vivacious and sympathetic chirping.

The patent leather finish to this cricket's clothes is of great use; for, although the cricket is an efficicnt jumper, it is after all, mostly by running between grass blades that it escapes its enemies. If we try to catch one, we realize how slippery it is, and how efficiently it is thus able to slide through the fingers.

The haunts of the cricket are usually sunny; it digs a little cave beneath a stune or clod in some field, where it can have the whole benefit of all the sunshine, when it issues from its door. These crickets cannot fly, since they have no wings under their wing-covers, as do the grasshoppers. The hind legs have a strong femur, and a short but strong tibia with downward slanting spines along the hind edge, which undoubtedly help the insect in scrambling through the grass. At the cnd of the tibia, next to the foot, is a rosette of five spines, the two longer ones slanting to

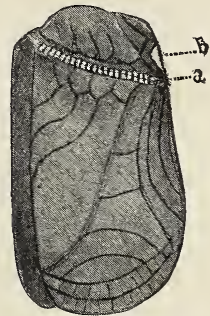

The wing of male cricket enlarged.

a, file b, scraper.

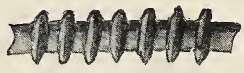

A section of the file enlarged.

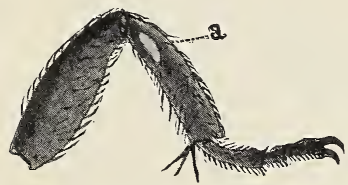

The front leg of a cricket enlarged showing ear at a.

mect the foot; these spines give the insect a firm hold, when making ready for its spring. When walking, the cricket places the whole hind foot flat on the ground, but rests only upon the claw and the segment next to it, of the front pairs of feet. The claws have no pads like those of the katydid or grasshopper; the segment of the tarsus next the claw has long spines on the hind feet and shorter spines on the middle and front feet, thus showing that the feet are not made for climbing, but for scrambling along the ground. When getting ready to jump, the cricket crouches so that the tibia and $f$ mur of the hind legs are shut together and almost on the ground. The dynamics of the cricket's leap are well worth studying. 
The cricket's features are not so easily made out, because the head is polished and black; the eyes are not so polished as the head, and the simple eyes are present but are discerned with difficulty. The antennie are longer than the budy and very active; there is a globular segment where they join the face. I have not discovered that the crickets are so fastidious about keeping generally clean as are some other insects, but they are always cleaning their antennæ : I have seen a cricket play his wing mandolin lustily and at the same tinie carefully clean his antennie; he polished these by putting up a foot and bending the antenna down so that his mouth reached it near the base; he then pulled the antenna through his jaws with great deliberation, nibbling it clean to the very end. The lens reveals to us that the flexibility of the antenna is due to the fact that they are many jointed. The palpi are easily seen, a large pair above and a smaller pair beneath the "chin." The palpi are used to test food and prove if it be palatable. The crickets are fond of melon or other sweet, juicy fruits, and by putting such food into the cage we can see them bite out pieces with their sidewise working jaws, chewing the toothsome morsel with gusto. They take huld of the substance they are eating with the front feet as if to make sure of it.

The wing-covers of the cricket are bent down at the sides at right angles, like a box cover. The wing-covers are much shorter than the abdomen and beneath them are vestiges of wings, which are never used. The nale has larger wing-covers than the female, and they are veined in a peculiar scroll pattern. This veining

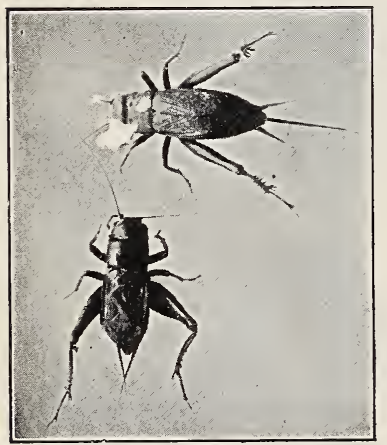

Male and female of the common black cricket, showing differences in their wings. The male is below.

Photo by M. V. Slingerland. seems to be a framework for the purpose of making a sounding board of the wing mernbrane, by stretching it out as a drum-head is stretched. Near the base of the wing-cover, there is a heavy crossvein covered with transverse ridges, which is called the file; on the inner edge of the same wing, near the base, is a hardened portion called the scraper. When he makes his cry, the cricket lifts his wing-covers at an angle of forty-five degrees and draws the scraper of the under wing against the file of the overlapping one; lest his musical apparatus become worn out, he can change by putting the other wing-cover above. The wing-covers are excellent sounding boards and they quiver as the note is made, setting the air in vibration, and sending the sound a long distance. The remale cricket's wing-covers are more normal in venation; and she may always be distinguished from her spouse by the long sword-like ovipositor at the end of her body; this she thrusts into the ground when she lays he- eggs, thus placing them where they will remain safely protected during the winter. Both sexes have a pair of "tail feathers," as the children call them, which are known as the cerci (sing. cerca) and are fleshy prongs at the end of the abdomen. 
There would be no use of the cricket's playing his mandolin if there were not an appreciative ear to listen to his music. This ear is placed most conveniently in the tibia of the front leg, so that the crickets literally hear with their elbows, as do the katydids and the meadow grasshoppers. The ear is easily seen with the naked eye as a little white, disklike spot.

The chirp of the cricket is, in literature, usually assuciated with the coming of autunin; but the careful listener may hear it in early summer, although the song is not then so insistent as later in the season. He usually commences singing in the afternoon and keeps it up periodically all night. I have always been an artmirer of the manly, dignified methods of this little "minnesinger," who does not wander abroad to seek his lady love but stands sturdily at his own gate, playing his mandolin the best he is able; he has faith that his sable sweetheart is not far away, and that if she likes his sung she will come to him of her own free will. The cricket is ever a lover of warmith and his mandolin gets out of tune soon after the evenings become frosty. He is a jealous musician. When he hears the note of a rival, he at once "bristles up," lifting his wings at a higher angle and giving off a sharp nilitant nute. If the two rivals come in sight of each other, there is a fierce duel. They rush at each other with wide open jaws, and fight until one is conquered and retreats, often minus an antenna, cerca, or even a leg. The cricket's note has a wide range of expression. When waiting for his lady love, he keeps up a constant droning: if he hears his rival, the tone is sharp and defiant; but as the object of his affection approaches, the music changes to a seductive whispering, even having in it an uncertain quiver, as if his feelings were too strong for utterance.

References-Manual for Sturly of Insects, p. IJ 5; Insect Musicians;" Ways of the Six Footed, Comstock.

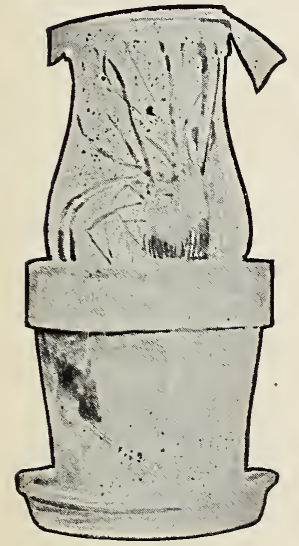

A cricket cage.

\section{LESSON LXXXII}

\section{The BLACK CRICKet}

Leading thought-The crickets are among the most famous of the insect musicians. They live in the fields under stones and in burrows, and feed upon grass and clover. As with the song birds, the male only niakes music; he has his wingcovers developed into a mandolin or violin, which he plays to attract his mate and also for his own pleasure.

Method-Make some cricket cages as follows: Take a snall flower-pot and plant in it a root of fresh grass or clover. Place orer this and press well into the soil a lantern or lanip chiminey. Cover the top with mosquito netting. Place the pot in its saucer, so that it may be watered by keeping the saucer filled. Ask the pupils to collect some crickets. In each case, place a male and one or more fenales, the latter being readily distinguished by the long ovipositors. Place the cages in a sunny window, where the pupils may 
observe them at recess, and ask for the following observations. In studying the cricket closely, it may be well to put one in a vial and pass it around. In observing the crickets eat, it is well to give them a piece of sweet apple or melon rind, as they are very fond of pulpy fruits.

Observations- $\mathrm{x}$. Is the covering of the cricket shining, like black patent leather, or is it dull? What portions are dull? Of what use do you think it is to the cricket to be so smoothly polished?

2. Where did you find the crickets? When you tried to catch them, how did they act? Did they fly like grasshoppers or did they run and leap?

3. Look carefully at the cricket's legs. Which is the largest of the three pairs? Of what use are these strong legs? Look carefully at the tibia of the hind leg. Can you see the strong spines at the end, just behind the foot or tarsus? Watch the cricket jump and see if you can discover the use of these spines. How many joints in the tarsus? Has the cricket a pad like the grasshopper's between its claws? When the cricket walks or jumps does it walk on all the tarsus of each pair of legs?

4. Study the cricket's head. Can you see the eyes? Describe the antennæ- their color, length, and the way they are used. Watch the cricket clean its antennæ and describe the process. Can you see the little feelers, or palpi, connected with the mouth? How many are there? How does it use these feelers in tasting fond before it eats? Watch the cricket eat, and see whether you can tell whether its mouth is made for biting or sucking.

5. Study the wings. Are the wings of the mother cricket the same size and shape as those of her mate? How do they differ? Does the cricket have any wings under these front wings, as the grasshopper does? Note the cricket when he is playing his wing mandolin to attract his mate. How does he make the noise? Can you see the wings vibrate? Ask your teacher to show you a picture of the musical wings of the cricket, or to show you the wings thenselves under the microscope, so that you may see how the music is made.

6. Why does the mother cricket need such a long ovipositor? Where does she put her eggs in the fall to keep them safe until spring?

7. Look in the tibia, or elbow, of the front leg for a little white spot. What do you suppose this is? Are there any white spots like it on the other legs? Ask your teacher to tell you what this is.

8. Can you find the homes of the crickets in the fields? Do the black crickets chirp in the day-time or after dark? Do they chirp in cold or windy weather, or only when the sun shines?

Supplementary Reading-Grasshopper Land, Morley, Chapter XIX.

\section{CRICKET SONG.}

Welcome with thy clicking, cricket!

Clicking songs of sober mirth;

Autumn, stripping field and thicket, Brings thee to my hearth,

Where thy clicking shrills and quickens, While the mist of twilight thickens.
No annoy, good-humored cricket,

With thy trills is ever blent;

Spleen of mine, how dost thou trick it

To a calm content?

So, bv thicket, hearth, or wicket,

Click thy little lifetime, cricket! 


\section{THE SNOWY TREE-CRICKET}

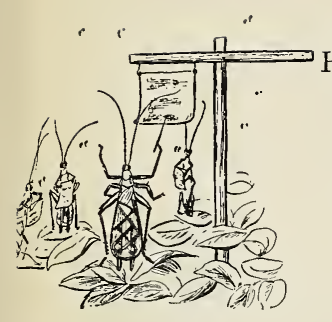

\section{Teacher's Story}

HIS is a slim, ghost-like cricket. It is pale green, almost white in color, and about three-fourths of an inch long. Its long, slender hind legs show that it is a good jumper. Its long antennæ, living threads, pale gray in color, join the head with amber globe-like segments. The pale eyes have a darker center and the palpi are very long. The male has the winga covers shaped and veined like those of the black cricket, but they are not so broad and are whitish and very delicate. The wings beneath are wide, for these crickets can fly. The female has a long, sword-like ovipositor.

The snowy tree-cricket, like its relatives, spends much time at its toilet. It whips the front foot over an antenna and brings the base of the latter to the mandibles with the palpi and then cleans it carefully to the very tip. It washes its face with the front foot, always with a downward movement. If the hind foot becomes entangled in anything it first tries to kick it clean, and then drawing it beneath the body, bends the head so as to reach it with the mandibles and nibbles it clean. The middle foot it also thrusts beneath the body, bringing it forward between the front legs for cleaning. But when cleaning its front feet, the snowy tree-cricket puts on airs; it lifts the elbow high and draws the foot through the mouth with a gesture very like that of a young lady with a seal ring on her little finger, holding the ornate member out from its companions as if it were stiff with a consciousness of its own importance.

There are two common species of the snowy treecrickets which can hardly be separated except by specialists or by watching their habits. One is called "the whistler" and lives on low shrubs or grass; it gives a clear, soft, prolonged, unbroken note. The other is called "the fiddler" and lives on shrubs and in trees and vines. Its note is a pianissimo performance of the katydid's song; it is delightful, rhythmic and sleep-inspiring; it begins in the late afternoon and continues all night until the early, cold hours of the approaching dawn. The vivacity of the music depends upon the temperature, as the notes are given much more rapidly during the hot nights.

"S? far as we know, this snowy tree-cricket is the only one of the insect musicians that seems conscious of the fact that he belongs to an orchestra. If you listen on a September evening, you will hear the first player begin; soon another will join, but not in harmony at first. For some time there may be a

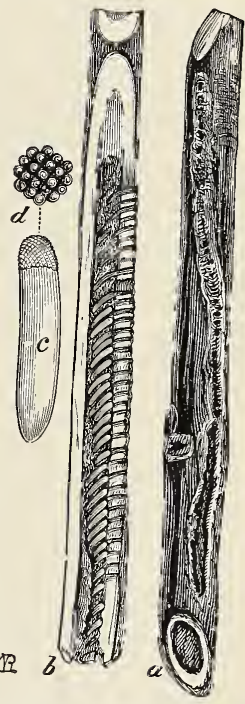

Eggs of snowy tree. cricket, laid in rasp. berry cane.

After C. V. Riley. see-saw of accented and unaccented notes; but after a while the two will be in unison; perhaps not, however, until many more players have joined 
the concert. When the rhythmical beat is once established it is in as perfect tinie as if governed by the baton of a Damrosch or a Thomas. The throbbing of the cricket heart of September, it has been fitly named. Sometimes an injudicious player joins the chorus at the wrong beat, but he soon discovers his error and rectifies it. Sonietimes, also, late at night, one part of the orchestra in an orchard gets out c.f time with the majority, and discord may continue for some moments, as if the players were too cold and too sleepy to play good attention. This delectable concert begins usually in the late afternoons and continues without ceasing until just before dawn the next morning. Many times I have heard the close of the concert; with the "wee sma" hours the rhythmic beat becomes slower; toward dawn there is a falling off in the number of players; the beat is still slower, and the notes are hoarse, as if the fiddlers were tired and coid; finally, when only two or

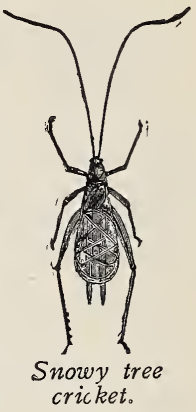
three are left the music stops abruptly." (Ways of the Six-Footed, Coinstock.)

The lesson on this cricket may be adapted from that on the black cricket.

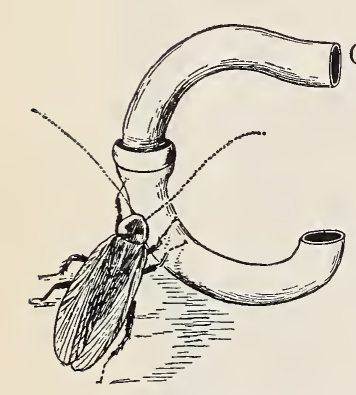

\section{THE COCKROACH}

\section{Teacher's Story}

OCKROACHES in our kitchens are undoubtedly an unmitigated nuisance, and yet, as in many other instances. When we come to consider the individual cockroach, we find him an interesting fellow and exceedingly well adapted for living in our kitchens despite us.

In shape, the cockroach is flat, and is thus well adapted to slide beneath utensils and into crevices and corners. Its covering is smooth and polished like patent leather, and this makes it slippery and enables it to get into food without becoming clogged by the adherence of any sticky substance. The antennæ are very long and flexible and can be bent in any direction. They may be placed far forward to touch things which the insect is approaching, or may be placed over the back in order to be out of the way. They are like graceful, living threads, and the cockroach tests its whole environment with their aid. The mouth has two pairs of palpi or feelers, one of which is very long and noticeable; these are kept. in constant motion as if to test the appetizing qualities of food. The mouth-parts are provided with jaws for biting and, like all insect ja.ws, these work sidewise instead of up and down. The eyes are black but not prominent or large, and seem to be merely a part of the sleek, polished head-covering.

Some species of cockroaches have wings, and some do not.

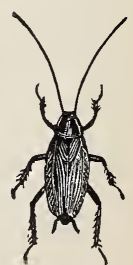

Croton bug. Those which have wings, have the upper pair thickened and used for wing- 
covers. The under pair are thinner and are laid in plaits like a fan. The wing-covers are as polished as the body and quite as successful in shedding dirt.

The legs are armed with long spines which are very noticeable and might prove to be a disadvantaye in accumulating filth; but they are polished also; and too, this insect spends much time at its toilet.

Cockroaches run "like a streak", children say; so speedily, indeed, do they go that they escape our notice, although we may be looking directly at them. This celerity in ranishing, saves many a cockroach from being crushed by an avenging foot.

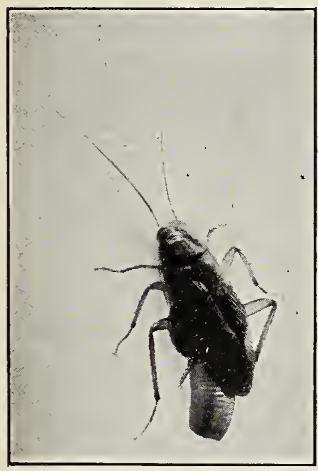

Cockroach laying her case of eggs.

When making its toilet, the cockroach draws its long antenna through its jaws as if it were a whiplash, beginning at the base and finishing at the tip. It cleans each leg by beginning near the body and so stroking downward the long spines which seem to shut against the leg. It nibbles its feet clean to the very claws, and scrubs its head vigorously with the front femur.

The cockroach's

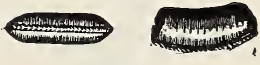

Egg-case of cockroach. eggs are laid in a mass enclosed in a podshaped covering, which is waterproof and polished and protects its contents from dampness. When the cockroaches, or the croton bugs, as the small introduced species of cockroach is called, once become established in a house, the only way to get rid of them is to fumigate the kitchen with carbon bisulphide

Photo hy M. V. Slingerland. which is a dangerous performance and should be done only by an expert.

\section{LESSON LXXXIII}

\section{The Cockruach}

Leading thought-The cockroach is adapted for living in crevices, and although its haunts may be anything but clean, the cockroach keeps itself quite clean. The American species live in fields and woods and under stones and sticks and only occasionally venture into dwellings. The species that infest our kitchens and water-pipes are European.

Method-Place a cockroach in a vial with bread, potato or sorne nther food, cork the vial, and pass it around so that the children may cb serve the prisoner at their leisure.

Observations-I. What is the general shape of the cockroach? Why is this an advantage? What is the texture of its covering? Why is this ais advantage?

2. Describe the antennæ and the way they are used. Note the two little pairs of feelers at the mouth. If possible, see how they are used when the cockroach is inspecting something to eat. Can you see whether its mouth is fitted for biting, lapping or sucking its food? 
3. Note the eyes. Are they as large and prominent as those of the bees or butterflies?

4. Has this cockroach wings? If so, how many and what are they like? Note two little organs at the end of the body? These are the cerci, like those of the crickets.

5. Describe the general appearance of the cockroach's legs, and tell what you think about its ability as a runner.

6. Note how the cockroach cleans itself and how completely and carefully this act is performed. Have you ever seen cockroach's eggs? If so, describe them.

7. How can you get rid of cockroaches if they invade your kitchen?

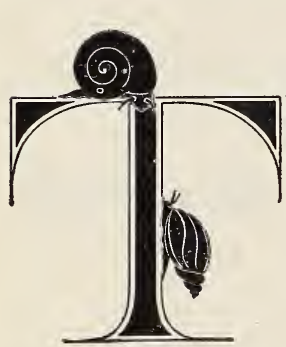

\section{LESSON LXXXIV}

\section{How to Make an Aquarium}

HE schoolroom aquarium may be a very simple affair and still be effective. Almost any glass receptacle will do, glass being chosen because of its transparency, so that the life within may be observed. Tumblers, jelly tumblers, fruit jars, butter jars, candy jars and battery jars are all available for aquaria. The tumblers are especially recommended for observing the habits of aquatic insects.

To make an aquarium: I. Place in the jar a layer of sand an inch or more in depth.

2. In this sand plant the water plants which you find growing under water in a pond or stream; the plants most available are Water-weed, Bladderwort, Water Starwort, Watercress, Stoneworts, Frog-spittle or Water-silk.

3. Place on top a layer of small stones or gravel; this is to hold the plants in place.

4. Tip the jar a little and pour in very gently at one side water taken from a pond or stream. Fill the jar to within two or three inches of the top; if it be a jelly tumbler, fill to within an inch of the top.

5. Let it settle.

6. Place it in a window which does not get too direct sunlight. A north window is the best place; if there is no north window to the school room, place it far enough at one side of some other window so that it will not receive too much sunlight.

7. To get living creatures for the aquarium use a dip-net, which is made like a sha1low, insect net.

8. Dip deep into the edges of the pond and be sure to bring up some of the leaves and mud, for it is in these that the little water animals live.

9. As fast as dipped up, these should be placed in a pail of water, so that they may be carried to the schoolroom.

ro. In introducing the water animals into the aquarium $i t$, is well to put but a few in each jar.

The care of the aquarium-Care should be taken to preserve the plant life in the aquarium, as the plants are necessary to the life of the animals. They not only supply the food, but they give off oxygen which the animals 
need for breathing, and they also take up from the water the poisonous carbonic acid gas given off from the bodies of the animals. air.

I. The aquarium should be kept where there is a free circulation of

2. If necessary to cover the aquarium to prevent the insects, like the water boatmen and water beetles, from escaping, tie over it a bit of mosquito netting, or lay upon the top a little square of wire netting used for window screens.

3. The temperature should be kept rather cool; it is better that the water of the aquarium should not be warmer than 50 deg. Fahrenheit, but this is not always possible in the schoolroom.

4. If any insects or animals die in the aquarium they should be removed at once, as the decomposing bodies render the water foul.

5. To feed the animals that live upon other animals take a bit of raw beef, tie a string to it and drop it in, leaving the free end of the string outside of the jar. After it has been in one day, pull it out; for if it remains longe: it will make the water foul.

6. As the water evaporates it should be replaced with water from the pond.

References-The Fresh Water Aquarium, Eggeling and Ehrenberg; Insect Life, Comstock; The Brook Book, Miller; Nature Study and Life, Hodge ' The Home Aquarium, How to Care for It, Eugene S.mith.

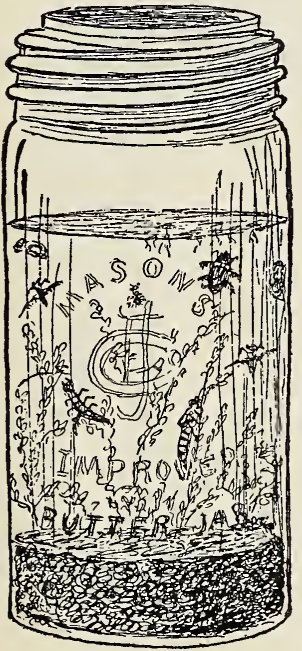

A humble, but useful, aquarium.

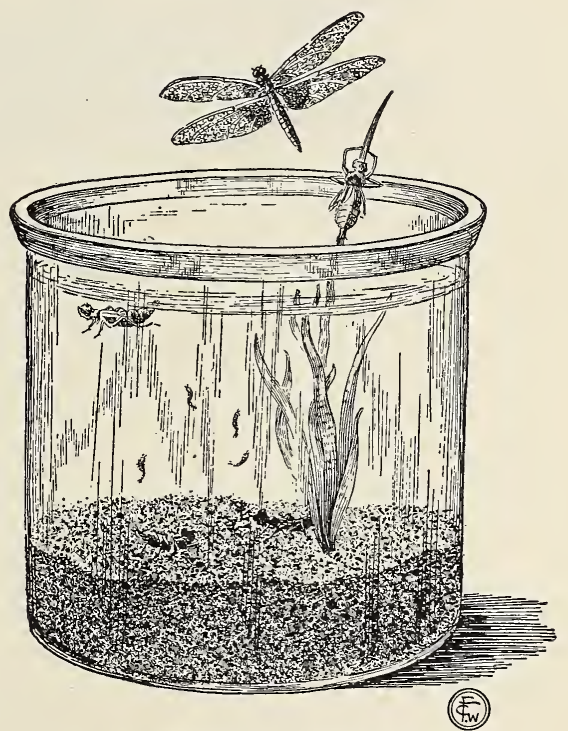

An inexpensive and durable aquarium. 


\section{THE DR.AGON-FLIES AND DAMSEL-FLIES}

\section{Teacher's Story}

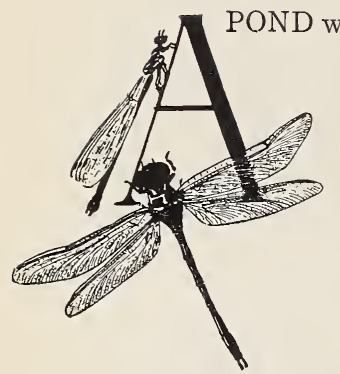

without dragon-flies darting above it, or without the exquisitely iridescent damsel-flies clinging to the leaves of its border would be a lonely place indeed. As one watches these beautiful insects, one wonders at the absurd errors which have crept into popular credence about them. Who could be so silly as to believe that they could sew up ears or that they could bring dead snakes to life! The queer names of these in. sects illustrate the prejudices of the ignorant-devil's darning needles, snake doctors, snake feeders, etc. Despite all this slander, the dragon-flies remain not only entirely harmless to man, but in reality are his friends and allies in waging war against flies and mosquitoes; they are especially valuable in battling mosquitoes since the nymphs, or young, of the dragon-fly, take the wrigglers in the water, and the adults, on swiftest wings, take the mosquitoes while hovering over ponds laying their eggs.

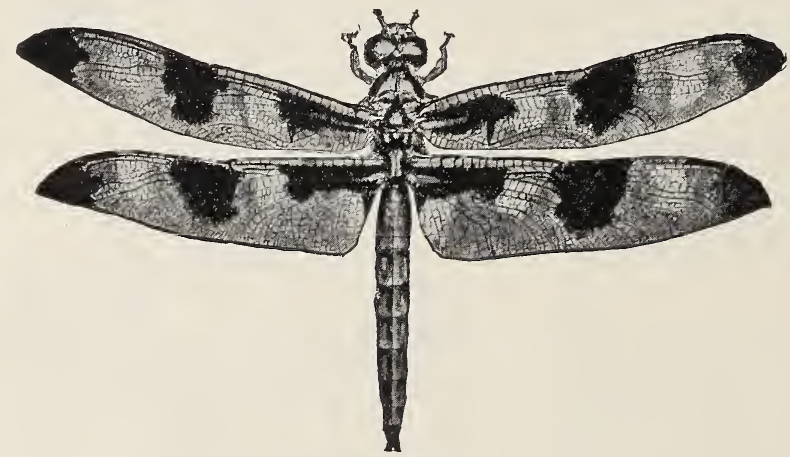

The ten-spot.

From Outdoor Studies, Needham.

The poets have been lavish in their attention to these interesting insects and have paid them delightful tributes. Riley says:

"Till the dragon Ay", in light gauzy armor burnished bright,

Came tilting down the waters in a wild, bewildered fight."

While Tennyson drew inspiration for one of his most beautiful poems from the two stages of dragon-fly life. But perhaps Lowell in that exquisite poem, "The Fountain of Youth," gives us the perfect descriw tion of these insects:

In summer-noon fushes

When all the wood hushes,

Blue dragon-flies knitting

To and fro in the sun,

With sidelong jerk fitting,

Sink donen on the rushes.
And, motionless sitting, Hear it bubble and run, Hear its low inward singing With level wings swinging On green tasselled rushes, Io dream in the sun. 
It is while we, ourserves, are dreaming in the sun by the margin of some pond, that these swift children of the air seem but a natural part of the dream. Yet if we waken to note them more closely, we find many things very real to interest us. First, they are truly children of the sun, and if some cloud throws its shadow on the waters for some moments, the dragon-flies disappear as if they wore the invisible cloak of the fairy tale. Only a few of the common species fly alike in shade and sunshine, and early and late. The best known of these is

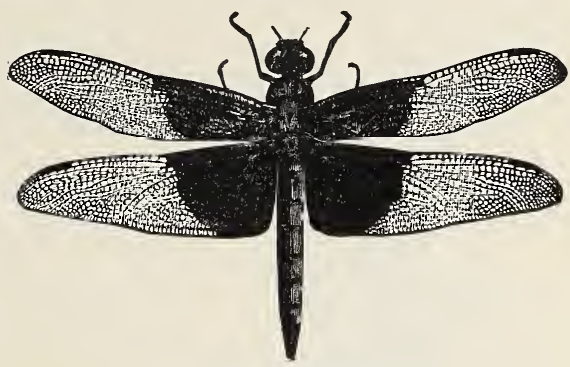

A common dragon-fly.

Comstock's Manual. the big, green skimmer, which does not care so much for ponds, but darts over fields and even dashes into our houses, now and then. Probably it is this species which has started all of the dragon-fly slander, for it is full of curiosity, and will hold itself on wings whirring too rapidly to even make a blur, while it examines our faces or inspects the pictures or furniture or other objects which attract it.

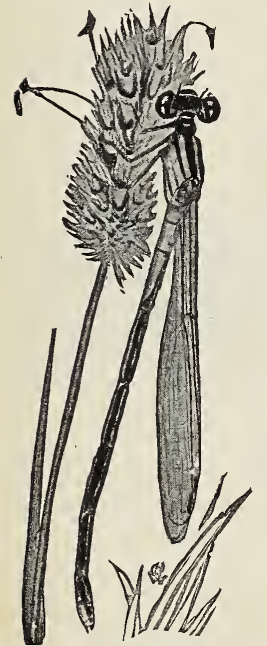

A damsel-fly.

Outdoor Studies Needham.

Another thing we may note when dreaming by the pond is that the larger species of dragon-flies keep to the higher regions above the water, while the smaller species and the damsel-flies flit near its surface. Well may the smaller species keep below their fierce kindred, otherwise they would surely be utilized to sate their hunger, for these insects are well named dragons, and dragons do not stop to inquire whether their victims are relatives or not. It is when they are resting, that the dragon and damsel-flies reveal their most noticeable differences. The dragon-fly extends both wings as if in flight while it basks in the sun or rests in the shadow. There is a big, white-bodied species called the whitetail which slants its wings forward and down when it rests; but the damsel-flies fold their wings together over the back when resting. The damselflies have more brilliantly colored bodies than do the dragon-flies, many of them being iridescent green or coppery; they are more slender and delicate in form. The damsel-fly has eyes which are so placed on the sides of the head as to make it look like a cross on the front of the body fastened to the slender neck, and with an eye at the tip of each arm. There are very many species of dragon and damsel-flies. but they all have the same general habits.

The dragon-fly nymphs are the ogres of the pond or stream. To anyone unused to them and their ways in the aquarium, there is a surprise in store, so ferocious are they in their attacks upon creatures twice 
their size. The dragon-fly's eggs are laid in the water; in some

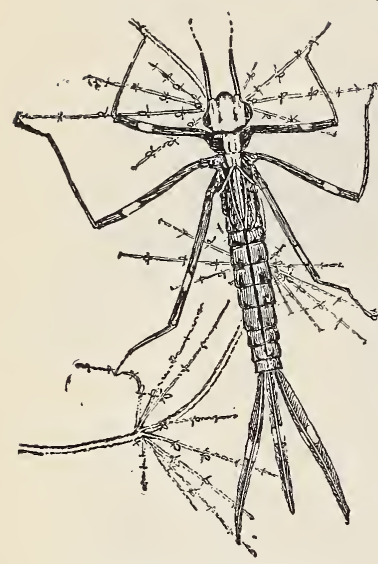
instances they are simply dropped and sink to the bottom; but in the case of damsel-flies, the mother punctures the stems of aquatic plants and places the eggs within them. The nymph in no wise resembles the parent dragon-fly. It is a dingy little creature, with six queer, spider-like legs and no wings; although there are four little wing-pads extending down its back, which encase the growing wings. It may remain hidden in the rubbish at the bottom of the pond or may cling to water weeds at the sides, for different species have different habits. But in them all we find a most amazing lower lip. This is so large that it covers the lower part of the face like a mask, and when folded back reaches down between the front legs. It is in reality a grappling organ with hooks and spines for holding prey; it is hinged in such a manner that it can be thrust out far beyond the head to seize some insect, unsuspecting of danger.

Nymph of a damsel-fly. These nymphs move so slowly and look so much Outdoor Studies, Needham. like their background, that they are always practically in ambush awaiting their victims.

The breathing of the dragon-fly nymphs is peculiar; there is an enlargement of the rear end of the alimentary canal, in the walls of which tracheæ or breathing tubes extend in all directions. The nymph draws water into this cavity and then expels it, thus bathing the tracheæ with the air mixed with water and purifying the air within them. Expelling the water so forcibly, propels the nymph ahead, so this act serves as a method of swimming as well as of breathing. Damsel-fly nymphs, on the other hand, have at the rear end of the body, three long, plate-like gills, each ramified with tracheæ.

Nymphs grow by shedding the skin as fast as it becomes too small; and when finally ready to emerge, they crawl up on some object out of the water, and molt for the last time, and are thereafter swift creatures of the air.

References-American Insects, Kellogg. Comstock's Manual

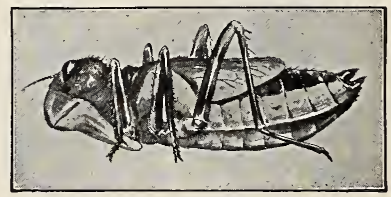

Nymph of a dragon-fly.

Seen from the side, showing the position of the great lower lip when folded beneath the head.

From Outdoor Studies, Needha m.

\section{LESSON LXXXV}

\section{The Dragon-flies and Damsel-flies}

Leading thought-The dragon-flies are among the swiftest of all winged creatures and their rapid, darting flight enables them to hawk their prey, which consists of other flying insects. Their first stages are passed in the bottoms of ponds where they feed voraciously on aquatic creatures. The dragon-flies are beneficial to us because, when very young and when full grown, they feed largely upon mosquitoes. 
Method-The work of observing the habits of adult dragon-flies should be largely done in the field during late summer and early autumn. The points for observation should be given the pupils for summer vacation use, and the results placed in the field note-book.

The nymphs may be studied in the spring, when getting material for the aquarium. April and May are the best months for securing them. They are collected by using a dip-net, and arefound in the bottoms of reedy ponds or along the edges of slow-flowing streams. These nymphs are so voracious that they cannot be trusted in the aquarium with other insects; each must be kept by itself. They may be fed by placing other water insects in the aquarium with them or by giving them pieces of fresh meat. In the latter case, tie the meat to a thread so that it may be removed after a few hours, if not eaten, since it soon renders the water foul.

The dragon-fly aquarium should have sand at the bottom and some water weeds planted in it, and there should be some object in it which extends above the surface of the water which the nymphs, when ready to change to adults, can climb upon while they are shedding the last nymphal skin, and spreading their new wings.

Observations on the young of dragonfies-r. Where did you find these insects? Were they at the bottom of the pond or along the edges among the water weeds?

2. Are there any plume-like gills at the end of the body? If so, how many? Are these plate-like gills used for swimming? If there are three of these, which is the longer? Do you know whether the nymphs with these long gills develop into dragon or into damsel-flies?

3. If there are no plume-like gills at

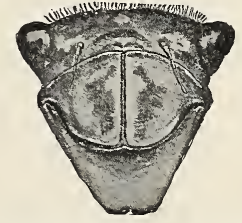

Front view of the same nymph. Outdoor Studies, Needham.

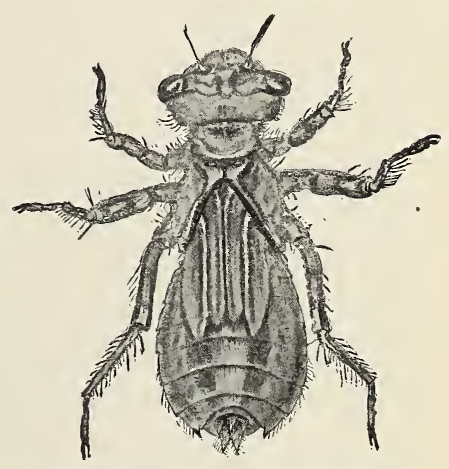

The same nymph seen from above. Outdoor Studies, Needham. the end of the body, how do the insects move? Can they swim? What is the general color of the body? Explain how this color protects them from observation? What enemies does it protect them from?

4. Are the eyes large? Can you see the little wing-pads on the back in which the wings are developing? Are the antennæ long?

5. Observe how the nymphs of both dragon and damsel-flies seize their prey. Describe the great lower lip when extended for prey. How does it look when folded up?

6. Can you see how a nymph without the plume-like gills breathes? Notice if the water is drawn into the rear end of the body and then expelled. Does this process help the insect in swimming?

7. When the dragon or damsel-fly nymph has reached its full growth, where does it go to change to the winged form? How does this change take place? Look on the rushes and reeds along the pond margin, and see 
if you can find the empty nymph skins from which the adults emerged. Where is the opening in them?

Observations on the adult dragon-fies-I. Catch a dragon-fly, place it under a tumbler and see how it is fitted for life in the air. Which is the widest part of its body? Note the size of the eyes compared with the remainder of the head. Do they almost meet at the top of the head? How far do they extend down the sides of the head? Why does the dragon-fly need such large eyes? Why does a creature with such eyes not need long antennæ? Can you see the dragon-fly's antennæ? Look with a lens at the little, swollen triangle between the place where the two eyes join and the forehead; can you see the little, simple eyes? Can you see the mouth-parts?

2. Next to the head, which is the widest and strongest part of the body? Why does the thorax need to be so big and strong? Study the wings. How do the hind wings differ in shape from the front wings? How is the thin membrane of the wings made strong? Are the wings spotted or colored? If so, how? Can you see if the wings are folded along the front edges? Does this give strength to the part of the wing which cuts the air? Take a piece of writing paper and see how easily it bends; fold it two or three times like a fan and note how much stiffer it is. Is it this principle which strengthens the dragon-fly's wings? Why do these wings need to be strong?

3. Is the dragon-fly's abdomen as wide as the front part of the body? What help is it to the insect when flying to have such a long abdomen?

Outline for field notes - Go to a pond or sluggish stream when the sun is shining, preferably at midday, and note as far as possible the following things:

I. Do you see dragon-flies darting over the pond? Describe their flight. They are hunting flies and mosquitoes and other insects on the wing; note how they do it. If the sky becomes cloudy, can you see the dragon-flies hunting? In looking over a pond where there are many dragon-flies darting about, do the larger species fly higher than the smaller ones?

2. Note the way the dragon-flies hold their wings when they are resting. Do they rest with their wings folded together over the abdomen or are they extended out at an angle to the abdomen? Do you know how this difference in attitude of resting determines one difference between the damsel-flies and the dragon-flies?

3. The damsel-flies are those which hold their wings folded above the back when resting. Are these as large and strong-bodied as the dragonflies? Are their bodies more brilliantly colored? How does the shape of the head and eyes differ from those of the dragon-flies? How many different colored damsel-flies can you find?

4. Do you see some dragon-flies dipping down in the water as they fly? If so, they are laying their eggs. Note if you find others clinging to reeds or other plants with the abdomen thrust below the surface of the water. If so, these are inserting their eggs into the stem of the plant.

Supplementary reading-Outdoor Studies, Needham, p. 54; "The Dragon of L?'unita" in Insect Stories, Kellogg. 


\section{THE CADDIS-WORMS AND THE CADDIS-FLIES}

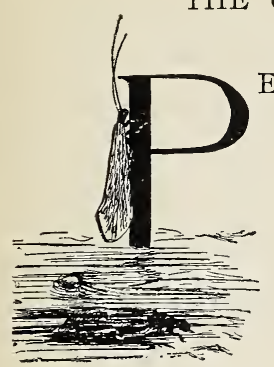

\section{Teacher's Story}

EOPLE are to be pitied who have never tried to fathom the mysteries of the bottom of brook or pond. Just to lie flat, face downward, and watch for a time all that happens down there in that water world, is far more interesting than witnessing any play ever given at matinee. At first one sees nothing, since all the swiftmoving creatures have whisked out of sight, because they have learned to be shy of moving shadows; but soon the crayfish thrusts out his boxing gloves irom some crevice, then a school of tiny minnows "stay their wavy bodies "gainst the stream;" and then something strange happens! A bit of rubbish on the bottom of the brook walks off. Perhaps it is a dream, or we are under the enchantment of the water witches! But no, there goes another, and now a little bundle of sand and pebbles takes unto itself legs. These mysteries can only be solved with a dip-net and a pail half filled with water, in which we may carry home the treasure trove.

When we finally lodge our catch in the aquarium jar, our mysterious moving sticks and stones resolve themselves into little houses built in various fashions, and each containing one inmate. Some of the houses are made of sticks fastened together lengthwise; some are built like log cabins, crosswise; some consist simply of a hollow stem cut a convenient length; and some are made of sand and pebbles, and one, the liveliest of all, is a little tube made of bits of rubbish and silk spun in a spiral, making a little cornucopia.

On the whole, the species which live in the log cabins are the most convenient to study. Whatever the shape of the case or house, it has a very tough lining of silk, which is smooth within, and forms the framework to which the sticks and stones are fastened. These little dwellings always have a front door and a back door. Out of the front door may protrude the dark-colored head followed by two dark segments and six perfectly active legs, the front pair being so much shorter than the other two pairs that they look almost like mouth palpi. In time of utter peace, thore of the little hermit

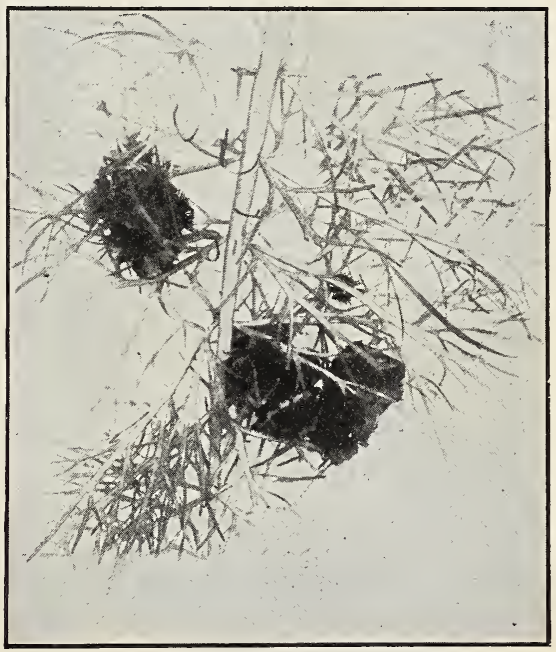

Log cabin caddis-worms in their cases feeding upon a werter plant. Photo by J. T. Lloyd. 
is thrust out and we see the hind segment of the thorax which is whitish, and behind this the abdomen of nine segments. At the sides of the abdomen, and apparently between the segments, are little tassels of short, white thread-like gills. These are filled with air, impure from

$A$ caddis-fly.

Photo by J. T. Lloyd, contact with the blood, and which exchanges its impurities speedily for the oxygen from the air which is mixed with the water. Water is kept flowing in at the front door of the cabin, over the gills and out at the back door, by the rhythmic movement of the body of the little hermit, and thus a supply of oxygen is steadily maintained.

The caddis-worm is not grown fast to its case as is the snail to its shell. If we hold down with forceps a case in which the occupant is wrong side up, after a few struggles to turn itself over, case and all, it will turn over within the case. It keeps its hold upon the case by two forward-curving hooks, one on each side of the tip of the rear segment. These hooks are inserted in the tough silk and hold fast. It also has on top of the first segment of the abdomen a tubercle, which may be extended at will; this helps to brace the larva in its stronghold, and also permits the water to flow freely around the insect. So the little hermit is entrenched in its cell at both ends. When the logcabin species wishes to swim, it pushes almost its entire body out of the case, thrusts back the head,

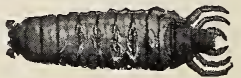

A caddis-worm removed from its case.

Showing gills and the hooks on the last segment for holding fast to the case. spreads the legs wide apart, and then doubles up, thus moving through the water spasmodically, in a manner that reminds us of the crayfish's swimming except that the caddis-worm goes head first. This log cabin species can turn its case over dexterously by movements of its legs.

The front legs of the caddis-worm are so much shorter than the other two pairs that they look like palpi, and their use is to hold close to the jaws bits of food, which are being eaten. The other legs are used for this too if the little legs cannot manage it; perhaps also these short front legs help hold the bits of building material in place while the web is woven to hold it there. The caddis-worm, like the true caterpillars, has the opening of the silk gland near the lower lip. The food of most caddis-worms

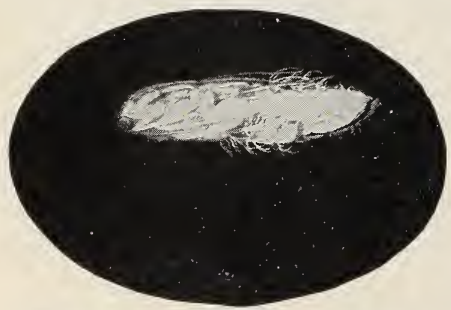

Pupa of caddis-fly removed from its case. Note the thread-like gills. Photo by J. T. Lloyd. is vegetable, usually the various species of water plants; but there are some species which are carnivorous, like the net-builder, which is a fisherman.

The caddis-worm case protects its inmate in two ways: First, from the sight of the enemy, and second, from its jaws. A fish comes along and sees a nice white worm and darts after it, only to find a bundle of unappetizing sticks where the worm was. All of the hungry predatory creatures of the pond and stream would be glad to 
get the caddis-worm, if they knew where it went. Sometimes caddisworm cases have been found in the stomachs of fishes; perhaps they serve as fish breakfast-food.

While it is difficult to see the exact operation of building the caddis-worm house, the general proceeding may bereadily observed. Take a vigorous half-grown larva, tear off part of the sticks and bits of leaves that make the log cabin, and

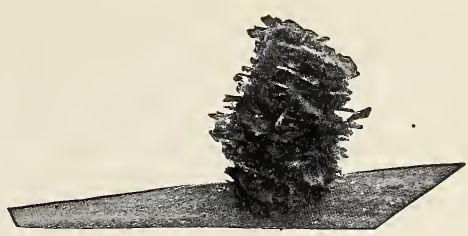

Caddis-worm case fastened to leaf for pupation period.

Photo by J. T. Lloyd. then place the little builder in a tumbler with half an inch of water at the bottom, in which are many bright flower petals cut into strips, fit for caddis lumber. In a few hours the little house will look like a blossom with several rows of bright petals set around its doorway.

When the caddis-worm gets ready to pupate, it fastens its case to some

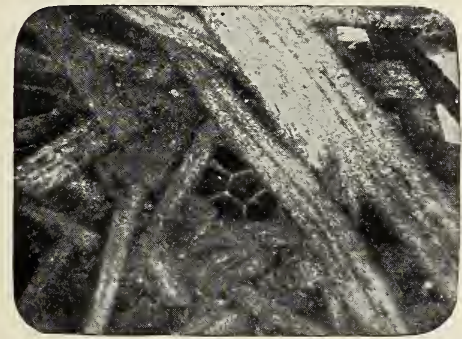

Grating of silk over the door of a caddisworm case to protect the pupa. Photomicrograph by J. T. Lloyd. object in the water and then closes its front and back doors. Different species accomplish this in different ways; some spin and fasten a silken covering over the doors; often this is in the form of a pretty grating; others simply fasten the material of which the case is made across the door. But though the door be shut, it is so arranged as to allow the water to flow through and to bring oxygen to the thread-like gills, which are on the pupæ as well as on the larvæ. When ready to emerge, the pupa crawls out of its case and climbs to some object above the water, sheds its pupa skin, and the adult insect flies off. In some species, living in swift water, the adult issues directly from the water, its wings expanding as soon as touched by the air.

Caddis-flies are familiar to us all even if we do not know them by name. They are night fliers and flame worshippers. Their parchment-like or leathery wings are folded like a roof over the back, and from the side the caddis-fly appears as an elongated triangle with unequal sides. The front wings are long and the hind ones shorter and wider; the antennæ are long and threadlike and always waving about for impressions; the eyes are round and beadlike; the tarsi, or feet, are long and these insects have an awkward way of walking on the entire tarsus which gives them an appearance of kneeling. Most of the species are dull-colored, brownish or gray, the entire insect often being of one color. Caddis-flies would not be so fond of burning themselves in lamps if they had the human sense of smell, for the stench they make when scorching is nauseat-

Caddis-fly.

Photo by J. T. Lloyd. 
ing. The mother caddis-flies lay their eggs in the water. Perhaps some species drop the eggs in when hovering above, but in some cases the insect must make a diving bell of her wings and go down into the water to place her eggs securely. The wings are covered with hairs and not with scales, and therefore they are better fitted for diving than would be those of the moth. I have seen caddis-flies swim vigorously.

References-Aquatic Insects, Miall; Manual for the Study of Insects, Comstock.

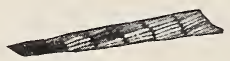

A spiral ribbon caddis-worm case. The inmate of this case is a rapid swimmer. Photo by J. T. Lloyd.

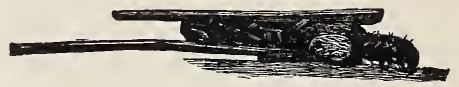

Case and caddis-worm. Comstock's Manual.

\section{LESSON LXXXVI}

\section{The Caddis-worms and Caddis-flies}

Leading thought-The caddis-worms build around themselves little houses out of bits of sticks, leaves or stones. They crawl about on the bottom of the pond or stream, protected from sight, and able to withdraw into their houses when attacked. The adult of the caddis-worm is a winged moth-like creature which comes in numbers to the light at night.

Method-With a dip-net the caddis-worms may be captured and then may be placed in the school aquarium. Duckweed and other water plants should be kept growing in the aquarium. The log cabin species is best for this study, because it lives in stagnant water and will therefore thrive in an aquarium.

Observations - $\mathrm{I}$. Where do you find the caddis-worms? Can you see them easily on the bottom of the stream or pond? Why?

2. Of what are the caddis-worm houses made? How many kinds have you ever found? How many kinds of materials can you find on one case? Describe one as exactly as possible. Find an empty case and describe it inside. Why is it so smooth inside? How is it made so smooth? Are all the cases the same size?

3. What does the caddis-worm do when it wishes to walk around? What is the color of the head and the two segments back of it? What is the color of the body? Why is this difference of color between the head and body protective? Is the caddis-worm grown fast to its case, as the turtle is to its shell?

4. Note the legs. Which is the shorter pair? How many pairs? What is the use of the legs so much shorter than the others? If the caddis-worm case happens to be wrong side up, how does it turn over?

5. When it wishes to come to the surface or swim, what does the caddis-worm do? When reaching far out of its case does it ever lose its hold? How does it hold on? Pull the caddis-worm out of its case and see the hooks at the end of the body with which it holds fast.

6. How does the caddis-worm breathe? When it reaches far out of its case, note the breathing gills. Describe them. Can you see how many 
there are on the segments? How is the blood purified through these gills?

7. What are the caddis-worm's enemies? How does it escape them? Touch one when it is walking, what does it do?

8. On top of the first segment of the abdomen is a tubercle. Do you suppose that this helps to hold the caddis-worm in its case?

9. What does the caddis-worm eat? Describe how it acts when eating.

ro. How does the caddis-worm build its case? Watch one when it mzkes an addition to its case, and describe all that you can see.

I I. Can you find any of the cases with the front and back doors closed? How are they closed? Open one and see if there is a pripa within it. Can you see the growing wings, antennæ and legs? Has it breathing filaments like the larva? Cover the aquarium with mosquito netting so as to get all the moths which emerge. See if you can discover how the pupa changes into a caddis-fly.

r 2. How does the caddis-fly fold its wings? What is the general shape of the insect when seen from the side with wings closed? What is the texture of the wings? How many wings are there? Which pair is the longer?

I3. Describe the eyes. The antennæ. Does the caddis-fly walk on its toes, or on its complete foot?

I4. Examine the moths which come around the lights at night in the spring and summer. Can you tell the caddis-flies from other insects? Do they dash into the light? Do they seem anxious to burn themselves?

Supplementary reading - "A Little Fisherman," Ways of the SixFooted, Comstock.
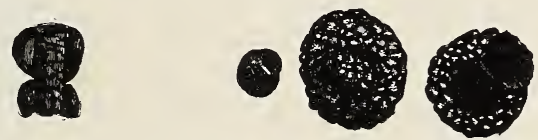

Spiral case of caddis-worm made of small pebbles and sand. Comstock's Manual.

Little brook, so simple so unassuming-and yet how many things love thee!

Lo! Sun and Moon look down and glass themselves in thy waters.

And the trout balances itself hour-long against the stream, watching for its prey; or retires under a stone to rest.

And the water-rats nibble off the willow leaves and carry them below the wave to their nests-or sit on a dry stone to trim their whiskers.

And the May-fly practices for the millionth time the miracle of the resurre: $: 0 n$, floating up an ungainly. grub from the mud below, and in an instant, in the twinkling of an eye (even from the jaws of the baffled trout) emerging, an aerial fairy with pearl-green wings.

And the caddis-fly from its quaint disguise likewise emerges.

And the prick-eared earth-people, the rabbits, in the stillness of early morning play beside thee undisturbed, while the level sunbeams yet grope through the dewy grass.

And the squirrel on a tree-root-its tail stretched far behind-leans forward to kiss thee,

Little brook, for so many things lone thee.

Edward Carpenter. 


\section{THE APHIDS, OR PLANT-LICE}

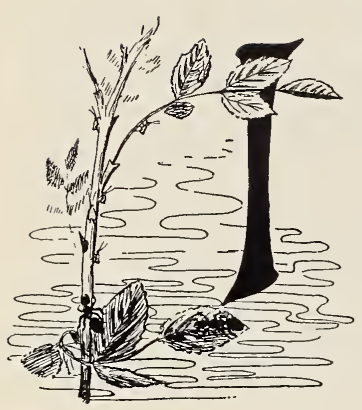

\section{Teacher's Story}

KNOW of no more diverting occupation than watching a colony of aphids through a lens; these insects are the most helpless and amiable little ninnies in the whole insect world; and they look the part, probably because their eyes, so large and wide apart, seem so innocent and wondering. The usual color of aphids is green. As they feed upon leaves, this color protects them from sight; but there are many species which are otherwise colored, and some have most bizarre and striking ornamentations. In looking along an infested leaf stalk, we see them in all stages and positions. One may

have thrust its beak to the hilt in a plant stem, and is so satisfied and absorbed in sucking the juice that its hind feet are lifted high in the air and its antennæ curved backward, making altogether a gesture which seems an adequate expression of bliss; another may conclude to seek a new well, and pulls upits sucking tube, folding it back underneath the body so it will be out of the way, and walks off slowly on its six rather stiff legs; when thus moving, it thrusts the antennæ forward, patting its pathway to insure safety. Perhaps this pathway may lead over other aphids which are feeding, but this does not deter the traveler nor turn it aside; over the

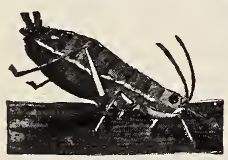

Perfect bliss! backs of the obstructionists it crawls, at which the disturbed ones kick the intruder with both hind legs; it is not a vicious kick but a push rather, which says, "This seat reserved, please!" It is comical to see a row of them sucking a plant stem for "dear life," the heads all in the same direction, and they packed in and around each other as if there were no other plants in the world to give them room, the little ones wedged in between the big ones, until sometimes some of them are obliged to rest their hind legs on the antennæ of the neighbors next behind.

Aphids are born for food for other creaturesthey are simply little machines for making sap into honey-dew, which they produce from the alimentary canal for the delectation of ants; they are, in fact, merely little animated drops of sap on legs. How helpless they are when attacked by any one of their many enemies! All they do, when they are seized, is to claw the air with their six impotent legs and two antennæ, keeping up this performance

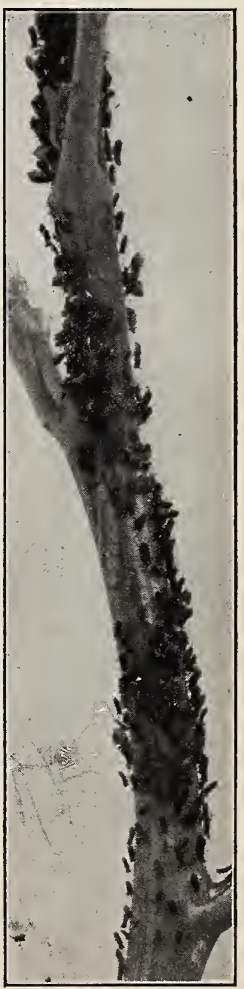

Aphids on plant. Photo by Slingerland. 
as long as there is left a leg, and apparently to the very last, never realizing "what is doing." But they are not without means of defence; those two little tubes at the end of the body are not for ornament nor for producing honey-dew for the ants, but for secreting at their tips a globule of waxy substance meant to smear the eyes of the attacking insect. I once saw an aphid perform this act, when confronted by a baby spider; a drop of yellow liquid oozed out of one tube, and the aphid almost stood on its head in order to thrust this offensive globule directly into the face of the spider-the whole performance reminding me of a boy who shakes his clenched fist in his opponent's face and says, "Smell of that!" The spider beat a hasty retreat.

A German scientist, Mr. Busgen, discovered that a plant-louse smeared the eyes and jaws of its enemy, the aphislion, with this wax which dried as soon as applied. In action it was something like throwing a basin of paste at the head of the attacking party; the aphis-lion thus treated, was obliged to stop and clean itself before it could go on with its hunt, and the aphid walked off in safety. The aphids surely need this protection because they have two fierce enemies, the larvæ of the aphis-lions

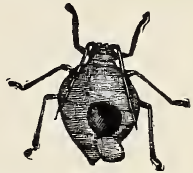

A parasitized aphid enlarged, showing the door cut by the parasite.

and of the ladybirds. They are also the victims of parasitic insects; a tiny four-winged "fly" lays an egg within an aphid; the larva hatching from it feeds upon the inner portions of the aphid, causing it to swell as if afflicted with dropsy. Later the aphid dies, and the interloper with malicious impertinence cuts a neat circular door in the poor aphid's skeleton skin and issues from it a full fledged insect.

The aphids are not without their resources to meet the exigencies of their lives in colonies. There are several distinct forms in each species, and they seem to be needed for the general good. During the summer, we find most of the aphids on plants are without wings; these are females which give birth to living young and do not lay eggs. They do this until the plant is overstocked and the food supply seems to be giving out, then another form is produced which has four wings. These fly away to some other plant and start a colony there; but at the approach of cold weather, or if the food plants give out, there are male and female individuals developed, the females being always wingless, and it is their office to lay the eggs which shall last during the long winter months, when the living aphids must die for lack of food plants. The next spring each winter-egg hatches into a female which we call the "stem mother" since she with her descendants will populate the entire plant.

Plant-lice vary in their habits. Some live in

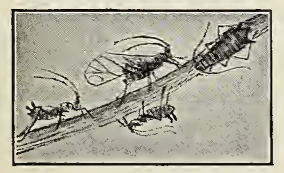

Winged and wingless forms of plant-lice. the ground on the roots of plants and are very destructive; but the greater number of species live on the foliage of plants and are very fond of the young, tender leaves and thus do great damage. Some aphids have their bodies covered with white powder or with tiny fringes, which give them the appearance of being covered with cotton. 
The aphids injuring our flowers and plants may be killed by spraying them with soapsuds made in the proportion of one-quarter pound of ivory soap to one gallon of water. The spraying must be done very thoroughly so as to reach all the aphids hidden on the stems and beneath the leaves. It should be repeated every three days until the aphids are destroyed.

\section{LESSON LXXXVII}

\section{The Aphids, or Plant-lice}

Leading thought-Aphids have the mouth in the form of a sucking tube which is thrust into the stems and leaves of plants; through it the plant juices are drawn for nourishment. Aphids are the source of honey-dew of which ants are fond.

Method-Briilg into the schoolroom a plant infested with aphids, place the stem in water and let the pupils examine the insects through the lens.

Observations-I. How are the aphids settled on the leaf? Are their heads in the same direction? What are they doing?

2. Touch one and make it move along. What does it do in order to leave its place? What does it do with its sucking tube as it walks off? On what part of the plant was it feeding? Why does not Paris green when applied to the leaves of plants kill aphids?

3. Describe an aphid, including its eyes, antennæ, legs and tubes upon the back. Does its color protect it from observation?

4. Can you see cast skins of aphids on the plant? Why does an aphid have to shed its skin?

5. Are all the aphids on a plant wingless? When a plant becomes dry are there, after several days, more winged aphids? Why do the aphids need wings?

6. Do you know what honey-dew is? Have you ever seen it upon the leaf? How is honey-dew made by the aphids? Does it come from the tubes on their back? What insects feed upon this honey-dew?

7. What enemies have the aphids?

8. What damage do aphids do to plants? How can you clean plants of plant-lice?

I saw it (an ant), at first, pass, without stupping, some aphids which it did not however disturb. It shortly after stationed itself near one of the smaliest, and appeared to caress it, by touching the extremity of its body, alternately with is antenne, with an extremely rapid movement. I saw, with much surprise, the fluid proceed from the body of the aphid, and the ant take it in its mouth. Its antennce were afterwards directed to a much larger aphid than the first, which, on being caressed after the same manner, discharged the nourishing fluid in greater quantity, which the ant immediately swallowed: it then passed to a third which it caressed, like the preceding, by giving it several gentle blows, with the antenna, on the posterior extremity of the body; and the liquid was ejected at the same moment, and the ant lapped it up.

Pierre Hubex, I 3 io. 


\section{THE ANT-LION}

\section{Teacher's Story}

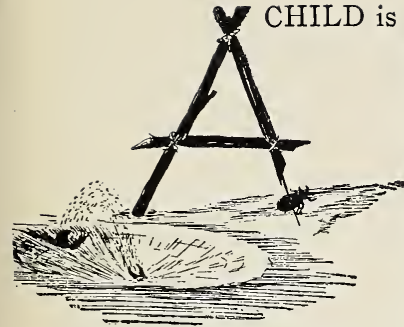

thrilled with fairy stories of ogres in their dens, with the bones of their victims strewn around. The ants have real ogres, but luckily, they do not know about it and so cannot suffer from agonizing fears. The ant ogres seem to have depended upon the fact that the ant is so absorbed in her work that she carries her booty up hill and down dale with small regard for the topography of the country. Thus they build their pits, with instinctive faith that they will some day be entered by these creatures, obsessed by industry and careless of what lies in the path. The pits vary with the size of the ogre at the bottom; there are as many sized pits as are beds in the story of Golden Locks and the bears; often the pits are not more than an inch across, or even less, while others are two inches in diameter. They are always made in sandy or crumbly soil and in a place protected from wind and rain; they vary' in depth in proportion to their width, for the slope is always as steep as the soil will stand without slipping.

All that can be seen of the ogre at the bottom, is a pair of long, curved jaws, looking innocent enough at the very center of the pit. If we dig the creature out, we find it a comical looking insect. It is humpbacked, with a big, spindle-shaped abdomen; from its great awkward body projects a flat, sneaking looking head, armed in front with the sickle jaws which are spiny and bristly near the base, and smooth, sharp and curved at the tip. The strange thing about these jaws is that they lead directly to the throat, since the ant-lion has no mouth. Each jaw is made up of two pieces which are grooved where they join and thus form a tube with a hole in the tip through which the industrious blood of the ants can be sucked; not only do the sharp sickle points hold the victim, but there are three teeth along the side of each jaw to help with this. The two front pairs of legs are small and spiny; the hind legs are strong and peculiarly twisted, and have a sharp spikelike claw at the end, which is so arranged as to push the insect backward vigorously if occasion requires; in fact, the ant-lion in walking about, moves more naturally backward than forward because of the peculiar structure of his legs.

Having studied the ogre, we can see better how he manages to trap his victim. As the ant goes scurrying along, she rushes over the edge of the pit and at once begins to slide downward; she is frightened and struggles to get back; just then a jet of sand, aimed well from the bottom of the pit, hits her and knocks her back. She still struggles,

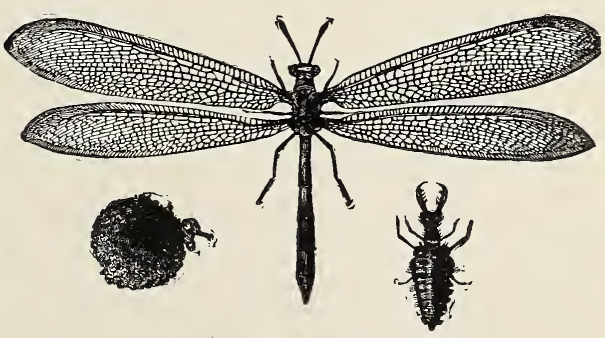

Ant-lion with its cocoon and larva. Comstock's Manual. 
and there follows a fusillade of sand jets, each hitting her from above and knocking her down to the fatal center where the sickle jaws await her and are promptly thrust into her; if she is large and still struggles, the big, unwieldy body of the ogre, buried in the sand, anchors him fast and his peculiar, crooked hind legs push his body backward in this strange tug of war; thus, the ant-ogre is not dragged out of his den by the struggles of the ant, and soon the loss of blood weakens her and she shrivels up.

The secret of the jets of sand, lies in the flat head of the ogre; if we look at it regarding it as a shovel, we can see that it is well fitted for its purpose; for it is a shovel with a strong mechanism working it. In fact, the who'e pit is dug with this shovel head. Wonderful storie; are told about the way that ant-lions dig their pits, marking out the outer margin in a circle, and working inward. However, our common ant-lion of the East simply digs down into the sand and flips the sand out until it makes a pit. If an ant-lion can be caught and put in a jar of sand it will soon make its pit, and the process may be noted carefuliy.

There is one quality in the ogre which merits praise, and that is his patience. There he lies in his hole for days or perhaps weeks, with nothing to eat and no ant coming that way; so when we see an absent-minded ant scrambling over into the pit, let us think of the empty stomach of this patient little engineer which has constructed his pit with such accuracy and so much labor. So precarious is the living jricked up by the ant-lions, that it may require one, two or three years to bring one to maturity. At that time it makes a perfectly globular cocoon of silk and sand, the size of a large pea, and within it, changes to a pupa; and when finally ready to emerge, the pupa pushes itself part way out of the cocoon and the skin is shed and left at the cocoon door. The adult resembles a small dragon-fly; it has large net-veined wings and is a most graceful insect, as different as can be from the humpbacked ogre which it once was-a transformation quite as marvelous as that which occurred in Beauty and the Beast. Throughout the Middle West, the ant-lion in its pit is called the "doodle-bug."

Reference-Manual for Study of Insects, Comstock.

\section{LESSON LXXXVIII}

\section{The Ant-Lion}

Leading thought-The ant-lion, or "doodle-bug" makes a little pit in the sand with very steep sides, and hidden at the bottom of it, waits for ants to tumble in to be seized by its waiting jaws. Later the ant-lion changes to a beautiful insect with gauzy wings, resembling a small dragonfly.

Method-The pupils should see the ant-lion pits in their natural situations, but the insects may be studied in the schoolroom. Some of the ant-lions may be dug out of their pits and placed in a dish of sand. They will soon make their pits, and may be watched during this interesting process. It is hardly advisable to try to rear these insects, as they may require two or three years for development.

Observations- - . Where were the ant-lion pits out of doors? Were they in a windy place? Were they in a place protected from storms? In what kind of soil were they made? 
2. Measure one of the pits. How broad across, and how deep? Are all the pits of the same size? Why?

3. What can you see as you look down into the ant-lion's pit? Roll a tiny pebble in and see what happens? Watch until an ant comes hurrying along and slips into the pit. What happens then? As she struggles to get out how is she knocked back in? What happens to her if she falls to the bottom?

4. Take a trowel and dig out the doodle-bug. What is the shape of its body? What part of the insect did you see at the bottom of the pit? Do you know that these great sickle-shaped jaws are hollow tubes for sucking blood? Does the ant-lion eat anything except the blood of its victim?

5. Can you see that the ant-lion moves backward more easily than forward? How are its hind legs formed to help push it backward? How does this help the ant-lion in holding its prey? How does the big awkward body of the ant-lion help to hold it in place at the bottom of the pit when it seizes an ant in its jaws?

6. What shape is the ant-lion's head? How does it use this head in taking its prey? In digging its pit?

7. Take a doodle-bug to the schoolroom, place it in a dish of sand, covered with glass, and watch it build its pit.

8. Read in the entomological books about the cocoon of the ant-lion and what the adult looks like, and then write an ant-lion autobiography.

Supplementary reading - Insect Stories, Kellogg, "The True Story of Morrowbie Jukes."

\section{THE MOTHER LACE-WING AND THE APHIS-LION}

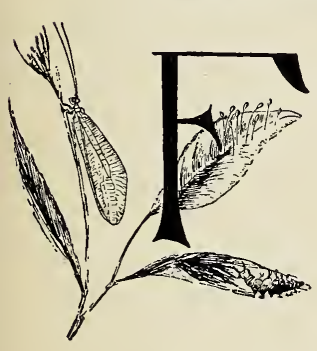

\section{Teacher's Story}

LITTING leisurely through the air on her green gauze wings, the lace-wing seems like a filmy leaf, broken loose and drifting on the breeze. But there is purpose in her flight, and through some instinct she is enabled to seek out an aphis-ridden plant or tree, to which she comes as a friend in need. As she alights upon a leaf, she is scarcely discernible because of the pale green of her delicate body and wings; however, her great globular eyes that shine like gold attract the attention of the careful observer. But though she is so fairy-like in appearance, if you pick her up, you will be sorry if your sense of smell is keen, for she exhales a most disagreeable odor when disturbed - a habit which probably protects her from birds or other creatures which might otherwise eat her.

However, if we watch her we shall see that she is a canny creature despite her frivolous appearance; her actions are surely peculiar. A drop of sticky fluid issues from the tip of her body, and she presses it down on the surface of the leaf; then lifting up her slender abdomen like a distaff, she spins the drop into a thread a half inch long or more, which the air soon dries; and this silken thread is stiff enough to sustain an oblong egg, as large as the point of a pin, which she lays at the very tip of it. This done she lays another egg in a like manner, and when she is through, the 
leaf looks as if it were covered with spore cases of a glittering white mold. This done she flies off and disports herself in the sunshine, care free, knowing that she has done all she can for her family.

After a few days the eggs begin to look dark, and then if we examine them with a lens, we may detect that they contain little doubled-up creatures. The first we see of the egg inmate as it hatches, is a pair of jaws thrust through the shell, opening it for a peep-hole; a little later the owner of the jaws, after resting a while with an eye on the world which he is so soon to enter, pushes out his head and legs and drags out a tiny, long body, very callow-looking and clothed in long, soft hairs. At first the

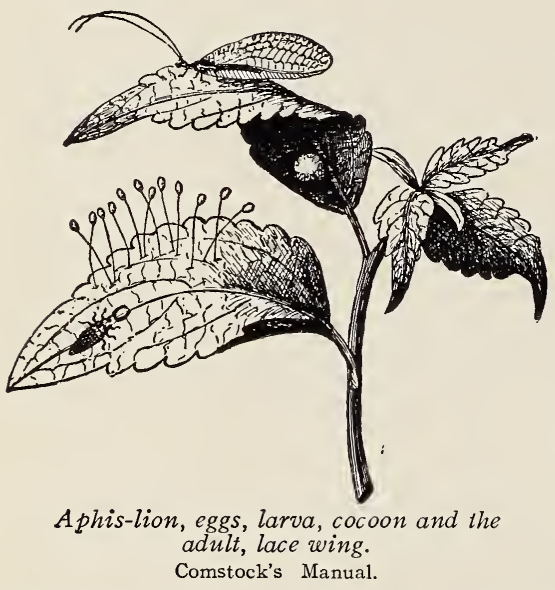
little creature crawls about his egg-shell, clinging tightly with all his six claws, as if fearful of such a dizzy height above his green floor; then he squirms around a little and thrusts out a head inquiringly while still hanging on "for dear life." Finally he gains courage and prospects around until he discovers his egg stalk, and then begins a rope climbing performance, rather difficult for a little chap not more than ten minutes old. He takes a careful hold with his front claws, the two other pairs of legs carefully balanc:ing for a second, and then desperately seizing the stalk with all his clasping claws,

and with many new grips and panics, he finally achieves the bottorn in safety. As if dazed by his good luck, he stands still for a time, trying to make up his mind what has happened and what to do next; he settles the matter by trotting off to make his first breakfast of aphids; and now we can see that it is a lucky thing for his brothers and sisters, still unhatched, that they are high above his head and out of reach, for he might not be discriminating in the matter of his breakfast food, never having met any of his family before. He is a queer looking little insect, spindle-shaped and with peculiarly long, sickle-shaped jaws projecting from his head. Each of these jaws is made up of two pieces joined lengthwise so as to make a hollow tube, which has an opening at the tip of the jaw, and another one at the base which leads directly to the little lion's throat. Watch him as he catches an aphid; seizing the stupid little bag of sap in his great pincers, he lifts it high in the air, as if drinking a bumper, and sucks its green blood until it shrivels up, kicking a remonstrating leg to the last. It is my conviction that aphids never realize when they are being eaten; they simply dimly wonder what is happening.

It takes a great many aphids to keep an aphis-lion nourished until he gets his growth; he grows like any other insect by shedding his skeleton skin when it becomes too tight. Finally he doubles up and spins around himself a cocoon of glistening white silk, leaving it fastened to the leaf; 
when it is finished, it looks like a seed pearl, round and polished. I wish some child would watch an aphis-lion weave its cocoon and tell us how it is done! After a time, a week or two perhaps, a round little hole is cut in the cocoon, and there issues from it a lively little green pupa, with wing pads on its back; but he very soon sheds his pupa skin and issues as a beautiful lace-wing fly with golden eyes and large, filmy, iridescent, pale green wings.

\section{LESSON LXXXIX}

\section{The Mother Lace-wing and the Aphis-lion}

Leading thought-The lace-wing fly or golden-eyes, as she is called, is the mother of the aphis-lion. She lays her eggs on the top of stiff, silken stalks. The young aphis-lions when hatched, clamber down upon the leaf and feed upon plant-lice, sucking their blood through their tubular jaws.

Method-Through July and until frost, the aphis-lions may be found on almost any plant infested with plant-lice; and the lace-wing's eggs or egg-shells on the long stalks are also readily found. All these may be brought to the schoolroom. Place the stem of a plant infested with aphids in a jar of water, and the acts of the aphis-lions as well as the habits of the aphids may be observed during recess or at other convenient times, by all the pupils.

Observations-r. When you see a leaf with some white mold upon it, examine it with a lens; the mold is likely to be the eggs of the lace-wing. Is the egg as large as a pin head? What is its shape? What is its color? How long is the stalk on which it is placed? Of what material do you think the stalk is made? Why do you suppose the lace-wing mother lays her eggs on the tips of stalks? Are there any of these eggs near each other on the leaf?

2. If the egg is not empty, observe through a lenshow the young a phis-lion breaks its egg-shell and climbs down.

3. Watch an aphis-lion among the plant-lice. How does it act? Do the aphids seem afraid? Does the aphis-lion move rapidly? How does it act when eating an aphid?

4. What is the general shape of the aphis-lion? Describe the jaws. Do you think these jaws are used for chewing, or merely as tubes through which the green blood of the aphids is sucked? Do the aphis-lions ever attack each other or other insects? How does the aphis-lion differ in appearance from the ladybird larva?

5. What happens to the aphis-lion after it gets its growth? Describe its cocoon if you can find one.

6. Describe the little lace-wing fly that comes from the cocoon. Why is she called, golden-eyes? Why lace-wing? Does she fly rapidly? Do you suppose that if she should lay her eggs flat on a leaf, that the first aphis-lion that hatched would run about and eat all its little brothers and sisters which were still in their egg-shells? How do the aphis-lions benefit our rose bushes and other cultivated plants? Footed.

Supplementary Reading- "A Tactful Mother" in Ways of the Six. 


\section{THE MOSQUITO}

\section{Teacher's Story}

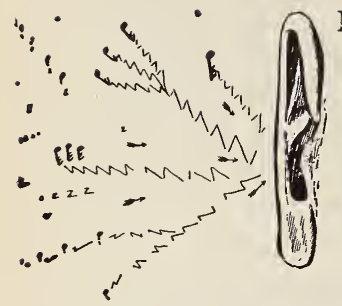

$\mathrm{N}$ DEFIANCE of the adage, the mother of our most common mosquitoes does not hesitate to put her eggs all in one basket, but perhaps she knows it is about the safest little basket for eggs in this world of uncertainties. If it were possible to begin this lesson with the little boat-shaped egg baskets, I should advise it. They may be found in almost any rain barrel, and the eggs look like a lot of tiny cartridges set side by side, points up, and lashed or glued together, so there shall be no spilling. Like a certain famous soap, they "float," coming up as dry as varnished corks when water is poured upon them.

The young mosquito, or wriggler, breaks through the shell of the lower end of the egg and passes down into the water, and from the first, it is a most interesting creature to view through a hand lens. The head and the thorax are rather large while the body is tapering and

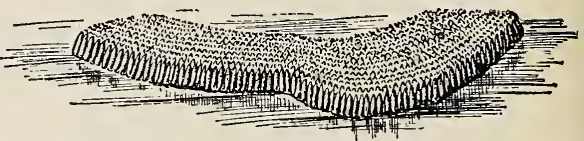

The egg-rajı c, a mosquito enlarged. armed with bunches of hairs. At the rear of the body are two tubes very different in shape; one is long, straight and unadorned; this is the breathing tube through which air passes to the tracheæ of the body. This tube has a star-shaped valve at the tip, which can be opened and shut; when it is opened at the surface of the water, it keeps the little creature afloat and meanwhile allows air to pass into the body. When the wriggler is thus hanging at an angle of 45 degrees to the surface of the water, it feeds upon small particles of decaying vegeta-

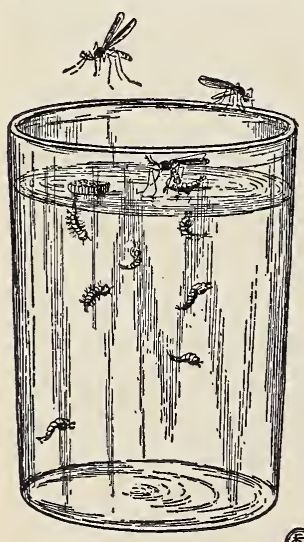

A mosquito aquarium. tion; it has a remarkable pair of jaws which are armed with brushes, which in our common species, by moving rapidly, set up currents and bring the food to the mouth. This process can be seen plainly with a lens. When disturbed, the wriggler shuts the valve to its breathing tube, and sinks. However, it is not much heavier than the water; I have often seen one rise for some distance without apparent effort. The other tube at the end of the body, supports the swimming organs, which consist of four finger-like processes and various bunches of hairs. When swimming, the wriggler goes tail first, the swimming organs seeming to take hold of the water and to pull the creature backward, in a series of spasmodic jerks; in fact, the insect seems simply to "throw somersaults," like an acrobat. I have often observed wrigglers standing on their heads in the bottom of the aquarium, with their jaws bent 
under, revolving their brushes briskly; but they never remain very long below the surface, as it is necessary for them to take in fresh air often.

The pupa has the head and thoracic segments much enlarged, making it all "head and shoulders" with a quite insignificant body attached. Upon the thorax are two breathing tubes, which look like two ears, and therefore when the pupa rests at the surface of the water, it remains head up so that these tubes may take in the air; at the end of the body are two swimming organs which are little, leaf-like projections. At this stage the insect is getting ready to live its life in the air, and for this reason probably, the pupa rests for long periods at the surface of the water and does not swim about much, unless disturbed. However, it is a very strange habit for a pupa to move about at all. In the case of other flies, butterflies, and moths, the pupa stage is quiet.

When fully mature, the pupa rises to the surface of the water, the skeleton skin breaks open down its back and the mosquito carefully works itself out, until its wings are free and dry, meanwhile resting upon the floating pupa skin. This is indeed a frail bark, and if the slightest breeze ruffles the water, the insect is likely to drown before its wings are hard enough for flight.

The reason that kerosene oil, put upon the surface of the water where mosquitoes breed, kills the insects is because both the larvæ and pupæ of mosquitoes are

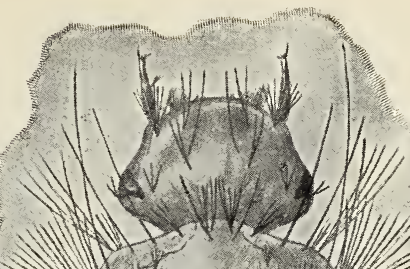
- 14

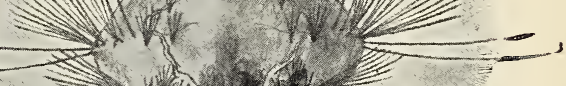
obliged to rise to the surface, and push their breathing tubes through the surface film so that they will open to the air; a coating of oil on the water prevents this, and they are suffocated. Also when the mosquito emerges from the pupa skin, if it is even touched by the oil, it is unable to fly and soon dies.

A wriggler or larva of mosquito (culex) greatly enlarged.

Drawn by Evelyn Mitcheil.

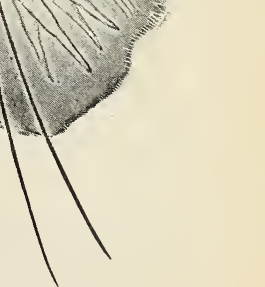


The male mosquitoes have bushy, or feathery, antennæ These antennæ are hearing organs of very remarkable construction; (see Ways of the Six-Footed, p. 8.) The Anopheles may be distinguished from the Culex by the following characteristics: Its wings are spotted instead of

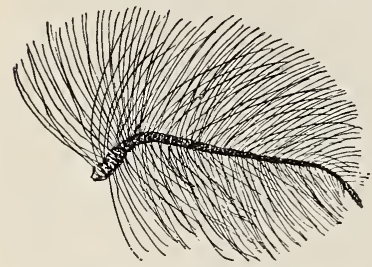

Antenna of mále mosquito enlarged. plain. When at rest it is perfectly straight, and is likely to have the hind legs in the air. It may also rest at an angle to the surface to which it clings. The Culex is not spotted on the wings and is likely to be humped up when at rest. In our climate the Anopheles is more dangerous than the Culex because it carries the germs of malaria. A mosquito's wing under a microscope is a most beautiful object, as it is "trimmed" with ornamental scales about the edges and along the veins. The male mosquitoes neither sing nor bite; the song of the female mosquito is supposed to be made by the rapid vibration of the wings, and her musical performances are for the purpose of attracting her mate, as it has been shown that he can hear through his antennæ a range of notes covering the middle and next higher octaves of the piano.

Of late we are learning that the mosquitoes are in a very strange way a menace to health. Through a heroism, as great as ever shown on field of battle, men have imperiled their lives to prove that the germs of the terrible yellow fever were transmitted by the biting mosquito, and with almost equal bravery other men have demonstrated that the germs of malaria are also thus carried.

In the North, our greatest danger is from the mosquitoes which carry the malarial germs, and these are the mosquitoes with spotted wings and belong to the genus Anopheles. This mosquito, in order to be of danger to us must first feed upon the blood of some person suffering from malaria (ague) and thus take the germ of the disease into its stomach. Here the germ develops and multiplies into many minute germs, which pass through another stage and finally get into the blood of the mosquito and accumulate in the salivary glands. The reason any mosquito bite or insect bite swells and itches is because, as the insect's beak is inserted into the flesh, it carries with it some of the saliva from the insect's mouth. In the case of Anopheles these malarial germs are carried with the saliva into the blood of the victim. It has been proven that in the most

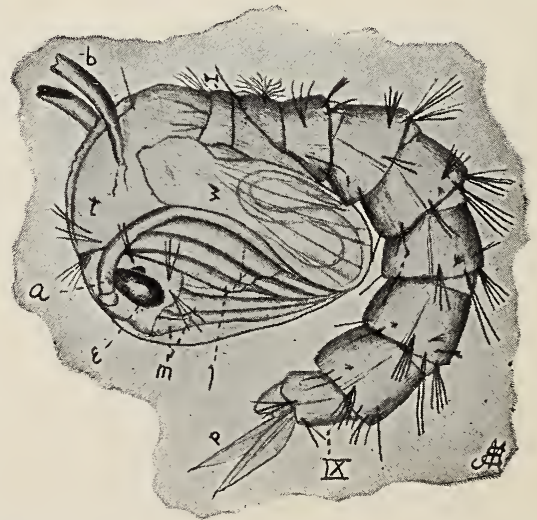

The pupa of a mosquito, greatly magnified. Note $\mathrm{b}$ the breathing tubes near the head. Drawn by Evelyn Mitchell. 
nalarial countries, like Italy and India, people are entirely free from nalaria if they are not bitten by mosquitoes.

After this explanation has been made, it would be well for the teacher to take the pupils on a tour of inspection through the neighborhood to see if there are any mosquito larvæ in rain barrels, ponds or pools of stagnant water. If such places are found, let the pupils themselves apply the following remedies:

I. Rain barrels should be securely covered.

2. All stagnant pools should be drained and filled up if possible.

3. Wherever there are ponds or pools where mosquitoes breed that cannot be filled or drained, the surface of the water should be covered with a spray of kerosene oil. This may be applied with a spray pump or from a watering can.

4. If it is impracticable to cover such places with oil, introduce into such pools the following fish: Minnows, sticklebacks, sunfish and goldfish.

The effect of this lesson upon the children should be to impress them with the danger to life and health from mosquitoes and to implant in them a determination to rid the premises about their homes of these pests.

References-Farmers' Bulletin No. I55, U. S. Department of Agriculture, by L. O. Howard; leaflet in Reading Course for Farmers' Wives, series 2, No. ro, by M. V. Slingerland; American Insects, Kellogg; The Insect Book, Howard; Insect Life, The Manual for the Study of Insects, Comstock; Ways of the Six-Footed, Comstock.

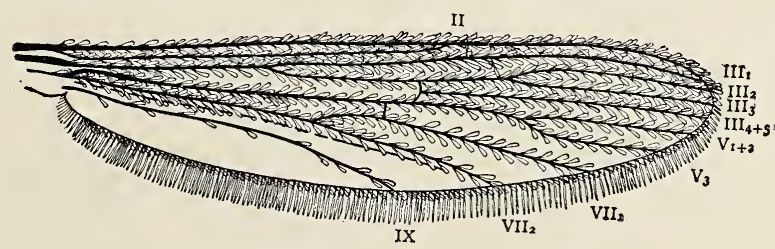

Wing of mosquito enlarged.

Comstock's Manual.

\section{LESSON XC}

\section{The Mosouito}

Leading thought-The wrigglers, or wigglers, which we find in rainbarrels and stagnant water are the larvæ of mosquitoes. We should study their life history carefully if we would know how to get rid of mosquitoes.

Method-There is no better way to interest the pupils in mosquitoes than to place in an aquarium jar in the schoolroom a family of wrigglers from some pond or rain barrel. For the pupils' personal observation, take some of the wrigglers from the aquarium with a pipette and place them in a homeopathic vial; fill the vial three-fourths full of water and cork it. Pass it around with a hand lens and give each pupil the opportunity to nbserve it for five or ten minutes. It would be well if this vial could be left on each desk for an hour or so during study periods, so that the 
observations may be made casually and leisurely. While the pupils are studying the wrigglers, the following questions should be placed upon the blackboard, and each pupil should make notes which may finally be given at a lesson period. This is particularly available work for September.

In studying the adult mosquito, a lens or microscope is necessary. But it is of great importance that the pupils be taught to discriminate between the comparatively harmless species of Culex and the dangerous Anopheles and therefore they should be taught to be observant of the way mosquitoes rest upon the walls, and whether they have mottled or ciear wings.

\section{The Larva}

Observations: I. Note if all the wrigglers are of the same gen eral shape, or if some of them have a very large head; these latter are the pupæ and the former are the larvæ. We will study the larvæ first. Where do they rest when undisturbed? Do they rest head up or down? Is there any part of their body that comes to the surface of the water?

2. When disturbed what do they do? When they swim, do they go head or tail first? When they float do they go upward or downward?

3. Observe one resting at the top. At what angle does it hold itself to the surface of the water? Observe its head. Can you see the jaw brushes revolving rapidly? What is the purpose of this? Describe its eyes. Can you see its antennæ?

4. Note the two peculiar tubes at the end of the body and see if you can make out their use.

5. Note especially the tube that is thrust up to the surface of the water when the creatures are resting. Can you see how the opening of this tube helps to keep the wriggler afloat? What do you think is the purpose of this tube? Why does it not become filled with water when the wriggler is swimming? Can you see the two air vessels, or trachæ, extending from this tube along the back the whole length of the body?

6. Note the peculiarities of the other tube at the rear end of the body. Do you think the little finger-like projections are an aid in swimming? How many are there?

7. Can you see the long hairs along the side of the body?

8. Does the mosquito rest at the bottom of the bottle or aquarium?

\section{The Pupa}

9. What is the most noticeable difference in appearance between the larva and pupa?

Io. When the pupa rests at the surface of the water, is it the same end up as the wriggler?

I I. Note on the "head" of the pupa two little tubes extending up like ears. These are the breathing tubes. Note if these open to the air when the pupa rests at the surface of the water.

I 2. Can you see the swimming organs at the rear of the body of the pupa? Does the pupa spend a longer time resting at the surface than the larva. How does it act differently from the pupæ of other flies and moths and butterflies?

I3. How does the mosquito emerge from the pupa skin? Why does kerosene oil poured on the surface of the water kill mosquitoes? 


\section{The Adult Mosquito}

I. Has the mosquito feathery antennæ extending out in front? If so, what kind of mosquitoes are such?

2. Do the mosquitoes with bushy antennæ bite? Do they sing?

3. Are the wings of the mosquito spotted or plain? How many has it?

4. When at rest, is it shortened and humpbacked or does it stand straight out with perhaps its hind legs in the air?

5. What are the characteristics by which you can tell the dangerous Anopheles?

6. Why is the Anopheles more dangerous than the Culex?

7. Examine a mosquito's wing under a microscope and describe it.

8. Examine the antennæ of a male and a female mosquito under a microscope, and describe the difference.

9. Which sex of the mosquito does the biting and the singing?

ro. How is the singing done?

\section{THE HOUSE-FLY}

\section{Teacher's Story}

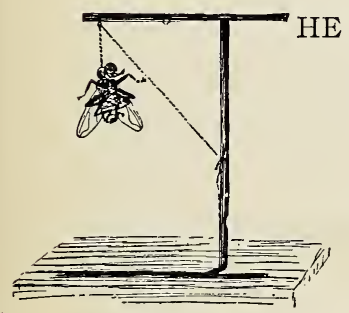

house-fly is surely an up-to-date member of that select class which evolutionists call the "fit." It flourishes in every land, plumping itself down in front of us at table, whether we be eating rice in Hong Kong, dhura in Egypt, macaroni in Italy, pie in America, or tamales in Mexico. There it sits, impertinent and imperturbable, taking its toll, letting down its long elephant-trunk tongue, rasping and sucking up such of our meal as fits its needs. As long as we simply knew it as a thief we, during untold ages, merely slapped it and shooed it, which effort on our part apparently gave it exhilarating exercise. But duringrecent years we have begun trapping and poisoning, trying to match our brains against its agility; although we slay it by thousands, we seem only to make more room for its well-fed progeny of the future, and in the end we seem to have gained nothing. But the most recent discoveries of science have revealed to us, that what the house-fly takes of our food, is of little consequence to what it leaves behind. Because of this, we have girded up our loins and gone into battle in earnest.

I have always held that nature-study should follow its own peaceful path and not be the slave of economic science. But occasionally it seems necessary, when it is a question of creating public sentiment, and of cuitivating public intelligence in combating a great peril, to make naturestudy a handmaiden, if not a slave, in this work. If our woods were filled with wolves and bears, as they were in the days of my grandfather, I should give nature-study lessons on these animals, which would lead to their subjugation. Bears and wolves trouble us no more; but now we have enemies far more subtle, in the ever-present microbes, which we may never hope to conquer but which, with proper precautions, we may render comparatively harmless. Thus, our nature-study with insects which 
carry disease, like the mosquitoes, flies and fleas, must be a reconnaissance for a war of extermination; the fighting tactics may be given in lesson.; on health and hygiene.

Perhaps if a fly were less wonderfully made, it would be a less convenient vehicle for microbes. Its eyes are two great, brown spheres on either side of the head, and are composed of thousands of tiny six-sided

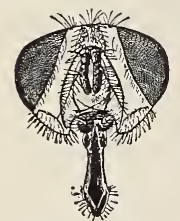

Head of fly showing eyes, antenne and mouthparts. eyes that give information of what is coming in any direction; in addition, it has on top of the head, looking straight up, three tiny, shining, simple eyes, which cannot be seen without a lens. Its antennæ are peculiar in shape, but are evidently sense organs; it is attracted from afar by certain odors, and so far as we can discover, its antennæ are all the nose it has. Its mouth-parts are all combined to make a most amazing and efficient organ for getting food; at the tip are two flaps, which can rasp a substance so as to set free the juices, and above this is a tube, through which the juices may be drawn to the stomach. This tube is extensible, being conveniently jointed so that it can be folded under the "chin" when not in use. This is usually called the fly's tongue, but it is really all the mouth parts combined, as if a boy had his lips, teeth and tongue, standing out from his face, at the end of a tube a foot long.

The thorax can be easily studied; it is striped black and white above and bears the two wings, and the two little flaps that are called balancers and which are probably remnants of hind wings which the remote ancestors of flies flew with. The fly's wing is a transparent but strong membrane strengthened by veins, and is prettily iridescent. The thorax bears on its lower side the three pairs of legs. The abdomen consists of five segments and is covered with stiff hairs. The parts of the leg, seen when the fly is walking, consists of three segments, the last segment or tarsus being more slender, and if looked at with a lens, is seen to be composed of five segments, the last of which bears the claws; it is with these claws that the fly walks, although all of the five segments really form the foot; in other words, it walks on its tip-toes. But it clings to ceilings by means of the two little pads below the claws, which are covered with hairs that excrete at the tips, a sticky fluid. Because of the hairs on its feet, the fly becomes a carrier of microbes and a menace to health.

The greatest grudge I have against this little, persistent companion of our household is the way it has misled us by appearing to be so fastidious in its personal habits. We have all of us seen, with curiosity and admiration, its complex ablutions and brushings. It usually begins, logically, with its front feet, the hands; these it cleans by rubbing them against each other lengthwise. The hairs and spines on one leg act as a brush for the other, and then lest they be not clean, it nibbles them with its rasping disc, which is all the teeth it has. It then cleans its head with these clean hands, rubbing them over its big eyes with a vigor that makes us wink simply to contemplate; then bobbing its head down so as to reach what is literally its back hair, it brushes valiantly. After this is done, it reaches forward first one and then the other foot of the middle pair of legs, and taking each in turn between the front feet, brushes it vigorously, and maybe

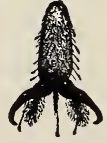

Foot of house-fly enlarged. 
nibbles it. But as a pair of military brushes, its hind feet are conspicuously efficient; they clean each other by being rubbed together and then they work simultaneously on each side in cleaning the wings, first the under side and then the upper side. Then over they come and comb the top of the thorax; then they brush the sides, top and under sides of the abdomen, cleaning each other between the acts. Who, after witnessing all this, could believe that the fly could leave any tracks on our food, which would lead to our undoing! But the house-fly, like many housekeepers with the best intentions in the matter of keeping clean, has not mastered the art of getting rid of the microbes. Although it has so many little eyes, none of them can magnify a germ so as to make it visible; and thus it is that, when feeding around where there have been cases of typhoid and other enteric diseases, the house-fly's little claws become infested with disease germs; and when it stops some day to clean up on our table, it leaves the germs with us. Thus our only safety lies in the final extermination of this little nuisance.

It is astonishing how few people know about the growth of flies. People of the highest intelligence in other matters, think that a small fly can grow into a large one. A fly, when it comes from the pupa stage, is as large as it will ever be, the young stages of flies being maggots. The house-fly's eggs are little, white, elongated bodies about as large as the point of a pin. These are laid preferably in horse manure. After a few hours, they hatch into slender, pointed, white maggots which feed upon the excrement. After five or six days, the larval skin thickens, turns brown, making the insect look like a small grain of wheat. This is the pupal stage, which lasts about five days, and then the skin bursts open and the full-grown fly appears. Of course,

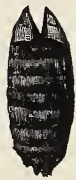

Empty pupa skin of fly, enlarged. not all the flies multiply according to the example given to the children. The house-fly has many enemies and, therefore, probably no one hibernating mother fly is the ancestress of billions by September; however, despite enemies, flies multiply with great rapidity.

I know of no more convincing experiment as an example of the dangerous trail of the fly, than that of letting a house-fly walk over a saucer of nutrient gelatin. After three or four days, each track is plainly visible as a little white growth of bacteria.

Much is being done now to eradicate the house-fly, and undoubtedly there will be new methods of fighting it devised every year. The teacher should keep in touch with the bulletins on this subject published by the United States Department of Agriculture, and should give the pupils instructions according to the latest ideas. At present the following are the methods of fighting this pest: Keep the stable clean and place the manure under cover. All of the windows of the house should be well screened. All the flies which get into the house should be killed by using the commercial fly papers. 


\section{LESSON XCI}

\section{The House-Fly}

Leading thought-The house-fly has conquered the world and is found everywhere. It breeds in filth and especially in horse manure. It is very prolific; the few flies that manage to pass the winter in this northern climate, are ancestors of the millions which attack us and our food later in the season. These are a menace to health because they carry germs of disease from sputa and excrementitious matter to our tables, leaving them upon our food.

Method-Give out the questions for observation and let the pupils answer them either orally or in their note-books. If possible, every pupil should look at a house-fly through a three-quarters objective. If this is not possible, pictures should be shown to demonstrate its appearance.

Observations-r. Look at a fly, using a lens if you have one. Describe its eyes. Do you see that they have a honeycomb arrangement of little eyes? Can you see, on top of the head between the big eyes, a dot? A microscope reveals this dot to be made of three tiny eyes, huddled together. After seeing a fly's eyes, do you wonder that you have so much difficulty in hitting it or catching it?

2. Can you see the fly's antennæ? Do you think that it has a keen sense of smell? Why?

3. How many wings has the fly? How does it differ from the bee in this respect? Can you see two little white objects, one just behind the base of each wing? These are called poisers, or balancers, and all flies have them in some form. What is the color of the wings? Are they transparent? Can you see the veins in them? On what part of the body do the wings grow?

4. Look at the fly from below. How many legs has it? From what part of the body do the legs come? What is that part of the insect's body called, to which the legs and wings are attached?

5. How does the fly's abdomen look? 'What is its color and its covering?

6. Look at the fly's legs. How many segments can you see in a leg? Can you see that the segment on which the fly walks has several joints? Does it walk on all of these segments or on the one at the tip?

7. When the fly eats, can you see its tongue? Can you feel its tongue when it rasps your hand? Where does it keep its tongue usually?

8. Describe how a fly makes its toilet as follows: How does it clean its front feet? Its head? Its middle feet? Its hind feet? Its wings?

9. Do you know how flies carry disease? Did you ever see them making their toilet on your food at the table? Do you know what diseases are carried by flies? What must you do to prevent flies from bringing disease to your family?

ro. Do you think that a small fly ever grows to be a large fly? How do the young of all kinds of flies look? Do you know where the house-fly lays its eggs? On what do the maggots feed? How long before they change to pupæ? How long does it take them to grow from eggs to flies? How do the house-flies in our northern climate pass the winter?

r r. Lesson in Arithmetic-It requires perhaps twenty days to span the time from the eggs of one generation of the house-fly to the eggs of the next, and thus there might easily be five generations in one summer. 
Supposing the fly which wintered behind the window curtain in your home last winter, flew out to the stables about May ist and laid I2o eggs in the sweepings from the horse stable, all of which hatched and matured. Supposing one-half of these were mother flies and each of them, in turn, laid I 20 eggs, and so on for five generations, all eggs laid developing into flies, and one-half of the flies of each generation being mother flies. How many flies would the fly that wintered behind your curtain have produced by September?

I2. Pour some gelatin unsweetened, on a clean plate. Let a housefly walk around on the gelatin as soon as it is cool; cover the plate to keep out the dust and leave it for two or three days. Examine it then and see if you can tell where the fly walked. What did it leave in its tracks?

I3. Write an essay on the house-fly, its dangers and how to combat it, basing the essay on Bulletins of the U. S. Department of Agriculture.

\section{THE COLORADO POTATO-BEETLE}

\section{Teacher's Story}

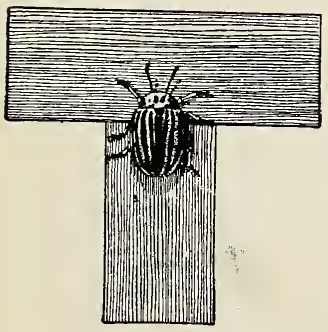

$\mathrm{HE}$ potato-beetle is not a very attractive insect, but it has many interesting peculiarities. No other common insect so clearly illustrates the advantage of warning colors. If we take a beetle in the hand, it at first promptly falls upon its back, folds its legs, and antennæ down close to its body, and "plays possum" in a very canny manner. But if we squeeze it a little, immediately an orange-red liquid is ejected on the hand, and a very ill-smelling liquid it is. If we press lightly, only a little of the secretion is thrown off; but if we squeeze harder it

flows copiously. Thus a bird trying to swallow one of these beetles, would surely get a large dose. The liquid is very distasteful to birds, and it is indeed a stupid bird that does not soon learn to let severely alone orange and yellow beetles, striped with black. The source of this offensive and defensive juice is at first a mystery, but if we observe closely we can see it issuing along the hind edge of the thorax and the front portion of the wing-covers; the glands in these situations secrete the protective juice as it is needed. The larvæ are also equipped with similar glands and, therefore, have the brazen habit of eating the leaves of our precious potatoes without attempting to hide. They seem to know that they are far safer when seen by birds than when concealed from them.

The life history of the potato-beetle is briefly as follows: Some of the adult beetles or pupæ winter beneath the surface of the soil, burrowing down a foot or more to escape freezing. As soon as the potato plants appear above ground the mother beetle comes out and lays her eggs upon the under sides of the leaves. These orange-yellow eggs are usually laid in clusters. In about a week there hatches from the eggs little yellow or orange humpbacked larvæ, which begin at once to feed upon the leaves. These larvæ grow as do other insects, by shedding 
their skins. They do this four times, and during the last stages, are

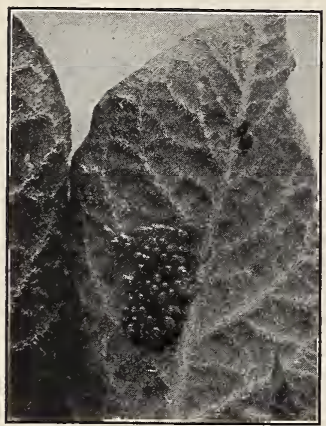

Eggs of Colorado potato. beetle.

Photo by Slingerland. very conspicuous insects on the green leaves; they are orange or yellow with black dots along the sides, and so humpbacked are they that they seem to be "gathered with a puckering string" along the lower side. It requires from sixteen days to three weeks for a larva to complete its growth. It then descends into the earth and forms a little cell in which it changes to a pupa. It remains in this condition for one or two weeks, according to the temperature, and then the full-fledged beetle appears. The entire life cycle from egg to adult beetle may be passed in about a month, although if the weather is cold, this period will be longer. The beetles are very prolific, a mother beetle having been known to produce five hundred eggs, and there are two generations each year. These beetles not only damage the potato crop by stopping the growth through destroying the leaves, but they also cause the potatoes to be of inferior quality.

The adult beetle is an excellent object lesson in the study of beetle form. Attenticn should be called to the three regions of the body: A head which is bright orange; the compound eyes, which are black; and three simple eyes on the top of the head, which are difficult to see without a lens. The antennæ are short, their joints easily noted, and special attention should be paid to their use, for they are constantly moving to feel approaching objects. The two pairs of mouth palpi may be seen, and the beetle will eagerly eat raw potatoes, so that the pupils may see that it has biting mouthparts. The thoracic shield is orange, ornamented with black. The three pairs of legs are short, which is a proof that these beetles do not migrate on foot. The claws and the pads beneath can be seen with the naked eye. Each wing-

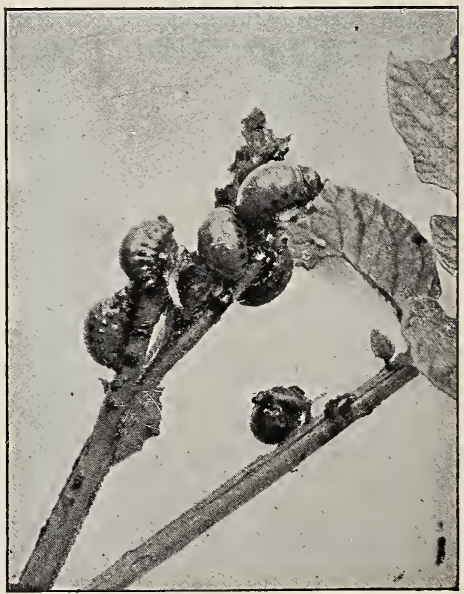

Larvae of Colorado potato-beetle Photo by Slingerland. cover bears five ye:low stripes, also five black ones, although the outside black stripe is rather narrow. These beetles are very successful flyers. During flight, the wing-covers are raised and held motionless while the gauzy wings beneath are unfolded and do the work. Children are always interested in seeing the way the beetles fold their wings beneath the wing-covers. 
One of the most remarkable things about the Colorado potato-beetle is its history. It is one of the few insect pests which is native to America. It formerly fed upon sandbur, a wild plant allied to the potato, which grows in the region of Colorado, Arizona and Mexico, and was a well behaved, harmless insect. With the advance of civilization westward, the potato came also, and proved to be an acceptable plant to this insect; and here we have an example of what an unlimited food supply will do for an insect species. The beetles multiplied so much faster than their parasites, that it seemed at one time as if they would conquer the earth by moving on from potato field to potato field. They started on their march to the Atlantic seaboard in 1859 ; in 1874 , they reached the coast and judging by the numbers washed ashore, they sought to fly or swim across the Atlantic. By I879, they had spread over an area consisting of more than one-third of the United States.

Reference-The Colorado Potato-Beetle,

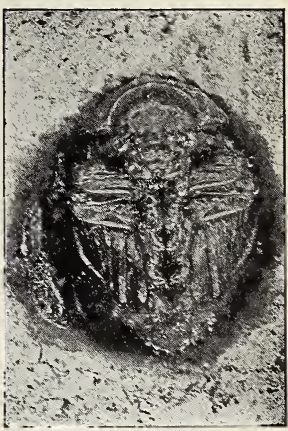

Pupa of potato-beetle, enlarged.

Photo by Slingerland. Chittenden, Bulletin of U. S. Department of Agriculture.

\section{LESSON XCII}

\section{The Colorado Potato-beetle}

Leading thought-The Colorado potato-beetle is a very important insect, since it affects the price of potatoes each year. It is disagreeable as a food for birds, because of an acrid juice which it secretes. We should learn its life-history and thus be able to deal with it intelligently in preventing its ravages.

Method-The study of the potato-beetle naturally follows and belongs to gardening. The larvæ should be brought into the schoolroom and placed in a breeding cage on leaves of the potato vine. Other plants may be put into the cage to prove that these insects will only eat the potato. The children should observe how the larvæ eat and how many leaves a full grown larva will destroy in a day. Earth should be put in the bottom of the breeding cage so that the children may see the larvæ descend and burrow into it. The adult beetles should be studied carefully, and especially, the children should see the excretion of the acrid juice.

Observations - I. At what time do you see the potato-beetles? Why are they more numerous in the fall than in the spring? Where do those which we find in the spring come from? What will they do if they are allowed to live?

2. What is the shape of the potato-beetle? Describe the markings on its head. What color are its eyes? Describe its antennæ. How are they constantly used? Can you see the palpi of the mouth? Give the beetle a bit of potato and note how it eats.

3. What is the color of the shield of the thorax? Describe the legs. Do you think the beetle can run fast? Why not? How many segments has the foot? Describe the claws. Describe how it clings to the sides of a tumbler or bottle. 


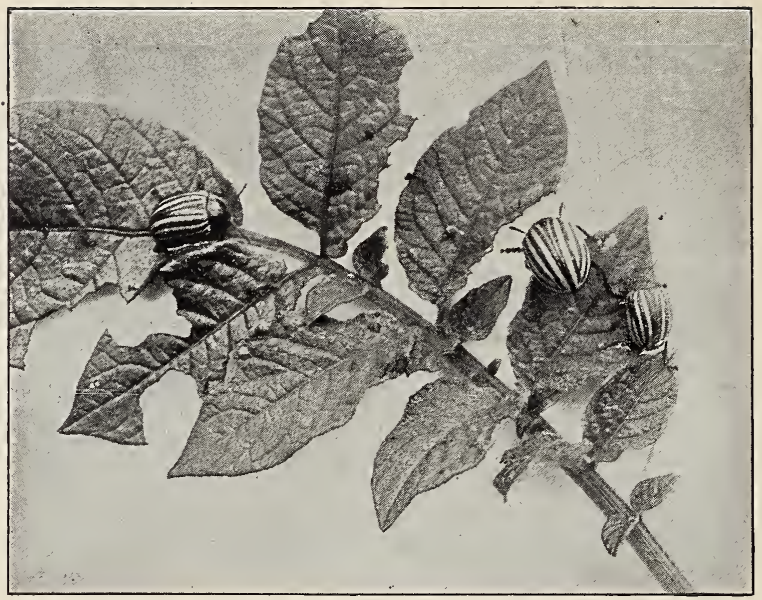

The Colorado potato-beetle. Photo by Slingerland.

4. If the beetle cannot run rapidly, how does it travel? Describe the wing-covers. Why is this insect called the ten-lined potato beetle?

5. Describe the wings. How are they folded when at rest? How are the wing-covers carried when the beetle is flying?

6. Take a beetle in your hand. What does it do? Of what advantage is it to the insect to pretend that it is dead? If you squeeze the beetle what happens? How does the fluid which it ejects look and smell? Try and discover where this fluid comes from? Of what use is it to the beetle? Why will birds not eat the potato-beetle?

7. Where does the mother beetle lay her eggs? Are they laid singly or in clusters? What color are the eggs? How long after they are laid before they hatch?

8. Describe the young larva when it first hatches. What color is it at first? Does it change color later? Describe the colors and markings of a full grown larva.

9. How does this larva injure the potato vines? Does it remain in sight while it is feeding? Does it act as if it were afraid of birds? Why is it not eaten by birds?

Io. Where does the larva go when it is full grown? How many times does it shed its skin during its growth? Does it make a little cell in the ground? How does the pupa look? Can you see in it the eyes, antennæ, legs and wings of the beetle?

II. Write an English theme giving the history of the Colorado potato-beetle, and the reasons for its migration from its native place. 


\section{THE LADYBIRD}

\section{Teacher's Story}

Ladybird, Ladybird, fly away home!

Your house is on fire, your children are burning.

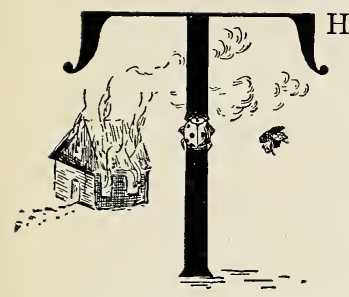

HIS incantation we, as children, repeated to this unhearing little beetle, probably because she is and ever has been, the incarnation of energetic indecision. She runs as fast as her short legs can carry her in one direction, as if her life depended on getting there, then she turns about and goes with quite as much vim in another direction. Thus, it is no wonder the children think that when she hears this news of her domestic disasters, she wheels about and starts for home; but she has not any home now nor did she ever have a home, and she does not carry even a trunk. Perhaps it would be truer to say that she has a home everywhere, whether she is cuddled under a leaf for a night's lodging or industriously climbing out on twigs, only to scramble back again, or perchance to take flight from their tips.

There are many species of ladybirds, but in general they all resemble a tiny pill cut in half, with legs attached to the flat side. Sometimes it may be a round and sometimes an oval pill, but it is always shining and the colors are always dull dark red, or yellow, or whitish, and black. Sometimes she is black with red or yellow spots, sometimes red or yellow with black spots and the spots are usually on either side of the thorax and one on each snug little wing-cover. But if we

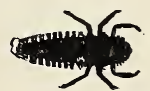

Ladybird larva. look at the ladybird carefully we can see the head and the short, clublike antennæ. Behind the head is the thorax with its shield, broadening toward the rear, spotted and ornamented in various ways; the head and thorax together occupy scarcely a fourth of the length of the insect, and the remainder consists of the hemispherical body, encased with polished wing-covers. The little black legs, while quite efficient because they can be moved so rapidly, are not the ladybird's only means of locomotion; she is a good flier and has a long pair of dark wings which she folds crosswise under her wing-covers. It is comical to see her pull up her wings, as a lady tucks up a long petticoat; and sometimes ladybi $d$ is rather slovenly about it and runs around with the tips of her wings hanging out behind, quite untidily.

But any untidiness must be inadvertent, because the ladybird takes very good care of herself and spends much time in "washing up." She begins with her front legs, cleaning them with her mandibles, industriously nibbling off every grain of dust; she then cleans her middle and hind legs by rubbing the two on the same side, back and forth against each other, each acting as a whisk broom for the other; she cleans her wings by brushing them between the edges of the wing-cover above and the tarsus of her hind leg below.

The ladybird is a clever little creature, even if it does look like a pill. and if you disturb it, it will fold up its legs and drop as if dead, playing possum in a most deceptive manner. It will remain in this attitude of 
rigid death for at least a minute or two and then will begin to claw the air with all its six legs in an effort to turn right side up.

From our standpoint the ladybird is of great value, for during the larval as well as adult stages, all species except one, feed upon those insects which we are glad to be rid of. They are especially fond of aphids and scale insects. One of the greatest achievements of economic entomology was the introduction on the Pacific Coast of the ladybird from Australia, called the Vedalia, which preys upon the cottony cushion scale insect, a species very dangerous to orange and lemon trees. Within a few years the introduced ladybirds had completely exterminated this pest.

The ladybird's history is as follows: The mother beetle, in the spring, lays her eggs here and there on plants: as soon as the larva hatches, it starts out to hunt for aphids and other insects. It is safe to say that no ladybird would recognize her own children in time to save them, even if the house were burning, for they do not in the least resemble her; they are neither roly-poly nor shiny, but are long and segmented and velvety, with six queer, short legs that look and act as if they were whittled out of wood; they seem only efficient for clinging around a stem The larvæ are

Ladybird usually black, spotted with orange or yellow; there are six pupa. warts on each segment, which make the creature's back look quite rough. The absorbing business of the larva is to crawl around on plants and chew up the foolish aphids or the scale insects. I have seen one use its front foot to push an aphid, which it was eating, closer to its jaws; but when one green leg of its victim still clung to its head, it did not try to rub it off as its mother would have done, but twisted its head over this way and that, wiping off the fragment on a plant stem and then gobbling it up.

After the larva has shed its skeleton skin several times, and destroyed many times its own bulk of insects, it hunts for some quiet corner, hangs itself up by the tail and condenses itself into a sub-globular form; it sheds its spiny skin pushing it up around the point of attachment, and there lets it stay like the lion's skin of Hercules. As a pupa, it is more nearly rectangular than round, and if we look closely. we can see the wing-cases, the spotted segments of the Ladybird abdomen, and the eyes, all encased in the pupa skin; the latter beetle, bursts open after a few days and the shining, little half-globe "the emerges a full-grown ladybird, ready for hiding in some cozy spot spotted to pass the winter, from which she will emerge in the spring, to lady-, stock our trees and vines, next year, with her busy little progeny.

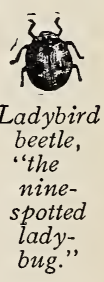

References-American Insects, Kellogg; Manual for the Study of Insects, Comstock.

\section{LESSON XCIII}

\section{The Ladybird}

Leading thought-The ladybird is a beetle. Its young are very different from the adult in appearance, and feed upon plant-lice.

Method-These little beetles are very common in autumn and may be brought to the schoolroom and passed around in vials for the children to observe. Their larvæ may be found on almost any plant infested with 
plant-lice. Plant and all may be brought into the schoolroom and the actions of the larvæ noted by the pupils during recess.

Observations-I. How large is the ladybird? What is its shape? Would two of them make a little globe if they were put flat sides together?

2. What colors do you find on your ladybird?

3. Do you see the ladybird's head and antennæ? What isithe broad shield directly back of the head called? How is it marked, and with what colors? What color are the wing-covers? Are there any spots upon them? How many? Does the ladybird use its wing-covers when it flies? Describe her true wings. Does she fold them beneath the wing-covers?

4. Note the legs and feet. Are the legs long? Are they fitted for running? To which part of the body are they attached?

5. If you disturb the ladybird how does she "play possum?" Describe how she makes her toilet.

The larva-I. Describe the ladybird larva. Does it look like its mother? What is its form? Is it warty and velvety or shiny?

2. Describe its head and jaws as far as you can see. How does it act when eating? Can you see its little stiff legs? Is there a claw at the end of each?

3. Describe the actions of the ladybird larva in attacking and eating the plant-lice. Does it shed its skin as it grows?

4. Watch a larva until it changes to a pupa. How does the pupa look? Can you see the shed skin? Where is it? To what is the pupa attached? When the pupa skin breaks open what comes out of it?

5. Why is the ladybird of great use to us? Write an English theme upon the ladybird, called Vedalia, which saved the orange orchards of California.

1

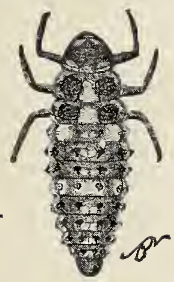

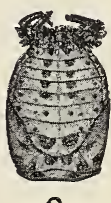

2

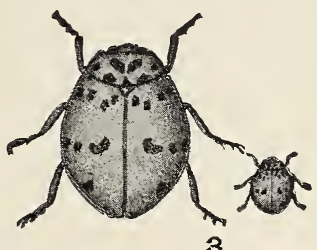

3

I. Larva; 2, pupa and 3, adult of a species of ladybird, enlarged. The small beetle represents actual size. 


\title{
THE FIREFLY
}

\author{
Teacher's Story
}

And lavishly to left and right,

The fireflies, like golden seeds, Are sown upon the night.

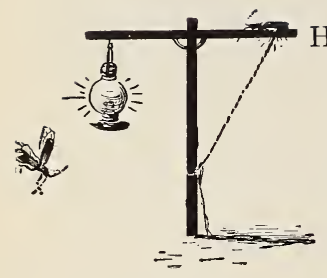

-RILEY。

HE time of this sowing is during warm, damp nights in July and August, and even in September, although they are sown less lavishly then. How little most of us know of the harvest, although we see the sowing which begins in the early twilight against the background of tree shadows, and lasts until the cold atmosphere of the later night dampens the firefly ardor! There is a difference in species as to the height from the ground of their flight; some species hover next to the grass, others fly above our heads, but rarely as high as the tree tops in northern latitudes. Some species give a short flash that might be called a refulgent blinking; others give a longer flash so that we get an idea of the direction of their flight; and there is a common species in the Gulf States which gives such long flashes that they mark the night with gleaming curlicues.

It is likely to be an exciting chase, before we are able to capture a few of these insects for closer inspection; but when once captured, they do not sulk but will keep on with their flashing and give us a most edifying display. The portion of the firefly which gives the light is in the abdomen, and it glows steadily like "phosphorescent wood"; then suddenly it gleams with a green light that is strong enough to reveal all its surroundings; and it is so evidently an act of will on the part of the beetle, that it is startling to members of our race, who cannot even blush or turn pale voluntarily. The fireflies may be truly said to be socially brilliant, for the flashing of their lights is for the attraction of their mates.

The fireflies are beetles, and there are many species which are luminous. A common one is here figured (Photinus pyralis). It is pale gray above and the head is completely hidden by the big shield of the thorax. The legs are short; thus this beetle trusts mostly to its wings as a means of locomotion. The antennæ are rather long and are kept in constant motion, evidently conveying intelligence of surroundings to the insect. Beneath the gray elytra, or wing-covers, is a pair of large, darkveined membranous wings which are folded in a very neat manner crosswise and lengthwise,
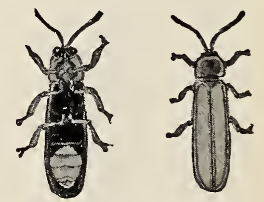

A common firefly - The view of the lower side shows the "lamp." when not in use. When in use, the wing-covers are lifted stiffly and the flying is done wholly with the membranous wings. Looked at from beneath, we can at once see that some of the segments of the abdomen are partly or entirely sulphur yellow, and we recognize them as the lamp. If the specimen is a male, the yellow area covers all of the end of the abdomen up to the fourth or fifth segment; but if it is a female, only the middle portion of the abdomen, especially the fifth segment, is converted into a lamp. These yellow areas, when dissected under the 
microscope, prove to be filled with fine tracheæ, or air-tubes; and although we know very little about the way the light is made, it is believed that by flooding the tubes with air, the oxygen in some way produces the light.

In some species, the female is wingless and has very short wingcovers, and a portion of her body emits a steady, greenish light which tells her lord and master where to find her. These wingless females are called glow-worms.

Fireflies during their larval stages are popularly called wire worms, although there are many other beetle larvæ thus called. In many of the species, the firefly eggs, larvæ and pupæ are all luminescent, but not so brilliant as when adults. The larva of the species here figured, was studied by C. V. Riley, who gave us an interesting account of its habits.

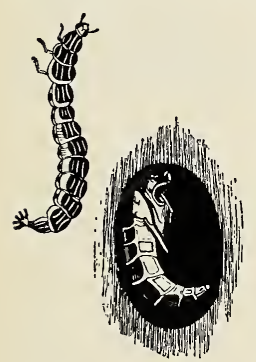

Larva and pupa of a common firefly. After C. V. Riley. It lives in the ground and feeds on soft-bodied insects, probably earth-worms. Each segment of this wire worm has a horny, brown plate above, with a straight white line running through the middle and a slightly curved white line on each side; the sides of the larva are soft and rose-colored; the white spiracles show against little, oval, brown patches. Beneath, the larva is cream color with two brown comma-like dots at the center of each segment. The head can be pulled back completely beneath the first segment. The most interesting thing about this larva is the prop-leg at the end of its body, which naturally aids it in locomotion; but this prop-leg also functions as a brush; after the larva has become soiled with too eager delving into the tissues of some earthworm, it curls its body over, and with this fanshaped hind foot scrubs its head and face very clean. This is a rare instance of a larva paying any attention to its toilet.

When full-grown, the larva makes a little oval cell within the earth and changes to a pupa; after about ten days, the pupa skin is shed and the full-fledged beetle comes forth. The larva and pupa of this species give off light, but are not so brilliant as the adult. The pupils should be encouraged to study the early stages of the fireflies, because very little is known concerning them.

In Cuba a large beetle called the cucujo has two great oval spots on its thorax, resembling eyes, which give off light. The Cuban ladies wear cucujos at the opera, in nets, in the hair. I once had a pair which I tethered with gold chains to the bodice of my ball gown. The eye-spots glowed steadily, but with the movement of dancing, they grew more brilliant until no glittering diamonds could compete with their glow.

\section{LESSON XCIV}

\section{The Firefly}

Leading thought-When the firefly wishes to make a light, it can produce one that, if we knew how to make, would greatly reduce the price of artificial light; for the light made by fireflies and other creatures, requires less energy than any other light known.

Method-After the outdoor observations have been made, collect some of these beetles in the evening with a sweep net; place them under a 
glass jar or tumbler, so that their light can be studied at close range. The next day give the observation lesson on the insects.

Observations - $\mathrm{r}$. At what time of year do you see fireflies? Do they begin to lighten before it is dark? Do you see them high in the air or near the ground? Is the flash they give short, or long enough to make a streak of light? Do you see them on cold and windy nights or on warm, still, damp evenings? Make a note of the hour when you see the first one flash in an evening.

2. Catch a few fireflies in the night; put them under a glass jar. Can you see the light when they are not flashing? What color is it? When they make the flash can you see the outline of the "firefly lamp?" Watch closely and see if you think the flashing is a matter of will on the part of the firefly. Do you think the firefly is signaling to his mate when he flashes?

3. Stuaiy the firefly in daylight. Is it a fly or is it a beetle? What color is it above? When you look squarely down upon it, can you see its head and eyes?

4. Are the firefly's legs long or short? When a beetle has short legs is it a sign that it usually walks, runs or flies?

5. Describe the antennæ. Are they in constant motion? What service do you think the firefly's antennæ perform for it?

6. Lift one of the wing-covers carefully. What do you find beneath it? Does the beetle use its wing-covers to beat the air and help it during flight? How does the beetle hold its wing-covers when flying?

7. Turn the beetle on its back. Can you see the part of the body that flashes? What color is it?

8. Do you know the life history of the firefly? What is it like in its earlier stages? Where does it live? Does it have the power of making light when it is in the larval stage?

"There, in warm Augusv gloaming,

With quick silent brightenings,

From meadow-lands roaming,

The firefly twinkles

His fitful heat-lightnings."

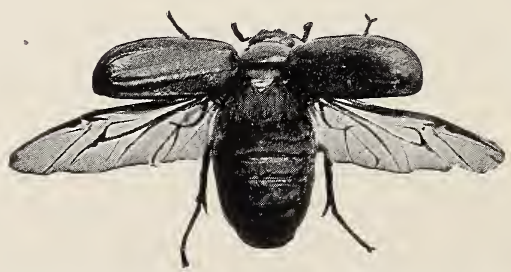

A Maybeetle flying, showing that the beetles hold the wing-covers stiff and still in fight, the

hind wings doing the work.

Photo by M. V. Slingerland. 


\section{THE WAYS OF THE ANT}

$M y$ child, behold the cheerful ant,

How hard she works, each day;

She works as hard as adamant

Which is very hard, they say.

-Oliver Herford.

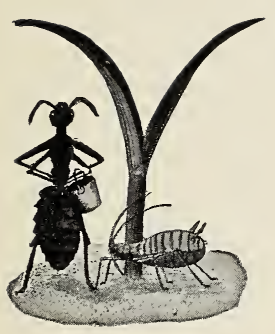

ERY many performances on the part of the ant seem to us without reason; undoubtedly many of our performances seem likewise to her. But the more understandingly we study her and her ways, the more we are forced to the conclusion that she knows what she is about; I am sure that none of us can sit down by an ant-nest and watch its citizens come and go, without discovering things to make us marvel.

By far the greater number of species of ants find exit from their underground burrows, beneath stones in fields. They like the stone for more reasons than one; it becomes hot under the noon sun and remains warm during the night, thus giving them a cozy nursery in the evening for their young. Some species make mounds, and often several neighboring mounds belong to the same colony, and are connected by underground galleries. There are usually several openings into these mounds. In case of some of the western species which make galleries beneath the ground, there is but one opening to the nest and Dr. McCook says that this gate is closed at night; at every gate in any ants' nest, there are likely to be sentinels stationed, to give warning of intruders.

$A$; soon as a nest is disturbed, the scared little citizens run helter skelter to get out of the way; but if there are any larvæ or pupæ about, they are never too frightened to take them up and make off with them; but when too hard prassed, they will in most cases drop the precious burden, although I have several times seen an ant, when she dropped a pupa, stand guard over it and refuse to budge without it. The ant's $\mathrm{eggs}$ ar 2 very small objects, being oblong and about the size of a pin point. The larvæ are translucent creatures, like rice grains with one end pointed. The pupæ are yellowish, covered with a parchment-like sac, and resemble grains of wheat. When we lift stones in a field, we usually find directly beneath, the young of a certain size.

There are often, in the same species of ants, two sizes; the large ones are called majors and the smaller minors; sometimes there is a smaller size yet, called minims. The smaller sizes are probably the result of lack of nutrition. But whatever their size, they all work together to bring food ior the young and in caring for the nest. We often see an ant carrying a dead insect or some other object larger than herself. If she cannot lift it or shove it, she turns around, and going backwards, pulls it along. It is rarely that we see two carrying the same load, although we have observed this several times. In one or two cases, the two seemed not to be in perfect accord as to which path to take. If the ants find some large supp'y of food, many of them will form a procession to bring it into the nest bit by bit; such processions go back by making a little detour so as not to meet and inte-fere with thore coming. During most of the year, an ant colony consists only of workers and laying queens, but in early 
summer the nest may be found swarming with winged forms which are the kings and queens. Some warm day these will issue from the nest and take their marriage flight, the only time in their lives when they use their wings; for ants, like seeds. seem to be provided with wings simply for the sake of scattering wide the species. It is a strange fact, that often on the same day swarms will issue from all the nests of one species in the whole region; by what mysterious messenger, word is sent that brings about this unanimous exodus, is still a

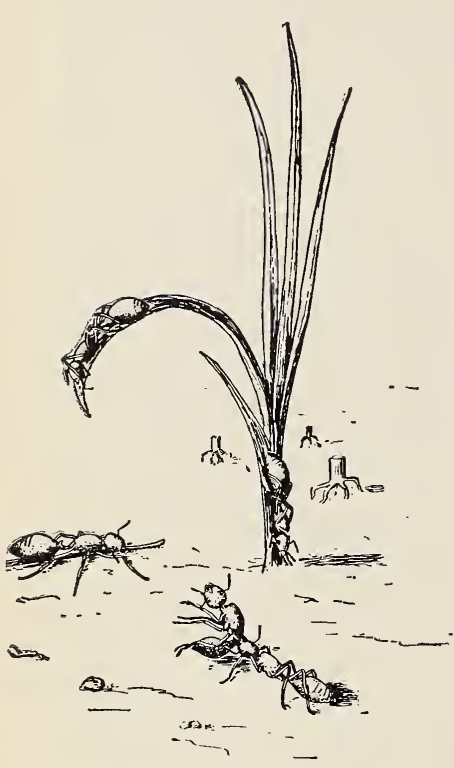

Agricultural ants. Note that one ant is carrying a sister.

Drawn by Evelyn Mitchell. mystery to us. This seems to be a provision for cross-breeding; and as bearing upon this, Miss Fielde discovered that an alien king is not only made welcome in a nest, but is sometimes seized by workers and pulled into a nest; this is most significant, since no worker of any other colony of the same species, is permitted to live in any but its own nest.

After the marriage flight, the ants fall to the ground and undoubtedly a large number perish; however, just here our knowledge is lamentably lacking, and observations on the part of pupils as to what happens to these winged forms will be valuable. In the case of most species, we know that a queen finds refuge in some shelter and there lays eggs. Mr. Comstock once studied a queen of the big, black carpenter ant which lives under the bark of trees. This queen, without taking any food herself, was able to lay her eggs and rear her first brood to maturity; she regurgitated food for this first brood, and then they went out foraging for the colony. However, Miss Fielde found that in the species she studied, the queen could not do this; a question most interesting to solve is whether any of the young queens, after the marriage flight, are adopted into other colonies of the same species. As soon as a queen begins laying eggs, she sheds her then useless wings, laying them aside as a bride does her veil.

When we are looking for ants' nests beneath stones, we often stumble upon a colony consisting of citizens differing in color. One has the head and thorax rust-red with the abdomen and legs brown; associated with this brown ant, is a black or ash-colored-species. These black ants are the slaves of the brown species; but slavery in the ant world has its ameliorations. When the slave makers attack the slave nest, they do not fight the inmates unless they are obliged to. They simply loot the nest of the larvæ or pupæ, which they carry off to their own nests; and there they are fed and reared, as carefully as are their own young. The slaves seem to be perfectly contented, and conduct the household affairs of their masters with apparent cheerfulness. They do all the taking care of the 
nest and feeding the young, but they are never permitted to go out with war parties; thus they never fight, unless their colony is attacked by marauders.

If one chances upon an ant battle, one must needs compare it to a battle of men before the invention of gunpowder; for in those days fighting was more gory and dreadful than now, since man fought man until one of the twain was slain. There is a great variation in military skill as well as in courage shown by different species of ants; the species most skilled in warfare, march to battle in a solid column and when they meet the enemy, the battle resolves itself into duels, although there is no code of ant honor which declares that one must fight the enemy single-handed. Although some ants are provided with venomous stings, our common species use their jaws for weapons; they also eject upon each other a very acid liquid which we know as fcrmic acid. Two enemies approach each other, rear on their hind legs, throw this ant vitriol at each other, then close in deadly combat, each trying to cut the other in two. Woe to the one on which the jaws of her enemy are once set! For the ant has bulldog qualities, and if she once gets hold, she never lets go even though she be rent in pieces herself. At night the ant armies retreat to their citadels, but in the morning fare forth again to battle; and thus the war may be waged for days, and the battlefield be strewn with the remains of the dead and dying. So far as we are able to observe, there are two chief causes for ant wars; one is when two colonies desire the same ground, and the other is for the purpose of making slaves.

Perhaps the most interesting as well as most easily observed of all ant practices, are those that have to do with plant-lice, or aphids. If we find an ant climbing a plant of any sort, it is very likely that we shall find she is doing it for the purpose of tending her aphid herds. The aphid is a stupid little creature which lives by thrusting its bill or sucking tube into a stem or leaf of a plant, and thus settles down for life, nourished by the

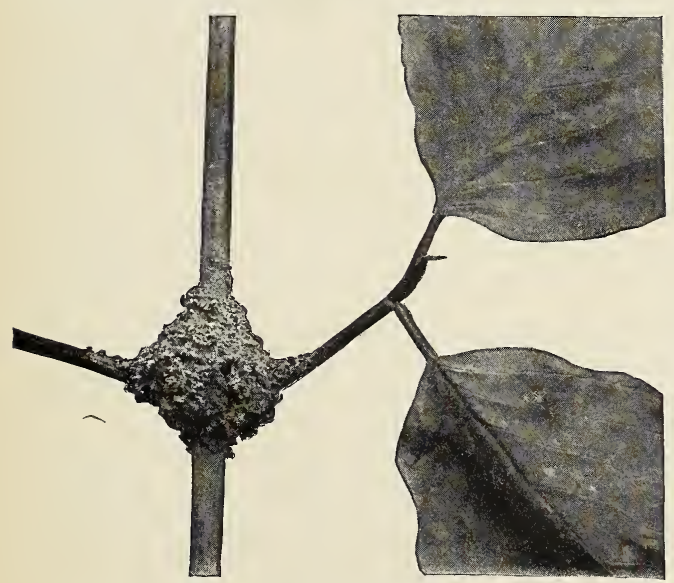

An aphid stable, built by ants to protect their herds. Photo by Slingerland. sap which it sucks up; it has a peculiar habit of exuding from its alimentary canal drops of honey-dew, when it feels the caress of the ant's antennæ upon its back. I had one year under observation, a nest of elegant little ants with shining triangular abdomens which they waved in the air like pennants when excited. These ants were most devoted attendants on the plant-lice infesting an evening primrose; if I jarred the primrose stem, the ants had a panic, 
and often one would seize an aphid in her jaws and dash about madly, as if to rescue it at all hazards. When the ant wishes honey-dew, she approaches the aphid, stroking it or patting it gently with her antennæ, and if a drop of the sweet fluid is not at once forthcoming, it is probably because other ants have previously exhausted its individual supply; if the ant gets no response, she hurries on to some other aphid not yet milked dry.

This devotion of ants to aphids has been known for a hundred years, bit only recently has it been discovered to be of economic importance. Professor Forbes, in studying the corn root-louse, discovered that the ants care for the eggs of this aphid in their own nests during the winter, and take the young aphids out early in the spring, placing them on the roots of sinartweed; later, after the corn is planted, the ants move their charges to the roots of the corn. Ants have been seen to give battle to the enemies of the aphid. The aphids of one species living on dogwood are protected while feeding by stables, which a certain species of ant builds around them, from a mortar made of earth and vegetable matter.

References-Ants, W. M Wheeler, Ant Communities, McCook

\section{LESSON XCV}

\section{Field Observatio:is on ANTS}

Leading thonght-However aimless to us may seem the course of the ant as we see her running about, undoubtedly if we understood her well enough, we should find that there is rational ant-sense in her performances. Therefore, whenever we are walking and have time, let us make careful observations as to the actions of the ants which we may see.

Method--The following questions should be written on the blackboard and copied by the pupils in their note-books. This should be done in May or Jurie, and the answers to the questions worked out by observations mace during the summer vacation.

Observations--I. Where do you find ants' nests? Describe all the different kinds you have found. In what sort of soil do they make their nests? Describe the entrance to the nest. If the nest is a mound, is there more than one entrance? Are there many mounds near each other? If so, do you think they all belong to the same colony?

2. When the nest is disturbed, how do the ants act? Do they usually try to save themselves alone? Do they seek to save their young at the risk of their own lives? If an ant, carrying a young one is hard pressed, will she drop it?

3. Make notes on the difference in appearance of eggs, larva and pupæ in any ants' nest.

4. In nests under stones, can you find jarvæ and pupæ assorted according to sizes?

5. How many sizes of ants do you find living in the same nest?

6 . What objects do you find ants carrying to their nests? Are these for food? How does an ant manage to carry an object larger than herself? Do you ever see two ants working together carrying the same load?

7. If you find a procession of ants carrying food to their nest, note if they follow the same path coming and going. 
8. If you find winged ants in a nest, catch a few in a vial with a few of the workers, and compare the two. The winged ants are kings and queens, the kings being much smaller than the queens.

9. If you chance to encounter a swarm of winged ants taking flight, make observations as to the size of swarm, the height above the ground, and whether any are falling to the earth.

ro. Look under the loose bark of trees for nests of the big, black carpenter ant. You may find in such situations a queen ant starting a colony, which will prove most desirable for stocking an artificial ant's nest.

Ir. If you find ants climbing shrubs, trees or other plants, look upon the leaves for aphids and note the following points:

a. How does an ant act as she approaches an aphid?

b. If the aphids are crowded on the leaf, does she step on them?

c. Watch carefully to see how the ant touches the aphid when she wishes the honey-dew.

d. Watch how the aphid excretes the honey-dew, and note if the ant eats it.

e. If you disturb aphids which have ants tending them, note whether the ants attempt to defend or rescue their herds.

f. If there are aphis-lions or ladybird larvæ eating the aphids, note if the ants attack them.

I2. If you find a colony of ants under stones where there are brown and black ants living together, the black members are the slaves of the brown. Observe as carefully as possible the actions of both the black and the brown inhabitants of the nest.

13. If you chance to see ants fighting, note how they make the attack. With what weapons do they fight? How do they try to get at the adversary?

I4. Write an English theme cuvering the following points: How ants take their slaves; the attitude of masters and slaves toward each other; the work which the slaves do, and the story of the ant battle. How ants care for and use their herds.

References-American Insects, Kellogg, Manual for the Study of Insects, Comstock; Ants, McCook; True Tales, Jordan, page 6.

\section{LESSON XCVI \\ How to Make the Lubbock Ant-nest}

Material-Two pieces of window glass, ro inches square; a sheet of tin, I I inches square; a piece of plank, I I/4 inch thick; 20 inches long and at least $\mathrm{r} 6$ inches wide; a sheet of tin or a thin, flat board, ro inches square.

To make the nest---Take the plank and on the upper side, a short distance from the edge, cut a deep furrow. This furrow is to be filied with water, as a moat, to keep the ants imprisoned. It is necessary, therefore, that the plank should have no knot holes, and that it be painted thoroughly to keep it from checking. Take the sheet of tin II inches square, and make $i^{\text {t: }}$ into a tray by turning up the edges three-eighths of an inch. Place this tray in the middie of the plank. Place within the tray one pane of glass. Lay around the edges of this glass four strips of wood about half an inch wide and a little thicker than the height of the ants which are to live in the nest. Cover the glass with a thin layer of fine earth. Take the remaining pane of glass and cut a triangular piece off 
of one corner, then place the pane on top of the other, resting upon the pieces of wood around the sides. The cover of the nest may be a piece of tin, with a handle soldered to the center, or a board with a screw-eye in the center with which to lift it. There should be a piece of blotter or of very thin sponge, introduced into the nest between the two panes of glass, in a position where it may be reached with a pipette, without removing the upper glass, for it must be kept always damp.

To establish a colony in this nest proceed as follows: Take a twoquart glass fruit jar and a garden trowel. Armed with these, visit some pasture or meadow near by, and find under some stone, a small colony of ants which have plenty of eggs and larvæ. Scoop up carefully eggs, ants, dirt and all and place in the jar, being as careful as possible not to injure the specimens. While digging, search carefully for the queen, which is a larger ant and is sometimes thus found. But if you have plenty of eggs, larvæ and pupæ, the ants will become very contented in their new nest while taking care of them. After you have taken all the ants desirable, place the cover on the jar, carry them to the Lubbock nest and carefully empty the contents of the fruit jar on top of the board which covers the nest. Of course the furrow around the plank has been filled with water, so the stragglers cannot escape. The ants will soon find the way into the nest through the cut corner of the upper pane of glass, and will transfer their larvæe to it because it is dark. After they are in the nest, which should be within two or three hours, remove the dirt on the cover, and the nest is ready for observation. But, since light disturbs the little prisoners, the cover should be removed only for short periods.

The Fielde nest is better adapted for a serious study of ants, but it is not so well adapted for the schoolroom as is the Lubbock nest.

Reference-Ants, W. M. Wheeler.

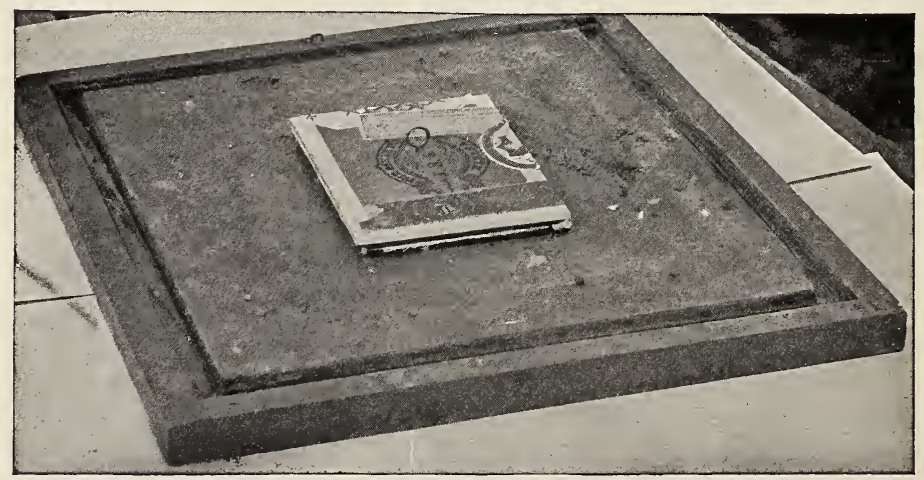

A Lubbock ant-nest. 


\section{THE ANT-NEST, AND WHAT MAY BE SEEN WITHIN IT}

\section{Teacher's Story}

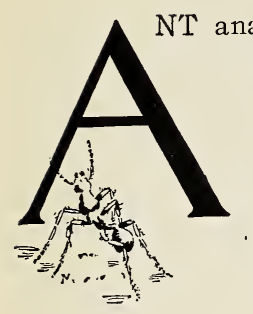

tomy becomes a very interesting study when we note the vigorous way the ant uses it-even to the least part. The slender waist characterizes the ant as well as the wasp; the three regions of the body are easily seen, the head with its ever moving antennæ, the slender thorax with its three pairs of most efficient legs, and the long abdomen. The ant's legs are fairly long as compared with the size of the body and the ant can run with a rapidity that, comparatively, would soon outdistance any Marathon runner, however famed. I timed an ant one day when she was taking a constitutional on my foot rule. She was in no hurry, and yet she made time that if translated into human terms would mean 16 yards per second. In addition to running, many ants when frightened will make leaps with incredible swiftness.

The ant does not show her cleverness in her physiognomy, probably because her eyes seem small and dull and she has a decidedly "retreating forehead;" but the brain behind this unpromising appearance is far more active and efficient than that behind the gorgeous great eyes of the dragon-fly or behind the "high brow" of the grasshopper. The ant's jaws are very large compared with her head; they work sidewise like a pair of shears and are armed with triangular teeth along the biting edges; these are not teeth in a vertebrate sense, but are like the teeth of a saw. These jaws are the ant's chief utensils and weaporss; with them she seizes the burdens of food which she carries home; with

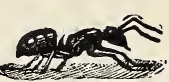

A common

ant. them she gently lifts her infant charges; with them she crushes and breaks up hard food; with them she carries out soil from her tunnel, and with them she fights her enemies. She also has a pair of long palpi, or feelers.

Although her eyes are so small and furnished with coarse facets, as compared with other insects, this fact need not count against her, for she has little need of eyes. Her home life is passed in dark burrows where her antennæ give her information of her surroundings. Note how these antennæ are always moving, seeming to be atremble in eagerness to receive sensations. But aside from their powers of telling things by the touch, wherein they are more delicate than the fingers of the blind, they have other sense organs which are comparable to our sense of smell. Miss Fielde has shown that the five end segments of the antennæ have each its own powers in detecting odor. The end segment detects the odor of the ant's own nest and enables her to distinguish this from other nests. The next, or eleventh segment, detects the odor of any descendant of the same queen; by this, she recognizes her sisters wherever she finds them. Through the next, or tenth segment, she recognizes the odor of her own feet on the trail, and thus can retrace her own steps. The eighth and ninth segments convey to her the intelligence and means of caring for the young. If an ant is deprived of these five end-joints of the antennæ, she loses all power as a social ant and becomes completely disenfranchised. Miss Fielde gives her most interesting experiments in detail in the Pro- 
ceedings of the Academy of Natural Sciences of Philadeiphia, July and October, Igor.

It is natural enough that the ant, depending so much on her antennæ for impressions and stimuli, should be very particular to keep them clean and in good order. She is well equipped to do this, for she has a most efficient antennæ brush on her wrist; it is practically a circular comb, which just fits over the antenna; and to see the ants using these brushes is one of the most common sights in the ant-nest and one of the most amusing. The ant usually commences by lifting her leg over one antenna and deftly passing it through the brush, and then licks the brush clean by

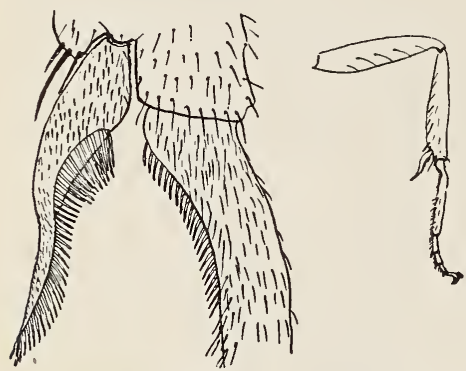

The antenna-comb on the front leg of an ant. passing it through her mouth, as a cat washes her face; then she cleans the other in a similar manner and possibly finishes by doing both alternately, winding up with a flourish, like a European geritleman curling his mus. taches. Her antennæ cleaned, she starts promptly to do something, for she is a little six-footed Martha, always weighed down or buoyed up by many duties and cares. Keeping her antennie on the qui vive, she assures herself, by touch, of the nature of any obstacle in her path. If she meets another ant, their antennæ cross and pat each other, and thus they learn whether they are sisters or aliens; if they are sisters, they may stand for some time with their antennæ fluttering. One who has watched ants carefully, is compelled to believe that they thus convey intelligence of some sort, one to the other. The ant is a good sister "according to her lights;" if her sister is hungry, she will give to her, even from her own partially digested food; the two will often stand mouth to mouth for some minutes during this process; if she feels inclined, she will also help a sister at her toilet, and lick her with her tongue as one cow licks another. The tongue of the ant is very useful in several ways; with it she takes up liquids, and also uses it with much vigor as a washcloth. Sometimes an ant will spend a half hour or more at her own toilet, licking every part of her own body that her tongue can reach, meanwhile going through all sorts of contortions to accomplish it; she uses her feet to scrub portions of her body, not to be reached by her tongue.

But it is as infant nurse that the ant is a shining example. No mother instinct is hers, for she has yielded the power of motherhood to the exigencies of business life, since all workers are females but are undeveloped sexually. She shows far more sense in the care of her infant sisters, than the mother instinct often supplies to human mothers.

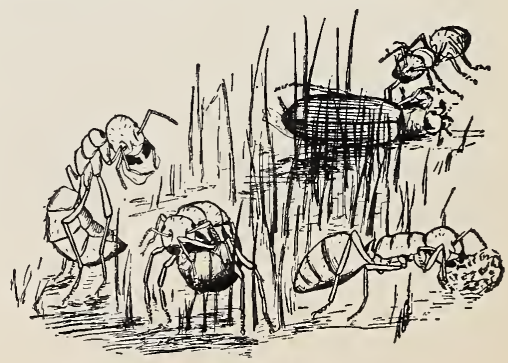

Ants making their toilets 
The ant nurse takes the eggs as soon as laid, and whether or not her care retards or hastens hatching we know not; but we do know, that although the queen ant may not lay more than two eggs per day, a goodly number of these seem to hatch at the same time. The eggs are massed in bundles and are sticky on the outside so as to hold the bundle together. Miss Fielde says, as the eggs are hatching, one ant will hold up the bundle, while another feeds those which have broken the shell. The larvæ, when young, also hang together by means of tiny hooks on their bodies. This habit of the eggs and young larvæ is a convenient one, since an ant is thus able to carry many at a time.

The larvæ are odd looking little creatures, shaped like crookneck squashes, the small end being the head and neck and the latter being very extensible. The ant nurses, by feeding some more than others, are able to keep a brood at the same stage of development; and in a well ordered ant-nest, we find those of the same size in one nursery. I have often thought of a graded school as I have noted in ant-nests the youngsters assorted according to size.

The ants seem to realize the cost and care of rearing their young; and when a nest is attacked, the oldest, which are usually in the pupa stage, are saved first. When the larvæ are young, they are fed on regurgitated food; but as they grow older, the food is brought to them, or they to the food, and they do their own eating. In one of my nests, I placed part of the yolk of an egg hard boiled, and the ant nurses dumped the larvæ do wn around the edges of it; there they munched industriously, until through their transparent bodies I could see the yellow of the egg the whole length of the alimentary canal. The ant nurses are very particular about temperatures for their young, and Miss Fielde says they are even more careful about draughts. Thus they are obliged to move them about in the ground nests, carrying them down to the lower nurseries in the heat of the day, and bringing them up, nearer to the warm stones, during the evenings. This moving is always done carefully, and though the ant's jaws are such formidable nippers, she carries her baby sisters with gentleness; and if they be pupæ, she holds them by the loose pupal skin, like carrying a baby by its clothes. The pupæ look like plump little grain bags, tied at one end with a black string. They are the size of small grains of wheat, and are often called ants' eggs, which is absurd, since they are almost as large as the ant. Ants' eggs are not larger than pin points.

The ant nurses keep the larvæ and pupæ very clean by licking them; and when a youngster issues from the pupa skin, it is a matter of much interest to the nurses. I have often seen two or three of them help straighten out the cramped legs and antennæ of the young one, and hasten to feed her with regurgitated food. When ants first issue from the pupa skin they are pale in color, their eyes being very black in contrast; they are usually helpless and stupid, although they often try to clean their antennæ and make a toilet; but they do not know enough to follow their elders from one room to another, and they are a source of much care to the nurses. In case of moving, a nurse will lock jaws with a "callow, " as a freshly hatched adult ant is called, and drag her along, the legs of the callow sprawling helplessly meanwhile. If in haste, the nurse takes hold anywhere, by the neck or the leg, and hustles her charge along; if she takes her by the waist the callow curls up like a kitten, and is thus more easily moved. After moving them from one chamber to the next, I have noticed 
that the callows are herded together, their attendants ranged in a circle about them. Often we see one ant carrying another which is not a callow, and this means that a certain number of the colony $h$ ve made up their minds to move, while the others are not awake to this necessity. In such a case, one of these energetic sisters will seize another by the waist, and carry her off with an air that says plainly, "Come along, you stupid!"

Ants are very cleanly in their nests, and we find the refuse piled in a heap at one corner, or as far as possible from the brood.

If we are fortunate enough to find a queen for the nest, then we may observe the attention she gets; she is always kept in a special compartment, and is surrounded by ladies in waiting, who feed her and lick hor clean and show solicitude for her welfare; although I have never obscrved in an ants' nest, that devotion to royalty which we see in a beehive.

Not the least interesting scene in an ants' nest is when all, or some, are asleep and are as motionless as if dead.

\section{LESSON XCVII}

\section{Observations of Ants in an Artificial Nest}

Leading thought-The ants are very devoted to their young and perhaps the care of them is the most interesting feature in the study of the artificial nest.

Method-Have, in the schoolroom, a Lubbock's nest with a colony of ants within it, with their larvæ in all stages, and if possible, their queen. For observing the form of the ant, pass one or two around in a vial.

Observations-r. What is there peculiar about the shape of the ant's body? Can you see which section bears the legs? Are the ants' legs long compared with her body? Can she run rapidly?

2. Look at the ant's head through a lens, and describe the antennæ, the jaws and the eyes.

3. Note how the ant keeps her antennæ in motion. Note how she gropes with them as a blind person with his hands. Note how she uses them in conversing with her companions.

4. How does the ant clean her antennæ? Does she clean them more often than any other part of her body? How does she make her toilet?

5. See how an ant eats syrup. How do ants feed each other?

6. How does the ant carry an object? How does she carry a larva or a pupa? Have you ever seen one ant carry another? If so, describe it.

7. Note the way the ants feed their young. How do they keep them clean? Does an ant carry one egg or one small larva at a time or a bundle of them? How do you suppose the bundle is fastened together?

8. Describe an egg, a larva and a pupa of the ant and tell how they differ. Do you know which ant is the mother of the larvæ in the nest?

9. Do you find larvæ of different sizes all together in your nest? Do you find larvæ and pupæ in the same group? Do the ants move the young often from one nest to another? Why do you sisppose they do this?

Io. Note how the ant nurses take care of the callow ant when it is coming out from the pupa skin. How do the $y$ assist her and care for her? How do they lead her around? How do ants look when resting?

I I. Note where the ants throw the refuse from the nest. Do they ever change the position of this dump heap? 


\section{THE MUD-DAUBER}

\section{Teacher's Story}

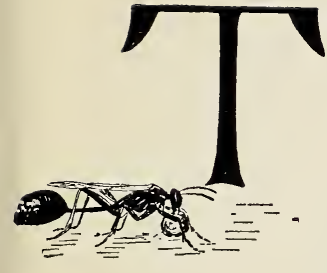

HIS little cement worker is a nervousand fidgety creature, jerking her wings constantly as she walks around in the sunshine; but perhaps this is not nervousness, but rather to show off the rainbow iridescence of her black wings; surely such a slim-waisted being as she, has a right to be vain. No tight lacing ever brought about such a long, slim waist as hers; it is a mere pedicel and the abdomen is a mere knob at the end of it. The latter seen from the outside, would seem of little use as an abdomen; but if we watch the insect flying, we can see plainly that it is used to steer with.

In early summer, we find this black wasp at her trade as a mason. She seeks the edges of pools or puddles where she works industriously, leaving many little holes whence she takes mud to mix with the saliva, which she secretes from her mouth to make firm her cement. This cement she plasters on the under side of some roof or rafter or other protected place, 'going back and forth until she has built a suitable foundation. She works methodically, making a tube about an inch long, smooth inside but rough outside, the walls about one-eighth of an inch thick. She does all of the plastering with her jaws, which she uses as a trowel. When the tube is completed except that the end is left open, she starts off in quest of spiders, and very earnestly does she seek them. I have seen her hunt every nook and corner of a piazza for this prey. When she finds a spider, she pounces upon it and stings it until it is helpless, and carries it to her cement tube, which is indeed a spider sarcophagus, and thrusts it within. She brings more spiders until her tube is nearly full; she then lays an egg within it and then makes more cement and neatly closes the door of the tube. She then places another tube by the side of this, which she provisions and closes in the same way; and then she may make another and another tube, often a half dozen, under one adobe roof.

The wasp in some mysterious way knows how to thrust her sting into the spider's nervous system in a pecuiiar way, which renders her victim unable to move although it yet lives. The wasp is no vegetarian like the bee,

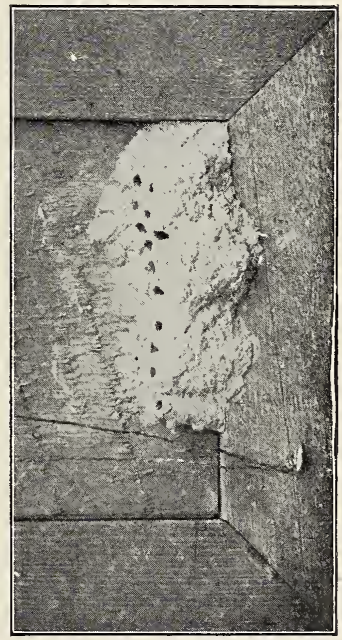

Nests of a mud-dauber on the back of a picture frame. and she must supply her young with waspmeat instead of bee-bread. Since it is during the summer and hot weather when the young wasps are hatched and begin their growth, their meat must be kept fresh for a period of two or three weeks. So these paralyzed spiders do not die, although they are helpless. It is certainly a practical joke with justice in it, that these ferocious creatures lie 
helpless while being eaten by a fat little grub which they would gladly devour, if they could move.

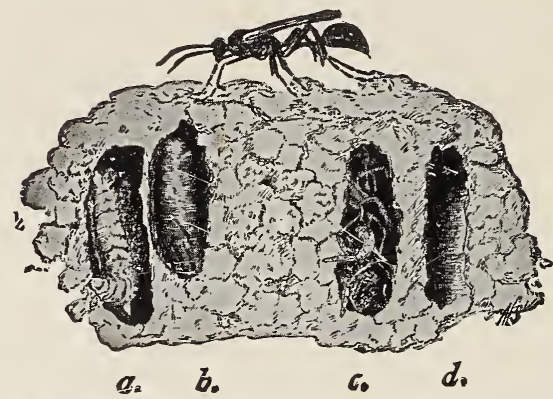

A mud-dauber and her nests, with cells cut open showing $a$, larva full grown; $b$, cocoon; $c$, young larva feeding on its spider-meat and d, an empty cell.

Drawn by Anna C. Stryke.

The wasp larva is a whitish, plump grub and it eats industriously until the spider meat is exhausted. It then weaves a cocoon of silk about itself which just covers the walls of its home tube, like a silken tapestry: within this cocoon the grub changes to a pupa. When it finally emerges, it is a full-grown wasp with jaws which are able to cut a door in the end of its tube, through which it comes out into the world, a free and accepted mason. The females or queens, which issue late in the season, hide in warm or protected places during the winter; they particularly like the folds of lace window curtains for hibernating quarters. There they remain until spring comes, when they go off to build their plaster houses.

There are about seventy species of mud wasps in our country. Some provision their nests with caterpillars instead of spiders. This is true of the jug-builder, which makes her nest jug-shaped and places two or three of them side by side upon a twig. She uses hair in her mortar, which makes it stronger. This is necessary, since the jug is saddied upon twigs and is more exposed to the rain than is the nest of the most common muddauber. The jug-builder is brown in color and has yellow markings on the abdomen; but she does not resemble the yellow-jackets, because she has a threadlike waist. There are other species of mud wasps which use any small cavity they can find for the nest, plastering up the opening after the nest has been provisioned and the egg laid. We often find keyholes, knot-holes and even the cavity in the telephone receiver, plastered up by these small opportunists.

The mud-dauber which is the most common, and most likely to be selected for this lesson, is a slender creature and looks as if she were made of black tinsel; her body gives off glints of steel and blue; her abdomen constantly vibrates with the movement of breathing. Her eyes are large and like black beads; her black antennæ curve gracefully outward, and her wings, corrugated with veins, shimmer with a smoky blue, green and purple. She stands on her black tip-toes when she walks, and she has a 
way of turning around constantly as if she expected an attack from the rear. Her wings, like those of other mud-wasps are not folded fan-wise like those of the yellow-jacket, but are folded by each other over her back.

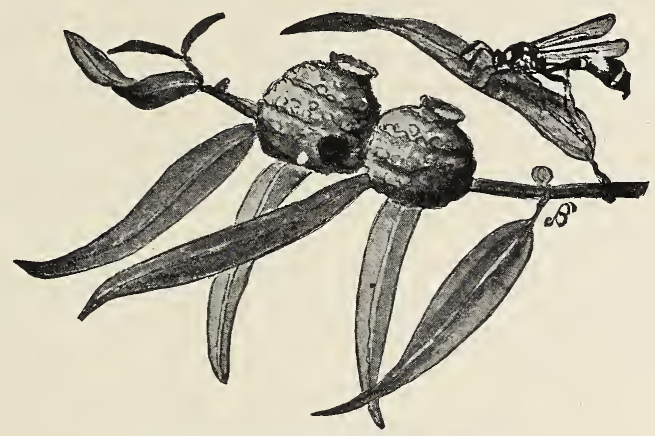

The Jug-builder and her nests.

\section{I.ESSON XCVIII}

\section{The Mud-dauber}

Lealing thought-There are certain wasps which gather mud and mix it into mortar with which to build nests for their young. Within these nests, the mother wasp places spiders or insects which are disabled by her sting, for the food of the young wasps.

Method-Have the pupils bring the homes of the mud wasps to school for observation. The wasps themselves are very common in June and also in September, and they also may be studied at school and may be passed around in vials for closer observation; they do not sting severely when handled, the sting being a mere prick. The purpose of the lesson should be to stimulate the pupils to watch the mud-daubers while building their nests and capturing their prey.

Observations-I. Where did you find the mud-dauber's nest? How was it protected from the rain? Was it easily removed? Could you remove it all, or did some of it remain stuck fast?

2. What is the shape of the nest? How does it look inside? Of how many tubes does it consist? How long is each tube? Were the tubes laid side by side?

3. Of what material was the nest made? Is it not much harder than mud? How did the wasp change the mud to cement? Where did she get the mud? How did she carry it? With what tools did she plaster it?

4. For what purpose was the nest made? Is the inside of the tubes smooth as compared with the outside of the nest?

5. Write a little story about all that happens in one of these fubes, including the fullowing points: What did the mother wasp place in the tube? How and why did she close it? What hatched from the egg she placed within it? How does the young wasp look? On what does it feed? What sort of a cocoon does it spin? How does it get out of the nest when full-grown? 
6. Describe the mud-lauber wasp. How large is she? What is the color of her body? Of her wings? How many wings has she? How are her wings folded differently from those of the yellow-jacket? Describe her eyes; her antennæ; her legs; her waist; her abdomen.

7. Where did you find the wasp? How did she act? Do you think that she can sting? How does she pass the winter?

8. Do you kicw the mud wasps which build the little, jug-shaped nests for their young? Do you know the mud wasps which utilize crevices and keyholes for their nests and plaster up the opening?

9. Do you know about the digger wasps which pack away grasshoppers or caterpillars in a bole in the ground, in which they lay their egg and then cover it?

Supplementary reading-Insect Stories, Kellogg; Wasps, Social and Solitary, Peckham; Wasps and their Ways, Morley; The Ways of the Sixfooted, Comstock: Home Studies in Nature, Treat.

\section{THE YELLOW-JACKET}

\section{Teacher's Story}

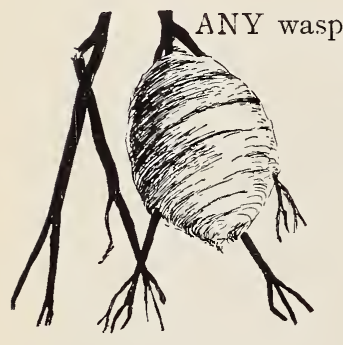

are not so waspish after all when we understand one important fact about them; i. e., although they are very nervous themselves, they detest that quality in others. For years the yellow-jackets have shared with us our meals at our summer camp on the lake shore. They make inquisitive tours of inspection over the viands on the table, often seeming to include ourselves, and coming so near that they fan our faces with their wings. They usually end by selecting the sweetened fruits, but they also carry off bits of roast beef, pouncing down upon the ineat platter and seizing a tilbit as a hawk does a chicken. We always remain calm during these visitations, for we know that unless we inadvertently pinch one, we shall not be harmed; and it is great fun to watch one of these graceful creatures poising daintily on the side of the dish lapping up the fruit juice as a cat does milk, the slender, ycllow-banded abdomen palpitating as she breathes. Occasionally, two desire the same place, and a wrestling match ensues which is fierce while it lasts, but the participants always come back to the dish unharmed. They are extra polite in their manners, for after one has delived eagerly into the fruit syrup, she proceeds to clean her front feet by passing them through her jaws, which is a wasp way of using a finger bowl.

Both yellow-jackets and the white-faced blackhornets build in trees and similarly, although the paper made by the yellow-jackets is finer in texture. However, some species of yellow-jackets build their nests in the ground, hut of similar form. The nest is of paper made of bits of wood which the wasps pull off with their jaws

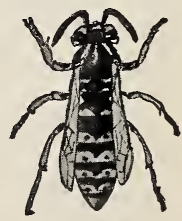

A yellow. jacket from weather-worn fences or boards. This wood is reduced to a pulp by saliva which is secreted from the wasp's mouth, and is laid on in little 
layers which can be easily seen by examining the outside of the nest. These layers may be of different colors. A wasp will cume with her load of paper pulp, and using her jaws and front feet for tools she will join a strip to the edge of the paper and pat it into shape. The paper tears more readily along the lines of the joining, than across. The cover of the nest is made of many layers of stiell-like pieces fastened together and the outer layers are waterproof; the opening of a nest is at the bottom. Mr. Lubbock has shown that certain wasps are stationed at the door, as sentinels, to give warning on the approach of the enemy. The number of stories of combs in a nest depends upon the age and size of the colony. They are fastened together firmly near the center, by a central core or axis of very strong, firm paper, which at the top is attaclied to a branch or whatever supports the nest. The cells all open downward, in this respect differing from those of the honey-bee, which are usually placed horizontal. The wasp-comb differs from the honey-comb in that it is made of paper insteac of wax, and that the rows of cells are single instead of double. The cells in the wasp-comb are not for storing honey, but are simply the cradles for the young wasps. (See Fig. p, 457.)

Sometimes a wasp family disaster makes it possible for us to examine one of these nests with its inmates. Here we find in some of the cells, the long white eggs fastened to the very bottom of the cell, in an inner angle, as if a larva when hatched needed to have a cozy corner. These wasp larvæ are the chubbiest little grubs imaginable and are very soft bodied. It was once a mystery to me how they were able to hang in the cells, head down, without getting "black in the face" or falling out; but this was made plain by studying the little disk at the rear end of the larva's body, which is decidedly sticky; after a larva is dead, its heavy body can be lifted by pressing a match against this disk; thus it evidently suffices to keep the baby wasp stuck fast to its cradle. The larva's body is mostly covered with a white, papery, soft skeleton skin; the head is yellowish and highly polished, looking like a drop of honey. At one side may be seen a pair of toothed jaws, showing that it is able to take and chew any food brought by the nurses. They seem to be well trained youngsters for they all face toward the center of the nest, so that a nurse, when feeding them, can move from one to another without having to pass to the other side of the cell. It is a funny sight to behold a combful of well grown larvæ, each fitting in its cell like meal in a bag and with head and several segments projecting out as if the bag were overflowing. It behooves the wasp larva to get its head as far out of the cell as possible, so that it will not be overlooked by the nurses; the little ones do this by holding themselves at the angle of the cell; this they accomplish by wedging the back into the corner. These young larvæ do not face inwards like the older ones, but hey rest in an inner angle of the cell.

After a larva has reached the limit of its cell room, it spins a veil around itself and fastens it at the sides, so that it forms a lining to the upper part of the cell and makes a bag over the "head and shoulders" of the insect. This cocoon is very tough, and beneath its loose dome the larva skin is shed; the pupa takes on a decidedly waspish form, except that the color is all black; the legs and the wings are folded piously down the breast and the antennæ lie meekly each side of the face, with the "hands" folded outside of them; the strong toothed jaws are ready, so that when the pupa skin is molted, the insect can cut its silken curtain, and come out into its little nest world, as a full-fledged yellow-jacket. 
What a harlequin the wasp is, in her costume of yellow and black! Often in the invertebrate world these colors mean "sit up and take

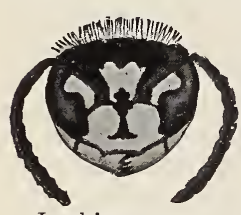

Looking a wasp in the face. notice," and the wasp's costume is no exception. Whoever has had any experience in meddling with yellow-jackets, avoids acquaintance with all yellow and black insects. Yet we must confess that the lady wasp has good taste in dress. The yellow cross bands on her black skirt are scalloped, and, in fact, all her yellow is put on in a most chic manner; she, being slender, can well afford to dress in roundwise stripes, and she folis her wings prettily like a fan, and not over her back like the mud wasp, which would cover her decorations. There is a sensation coming to the one who, armed with a lens, looks a wasp in the face; she always does her hair pomparlour, and the yellow is here put on with a most bizarre effect, in points and arabesques. Even her jaws are yellow with black borders and black notches. Her antennæ are velvety black, her legs are yellow, and her antennæ comb, on her wrist, is a real comb and quite ornate.

In the nest which we studied in late August, the queen cells were just being developed. They were placed in a story all by themselves, and they were a third larger than the cells of the workers. The queen of this nest was a most majestic wasp, fully twice as large as any of her subjects; her face was entirely black, and the yellow bands on her long abdomen were of quite a different pattern than those on the workers; her sting was not so long in proportion, but I must confess it looked efficient. In fact, a yellow-jacket's sting is a formidable looking spear

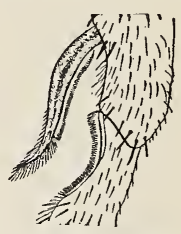

The antennacomb on the wrist of my Lady Wasp when seen through a microscope, since it has on one side sone backward projecting barbs, meant to hold it firm when driving home the thrust.

While wasps are fond of honey and other sweets, they are also fond of arimal food and eat a great many insects, benefiting us greatly by destroying mosquitoes and flies. As no food is stored for their winter use, all wasps excepting the queens die of the cold. The queens crawl away to protected places and seem to he able to withstand the rigors of winter; each queen, in the spring, makes a little comb of a few cells, covering it with a thin layer of paper. She then lays eggs in these cells and gathers food for the young; but when these first members of the family, which are always workers, come to maturity, they take upon themselves the work of enlarging the nest and caring for the young. After that, the queen devotes her energies to laying eggs.

Wasps enlarge their houses by cutting away the paper from the inside of the covering, to give nore room for building the combs wider; to compensate for this, they build additional layers on the outside of the nest. Thus it is, that every wasp's nest, however large, began as a little comb of a few cells and was enlarged to meet the needs of the rapidly growing family. Ordinarily the nest made one year is not used again. 


\section{LESSON XCIX}

\section{The Yellow-JACKet}

Leading thought-The wasps were the original paper makers, using wood pulp for the purpose. Some species construct their houses of paper in the trees or bushes while others build in the ground.

Method-Take a deserted wasp-nest, the larger the better, with sharp scissors remove one side of the covering of the nest, leaving the combs exposed and follow with the questions and suggestions indicated. From this study of the nest encourage the children to observe more closely the wasps and their habits, which they can do in safety if they learn to move quietly while observing. (See Fig. page 457.)

Observations-I. Which kind of wasp do you think made this nest? Of what is the nest made? Where did the wasp get the material? How do the wasps make wood into paper?

2. What is the general shape of the nest? Is the nest well covered to protect it from rain? Where is the door where the wasps went in and out? Is the covering of the nest all of the same color? Do these differences in color give you any idea of how the wasps build the paper into the nest? Does the paper tear more easily one way than another? Is the covering of the nest solid or in layers?

3. How many combs or stories are there in the wasp house? How are they fastened together and how suspended?

4. Ccmpare the combs of the wasp-nest with those of the honey-bee. How do they resemble each other and how differ? Do the cells open upward or downward? For what purpose are the combs in the wasp-nest used? Are all the cells of the same size? Do you know the reason for this difference in size?

5. How do the young wasp grubs manage to cling to the cells head downward? Are the cells lined with a different color and does this lining extend out over the opening in some cases? Is this lining of the cells made of paper also? Do you know how a young wasp looks and how the white lining of the cells is made?

6. Do you believe that some wasps of the colony are always posted as sentinels at the door to give warning if the colony is attacked?

7. Do wasps store food to sustain them during the winter? What happens to them during winter? Is the same nest used year after year.

8. Can you describe the beginning of this wasp-nest? When was it made? Tell the story of the wasp that made it. How large was the nest at first? How was the nest enlarged?

9. What is the food of wasps? How do these insects benefit us?

ro. Write a story giving the life history of a wasp.

Ir. In the summer watch a yellow-jacket eat from a dish of sweetened fruit which you may place out of doors to coax her to come where you can carefully observe her. What are the colors of the yellow-jacket? Where is the yellow? How are the yellow bands made ornamental? How does she fold her wings? How many wings has she? What is the color of her legs? Describe her antennæ and eyes. How does she eat the fruit juice? Can you see the motion of her body when she breathes? 


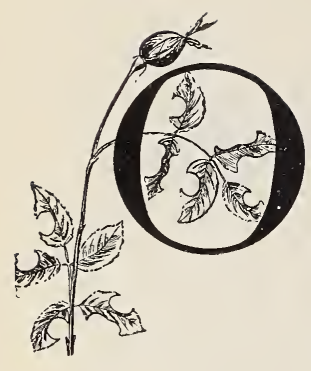

\section{THE LEAF-CUTTER BEE}

$\mathrm{NE}$ beautiful day in late June when I was picking some roses, I saw a bee, almost as large as a honey-bee but different in shape and darker in color, alight on a leaf and moving with nervous rapidity, cut a circle out of a leaf with her jaws "quicker'n a wink;" then taking the piece between her fore-feet and perhaps holding it also with her jaws, she flew away, the green disk looking as large in proportion to her size as a big base. drum hung to the neck of a small drummer. I waited long for her to come back, but she came not; meanwhile I examined the leaves of the rose bush and found many circlets, and also many oblong holes with the ends deeply rounded, cut from the leaflets.

I knew the story of the little bee and was glad I had seen her cut a leaflet with her jaw shears, which work sidewise like real shears. I knew that somewhere she had found a cavity big enough for her needs; perhaps she had tunneled it herself in the dead wood of some post or stump, using her jaws to cut away the chips; maybe she had found a crevice beneath the shingles of a roof or beneath a stone in the field, or she may have rolled a leaf; anyway, her little cave was several inches long, circular in outline and large enough to admit her body. She first cut a long piece from the rose leaf and folded it at the end of the tunnel; and then she brought another and another long piece and bent and shaped them into a little thimble-like cup, fastening them together with some saliva glue, from her mouth. After the cup was made to her liking, she went in search of food, which was found in the pollen of some flowers. This pollen was carried not as the honey-bees do, because she has no pollen baskets on her legs; but it was dusted into the fur on the lower side of her body; as she scraped the pollen off, she mixed it with some nectar which she had also found in the flowers, and made it into a pasty mass and heaped it at the bottom of the cup; she probably made many visits to flowers before she had a sufficient amount of this bee pastry, and then she laid an egg upon it; after this, she immediately flew back to the rose bush to cut a lid for her cup. She is a nice mathematician and she cuts the lid just a little larger than the rim of the cup, so that it may be pushed down in, making it fit very closely around the edges; she then cuts another and perhaps another of the same size and puts them over and fastened to the first cover. When finished, it is surely the prettiest baby basket ever made by a mother, all safely enclosed to keep out enemies. But her work is then only begun. She has other baby baskets to make and she perhaps makes ten or more, placing one cup just ahead of another in the little tunnel.

But what is happening meanwhile to the bee babies in the baskets? The egg hatches into a little white bee grub which falls to and eats the pollen and nectar paste with great eagerness. As it eats, it grows and sheds its skeleton skin as often as it becomes too tight, and then eats and grows some more. How many mothers would know just how much food it would require to develop a child from infancy until it grows up! This bee mother knows well this amount and when the food is all gone, the little bee grub is old enough to change to a pupa; it looks very different now, 
and although mummy-shaped we can see its folded wings and antennæ. After remaining a motionless pupa for a few days, it sheds its pupa skin and now it is a bee just like its mother; but as the oldest bee is at the bottom of the tunnel, even after it gets its wings and gnaws its way out of its basket, it very likely cannot escape and find its way out into the sunshiny world, until its younger brothers and sisters have gone out before it.

There are many species of these leaf-cutter bees and each species makes its own kind of a nest, always cutting the same size of circlets and usually choosing its own special kind of leaf to make this cradle. Some are daintier in their tastes and use rolled petals instead of leaves; and we have found some tiny cups made of gorgeous peony petals, and some of pansy petals, a most exquisite material.

At Chautauqua we found a species which rolled maple leaves into a tube which held three or four cups, and we also found there a bee stowing her cups in the open end of a tubular rod, used to hold up an awning. There are other species which make short tunnels in the ground for their nests, but perhaps the most common of all wedge their cups between or beneath the shingles on the roofs of summer cottages. But, however or wherever the leaf-cutter works, she is a master mechanic and does her work with niceness and daintiness.

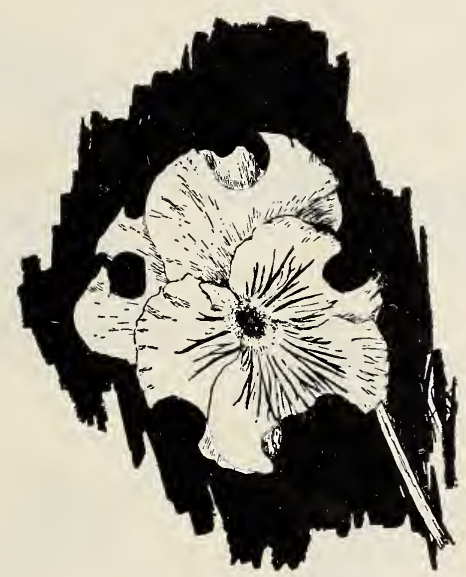

Pansy cut by leaf-cutter bee.

Drawing by Anna C. Stryke. 


\section{LESSON C}

\section{The Leaf-cutter Bee}

Leading thought-When we see the edges of rose leaves with holes of regular pattern in them, some of the holes being oblong and some sircular, we know the leaf-cutter bee has cut them to make her cradle cups.

Method-It is very easy to find in June or autumn the leaves from which the leaf-cutter bee has cut the bedding for her young. Encourage the pupils to look for the nest during the summerand to bring some of the cups to school when they return, where they may be studied in detail; meanwhile the teacher may tell the story of the nest. This is rather difficult for the pupils to work out.

Observations - - . Do you find rose leaves with round holes cut in their edges? Do you find on the same bush some leaflets with oblong holes in them? Sketch or describe the rose leaf this cut, noting exactly the shape of the holes. Are the circular holes of the same size? Are the long holes about equal in size and shape? Do you find any other plants with holes like these cut in them? Do you find any petals of flowers thus cut?

2. What do you think made these holes? If an insect was taking a leaf for food would the holes be as regular? Watch the rose bush carefully and see if you can discover the insect which cuts the leaf.

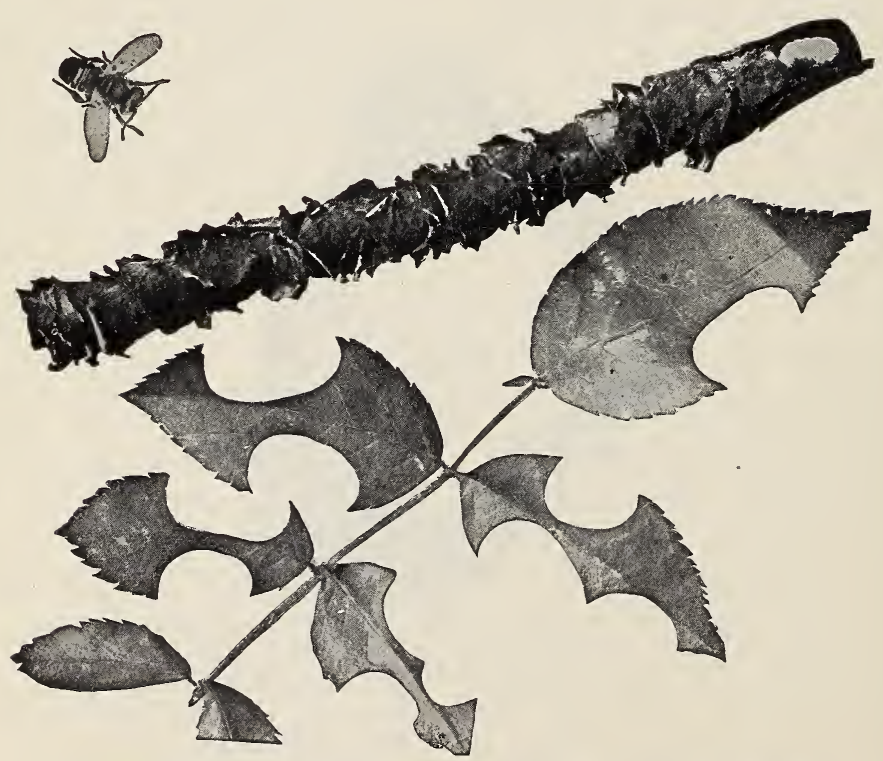

Leaf-cutter bee; the rose leaf cut by her; her nest-cups removed from the tube in which they were built, the cup made first. cut open to show bee iarvu.

Photo by silingertand. 
3. Have you ever seen the little black bee carrying pieces of rose leaves between her front feet? With what instrument do you suppose she cut the leaves? Where do you think she was going?

4. Have you ever found the nest of the leaf-cutter bee? Was it in a tunnel made in dead wood or in some crack or cranny? How many of the little rose leaf cups are there in it? How are the cups placed? Are the little bees still in the cups or can you see the holes through which they crawled out?

5. Take one cup and study it carefully. How are the pieces of leaves folded to make the cups? How is the lid put on? Soak the cup in water until it comes apart easily. Describe how many of the long pieces were used and how they were bent to make a cup. Of how many thicknesses is the cover made? Are the covers just the same size or a little larger than the top of the cup? How does the cover fit so tightly?

6. If you find the nest in July or early August, examine one of the cups carefully and see what there is in it. Take off the cover without injuring it. What is at the bottom of the nest? Is there an insect within it? How does it look? What is it doing? Of what do you think its food was made? How and by whom was the food placed in the cup? Place the nest in a box or jar with mosquito netting over the top, and put it out of doors in a safe and shaded place. Look at it often and see what this insect changes into.

7. If the mother bee made each little nest cup and put in the beebread, and honey for her young, which cup contains the oldest of the family? Which the youngest? How do you think the full-grown bees get out of the cup?

8. Do you think that the same species of bee always cuts the same sized holes in a leaf? Is it the same species which cuts the rose leaves and the pansy petals?

\section{THE LITTLE CARPENTER-BEE}

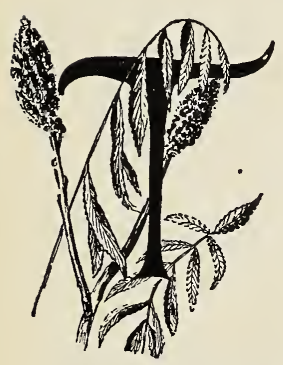

\section{Teacher's Story}

AKE a dozen dead twigs from almost any sumac or elder, split them lengthwise, and you will find in at least one or two of them, a little tunnel down the center where the pith once was. In the month of June or July, this narrow tunnel is made into an insect apartment house, one little creature in each apartment, partitioned off from the one above and the one below. The nature of this partition reveals to us whether the occupants are bees or wasps; if it is made of tiny chips, like fine sawdust glued together, a bee made it and there are little bees in the cells; if it is made of bits of sand or mud glued together, a wasp was the architect and young wasps are the inhabitants. Also, if the food in the cells is pollen paste, it was placed there by a bee; if of paralyzed insects or spiders, a wasp made the nest.

The little carpenter-bee (Ceratina dupla) is a beautiful creature, scarcely one quarter of an inch in length, with metallic blue body and 


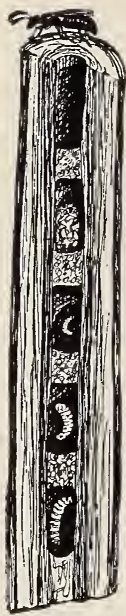

The little carpenter-bee; her nest, cut open, showing the eldest larva at the bottom and the youngest nearest the entrance.

rainbow tinted wings. In May, she selects some broken twig of sumac, elder or raspberry, which gives her access to the pith; this she at once begins to dig out, mouthful by mouth. fui, until she has made a smooth tunnel several inches long; she then gathers pollen and packs bee-bread in the bottom of the cell to the depth of a quarter-inch, and then lays upon it, a tiny white egg. She then brings back some of her chips of pith and glues them together, making a partition about onetenth of an inch thick, which she fastens firmly to the sides of the tunnel; this is the roof for the first cell and the floor of the next one; she then gathers more pollen, lays another egg, and builds another partition.

Thus she fills the tunnel, almost to the opening, with cells, sometimes as many as fourteen; but she always leaves a space for a vestibule near the door, and in this she makes her home while her family below her are growing up.

The egg in the lowest cell of course hatches first; a little bee grub issues from it and eats the bee-bread industriously and grows by shedding his skin when it becomes too tight; then he changes to a pupa and later to a bee resembling his mother. But, though fully grown, he cannot get out in to the sunshine, for all his younger brothers and sisters are blocking the tunnel ahead of him; so he simply tears down the partition above him and kicks the little pieces of it behind him, and bides his time until the next youngest brother tears down the partition above his head and pushes its fragments behind him into the very face of the elder which, in turn, performs a similar act; and thus, while he is waiting, he is kept more or less busy pushing behind him the broken bits of all the partitions above him. Finally, the youngest gets his growth, and thre they all are in the tunnel, the broken partitions behind the hindmost at the bottom of the nest, and the young bees packed closely together in a row with heads toward the door. When we find the nest at this period, we know the mother because her head is toward her young ones and her back to the door. A little later, on some bright morning, they all come out into the sunshine and flit about on gauzy, rainbow wings, a very happy family, out of prison.

But if the brood is a late one, the home must be cleaned out and used as a winter nest, and still the loyal little mother bee stays true to her post; she is the last one to enter the nest; and not until they are all housed within, does she enter. It is easy to distinguish her for her poor wings are torn and frayed with her long labor of building the nest, until they scarcely serve to carry her afield; but despite this she remains on guard over her brood, for which she has worn out her own life.

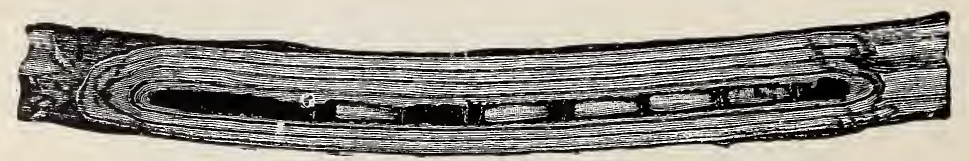

Nest of carpenter-wasp.

Comstock's Manual. 
The story of the little carpenter-wasps is similar to that of the bee, except that we have reason to believe they often use her abandoned tunnels instead of making new ones They make their little partitions out of mud; their pupæ are always in long, slender, silken cocoons, and we have no evidence that the mother remains in attendance.

\section{LESSON CI}

\section{The Little Carpenter-bee}

Leading thought-Not all bees live in colonies like the honey-bees and bumblebees. One tiny bee rears her brood within a tunnel which she makes in the pith of sumac, elder or raspberry.

Method-This lesson may be given in June or in October. In June, the whole family of bees in their apartments may be observed; in autumn, the empty tenement with the fragments of the partitions still clinging may be readily found and examined; and sometimes a whole family may be found, stowed away in the home tunnel, for the winter.

Observations-I. Collect dead twigs of sumac or elder and cut them in half, lengthwise. Do you find any with the pith tunneled out?

2 How long is the tunnel? Are its sides smooth? Can you see the partitions which divide the long narrow tunnel into cells? Look at the partitions with a lens, if necessary, to determine whether they are made of tiny bits of wood or of mud. If made of mud, what insect made them? If of little chips how and by what were they constructed?

3. Are there any insects in the cells? If so. describe them. Is there bee-bread in the cells?

4. For what was the tunnel made? With what tools was it made? How are the partitions fastened together? How does a young bee look?

5. Write the story of the oldest of the bee family which lived in this tunnel. Why did it hatch first? On what did it feed? When it became a full fledged bee, what did it do? How did it finally get out?

6 Take a glass tube, the hollow at the center being about one-eighth of an inch across, a tube which you can get in any drug-store. Break this tube into sections, six or seven inches long, wrap around each a black paper or cloth, made fast with rubber bands and suspend them in a hedge or among thick bushes in May. Examine these tubes each week to see if the wasps or bees are using them.

Supplementary reading - "The Story We Love Best," in Ways of the Six-footed, Comstock.

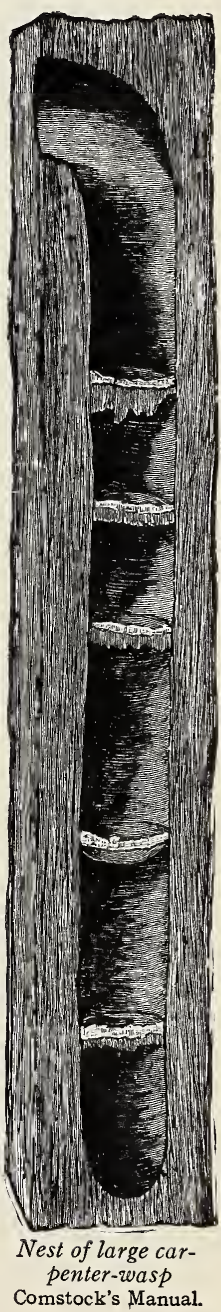




\section{THE BUMBLEBEE}

\section{Teacher's Story}

Thou, in sunny solitudes, Rover of the underwoods, The green silence dost replace With thy mellow, breezy bass.

-EMERSon.
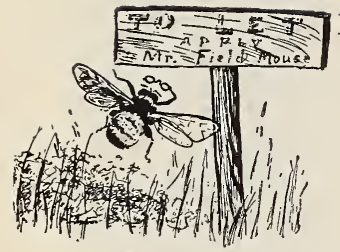

HERE seems to have been an hereditary war between the farm boy and the bumblebee, the hostilities usually initiated by the boy. Like many wars, it is very foolish and wicked, and has resulted in great harm to both parties. Luckily, the boys of to-day are more enlightened; and it is to be hoped that they will learn to endure a bee sting or two for the sake of protecting these diminishing hosts, upon which so many flowers depend for carrying their pollen; for of all the insects of the field, the bumblebees are the best and most needed friends of the flowers.

The bumblebees are not so thrifty and forehanded as are the honeybees, and do not provide enough honey to sustain the whole colony during the winter. Only the mother bees, or queens as they are called, survive the cold season. Just how they do it, we do not know, but probably they are better nourished and therefore have more endurance than the workers. In early May, one of the most delightful of spring visitants is one of these great buzzing queens, flying low over the freshening meadows, trying to find a suitable place for her nest; and the farmer or fruit grower who knows his business, is as anxious as she that she find suitable quarters, knowing well that she and her children will render him most efficient aid in growing his fruit and seed. She finally selects some cusy place, very likely a deserted nest of the field mouse, and there begins to build her home. She toils early and late, gathering pollen and nectar from the blossoms of the orchard and other flowers which she mixes into a loaf as large as a bean upon which she lays a few tiny eggs and then covers with wax. She then makes a honey-pot of wax as large as a small thimble and fills it with honey; thus provided with food she broods over her eggs, keeping them warm until they hatch. Each little bee grub then burrows into the bee-bread making for itself a cave while satisfying its hunger. When fully grown, it spins about itself a cocoon, changes to a pupa and then comes out a true bumblebee but smaller than her queen mother. These workers are daughters and are happy in caring for the growing family; they gather pollen and nectar and add to the mass of bee-bread for the young to burrow in, meanwhile the queen remains at home and devotes her energies to laying eggs. The workers not only care for the young, but later they strengthen the silken pupa cradles with wax, and thus make them into cells for storing honey. When we understand that the cells in the bumblebee's nest are simply made by the young bees burrowing in any direction, we can understand why the bumblebee comb is so disorderly in the arrangement of its cells. Perhaps the boy of the farm would find the rank bumblebee honey less like the ambrosia of the gods if he knew that it was stored in the deserted cradles and swaddling clothes of the bumblebee grubs. 


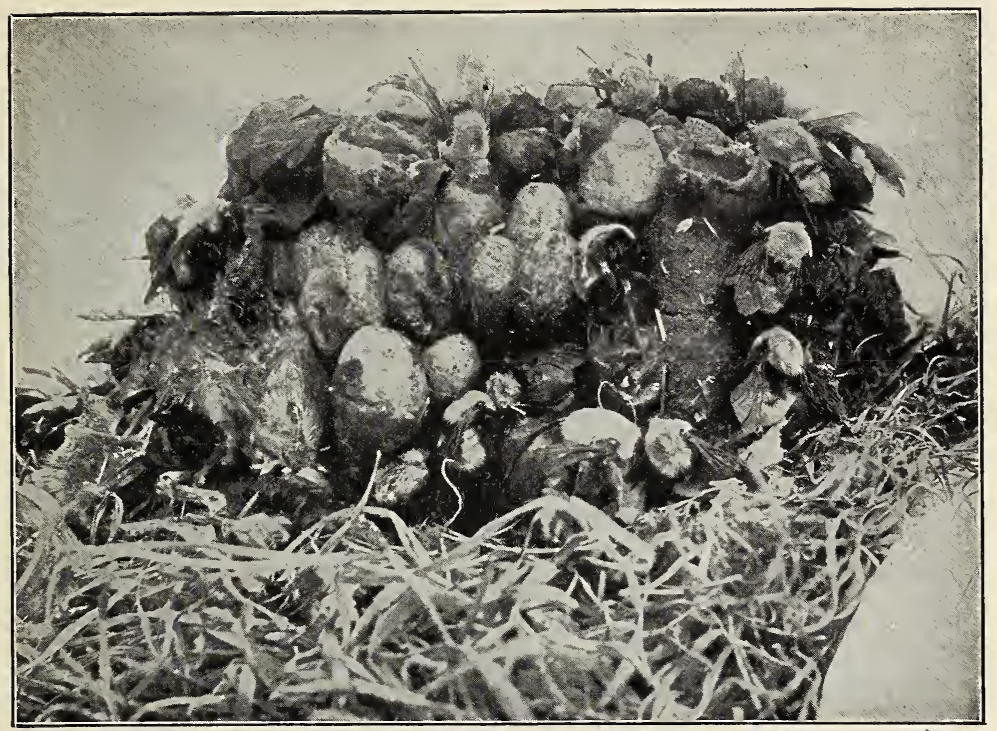

A bumblebee's nest after a frost. Note the mummv of the first owner of the nest. Photo by Slingerland.

All of the eggs in the bumblebee nest in the spring and early summer develop into workers which do incidentally the vast labor of carrying pollen for thousands of flowers; to these only is granted the privilege of carrying the pollen for the red clover, since the tongues of the other bees are not sufficiently long to reach the nectar. The red clover does not produce seed in sufficient quantity to be a profitable crop, unless there are bumblebees to pollinate its blossoms. Late in the summer, queens and drones are developed in the bumblebee nest, the drones, as with the honey-bees, being mates for the queens. But of all the numerous population of the bumblebee nest, only the queens survive the rigors of winter, and on them and their success depends the future of the bumblebee species.

There are many species of bumblebees, some much smaller than others, but they all have the thorax covered with plush above and the abdomen hairy, and their fur is usually marked in various patterns of pale yellow and black. The bumblebee of whatever species, has short but very active antennæ and a mouth fitted for biting as well as for sucking. Between the large compound eyes are three simple eyes. The wings are four in number and strong; the front legs are very short; all the legs have hairs over them and end in a three-jointed foot, tipped by a claw. On the hind leg, the tibia and the first tarsal joint are enlarged, making the pollen baskets on which the pollen is heaped in golden masses. One of the most interesting observations possible to make, is to note how the bumblebee brushes the pollen from her fur and packs it into her pollen baskets. 


\section{LESSON CII}

\section{The Bumblebee}

Leading thought-The bumblebees are the chief pollen carriers for most of our wild flowers as well as for the clovers and other farm plants. They should, therefore, be kindly treated everywhere; and we should be careful not to hurt the big queen bumblebee which we see often in May.

Method-Ask the questions and encourage the pupils to answer them as they have opportunity to observe the bumblebees working in the flowers. A bumblebee may be imprisoned in a tumbler for a short period for observarion, and then allowed to go unharmed. It is not advisable to

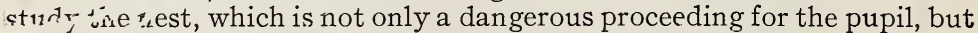
it als sneans the destruction of a colony of these very useful insects. However, if the location of a nest is discovered, it may be dug up and studied after the first heavy frost. Special stress should be laid upon the observations of the actions of the bees when visiting flowers.

Observations-I. In how many flowers do you find the bumblebee? Watch her closely and see how she gets the nectar. Notice how she "bumbles around" in a flower and becomes dusted with pollen. Watch her and note how she gets the pollen off her fur and packs it in her pollen baskets. On which legs are her pollen baskets? How does the pollen look when packed in them? What does she do with pollen and nectar?

2. Catch a bumblebee in a jelly glass and look at her closely. Can you see three little eyes between the big compound eyes? Describe her antennæ. Are they active? How many pairs of wings has she? Do you think they are strong? Which pair of legs is the shortest? How many segments are there in the leg? Do you see the claws on the foot?

3. What is the bumblebee's covering? What is the color of her plush? Is she furry above and below?

4. Can you see that she can bite as well as suck with her mouth-parts? Will a bumblebee sting a person unless she is first attacked?

5. Have you seen the very large queen bumblebee in the spring, flying near the ground hunting for a place to build a nest? Why must you be very careful not to hurt her? How does she pass the winter? What does she do first, in starting the nest?

6. In how many ways does the bumblebee benefit us?

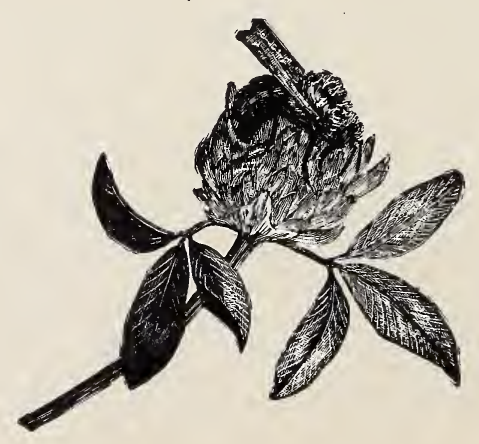




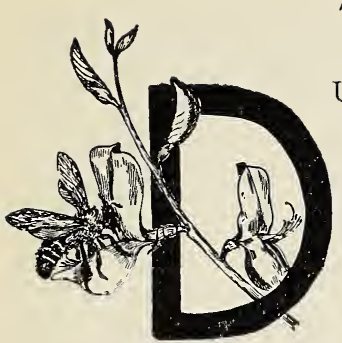

\section{THE HONEY-BEE}

\section{Teacher's Story}

URING many years naturalists have been study ing the habits and adaptations of the honeybees, and, as yet, the story of their wonderful ways is not half told. Although we know fairly well what the bees do, yet we have no inkling of the processes which lead to a perfect government and management of the bee community; and even the beginner may discover things never known before about these fascinating little workers. In beginning this work it might be well to ask the pupils if they have ever heard of a republic that has many kings and only one queen; and where the citizens do all the governing without voting, and where the kings are powerless and the queen works as hard and longer than any of her subjects; and then tell them that the pages of history contain no account of a republic so wonderful as this; yet the nearest beehive is the home of just this sort of government.

In addition to the interest of the bee colony from a nature-study standpoint, it is well to get the children interested in bee-keeping as a commercial enterprise. A small apiary well managed may bring in an acceptable income; and it should be the source of a regular revenue to the boys and girls of the farm, for one hive should net the young bee-keeper from three to five dollars per year and prove a business education to him in the meantime.

Bees are perfect socialists. They have non-competitive labor, united capital, communal habitations and unity of interests. The bee commune is composed of castes as immutable as those of the Brahmins, but these castes exist for the benefit of the whole society instead of for the individuals belonging to them. These castes we have named queens, drones and workers, and perhaps, first of all, we should study the physical adaptations of the members of these castes for their special work in the community.

\section{The Worker (p. 446, Fig. 3.)}

There are three divisions to the body of the bee, as in all insects-head, thorax and abdomen. The head bears the eyes, antennæ and mouthparts, (p. 448, W.) There are two large compound eyes on either side of the head and three simple eyes between them. The antennæ arise from the face, each consisting of two parts, one straight segment at the base, and the end portion which is curved and made up of many segments. There is also a short, bead-like segment where the antenna joins the face. A lens is needed to see the jaws of the bee, folded across, much like a pair of hooks, and below them the tongue, which is a sucking tube; the length of the tongue is very important, for upon this depends the ability of the bee to get nectar from the flowers.

The thorax bears three pairs of legs below and two pairs of wings above. Each leg consists of six segments, and the foot or tarsus has four segments and a pair of claws. The iront leg has an antennae comb between the tibia and tarsus, (p. 447, F, a, ) the hind leg has a pollen basket, which is a long cavity bordered by hairs wherein the pollen is packed and carried (p. $447, \mathrm{~A}, \mathrm{pb}$.) On the other side of the large ioint beyond the pollen 
basket are rows of spines which are used to remove the pollen from the baskets (p. 447, B, pc,) and between these two large segments are the pincers for removing the wax (p. 447, B,wp.)

The front pair of wings is larger than the hind pair. The wings of the old bees that have done much work are always frayed at the edges.

There are six segments or rings to the abdomen, plainly visible from above. If the five segments next the thorax are marked above with yellow bands on their front edges, the bee is an Italian. On the lower side of the abdomen, each segment is made up of a central plate with an overlapping plate on each side; just at the front edge on each side of the central plate is a wax pocket which cannot be seen unless the bee is dissected under a microscope. From these pockets are secreted little flecks of wax (p. 448, X.)

\section{The Queen}

The queen bee is a truly royal insect. She is much larger than the worker, her body being long, pointed, and extending far beyond the tips of

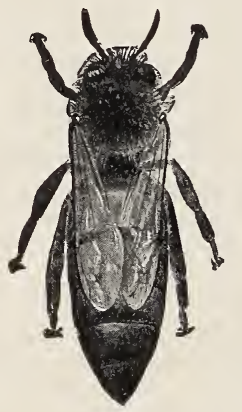

Fig. 1

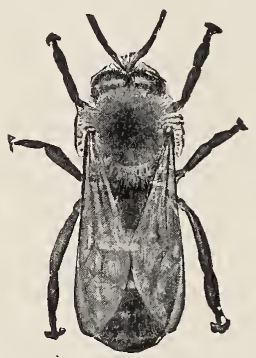

Fig. 2

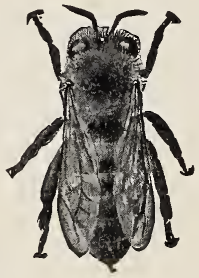

Fig. 3

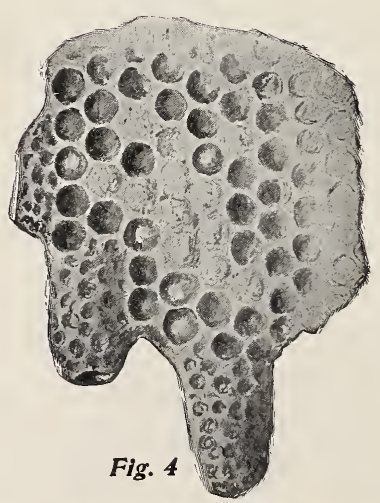

I. Queen bee. 2. Drone. 3. Worker; all enlarged. 4. Queen cells.

From How to Keep Bees-Comstock. Drawn by A. J. Hammar. 
her closed wings, giving her a graceful form. She has no pollen baskets or pollen comb upon her legs, because it is not a part of her work to gather pollen or honey. The queen bee starts life as an ordinary worker egg,

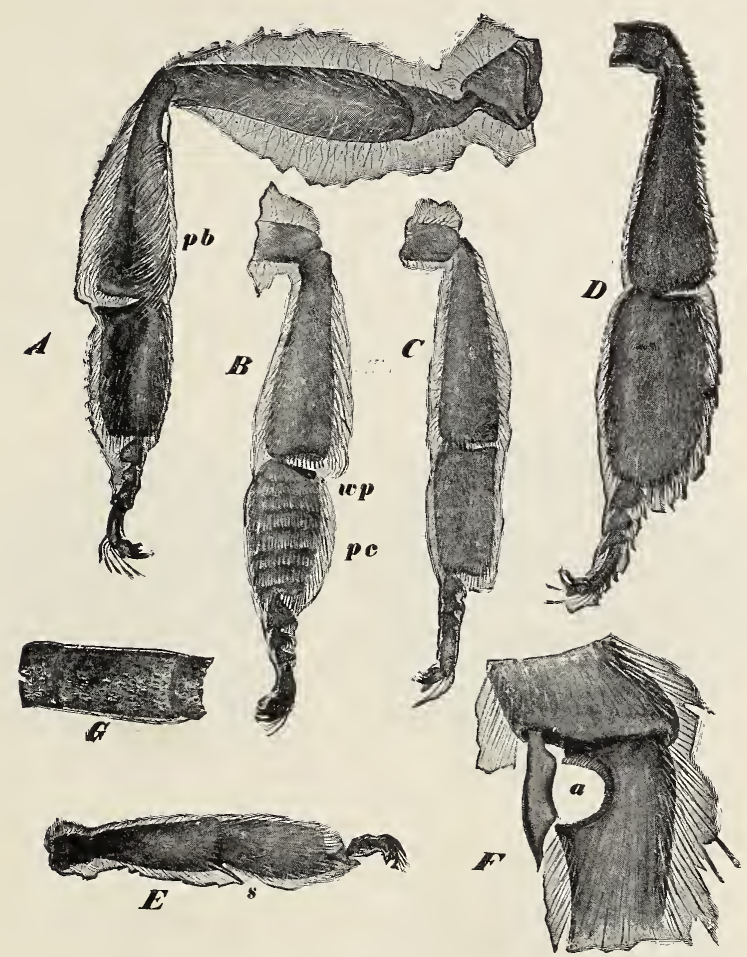

Legs of worker honey-bee.

$A$, outer surface of hind leg showing the nine segments and claws; $p b$, the pollen basket of tibia; $B$. inner surface of part of hind leg; wp, waxpincers; pc, pollen-combs; $C$. inner surface of part of hind leg of queen. $D$, inner surface of part of hind leg of drone; $E$, part of middle leg of worker; s, spur; $F$, part of fore leg showing the antenna cleaner $a_{i}$ $G$, part of antenna showing sense-hairs and sense-pits.

From How to Keep Bees-Comstock.

Drawn by A. J. Hammar.

which is selected for special development. The workers tear down the partitions of the cells around the chosen egg and build a projection over the top, making an apartment, (p. 446, Fig. 4.) The little white bee grub, as soon as it hatches, is fed for five days on the same food as is given to the worker grubs for three days; it is a special substance, secreted by the worker bees, called royal jelly. This food is very nourishing, and after being reared upon it, the princess larva weaves around herself a silken cocoon and changes to a pupa. Meanwhile the workers have sealed her cell with wax. 
When the princess-pupa changes to the full-grown queen she cuts a circular door in the cover of the cell and pushes through it into the world. Her first real work is to hunt for other queen cells and if she finds one, she will, if not hindered, make a hole in its side and sting to death the poor princess within. If she finds another full-grown queen, the two fight until one succumbs. The queen never uses her sting upon anything or anyone except a rival queen.

After a few days she takes her marriage flight in the air, where she mates with some drone, and then returns to her hive and begins her great work as mother of the colony. She runs about on the comb, pokes her head into a cell to see if it is ready, then turning about thrusts her abdomen in and neatly glues an egg fast to the bottom.

When the honey season is at its height she works with great rapidity, sometimes laying at the rate of six eggs per minute, often producing 3,000 eggs during a day, which would equal twice her own weight. If the workers do not allow her to destroy the other queens, she then takes a portion of her colony with her and swarms out, seeking a home elsewhere.
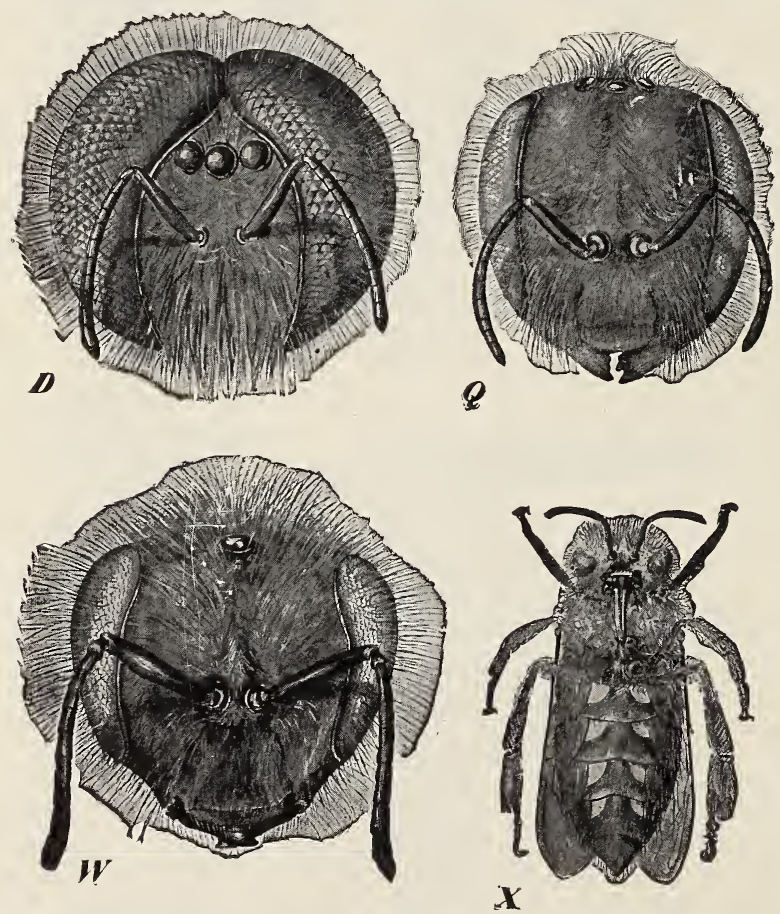

$D$, head of drone; $Q$, head of queen bee: $W$, head of worker;

$X$, worker bee seen from below, showing plates of wax secreted from wax pockets.

From How to Keep Bees-Comstock. Drawn by A. J. Hammar. 


\section{The Drone}

The drone differs much in shape from the queen and the worker. $\mathrm{He}$ is broad and blunt, being very different in shape from the queen, and larger than the worker, (p. 446, Fi६. 2.) He has no pollen baskets on his legs and has no sting. His eyes are very much larger than those of the queen or the worker and unite at the top of the head (p. $448, D$.) His wings are larger and stronger than those of the worker or queen. It is not his business to go out and gather honey or to help in the work of the hive. His tongue is not long onough to get honey from the flowers; he has no pollen basket in which to carry pollen; he has no sting to fight enemies and no pockets for secr ting wax; he is fed by his sister wo kers until the latter part of the season when the honey supply runs low, and then he is stung or bitten to death by these same sisters who have always given him such good care. The drone should be called a prince or king, since his particular office in the hive is to mate with the queen.

References-How to Keep Bees, Comstock; The Bee People, Morley.

\section{LESSON CIII}

\section{The Honey-bee}

Leading thought-In a colony of honey-bees there are three different forms of bees, the queens, the drones, and the workers. All of these have their own special work to do for the community.

Method-In almost every country or village community there is an apiary, or at least someone who keeps a few colonies of bees; to such the teacher must turn for material for this lesson. If this is not practical the teacher may purchase specimens from any bee dealer; she may, for instance, get an untested queen with attendant workers in a queen cage sent by mail for a small sum. These could be kept alive for some time by feeding them with honey, during which time the pupils can study the forms of the two castes. Any apiary during September will give enough dead drones for a class to observe. Although ordinarily we do not advocate the study of dead specimens, yet common sense surely has its place in nature-study; and in the case of the honey-bee, a closer study of the form of the insect is desirable than the living bee might see fit to permit. There are no more wonderful instances of adaptation of form to life than is found in the anatomy of the workers, queens and drones; moreover, it is highly desirable if the pupils are ever to become bee-keepers, that they shall know these adaptations.

A lens is almost necessary for these lessons and a compound microscope used with a low power would be a very desirable adjunct. This lesson should not be given below the fifth grade; and it is better adapted to eighth grade work.

\section{The Worker}

Observations-r. How many divisions of the body are there?

2. What organs are borne on the head?

3. Are there small, simple eyes between the large compound ones?

4. What is the difference between the large eyes and the small?

5. Describe the antennae.

6. What can you see of the mouth? Describe it. 
7. Look at the tongue under the microscope and see how it is fitted for getting nectar from flowers.

8. What organs are borne on the thorax?

9. Study the front or middle leg. How many joints has it? it.

I0. With a lens find the antennae cleaner on the front leg. Describe

I I. Describe the feet and claws.

I2. Compare the third segment of the hind leg with that of the front leg.

I3. Note that this segment of the hind leg is much wider. Note its form and describe how it forms the pollen basket.

I 4. Study the next segment of the hind leg, and note the wax pincers and the pollen combs.

I 5. Compare the front and hind wing as to shape and size.

I6. How many rings are there on the abdomen and how are the rings colored above.

I 7. Study the lower side of the body; do you know where the wax comes from?

I8. Write an English theme on the development of the larva of the worker bee; the duties of a worker bee from the time it issues from its cocoon until it dies working for the colony.

\section{The Queen Bee}

I. How does the queen differ in size and shape from the worker?

2. Has she pollen baskets or pollen combs on her hind legs?

3. How does the shape of the abdomen differ from that of the worker?

4. Write an English theme on the life of a queen bee. This should cover the following points: The kind of cell in which the queen is developed; the kind of food on which she is reared; the fact that she never stings people but reserves her sting for other queens; why she does not go out to gather honey; how and by whom and on what she is fed; she would not use pollen baskets if she had them; the work she does for the colony; the length of her life compared with that of a worker; the time of year when new queens are developed, and what becomes of the old queen when a new one takes her place; why she is called a queen.

\section{The Drone} worker?

I. How does the drone differ in size and form of body from the

2. How does he differ in these respects from the queen?

3. Has he pollen baskets on his legs?

4. Has he a sting?

5. Compare his eyes with those of the queen and worker.

6. Compare the size of his wings with those of the queen and worker.

7. Write an English theme on the drone. This should cover the following points: $\mathrm{n}$ what sort of cell is the drone developed; does he go out to gather honey or help in the work of the hive; how he is fed; how he is unfitted for work for the colony in the following particulars: Tongue, lack of pollen baskets, lack of sting, and of wax pockets; why the drone should be called a prince or king; the death of the drones; when and by what means it occurs. 


\section{HONEY-COMB}

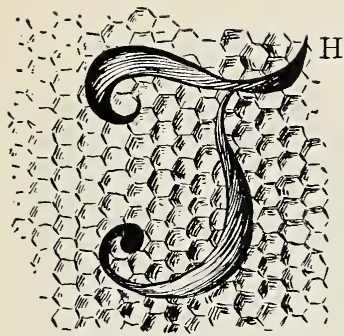

\section{Teacher's Story}

structure of honey-comb has been for ages admired by mathematicians, who have measured the angles of the cells and demonstrated the accurate manner in which the rhombshaped cell changes at its base to a three faced pyramid; and proven that, considering the material of construction, honey-comb exemplifies the strongest and most economic structure possible for the storing of liquid contents. While recent instruments of greater precision in measuring angles, show less perfection in honey-comb than the ancients believed, yet the fact still stands that the general plan of it is mathematically excellent.

Some have tried to detract from bee skill, by stating that the six-sided cell is simply the result of crowding cells together. Perhaps this was the remote origin of the hexagonal cell; but if we watch a bee build her comb, we find that she begins with a base laid out in triangular pyramids, on either side of which she builds out six-sided cells. A cell just begun, is as distinctly six-sided as when completed.

The shape of the cell of a honey-comb is six-sided in cross section. The bottom is a three-sided pyramid and its sides help form pyramids at the bottom of the cells opposite, thus economizing every particle of space. In the hive, the cells lie horizontal usually, although sometimes the combs are twisted. The honey is retained in the cell by a cap of wax which is made in a very cunning fashion; it consists of a circular disc at the middle supported from the six angles of the cell by six tiny girders. The comb is made fast to the section of the hive by being plastered upon it. The foundation comb sold to apiarists is quite thick, so that the edges of the cell may be drawn out and almost complete the sides of the cell. However, the founda-

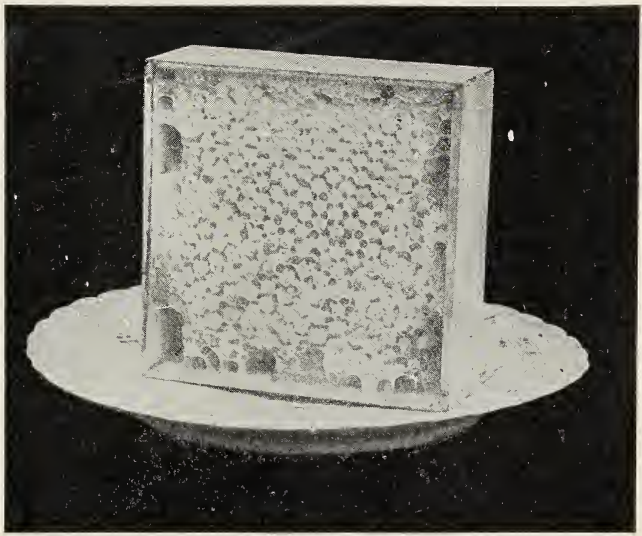

A section of honey. Note the caps to the cells, each supported by six girders. tion comb is expensive and is ordinarily used by the bee-keeper simply as a starter, which means a little strip a few inches or so in width fastened to the top of a section just to give the bees a hint that this is the direction in which the comb should be built, a hint which the bees invariably take. 
The ceils of honey-comb are used also for the storing of bee-bread and also as cradles for the young bees.

References-The Bee People, Morley; How to Keep Bees, Comstock.

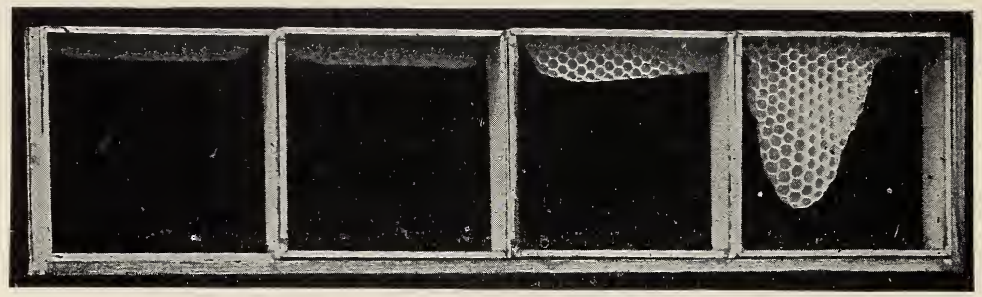

Starters of foundation comb in section boxes, partially built out by the bees.

The section at the left has a "starter" of foundation comb. The other sections show the work of the bees in drawing out and building on the "starters."

\section{LESSON CIV}

The Honey-COMB

Leading thought-The cells of honey-comb are six-sided and in double rows and are very perfectly arranged for the storing of honey, so as to save room.

Materials-A section filled with honey and also a bit of empty comb and a bit of commercial foundation comb which may be obtained in any apiary.

Observations-r. Look at a bit of empty honey-comb; what is the shape of the cell as you look down into it?

2. What is the shape of the bottom of the cell?

3. How does the bottom of the cell join the bottom of the cell opposite? Explain how honey-comb economizes space as storage for honey, and why an economy of space is of use to bees in the wild state.

4. In the hive is the honey-comb placed so that the length of the cells are horizontal or $u_{p}$ and down?

5. Observe honey-comb containing honey; how is the honey retained in the cells?

6. Carefully take off a cap from the honey cell and see if you can find the six girders that extend inward from the angles of the cell to support the circular portion in the center.

7. By what means is the honey-comb made fast to the sides of the section or the hive?

8. Study a bit of foundation comb and note where the bees will pull out the wax to form the cell.

9. Why and how is foundation comb used by the bee-keeper?

ro. For what purpose besides storing honey are the cells of honey. comb used by the bees? 


\section{INDUSTRIES OF THE HIVE AND THE OBSERVATION HIVE}

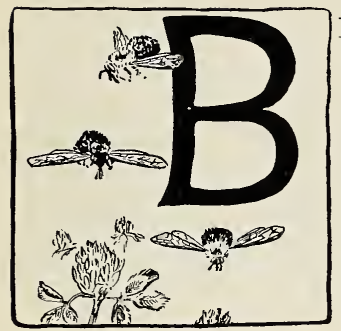

\section{Teacher's Story}

EE-hives are the houses which man furnishes for the bee colonies, the wild bees ordinarily living in hollow trees or in caves. The usual hive consists of a box which is the lower story and of one or more upper stories, called "supers." In the lower story are placed frames for the brood and for storing the honey for the winter use of the bees. In the supers are placed the sections, each of which is planned to hold a pound of honey. It is the habit of the bees to place their brood in the lower part of their nests and store honey in the upper portions.

The bee-keepers have taken advantage of this habit of the bees and remove the supers with their filled sections and replace them with others to be filled, and thus get a large crop of honey. The number of bees in a colony varies; there should be at least 40,000 in a healthy colony. Of these a large proportion are workers; there may be a few hundred drones the latter part of the season but only one queen.

Honey-comb is built of wax and is hung from the frame so that the cells are horizontal; its purpose is to cradle the young and for the storage of pollen and honey. The wax used for building the comb is a secretion of the bees; when comb is needed, a number of self-elected bee citizens gorge themselves with honey and hang themselves up in a curtain, each bee reaching up with her fore feet and taking hold of the hind feet of the one above her. After remaining thus for some time the wax appears in little plates, one on each side of the second, third, fourth and fifth segments of the abdomen. This wax is chewed by the bees and made into comb.

Honey is made from the nectar of flowers which the bee takes into her honey stomach. This, by the way, is not the true stomach of the bee and has nothing to do with digestion. It is simply a receptacle for storing the nectar, which is mixed with some secretion from the glands of the bee which brings about chemical changes, the chief of which is changing the

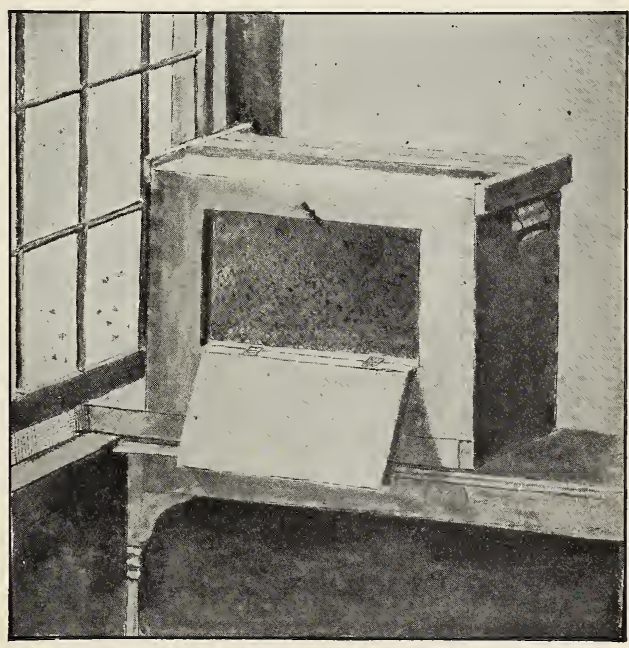

A home-made observation hive. 
cane sugar of the nectar into the more easily digested grape sugar of the honey. After the honey is emptied from the honey stomach into the cell, it remains exposed to the air for some time before the cell is capped, and thus ripens. It is an interesting fact that up to the seventeenth century honey was the only means people had for sweetening their food, as sugar was unknown.

Bee-bread is made from the pollen of flowers which is perhaps mixed with saliva so as to hold together; it is carried from the field on the pollen baskets of the hind legs of the workers; it is packed into the cell by the bees and is used for food. Propolis is bee glue; it is used as a cement and varnish; it is gathered by the bees from the leaf-buds of certain trees and plants, although when they can get it, the bees will take fresh varnish. It is used as a filler to make smooth the rough places of the hive; it often helps hold the combs in place; it calks every crack; it is applied as a varnish to the cells of the honey-comb if they remain unused for a time, and if the door of the observation hive be left open the bees will cover the inside of the glass with this glue, and thus make the interior of the hive dark.

The young bees are footless, white grubs. Each one lives in its own little cell and is fed by the nurse bees, which give it partly digested food from their own stomachs.

The removal of honey from the supers does not do any harm to the bee colony if there is enough honey left in the brood chambers to support the bees during the winter. There should be twenty-five or thirty pounds of honey left in the brood chamber for winter use. In winter, the hives should be protected from the cold by being placed in special houses or by being encased in larger boxes, leaving an opening so that the bees may come out in good weather. The chaff hive is best for both winter and summer, as it surrounds the hive with a space, which is filled with chaff, and keeps the hive warm in winter and cool in summer. Many bee. keepers put their bees in cellars during the winter, but this method is rot as safe as the chaff hive. Care should be taken in summer to place the hives so that they are shaded at least part of the day. The grass should be mown around the hives so that the bees will not become entangled in it as they return from the fields laden with honey.

What may be seen in the observation hive-First of ail, it is very interesting to watch the bees build their comb. When more comb is needed certain members of the colony gorge themselves with honey and remain suspended while it oozes out of the wax pockets on the lower side of the abdomen. This wax is collected and chewed to make it less brittle and then is carried to the place where the comb is being built and is molded into shape by the jaws of the workers. However, the bee that puts the wax in place is not always the one that molds it into comb.

A bee comes into the hive with her honey stomach filled with nectar and disgorges this into a cell. Whem a bee comes in loaded with pollen, she first brushes it from the pollen baskets on her hind legs into the cell; ater another worker comes along and packs the pollen grains into the cell with her head, which is a comical sight.

The bee nurses run about on the comb feeding the young bee grubs partially digested honey and pollen regurgitated from their own stomachs Whenever the queen moves about the comb she is followed by a retinue of devoted attendants which feed her on the rich and perfectly digested royal 


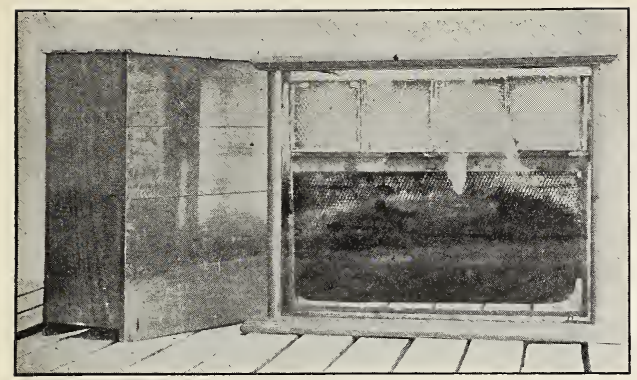

The observation hive made and sold by A.I. Root.

jelly and also take care of her royal person and give her every attention possible. The queen, when laying, thrusts her abdomen into the cell and glues a little white egg to the bottom. The specially interesting thing about this is that the queen always lays an egg which will produce a female, or worker in the smaller cells and will always lay an egg to produce a drone or male in the larger cells.

If there is any foreign substance in the observation hive it is interesting to see the bees go to work at once to remove it. They dump all of the debris out in front of the hive. They close all crevices in the hive; and they will always curtain the glass, if the door is kept open too much, with propolis or bee glue, which is a very sticky substance which they get from leaf buds and other vegetable sources. When bees fan to set up a current of air in the hive, they glide back and forth, moving the wings so rapidly that we can only see a blur about their bodies.

If drones are developed in the hive, it is interesting to see how tenderly they are fed by their sister workers, although they do not hesitate to help themselves to the honey stored in the cells; and if the observation hive is working during September, undoubtedly the pupils may be able to see the murder of the drones by their sisters. But the children should understand that this killing of the drones is necessary for the preservation of the colony, as the workers cannot store enough honey to keep the colony alive during the winter if the drones were allowed to go on feeding.

If you see the worker bees fighting, it means that robbers are attempting to get at the stores of the observation hive. The entrance to the hive should at once be contracted by placing a block of wood in front, so that there is room for only one bee at a time to pass in and out.

\section{LESSON CV}

\section{The Industries of the Hive}

Leading thought-In the hive are carried on the industries of waxmaking, building of honey-comb, storing of honey and bee-bread, caring for the young, keeping the hive clean and ventilated and calking all crevices with bee glue.

Method-This lesson should be in the nature of a demonstration. If there is an apiary in the neighborhood, it is quite possible that the teacher may. show the pupils a hive ready for occupancy by the bees; in any case she will have no difficulty in borrowing a frame of brood comb, and this with a section of honey which can be bought at the grocery store, is sufficient if there is no observation hive. This lesson shoule be an informal talk between teacher and pupils. 
An obserration hive in the schoolroom is an object of greatest interest to the pupils, as through its glass sides they may be able to verify for themselves the wonderful tales concerning the lives and doings of the bees which have been told us by naturalists. Moreover, the study thus made of the habits of the bees is an excellent preparation for the practical apiarist, and we sincerely believe that bee-keeping is one of the ways by which the boys and girls of the farm may obtain money for their own use.

The observation hive is very simply constructed and can be made by anyone who knows how to use ordinary carpenter tools. It is simply a small, ordinary hive with a pane of glass on each side which is covered by a hinged door. A hive thus made is placed so that the front end rests upon a window sill; the sash is lifted an inch or so, a strip of wood, or a piece of wire netting being inserted underneath the sash except in front of the entrance of the hive, to hinder the bees from coming back into the room. A covered passageway should extend from the entrance of the hive to the outside of the window sill. This window should be one which opens away from the playground so that the bees coming and going, will not come into collision with the pupils. The observation window should be kept carefully shut, except when the pupils are using it, since the bees object to light in their homes.

The A. I. Root Co., of Medina, Ohio, sell a pretty observation hive which we have used successfully by stocking it afresh each season, it being too small for a self-sustaining colony. But it has the advantage of smallness which enables us to see all that is going on within it, which would be impossible in a larger hive. This hive comes in several sizes, and will be shipped from the makers stocked with bees at prices ranging from $\$ 1.25$ to $\$ 4.00$.

Observations-Industries and care of the hive-r. What is the hive, and what do wild bees use instead of the hive? Describe as follows:

2. Describe a brood chamber and a super and the uses of each.

3. How many and what bees live in a hive.

4. How the honey-comb is made and placed and the purpose of it.

5. How the wax is produced and built into the comb.

6. How honey is made.

7. What bee-bread is and its uses.

8. What propolis is and what it is used for.

9. How young bees look and how they are cradled and fed.

I0. Does the removal of the honey from the supers in the fall do any harm to the bee colony?

Ir. How much honey should a good-sized colony have in the fall to winter well?

I2. How should the hives be protected in the winter and summer?

What may be'seen in the observation hive-13. Describe how a bee works when building honey-comb.

I4. How does the bee act when storing honey in a cell?

I 5. How does a bee place pollen in a cell and pack it into bee-bread?

I6. Describe how the nurse bees feed the young, and how the young look when eating.

I 7. Describe how the "ladies in waiting" feed and care for the queen.

I8. Try to observe the queen when she is laying eggs and describe her actions.

I9. How do the bee workers keep their house clean? 
20. How do they stop all crevices in the hive? If you keep the hive uncovered too long, how will they curtain the window?

2I. Describe the actions of the bees when they are ventilating the hive.

22. If there are any drones in the hive, describe how they are fed.

23. How can you tell queens, drones and workers apart?

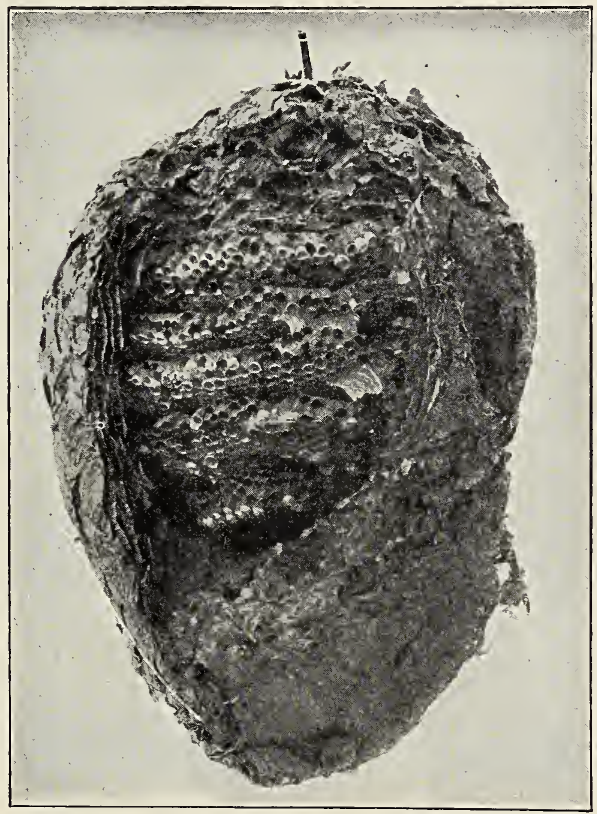

A wasp's nest with side walls removed. 


\section{OTHER INVERTEBRATE-ANIMAL STLDY}

\section{THE GARDEN SNAIL}

\section{Teacher's Story}

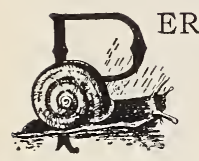

CHANCE if those who speak so glibly of a "snail's pace. should study it, they would not sneer at it, for carefully observed, it seems the most wonderful method of locomotion ever devised by animal. Naturally enough, the snail cannot gallop since it has but one foot; but it is safe to assert that this foot, which is the entire lower side of the body, is a remarkable organ of locomotion. Let a snail crawl up the side of a tumbler and note how this foot stretches out and holds on. It has flanges along the sides, which secrete an adhesive substance that enables the snail to cling, and yet it also has the power of letting go at will. The slow, even, pushing forward of the whole body, weighted by the unbalanced shell, is as mysterious and seemingly as inevitable, as the march of fate, so little is the motion connected with any apparent muscular effort. But when his snailship wishes to let go and retire from the world, this foot performs a feat which is certainly worthy of a juggler; it folds itself lengthwise, and the end on which the head is retires first into the shell, the tail end of the foot being the last to disappear. And now find your snail!

Never was an animal so capable of stretching out and then folding up all its organs, as is this little tramp who carries his house with him. Turn one on his back when he has withdrawn into his little hermitage, and watch what happens. Soon he concludes he will find out where he is, and why he is bottomside up; as the first evidence of this, the hind end of the foot, which was folded together, pushes forth; then the head and horns come bubbling out. The horns are not horns at all, but each is a stalk bearing an eye on the tip. This is arranged conveniently, like a marble fastened to the tip of a glove finger. When a snail wishes to see, it stretches forth the stalk as if it were made of rubber; but if danger is perceived, the eye is pulled back exactly as if the marble were pulled back through the middle of the glove finger; or as a boy would say, "it goes into the hole and pulls the hole in after it." Just below the stalked eyes, is another pair of shorter horns, which are feelers, and which may be drawn back in the same manner; they are used constantly for testing the nature of the surface on which the snail is crawling. It is an interesting experiment to see how near to the eyes and the feelers we can place an object, before driving them back in. With these two pairs of sense organs pushed out in front of him, the snail is well equipped to observe the topography of his immediate vicinity; if he wishes to explore above, he can stand on the tip of his tail and reach far up; and if there is anything to take hold of, he can glue his toe fast to it and pull himself up. Moreover, I am convinced that snails have decided views about where they wish to go, for I have tried by the hour to keep them marching lengthwise on the piazza railing, so as to study them; and every snail was determined to go crosswise and crawl under the edge, where it was nice and dark. 
It is interesting to observe through a lens, the way a snail takes his dinner; place before him a piece of sweet apple or other soft fruit, and he will lift himself on his front toe and begin to work his way into the fruit.

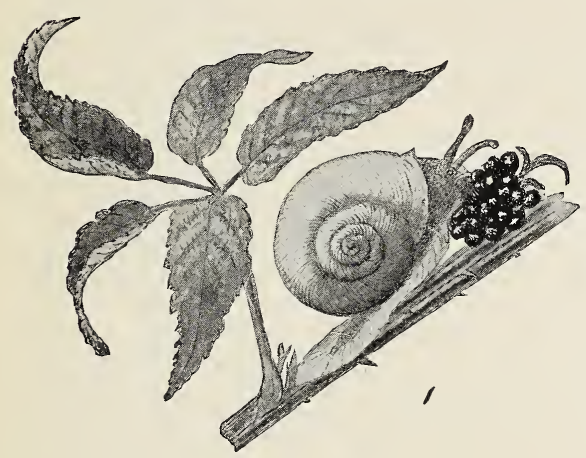

$\mathrm{He}$ has an efficient set of upper teeth, which look like a saw and are colored as if he chewed tobacco; with these teeth and with his round tongue, which we can see popping out, he soon makes an appreciable hole in the pulp; but his table manners are not nice, since he is a hopeless slobberer.

There are right and left spiraled snails. All those observed for this.lesson show the spiral wound about the center from left over to right, or in the direction of the movement of the hands of a clock, aná

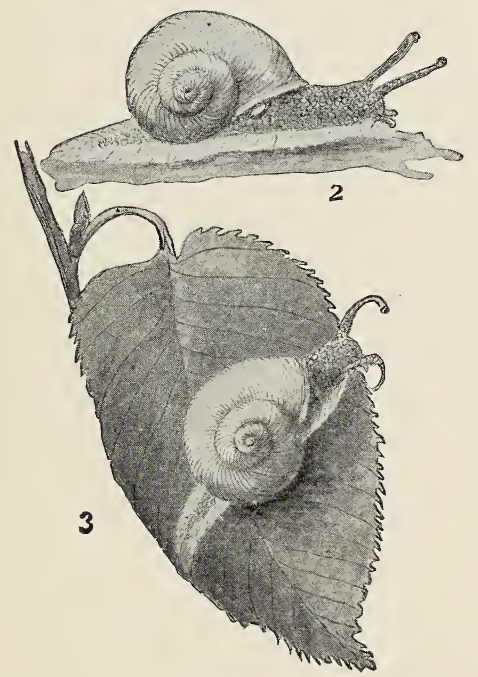

Snail sketches.

I. The thorny path to bliss; 2. Snail showing the breathing-pore; 3 . Prospecting. obliged to experience a drought, he makes a pane of glass out of mucus across his door, and thus stops evaporation. This is a very wise precaution, because the snail is made up largely of moisture and much water is needed to keep his mucilage factory running. 
The way the snail uses his eyes is comical; he goes to the edge of a leaf and pokes one eye over to see what the new territory is like; but if his eye strikes an object, he pulls that one back, and prospects for a time with the other. He can lengthen the eye-stalk amazingly if he has need. How convenient for us if we could thus see around a corner. If a small boy were as well off as a snail, he could see the entire ball game through a knot-hole in the fence. In fact, the more we study the snail, the more we admire, first his powers of ascertaining what there is in the world, and then his power of getting around in the world by climbing recklessly and relentlessly over obstacles, not caring whether he is right side up on the floor or hanging wrong side up from the ceiling; and, finally, we admire his utter reticence when things do not go to suit him. I think the reason I always call a snail "he" is because he seems such a philosopher-a Diogenes in his tub. However, since the snail combines both sexes in one individual the pronoun is surely applicable.

When observed through a lens, the snail's skin looks like that of the alligator, rough and divided into plates, with a surface like pebbled leather; and no insect intruder can crawl up his foot and get into the shell "unbeknownst," for the shell is grown fast to the flange, that grows out of the middle of the snail's back. The smoother the surface the snail is crawling upon, the harder to make him let go. The reason for this lies in the mucus, which he secretes as he goes, and which enables him to fasten himself anywhere; he can crawl up walls or beneath any horizontal surface, shell downward, and he leaves a shining trail behind him wherever he goes.

Snail eggs are as large as small peas, almost transparent, covered with very soft shells, and fastened together by mucus. They are laid under stones and decaying leaves. As soon as the baby snail hatches, it has a shell with only one spiral turn in it; as it grows, it adds layer after layer to the shell on the rim about the opening $\rightarrow$ which is called the lip; these layers we can see as ridges on the shell. If we open an empty shell, we can see the progress of growth in the size of the spirals. Snails eat succulent leaves and other soft vegetable matter. During the winter, they bury themselves beneath objects or retire into soft humus. In preparing for the winter, the snail makes a door of mucus and lime, or sometimes three doors, one behind another, across the entrance to his shell, leaving a tiny hole to admit the air. There are varieties of snails which are eaten as dainties in Europe, and are grown on snail farms for the markets. The species most commonly used is the same as that which was regarded as a table luxury by the ancient Romans.

References-Wild Life, Ingersoll; The Natural History of Some Cominon Animals, Latter.

\section{LESSON CVI \\ The Garden SnaIL}

Leading thought-The snail carries his dwelling with nim, and retires within it in time of danger. He can climb on any smooth surface.

Method-The pupils should make a snailery, which may consist of any glass jar, with a little soil and some moss or leaves at the bottom, and a shallow dish of water at one side. The moss and soil should be kept moist. Place the snails in this and give them fresh leaves or pulpy fruit, and they will live comfortably in confinement. A bit of cheese-cloth fastened with 
a rubber band should be placed over the top of the jar. A tumbler inverted over a dish, on which is a leaf or two, makes a good observation cage to pass around the room for closer examination. An empty shell should be at hand, which may be opened and examined.

Observations-I. Where do you find snails? Why do they like to tive in such places?

2. How does a snail walk? Describe its "foot." How can it move with only one foot? Describe how it climbs the side of the glass jar. How does it cling?

3. What sort of a track does a snail leave behind it? What is the use of this mucus?

4. Where are the snail's eyes? Why is this arrangement convenient? If we touch one of the eyes what happens? What advantage is this to the snail? Can it pull in one eye and leave the other out?

5. Look below the eyes for a pair of feelers. What happens to these if you touch them?

6. What is the use of its shell to a snail? What does the snail do if startled? If attacked? When a snail is withdrawn into its shell can you see any part of the body? Is the shell attached to the middle of the foot? How did the shell grow on the snail's back? How many spiral turns are there in the full-grown shell? Are there as many in the shell of a young snail? Can you see the little ridges on the shell? Do you think that these show the way the shell grew?

7. Can you find the opening through which the snail draws its breath? Where is this opening? Describe its action.

8. Put the snail in a dry place for two or three days, and see what happens. Do you think this is for the purpose of keeping in moisture? What does the snail do during the winter?

9. Place a snail on its back and see how it rights itself. Describe the way it eats. Can you see the horny upper jaw? Can you see the rasping tongue? What do snails live on?

I0. Do you know how the snail eggs look and where they are laid? How large is the shell of the smallest garden snail you ever saw? How many spiral turns were there in it? Open an empty snail shell and see how the spirals widened as the snail grew. Do you think the shell grew by layers added to the lip?

I I. Do all snails have shells? Describe all the kinds of snails you know. What people consider snails a table delicacy?

\section{TO A SNAIL}

Little Diogenes bearing your tub, whither away so gay,

With your eyes on stalks, and a foot that walks, tell me this I pray!

Is it an honest snail you seek that makes you go so slow,

And over the edges of all things peek? Have you found him, I want to know;

Or do you go slow because you know, your house is near and tight?

And there is no hurry and surely no worry lest you stay out late at night. 


\section{THE EARTHWORM}

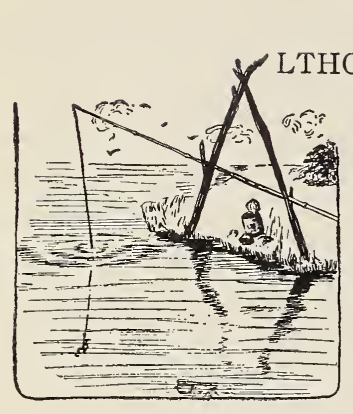

\section{Teacher's Story}

UGH not generally considered attractive, for two reasons the earthworm has an important place in nature-study: it furnishes an interesting example of lowly organized creatures, and it is of great economic importance to the agriculturist. The lesson should have special reference to the work done by earthworms and to the simplicity of the tools with which the work is done.

The earthworm is, among lower animals, essentially the farmer. Long before man conceived the idea of tilling the soil, this seemingly insignificant creature was busily at work plowing, harrowing, and fertilizing the land. Nor did it overlook the importance of drainage and the addition of amendmentsfactors of comparatively recent development in the management of the soil by man.

Down into the depths, sometimes as far as seven or eight feet, but usually from twelve to eighteen inches, goes the little plowman, bringing to the surface the subsoil, which is exactly what we do when we plow deeply. To break up the soil as our harrows do, the earthworm grinds it in a gizzard stocked with grains of sand or fine gravel, which act as millstones. Thus it turns out soil of much finer texture than we, by harrowing or raking, can produce. In its stomach it adds the lime amendment, so much used by the modern farmer. The earthworm is apparently an adept in the use of fertilizers; it even shows discrimination in keeping the organic matter near the surface, where it may be incorporated into the soil of the root zone. It drags into its burrows dead leaves, flowers and grasses, with which to line the upper part. Bones of dead animals, shells, and twigs are buried by it, and, being more or less decayed, furnish food for plants. These minute agriculturists have never studied any system of drainage, but they bore holes to some depth which carry off the surplus water. They plant seeds by covering those that lie on the ground with soil from below the surface-good, enriched, well granulated soil it is, too. They further care for the growing plants by cultivating, that is keeping fine and granular, the soil about the roots.

It was estimated by Darwin that, in garden soil in England, there are more than 50,000 earthworms in an acre, and that the whole superficial layer of vegetable mold passes through their bodies in the course of every few years, at the rate of eighteen tons per acre yearly.

This agricultural work of the earthworm has been going on for ages. Wild land owes much of its beauty to this diminutive creature which keeps the soil in good condition. The earthworm has undermined and buried rocks, changing greatly the aspect of the landscape. It has preserved ruins and ancient works of art. Several Roman villas in England owe their preservation to the earthworm. All this work is accomplished with the most primitive tools, a tiny proboscis, a distensible pharynx, a rather indeterminate tail, a gizzard and the calcareous glands peculiar to this lowly creature. 
An earthworm has a peculiar, crawling movement. Unlike the snake, which also moves without legs, it has no scales to function in part as legs: but it has a very special provision for locomotion. On the under side of a worm are found numerous setae-tiny, bristlelike projections. These will be seen to be in double rows on each segment, excepting the first three and the last. The setae turn so that they point in the opposite direction from which the worm is moving. It is this use of these clinging bristles, together with strong muscles, which enables a worm to hold tightly to it: burrow when bird or man attempts its removal. A piece of round elastic furnishes an excellent example of contraction and extension, such as the earthworm exhibits. Under the skin of the worm are two sets of muscles; the outer passing in circular direction around the body, the inner running lengthwise. The movement of these may be easily seen in a good-sized, living specimen. The body is lengthened by the contraction of circular and the extension of longitudinal muscles, and shortened by the opposite movement.

The number of segments rinay vary with the age of the worm. In the immature, the clitellum, a thick, whitish ring near the end, is absent. The laying of the earthworm's egg is an interesting performance. A saclike ring is formed about the body in the region of the clitellum. This girdle is gradually worked forward and, as it is cast over the head, the sacends snap together enclosing the eggs. These capsules, yellowish-brown, football-shaped, about the size of a grain of wheat, may be found in May or June about manure piles or under stones.

Earthworms are completely deaf, although sensitive to vibration. They have no eyes, but can distinguish between light and darkness. The power of smell is feeble. The sense of taste is well developed; the sense of touch is very acute; and we are not so sure as is Dr. Jordan, that the angleworm is at ease on the hook.

Any garden furnishes good examples of the home of the earthworm. The burrows are made straight down at first, then wind about irregularly. Usually they are about one or two feet deep, but may reach even eight feet. The burrow terminates generally in an enlargement where one or several worms pass the winter. Toward the surface, the burrow is lined with a thin layer of fine, dark colored earth, voided by the worm. This creature is an excavator and builder of no mean ability. The towerlike "castings" so characteristic of the earthworm, are formed with excreted earth. Using the tail as a trowel, it places earth, now on one side and now on the other. In this work, of course, the tail protrudes; in the search for food, the head is out. A worm, then, must make its home, narrow as it is, with a view to being able to turn in it.

An earthworm will bury itself in loose earth in two or three minutes, and in compact soil, in fifteen minutes. Pupils should be able to make these observations easily either in the terrarium or in the garden.

In plugging the mouths of their burrows, earthworms show something that seems like intelligence. Triangular leaves are invariably drawn in by the apex, pine-needles by the common base, the manner varying with the shape of the leaf. They do not drag in a leaf by the footstalk, unless its basal part is as narrow as the apex. The mouth of the burrow may be ined with leaves for several inches.

The burrows are not found in dry ground nor in loose sand. The earthworm lives in the finer, moderately wet soils. It must have moisture 
since it breathes through the skin, and it has sufficient knowledge of soil texture and plasticity to recognize the futility of attempts at burrow building with unmanageable, large grains of sand.

These creatures are nocturnal, rarely appearing by day unless "drowned out" of the burrows. During the day they lie near the surface extended at full length, the head uppermost. Here they are discovered by keeneyed birds and sacrificed by thousands, notwithstanding the strong muscular protest of which they are capable.

Seemingly conscious of its inability to find the way back to its home, 3. an earthworm anchors tight by its tail while stretching its elastic length in a foraging expedition. It is an omnivorous creature, including in its diet earth, leaves, flowers, raw meat, fat, and even showing cannibalistic designs on fellow earthworms. In the schoolroom, earthworms may be fed on pieces of lettuce or cabbage leaves. A feeding worm will show the proboscis, an extension of the upper lip used to push food into the mouth. The earthworm has no hard jaws or teeth, yet it eats through the hardest soil. Inside the mouth opening is a very muscular pharynx, which can be extended or withdrawn. Applied to the surface of any small object it acts as a suction pump, drawing food into the food tube. The earth taken in furnishes some organic matter for food; calcareous matter is added to the remainder before being voided. This process is unique among animals. The calcareous matter is supposed to be derived from leaves which the worms eat. Generally the earth is swallowed at some distance below the surface, and finally ejected in characteristic "castings." Thus, the soil is slowly worked over and kept in good condition by earth. worms, of which Darwin says: "It may be doubted whether there are many other animals which have played so important a part in the history of the world as have these lowly organized creatures."

References-The Earthworm, Darwin; The Natural History of Some Common Animals, Latter.

"Fly fishing is an art, a fine art beyond a doubt, but it is an art and, like all art, it is artificial. Fishing with an angleworm is natural. It fits into the need of the occasion. It fits in with the spirit of the boy. It is not by chance that the angleworm, earthworm, fishworm, is found in every damp bank, in every handy bit of sod, the green earth over, where there are races whose boys are real boys with energy enough to catch a fish. It is not by chance that the angleworm makes a perfect fit on a hook, with no anatomy with which to feel pains, and no arms or legs to be broken off or to be waved helplessly in the air. Its skin is tough enough so as not to tear, not so tough as to receive unseemly bruises, when the boy is placing it on the hook. The angleworm is perfectly at home on the hook. It is not quite comfortable anywhere else. It crawls about on sidewalks after rain, "ivached and emaciated. It is never quite at ease even in the ground, but on the hook it rests peacefully, with the apparent feeling that its natural mission is performed." - "Boys' Fish and Boys' Fishing," by David Starr Jordan.

\section{LESSON CVII}

\section{THE EARTHWORM}

Leading thought-The earthworm is a creature of the soil and is of much economic importance.

Method-Any garden furnishes abundant material for the study of earthworms. They are nocturnal workers and may be observed by lan- 
tern light. To form some estimate of the work done in a single night, remove the "casts" from a square yard of earth one day, and examine that piece of earth the next. It is well to have a terrarium in the schoolroom for frequent observation. Scatter grass or dead leaves on top of the soil, and note what happens. For the study of the individual worm and its movements, each pupil should have a worm with some earth upon his desk.

Observations-I. How does the earthworm crawl? How does it turn over? Has it legs? Compare its movement with that of a snake, another legless animal. What special provision for locomotion has the earthworm?

2. Compare the lengths of the contracted and extended body. How accounted for?

3. Describe the body-its shape and color, above and below. Examine the segments. Do all the worms have the same number? Compare the head end with the tail end of the body. Has every worm a "saddle," or clitellum?

4. Does the earthworm hear easily? Has it eyes? Is it sensible to smell or to touch? What sense is most strongly developed?

5. Describe the home of the earthworm. Is it occupied by more than one worm? How long does it take a worm to make a burrow? How does it protect its home? How does it make a burrow? In what kind of soil do you find earthworms at work?

6. Is the earthworm seen most often at night or by day? Where is it the rest of the time? How does it hold to its burrow? When is the tail end at the top? When the head end?

7. What is the food of the earthworm? How does it get its food?

8. Look for the eggs of the earthworm about manure piles or under stones.

9. What are the enemies of the earthworm? Is it a friend or an enemy to us? Why?

Io. The earthworm is a good agriculturist. Why?

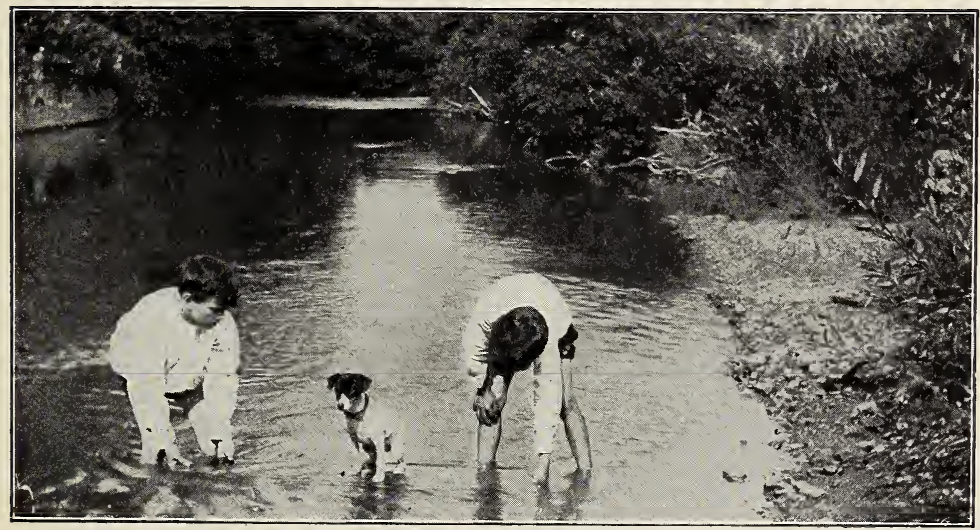

Where the crayfish lurks. 


\section{THE CRAYFISH}

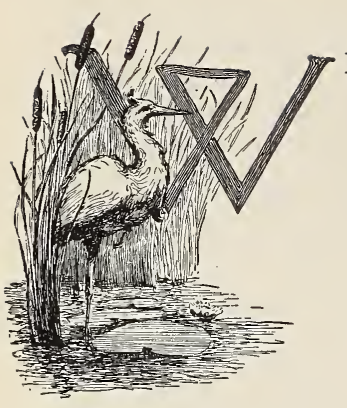

\section{Teacher's Story}

HEN I look at a crayfish I envy it, so rich is it in organs with which to do all that it has to do. From the head to the tail, it is crowded with a large assortment of executive appendages. In this day of multiplicity of duties, if we poor human creatures only had the crayfish's capabilities, then might we hope to achieve what lies before us.

The most striking thing in the appearance of the crayfish is the great pair of nippers on each of the front legs. Wonderfully are its "thumb and finger" put together; the "thumb" is jointed so that it can move back and forth freely; and both are armed, along the inside edge, with saw teeth and with a sharp claw at the tip so that they can get a firm grip upon an object. Five segments in these great legs can be easily seen; that joining the body is small, but each successive one is wider and larger, to the great forceps at the end. The two stout segments behind the nippers give strength, and also a suppleness that enables the claws to be bent in any direction.

The legs of the pair behind the big nippers have five segments readily visible; but these legs are slender and the nippers at the end are small; the third pair of legs is armed like the second pair; but the fourth and fifth pairs lack the pincers, and end in a single claw.

But the tale of the crayfish's legs is by no means told; for between and above the great pincers is a pair of short, small legs tipped with single claws, and fringed on their inner edges. These are the maxillapeds, or jaw-feet; and behind them, but too close to be seen easily, are two more pairs of jaw-feet. As all of these jaw-feet assist at meals, the crayfish apparently always has a "three fork" dinner; and as if to provide accommodations for so many eating utensils, it has three pairs of jaws all working sidewise, one behind the other. Two of these pairs are maxillæ and one, mandibles. The mandibles are the only ones we see as we look in between the jaw-feet; they are notched along the biting edge. Connected with the maxillæ, on each side, are two pairs of threadlike flappers, that wave back and forth vigorously and have to do with setting up cur-1 rents of water over the gills.

Thus we see that, in all, the crayfish has three pairs of jaw-feet, one pair of great nippers and four pairs of walking feet, two of which also have nippers and are used for digging and carrying.

When we look upon the crayfish from above, we see that the head and thorax are fastened solidly together, making what is called a cephalothorax. The cephalothorax is covered with a shell called the carapace, which is the name given also to the upper part of the turtle's shell. The suture where the head joins the thorax is quite evident. In looking at the head, the eyes first attract our attention; each is black and oval and placed on the tip of a stalk, so it can be extended or retracted or pushed in any direction, to look for danger. These eyes are like the compound eyes of insects, in that they are made up of many small eyes, set together in a honeycomb pattern. 
The long antennæ are as flexible as braided whiplashes, large at the base and ending in a threadlike tip. They are composed of many segments, the basal ones being quite large. Above the antennæ on each side, is a pair of shorter ones called antennules, which come from the same basal segment; the lower one is the more slender and is usually directed forward; the upper one is stouter, curves upward, and is kept always moving, as if it were constantly on the alert for impressions. The antennæ are used for exploring far ahead or behind the creature, and are often thrust down into the mud and gravel at the bottom of the aquarium, as if probing for treasure. The antennules seem to give warning of things closer at hand. Between the antennæ and antennules is a pair of fingerlike organs, that are hinged at the outer ends and can be lifted back, if we do it carefully.

In looking down upon a crayfish, we can see six abdominal segments and the flaring tail at the end, which is really another segment greatly modified. The first segment, or that next to the cephalothorax, is narrow; the others are about equal in size, each graceful in shape, with a widened part at each side which extends down along the sides of the creature. These segments are well hinged together so that the abdomen may be completely curled beneath the cephalothorax. The plates along the sides are edged with fringe. The tail consists of five parts, one semicircular in the center, and two fan-shaped pieces at each side, and all are margined with fringe. This tail is a remarkable organ. It can be closed or extended sidewise like a fan; it can be lifted up or curled beneath.

Looking at the crayfish from below, we see on the abdomen some very beautiful featherlike organs called swimmerets. Each swimmeret consists of a basal segment with twin paddles joined to its tip, each paddle being narrow and long and fringed with hairs. The mother crayfish has four pairs of these, one pair on each of the second, third, fourth and fifth segments; her mate has an additional larger pair on the first segment. These swimmerets, when at rest, lie close to the abdomen and are directed forward and slightly inward. When in motion, they paddle with a backward, rhythmic motion, the first pair setting the stroke and the other pairs following in succession. This motion sends the body forward, and the swimmerets are chiefly used to aid the legs in forward locomotion. A crayfish, on the bottom of a pond, seems to glide about with great ease; but place it on land, and it is an awkward walker. The reason for this difference lies, I believe, in the aid given by the swimmerets when the creature is in water. Latter says: "In walking, the first three pairs of legs pull and the fourth pair pushes. Their order of movement is as follows: The first on the right and the third on the left side move together, next the third right and the first left, then the second right and fourth left, and lastly the fourth right and second left."

When the crayfish really wishes to swim, the tail is suddenly brought into use; it is thrust out backward, lays hold of the water by spreading out widely, and then doubles under with a spasmodic jerk which pulls the creature swiftly backward.

The crayfish's appearance is magically transformed when it begins to swim; it is no longer a creature of sprawling awkward legs and great clumsy nippers; now, its many legs lie side by side supinely and the great claws are limp and flow along in graceful lines after the body, all obedient to the force which sends the creature flying through the water. I cannot discover that the swimmerets help in this movement. 


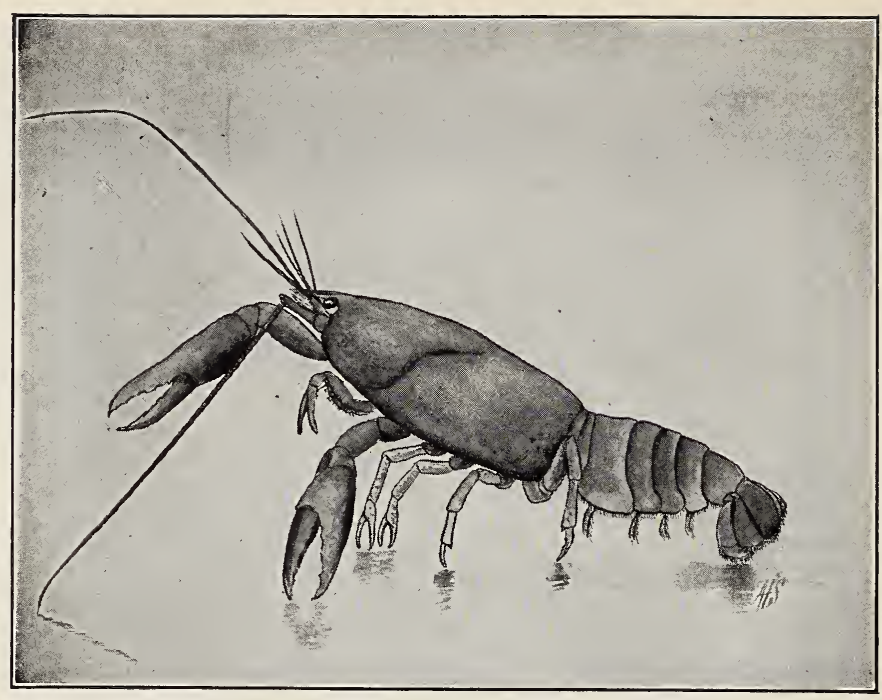

A crayfish.

Drawn by Anna C. Stryke.

The mother crayfish has another use for her swimmerets; in the spring, when she is ready to lay eggs, she cleans off her paddles with her hind legs, covers them with waterproof glue, and then plasters her eggs on them in grapelike clusters of little dark globules. What a nice way to look after her family! The little ones hatch, but remain clinging to the maternal swimmerets, until they are large enough to scuttle around on the brook bottom and look out for themselves.

The breathing apparatus of the crayfish cannot be seen without dissection. All the walking legs, except the last pair, have gills attached to that portion of them which joins the body, and which lies hidden underneath the sides of the carapace or shell. The blood is forced into these gills, sends off its impurities through their thin walls and takes in the oxygen from the water, currents of which are kept steadily flowing forward.

Crayfishes haunt still pools along brooksides and river margins and the shallow ponds of our fresh waters. There they hide beneath sticks and stones, or in caves of their own making, the doors of which they guard with the big and threatening nippers, which stand ready to grapple with anybody that comes to inquire if the folks are at home. The upper surface of the crayfish's body is always so nearly the color of the brook bottom, that the eye seldom detects the creature until it moves; and if some enemy surprises one, it swims off with terrific jerks which roil all the water around and thus covers its retreat. In the winter, our brook forms hibernate in the muddy bottoms of their summer haunts. There are many species; some in our Southern States, when the dry season comes on, live in little wells which they dig deep enough to reach water. They heap 
up the soil which they excavate around the mouth of the well, making well-curbs of mud; these are ordinarily called "crawfish chimnies." The crayfishes find their food in the flotsam and jetsam of the pool. They seem fond of the flesh of dead fishes and are often trapped by its use as bait.

The growth of the crayfish is like that of insects; as its outer covering is a hard skeleton that will not stretch, it is shed as often as necessary; it breaks open down the middle of the back of the carapace, and the soft. bodied creature pulls itself out, even to the last one of its claws. While its new skin is yet elastic, it stretches to its utmost; but this skin also hardens after a time and is, in its turn, shed. Woe to the crayfish caught in this helpless, soft condition after molting! For it then has no way to protect itself. We sometimes find the old skin floating, perfect in every detail, and so transparent that it seems the ghost of a crayfish.

Not only is the crayfish armed in the beginning with a great number of legs, antennæ, etc., but if it happens to lose any of these organs, they will grow again. It is said that, when attacked, it can voluntarily throw off one or more of its legs. We have often found one of these creatures with one of the front claws much larger than the other; it had probably lost. its big claw in a fight, and the new growth was not yet completed.

I have been greatly entertained by watching a female crayfish make her nest in my aquarium which has, for her comfort, a bottom of three inches of clean gravel. She always commences at one side by thrusting down her antennæ and nippers between the glass and stones; she seizes a pebble in each claw and pulls it up and in this way starts her excavation: but when she gets ready to carry off her load, she comes to the task with her tail tucked under her body, as a lady tucks up her skirts when she has something to do that requires freedom of movement. Then with her great nippers and the two pairs of walking feet, also armed with nippers, she loads up as much as she can carry between her great claws and her breast. She keeps her load from overflowing by holding it down with her first pair of jaw-feet, just as I have seen a schoolboy use his chin, when carrying a too large load of books; and she keeps the load from falling out by supporting it from beneath with her first pair of walking legs. Thus, she starts off with her "apron" full, walking on three pairs of feet, until she gets to the dumping place; then she suddenly lets go and at the same time her tail straightens out with a gesture which says plainly, "There!" Sometimes when she gets a very large load, she uses her second pair of walking legs to hold up the burden, and crawls off successfully, if not with ease, on two pairs of legs, - a most unnatural quadruped.

I had two crayfishes in a cage in an aquarium, and each made a nest in the gravel at opposite ends of the cage, heaping up the debris into a partition between them. I gave one an earthworm, which she promptly seized with her nippers; she then took up a good sized pebble in the nippers of her front pair of walking legs, glided over to the other nest, spite. fully threw down both worm and pebble on top of her fellow prisoner, and then sped homeward. Her victim responded to the act by rising up and expressing perfectly, in his attitude and the gestures of his great claws, the most eloquent of crayfish profanity. In watching crayfishes carry pebbles, I have been astonished to see how constantly the larger pair of jaw-feet are used to help pick up and carry the loads. 


\section{LESSON CVIII \\ The Crayfish}

Leading thought-The crayfish, or crawfish, as it is sometimes called, has one pair of legs developed into great pincers for seizing and tearing its food and for defending itself from enemies. It can live in mud or water. It belongs to the same animal group as do the insects, and it is a near cousin of the lobster.

Method-Place a crayfish in an aquarium (a battery jar or a two-quart Mason jar) in the schoolroom, keeping it in clear water until the pupils have studied its form. It will rise to explore the sides of the aquarium at first, and thus show its mouth parts, legs and swimmerets. Afterwards, place gravel and stone in the bottom of the aquarium, so that it can hide itself in a little cavity which it will make by carrying pebbles from one side. Wash the gravel well before it is put in, so that the water will be unclouded and the children can watch the process of excavation.

Observations - I. What is there peculiar about the crayfish which makes it difficult to pick it up? Examine one of these great front legs carefully and see how wonderfully it is made. How many parts are there: to it? Note how each succeeding part is larger from the body to the claws. Note the tips which form the nippers or chelæ, as they are called. How are they armed? How are the gripping edges formed to take hold of an object? How wide can the nippers be opened, and how is this done? Note the two segments behind the great claw and describe how they help the work of the nippers.

2. Study the pair of legs behind the great claws or chelæ, and compare the two pairs, segment by segment. How do they differ except as to. size? How do the nippers at the end compare with the big ones? Look at the next pair of legs behind these; are they similar? How do the two pairs of hind legs differ in shape from the two pairs in front of them?

3. Look between the great front claws and see if you can find another pair of small legs. Can you see anything more behind or above these little legs?

4. When the crayfish lifts itself up against the side of the jar, study its mouth. Can you see a pair of notched jaws that work sidewise? Can you see two or three pairs of threadlike organs that wave back and forth in and out the mouth?

5. How many legs, in all, has the crayfish? What are the short legs near the mouth used for? What are the great nippers used for? How many legs does the crayfish use when walking? In what order are they moved? Is the hind pair used for pushing? What use does it make of the pincers on the first and second pairs of walking legs?

6. Look at the crayfish from above; the head and the covering of the thorax are soldered together into one piece. When this occurs, the whole is called a cephalothorax; and the cover is called by the same name as the upper shell of the turtle, the carapace. Can you see where the head is joined to the thorax?

7. Look carefully at the eyes. Describe how they are set. Can they be pushed out or pulled in? Can they be moved in all directions? Of what advantage is this to the crayfish?

8. How many antennæ has the crayfish? Describe the long ones and tell how they are used. Do the two short ones on each side come from the same basal segment? These little ones are called the antennules. 
Describe the antennules of each side and tell how they differ. Can you see the little fingerlike organs which clasp above the antennæ and below the antennules on each side of the head? Can these be moved?

9. Look at the crayfish from above. How many segments are there in the abdomen? Note how graceful the shape of each segment. Note that each has a fan-shaped piece down the side. Describe how theedges of the segments along the sides are margined.

Io. Of how many pieces is the tail made? Make a sketch of it. How are the pieces bordered? Can the pieces shut and spread out sidewise? Is the tail hinged so it can be lifted up against the back or curled under the body?

II. Look underneath the abdomen and describe the little fringed organs called the swimmerets. How many are there?

I2. How does the crayfish swim? With what does it make the stroke? Describe carefully this action of the tail. When it is swimming, does it use its swimmerets? Why do not the many legs and big nippers obstruct the progress of the crayfish, when it is swimming?

I3. When does the crayfish use its swimmerets? Do they work so as to push the body backward or forward? Do you know to what. use the mother crayfish puts her swimmerets?

I4. Do you know how crayfishes breathe? Do you know what they eat and where they find it?

I 5. Where do you find crayfishes? Where do they like to hide? Do they go headfirst into their hiding place, or do they back in? Do they stand ready to defend their retreat? When you look down into the brook, are the crayfishes usually seen until they move? Why is this? Where do the crayfishes pass the winter? Did you ever see the crayfish burrows or mud chimnies?

r6. If the crayfish loses one of its legs or antennæ, does it grow out again? How does the crayfish grow?

r7. Put a crayfish in an aquarium which has three inches of coarse gravel on the bottom, and watch it make its den. How does it loosen up a stone? With how many legs does it carry its burden of pebbles when digging its cave? How does it use its jaw-feet, its nippers, and its first and second pairs of walking legs in this work?

\footnotetext{
"A rock-lined, wood-embosomed nook, Dim cloister of the chanting brook! A chamber within the channelled hills, Where the cold crystal brims and spills, By dark-browed caverns blackly flow's, Falls from the cleft like crumbling snows, And purls and splashes, breathing round A soft, suffusing mist of sound."
}

-J. T. Trowbridge. 


\section{DADDY-LONGLEGS, OR GRANDFATHER GREYBEARD}

\section{Teacher's Story}

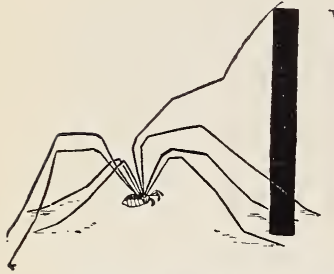

WONDER if there ever was a country child who has not grasped firmly the leg of one of these little sprawling creatures and demanded: "Grandfather Greybeard, tell me where the cows are or I'll kill you," and Grandfather Greybeard, striving to get away, puts out one of his long legs this way, and another that way, and points in so many directions that he usually saves his life, since the cows must be somewhere. It would be more interesting to the children and less embarrassing to the "daddy" if they were taught to look more closely at those slender, hairlike legs.

"Daddy's" long legs are seven jointed. The first segment is seemingly soldered fast to the lower side of his body, and is called the coxa. The next segment is a mere knob, usually black and ornamental, and is called the trochanter. Then comes the femur, a rather long segment directed upward; next is a short swollen segment-the "knee joint" or patella; next the tibia, which is also rather long. Then comes the metatarsus and tarsus, which seemingly make one long downward-directed segment, outcurving at the tips, on which the "daddy" tip-toes along.

I have seen a "daddy" walk into a drop of water and his foot was never wetted, so light was his touch on the water surface film. The second pair of legs is the longest; the fourth pair next, and the first pair usually the shortest. The legs of the second pair are ordinarily used in exploring the surroundings. Notice that, when the "daddy" is running, these two legs are spread wide apart and keep in rapid motion; their tips, far more sensi. tive than any nerves of our own, tell him the nature of his surroundings, by a touch so light that we cannot feel it on the hand. We have more respect for one of these hairlike legs, when we know it is capable of transmitting intelligence from its tip.

The "daddy" is a good traveler and moves with remarkable rapidity. And why not? If our legs were as long in comparison as his, they would be about forty feet in length. When the "daddy" is running, the body is always held a little distance above the ground; but when the second pair of legs suggests to him that there may be something good to eat in the neighborhood, he commences a peculiar teetering motion of the body, apparently touching it to the ground at every step; as the body is carried tilted with the head down, this movement enables the creature to explore

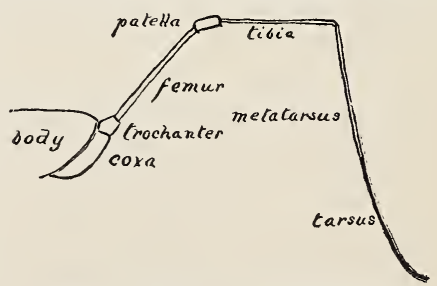

One of "dacidy's" long legs with segments named. the surface below him with his palpi, which he ordinarily carries bent be. neath his face, with the ends curled up under his "chin." The palpi have four segments that are easily seen, and although they are ordinarily carried bent up beneath the head, they can be extended out quite a distance if "daddy" wishes to test a substance. The end segment of the palpus is tipped with a single claw 
Beneath the palpi is a pair of jaws; these, in some species, extend beyond the palpi. I have seen a daddy-longlegs hold food to his jaws with his palpi and he seemed also to use them for stuffing it into his mouth.

The body of the daddy-longlegs is a little oblong object, looking more like a big grain of wheat than anything else, because in these creatures the head, thorax and abdomen are all grown together compactly. On top of the body, between the feeler-legs, is a little black dot, and to the nakec eye it would seem that if this were an organ of sight the creature must be a Cyclops with only one eye. But under the lens this is seen to be a raised knob and there is on each side of it, a little shining black eye. We hardly, see the use of two eyes set so closely together, Dut probably the "daddy" does.

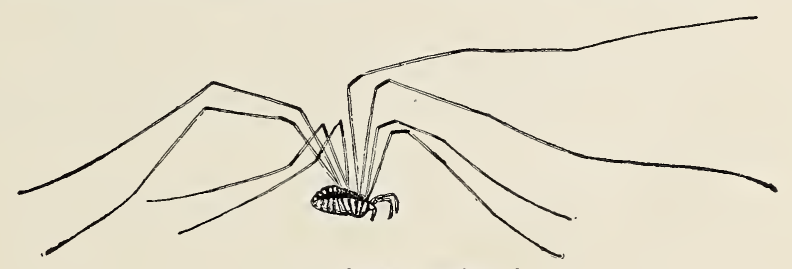

Grandfather-greybeard.

Comstock's Manual.

The most entertaining thing which a "daddy" in captivity is likely to do, is to clean his legs; he is very particular about his legs, and he will grasp one close to the basal joint in his jaws and slowly pull it through, meanwhile holding the leg up to the jaws with the palpi, while he industriously nibbles it clean for the whole length to the very toe. Owing to the likelihood of his losing one of his legs, he has the power of growing a new one; so we often see a "daddy" with one or more legs only half grown.

There are many species of daddy-longlegs in the United States, and some of them do not have the characteristic long legs. In the North, all except one species die at the approach of winter; but not until after the female, which, by the way, ought to be called "granny-longlegs," has laid her eggs in the ground, or under some protecting stone, or in some safe crevice of wood or bark. In the spring the eggs hatch into tiny little creatures which look just like the old daddy-longlegs, except for their size. They get their growth like insects, by shedding their skins as fast as they outgrow them. It is interesting to study one of these cast skins with a lens. There it stands with a slit down its back, and with the skin of each leg absolutely perfect to the tiny claw! Again we marvel at these legs that seem so threadlike, and which have an outer covering that can be shed. Some say that the daddy-longlegs live on small insects which they straddle over and pounce down upon, and some say they feed upon decay. ing matter and vegetable juices. This would be an interesting line of investigation for pupils, since they might be able to give many new facts 2"out the food of these creatures. The "daddies" are night prowlers, and like to hide in crevices by day, waiting sor the dark to hunt for their food. They have several common names. Besides the two given they 
are called "harvestmen" and the French call them "haymakers." Both of these names were very probably given, because the creatures appear in greater numbers at the time of haying and harvesting.

\section{LESSON CIX}

\section{The Daddy-Longlegs}

Leading thought-These long-legged creatures have one pair of legs too many to allow them to be classed with the insects. They are more nearly related to the spiders, who also have eight legs. They are pretty creatures when examined closely, and they do many interesting things.

Method-Put a grandfather greybeard in a breeding cage or under a large tumbler, and let the pupils observe him at leisure. If you place a few drops of sweetened water at one side of the cage, the children will surely have an opportunity to see this amusing creature clean his legs.

Observations-r. Where did you find the harvestman? What did it do as soon as it was disturbed? How many names do you know for this little creature?

2. A "daddy" with such long legs certainly ought to have them studied. How many segments in each leg? How do the segments look? How do the legs look where they are fastened to the body? Which is the longest pair of legs? The next? The next? The shortest?

3. If you had such long stilts as he has, they would be about forty feet long. Would you lift yourself that high in the air? Does the "daddy" lift his body high or swing it near the ground? What shape is the body? Can you see if there is a distinct head? Can you see a black dot on top of the front end of the body? If you should see this dot through a microscope it would prove to be two bright black eyes. Why should the daddy's eyes be on top?

4. Do you see a pair of organs that look like feelers at the front end of the body? These are called palpi. How does he use his palpi? Give him a little bruised or decaying fruit, and see him eat. Where do you think his mouth is? Where does he keep his palpi when he is not using them for eating?

5. Note what care he takes of his legs. How does he clean them? Which does he clean the oftenest? Do you think the very long second pair of legs is used as much for feeling as for walking? Put some object in front of the "daddy" and see him explore it with his legs. How much of the leg is used as a foot when the "daddy" stands or runs?

6. When running fast, how does the "daddy" carry his body? When exploring how does he carry it? Do you ever find the "daddy" with his body resting on the surface on which he is standing? When resting, are all eight of his legs on the ground? Which are in the air? Is the head end usually tilted up or down?

7. Do you see the daddy-longlegs early in the spring? When do you find him most often? How do you suppose he passes the winter in our climate? Have you ever seen a "daddy" with one leg much shorter than the other? How could you explain this?

8. Try and discover what the daddy-longlegs eats, and where he finds his food? 


\section{SPIDERS}

\section{Teacher's Story}

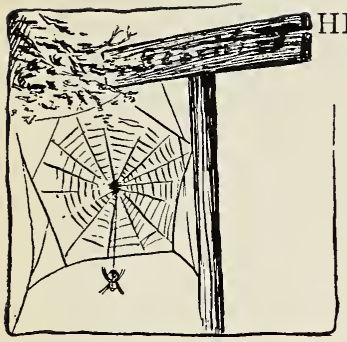

like flies, mosquitoes, bugs and grasshoppers.

spiders are the civil engineers among the small inhabitants of our fields and woods. They build strong suspension bridges, from which they hang nets made with exquisite precision; and they build aeroplanes and balloons, which are more efficient than any that we have yet constructed; for although they are not exactly dirigible, yet they carry the little balloonists where they wish to go, and there are few fatal accidents. Moreover, the spiders are of much economic importance, since they destroy countless millions of insects every year, most of which are noxious-

There is an impression abroad that all spiders are dangerous to handle. Thi is a mistake; the bite of any of our common spiders is not nearly so dangerous as the bite of a malaria-laden mosquito. Although there is a little venom injected into the wound by the bite of any spider, yet there is no species found in the Northern States whose bite is sufficiently venomous to be feared.

There is no need for studying the anatomy of the spider closely in nature-study. Our interest lies much more in the wonderful structures made by the spiders, than in a detailed study of the little creatures themselves.

\section{Coвwebs}

"Here shy Arachne winds her endless thread, And weaves her silken tapestry unseen, Veiling the rough-hewn timbers overhead, And looping gossamer festoons between."

-Elizabeth Akers.

Our house spiders are indefatigable curtain-weavers. We never suspect their presence, until suddenly their curtains appear before our eyes, in the angles of the ceilings-invisible until laden with dust. The cobwebs are made of crisscrossed lines, which are so placed as to entangle any fly that comes near. The lines are stayed to the sides of the wall and to each other quite firmly, and thus they are able to hold a fly that touches them. The spider is likely to be in its little den at the side of the web; this den may be in a crevice in the corner or in a tunnel made of the silk. As soon as a fly becomes entangled in the web the spider runs to it, seizes it in its jaws, sucks its blood, and then throws away the shell, the wings and legs. If a spider is frightened, it at first tries to hide and then may drop by a thread to the floor. If we catch the little acrobat it will usually "play possum" and we may examine it more closely through a lens. We shall find it is quite different in form from an insect. First to be noted, it has eight legs; but most important of all, it has only two parts to the body. The head and thorax are consolidated into one piece, which is called the cephalothorax. The abdomen has no segments like that of the insects, and is joined to the cephalothorax by a short, narrow stalk. At the front 
cf the head is the mouth, guarded by two mandibles, each ending in a sharp claw, at the tip of which the poison gland opens. It is by thrusting these mandibles into its prey that it kills its victims. On each side of the mandible is a palpus, which in the males is of very strange shape. The eyes are situated on the top of the head. There are usually four pairs of these eyes, and each looks as beady and alert as if it were the only one.

The spinning organs of the spider are situated near the tip of the abdomen, while the spinning organ of the caterpillar is situated near its lower lip. The spider's silk comes from two or three pairs of spinnerets which are fingerlike in form, and upon the end of each are many small tubes from which the silk is spun. The silk is in a fluid state as it issues from the spinnerets, but it hardens immediately on contact with the air. In making their webs, spiders produce two kinds of silk, one is dry and inelastic, making the framework of the web; the other is sticky and elastic, clinging to anything that it touches. The body and the legs of spiders are usually hairy.

\section{LESSON CX}

CoBwebs

Leading thought-The cobwebs which are found in the corners of ceilings and in other dark places in our houses, are made by the house spider which spins its web in these situations for the purpose of catching insects.

Method-The pupils should have under observation a cobweb in a corner of a room, preferably with a spider in it.

Observations-I. Is the web in a sheet or is it a mass of crisscrossed, tangled threads? How are the threads held in place?

2. What is the purpose of this web? Where does the spider hide? Describe its den.

3. If a fly becomes tangled in a web, describe the action of the spider. Does the spider eat all of the fly? What does it do with the remains?

4. If the spider is frightened, what does it do? Where does the silken thread come from, and how does its source differ from the source of the silken thread spun by caterpillars?

5. Imprison a spider under a tumbler or in a vial, and look at it very carefully. How many legs has it? How does the spider differ from insects in this respect? How many sections are there to the body? How does the spider differ from insects in this respect?

6. Look closely at the head. Can you see the hooked jaws, or fangs? Can you see the palpi on each side of the jaws? Where are the spider's eyes? How many pairs has it?

When the tangled cobweb pulls

The cornflower's cap awry, And the lilies tall lean over the wall

To bow to the butterfly.

It is July. 


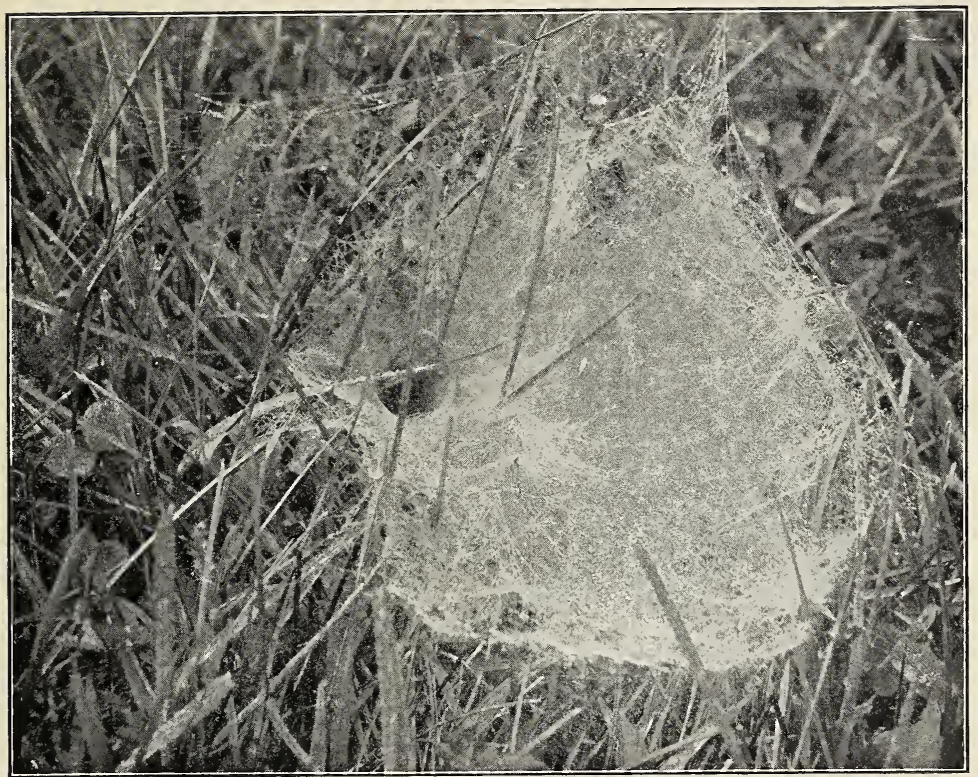

A funnel web.

Photo by J. H. Comstock

THE FUNNEL WEB

\section{Teacher's Story}

"And dew-bright webs festoon the grass

In roadside fields at morning."

-Elizabeth Akers.

Sometimes on a dewy morning, a field will seem carpeted with these webs, each with its opening stretched wide, and each with its narrow hallway of retreat. The general shape of the web is like that of a broad funnel with a tube leading down at one side. This tube is used as a hiding place for the spider, which thus escapes the eyes of its enemies, and also keeps out of sight of any insects that might be frightened at seeing it, and so avoid the web. But the tube is no cul-de-sac; quite to the contrary, it has a rear exit, through which the spider, if frightened, escapes from attack.

The web is formed of many lines of silk crossing each other irregularly, forming a firm sheet. This sheet is held in place by many guy-lines, which fasten it to surrounding objects. If the web is touched lightly, the spider rushes forth from its lair to seize its prey; but if the web be jarred roughly, the spider speeds out through its back door and can be found only with difficulty. The smaller insects of the field, such as flies and bugs, are the chief food of this spider; it rarely attempts to seize a grown grasshopper. 
The funnel-shaped webs in dark corners of cellars are made by a species which is closely related to the grass spider and has the same general habits, but which builds in these locations instead of in the grass.

\section{LESSON CXI \\ The Funnel Web}

Leading thought-The grass spider spins funnel-shaped webs in the grass to entrap the insects of the field. This web has a back door.

Method-Ask the pupils to observe a web on the grass with a spider within it.

Observations-I. What is the general shape of the web? Is there a tunnel leading down from it? Why is it called a funnel web?

2 Of what use is the funnel tube, and what is its shape? Where does it lead, and of what use is it to the spider? Can you corner a spider in its funnel tube? Why not?

3. How is the web made? Is there any regularity in the position of the threads that make it? How is it stayed in place?

4. Touch the web lightly, and note how the spider acts? Jar the web roughly, and what does the spider do?

5. What insects become entangled in this web?

6. Compare this web with similar funnel webs found in corners of cellars, sheds or piazzas, and see if you think the same kind of spider made both.

\section{THE ORB-WEB \\ Teacher's Story}

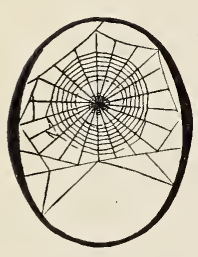

$\mathrm{F}$ all the structures made by the lower creatures, the orbweb of the spider is, beyond question, the most intricate and beautiful in design, and the most exquisite in workmanship. The watching of the construction of one of these webs is an experience that brings us close to those mysteries which seem to be as fundamental as they are inexplicable in the plan of the universe. It is akin to watching the growth of a crystal, or the stars wheeling across the heavens in their appointed courses.

The orb-web of the large, black and yellow garden spider is, perhaps, the best subject for this study, although many of the smaller orbs are far more delicate in structure. These orb-webs are most often placed vertically, since they are thus more likely to be in the path of flying insects. The number of radii, or spokes, differs with the different species of spiders, and they are usually fastened to a silken framework, which in turn is fastened by guy-lines to surrounding objects. These radii or spokes are connected by a continuous spiral line, spaced regularly except at the center or hub; this hub or center is of more solid silk, and is usually surrounded by an open space; and it may be merely an irregular network, or it may have wide bands of silk laid across it.

The radii or spokes, the guy-lines, the framework and the center of the web are all made of inelastic silk, which does not adhere to an object that touches it. The spiral line, on the contrary, is very elastic, and ad. 
heres to any object brought in contact with it. An insect which touches one of these spirals and tries to escape, becomes entangled in the neighboring lines and is thus held fast until the spider can reach it. If one of these elastic lines be examined with a microscope, it is a most beautiful object. There are strung upon it, like pearls, little drops of sticky fluid, which render it not only elastic but adhesive.

Some species of orb-weavers remain at the center of the web, while others hide in some little retreat near at hand. If in the middle, the

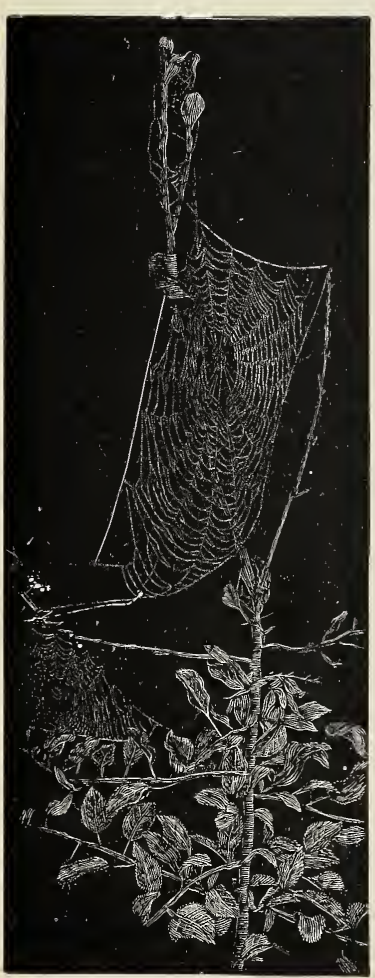

A dewy morning.

Insect Life, Comstock. spider always keeps watchful claws upon the radii of the web so that if there is any jarring of the structure by an entrapped insect, it is at once apprised of the fact; if the spider is in a den at one side, it keeps a claw upon a trap line which is stretched tightly from the hub of the web to the den, and thus communicates any vibration of the web to the hidden sentinel. When the insect becomes entangled, the spider rushes out and envelops it in a band of silk, which feat it accomplishes, by turning the insect over and over rapidly, meanwhile spinning a broad, silken band which swathes it. It may bite the insect before it begins to swathe it in silk, or afterwards. It usually hangs the swathed insect to the web near where it was caught, until ready to eat it; it then takes the prey to the center of the web, if there is where the spider usually sits, or to its den at one side, if it is a den-making species, and there sucks the insect's blood, carefully throwing away the hard parts.

The spider does not become entangled in the web, because, when it runs it steps upon the dry radii and not upon the sticky spiral lines. During the busy season, the spider is likely to make a new web every twenty-four hours, but this depends largely upon whether the web has meanwhile been destroyed by large insects.

The spider's method of making its first bridge is to place itself upon some high point and, lifting its abdomen in the air, to spin out on the breeze a thread of silk. - When this touches any object, it adheres, and the spider draws in the slack until the line is "taut;" it then travels across this bridge, which is to support its web, and makes it stronger by doubling the line. From this line, it stretches other lines by fastening a thread to one point, and then walking along to some other point, spinning the thread as it goes and holding the line clear of the object on which it is walking by means of one of its hind legs. When the right point is reached, it pulls the line tight, fastens it, and then, in a similar fashion, proceeds to make 
another. It may make its first radius by dropping from its bridge to some point below; then climbing back to the center, it fastens the line for another radius, and spinning as it goes, walks down and out to some other point, holding the thread clear and then pulling it tight before fastening it. Having this selected the center of the web, it goes back and forth to and from it, spinning lines until all of the radii are completed and fastened at one center. It then starts at the center and spins a spiral, laying it onto the radii to hold them firm. However, the lines of this spiral are farther a part and much more irregular than the final spiral. Thus far, all of the threads the spider has spun are inelastic and not sticky; and this first, or temporary spiral is used by the spicler to walk upon when spinning the final spiral. It begins the latter at the outer edge instead of at the center, and works toward the middle. As the second spiral progresses, the spider with its jaws cuts away the spiral which it first made, and which it has used as a scaffolding. A careful observer may often see remnants of this first spiral on the radii between the lines of the permanent spiral. The spider works very rapidly and will complete a web in a very short time. The final spiral is made of the elastic and adhesive silk.

References-Comstock's Manual; Common Spiders, Emerton; The Spider Book, Comstock; Nature's Craftsmen, McCook.

\section{LESSON CXII}

\section{The Orb-Web}

Leading thought-No structure made by a creature lower than man is so exquisitely perfect as the orb-web of the spider.

Method-There should be an orb-web where the pupils can observe it, preferably with the spider in attendance.

Observations-I. Is the orb-web usually hung horizontally or vertically?

2. Observe the radii, or "spokes," of the web. How many are there? How are they fastened to surrounding objects? Is each spoke fastened to some object or to a framework of silken lines?

3. Observe the silken thread laid around the spokes. Is it a spiral line or is each circle complete? Are the lines the same distance apart on the outer part of the web as at the center? How many of the circling lines are there?

4. Is the center of the web merely an irregular net, or are there bands of silk put on in zigzag shape?

5. Touch any of the "spokes" lightly with the point of a pencil. Does it adhere to the pencil and stretch out as you pull the pencil away? Touch one of the circling lines with a pencil point, and see if it adheres to the point and is elastic. What is the reason for this difference in the stickiness and elasticity of the different kinds of silk in the orb-web?

6. If an insect touches the web, how does it become more entangled by seeking to get away?

7. Where does the spider stay, at the eenter of the web or in a little retreat at one side?

8. If an insect becumes entangled in the web, how does the spider discover the fact and act?

9. If the spider sits at the middle of the orb, it has a different method for discovering when an insert strikes the web than does the spider that hides in a den at one side. Describe the methods of each. 
Io. How does the spider make fast an insect? Does it bite the insect before it envelops it in silk? Where does it carry the insect to feed upon it?

I . How does the spider manage to run about its web without becoming entangled in the sticky thread? How often does the orb-weaver make a new web?

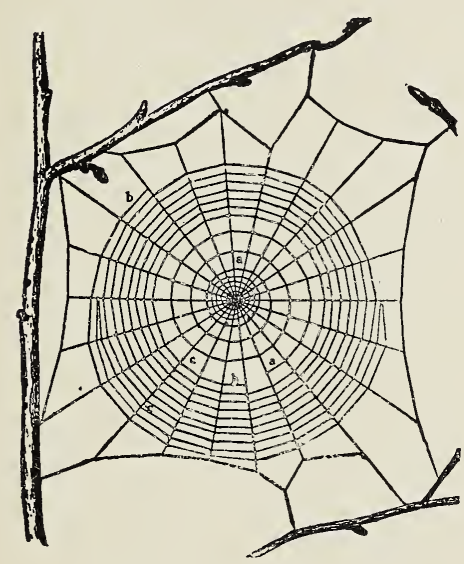

A partially completea orb-web.

$a$, the temporary spiral stay line; $b$, the sticky spiral line; $c$, the fragments of the temporary spiral hanging to a radius. Comstock's Manual.

\section{How an Orb-web is Made}

Spiders may be seen making their webs in the early morning or in the evening. Find an orb-web with a spider in attendance; break the web without frightening the spider and see it replace it in the early evening, or in the morning about daybreak. An orb. weaver may be brought into the house on its web, when the wcb is on a branch, and placed where it will not be disturbed, and this be watched at leisure.

Observations-r. $\quad \mathrm{H}$ o $\mathrm{w}$ does the spider manage to place the supporting line between two points?

2. How does it make the framework for holding the web in place?

3. How does it make the first radius?

4. How does it make the other radii and select the point which is to be the center of the web?

5. How does it keep the line which it is spinning clear of the line it walks upon?

6 . After the radii are all made, are they fastened at the center?

7. How and where does the spider first begin to spin a spiral? Are the lines of this spiral close together or far apart? For what is the first spiral used?

8. Where does it begin to spin the permanent spiral? Where does it walk when spinning it? By the way it walks on the first spiral, do you think it is sticky and elastic? What does it do with the first

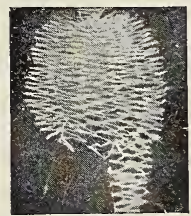

The zigzag strengthening band at center of an orb-web. spiral while the second one is being finished? on?

9. If the center of the web has a zigzag ribbon of silk, when was it put

ro. How many minutes did it take the spider to complete the web?

Supplementary reading - "Argiope of The Silver Shield," Insect Stories, Kellogg. 


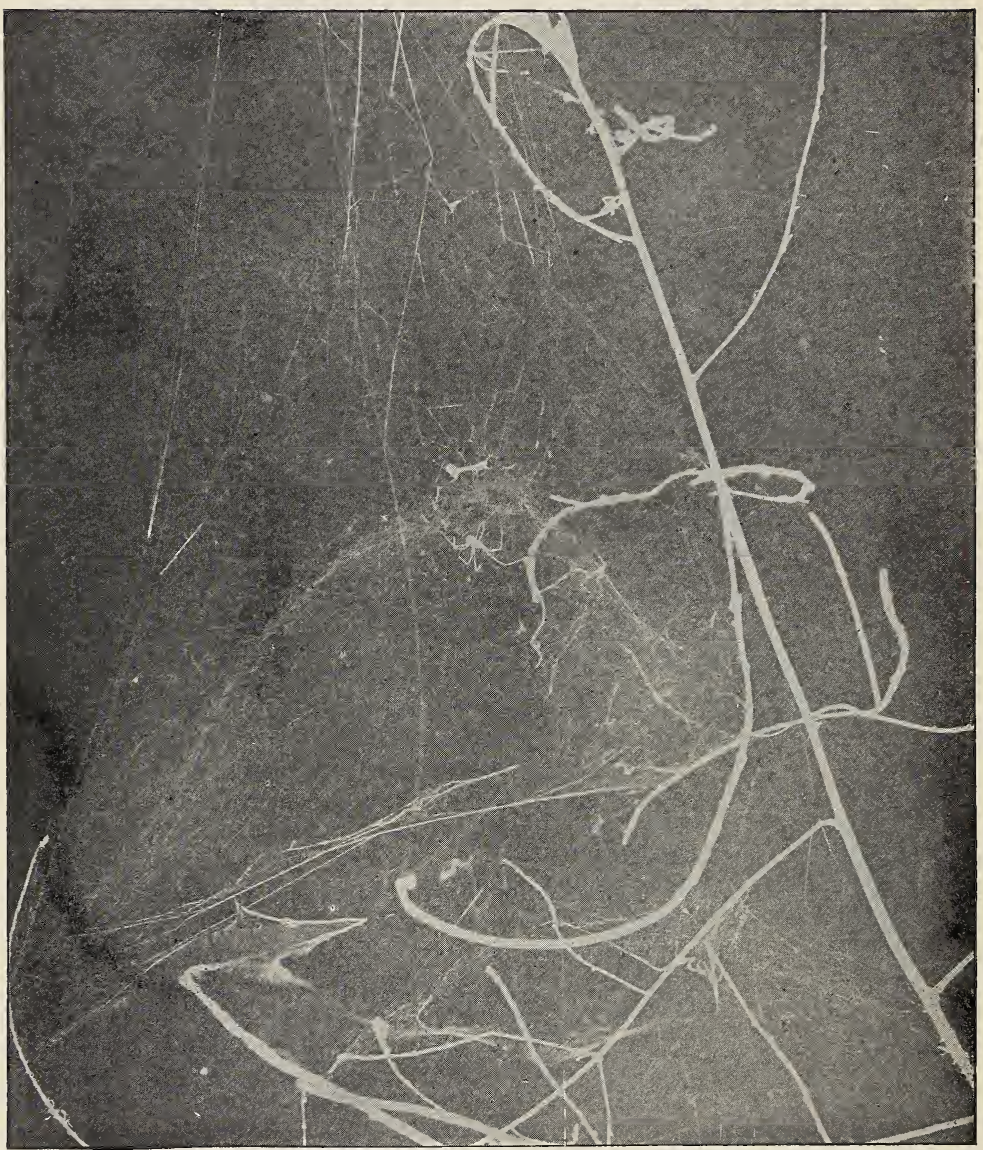

A filmy-dome web with its maker. Photo by J. H. Comstock. 


\section{THE FILMY DOME}

\section{Teacher's Story}

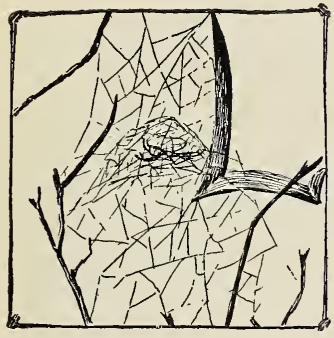

IKE bubbles cut in half, these delicate domes catch the light rays and separate them like a prism into waves of rainbow colors. One of these domes is usually about the size of an ordinary bowl, and is suspended with the opening on the lower side. It is held in place by many guy-lines which attach it to surrounding objects. Above a filmy dome are always stretched many crisscrossed threads for some distance up. These are for the purpose of hindering the flight of insects, so that they will fall into the web. The little spider, which always hangs, back downward, just below the center of the dome, rushes to its prey from the lower side, pulls it through the meshes of the web, and feeds upon it. But any remains of the insect or pieces of sticks or leaves which may drop upon the web, it carefully cuts out and drops to the ground, mending the hole very neatly.

\section{LESSON CXIII}

\section{The Filmy Dome}

Leading thought-One little spider spins a filmy dome, beneath the apex of which it hangs, back downward, awaiting its prey.

Method-On a sunny day in late summer or early autumn, while walking along woodland paths, the careful observer is sure to see suspended among the bushes or in the tops of weeds, or among dead branches of young hemlocks, the filmy dome webs. They are about as large as a small bowl, and usually so delicate that they cannot be seen unless the sun shines upon them; they are likely to be exquisitely iridescent under the sun's rays. Such a dome may be studied by a class or by the pupils individually.

Observations- $\mathrm{I}$. Where did you discover the filmy dome? What is the size of the dome? Does it open above or below? How is it held in place?

2. Are there many crisscrossed threads extending above the dome? If so, what do you think they are for?

3. Where does the spider stay? Is the spider large and heavy, or small and delicate?

4. What does the spider do if an insect becomes entangled in its web?

5. Throw a bit of stick or leaf upon a filmy dome web, and note what becomes of it.

"With spiders I had friendship made, And watch'd them in their sullen trade." 


\section{BALLOONING SPIDERS \\ Teacher's Story}

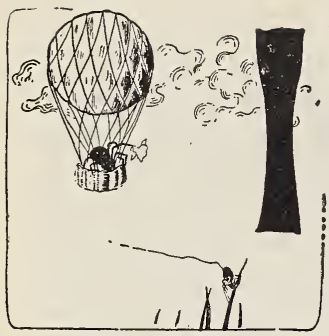

F we look across the grass some warm sunny morn. ing or evening of early fall, we see threads of spider silk clinging everywhere; these are not regular webs for trapping insects, but are single threads spun from grass stalk to grass stalk until the fields are carpeted with glistening silk. We have a photograph of a plowed field, taken in autumn, which looks likes the waves of a lake: so completely is the ground covered with spides threads that it shows the "path of the sun" like water.

When we see so many of these random threads, it is a sign that the young spiders have started on their travels, and it is not difficult then to find one in the act. The spiderling climbs up some tall object, like a twig or a blade of grass, and sends out its thread of silk upon the air. If the thread becomes entangled, the spiderling sometimes walks off on it, using it as a bridge, or sometimes it begins again. If the thread does not become entangled with any object, there is soon enough given off, so that the friction of the air current upon it supports the weight of the body of the little creature, which promptly lets go its hold of earth as soon as it feels safely buoyed up, and off it floats to lands unknown. Spiders thus sailing through the air have been discovered in mid-ocean.

Thus we see that the spiders have the same way of distributing their species over the globe, as have the thistles and dandelions. It has been asked what the spiders live upon while they are making these long journeys, especially those that have drifted out to sea. The spider has very convenient habits of eating. When it finds plenty of food it eats a great deal; but in time of famine it lives on, apparently comfortably, without eating. One of our captive spiders was mislaid for six months and when we found her she was as full of "grit" as ever, and she did not seem to be abnormally hungry when food was offered her.

" A noiseless, patient spider,

I mark'd where, on a little promontory, it stood isolated:

Mark'd how to explore the vacant, vast surrounding,

It launch'd forth filament out of itself:

Ever unreeling them-ever tirelessly speeding them.

"And you, O my soul, where you stand,

Surrounded, surrounded, in measureless oceans of space,

Ceaselessly, musing, venturing, throwing, seeking the spheres to connect them;

Till tbe bridge you will need be form'd - till the ductile anchor hold;

Till the gossamer thread you fing catch somewhere, O my soul."

- Walt Whitman. 


\section{LESSON CXIV \\ Ballooning Spiders}

Leading thought-The young of many species of spiders scatter them. selves like thistle seeds in balloons which they make of silk.

Method-These observations should be made out of doors during some warm sunny day in October. Read Nature's Craftsmen, McCook, p. I82.

Observations-r. Look across the grass some warm sunny morning or evening of early fall, and note the threads of spider silk gleaming everywhere, not regular webs, but single threads spun from grass stalk to grass stalk, or from one object to another, until the ground seems glistening with silk threads.

2. Find a small spider on a bush, fence post, or at the top of some tall grass stalk; watch it until it begins to spin out its thread.

3. What happens to the thread as it is spun out?

4. If the thread does not become entangled in any surrounding object what happens? If the thread does become entangled, what happens?

5. How far do you suppose a spider can travel on this silken aeroplane? Why should the young spider wish to travel?

\section{THE WHITE CRAB-SPIDER}

\section{Teacher's Story}

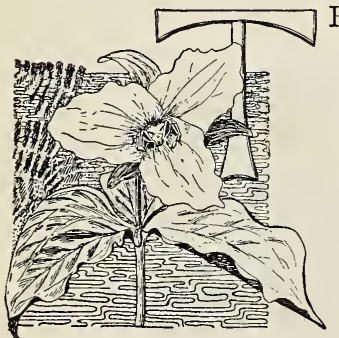

HERE are certain spiders which are crablike in form, and their legs are so arranged that they can walk more easily sidewise or backward than forward. These spiders spin no webs, but lie in wait for their prey. Many of them live upon plants and fences and, in winter, hide in protected places.

The white crab-spider is a little rascal that has discovered the advantage of protective coloring as a means of hiding itself from the view of its victims, until too late to save themselves; the small assassin always takes on the color of the flower in which it lies concealed. In the white trillium, it is greenish white; while in the golden-rod its decorations are yellow. It waits in the heart of the flower, or in the flower clusters, until the visiting insect alights and seeks to probe for the nectar; it then leaps forward and fastens its fangs into its struggling victim. I have seen a crab-spider in a milkweed attack a bee three times its size. This spider was white with lilac or purple markings. If disturbed, the crabspider can walk off awkwardly or it may drop by a silken thread. It is especially interesting, since it illustrates

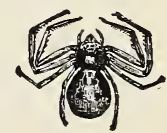

A common crab-spider. another use for protective coloring; and also because this species seems to be able to change its colors to suit its surroundings. 


\section{LESSON CXV \\ The White Crab-spider}

Leading thought-r. The white crab spider has markings upon its body of the same color as the flower in which it rests and is thus enabled to hide in ambush out of the sight of its victims-the insects which come to the flower for nectar.

Method-Ask the children to bring one of these spiders to school in the flower in which it was found; note how inconspicuous it is, and arouse an interest in the different colors which these spiders assume in different flowers.

Observations-I. What is the shape of the body of the crab-spider? Which of the legs are the longest? Are these legs directed forward or backward?

2. How is the body marked? What colors do you find upon it? Are the colors the same in the spiders found in the trilliums, as those in other flowers? Why is this? Do you think that the color of the spider keeps it from being seen?

3. Place the white spider which you may find in a trillium in a daffodil, and note if the color changes.

4. Do the crab-spiders make webs? How do they trap their prey?

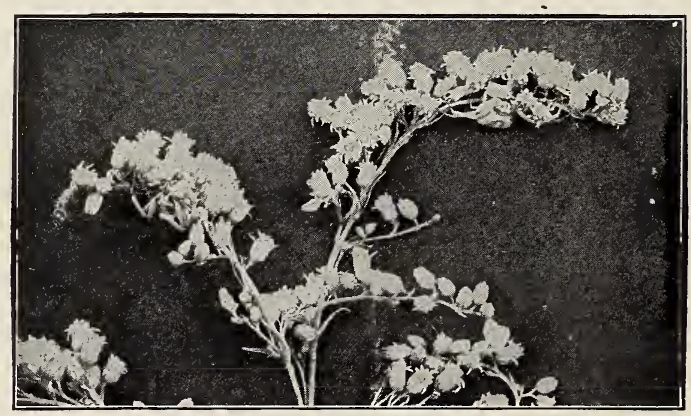

Crab-spiders on golden-rod.

This species is white when lurking in the white trillium and yellow when among flowers of the golden-rod.

Photo by Slingerland. 


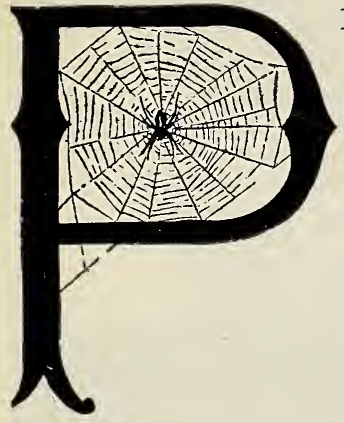

ROTECTING her eggs from the vicissitudes of the weather seems to be the spider mother's chief care; though at the same time and by the same means, she protects them from the attacks of predacious insects. Many of the species make silken egg-sacs, which are often elaborate in construction, and are carefully placed in protected situations.

Often a little silvery disk may be seen attached to a stone in a field. It resembles a circular lichen on the stone, but if it is examined it is found to consist of an upper, very smooth, waterproof coat, while below is a soft, downy nest, completely enfolding the spider's eggs.

The egg-sacs of the cobweb weavers are often found suspended in their webs. One of the large orbweavers makes a very remarkable nest, which it attaches to the branches of weeds or shrubs. This sac is about as large as a hickory nut, and opens like a vase at the top. It is very securely suspended by many strong threads of silk, so that the blasts of winter cannot tear it loose. The outside is shining and waterproof, while inside it has a fit lining for a spiderling cradle.

Dr. Burt G. Wilder studied the development of the inmates of one of these nests by cutting open different nests at different periods of the winter. In the autumn, the nest contained five hundred or more eggs. These eggs hatched in early winter but it seemed foreordained that some of the little spiders were born for food for their stronger brethren. They seemed resigned to their fate, for when one of these victims was seized by its cannibalistic brother, it curled up its legs and submitted meekly. The result of this process was that, out of the five hundred little spiders hatched from the eggs, only a few healthy and apparently happy young spiders emerged from the nest in the spring, sustained by the nourishment afforded

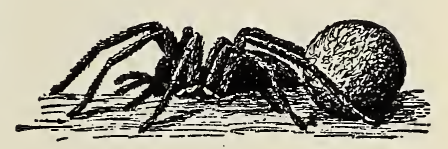

A wolf-spider carrying her egg-sac. them by their own family, and fitted for their life in the outside world.

Some spiders make a nest for their eggs within folded leaves, and some build them in crevices of rocks and boards.

The running spiders, which are the large ones found under stones, make globular egg-sacs; the mother spider drags after her this egg-sac attached to her spinnerets; the young, when they hatch, climb upon their mother's back, and there remain for a time.

\section{LESSON CXVI}

\section{The Nests of Spiders}

Leading thought-The spider mothers have many interesting ways of protecting their eggs, which the $y$ envelop in silken sacs and place in safety. 
Method-Ask the pupils to bring in all the spider egg-sacs that they can find. Keep some of them unopened, and open others of the same kind, and thus discover how many eggs are in the sac, and how many spiderlings come out. This is a good lesson for September and October.

Observations-I. In what situation did you find the nest? How was it protected from rain and snow? To what was it attached?

2. Of what texture is the outside of the sac? Is the outside made of waterproof silk? What is the texture of the lining?

3. How many eggs in this sac? What is the color of the eggs? When do the spiderlings hatch? Do as many spiders come out of the sac as there were eggs? Why is this?

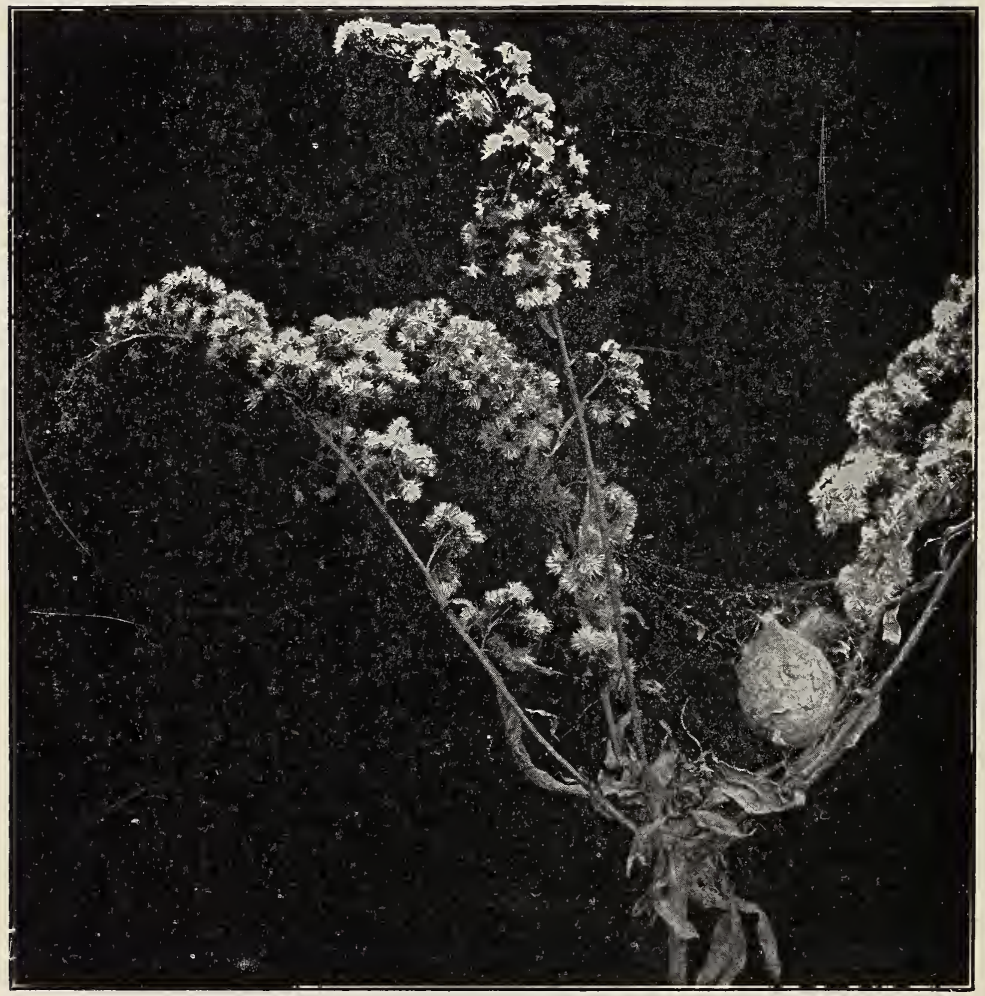

The egg-sac of the large, black and yellow garden-spider suspended for the winter in a branch of golden-rod.

Photo by Slingerland. 


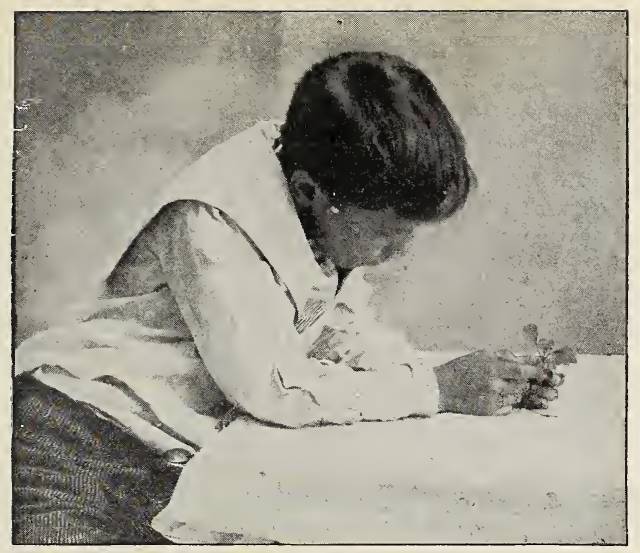

PART III

\section{PLANT LIFE}

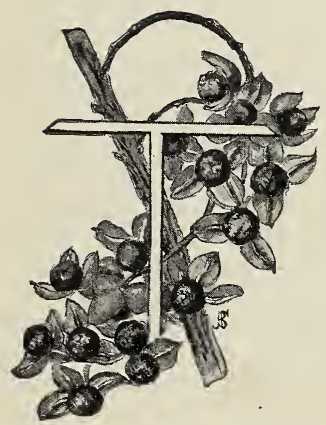

\section{HOW TO BEGIN THE STUDY OF PLANTS} AND FLOWERS

$\mathrm{HE}$ only right way to begin plant study with young children is through awakening their interest in and love for flowers. Most children love flowers naturally; they enjoy bringing flowers to school, and here, by teaching the recognition of flowers by name, may be begun this delightful study. This should be done naturally and informally. The teacher may say: "Thank you, John, for this bouquet. Why, here is a pansy, a bachelor's button, a larkspur and a poppy." Or, "Julia has brought me a beautiful flower. What is its name, I wonder?" Then may follow a little discussion, which the teacher leads to the proper conclusion. If this course is consistently followed, the children will learn the names of the common flowers of wood, field and garden, and never realize that they are learning anything.

The next step is to inspire the child with a desire to care for and preserve his bouquet. The posies brought in the perspiring little hand may be wilted and look dejected; ask their owner to place the stems in water. and call attention to the way they lift their drooping heads. Parents and teachers should very early inculcate in children this respect for the rights of flowers which they gather; no matter how tired the child or how disinclined to further effort, when he returns from the woods or fields or garden with plucked flowers, he should be made to place their stems in water immediately. This is a lesson in duty as well as in plant study. 
Attention to the behavior of the thirsty flowers may be gained by asking the following questions:

r. When a plant is wilted how does it look? How does its stem act? Do its leaves stand up? What happens to the flower?

2. Place the cut end of the stem in water and look at it occasionally during an hour; describe what happens to the stem, the leaves, the blossom.

3. To find how flowers drink, place the stem of a wilted plant in red ink; the next day cut the stem across and find how far the ink has been lifted into it.

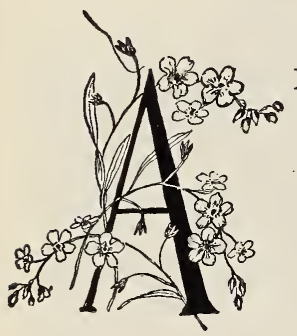

HOW TO MAKE PLANTS COMFORTABLE

NOTHER step in plant study comes naturally from planting the seeds in window-boxes or garden. This may be done in the kindergarten or in the primary grades. As soon as the children have had some experience in the growing of flowers, they should conduct some experiments which will teach them about the needs of plants. These experiments are fit for the work of the second or third grade. Uncle John says, "All plants want to grow; all they ask is that they shall be made comfortable." The following experiments should be made vital and full of interest, by impressing upon the children that through them they will learn to make their plants comfortable.

Experiment I. To find out what kind of soil plants love best to grow inHave the children of a class, or individuals representing a class, prepare four little pots or boxes, as follows: Fill one with rich, woods humus, or with potting earth from a florist's; another with poor, hard soil, which may be found near excavations; another with clean sand; another with sawdust. Plant the same kind of seeds in all four, and place them where they will get plenty of light. Water them as often as needful. Note which plants grow the best. This trial should cover six weeks at least and attention should now and then be called to the relative growth of the plants.

Experiment 2. To prove that plants need light in order to grow.-Fill two pots with the same rich soil; plant in these the same kind of seeds, and give them both the same amount of water; keep one in the window and place the other in a dark closet or under a box, and note what happens. Or take two potted geraniums which look equally thrifty; keep one in the light and the other in darkness. What happens?

Experiment 3. To show that the leaves love the light-Place a geranium in a window and let it remain in the same position for two weeks. Which way do all the leaves face? Turn it. around, and note what the leaves have done after a few days.

Experiment 4. To show that plants need water-Fill three pots with rich earth, plant the same kinds of seeds in each, and place them all in the same window. Give one water as it needs it, keep another flooded with water, and give the other none at all. What happens to the seeds in the three pots? 
The success of these four experiments depends upon the genius of the teacher. The interest in the result should be keen; every child should feel that every seed planted is a living germ and that it is struggling to grow; every look at the experiments should be like another chapter in a continued story. In the case of young children, I have gone so far as to name the seeds, "Robbie Radish" or "Polly Peppergrass." I did this to focus the attention of the child on the efforts of this living being to grow, After the experiments, the children told the story, personating each seed, thus: "I am Susie Sweet Pea and Johnny Smith planted me in sand. I started to grow, for I had some lunch with me which my mother put up for me to eat when I was hungry; but after the lunch was all gone, I could find very little food in the sand, although my little roots reached down and tried and tried to find something for me to eat. I finally grew pale and could not put out another leaf.'

The explanations of these experiments should be simple, with no attempt to teach the details of plant physiology. The need of plants for rich, loose earth and for water is easily understood by the children; but the need for light is not so apparent, and Uncle John's story of the starch factory is the most simple and graphic way of making known to the children the processes of plant nourishment. This is how he tells it: "Plants are just like us; they have to have food to make them grow; where is the food and how do they find it? Every green leaf is a factory to make food for the plant; the green pulp in the leaf is the machinery; the leaves get the raw materials from the sap and from the air, and the machinery unites them and makes them into plant food. This is mostly starch, for this is the chief food of plants, although they require some other kinds of food also. The machinery is run by sunshine-power, so the leaf-factory can make nothing without the aid of light; the leaf-factories begin to work as soon as the sun rises, and only stop working when it sets. But the starch has to be changed to sugar before the baby, growing tips of the plant can use it for nourishment and growth; and so the leaves, after making the starch from the sap and the air, are obliged to digest it, changing the starch to sugar; for the growing parts of the plant feed upon sweet sap. Although the starch-factory in the leaves can work only during the daytime, the leaves. can change the starch to sugar during the night. So far as we know, there is no starch in the whole world which is not made in the leaffactories."

This story should be told and repeated often, until the children realize the work done by leaves for the plants and their need of light.

"The clouds are at play in the azure space

And their shadows at play on the bright green rals.

And here they stretch to the frolic chase;

And there they roll on the easy gale.

"There's a dance of leaves in that aspen bower.

There's a titter of winds in that beechen tree,

There's a smile on the fruit and a smile on the flower,

And a laugh from the brook that runs to the sea."

-BRYANT. 
HOW TO TEACH THE NAMES OF THE PARTS OF A FLOWER AND OF THE PLANT

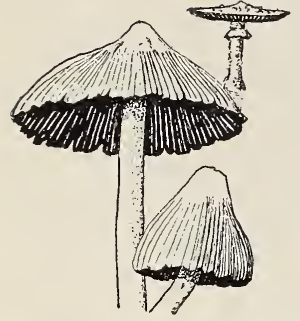

HE scientific names given to the parts of plants have been the stumbling block to many teachers, and yet no part of plant study is more easily accomplished. First of all, the teacher should have in mind clearly the names of the parts which she wishes to teach; the illustrations here given are for her convenience. When talking with the pupils about flowers let her use these names naturally:

"See how many geraniums we have; the corolla of this one is red and of that one is pink. The red corolla has fourteen petals and the pink one only five," etc.

"This arbutus which James brought has a pretty little pink bell for a corolla."

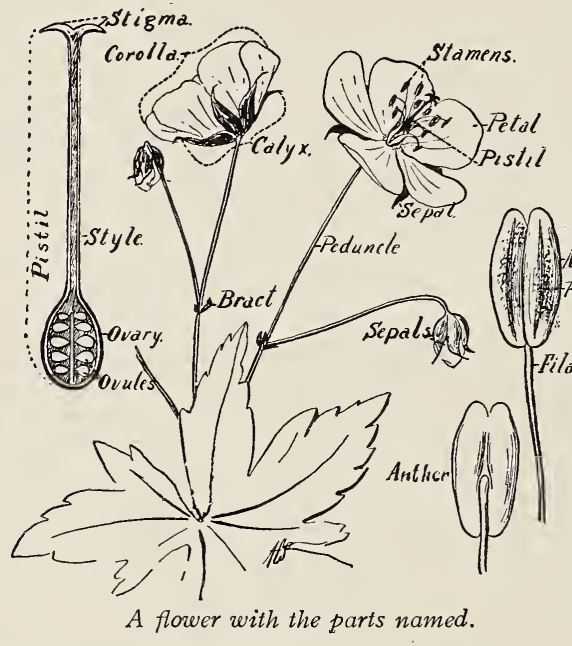

"The purple trillium has a purple corolla, the white trilliun a white corolla; and both have green sepals."

The points to be borne in mind are that children like to call things by their names because they are real names, and they also like to use "grown up" names for things; but they do not like to commit to memory names which to them are meaningless. Circumlocution is a waste of breath; calling a petal a "leaf of a flower" or the petiole "the stem of a leaf," is like calling a boy's arm "the projecting part of James' body" or Molly's golden hair "the yellow

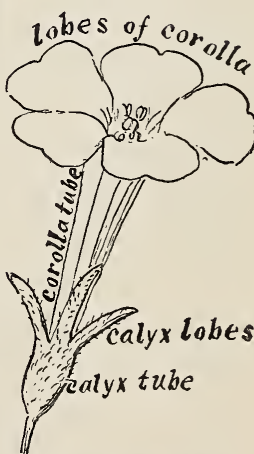

A flower with petals united forming a tube, and with sepals likewise united. 
top" to her head. All the names should be taught gradually by constant unemphasized use on the part of the teacher; and if the child does not learn the names naturally then do not make him do it innatirally.

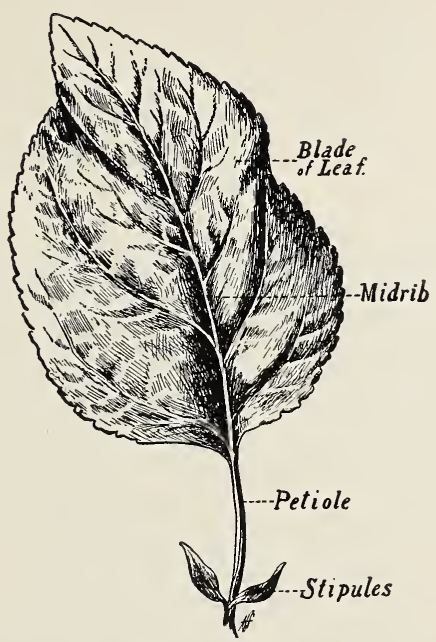

A leaf with parts named.

The lesson on the garden, or horseshoe geranium with single flowers, is the one to be given first in teaching the structure of a flower since the geranium blossom is simple and easily understood.

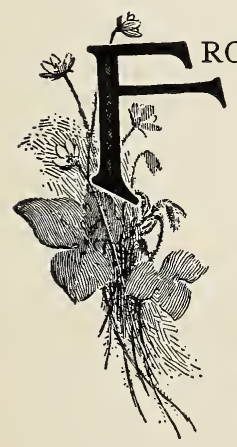

TEACH THE USE OF THE FLOWER

ROM first to last the children should be taught that the object of the flower is to develop seed. They should look eagerly into the maturing flower for the growing fruit. Poetry is full of the sadness of the fading flower, while rightly it should be the gladness of the flower that fades, because its work is done for the precious seed at its heart. The whole attention of the child should be fixed upon the developing fruit instead of the fading and falling petals.

"In all places then and in all seasons.

Flowers expand their light and soul-like wings,

Teaching us by most persuasive reasons,

How akin they are to human things."

-LONGFELLOW. 


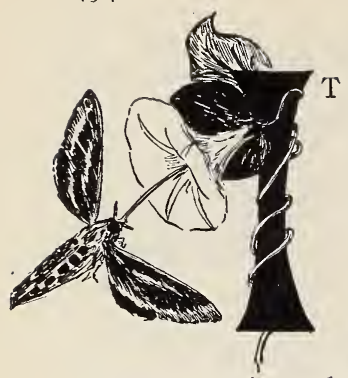

FLOWERS AND INSECT PARTNERS

is undoubtedly true that while the processes of cross-pollenation and the complicated devices of flowers for insuring it can only be well taught to older pupils and only fully understood in the college laboratory, yet there are a few simple facts which even the young child may know, as follows:

I. Pollen is needed to make the seeds grow; some flowers need the pollen from other flowers of the same kind, to make their seeds grow; but many flowers also use the pollen from their own flowers to pollenate their ovules, which grow into seeds.

2. Flowers have neither legs like animals nor wings like butterflies, to go after pollen; so they give insects nectar to drink and pollen to eat, and thus pay them for fetching and carrying the pollen.

I taught this to a four-year-old once in the following manner: A pine tree in the yard was sifting its pollen over us and little Jack asked what the yellow dust was; we went to the tree and saw where it came from, then I found a tiny young cone and explained to him that this was a pine blossom, and that in order to become a cone with seeds, it must have some pollen fall upon it; and we saw how the wind sifted the pollen over it and then we examined a ripe cone and found the seeds. Then we looked at the clovers in the lawn. They did not have so much pollen and they were so low in the grass that the wind could not carry it for them; but right there was a bee. What was she doing? She was getting honey for her hive or pollen for her brood, and she went from one clover head to another; we caught her in a glass fruit jar, and found she was dusted with pollen and that she had pollen packed in the baskets on her hind legs; and we concluded that she carried plenty of pollen on her clothes for the clovers, and that the pollen in her baskets was for her own use. After that he was always watching the bees at work; and we found afterwards that flowers had two ways of telling the insects that they wanted pollen. One was by their color, for the dandelions and clovers hide their colors during dark, rainy days when the bees remain in their hives. Then we found the bees working on mignonette, whose blossoms were so small that Jack did not think they were blossoms at all, and we concluded that the mignonette called the bees by its fragrance. We found other flowers which called with both color and fragrance; and this insect-flower partnership remained a factor of great interest in the child's mind ever after.

"Roly-poly honey-bee,

Humming in the clover,

Under you the tossing leaves,

And the blue sky over,

Why are you so busy, pray?

Never still a minute,

Hovering now above a flower,

Now half buried in it!"

- Julia C. R. DORR. 
THE RELATION OF PLANTS TO GEOGRAPHY

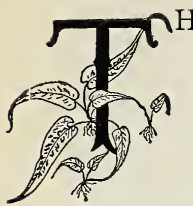

HERE should be from first to last a steady growth in the intelligence of the child as to the places where certain plants grow. He finds hepaticas and trilliums in the woods, daisies and buttercups in the sunny fields, mullein on the dry hillsides, cat-tails in the swamp, and water lilies floating on the pond. This may all be taught by simply asking the pupils questions relating to the soil and the special conditions of the locality where they found the flowers they bring to school.

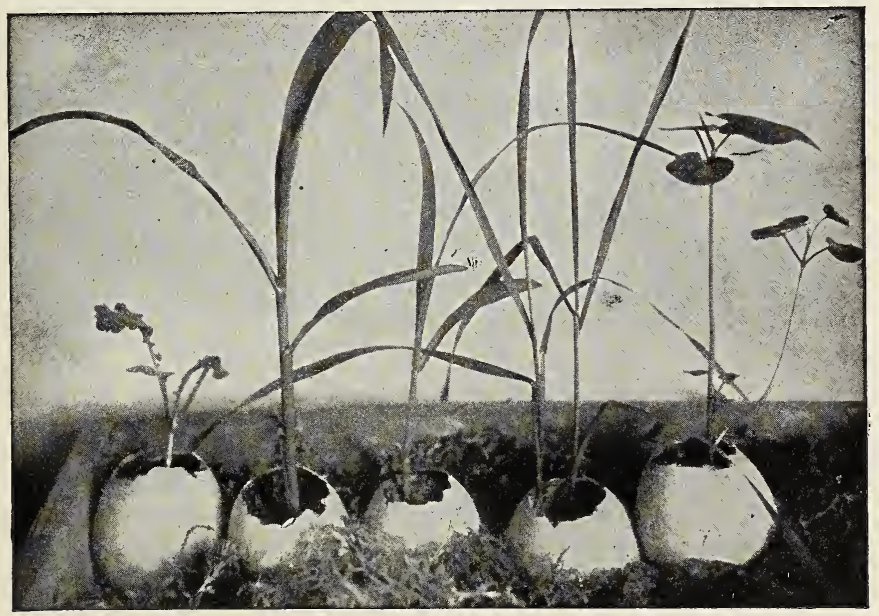

Egg-shell experiment farm.

The plants from left to right are: cabbage, field corn, popcorn, wheat, buckwheat.

\section{SEED GERMINATION}

Less than three decades ago, this one feature of plant life once came near "gobbling up" all of nature-study, and yet it is merely an incident in the growth of the plant. To sprout seeds is absurd as an object in itself; it is incidental as is the breaking of the egg-shell to the study of the chicken. The peeping into a seed like a bean or a pea, to see that the plant is really there, with its lunch put up by its mother packed all around it, is interesting to the child. To watch the little plant develop, to study its seed-leaves and what becomes of them, to know that they give the plant its first food and to know how a young plant looks and acts, are all items of legitimate interest in the study of the life of a plant; in fact the struggle of the little plant to get free from its seed-coats may be a truly dramatic story. (See "First Lessons with Plants," Bailey, page 79). But to regard this feature as the chief object of planting seed is manifestly absurd. 
The object of planting any seed should be to rear a plant which shall fulfill its whole duty and produce other seed. The following observations regarding the germination of seeds should be made while the children are eagerly watching the coming of the plants in their gardens or window-boxes:

I. Which comes out of the seed first, the root or the leaf? Which way does the root always grow, up or down? Which way do the leaves always grow, no matter which side up the seed is planted?

2. How do the seed-leaves try to get out of the seed-coat, or shell? How do the seed-leaves differ in form from the leaves which come later? What becomes of the seed-leaves after the plant begins to grow?

References-First Lessons with Plants, L. H. Bailey; First Lessons in Plant Life, Atkinson; Plants and their Children, Dana; Plants, Coulter; How Plants Grow, Gray; How Plants Behave, Gray.

\section{WILD-FLOWER STUDY}

\section{THE HEPATICA}

\section{Teacher's Story}

"The wise men say the hepatica flower has no petals but has pink, white or purple sepals instead: and they say, too, that the three leaflets of the cup which holds the flower are not sepals but are bracts; and they offer as proof the fact that they do not grow close to the blossom, but are placed a little way down the stem. But the hepatica does not care what names the wise men give to the parts of its blossom: it says as plainly as if it could talk: 'The bees do not care whether they are sepals or petals since they are pretty in color, and show where the pollen is to le found. I will teach the world that bracts are just as good to wrap around flower-buds as are sepals, and that sepals may be just as beautiful as petals. Since my petticoat is pretty enough for a dress why should not 1 wear it thus? "- "The Child's Own Book of Wild Flowers."

We seek the hepatica in its own haunts, because there is a longing for spring in our hearts that awakens with the first warm sunshine. As we thread our way into sodden woods, avoiding the streams and puddles which are little glacial rivers and lakes, having their sources in the snowdrifts still heaped on the north side of things, we look eagerly for signs of returning life. Our eyes slowly distinguish among the various shades of brown in the floor of the forest, a bit of pale-blue or pink-purple that at first seems like an optical delusion; but as we look again to make sure, Lo! it is the hepatica, lifting its delicate blossoms above its mass of purple-brown leaves. These leaves, moreover, are always beautiful in shape and color and suggest patterns for sculpture like the acanthus, or for rich tapestries like the palm-leaf in the Orient. It warms the hea t to see these brave little flowers stand with their faces to the sun and their backs to the snow-drifts, looking out on a gray-brown world, nodding to it and calling it good.

The hepatica is forehanded in several ways. After the leaves have fallen from the trees in the autumn and let in the sunshine, it puts up new leaves which make food that is stored in the crown bud; the little flower buds are then started, and wrapped cozily, are cuddled down at the very 


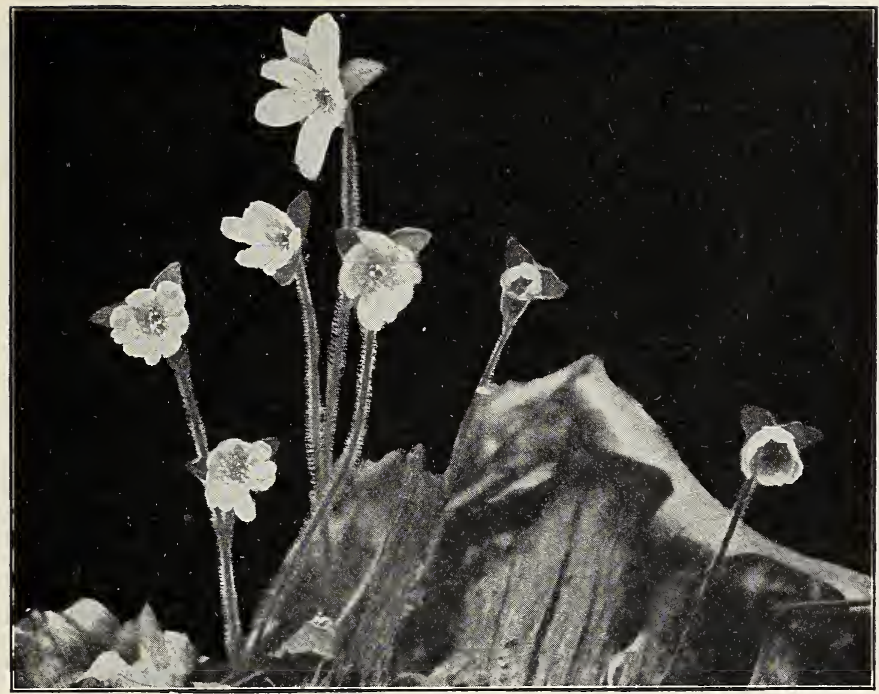

Hepaticas.

center of the plant. These buds, perfected in the autumn, are ready to stretch up and blossom when the first warmth of spring shall reach them. The stems and the bracts of the flower are soft and downy, and are much more furry than those which appear later; while this down is not for the purpose of keeping the plant at a higher temperature, yet it acts as a blanket to prevent too rapid transpiration, which is a cooliiig process, and thus it does, as a matter of fact, keep the flower warmer. As the stems lift up, the buds are bent, which position protects them from the beating storms. The hepatica flowers are white, pink and lavender. The latter are sometimes called "blue." The so-called "petals" number from six to twelve; there are usually six. The three outer ones are sepals and are exactly like the three inner ones, the petals, but may be distinguished by their outside position in the half-opened flower. The three green bracts which encase the flower bud, and later remain with the seed, are placed on the stem quite distinctly below the flower. On dark days and during the nights, the young blossoms close; but when they become old and faded, they remain open all the time. Thus, the flowers are closed except when bees are likely to visit them; but after they have shed their pollen, they do not need to remain closed any longer. Not all hepatica blossoms are fragrant; and those that are so, lose their fragrance as their colors begin to fade to white. If a snow-storm comes, the hepatica blossoms close and bow their heads.

There are many stamens with greenish white anthers and pollen. They stand erect around the many pistils at the center of the flower. The number of pistils varies from six to twenty-four. Each pistil holds aloft the little horseshoe-shaped, whitish stigma and, if pollenated, 
develops into a seed. The hepatica is a perennial and grows only in rich, moist woods. It is so adapted to the shade, that it dies if transplanted to sunny places. The leaves which have passed the winter under the snow are rich purple beneath; and mottled green and purple above, making beautiful objects for water-color drawings. The new leaves are put forth in spring before the leaves of the trees create too much shade. In the fall, after the trees are bare, the leaves again become active. The roots are quite numerous and fine.

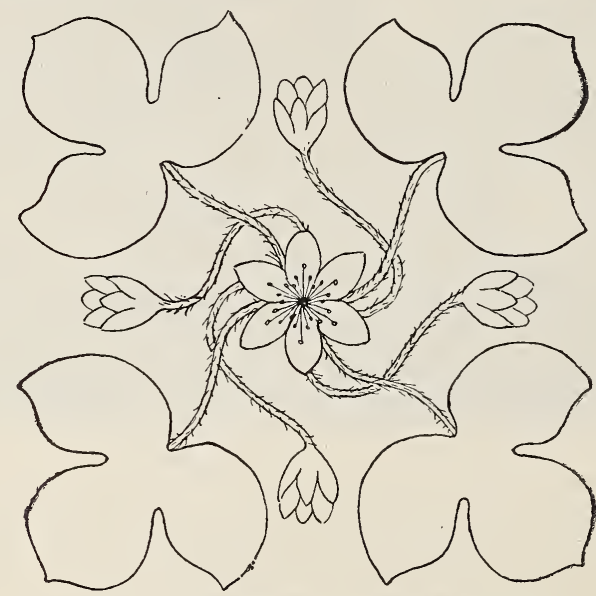

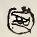

Embroidery design from the hepatica.

The Child's Own Book of Wild Flowers, drawn by Evelyn Mitchell.

\section{LESSON CXVII}

\section{The Hepatica}

Leading thought-The hepatica flower buds are developed in the fall, so as to be ready to blossom early in the spring. This plant lives only in moist and shady woods.

Method-The pupils should have the questions before they go into the woods to gather spring flowers, and should answer them individually. However, the hepatica plant may be potted early in the spring, and the flowers may be watched during their development, and studied in the schoolroom.

Observations-I. Where do you find the hepaticas? Do you ever find them in the open fields? Do you ever find them in the pine woods?

2. How do the leaves look in early spring? Sketch in color one of these old leaves. How do the young leaves look? Are the leaves that come up late in the spring as fuzzy as those that appear early? What is the difference in texture and color between the leaves that were perfected in the fall and those that appear in the spring?

3. Find a hepatica plant before it begins to blossom. Look, if possible, at its very center. Describe these little flower buds. When were they formed? 
4. How does the bud look when it begins to lift up? Describe the stems and the three little blankets that hold the bud. Ask your teacher how these fuzzy blankets keep the bud from being killed by cold.

5. Are the hepaticas in your woods all pink, or blue, or white? Do those which are at first pink or blue fade to white later? Do the blossoms keep open during the night and stormy weather? Why not? Are they all fragrant?

6. How many petals has your hepatica? Can you see that the outer ones are sepals, although they look just like the petals? Peel back the three sepal-like bracts and see that they are not a part of the flower at all but join the stem below the flower.

7. Describe the stamens in the hepatica. How many pistils are there? Does each pistil develop into a seed? How do the three bracts protect the seeds as they ripen?

8. What insects do you find visiting the hepaticas?

9. Describe a hepatica plant in the woods; mark it so that you will know it, and visit it occasionally during the summer and autumn, noting what happens to it.

\section{THE YELLOW ADDER'S TONGUE}

\section{Teacher's Story}

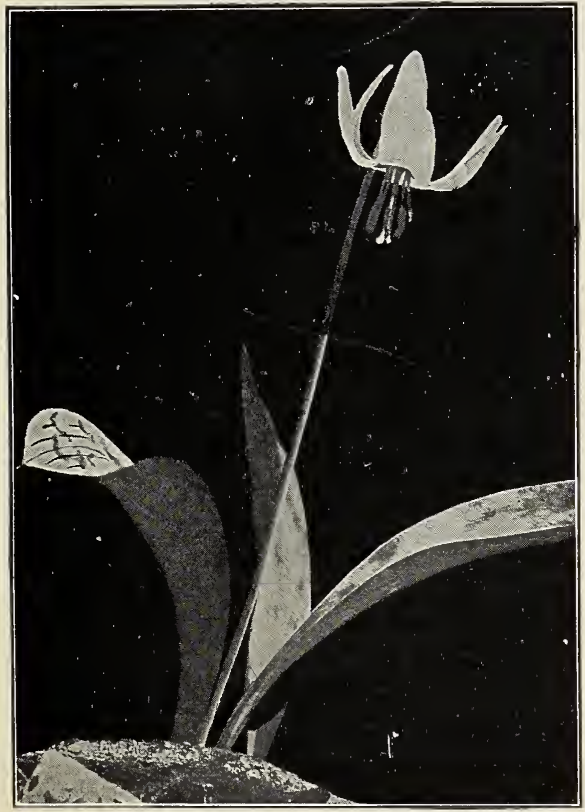

Adder's tongue.

"Once a prize was offered to a child if she would find two leaves of the adder's tongue that were marked exactly alike: and she sought long and faithfully, but the only prize she won was a lesson in Nature's book of variations, where no two leaves of any plant, shrub or tree are exactly alike: for even if they seemed so to our eyes, yet there would exist in them differences of strength and growth too subtle for us to detect. But this child was slow in learning this great fact, and, until she was a woman, the adder's tongue leaves, so beautifully embroidered with purple and green, were to her a miracle, revealing the infinite diversity of Nature's patterns." "The Child's OWN Book of Wild Flowers."

This little lily of the woods is a fascinating plant. Its leaves of pale green mottled with brownish purple often cover closely large irregular areas in the rich 
soil of our woodlands; and yet I doubt if the underground story of these forest rugs is often thought of. The leaves are twins, and to the one who plucks them carelessly they seem to come from one slender stem. It requires muscle as well as decision of character to follow this weak stem down several inches, by digging around it, until we find the corm at its base. A corm is the swollen base of a stem and is bulb-like in form; but it is not made up of layers, as is a bulb. It is a storehouse for food and also a means of spreading the species; for from the corms there grow little corms called cormels, and each cormel develops a separate plant. This underground method of reproduction is the secret of why the leaves of the adder's tongue appear in patches, closely crowded together.

Only a few of the plants in a "patch" produce flowers, and it is interesting to see how cleverly these lily bells hide from the casual eye. Like many of the lilies, the three sepals are petal-like and are identified as sepals

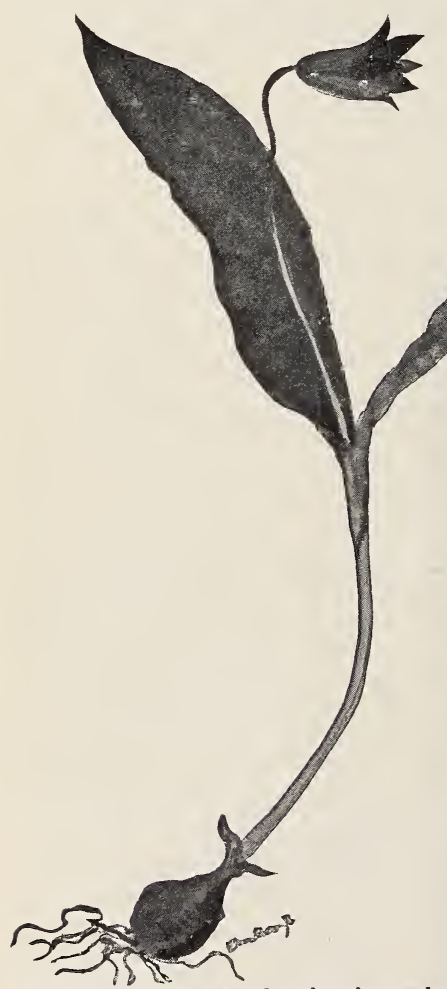

The adder's tongue, showing its underground storehouse.

Drawn by F. Dana Gibson. a pupil in seventh grade. only by their outside position, although they are thicker in texture. They are purplish brown outside, which serves to render the flower inconspicuous as we look down upon it; on the inner side, they are a pure yellow, spotted with darker yellow near where they join the stem. The three petals are pure yellow, paler outside than in, and they have dark spots like the tiger

lilies near the heart of the flower; and where they join the stem, each has on each side an ear-shaped lobe.

The open flower is bell-shaped; and like other bells it has a clapper, or tongue. This is formed by six downward-hanging stamens, the yellow filaments of which have broad bases and taper to points where the oblong anthers join them. The anthers are red or yellow. It is this stamen clapper that the visiting insects must cling to when probing upward for nectar from this flower at the upper end of the bell. The pale green pistil is somewhat three-sided, and the long style remains attached long after the flower disappears. The flower is slightly fragrant, and it is visited by the queen bumblebees and the solitary bees, of which there are many species. The flower closes nights and during cloudy, stormy days. The seed capsule is plump and rather triangular, 


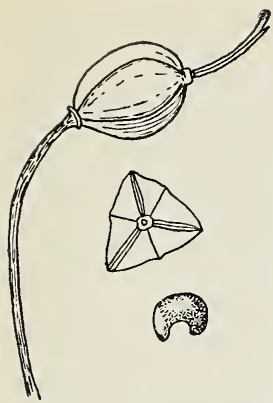

and splits into three sections when ripe. The seeds are numerous and are fleshy and crescentshaped.

But the adder's tongue, like many other early blooming flowers, is a child of the spring. The leaves, at first so prettily mottled, fade out to plain green; and by midsummer they have entirely disappeared, the place where they were, being covered with other foliage of far different pattern. But down in the rich woods soil are the plump globular corms filled with the food gathered by the spotted leaves during their brief stay, and next spring two pairs of spotted leaves may appear where there was Fruit capsule and seed. but one pair this year.

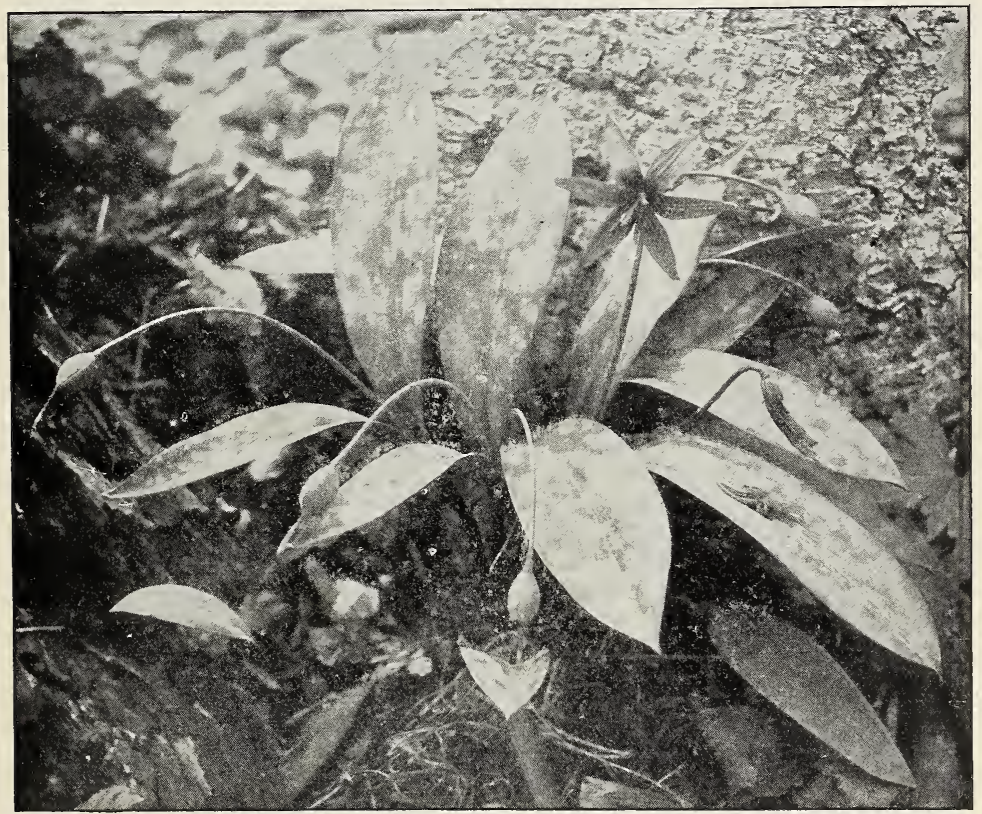

The adder's tongue going to seed

Photo by Verne Morton.

\section{LESSON CXVIII}

Adder's Tongue, or Dog-tooth Violet

Leading thought-The adder's tongue is a lily, and its mottled leaves appear early in the spring, each pair coming from a corm deep in the soil below. It has two ways of spreading, one underground by means of new corms growing from the larger ones, and the other by means of seeds, 
many of which are probably perfected through the pollen sarried by insects.

Method-This plant should be studied in the woods, notes being made on it there. But a plant showing corm, roots, leaves and blossom should be brought to the schoolhouse for detailed study, and then planted in a shady place in the school garden.

Observations- $\mathrm{r}$. Where does the adder's tongue grow? Do you ever find it in open fields? How early do you find its leaves above ground? At what time does its blossoms appear?

2. How many leaves has each plant? What colors do you find in them? What is the color of their petioles? Do the leaves remain mottled later in the season?

3. Do the adder's tongue plants occur singly or in patches? Dig out a plant and see if you can find why the plants grow so many together?

4. How far below the surface of the ground did you find the corm or bulb-like growth? Is this the root of the plant? How does it differ from the roots? How does it differ from a bulb? Of what use is it to the plant?

5. Is the flower lifted up, or is it drooping? What is its general shape? How many sepals? How would you know they were sepals? How do they differ in color, outside and in, from the petals? How are the petals marked? Can you see the lobes at the base of each petal? When sepals and petals are so much alike the botanists call them all together the perianth.

6. If the perianth, or the sepals and petals together, make a bellshaped flower, what makes the clapper to the bell? How do the insects use this clapper when they visit the flower? Do the flowers stay open nights and dark days? Why?

7. How many stamens are there? Describe or sketch one, noting its peculiar shape. Are the stamens all the same length? Can you see the pistil and its stigma? Where is it situated in relation to the stamens? Do you think the stigma is ready for pollen at the time the anthers are shedding it?

8. After the petals and sepals fall what remains? How does the ripe seed-capsule look? How does it open to let out the seeds? Are there many seeds in a capsule? What is their shape?

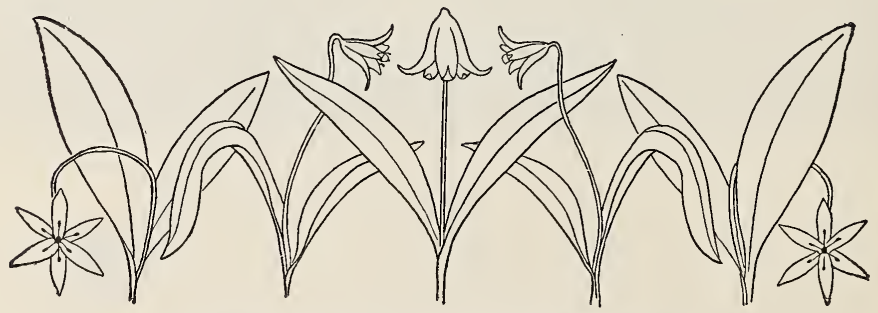

Design for embroidery from adder's tongue.

Drawn by Evelyn Mitchell for Child's Own Book of Wild Flowers. 


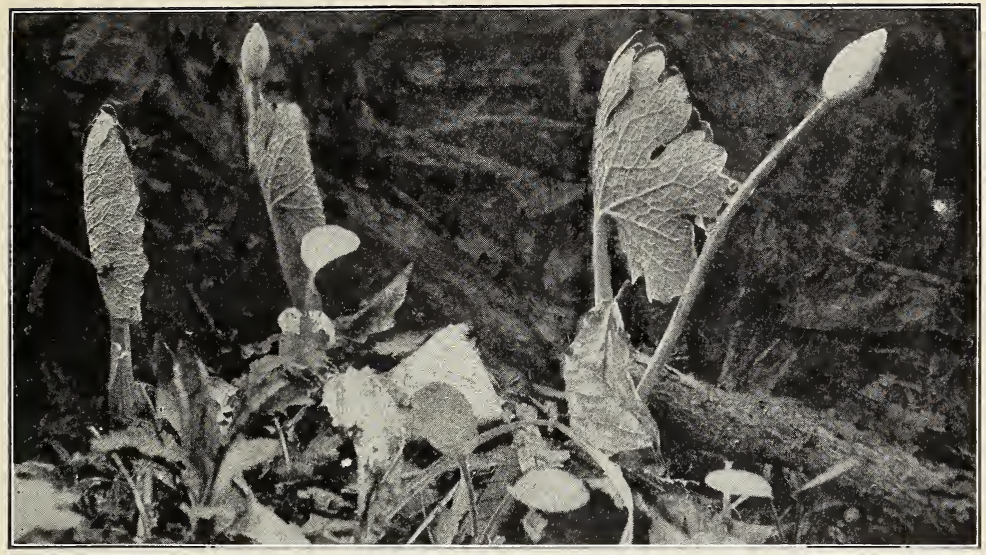

"Bloodroots, whose rolled-up leaves ef you oncurl

Each on em's cradle to a baby pearl."-Lowell. Photo by O. L. Foster.

\section{BLOODROOT}

\section{Teacher's Story}

"What time the earliest ferns unfold, And meadow cowslips count their gold; A countless multitude they stood, A Milky Way within the wood."

-Danske Dandridge.

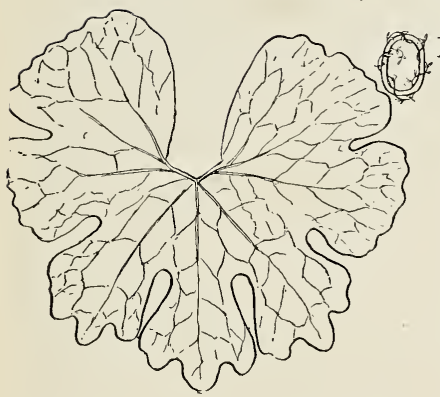

NLY a few generations ago, and this land of ours was peopled by those who found it fitting to paint their bodies to represent their mental or spiritual conditions or intentions. For this purpose they had studied the plants of our forests to learn the secrets of the dyes which they yielded, and a dye that would remain on the flesh permanently, or until it wore off, was highly prized. Such a dye was found in the bloodroot, a dye appropriate in its color to represent a thirst for blood; and with it they made their war paint, and with it they ornamented their tomahawks to symbolize their sanguinary purpose.

The Indian warriors have passed away from our forests, and the forests themselves are passing away, but the bloodroot still lingers, growing abundantly in rich moist woods or in shaded areas in glades, borders of meadows and fence corners. Its beautiful white flowers open to the morning sun in early April, calling the hungry bees to come for pollen; for, like many other early flowers, it offers no nectar. Probably many of the Jittle wild bees prefer pollen to nectar at this time of year, for it is an 
important element in the food of all kinds of bee brood. But the blood. root's fragile blossoms are elusive and do not remain long; like their relatives, the poppies, their petals soon fall, and their white masses disappear like the snow-drifts which so recently occupied the same nooks.

The way the bloodroot leaf enfolds the flower-bud seems like such an obvious plan for protection, that we are unthinkingly prone to attribute consciousness to the little plants.

Not only does the leaf enfold the bud, but it continues to enfold the flower stem after the blossom opens. There are two sepals which enclose the bud, but fall off as the flower opens. There are ordinarily eight white petals, although there may be twelve; usually every other one of the eight petals is longer than its neighbors, and this makes the blossom rather square than circular in outline. There are many stamens, often 24 , and the anthers are brilliant yellow with whitish filaments. The twolobed stigma opens to receive pollen before the pollen of its own flower is ripe. The stigma is large, yellow, and set directly on the ovary, and is quite noticeable in the freshly opened blossoms. It is likely to shrivel before its home-grown pollen is ripe. The blossoms open wide or sunny mornings; the petals rise up in the afternoon and close at night, and also remain closed during dark, stormy days until they are quite sld, when they remain carelessly open; they are now ready to fall to the ground at the slightest jar, leaving the oblong, green seed-pod set on the stem at a neat bevel, and perhaps still crowned with the yellowish stigma. The seed-pod is oblong and pointed and remains below the protecting leaf. There are many yellowish or brownish seeds.

When the plant appears above ground, the leaf is wrapped in a cylinder about the bud, and it is a very pretty leaf, especially the "wrong side," which forms the outside of the roll; it is pale green with a network of pinkish veins, and its edges are attractively lobed; the petiole is fleshy, stout and reddish amber in color. The flower stem is likewise fleshy and is tinged with raw sienna; the stems of both leaf and flower stand side by side, and are held together at the base by two scapes with parallel veins. Later in the season, the leaf having done its full duty as a nurse waxes opulent, often measuring six inches across and having a petiole ten inches long. It is then one of the most beautiful leaves in the forest carpet, its circular form and deeply lobed edges rendering it a fit subject for decora. tive design.

The rootstock is large and fleshy, and in it is stored the food which enables the flower to blossom early, before any food has been made by the new leaves. There are many stout and rather short roots that fringe the rootstock. Once in clearing a path through a woodland, we happened to hack off a mass of these rootstocks, and we stood aghast at the gory results. We had admired the bloodroot flowers in this place in the spring, and we felt as guilty as if we had inadvertently hacked into a friend.

\section{LESSON CXIX}

\section{BLOODROOT}

Leading thought-The bloodroot has a fleshy rootstock, in which is stored tood for the nourishment of the blossom in early spring. The flower bud is at first protected by the folded leaf. The juice of the rootstock is a vivid light crimson, and was used by Indians as a war paint. 
The juice is acrid, and the bloodroot is not relished as food by grazing animals, but it is used by us as a medicine.

Method-The bloodroot may, in the fall, be transplanted in a pot of woods earth, care being taken not to disturb its roots. It should be placed out of doors in a protected place where it may have natural conditions, and be brought to the schoolroom for study in March, so that the whole act of the unfolding of leaves and flowers may be observed by the pupils. Otherwise the questions must be given the pupils to answer as they find the plants blossoming in the woods in April. The blossoms are too fragile to be successfully transported for study at home or school.

Observations-I. At what time of year does bloodroot blossom? In what situations does it thrive?

2. What do we see first when the bloodroot puts its head above the soil? Where is the flower bud? How is it protected by the leaf? How does the leaf hold the flower stem after the flower is in blossom?

3. Study the flower. How many sepals has it? What is their color? What is the position of the sepals when the flower is in bud? What is their position when the flower opens? How many petals? What is their color and texture? Describe the position of the petals in the bud and in the open flower. Look straight into the flower; is its shape circular or square?

4. Do the flowers close nights and during dark days? Do the flowers longest open do this? Describe how the petals and sepals fall.

5. Describe the stamens. What is the color of the anthers? Of the pollen? Describe the pistil. Does the two-grooved stigma open before

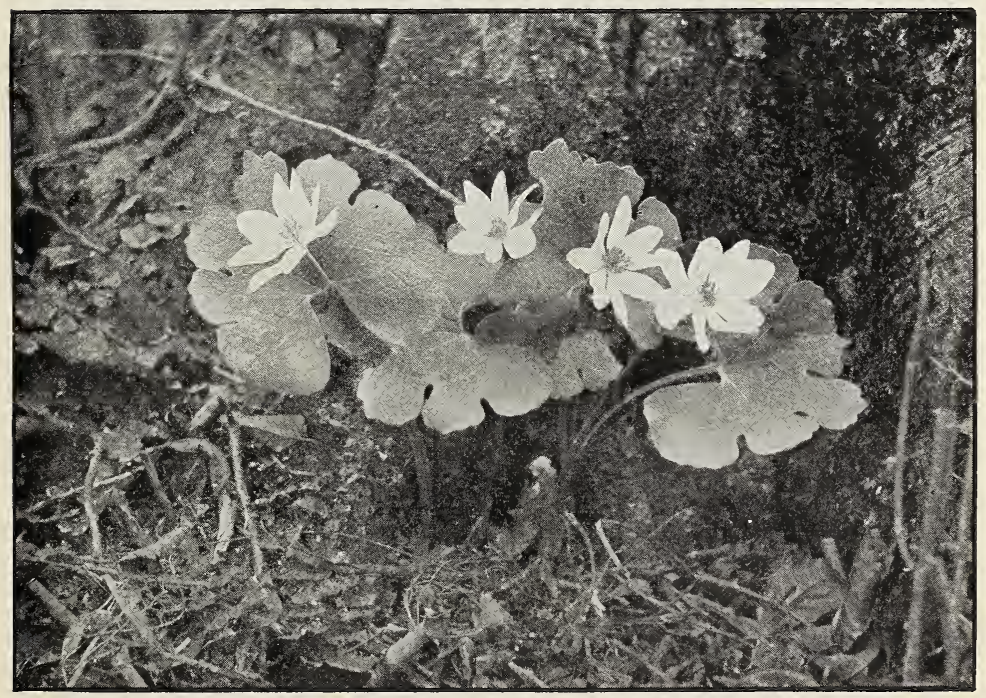

Bloodroot.

Photographed by Verne Morton. 
the pollen is shed, or after? What insects do you find visiting the bloodroot?

6. Sketch or describe a bloodroot leaf as it is wrapped around the stem of the flower. How are both flower stem and leaf petiole protected at the base? Describe or sketch a leaf after it is unfolded and open. Describe the difference between the upper and lower surfaces of the leaf. What sort of petiole has it? Break the petiole; what sort of juice comes from it? Describe and measure the leaf later in the season; do they all have the same number of lobes?

7. Break a bit off the root of the plant and note the color of the juice.

8. Compare the bloodroot with the poppies; do you find any resemblance in habits?

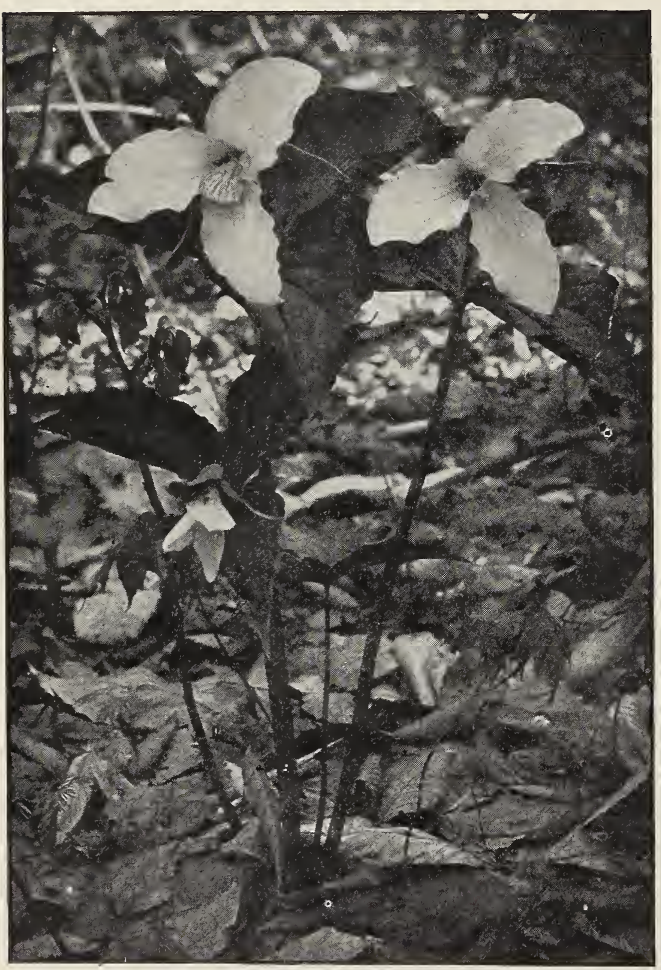

The white trillium. A white butterfly visiting the flower at the left.

Photo by Verne Morton.

\section{THE TRILLIUM}

\section{Teacher's Story}

It would be well for the designer of tapestries to study the carpets of our forests for his patterns, for he would find there a new carpet every month, quite different in plan and design from the one spread there, earlier or later. One of the most. beautifuldesigns from Nature's looms is a trillium carpet, which is at its best when the white trilliums are in blossom. It is a fine study of the artistic possibilities of the triangle when reduced to terms of leaves, petals and sepals.

The trillium season is a long one; it begins in April with the purple wake-robin or birthroot, the species with purple, red, or sometimes yellowish flowers. The season ends in June with the last of the great white

trilliums, which flush pink instead of fading, when old age comes upon them. 
The color of the trillium flower depends upon the species studied; there are three petals, and the white and painted trilliums have the edges of the petals ruffled; the red and nodding trilliums have petals and sepals nearly the same size, but in the white trillium the sepals are narrower and shorter than the petals. The sepals are alternate the petals, so that when we look straight into the flower we see it as a six-pointed star, three of the points being green sepals. The pistil of the trillium is six-lobed. It is dark red in the purple trillium and very large; in the white species, it is pale green and smaller; it opens at the top with three flaring stigmas. There are six stamens with long anthers, and they stand between the lobes of the pistil. The flower stalk rises from the center where three large leaves join. The flower stalk has a tendency to bend a little, and is rather delicate. The three leaves have an interesting venation, and make a good subject for careful drawing. The flower stem varies with different species, and so does the length of the stem of the plant, the latter being fleshy and green toward the top and reddish

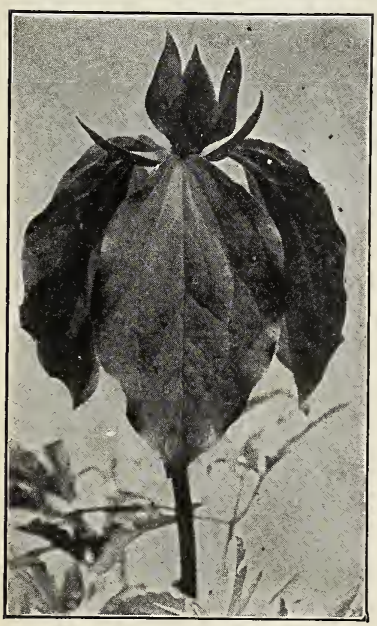

The stemless trillium toward the root. The trilliums have a thick, fleshy, and much scarred rootstock from which extend rootlets which are often corrugated. The trilliums are perennial, and grow mostly in damp, rich woods. The painted trillium is found in cold, damp woods along the banks of brooks; the white trillium is likely to be found in large numbers in the same locality, while the purple trillium is found only here and there. Flies and beetles carry the pollen for the red trillium, being attracted to it by its rank odor, which is very disagreeable to us but very agreeable to them. The large white trillium is visited by bees and butterflies. The fruit of the trillium is a berry, that of the purple species is somewhat six-lobed and reddish. In late July the fruit of the white trillium is a cone with six sharp wings, or ridges, from apex to base, the latter being three-quarters of an inch across. These vertical ridges are not evenly spaced, and beneath them are packed as closely as possible the yellow-green seeds, which are as large as homeopathic pills. In cross section, it can be seen that the trillium berry is star-shaped with three compartments, the seeds growing on the partitions. This trillium fruit is very rough outside, but smooth inside, and the dried stamens often still cling to it.

The trilliums are so called from the word triplum, meaning three, as there are three leaves, three petals, and three sepals.

\section{LESSON CXX}

\section{The Trillium}

Leading thought-The trilliums are lilies, and are often called wood lilies, because of their favorite haunts. There are several species, but 


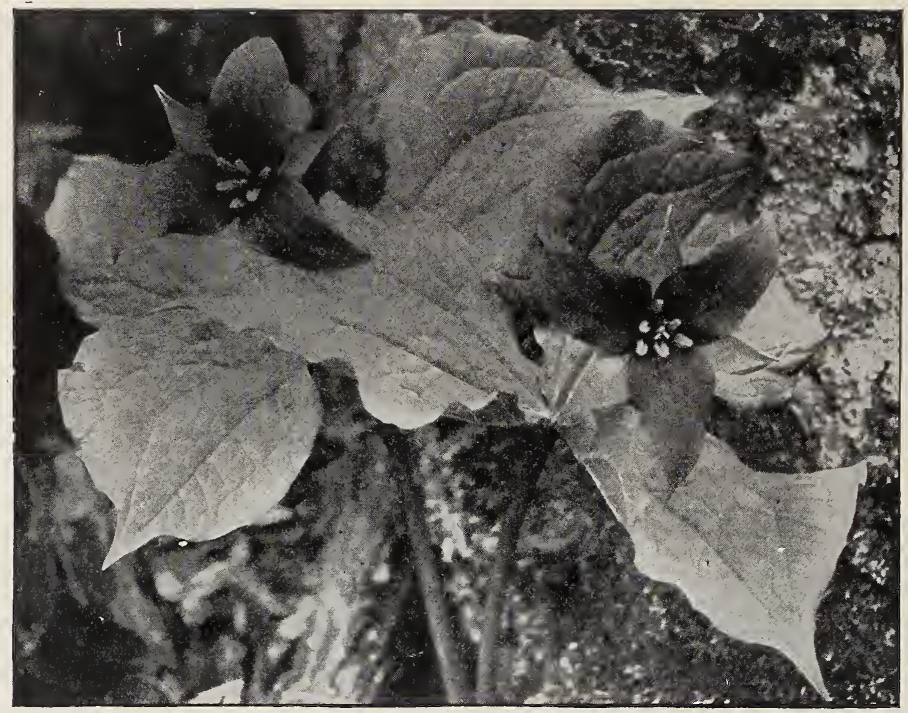

The purple trillium.

Photo by Verne Morton.

they are all alike in that they have three sepals, three petals and three leaves.

Method-This lesson may be given from trilliums brought to the schoolroom by the pupils, who should be encouraged to watch the development of the berry and also to learn all the different species common to a locality.

Observations-I. How many leaves has the trillium? How are they arranged? Draw a leaf showing its shape and veins. Describe the stem of the plant below the leaves, giving the length and color.

2. How far above the leaves does the flower stem or pedicel extend? Does the flower stand upright or droop? Describe or sketch the colors, shape and arrangement of the petals and sepals. Do the petals have ruffled margins?

3. Describe the pistil and the stigmas. Describe the stamens and how they are placed in relation to the pistil.

4. Do the flowers remain open during cloudy days and nights?

5. What insects do you find visiting the trilliums? Do the same insects visit the purple and the white trilliums? What is the difference in odor between the purple and the white trillium? Would this bring different kinds of insects to each?

6. How does the color of the white trillium change as the blossom matures? What is the color and shape of the fruit of each different species of trillium? When is the fruit ripe?

7. What kind of a root have the wake-robins? Do they grow from seed each year, or are they perennial? Where do you find them growing? 


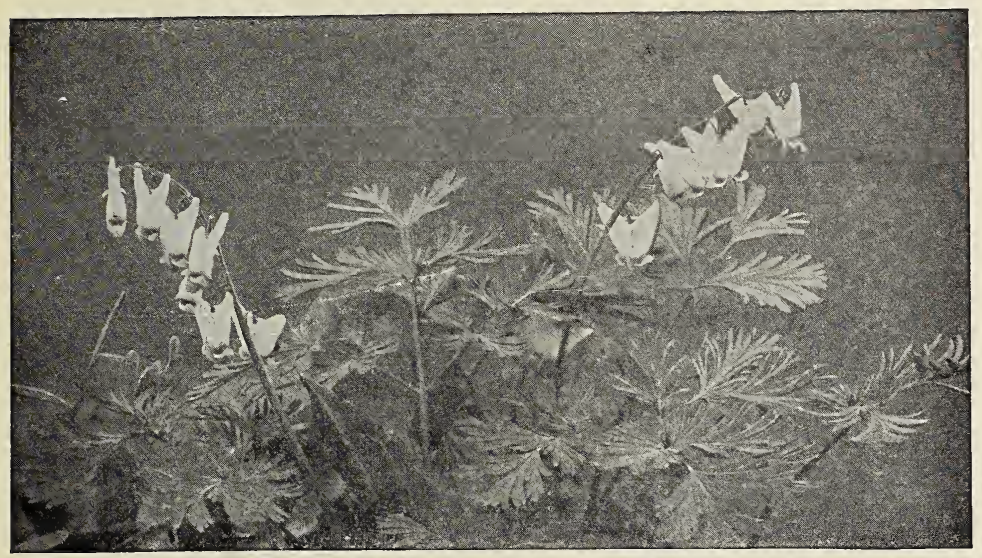

Dutchman's breeches, or "boys and girls." Photo by O. L. Foster.

\title{
DUTCHMAN'S BREECHES AND SQUIRREL CORN \\ Teacher's Story
}

\begin{abstract}
"In a gymnasium where things grow, Jolly boys and girls in a row, Hanging down from cross-bar stem Builded purposely for them.

Stout little legs up in the air, Kick at the breeze as it passes there; Dizzy heads in collars wide. Look at the world from the underside; Happy acrobats a-swing, Ai the woodside show in early spring."

A. B. C.

"And toward the sun, which kindlier burns, The earth awaking, looks and yearns, And still, as in all other A prils, The annual mirccle returns."
\end{abstract}

\section{Elizabeth AKers.}

There are many beautiful carpets spread before the feet of advancing spring, but perhaps none of them are so delicate in pattern as those woven by these two plants that spread their fernlike leaves in April and May. There is little difference in the foliage of the two; both are delicate green and lacelike above, and pale, bluish green on the underside. And each leaf, although so finely divided, is, after all, quite simple; for it has three chief divisions, and these in turn are divided into three, and all the leaves 
come directly from the root and not from stems. These plants love the woodlands, and by spreading their green leaves early, before the trees are in foliage, they have the advantage of the spring sunshine. Thus they make their food for maturing their seeds, and also store some of it in their roots for use early the following spring. By midsummer the leaves have entirely disappeared, and another carpet is spread in the place which they once covered.

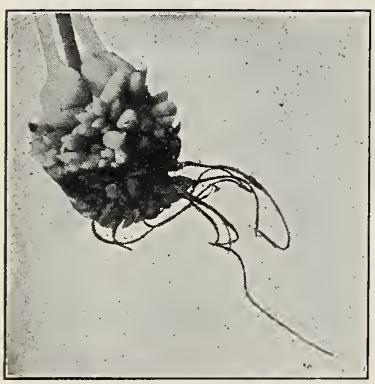

The underground store-house of Dutchman's breeches.

Dutchman's breeches and squirrel corn resemble each other so closely that they are often confused; however, they are quite different in form; the "legs" of the Dutchman's breeches are quite long and spread wide apart, while the blossoms of the squirrel corn are rounded bags instead of "legs." The roots of the two are quite different. The Dutchman's breeches grows from a little bulb made up of grayish scales, while the squirrel corn develops from a round, yellow tuber; these yellow, kernel-like tubers are scattered along the roots, each capable of developing a plant next year. The Dutchman's breeches likes thin woodlands and rocky hillsides, but the squirrel corn prefers rich, moist woods. The blossom of the Dutchman's breeches comes the earlier of the two. These flowers are white with yellow tips, and are not fragrant. The flowers of the squirrel corn are grayish with a tinge of magenta, and are fragrant.

The legs of the Dutchman's breeches are nectar pockets with tubes leading to them, and are formed by two petals. Opposite these two petals are two others more or less spoon-shaped, with the spoon bowls united to protect the anthers and stigma. There are two little sepals which are scalelike.

The seed capsule of the Dutchman's breeches is a long pod with a slender, pointed end, and it opens lengthwise. The seed capsules of the squirrel corn are similar and I have found in one capsule, I 2 seeds, which were shaped like little kernels of corn, black in color and polished like patent leather.

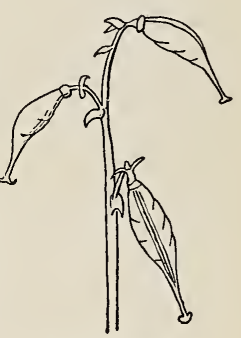

Seed capsule of squirel corn.

\section{LESSON CXXI}

\section{Dutchman's Breeches and Souirrel Corn}

Leading thought-The Dutchman's breeches, or "boys and girls," as it is often called, is one of the earliest flowers of rich woodlands. There are interesting differences between this flower and its close relative, squirrel corn. The flowers of both of these resemble in structure the flowers of the bleeding heart.

Method-As the Dutchman's breeches blossoms in April and May and the squirrel corn in May and June, we naturally study the former first and compare the latter with it in form and in habits. The questions 


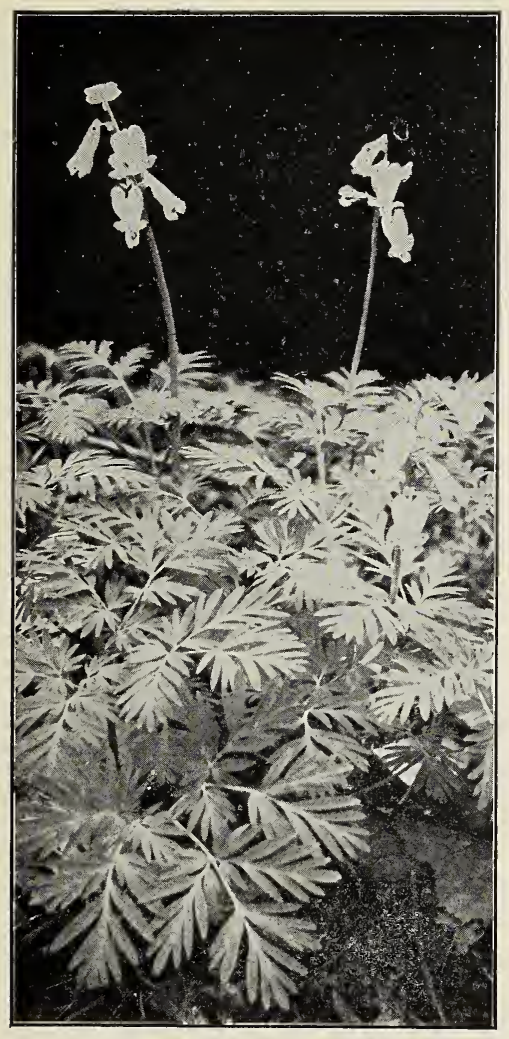

Squirrel corn.

should be given the pupils, for them to answer for themselves during their spring walks in the woodlands.

Observations-I. Where do you find Dutchman's breeches? Which do you prefer to call these flowers, Dutchman's breeches or boys and girls? Are there leaves on the trees when these flowers are in bloom?

2. Which blossoms earlier in the season, Dutchman's breeches or squirrel corn? How do the flowers of the two differ in shape? In odor?

3. In the flower of the Dutchman's breeches find two petals which protect the nectar. How do they look? What part do they form of the breeches? Find two other petals which protect the pollen and stigma.

4. Find the two sepals. How many bracts do you find on the flower stem?

5. What insects visit these flowers? Describe how they get the nectar.

6. What sort of root has the Dutchman's breeches? What is the difference between its root and that of the squirrel corn? Have you ever seen squirrels harvesting squirrel corn? What is the purpose of the kernels of the squirrel corn?

7. Study the leaf. How many main parts are there to it? How are these parts divided? Does the leaf come straight from the root or from a stem? What is the color of the leaf above? Below? Can you distinguish the leaves of the Dutchman's breeches from those of the squirrel corn?

8. Describe the seed capsule of Dutchman's breeches. How does it open? How many seeds has it? Compare this with the fruit of squirrel corn and describe the difference.

9. What happens to the leaves of these two plants late in summer. How do the plants manage to get enough sunlight to make food to mature their seed? What preparations have they made for early blossoming the next spring? 


\section{JACK-IN-THE-PULPIT Teacher's Story}

"Wi:h hooded heads and shields of green, Monks of the wooded glen,

I know you well; you are, I ween, Robiin Hood's merry men."

- "Child's Own Book of Flowers."

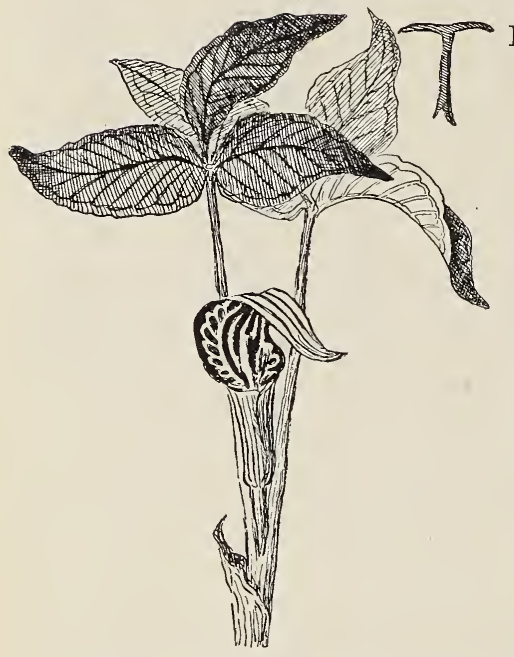

HIS little preacher is a prime favorite with all children, its very shape, like that of the pitcher plant, suggesting mystery; and what child could fail to lift the striped hood to discover what might be hidden beneath! And the interest is enhanced when it is discovered that the hood is but a protection for the true flowers, standing upon a clubshaped stem, which has been made through imagination into "Jack," the little preacher.

Jack-in-the-pulpit prefers wet locations but is sometimes found on dry, wooded hillsides; the greater abundance of blossoms occurs in late May. This plant has another name, which it earned by being interesting below ground as well as above. It has a solid, flattened, food-storehouse called a corm with a fringe of coarse rootıets encircling its upper portion. This corm was used as a food by the Indians, which fact gave the plant the name of Indian turnip. I think all children test the corm as a food for curiosity, and retire from the field with a new respect for the stoicism of the Indian when enduring torture; but this is an undeserved tribute. When raw, these corms are peppery because they are filled with minute, needle-like spicules which, however, soften with boiling, and the Indians boiled them before eating them.

Jack-in-the-pulpit is a near cousin to the calla lily; the white part of the calla and the striped hood over "Jack" are both spathes, and a spathe is a leaf modified for the protection of a flower or flowers. "Jack" has but one leg and his flowers are set around it, all safely enfolded in the lower part of the spathe. The pistillate flowers which make the berries are round and greenish, and are packed like berries on the stalk; they have purple stigmas with whitish centers. The pollen-bearing flowers are mere little projections, almost white in color, each usually bearing four purplish, cup-like anthers filled with white pollen. Occasionally both kinds of flowers may be found on one spadix, (as "Jack" is called in the botanies), the pollen-bearing flowers being set above the others; but usually they are on separate plants. Professor Atkinson has demon- 

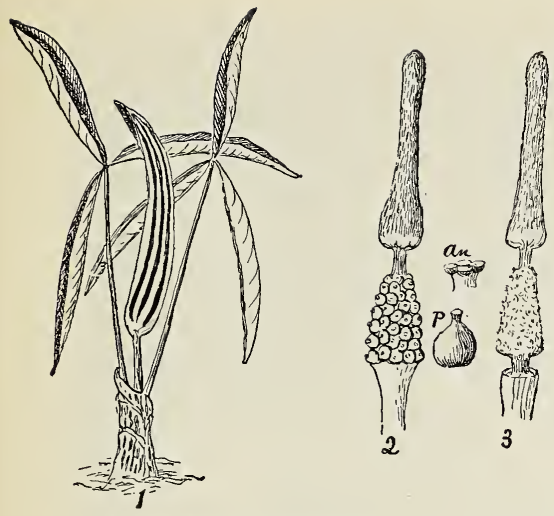

I. Jack-in-the-pulpit unfolding; 2. Spadix with pistillate flowers; $P$, pistillate flower enlarged; 3. Spadix with staminate flowers; an, a staminate flower enlarged, showing the four anthers.

strated that when a plant becomes very strong and thrifty, its spadix will be set with the pistillate flowers and its berries will be many; but if the same plant becomes weak, it produces the pollen-bearing flowers the next year.

When "Jack" first appears in the spring it looks like a mottled, pointed Feg, for it is well sheathed. Within this sheath the leaves are rolled lengthwise to a point, and at the very center of the rolled leaves is a spathe, also rolled lengthwise, and holding at its heart the developing flower-buds. It is a most interesting process to watch the unfolding of one of these plants. On the older plants there are two, or sometimes three leaves, each with three large leaflets; on the younger plants there may be but; one of these compound leaves, but the leaflets are so large that they seem like three entire leaves.

The spathes, or pulpits, vary in color, some being maroon and white or greenish, and some greenish and white. They are very pretty objects' for water-color drawings.

Small flies and some beetles seem to be the pollen carriers for this plant. Various ingenious theories have been suggested to prove that our Jack-in-thepulpit acts as a trap to imprison visiting insects, as does the English species; but I have studied the flowers in every stage, and have seen the insects crawl out of the hoods as easily as they crawled in, and by the same open, though somewhat narrow, passage between the spadix and the spathe.

After a time the spathe falls away showing the globular, green, shining berries. In August even the leaves may wither away, at which time the berries are brilliant scarlet. Jack-in-the-pulpit is a perennial. It does not blossom the first year after it is a seedling. I have known at least one case where blossoms were not

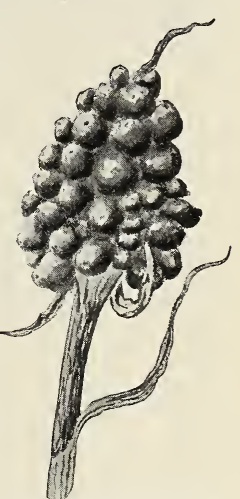

The berries of Jack. in-the-pulpit. produced until the third year. Below ground, the main corm gives off smaller corms and thus the plant spreads by this means as well as bv seeds. 


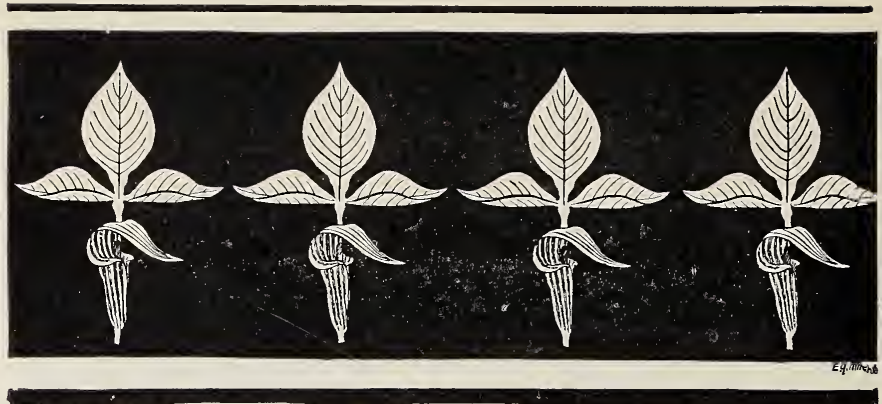

Border design by Evelyn Mitchell.

From the Child's Own Book of Wild Flowers.

\section{LESSON CXXII \\ JACK-IN-THE-PULPIT}

Leading thought-The real flowers of Jack-in-the-pulpit are hidden by the striped spathe which is usually spoken of as the flower. This plant has a peppery root which the Indians used for food.

Method-The questions should be answered from observation in the woods; a single plant may be dug up and brought to school for study, and later planted in some shady spot in the school garden.

Observations - I. Where do you find Jack-in-the-pulpit? Is the soil dry or damp? Do you ever find it in the fields?

2. How early in the season does this plant blossom? How late?

3. How does the Jack-in-the-pulpit look when it first pushes out from the ground? How are its leaves rolled in its spring overcoat?

4. How does the pulpit, or spathe, look when the plant first unfolds? Is its tip bent over or is it straight?

5. Describe or sketch the leaves of Jack-in-the-pulpit. How do they rise above and protect the flower? How many leaflets has each leaf? Sketch the leaflets to show the venation. How do these stand above the flower? Can you find any of the plants with only one leaf?

6. Why is the spathe called a pulpit? What are the colors of the spathe? Are all the spathes of the same colors?

7. Open up the spathe and see the rows of blossoms around the base of the spadix, or if you call the spadix, "Jack," then the flowers clothe his one leg. Are all the blossoms alike? Describe, if you can, those flowers which will produce the seed and those which produce the pollen. Do you find the two on the same spadix or on different plants?

8. What insects do you find carrying the poilien for "Jack?" Do you know how its seeds look in June? How do they look in August? Do the leaves last as long as the seeds?

9. What sort of a root has "Jack?" How does it taste? Do you think the Inclians boiled it before they ate it? What other name has "Jack?" How does the plant multiply below the ground?

Io. Compare the Jack-in-the-pulpit with the calla lily.

I I. Write an English theme on "The Sermon that Jack Preached from His Pulpit." 


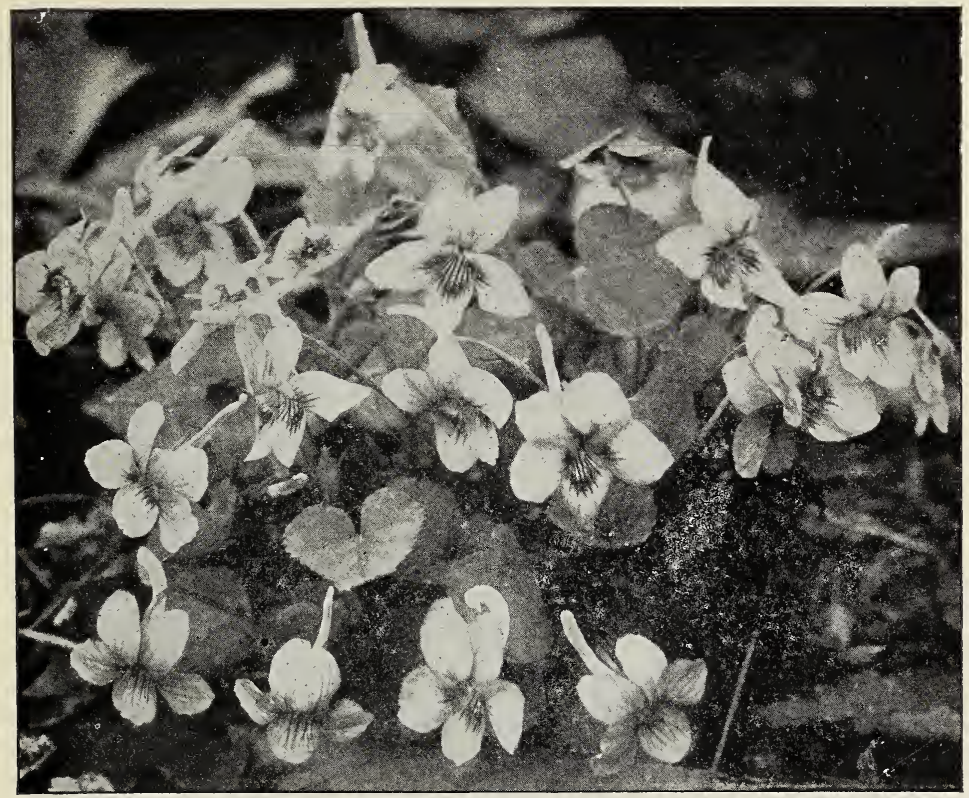

The Long-spurred violet. Color of flowers, pale lavender.

Photo by Verne Morton.

\section{THE VIOLET \\ Teacher's Story}

It is interesting to note the flowers which have impinged upon the imagination of the poets; the violet more than most flowers has been loved by them, and they have sung in varied strains of its fragrance and lowliness.

Browning says :

\footnotetext{
"Such a starved bank of moss, 'Till that May morn, Blue ran the flash across; Violets were born."
}

And Wordsworth sings:

"A violet by a mossy stone, Half hidden from the eye;

Fair as a star, when only one

Is shining in the sky."

And Barry Cornwall declares that the violet

"Stands first with most, but always wrth the lover:"

But Shakespeare's tribute is the most glowing of all, since the charms of both the goddesses of beauty and of love are made to pay tribute $t r$, it:

"Violets dim, but sweeter than the lids of Juno's eyes, or Cytherea's breath." 
However, the violets go on living their own lives, in their own way, quite unmindful of the poets. There are many different species, and they frequent quite different locations. Some live in the woods, others in meadows and others in damp, marshy ground. They are divided into two distinct groups-those where the leaf-stems come directly from the root, and those where the leaves come from a common stem, the latter being called the leafy-stemmed violets. Much attention should be given to sketching and studying the leaf accurately of the specimens under observation, for the differences in the shapes of the leaves, in many instances, determine the species; in some cases the size and shape of the stipules determines the species; and whether the leaves and stems are downy or smooth is another important characteristic. In the case of those species where the leaves spring from the root, the flower stems rise from the same situation; but in the leafy-stemmed violets the flower stems come off at the axils of the leaves. In some species the flower stems are long enough to lift the flowers far above the foliage, while in others they are so short that the flowers are hidden.

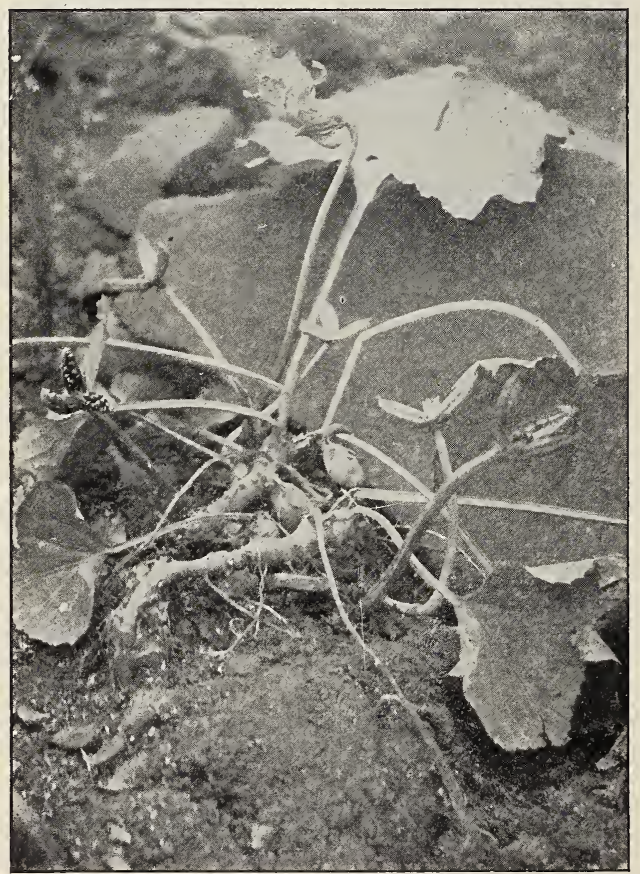

Common blue violet, showing two of the little flowers which never open, lying between the bare

rootstocks. Note the three-valved seed capsules.

Photo by Verne Morton.
The violet has five sepals and their shape and length is a distinguishing mark. There are five petals, one pair above, a pair one at each side, and a broad lower petal which gives the bees and butterflies a resting place when they cre seeking nectar. This lower petal is prolonged backward into a spur which holds the nectar.

The spur forms the nectary of the violet, and in order to reach the sweet treasure, which is at the rearmost point of the nectary, the insect must thrust its tongue through a little docr guarded by both anthers and pistil; the insect thus becomes laden with pollen, and carries it from flower to flower. In many of the species, the side petals have at their bases a little fringe which forms an arch over the door or throat leading to the nectary. While this is considered 
a guard to keep out undesirable insects like ants, I am convinced that it is also useful in brushing the pollen from the tongues of the insect visitors.

Some species of violets are

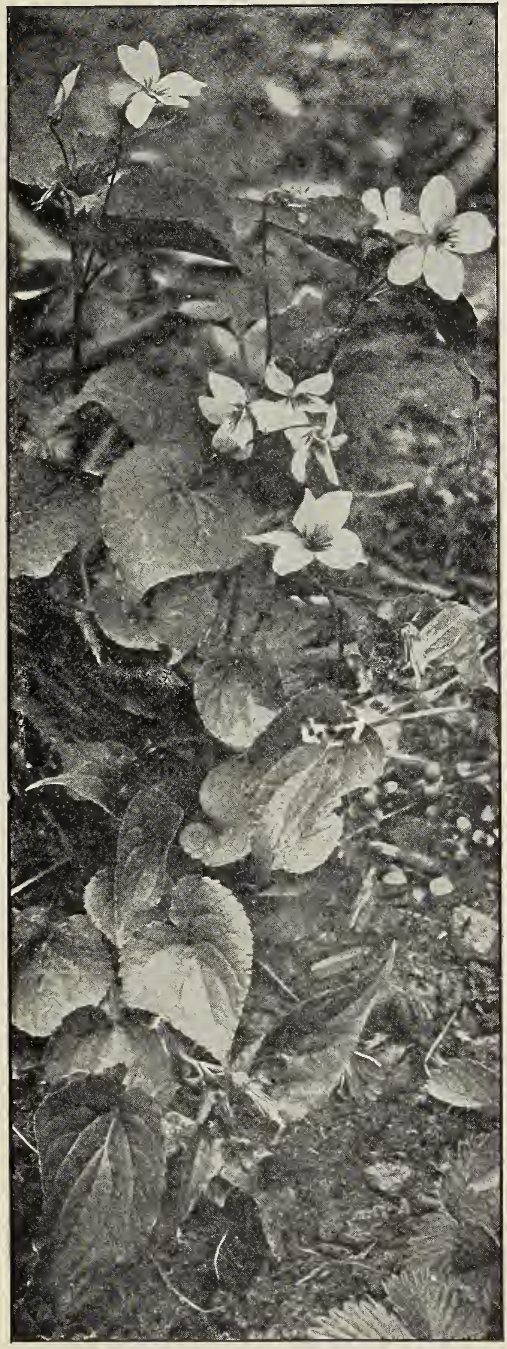

The Canada white violet, a leafy-stemmed species.

Photo by Verne Morton. very fragrant, while others have little odor. The color of the anthers also differs with different species. The children should be interested in watching the development of the seeds from the flower. The seed-pods are three-lobed, each one of these lobes dividing lengthwise, with a double row of seeds within. Each lobe curls back and thus scatters the seed.

At the base of most of the species of violets can be found the small flowers which never open; they have no petals, but within them the pollen and the pistil are fully developed. The flowers seem to be developed purposely for self-pollenation, and in the botanies they are called cleistogamous flowers; in some species they are on upright stems, in others they lie flat. There is much difference in the shape of the rootstock in the different species of violec; some are delicate and others are strong, and some are creeping.

\section{LESSON CXXIII}

\section{The Violet}

Leading thought-Each violet flower has a well of nectar, with lines pointing to it so that the insects may find it. They alsc have down near their roots, flowers which never open, which are self-pollenated and develop seeds.

Method-To make this work of the greatest use and interest, each pupil should make a portfolio of the violets of the locality. This may be in the form of pressed and mounted specimens, or of water-color drawings. In either case, the leaf, leaf-stem, 
flower, flower stem, and rootstock should be shown, and each blossom should be neatly labelled with name, locality and date. From the nature-study standpoint, a portfolio of drawings is the more desirable, since from making the drawings the pupils become more observant of the differences in structure and color which distinguish the species. Such a portfolio may be a most beautiful object; the cover of thick cardboard may have an original, conventionalized design made from the flowers and leaves of the violets. Each drawing may be followed by a page containing notes by the pupil and some appropriate quotation from botany, poetry or other literature.

Observations-r. Describe the locality and general nature of the soil where the violet was found. That is, was it in the woods, dry fields or near a stream?

2. Sketch or describe the shape of the leaf, paying particular attention to its margin and noting whether it is rolled toward the stem at its base. Is the petiole longer or shorter than the leaf? Does the leaf stem spring directly from the root, or does it branch from another? If the latter, are the leaves opposite or alternate? Is there a stipule where the leaf joins the main stem? If so, is it toothed on the edge?

3. What is the color of the leaf above? Are the leaves and stems downy and velvety, or smooth and glossy?

4. Does the flower stem come from the root of the plant, or does it grow from the main stem at the axil of the leaf? Are the flower stems long enough to lift the flowers above the foliage of the plant?

5. How many sepals has the violet? Are they long or short; pointed or rounded? How many petals has the violet? How are they arranged? Is the lower petal shaped like the others? What is the use of this broad lower petal? Are there any marks upon it? If you should follow one of these lines, where would it lead to?

6. Look at the spur at the back of the flower. Of which petal is it a part? How long is it, compared with the whole flower? What is the use of this spur?

7. Find the door that leads to the nectar-spur and note what the tongue of the bee or butterfly would brush against when reaching for the nectar. Are the side petals which form the arch over the door that leads to the nectar fringed at their bases? If so, what is the use of this fringe?

8. What colors are the petals? Are they the same on both sides? How are they marked and veined? Are the flowers fragrant?

9. What color are the anthers? What color is the stigma? Examine a fading violet, and describe how the seed is developed from the flower.

ro. Find the seed-pods of the violet. How are the seeds arranged within them? How do the pods open? How are the seeds scattered?

II. Look at the base of the violet and find the little flowers there which never open. Examine one of these flowers and find if it has sepals, petals, anthers and pistil. Are these closed flowers on upright stems or do the stems lie flat on the earth? Of what use to the plant are these little closed flowers?

I2. What sort of rootstock has the violet? Is it short and thick or slender? Is it erect, oblique or creeping? 


\section{THE MAY APPLE, OR MANDRAKE}

\section{Teacher's Story}

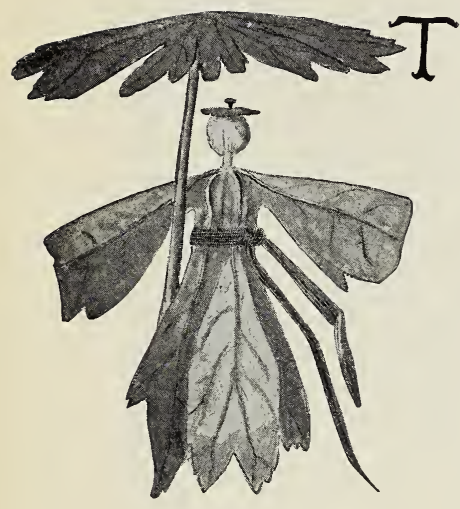

IIS is a study of parasols and, therefore, of perennial interest to the little girls who use the small ones for their dolls, and with inany airs and graces hold the large ones above their own heads. And when this diversion palls, they make mandarin dolls of these fascinating plants. This is easily done by taking one of the small plant umbrellas and tying with a grasssash all but two of the lobes closely around the stem, thus making a dress, the lobes left out being cut in proper shape for flowing sleeves; then for a head some other flower is robbed of its flower bud, which is put into place and surmounted with a clover leaflet hat, and a pin is then thrust through hat, head and neck into the stem of the dressed plant; the whole is properly finished by placing a small umbrella above the little green mandarin.

The mandrakes grow in open places where there is sun, and yet not too much of it; they like plenty of moisture, and grow luxuriantly in open glades or in meadows or pastures bordering woodlands, and they especially rejoice in the fence-corners, along roadsides. The first lesson of all should be how nature folds her little umbrellas. Study the plants when they first put their heads above ground, each parasol wrapped in its case, and note how similarly to a real umbrella it is folded around its stem. Later, after the umbrellas are fairly spread, they afford a most interesting study in varieties of form and size. Some of the parasols have only four lobes while others have many more. I have found them with as many as nine, although the botanies declare seven to be the normal number. One of the special joys afforded by nature-study is finding things different from the descriptions of them in the books.

One of these little parasols is a worthy object for careful observation. Its stem is stout and solid, and at its base may be seen the umbrella-case, now discarded like other umbrella-cases; the stem is pink wherever the sun touches it, but close up under the leaves it is likely to be green; it ends at the middle of the parasol by sending out strong, pale green, fuzzy ribs into each lobe. The lobes are narrow toward the stem but broad at the outer edge, each lobe being sparsely toothed on its outer margins and with a deep, smooth notch at the center. From the ribs of each lobe extend other ribs, an arrangement quite different from that we find in cloth umbrellas. The lobes of the mandrake parasol are divided almost to the center, and it is therefore evident that it is much better fitted for protection from the sun than from the rain. The parasol is a beautiful shining green on the upper side, and has a pale green lining that feels somewhat woolly.

In examining any patch of May apples, we find that many of the parasols are double; the secret of this is, that the mandrake baby needs 


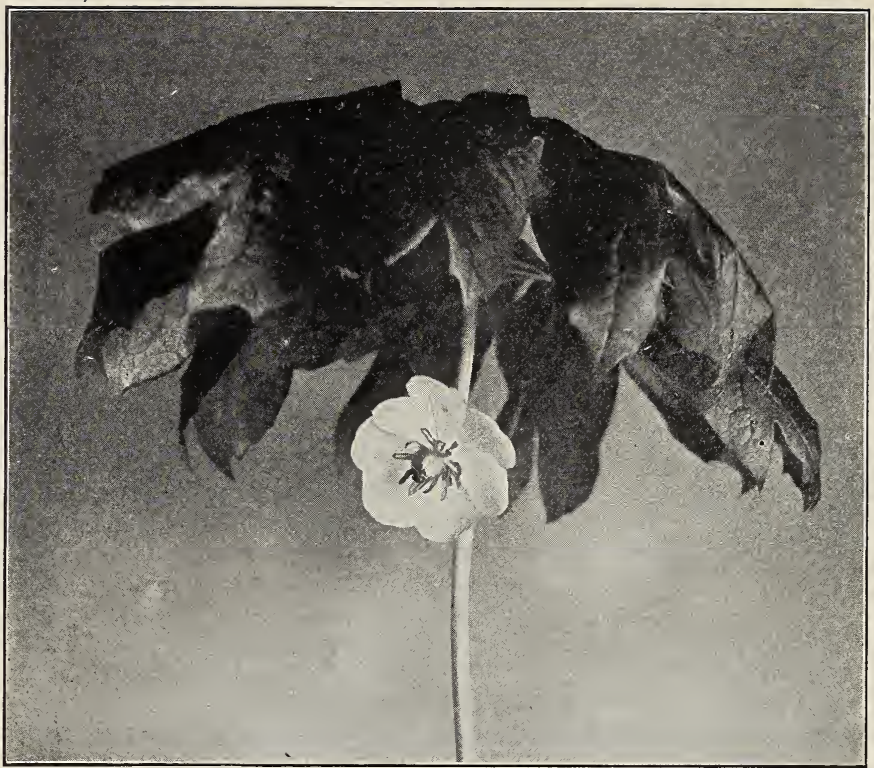

The blossom of the May apple.

two parasols to shield it from the sun; one of these twin parasols is always larger than the other and evidently belongs to the main stem, since its stem is stouter, and it is likely to have seven lobes while the smaller one may have but five. However, the number of lobes varies. Neither of these double parasols has its ribs extending out toward the other, and thus interfering; instead of having their "sticks" at the center of the parasol, they are at the side next each other, exactly as if the original single stem had been split and the whole parasol had been torn in twain.

But of greatest interest is the blossom-baby carried under this double parasol. At first it is a little, elongate, green ball on a rather stiff little stem, which droops because it wants to and not because it has to, and which arises just where the two branches fork. One of the strange things about this precocious baby-bud is, that when the plant is just coming from the ground, the bud pushes its head out from between the two folded parasols, and takes a look at the world before it retires under its green sunshade. As the bud unfolds, it looks as if it had three green sepals, each keeping its cup form and soon falling off, as a little girl drops her hood on a warm day; but each of these sepals, if examined, will be found to be two instead of one; the outer is the outside of the green hood while the inner is a soft, whitish membrane,

"A rabbit skin,

To wrap the Baby Bunting in."

As the greenish white petals spread out, they disclose a triangular mass of yellow stamens grouped about the big seed-box, each side of the triangle 
being opposite one of the inner petals. After the flower is fully open, the stamens spread and each anther is easily seen to be grooved, and each edge of the groove opens for the whole of its length; but because of its shape and position, it lets the pollen fall away from the pistil instead of toward it; nor do the tips of the anthers reach the waxy, white, ruffled stigma. There is no nectar in this flower; but the big queen bumblebee likes the pollen for her new nest, and she "bumbles" around in the flower while getting her load, so that she becomes well dusted with the pollen, and thus carries it from flower to flower. But the whole story of the pollen carriers of the May apple is, as yet, untold; and any child who is willing to give time and attention to discovering the different insects which visit this flower, may give to the world valuable and, as yet, unknown facts. It is said that a white moth is often found hanging to the flowers, but it is difficult to understand why the moth should be there if the flower does not have any nectar.

The seed-vessel at the center of the flower is large and chunky, and, although crowned with its ruffled stigma, looks as if it were surely going to "grow up" into a May apple. There are usually six wide, white, rounded petals, three on the outside and three on the inside; but sometimes there are as many as nine. There are usually twice as many stamens as petals, but I have often found thirteen stamens, which is not twice any possible number of petals. The petals soon fall, and, safely hidden from the eyes of enemies, the green fruit-which is a berry instead of an apple-has nothing to do but gather sweetness, until in July it is as juicy and luscious to the thirsty child as if it were the fruit of the gods. It is about two inches long, a rich yellow in color, and is sometimes called the "wild lemon," although it is not sour. It is also called the hog-apple because the clever swine of the South know how to find it, despite its parasol. Riley thus celebrates this fruit:
"And will any poet sing of a lusher, richer thing,
Than a ripe May apple, rolled like a pulpy lump of gold
Under thumb and finger tips; and poured molten through the lips?"

If the May apple itself is edible, certainly its root is not, except when given by physicians as a medicine, for it is quite poisonous when eaten. When we see plants growing in colonies or patches, it usually means that very interesting things are going on underground beneath them, and the mandrake is no exception to this. Each plant has a running underground stem, straight and brown and fairly smooth; at intervals of a few inches, there are attached to it rosettes of stout, white roots, which divide into tiny, crooked rootlets. There is a large rosette of these roots under the plant we are studying, and we can always find a rosette of them under the place where the plant stood last year. Beneath the present plant we can find the bud from which will grow the root-stem for the coming year. The working out of the branching and the peculiarities of these root-stems, is an excellent lesson in this peculiar and interesting kind of plant reproduction.

\section{LESSON CXXIV}

The MANDRAKE

Leading thought-These interesting plants grow in colonies because of the spreading of their underground stems. Their odor and poisonou: qualities protect them from being eaten by animals, and their fruit is well hidden by its green parasol until it is ripe. 
Method-Begin the study just as the mandrakes are thrusting their heads up through the soil in April, and continue the work at intervals until the fruit is ripe.

Observations-I. How do the mandrakes look when they first appear above the ground? How are the little umbrellas folded in their cases? What do the cases look like? How can you tell from the first, the plants which are to bear the flowers and fruit?

2. Study a patch of mandrakes, and see how many varieties of parasols you can find? Do they all have the same number of main ribs and lobes? How many lobes do most of them have? Are there more single or double parasols in the patch?

3. Take a single plant and study it carefully. What sort of stem has it? Can you find at its base the old umbrella case? How high is the stem? What is its color at the bottom and at the top? How many ribs does it divide into at the top? Are these ribs as smooth as the stem? How does the parasol lining differ from its outside in color and feeling?

4. Study the parasol lobes. What is their general shape? Are they all notched at the wide end? How close to the stem does the division between them extend? Do you not think they are better fitted for keeping off the sun than the rain?

5. Take one of the double parasols. Where is the flower bud to be found? How is it protected from the sun? Does the stem divide equally on each side of it or is one part larger than the other? Are the twir parasols of the same size? How many lobes has each? What are the chief differences in shape between one of these twin parasols and one of the parasols which has no flower bud?

6. How does the flower bud look? Does it droop because its stem is weak? What happens to the green hood or sepals when the flower opens? Can you find six sepals in the hood?

7. Does the open flower bow downward? As the flower opens, what is the shape of the group of stamens at the center? Are there the same number of white, waxy petals in all the flowers? Are there always about twice as many stamens as petals? How do the anthers open to shed the pollen? Do they let the pollen fall away from the ruffled stigma of the "fat" little seed box at the center of the flower?

8. Does the flower have a strong odor? Does not the plant itself give off this odor? Do you think it is pleasant? Do the cattle eat the mandrake when it is in pastures?

9. What insects do you find visiting the mandrake flowers?

ro. Do you like the May apple?. When is it ripe? Cut a fruit across and see how the seeds are arranged.

II. Where are mandrakes found? Do they always grow in patches? Dig up a few plants and find why this is so?

I 2. Describe the underground stem. Can you find where the last year's plant grew? How are the roots arranged upon the stem? Can you see places which will produce the stem for next year's growth? How does the underground stem differ in appearance from the true roots? Why must we not taste of the mandrake root?

13. In late July, visit the mandrake patch again. Are there any umbrellas now? What is left of the plants? Look at the underground stems again and see if there are new growths, and if they are larger and stored with food for next year's plants. 


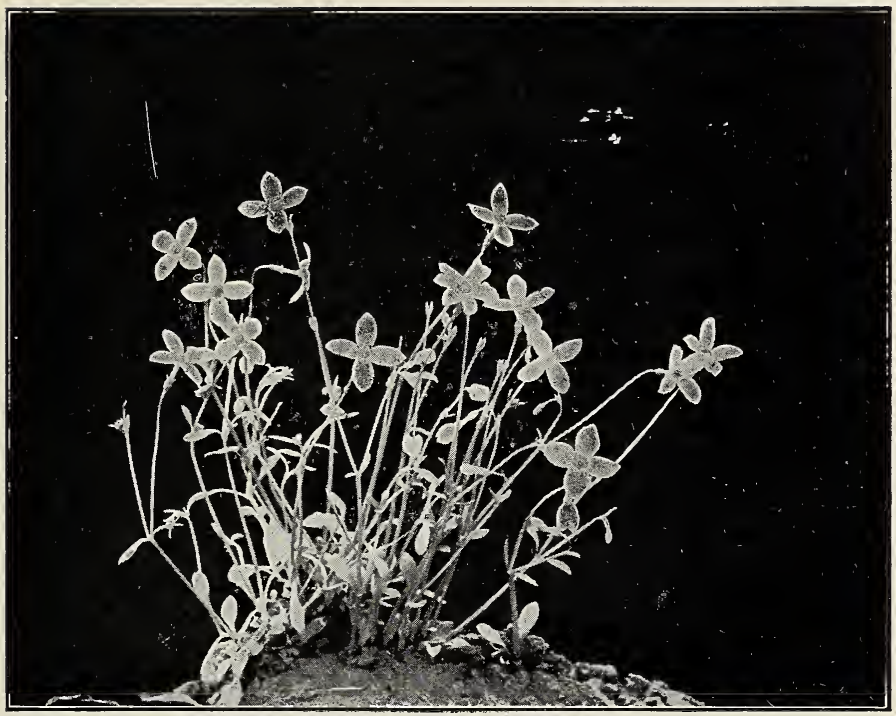

Bluets.

Photo by Cyrus Crosby.

\section{THE BLUETS \\ Teacher's Story}

During April, great patches of blue appear in certain meadows, seeming almost like reflections from the sky; and yet when we look closely at the flowers which give this azure hue to the fields, we find that they are more lavender than blue. The corolla of the bluet is a tube, spreading out into four long, lavender, petal-like lobes; each lobe is paler toward its base and the opening of the tube has a ring of vivid yellow about it, the tube itself being yellow even to its very base, where the four delicate sepals clasp it fast to the ovary until the flower has done its work; and after the corolla has fallen the sepals remain;

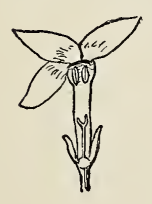

1

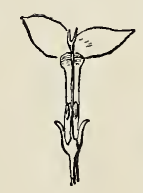

2 standing guard over the growing seed.

If we look carefully at the bluets we find two forms of flowers: (a) Those with a two-lobed stigma protruding from the opening of the flower tube. (b) Those where the throat of the tube seems closed by four anthers which join like four fingertips pressed together. In opening the flower, we observe that those which have the stigmas

I. Section of a bluet blos-protruding from the tube, have four anthers som that has the anthers fastened to the sides of the tube about halfat the throat of the tube and the stigmas below.

2. Section of a bluet with way down; while those that have the tour anthers near the opening of the tube, have a the strgmas protruding pistil with a short style which brings the stigmas and the anthers below. about half-way up the tube. Thus an insect 
visiting flower (a) gets her tongue dusted with pollen from the anthers at the middle of the tube; and this pollen is applied at exactly the right place on her tongue to brush off against the stigmas of a flower of the (b) form. While a bee visiting a bluet of the (b) form receives the pollen at the base of her tongue, where it is conveniently placed to be brushed off by the protruding stigmas of the flowers of the (a) form.

This arrangement in flowers for the reciprocal exchange of pollen characterizes members of the primrose family also; it is certainly a very' clever arrangement for securing cross-pollenation.

\section{LESSON CXXV}

The Bluets

Leading thought-The bluets have two forms of flowers, the anthers and stigmas being placed in different positions in the two, in order to secure cross-pollenation by visiting insects.

Method-Ask the children to bring in several bits of sod covered with bluets. During recess let the pupils, with the aid of a lens if necessary, find the two different forms of flowers. Later, let each see a flower of each form with the tube opened lengthwise.

Observations-r. Where do the bluets grow? Do they grow singly or in masses? On what kind of soil do they grow, in woods or meadows? At what time of year do they bloom?

2. Describe the bluet flower, its color, the shape of its sepals, the form of the corolla, the color of the corolla-tube and lobes.

3. Where is the nectar in the bluet? What color shows where the nectar is to be found?

4. Look directly into the flowers. Do you see any with the stigmas thrust out of the corolla-tube? Is there more than one style? Has it one or two stigmas? Open this flower-tube and describe where the anthers are situated in it. How many anthers are there?

5. Look for a flower where the stigmas do not protrude and the anthers close the throat of the tube. Where are the stigmas in this flower, below or above the anthers? Where are the anthers attached?

6. Work out this problem: How do the insects gathering nectar from one form of the bluets become dusted with pollen in such a way as to leave it upon the stigma of the other form of the bluet flower? falls?

7. How many sepals are there? Do they fall off when the blossom

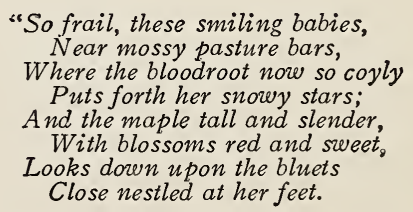

"So frail, these smiling babies, Near mossy pasture bars,

Where the bloodroot now so coyly Puts forth her snowy stars;

And the maple tall and slender, With blossoms red and sweet.

Looks down upon the bluets Close nestled at her feet.

'Innocents', the children call them,These floral babies small,

Of Mother Nature olden, Whose broad lap holds them all." 


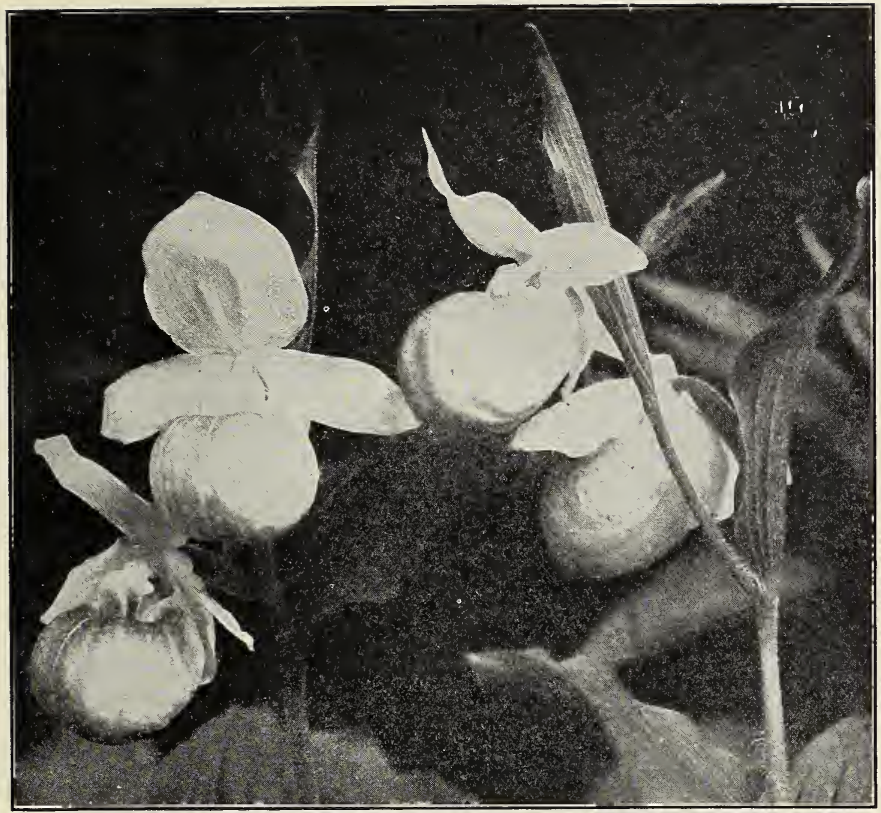

Showy ladies' slipper

Photo by Verne Morton.

\section{THE YELLOW LADY'S SLIPPER}

\section{Teacher's Story}

"Graceful and tall the slender drooping stem, With two broad leaves below,

Shapely the flower so lightly poised between, And warm its rosy glow."-Elaine Goodale.

These showy flowers look so strange in our woodlands that we gaze at them as curiously as we might upon a veiled lady from the Orient who had settled in our midst. There is something abnormal and mysterious in the shape of this flower, and though it be called the lady's slipper, yet it would be a strange foot that could fit such a slipper; and if it is strange at the first glance, it is still more so as we try to compare it with other flowers. There are two long sepals that extend up and down, the lower one being made up of two grown together-but the "seam" does not show. The sepals are yellow, and are wider than the two long streamers that extend out at right angles to them, and which are petals; the brighter color of the latter, their markings of reddish dots, the hairs near their bases, all go to show that these petals, although so different in shape, belong to the same series as the big lower petal which is puffed out into a sac, shaped like a deep, long bowl, with its upper edges incurved. If we 
look carefully at this bowl, we find two openings besides the main one these two are near the stem, and their edges are not incurved. Extending out into each of these openings is a strange little round object, which is an anther; but if we try to get pollen from this anther with a pencil or a knife we get, instead of powdery pollen, a smear that sticks to what it touches, like melted rubber or gum. The secret of this is, that the lower side of the anther is gummy, and adheres to whatever touches it and brings with it, when pulled away, the mealy pollen which lies loose above it. Another strange thing is that, if this lower part of the anther is not carried away, it seems to partially harden and opens downward, letting the pollen escape in a way usual with other flowers. We have to remove a side of the bowl to see the stigma; it is fan-shaped, and is bent at right angles to the flower stem; and above it, as if to protect it, is a stiff triangular piece which is really a strangely modified stamen. I think one reason why the lady's slipper always is called "she" is because of this tendency on her part to divert an object from its natural use. Surely a hairpin used for a paper knife or a monkey-wrench for a hammer, is not nearly so feminine a diversion as a stamen grown wide and long to make an awning above a stigma.

The general color of the flower is yellow, and there are some seductive dark red spots on the stamen-awning and along the folded-in surface of

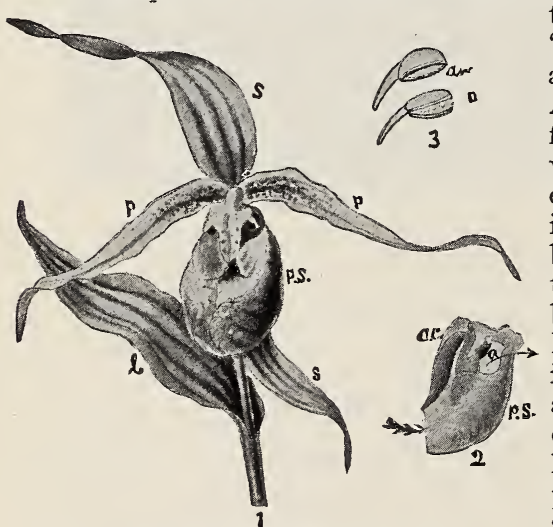

Detail of yellow lady's slipper.

$1, l$, leaf; $s, s$, sepals; p,p, petals; p.s, petal-sac. 2, Side-view: ac, anther cover; p.s, petal-sac. $a$, anther. The arrow shows the path of the insect. 3, an, anther closed; o, anther open. the petal-sac which say plainly, "Come here, Madam Mining-bee, and see what these spots mean." And the little bee alights on the flower and soon crawls into the well at the center, the recurved edges preventing it from returning by the same door. At the bottom of the sac there are delectable vegetable hairs to be browsed upon; if there is nectar, I have never been able to detect it with my coarse organs of taste; and Mr. Eugene Barker who has examined hundreds of the flowers has not been able to detect the presence of nectar in them at any stage; but he made no histological study of the glands.

After a satisfying meal the bee, which is a lively crawler, seeks to get out where it sees the light shining through one of the openings near to the stem. In doing this, she presses her head and back, first against the projecting stigma and then against the sticky anther, which smears he: with a queer kind of plaster; and it sticks there until she brushes it off on the stigma of another flower, when crowding past it; and there she again becomes smeared with pollen plaster from this flower's anthers. Mr. Barker, who has especially studied these flowers, has found that the little mining bees of the genus Andrena were the most frequent visitors; he also found honey-bees and one stray young grasshopper in the sacs. The mining 
bees which he sent to me had their backs plastered with the pollen. Mr. Barker states that the flowers are not visited frequently by insects, and adds feelingly; "My long waiting was rewarded with little insect activity, aside from the mosquitoes which furnished plenty of entertainment."

The ovary looks like a widened and ribbed portion of the flower-stem, and is hairy outside; its walls are thick and obscurely three-angled; seen in cross-section the seeds are arranged in a triangular fashion which is very pretty.

The leaves of the yellow lady's slipper are oval or elliptic, with smooth edges and parallel veins; they often have narrow veins between each two heavier ones. The leaves are of vivid yellowish green and are scattered, in a picturesque manner, alternately along the stem, which their bases completely clasp. The stem is somewhat rough and ribbed and is likely to grow crooked; it grows from one to two feet in height. The roots are a mass of small rootlets. The species is found in woods and in thickets.

The pink moccasin flower, also called the stemless lady's slipper $(C$. acaule, is perhaps prettier than the yellow species, and differs from it in several particulars. The sac opens by the merest crevice, and there are plenty of dark-pink guiding lines which lead to the little opening of the well. The downward-folded edges prevent the visiting insect from getting out by this door even more surely than in the other species. The side petals are not so long as in the yellow species, and they extend forward as if to guide the insect to the well in the lower petal. The sepals are greenish purple, and are likewise shorter; and the lower one is wide, indicating that it is made up of two grown together. At the base of the ovary there is a pointed green bract or leaf, which lifts up and bends above the flower. There are but two leaves on the stemless lady's slipper; they arise from the base of the stem. They are broadly ovate, and from six to seven inches long. This species grows in sandy or rocky woods.

Another species more beautiful than these is the showy lady's slipper, which is white with a pink entrance to the petal sac. This grows in peaty bogs, and is not so common as the others.

The interesting points for observation in these flowers are the careful noting of the kinds of insects which visit them, and how they enter and leave the "slipper," or sac.

\section{LESSON CXXVI}

\section{The Yellow Lady's Slipper}

Leading thought-The moccasin flower belongs to that famiiy of flowers known as orchids which especially depend upon insects for bringing and carrying pollen, and which have developed many strange devices to secure insect aid in pollenation.

Method-A bouquet of lady's slippers should be brought to the schoolroom. Children who bring them should describe the place where they were found.

Observations-r. Where does the yellow lady's slipper grow? Look carefully at its leaves and describe them. How do they join the stem? Are they opposite or alternate?

2. What is there peculiar about the sepals? How many are there? 
3. Describe the three petals and the difference and likeness in their form and color. What is the shape of the lower petal? Is there a hole in this sac? Is there more than one hole leading into it? What is the color of the sac? Is there anything about it to attract insects? If an insect should enter the mouth of the well in the lower petal could it easily come out by the same opening? Why not? Where do you think it would emerge?

4. Note the two roundish objects projecting into the two openings of the sac near the stem. Thrust a pencil against the under side of one of these. What happens? How does this pollen differ from the pollen of ordinary flowers?

5. Cut away one side of the petal-sac and find the stigma. What shape is it? Where is it situated with relation to the anthers? How is the stigma protected above? Where is the ovary, or seed-box?

6. Explain how a bee visiting these flowers, one after another, must carry the pollen from one to another and deposit it on the waiting stigmas.

7. How is the insect attracted? How is it trapped and made to do the work?

8. Look at the seed-capsule and describe it from the outside. Cut it across, and describe the arrangement of the seeds. How many sides of the seed-capsule open, to let loose the seeds?

9. How many species of lady's slippers do you know? Do you know the pink, or stemless species? How does it differ from the yellow species in the following particulars: The shape of the sac; its color and markings; the length and shape of sepals; the number and position of the leaves.

\section{THE COMMON BUTTERCUP}

\section{Teacher's Story}

"The buttercups, bright-cyed and bold,

Held up their chalices of gold

To catch the sunshine and the dew."

Buttercups and daisies are always associated in the minds of the children, because they grow in the same fields; yet the two are so widely different in structure that they may reveal to the child something of the marvelous differences between common flowers; for the buttercup is a single flower, while the single daisy is a large family of flowers.

The buttercup sepals are five elongated cups, about one-half as long as the petals; they are pale yellow with brownish tips, but in the globular buds, they are green. The petals are normally five in number, but have a tendency to double, so that often there are six or more; the petals are pale beneath, but on the inside they are most brilliant yellow, and shine as if varnished. Probably it is due to this luminous color that one child is able to determine whether another likes butter or not, by noting when the flower is held beneath the chin, if it makes a yellow reflection; it would be a sodden complexion indeed that would not reflect yellow under this provocation. Each petal is wedge-shaped, and its broad outer edge is curved so as to help make a cuplike flower; if a fallen petal be examined, a tiny scale will be found at its base, as if its point had been folded back a 


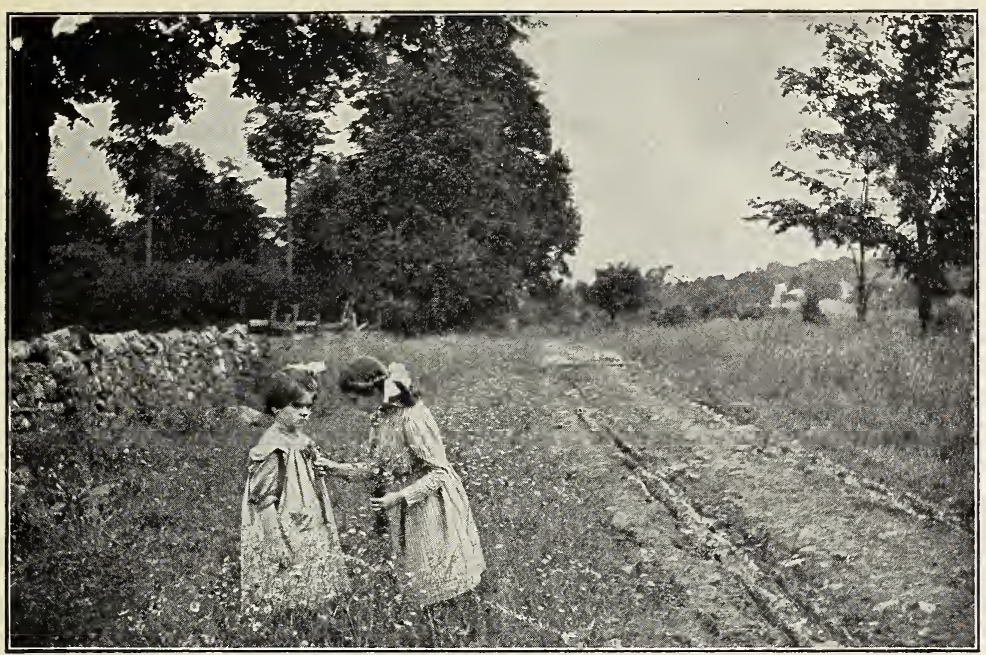

Do you like butter?

trifle. However, this is not a mere fold, but is a little scale growing there - a scale with a mission, for beneath it is developed the nectar.

When the buttercup first opens, all of the anthers are huddled in the center, so that it looks like a golden nest full of golden eggs. Later the filaments stretch up, lifting the anthers into a loose, rounded tuft, almost concealing the bunch of pistils which are packed close together beneath every stigma, like Bre'r Rabbitt, "laying low." Later, the filaments straighten back, throwing the anthers in a fringy ring about the pale green pistils; and each pistil sends up a short, yellowish stigma. The anthers open away from the pistils and thus prevent self-pollenation to some degree; they also seem to shed much of their pollen before the stigmas are ready to receive it.

Sometimes petals and sepals fall simultaneously and sometimes first one or the other; but they always leave the green bunch of pistils with a ragged fringe of old stamens clinging to them. Later the seeds mature, making a globular head. Each seed is a true akene; it is flattened and has at its upper end a short, recurved hook which may serve to help it to catch a ride on passers-by. However, the seeds are largely scattered by the winds.

The buttercup grows in sunny situations, in fields and along roadsides, but it cannot stand the shade of the woods. It is a pretty plant; its long stems are downy near the bottom, but smooth near the flower; the leaves show a variety of forms on the same plant; the lower ones have many, (often seven) deeply cut divisions, while the upper ones may have three irregular lobes, the middle one being the longest. Beetles are very fond of the nectar and pollen of buttercups, and therefore are its chief pollen carriers; but flies and small bees and other insects also find their food in these brilliant colored cups. 


\section{LESSON CXXVII}

The Buttercup

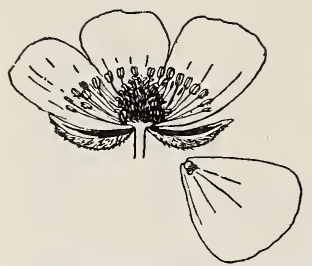

Buttercup flower enlarged. Note the scale covering the nectar at the base of the falling petal.

Leading thought-The buttercup grows with the white daisies, in sunny places, but each buttercup is a single flower, while each daisy is a flower family.

Method-Buttercups brought by the pupils to school may serve for this lesson.

Observations-I. Look at the back of a flower of the buttercup. What is there peculiar about the sepals? How do the sepals look on the buttercup bud? How do they look later?

2. Look into the flower. How many petals are there? Are there the same number of petals in all the flowers of the same plant? What is the shape of a petal? Compare its upper and lower sides. Take a fallen petal, and look at its pointed base with a lens and note what is there.

3. How do the stamens look? Do you think you can count them? When the flower first opens how are the stamens arranged? How, later? Do the anthers open towards, or away, from the pistils?

4. Note the bunch of pistils at the center of the flower. How do they look when the flower first opens? How, later?

5. When the petals fall, what is left? Can you see now how each little pistil will develop into a seed?

6. Describe the seed-ball and the seed.

7. Look at the buttercup's stems. Are they as smooth near the base as near the flower? Compare the upper leaf with the lower leaf, and note the difference in shape and size.

8. Where do the buttercups grow? Do we find them in the woods? What insects do you find visiting the flowers?

\section{THE EVENING PRIMROSE Teacher's Story}

"Children came

To watch the primrose blow. Silent they stood, Hand clasped in hand, in breathless hush around, And saw her shyly doff her soft green hood And blossom-with a silken burst of sound."

-MaRgaret Deland.

To the one who has seen the evening primrose unfold, life is richer by a beautiful, mysterious experience. Although it may be no more wonderful than the unfolding of any other flower, yet the suddenness of it makes it seem more marvelous. For two or three days it may have been getting ready; the long tube which looks like the flower stem has been turning 


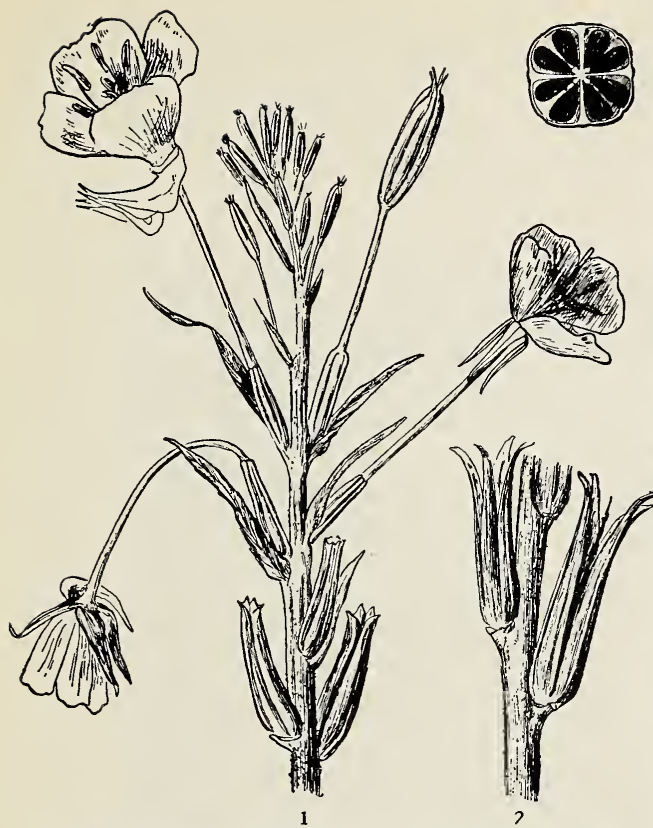

I, Evening primrose, showing buds, one ready to open, a flower just opened above at the left, an older flower at the right, a fading flower and seedcapsules below. 2, Seed-capsules. Cross section of seed-capsule with seeds above. yellow; pushing up between two of the sepals, which clasp tips beyond it, there appears a row of petals. Then some warm evening, usually about sunset, but varying from four o'clock in the afternoon to nine or ten in the evening, the petals begin to unfurl; they are wrapped around each other in the bud as an umbrella is folded, and thus one edge of each petal becomes free first. The petal first in freeing its edge seems to be doing all the work, but we may be sure that all the others are pushing for freedom; little by little the sepals are pushed downward, until their tips, still clasped, are left beneath; and the petals now free, suddenly flare open before our delighted eyes, with a movement so rapid that it is difficult for us not to attribute to them consciousness of action. Three or four of these flowers may open on a plant the same evening; and they, with their fellows on the neighboring plants, form constellations of starry bloom that invite attention from the winged creatures of the twilight and the night. There is a difference in the time required for a primrose flower to unfold, probably depending upon its vigor; once I watched for half an hour to see it accomplished, and again $I$ have seen it done in two or three minutes. The garden species seems to unfold more rapidly than the wild species, and is much more fragrant. The rapidity of the opening of the blossom depends upon the petals getting free from the sepals, which seem to try to repress them. The bud is long, conical, obscurely four-sided, and is completely covered by the four sepals, the tips of which are cylindrical and twisted together; this is an interesting habit, and one wonders if they hold the petals back until the latter are obliged to burst out with the force of repressed energy; after they let go of the petals, they drop below the flower angularly, and finally their tips open and each sepal turns back lengthwise along the seed-tube.

The four lemon-yellow petals are broad, with the outer margin notched. The eight stamens are stout, and set one at the middle of each petal and one between each two petals. The long, pale yellow anthers 
tischarge their pollen in cobwebby strings. When the flower first opens, the stigma is egg.shaped and lies below the anthers; later, it opens into a cross and usually hangs off at one side of the anthers. If we try to trace the style back to the ovary, we find that it extends down into what seems to be the very base of the flower stem, where it joins the main stem. This base is enlarged and ribbed and is the seed-box, or ovary. The tube is rich in nectar, but only the long sucking-tubes of moths can reach it, although I have sometimes seen the ubiquitous bees attempting it. The butterflies may take the nectar in the daytime, for the blossoms of the wild species remain open, or partially open, for a day or two. But the night-flying moths which love nectar have the first chance, and it is on them the flower depends for carrying its pollen, threaded on filmy strings.

There are times when we may find the primrose blossoms with holes in the petals, which make them look very ragged. If we look at such plants carefully, we may find the culprit in the form of a green caterpillar very much resembling the green tube of the bud; and we may conclude, as Dr. Asa Fitch diu, that this caterpillar is a rascal, because it crawls out on the bud-ends and nibbles into them, thus damaging several flowers. But this is only half the story. Later this caterpillar descends to the ground, digs down into it and there changes to a pupa; it remains there until the next summer, then, from this winter cell, emerges an exquisitely beautiful moth called the Alaria florida; its wings expand about an inch, and all except the outer edges of the front wings are rose-pink, slightly mottled with lemon-yellow, which latter color decorates the outer margins for about one-quarter of their length; the body and hind-wings are whitish and silky, the face and antennæ are pinkish. Coiled up beneath the head is a long sucking-tube which may be unfolded at will. This moth is the special pollen-carrier of the evening primrose; it flies about during the evening, and thrusts its long, tubular mouth into the flower to suck the nectar, meanwhile gathering strings of pollen upon the front part of its body. During the day, it hides within the partially closed flower, thus carrying the pollen to the ripened stigmas, its colors meanwhile protecting it almost completely from observation. The fading petals of the primrose turn pinkish, and the pink color of the moth renders it invisible when in the old flowers, while the lemon-yellow tips of its wings protruding from a flower still fresh and yellow, forms an equally perfect protection from observation.

The evening primrose is an ornamental plant in both summer and winter. It is straight, and is ordinarily three or four feet tall, although it sometimes reaches twice that height. It is branched somewhat, the lower portion being covered with leaves and the upper portion bearing the flowers. The leaves are pointed and lanceolate, with few whitish veins. The leaf edges are somewhat ruffled and obscurely toothed, especially in the lower leaves. The leaves stand up in a peculiar way, having a short, pink petiole, which is swollen and joins the stalk like a bracket. The upper leaves are narrower; the leafy bracts at the base of the flower grow from the merest slender leaflet at the base of the bud, to a leaf as long as the seed-pod, when the flower blooms.

The seed-capsules are four-sided, long and dark green. In winter they are crowded in purplish-brown masses on the dry stalks, each one a graceful vase with four flaring tips. At the center of each there projects a needlelike point; and within the flaring, pale, satin-lined divisions of 
these urns, we may see the brown seeds which are tossed by the winter winds far and near. The young plants develop into vigorous rosettes during the late summer and autumn, and thus discreetly pass the winter under the snow coverlet.

LESSON CXXVIII

The Evening Primrose

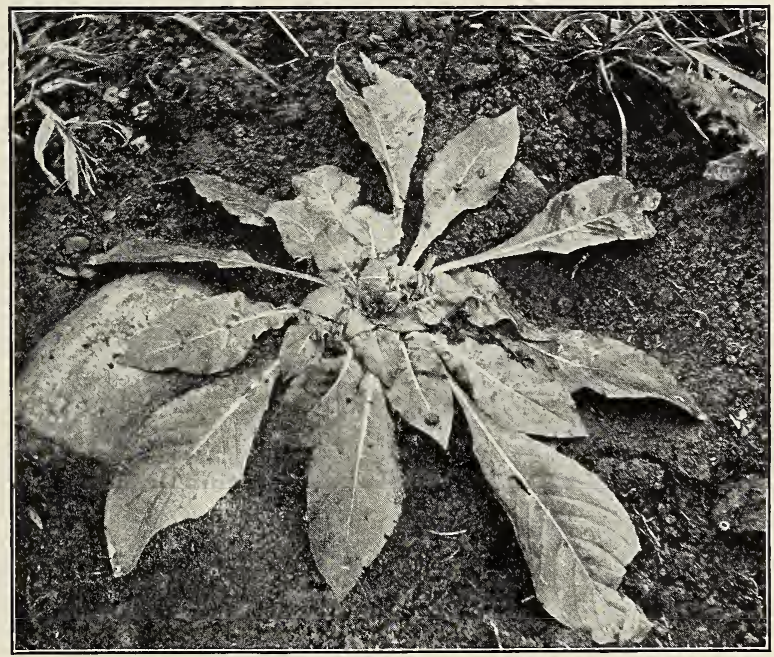

Winter rosette of evening primrose.

Photo by Verne Morton.

Leading thought-Some flowers have developed the habit of relying on the night-flying insects for carrying their pollen. The evening primrose is one of these; its flowers open in the evening and their pale yellow color makes them noticeable objects in the twilight, and even in the dark.

Method-The form of the evening primrose may be studied from plants brought to the schoolroom; but its special interest lies in the way its petals expand in the evening, so the study should be continued by the pupils individually in the field. This is one of the plants which is an especially fit subject for the summer note-book; but since it blossoms very late and the plants are available even in October, it is also a convenient plant to study during the school year. The garden species is well adapted for this lesson.

Observations-r. Look at the plant as a whole. How tall is it? Is the stem stiff and straight? Where do you find it growing? Does it grow in the woods?

2. Are the leaves near the base the same shape as those at the top of the plant? What is their shape? Are the edges toothed? What is there peculiar about the veins? How do the leaves join the stem? How 
do the leaves look which are at the base of the flower stem? Those at the base of the buds?

3. Where on the plant do the flowers grow? Which flowers blossom first, those above or below? Take a bud nearly ready to open; what is there peculiar in the appearance of the bud stem? What is the general shape of the bud? Describe the sepals. Look at their tips carefully, and see how they hold together. Cut a bud across and see how the petals are folded within it.

4. Take an open flower; where are the sepals now? Describe the open petals, their shape and color.

5. How many stamens are there? How are they placed? What is the shape of the anthers? How does the pollen look?

6. What is the shape and the position of the stigma in the freshly opened flower? Later? Open the flower-tube and find how far down the style extends. Where is the ovary? How does the ovary look on the outside? Taste the opened tube; can you detect the nectar? What sort of a tongue must an insect have to reach this nectar? How do the fading flowers look and act?

7. Describe the seed-pod. Cut it across, and see how many compartments there are within it. How are the seeds arranged in it? How do the pods open and how are the seeds scattered?

8. Watch the flower of the evening primrose open, and describe the process carefully. At what hour did it open? What was the movement of the petals? Can you see how they unfold in relation one to another? How do they get free from the sepals? How many minutes is required for the whole process of the opening of the flower? How many flowers on a plant expand during the same evening? Look at the open blossoms in the dark; can you see them? How do they look? What insects do you find visiting these flowers?

9. How long does the primrose blossom remain open? How do the young plants of the evening primrose pass the winter?

Supplementary reading-Blossom Hosts and Insect Guests, Gibson.

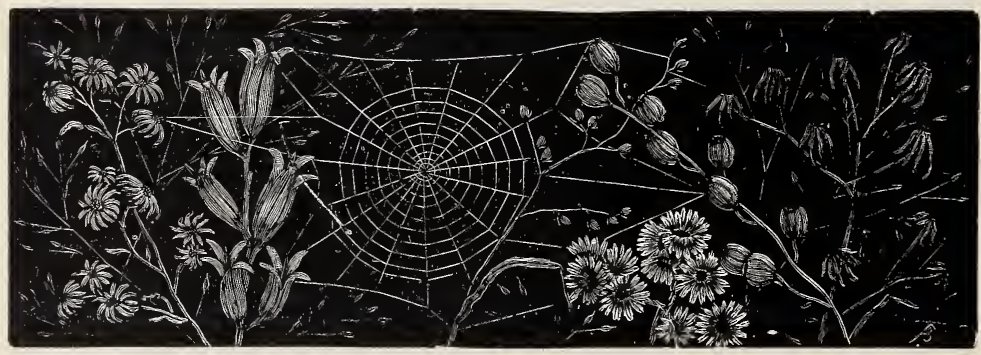




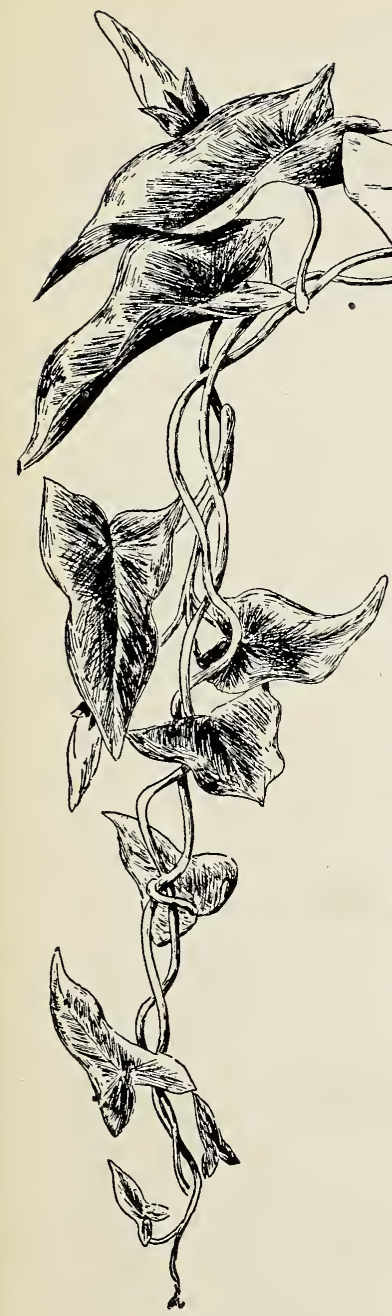

Hedge bindweed.

THE HEDGE BINDWEED

Teacher's Story

I once saw by the roadside a beautiful pyramid, covered completely with green leaves and beset with pink flowers. I stopped to examine this bit of landscape gardening, and for the first time in my life I felt sorry for a burdock; for this burdock had met its match and more in standing up against a weakling plant which it must have scorned at first, had it been capable of this sensation. Its mighty leaves had withered, its flowerstems showed no burs, for the bindweed had caught it in its hundred embraces and had squeezed the life out of it. Once in Northern Florida our eyes were delighted with the most beautiful garden we had ever seen and which resolved itself later into a field of corn, in which every plant had been made a trellis for the bindweed; there it flaunted its pink and white flowers in the sunshine with a grace and charm that suggested nothing of the oppressor.

Sometimes the bindweed fails to ind support to lift it into the air. Then it quite as cheerfully mats itself over the grass, making a carpet of exquisite pattern. This vine has quite an efficient way of taking hold. . It lifts its growing tips into the air, swaying them joyously with every breeze; and the way each extreme tip is bent into a hook seems just a matter of grace and beauty, as do the two or three loose quirls below it; when during its graceful swaying the hook catches to some object, it makes fast with amazing rapidity; later the young arrowshaped leaves manage to get an ear over the support, and in a very short time the vine makes its first loop, and the deed is done. It is very particular to twine and wind in one way, followirg the direction of the hands of the clock-from the right, under, and from the left, over the object to which it clings. If the support is firm, it only makes enough turns around 
it to hold itself firmly; but if it catches to something as unstable as its own tendrils, they twist until so hard-twisted that they form a support in themselves.

It is rather difficult to perceive the alternate arrangement of the leaves on the bindweed stem, so skillful are they in twisting under or over in order to spread their whole graccful length and breadth to the sun; to the careless observer they seem only to grow on the upper or outer side of the vine. The leaves are arrow-shaped, with two long, backward, and outward projecting points, or "ears," which are often gracefully lobed. Early in the year the leaves are glossy and perfect; but many insects love to nibble them, so that by September, they are usually riddled with holes.

The flower bud is twisted as if the bindweed were so in the habit of twisting that it carried the matter farther than necessary. Enveloping the base of the flower bud are two large sepal-like bracts, each keeled like a duck's breast down the center; if these are pulled back, it is seen that they are not part of the flower, because they join the stem below it. There are five pale green sepals of unequal sizes, so that some look like fragments of sepals. The corolla is long, bell-shaped, opening with five, starlike lobes; each lobe has a thickened white center; and while its margins are usually pink, they are sometimes a vivid pink-purple and sometimes entirely white. Looking down into this flower-bell, and following the way pointed out by the white star-points which hold out the lobes, we find five little nectar-wells; and each two of these wells are separated by a stamen which is joined to the corolla at its base and at its anther-end presies close abolit the style of the pistil. When the flower first opens, it shows the spoon-shaped stigmas close together, pushing up through the anther cluster; later, the style elongates, bringing the stigmas far beyond the anthers. The pollen is white, and through the lens looks like tiny pearls.

When we study the maturing seed-capsule, we can understand the uneven size of the sepals better; for after the corolla with the attached stamens falls, the sepals close up around the pistil; the smallest sepal wraps it first, and the larger ones in order of size, enfolding the precious parcel; and outside of all, the great, leafy bracts with their strong keels provide protection. The pod has two cells and two seeds in each cell. But it is not by seeds alone that the bindweed spreads; it is the running rootstock which, when the plant once gets a start, helps it to cover a large area. The bindweed is a relative of the morning-glory and it will prove an interesting study to compare the two in methods of twining, in the time of day of the opening of the flowers, the shape of the leaves, etc. So far as my own observations go, the bindweed flowers seem to remain open only during the middle of the day, but Müller says the flowers stay open on moonilight nights to invite the hawk-moths. This is an interesting question for investigation, and it may be settled by a child old enough to make and record truthful observations.

There are several species of bindweed, but all agree in general habits. The field bindweed lacks the bracts at the base of the flower. 


\section{LESSON CXXIX \\ The Hedge Bindweed}

Leading thought-There are some plants which have such weak stems that they are obliged to cling to objects for support. The bindweed is one of these, and the way that it takes hold of objects and grows upon them is an interesting story.

Method-It is better to study this plant where it grows; but if this is not practical, the vine with its support should be brought into the schoolroom, the two being carefully kept in their natural relative positions. Several of the questions should be given to the pupils for their personal observation upon this vine in the field. It is an exoellent study for pencil or water-color drawing.

Observations-r. How does the bindweed get support, so that its leaves and its flowers may spread out in the sunshine? Why does its own stem not support it? What would happen to a plant with such a weak stem, if it did not twine upon other objects?

2. How does it climb upon other plants? Does its stem always wind or twist in the same direction? How does it first catch hold of the other plant? If the supporting object is firm, does it wind as often for a given space as when it has a frail support? Can you see the reason for this?

3. Look at the leaves. Sketch one, to be sure that you see its beautiful form and veins. Note if the leaves are arranged alternately on the stem, and then observe how and why they seem to come from one side of the stem. Why do they do this?

4. What is there peculiar about the flower bud? Look at its stem carefully and describe it. Cut it across and look at the end with a lens and describe it. Turn back two sepal-like bracts at the base of the flower or bud. Are they a part of the flower, or are they below it? Find the true sepals. How many are there? Are they all the same size?

5. Examine the flower in blossom. What is its shape? Describe its colors. Look down into it. How many stamens are there, and how are they set in the flower? How does the pistil look when the flower first opens? Later? Can you see the color of the pollen? Can you find where the nectar is borne? How many nectar-wells are there?

6. What insects do you find visiting bindweed flowers? Do the flowers remain open at night or on dark days?

7. Study the seed-capsule. How is it protected on the outside? What next enfolds it? Can you see now the uses of the sepals of severa1 sizes? Cut a seed-capsule across with all its coverings, and see how it is protected. How many seeds are there in the capsule?

8. Has the bindweed other methods of spreading than by seeds? Look at the roots and tell what you observe about them.

9. Make a study of the plant on which the bindweed is climbing, and tell what has happened to it.

Io. Compare the bindweed with the morning-glory, and notice the differences and resemblancas.

Supplementary reading: "Morning-Glory Stories," in Flowers and Their Friends, Morley; Botany Reader, Newell, Chap. ro; Golden Numbers, page 74 . 


\section{THE DODDER}

\section{Teacher's Story}

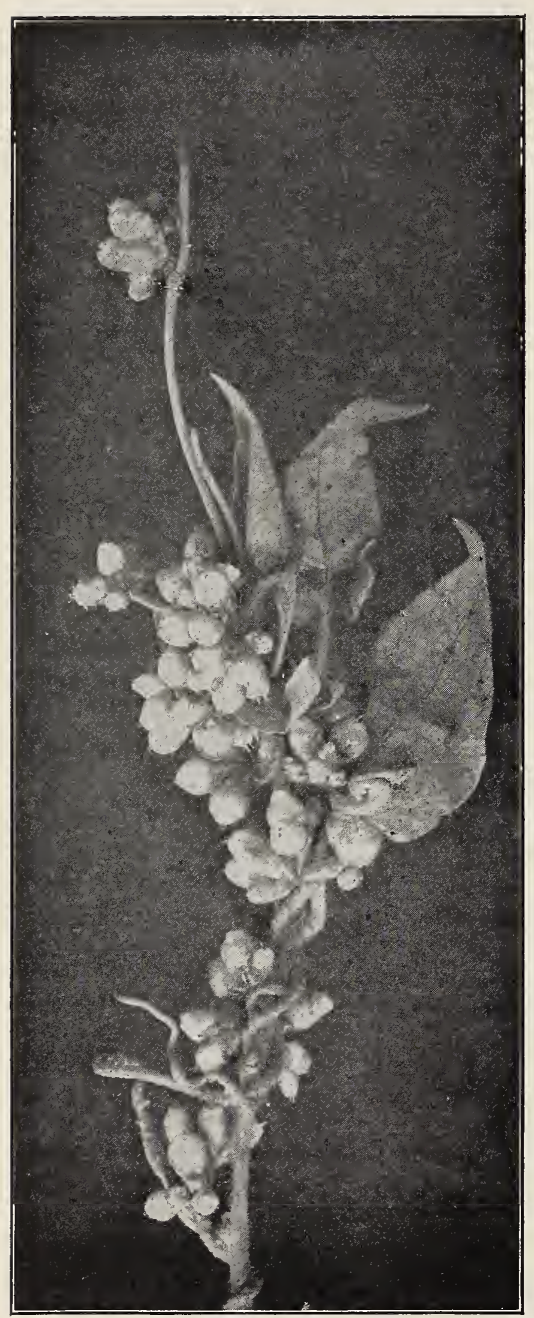

Dodder in blossom.

Photo by Cyrus Crosby.

If Sinbad's "Old Man of the Sea" had been also a sneak thief, then we might well liken him to dodder. There is an opportunity for an excellent moral lesson connected with the study of dodder and its underhand ways. When a plant ceases to be selfsupporting, when it gets its own living from the food made by other plants for their own sustenance, it loses its own power of food-making; and the dodder is an excellent example of the inevitable punishment for "sponging" a living. The dodder has no leaves of its own for it does not need to manufacture food nor to digest it. Its dull yellow stems reach out in long tendrils, swayed by eve1y breeze, until they come in contact with some other plant to which they at once make fast. One of these tendrils seizes its victim plant as a serpent winds its prey, except that it always winds in the same direction-it passes under from the right side and over from the left. Who knows whether the serpents are always so methodical! After dodder gets its hold, little projections appear upon its coiled stems, which look like the prolegs of a caterpillar; but they are not legs, they are suckers, worse than those of the devil-fish; for the latter uses its suckers only to hold fast its prey; but the dodder uses its suckers to penetrate the bark of its victim, and reach down to the sap channels where they may, vampirelike, suck the blood from their victims, or rather the matured sap which is flowing from the leaves to the growing points of the host plant. Not having anything else to do, dodder devotes its energies to the producing of seeds, in order to do more mischief. The species which, 
attack clover and other farm crops seem to manage to get their seeds harvested with the rest; and the farmer who does not know how to test his clover seed for impurities, sows with it the seeds of its enemy.

The dodder flowers are small, globular and crowded together. The calyx has five lobes; the corolla is globular, with five little lobes around its margin and a stamen set in each notch. A ew of the species have a four-lobed calyx and corolla; but however many the lobes, the flowers are shiftless looking and are yellowish or greenish white; despite its shiftless appearance, however, each flower manages to mature four perfectly good, plump seeds.

There are, according to Gray, nine species of dodder more or less common in America. Some of the species, among which is the flax dodder, live only upon certain other species of plant life, while others take almost anything that comes within reach. Where it flourishes, it grows so abundantly that it makes large yellow patches in fields, completely choking out the leaves of its victims.

\section{LESSON CXXX}

\section{The Dodder}

Leading thought-There are some plants which not only depend upon other plants to hold them up, but they suck the life-juice from these plants and thus they steal their living.

Method-Bring in dodder with the host plant for the pupils to study in the schoolroom, and ask them to observe afterwards the deadly work of this parasite in the field.

Observations-r. What is the color of the stem? In which direction does it wind?

2. How is the stem fastened to the host plant? Tear off these suckers and examine the place where they were attached with a lens, and note if they enter into the stem of the host plant.

3. How does the dodder get hold of its victim? Has the dodder any leaves of its own? How can it get along and grow without leaves?

4. How do the flowers look through a lens? Are there many flowers? Can you see the petal lobes and the stamens?

5. How many seeds does each flower develop? How do the seeds look? In what way are they a danger to our agriculture?

I should also avoid the information method. It does a child little good merely to tell him matters of fact. The facts are not central to him and he must retain them by a process of sheer memory; and in order that the teacher may know whether he remembers, the recitation is employed,-re-cite, to tell over again. The educational processes of my younger days were mostly of this order, - the book or the teacher told, I re-told, but the results were always modified by an unpredictable coefficient of evaporation. Good teachers now question the child to discover what he has found out or what he feels, or to suggest what further steps may be taken, and not to mark him on what he remembers. In other words, the present-day process is to set the pupil independently at work, whether he is young or old, and the information-leaflet or lesson does not do this. Of course, it is necessary to give some information, but chiefly for the purpose of putting the pupil in the way of acquiring for himself and to answer his natural imquiries; but information-giving about nature subjects is not nature-study.-L. H. BAILEY in "The Outlook to Nature." 


\section{THE MILKWEED \\ Teacher's Story}

"Little weavers of the summer, with sunbeam shuttle bright, And loom unseen by mortals, you are busy day and night, Weaving farry threads as filmy, and soft as cloud swans, seen In broad blue sky-land rivers, above earth's fields of green."

\section{-Ray Laurance.}

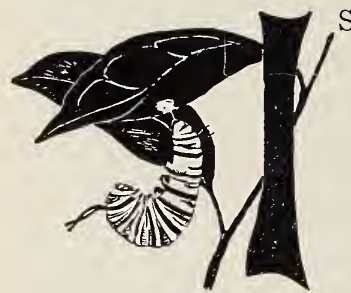

there any other young plant that shows off its baby-clothes as does the young milkweed! When it comes up through the soil, each leaf is folded lengthwise around the stem, flannel side out, and it is entirely soft and white and infantile. The most striking peculiarity of the milkweed plant is its white juice, which is a kind of rubber. Let a drop of it dry on the back of the hand, and when we try to remove it we find it quite elastic and possessed of all of the qualities of crude rubber. At the first trial it seems quite impossible to tell from which part of the stem this white juice comes, but by blotting the cut end once or twice, the hollow of the center of the stem is seen to have around it a dark 'green |ring, and outside this is a light green ring. It is from the dark green ring encircling the stem cavity that the milk exudes. This milk is not the sap of the plant any more than resin is the sap of the pine; it is a special secretion, and is very acrid to the taste, rendering milkweed disgusting to grazing animals. If a milkweed stem be broken or gashed, this juice soon heals the wound and keeps out germs, and thus is of great use to the plant, since many insects feed upon 1 t. If cut across, every vein in every leaf produces "milk", and so does every small flower pedicel. When the "milk" is by chance smeared on cloth and allowed to dry, soap and water will not remove it, but it yields readily to chloroform, which is a solvent of rubber.

The milkweed leaves are in stately conventional

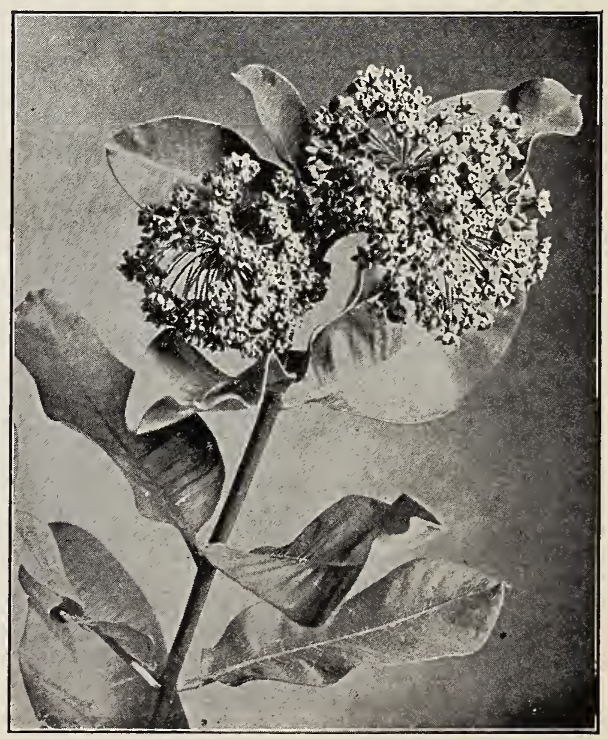

Milkweed in blossom. Photo by Verne Morton. 
pairs; if one pair points east and west, the pair above and the pair below point north and south. The leaf is beautiful in every particular; it has a dark green upper surface, diversified with veins that join in scallops near the border; it is soft to the touch on the upper surface, and is velvety below. The lens reveals that the white under surface, or the nap of the velvet, is a cover of fine white hairs.

The flower of the milkweed is too complicated for little folks even to try to understand; but for the pupils of the seventh and eighth grades it will prove an interesting subject for investigation, if they study it with the help of a lens. In examining the globular bud, we see the five hairy sepals, which are later hidden by the five long, pinkish green petals which bend back around the stem. When we look into the flower, we see five little cornucopias-which are really horns of plenty, since they are filled with nectar; from the center of each is a little, fleshy tongue, with its curved point resting on the disk at the center of the flower. Between each two of these nectar-horns can be seen the white bordered opening of a long pocket-like a dress-pocket-at the upper end of the opening of which is a black dot. Slip a needle into the pocket opening until it pushes against the black dot, and out pops a pair of yellow saddle-bags, each attached to the black dot which joins them. These are the pollen-bags, and each was borne in a sac, shaped like a vest-pocket, one lying either side of the upper end of the long pocket. These pollen-bags are sticky, and they contract so as to close over the feet of the visiting bee.

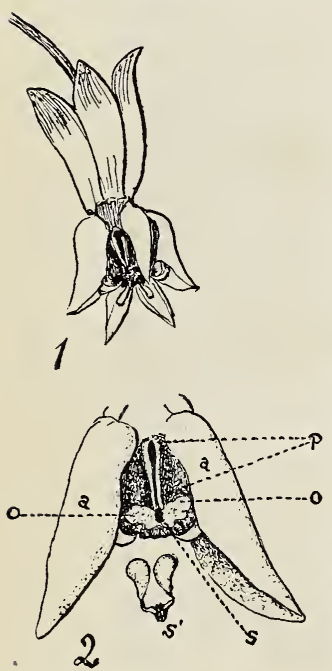

Since the stem of the flower cluster droops and each flower pedicel drcops, the bee is obliged to cling, hanging back down, while getting the nectar, and has to turn about as if on a pivot in order to thrust her tongue into the five cornucopias in succession; she is then certain to thrust her claws into a long pocket, and it proceeds to close upon them, its edges being like the jaws of a trap. The bee, in trying to extricate her feet, leaves whatever pollen-bags she had inadvertently gathered in this trap-pocket, which gives them passage to the stigma. But the milkweed flower, like some folks, is likely to overdo matters, and sometimes these pockets grasp too firmly the legs of the bee and hold her a prisoner. We often find insects thus caught and dead-a result as far from the plan of the flower as from that of the insect victim, had both been conscious. Sometimes bees become so covered with these pollen. bags, which they are unable to scrape off, that they die because of the clogging. But for one bee that suffers there are thousands that carry i, Milkweed flower, enlarged. off the nectar triumphantly, just as thousands of 2, Same more enlarged. a,a, people travel by water for one that is drowned. nectar-horns; $p$, pocket; o,o, The milkweed pod has been the admiration of
openings to the pocket; $s$, openings to the pocket; $s$, nature students from the beginning, and surely pollen-bags removed. there is no plant structure that so interests the 
child as this house in which the milkweed carries its seeds. When we look at a green pod, we first admire its beautiful shape; on either side of the seam, which will sometime open, are three or four rows of projecting points rising from the felty surface of the pod in a way that suggests embossed embroidery. We open the pod by pulling it apart along the seam; and this is not a seam with a raw edge but is finished with a most perfect selvage. When we were children we were wont to dispossess these large green pods of their natural contents, and because they snapped shut so easily, we imprisoned therein bumblebees "to hear them sing," but we always let them go again. We now know that there is nothing so interesting as to study the contents of the pod just as it is. Below the opening is a line of white velvet; at one end, and with their "heads all in one direction," are the beautiful, pale-rimmed, brown, overlapping seeds; and at the other end we see the exquisite milkweed silk with the skein so polished that no human reel could give us a skein of such luster. If we remove the contents of the pod as a whole, we see that the velvety portion is really the seed-support and that it joins the pod at either end. It is like a hammock full of babies, except that the milkweed babies are fastened on the outside of the hammock.

No sooner is our treasure open to the air than the shining silk begins to separate into floss of fairy texture. But before one seed comes off, let us look at the beautiful pattern formed by the seeds overlapping - such patterns we may see in the mosaics of mosques.

Pull off a seed, and with it comes its own skein of floss, shining like a pearl; but if we hold the seed in the hand a moment the skein unwinds itself into a fluff of shining threads as fine as spiders' silk, and each individual thread thrusts itself out and rests upon the air: and altogether there are enough of the threads to float the seed, a balloon of the safest sort. If we wreck the balloon by rubbing the floss through our fingers, we shall feel the very softest textile fiber spun by Mother Nature.

If we look closely at our seed we see a margin all around it. Well, what if the balloon should be driven over sea, and the seed dropped upon the water? It must then drown unless it has a life preserver; this margin that we have noted is of the safest cork, and is warranted to float; if you do not believe it, try it.

If we pull off all the seeds, we can see that the velvety support is flat and that all of the seeds are attached to it, but before we stop our admiring study we should look carefully again at the inside of the pod, for never was there a seed cradle with a lining more soft and satiny.

\section{LESSON CXXXI}

\section{The Milkweed}

Leading thought-The milkweed when wounded secretes a milky juice which is of a rubberlike composition; it flows out of the wounded plant and soon hardens, thus protecting the wound from germs. Milkweed flowers depend entirely upon insects for pollenation; the pollen is not a. free, yellow powder, but it is contained in paired sacs, which are joined in V-shape. The seeds are carried by balloons, and they can float on water as well.

Method-Begin the study of the plant when it first appears above ground in April or May. Give the pupils the anestions about the blossom 


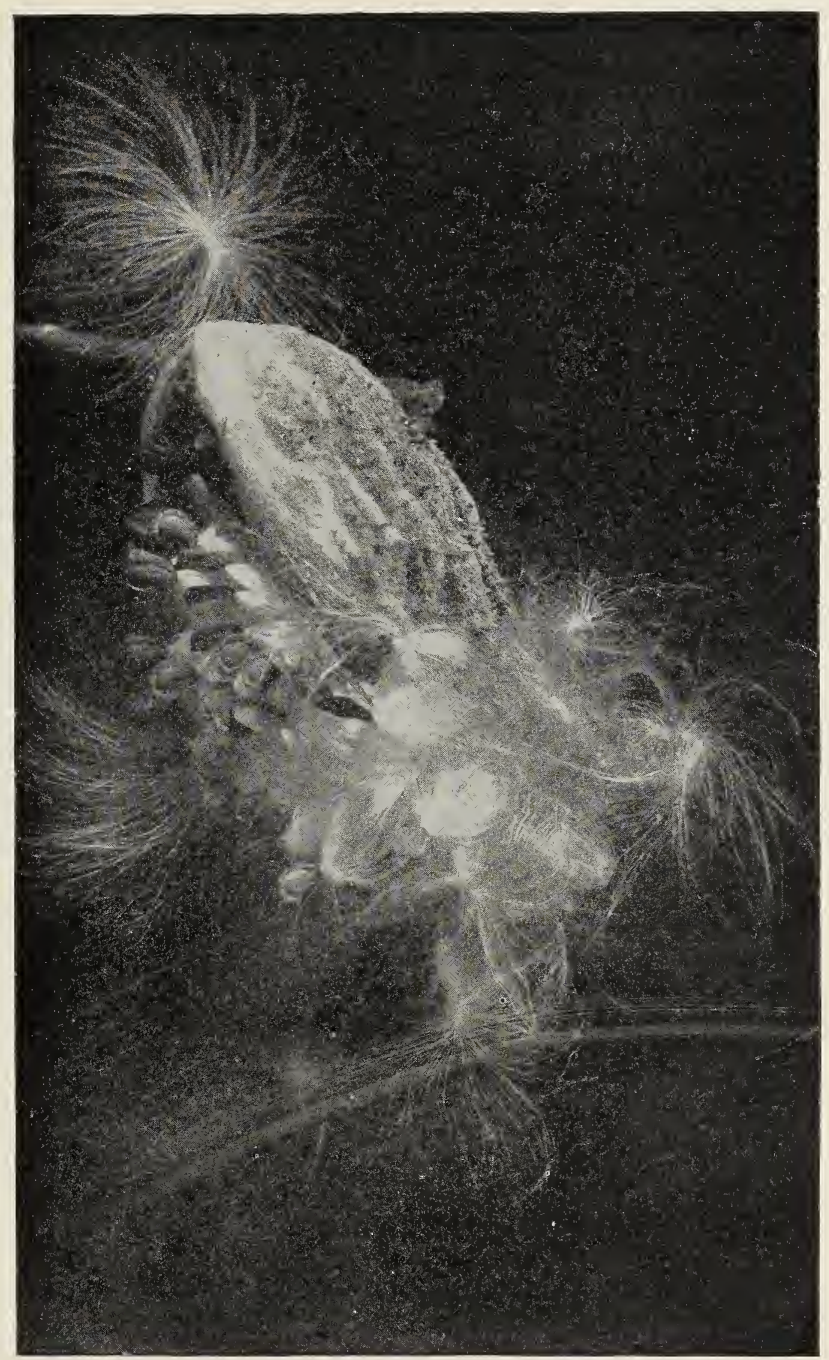

Milkweed seed-balloons just leaving the sheltering pod. 
for a vacation study, and ask that their observations be kept in their notebooks. The study of the pods and seeds may be made in September or October. When studying the milky juice, add a geography lesson on rubber trees and the way that rubber is made.

Observations-I. The plant. How does the milkweed look as it appears above ground in the spring? How are its leaves folded when it first puts its head up? Cut off a fully expanded plant a few inches above the ground. What flows out of the stem? Blot off the "milk" and study the cross-section of the stem. What is at the center? How many layers do you see around this center? Can you see from which the milkweed juice comes? How does the juice feel as it dries on your fingers? How does it look when dry? Place a few drops on a piece of paper and when it is dry pull it off and see if it is elastic. Break the edge of the leaf. Does the milky juice flow from it?. Does it come from the veins? Do you think that this is the sap of the milkweed? Cut a gash in the milk. weed stem and see how the "milk" fills the wound. How does this help the plant? Do cattle feed upon the milkweed when it grows in pastures? If not, why?

2. How are the leaves arranged on the stem? How do the upper and under sides of the leaves differ? Examine with a lens, and see what makes the nap of the velvet. What gives the light color to the under side? Sketch a leaf showing its shape and venation, noting especially the direction of the veins as they approach the edge of the leaf.

3. The flower. Where do the flower clusters come off the stems in relation to the leaves? Does the stem of the flower cluster stand stiff or droop? Take a good sized flower cluster and count the flowers in it. What would happen if all these flowers should develop into pods? How many flower clusters do you find on one plant? Which of these clusters open first? Last?

4. Take off a single bud with its stem, or pedicel. Does the milky juice come at the break? Is the bud stem stiff or drooping? What is its color and how does it feel? What is the shape of the bud? How many sepals has it? Look at the stem, sepals and bud with a lens and describe their covering. Look for a flower just opening where the petals stand out around it like a five-pointed star. What is their color? What happens to the petals when the flower is fully expanded? Can you see the sepals then? Look straight into the flower. Do you see the five nectar-horns? Look at them with a lens and describe them. What do you suppose is the use of the little curved tongue coming out of each? Where does the tip of the tongue rest? With a lens, look between two of the nectar horns; can you see a little slit or pocket, with white protruding edges? Note just above the pocket a black dot; thrust a needle into this pocket near its base and lift it toward the crown of the flower, touching the black dot. What happens?

5. Describe the little branched object that came out when you touched it with a needle. These are the pollen saddle-bags and each bag comes from a pocket at one side of, and above the long pocket. Do these saddlebags cling to the needle? Look with a lens at some of the older flowers, and see if you can find the pollen-bags protruding from the long pocket. See if you can find how the long pocket is a passageway to the stigma. To see how the little saddle-bags were transported, watch a bee gathering nectar. Describe what happens. 
6. Since the flowers bend over, how must the bee hold on to the flower while she gathers nectar from the horns? As she turns around, would she naturally pull out some of the saddle-bags? Catch a bee in a collecting tube and see if her feet have upon them these pollen-sacs. After gathering these pollen-sacs upon her feet, what happens to them when she visits the next flower? Is the opening of the long pocket like a trap to scrape the sacs off? Can you find on milkweed flowers any bees or other insects that have been entangled in these little traps and have thus perished? Try the experiment of drawing a thread into one of these traps and with your lens see if the opening closes over it.

7. How many kinds of insects do you find visiting the milkweed flowers? Can you detect the strong odor of the flowers? Why must the milkweed develop so many flowers and offer such an abundance of nectar?

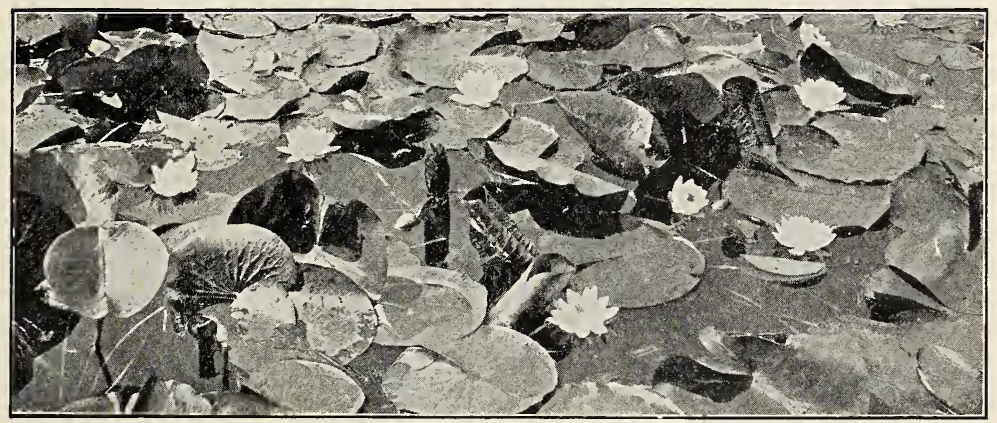

Photo by Verne Morton.

\author{
THE WHITE WATER LILY \\ Teacher's Story \\ "Whence O fragrant form of light, \\ Hast thou drifted through the night \\ Swanlike, to a leafy nest, \\ On the restless waves at rest."
}

Thus asks Father Tabb, and if the lily could answer it would have to say: "Through ages untold have the waves upheld me until my leaves and my flowers have changed into boats, my root to an anchor, and my stems to anchor-ropes."

There is no better example for teaching the relation between geography and plant life than the water lily. Here is a plant that has dwelt so long in a certain situation that it cannot live elsewhere. The conditions which it demands are quiet water, not too deep, and with silt bottom. Every part of the plant relies upon these conditions. The rootstock has but few root hairs; and it lies buried in the silt, not only because this gives it food, but because it can there act as an anchor. Rising from the rootstock is a stem as pliable as if made of rubber, and yet it is strong; 
its strength and flexibility are gained by having at its center four hollow tubular channels, and smaller channels near the outside. These tubes extend the whole length of the stem, making it light so that it will float, and at the same time giving it strength as well as flexibility. At the upper end of the stem is a leaf or flower, which is fashioned as a boat. The circular leaf is leathery and often bronze-red below, with prominent veins, making an excellent bottom to the boat; above, it is green with a polished surface, and here are situated its breathing-pores, although the leaves of most plants have these stomata in the lower surface. But how could the water lily leaf breathe, if its stomata opened in the water? The leaf is large, circular and quite heavy; it would require a very strong, stiff stem to hold it aloft, but by its form and structure it is fitted to float upon the water, a little green dory, varnished inside, and waterproof outside.

The bud is a little, egg-shaped buoy protected by its four pinkish brown, leathery sepals; as it opens, we can see four rows of petals, each overlapping the space between the next inner ones; at the center there is a fine display of brilliant yellow anthers. Those hanging over the greenish yellow pit, which has the stigma at its center, are merely golden hooks.

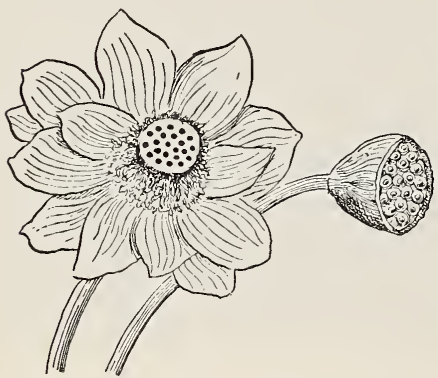

Egyptian lotus flower and seed-vessel. When the flower is quite open, the four sepals, each a canoe in form, lie under the lily and float it; although the sepals are brownish outside, they are soft white on the inside next the flower. Between each two sepals stands a large petal, also canoe-shaped, and perhaps pinkish on the outside; these help the sepals in floating the flower. Inside of these there is a row of large creamy white petals which stand upright; the succeeding rows of petals are smaller toward the center and grade into the outer rows of stamens, which are petallike at the base and pointed at the tip. The inner rows of stamens make a fine golden fringe around the cup-shaped pistil. This flower is of great use in teaching that sepals, petals and stamens have the same origin and grade into each other, showing the intermediate stages.

It has been stated that pond lilies, in the state of nature, lave an interesting way of opening in the early morning, closing at noon and opening again toward evening. If we knew better the habits of the insects which pollenate these flowers, we should possibly have the key to this action. In our ponds in parks and grounds we find that each species of pond lily opens and closes at its own particular time each day. Each flower opens usually for several consecutive days, and the first day of its blooming it opens about an hour later and closes an hour earlier than on the days following. After the lilies have blossomed, the flower stem coils in a spiral and brings the ripening seeds below the surface of the water. The reason for this has not yet been discovered. After about two months the pod bursts letting the seeds out in the water. Each seed is in a little bag, which the botanists call an aril, and which serves as a life preserver floating the seed off for some distance from the parent plant. The aril 
finally decays and the seed falls to the bottom where, if the conditions are favorable, it develops into a new plant.

To emphasize the fact that the water lily is dependent upon certain geographical conditions, ask the pupils to imagine a water lily planted

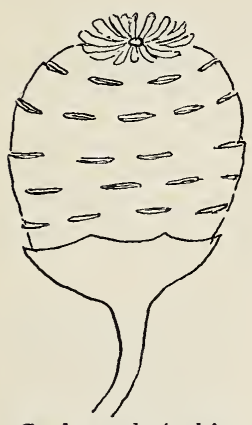

Seed vessel of white pond lily. upon a hillside. How could its roots, furnished with such insufficient rootlets, get nourishment there? How could its soft, flexible stems hold aloft the heavy leaves and blossoms to the sunlight? In such a situation it would be a mere drooping mass. Moreover, if the pupils understand the conditions in which the water lilies grow in their own neighborhood, they can understand the conditions under which the plant grows in other countries. Thus, when they read about the great Victoria regia of the Amazon, - that water lily whose leaves are large enough to support $\varepsilon$ man,- - they would have visions of broad stretches of still water and they should realize that the bottom must be silt. If they read about the lotus. of Egypt, then they should see the Nile as a river with borders of sti1l water and with bottom of silt. Thus, from the conditions near at hand, we may cultivate in the child an intelligent geographical imagination.

\section{LESSON CXXXII}

\section{The Water Lily}

Leading thought-The water lily has become dependert upon certain conditions in pond or stream, and has become unfitted in form to live elsewhere. It must have quiet waters, not too deep, and with silt bottom.

Method-The study should be made first with the water lilies in a stream or pond, to discover just how they grow. For the special structure, the leaves and flowers may be brought to the schoolroom and floated in a pan of water. The lesson may easily be modified to fit the yellow water lily, which is in many ways even more interesting, since in shallow water it holds its leaves erect while in deeper water its leaves float.

Observations-r. Where is the water lily found? If in a pond, how deep is the water? If in a stream, is it in the current? What kind of bottom is there to the stream or pond? Do you find lilies in the water of a limestone region? Why?

2. What is the shape of the leaf? What is the color above and below? What is the texture? How is it especially fitted to float? How does it look when very young?

3. Examine the petiole. How long is it? Is it stiff enough to hold up the leaf? Why does it not need to hold up the leaf? How does it serve as an anchor? Cut a stem across and describe its inside structure. How does this structure help it float?

4. Examine the open flower. How many sepals? How many rows of petals? How do the stamens resemble the petals? Can you see in the water lily how the sepals, petals and stamens may all be different forms of the same thing? How are the sepals fitted to keep the flower afloat? At what times of the day does the lily open? At what hours does it close? 
5. Describe the pistil. When the lily first opens, how are the stamens placed around the pis'il? What happens to the seed-box after the blossoms have faded? Does the seed-pod float upon the water as did the flower? What sort of stem has the flower? How does this stem hold the seed-pod below the water?

6. What sort of seed has the water lily? Sketch the seed-pod. How does the seed escape from it? How is it scattered and planted?

7. What sort of a root has the water lily? Are there many fine rootlets upon it? Why? How does this rootstock serve the plant aside from getting food?

8. Imagine a water lily set on a dry hillside. Could the stems uphold the flowers or leaves? Is the petiole large enough to hold out such a thick, heavy leaf? Could the root get food from a dry location? Why?

9. Judging from what you know of the places where water lilies grow and the condition of the water there, describe the Nile where the lotus grows. Describe the Amazon where the Victoria regia grows.

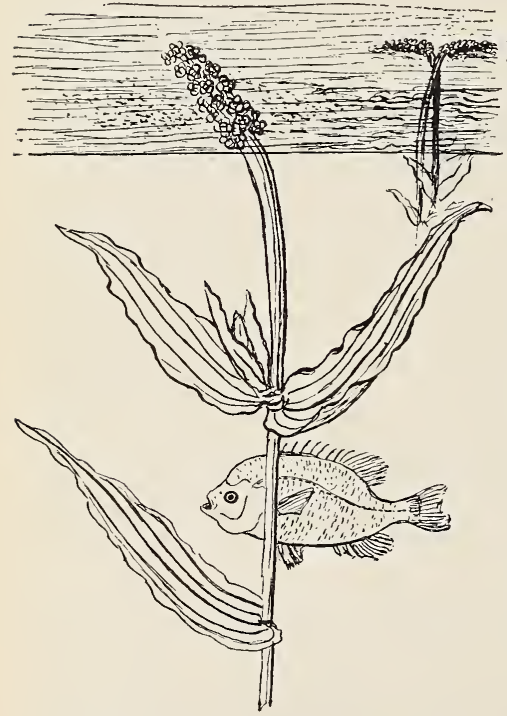

\section{PONDWEED}

\section{Teacher's Story}

HE study of any plant which has obvious limitations as to where it may grow should be made a help in the study of geography. Pondweed is an excellent subject to illustrate this principle; it grows only in quiet beds of sluggish streams or in ponds, or in the shallow protected portions of lakes. It has tremendous powers of stretching up, which render it able to grow at greater depth than one would suppose possible, often flourishing where the water is from ten to twenty feet deep. Often, when the sun is shining, it may be seen like a bed of seaweed on the bottom. Its roots, like those of most water plants, have less to do with the matter of absorbing water and nourishment than do the roots of land plants, one of their chief functions being to anchor the plant fast: they have a firm grip on the bottom; and if pondweed is cut loose, it at once comes to the sur. face, floats helplessly on its side, and soon dies.

The stem is very soft and pliable and the plant relies entirely on the water to keep it upright. A cross-section of the stem shows that its substance is spongy, with the larger open cells near the outer edge, thus helping it to float. The leaves are two or three inches long, their broad bases encircling the stem, their tips tapering to slender points. They have 
parallel veins and ruffled edges. They are dull olive green in color, much darker than the stems; in texture they are very thin, papery, and so shining as to give the impression of being varnished. No land p'ants have such leaves; they remind us at once of kelp or other seaweeds. The leaves are scattered along the stems, by no means thickly, for water plants do not seem to need profuse foliage.

In blossom time the pondweed shows its real beauty. The stems grow and grow, like Jack's bean stalk, and what was a bed of leaves on the pond bottom suddenly changes into a forest of high plants, each one standing tall and straight and with every leaf extended, as if its stems were as strong and stiff as ironwood; but if a wave disturbs the water the graceful undulations of the plant tell the true story of the pliant stems. There is something that arouses our admiration when we see one of these pondweeds grown so straight and tall, often three or four yards high, in order to place its little, greenish-brown flower-head above the water's surface.

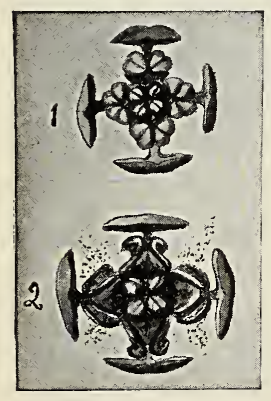

We have spent hours looking down into such a submerged forest, dreaming and wondering about the real meaning of such adaptations.

Although the stem is flexible, the somewhat curved, enlarged portion of it just below the flowerhead is rigid; it is also more spongy than the lower part of the stem and is thus fitted to float the flower. The flower itself is one of the prettiest sights that nature has to show us through a lens. It is a Maltese cross, the four reddish stigmas arranged in a solid square at the center; at each side of this central square is a double-barrelled anther, and outside of each anther is a queer, little, dipper-shaped, green sepal. When the anthers open, they push away I, Flower of a pond - from the stigmas and throw their pollen toward the weed enlarged, early stage, outside. There may be thirty or more of these 2, Same at later stage. tiny, cross-shaped flowers in one flower-head. In the bud, the cup-shaped sepals shut down closely, exposing the stigmas first, which would indicate that they ripen before the pollen is shed. The pollen is white, and is floated from plant to plant on the surface of the water; often the water for yards will be covered with this living dust.

\section{LESSON CXXXIII}

PONDWEED

Leading thought-The pondweed lives entirely below the water; at blossom time, however, it sends up its flower stems to the surface of the water, and there sheds its pollen, thus securing cross-pollenation.

Method-As this is primarily a lesson that relates to geography, the pondweed should be studied where it is growing. It may be studiea in the spring or fall, and the pupils asked to observe the blossoming which occurs in late July. After the pupils have seen where it grows, the plants themselves may be studied in an aquarium, or by placing them in a pail or basin of water. There are confusing numbers of pondweeds but any of them will do for this lesson. The one described in the Teacher's Story is probably $P$. perfoliatus. 
Observations-I. Where is the pondweed found? Does it ever grow out of water? Does it ever grow in very deep water? Does it ever grow in swiftly flowing water?

2. Has the pondweed a root? Does the pondweed need to have water carried to its leaves, as it would if it were living in the air? What is -ne of the chief uses of the roots to the pondweed? Break off a plant, does it float? Do you think it would float off and die, if it was not anchored by its root?

3. Compare the stem of pondweed with that of any land plant standing straight. What is the chief difference? Why does the pondweed not need a stiff stem to hold it up? Cut the stem across, and see if you can observe why it floats?

4. Examine the leaves. Are all of them below the surface of the water? If some float, how do they differ in texture and form from those submerged? How are they arranged on the stem? Are they set close together? What is the difference in texture between its leaves and those of the jewelweed, dock or any other land plant? If any leaves project out of the water are they different in form and texture from those submerged? Sketch the leaf, showing its shape, its edges, and the way it joins the stem.

5. How far below the surface of the water does the pondweed usually lie? Does it ever rise up to the water's surface? When? Have you ever noticed the pondweed in blossom? How does the blossom look on the water? Can you see the white pollen floating on the surface of the water? Look down into the water and see the way the pondweed stands in order to float its blossoms.

6. Study the blossom. Note the stem that bears it. Is the part that bears the flower enlarged and stiffer than the stem below? Do you think that this enlarged part of the stem acts like the bob on a fish-line? Examine a flower cluster with a lens. How many flowers upon it? Study one flower carefully. Describe the four stigmas at the center. Describe the anthers arranged around them. Describe the sepal which protects each anther. When the anthers open do they discharge the pollen toward or away from the stigmas?

7. What happens after the flowers are pollenated? Do they still float? What sort of seed-capsule has the pondweed? Do the seeds break away and float

\footnotetext{
"Again the wild cow-lily floats

Her golden-freighted, tented boats, In thy cool caves of softened gloom,

O'ershadowed by the whispering reed,

And purple plumes of pickerel weed, And meadow-sweet in tangled bloom.

"The startled minnows dart in flocks,

Beneath thy glimmering amber rocks, If but a zephyr stirs the brake;

The silent swallow swoops, a flash

Of light, and leaves with dainty plash, A ring of ripples in her wake."
}

- "Birch Stream", Anna Boynton Averizs. 


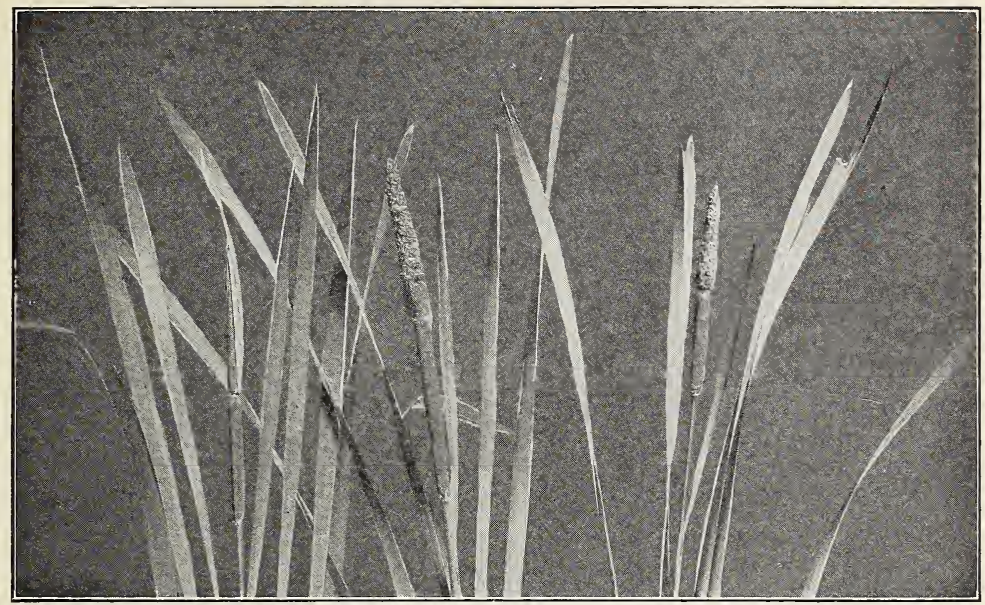

Cat-tail flag in blossom.

The staminate flowers are massed at the tip, and the pistillate flowers which form the "cat-tail" are massed lower down on the stalk.

Photo by Verne Morton.

\section{THE CAT-TAIL}

\section{Teacher's Story}

In June and early July, if the cat-tail be closely observed, it will be seen to have the upper half of the cat's tail much narrower and different in shape from the lower half-as if it were covered with a quite different fur. It seems to be clothed with a fine drooping fringe of olive-yellow. With the aid of a lens, we can see that this fringe is a mass of crowded anthers, two or three of them being attached to the same stalk by a short filament. These anthers are packed full of pollen, which is sifted down upon the pistillate flowers below by every breeze; and with every puff of

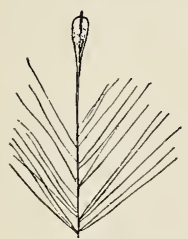

A cat-tail seed with its balloon. stronger wind, the pollen is showered over all neighboring flowers to the leeward. There is not much use in trying to find the pistillate flowers in the plush of the cat-tail. They have no sepals nor petals, and are so imbedded in the thick pappus which forms the plush that the search is hardly worth while for nature-study, unless a microscope is used. The ovary is rather long, the style slender, and the stigma reaches out to the cut-plush surface of the cat-tail. The pupils can find what these flowers are by studying the seed; in fact, the seed does not differ very much from the flower, except that it is mature and is browner in color.

It is an interesting process to take apart a cat-tail plant; the lower, shorter leaves surround the base of the plant, giving it size and strength. All the leaves have the same general shape, but vary in length. Each leaf consists of the free portion, which is long and narrow and flat towards its tapering tip but is bent into a trough as it nears the plant, and the lower 
portion of the leaf, which clasps the plant entirely or partially, depending upon whether it is an outer or inner leaf, and thus adds to its strength. We almost feel as if these alternate leaves were consciously doing their best to protect the slender, flower stem. The free part of the leaves is strengthened by lengthwise veins, and they form edges that never tear nor break. They are very flexible, and therefore yield to the wind rather than defy it. If we look at a leaf in cross-section, we can see the two thick walls strengthened by the framework of stiff veins which divide the interior into long cells. If we cut the leaf lengthwise we can see that these long cells are supported by stiff, coarse partitions.

Where the leaf clasps the stem, it is very stiff and will break rather than bend. The texture of the leaf is soft and smooth, and its shade of green is attractive. The length of the leaves is often greater thar that of the blossom stalk, and their graceful curves contrast pleasantly with its ramrod-like stiffness. It is no wonder that artists and the decorators have used the cat-tail lavishly as a model. It is interesting to note that the only portion of the leaves injured by the wind is the extreme tip.

The cat-tail is adapted for living in swamps where the soil is wet but not under water all the time. When the land is drained, or when it is flooded for a considerable time, the cat-tails die out and disappear. They usually occur in marshy zones along lakes or streams; and such a zone is always sharply defined by dry land on one side and water on the other. The cat-tail roots are fine and fibrous and are especially fitted, like the roots of the tamarack, to thread the mud of marshy ground and thus gain a foothold. The cat-tails form one of the cohorts in the phalanx of encroaching plants, like the reeds and rushes, which surround and, by a slow march of years, finally conquer and dry up ponds. But in this they overdo the matter, since after a time the soil becomes too dry for them and they disappear, giving place to other plants which find there a congenial environment. The place where I studied the cat-tails as a child is now a garden of joe pye weed and wild sunflowers.

Reference-Plant Life, Coulter.

\section{LESSON CXXXIV}

The CAT-TAIL.

Leading thought - The cat-tail is adapted to places where the soil is wet but not under water; its pollen is scattered by the wind, and its seeds are scattered by wind and water. Its leaves and stalks are not injured nor broken by the wind.

Method-As this is primarily a geography lesson, it should be given in the field if possible; otherwise the pupils must explore for themselves to discover the facts. The plant itself can be brought into the schoolroom for study. When studying the seeds, it is well to be careful, or the schoolroom and the pupils will be clothed with the pappus for weeks.

Observations-I. Where are the cat-tails found? Is the land on which they grow under water all the year? At any part of the year? Is it dry land all the year? What happens to the cat-tails, if the land on which they grow is flooded for a season? What happens tc them, if the land is drained?

2. How wide a strip do the cat-tails cover, where you have found them? Are they near a pond or brook or stream Do they grow out in 


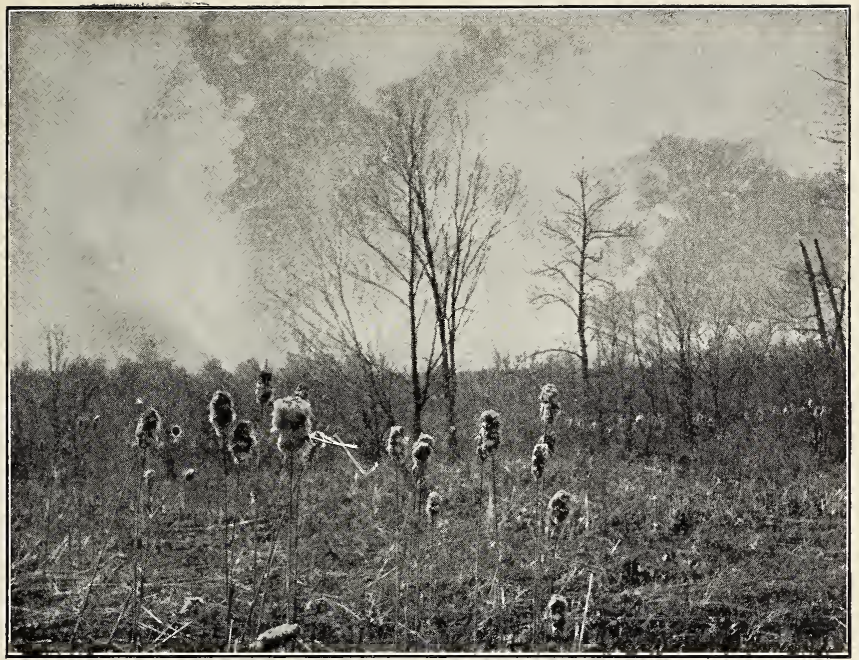

Cut-tails sending off their seed balloons.

Photo by Verne Morton.

the stream? Why do they not extend further inland? What is the character of the soil on which they grow?

3. What sort of a root has the cat-tail? Why is this root especially adapted to the soil where cat-tails grow? Describe the rootstock.

4. The cat-tail plant. Are the leaves arranged opposite or alternate? Tear off a few of the leaves and describe the difference between the lower and the upper end of a leaf as follows: How do they differ in shape? Texture? Pliability? Color? Width? Does each leaf completely encircle the stalk at its base? Of what use is this to the plant? Of what use is it to have the plant stiffer where the leaves clasp the stalk? What would happen in a wind storm if this top-heavy, slender seed stalk was bare and not supported by the leaves? What is the special enemy of long, tall, slender-leafed plants?

5. Take a single leaf, cut it across near where it joins the main stalk and also near its tip. Look at the cross-section and see how the leaf is veined. What do its long veins or ribs do for the leaf? Split the leaf lengthwise and see what other supports it has. Does the cat-tail leaf break or tear along its edges easily? Does the wind injure any part of the leaf?

6. Study the cat-tail flowers the last half of June. Note the part that will develop into the cat's tail. Describe the part above it. Can you see where the pollen comes from? The pistillate flowers which are in the plush of the cat-tail have no sepals, petals, odor nor nectar. Do you think that their pollen is carried to them by the bees? How is it carried?

7. Examine the cat-tail in fall or winter. What has happened to that part of the stalk above the cat-tail where the anthers grew? Study 
two or three of the seeds, and see how they are proviaed for traveling. What scatters them? Will the cat-tail seed balloons float? Would the wind or the water be more likely to carry the cat-tail seeds to a place where they would grow? Describe the difference between the cat-tail balloon and the thistle balloon.

8. How crowded do the cat-tail plants grow? How are they arranged to keep from shading each other? In how many ways is the wind a friend of the cat-tails?

9. How do the cat-tails help to build up land and make narrower ponds and streams?

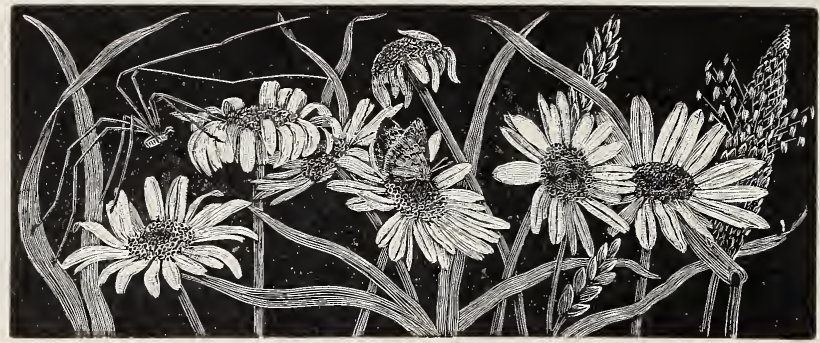

Daises and grasses,

\section{LESSON CXXXV}

A Type Lesson for a Composite Flower

Leading thought-Many plants have their flowers set close together to make a mass of color, like the geraniums or the clovers. But there are other plants where the flowers of one flower-head act like the members of a family, those at the center doing a certain kind of work for the production of seed, and those around the edges doing another kind of work. The sunflower, goldenrod, asters, daisies, cone-flower, thistle, dandelion, burdock, everlasting, and many other common flowers have their blossoms arranged in this way. Before any of the wild-flower members of this family are studied, the lesson on the garden sunflower should be given. (See Lesson CLXII).

Method-These flowers may be studied in the schoolroom with suggestions for field observations. A lens is almost necessary for the study of most of these flowers.

Observations-I. Can you see that what you call the flower consists of many flowers set together like a beautiful mosaic? Those at the center are called disk-flowers; those around the edges banner or ray-flowers.

2. Note that the flowers around the edges have differently shaped corollas than those at the center. How do they differ? Why should these be called the banner flowers? Why should they be called the ray. flowers? How many banner-flowers are there in the flower family you are studying? How are the banners arranged to make the flower-head more attractive? Cut off or pull out all the banner-flowers and see how the flower-head looks. What do the banner-flowers hold out their ban- 
ners for? Is it to attract us or the insects? Has the banner-flower any stigma or stamens?

3. Study the flowers at the center. Are they open, or are they unfolded, buds? Can you make a sketch of how they are arranged? Are any of the florets open? What is the shape and the color of the corolla? Can you see the stamen-tubes pushing out from some? What color are the stamen-tubes? Can you see the two-parted stigmas in others? What color is the pollen. Do the florets at the center or at the outside of the disk open first? When they first open, do you see the stamen-tube or the stigma?

4. The flower-heads are protected before they open with overlapping bracts, which may be compared to a shinglec. house protecting the flower family. As the flower-head opens, these bracts are pushed back beneath it. Describe the shape of these bracts. Are they set in regular, overlapping rows? Are they rough or smooth? Do they end bluntly, with a short point, with a long point, with a spine, or a hook? How do the bracts act when the flower family goes to sleep? Do they remain after the seeds are ripened?

5. Take a flower-head apart, and examine the florets. Can you see what part of the floret will be the seed? Is there a fringe of pappus above it? If so, what will this be on the seed?

6. Study the ripe seeds. How are they scattered? Do they have balloons? Is the balloon close to the seed? Is it fastened to all parts of it?

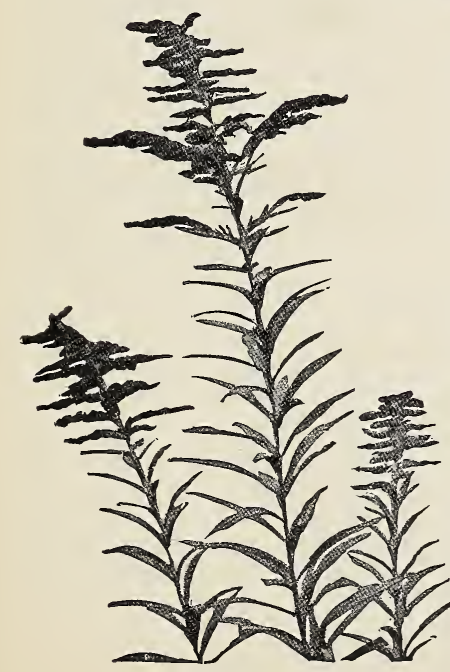

Goldenrcd.

\section{THE GOLDENROD}

\section{Teacher's Story}

Once I was called upon to take some children into the field to study autumn flowers. The day we studied goldenrod, I told them the following story on the way, and I found that they were pleased with the fancy and through it were led to see the true purpose of the goldenrod blossoming:

"There are flowers which live in villages and cities, but people who also live in villages and cities are so stupid that they hardly know a flower city when they see it. This morning we are going to visit a golden city where the people are all dressed in yellow, and where they live together in families; and the families all live on top of their little, green, shingled houses, which are set in even rows along the street. In each of these families, there are some flowers whose business it is to furnish nectar and pollen and to produce seeds which have fuzzy balloons; while there are other 
flowers in each family which wave yellow banners to all the insects that pass by and signal them with a code of their own, thus: 'Here, right this way is a flower family that needs a bee or a beetle or an insect of some sort to bring it pollen from abroad, so that it can ripen its seed; and it will give nectar and plenty of pollen in exchange.' Of course, if the flowers could walk around like people, or fly like insects, they could fetch and carry their own pollen, but as it is, they have to depend upon insect messengers to do this for them. Let us see who of us will be the first to guess what the name of this golden city is, and who will be the first to find it."

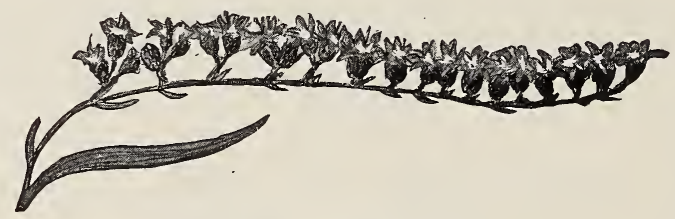

A street in goldenrod city.

The children were delighted with this riddle and soon found the goldenrod city. We examined each little house with its ornate, green "shingles." These little houses, looking like cups, were arranged on the street stem, right side up, in an orderly manner and very close together; and where each joined the stem, there was a little, green bract for a doorstep. Living on these houses we found the flower families, each consisting of a few tubular disk-flowers opening out like bells, and coming from their centers were the long pollen-tubes or the yellow, two-parted stigmas. The ray-flowers had short but brilliant banners; and they, as well as the disk-flowers, had young seeds with pretty fringed pappus developing upon them. The banner-flowers were not set so regularly around the edges as in the asters; but the families were such close neighbors, that the banners reached from one house to another. And all of the families on all of the little, green streets were signalling insects, and one boy said, "They must be making a very loud yellow noise." We found that /very many insects had responded to this call-honeybees, bumblebees, mining and carpenter bees, blue-black blister beetles with short wings and awkward bodies, beautiful golden-green chalcid flies, soldier beetles and many others; and we found the spherical gall and the spindle-shaped gall in the stems, and the strange gall up near the top which grew among the leaves.

Unless one is a trained botanist it is wasted energy to try to distinguish any but the well-marked species of goldenrod; for, according to Gray, we have 56 species, the account of which makes twelve pages of most uninteresting reading in the new Manual. The goldenrod family is not in the least cliquish, the species have a habit of interbreeding to the confusion of the systematic botanist. Matthew's Field Book serves as well as any for distinguishing the well-marked species. 


\section{LESSON CXXXVI}

The Goldenrod

Leading thought-In the goldenrod the flower-heads or families are so small that, in order to attract the attention of tine insects, they are set closely together along the stem to produce a mass of color.

Method-Bring to the school-room any kind of goldenrod, and give the lesson on the flowers there. This should be followed by a field excursion to get as many kinds of goldenrod as possible. The following observations will bring out differences in well-marked species:

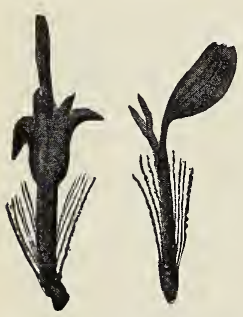

Disk-flower and banner-flower of goldenrod.

Observations-I. Use Lesson CXXXV to study the flower. How many banner-flowers in the family? How many disk-flowers? Are the banners arranged as regularly around the edges as in the asters and daisies? How are the flower-heads set upon the stems? Which flower-heads open first-those at the base or at the tip of the stem? Do the upper stems of the plant blossom before those lower down?

2. Do the stems bearing flowers come from the axils of the leaves? What is the general shape of the flower branches? Do they come off evenly at each side, or more at one side? Are the flower branches long or short? Make a sketch of the general shape of the goldenrod you are studying.

3. Is the stem smooth, downy, or covered with bloom? What is its color? In cross-section, is it circular or angular?

4. What is the shape and form of the edges of the lower leaves? The upper ones? Are they set with, or without, petioles on the stem? Do they have a heart-shaped base? Are the leaves smooth or downy? Are they light, or dark green?

5. Field notes. Where do you find the goldenrod growing? Do you find one kind growing alone or several kinds growing together? Do you find any growing in the woods? If so, how do they differ in shape from those in the field?

6. How many kinds of insects do you find visiting goldenrod flowers? How many kinds of galls do you find on the goldenrod stems and leaves?

7. Study the goldenrods in November. Describe their seeds and how they are scattered.

"I am alone with nature,

With the soft September day;

The lifting hills above me,

With goldenrod are gay.

Across the fields of ether

Flit butterflies at play;

And cones of garnet sumac

Glow down the country way.

"The autumn dandelion

Beside the roadway burns;

Above the lichened boulders

Quiver the plumed ferns.

The cream-white silk of the milkweed Floats from it's sea-green pod;

From out the mossy rock-seams Flashes the goldenrod." 


\section{THE ASTERS \\ Teacher's Story}

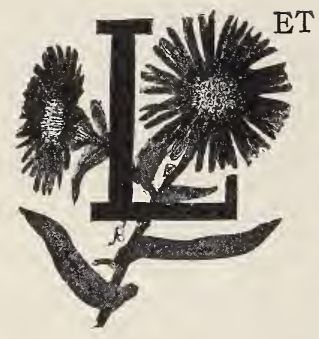

us believe that the scientist who gave to the asters their Latin name was inspired. Aster means star and these, of all flowers, are most starlike; and in beautiful constellations they border our fields and woodsides. The aster combination of colors is often exquisite. Many have the rays or banners lavender, oar-shaped and set like the rays of a star around the yellow disk-flowers; these latter send out long, yellow anther tubes, overflowing with yellow pollen, and add to the stellar appearance of the flowerhead.

"And asters by the brookside make asters in the brook."

Thus sang $\mathrm{H}$. $\mathrm{H}$. of these beautiful masses of autumn flowers. But if H. H. had attempted to distinguish the species, she would have said rather that asters by the brookside make more asters in the book: for Gray's Manual assures us that we have 77 species including widely different forms, varying in size, color and also as to the $\epsilon$ nvironment in which they will grow. They range from the shiftless woodland species, which has a few whitish ray-flowers hanging shabbily about its yellow disk and with great, coarse leaves on long, gawky petioles climbing the zigzag stem, to the beautiful and dignified New England aster, which brings the glorious purple and orange of its great flower-heads to decorate our hills in September and October.

Luckily, there are a few sp cies which are fairly well marked, and still more luckily, it is not of any consequence whether we know the species or not, so far as our enjoyment of the flowers themselves is concerned. The outline of this lesson will call the attention of the pupils to the chief points of difference and likeness in the aster species, and they will thus learn to discriminate in a general way. The asters, like the goldenrods, begin to bloom at the tip of the branches, the flower-heads nearest the central stem, blooming last. All of the asters are very sensitive, and the flowerheads will close promptly as soon as they are gathered. The ray or banner-flowers are pistillate, and therefore develop seed. The seed has
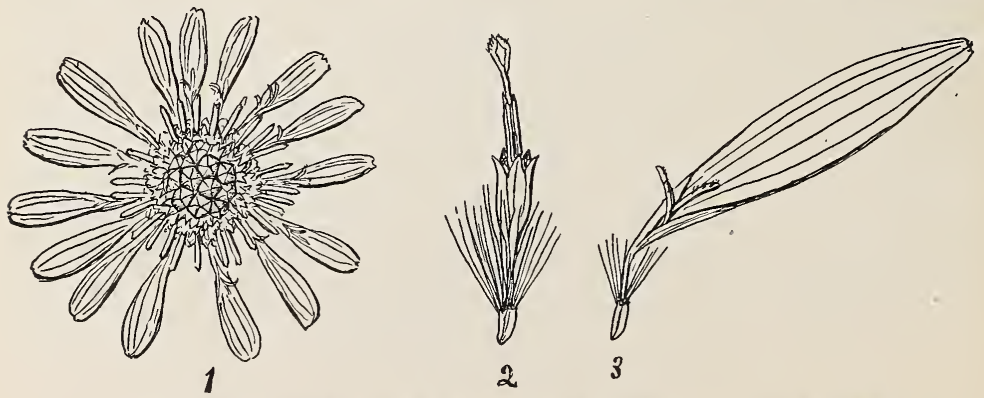

I, an aster flower-head enlarged; 2, a disk-flower; 3, a banner-flowes. 
attached to its rim a ring of pappus, and is ballooned to its final destina. tion. In November, the matured flower-heads are fuzzy, with seeds ready for invitations from any passing wind to fly whither it listeth.

\section{LESSON CXXXVIJ}

\section{The Asters}

Leading thought-There are very many different kinds of asters, and they all have their flowers arranged similarly to those of the sunflower.

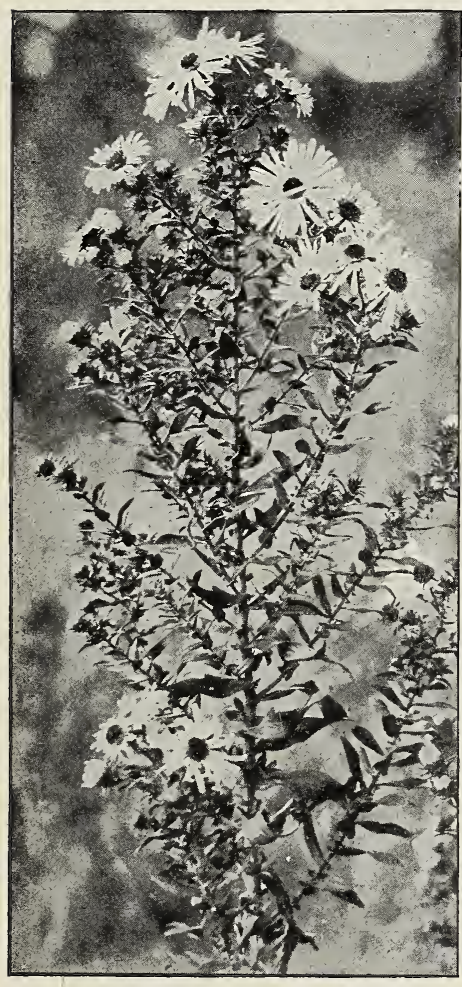

Asters.

Method-Have the pupils collect as many kinds of asters as possible, being careful to get the basal leaves and to take notes on where each kind was found-that is, whether in the woodlands, by the brooksides or in the open fields. This lesson should follow that on the sunflower.

Observations-I. What was the character of the soil and surroundings where this aster grew? Were there large numbers of this kind growing together? Were the flowers wide open when you gathered them? How soon did they close?

2. How high did the plants stand when growing? Were there many flowers, or few, on each plant?

3. Study the lower and the upper leaves. Describe each as follows: the shape, the size, the edges, the way it was joined to the stem.

4. Is the stem many-branched or few? Do the branches bearing flowers extend in all directions? Are the stems hairy or smooth, and what is their color?

5. What is the diameter of the single flower-head? What is the color of the ray-flowers? How many ray or banner-flowers are there? What is the shape of a single banner as compared with that of a sunflower? What are the colors of the disk-flowers? Of the pollen? Do the disk-flowers change color after blossoming?

6. Look at the bracts below the flower-head. Are they all the same shape? What is their color? Do they have recurved tips or do they overlap closely? Are they sticky?

7. Take the aster flower-head apart and look at it with a lens. In a disk-flcwer, note the young seed, the pappus, the tubular five-parted corolla, the anther tube and the stigmas. In the ray-flower, find the voung seed. the pappus and the stigma. 
8. Watch the bees working on asters, and find where they thrust their tongues to reach the nectar.

9. Study an aster plant in November, and describe the seeds and how they are scattered.

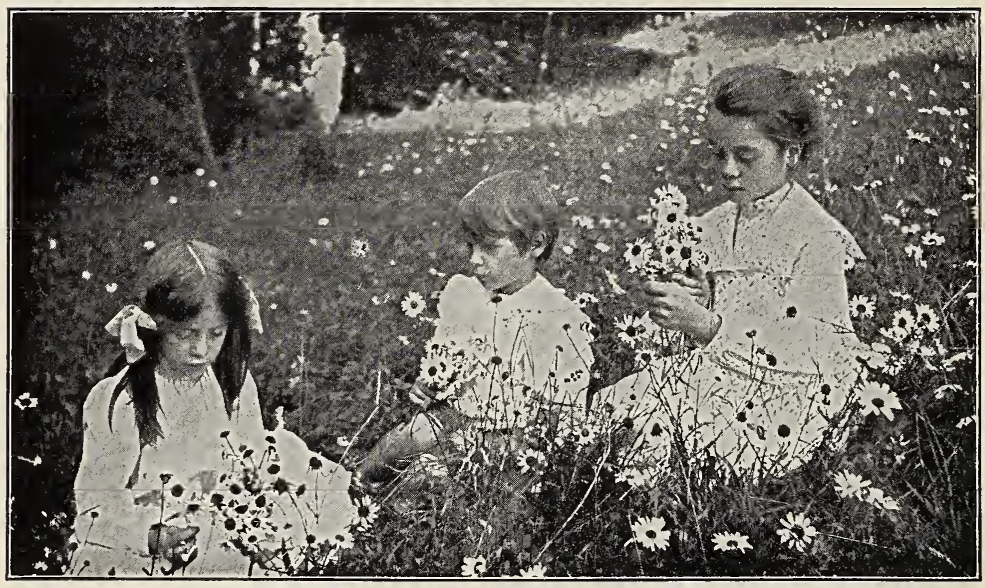

Gathering daisies.

Photo by Verne Morton

\section{THE WHITE DAISY}

Teacher's Story

Every child loves this flower, and yet it is not well understood; it is always at hand for study from June until the frosts have laid

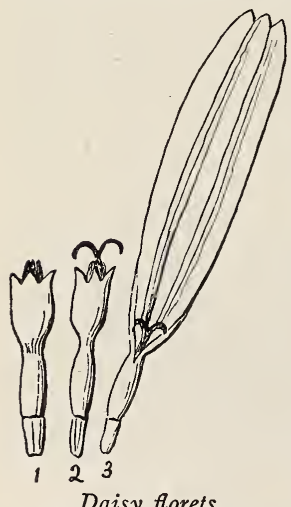

Daisy florets.

1. Disk-flower in pollen-stage; 2. Disk-flower in stigma-stage; waste the fields. However much enjoyment we get from the study of this beautiful flowerhead, we should study the plant as a weed also, for it is indeed a pest to those farmers who do not practice a rotation of crops. Its root is long and tenacious of the soil, and it ripens many seeds which mingle with the grass seed, and thus the farmer sows it to his own undoing. The bracts of the involucre, or the shingles of the daisy-house, are rather long, and have parchment like margins. They overlap in two or three rows. In the daisy flower-head, the bannerflowers are white; there may be twenty or thirty of these, making a beautiful frame for the goldenyellow disk-flowers. The banner is rather broad, is veined, and toothed at the tip. The bannerflower has a pistil which shows its two-parted stigma at the base of the banner, and it matures a seed. The disk-flowers are brilliant yellow, tubular, rather short, with the five points of the 
corolla curling back. The anther-tubes and the pallen are yellow, so are the stigmas. The arrangement of the buds at the center is exceedingly pretty. The flowers develop no pappus, and therefore the seeds have no balloons. They depend upon the ignorance and helplessness of man to scatter their seeds far and wide with the grass and clover seed, which he sows for his own crops. It was thus that it came to America, and in this manner still continues to flaunt its banners in our meadows and pastures. The white daisy is not a daisy, but a chrysanthemum. It has never been called by this name popularly, but has at least twenty other common names, among them the ox-eye daisy, moon-penny, and herb-Margaret.

\section{LESSON CXXXVIII \\ The White Daisy}

Leading thought-The white-daisy is not a single flower but is made up of many little flowers and should be studied by the outline given in Lesson CXXXV.

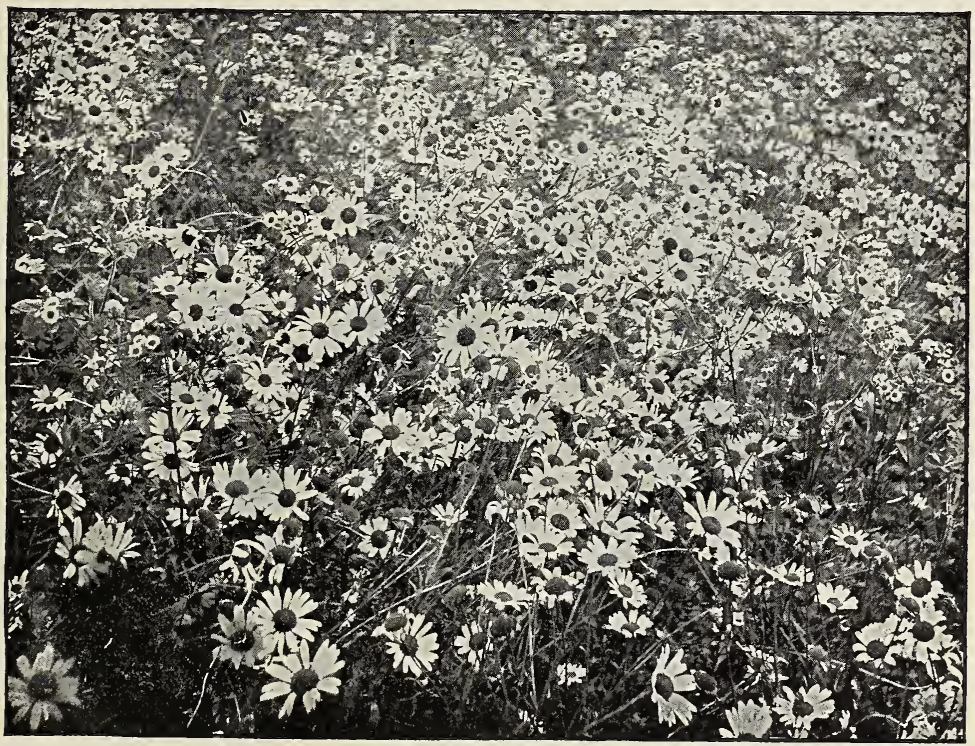

A daisy meadow. 


\section{THE YELLOW DAISY, OR BLACK-EYED SUSAN Teacher's Story}

These beautiful, showy flowers have rich contrasts in their color scheme. The ten to twenty-ray flowers wave rich, orange banners

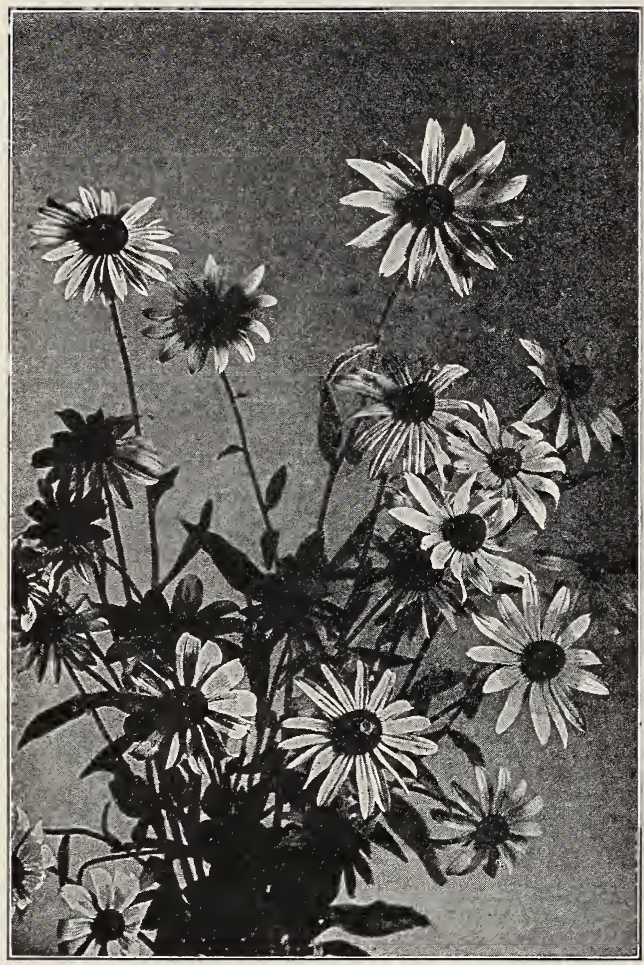
around the cone of purple-brown disk-flowers. The banners are notched and bent downward at their tips; each banner-flower has a pistil, and develops a seed. The disk-flowers are arranged in a conical, button-like center; the corollas are pink-purple at the base of the tube, but their five recurved, pointed lobes are purple-brown. The anthertube is purple-brown and the stigmas show the same color; but the pollen is brilliant orange, and adds much to the beauty of the rich, dark florets when it is pushed from the anther-tubes. There is no pappus developed, and the seeds are carried as are the seeds of the white daisy, by being harvested with the seeds of grain.

The stem is strong and erect; the bracts of the involucre, or "shingles", are long, narrow and hairy, the lower ones being longer and wider than those above; they all spread out flat, or recurve below the open flower-head. In blossoming, first the ray-flowers spread wide their banners; then the flowerets around the base of the cone open and push out their yellow pollen through the brown tubes; then day by day the blossoming circle climbs toward the apex-a beautiful way of blossoming upward.

\section{LESSON CXXXIX}

\section{The Black-Eyed Susan}

Leading thought-This flower should be studied by the outline given in Lesson CXXXV.

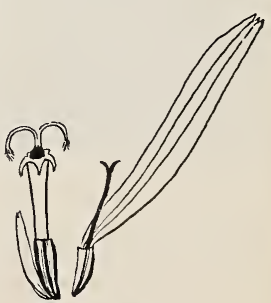

Disk-flower and ray. flower. 


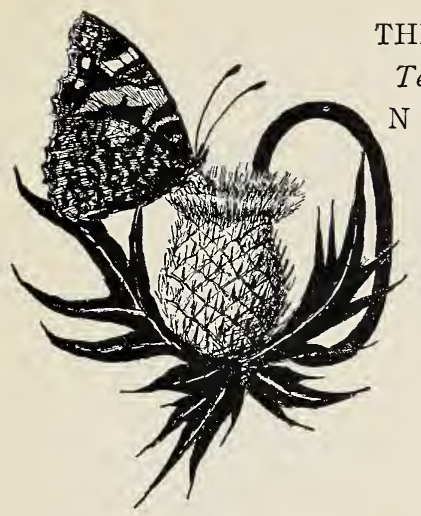

THE THISTLE

Teacher's Story

$\mathrm{N}$ looking at the thistle from its own standpoint, we must acknowledge it to be a beautiful and wonderful plant. It is like a knight of old encased in armor and with lance set, ready for the fray. The most impressive species is the great pasture, or bull, thistle (C. pumilis), which has a blossom-head three inches across. This is not so common as the lance-leaved thistle, which ornaments roadsides and fence corners, where it may remain undisturbed for the necessary second year of growth before it can mature its seeds. The most pernicious species, from the farmer's standpoint, is the Canada thistle. Its roots are perennial, and they invade garden, grain field and meadow. They creep for yards in all directions, just deep enough to be sure of moisture, and send up new plants here and there, especially if the main stalk is cut off. Roots severed by the plow, send up shoots from both of the broken parts. Not so with the common thistle, which has a single main root, with many fibrous and clustered branches but with no side shoots.

The stalk of the lance-leaved thistle is strong and woody, and is closely hugged by pricky leaf stems, except for a few inches above the root. The leaves are placed alternately. on the stalk; they are deep green, covered above with rough and bristling hairs, and when young are covered on the under side with soft, gray wool which falls away later. The spines grow on the edges of the leaves, which are deeply lobed and are also somewhat wavy and ruffled, thus causing the savage spears to meet the enemy in any direction. The ribs and veins are without spines. Small buds or branches may be found at the axils of the leaves; and if a plant is beheaded, those axiliary buds nearest the top of the stem will grow vigorously.

The thistle flowers are purple in color and very fragrant; they grow in single heads at the summit of the stalk, and from the axils of the upper leaves. The topmost heads open first. Of the individual flnwers in the head, those of the

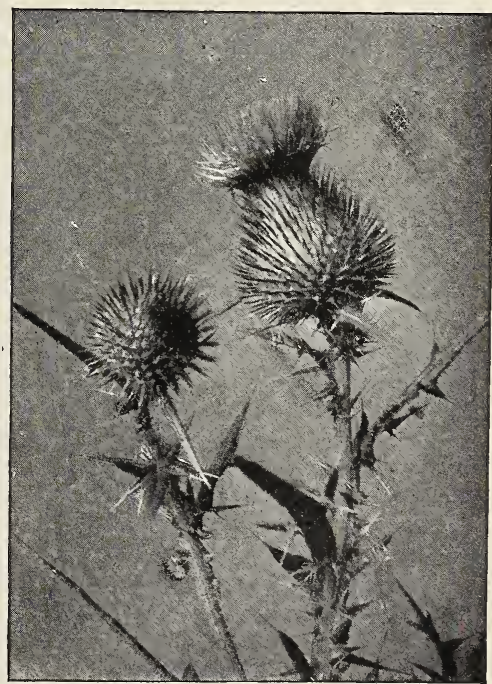

Lance-leaved thistle. 
outer rows first mature and protrude their pistils; the pollen grains are white. In each flower, the corolla is tube-shaped and purple, parting into five fringelike lobes at the top, and fading to white at its nectar-filled base.

The stamens have dark purple anthers, united in a tube in which their pollen is discharged. The pistil, ripening later, shoves out the pollen with its stigma, which at first is blunt at the end, its two-parted lips so tightly held together that not a grain of its own flower's pollen can be taken. But when thrust far out beyond the anther-tube, the two-parted stigma opens to receive the pollen which is brought by the many winged visitors; for of all flowers, the thistles with their abundant nectar are the favorites of insects. Butterflies of many species, moths, beetles and bees - especially the bumblebees - are the happy guests of the thistle blooms.

The thistles believe in large families; a single head of the lance-leaved thistle has been known to have $r \mathrm{r} 6$ seeds. The seeds are oblong, pointed, little akenes, with hard shells. Very beautiful and wonderful is the pappus of the thistle; it is really the calyx of the flower, its tube being a narrow collar, and the lobes are split up into the silken floss. At the larger end of the seed is a circular depression with a tiny hub at its center; into this ring, and around the knob, is fitted the collar which attaches the down to the seed. Hold the balloon between the eye and the light, and it is easy to see that the down is made of many-branched plumes which interlace and make it more buoyant. When first taken from its crowded position on the flower-head, the pappus surrounds the corolla in a straight, close tube; but if placed for just a few moments in the sun, the threads spread, the filmy branchlets open out, and a fairy parachute is formed, with the seed hanging beneath; if no breath of air touches it while spreading, it will sometimes form a perfect funnel; when blown upon, some of the silken threads lose their places on the rim and rise to the center. When driven before the breeze, this balloon will float for a long distance. When it falls, it lets go of the seed as the wind moves it along the rough surface of the ground, and when' A flrret from it is thus unburdened the down fluffs out in every direction, a thistle making a perfect globe.

flower-head. For the first season after the seed has rooted, the thistle develops only rosettes, meanwhile putting down roots and becoming permanently established. The next season, the flowers and seeds are developed, and then the plant dies. Would that this fact were true of the Canada thistle; but that, unfortunately, is perennial, and its persistent roots can only be starved out by keeping the stalks cut to the ground for the entire season. This thistle trusts to its extensively creeping rootstocks more than to its seeds for retaining its foothold and for spreading. While it develops many seed balloons, a large number of its seeds are infertile and will not grow.

\section{LESSON CXL}

\section{The Common, or Lance-leaved, Thistle}

Leading thought-The thistle is covered with sharp spines, and these serve to protect it from grazing animals. It has beautiful purple flowers, arranged in heads similar to those of the sunflower. 


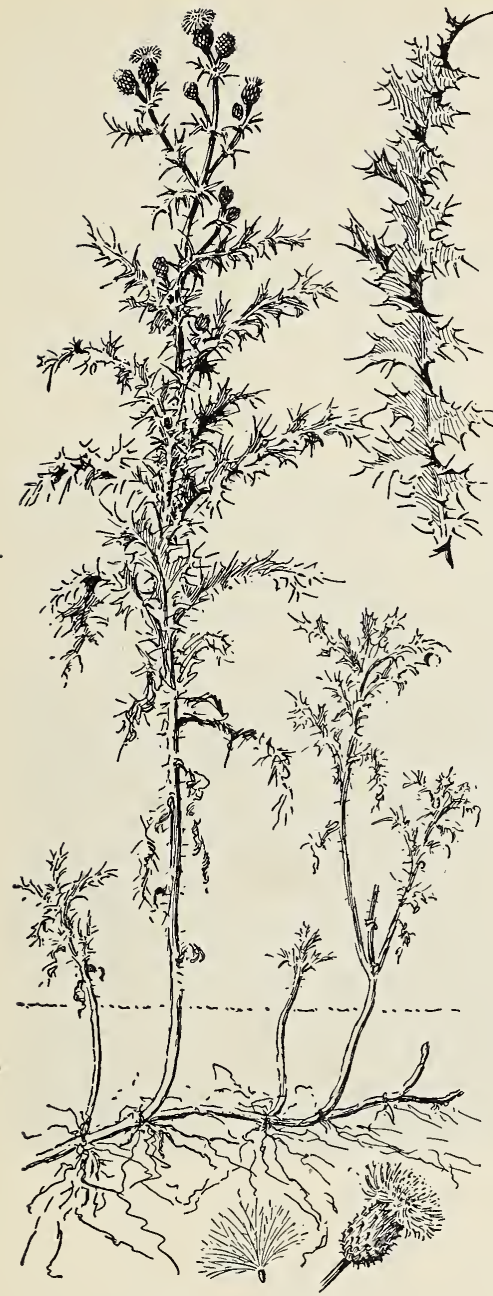

The Canada thistle.

Drawing by W. C. Baker.

Method-A thistle plant brought into the schoolroomroot and all-and placed in water will serve well for this lesson. The questions should be given the pupils as to where thistles are found. Any thistle will do for the lesson.

Observations-I. Where do you find the thistles growing? Do you find more than one species growing thickly together? Do you find any of the common thistles growing in soil which has been cultivated this season?

2. Describe the stalk, is it smooth? Is it weak or strong and woody? What sort of root has it?

3 . Do the leaves grow alternately or opposite? Are they smooth or downy on one or both sides? Do the spines grow around the margins, or on the leaves and veins? Are the leaf edges flat, or wavy and ruffled?

4. How does this affect the direction in which the spines point? Are the leaves entire or deeply lobed? Have they petioles, or are they attached cirrectly to the stalk?

5. Note if any buds or small branches nestle in the axils of the lower leaves. What effect does cutting the main stalk seem to have on each side shoot?

6. Do the flower-heads of the thistle grow singly or in clusters? Do they come from the summit of the stalk, or do they branch from its sides? Which blossomheads open first-the topmost or those lowest on the stalk? Are the flowers fragrant? What insects do you most often see visiting thistle blossoms for polIen or nectar? Study the thistle flower according to Lesson CXXXV.

7. Carefully study a thistle balloon. How is the floss attached to the seed? Is it attached to the smaller, or the larger end? Hold the thistle balloon between your eye and the light. Does the down consist of single separate hairs, or have they many fine branches? Hovr is the down 
arranged when all the flowers are packed together in the thistle-head? Take a seed from among its closely packed fellows in the thistle-head, and put it in the sun or in a warm, dry place where it cannot blow away. How long does it take for the balloon to open out? What is its shape? Is there any down at the center of the balloon or is it arranged in a funnelshaped ring? Can you find a perfectly globular thistle balloon with the seeds still attached to it? How far do you think the thistle balloons might travel?

8. If a thistle seed finds a place for planting during the autumn, how does the young plant look the next season? Describe the thistle rosette. What growth does it make the second summer? What happens to it then?

9. Why can you not cultivate out the Canada thistles as you can the other species?

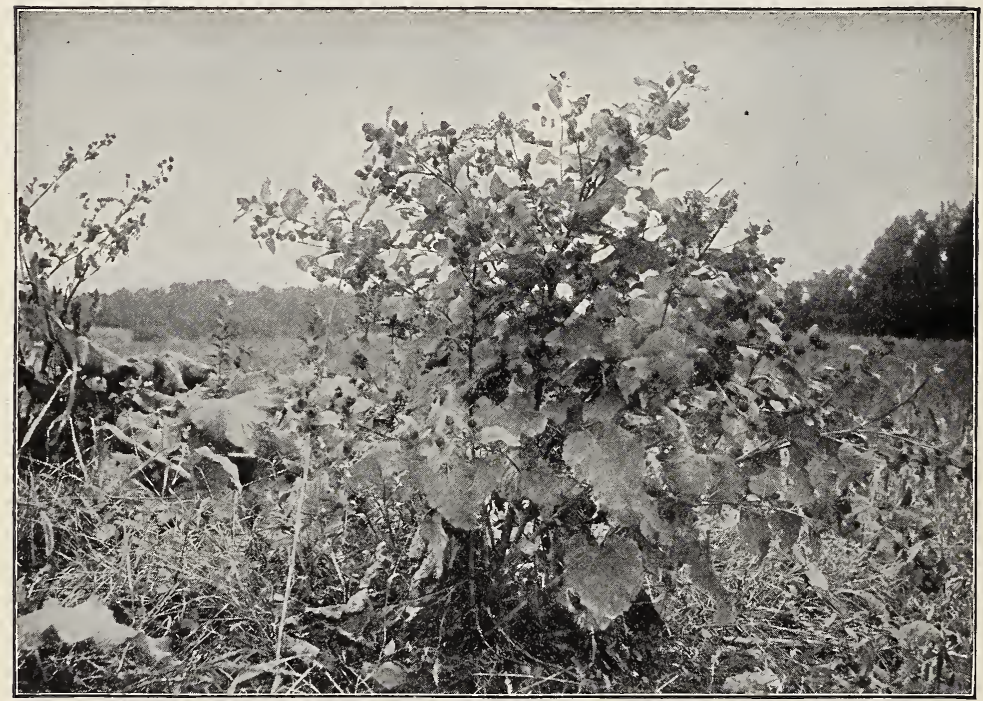

A successful life.

\section{THE BURDOCK \\ Teacher's Story}

Psychologists say that all young things are selfish, and the young burdock is a shining example of this principle. Its first leaves are broad and long, with long petioles by means of which they sprawl out from the growing stem in every direction, covering up and choking out all the lesser plants near them. In fact, the burdock remains selfish in this respect always, for its great basal leaves see to it that no other plants shall get the good from the soil near its own roots. One wonders at first how a plant with such large leaves can avoid shading itself; but there are some people 
very selfish toward the world who are very thoughtful of their own families, and the burdock belongs to this class. We must study carefully the arrangement of its leaves in order to understand its cleverness. The long basal leaves are stretched out flat; the next higher, somewhat smaller ones are lifted at a polite angle so as not to stand in their light. This courtesy characterizes all the leaves of the plant, for each higher leaf is smaller and has a shorter petiole, which is lifted at a narrower angle from the stalk; and all the leaves are so nicely adjusted as to form a pyramid, allowing the sunlight to sift down to each part. While some of the uppermost leaves may be scarcely more than an inch long, the lower ones are very large. They are pointed at the tip and wide at the base; where the leaf joins the petiole it is irregular, bordered for a short distance on each side with a vein, and then finished with a "flounce," which is so full that it even reaches around the main stem-another device for getting more sunlight for itself and shutting it off from plants below. On the lower side, the leaf is whitish and feltlike to the touch; above it is a raw green, often somewhat smooth and shining. The leaf is in quality poor, coarse and flimsy, and it hangs-a web of shoddy-on its strong supporting ribs; lucky for it that its edges are slightly notched and much ruffled, else they would be torn and tattered. The petiole and stems are felty in texture; the petiole is grooved, and expands at its base to grasp the stems on both sides with a certain vicious pertinacity which characterizes the whole plant.

The flower-heads come off at the axils of the upper leaves, and are often so crowded that the leaf is almost lost to sight. It is amazing to behold the number of flower-heads which develop on one thrifty plant. The main stem and the pyramid of lower branching stems, are often crowded with the green balls beset with bracts which are hooked, spiny, and which hold safe the flowers. This composite flower-house is a fortress bristling with spears which are not changed to peaceful pruninghooks, although they are hooked at the sharp end, every hook turning toward the flowers at the center; the lower bracts are shorter and stand out at right angles, while the others come off at lesser angles, graded so as to form a globular involucre-a veritable block-house. The flower might be a tidbit for the grazing animal; but, if so, he has never discovered it, for these protective hooks have kept him from ever enjoying a taste. The bracts protect, not only by hooks at the tip, but by spreading out at

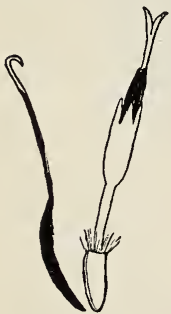

A burdock floret with hookec' bract. the bases so as to make a thickly battened dwelling for the flower-family.

But if we tear open one of these little fortresses, we are well repaid in seeing the quite pretty florets. The corollas are long, slender, pink tubes, with five, pointed lobes. The anther-tubes are purple, the pistils and the stigmas white; the stigmas are broad and feathery when they are dusting out the pollen from the anther-tubes, but later they change to very delicate pairs of curly Y's. The young seed is shining white, and the pappus forms a short, white fluff at the upper margin; but this is simply a family trait, for the burdock seeds never need to be ballooned to their destination; they have a surer method of travel. When in full bloom, the burdock flower- 
heads are very pretty and the skillful child weaver makes them irito beautiful baskets. When I was a small girl, I made whole sets of furniture from these flowers; and then, becoming more ambitious, wove some into a coronet which I wore proudly for a few short hours, only to discover later, from my own experience, that great truth which Shakespeare voiced,- - "uneasy lies the head that wears the crown."

In winter, the tough, gray stalks of the burdock still stand; although they may partially break, if they can thus better accomplish their purpose, - always falling toward the path. In this way, they may be sure of inserting the hooks of their seed storehouses into the clothing or covering of the passer-by; and when one gets a hold, mayhap a dozen others will hold hands and follow. If they catch the tail of horse or cow, then indeed they must feel their destiny fulfilled; for the animal, switching about with its uneasy appendage, threshes out the seeds, and unheedingly plants them by trampling them into the ground. Probably some of the livestock of our Pilgrim Fathers came to America thus burdened; for the burdock is a European weed, although now it flourishes too successfully in America. The leaves of the burdock are bitter, and are avoided by grazing animals. Fortunately for us, certain flies and other insects like their bitter taste, and lay eggs upon them, which hatch into larvæ that live all their lives between the upper and lower surfaces of the leaf. Often the leaves are entirely destroyed by the minute larvæ of a fly, which live together cozily between these leaf blankets, giving the leaves the appearance of being afflicted with large blisters.

The burdocks have long vigorous taproots, and it is therefore difficult to eradicate them without much labor. But persistent cutting off the plant at the root will, if the cut be deep, finally discourage this determined weed.
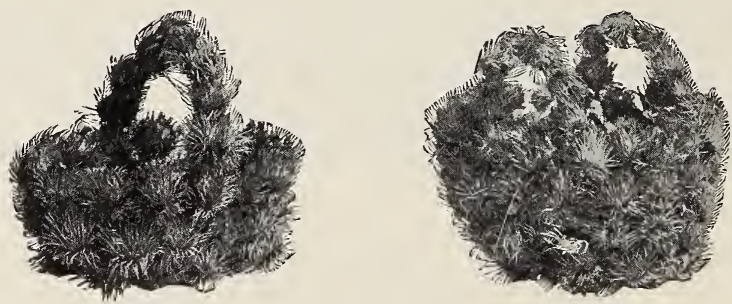

Baskets made from the burdock flower-heads. 


\section{LESSON CXLI}

\section{THE BURDOCK}

Leading thought-The burdock wins because its great leaves shade down plants in its vicinity, and also by having taproots. It scatters its seed by hooking its seed-heads fast to the passer-by.

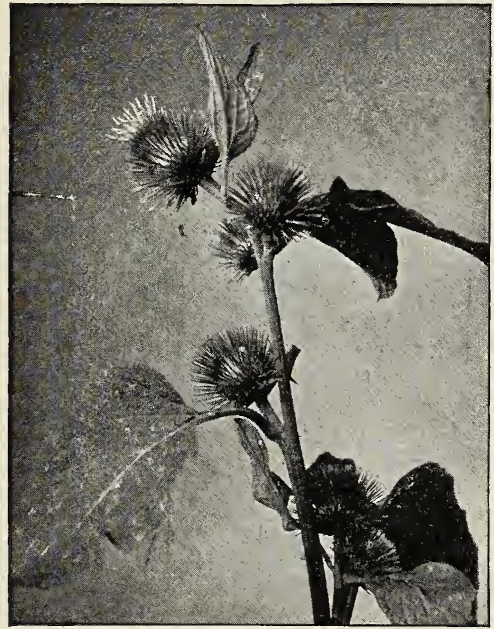

Burdock blossoming.

Method-Stuidy a healthy burdock plant in the field, to show how it shades down other plants and does not shac'e itself. The flowers and the seed-heads may be brought into the schoolroom for detailed study.

Observations-I. Note a young plant. How much space does its leaves cover? Is anything growing beneath them? How are its leaves arranged to cover so much space? Of what advantage is this to the plant?

2. Study the full-grown plant. How are the lower leaves arranged? At what angles to the stalks do the petioles lie? Are the upper leaves as large as the lower ones? Do they stand at different angles to the stalk?

3. Study the arrangement of leaves on a burdock plant, to discover how it manages to shade down other plants with its leaves and yet does not let its own upper leaves shade those below.

4. Study a lower and an upper leaf. What is the general shape? What peculiarity where it joins the petiole? What is the texture of the leaf above and below? The color? Describe the petiole and how it joins the stem.

5. Where do the flowers appear on the stem? Are there many flowers developed? Count all the flower-heads on a thrifty burdock.

6. The burdock has its flowers gathered into families, like the sunflower and thistle. Describe the burdock flower-family according to Lesson CXXXV.

7. What insects visit the burdock flowers? Can you make baskets from the flower-heads?

8. Study the burdock again in winter, and see what has happened to it. Describe the seed and the seed-heads. How are the seed-heads carried far away from the parent plant? How many seeds in a single "house?" How do they escape?

9. Write the biography of a burdock plant which came to America as a seed, attached to the tail of a Shetland pony. 


\section{PRICKLY LETTUCE, A COMPASS PLANT \\ Teacher's Story}

The more we know of plants, the more we admire their ways of attaining success in a world where it is only attained by a species after a long struggle. While plants may not be conscious of their own efforts for living on successfully, they have developed them just the same, and they merit our admiration perhaps even more, than as if their strategy was the result of conscious thought. The prickly lettuce has a

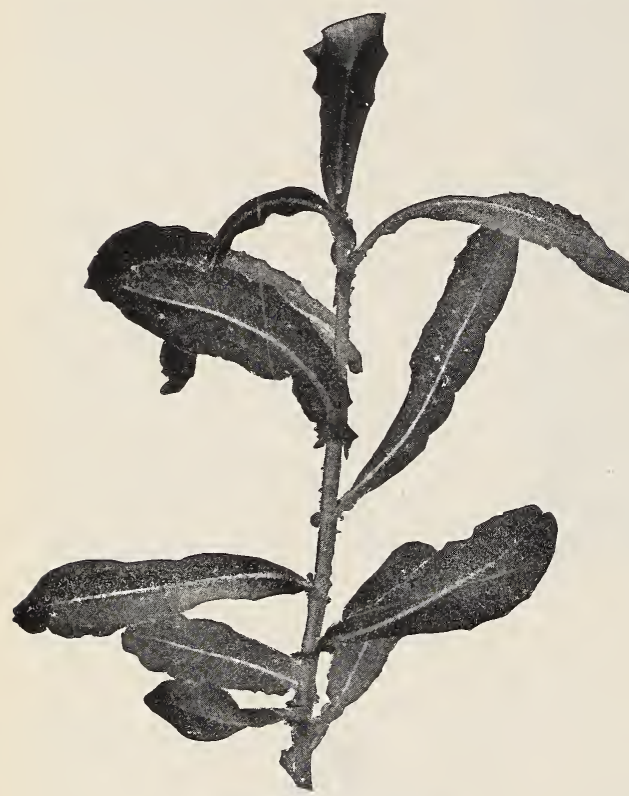

A common compass plant.

Photo by Cyrus Crosby. story to tell us about success attained by the prevention of exhaustion from thirst. In fact, the success of this weed depends much upon its being able to live in dry situations and withstand the long droughts of late summer. The pale green stems grow up slim and tall, bearing leaves arranged alternately and from all sides, since between two, one of which is exactly above the other, two other leaves are borne. Thus, if the leaves stood out naturally, the shape of the whole plant would be a somewhat blunt pyramid. But during the hot, dry weather, the leaves do not stand out straight from the stem; instead, they twist about so that they are practically all in one plane, and usually point north and south, although this is not invariably the case. The way this twisting is accomplished is what interests us in this plant. The long spatulate leaf has a thick, fleshy midrib, and at the base are developed two pointed lobes which clasp the stalk. The leaf is soft and leathery and always seems succulent, because it retains its moisture; it has a ruffled edge near its base, which gives it room for turning without tearing its margin. Each leaf tips over sidewise toward the stem, and as far as necessary to bring one edge uppermost. Thus the sun cannot reach its upper surface to pump water from its tissues. The ruffled margin of the upper edge is pulled out straight when the leaf stands in this position, while the lower margin is more ruffled than ever. Thus, it stands triumphantly, turning edgewise to the sun, retaining its moisture and thriving when cultivated plants are dry and dying. 
It also has another "anchor to the windward." A plant so full of juice would prove attractive food for cattle when pastures are dry. The leaves of this perhaps escape, because each has a row of very sharp spines on the lower side of the midrib. At first we might wonder why they are thus placed; but if we watch a grazing animal, as a cow, reach out her tongue to pull the herbage into her mouth, we see that these spines are placed where they will do the most efficient work. The teasel has the same clever way of warning off meddlesome tongues. The prickly lettuce also has spines on its stem, and the leaves are toothed with spines at their points.

\section{LESSON CXLII \\ PRICKLY LetTUCE}

Leading thought-The sunshine sets the machinery in the leaf-factornes going, and incidentally pumps up water from the soil, which pours out into the air from the leaves; but if the soil is dry the pump works just the same, and the plant thus robbed of its water soon withers and dies. The young plants of wild lettuce prevent the sun from pumping them dry during drought, by turning the edges of their leaves toward the sun, and thus not exposing the leaf surface to its rays. The leaves thus lifted stand in one plane. They are usually directed north and south. The lettuce also has spines to protect it from grazing animals.

Method-The lettuce should be studied in the field, and is a good subject for a lesson in late summer or September. This lesson should supplement the one on transpiration. The young plants show this arrangement of the leaves best. The flowers may be studied by the outline given in Lesson CXXXV.

Observations-I. Where does the prickly lettuce grow? What sort of a stem has it? How are the leaves arranged on the stem?

2. If the leaves stood straight out from the stem, what would be the shape of the plant? How do the leaves stand? Is their upper surface exposed to the rays of the sun? Which portion of the leaf is turned toward the sun?

3. If the leaves turn sideways and stand in one plane, do they stand north and south or east and west. How does the edgewise position of the leaf protect the plant during drought? Why does any plant wither during drought? If the leaves of the lettuce should extend east and west instead of north and south, would they get more sun? (See lesson on the Sun.)

4. What is the shape of the lettuce leaf? How does it clasp the stalk? How is the base shaped so that the leaf can turn without tearing its edges? Sketch a leaf thus turned fully, showing how it is done. Does the leaf turn toward the stem or away from it?

5. How are the leaves protected against grazing cattle? How does the cow use her tongue to help bring herbage to her mouth? How are the prickly spines placed on the lettuce leaf, to make the cow's tongue uncomfortable? Sketch a leaf showing its shape, its venation and its spines. 


\section{THE DANDELION}

\section{Teacher's Story}

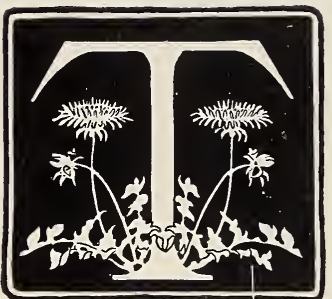

HIS is the most persistent and indomitable of weeds, yet I think the world would be very lonesome without its golden flowerheads and fluffy seed-spheres. Professor Bailey once said that dandelions in his lawn were a great trouble to him until he learned to love them, and then the sight of them gave him keenest pleasure. And Lowell says of this "dear common flower"-

\footnotetext{
"Tis Spring's largess, which she scatters now

To rich and poor alike, with lavish hand;

Though most hearts never understand

To take it at God's value, and pass by

The offered wealth with unrewarded eye."
}

It is very difficult for us, when we watch the behavior of the dandelions, not to attribute to them thinking power, they have so many ways of getting ahead of us. I always look at a dandelion and talk to it as if it were a real person. One spring when all the vegetables in my garden were callow weaklings, I found there, in their midst, a dandelion rosette with ten great leaves spreading out and completely shading a circle ten inches in diameter; I said, "Look here, Madam, this is my garden!" and I pulled up the squatter. But I could not help paying admiring tribute to the taproot, which lacked only an inch of being a foot in length. It was smooth, whitish, fleshy and, when cut, bled a milky juice showing that it was full of food; and it was as strong from the end-pull as a whipcord; it also had a bunch of rather fine rootlets about an inch below the surface of the soil and an occasional rootlet farther down; and then I said "Madam, I beg your pardon; I think this was your garden and not mine."

Dandelion leaves afford an excellent study in variation of form. The edges of the leaf are notched in a peculiar way, so that the lobes were, by some one, supposed to look like lions' teeth in profile; thus the plant was called in France "dents-de-lion" (teeth of the lion), and we have made from this the name dandelion. The leaves are so bitter that grazing animals do not like to eat them, and thus the plants are safe even in pastures.

The hollow stem of the blossom-head from time immemorial has been a joy to children. It may be made into a trombone, which will give to the enterprising teacher an opportunity for a lesson in the physics of sound, since by varying its length, the pitch is varied. The dandelion-curls, which the little girls enjoy making, offer another lesson in physics - that of surface tension, too difficult for little girls to understand. But the action of this flower stem is what makes the dandelion seem so endowed with acumen. If the plant is in a lawn, the stem is short, indeed so short that the lawn-mower cannot cut off the flower-head. In this situation it will blossom and seed within two inches of the ground; but if the plant is in a meadow or in other high grass, the stem lifts up sometimes two feet or more, so that its blossom may be seen by bees and its seeds be carried off by the breeze without let or hindrance from the grass. We found two such stems each measuring over 30 inches in height. 
Before a dandelion head opens, the stem, uniess very short, is likely to bend down to protect the young flowers, but the night before it is to bloom it straightens up; after the blossoms have matured it may again bend over, but straightens up when the seeds are to be cast off.

It often requires an hour for a dandelion head to open in the morning and it rarely stays open longer than five or six hours; it may require another hour to close. Usually not more than half the flowers of the head open the first day, and it may require several days for them all to blossom. After they have all bloomed and retired into their green house and put up the shutters, it may take them from one to two weeks to perfect their seeds.

In the life of the flower-head the involucre, or the house in which the flower family lives, plays an important part. The involucral bracts, in the row set next to the flowers, are sufficiently long to cover the unopened flowers; the bracts near the stem are shorter and curl back, making a frill. In the freshly opened flower-head, the buds at the middle all curve slightly toward the center, each bud showing a blunt, five-lobed tip which looks like the tips of five fingers held tightly together. The flowers in the outer row blossom first, straightening back and pushing the banner outward; and now we can see that the five lobes in the bud are the five .notches at the end of the banner. All the flowers in the dandelion-head have banners, but those at the center, belonging to the younger flowers, have shorter and darker yellow banners. After a banner is unfurled, there pushes out from its tubular base a darker yellow anther-tube; the five filaments below the tube are visible with a lens. A little later, the stigma-ramrod pushes forth from the tube, its fuzzy sides acting like a brush to bring out all the pollen; later it rises far above the anther-tube and quirls back its stigma-lobes, as if every floret were making a dandelion curl of its own. The lens shows us, below the corolla, the seed. The pappus is not set in a collar upon the dandelion seed, as it is in the aster seed; there is a short stem above the seed which is called the "beak" and the pappus is attached to this.

Every day more blossoms open; but on dark, rainy days and during the night the little green house puts up its shutters around the flowerfamily, and if the bracts are not wide enough to cover the growing family, the banners of the outer flowers have thick or brownish portions along their lower sides which serve to calk the chinks. It is interesting to watch the dandelion stars close as the night falls, and still more interesting to watch the sleepy-heads awaken long after the sun is up in the morning; they often do not open until eight o'clock. The dandelion flower-families are very economical of their pollen and profuse nectar, and do not expose them until the bees and other insects are abroad ready to make morning calls.

After all the florets of a dandelion family have blossomed, they retire again into their green house and devote themselves to perfecting their seeds. They may stay thus in retirement for several days, and during this period the flower stem often grows industriously; and when the shutters of the little green house are again let down, what a different appearance has the dandelion family! The seeds with their balloons are set so as to make an exquisite, filmy globe; and now they are ready to coquette with the wind and, one after another, all the balloons go sailing off. One of these seeds is well worth careful observation through a lens. 
The balloon is attached to the top of the beak as an umbrella frame is attached to the handle, except that the "ribs" are many and fluffy; while the dandelion youngster, hanging below, has an overcoat armed with grappling hooks, which enable it to cling fast when the balloon chances to settle to the ground.

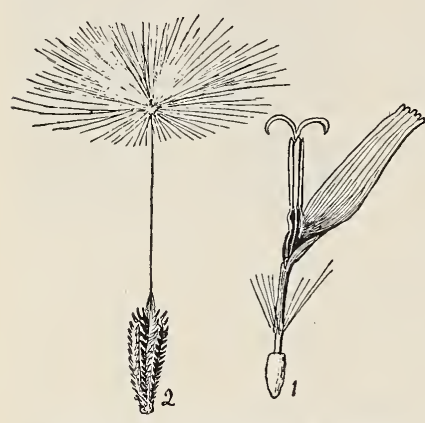

I, Floret of dandelion; 2, seed of dandelion. Both enlarged.

Father Tabb says of the dandelion,"With locks of gold today; tomorrow silver gray; then blossom bald." But not the least beautiful part of the dandelion is this blossom-bald head after all the seeds are gone; it is like a mosaic, with a pit at the center of each figure where the seed was attached. There is an interesting mechanism connected with this receptacle. Before the seeds are fully out this soon-to-be-bald head is concave at the center, later it becomes convex, and the mechanism of this movement liberates the seeds which are em. bedded in it.

Each freshly opened corolla-tube is full to overflowing with nectar, and much pollen is developed; therefore, the dandelion has many kinds of insect visitors. But perhaps the bee shows us best where the nectar is found; she thrusts her tongue down into the little tubes below the banners, working very rapidly from floret to floret. The dandelion stigmas have a special provision for securing cross-pollenation; and if that fails, to secure pollen from their own flower-family; and now the savants have found that the pistils can also grow seeds without any pollen from anywhere. It surely is a resourceful plant!

The following are the tactics by which the dandelion conquers us and takes possession of our lands: (a) It blossoms early in the spring and until snow falls, producing seed for a long season. (b) It is broadminded as to its location, and flourishes on all sorts of soils. (c) It thrusts its long tap-roots down into the soil, and thus gets moisture and food not reached by other plants. (d) Its leaves spread out from the base, and crowd and shade many neighboring plants out of existence. (e) It is on good terms with many insects, and so has plenty of pollen carriers to insure strong seeds; it can also develop seeds from its own pollen, and as a last resort it can develop seeds without any pollen. (f) It develops almost numberless seeds, and the wind scatters them far and wide and they thus take possession of new territory. (g) It forms vigorous leafrosettes in the fall. and thus is able to begin growth early in the spring.

\section{LESSON CXLIII \\ The Dandelion}

Leading thought-The dandelions flourish despite our determined efforts to exterminate them. Let us study the way in which they conquer.

Method-The study should be made with the dandelions on the school grounds. Questions should be given, a few at a time, and then let the pupils consult the dandelions as to the answers. 
The dandelion is a composite flower and may be studied according to Lesson CXXXV. All the florets have banners or rays.

Observations I. Where do you find dandelions growing? If they are on the lawn, how long are their blossom or seed stems? If in a meadow or among high grass, how long is the blossom stem? Why is this? Is the blossom stem solid or hollow? Does it break easily?

2. Dig up a dandelion root and then explain why this weed withstands drought, and why it remains, when once planted.

3. Sketch or describe a dandelion leaf. Why was the plant named "lion's teeth?" How are the leaves arranged about the root? How does this help the dandelion and hinder other plants? In what condition do the leaves pass the winter under the snow? Why is this useful to the plant?

4. Take a blossom not yet open. Note the bracts that cover the unopened flower-head. Note the ones below and describe them.

5. Note the dandelion flower-head just open. Which flowers open first? How do the buds look at the center? Do all the florets have banners? Are the banners of the central florets the same color and length as of those outside? Examine a floret and note the young seed. Is the pappus attached to it or above it?

6. What happens to the dandelion blossom on rainy or dark days? How is the dandelion family hidden during the rain? When does it appear again? Do you think that this has anything to do with the insect visitors? Do bees and other insects gather nectar during dark or rainy days?

7. Note at what hour the dandelions on the lawn go to sleep and at what hour they awaken on pleasant days?

8. Make notes on a certain dandelion plant three times a day: How long does it take the dandelion head to open fully on a sunny morning? How long does it remain open? How long does it take the flower-head to close? What proportion of the flowers in the head, blossoms during the first day? What proportion of the flowers in the head, blossoms during the second day? How long before they all blossom? Does the flower-head remain open longer in the afternoon on some days than on others, equally sunny? Does the stem bend over before the blossom-head opens?

9. After all the little flowers of a dandelion family have blossomed, what happens to it? How long does it stay shut up in its house? Measure the stem, and see if it stretches up during the time. How does the dandelion look when it opens again? Look at a dandelion-head full of seed, and see how the seeds are arranged to make a perfect globe. Shake the seeds off and examine the "bald head" with a lens. Can you see where the seeds were set?

г. Examine a dandelion seed with a lens. Describe the balloon, the beak or stem of the balloon, and the seed. Why do you suppcre the seed has these hooks?

I I. How early in the spring, and how late in the fall, do dandelions blossom?

I2. Watch a bee when she is working on a dandelion flower, and see where she thrusts her tongue and whick flowers she probes.

I3. Tell all the things that you can remember which the dandelion does in order to live and thrive in spite of us.

I4. What use do we make of the dandelions? 


\section{THE PEARLY EVERLASTING \\ Teacher's Story}

These wraithlike flowers seem never to have been alive, rather than to have been endowed with everlasting life. The cattle share this opinion and would no sooner eat these plants than if they were made of cotton batting. The stems are covered with white felt; the long narrow leaves

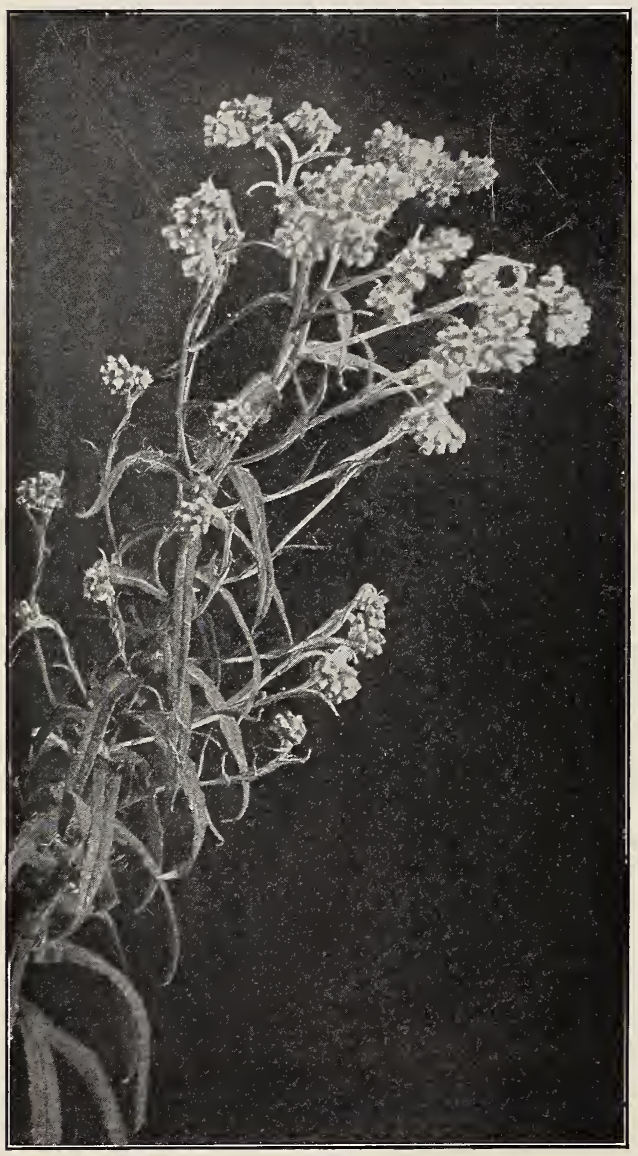

The pistillate flower-heads of the pearly everlasting. Photo by Verne Morton. are very pale green, and when examined with a lens, look as if they were covered with a layer of cotton which disguises all venation except the thick midrib. The leaves are set alternate, and become shorter and narrower and whiter toward the top of the plant, where they are obliged to give their sustenance to the flower stems borne in their axils. All this cottony covering has its uses to prevent the evaporation of water from the plant during the long droughts. The everlasting never has much juice in its leaves but what it has, it keeps.

The flower stems are rather stout, woolly, soft and pliable. They come off at the axils of the threadlike whitish leaves. The pistillate and the staminate flowers are borne on separate plants, and usually in separate patches. The pistillate, or seeddeveloping, plants have globular I flowerl buds, almost egg-shaped, with a fluffy lemon-yellow knob at the tip; this fluff is made up of stigmas split at the end.

At the center of this tassel of lemon-yellow stigma-plush, may often be seen a depression; at the bottom of this well, there are three or four 
perfect flowers. One of the secrets of the everlasting is, evidently, that it does not put all of its eggs in one basket; it has a few perfect flowers for insurance. This pistillate or seed-bearing flower has a long, delicate tube, ending in five needlelike points and surrounded by a pretty pappus.
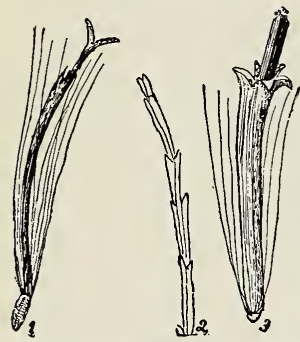

I, Pistillate floret; 2 , pappus, 3, staminate floret. All enlarged.

The bracts of the flower-cluster seem to cling around the base of the beautiful yellow tassel of fertile flowers, as if to emphasize it. They look as if they were made of white Japanese paper, and when looked at through a lens, they resemble the petals of a water lily They are dry to begin with, so they cannot wither.

The staminate, or pollen-bearing, flower-heads are like white birds' nests, the white bracts forming the nest and the little yellow flowers the eggs. The flower has a tubular, five-pointed starlike corolla, with five stamens joined in a tube at the middle, standing up like a barrel from the corolla. The anther-tube is ocher-yellow with brown stripes, and is closed at first with five little flaps, making a cone at the top. Later, the orange-yellow pollen bulges out as if it were boiling over. The flowers around the edges of the flower-disk open first.

\section{LESSON CXLIV}

\section{The Pearly Ever- LASTING \\ Leading thought-} There are often found growing on the poor soil in dry pastures, clumps of soft, whitish plants which are never eaten by cattle. There is so little juice in them that they retain their form when dried and thus have won their name.

Method-The pupils should see tnese plants growing, so that they may observe the staminate and pistillate flowers, which are on separate plants and in separate clumps. If this is not practicable, bring both kinds of flowers into the schoolroom for study.

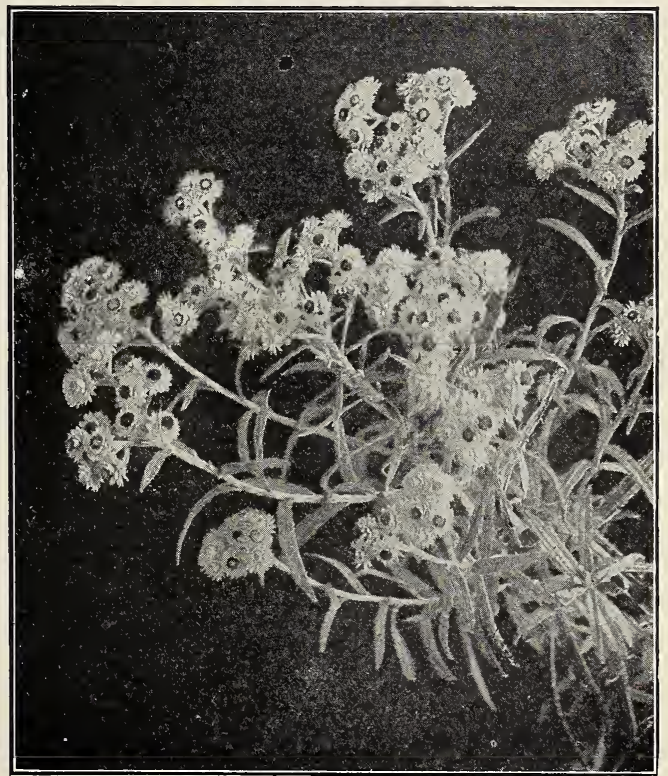

The strminate flower-head of pearly everiasting. 
Observations-I. Where does the pearly everlasting grow? Do cattle eat it? Why is this? What is the general color of the plant? What is the stem covered with?

2. What is the shape of the leaves? How are they veined? With what are they covered? How are they placed on the stem? What is the relative size of the lower and upper leaves? Why is there a difference?

3. Do you see some plants which have egg-shaped blossoms, each with a yellow knob at the tip? Take one apart and look at it with a lens, and see what forms the white part and what forms the yellow knob. Do you see other flowers that look like little white birds' nests filled with yellow eggs? Look at one of them with a lens, and tell what kind of a flower it is.

4. Except that the pistillate and staminate flowers are on different plants, the flowers of the pearly everlasting should be studied according to Lesson CXXXV.

5. What do you know of the edelweiss of the Alps? How does it resemble the pearly everlasting? Do you know another common kind of everlasting called pussy's toes?

\section{THE JEWELWEED, OR TOUCH-ME-NOT}

\section{Teacher's Story}

"Cup bearer to the summer, this floral Hebe shy

Is loitering by the brookside as the season passes by;

And she's strung her golden ewers with spots of brown all flecked,

O'er dainty emerald garments, like a queen with gems bedecked.

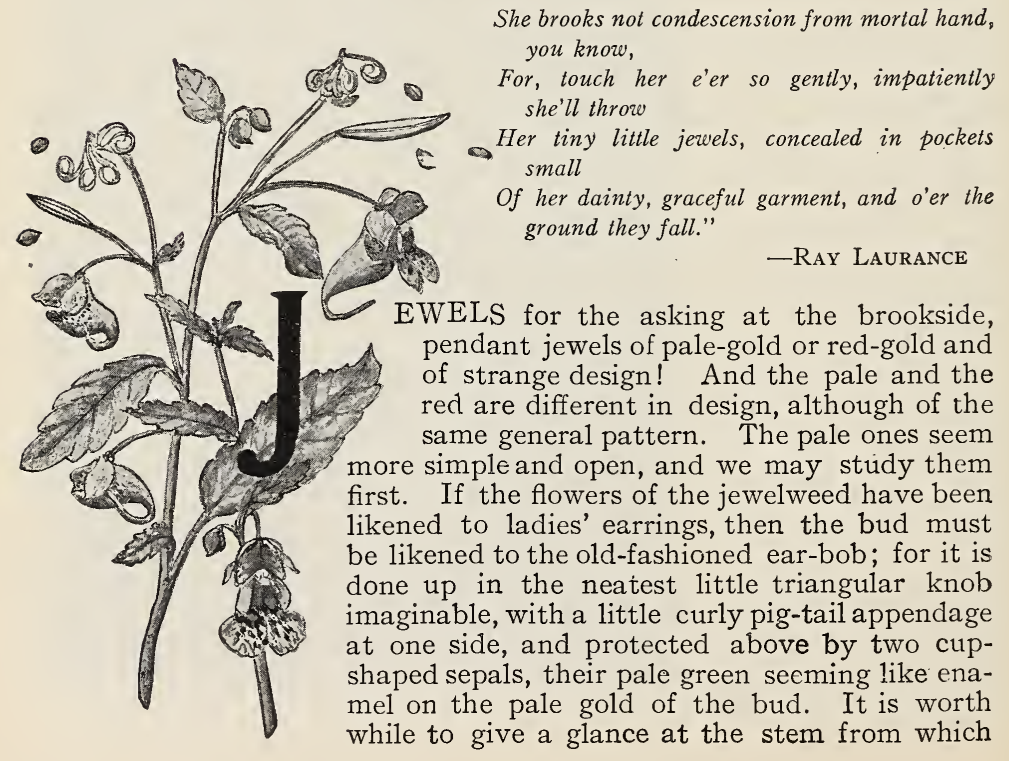


this jewel hangs; it is so delicate and so gracefully curved; and just above the twin sepals is a tiny green bract, elongate, and following the curve of the stem as if it were just a last artistic touch; and though the flowers fall, this little bract remains to keep guard above the seed-pod.

It would take a Yankee, very'good at guessing, to make out the parts of this flower, so strange are they in form. We had best begin by looking at the blossom from the back side. The two little, greenish sepals are lifted back like butterfly wings, and we may guess from their position that there are two more sepals, making four in all. These latter are yellow; one is notched at the tip and is lifted above the flower; the other is below and is made into a wide-mouthed triangular sac, ending in a quirl at the bottom, which, if we test it, we shall find is the nectary, very full of sweetness. Now, if we look the flower in the face, perhaps we can find the petals; there are two of them "holding arms" around the mouth of the nectar-sac. And stiff arms they are too, two on a side, for each petal is two-lobed, the front lobe being very short and the posterior lobe widening out below into a long frill, very convenient for the bee to cling to, if she has learned the trick, when prospecting the nectar-sac behind for its treasure. The way this treasure-sac swings backward from its point of attachment above when the insect is probing it, must make the lady bee feel that the joys of life are elusive. Meanwhile, what is the knob projecting down above the entrance to the nectar-sac, as if it were a chandelier in a vestibule? If we look at it with a lens, we can see that it is made up of five chubby anthers, two in front, one at each side and one behind; their short, stout little filaments are crooked just right to bring the anthers together like five closed fingers holding a fist full of pollen-dust, just ready to sift it on the first one that chances to pass below. Thus it is that Madame Bumblebee, who dearly loves the nectar from these flowers, gets her back well dusted with the creamy-white pollen and does a great business for the jewelweed in transferring it. But after the pollen is shed, some day the bumblebee pushes up too hard against the anthers and they break loose, all in a bunch, looking like a crooked legged table; and there in their stead, thus left bare and ready for pollen, is the long green pistil with its pointed stigma ready to rake the pollen out of the fur of any bumblebee that calls.

The red-gold jewelweed is quite different in shape from the pale species. The sepal-sac is not nearly so flaring at the mouth, and the nectar-spur is half as long as the sac and curves and curls under in a most secretive fashion. The shape of the nectar-spur suggests that it was meant for an insect with a long, flexible sucking tube that could curl around and probe it to the bottom; and some butterflies do avail themselves of the contents of this bronze pitcher. Mr. Mathews mentions the Papilio troilus, and I have seen the yellow roadside butterfly partaking of the nectar. Professor Robertson believes that the form of the nectarspur is especially adapted for the hummingbird. But I am sure that the flowers which I have had under observation are the special partners of a small species of bumblebee, which visits these flowers with avidity, celerity, and certainty, plunging into the nectar-sac "like a shot," and out again and in again so rapidly that the eye can hardly follow. One day, one of them accommodatingly alighted on a leaf near me, while she combed from her fur a creamy-white mass of pollen, which matched in color the fuzz on her back, heaping it on her leg baskets. She seemed to 
know that the pollen was on her back, and it was comical to see her contortions to get it off. The action of these bumblebees in these flowers is in marked contrast to those of the large bumblebees and the honeybees. One medium-sized species of bumblebee has learned the trick of embracing with the front legs the narrow, stiff portion of the petals which encircles the opening to the sac, thus holding the flower firm while thrusting the head in to the sac. While the huge species-black with very yellow plush-does not attempt to get the nectar in a legitimate manner, but systematically alights, back downward, below the sac of the flower, with head toward the curved spur, and cuts open the sac for the nectar. A nectar-robber of the most pronounced type! The honey-bees, Italian hybrids, are the most awkward in their attempts to get nectar from these flowers; they attempt to alight on the expanded portion of the petals and almost invariably slide off between the two petals. They then circle around and take observations with a note of determination in their buzzing, and finally succeed, as a rule, in gaining a foothold and securing the nectar. But the midget bumblebees show a savoir faire in probing the orange jewelweed that is convincing; they are so small that they are quite out of sight when in the nectar-sacs.

The jewelweed flowers of the pale species and the pale flowers of the orange species-for this latter has sometimes pale yellow flowers-are not invariably marked with freckles in the nectar-sac. But the most common forms are thus speckled. There is something particularly seductive to insects in these brownish or reddish flecks, and wherever we find them in flowers, we may with some confidence watch for the insects they were meant to allure. The orange jewelweed flower is a model for an artist in its strange, graceful form and its color combination of yellow spotted and marbled with red.

Gray's Manual states that in the jewelweeds are often flowers of two sorts "The large ones which seldom ripen seeds, and very small ones which are fertilized early in the bud, their floral envelopes never expanding but forced off by the growing pod and carried upward on its apex." My jewelweed patch has not given me the pleasure of observing these two kinds of flowers; my plants blossom luxuriously and profusely, and a large proportion of the flowers develop seed. The little, straight, elongated seed-pods are striped prettily and become quite plump from the large seeds within them. Impatiens? We should say so! This pod which looks so smug and straight-laced that we should never suspect it of being so touchy, at the slightest jar when it is ripe, splits lengthwise into five ribbon-like parts, all of which tear loose at the lower end and fly up in spirals around what was once the tip of the pod, but which now looks like a crazy little turbine wheel with five arms. And meanwhile, through this act the fat, wrinkled seeds have been flung, perhaps several feet away from the parent plant, and presumably to some congenial place for growth the following spring. This surprising method of throwing its seeds is the origin of the popular name touch-me-not, and the scientific name Impatiens by which these plants are known.

The jewelweed has other names - celandine and silver-leaf, and ladies' ear-drop. It is an annual with a slight and surface-spreading growth of roots, seeming scarcely strong enough to anchor the branching stems, did not the plants have the habit of growing in a community, each helping to support its neighbor. The stem is round, hollow and much swollen at the 
joints; it is translucent, filled with moisture, and its outer covering is a smooth silken skin, which may be readily stripped off. Both species of jewelweed vary in the color of their stems, some being green, others red and some dark purple; and all the differing colors may be found within a few yards of each other.

The leaves are alternate, dark green above and a lighter shade below, ovate in form with scalloped edges, with midrib and veins very prominent beneath and depressed on the upper side; they are smooth on both sides to the unaided eye, but with a lens a film of fine, short hairs may be seen, particularly on the under side. When plunged beneath clear water, they immediately take on the appearance of burnished silver; when removed, no drop remains on their surface.

The flower stems spring from the axils of the leaves and are very slender and thread-like, and the flowers nod and swing with every breeze. They grow in open, drooping clusters, few blossoms open at a time, and with buds and seed-capsules present in various stages of growth.

The jewelweed is involuntarily most hospitable, and always houses many uninvited guests, as well as the bee-callers which are invited. Galls are formed on the leaves and flowers; the hollow stems are inhabited by stalk-borers; leaf-miners live between the upper and under surfaces of the leaves, making curious arabesque patterns and initials as if embroidering milady's green gown.

\section{LESSON CXLV}

\section{The Jewelweed, OR Touch-Nïe-Not}

Leading thought-The jewelweed may be found by the brookside, in swamps, or in any damp and well-shaded area. It is provided with a remarkable contrivance for scattering its seeds far afield. It has no liking for open sunny places, unless very damp. There are two kinds, often found growing together, though the spotted touch-me-not (Impatiens biflora) is said to be more widely distributed than its relative-the golden, or pale, touch-me-not (Impatiens aurea).

Method-The jewelweeds should be studied where they are growing; but if this is impracticable, a large bouquet of both kinds (if possible), bearing buds, blossoms, and seed-capsules, and one or two plants with roots, may be brought to the schoolroom.

In the fields the children may see how well the plant is provided with means to sustain itself in its chosen ground, and thus lead them to look with keener eyes at other common weeds.

Observations- $\mathrm{I}$. Do you think the jewelweed is an annual, sustaining life in its seeds during winter, or do its roots survive?

2. Do the roots strike deeply into the soil, or spread near the surface?

3. Study the stem; is it hard and woody or juicy and translucent: rough or smooth, solid or hollow?

4. Note the shape and position of the leaves; do they grow opposite or alternately on the stalk? Are their edges entire, toothed or scalloped? Do they vary in color on upper and lower surface? Are they smooth or in the least degree rough or hairy? Plunge a plant under clear water in a good light and observe the beautiful transformation. Does the water cling to the leaves? 
5. Where do the flower-stems spring from the main stalk? Do the flowers grow singly or in clusters? Do the blossoms all open at nearly the same time or form a succession of bud, flower and seed on the same stem?

6. Study the parts of the flower. Find the four sepals and describe the shape and position of each. Describe the nectar-sac in the nectarhorn. Can you find the two petals? Can you see that each petal has a lobe near where it joins the stem? Find the little knob hanging down above the entrance of the nectar-sac; of what is it composed? Look at it with a lens, and tell how many stamens unite to make the knob? Where is the pollen and what is its color? What insect do you think could reach the nec ar at the bottom of the spurred sac? Could any insect get at the nectar without rubbing its back against the flat surface of the pollen boxes? What remains after the stamens fall off? Describe how the bees do the work of pollenation of the jewelweeds. Write or tell as a story your own observations on the actions of the different bees visiting these flowers.

7. Carefully observe a seed-capsule without touching it; can you see the lines of separation between its sections? How many are there? What happens when the pod is touched? Are the loosened sections attached at the stem, or at the apex of the pod? Hold a pod at arm's length when discharging its contents and measure the distance to which the seeds are thrown. Of what use is this habit of seed-throwing to the plant?

8. Describe the differences in shape and color between the pale yellow and the orange jewelweeds. Watch to see if the same insects visit both. Which species do you think is best suited to the bumblebees?

\title{
MULLEIN
}

Teacher's Story

\author{
"I like the plants that you call weeds,- \\ Sedge, hardhack, mullein, yarrow,- \\ Which knit their leaves and sift their seeds \\ Where any grassy wheel-track leads \\ Through country by-ways narrow."
} - Lucy Larcom.

We take much pride unto ourselves because we belong to the chosen few of the "fittest," which have survived in the struggle for existence. But, if we look around upon other members of this select band, we shall find many lowly beings which we do not ordinarily recognize as our peers. Mullein is one of them, and after we study its many ways of "winning out" then may we bow to it and call it "brother."

I was wandering one day in a sheep pasture and looking curiously at the few plants left uneaten. There was a great thistle with its sharp spines and the pearly everlasting - too woolly and anæmic to be appetizing even to a sheep; and besides these, there was an army of mullein stalks-tall, slim, and stiff-necked, or branching like great candelabra, their upper leaves adhering alternately to the stalks for half their length. I stopped before one of them and mentally asked, "Why do 


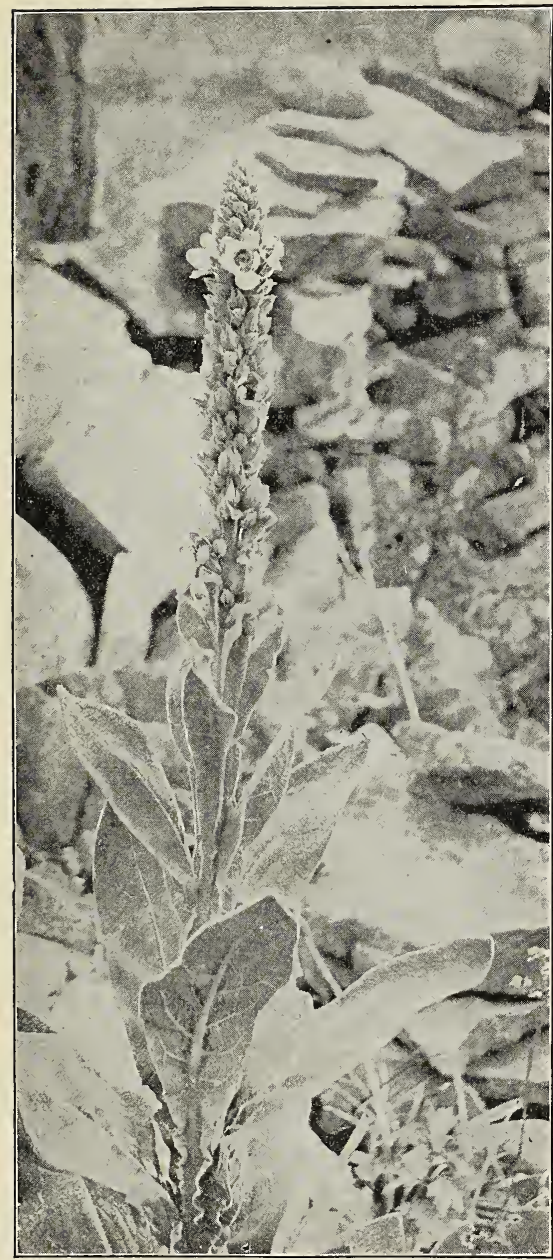

Mullein.

Photo by Verne Morton

the sheep not relish you? Are you bitter?" I took a bite, Nebuchadnezzar-like. and to my untrained taste it seemed as good fodder as any; but my tongue smarted and burned for some time after, from being pricked by the felt which covered the leaf. I recalled the practical joke of which my grandmother once made me the victim; she told me that to be beautiful, I needed only to rub my cheeks with mullein leaves, an experience which convinced me that there were other things far more desirable than beauty - comfort, for instance. This felt on the mullein is beautiful, when looked at through a microscope; it consists of a fretwork of little, white, sharp spikes. No wonder my cheeks were red one day and purple the next, and no wonder the sheep will not eat it unless starved! This frostlike felt covering not only keeps the mullein safe from grazing animals but it also keeps the water from evaporating from the leaf and this enables the plant to withstand drought. I soon discovered another means devised by the mullein for this same purpose, when I tried to dig up the plant with a stick; I followed its taproot down far enough to understand that it was a subsoiler and reached below most other plants for moisture and food. Although it was late autumn, the mullein was still in blossom; there were flowers near the tip and also one here and there on the seed-crowded stem. I estimated there were hundreds of seed-capsules on that one plant; I opened one, siill covered with the calyx-lobes, and found that the mullein was still battling for survival; for I found this capsule and many others inhabited by little brown-headed white grubs, which gave an exhibition of St. Vitus dance as I laid open their home. They were the 
young of a snout beetle, which is a far more dangerous enemy of the muliein than is the sheep.

The mullein plant is like the old woman who lived in a shoe in the matter of blossom-children; she has so many that they are unkempt and
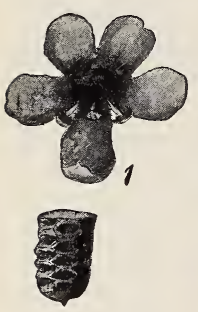

3
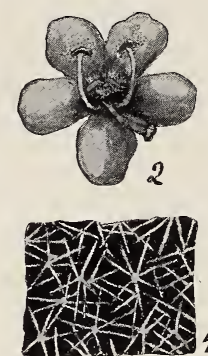
irregular, but there are normally four yellow or white petals and a five-lobed calyx. I have never been able to solve the problem of the five stamens which, when the flower opens, are folded together in a knock-kneed fashion. The upper three are bearded below the anthers, the middle being the shortest. The lower two are much longer and have no fuzz on their filaments; they at first stand straight out, with the stigma between them; but after the upper anthers have shed their pollen, these 1, 2. Mullein flowers in different stages. Stamens curve up like boars' teeth and
3. Mullein seed enlarged. 4. A bit splash their pollen on the upper petals, 3. Mullein seed enlarged. 4. A bit splash their pollen on the upper petals,
of Mullein leaf enlarged. one-sidedly below. Later the corolla, stamens and all, falls off, leaving the stigma and style attached to the seed-capsule.

The color of the mullein flowers varies from lemon-yellow to white. The filaments are pale yellow; the anthers and pollen, orange. The seedcapsule is encased in the long calyx-lobes, and is shaped like a blunt egg. Cutting it in two crosswise, the central core, tough and flattened and almost filling the capsule, is revealed and, growing upon its surface, are numberless tiny, brown seeds, as fine as gunpowder. Later the capsule divides partially in quarters, opening wide enough to shake out the tiny seeds with every wandering blast. The seed, when seen through a lens, is very pretty; it looks like a section of a corncob, pitted and ribbed. A nice point of investigation for some junior naturalist is to work out the fertilization of the mullein flower, and note what insects assist. The mullein has another spoke in the wheel of its success. The seed, scattered from the sere and dried plants, settles comfortably in any place where it can reach the soil, and during the first season grows a beautiful velvety rosette of frosted leaves. No wonder Europeans grow it in gardens under the name of the "American velvet plant." These rosettes lie flat under the snow, with their tap-roots strong and already deep in the soil, and are ready to begin their work of food-making as soon as the spring sun gives them power.

\section{LESSON CXLVI}

\section{Mullein}

Leading thought-The mullein has its leaves covered with felt, which prevents evaporation during the dry weather and also prevents animals from grazing upon the plant. It has a deep root, and this gives moisture and food beyond the reach of most other plants. It blossoms all summer and until the snow comes in the autumn, and thus forms many, many seeds, which the wind plants for it; and here in our midst it lives and thrives despite us. 
Method - The pupils should have a field trip to see what plants are left uneaten in pastures, and thus learn where mullein grows best. The flower or seed stalk, with basal leaves and root, may be brought to the sctoolroom for the lesson.

Observations-I. Where does the mullein grow? Do you ever see it in swamps or woodlands? Do cattle or sheep eat it? Why? Does it flourish during the summer drought? How is it clothed to prevent the evaporation of its sap? Look at a mullein leaf with a lens and describe its appearance.

2. What sort of a root has the mullein? How is its root adapted to get moisture and plant food which other plants cannot reach? Describe the flowering stalk. How are the leaves arranged on it and attached to it? Are there several branching flower stalks or a single one?

3. Describe the flower bud. Do the mullein flowers nearest the base or the tip begin to blossom first? Is this invariable, or do flowers open here and there irregularly on the stem during the season?

4. Describe the mullein flower. How many lobes has the calyx? Are these covered with felt? How many petals? Are there always this number? Are the petals of the same size? Are they always regular in shape?

5. How many stamens? How do the upper three differ from the lower two? Describe the style and stigma. What are the colors of petals, anthers and stigma? What insects do you find visiting the flowers?

6. Describe the seed-capsule, its shape and covering. Cut it across and describe the inside. Where are the seeds borne? Are there many? Look at the seed with a lens, and describe it. How does the capsule open and by what means are the seeds scattered?

7. Does the mullein grow from the seed to maturity in one year? How does it look at the end of the first season? Describe the winter rosette, telling how it is fitted to live beneath the snows of winter. What is the advantage of this habit?

8. Write a theme telling all the ways the mullein has of flourishing and of combating other plants.

\footnotetext{
"The mullein's pillar, tipped with golden flowers, Slim rises uproard, and yon yellow bird Shoots to its top."
}

—“The Hill Hollow," A. B. Street.

\footnotetext{
"Sober dress never yet made you sullen, Style or size never brought you a blush; You're the envy of weavers, $O$, Mullein, For no shuttle can mimic your plush. With your feet in the sand you were born, Woolly monk of the thorn-field and fallow, But your heart holds the milk of the mallow, And your head wears the bloom of the corn."
} 


\section{THE TEASEL \\ Teacher's Story}

The old teasel stalks standing gaunt and gray in the fields, braving the blasts of winter, seem like old suits of armor, which elicit admiration from us for the strength and beauty of the protecting visor, breast-plate and gauntlets, and at the same time veer our thoughts to the knights of old who once wore them

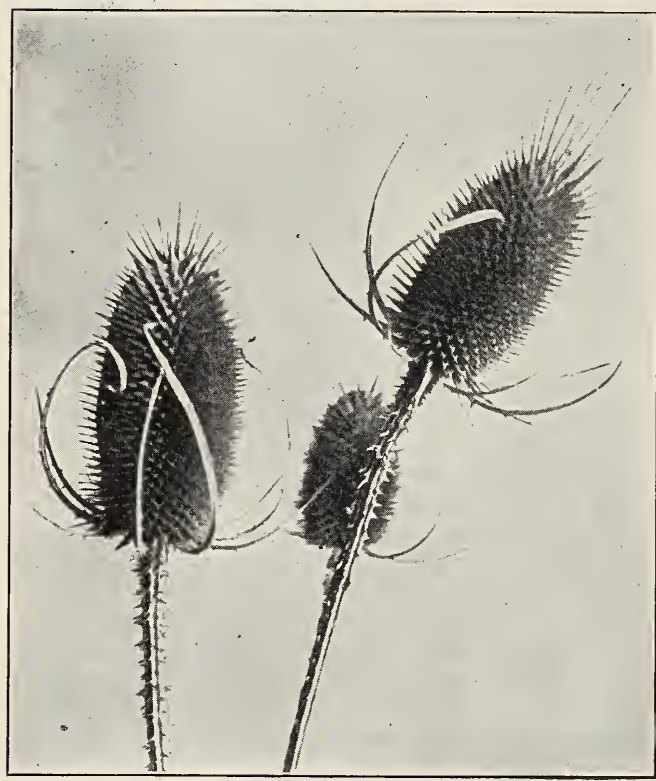

The teasel. in the fray. Thus, with the teasel, we admire this panoply of spears, and they recall the purple flowers and the ribbed seeds which were once the treasure of every spear-guarded cavity and the proud reason of every lance at rest.

Let us study this plant in armor: First, its stem is tough, woody, hollow, with ridges extending its full length and each ridge armed with spines which are quite wide at the base and very sharp. It is im= possible to take hold anywhere without being pricked by either large or small spines. The leaves are just fitted for such a stem. They are long, lanceolate, set opposite in pairs, rather coarse in texture, with a stiff, whitish midrib; the bases of the two leaves closely clasp the stem; the midrib is armed below with a row of long, white, recurved prickers, and woe unto the tongue of grazing beast that tries to lift this leaf into the mouth. If one pair of clasping leaves point east and west, the next pairs above and below point north and south.

The flower stems come off at the axils of the leaves and therefore each pair stands at right angles to the ones above and below. But if the teasel protects its stem and leaves with spikes, it does more for its flowers, which are set in dense heads armed with spines, and the head is set in an involucre of long, upcurving spiny prongs. If we look at it carefully, the teasel flower-head wins our admiration, because of the exquisite geometrical design made by the folded bases of the spines, set in diagonal rows. If we pull out a spine, we find that it enlarges toward the base to a triangular piece that is folded at right angles for holding the flower. Note 
that the spiny bracts at the tip of the flower-head are longer and more awesome than those at the sides; if we pass our hands down over the flower-head we feel how stiff the spines, or bracts are, and can hear them crackle as they spring back.

The teasel has a qui e original method of blossoming. The goldenrod begins to blossom at the tip of the flowering branches and the blossom-tide runs inward and downward toward the base. The clover begins at the base and blossoms toward the tip, or the center. But the teasel begins at the middle and blossoms both ways, and how it knows just where to begin is more than we can tell. But some summer morning we will find its flower-head girt about its middle with a wide band of purple blossoms; after a few days, these fade and drop off, and then there a.e two bands, sometimes four rows of flowers in each, and sometimes only two. Below the lower band and above the upper band, the enfolding bracts are filled with little, round-headed lilac buds, while between the two rows of blossoms the protecting bracts hold the precious growing seed. Away from each other this double procession moves, until the lower band reaches the pronged involucre and the upper one forms a solid patch on the apex of the flower-head. Since the secondary blossom-heads starting from the leaf axils are younger, we may find all stages of this blossoming in the flowerheads of one plant.

No small flower pays better for close examination than does that of the teasel. If we do not pull the flower-head apart, what we see is a little purple flower consisting of a white tube with four purple lobes at the end, the lower lobe being a little longer than the others and turning up slightly at its tip; projecting from between each of the lobes, and fastened to the tube, are four stamens with long, white filaments and beautiful purple anthers filled with large, pearly white pollen grains; at the very heart of the flower, the white stigma may be seen far down the tube. But a little later, after the anthers have fallen or shriveled, the white stigma extends out of the blossom like a long, white tongue and is crowded with white pollen grains.

But to see the flower completely we reed to break or cut a flower-head in two. Then we see that the long white tube is tipped at one end with purple lobes and a fringe of anthers, and at the other is set upon a little green, fluffy cushion which caps the ovary; the shape of the ovary in the flower tells us by its form how the seed will look later. Enfolding ovary and tube is the bract with its spiny edges, pushing its protecting spear outward, but not so far out as the opening of the flower, for that might

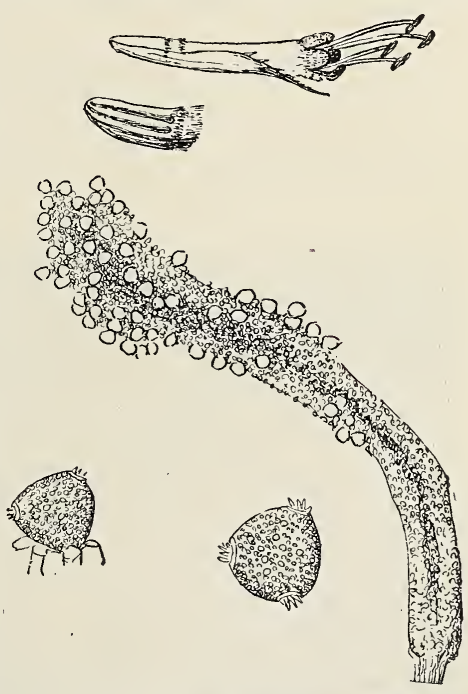

Teasel flower and seed enlarged. The stigma of a teasel floret much magnified to show the pollen adhering to it. Below, are pollen grains greatly magnified. 
keep away the insects which carry the teasel's pollen. The pollen of the teasel is white and globular, with three little rosettes arranged at equal distances upon it like a bomb with three fuses. These little rosettes are the growing points of the pollen grains and from any of them may emerge the pollen tube to push down into the stigma. The teasel pollen is an excellent subject for the children to stury, since it is so very large; and if examined with a microscope with a three-fourths objective, the tubes running from the pollen grains into the stigma may be easily seen.

In blossoming, the teasel does not always seem to count straight in the matter of rows of flowers. There may be more rows in the upper band than in the lower, or vice versa; this is especially true of the smaller secondary blossoms. But though the teasel flowers fade and the leaves fall off, still the spiny skeleton stands, the thorny stalks holding up the empty flower-heads like candelabra, from which the seeds are tossed far and wide, shaken out by the winds of autumn. But though battered by wintry blasts, the teasel staunchly stands; even until the ensuing summer, each bract on guard and its heart empty where once was cherished blossom and seed. Alas, because of this emptiness, it has been debased by practical New England housewives into a utensil for sprinkling clothes for ironing.

The spines of one species of teasel were, in earlier times, used for raising the nap on woolen cloth, and the plant was grown extensively for that purpose. The bees are fond of the teasel blossoms and teasel honey has an especially fine flavor.

The teasels are biennial, and during the first season, develop a rosette of crinkled leaves which have upon them short spines.

\section{LESSON CXLVII}

\section{The Teasel}

Leading thought-The teasel is a plant in armor, so protected that it can flourish and raise its seeds in pastures where cattle graze. It has a peculiar method of beginning to blossom in the middle of the flower-head

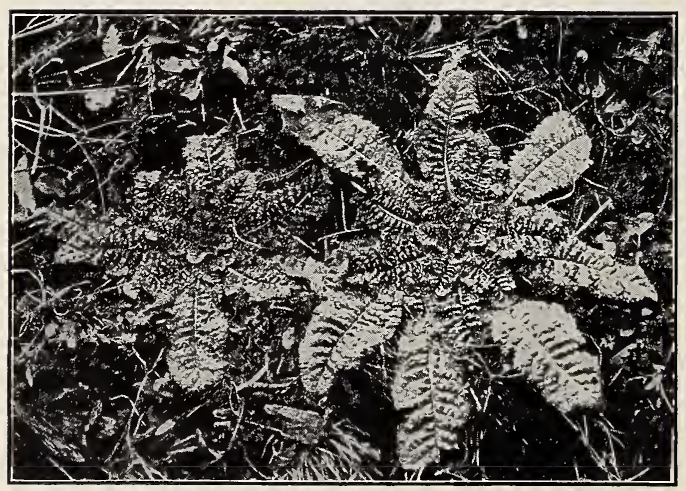

A teasel winter rosette. Photo by Verne Morton and then blossoming upward and downward from this point.

Method-In September, bring in a teasel plant which shows all stages of blossoming, and let the pupils make observations in the schoolroom.

Observations- I. Where does the teasel grow? Is it ever eaten by cattle? Why not? How is it protected?

2. What sort of stem has it? Is it 
hollow or solid? Where upon it are the spines situated? Are the spines all of the same size? Can you take hold of the stem anywhere without being pricked?

3. What is the shape of the leaves? How do they join the stem? Are the leaves set opposite or alternate? If one pair points east and west in which direction will the pairs above and below point? How and where are the leaves armed? How does the cow or sheep draw the leaves into the mouth with the tongue? If either should try to do this with the teasel, how would the tongue be injured?

4. Where do the flower stems come off? Do they come off in pairs? How are the pairs set in relation to each other?

5. What is the general appearance of the teasel flower-head? Describe the long involucre prongs at the base. If the teasel is in blossom, where do you find the flowers? How many girdles of flowers are there around the flower-head? How many rows in one girdle? Where did the first flowers blossom in the teasel flower-head? Where on the head will the last blossoms appear? Where are the buds just ready to open? Where are the ripened seeds?

6. Examine a single flower. How is it protected? Cut out a flower and bract and see how the long-spined bract enfolds it. Is the bract spear long enough to keep the cattle from grazing on the blossom? Is it long enough to keep the bees and other insects from visiting the flowers? Where are the longest spines on the teasel head?

7. Study a single flower. What is the shape of its corolla? How is it colored? What color are the stamens? How many? Describe the pollen. If the pollen is being shed where is the stigma? After the pollen is shed, what happens to the stigma?

8. What do you find at the base of the flower? How does the young seed look? Later in the season take a teasel head and describe how it scatters its seed. How do the ripe seeds look? How long will the old teasel plants stand?

9. For what were teasels once used? How many years does a teasel plant live? How does it look at the end of its first season? How is this an advantage as a method of passing the winter?

\section{QUEEN ANNE'S LACE, OR WILD CARROT Teacher's Story}

Queen Anne was apparently given to wearing lace made in medallion patterns; and even though we grant that her lace is most exquisite in design as well as in execution, we wish most sincerely that there had been established in America such a high tariff on this royal fabric as to have prohibited its importation. It has for decades held us and our lands prisoners in its delicate meshes, it being one of the most stubborn and persistent weeds that ever came to us from over the seas.

But for those people who admire lace of intricate pattern, and beautiful blossoms whether they grow on scalawag plants or not, this medallion flower attributed to Queen Anne is well worth studying. It belongs to the family Umbelliferae, which one of my small pupils always 


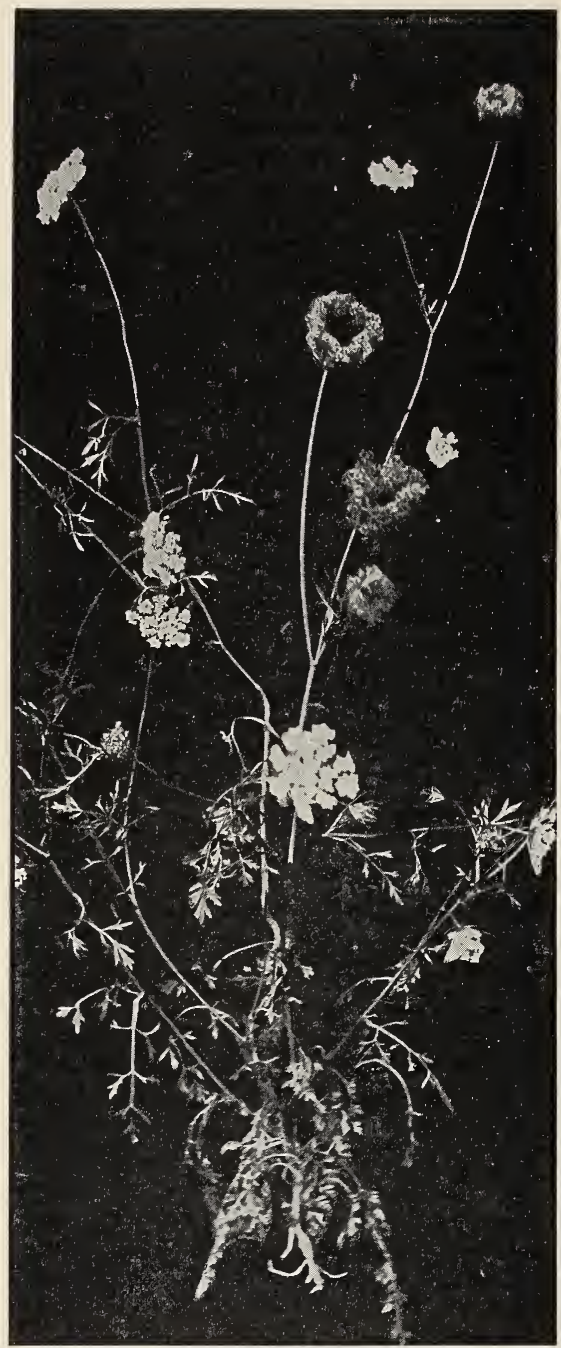

Queen Anne's lace, or wild carrot Photo by Verne Morton.

called umbrelliferae because, he averred, they have umbrella blossoms. In the case of Queen Anne's lace the flower-cluster, or umbel, is made up of many smaller umbels, each a most perfect flower-cluster in itself. Each tiny white floret has five petals and should have five stamens with creamy anthers, but often has only two. However, it has always at its center two fat little pistils set snugly together, and it rests in a solid, bristly, green, cuplike calyx. Twenty or thirty of these little blossoms are set in a rosette, the stems of graded length; and where the bases of the stems meet are some long, pointed, narrow bracts, which protectingly brood the flowers in the bud and the seeds as they ripen. Each of these little flower. clusters, or umbels, has a long stem, its length being just fit to bring it to its right place in the medallion pattern of this royal lace. And these stems also have set at their bases some bracts with long, threadlike lobes, which make a delicate, green background for the opening blossoms; these bracts curl up protectingly about the buds and the seeds. If we look straight into the large flower-cluster, we can see that each component cluster, or umbelicel, seems to have its own share in making the larger pattern; the outside blossoms of the outside clusters have the outside petals larger, thus forming a beautiful border and calling to mind the beautiful flowers of the Composites. At the very center of this flower medallion, there is often a larger floret with delicate winecolored petals; this striking floret is not a part of a smaller flower-cluster, but stands in stately solitude upon its own isolated stem. The reason 
for this giant floret at the center of the wide, circular flower-cluster is a mystery; and so far as I know, the botanists have not yet explained the reason for its presence. May.we not, then, be at liberty to explain its origin on the supposition that her Royal Highness, Queen Anne, was wont to fasten her lace medallions upon her royal person with garnet-headed pins?

When the flowers wither and the seeds begin to form, the flower-cluster then becomes very secretive; every one of the little umbels turns toward the center, its stem curving over so that the outside umbels reach over and "tuck in" the whole family; and the threadlike bracts at the base reach up as if they, too, were in the family councils, and must do their slender duty in helping to make the fading flowers into a little, tightfisted clump; and all of this is done so that the precious seeds may be safe while they are ripening. Such little porcupines as these seeds are! Each seed is clothed with long spines set in bristling rows, and is a most forbidding-looking youngster when examined through a lens; and yet there is method in its spininess, and we must grudgingly grant that it is not only beautiful in its ornamentation but is also well fitted to take hold with a will when wandering winds sift it down to the soil.

The wild carrot is known in some localities as the "bird's-nest weed," because the maturing seed-clusters, their edges curving inward, look like little birds' nests. But no bird's nest ever contained so many eggs as does this imitation one. In one we counted 34 tiny umbels on which ripened 782 seeds; and the plant, from which this "bird's nest" was taken, developed nine more quite as large.

Altogether the wild carrot is well

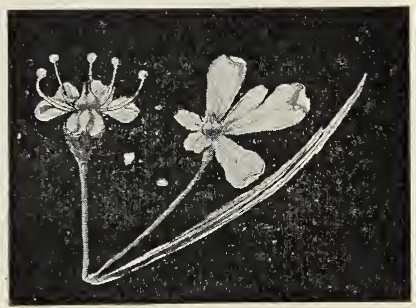

An inner and a border floret and a bract of Queen Anne's lace, enlarged. fitted to maintain itself in the struggle for existence, and is most successful in crowding out its betters in pasture and meadow. Birds do not like its spiny seeds; the stem of the plant is tough and its leaves are rough and have an unpleasant odor and acrid taste, which render it unpalatable to grazing animals. Winter's cold cannot harm it, for it is a biennial; its seeds often germinate in the fall, sending down long, slender taproots crowned with tufts of inconspicuous leaves; it thus stores up a supply of starchy food which enables it to start early the next season with great vigor. The root, when the plant is fully grown, is six or eight inches long, as thick as a finger and yellowish white in color; it is very acrid and somewhat poisonous.

The surest way of exterminating the Queen Anne's lace is to prevent its prolific seed production by cutting or uprooting the plants as soon as the first blossoms open.

"'Tis Eden everywhere to hearts that listen And watch the woods and meadows grow." 


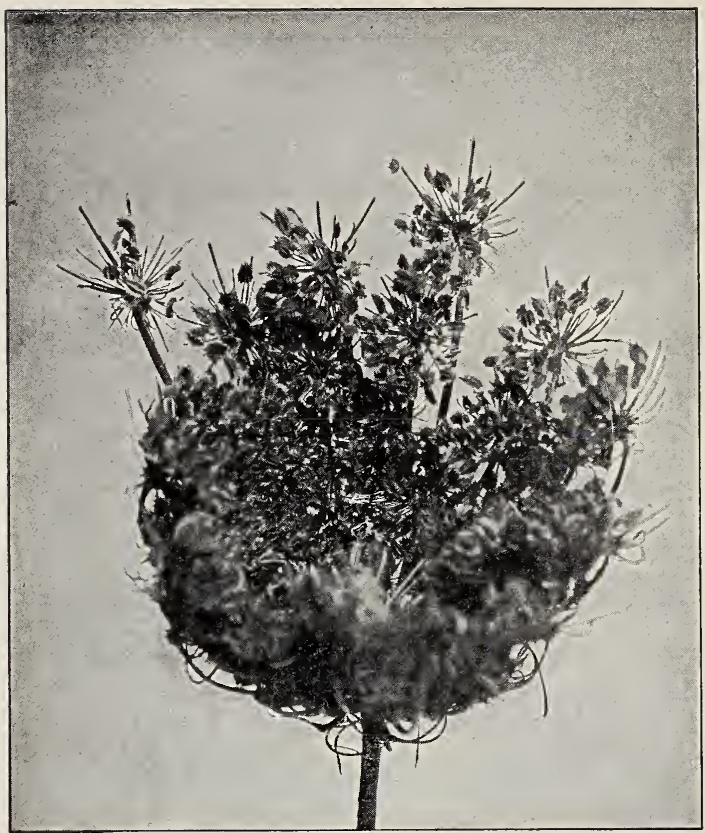

Seed-cluster, or "bird's nest," of wild carrot. Photo by Charles F. Fudge.

\section{LESSON CXLVIII}

\section{Queen Anne's Lace, or Wild Carrot}

Leading thought-Queen Anne's lace is a weed which came to us from Europe and flourishes better here than on its native soil. It has beautiful blossoms set in clusters, and it matures many seeds which it manages to plant successfully.

Method-The object of this lesson should be to show the pupils how this weed survives the winter and how it is able to grow where it is not wanted, maintaining itself successfully, despite man's enmity. The weed is very common along most country roadsides, and in many pastures and meadows. It blossoms very late in the autumn, and is available for lessons often as late as November. Its seed-clusters may be used for a lesson at almost any time during the winter.

Observations-r. Look at a wild carrot plant; how are its blossoms arranged? Take a flower-cluster, what is its shape? How many small flower-clusters make the large one? How are these arranged to make the large cluster symmetrical?

2. Take one of the little flower-clusters from near the center, and one from the outside, of the large cluster; how many little flowers, or florets make up the smaller cluster? Look at one of the florets through a lens; 
can you see the cup-shaped calyx? How many petals has it? Can you see its five anthers and its two white pistils?

3. Take one of the outer florets of the outside cluster; are all its flowers the same shape? How do they differ? Where are the florets with the large petals placed in the big flower-cluster? How does this help to make "the pattern?"

4. Do the outside or the central flowers of the large clusters open first? Can you find a cluster with an almost black or very dark red floret at its center? Is this dark flower a part of one of the little clusters or does it stand alone, its stem reaching directly to the main stalk? Do you think it makes the flowers of the Queen Anne's lace prettier to have this dark red floret at the center?

5. Take a flower-cluster with the flowers not yet open. Can you see the threadlike green bracts that close up around each bud? Can you see finely divided, threadlike bracts that stand out around the whole cluster? What position do these bracts assume when the flowers are open? What do they do after the flowers fade and the seeds are being matured?

6. What is the general shape of the seed-cluster of the wild carrot? Have you ever found such a cluster broken off and blowing across the snow? Do you think this is one way the seed is planted?

7. Examine a single seed of the wild carrot with a lens. Is it round or oblong? Thin or flat? Is it ridged or grooved? Has it any hooks or spines by which it might cling to the clothing of passers-by, or to the hair or fleece of animals, and thus be scattered more widely? Does the seed cling to its stem or break away readily when it is touched?

8. Take one seed-cluster and count the number of seeds within it. How many seed-clusters do you find on a single plant? How many seeds do you, therefore, think a single plant produces?

9. What should you consider the best means of destroying this prolific weed?

Io. What do you think is the reason that the wild carrot remains untouched, so that it grows vigorously and matures its seeds in lanes and pastures where cattle graze?

I I. Have you noticed any birds feeding on the seeds of the wild carrot?

I do not want change: I want the same old and loved things, the same wild flowers, the same trees and soft ash-green; the turtle-doves, the blackbirds, the coloured yellowhammer sing, sing, singing so long as there is light to cast a shadow on the dial, for such is the measure of his song, and I want them in the same place. Let me find them morning after morning, the starry-white petals radiating, striving upwards to their ideal. Let me see the idle shadows resting on the white dust; let me hear the humble-bees, and stay to look down on the rich dandelion disc. Let me see the very thistles opening their great crowns-I should miss the thistles; the reed-grasses hiding the moor-hen; the bryony bine, at first crudely ambitious and lifted by force of youthful sap straight above the hedgerow to sink of its own weight presently and progress with crafty tendrils; swifts shot through the air with outstretched wings like crescent-headed shaftless arrows darted from the clouds; the chaffinch with a feather in her bill; all the living staircase of the spring, step by step, upwards to the great gallery of the summer-let me watch the same succession year by year.

- "The Pageant of Summer," by Richard Jefferies. 


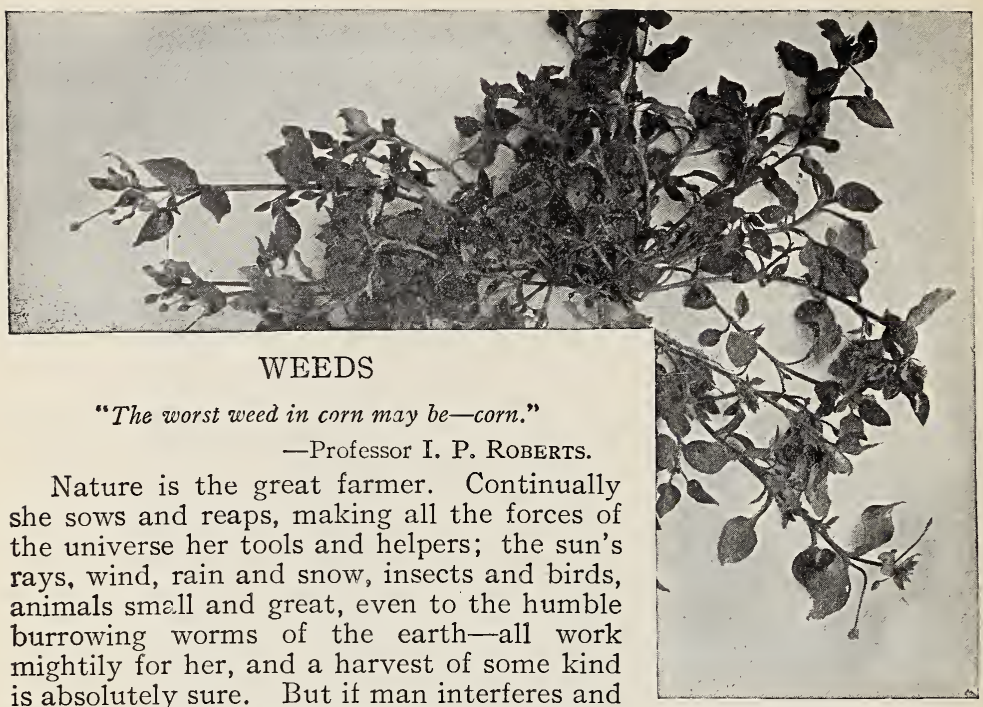
insists that the crops shall be only such as may benefit and enrich himself, she seems to yield a willing obedience, and under his control does immensely better work than when unguided. "eye-servant." Let the master relax his vigilance for ever so short a time, and among the crops of his desire will come stealing in the hardy, aggressive, and to him, useless plants that seem to be her favorites.

A weed is a plant growing where we wish something else to grow, and a plant may, therefore, be a weed in some locations and not in others. The mullein is grown in greenhouses in England as the American velvetplant. Our grandmothers considered "butter-and-eggs," a pretty posy, and planted it in their gardens. wherefrom it escaped, and is now a bad weed wherever it grows. A weed may crowd out our cultivated plants, by stealing the moisture and nourishment in the soil which they should have; or it may shade them out by putting out broad leaves and shutting off their sunlight. When harvested with a crop, weeds may be unpalatable to the stock which feed upon it; or in some cases, as in the wild parsnip, the plant may be poisonous.

Each weed has its own way of winning in the struggle with our crops, and it behooves us to find that way as soon as possible in order to circumvent it. This we can only do by a careful study of the peculiarities of the species. To do this we must know the plant's life history; whether it is an annual, surviving the winter only in its seeds; or a biennial, storing in fleshy root or in broad, green leafy rosette the food drawn from the soil and air during tre first season, to perfect its fruitage in the second year; or a perennial, surviving and springing up to spread its kind and pester the farmer year after year, unless he can destroy it "root and branch." Purslane is an example of the first class, burdock or mullein of the second, and the field sorrel or Canada thistle of the third. According 
to their nature the farmer must use different means of extermination: he must strive to hinder the annuals and biennials from forming any seed whatever; and where perennials have made themselves a pest, he must put in a "hoed crop," requiring such constant and thorough tillage that the weed roots will be deprived of all starchy food manufactured by green leaves and be starved out. Especially every one who plants a garden should know how the weeds look when young, for seedlings of all kinds are delicate and easy to kill before their roots are well established.

\section{LESSON CXLIX}

\section{OUtLine For the StUdy of A WeED}

I. Why do we call a plant a weed? Is a weed a weed wherever it grows? How about "butter and eggs" when it grew in Grandmother's garden? Why do we call that a weed now? What did Grandmother call it?

2. In how many ways may a weed injure our cultivated crops?

3. Why must we study the habits of a weed before we know how to fight it?

We should ask of every weed in our garden or on our land the following questions, and let it answer them through our observations in order to know why the weed grows where it chooses, despite our efforts.

4. How did this weed plant itself where I find it growing? By what agency was its seed brought and dropped?

5. What kind of root has it? If it has a tap-root like the mullein, what advantage does it derive from it? If it has a spreading shallowgrowing root like the purslane what advantage does it gain? If it has a creeping rootstock with underground buds like the Canada thistle, how is it thereby helped?

6. Is the stem woody or fleshy? Is it erect or reclining or climbing? Does it gain any advantage through the character of its stem?

7. Note carefully the leaves. Are they eaten by grazing animals? If not, why? Are they covered with prickles like the teazel or fuzz like the mullein, or are they bitter and acrid like the wild carrot?

8. Study the blossoms. How early does the weed bloom? How long does it remain in bloom? Do insects carry pollen for the flowers? If so, what insects? What do the insects get in return? How are the flower buds and the ripening seeds protected?

9. Does it ripen many seeds? Are these ripened at the same time or are they ripened during a long period? Of what advantage is this? How are the seeds scattered, carried and planted? Compute how many seeds one plant of this weed matures in one year.

"That which ye sow ye reap. See yonder fields!

The sesamum was sesamum, the corn

Was corn. The Silence and the Darkness know!"

-Edwin ARNold. 


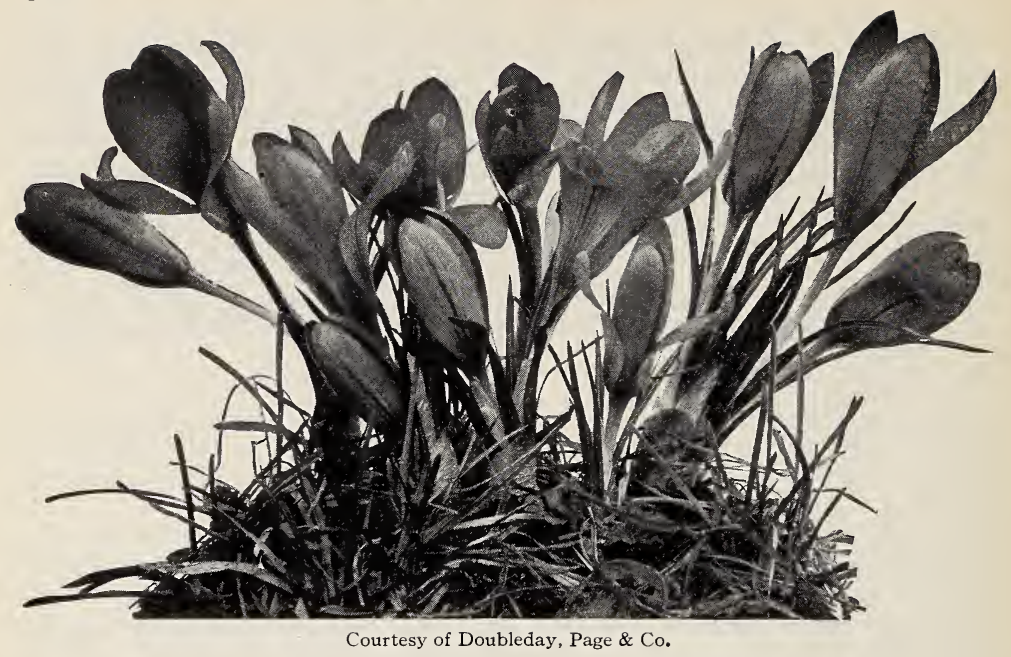

CULTIVATED-PLANT STUDY

\section{THE CROCUS \\ Teacher's Story}

The crocus, like the snowdrop, cannot wait for the snow to be off the ground before it pushes up its gay blossoms, and it has thus earned the gratitude of those who are winter weary.

The crocus has a corm instead of a bulb like the snowdrop or daffodil. A corm is a solid, thickened, underground stem, and is not in layers, like the onion. The roots come off the lower side of the corm. The corm of the crocus is well wrapped in several, usually five, white coats with papery tips. When the plant begins to grow the leaves push up through the coats.

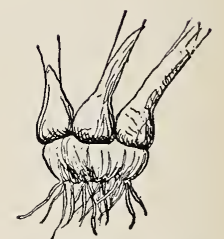

The old and young corms of the

crocus. The leaves are grasslike and may be in number from two to eight, depending on the variety. Each leaf has its edge folded, and the white midrib has a plait on either side, giving it the appearance of being box-plaited on the under side. The bases of the leaves enclosed in the corm coats are yellow, since they have had no sunlight to start their starch factories and the green within their cells. At the center of the leaves appear the blossom buds, each enclosed in a sheath.

The petals and sepals are similar in color, but the three sepals are on the outside, and their texture, especially on the outer side, is coarser than that of the three protected petals. But sepals and petals unite into a long tube at the base. At the very base of this corolla tube, away down out of sight, even below the surface of the ground, is the seed-box, or ovary. From the tip of the ovary the style extends up through the corolla-tube and is tipped with a ruffled three-lobed stigma. 
The three stamens are set at the throat of the corolla tube. The anthers are very long and open along the sides. The anthers mature first, and shed their pollen in the cup of the blossom where any insect, seeking the nectar in the tube of the corolla, must become dusted with it. However, if the stigma lobes fail to get pollen from other flowers, they later spread apart and curl over until they reach some of the pollen of their own flower.

Crocus blossoms have varied colors: white, yellow, orange, purple, the latter often striped or feather-veined. And, while many seeds like tiny pearls, are developed in the oblong capsule, yet it is chiefly by its corms that the crocus multiplies. On top of the mother corm of this year develop several small corms, each capable of growing a plant next year. But after two years of this second-story sort of multiplication the young crocuses are pushed above the surface of the ground. Thus, they need to be replanted every two or three years. Crocuses may be planted from the first of October until the ground freezes. They make pretty borders to garden beds and paths. Or they may be planted in lawns

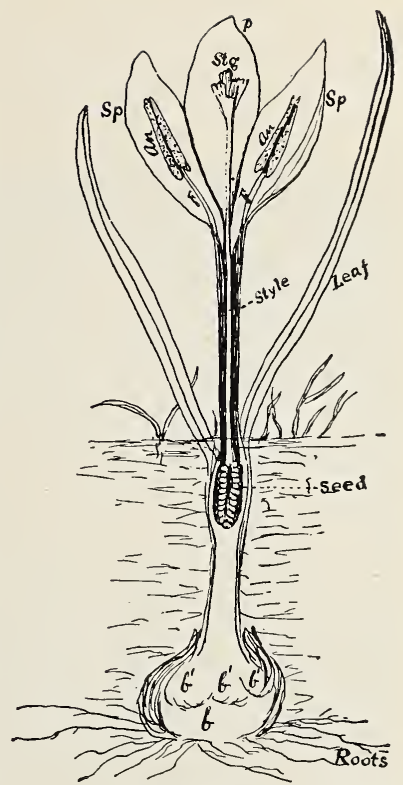

The crocus.

$p$, petal; sp, sepal; an, anther; $f$, fila. ment; stg. stigma; $b$, mother corm; $b^{x} b^{x} b^{x}$ young corms.

without disturbing the grass, by punching a hole with a stick or dibble and dropping in a corm and then pressing back the soil in place above it. The plants will mature before the grass needs to be mowed.

\section{LESSON CL \\ The Crocus}

Leading thought-The crocuses appear so early in the spring, because they have food stored in underground storehouses. They multiply by seeds and by corms.

Method-If it is possible to have crocuses in boxes in the schoolroom windows, the flowers may thus best be studied. Otherwise, when crocuses are in bloom bring them into the schoolroom, bulbs and all, and place them where the children may study them at leisure.

Observations- $r$. At what date in the spring have you found crocuses in blossom? Why are they able to blossom so much earlier than other flowers?

2. Take a crocus just pushing up out of its bulb. How many overcoats protect its leaves? What is at the very center of the bulb? Has the flower bud a special overcoat? 
3. Describe the leaves. How are they folded in thcir ovorcouts? What color are they where they have pushed out above their operconts? What color are they within the overcoats? Why?

4. Do the flowers or the leaves have stems, or do they arise dircctly from the bulb?

5. What is the shape of the open crocus flower? Can you foll the difference between sepals and petals in color? Can you tell the ciiriorcinco by their position? Or by their texture above or below? As you lool:in to the flower, which make the points of the triangle, the sepalk or cinc petals?

6. Describe the anthers. How long are they? How many are thore? How do they open? What is the color of the pollen? Describe horr a ioce becomes dusted with pollen? Why does the bee visit the crocus blosssos:1? If she finds nectar there, where is it?

7. Describe the stigma. Open a flower and see how long tho sts:-lo is? How do the sepals and petals unite to protect the style? Where is inge seed-box? Is it so far down that it is below ground? Howr szossy scocls are devcloped from a single blossom?

8. How many colors do you find in the crocus flowers? Whick, esse the prettiest in the lawn? Which, in the flower beds?

9. How do the crocus blossoms act in dark and stormin ronithor? When do they open? How does this benefit them?

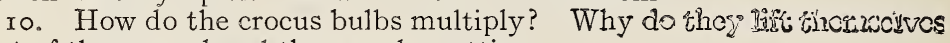
out of the ground and thus need resetting.

xx. Describe how to raise crocuses best; the kind of soils the time of planting, and the best situations.

Out of the frozen earth below.

Out of the melting of the snow.

No flower, but a film, I push to light;

No stem, no bud-yet I have burst

The bars of winter, I am the first

O Sun, to greet thee out of the night!

Deep in the warm sleep underground

Life is still, and the peace profound:

Yet a beam that pierced, and a thrill that smote

Call'd me and drew me from far away;

I rose, I came, to the open day

I have won, unshelter'd, alone, remote.

- "The Crocus," by Harriet E. H. King.

When first the crocus thrusts its point of gold,

Up through the still snow-drifted garden-mould,

And folded green things in dim woods unclose

Their crinkled spears, a sudden tremor goes

Into my veins and makes me kith and lin

To every wild-born thing thai thrills and blows.

- "A Touch of NATURE," BI T. B. ALtric I. 


\section{'THE DAFFODILS AND THEIR RELA'TIVES \\ Teacher's Story \\ "Daffydown Dilly came up in ihe cold from the brown mold, Although the March breezes blew keen in her face, Although the white snow lay on many a place."}

Thus, it is that Miss Warner's stanzas tell us the special reason we so love the daffodils. They bring the sunshine color to the sodden earth, when the sun is chary oî his favors in our northern latitude; and the sight of the daffodils floods the spirit with a sense of sunlight.

The daffodils and their relatives, the jonquils and narcissus, are interesting when we stop to read their story in their form. The six segments of the perianth, or, as we would say, the three bright-colored sepals and the three inner petals of the flower, are different in shape; but they all look like petals and stand out in star-shape around the flaring end of the flower tube, which, because of its shape, is called the corona, or crown; however, it looks more like a stiff little petticoat extending out in the middle of the flower than it does like a crown. The crown is simply the widened end of the tube of the flower, as may be seen by opening a flower lengthwise; the six seem-

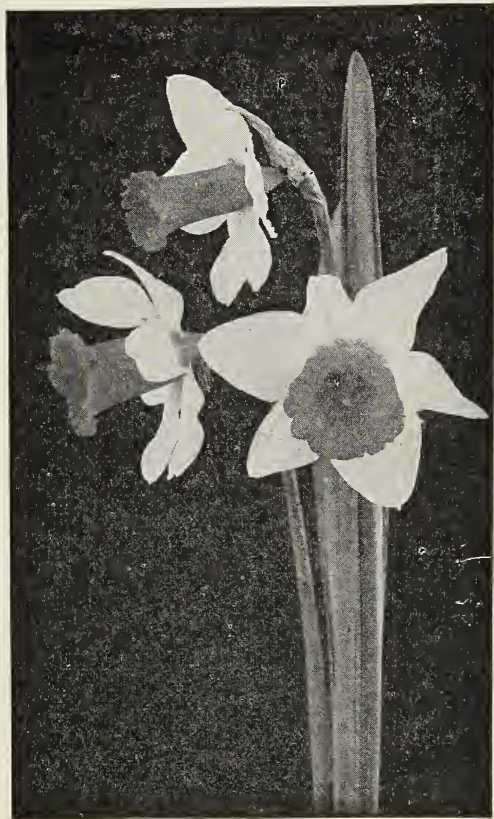

Daffodil. ing petals will peel off the tube, showing that they are fastened to the outside of it. When we look down into the crown of one of these flowers, we see the long style with its three-lobed stigma pushing out beyond the anthers, which are pressed close about it at the throat of the tube; between each two anthers may be seen a little deep passage, through which the tongues of the moth or butterfly can be thrust to reach the nectar. In a tube, slit open, we can see the nectar at the very bottom of it, and it is sweet to the taste and has a decided flavor. In this open tube we may see that the filaments of the stamens are grown fast to the sides of the tube for much of their length, enough remaining iree to press the anthers close to the style. The ovary of the pistil is a green swelling at the base of the tube; by cutting it across we can see it is triangular in outline, and has a little cavity in each angle large enough to hold two rows of the little, white, shining, unripe seeds. Each of these cavities is partitioned from the others by a green wall; the partition is marked by a suture on the outside of the seed-pod. 
When the flower stalk first appears, it comes up like a sheathed sword, pointing toward the zenith, green, veined lengthwise, and with a noticeable thickening at each edge. As the petals grow, the sheath begins to round out; and then as if to confuse those people who are so stupid as to believe that plants do not really do things, the stiff stem at the base of the sheath

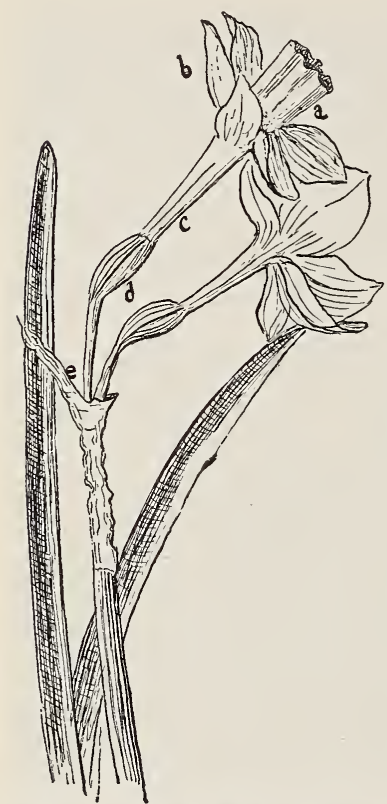

Daffodil showing detail of flower.

$a$ corona or crown; $b$, sepals and petals forming perianth; c, corolla tube;
d, ovary or seed-case; e, sheath or spathe.

\section{very early in the spring.}

bends at right angles. This brings a strain upon the sheath which bursts it, usually along the upper side, although sometimes it tears it off completely at the base. The slitted sheath, or spathe, hangs around the stem, wrinkled and parchment-like, very like the loose wrist of a suede glove. The stalk is a strong green tube; the leaves are fleshy and are grooved on the inner side, the groove being deep enough to clasp part way around the flower stem. The number of leaves varies with the variety, and they are usually as tall as the flower stalk. There is one flower on a stalk in the daffodils and the poet's narcissus, but the jonquils and paper-white narcissus have two or more flowers on the same stalk.

A bed should be prepared by digging deep and fertilizing with stable manure. The bulbs should be planted in September or early October, and should be from four to six inches apart, the upper end of the bulbs at least four inches below the surface of the soil. They should not be disturbed but allowed to occupy the bed for a number of years, or as long as they give plenty of flowers. As soon as the surface of the ground is frozen in the winter, the beds should be covered from four to six inches in depth with straw-mixed stable manure, which can be raked off

The new bulbs are formed at the sides of the old one; for this reason the daffodils will remain permanently planted, and do not lift themselves out of the ground like the crocuses. The leaves of the plant should be allowed to stand as long as they will after the flowers have disappeared, so that they may furnish the bulbs with plenty of food for storing. The seeds should not be allowed to ripen, as it costs the plant too much energy and thus robs the bulbs. The flowers should be cut just as they are opening. Of the white varieties, the poet's narcissus is the most satisfactory, as it is very hardy and very pretty, its corona being a shallow, flaring, greenish yellow rosette with orange-red border, the anthers of its three longest stamens making a pretty center. No wonder Narcissus bent over the pool in joy at viewing himself, if he was as beautiful a man as the pciet's narcissus is as a flower. 


\section{LESSON CLI}

\section{Daffodils, Jonguils and Narcissus}

Leading thought - The daffodil, jonquil and narcissus are very closely related, and quite similar. They all come from bulbs which should be planted in September; but after the first planting, they will flower on year after year, bringing much brightness to the gardens in the early spring.

Method-The flowers brought to school may be studied for form, and there should be a special study of the way the flower develops its seed, and how it is propagated by bulbs. The work should lead directly to an interest in the cultivation of the plants. In seedsmen's catalogues or other books, the children will find methods of planting and cultivating these flowers in cities. Daffodils are especially adapted for both window gardens and school gardens.

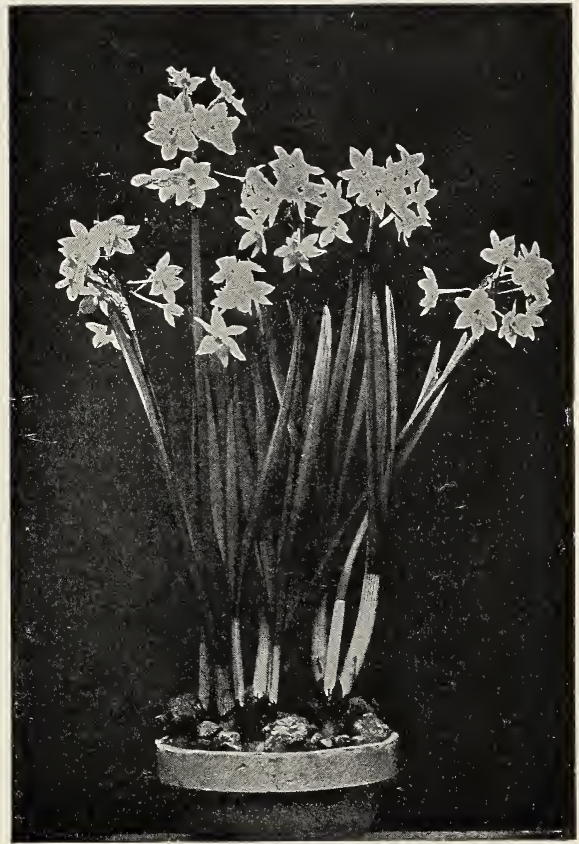

Paper-white narcissus.

Observations-I. Note the snape of the flower. Has it any sepals? What do we call the flowers that have their sepals colored like petals, thus forming a part of the beauty of the flower? Can you see any difference in color, position and texture between the petals and sepals?

2. How do the petal-like parts of these flowers look? How many of them are there? Do they make the most showy part of the flower?

3. What does the central part of the flower look like? Why is it called the corona, or crown? Is it a part of the tube which joins the flower to the stem? Do the petals and sepals peel off this tube? Peel them off one flower, and see that the tube is shaped like a trumpet.

4. Look down into the crown of the flower and tell what you see. Can you see where the insect's tongue must go to reach the nectar?

5. Cut open a trumpet lengthwise to find where the nectar is. How far is it from the mouth of the tube? How long would the insect's tongue have to be to reach it? What insects have tongues as long as this?

6. In order to reach the nectar how would an insect become dusted with pollen? Are the stamens loose in the flower-tube? Is the pistil longer than the stamens? How many parts to the stigma? Can you see 
how the flowers are arranged so that insects can carry pollen from flower to flower?

7. What is the green sweiling in the stem at the base of the trumpet? Is it connected with the style? Cut it across and describe what you see. How do the young seeds look and how are they arranged?

8. Where the flower stem joins the stalk, what do you see? What is this dry spathe there for? Are there one or more flower stems coming from this spathe?

c. Describe the flower stalk? Are the leaves wide or narrow? Are they as long as the flower stalk, are they flat, or are they grooved to fit around the flower stalk?

IO. What are the differences between daffodils, jonquils and poet's narcissus? When should the bulbs for these flowers be planted? Will there be more bulbs formed around the one you plant? Will the same bulb ever send up flowers and leaves again? How do the bulbs divide to make new bulbs?

II. How should the bed for the bulbs be prepared? How near together should the bulbs be planted? How deep in the earth? How protect them in the North during the winter?

I 2. Why should you not cut the leaves off after the flowers have died? Why should you not let the seeds ripen? When should the flowers be cut for bouquets? Who was Narcissus, and why should these early spring flowers be named after him?

Supplementary reading-Green Things Growing, Mulock; The Daffodils, Wordsworth; The Story of Narcissus, Child's Study of the Classics: Mary's Garden, Duncan, Chapters XXVI and XXVII.

"I emphatically deny the common notion that the farm boy's life is drudgery. Much of the work is laborious, and this it shares with all work that is productive; for the easier the job the less it is worth doing. But every piece of farm work is also an attempt to solve a problem, and therefore it should have its intellectual interest; and the problems are as many as the hours of the day and as varied as the face of nature. It needs but the informing of the mind and the quickening of the imagination to raise any constructive work above the level of drudgery. It is not mere dull work to follow the plow-I have followed it day after day-if one is conscious of all the myriad forces that are set at work by the breaking of the furrow; and there is always the landscape, the free fields, the clean soil, the rain, the promise of the crops. Of all men's labor, the farmer's is the most creative. I cannot help wondering why it is that men will eagerly seek work in the grease and grime of a noisy factory, but will recoil at what they call the dirty work of the farm. So much are we yet bound by tradition!" 

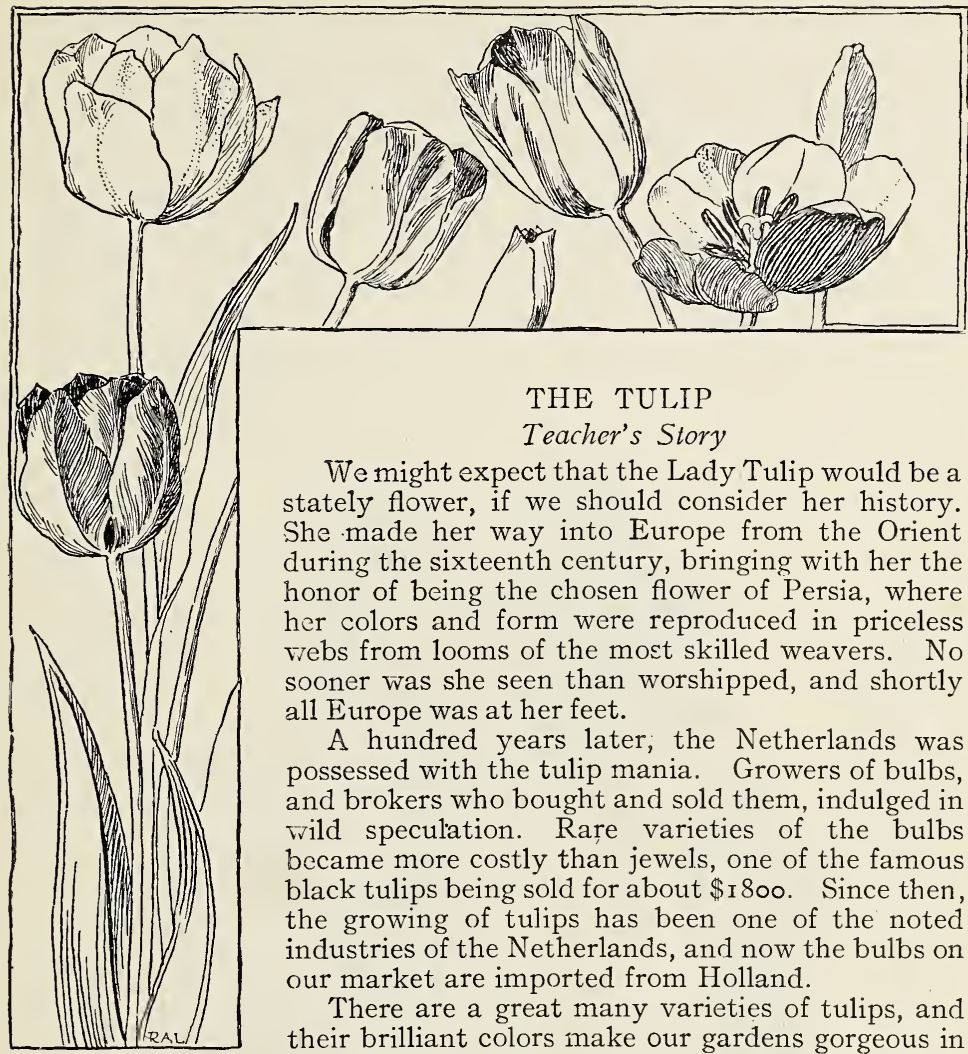

THE TULIP

Teacher's Story

We might expect that the Lady Tulip would be a stately flower, if we should consider her history. She made her way into Europe from the Orient during the sixteenth century, bringing with her the honor of being the chosen flower of Persia, where her colors and form were reproduced in priceless webs from looms of the most skilled weavers. No sooner was she seen than worshipped, and shortly all Europe was at her feet.

A hundred years later; the Netherlands was possessed with the tulip mania. Growers of bulbs, and brokers who bought and sold them, indulged in wild speculation. Rare varieties of the bulbs became more costly than jewels, one of the famous black tulips being sold for about $\$$ I 800 . Since then, the growing of tulips has been one of the noted industries of the Netherlands, and now the bulbs on our market are imported from Holland.

There are a great many varieties of tulips, and their brilliant colors make our gardens gorgeous in early spring. Although this flower is so prim, yet it bears well close observation. The three petals, or inner segments of the perianth, are more exquisite in texture and in satiny gloss on their inner surface than are the three outer segments or sepals; each petal is like grosgrain sills, the fine ridges uniting at the central thicker portion. In the red varieties, there is a six pointed star at the heart of the flower, usually yellow or yellow-margined, each point of the star being at the middle of a petal or sepal; the three points on the petals are longer than those on the sepals.

When the flower's bud first appears, it is nestled down in the center of the plant, scarcely above the ground. It is protected by three green sepals. As it stretches up, the bud becomes larger and the green of the sepals talkes on the color of the tulip flower, until when it opens there is little on the outside of the sepals to indicate that they once were green. But they still show that they are sepals, for they surround the petals, each standing out and malsing the flower triangular in shape as we look into it. During strizms and dark days, the sepals again partially close about the flower. 
The seed-vessel stands up, a stout, three-sided, pale green column at the center of the flower, in some varieties, its three-lobed yellowish stigma making a Doric capital; in others, the divisions are so curled as to make the capital almost Ionian. The six stout, paddle-shaped stamens have their bases expanded so as to encircle completely the base of the pistil column; these wide filaments are narrower just below the point where the large anthers join. The anther opens along each side to discharge the pollen; however, the anthers flare out around the seed vessel and do not reach half way to the stigma, which is probably the tulips' way of inducing the insects to carry their pollen, since the bees cannot reach the nectar at the base of the pistil without dusting themselves with pollen.

The flower stem is stout, pale green, covered with a whitish bloom. The leaves are long, trough-shaped and narrow with parallel veins; the bases of the lower ones encircle the flower stem and have their edges more or less ruffled and their tips recurved; the upper leaves do not completely encircle the flower stem at their bases. The texture of the leaves is somewhat softer on the inside than on the outside, and both sides are grayish green.

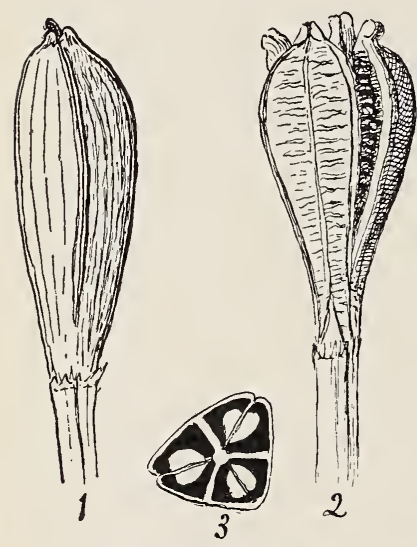

Tulip seed-capsule.

After the petals and stamens are dropped the seed-vessel looks like an ornamental tip to the flower stem; it is three-sided, and has within double rows of seeds along each angle. The seeds should not be allowed to ripen as they thus take too much strength from the bulbs.

The bulb is formed of several coats, or layers, each of which extends upwards and may grow into a leaf; this shows that the bulb is made up of leaves which are thickened with the food which is stored up in them during one season, so as to start the plant growing early the next spring. In the heart of each bulb is a flower bud, sheltered and cuddled by the fleshy leaflayers around it, which protect it during the winter and furnish it food in the spring. This structure of the bulb explains why the leaves clasp the flower stem at their bases. 8. Tulip seed-cansule; 2 , the same open- The true roots are below the bulb, making
ed; 3 , cross section of same. a thick tassel of white rootlets, which reach deep into the soil for food and water.

Tulips are very accommodating; they will grow in almost any soil if it is well drained, so that excessive moisture may not rot the bulbs. In preparing a bed, it should be rounded up so as to shed water; it should also be worked deep and made rich. If the soil is stiff and clayey, set bulbs only three inches deep, with a handful of sand beneath each. If the soil is mellow loam, set the bulbs four inches deep and from four to six inches apart each way, depending on the size of the bulbs. They should be near enough so that when they blossom the bed will be covered and show no gaps. Take care that the pointed tip of the bulb is upward and that it does not fall to one side as it is covered. October is the usual time for planting as the beds are often used for other flowers during the summer. 
However, September is not too early for the planting, as the more root growth made before the ground freezes, the better; moreover, the early buyers have best choice of bulbs. The beds should be protected by a mulch of straw or leaves during the winter, which should be raked off as soon as the ground is thawed in the spring. The blossoms should be cut as soon as they wither, in order that the new bulbs which form within and at the sides of the parent bulb may have all of the plant food, which would otherwise go to form seed. Tulips may be grown from seed, but it takes from five to seven years to obtain blossoms, which may be quite unlike the parent and worthless. The bulblets grow to a size for blooming in two or three years; the large one which forms in the center of the plant will bloom the next season.

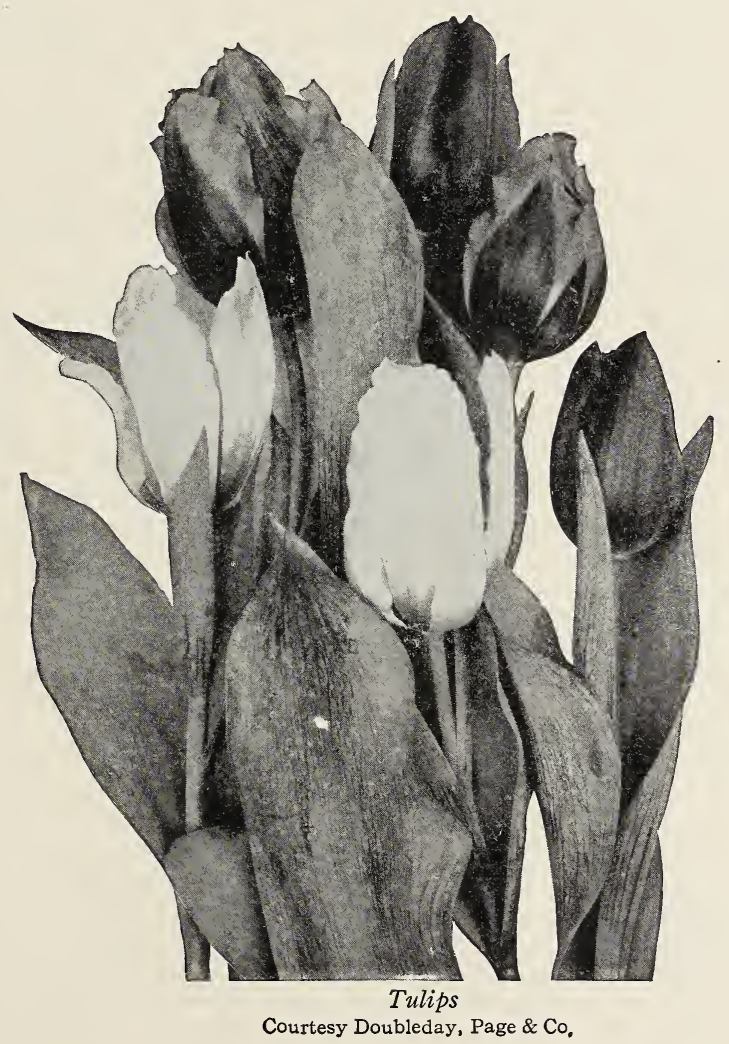




\section{LESSON CLII}

\section{The Tulips}

Leading thought - The tulips blossom early, because they have food stored in the bulbs the year before, ready to use early in the spring. There are many varieties; each is worth studying carefully, and we should all know how to grow these beautiful flowers.

Methods-These observations may be made upon tulips in school gardens or bouquets. The best methods of cultivating should be a part of the garden training. For this, consult the seed catalogues; also let the pupils form some idea of the number of varieties from the seed catalogues. Water-color drawings should be a large factor in studying the tulip. The red varieties are best for beginning the study, and then follow with the other.colors; note differences.

Observations-I. What is the color of your tulip? Is it all the same color? Is the bottom of the flower different in color? What is the pretty shape of these different colors at the heart of the flower?

2. Look at a tulip just opening. What causes it to appear so triangular? Can you see that the three sepals are placed outside the petals? Is there any difference in color between the sepals and petals on the inside On the outside? Are the sepals and petals the same in length and shape? Do you know the name given to this arrangement when sepals and petals look alike in color? Are the three petals more satiny on the inside than the sepals? Is the center part of the petal as soft as the edges?

3. When the tulip flower bud first begins to show, where is it? What color are the sepals which cover it? Describe the opening of the flower? Do the green sepals fall off? What becomes of them?

4. In the open flower, where is the seed-pod, and how does it look? How do the anthers surround the seed-pod, or ovary? Describe the anthers, or pollen-boxes? What color are they? What color is the pollen? Do the anthers reach up to the stigma, or tip of seed-pod? Where is the nectar in tulips? How do the insects become covered with the pollen in reaching it? Do the flowers remain open during dark and stormy days? Why?

5. Describe the tulip stem and the leaves. Do the leaves completely encircle the flower stem at the base? Are their edges ruffled? In the sprouting plant, do these outer basal leaves enfold the leaves which grow higher on the stem? Are the leaves the same color above and below? What shade of green are they?

6. After the petals have dropped, study the seed-pod. Cut it crosswise and note how many angles it has. How are these angles filled? Should tulips be allowed to ripen seeds? Why not?

7. Study a bulb of a tulip. There are outer and inner layers and a heart. What part of the plant do the outer layers make? What part does the center make? Where are the true roots of the tulip?

8. When should tulip bulbs be planted? How should you prepare the soil? How protect the bed during the winter? How long would it take to grow the flowers from the seed? Where are most of our bulbs grown? Do you know about the history of tulips?

Supplementary reading-Bulbs and Bulb-Culture, Peter Henderson; Plants and their Children, Dana, p. 2 I6; Mary's Garden and How It Grew, Duncan, Ch. XXVI; Bulbs and How to Grow Them, Doubleday-Page Co. 


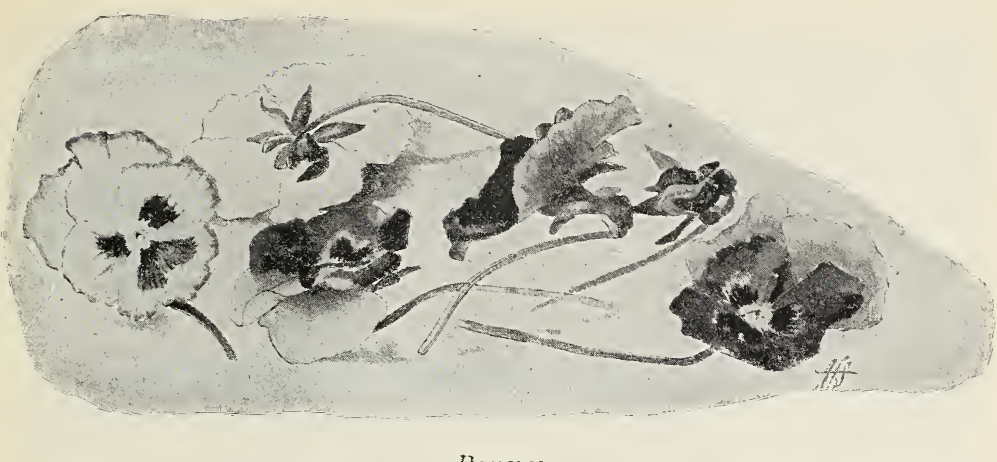

Pansies.

Drawn by Anna C. Stryke.

THE PANSY

Teacher's Story

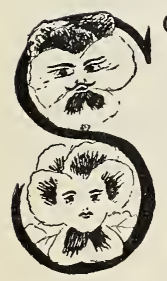

OME people are pansy-faced and some pansies are humanfaced, and for some occult reason this puts people and pansies on a distinctly chummy basis. When we analyze the pansy face, we find that the dark spots at the bases of the side petals make the eyes, the lines radiating from them looking quite eyelashy. The opening to the nectartube makes the nose, while the spot near the base of the lower petal has to do for a mouth, the nectar guiding-lines being not unlike whiskers. Meanwhile, the two upper petals give a "high-browed" look to the pansy countenance, and make it a wise and knowing little face.

The pansy nectar is hidden in the spur made by the lower petal extend. ing behind the flower. The guiding lines on the lower and side petals all converge, pointing directly to the openine which leads to this nectar-well, telling the secret to every bee that flies. Moreover, the broad lower petal is a platform for the lady bee to alight upon, while she probes the nectarwell with her tongue.

But at the door leading to the nectar-well sits a little man; his head is green, he wears a white cape with a scalloped, reddish brown collar, and he sits with his bandy legs puished back into the spur as if he were taking a foot bath in nectar. This little pansy man has plenty of work to do; for his mouth, which is large and at the top of his green head, is the stigma. The cape is made of five overlapping stamens, the brown, scalloped collar being the anthers; his legs consist of prolongations of the two lower stamens. And when the bee probes the nectar-well with her tongue, she tickles the little man's feet so that his head and shoulders wriggle; and thus she brushes the pollen dust from his collar against her fuzzy

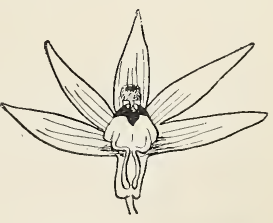

The little pansy-man. face, and at the same time his mouth receives the pollen from her dusty coat. 
As the pansy matures, the little man grows still more manlike; after a time he sheds his anther cape, and we can see that his body is the ribbed seed-pod. He did not eat pollen for nothing, for he is full of growing seeds. Sometimes the plush brushes, which are above his head in the pansy flower, become filled with pollen, and perhaps he gets a mouthful of it, although these brushes are supposed to keep out intruders.

The pansy sepals, five in number, are fastened at about one-third of their length, their heart-shaped bases making a little green ruffle around the stem where it joins the flower. There is one sepal above and two at each side, but none below the nectar-spur. The flower stem is quite short and always bends politely so the pansy can look sidewise at us instead of staring straight upward. The plant stem is angled and crooked and stout. In form, the leaves are most capricious; some are long and pointed, others wide and rounded. The edges are slightly scalloped and the leaf may have at its base a pair of large, deeply lobed stipules. In a whole pansy bed it would be quite impossible to find two leaves just alike.

The pansy ripens many seeds. The ribbed seed-capsule, with its base set comfortably in the faithful sepals, finally opens in three valves and the many seeds are scattered. To send them as far afield as possible, the edges of each valve of the pod curl inward, and snap the seeds out as boys snap apple seeds from the thumb and finger.

Pansies like deep, rich and cool, moist soil. They are best suited to a northern climate, and prefer the shady side of a garden to the full sunshine. The choice varieties are perpetuated through cuttings. They may be stuck in the open ground in summer in a half-shady place and should be well-watered in dry weather. All sorts of pansies are readily raised from seed sown in spring or early summer, and seedlings, when well established, do not suffer, as a rule, from winter frosts.

The general sowing for the production of early spring bloom is made out of doors in August, while seeds sown indoors from February to June will produce plants to flower intermittently during the late summer and fall months. When sowing pansy seed in August, sow the seed broadcast in a seed-bed out of doors, cover very lightly with fine soil or well-rotted manure, and press the seed in with a small board; then mulch the seedbed with long, strawy horse manure, from which the small particles have been shaken off, to the thickness of one inch, so as to have the soil well and evenly covered. At the end of two weeks the plants will be up. Then remove the straw gradually, a little at a time, selecting a dull day if possible. Keep the bed moist.

If the pansies are allowed to ripen seeds the season of bloom will be short, for when its seeds are scattered the object of the plant's life is accomplished. Besides, the plant has not vitality enough to perfect seeds and continue its bloom, and flowers borne with the forming seeds are smaller than the earlier ones. But if the flowers are kept plucked as they open, the plants persistently put forth new buds. The plucked flowers will remain in good condition longer if picked in the early morning before the bees begin paying calls, for a fertilized flower fades more quickly than one which has received no pollen. 


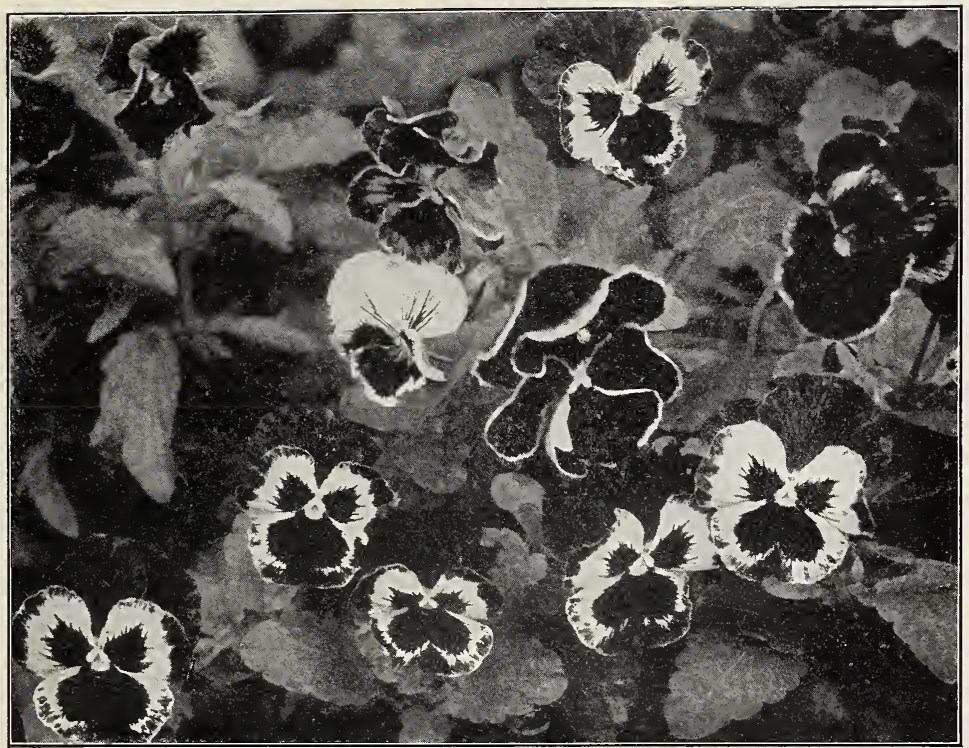

Photo by Verne Morton

\section{LESSON CLIII}

The Pansy

Leading thought-The pansy is a member of the violet family. The flower often resembles a face; the colors, markings and fragrance all attract the bees, who visit it for the nectar hidden in the spur of the lower petal.

Method-The children naturally love pansies because of the resem. blance of these flowers to quaint little faces. They become still more interested after they see the little man with the green head, which appears in the flower as it fades. A more practical interest may be cultivated by studying the great numbers of varieties in the seed catalogs and learning their names. This is one of the studies which leads directly to gardening. There are many beautiful pansy poems which should be read in connection with the lesson.

Observations - r. How does the pansy flower resemble a face? Where are the eyes? The nose? The mouth? How many petals make the pansy forehead? The cheeks? The chin?

3. Describe how a bee gets the nectar. Where does she stand while

2. Where is the nectar in the pansy? Which petal forms the nectarprobing with her tongue?

4. Where is the pollen in the pansy? What is the peculiar shape of the anthers? How do the two lower stamens differ in form from the three upper ones? 
5. Where is the stigma? Does the bee's tongue go over it or under it to reach the nectar? Describe the pansy arrangement for dusting the bee with pollen and for getting pollen from her tongue.

6. Observe the soft little brushes at the base of the two side petals. What do you think they are for?

7. Take a fading flower; remove the petals, and see the little man sitting with his crooked legs in the nectar-tube. What part of the flower makes the man's head? What parts form his cape? Of what is his pointed, scalloped collar formed?

8. How many sepals has the pansy? Describe them. How are they attached? When the flower fades and the petals fall, do the sepals also fall?

9. Where in the flower is the young seed-pod? Describe how this looks after the petals have fallen.

xo. Describe how the seed-pod opens. How many seeds are there in it? How are they scattered?

II. Study the pansy stem. Is it solid? Is it smooth or rough? Is it curved? Does it stand up straight or partially recline on the ground?

I2. Take a pansy leaf and sketch it with the stipules at its base. Can you find two pansy leaves exactly alike in shape, color and size?

I3. At what time should the pansy seed be planted? How should the soil be prepared?

Supplementary reading-“April Fools" (p. 50), "Pansy Song" (p. I 25), Nature in Verse, compiled by Mary J. Lovejoy; "Garden Folk" (p. I 79), "Pansies" pp. I 83-184, Among Flowers and Trees with the Poets, Wait \& Leonard; "A Yellow Pansy" (p. I 24), Nature Pictures by American Poets compiled by Annie Russell Marble.

I dropped a seea into the earth. It grew, and the plant was mine.

It was a wonderful thing, this piant of mine. I did not know its name, and the plant did not bloom. All I know is that I planted something apparently as lifeless as a grain of sand and there came forth a green and living thing unlike the seed, unlike the soil in which it stood, unlike the air into which it grew. No one could tell me why it grew, nor how. It had secrets all its own, secrets that baffle the wisest men; yet this plant was my friend. It faded when I wiihheld the light, it wilted when I neglected to give it water, it flourished when I supplied its simple needs. One week I went away on a vacation, and when I returned the plant was dead; and I missed it.

Although my little plant had died so soon, it had taught me a lesson; and the lesson is ihat it is worth while to have a plant.-The Nature-Study IdeA, L。H. Bailey。 


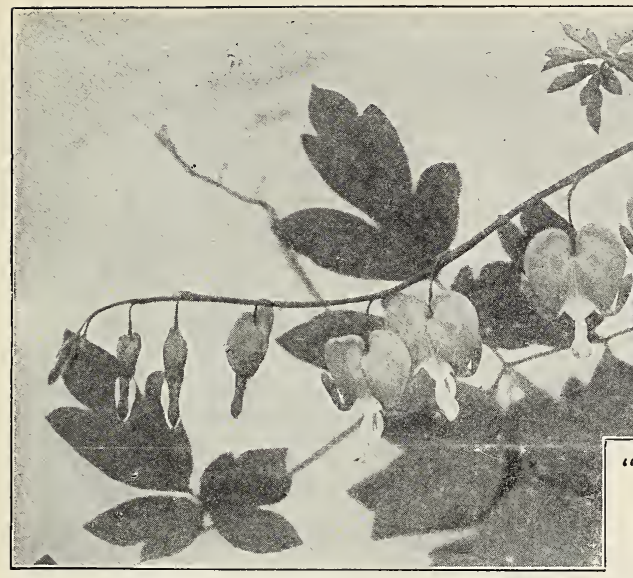

Photo by Verne Morton.

\section{THE BLEEDING HEART \\ Teacher's Story}

For the intricate structure of this type of flower, the bleeding heart is much more easily studied than its smaller wild sisters, the Dutchman's breeches or squirrel corn; therefore it is well to study these flowers when we find them in profusion in our gardens, and the next spring we may study the wildwood species more understandingly.

The flowers of the bleeding heart are beautiful jewel-like pendants arranged along the stem according to their age; the mature flower, ready to shed its petals, is near the main stem, while the tiny unopened bud is hung at the very tip, where new buds are constantly being formed during a
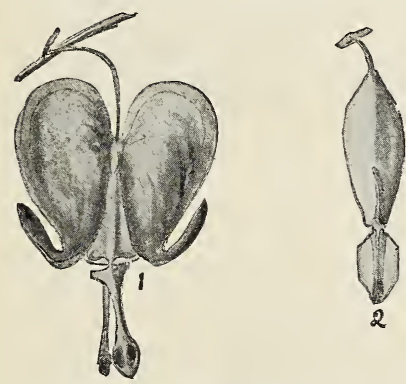

$I$, Flower of bleeding heart with swing-door ajar. 2, Side-view of flower showing the broad tips of the inner petals. 3, Flower with outer petals removed showing inner petals-and the heart-shaped bases of the stamens.

wise; and the parts that extend beyond are almost divided cross f uf two spoons which have been pinched out so as to make a wide, flat long season of bloom. This flower has a strange modification of its petals; the two pink outer ones, which make the heart, are really little pitchers with nectar at their bottoms, and although they hang mouth downwards the nectar does not flow out. When these outer petals are removed, we can see the inner pair placed opposite to them, the two of them close together and facing each other like two grooved ladles. Just at the mouth of the pitchers these inner petals are almost divided cross- 
ridge along their centers. These spoon-bowls unite at the tip, and between them they clasp the anthers and stigma. Special attention should be given to the division between the two portions of these inner petals; for it is a hinge, the workings of which are of much importance to the flower. On removing the outer petals, we find a strange framework around which the heart-shaped part of the flower seems to be modeled. These are filaments of the stamens grouped in threes on each side; the two outer ones of each group are widened into frills on the outer edge, while the central one is stiffer and narrower. At the mouth of the pitchers all these filaments unite in a tube around the style; near the stigma they split apart into six short, white, threadlike filaments, each bearing a small, brilliant yellow anther. So close together are these anthers that they are completely covered by the spoon-bowls made by the inner petals, the pollen mass being flat and disklike. During the period when the pollen is produced, the stigma is flat and immature; but after the pollen is shed, it becomes rounded into lobes ready to receive pollen from other flowers.

Although the description of the plant of this flower is most complex and elaborate, the workings of the flower are most simple. As the nectarpitchers hang mouth down, the bee must cling to the flower while probing upward. In doing this she invariably pushes against the outside of the spoon-bowls, and the hinge at their base allows her to push them back while the mass of pollen is thrust against her body; as this hinge works both ways, she receives the pollen first on one side and then on the other, as she probes the nectar-pitchers. And perhaps the next flower she visits may have shed its pollen, and the swing door will uncover the ripe stigma ready to receive the pollen she brings.

The sepals are two little scales opposite the bases of the outer petals. Before the flower opens, the "spouts of the nectar-pitchers" are clamped up on either side of the spoon-bowls, as if to keep everything safe until the right moment comes; at first they simply spread apart, but later curve backward. The seed-pod is long and narrow, and in cross-section is seen to contain two compartments with seeds growing on every side of the partition.

The bleeding heart is a native of China, and was introduced into Europe about the middle of the last century.

Reference-Our Garden Flowers, Keeler.

\section{LESSON CLIV}

\section{The Bleeding Heart}

Leading thought-The bleeding heart flower has its pollen and stigma covered by a double swing door, which the bees push back and forth when they gather the nectar.

Method-Bring a bouquet of the bleeding heart to the schoolroom, and let each pupil have a stem with its flowers in all stages. From this study, encourage them to watch these flowers when the insects are visiting them.

Observations-I. How are these flowers supported? Do they open upward or downward? Can you see the tiny sepals?

2. How many petals can you see in this flower? What is the shape of the two outer petals? How do they open? Where is the nectar developed in these petals? 
3. Take off the two outer petals and study the two inner ones. What is their shape near the base? How are their parts shaped which project beyond the outer petals? What does the spoon-end of these petals cover? Can you find the hinge in these petals?

4. Where are the stamens? How many are there? Describe the shape of the stamens near the base. How are they united at the tip?

5. Where is the stigma? The style? The ovary?

6. Supposing a bee is after the nectar, where must she rest while probing for it? Can she get the nectar without pushing against the flat projecting portion of the inner petals? When she pushes these spoonbowls back, what happens? Does she get dusted with pollen? After she leaves, does the door swing back? Suppose she visits another flower which has shed its pollen, will she carry pollen to its stigma? Does she have to work the hinged door to do this?

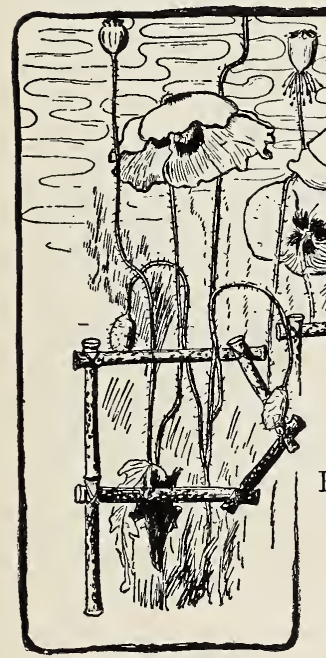

Poppies.

Drawn by Anna C. Stryke. and the ripened seed-capsule must be far heavier than the bud; and yet, as soon as the flower is ready to open, the stem straightens up, although it does not always remove the traces of the crook; and after the capsule is full of ripened seed, the stem holds it up particularly stiff, as if inviting the wind to shake out the seeds.

The rough covering of the bud consists of two sepals, as can be easily seen; but if we wish to see the poppy shed its sepals, we must get up in the morning, for the deed is usually done as soon as the first rays of the early sun bring their message of a fair day. The sepals break off at their base and fall to the ground. The two opposite outer petals unfold, leaving the 
two inner petals standing erect and on guard about the precious pollen, until the sunshine folds them back. An open poppy, when looked at below, shows two petals, each semicircular, and overlapping each other slightly; looked at from above, we see two petals, also half circles, set at right angles to the lower two, and divided from each other by the pistil.

The pistil of the poppy is, from the beginning, a fascinating box. At first, it is a vase with a round, circular cover, upon which are ridges, placed like the spokes of a wheel. If these ridges are looked at with a lens, particles of pollen may be seen adhering to them; this fact reveals the secret that each ridge is a stigma, and all of these radiating stigmas are joined so as better to catch the pollen. In a circle of fringe about the pistil are the stamens. In the study of the stamens, we should note

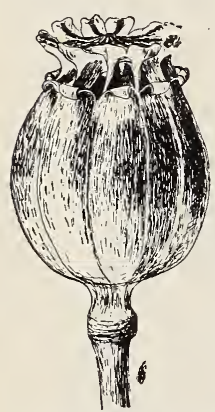

The poppy seedshaker.

Drawn by Anna C. Stryke. whether their filaments expand or dilate near the anthers, and we should also note the color of the masses of pollen which crowd out from the anthers.

Despite the many varieties of poppies, there are only four species commonly cultivated. The opium poppy has upon its foliage a white bloom, the filaments of its stamens are dilated at the top, and its seed-capsule is smooth. The oriental poppy has all of these characters, except that its foliage is green and not covered with bloom. Its blossom is scarlet and very large and has a purple center in the petals and purple stamens; it has three sepals. Its flower stalks are stout and leafy. The corn poppy, which grows in the fields of Europe, is a weed we gladly cultivate. This, naturally, has red petals and is dark at the center of the flower; but it has been changed by breeding until now we have many varieties. Its foliage is finely cut and very bristly or hairy. Its seed-capsule is not bristly. To see this poppy at its best, we should visit northern Italy or southern France in late May, where it makes the grain fields gorgeous. This is the originai parent of all the Shirley poppies. The Arctic, or Iceland poppy, has flowers of satiny texture and finely crumpled; its colors are yellow, orange or white, but never scarlet like the corn poppy; it has no leaves on its flower stem, and its seed-capsule is hairy. Of these four species, the opium poppy and the corn poppy are annuals, while the Arctic and the Oriental species are perennials.

The bees are over-fond of the poppy pollen and it is a delight to watch the fervor with which they simply wallow in it, brushing off all of the grains possible on to their hairy bodies. I have often seen a honey-bee seize a bunch of the anthers and rub them against the under side of her body, meanwhile standing on her head in an attitude of delirious joy. As showing the honey-bee's eye for color, I have several times seen a bee drop to the ground to examine a red petal which had fallen. This was plain evidence that she trusted to the color to guide her to the pollen.

But perhaps it is the development of the poppy seed-capsule which we find the most interesting of the poppy performances. After fertiliza. tion, the stigma-disk develops a scalloped edge, a stigma rounding out the point of each scallop; and a sharp ridge, which continues the length of the globular capsule, runs from the center of each scallop. If examined on the inside, it will be seen that the ridge on the capsule is the edge of a 
partition which extends only part way toward the center of the capsule. On these partitions, the little seeds are grown in great profusion, and when they ripen, they fall together in the hollow center of the seed-box. But how are they to get out? This is a point of interest for the children to observe, and they should watch the whole process. Just beneath the stigma-disk, and between each two of the sharp ridges, the point loosens; later, it turns outward and back, leaving a hole which leads directly into the central hollow portion of the capsule. The way these points open is as pretty a story as I know in flower history. This beautiful globular cap sule, with its graceful pedestal where it joins the stem, is a seed-shaker instead of a salt or pepper-shaker. Passing people and animals push against it and the stiff stem bends and then springs back, sending a little shower of seeds this way and that; or a wind sways the stalk, and the seeds are sown, a few at a time, and in different conditions of season and weather. Thus, although the poppy puts all her eggs in one basket, she sends them to market a few at a time. The poppy sced is a pretty object, as seen through the lens. It is shaped like a round bean, and is covered with a honeycomb network.

\section{LESSON CLV}

\section{The Poppy}

Leading thought-The poppies shed their sepals when the flowers expand; they offer quantities of pollen to the bees, which are very fond of it. The seed-capsule develops holes around the top, through which the seeds are shaken, a few at a time.

Method-It is best to study these flowers in the garden, but the lesson may be given if some of the plants with the buds are brought to the schoolroom, care being taken that they do not droop. If the teacher thinks wise, the pupils might prepare an English theme on the subject of the opium poppy and the terrible effects of opium upon the eastern nations.

Observations-I. Look $\mathrm{r}^{t}$, the bud of the poppy; how is it covered? How many sepals? Can you see where they unite? Is the stem bent because the bud is heavy? What happens to this crook in the stem when the flower opens? Does the crook always straighten out completely?

2. Describe how the poppy sheds its sepals. At what time of day do the poppies usually open?

3. Look at the back of, or beneath, an open flower. How many petals do you see? How are they arranged? Look at the base of the flower. How many petals do you see? How are they arranged in relation to the lower petals and to the pistil?

4. Look at the globular pistil. Describe the disk which covers it. How many ridges on this disk? How are they arranged? Look at the ridges with a lens and tell what they are.

5. Look at the stamens. How are they arranged? Describe the anthers-their color, and the color of the pollen. Watch the bees working on the poppies, and note if they are after nectar or pollen.

6. Find all the varieties of poppies possible, and note the colors of the petals on the outside, the inside and at the base; of the stamens, including filaments, anthers and pollen; of the pistil-disk and ovary. Sketch the 
poppy opened, and also in the bud. Sketch a petal, a stamen and the pistil, in separate studies.

7. Study the poppy seed-box as it ripens. How does the stigma-disk look? What is the shape of the capsule below the disk? Is it ridged? What relation do its ridges bear to the stigma ridges on the disk? C11t a capsule open, and note what these ridges on the outside have to do with the partitions inside. Where are the seeds borne?

8. Note the development of the holes beneath the edge of the disk of the poppy capsule. How are they made? What are they for? How are the seeds shaken from these holes? What shakes the poppy seed-box and helps sow the seeds? Look at a seed through a lens, and describe its form and decoration.

9. Notice the form of the poppy leaf, and note whether it is hairy or covered with bloom. What is there peculiar about the smell of the poppy plant? Where do poppies grow wild?

Io. Is the slender stem smooth or grooved and hairy? Is it solid or hollow?

II. When a stem or leaf is pierced or broken off, what is the color of the juice which exudes? Does this juice taste sweet or bitter and un. pleasant? Do you know what harmful drug is manufactured from the juice of one species of poppy? What countries cultivate and use it most extensively?

\section{THE CALIFORNIA POPPY}

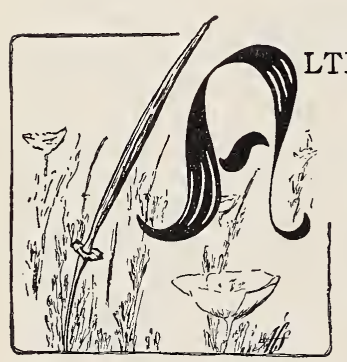

\section{Teacher's Story}

LTHOUGH this brilliant flower blossoms cheerfully for us in our Eastern gardens, we can never understand its beauty until we see it glowing in masses on the California foothills. We can easily understand why it was selected as the flower of that great State, since it burnished with gold the hills, above the gold buried below; and in that land that prides itself upon its sunshine, these poppies seem to shine up as the sun shines down. The literature of California, and it has a noble literature of its own, is rich in tributes to this favored flower. There is a peculiar beauty in the contrast between the shining flower and its pale blue-green, delicate masses of foliage. Although it is called a poppy and belongs to the poppy family, yet it is not a true poppy, but belongs to a genus named after a German who visited California early in the nineteenth century, accompanying a Russian scientific expcdition; this German's name was Eschscholtz, and he, like all visitors, fell in love with this brilliant flower, and in his honor it was named Eschscholtzia (es-sholts-ia) californica. This is not nearly so pretty, nor so descriptive, as the name given to this poppy by the Spanish settlers on the Pacific Coast, for they called it Copa-de-oro, cups of gold.

The bud of the Eschscholtzia is a pretty thing; it stands erect on the slender. rather long stem, which flares near the bud to an urnlike pedestal 
with a slightly ruffled rim, on which the bud is set. This rim is often pink above, and remains as a pretty base for the seed-pod. But in some garden varieties, the rim is lacking. The bud itself is covered with a peaked cap, like a Brownie's toboggan cap stuffed full to the tip. It is the shape of an old-fashioned candle extinguisher; it is pale green, somewhat ribbed, and has a rosy tip; it consists of two sepals, which have been sewed together by Mother Nature so skillfully that we cannot see the seams. One of the most interesting performances to watch that I know, is the way this poppy takes off its cap before it bows to the world. Like magic the cap loosens around the base; it is then pushed off by the swelling expanding petals until completely loosened, and finally it drops.

The petals are folded under the cap in an interesting manner. The outer petal enfolds all the others as closely as it can, and its mate within it

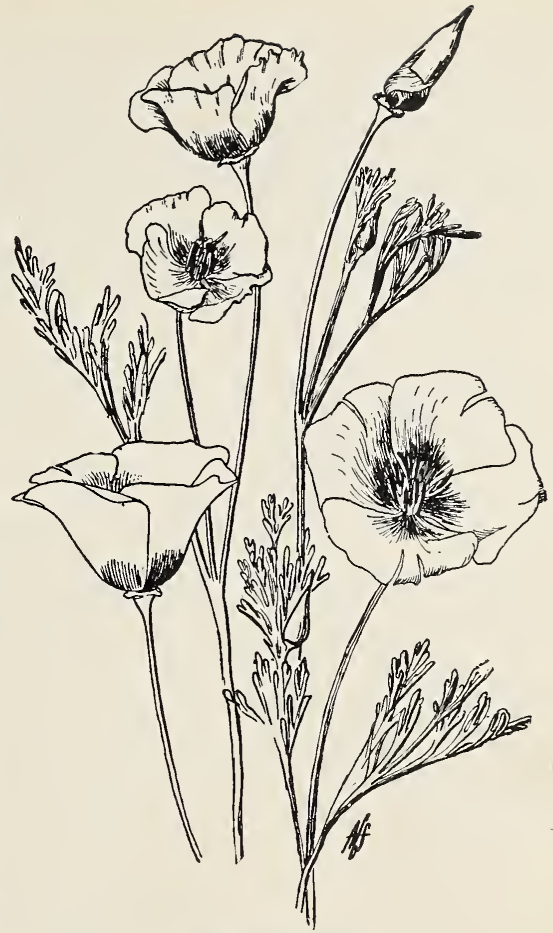

California poppy.

Drawn by Anna C. Stryke. enfolds the other two, and the inner two enfold the stamens with their precious gold dust. When only partially opened, the petals cling protectingly about the many long stamens; but when completely opened, the four petals flare wide, making a flower with a golden rim and orange center, although among our cultivated varieties they range from orange to an anaemic white. To one who loves them in their glorious native hues, the white varieties seem almost repulsive. Compare one of these small, pale flowers with the great, rich, orange ones that glorify some favored regions in the Mojave Desert, and we feel the enervating and decadent influence of civilization.

The anthers are many and long, and are likely to have a black dot on the short filament; at first, the anthers stand in a close cluster at the center of the flower, but later they flare out in a many pointed star. Often, when the flowers first open, especially the earlier ones, the stigmas cannot be seen at all; but after a time the three, or even six stigmas, spread wide athwart the flower and above the stamen-star, where they may receive pollen from the visiting insects. The anthers give abundance of pollen, but there is said to be no nectary present. This flower is a good guardian of its pollen, for it closes during the nights and also on dark 
and rainy days, only exposing its riches when the sunshine insures insect visitors. It closes its petals in the same order in which they were opened in our Eastern gardens, although there are statements that in California, each petal folds singly around its own quota of anthers. The insects in California take advantage of the closing petals and often get a night's lodging within them, where they are cozily housed with plenty of pollen for supper and breakfast; and they pay their bill in a strange way by carrying off as much of the golden meal as adheres to them, just as the man who weighs gold-dust gets his pay from what adheres to the pan of his scales.

After the petals fall, the little pod is very small, but its growth is as astonishing as that of Jack's beanstalk; it finally attains a slim length of three inches, and often more. It is grooved, the groove running straight from its rimmed base to its rosy tip; but later a strange twisting takes place. If we open one of these capsules. lengthwise, we must admire the orderly way in which the little green seeds are fastened by delicate white threads, in two crowded rows, the whole length of the pod.

The leaf is delicately cut and makes the foliage a fine mass, but each leaf is quite regular in its form. It has a long, flattened petiole, which broadens and clasps the stem somewhat at its base. Its blade has five main divisions, each of which is deeply cut into fingerlike lobes. The color of this foliage and its form show adaptations to desert conditions.

This plant has a long, smooth tap root, especially adapted for storing food and moisture needed during the long, dry California summers; for it is perennial in its native state, althnugh in the wintry East, we plant it as an annual.

\section{LESSON CLVI \\ The California Poppy}

Leading thought-The California poppy is a native of California. It blossoms during the months of February, March and April in greatest abundance. It is found in the desert as well as among the foothills.

Method-If possible, the students should study this in the garden. In the East, it flowers until frost comes, and affords a delightful subject for a September lesson. In California it should be studied in the spring, when the hills are covered with them. But the plant may be brought into the schoolroom, root and all, and placed in a jar, under which conditions it will continue to blossom.

Observations-r. Look at the California poppy as a whole and tell, if you can, why it is so beautiful when in blossom.

2. Look at the flower bud. What sort of a stem has it? What is the shape of the stem just below the bud? What is the color of the little rim on which the bud rests? What peculiarity has this bud? Describe the little cap.

3. Watch a flower unfold. What happens to the "toboggan cap?" How does the bud look after the cap is gone? What is its appearance when the petals first open? When they are completely open?

4. Describe the anthers. How do they stand when the flower first opens? How later? Can you see the stigmas at first? Describe them as they look later. 
5. Does the poppy remain open at night? Does it remain open duiting cloudy or rainy weather? Why?

6. Do the petals have the same position that they did in the bud? As the flower matures, note how each petal curls. Do they all fall at once? Are there any anthers left after the petals fall?

7. How does the little pod look when the petals first fall? What happens to it later? Note the little rim at its base. Cut the seed-pod open lengthwise, examine the seeds with a lens, and describe how they are fastened to the sides of the pod. Are the ribs straight from end to end in the pod at first? Do they remain in this position? How does the pod open and scatter its seeds?

8. Study the leaf of this California poppy. Describe how it joins the stem. Sketch a leaf showing its chief divisions into leaflets and how each leaflet is divided. Note that the juice of the stem has the peculiar odor of muriatic acid.

9. Look at the root. Do you think it is fitted to sustain the plant through a long, dry summer? What kind of summers do they have in California? Where does the poppy grow wild?

Io. Read all the accounts you can find of the California poppy, and write a little theme describing why it was chosen as the flower of that great State, and how it came by its name.

In a low brown meadow on a day

Down by the autumn sea,

I saw a flash of sudden light

In a sweep of lonely gray;

As if a star in a clouded night

One moment had looked on me

And then withdrawn; as if the spring

Had sent an oriole back to sing

A silent song in color, where

Other silence was too hard to bear.

I found it and left it in its place,

The sun-born flower in cloth of gold

That A pril owns, but cannot hold

From spending its glory and its grace

On months that always. love it less,

But take its splendid alms in their distress.

Back I went through the gray and the brown,

Through the weed-woven trail to the distant town;

The flower went with me, fairly wrought

Into the finest fiber of my thought.

-A California Poppy in November, Irene Hardy 


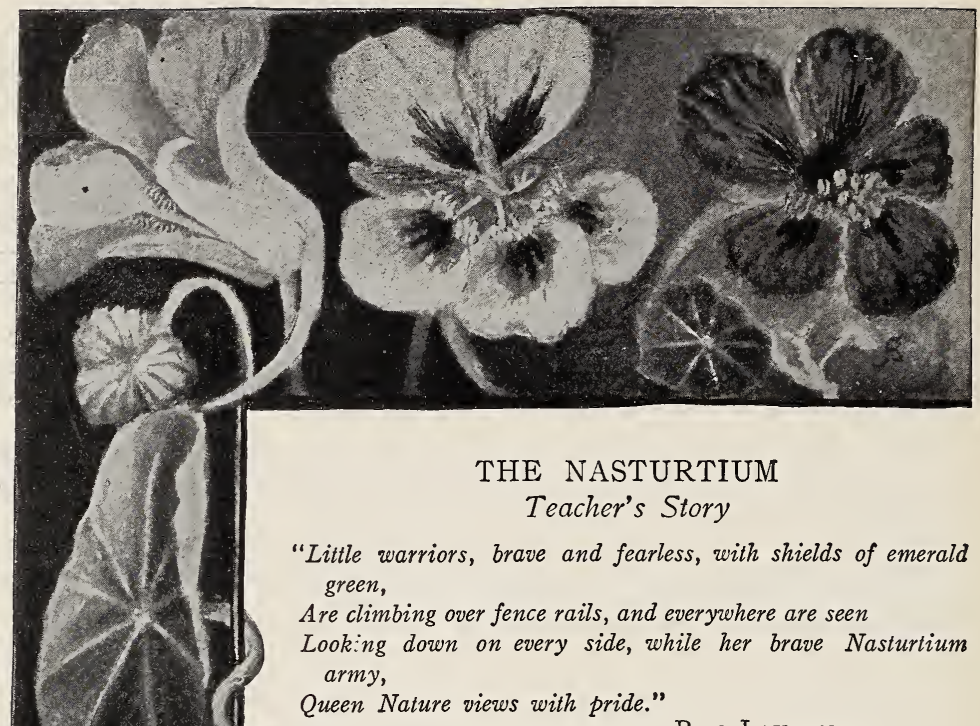

-Ray Laurance.

It is quite fitting that the nasturtium leaves should be shaped like shields, for that is one of their uses; they are shields to protect the young nastur.. tium seeds from the hot sun and from the view of devouring enemies. The nasturtiums are natives of Peru and Chili, and it is fitting that the leaves should develop in shield-shape, and the shields overlap until they form a tent to shade the tender developing fruit from the burning sun. But they were never meant to shield the flower, which thrusts its brilliant petals out between the shields, and calls loudly to the world to admire it. It would indeed be a pity for such a remarkable flower to remain hidden; its five sepals are united at their base, and the posterior one is extended into a long spur, a tube with a delectable nectar-well at its tip. The five petals are set around the mouth of this tube, the two upper ones differing in appearance and office from those below; these two stand up like a pair of fans, and on them are lines which converge; on the upper sepals are similar lines pointing toward the same interesting spot. And what do all these lines lead to, except a veritable treasure-cave filled with nectar! The lower petals tell another story; they stand out, making a platform, or doorstep, on which the visiting bee alights. But it requires a big insect to do the work of this flower, and what if some inefficient little bee or fly should alight on the 
petal-doorstep and steal into the cave surreptitiously! This contingency is guarded against thus: Each of these lower petals narrows to a mere insect footbridge at their inner end; and in order to render this footbridge quite impassable, it is beset with irregular little spikes and projecting fringes, sufficient to perplex or discourage any small insect from crawling that way.

But why all these guiding lines and guarded bridges? If you watch the same blossom for several successive days, it will reveal this secret. When a flower first opens, the stamens are all bent downward, but when an anther is ready to open its pollen doors, the filament lifts it up anc: places it like a sentinel blocking the doorway to the nectar treasure. Then when the robber comes, whether it be butterfly, bee or hummingoird, it gets a round of pollen ammunition for its daring. Perhaps there
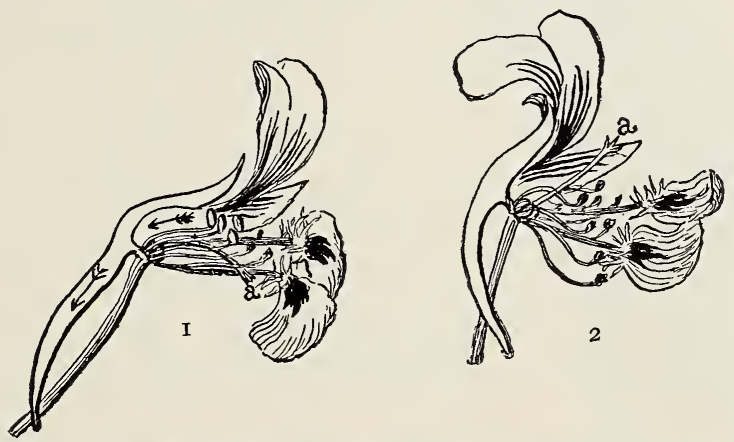

I. Nasturtium flower in early stage of blossoming. Note the anthers lifted in the path to the nectar which is indicated by the arrow. The closed stigma is shown deflected at a.

2. The same flower in later stage; the anthers are empty and deflected. The stigma is raised (a) in the nectar path.

may be two or three anthers standing guard at the same time, but, as soon as their pollen is exhausted, they shrivel and give room for fresh anthers. Meanwhile, the stigma has its three lobes closed and lying idly behind and below the anthers; after all the pollen is shed, the style raises and takes its position at the cave entrance and opens up its stigmas, like a threetined fork, to rake the pollen from any visiting insect, thus robbing the robber of precious gold-dust which shall fertilize the seeds in its threelobed ovary. Although the flower needs to flare its colors wide to call the bees and hummingbirds, yet the growing seeds must be protected; therefore, the stem which held the flower up straight, now twists around in a spiral and draws the triplet seeds down behind the green shields.

Nasturtium leaves are very pretty, and are of ten used as subjects for decorative water-color drawings. The almost circular leaf has its stem attached below and a little at one side of the center; the leaves are brilliant green above but quite pale beneath, and are silvery when placed beneath the water. The succulent stems have a way of twisting half around the wires of the trellis and thus holding the plant secure to its support. But if there is no trellis, the main stem seems to a waken to the 
esponsibility and grows quite stocky, often lifting the plant a foot or two in height, and from its summit sending out a fountain of leaf and flower stems.

The nasturtium is among the most interesting and beautiful of our garden flowers, and will thrive in any warm, sunny, fairly moist place. Its combinations of color are exceedingly rich and brilliant. H. H. says of it:

\author{
"How carelessly it wears the velvet of the same \\ Unfathomed red, which ceased when Titian ceased \\ To paint it in the robes of doge and priest."
}

\title{
LESSON CLVII \\ The Nasturtium
}

Leading thought-The nasturtium has a special arrangement by which it sends its own pollen to other flowers and receives pollen from other flowers by insect messengers.

Method-The nasturtiums and their foliage should be brought into the schoolroom in sufficient quantity so that each child may have a leaf and a flower for study. The object of the lesson is to interest the pupils in studying, in their gardens, one flower from the bud until the petals wither, taking note of what happens each day and keeping a list of the insect visitors.

Observations- . Look at the back of the flower. What is there peculiar about the sepals? How many sepals are there? How many join to make the spur? What is in this spur? Taste of the tip. Find where the nectar is.

2. Look the flower in the face. How do the two upper petals differ in shape from the three lower ones? What markings are there on the upper petals? Where do these lines point? Are there any markings on the sepals pointing in the same direction? If an insect visiting a flower should follow these lines, where would it go?

3. Describe the shape of the lower petals. Suppose a little ant were on one of these petals and she tried to pass over to the nectar-tube or spur, would the fringes hinder her?

4. Look down the throat of the spur, and tell what a bee or other insect would have to crawl over before it could get at the nectar.

5. In your garden, or in the bouquet in the window if you cannot visit a garden, select a nasturtium that is just opening and watch it every day, making the following notes: When the blossom first opens where are the eight stamens? Are the unripe, closed anthers lifted so as to be in the path of the bee which is gathering nectar? How do the anthers open? How is the pollen held up in the path to the nectar? Can you see the stigma of this flower? Where is it? Note the same flower on successive days: How many anthers are, open and shedding pollen to-day? Are they all in the same position as yesterday? What happens to the anthers which have shed their pollen?

6. When the stigma rises in the nectar path, how does it look? Where are all the anthers when the stigma raises its three tines to rake the pollen off the visiting insect? Do you know why it is an advantage to the nasturtium to develop its seed by the aid of the pollen from another plant? 
7. Can you see the beginning of the seed-case when the stigma arises to receive the pollen?

8. The flowers project beyond the leaves. Do the ripening seedcases do this? What happens to their stems to withdraw them behind the leaf?

9. Sketch a nasturtium leaf, and explain why it is like a shield. How does the leaf look when under water?

Io. What sort of stem has the nasturtium? How does it manage to climb the trellis? If it has no trellis to climb, does it lie flat upon the ground?

\section{THE BEE-LARKSPUR}

\section{Teacher's Story}

This common flower of our gardens, sending up from a mass of dark, deeply-cut leaves tall racemes of purple or blue flowers, has a very interesting story to tell those who watch it day by day and get acquainted with it and its insects guests. The brilliant color of the flowers is due to the sepals, which are purple or blue, in varying shades; but as if to show that they are sepals instead of petals, each hasion the back side near its tip, a grcen thickened spot. If we glance up the flower stalk, we can see that, in the upper buds, the scpals are green, but in the lower buds they bcgin to show the blue color; and in a bud just rea $1 y$ to open, we can see that the blue sepals are each tipped with a grecn knob, and this remains green after the sepals expand. The upper and rearmost sepal is prolonged into a spur, which forms the outside covering of the nectar-spur; it is grecnish and wrinkled like a long-wristed, sucde glove; two sepals spread wide at the sides and two morc below. All this expanse of blue sepals is simply for a background for the petals, which, by their contrasting color, show the bees where to probe for nectar. Such inconsequential petals as they are! Two of them "hold hands" to make an arch over the entrance to the nectar tube; and just below these on each side are two more tiny, fuzzy, spreading petals, often notched at the tip and always hinged in a peculiar way about the upper petal; they stand guard at the door to the nectar storehouse. If we peel off the wrinkled sepal-covering 
of the spur, we can see the upper petals extending back into it, making a somewhat double-barreled nectary.

If we look into a larkspur flower just opened, we see below the petals a bunch of green anthers, hanging by white threadlike filaments to the center of the flower and looking like a bunch of lilliputian bananas. Behind these anthers is an undeveloped stigma, not visible as yet. After the flower has been open for a short time, three or four of the anthers rise up and stand within the lower petals; while in this position, their white pollen bursts from them, and no bee may then thrust her tongue into the nectar-spur without being powdered with pollen. As soon as the anthers have discharged their pollen, they shrivel and their places are taken by fresh ones. It may require two or three days for all the anthers to lift up and get rid of their pollen. After this has been accomplished, the three white, closely
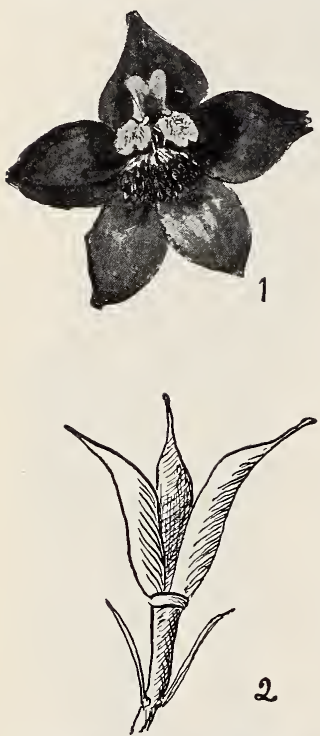

$x$, Drawing of the bee-lark. spur flower enlarged.

2, The seed capsule of the bee-larkspur. adhering pistils lift up their three stigmas in the self-same path to the nectar; and now they are ready to receive the pollen which the blundering bee brings from other flowers. Since we cannot always study the same flower for several consecutive days, we can read the whole story by studying the flowers freshly opened on the upper portion of the stalk, and those below them that are in more advanced stages.

The bees, especially the bumblebee, will tell the pollenation story to us in the garden. The contrasting color of the petals and sepals tells her where to alight; this she does accurately, and the inconsequential lower petals seem made for her to grasp; she presses them to her breast with her front and middle legs with a dramatic, almost ecstatic, gesture that is comical to witness, and holds them firmly while she thrusts her head into the opening between them; she probes the spur twice, evidently finding there the two nectar-wells. It is a fascinating pasttime to follow her as she goes from flower to flower like a Madam Pompadour, powdered with her white pollen. In order that a bee may work on these flowers, it is necessary that they hang vertically. The tips of the tall flower stalks are likely to bend or curl over; but no matter what the direction the broken or bent stem takes, the flowers will twist around on their pedicels until they face the world and the bee, exactly as if they were on a normally erect stem.

All the larkspurs have essentially the same pollen story, although some have only two petals; in every case the anthers at first hang down, and later rise up in the path to the nectar, in order to discharge their pollen; after they wither, the stigmas arise in a similar position.

The bee-larkspur has a very heautiful fruit. It consists of three graceful capsules rising from the same base and flaring out into pointed tips. The seeds are fastened to the curved side of each capsule, which, 
when ripe, opens so that they may be shaken out by the winds. When studying the bud, we notice two little bracts set at its base and these remain with the fruit.

\section{LESSON CLVIII}

THE BEE-LARKSPUR

Leading thought-The bee-larkspur begins blossoming early in the season, the blossom stalk elongating and developing new buds at its tip until late in autumn. The flower has a very interesting way of making the bees carry its pollen.

Method-Bring to the schoolroom a flower stalk of the bee-larkspur, and there study the structure and mechanism of the flower. This lesson should inspire the pupils to observe for themselves the visiting bees and the maturing seeds. Ask them to write an account of a bumblebee making morning calls on the larkspurs

Observations-I. Which flowers of the larkspur open first- those near the tip of the stem or those below?

2. Examine the buds toward the tip of the flower stalk. What color are the sepals in these buds? Do the sepals change color as the flower opens? Note the little green knobs which tip the closed sepals that clasp the bud. What color are the sepals on the open flower? Is there any green upon them when open?

3. Where is the nectar-spur? Which sepal forms this? How are the other sepals.arranged?

4. Now that we know the flower gets its brilliant color from its sepals, let us find the petals. Look straight into the flower, and note what forms the contrasting color of the heart of the flower; these are the petals. Can you see that two are joined above the open-

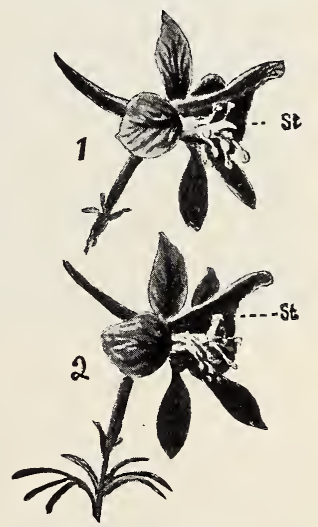

The larkspur.

$x$, showing early stage with stigma deflected.

2, showing advanced stage with stigma raised. ing into the nectar-tube? How many guard the entrance from below? How are these lower petals hinged about the upper one? Peel a sepalcover from the nectar-spur, and see if the upper petals extend back within the spur, forming nectar-tubes?

5. Take a flower just opened, and describe what you see below the petals. What is the color of the anthers? Of the filaments? Can you see the stigma?

6. Take a flower farther down the stalk, which has therefore been open longer, and describe the position of the anthers in this. Are there any of them standing upright? Are they discharging their pollen? What color is the pollen? Are these upright anthers in the way of the bee, when she thrusts her tongue into the nectar-tube?

7. Take the oldest flower you can find. What has happened to the anthers? Can you see the pistils in this? In what position now are the stigmas?

8. Push aside the anthers in a freshly opened flower and see if you can find the stigmas. What is their position? How do they change in form 
and position after the pollen is shed? Do they arise in the path of the bee before all the pollen from the anthers of their own flower is shed? If so, how are they pollenated?

9. Suggestions for Observation in the Garden-Watch a bumblebee working on the larkspur and answer the following questions: How does she hold on to the flower? Where does she thrust her tongue? Can she get the nectar without brushing the pollen from the anthers which are lifting up at the opening of the nectar-tube? In probing the older flowers, how would she come in contact with the lifter stigmas? How do the petals contrast in color with the sepals? Does this tell the bees where to look for nectar? Compare the common larkspur with the bee-larkspur, and notice the likeness and difference. What kind of fruit capsules has the bee-larkspur? Describe the seeds, and how they are scattered.

\author{
THE BLUE FLAG, OR IRIS \\ Teacher's Story \\ Beautiful lily, dwelling by still rivers \\ Or solitary mere, \\ Or where the sluggish meadow brook delivers \\ Its waters to the weir!
}

The burnished dragon fly is thine attendant, And tilts against the field,

And down the listed sunbeams rides resplendent

With steel-blue mail and shield.

-From "Flower-de-luce," Henry W. Longfellow.

The iris biossom has a strange appearance, and this is because nothing in it is as it seems. The style of the pistil is divided into three broad branches and they look like petals; and they have formed a conspiracy with the sepals to make a tunnel for bees, leaving the petals out of the plan entirely and the sepals "rise to the occasion." The petals stand up lonely between the three strangely matched pairs, and all they accomplish by their purple guiding lines, is to basely deceive the butterflies and other insects which are in the habit of looking for nectar at the center of a flower. If we look directly down into the flower of the blue flag, there are ridges on the broad styles and purple veins on the petals, all pointing plainly to the center of the flower, and any insect aligbting there would naturally seek for nectar-wells where all these lines so plainly lead. But there is an "April fool" for the insects which trust to these guides, for there is no nectar to be had there. Dr. Needham, in his admirable study of this flower and its visitors (American Naturalist, May, I900), tells us that he has seen the little butterflies called "skippers," the flag weevils and the flower beetles all made victims of this deceptive appearance; this is evidence that the nectar guiding lines on flowers are noted and followed by insects.

The blue flag is made for bees; the butterflies and beetles are interlopers and thieves at best. The bees are never deceived into seeking the nectar in the wrong place. They know to a certainty that the sepal with 


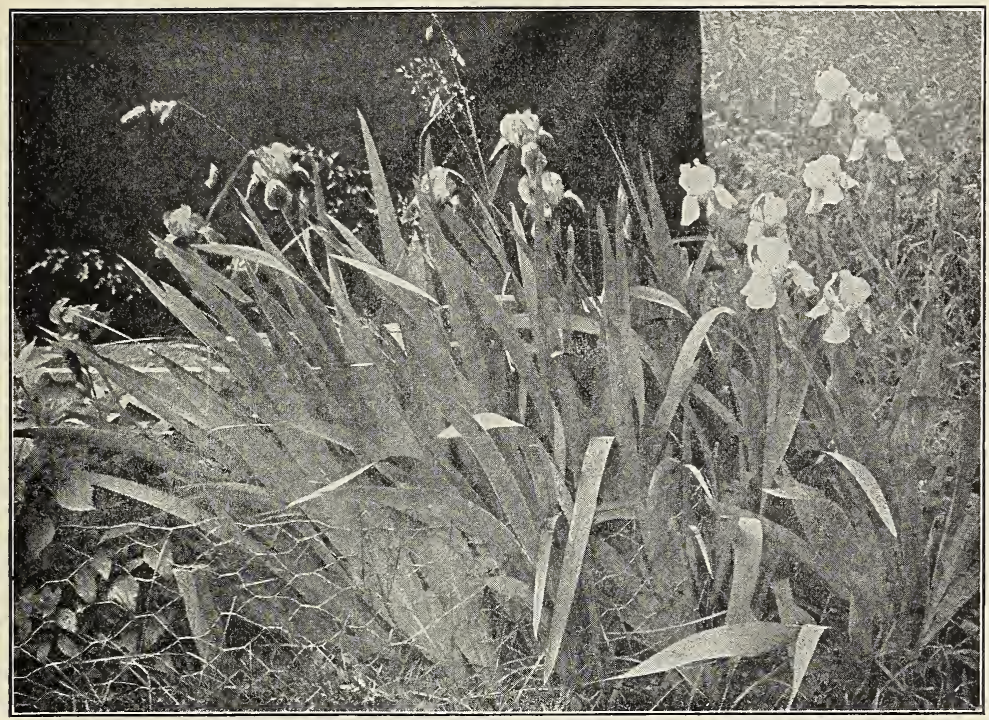

Iris in blossom.

Photo by Verne Morton.

its purple and yellow tip and many guiding lines although far from the center of the flower, is the sure path to the nectar. A bee alights on the lip of the sepal, presses forward scraping her back against the downhanging stigma, then scrapes along the open anther which lies along the roof of the tunnel; and she here finds a pair of guiding lines each leading to a nectar-well at the very base of the sepal. The bees which Dr. Needham found doing the greatest work as pollen-carriers were small solitary bees (Clisodon terminalis and Osmia destructa); each of these alighted with precision on the threshhold of the side door, pushed its way in, got the nectar from both wells, came out and sought another side door speedily. One might ask why the bee in coming out did not deposit the pollen from its own anther upon the stigma; but the stigma avoids this by hanging down, like a flap to a tent, above the entrance, and its surface for receiving pollen is directed so that it gathers pollen from the entering bee and turns its back to the bee that is just making its exit.

The arrangement of the flower parts of the iris may be described briefly thus: three petals, three sepals, a style with three branches; the latter being broad and flat and covering the bases of the three sepals, making tubes which lead to the nectar; three anthers lie along the under side of the styles. The wild yellow iris is especially fitted for welcoming the bumblebee as a pollen-carrier, since the door between the style and the sepal is large enough to admit this larger insect. The bumblebees and the honey-bees work in the different varieties of iris in gardens. 


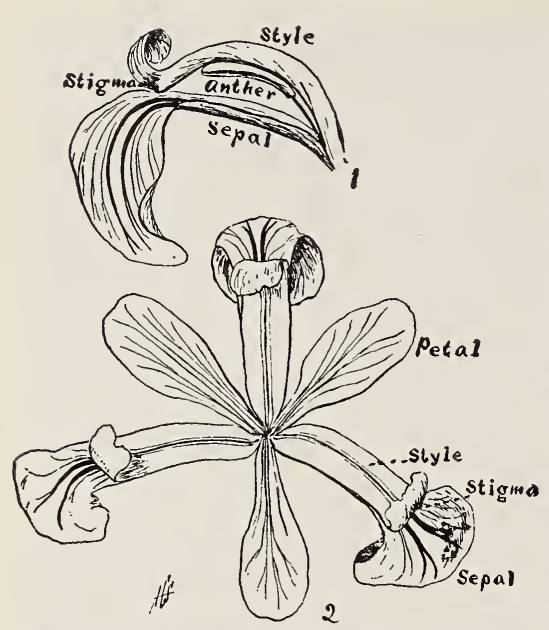

Detail of the blossoms of the blue flag flower.

1. Side-view of the passage to the nectar.

2, Looking directly into the iris flowers. Note the deceiving guide-lines in the petals.
In some varieties of iris there is a plush rug along the vestibule floor over which the bee passes to get the nectar. Through a lens, this plush is exquisite-the nap of white filaments standing up and tipped with brilliant yellow. Various theories as to the use of this plush have been advanced, the most plausible being that it is to keep the ants out; but the ant could easily pass along either side of it. While holding an iris in my hand, one day in the garden, a bumblebee visited it eagerly, never noting me; after she had probed the nectarwells, she probed or nibbled among the plush, working it thoroughly on her way out. Was she a foolish bee, or did she find something there to eat? What child will find if other bees do this?

\section{LESSON CLIX}

\section{The Blue Flag or Iris}

Leading thought-Each iris flower has three side doors leading to the nectar-wells; and the bees, in order to get the nectar, must brush off the pollen dust on their backs.

Method-While the blue flag is the most interesting of our wild species of iris, yet the flower-de-luce, or the garden iris, is quite as valuable for this lesson. The form of the flowers may be studied in the schoolroom, but the pupils should watch the visiting insects in the garden or field.

Observations-I. Look for the side doors of the iris blossom. Which part of the flower forms the doorstep? How is it marked to show the way in? Which part of the flower makes the arch above the door?

2. Find the anther, and describe how it is placed. Can you see two nectar-wells? Explain how a bee will become dusted with pollen while getting the nectar.

3. Where is the stigma? What is there very peculiar about the styles of the iris? Can a bee, when backing out from the side door, dust the stigma with the pollen she has just swept off? Why not? How does the stigma of the next flower that the bee visits get some of the pollen from her back?

4. Look straight down into an iris flower. Can you see the three petals? How are they marked? How would these lines on the petals mislead any insect that was searching for nectar?

5. Watch the insects visiting the iris. Do you know what they are? What do they do? 
6. Describe the way the iris flower-bud is enfolded in bracts. What is there peculiar about the way the iris leaves join the stem?

7. How many kinds of flag, or iris, do you know?

8. Describe the seed-vessel and seec s of the iris.

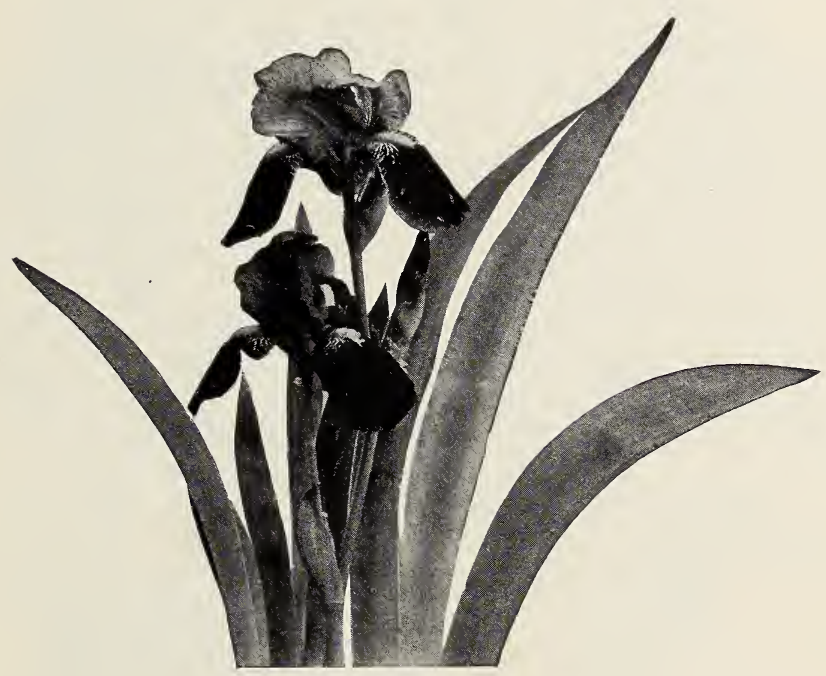

Fleur-de-lis.

Photo by Cyrus Crosby.

The fleur-de-lis is the national flower of France.

"It is said that the Franks of old had a custom, at the proclamation of a king, of elevating him upon a shield or target, and placing in his hand a reed, or flag in blossom, instead of a sceptre."

- "Among the Flowers and Trees with the Poets", WAIT AND LEONARD. 


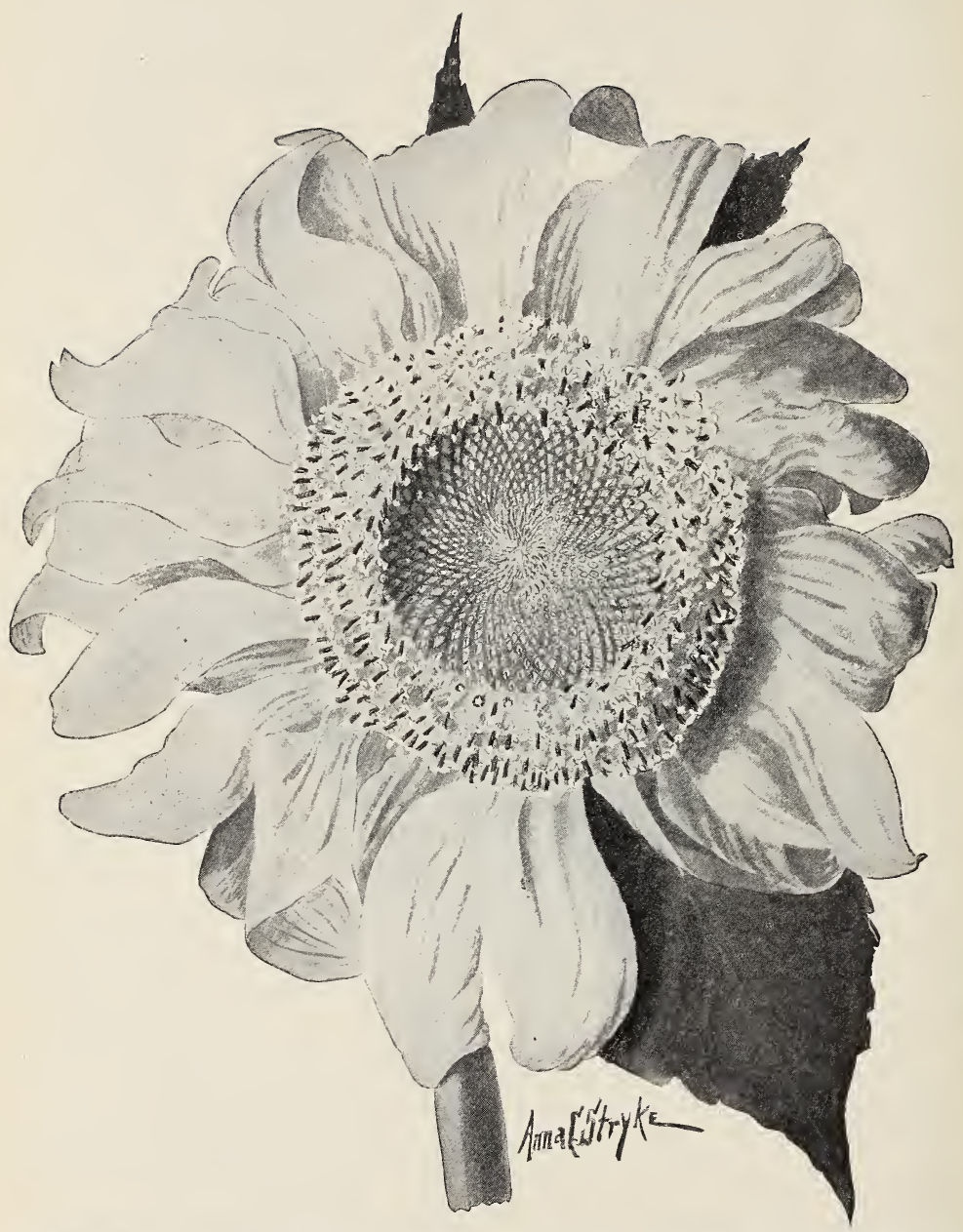

The sunflower. Next to the ray-flowers are the florets in last stages of blossoming with stigmas protruding; next within are rows in the earlier stage with pollen bursting from anther-tubes, while at center are the unopened buds. 


\section{THE SUNFLOWER}

\section{Teacher's Story}

Many of the most beautiful of the autumn flowers belong to the Compositae, a family of such complicated flower arrangement that it is very difficult for the child or the beginner in botany to comprehend it; and yet, when once understood, the composite scheme is very simple and beautiful, and is repeated over and over in flowers of very different appearance. It is a plan of flower cooperation; there are many flowers associated to form a single flower-head. Some of these, the "ray," or "banner," flowers, hold out bright pennants to attract the attention of insects; while the disk-flowers, which they surround, attend to the matter of the pollenation and production of seed.

The large. garden sunflower is the teacher's ally to illustrate to the children the story of the composites. Its florets are so large that it is like a great wax model. And what could be more interesting than to watch its beautiful inflorescence-that orderly march toward the center in double lines of anther columns, with phalanxes bearing the stigmas surrounding them; and outside all, the ranks of ray-flowers flaunting their flags to herald to the world this peaceful conquest of the sleeping, tented buds at the center?

Ordinarily, in nature-study we do not pull the flowers apart, as is necessary in botany; in nature-study, all that we care to know of the flower is what it does, and we can see that without dissection. But with the compositæ the situation is quite different. Here we have an assemblage of flowers, each individual doing its own work for the community; and in order to make the pupils understand this fact it is necessary to study the individual florets.

We begin with the study of one of the buds at the center of the flowerhead; this shows the white, immature seed below, and the closed, yellow corolla-tube above. Within the corolla may be seen the brown anthertube, and on the upper part of the seed are two little, white, earlike scales, to which especial notice should be directed, since in other composites there are many of these scales and they form the pappus-the balloon to carry the seed. The bud shows best the protecting chaffy scaie which enfolds the seed, its pointed, spine-edged tip being folded over the young bud, as may be seen by examining carefully the center of a freshly opened sunflower. In this tubular bud (see Fig. p. 632), there is a telescopic arrangement of the organs, and one after another is pushed out. First, the corolla-tube opens, starlike, with five pointed lobes, very pretty and graceful, with a bulblike base; from this corolla pushes out the darkbrown tube, made up of five anthers grown together. By opening the corclla, we see the filaments of the stamens below the joined anthers. This anther tube, if examined through a lens, shows rows of tiny points above and below, two to each anther, as if they had been opened like a book to join edges with their neighbors. The anther-tuhe is closed at the tip, making a five-sided cone; and at the seams, the yellow pollen bulges out, in starlike rays. The pollen bulges out for good reason, for behind it is the stigma, like a ramrod, pushing all before it in the tube for it is its turn next to greet the outer world. The two stigma-lobes are pressed together like the halves of $a_{s}$ sharpened pencil, and they protrude through the anther-tube as soon as all the pollen is safely pushed out; then the 


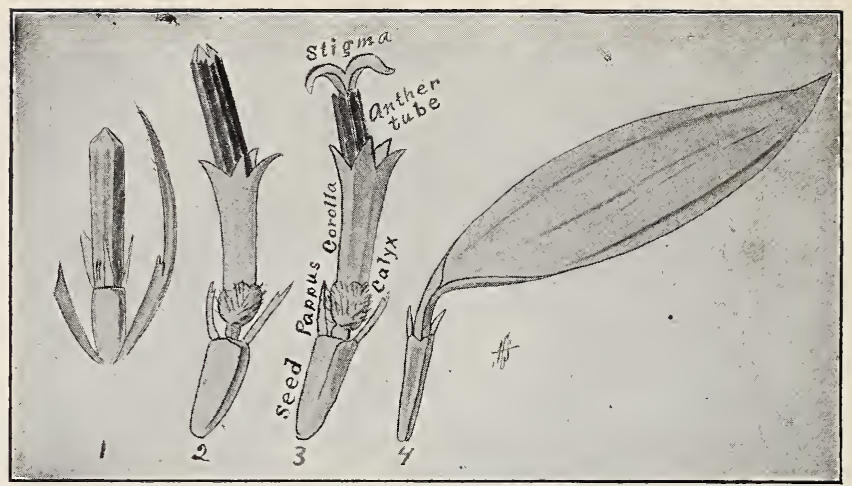

The flower of the sunflower-head enlarged.

1. A floret of the sunflower in the bud-stage as it appears at the center of the sunflower. Note the protecting bract at the right,

2. A floret in earliest stage of blossoming.

3. A floret in the latest stage of bloom with the parts named

4. A ray or banner-flower.

stigma-lobes separate, each curling backwards so as to offer a receptive surface to welcome pollen grains from other florets, or even other sunflowers. In the process of curling back, they press the anther-tube down into the corolla, and thus make the floret shorter than when in the pollen stage. The banner-flower differs in many essentials from the perfect florets of the disk. If we remove one from the flower-head, we find at its base a seedlike portion, which is a mere pretense; it is shrunken, and never can be a seed because it has connected with it no stigma to bring to it the pollen. Nor does this flower have stamens nor a tubular corolla; instead it has one great, petallike banner, many times longer and wider than the corollas of the other flowers. All this flower has to do is to hold its banner aloft as a sign to the world, especially the insect world, that here is to be found pollen in plenty, and nectar for the probing.

But more wonderful than the perfection of each floret is their arrangement in the flower-head. Around the edge of the disk the banner-flowers, in double or treble rank, flare wide their long petals like the rays of the sun, making the sunflower a most striking object in the landscape. If the sunflower has been open for several days, next to the ray-flowers will be seen a circle of star-mouthed corollas from which both ripened pollen and stigmas have disappeared, and the fertilized seeds below them are attaining their growth. Next comes a two or three-ranked circle, where the split, coiled-back stigma-lobes protrude from the anther-tubes; within this circle may be two or three rows of florets, where pollen is being pushed out in starry radiance; and within this ring there may be a circle where the anther-tubes are still closed; while at the center lie the buds, arranged in exquisite pattern of circling radii, cut by radii circling in the opposite direction; and at the very center the buds are covered with the green spear-points of their bracts. I never look at the buds in the sunflower without wondering if the study of their arrangement is not the basis of much of the most exquisite decoration in Moorish architecture. To 
appreciate fully this procession of the bloom of the sunflower from its rim to its center, we need to watch it day by day-then only can its beauty become a part of us.

The great, green bracts, with their long pointed tips, which "shingle" the house of every sunflower family, should be noted with care, because these bracts have manifold forms in the great Compositae family; and the pupil should learn to recognize this part of the flower-head, merely from its position. In the burdocks, these bracts form the hooks which fasten to the passer-by; in the thistle, they form the prickly vase about the blossom; while in the pearly everlasting, they make the beautiful, white, shell-like mass of the flower which we treasure as immortal. In the sunflower, these bracts are very ornamental, being feltlike outside and very smooth inside, bordered with fringes of pretty hairs, which may be seen best through a lens. They overlap each other regularly in circular rows, and each bract is bent so as to fit around the disk.

In looking at a mass of garden sunflowers, we are convinced that the heavy heads bend the stems, and this is probably true, in a measure. But the stems are very solid and firm, and the bend is as stiff as the elbow of a stovepipe; and after examining it, we are sure that this bend is made with the connivance of the stem, rather than despite it. Probably most people, the world over, believe that sunflowers twist their stems so that their blossoms face the sun all day. This belief shows the utter contentment of most people with a pretty theory. If you believe it, you had best ask the first sunflower you see if it is true, and she will answer you if you will ask the question morning, noon and night. My own observations make me believe that the sunflower, during the later weeks of its bloom, is like the Mohammedan, keeping its face toward the east. True, I have found many exceptions to this rule, although I have seen whole fields of sunflowers facing eastward, when the setting sun was gilding the backs of their great heads. If they do turn with the sun, it must be in the period of earliest blossoming before they become heavy with ripening seeds.

The sunflower seed is eagerly sought by many birds, and it is raised extensively for chicken-feed. The inadequate little pappus falls off, and the seeds are set, large end up, in the very ornamental diamond-shaped sockets. They finally become loosened, and now we see a reason for the bending flower-head; for, as the great stem is assaulted by the winds of autumn, the bended heads shake out their seed and scatter them far afield.

\section{LESSON CLX}

\section{The Sunflower}

Leading thought-'The sunflower is not a single flower, but is a large family of flowers living together; and each little flower, or floret, as it is called, has its own work to do for the family welfare.

Method-Early in September, when school first opens, is the time for this lesson. If sunflowers are yrowing near by, they should be studied where they stand; and their story may thus be more completely told. Otherwise, a sunflower should be brought to the schoolroom and placed in water. If one is selected which has just begun to blossom, it will show, day by day, the advance of the blossoming ranks. I have kept such a flower fourteen days, and it blossomed cheerfully from its rim to its very 
center A large sunflower that has only partially blossomed is also needed for taking apart to show the arrangement of this big flower-family. Take a bud from the center, a floret showing anther-tube and another showing the curled pair of stigmas, and a ray or banner-flower. (See Fig.p. 632). Each pupil should be furnished with these four florets; and after they have studied them, show them the other half of the sunflower, with each floret in place. After this preliminary study, let them observe the blossoming sunflower for several consecutive days.

Observations- $\mathrm{r}$. A little flower which is part of a big flower-family is called a floret. You have before you three flurets of a sunflower and a banner-flower. Study first the bud. Of how many parts is it composed? What will the lower, white part develop into? Can you see two little white points standing up from it on each side of the bud? Note the shape and color of the unopened floret. Note that there is a narrow, stiff, leaflike bract, which at its base clasps the young seed, while its pointed tip bends protectingly over the top of the bud.

2. Take an open floret with the long, dark brown tube projecting from it. Note that the young seed is somewhat larger than in the bud, and that it still has its earlike projections at the top. Describe the shape of the open corolla. Look at the brown tube with a lens. How many sides has it? How many litile points projecting at the top and bottom on each side of the tube? How does the tube look at the tip, through a lens? Can you see the pollen bursting out? If so, how does it look? Do you think that there is just one tubular anther, or do you think several anthers are joined together to make this tube? Open the corolla-tube carefully, and see if you can answer this last cuestion. Open the anthertube, and see if you can find the pistil with its stigmas.

3. Take a floret with the two yellow horns of the stigma projecting. Where is the brown anther-tube now? Is it as long as in the floret you have just studied? What has happened to it? What did the stigmas do to the pollen in the anther-tube? How do the two parts or lobes of the stigma look when they first project? How later?

4. Make a banner-flower. How many parts are there to it? How does the seedlike portion of the blossom look? Do you think it will ever be a good seed? Describe the corolla of this flower. How much larger is it than the corolla of the florets? Has the banner-flower any pistil or stamens? Of what use is the banner-flower to the sunflower fainily? Do you think that we would plant sunflowers in our gardens for their beauty if they had no banner-flowers?

5. After studying the separate flowers, study a sunflower in blossor, and note the following. Where are the banner-flowers placed? How many rows are there? How are they set so that their banners make the sunflower look like the sun? Do you see why the central portion of the sunflower is called the disk, and the banner-flowers are called the raysin imitation of the sun?

6. Next to the banner-flowers, what sort of florets appear? How many rows are there? What kind form the next circle, and in how many rows? What stages of the florets do you find forming the inner circle, and how many rows? What do you find at the center of the flower-head? Note the beautiful pattern in which the buds are arranged. Can you see the separate buds at the very center of the sunflower? If not, why? 
3. Make notes on a sunflower that has just opened, describing the stages of the florets that are in blossom; continue these notes every day for a week, describing, each day, what has happened. If the sunflower you are observing is in garden or field, note how many days elapse between the opening of the outer row of flowers and the opening of the central buds.

8. Look below or behind the sunflower, and note the way it is attached to the stem. What covers the disk? These green, overlapping, leaflike structures are called bracts. What is the shape of one of these bracts? What is its texture, outside and inside? Look at it, with a lens, along the edges, and note what you see. How are the bracts arranged? Do they not "shingle" the house in which the sunflower-family lives? This covering of the disk, or the house where the sunflower-family lives, is called the invo!ucre.

9. Does the stem of the sunflower hold it upright? Some people declare that it twists its stem so as to face the sun all day. Do you think this is true?

ro. Study a sunflower-head after the seeds are ripe. Do the little ears which you saw at the top of the seeds still remain? How does the sunflower scatter the seeds? Note how the disk looks after the seeds are all gone. What birds are especially fond of sunflower seeds? Of what use are the seeds commercially?

"Flowers have an expression of countenance as much as men or animals. Some seem to smile; some have a sad expression; some are pensive and diffident; others again are plain, honest, and upright, like the broad-faced Sunflower, and the hollyhock.'

- Henry WARd BeEcher.

"Eagle of flowers! I see thee stand,

And on the sun's noon-glory gaze;

With eye like his thy lids expand

And fringe their disk with golden rays;

Though fixed on earth, in darkness rooted there,

Light is thy element, thy dwelling air,

Thy prospect heaven."

- "The Sunflower", Montgomery. 


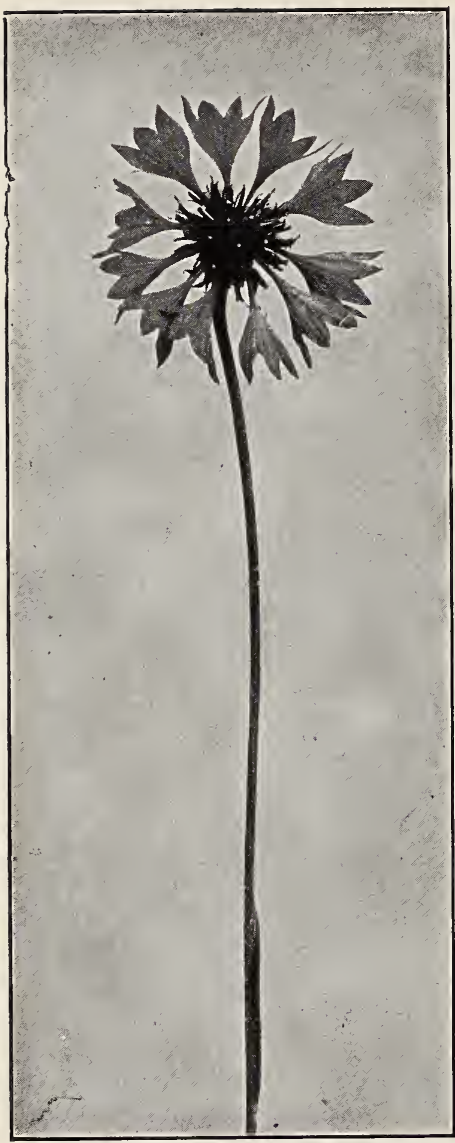

A bachelor's button. Note the trumpetshape of the ray-flowers. Photo by Cyrus Crosby.

\section{THE BACHELOR'S BUTTON} Teacher's Story

This beautiful garden flower gives a variation in form from other composites when studied according to Lesson CXXXV. This valued garden flower came to us from Europe and it sometimes escapes cultivation and runs wild in a gentle way. We call it bachelor's button; but in Europe it is called the cornflower, and under this name it found its way into literature. None of the flowers that live in families repays close study better than does the bachelor's button. The ray-flowers are tubular but they do not have banners. Their tubes flare open like trumpets, and they are indeed color trumpets heralding to the insect world that there is nectar for the probing and pollen for exchange. Looked at from above, the ray-flowers do not seem tubular; from the sides, they show as unevenmouthed trumpets with lobed edyes; but though we search each trumpet to its slender depths we can find no pistils. These ray-flowers have no duty in the way of maturing seeds. In some varieties the ray-flowers are white, and in others they are blue and purple. They vary in number from 7 to 14 , or more.

The disk-flowers have a long corolla-tube, which is white and delicately lobed and is enlarged toward the upper end to a purple bulb with five, long, slender lobes. The anther-tube is purplish black, and is bent into almost a hook, the tip opening toward the middle of the flower-head. The

pollen is glistening white tinged with yellow, and looks very pretty as it bursts out from the dark tubes. The purple stigma first appears with its tips close together, but with a pollen brush just below it; later it opens into a short Y. The buds at the center of the flower are bent hook-shaped over the center of the flower-head. The involucral bracts or "shingles" are very pretty, each one ornamented with a scaly fringe; they form a long, elegantly shaped base to the flower-head. After the flowers have gone larged.

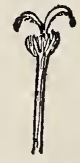

Stigma open and showing pollen-brush pollen-brush larged. 
and the seeds have ripened, these bracts flare open, making a widemouthed urn from which the ripened seeds are shaken by the winds; and after the seeds are gone, the white fuzz of their empty cases remains at the bottom of the urn. The seed is plump and shining, with a short fringe of pappus around the top and a contracted place at one side near the base where it grew fast to the receptacle; for these seeds arenot set on end, as are those of the sunflower. The short pappus is hardly sufficient to buoy up the seed, and yet undoubtedly aids it to make a flying jump with the passing breeze.

\section{LESSON CLXI}

\section{The Bachelor's} ButTon

Leading thoughtEach bachelor's button is made up of many little flowers which may be studied by the outline given in Lesson CXXXV.

\section{THE SALVIA, OR} SCARLET SAGE

\section{Teacher's Story}

The flower story of the sage is so peculiar that Darwin has used it to illustrate the mechanisms present in some flowers which the visiting insects must work in order to get the nectar. The scarlet sage, which gladdens our flower beds during the summer and autumn with its brilliance, has as interesting

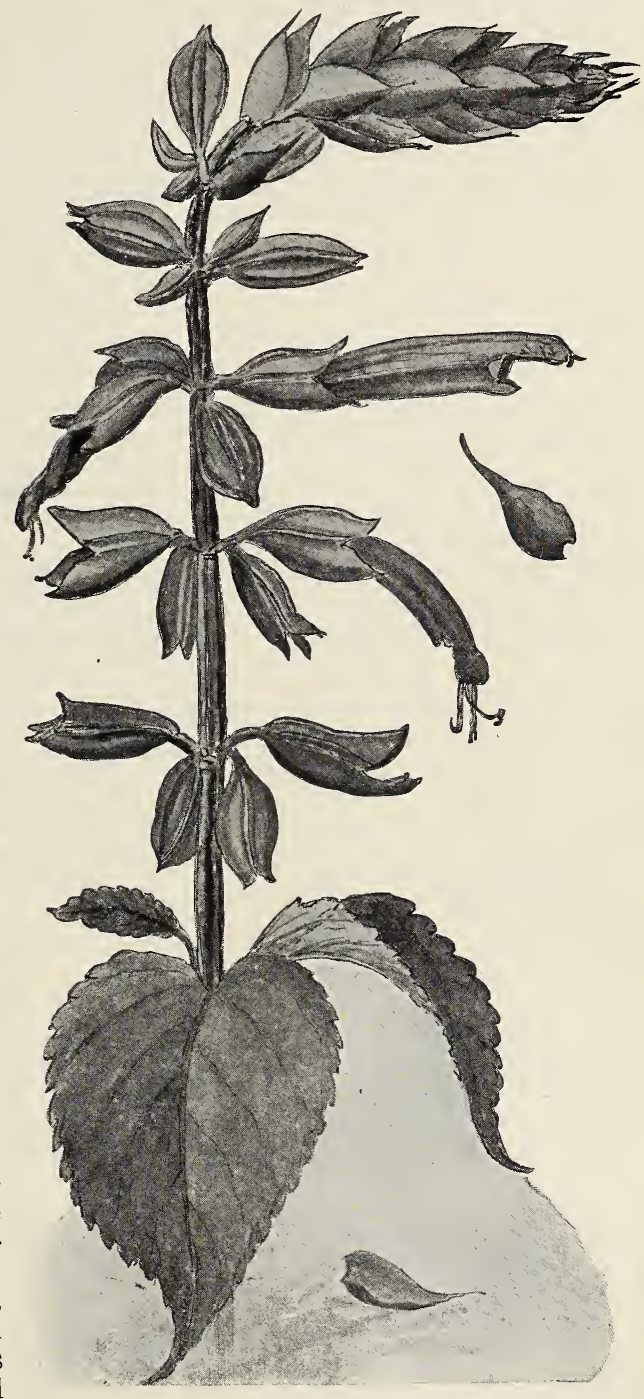

The salvia, or scarlet sage, showing the bracts still present above and falling as the flowers open. 
a story as has any of its family. Looking at it from the outside, we should say that its nectar-wells lie too deep to be reached by any insect except a moth or butterfly, or a humming bird; there is no platform for a bee to alight upon, and the tube is too long to be fathomed by a bee's tongue; but the bees are very good business folk; they adapt themselves to flowers that are not adapted to them, and in autumn the glow of the salvia attracts the eye scarcely more than the hum of the visiting bees attracts the ear.

The calyx of the salvia is as red as the corolla, and is somewhat fuzzy while the corolla is smooth. The calyx is a three-lobed bulging tube held stiff by rather.strong veins; there is one large lobe above and two small ones below the corolla. The corolla is a tube which is more than twice the length of the calyx; it is prolonged above into a projecting hood, which holds the anthers and the stigma; it has a short, cuplike lower lip and two little turned-back, earlike lohes at the side.

The special mechanism of the salvia is shown in the stamens; there are two of these lying flat along the floor of the corolla-tube and grown fast to it. Near the mouth of the tube, each of these lifts up at a broad angle to the roof, and is more or less T-shaped: at the tip of one of the arms of the $T$ is an anther while the other arm is longer and slants down and inward to the floor of the tube, as shown at 2 in the figure.

The bee visiting the flower and entering the corolla-tube, pushes her head against the inner arms of the stamens, lifting them, and in so doing causes the anthers on the front arms of the T to lower and leave streaks of pollen along her fuzzy sides. The stigma is at first concealed in the hood:
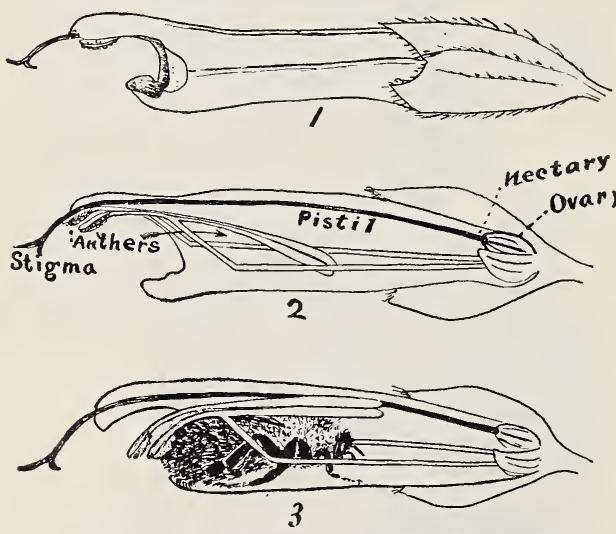

4. Blossom of scarlet sage as seen from outside.

2. The same flower with side removed showing the arrangement of its parts.

3. A bee working the stamen's mechanism as she seeks the nectar.

bases of the corolla-tubes which have fallen to the ground, in order to get what is left of the sweet treasure. jects and hangs down in front of the opening of the corolla-tube, whe. it may be brushed along one side or the other $y$ the visiting insect, shich has been dusted with the pollen of some other flower. The stigmalobes open in such a manner that 'hey do not catch the pollen from the insect backing out of their own corolla. As the nectar is at the base of the corolla-tube, the bees, in order to get it, crawl in almost out of sight. Late in the season they seem to "go crazy" when gathering this nectar; I have often seen them searching the
the ground, in order to get

but, when ripe, it pro- 
But the pollen story is not all that is of interest in the salvia. Some of the parts of the flower which are green in most blossoms, are scarlet as a cardinal's robe in this. If we glance at a flower stalk, we see that at its tip it looks like a braided, flattened cone; this appearance is caused by the scarlet, long-pointed bracts, each of which covers, with its bulging base, the scarlet calyx which in turn enfolds the scarlet flower bud. These bracts fall as the flowers are ready to open, making a brilliant carpet about the plant. Each flower stem continues to develop buds at its tip for a long season; and this, taken together with its scarlet bracts and flowers, renders the salvia a thing of beauty in our gardens, and makes it cry aloud to pollen-carriers that here, even in late autumn, there is plenty of nectar.

\section{LESSON CLXII \\ Salvia, or Scarlet Sage}

Leading thought-This flower has the bracts and calyx scarlet instead of green, and this makes it a brilliant mass of color to please our eyes and attract the pollen-carrying insects. Its anthers are arranged at the tip of two levers, which the insects push up and down as they enter the flower, thus becoming dusted with pollen.

Method-The structure of this flower may be studied in the schoolroom and its mechanism there understood; but the most important part of the lesson is the observation out-of-doors upon the way the bees work the stamen levers when seeking the nectar. This is best observed during late September or October, after other flowers are mostly gone, and when the bees are working with frantic haste to get all the honey possible.

Observations-I. How does the calyx of the salvia differ from that of other flowers in color? How does it differ from the corolla in texture? How many lobes has it? How are they placed about the corolla?

2. What is the shape of the corolla? How does it make a hood over the entrance to the tube? What does the hood hold? Is there any platform made by the lower lip of the corolla for a visiting insect to alight upon?

3. Cut open one side of the corolla and describe how the stamens are arranged. Thrust your pencil into an uninjured flower and see if the anthers in the hood are moved by it. How? Describe how a bee in visiting this flower moves the anthers so as to become dusted with pollen.

4. Where is the stigma? How does it receive pollen from visiting insects? Would it be likely to get the pollen which has just been scraped off from its own anthers by the bee? Why?

5. Experiment to find where the nectar is. Do you ever see bees getting the nectar from fallen flowers? Do they get it from the "front" or the "back door?"

6. What other parts of this flower are red, which in other flowers are green? How does this make the budding portions of the flower stem look? Why does this make the salvia a more beautiful plant for our gardens?

7. Compare the mechanism of the stamens of the scarlet sage with the mechanism of the stamens of the common garden sage. 


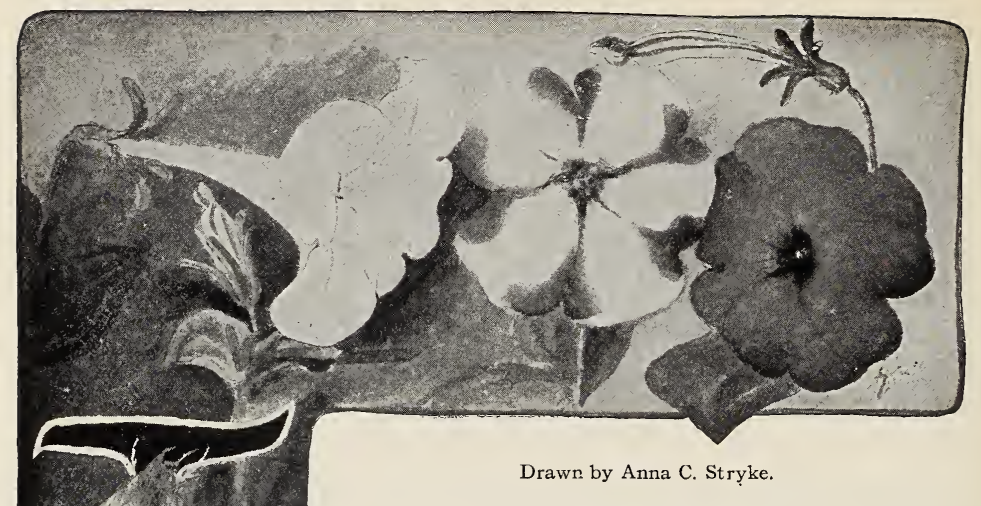

\section{PETUNIAS \\ Teacher's Story}

HESE red-purple and white flowers, which, massed in borders and beds, make gay our gardens and grounds in late summer and early autumn, have an interesting history. Professor L. H. Bailey uses it as an illustration in his thought-inspiring book, "The Survival of the Unlike;" he says that our modern petunias are a strange compound of two original species; the first one was found on the shores of the La Plata in South America and was introduced into Europe in 1823 . "It is a plant of upright habit, thick sticky leaves and sticky stems, and very long-tubed white flowers which exhale a strong perfume at nightfall." The second species of petunia came from seeds sent from Argentina to the Glasgow Botanical Gardens in $183 \mathrm{r}$. "This is a more compact plant than the other, with a decumbent base, narrower leaves and small, redpurple flowers which have a very broad or ventricose tube, scarcely twice longer than the slender calyx lobes." This plant was called Petunia violacea and it was easily hybridized with the white species; it is now, strangely enough, lost to cultivation, although the white species is found in some old gardens. The hybrids of these two species are the ancestors of our garden petunias, which show the purple-red and white of their pro. genitors. The petunias are of the Nightshade family and are kin to the potato, tomato, egg-plant, tobacco and Jimson-weed, and, like the latter, the flowers are especially adapted to give nectar to the longtongued sphinx or humming bird moths.

The petunia corolla is tubular, and the five lobes open out in salvershape; each lobe is slightly notched at its middle, from which point a marked midrib extends to the base of the tube. In some varieties the edges of the lobes are ruffled. Within the throat of the tube may be seen a network of darker veins, and in some varieties this network spreads out over the corolla-lobes. Although many colors have been developed in petunias, the red-purple and white still predominate; when the two colors combine in one flower, the pattern may be symmetrical, but is often broken and blotchy. 
When a flower-bud is nearly ready to open the long, bristly tube of the corolla lies with its narrow base set in the calyx, the long, fuzzy lobes of which flare out in bell-shape; the tube is marked by lengthwise lines made by the five midribs; the lobes of the corolla are folded along the outer portions of these midribs, and these folded tips are twisted together much as if some one had given them a half turn with the thumb and finger. It is a pleasing experience to watch one of these flowers unfold. When a flower first opens, there lies near the bottom of the throat of the tube the green stigma, with two anthers snuggled up in front of it and two behind it, the latter being not quite so advanced in age as the former. As the filaments of the front pair of anthers are longer than those of the rear pair. the little group lies at a low angle offering a dusty doormat for entering insects. If we open a flower at this stage, we find another anther, as yet unopened, and which is on the shortest stamen of the five. This seems to be a little pollen-reserve, perhaps for its own use later in the season. There is an interesting mechanism connected with these stamens; each is attached to the corolla-tube at the base for about half its length, and at the point of attachment curves suddenly inward so as to "cuddle up" to the pistil, the base of which is set in the nectar-well at the bottom of the flower. If we introduce a slender pencil or a toothpick into the flowertube along the path which the moth's tongue mus, follow to reach the nectar, we can see that the stamens, pressing against it at the point where they curve inward, cause the anthers to move about so as to discharge their pollen upon it; and as the toothpick is withdrawn they close upon it cogently so that it carries off all the pollen with which it is brought in contact.

If we look at the stigma at the center of its anther-guard, it has a certain close-fisted appearance, although its outer edges may be dusted with the pollen; as the flower grows older, the stigma stands above the empty anthers at the throat of the flower tube and opens out into two distinct lobes. Even though it may have accepted some of its own pollen, it apparently opens up a new stigmatic surface for the pollen brought from other flowers by visiting insects.

Dr. James G. Needham says that at Lake Forest he has been attracted to the petunia beds in the twilight by the whirring of the wings of countless numbers of sphinx, or hummingbird moths which were visiting these flowers. We also may find these moths hovering over petunia beds in almost any region if we visit them on the warmer evenings. And it is a safe guess that the remote white ancestor of our petunias had some special species of sphinx moth which it depended upon for carrying its pollen;

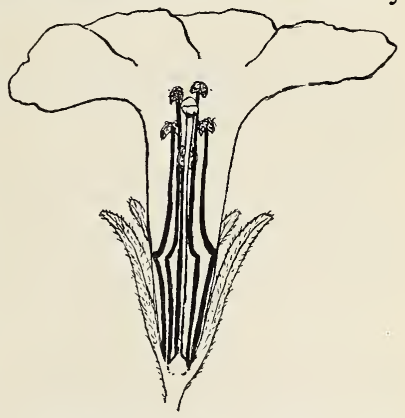

A petunia blossom cut open on the upper side, showing the pistil surrounded by the incurved stamens and the partiaily opened stigma surrounded by the anthers. Note the short stamen below the pistil.

and the strong perfume it exhaled at nightfall was an odor signal to its moth friends to come and feast. 
But even though the petunia flowers are especially adapted to the delectation of hummingbird moths, our bees which-like man-have claimed all the earth, will work industriously in the petunias, scrambling into the blossoms with much remonstrating, high-pitched buzzing because of the tight fit, and thus rifle the nectar-wells that were meant for insects of quite different build.

The leaves of the petunia are so broadly ovate as to be almost lozengeshape, especially the lower ones; they are soft, and have prominent veins on the lower side; they are without stipules, and have short flat petioles. The stems are soft and fuzzy and are usually decumbent at the base, except the central stems of a stool or clump which, though surrounded by kneeling sisters, seem to prefer to stand up straight.

The flower stems come off at the axils of the leaves, the lower flowers open first. The blossoms remain open about two days; at the first sign of fading, the lobes of the corolla droop dejectedly like a frill that has lost its starch, and finally the corolla - tube and all-drops off, leaving a little conical seed-capsule nestled snugly in the heart of the bell-shaped calyx. At this time, if this peaked cap of the seed-capsule be removed, the many seeds look like tiny white pearls set upon the fleshy, conical placenta. As the capsule ripens, it orows brown and glossy like glazed manila paper and it is nearly as thin; then it cracks precisely down its middle, and the seeds are spilled out at any stirring of the stems. The ripe seeds are dark brown, almost as fine as dust, and yet, when examined with a lens, they are seen to be exquisitely netted and pitted.

References-The Survival of the Unlike, L. H. Bailey; The Encyclopedia of Horticulture, Bailey; Our Garden Flowers, Harriet Keeler.

\section{LESSON CLXIII}

\section{The Petunia}

Leading thought-The petunias have an interesting history being native to South America. Their flowers are fitted by form and mechan ism to entice the hummingbird moths as visitors, and to use them for carrying pollen.

Method-The petunias are such determined bloomers that they give us flowers up to the time of killing frosts, and they are therefore good material for nature lessons. Each pupil should have a flower in hand to observe during the lesson, and should also have access to a petunia bed for observations on the habits of the plant.

Observations-r. What colors do you find in the petunia flowers? If striped or otherwise marked, what are the colors? Are the markings symmetrical and regular?

2. Sketch or describe a flower, looking into it. What is the shape of the corolla-lobes? How many lobes are there? How are they veined? What peculiar markings are at the throat of the flower?

3. What are the color and position of the stigma? How are the stamens arranged? How many anthers do you see? What is the color of the anthers? Of the pollen?

4. Sketch or describe the flower from the side. What is the shape of the corolla-tube? Is it smooth or fuzzy? How is it marked? What are the number and shape of the sepals, or lobes, of the calyx? 
5. Study a freshly opened flower, and describe the position and appearance of the anthers and stigma. Do they remain in these relative positions after the flower is old?

6. Cut open a flower, slitting it along the upper side. Describe the stamens and how they are attached. Is the pistil attached in the same manner? Where is the nectar? Thrust a slender pencil or a toothpick into the tube of a fresh flower. Does this spread the anthers apart and move them around? When it is withdrawn, is there pollen on it? Can you see in your open flower the mechanism by which the pollen is dusted on the object thrust into the flower?

7. What insects have tongues sufficiently long to reach the nectar. well at the bottom of the petunia flower? At what time do these insects fly? At what time of day do most of the petunia flowers open? Visit the petunia beds in the twilight, and note whether there are any insects visiting them. What insects do you find visiting these flowers during the day?

8. Sketch or describe the leaves of the petunia. How do the leaves feel? Look at a leaf with a lens and note the fringe of hair along its edges. Describe the veining of the leaf.

9. Describe the petunia stems. Are they stout or slender? How do they feel? With what are they covered? Where do the flower stems come off the main stalk?

Io. Describe or sketch a flower-bud just ready to open. How are the tips of the lobes folded? How long does the flower remain in bloom? What is the first sign of its fading?

I I. Describe the seed-capsule. Where does it open? Are the seeds many or few, large or small? What is their color when ripe? When examined with a lens, have they any pits or markings?

\section{THE HORSESHOE GERANIUM}

\section{Teacher's Story}

The geraniums perhaps do more to brighten the world than almost any other cultivated flowers. They will grow for every one, whether for the gardener in the conservatory of the rich, or in a tin can on the windowsill of the crowded tenement of the poor. And it is interesting to know that this common plant has a cultivated ancestry of two hundred years' standing. These geraniums, which are really not geraniums botanically but are pelargoniums, originally came from southern Africa, and the two ancestors of our common bedding geraniums were introduced into England in $\mathrm{I} 7 \mathrm{ro}$ and $\mathrm{I} 7 \mathrm{I} 4$.

The geranium is of special value to the teacher, since it is available for sturly at any season of the year, and has a most interesting blossom. The single-flowered varieties should be used for this lesson, since the blossoms that are double have lost their original form. Moreover, the geranium's blossom is so simple that it is of special value as a subject for a beginning lesson in teaching the parts of a flower; and its leaves and stems may likewise be used for the first lessons in plant structure.

The stem is thick and fleshy, and is downy on the new growth; there is much food stored in these stems, which accounts for the readiness with which cuttings from them will grow. Wherevcr a leaf comes off the stem, it is guarded. by two stipules at the base; these stipules often remain after 
the leaves have fallen, thus giving the stem an unkempt look. The leaves are of various shapes, although of one general pattern; they are circular and beautifully scalloped and lobed, with veins for every lobe radiating from the petiole; they are velvety above and of quite different

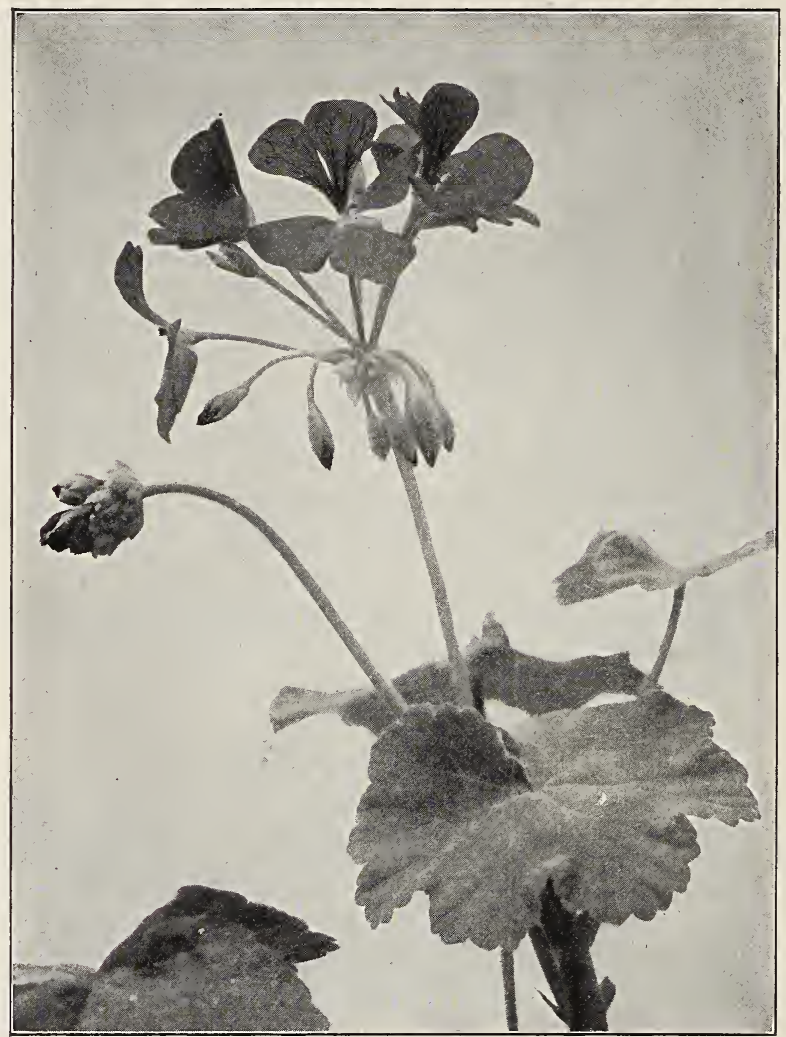

Horseshoe Geranium.

Photo by Sheldon.

Note the positions of the opened flowers and the buds. Note the shape of the two upper petals with their guide-lines, showing the position of the nectar-gland. The flower at the left, seen in profile, shows that these upper petals project farther forward than those below. Note, the cluster of young buds set in a circlet of bracts just below this flower.

texture beneath, and many show the dark horseshoe which gives the name to this variety. The petiole is usually long and stiff and the leaves are set alternately upon the stem.

The flower has five petals, and at first glance they seem of much the same shape and position; but if we look at them carefully, we see that the upper two are much narrower at the base and project farther forward than 
do the lower three. Moreover, there are certain lines on these upper petals all pointing toward the center of the flower; these are the nectar guidelines, and if we follow them we find a deep nectar-well just at the base of these upper petals and situated above the ovary of the flower. No other flower shows a prettier plan for guiding insects to the hidden sweets, and in none is there a more obvious and easily seen well of nectar. It extends almost the whole length of the flower stem, the nectar gland forming a hump near the base of the stem. If we thrust a needle down the whole length of this nectar tube we can see that this bright flower developed its nectar especially for some long-tongued insect, probably a butterfly. It is interesting to note that in the double geranium where the stamens have been all changed to petals and where, therefore, no seeds are formed, this nectar-well has been lost.

There are five sepals, the lower one being the largest. But the geranium is careless about the number of its stamens; most flowers are very good mathe-

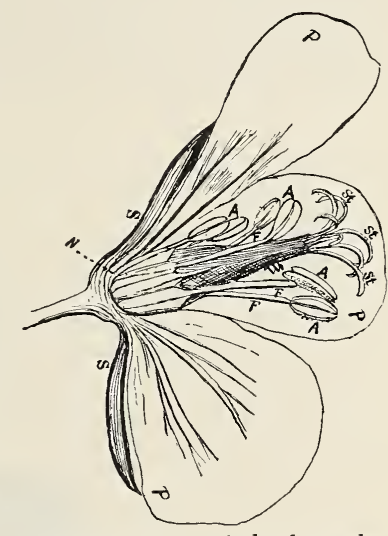

Diagram, flower of the horseshoe geranium.

S, sepals; $\mathrm{P}$, petals; A, anther; F, filament; $\mathrm{m}$, pistil; St., stigma;

$\mathrm{N}$, opening to nectar tube. maticians, and if they have five sepals and five petals they are likely to have five or ten stamens. The geranium often shows seven anthers, but if we look carefully we may find ten stamens, three of them without anthers. But this is not always true; there are sometimes five anthers and two or three filaments without anthers. The color of the anthers differs with the variety of the flower. The stamens broaden below, and their bases are joined making a cup around the lower part of the ovary. The pistil is at the center of the flower and has no style, but at the summit divides into five long, curving stigmas; but again the geranium cannot be trusted to count, for sometimes there are seven or eight stigmas. Although many of our common varieties of geraniums have been bred so long that they have almost lost the habit of producing seed, yet we may often find in these single blossoms the ovary changed into the peculiar, long, beaklike pod, which shows the relationship of this plant to the cranesbill or wild geranium.

When the buds of the geranium first appear, all of them are nestled in a nest of protecting bracts, each bud being enclosed in its own protecting sepals. But soon each flower stem grows longer and droops and often the bracts at its base fall off; from this mass of drooping buds, the ones at the center of the cluster lift up and open their blossoms first. Often, when the outside flowers are in bloom, those at the center have withered petals but are hidden by their fresher sisters.

It would be well to say something to the pupils about those plants which have depended upon man so long for their planting that they do not develop any more seed for themselves. In connection with the geraniums, there should be a lesson on how to make cuttings and start 
their growth. The small side branches or the tips of the main stems may be used as cuttings. With a sharp knife make a cut straight across. Fill shallow boxes with sand, place them in a cool room and keep them constantly moist; plant the cuttings in these boxes, putting the stems for one. third of their length in the sand. After about a month the plants may be repotted in fertile soil. The fall is the best time to make cuttings.

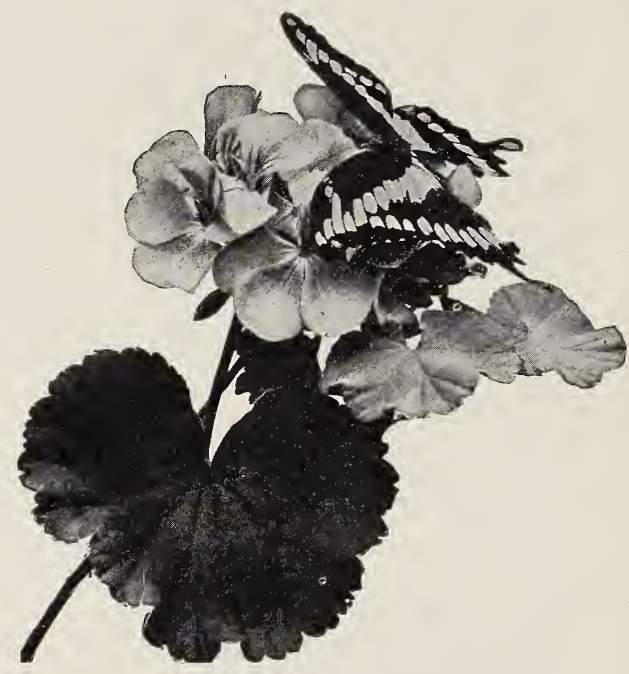

\section{LESSON CLXIV}

\section{The Horseshoe Geranium}

Leading thought-The geraniums are very much prized as flowers for ornamental beds. Let us see why they are so valued.

Method-A variety of geranium with single flowers should be chosen for this purpose, and it may be studied in the schoolhouse window or in the garden. As the parts of this flower are of a very general type, it is an excellent one with which to teach the names and purposes of the flower parts. Each child can make a little drawing of the sepals, petals, stamens and pistil, and label them with the proper names.

Observations-I. What sort of a stem has the geranium. Is it smooth or downy? What makes the geranium stem look so rough and untidy?

2. Study the leaf. Show by description or drawing its shape, its wings, its veins. What are its colors and texture above? Beneath? Is the petiole long or short? What grows at the base of the petiole where it joins the stem? What marking is there on the leaf, which makes us call this a "horseshoe geranium?" Are there other geraniums with leaves of similar shape that have no horseshoe mark?

3. Study the flower. Are the petals all the same size and shape? How many of them are broad? How many narrow? Do the narrow 
ones project in front of the others? Do these have guide-lines upon them? Where do these lines point? Find the nectar-well, how deep is it? Does it extend almost the entire length of the flower stem? For what insects must it have been developed? Are there nectar-tubes in the stems of the geraniums with double flowers? Why?

4. How many sepals are there? Are they all the same size? Where is the largest?

5. How many stamens can you see? What is the color of the filaments and of the anthers? How are the stamens joined at their bases? Can you find any stamens without anthers?

6. Where is the pistil situated? Can you see the ovary, or seed-box? How many stigmas? Describe their color and shape.

7 . In what part of the flower will the seeds be developed? $\mathrm{H}$ ) w does the geranium fruit look? Sketch the pod. Do the geraniums revelop many seeds? Why not? Do you know the seed-pod of the wild geranium? If so, compare it with the pod of this plant.

8. Take a flower cluster when the flowers are all in the bud, and note the following: When the buds first appear, what protects them? What becomes of these bracts later? How do the sepals protect the bud? Are the bud stems upright and stiff or drooping? How many buds are there in a cluster?

9. Take notes on successive days as follows: What happens to the stem as the bud gets ready to bloom? Is it a central or an outside blossom that opens first? How many new blossoms are there each day? How long is it from the time that the first bud opens until the last bud of the cluster blossoms? What has this to do with making the geranium a valuable ornamental plant?

Io. Make some geranium cuttings, and note how they develop into new plants. Place one of the cuttings in a bottle of water and describe how its roots appear and grow.

\footnotetext{
"God made the flowers to beautify

The earth, and cheer man's careful mood;

And he is happiest who hath power

To gather wisdom from a flower, And wake his heart in every hour

To pleasant gratitude."
}

-WORDSWORTH. 


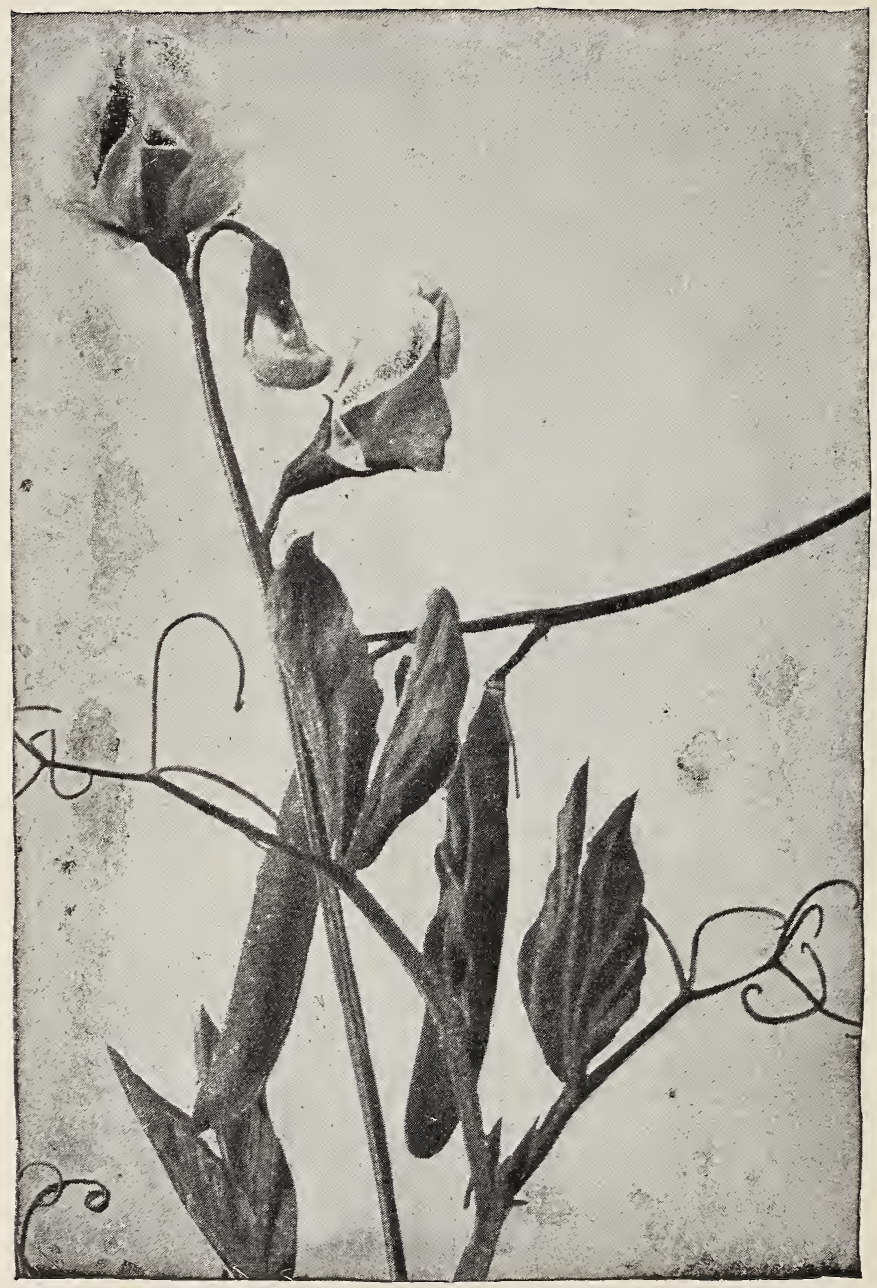

Sweet Peas.

"Here are sweet peas on tip for a fight, With wings of delicate flush o'er delicate white, And taper fingers catching at all things, To bind them all about with tiny rings." 


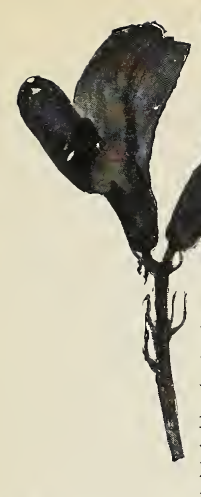

Cultrvated-Plant Study

\section{THE SWEET PEA}

\section{Teacher's Story}

MONG the mostattractive of the seeds which make up the treasure of the children's seed packets, the sweet peas are of the prettiest. They are smooth, little white or brown globules, marked with a scar on the side, showing where they were attached to the pod. One of these peas divides readily into two sections; and after it has been soaked in water for twenty-four hours, the germ of the future plant may, with the aid of a lens, be seen within it. After planting, the sprout pushes through the seed-coat at a point very near the scar, and leaf shoots emerge from the same place; but the two act very differently. The leaf lifts upward toward the light, and the root plunges down into the soil. As the plant grows, it absorbs the food stored in the seed; but the seed remains below ground and does not lift itself into the air, as happens with the bean. The root forms many slender branches, near the tips of which may be seen the fringe of feeding roots, which take up the food and water from the soil. The first leaves of the pea seedling put forth no tendrils, but otherwise look like the later ones. The leaves grow alternately on the stalk, and they are compound, each having from three to seven leaflets. The petiole is winged, as is also the stem of the plant. There is a pair of large, clasping stipules at the base of each leaf. If we compare one of these leaves with a spray of tendrils, we can see that they resemble each other in the following points: The basal leaflets of the petiole are similar and the stipules are present in each case; but the leaflets nearest the tip are marvelously changed to little, stiff stems with a quirl at the tip of each ready to reach out and hook upon any object that offers surface to cling to. Sometimes we find a leaflet paired with a tendril. The sweet pea could not thrive without a support outside of itself.

Of course, the great upper petal of the sweet pea blossom is called the banner! It stands aloft and proclaims the sweet pea as open; but before this occurs, it tenderly enfolds all the inner part of the flower in the unopened bud, and when the flower fares it again performs this duty. The wings are also well named; for these two petals which hang like a peaked roof above the keel, seem like wings just ready to open in flight. The two lower petals are sewed together in one of Nature's invisible seams, making a long, curved treasure chest resembling the keel of a boat, and it has thus been called. Within the keel are hidden the pistil and stamens. The ovary is long, pod-shaped and downy; from its tip the style projects, as strong as a wire, curving upwards, and covered with a brush of fine, white hairs; at the very tip of the style, and often projecting slightly from the keel, is the stigma. Around the sides and below the

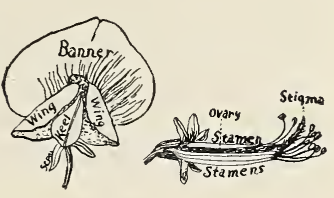

Blossom sweet pea with paris labelled. ovary and style, are nine stamens, their filaments broadening and uniting to make a white, silken tube about the ovary, or young pod. From the tip of this stamen-tube, each of the nine 
filaments disengages itself, and lying close to the style thrusts its anther up into the point of the keel, below the stigma. But strange to say, one lone, lorn stamen "flocks by itself" above the pistil, curving its anther up stigma-ward. If we touch the point of the keel with the finger, up fly-like a jack-in-the-box-the anthers splashing the finger with pollen; and if a bee, in her search for nectar, alights on the wings at the very base of the petals, up flies the pollen brush and daubs her with the yellow dust, which she may deposit on the stigma of

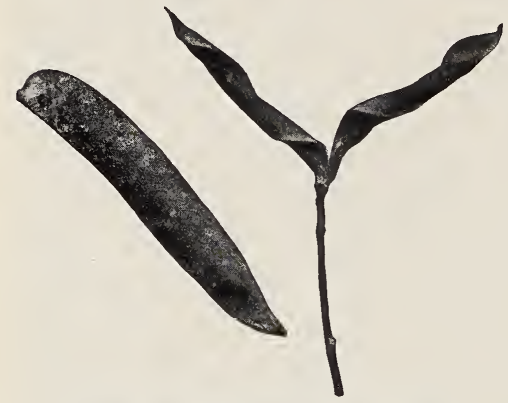

Sweet pea pod bursting in spiral. another flower. The interesting part of this mechanism is the brush near the tip of the style below the stigma-a veritahle broom, with splints all directed upward. As the pollen is discharged around it, the brush lifts it up when the keel is pressed down, and the stiff petals forming the keel, in springing back to place, scrape off the pollen and plaster it upon the visitor. But for all this elaborate mechanism, sweet peas, of all flowers. are the most difficult to cross-pollenate, since they are so likely to receive some of their own pollen during this process.

The sweet-pea bud droops, a tubular calyx with its five-pointed lobes forming a bell to protect it. Within the bud the banner petal clasps all in its protecting embrace.

After the petals fall, the young pod stands out from the calyx, the five lobes of which are recurved and remain until the pod is well grown. As the sweet pea ripens, all the moisture is lost and the pod becomes dry and hard, through the dampness of dews at night and the sun's heat which warps it by day, finally each side of the pod suddenly coils into a spiral, flinging the seed many feet distant in different directions.

\section{LESSON CLXV \\ The Sweet Pea}

Leading thought-The sweet pea has its leaflets changed to tendrils, which hold it to the trellis. Its flower is like that of the clover, the upper petal forming the banner, the two side petals the wings, and the two united lower petals the keel which protects the stamens and pistil.

Method-This should be a garden lesson. A study should be made of the peas before they are planted, and their germination carefully watched. Later, the method of climbing, the flower and the fruit should each be the subject of a lesson.

Observations on germination-I. Soak some sweet peas over night; split them the next morning. Can you see the little plant within?

2. Plant some of the soaked peas in cotton batting, which may be kept moist. At what point does the sprout break through the seed covering? Do the root and leaf-shoot emerge at the same place, or at different points? Which is the first to appear? 
3. Plant some of the soaked peas in the garden. How do the young plants look when they first appear? Does the fleshy part of the seed remain a part of the plant and appear above the ground, as is the case with the bean? What becomes of the meat of the seed after growth has started?

4. Do the first leaves which unfold from the seed pea look like the later ones? Are the leaves simple or compound? Do they grow opposite each other or alternately?

5. Take a leaf and also a spray of the tendrils. How many leaflets are there in a compound leaf? Describe the petiole and the basal leaves. How far apart are the leaflets on the mid-stem? Compare the stem on which the tendrils grow with this leaf. Are the basal leaflets like those of the leaf? Is the petiole like that of the leaf? Do you think that the leaflets toward the tip of the stem often change to tendrils? Why do you think so? Why must the sweet pea have tendrils? Do you see the earlike stipules at the base of the leaf? Are there similar stipules at the base of the tendril stem?

Observations on the flower and fruit-I. Take the sweet pea in blossoin. Why is the large upper petal called the banner? How does it compare in size with the other petals? What is its purpose when the flower is open? Why do you think the side petals are called wings? What is their position when the flower is open?

2. Describe that part of the flower below the wings. Do you think that it is made of two petals grown together? Why is it called the keel of the flower? Press down with your finger on the tip of the keel. What happens? Is your finger splashed with pollen? Where is the nectar in the sweet pea? Would an insect getting the nectar press down upon the keel and receive a splash of pollen?

3. Open the keel. How many stamens do you find within it? How many have their filaments joined together? Is there one separate from the others? Against what are the anthers pressed by the keel?

4. Remove the stamens and describe the pistil. Which part of this will make the pod in which the new peas will develop? Describe how the style is curved. How is the style covered near its tip? What is this brush for? Can you find the stigma with the help of the lens? When the bee is seeking for nectar and pushes down on the keel, does the stigma push out at the same point as the pollen? Does this enable the stigma sometimes to receive pollen which the bees bring from other flowers?

5. Describe an unopened flower bud. What is its position? How many lobes to the calyx? What is their shape, and how do they protect the bud? Which petal is folded over all the others? How does the position of the open flower differ from that of the bud?

6. How does the young pod look when the petals fall? How does it look when ripe? How does it open to scatter little, ripe sweet peas? Do the lobes of the sepals still remain with the pod? 


\section{THE CLOVERS}

\section{Teacher's Story}

"Sweet by the roadside, sweet by the rills,

Sweet in the meadows, sweet on the hills,

Sweet in its wine, sweet in its red,

Oh, half of its sweetness cannot be said;

Sweet in its every living breath,

Sweetest, perhaps, at last, in death."

- "A Song of Clover", Helen Hunt Jackson.

Clover has for centuries been a most valu.

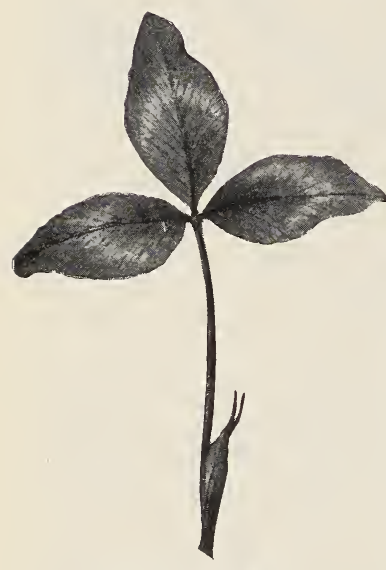

Drawn by Ida Baker. able forage crop; and for eons it has been the special partner of the bees, giving them honey for their service in carrying its pollen; and in recent years it has been discovered that it has also formed a mysterious and undoubtedly an ancient partnership with bacteria below ground, which, moreover, brings fertility to the soil. The making of a collection of the clovers of a region is a sure way of enlisting the pupils' interest in these valuable plants. The species have some similarities and differences, which give opportunity for much observation in comparing them. There may be found in most localities the white and yellow sweet clovers, the black and spotted medics and their relative the alfalfa; while of the true clovers there are the red, the zigzag, the buffalo, the rabbit's foot, the white, the alsike, the crimson, and two yellow or hop clovers.

In all the clovers, those blossoms which are iowest. or on the outside of the head, blossom first, and all of them have

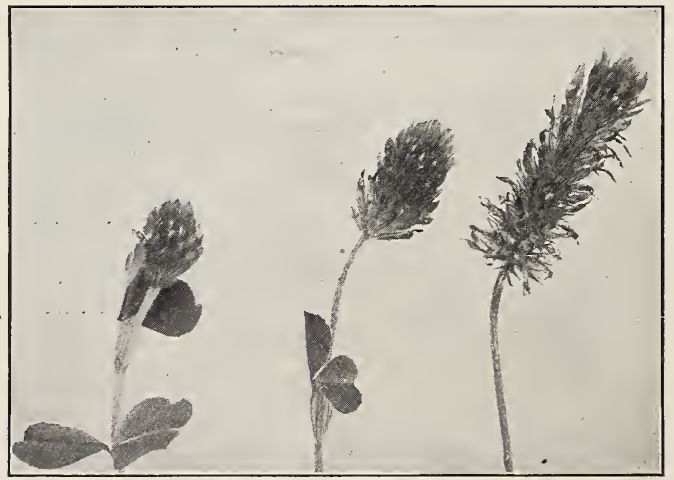

Crimson clover; just beginning to blossom at the left, more advanced at the middle, and at the end of its bloom at the right.

Photo by G. F. Morgan. 
upon their roots the little swellings, or nodules, which are the houses in which the beneficent bacteria grow.

If we pull up or dig out the roots of alfalfa, or of the true clovers or vetches, we find upon the rootlets little swellings which are called nodules, or root-tubercles. Although these tubercles look so uninteresting, no fairy story was ever more wonderful than is theirs. They are, in fact, the home of the clover brownies, which help the plants to do their work. Each nodule is a nestful of living beings, so small that it would take twenty-five thousand of them end to end to reach an inch; therefore, even a little swelling can hold many of these minute organisms, which are called bacteria. For many years people thought that these swellings were injurious to the roots of the clover, but now we know that the bacteria which live in them are simply underground partners of these plants. The clover roots give the bacteria homes and place to grow, and in return these are able to extract a very valuable chemical fertilizer from the air, and to change its form so that the clovers can absorb it. The name of this substance is nitrogen, and it makes up more than three-fourths of the air we breathe. Other plants are unable to take the nitrogen from the air and use it for food, but these little bacteria extract it from the air which fills every little space between every two grains of soil and then change it to a form which the clovers can use. After the clover crop is harvested, the roots remain in the ground, their little storehouses filled with this precious substance, and the soil falls heir to it.

Nitrogen in the form of commercial fertilizer is the most expensive which the farmer has to buy. So when he plants clover or alfalfa on his land, he is bringing to the soil this expensive element of plant growth, and it costs him nothing. This is why a good farmer practices the

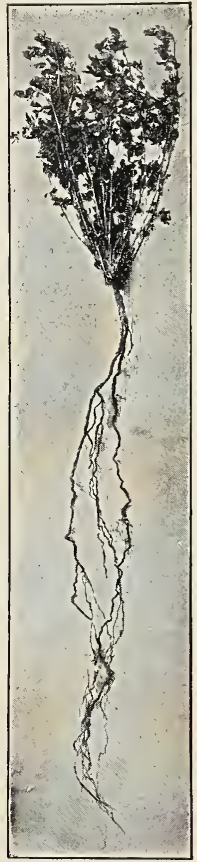

Alfalfa showing root-tubercles. rotation of crops and puts clover upon his land every three or four years.

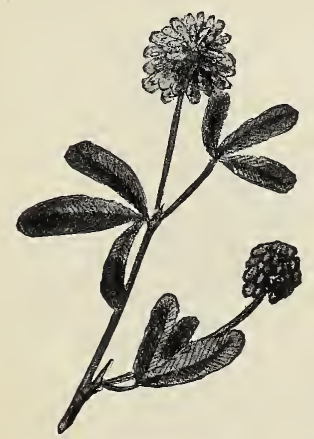

Yellow or hop clover.

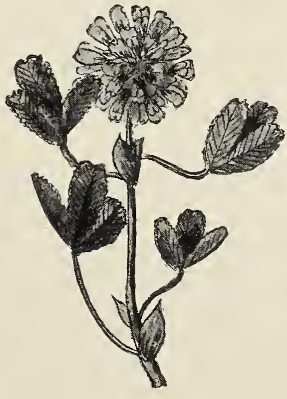

Buffalo clover.

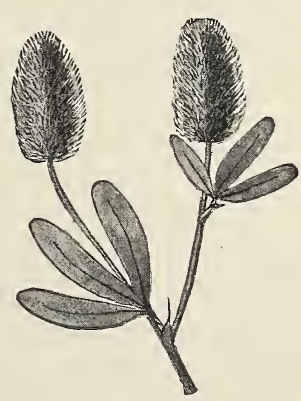

Rabbit-foot or pussy clover 
Alfalfa is so dependent on its little underground partners, that it cannot grow without them; and so the farmer plants, with the alfalfa seed, some of the soil from an old alfalfa field, which is rich in these bac-

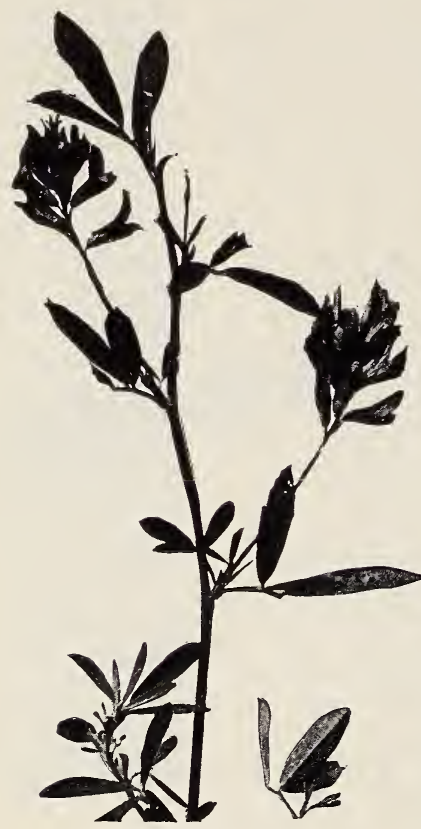

Aıfalfa in leaf and blossom. teria. On a farm I know, the bacterial soil gave out before all of the seed was planted; and when the crop was ready to cut it was easy to see just where the seed without the inoculated soil had been planted, for the plants that grew there were small and poor, while the remainder of the field showed a luxurious growth.

It is because of the great quantity of nitrogen absorbed from the air through the bacteria on its roots that the alfalfa is such a valuable fodder; for it contains the nitrogen which otherwise would have to be furnished to cattle in expensive grain or cotton-seed meal. The farmer who gives his stock alfalfa does not need to pay such large bills for grain. Other plants belonging to the same family as the clovers-like the vetches and cow-peas-also have bacteria on their roots. But each species of legume has its own species of bacteria; although in some cases soil inoculated with bacteria from one species of legume will grow it on roots of another species. Thus, the bacteria on the roots of sweet clover will grow on the roots of alfalfa and many farmers use the soil inoculated by sweet clover to start their alfalfa crops.

In addition to the enriching of the soil, clover roots, which penetrate very deeply, protect land from being washed away by freshets and heavy rains; and since clover foliage makes a thick carpet over the surface of the soil, it prevents evaporation and thus keeps the soil moist. Crimson clover is used extensively as a cover crop; it is sowed in the fall, especially where clean culture is practiced in orchards, and spreads its leaves above and its roots within the soil, keeping out weeds and protecting the land. In the spring it may be plowed under, and thus add again to the fertility. This is also an aesthetic crop, for a field of crimson clover in bloom is one of the most beautiful sights in our rural landscape.

Red clover has such deep florets that, of all our bees, only the bumblebees have

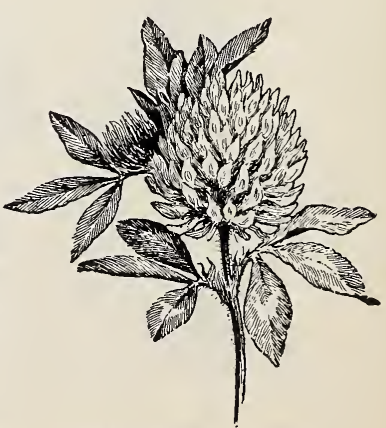

Red cl jver blossom. 
sufficientiy long tongues to reach the nectar. It is, therefore, dependent upon this bee for developing its seed, and the enlightened farmer of to-day looks upon the bumblebees as $h^{*}$, best friends. The export of clover seed frc.n the United States has sometimes reached the value of two million dollars per year, and this great industry can only be carried on with the aid of the bumblebee. There are sections of New York State where the growing of clover seed was once a most profitable business, but where now, owing to the dearth of bumblebees, no clover seed whatever is produced.

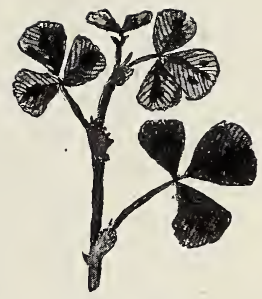

Spotted medic.

\section{LESSON CLXVI \\ The Clovers}

Leading thought-The clovers enrich with nitrogen the soil in which they are planted. They are very valuable as food for stock; and their flowers are pollenated by bees.

Method-Each pupil should dig up a root of red clover or alfalfa to use for the lesson on the nodules. The flowers should be studied in the field, and also in detail in the schoolroom.

Observations-I. How many kinds of clover do you know? How many of the medics?

2. In all clovers, which flowers of the head blossom first, those on the lower or outside, or those on the upper or inside?

3. Take up a root of red clover or alfalfa, noting how deep it grows. Wash the root free from soil, and find the little swellings on it. Write the story of what these swellings do for the clover, and incidentally for the soil.

4. How must the soil be prepared so that afalfa may grow success. fully? What does the farmer gain by feeding alfalfa, and why?

5. How do clover roots protect the land from being washed by heavy rains? farmer?

6. How do clovers keep the soil moist? How does this aid the

7. What is a cover crop, and what are its uses?

8. Upon what insects does the red clover depend for carrying pollen? Can it produce seed without the aid of these valuable bees? Why not?

\section{SWEET CLOVER}

\section{Teacher's Story}

In passing along the country roads, especially those which have suffered upheaval from the road machines, suddenly we are conscious of a perfume so sweet, so suggestive of honey and other delicate things, that we involuntarily stop to find its source. Close at hand we find this perfume laboratory in the blossoms of the sweet clover. It may be the species with white blossoms, or the one with yellow flowers, but the fragrance is the same. There stands the plant, lifting its beautiful 


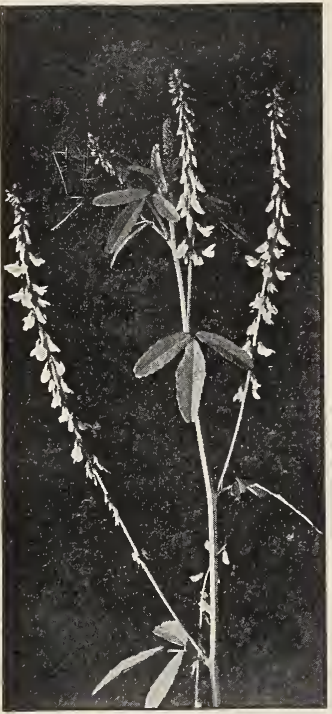

White sweet clover.

blue-green foliage and its spikes of flowers for the enjoyment of the passer-by, while its roots are feeling their way down deep in the poor, hard soil, taking air and drainage with them and building, with the aid of their underground partners, nitrogen factories which will enrich the poverty-stricken earth, so that other plants may find nourishment in it.

Never was there such another beneficent weed as the sweet clover-beneficent alike to man, bee and soil. Usually we see it growing on soil so poor that it can only attain a height of from two to four feet; but if it once gets foothold on a generous soil, it rises majestically ten feet tall.

Like the true clover, its leaf has three leaflets, the middle one being longer and larger than the other two and separated from them by a naked midrib; the leaflets are long, oval in shape, with narrow, toothed edges, and they are dull, velvety green; the two stipules at the base of the leaf are little and pointed.

The blossoming of the sweet clover is a pretty story. The blossom stem, which comes from the axil of the leaf, is at first an inch or so long, packed closely with little, green buds having pointed tips. But as soon as the blossoming begins, the stem elongates, bringing the flowers farther apart-just as if the buds had been fastened to a rubber cord which had been stretched. The buds lower down open first; each day some of the flowers bloom, while those of the day before linger, and thus the blossom tide rises, little by little up the stalk. But the growing tip develops more and more buds, and thus the blossom story continues until long after the frosts have killed most other plants; finally the tip is white with blossoms, while the seeds developed from the first flowers on the plant have been perfected and scattered.

The blossom is very much like a diminutive sweet pea; the calyx is like a cup with five points to its rim, and is attached to the stalk by a short stem. The banner petal is larger than the wings and the keel. A lens shows the stamens united in to two groups, with a threadlike pistil pushing out between; both stamens and pistil are covered by the keel, as in the pea blossom.

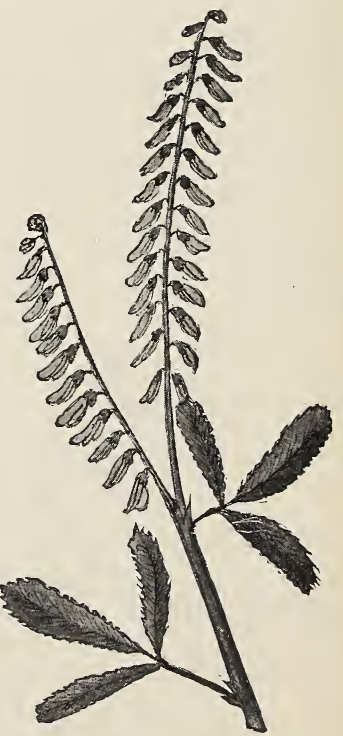

Yellow sweet clover. 
The flowers are beloved by bees and many other insects, which are attracted to them by their fragrance as well as by the white radiance of their blossoms. The ripened pod is well encased in the calyx at its base. The foliage of the sweet clover is fragrant, especially so when drying; it has been used for fodder. The sweet clovers came to us from Europe and are, in a measure, compensation for some of the other emigrant weeds which we wish had remained at home.

\section{LESSON CLXVII \\ SWeET Clover}

Leading thought-This beneficent plant grows in soil too poor for other plants to thrive in. It brings nitrogen and air into the soil, and thus makes it fertile so that other plants soon find in its vicinity nourishment for growth.

Method-Plants of the sweet clover with their roots may be brought to the schoolroom for study. The children should observe sweet clover in the field; its method of inflorescence, and the insects which visit it, should be noted.

Observations-I. What first makes you aware that you are near sweet clover? On what kinds of soil, and in what localities, does sweet clover abound?

2. Do you know how sweet clover growing in poor soils and waste places acts as a pioneer for other plants? soil?

3. Dig up a sweet clover plant, and see how far its stems go into the

4. How high does the plant grow? What is the color of its foliage?

5. Compare one of the leaves with the leaf of a red clover, and describe the likeness and the difference. Note especially the edges of the upper and the lower leaves, and also the stipules.

6. Describe the way the sweet clover blossoms. Do the lower or upper flowers open first? How does the flower stem look before it begins to blossom? What happens to it after the blossoming begins? How long will it continue to blossom?

7. Take a blossom and compare it with that of a sweet pea. Can you see the banner? The wings? The keel? Can you see if the stamens are united into two sets? Can you see the pistil? Note the shape of the calyx.

8. How many flowers are in blossom at a time? Does it make a mass of white to attract insects? In what other way does it attract insects? What insects do you find visiting it?

9. How do the ripened pods look?

"The blooming wilds His gardens are; some cheering Earth's ugliest waste has felt that flowers bequeath,

And all the winds o'er summer hills careering Sound softer for the sweetness that they breathe."

-Theron Brown. 


\section{THE WHITE CLOVER}

\section{Teacher's Story}

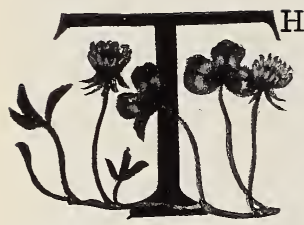

HE sweet clover should be studied first, for after making this study it is easier to understand the blossoming of the white and the red clover. In the sweet clovers, the flowers are strung along the stalk but in the red, the white, and many others, it is as if the blossom stalk were telescoped, so that the flowers are all in one bunch, the tip of the stalk making the center of the clover head. We use the white clover in our lawns because of a peculiarity of its stem, which, instead of standing erect, lies flat on the ground, sending leaves and blossoms upward and thus making a thick carpet over the ground. The leaves are very pretty; and although they grow upon the stems alternately, they always manage to twist around so as to lift their three leaflets upward to the light. The three leaflets are nearly equal in size, with fine, even veins and toothed edges; and each has upon it, near the middle a pale, angular spot. The white clover, in common with other clovers, has the pretty habit of going to sleep at night. Botanists may object to this human term, but the great Linnæus first called it sleep, and we may be permitted to follow his example. Certainly the way the clover leaves fold at the middle, the three drawing near each other, looks like going to sleep, and is one of the things which even the little child will enjoy observing.

The clover head is made up of many little flowers; each one has a tubular calyx with five delicate points and a little stem to hold it up into the world. In shape, the corolla is much like that of the sweet pea, and each secretes nectar at its base. The outside blossoms open first; and as soon as open, the honey bees, which eagerly visit white clover wherever it is growing, begin at once their work of gathering nectar and carrying pollen; as soon as the florets are pollenated they wither and droop below the flower-head.

"Where I made One, turn down an empty Glass."

Sings old Omar, and I always think of it when I see the turned-down florets of the white-clover blossom. But in this case the glass is not empty, but holds the maturing seed. This habit of the white clover flowers saves the bees much time, since only those which need pollenating are lifted upward to receive their visits. The length of time the little clover head requires for the maturing of its blossoms depends much upon the weather and upon the insect visitors.

White clover honey is in the opinion of many the most delicious honey made from any flowers except, perhaps, from orange blossoms. So valuable is the white clover as a honey plant, that apiarists often grow acres of it for their bees.

\section{LESSON CLXVIII}

The White Clover

Leading thought-The white clover has creeping stems. Its flowers depend upon the bees for their pollination. and the bees depend upon the white clover blossoms for honey. 
Method-The plant may be brought into the schoolroom while in blossom, and its form be studied there. Observations as to the fertilization of the flowers should be made out-of-doors.

Observations-r. Where does the white clover grow? Why is it so valuable in lawns?

2. Note carefully the clover leaf, the shape of the three leaflets, stems, and edges. Is part of the leaflet lighter colored than the rest? If so, describe the shape. Are the leaflets unequal or equal in size? Does each leaf come directly from the root? Are they alternately arranged? Why do they seem to come from the upper side of the stem?

3. Note the behavior of the clover leaves at night. How do the two side leaflets act? The central leaflet? Do you think that this is because the plant is sleepy?

4. Take a white clover head, and note that it is made up of many little flowers. How many? Study one of the little flowers with a lens. Can you see its calyx? Its petals? Its stem? In what way is it similar to the blossom of the sweet pea?

5. Take a head of white clover which has not yet blossomed. Tie a string about its stem so that you may be sure you are observing the same flower and make the following observations during several days: Which blossoms begin to open first-those outside or inside? How many buds open each day? What happens to the blossoms as they fade? Of what use is this to the plant? How many days pass from the time the flowers begin to blossom until the last flower at the center opens?

6. What insects do you see working on the white clover blossoms? How does the bee act when collecting nectar? Can you see where she thrusts her tongue? What does the bee do for the clover blossom? What sort of honey does the white clover give to the bee?

7. Tie little bags of cheesecloth over two or three heads of white clover and see if they produce any seed.

"Little flower; but if I could understand What you are, root and all, and all in all, I should know what God and man is."

-Tennyson.

"To me the meanest flower that blows, can give

Thoughts that do often lie too deep for tears."

-WORDSWORTH.

"I know a place where the sun is like gold, And the cherry blooms burst with snow, And down underneath is the loveliest nook Where the four leaf clovers grow."

-Ella Higginson. 


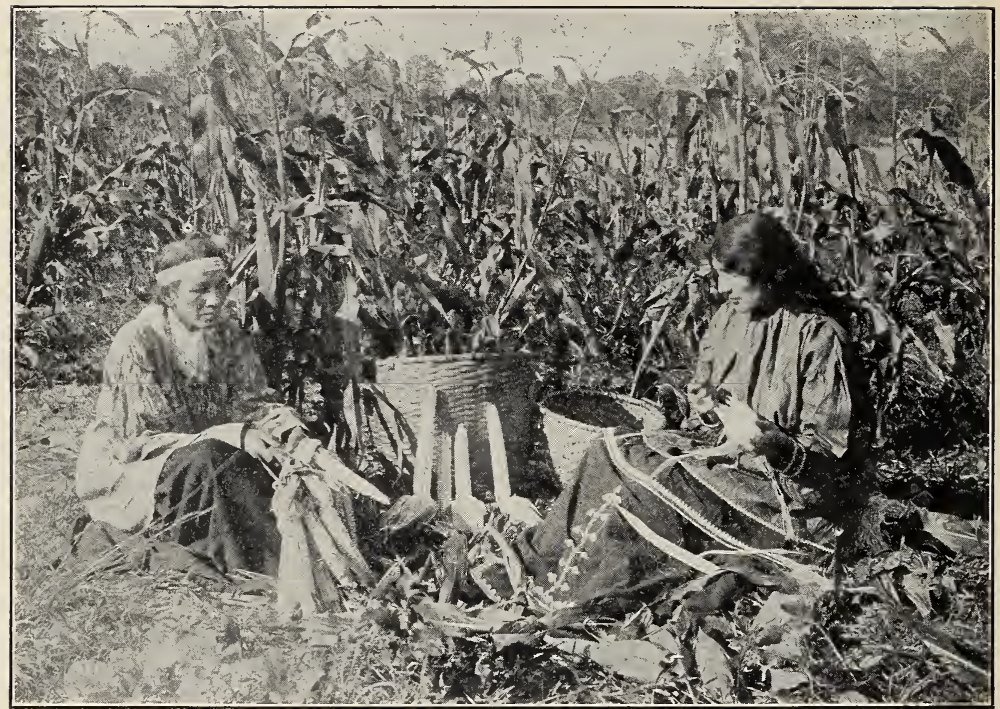

Seneca Indian women husking corn for braiding.

Photo by Arthur C. Parker. From Bulletin I44 of New York State Museum, "Iroquois uses of Maize and other Food Plants" by Arthur C. Parker.

THE MAIZE, OR INDIAN CORN

\section{Teacher's Story}

"Hail! Ha-wen-ni-yu! Listen with open ears to the words of thy people. Continue to listen. We thank our mother earth which sustains us. We thank the winds which have banished disease. We thank He-no for rain. We thank the moon and stars which give us light when the sun has gone to rest. We thank the sun for warmth and light by day. Keep us from evil ways that the sun may never hide his face from us for shame and leave us in darkness. We thank thee that thou hast made our corn to grow. Thou art our creator and our good ruler, thou canst do no evil. Everything thou doest is for our happiness."

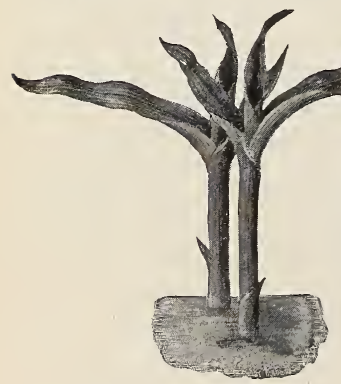

HUS prayed the Iroquois Indians when the corn had ripened on the hills and valleys of New York State long before it was a state, and even before Columbus had turned his ambitious prows westward in quest of the Indies. Had he found the Indies with their wealth of fabrics and spices, he would have found there nothing so valuable to the world as has proved this golden treasure of ripened corn.

The origin of Indian corn, or maize, is shrouded in mystery. There is a plant which grows on the table-lands of Mexico, which is possibly the original species; but so long had maize been cultivated by the American Indians that it was thoroughly domesticated when America was first 
discovered. In those early days of American colonization, it is doubtful, says Professor John Fiske, if our forefathers could have remained here had it not been for Indian corn. No plowing, nor even clearing, was necessary for the successful raising of this grain. The trees were girdled, thus killing their tops to let in the sunlight; the rich earth was scratched a little with a primitive tool, and the seed put in and covered; and the plants that grew therefrom took care of themselves. It the pioneers had been obliged to depend alone upon the wheat and rye of Europe, which only grows under good tilllage, they might have starved before they gained a foothold on our forest-covered shores.

\section{The Corn Plant}

In studying the maize it is well to keep in mind that a heavy wind is its worst enemy; such a wind will lay it low, and from such an injury it is difficult for the corn to recover and perfect its seed. Thus, the mechanism of the corn-stalk and leat is adapted for prevention of this disaster. The corn-stalk is, practically, a strong cylinder with a pithy center; the fibres of the stalks are very strong, and at short intervals the stalk is strengthened by hard nodes, or joints, it the whole stalk were as hard as the nodes, it would be inelastic and break instead of bend; as it is, the stalk is very elastic and will bend far over before it breaks. The nodes are nearer each other at the bottom, thus giving strength to the base; they are farther apart at the top, where the wind strikes, and where the bending and bowing of the stalk is necessary.

The leaf comes off at a node and clasps the stalk for a considerable distance, thus making it stronger, especially toward the base. Just where the leaf starts away from the stem there is a little growth called a rain-guard; if water should seep between the stalk and the clasping leaf, it would afford harbor for destructive fungi. The structure of the corn leaf is especially adapted to escape injury from the wind; the strong veins are parallel with a strong but flexible midrsb at the center; often, after the wind has whipped the leaves severely, only

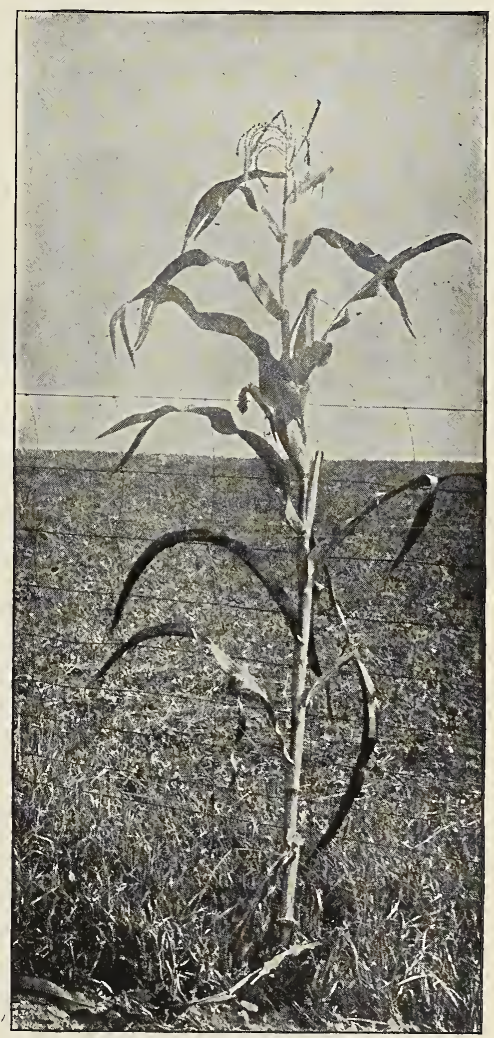

Stalk of corn with ear and tassel. 
the tips are split and injured. The edges of the corn leaf are ruffled and, where the leaf leaves the stalk, there is a wide fold in the edge at either side; this arrangement gives play for a sidewise movement without breaking the leaf margins. The leaf is thus protected from the wind, whether it is struck from above or horizontally. The true roots of the corn plant go quite deep into the soil, but are hardly adequate to the holding of such a tall,

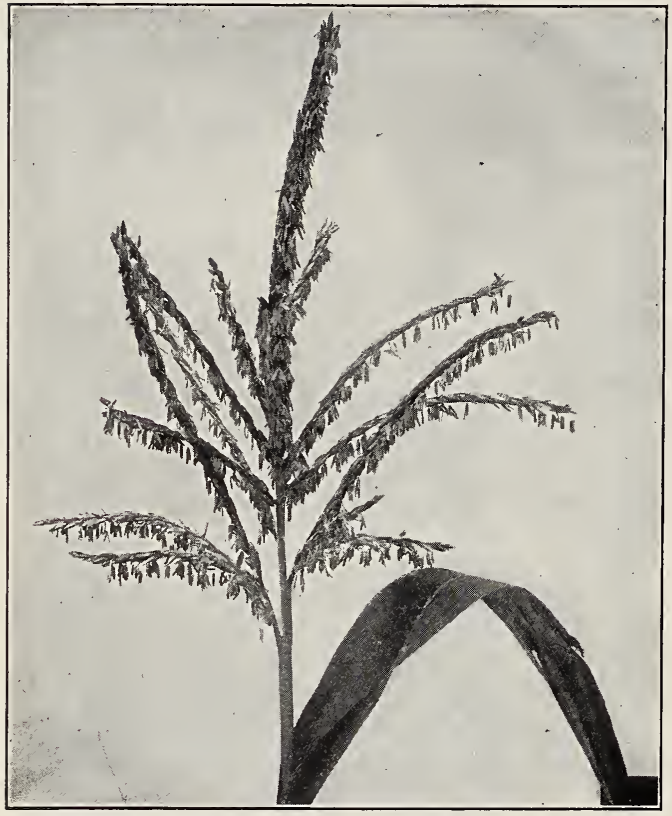

The pollen-bearing flowers of corn. slender stalk upright in a wind storm; therefore, all about the base of the plant are brace-roots, which serve to hold the stalk erect-like the stayropes about a flagpole.

\section{The EAR of Corn}

The ears of corn are borne at the joints or nodes; and the stalk, where the ear presses against it, is hollowed out so as to hold it snugly; this is very suggestive of a mother holding a baby in her arms. In the following ways, the husks show plainly that they are modified leaves: The husk has the same structure as the leaf, having parallel veins; it comes off the stem like a leaf; it is often green, and therefore does the work of a leaf; it changes to leaf shape at the tip of the ear, thus showing that the husk is really that part of the leaf which usually clasps the stem. If a husk tipped with a leaf is examined, the rain-guard will be found at the place where the two join. As a matter of fact, the ear of corn is on a branch stalk which has been very much shortened, so that the nodes are very close together, and therefore the leaves come off close together. By stripping the husks back one by one, the change from the outside, stiff, green leaf structure to the inner delicate, papery wrapping for the seed, may be seen in all its stages. This is a beautiful lesson in showing how the maize protects its seed, and the husk may well be compared to the clothing of a baby. The pistillate flowers of the corn, which finally develop into the kernels, grow in pairs alongthe sides of the end portion of the shortened stalk, which is what we call the "cob." Therefore, the ear will show an even number of rows, and 
the cob shows distinctly that the rows are paired. The corn-silk is the style of the pistillate flowers; and therefore, in order to secure pollen, it must extend from the ovule, which later develops into a kernel, to the tip of the ear, where it protrudes from the end of the husk. A computation of the number of kernels in a row and on the ear makes a very good arithmetic lesson for the primary pupils, especially as the kernels occur in pairs.

\section{The Growth of the Corn}
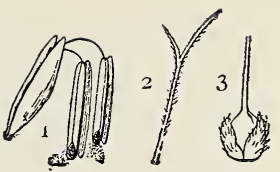

$I$, The anthers of corn; 2 , The tip of the corn-silk showing the stigma; 3 , The pistillate flower, which will develop into the kernel.

If we cut a kernel of corn crosswise we can see, near the point where it joins the cob, the little plant and the root. Corn should be germinated between wet blotters, in a seed-testing experiment, before observations are made on the growing corn of the fieids. When the corn first appears, the corn leaves are in a pointed roll which pierces the soil. Soon they spread apart, but it may be some time before the corn-stalk proper appears. Then it stretches up rapidly, and very soon will be tipped with beautiful pale brown tassels. These tassels merit careful study for they are the staminate flowers. Each floret has two anthers hanging down from it, and each half of each anther is a little bag of pollen-grains; and in order that they shall be shaken down upon the waiting corn-silk below, the bottom of each bag opens wide when the pollen is ripe. The corn-silk, at this stage, is branched at the tip and clothed with fine hairs, so that it may catch a grain of the precious pollen. Then occurs one of the most wonderful pollen stories in all nature, for the pollen-tube must push down through the center of the corn-silk for its whole length, in order to reach the waiting ovule and thus enable it to become a kernel of corn. These

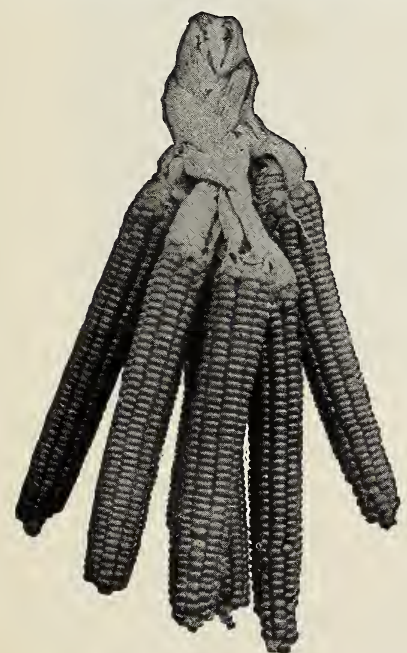

Corn ears with braided husks as the Indians used to carry them. young, unfertilized kernels are pretty objects, looking like seed-pearls, each wrapped in furry bracts. If the silk from one of these young flowers does not receive its grain of pollen, then the kernel will not develop and the ear will be im. perfect. On the other hand if the pollen from another variety of corn falls upon the waiting stigmas of the silk, we shall find the ear will have upon it a mixture of the two varieties. This is best exemplified when we have the black and white varieties of sweet corn growing near each other.

One reason why corn is such a valuable plant to us is that its growth is so rapid. It is usually not planted until late spring, yet, with some varieties, by September the stalks are twenty feet high. The secret of this is that the corn, unlike many other plants, has many points of growth. Whils young, the lower part of the stalk lying between every two nodes is a growing center 
and the tip of the stalk also grows; in most plants, the tip of the stems is the only center of growth. The first two experiments suggested will demonstrate this. When blown down by the wind, the corn has a wonderful way of lifting itself, by inserting growing wedges in the lower sides of the nodes. A corn-stalk blown down by the wind will often show this wedge-shape at every joint, and the result will be an upward curve of the whole stalk. Of course, this cannot be seen unless the stalk is cut lengthwise through the center. Experiment 3 is suggested to demonstrate this.

During drought the corn leaves check the transpiration of water by rolling together lengthwise in tubes, thus offering less surface to the sun and air. The farmer calls this the curling of the corn, and it is always a sign of lack of moisture. If a corn plant with leaves thus curled, be given pienty of water, the leaves will soon straighten out again into their normal shape.

References: Corn Plants, Sargent; Cornell Nature-Study Leaflets, Vol. I; Elements of Agriculture, Warren; The First Book of Farming, Goodrich; Agriculture, Jackson and Dougherty; Rural School Agriculture, Hays; Columbia's Emblem, Houghton, Mifflin and Co.

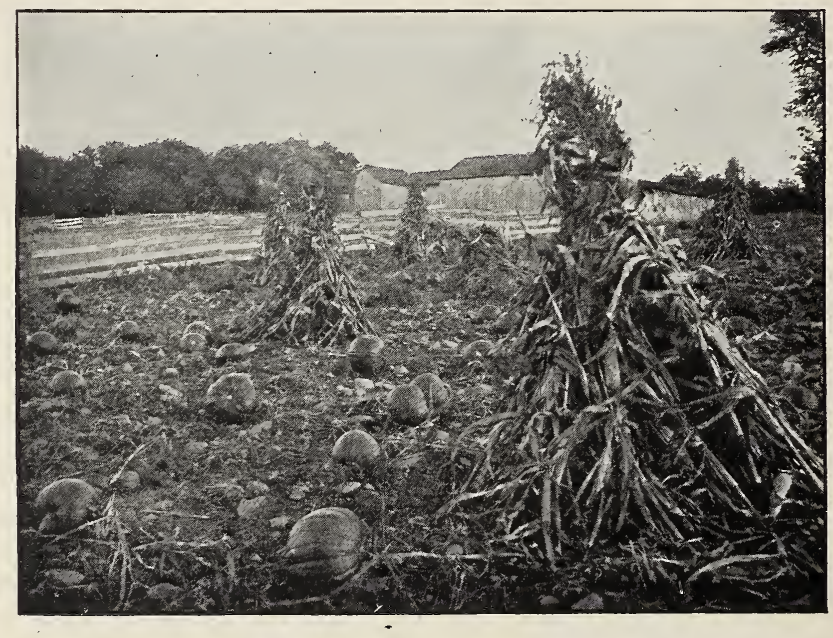

Corn in the shock.

\section{LESSON CLXIX}

\section{The Maize}

Leading thought-The Indian corn, or maize, is a plant of much beauty and dignity. It has wonderful adaptations for the development of its seed and for resisting its arch-enemy, the wind.

Method-The study may begin in spring when the corn is planted, giving the pupils the outline for observations to be filled out in their note: 
books during the summer, when they have opportunities for observing the plant; or. it may be studied in the autumn as a matured plant. It may be studied in the school room or in the field, or both.

Observations on the corn plant-r. Describe the central stem. How many joints, or nodes, has it? Of what use to the plant are these nodes? Are the joints nearer each other at the bottom or the top of the plant?

2. Where do the leaves come off the stem? Describe the relation of the bases of the leaves to the stem. Of what use is this to the plant?

3. Note the little growth on the leaf where it leaves the stalk. Describe how this prevents the rain from seeping down between the stalk and the clasping leaf. What danger would there be to the plant if the water could get into this narrow space?

4. What is the shape of the leaf? Describe the veins. Does the leaf tear easily across? Does it tear easily lengthwise? Of what use to the leaf is this condition?

5. Are the edges of the corn leaf straight or ruffled? How does this ruffled edge permit the leaf to turn without breaking? Describe at length the benefit the corn plant derives from having leaves which cannot be broken across and that can bend readily sidewise as well as up and down.

6. Describe the roots of the corn plant. Describe the brace-roots. Explain their use.

7. Describe all the ways in which the corn plant is strengthened against its enemy, the wind.

Observation on the ear of corn-8. Where on the corn plant are the ears borne? Are two ears borne on the same side of the stalk? Remove an ear, and see how the stalk is changed to give it room.

9. Where do the ears come off the stalk in relation to the leaves?

Io. Examine the outside husks, and compare them with the green leaves. What is there to suggest that the corn-husk is a leaf changed to protect the seed? Do you think that the husk represents that portion of the leaf which clasps the stalk? Why? Describe how the inner husk differs from the outer in color and texture. Describe how this is a special protection to the growing kernels.

I I. After carefully removing the husk, examine the silk and see if there is a thread for every kernel. Is there an equal amount of silk lying between every two rows? Do you know what part of the corn flower is the cornsilk? What part is the kernel?

I 2. How many rows of kernels are there on an ear? How many kernels in a row? How many on the whole ear? 'Do any of the rows disappear toward the tip of the ear? If so, do they disappear in pairs? Do you know why? Are the kernels on the tip of the ear and near the base as perfect as those along the middle? Do you know whether they will germinate as quickly and vigorously as the middle ones?

I3. Study a cob with nocorn on it and note if the rows of kernelsockets are in distinct pairs. This will, perhaps show best if you break the cob across.

I4. Break an ear of corn in two, and sketch the broken end showing the relation of the cob to the kernels.

r5. Are there any places on the ear you are studying. where the kernels did not grow or are blasted? What happened to cause this?

I6. Describe the requisites for a perfect ear of seed-corn. Why should the plant from which the seed-ear is taken be vigorous and perfect?, 
Observations on the growth of corn-Work for the Summer Vacation-

I 7. How does the corn look when it first comes up? How many leaves are there in the pointed roll which first appears above the ground? How long before the central stalk appears?

I8. When do the tassels first appear? What kind of flowers are the corn tassels? Describe the anthers. How many on each flower? Where do the anthers open to discharge their pollen?

I9. How large are the ears when the pollen is being shed? Study an ear of corn at this period. Note that the kernel is the ovule, the silk is attached to it and is the long style extending out beyond the husks. Note that the tip, or stigma is branched.

20. What carries the pollen for the corn plant? If you have rows of popcorn and sweet corn or of sweet corn and field corn next to each other why is it that the ears will show a mixture of both kinds?

\section{EXPERIMENT I}

Compare the growth of the corn plant with that of the pigweed. When the corn-stalk first appears above ground, tie two strings upon it, one just above a joint and one below it. Tie two strings the same distance apart on the stem of a pigweed. Measure carefully the distance between these two strings on the two plants. Two weeks later measure the distance between the strings again. What is the result?

\section{EXPERIMENT 2}

Measure the distance between two of the nodes or joints near the tip of a certain corn-stalk. Two weeks later measure this distance again and compare the two.

\section{EXPERIMENT 3}

When a stalk of corn is still green in August, bend it down and place a stick across it at about half its length. Describe how it tries to lift itself to an erect attitude after two or three weeks. Cut lengthwise across one of the nodes, beyond the point held down by the stick, and see the wedgeshaped growth within the joint which helps to raise the stalk to an upright position.

\section{EXPERIMENT 4}

During the August drought, note that the corn leaves are rolled. Give a corn plant with rolled leaves plenty of water and note what happens. Why?

\section{THE COTTON PLANT \\ Teacher's Story}

There are some plants which have made great chapters in the histories of nations, and cotton is one of them. The fibre of cotton was used for making clothing so long ago, that its discovery is shrouder in the myths of prehistoric times. But we helieve it first came into use in India, for in this land we find certain laws concerning cotton which were codified 800 B. C.; and allusions to the fine, white raiment of the peoples of India are frequent in ancient history. Cotton was introduced into Egypt from India at an early date: it was in common use there I 50 B. C. But not 
until our Civil War laid fallow the cotton fields of the United States, did Egypt realize the value of its crop; and although much money was lost there in agricultural speculation after our own product was again put on the market, yet cotton has remained since that time one of Egypt's most valuable exports.

When Columbus discovered America he found cotton growing in the West Indies, and the chief articles of clothing of the native Mexicans were made of cotton. Cloths of cotton were also found in ancient tombs of

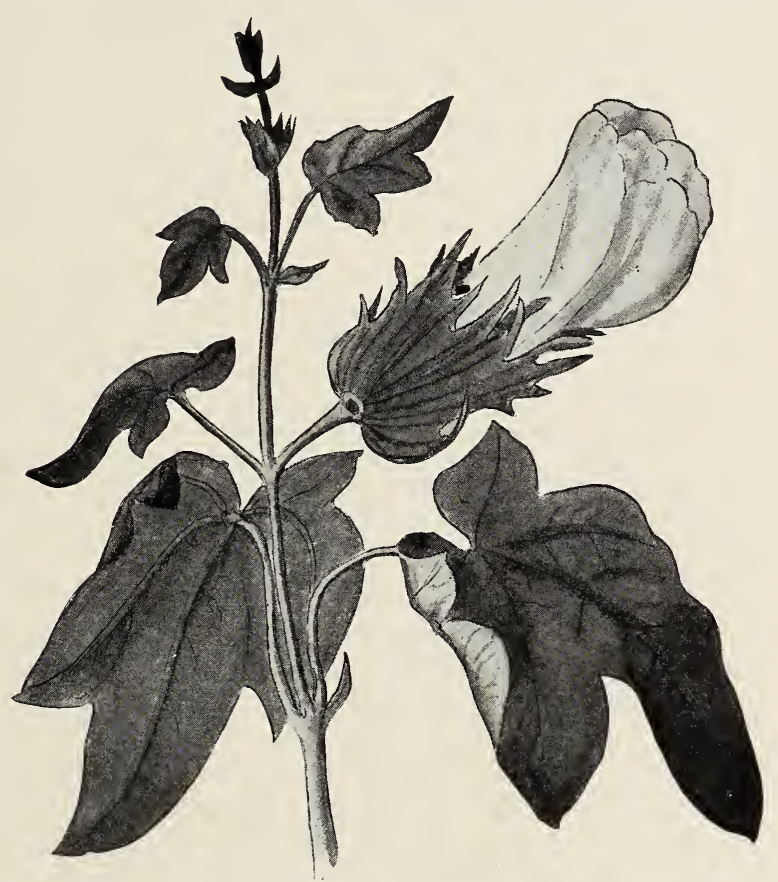

The cotton in blossom.

Peru, proving it was used there long before the white man set his foot upon those shores. When Magellan made his famous voyage around the world in I 500 , he found the cotton fibre in use in Brazil.

It is a strange fact that the only region of the world between the parallels of $40^{\circ}$ north and $40^{\circ}$ south latitude, where cotton did not grow as a native or cultivated plant when America was discovered, was the region or our Gulf States, which now produces more cotton than any other. The first mention of cotton as a crop in the American colonies is in the report published in I666. At the time of the Revolutionary War the cotton industry was thoroughly established. It is one of the significant facts of history that the invention of the cotton gin by Eli Whitney in I 793, which revolutionized the cotton industry and brought it to a much 
more profitable basis, wrought great evil to the United States, since it revived the profits of slave-holding. The institution of slavery was sinking out of sight by its own weight; Washington showed that it was the most expensive way to work land, and Jefferson failed to liberate his own slaves simply because he believed that liberty would come to all slaves inevitably, since slave-holding was such an expense to the plantation owners. But the cotton gin, which removed the seeds rapidly-theretofore done by slow and laborious hand process-suddenly made the raising of cotton so profitable that slaves were again employed in its production with great financial benefits. And thus it came about that the cotton plant innocently wielded a great influence in the political, as well as the industrial life of our country.

The cotton plant has a taproot, with branches which go deep into the soil. The stem is nearly cylindrical, the branches often spreading and sometimes irregular; the bark is dark and reddish; the wood is white. In Egypt, and probably in other arid countries, the stalks are gathered for fuel in winter.

The leaves are alternate, with long petioles. The upper leaves are deeply cut, some having five, some seven, some three, and some even nine lobes; strong veins extend from the petiole along the center of each lobe; the leaves near the ground may not be lobed at all. Where the petiole joins the stem, there is a pair of long, slender, pointed stipules, but they often fall off early. A strange characteristic of the cotton leaves is tha they bear nectar-glands; these may be seen on the under side and along the main ribs of the leaf; they appear as little pits in the rib; some leaves may have none, while others may have from one to five. It has been thought that perhaps these glands might aitract bees, wasps or ants, which would attack the caterpillars eating the leaves, but this has not jeen proved. However, many friendly insects get their nectar at these leaf-wells, and here is an opportunity for some young naturalist of the South to investigate this matter and discover what insects come to these glands at all times of day and what they do.

The flower bud is partially hidden beneath the clasping bracts of the involucre. These bracts are three or four in number, and they have the edges so deeply lobed that they seem branched. By pushing back the bracts we can find the calyx, which is a shallow cup with five shallow notches in its rim. The petals are rolled in the bud like a shut umbrella. The open flower has five broadly spreading petals; when the bud first opens in the morning, the petals are whitish or pale yellow with a purplish spot at the base, by noon they are pale pink, by the next day they are a deep purplish red and they fall at the end of the second day. There are nectar-glands also in the flower at the base of the calyx, and the insects are obliged to thrust their tongues between the bases of the petals to reach the nectar; only long-tongued bees, moths and butterflies are able to attain it.

There are many stamens which have their filaments united in a tube extending up into the middle of the flower and enlarging a little at the tip; below the enlarged base of this tube is the ovary which later develops into the cotton-boll; within the stamen-tube extends the long style, and from its tip are thrust out from three to five stigmas like little pennants from the top of a chimney; and sometimes they are more or less twisted together. The young boll is covered and protected by the fringed bracts: 
which cover the bud and remain attached to the ripened boli. The calyx, looking like a little saucer, also remains at the base of the boll. The boll soon assumes an elongated, oval shape, with long, pointed tip; it is green outside and covered with little pits, as large as pin points. There are, extending back from the pointed tip, three to five creases or sutures, which show where the bcll will open. If we open a nearly ripened boll, we find that half way between each two sutures where the boll will open, there is a partition extending into the boll dividing it into compartments. These are really carpels, as in the core of an apple, and their leaf origin may be plainly seen in the venation. The seeds are fastened by their pointed ends along each side of the central edge of the partition, from which they break away very easily. The number of seeds varies, usually two or three along each side; the young seeds are wrapped in the young cotton, which is a stringy, soft white mass. The cotton fibres are attacher to the covering of the seed around the blunt end, and

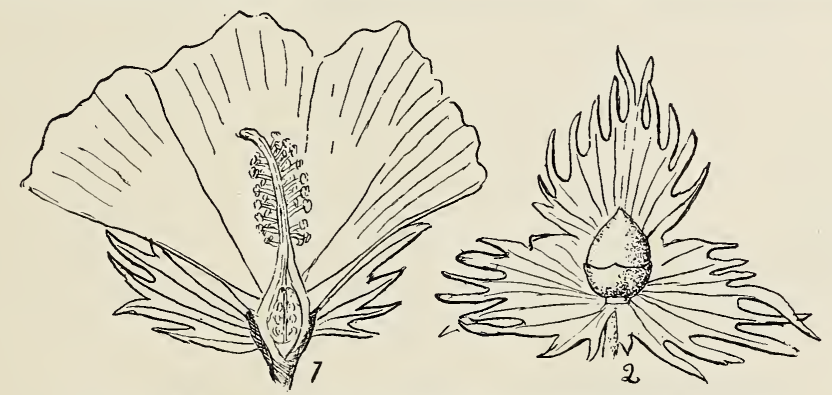

I, The cotton flower cut in half, showing the stamen-tube at the center, up through which extends the style of the pistil. Note the bracts and calyx.

2, A young boll, with calyx at its base and set in the involucral bracts.

usually the pointed end is bare. When the boll opens, the cotton becomes very fluffy and if not picked will blow away; for this cotton fibre is a device of the wild cotton for disseminating its seeds by sending them off on the wings of the wind. Heavy winds at the cotton-picking time, are a menace to the crop and often occasion serious loss.

The mechanism of the opening of the cotton-boll is very interesting; along the central edge of each partition and extending up like beaks into the point of the boll, is a stiff ridge, about the basal portion of which the seeds are attached; as the boll becomes dry, this ridged margin becomes as stiff as wire and warps outward; at the same time, the outside of the boll is shriveling. This action tears the boll apart along the sutures and exposes the seeds with their fluffy balloons to the action of the wind. The ripe, open, empty boll is worth looking at; the sections are wide apart and each white, delicate, parchment-like partition, or carpel, has its wire edge curved back gracefully. The outside of the boll is brown and shriveled, but inside it is still white and shows that it had a soft lining for its "seed babies."

The amount of the cotton crop per acre varies with the soil and climate; the amount that can be picked per day also depends upon the 
cotton as well as the picker. Children have been known to pick ono hundred pounds per day, and a first-class picker from five hundred to six hundred pounds, or even eight hundred; one man has made a record of picking sixty pounds in an hour. Cotton is one of the most important crops grown in America, and there are listed more than one hundred and thirty varieties which have originated in our country.

References-The various bulletins of the United States Department of Agriculture and of the experiment stations of the Southern States. The most complete of these is Bulletin No.33, Office of Experiment Stations, U. S. Dept. of Agriculture, published in I 896 .

\section{LESSON CLXX}

\section{Cotton}

Leading thought-Cotton has had a great influence upon our country

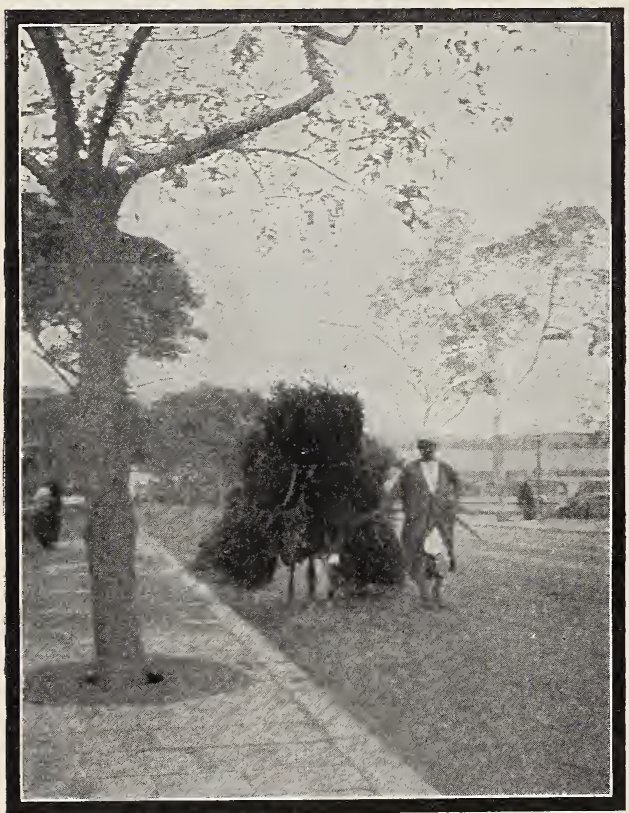

A donkey laden with cotton stalks in Cairo, Egypt, the bundles to be sold for fuel.

Photo by J. H. Comstock. politically as well as industrially. Its fibre was used by the ancients, and it is to-day one of the most important crops in the regions where it is grown.

Method-A cotton plant with blossoms and ripe bolls upon it may be brought into the schoolroom or studied in the field.

Observations-I. How many varieties of cotton do you know? Which kind is it you are study. ing?

2. What sort of root has the cotton plant? Does it go deep into the soil?

3. How high does the plant grow? Are the stems tough or brittle? What is the color of the bark? Of the wood? Do you know of a country where cotton stalks are used forfuel? Do the stem and branches grow erect or very spreading?

4. Are the leaves opposite or alternate? Are the petioles as long as the leaves? Are there any stipules where the petioles join the main stem? How many forms of leaves can you find on the same stem? How do the upper differ from the lower leaves? Describe or sketch one of the large upper leaves, paying especial attention to the veins and the shape of the lobes. 
5. Look at the lower side of a leaf and find, if you can, a little pit on the midrib near its base. How many of these pits can you find on the veins of one leaf? What is the fluid in these pits? Taste it and see if it is sweet. Watch carefully a growing plant and describe what insects you find feeding on this nectar. Note if the wasps and ants, feeding on this nectar, attack the caterpillars of the cotton worm which destroy the leaf. Where are the nectar-glands of plants usually situated?

6. Study the flower bud; what covers it? How many of these bracts cover the flower bud? What is their shape and how do their edges look? Push back the bracts and find and describe the calyx. How are the petals folded in the bud?

7. Take the open flower; how many petals are there, and what is their shape? At what time of day do the flowers open? What color are the petals when the flowers first open? What is their color later in the day? What is their color the next day? When do the petals fall?

8. Describe the stamens; how are they joined? How are the anthers situated on the stamen-tube? Is the stamen-tube perfectly straight or does it bend at the tip?

9. Peel off carefully the stamen-tube and describe what you find within it. How many stigmas come out of the tip of the tube? Find the ovary below the stamen-tube. Which part of the flower grows into the cotton-boll?

ro. Take a boll nearly ripe; what covers it? Push away the bracts; can you find the calyx still present? What is the shape of the boll? What is its color and texture? Can you see the creases where it will open? How many are there of these?

I I. Open a nearly ripe boll very carefully. How many partitions are there in it? Where are they in relation to the openings? Gently push back the cotton from the seeds without loosening them, and describe how the seeds are connected with the partitions. Is the seed attached by its pointed or blunt end?

I 2. How many seeds in each chamber in the cotton boll? Where on the seed does the-cotton grow? How does the cotton blanket wrap about the seed? If the cotton is not picked what happens to it? Of what use to the wild cotton plant are seeds covered with cotton?

r. What makes the cotton-boll open? Describe an open and empty boll outside and inside.

I4. How much cotton is considered a good crop per acre in your vicinity? How much cotton can a good picker gather in a day?

I 5. Write English themes on the following topics: "The history of the cotton plant from ancient times until to-day," "How the cotton plant has affected American history."

\footnotetext{
"Queen-consort of the kingly maize, The fair white cotton shares his throne, And o'er the Southland's realm she claims A just allegiance, all her own."
} 


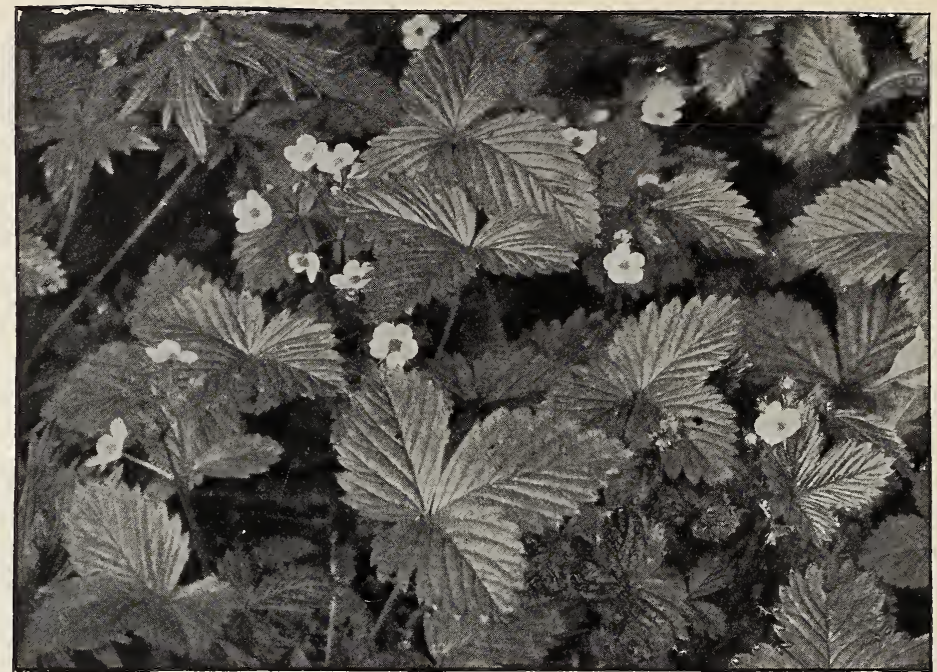

Photo by Verne Morton

\section{THE STRAWBERRY \\ Teacher's Story}

Of all the blossoms that clothe our open fields, one of the prettiest is that of the wild strawberry. And yet so influenced is man by his stomach that he seldom heeds this flower except as a promise of a crop of strawberries. It is comforting to know that the flowers of the field "do not care a rap" whether man notices them or not; insect attentions are what they covet, and they are surely as indifferent to our indifference as it is to them.

The field strawberry's five petals are little cups of white held up protectingly around a central treasure of anthers and pistils; each petal has its base narrowed into a little stem, which the botanists call a claw. When the blossom first opens, the anthers are little, flat, vividly lemonyellow discs, each disc consisting of two clamped together sternly and determinedly as if they meant never to open and yield their gold dust. At the very center of the flower is a little, greenish yellow cone, which if we examine with a lens, we can see is made up of many pistils set together, each lifting up a little, circular, eager stigma high as ever it can reach. Whether all the stigmas receive pollen or not determines the formation of a good strawberry.

The sepals are slender and pointed and seem to be ten in number, every other one being smaller and shorter than its neighbors; but the five shorter ones are not sepals but are bracts below the calyx. The sepals unite at their bases so that the strawberry has really a lobed calyx instead of sepatate sepals. The blossom stem is soft, pinkish and silky and wilts easily. There are several blossoms borne upon one stem and the central one opens first. 
The strawberry leaf is beautiful; each of its three leaflets is oval, deeply toothed, and has strong regular veins extending from the midrib to the tip of each tooth. In color it is rich, dark green and turns to wine-color in autumn. It has a very pretty way of coming out of its hairy bud scales, each leaflet folded lengthwise and the three pressed together. Its whole appearance then, is infantile in the extreme, it is so soft and helpless looking. But it soon opens out on its pink, downy stem and shows the world how beautiful a leaf can be.

If a comparison of the wild and cultivated strawberries is practicable, it
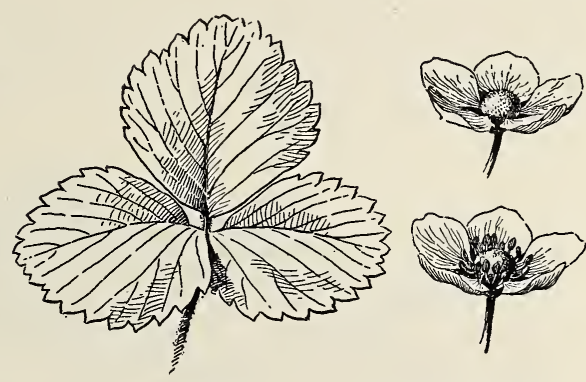

Strawberry leaf.

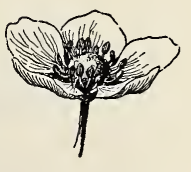

Pistillate flower above. Perfect flower below. makes this lesson more interesting. Much tillage an $\mathrm{d}$ food have caused the cultivated blossoms to double, and they may often have seven or eight petals. And while the wild flowers are usually perfect, many cultivated varieties have the pollen and pistils borne in different flowers, and they depend upon the bees to carry their pollen. The blossom stem of the garden strawberry is round, smooth and quite strong, holding its branching panicle of flowers erect, and it is usually shorter than the leaf stems among which it nestles. The flowers open in a series, so that ripe and green fruit, flowers and buds may often be found on the same stem. As the strawberry ripens, the petals and stamens wither and fall away; the green calyx remains as the hull, which holds in its cup the pyramid of pistils which swell and ripen into the juicy fruit. To the botanists the strawberry is not a berry, that definition being limited to fruits having a juicy pulp and containing many seeds, like the currant or grape. The strawberry is a fleshy fruit bearing its seed in shallow pits on its surface. These seeds are so small that we do not notice them when eating the fruit, but each one is a tiny nut, almondshaped, and containing within its tough, little shell a starchy meat to sustain the future plant which may grow from it. It is by planting these seeds that growers obtain new varieties.

The root of the strawberry is fibrous and threadlike. When growers desire plants for setting new strawberry beds they are careful to take only such as have light colored and fresh-looking roots. On old plants the roots are rather black and woody and are not so vigorous.

The stem of the strawberry is partially underground and so short as to be unnoticeable. However, the leaves grow upon it alternately one above another, so that the crown rises as it grows. The base of each leaf has a broad, clasping sheath which partly encircles the plant and extends upward in a pair of earlike stipules.

The runners begin to grow after the fruiting season has closed; they originate from the upper part of the crown; they are strong, fibrous and hairy when young. Some are short between joints, others seem to reach far out as if seeking for the best location before striking root; a young 
plant will often have several leaves before putting forth roots. Each runner may start one or more new strawberry plants. After the young plant has root growth so as to beable to feed itself, the runner ceases to carry sap from the main stem and withers to a mere dry fiber. The parent plant continues to live and bear fruit, for the strawberry is a per. ennial, but the later crops are of less value. Gardeners usually renew their plots each year, but if intending to harvest a second year's crop: they cut off the runners as they form.

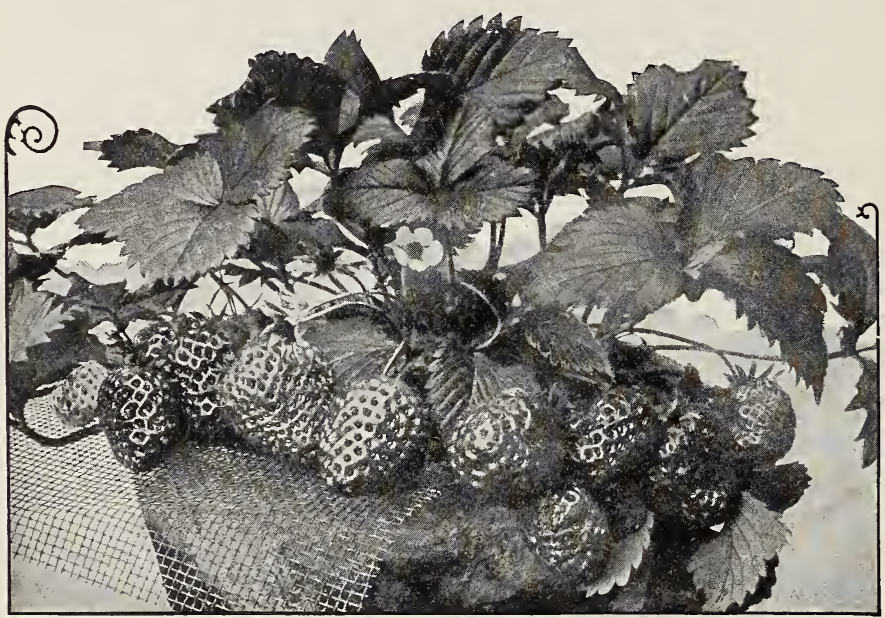

Strawberry fruit.

\section{LESSON CLXXI}

\section{The Strawberry}

Leading thought-The strawberry plant has two methods of perpetuating itself, one by the seeds which are grown on the outside of the strawberry fruits, and one by means of runners which start new plants wherever they find place to take root.

Method - It would be well to have a strawberry plant, with roots and runners attached, for an observation lesson by the class. Each pupil should have a leaf, including the clasping stipules and sheath at its base. Each one should also have a strawberry blossom and bud, and if possible a green or ripe fruit. color?

Observations-I. What kind of root has the strawberry? Whai is its

2. How are the leaves of the strawberry plant arranged? Describe the base of the leaf and the way it is attached to the stem. Has each leaflet a pedicel or stem of its own? How many leaflets are there? Sketch a strawberry leaf, showing the edges and form of the leaflets, and the veins. 
3. From what part of the plant do the runners spring? When do the runners begin to grow? Does the runner strike root before forming a new plant or does the little plant grow on the runner and draw sustenance from the parent plant?

4. What happens to the runners after the new plants have become established? Does the parent plant survive or die after it sends out many runners?

5. Describe the strawberry blossom. How many parts are there to the hull or calyx? Can you see that five of these are set below the other five?

6. How many petals has it? Does the number differ in different flowers? Has the wild strawberry as many petals as the cultivated ones?

7. Study with a lens the small green button at the center of the flower. This is made up of pistils so closely set that only their stigmas may be seen. Do you find this button of pistils in the same blossom with the stamens? Does the wild blossom have both stamens and pistils in the same flower?

8. Describe the stamens. What insects carry pollen for the strawberry plants?

9. Are the blossoms arranged in clusters? Do the flowers all open at the same time? What parts of the blossom fall away and what parts remain when the fruit begins to form?

Io. Are the fruits all of the same shape and color? Is the pulp of the same color within as on the surface? Has the fruit an outer coat or skin? What are the specks on its surface?

I I. How many kinds of wild strawberries do you know? How many kinds of cultivated strawberries do you know? bed.

I 2. Describe how you should prepare, plant and care for a strawberry

\section{THE PUMPKIN \\ Teacher's Story}

If the pumpkin were as rare as some orchids, people would make long pilgrimages to look upon so magnificent a plant. Although it trails along the ground, letting Mother Earth help it support its gigantic fruit, yet there is no sign of weakness in its appearance; the vine stem is strong, ridged, spiny and purposeful. And the spines upon it are surely a protection under some circumstances, for I remember distinctly when, as children, bare-footed and owning the world, we "played Indian" and found our ambush in the long rows of ripening corn, we skipped over the pumpkin vines, knowing well the punishment they inflicted on the unwary feet.

From the hollow, strongly angled stem arise in majesty the pumpkin leaves, of variously lobed patterns, but all formed on the same decorative plan. The pumpkin leaf is as worthy of the sculptor's chisel as is that of the classic acanthus: it is palmately veined, having from three to five lobes, and its broad base is supported for a distance on each side of the angled petiole by the two basal veins. The leaves are deep green above, paler below and are covered on both sides with minute bristles, and their edges are finely toothed. The bristly, angled stem which lifts it aloft is a 


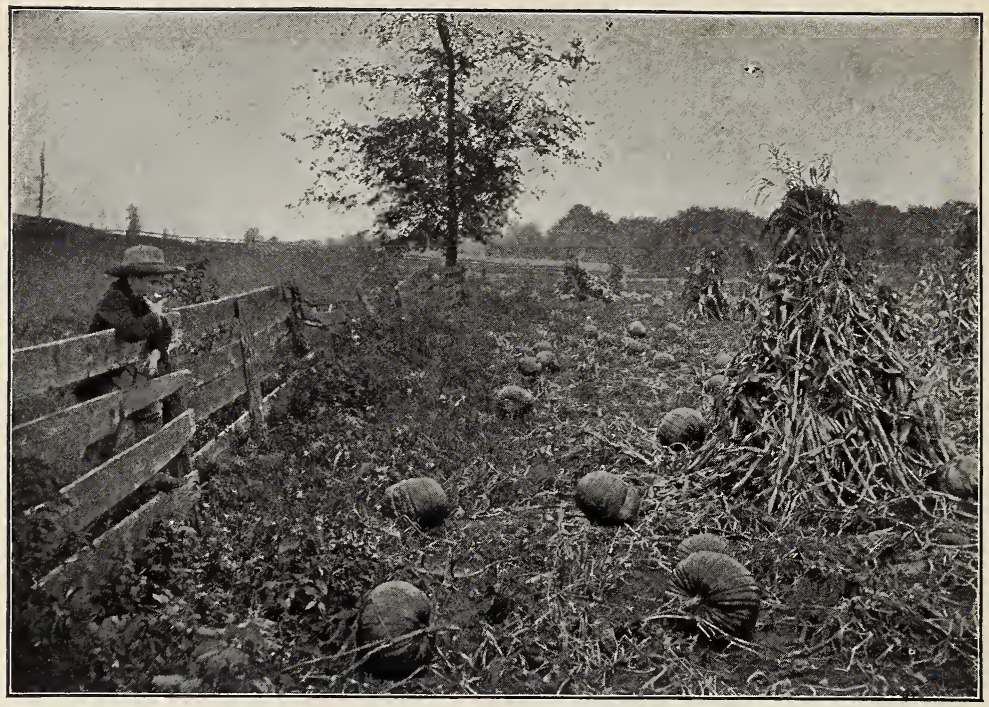

"When the frost is on the punkin and the fodder's in the shock."

Photo by Verne Morton.

quite worthy support for so beautiful a leaf. And, during our childhood, it was also highly esteemed as a trombone, for it added great richness of quality to our orchestral performances, balancing the shrillness of the basswood whistle and the sharp buzzing of the dandelion-stem pipe.

Growing from a point nearly opposite a leaf, may be seen the pumpkin's elaborate tendril. It has a stalk like that of the leaf, but instead of the leaf blade it seems to have the three to five naked ribs curled in long, small coils very even and exact. Perhaps, at some period in the past, the pumpkin vines lifted themselves by clinging to trees, as do the gourd vines of to-day. But the pumpkin was cultivated in fields with the maize by the North American Indians, long before the Pilgrim Fathers came to America, to make its fruit into pies. Since the pumplin cannot sustain itself in our Northern climate without the help of man, it was evidently a native of a warmer land; and, by growing for so long a time as a companion of the corn, it has learned to send its long stems out for many feet, resting entirely upon the ground. But, like a conservative, elderly maiden lady, it still wears corkscrew curls in memory of a fashion, long since obsolete. Occasionally, we see the pumpkin vines at the edge of the field pushing out and clambering over stone piles, and often attempting to climb the rail fences, as if there still remained within them the old instinct to climb.

But though its foliage is beautiful, the glory of the pumpkin is its vivid yellow blossom and, later, its orange fruit. When the blossom first starts on its career as a bud, it is enfolded in a bristly, ribbed calyx with five stiff, narrow lobes, which close up protectingly about the green, coneshaped bud, a rib of the cone appearing between each two lobes of the 
calyx. If we watch one of these buds day after day, we find that the green cone changes to a yellow color and $\approx$ softer texture as the bud unfolds, and then we discover that it is the corolla itseli; however, 'hese ribs which extend out to the tip of the corolla-lobes remain greenish below, permanently. The expanding of the flower bud is a pretty process; each lobe, supported by a strong midrib, spreads out into a five-pointed star. each point being very sharp and angular because, folded in along these edges in one of the prettiest of Nature's hems, is the ruffled margin of the flower. Not until the sun has shone upon the star for some little time of a summer 1norning, do these turned-in margins open out; and, late in the afternoon or during a storm, they fold down again neatly before the lobes close up; if a bee is not lively in escaping she may, willy-nilly, get a night's lodging, for these folded edges literally hem herin.

The story of the treasure at the

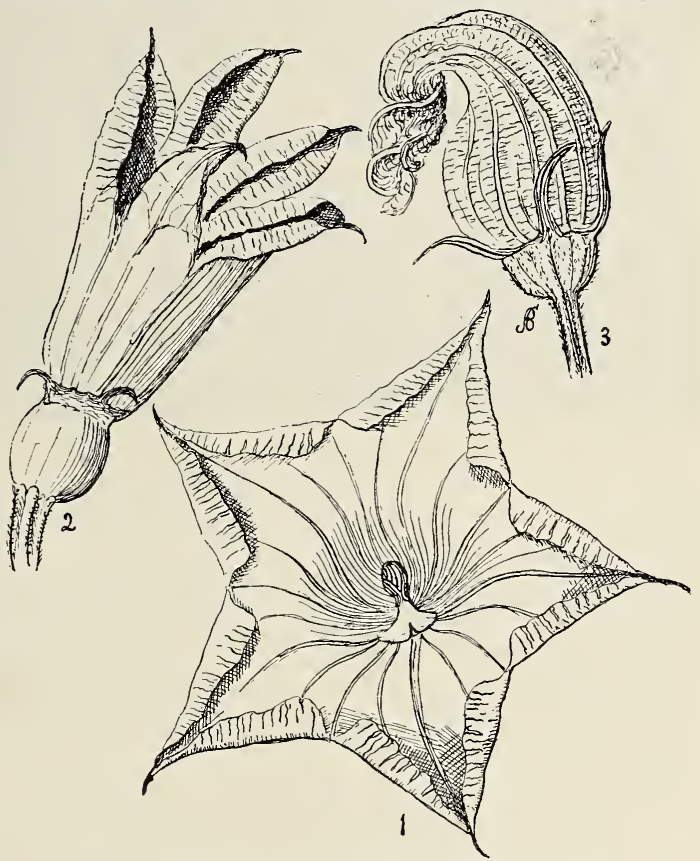

The closing of a pumpkin flower.

heart of this starry, 1, Staminate flower beginning to close; note the folded edges of the lobes bell-shaped flower is a double one, and

2 , Pistillate flower nearly closed. 3, Staminate flower closed and in its last stage.

we had best begin it by selecting a flower that has below it a little green globe-the ovary-which will later develop into a pumpkin. At the heart of such a flower there stand three stigmas, that look like liliputian boxing-gloves; each is set on a stout, postlike style, which has its base in 2 . great nectar-cup, the edges of which are slightly incurved over its welling sweetness. In order to reach this nectar, the lady bee must stand on her head and brush her pollen-dusted side against the greedy stigmas. Pro. fessor Duggar has noted that in dry weather the margins of this nectar-cup contract noticeably, and that in wet weather the stigmas close. down as if the boxing-gloves were on closed fists.

The other half of the pumpkin-blossom story is to be found in the flowers which have no green globes below them, for these produce the pollen. Such a flower has at its center a graceful pedestal with a broad 


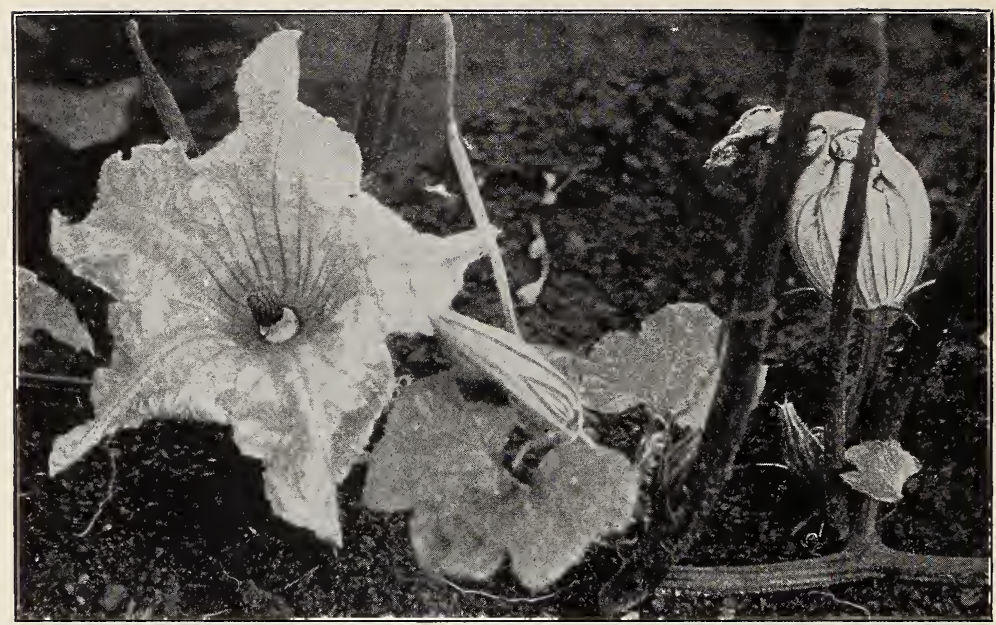

The staminate blossom of the pumpkin, showing the anther knob at the center. A bud of the staminate flower; and a closed blossom at the right.

Photo by Verne Morton.

base and a slender stem, which upholds a curiously folded, elongate knob, that looks like some ancient or primitive jewel wrought in gold. The corrugations on its surface are the anthar-cells, which are curiously joined and curved around a central oblong support; by cutting one across, we can see plainly the central core, bordered by cells filled with pollen. But where is the nectar well in the smooth cup of this flower? Some have

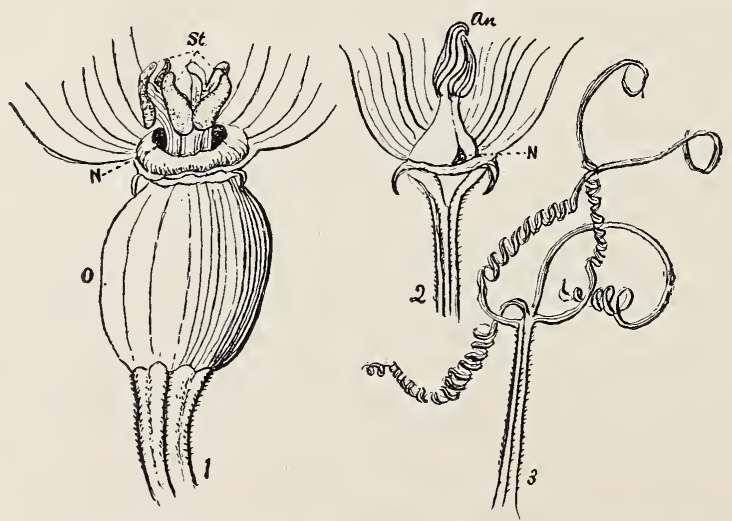

I, Base of pistillate blossom; o, ovary which develops into the pumpkin; n, nectar cup; st., stigmas. 2, Base of a staminate blossom; $n$, opening into the nectar cup; an: anthers joined, forming a knob. 3, Pumpkin tendril. 
maintained that the bees visit this flower for the sake of the pollen, but I am convinced that this is not all of the story. In the base of the pedestal which supports the anther knob there appear, after a time, three inconspicuous openings; and if we watch a bee, we shall see that she knows these openings are there and eagerly thrusts her tongue down through them. If we remove the anthers and the pedestal, we shall find below the latter, a treasure cave; it is carpeted with the softest of buff velvet, and while it does not reek with nectar, as does the cup which encompasses the styles of the pistil, yet it secretes enough of the sweet fluid so that we can taste it distinctly. Thus, although the bees find pollen in this flower they also find there, nectar. The pumpkin is absolutely dependent upon the work of bees and other insects for carrying its pollen from the blossom that bears it to the one which needs it, as this is the only way that the fruit may be developer.

And after the pollen has been shed and delivered, the flower closes, this time with an air of finality. The fading corolla looks as if its lobes had been twisted about by the thumb and finger to secure tightness; and woe betiile the bee caught in one of these prisons, unless she knows how to cut through its walls or can find within, sustenance to last until the withered flower falls. The young pumpkin is at first held up by its stiff stem but later rests upon the ground.

The ripe pumpkin is not only a colossal but also a beautiful fruit. The glossy rind is brilliant orange and makes a very efficient protection for the treasures within it. The stem is strong, five-angled and stubborn, and will not let go its hold until the fruit is over-ripe. It t en leaves a starshaped scar to match the one at the ther end of the fruit, where once the blossom sat enthroned. The pumpkin in shape is like a little world flattened at the poles, and with the lines of longitude creased into its surface. But the number of these longitudinal creases varies with individual pumpkins, and seems to have no relation to the angles of the stem or the three chambers within.

If we cut a small green pumpkin across, we find the entire inside solid There are three fibrous partitions extending from the center, dividing the pulp into thirds; at its outer end each partition divides, and the two ends curve in opposite directions. Within these curves the seeds are borne. A similar arrangement is seen in the sliced cucumber. As the pumpkin ripens, the partitions surrounding the seeds become stringy and very different from the "meat" next to the rind, which makes a thick, solid outer wall about the central chamber, where, within its "groined arches" are contained six rows of crowder seeds, attached by their pointed tips and supported by a network of yellow, coarse fibers-like babies supported in hammocks. All this network, making a loose and fibrous core, allows the seeds to fall out in a mass when the pumpkin is broken. If we observe where the cattle have been eating pumpkins we find these masses of seeds left and trampled into the mud, where, if our winter climate permitted, they could grow into plants next year. 


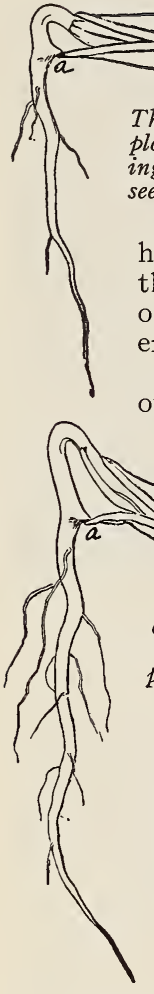

The squash plant breaking out of the seed-coats.

\section{halves} of the young plant. end, is the germ, which will develop into a new plant.

When sprouting, the root pushes out through the pointed end of the seed and grows downward. The shell of the seed is forced open by a little wedge-shaped projection, while the seed-leaves are pulled from their snug quarters. In watching one of these seeds sprout, it is difficult not to attribute to it conscious effort, while it is sturdily pulling hard to release its seed-leaves. If it fails to do this, the seed shell clamps the seed-leaves together

The operation like a vise, and the little plant is crippled.

further Both squashes and pumpkins figure in the spicy progressed Thanksgiving pies, but the chief value of the pumpkin crop in America is as food for milch cows; it causes a yield of milk so rich, that the butter made from it is as golden as its flesh. But the Hallow-e'en jack o'lantern appeals to the children. In this connection, a study of expression might be made interesting; the turning of the corners of the mouth up or down, and the angles of the eyebrows, making all the difference between a jolly grin and an "awful face."

\section{LESSON CLXXII}

\section{The Pumpkin}

Leading thought-The pumpkin and squash were cultivated by the American Indians in their cornfields long before Columbus discovered the new world. The flowers of these plants depend entirely upon insects for carrying their pollen, and are unable to develop their fruit without this aid.

Method-This work may be done in the garden or field in September or early October; or a vine bearing both kinds of flowers, leaves and tendrils may be brought to the schoolroom for observation. The lesson on the pumpkin fruit may be given later. A small green pumpkin should be studied with the ripe one, and also with the blossoms, so as to show the position of the seeds during development. This lesson can be modified to fit the cucumber, the melon and the squash.

\section{The Pumpkin Vine and Flowers}

Observations-r. How many different forms of flowers do you find on a pumpkin vine? What are the chief differences in their shape?

2. Look first at the flowers with the long slender stems: What is the shape and color of the blossom? How many lobes has it? Is each lobe 


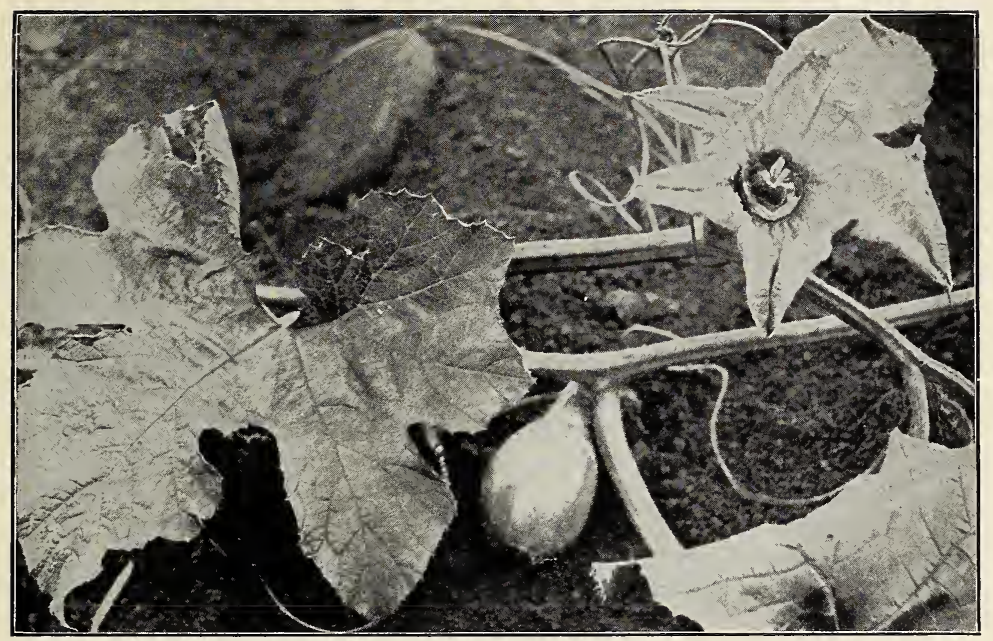

Partially closed pistillate blossom at the right, showing the stigmas and the nectar-cup at the center. Note the young pumpkin and the beautiful leaf; note also the angular, spiny stems.

Photo by Verne Morton.

distinctly ribbed or veined? Is the flower smooth on the inner and the outer surface? Are the edges of the lobes scalloped or ruffled?

3. What do you see at the bottom of the golden vase of this flower? This yellow club, or knob, is formed by the joining of three anthers, one of which is smaller than the others. Do all the pumpkin flowers have this knob at the center? Look at the base of the standard which bears the anther-knob, and note if there are some openings; how many? Cut off the anther pedestal, and describe what is hidden beneath it. Note if the bees find the openings to the nectar-well and probe there for the nectar. Do they become dusted with pollen while seeking the nectar?

4. What color is the pollen which is clinging to the anther? Is it soft and light, or moist and sticky? Do you think that the wind would be able to lift it from its deep cup and carry it to the cup of another flower?

5. Describe the calyx behind this pollen-bearing flower. How many lobes has it? Are the lobes slender and pointed?

6. Find one of the flowers which has below it a little green globe, which will later develop into a pumpkin. How does this flower differ from the one that bears the pollen?

7. Describe or sketch the pistil which is at the bottom of this flower vase. Into how many lobes does it divide? Do these three stigmas face outward, or toward each other? Are the stvles which uphold the stigmas short or long? Describe the cup in which they stand. Break away a bit of this little yellow cup and taste it. Why do you think the pumpkin flowers need such a large and well-filled nectary? Could insects get the nectar from the cup without rubbing against the stigmas, the pollen with 
which they became so thoroughly dusted when they visited the staminate flowers?

8. Cut through the center of one of the small green pumpkins. Can you see into how many sections it is divided? Does the number of seedclusters correspond with the number of stigmas in the flower? Make a sketch of a cross-section, showing where the seeds are placed.

9. What insects do you find visiting the pumpkin flowers?

Io. Carefully unfold a flower bud which is nearly ready to open, and note how it is folded. Then notice late in the afternoon how the $\mathrm{fl}$ wer c'oses. What part is folded over first? What next? How does it look when closed?

Ir. Describe the stems of the pumpkin vine; how are they strengthened and protected? Sketch or describe a pumpkin leaf.

I 2. Describe one of the tendrils of the pumpkin vine. Do you think that these tendrils could help the vine in climbing? Have you ever found a pumpkin vine climbing up any object?

\section{The Pumpkin Fruit}

Observations-I. Do you think the pumpkin is a beautiful fruit? Why? Describe its shape and the way it is creased. Describe the rind, its color and its texture, and tell how it protects the fruit. Describe the

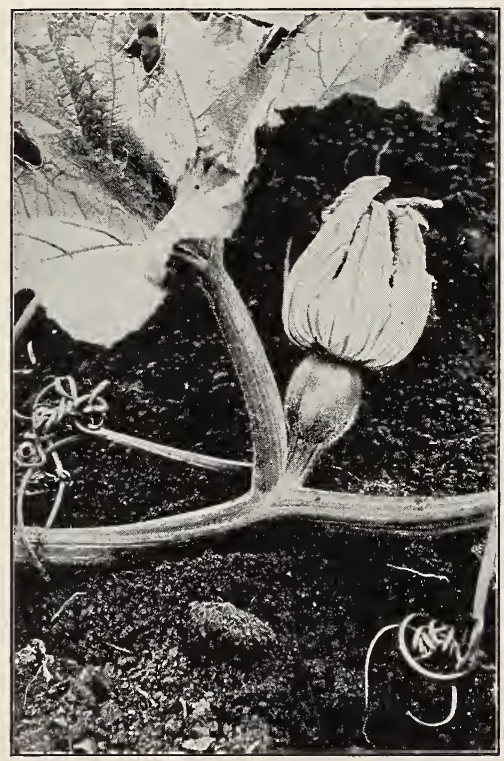

A closed pistillate flower of the pumpkin. Photo by Verne Morton. stem; does it cling to the pumpkin? How many ridges in the stem where it joins the vine? How many where it joins the pumpkin? Which part of the stem is larger? Does this give it a firmer hold?

2. Cut in halves crosswise a small green pumpkin and a ripe one. Which is the most solid? Can you see how the seeds are borne in the green pumpkin? How do they look in the ripe pumpkin? What is next to the rind in the ripe fruit? What part of the pumpkin do we use for pies?

3. Can you see in the ripe pumpkin where the seeds are borne? How are they suspended? How many rows of seeds lengthwise of the pumpkin? Of what use could it be to the pumpkin to have the seeds thus suspended within it by these threads or fibers? What is left of a pumpkin after the cattle have eaten it? Might the seeds thus left plant themselves?

4. Is the pumpkin seed attached at the round, or the pointed, end? Describe the pumpkin seed its shape and its edges? How does it feel when first taken from the pumpkin? How many coats has the seed? 
5. Describe the meat of the seed? Does it divide naturally into two parts? Can you see the little germ? Have you ever tried roasting and salting pumpkin and squash seeds, to prepare them for food as almonds and peanuts are prepared?

6. Plant a pumpkin seed in damp sand and give it warmth and light. From which end does it sprout? What comes first, the root or the leaves? What part of the seed forms the seed-leaves?

7. Describe how the pumpkin sprout pries open the shell to its seed, in order to get its seed-leaves out. What happens if it does not pull them out? Which part of the seedling pumpkin appears above ground first?

8. How do the true leaves differ in shape from the seed-leaves. What is the use of the seed-leaves to the plant?

Ah! on Thanksgiving day, when from East and from West, From North and from South come the pilgrim and guest, When the gray-haired New-Englander sees round his board The old broken lines of affection restored, When the care-wearied man seeks his mother once more, And the worn matron smiles where the girl smiled before, What moistens the lip and brightens the eye?

What calls back the past, like the rich Pumpkin pie?

Oh, fruit loved of boyhood! the old days recalling, When wood-grapes were purpling and brown nuts were falling When wild, ugly faces we carved in its skin, Glaring out through the dark with a candle within!

When we laughed round the corn-heap, with hearts all in tune, Our chair a broad pumpkin-our lantern the moon, Telling tales of the fairy who travelled like steam, In a pumpkin-shell coach, with two rats for her team!

-J. G. WhittieR。 


\section{FLOWERLESS-PLANT STUDY}

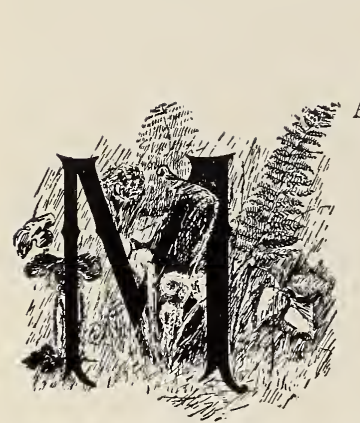

\section{FERNS}

ANY interesting things about ferns may be taught to the young child, but the more careful study of these plants is better adapted to the pupils in the higher grades, and is one of the wide-open doors that leads directly from nature-study to systematic scionce. While the pupils are studying the different forms in which ferns bear their fruit, they can make collections of all the ferns of the locality. Since ferns are easily pressed and are beautiful objects when mounted on white paper, the making of a fern herbarium is a delightful pastime; or leaf-prints may be made which give beautiful results (see page 734 ); but, better perhaps, than either collections or prints, are pencil or water-color drawings with details of the fruiting organs enlarged. Such a portfolio is not only a thing of beauty but the close observation needed for drawing brings much knowledge to the artist.

References.-Our Ferns in Their Haunts, W. N. Clute, (of greatest value to teachers because it gives much of fern literature); How to Know the Ferns, Parsons; Ferns, Waters; New England Ferns, Eastman.

\section{THE CHRISTMAS FERN}

\section{Teacher's Story}

"No shivering frond that shuns the blast sways on its slender chaffy stem; Full veined and lusty green it stands, of all the wintry woods the gem."

-W. N. Clute.

The rootstock of the fern is an humble example of "rising on stepping stones of our dead selves," this being almost literally true of the tree-ferns. The rootstock which is a stem and not a root-has, like other stems, a growing tip from which, each year, it sends up into the world several beautiful green fronds, and numerous rootlets down into the earth. These graceful fronds rejoice the world and our eyes for the summer, and make glad the one who, in winter, loves to wander often in the woods to inquire after the welfare of his many friends during their period of sleeping and waking. These fronds, after giving their message of winter cheer, and after the following summer has made the whole woodland green and the young fronds are growing thriftily from the tip of the rootstock, die down, and in midsummer we can find the old fronds lying sere and brown, with broken stipes, just back of the new fern clump; if we examine the rootstock we can detect behind them, remains of the stems of the fronds of year before last; and still farther behind we may trace all the stems of fronds which gladdened the world three years ago. Thus we learn that 


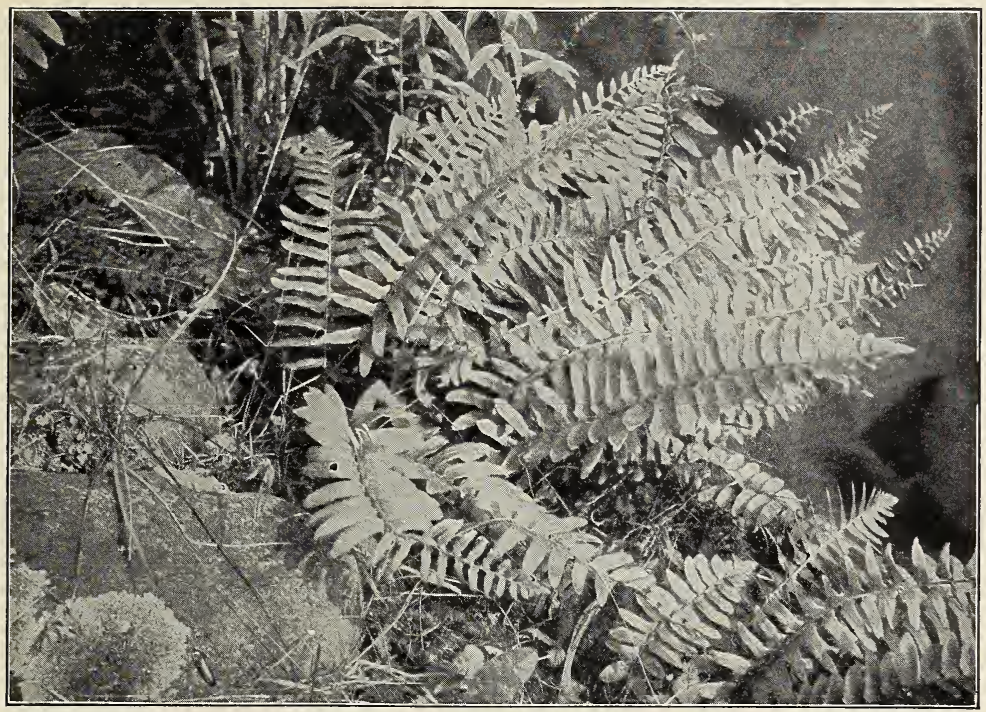

The Christmas fern. The contracted tips of some of the fronds consist of fruiting pinnce.

Photo by Verne Morton.

this rootstock may have been creeping on an inch or so each season for many years, always busy with the present and giving no heed to its dead past. One of the chief differences between our ferns and the tree-ferns of the tropics, which we often see in greenhouses, is that in the tree-fern the rootstock rises in the air instead of creeping on, or below, the surface of the ground. This upright rootstock of the tree-fern also bears fronds at its tip, and its old fronds gradually die down, leaving it rough below its crown of green plumes.

The Christmas fern has its green stipe, or petiole, and its rachis, or midrib, more or less covered with ragged, brownish scales, which give it an unkempt appearance. Its pinnæ, or leaflets, are individually very pretty; in color they are dark, shining green, lance-shaped, with a pointed lobe or ear at the base projecting upward. The edges of the pinnæ are delicately toothed, each point armed with a little spine, and the veins are fine, straight and free to the margin; the lower pinnæ often have the earlike lobe completely severed.

In studying a fertile fern from above, we notice that about a dozen pairs of the pinnæ near the tip are narrowed and roughened and are more distinctly toothed on the margins. Examining them underneath, we find on each a double row of circular raised dots which are the fruitdots, or sori; there is a row between the midrib and margin on each side, and also a double row extending up into the point at the base. Early in the season these spots look like pale blisters, later they turn pale brown, each blister having a depression at its center; by the middle of June, 
masses of tiny globules, not larger than pin points, push out from beneath the margin of these dots. The blisterlike membrane is simply a cover for the growing spores, and is called the indusium; by July it shrivels into an irregular scroll, still clinging to the pinnule by its depressed center; and
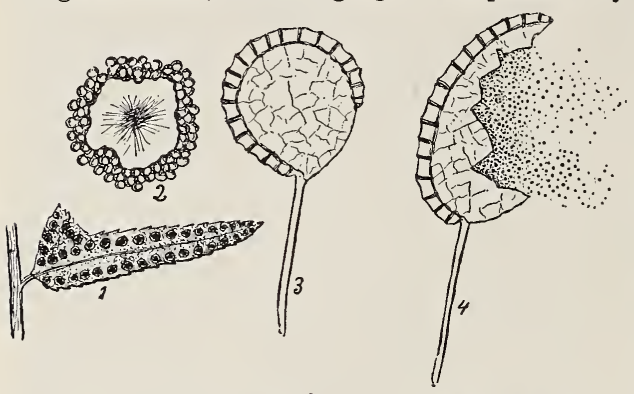

I. Fertile leaflet of Christmas fern showing indusia and spore-cases. 2. An indusium and spore-cases, enlarged. 3. A spore-case, enlarged. 4. A spore-case discharging spores, enlarged. by this time the profu. sion of tiny globules covers the entire under side of the pinna like a brown fuzz. If we scrape off some of this fuzz and examine it with a lens, we can see that it consists of numberless little globules, each with a stem to attach it to the leaf; these are the sporecases, or sporangia, each globule being packed full of spores which, even through the lens, look like yellowish powder. But each particle of this dust has its own structure and contains in its heart the living fern-substance.

Not all the fronds of the fern clump bear these fruit-dots. The ones we select for decoration are usually the sterile fronds, for the fertile ones are not so graceful, and many ignorant people think the brown spore-cases are a fungus. The Christmas fern being evergreen and very firm in tex-

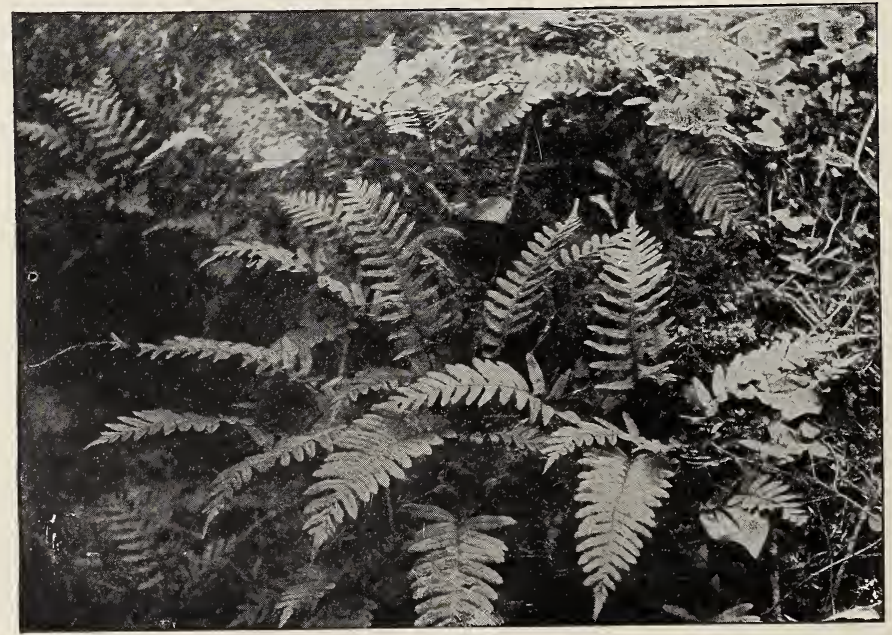

The common polypody often mistaken for the Christmus fern. Photo by Verne Morton. 
ture, is much used in holiday decoration, hence its common name, which is more easily remembered than Polystichum acrostichoides, which is its real name. It loves to grow in well-shaded woodlands, liking better the trees which shed their leaves than the evergreens; it is indeed welladapted to thrive in damp, cold shade; it is rarely found on slopes which face the south. and sunshine kills it.

\section{LESSON CLXXIII \\ The Christmas Fern}

Leading thought-The fern has a creeping underground stem called the rootstock, which pushes forward and sends up fresh fronds each year. Some of the fronds of the Christmas fern bear spores on the lower surface of the terminal pinnæ.

Method-This lesson should be given during the latter part of May, when the fruit-dots are still green. Take up a fern and transplant it, in a dish of moss, in the schoolroom, and later plant it in some convenient shady place. The pupils should sketch the fertile frond from the upper side so as to fix in their minds the contracted pinnæ of the tip; one of the lower pinnæe should be drawn in detail, showing the serrate edge, the ear and the venation. The teacher should use the following terms constantly and insistently, so as to make the fern nomenclature a part of the school vocabulary, and thus fit the pupils for using fern manuals.

A frond is all of the fern which grows on one stem from the rootstock; the blade is that portion which bears leaflets; the stipe is the stem or petiole; the rachis is the midrib and is a continuation of the stipe; the pinnule is a leaflet of the last division; the pinna is a chief division of the midrib or rachis, when the fern is compound; the sori are the fruit dots; the indusium isthe membrane covering the fruiting organs; the sporengia are the tiny brown globules, and are the spore

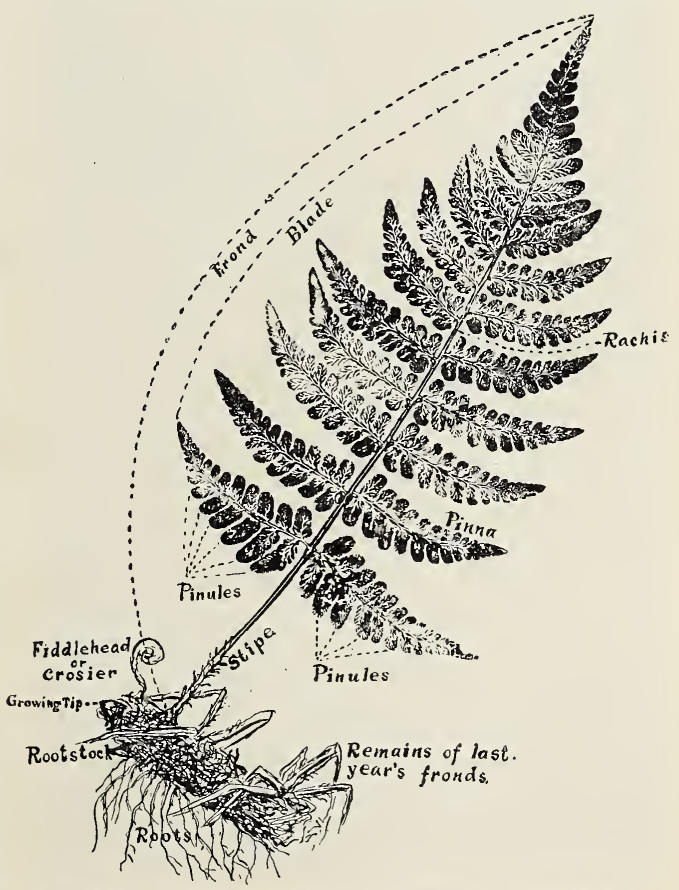

Leaf-print of a fern with the parts named. This fern is twice pinnate. 
cases; the spores make up the fine dust which comes from the spore-cases. It would be well to make a diagram on the blackboard of the fern with its parts named, so that the pupils may consult it while studying ferns.

Observations - I. Study a stump of the Christmas ferns. Are there any withered fronds? Where do they join the rootstock? Do the green fronds come from the same place on the rootstock as the withered ones? Do the green ferns come from near the tip of the rootstock? Can you find the growing tip of the rootstock? Can you trace back and find where the fronds of last year and year before last grew? Does that part of the rootstock seem alive now? Can you find the true root of the fern?

2. Take a frond of the Christmas fern. Is the stem, or stipe, and the midrib, or rachis, smooth or rough? What color are the scales of the stalk? Do you think that these scales once wrapped the fern bud?

3. Does each frond of a clump have the same number of pinnæ on each side? Can you find fronds where the pinnæ near the tip are narrower than those below? Take a lower pinna and draw it carefully, showing its shape, its edges and its veins. Is there a point, or ear, at the base of every pinna? Is it a separate lobe or a mere point of the pinna?

4. Take one of the narrow pinnæ near the tip of the frond, and examine it beneath. Can you see some circular, roundish blisterlike dots? Are they dented at the center? How many of these dots on a pinna? Make a little sketch showing how they are arranged on the pinna and on the little earlike point. Look at the fruiting pinnæ of a fern during July, and describe how they look then.

5. Do all the fronds of a fern clump have these narrowed spore. bearing pinnæ? Do you know what those fronds are called that bear the fruit-dots?

6. Where do you find the Christmas fern growing? Do you ever finc it in a sunny place? Why is it called the Christmas fern?

\section{FERN SONG}

Dance to the beat of the rain, little Fern

And spread out your palms again,

And say, "Tho' the sun

Hath my vesture spun,

He had labored, alas, in vain,

But for the shade

That the Cloud hath made, And the gift of the Dew and the Rain."

Then laugh and upturn

All your fronds, little Fern,

And rejoice in the beat of the rain!

-JoHN B. TABE. 
Teacher's Story

It is well for the children to study the animals and plants which have a worldwide distribution. There is something comforting in finding a familiar plant in strange countries; and when I have found the bracken on the coast ranges of California, on the rugged sides of the Alps, and in many other far places, I have always experienced a thrill of delightful memories of the fence corners of the homestead farm. Since the bracken is so widespread, it is natural that it should find a place in literature and popular legend. As it clothes the mountains of Scotland, it is much sung of in Scottish poetry. Many superstitions cluster around it-its seed, if caught at midnight on a white napkin, is supposed to render the possessor invisible. Professor Clute, in Our Ferns in Their Haunts, gives a delightful chapter about the relation of the bracken to people. For nature-study purposes, the bracken is valuable as a lesson on the intricate patterns of the fern leaf; it is in fact a lesson in pinnateness. The two lower branches are large and spreading'

\section{THE BRACKEN}

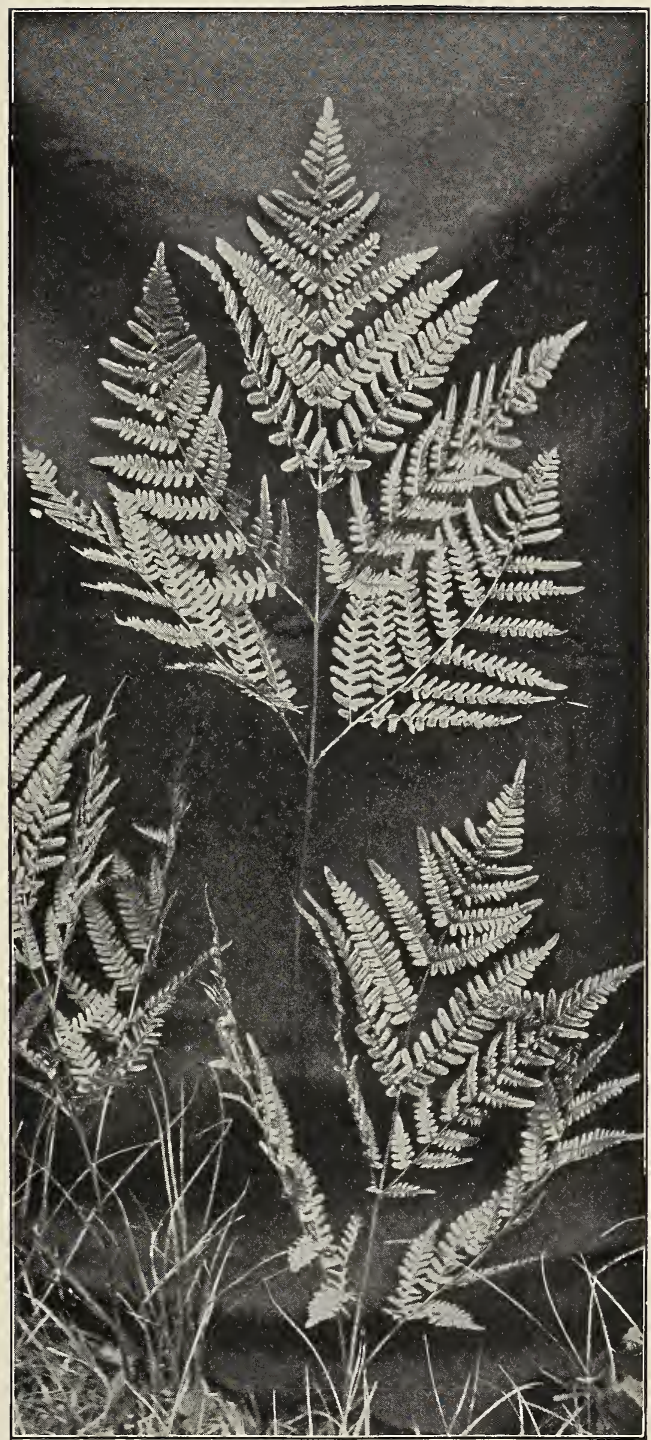

Bracken.

Photo by Verne Morton. 
and are in themselves often three times pinnate; the branches higher up are twice pinnate; while the main branch near the tip is once pinnate, and at the tip is merely lobed. The lesson, as illustrated in the diagram of the fern, should be well learned for future study, because this nomenclature is used in all the fern manuals. The fact that a pinnule is merely the last division of a frond, whether it be twice or thrice pinnate, should also be understood.

The bracken does not love complete shade and establishes itself in waste places, living contentedly in not too shaded locations; it is especially fond of woodsides, and fence corners on high and cold land. As Professor Clute says, "It is found both in woodland and in the open field; its favorite haunt is neither, but is that half-way ground where man leaves off and nature begins, the copse or the thicket." With us it usually grows : bout three feet high, but varies much in this respect. The great triangular fronds often measure two or three feet across, and are supposed to bear a likeness to an eagle with spread wings. Its rootstock is usually too deeply embedded in earth for the study of any except the most energetic; it is about the size of a lead pencil and is black and smooth; in its way it is a great traveler, sending up fronds fifteen or twenty feet from its starting place. It also sends off branching rootstocks.

The fruiting pinnules look as if they were hemmed and the edges of the hems embroidered with brown wool; but the embroidery is simply the spore-cases pushing out from under the folded margin which protected them while developing.

Much on which to base necromancy has been found in the figure shown in the cross-section of the stem or stipe. The letter C, supposed to stand for Christ, thus made is a potent pro-
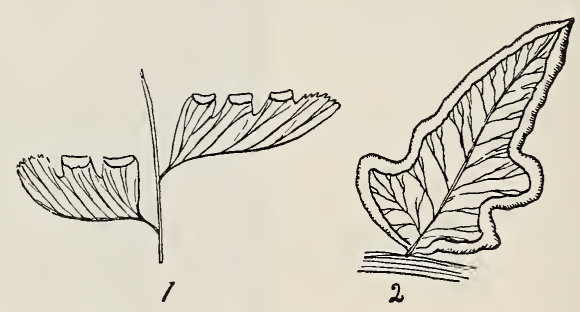

I. Fruiting pinnules of the maiden-hair fern, enlarged. 2. Fruiting pinnule of the bracken, enlarged. In both these species the spores are borne under the recurved edges of the pinnules.

tection from witches. But this figure has also been compared to the devil's hoof, an oak tree, or the initial of one's sweetheart, and all these imaginings have played their part in the lives of the people of past ages. It was believed in England that burning the bracken from the fields brought rain; the roots in time of scarcity have been ground and mixed with flour to make bread. The young ferns, or croziers, are sometimes coóked and eaten like asparagus. The fronds have been used extensively for tanning leather and for packing fish and fruit, and when burned theil ashes are used instead of soap.

In Europe, bracken grows so rankly that it is used for roof-thatching and for the bedding of cattle. The name "brake," which is loosely used for all ferns, comes from the word "bracken;" some people think that brakes are different from ferns, whereas this is simply a name which has strayed from the bracken to other species. Its scientific name, Pteris aquilina, signifies eagle's wing. 


\section{LESSON CLXXIV}

\section{THE BRACKEN}

Leading thought-The bracken is a fern which has taken possession of the world. It is much branched and divided, and it covers the ground in masses where it grows. The edges of its pinnules are folded under to protect the spores.

Method-Bring to the schoolroom large and small specimens of the bracken, and after a study is made tell about the superstitions connected with this fern and as far as possible interest the pupils in its literature.

Observations- - . Do you find the bracken growing in the woods or open places? Do you find it in the cultivated fields? How high does it stand? Could you find the rootstock?

2. Take a bracken frond. What is its general shape? Does it remind you of an eagle with spread wings? Look at its very tip. Is it pinnate or merely lobed? Can you find a place farther down where the leaflets, or pinnules, are not joined at their bases? This is once pinnate. Look farther down and find a pinna that is lobed at the tip; at the base it has distinct pinnules. This is twice pinnate. Look at the lowest divisions of all. Can you find any part of this which is three times pinnate? Four times pinnate? Pinna means feather, pinnate therefore means feathered. If a thing is once pinnate, it means that it has divisions along each side similar to 7 feather; twice pinnate means that each feather has little feathers along each side; thrice pinnate means that the lit:tle feathers have similar feathers along each side, and so on.

3. Can you see it the edges of the pinnules are folded under? Lift up one of these edges and see if you can find what is growing beneath it. How do these folded margins look during August and September?

4. Cut the stem, or stipe, of a bracken across and see the figure in it. Doas it look like the initial C? Or a hoof, or an oak tree, or another initial?

5. Discover, if you can, the different uses which people of other countries tind for this fern.

\section{HOW A FERN BUD UNFOLDS}

\section{Teacher's Story}

Of all "plant babies," that of the fern is most cozily cudd'ed; one feels when looking at it, that not only are its eyes shut but its fists are tightly closed. But the first glance at one of these little woolly spirals gives us but small conception of its marvelous enfolding, all so systematic and perfect that it seems another evidence of the divine origin of mathematics. Every part of the frond is present in that bud, even to the fruiting organs; all the pinnæ and the pinnules are packed in the smallest compass-each division, even to the smallest pinnule, coiled in a spiral towards its base. These coiled fern buds are called crosiers; they are woolly, with scales instead of hairs, and are thus well blanketed. Some botanists object to the comparison of the woolly or fuzzy clothing of young plants with the blankets of human infants. It is true that the young plant is not kept at a higher temperature by this covering; but because of it, transpiration which is a cooling process is prevented, and thus the 
plant is kept warmer. When the fern commences to grow, it stretches up and seems to lean over backward in its effort to be bigger. First the main

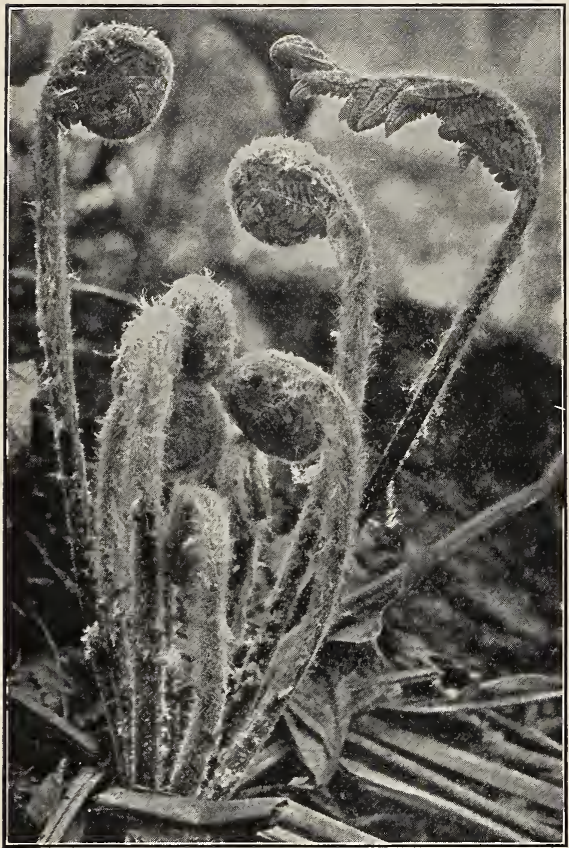

Fiddle heads, or crosiers. Young ferns unfolding. Photo by Verne Morton. stem, or rachis, loosens its coil; but before this is completed, the pinnæ, which are coiled at right angles to the main stem, begin to unfold; a little later the pinnules, which are folded at right angles to the pinnæ, loosen and seem to stretch and yawn before taking a look at the world which they have just entered; it may be several days before all signs of the complex coiling disappear. The crosiers of the bracken are queer look. ing creatures, soon developing three claws which some people say look like the talons of an eagle; and so intricate is the action of their multitudinous spirals, that to watch them unfolding impresses one as in the presence of a miracle.

\section{LESSON CLXXV How A Fern Bud Unfolds \\ Leading thought-All of the parts of the frond of a fern are tightly folded spir- ally within the bud, and} every lobe of every leaflet is also folded in a spiral.

Method-The bracken crosier is a most illuminating object for this lesson, because it has so many divisions and is so large; it is also convenient, because it may be found in September. However, any fern bud will do. The lesson may be best given in May when the woodland ferns are starting. A fern root with its buds should be brought to the schoolroom, where the process of unfolding may be watched at leisure.

Observations-I. Take a very young bud. How does it look? Do you see any reason why ignorant people call these buds caterpillars? Can you see why they are popularly called "fiddle heads?" What is their true name? How many turns of the coil can you count? What 's the covering of the crosier? Do you think this cover is a protection? How is the stem grooved to make the spiral compact?

2. Take a crosier a little further advanced. How are its pinnæ folded? How is each pinnule of each pinna folded? How is each lobe of a pinnule folded? Is each smaller part coiled toward each larger part? 
3. Write in your note-book the story of the uniolding fern, and sketch its stages each day from the time it is cuddled down in a spiral until it is a fully expanded frond.

\section{THE FRUITING OF THE FERN \\ Teacher's Story}

"If we were required to know the position of the fruit-dots or the character of the indusium, nothing could be easier than to ascertain it; but if it is required that you be affected by ferns, that they amount to anything, signify anything to you, that they be another sacred scripture and revelation to you, help to redeem your life, this end is not so easily accomplished."-THOREAU.

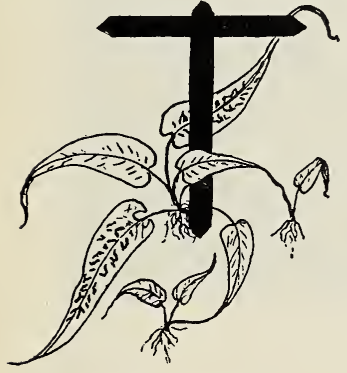

The walking fern.

HE fern, like the butterfly, seems to have several this-world incarnations; and perhaps the most wonderful of these is the spore. Shake the dust out of the ripened fern and each particle, although too small for the naked eye to see, has within it the possibilities of developing a mass of graceful ferns. Each spore has an outside hard layer, and within this an atom of fern-substance; but it cannot be developed unless it falls into some warm, damp place favorable for its growth; it may have to wait many years before chance gives it this favorable condition, but it is strong and patient and retains its vital power for years. There are cases known where spores grew after twenty years of waiting. But what does this microscopic atom grow into? It develops into a tiny heart-shaped, leaflike structure which botanists call the prothallium; this has on its lower side little roots which reach down into the soil for nourishment; and on its upper surface are two kinds of pockets, one round and the other long. In the round pockets are developed bodies which may be compared to the pollen; and in the long pockets, bodies which may be compared to the ovules of flowering plants. In the case of ferns, water is necessary to float the pollen from the round pockets to the ovules in the long pockets. From a germ thus fertilized in one of the long pockets, a little green fern starts to grow, although it may be several years before it becomes a plant strong enough to send up fronds with spore-dots on them. To study the structure of the spore requires the highest powers of the microscope; and even the prothallium in most species is very small, varying from the size of a pin-head to that of a small pea, and it is therefore quite difficult to find. I found some once on a mossy log that bridged a stream, and I was never so triumphant over any other outdoor achievement. They may be found in damp

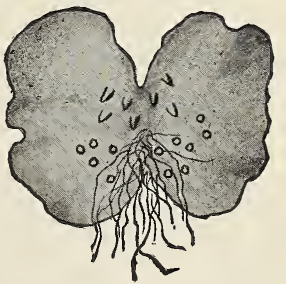

Prothallium, greatly enlarged, showing the two kinds of pockets and the rootlets. 
places, in greenhouses, but the teacher will be very fortunate who is able to show her pupils this stage of the fern. The prothallium is a stage of

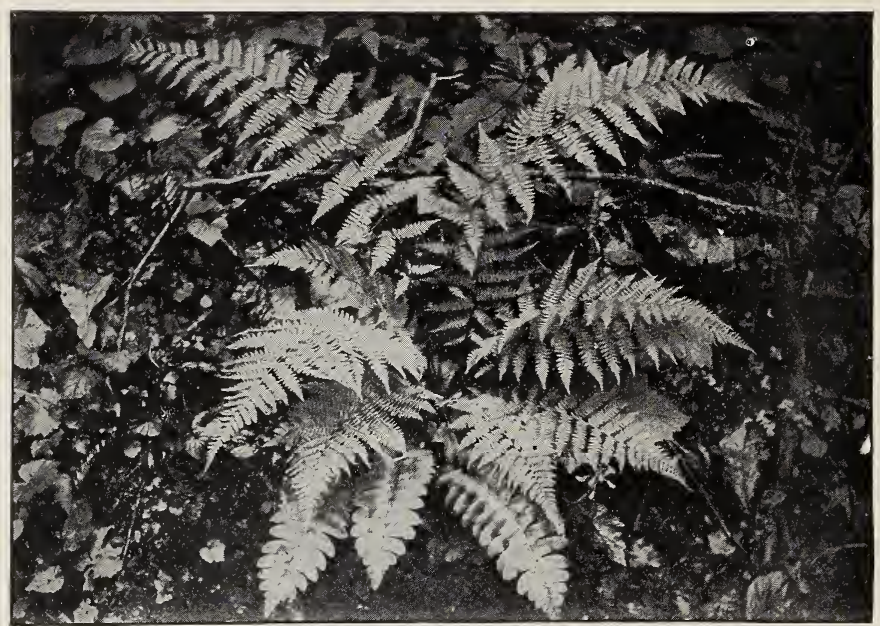

Christmas fern is below the others.

Photo by Verne Morton.

the fern to be compared to the flower and seed combined in the highe1 plants; but this is difficult for young minds to comprehend. I like to tell the children that the fern, like a butterfly, has several stages: Beginning
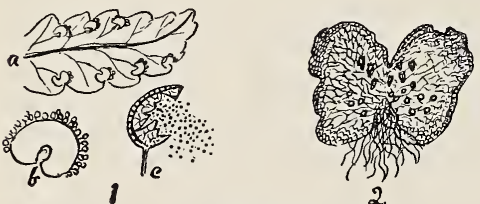

2

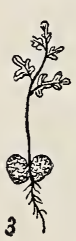

The life of a fern.

with the spore-bearing fern, we next have the spores, next the prothallium stage, and then the young fern. While in the other case we have first the egg, then the caterpillar, then the chrysalis, and then the 1. $a$, pinna bearing fruit: $b$, a fruit-dot, enlarged, showing spore- butterfly. Looking at cases pushing out around the edges of the indusium, $c$, sporecase, enlarged, showing how it discharges the spores.

2. Prothallium, enlarged

3. Young fern growing from the prothallium. the ripe fruit-dots on the lower side of the tern leaf, we can easily see with a lens a mass of tiny globules; each one of these is a spore-case, or sporangium, (plural sporangia), and is fastened to the leaf by a stalk and has, almost encircling it, a jointed ring. (See figure on page 686).

When the spores are ripe, this ring straightens out and ruptures the globule, and out fly the spores. By scraping a little of the brown fuzz from a fruiting pinna of the Christmas fern upon a glass slide and placing a cover glass upon it, we find it very easy to examine through the micro. scope, and we are able thus to find the spore-cases in all stages, and to see 
the spores distinctly. The spore-cases may also be seen with a hand lens, the spores seeming then to be mere dust.

The different ways the ferns blanket their spore-cases is a delightful study, and one which the pupils enjoy very much. All of our common ferns except the careless little polypody thus protect their spores. Whether this blanket be circular, or horseshoe-shaped, or oblong, or in the form of pocket or cup, depends upon the genus to which the fern belongs. The little protecting blanket-membrane is called the indusium, and while its shape distinguishes the genus, the position in which it grows determines the species. I shall never forget my surprise and delight when, as a young giil, I visited the Philadelphia Centennial Expositon, and there in the great conservatories saw for the first time the tree-ferns of the tropics. One of these was
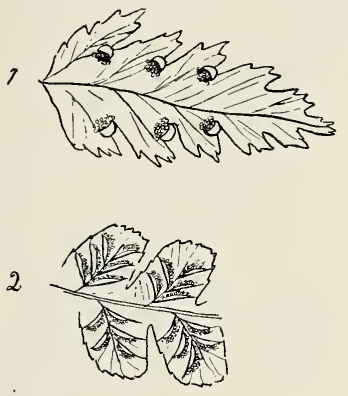

\section{Fruiting pinnule of the boulder} fern, enlarged. 2. Fruiting pinnules of spleenwort, enlarged. labelled Dicksonia, and mystified, I asked the privilege of examining the fronds for fruiting organs. When lo! the indusium proved to be a

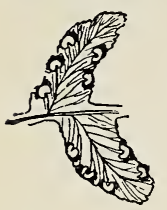

Fruiting pinnules of evergreen wood fern. little cup, borne at the base of the tooth of the pinnule, exactly like that of our boulder fern, which is also a Dicksonia. I had a sudden feeling that I must havefern friends all over the world.

The children are always interested in the way the maidenhair folds over the tips of her scallops to protect her spore nursery; and while many of our ferns have their fertile fronds very similar in form to the sterile ones, yet there are many common ferns with fertile fronds that look so different from the others, that one would not think they were originally of the same pattern; but although their pinnules are changed into cups, or spore-pockets, of various shapes, if they be examined carefully they will be seen to have the same general structure and the same divisions however much contracted, as have the large sterile fronds. The Osmundas, which include the interrupted, the cinnamon and the flowering ferns, are especially good for this part of the lesson. The sensitive fern, so common in damp places in open fields, is also an excellent illustration of this method of

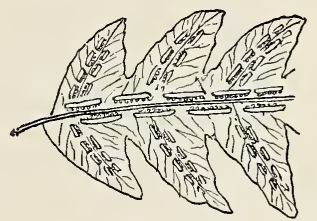

Fruiting pinnules of the chain fern. fruiting. While studying the ferns, the teacher should lay stress upon the fact that they represent the earliest and simplest forms of plants, that they reached the zenith of their growth in the Carboniferous age, and that, to a large extent, our coal is composed of them. It is interesting to think that the exquisite and intricate leaf patterns of the ferns should belong to a primitive type. Often when I have watched the forming by the frost, of the exquisite fernlike pictures on the window-pane, I have wondered if, after all, the first expression of the Creator did not 
find form in the most exquisite grace and beauty; and if perchance the first fishes, so fierce and terrible, did not mark the introduction of Satan.

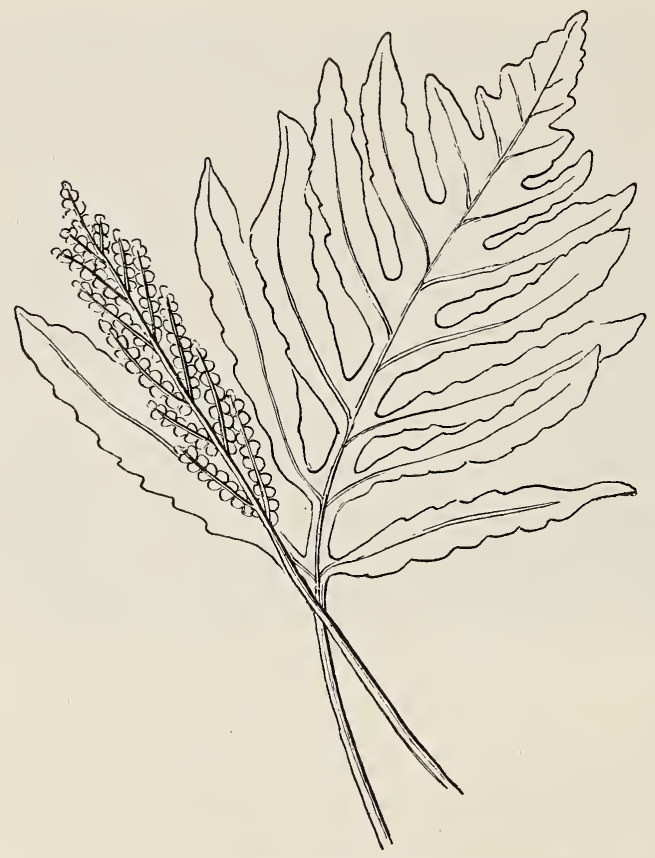

A sensitive fern, showing sterile and fertile fronds.

\section{LESSON CLXXVI}

The Fruiting of the Fern

Leading thought-Ferns do not have flowers, but they produce spores. Spores are not seeds; but they grow into something which may be compared to a true seed, and this in turn develops into young ferns. Each genus of ferns has its own peculiar way of protecting its spores; and if we learn these different ways, we can recognize ferns without effort.

Method-July is the best time for this lesson, which is well adapted for summer schools or camping trips. However, if it is desired to use it as a school lesson, it should be begun in June, when the fruiting organs are green, and it may be finished in September after the spores are discharged. Begin with the Christmas fern, which ripens in June, and make the fruiting of this species a basis for comparison. Follow this with other wood ferns which bear fruit-dots on the back of the fronds. Then study the ferns which live in more open places, and which have fronds changed in Lorm to bear the spores-like the sensitive, the ostrich, the royal and the flowering ferns. A study of the interrupted fern is a desirable preparation for the further study of those which have special fruiting fronds: the 
interrupted fern has, at about the middle of its frond, three pinnæ on each side, fitted for spore-bearing, the pinnules being changed into globular cups filled with spore-cases.

While not absolutely necessary, it is highly desirable that each member of the class should look at a fruit-dot of some fern through a threequarters objective of a compound microscope, and then examine the spore-cases and the spores through a one-sixth objective. It must be remembered that this lesson is for advanced grades, and is a preparation for systematic scientific work. If a microscope is not available, the work may be done with a hand lens aided by pictures.

Observations-r. Take a fern that is in fruit; lay it on a sheet of white paper and leave it thus for a day or two, where it will not be disturbed and where there is no draught; then take it up carefully; the form of the fern will be outlined in dust. What is this dust?

2. What conditions must the spores have in order to grow? What do they grow into? (See First Studies of Plant Life by Atkinson, p. 207).

3. Look at a ripe fruit-dot on the back of a fern leaf and see where the spores come from. Can you see with a lens many little, brown globules? Can you see that some of them are torn open? These are the spore-cases, called sporangia, each globule being packed with spores. Can you see how the sporangia are fastened to the leaf by little stems?

4. Almost all our common wood ferns have the spore-cases protected by a thin membrane, the spore-blanket, when very young; this little membrane is called the indusium, and it is of differefit shape in those ferns which do not have the same sirname, or generic name. Study as many kinds of wood ferns as you can find. If the blanket, or indusium, is circular with a dent at the center where it is fastened to the leaf, and the spore-cases push out around the margin, it is a Christmas fern; if horseshoeshaped, it is one of the wood ferns; if oblong, in rows on each side of the midrib, it is a chain fern; but if oblong and at an angle to the midrib, it is a spleenwort; if it is ocket-shaped and opening at one side, it is a bladder fern; if it is cup-shaped, it is a boulder fern; if it breaks open anc' lays back in star shape, it is a woodsia; if the edge of the fern leaf is folded over all along its margin to protect the spore-cases, it is a bracken; if the tips of the scallops of the leaf be delicately folded over to make a spore blanket, it is the maidenhair.

5. If you know of swampy land where there are many tall brakes, look for a kind that has some of its pinnæ withered and brown. Examine these withered pinnæ, and you will see that they are not withered at all but are changed into little cups to hold spore-cases. This is the interrupted fern. 'The flowering fern has the pinnæat its tip changed into cups for spore-cases. The cinnamon fern, which grows in swampy places, has whole fronds which are cinnamon-colored and look withered, but which bear the spores. The ostrich fern, which has fronds which look like mag- 
nificent ostrich feathers, has stiff, little stalks of fruiting fronds very unlike the magnificent sterile fronds. The sensitive fern, which grows in damp meadows and along roadsides, also has contracted fruiting fronds. If you find any of these, compare carefully the fruiting with the sterile fronds, and note in each case the resemblance in branching and in pinnules and also the shape of the openings through which the spores are sifted out.

6. Gather and press specimens of as many ferns in the fruiting stage as you can find, taking both sterile and fruiting fronds in those species which have this specialization.

7. Read in the geologies about the ferns which helped to make our coal beds.

Supplementary reading.-The Story of a Fern; First Studies of Plant Life, Atkinson: The Petrified Fern, M. L. B. Branch.

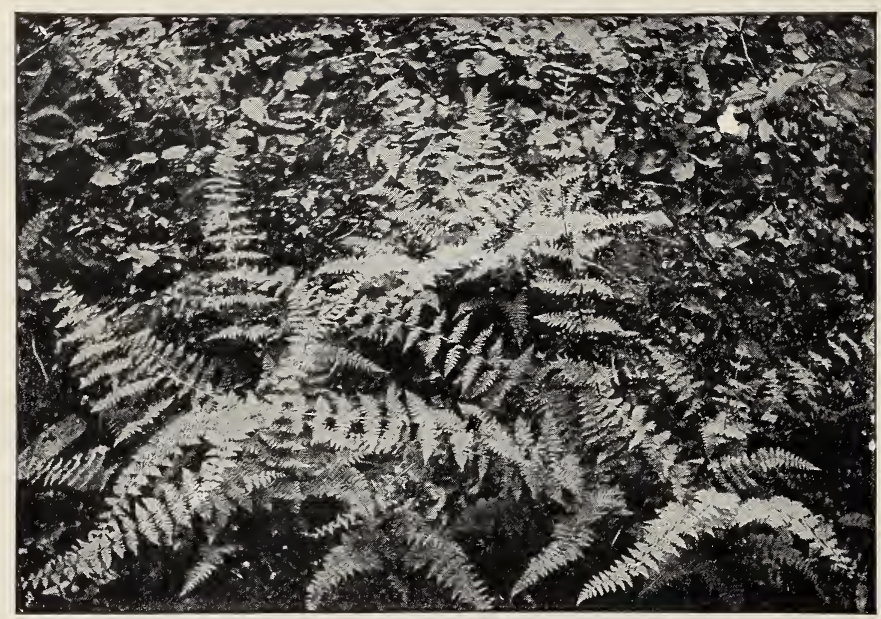

The bulb-bearing bladder fern. This beautiful fern clothes the banks of damp ravines. It has, in addition to fruiting organs, buds on the stem, which take root.

Photo by Verne Morton.

"Nature made ferns for pure leaves to see what she could do in that line."-THOREAu 


\section{THE FIELD HORSETAIL}

\section{Teacher's Story}

These queer, pale plants grow in sandy or gravelly soil, and since they appear so early in the spring they are objects of curiosity to children. The stalk is pale and uncanny looking; the pinkish stem, all the same size from bottom to top, is ornamented at intervals with upward-pointing, slender, black, sharp-pointed scales, which unite at the bottom and encircle the stalk in a slightly bulging ring, a ring which shows a ridge for every scale, extending down the stem. These black scales are really leaves springing from a joint in the stem, but they forgot long ago how to do a leaf's work of getting food from the air. The "blossom" which is not a real blossom in the eye of the botanist, is made up of rows of tiny discs which are set like miniature toadstools around the central stalk. Before it is ripe, there extends back from the edge of each disc a row of little sacs stuffed so full of green spores that they look united like a row of tiny green ridges. The discs at the top of the fertile spike discharge their spores first, as can be seen by shaking the plant over white paper, the falling spores looking $\boldsymbol{I}$, Fertile plant of the field horsetail; 2, spore, like pale green powder. The burst and 3, disk discharging spores; 4, disk with empty sacs are whitish, and hang

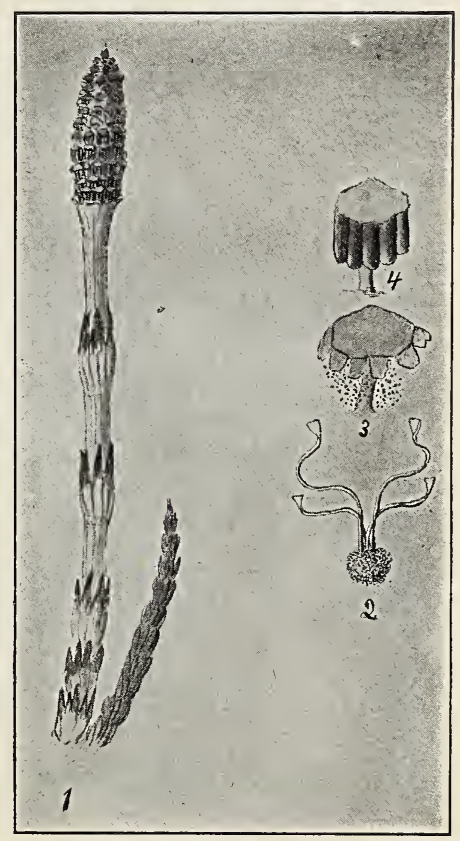
around the discs in torn scallops, after the spores are shed. The spores, when seen under the microscope, are wonderful objects, each a little green ball with four spiral bands wound about it. These spirals uncoil and throw the spore, giving it a movement as of something alive. The motor power in these living springs is the absorbing of moisture.

The beginning of the sterile shoot can be seen like a green bit of the blossom spike of the plantain; but later, after the fertile stalks have died down, these cover the ground with their strange fringes.

The person who first called these sterile plants "horsetails" had an overworked imagination, or none at all; for the only quality the two have in common is brushiness. A horse which had the hair of its tail set in whorls with the same precision as this plant has its branches would be one of the world's wonders. The Equicetum is one of the plants which give evidence of nature's resourcefulness; its remote ancestors probably had a whorl of leaves at each joint or node of the main stem and branches; but the plant now having so many green branches, does not really need the leaves, and thus they have been reduced to mere points, and look like 
nothing but "trimming," they are so purely ornamental. Each little cup or socket, of the joint or node, in branch or stem, has a row of points around its margin, and these points are terminals of the angles in the branch. If a branch is triangular in cross section, it will have three points at its socket, if quadrangular it will have four points, and the main

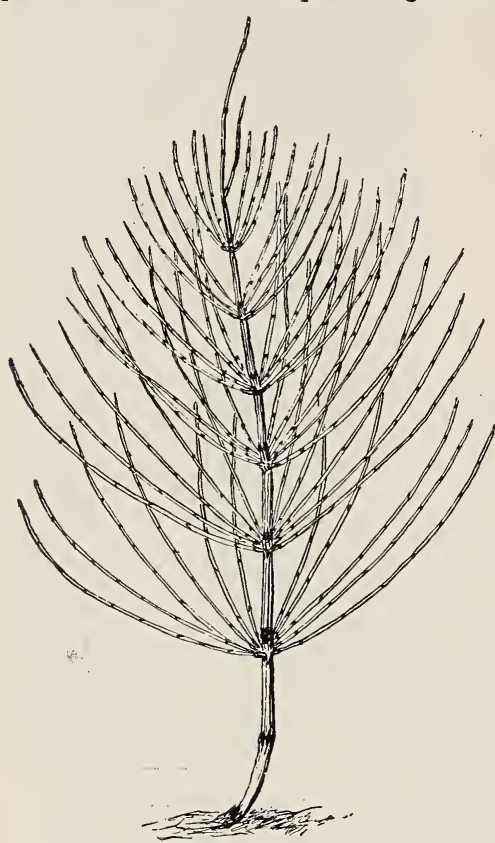

The sterile plant of the field horsetail, one-half natural size. stem may have six or a dozen, or even more points. The main stem and branches are made up entirely of these segments, each set at its lower end in the socket of the segment behind or below it. These green branches, rich in chlorophyl, manufacture for the plant all the food that it needs. Late in the season this food is stored in the rootstocks, so that early next spring the fertile plants, nourished by this stored material, are able to push forth before most other plants, and thus develop their spores early in the season. There is a prothallium stage as in the ferns.

Above where the whorl of stems comes from the main branch, may be seen a row of upward-standing points which are the remnants of leaves; each branch as it leaves the stem is set in a little dark cup with a toothed rim. There is a nice gradation from the stout lower part of the stem to the tip, which is as delicate as one of the side branches.

The rootstock dies out behind the plant and pushes on ahead like the rootstock of ferns. The true roots may be seen attached on the under side. The food made in the summer is stored in little tubers, which may be seen in the rootstocks.

\section{LESSON CLXXVII}

\section{The Field Horsetail}

\section{The Fertile Plant}

Leading thought-The horsetail is a plant that develops spores instead of seeds, and has green stems instead of leaves.

Method-In April and May, when the children are looking for flowers, they will find some of these weird looking plants. These should be brought to the schoolroom and the observation lesson given there. soilil?

Observations-r. Where are these plants found? On what kind of 
2. In what respect does this plant differ from other plants in appearance? Can you find any green part to it?

3. What color is the stem? Is it the same size its whole length? Is it smooth or rough?

4. Do you see any leaves on the stems? Do you see the blackpointed scales? In which direction do these scales point? Are they united at the bottom? What sort of a ring do they make around the stem? Split a stem lengthwise and see if there are joints, or nodes, where the ring joins the stalk.

5. How does the "blossom" look? What color are the little discs that make up the blossom? How are the discs set?

6. Take one of the plants which has the discs surrounded by green ridges. Shake it over a white paper. What comes from it? Where does it come from? Which discs on the stalk shed the green spores first?

\section{The Sterile Plants}

Leading thought-The horsetail or Equicetum is nourished by very different looking stems than those which bore the spores. It lacks leaves, but its branches are green and do the work of making food for the plant.

Method-The sterile plants of the horsetail do not appear for several weeks after the fertile ones; they are much more numerous, and do not resemble the fertile plants in form or color. These sterile plants may be used for a lesson in September or October. Some of these plants with their roots may be brought into the schoolroom for study.

Observations-I. Has this plant any leaves? How does it make and digest its food without leaves? What part of it is green? Wherever there is green in a plant, there is the chlorophyl-factory for making food. In the horsetail, then, what part of the plant does the work of leaves?

2. Take off one little branch and study with the lens. How does it look? Pull it apart? Where does it break easily? How many joints, or nodes, are there in the branch?

3. Study the socket from which one of the segments was pulled off. What do you see around its edge? How many of these points? Look at the branch in cross section. How many angles has it? What relation do the points bear to the angles? Do you think these points are all there are left of true leaves?

4. How do the little green branches come off the main stem? How many in a place? How many whorls of branches on the main stem?

5. Study the bases of the branches. What do you see? Look directly above where the whorl of branches comes off the main stem. What do you see? Cut the main stem in cross-section just below this place, and see if there are as many little points as there are angles, or ridges, in the stem. Do you suppose these little points are the remnants of leaves on the main stem?

6. What kind of root has the horsetail? Do you think this long running root is the true root or an underground stem? Where are the true roots? Do you think the rootstock dies off at the oldest end each year, like the fern? Can you find the little tubers in the rootstock, which contain nourishment for next year's spore-bearing stalks? 


\section{THE HAIR-CAP MOSS, OR PIGEON WHEAT}

\section{Teacher's Story}

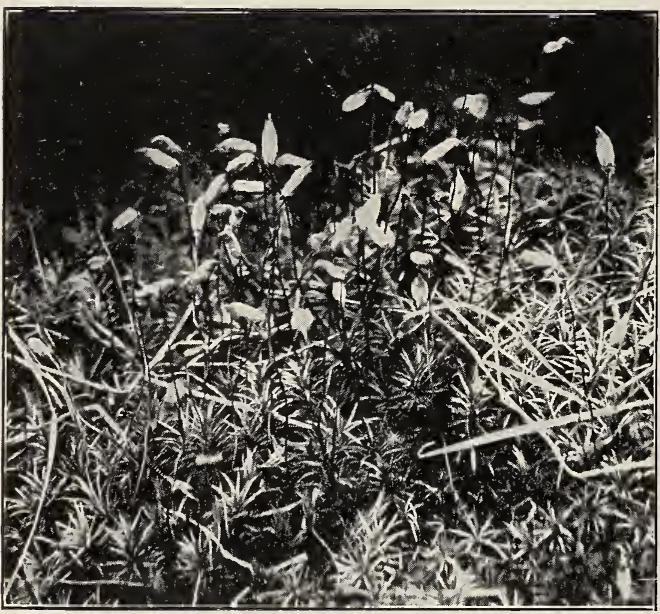

The hair-cap moss.
The mosses are. a special delight to children because they are green and beautiful before other plants have gained their greenness in the spring and after they have lost it in the fall; to the discerning eye, a mossy bankor a mossy $\log$ is a thingof beauty always. When we were children we regarded moss as a forest for fairy folk, each moss stem being a tree, and we naturaily concluded that fairy forests wereevergreen. We also had other diversions with pigeon wheat, for we took the fruiting stem,

pulled the cap off the spore-capsule, tucked the other end of the red stem into the middle of the capsule, making a beautiful coral ring with an emerald "set." To be sure these rings were rather too delicate to last long, but there were plenty more to be had for nothing; so we made these rings into long chains which we wore as necklaces for brief and happy moments, their evanescence being one of their charms.

Pigeon wheat is a rather large moss which grows on dry knolls, usually near the margins of damp woodlands in just those places where wintergreens love to grow. In fall or winter it forms a greenish brown mass of bristling stems; in the early summer the stems are tipped with the vivid green of the new growth. The bristling appearance comes from the long sharp leaves set thickly upon the ruddy brown stems; each leaf is pretty to look at with a lens, which reveals it as thick though narrow, grooved along the middle, the edges usually armed with sharp teeth and the base clasping the stem. These leaves, although so small, are wonderfully made; during the hot, dry weather they shut up lengthwise and twist into the merest threads, in order to keep their soft, green surfaces from losing their moisture by exposure to the air; more than this, they lift themselves and huddle close to the stem, and are thus as snug and safe as may be from the effect of drought; but as soon as the rains come, they straighten back at right angles to the stem, and curve their tips downward in a joyful expanding. Bring in some of this moss and let it dry, and then drop it into a glass of water and watch this miracle of leaf movement! And yet it is no miracle but a mechanism quite automatic-and therefore-like other miracles, when once they are understood. 
In early June the mossy knoll shows us the origin of the name pigeon grass or pigeon wheat, for it is then covered with a forest of shining, ruddy, stiff, little stems, each stem bearing on its tip a woolly object about the

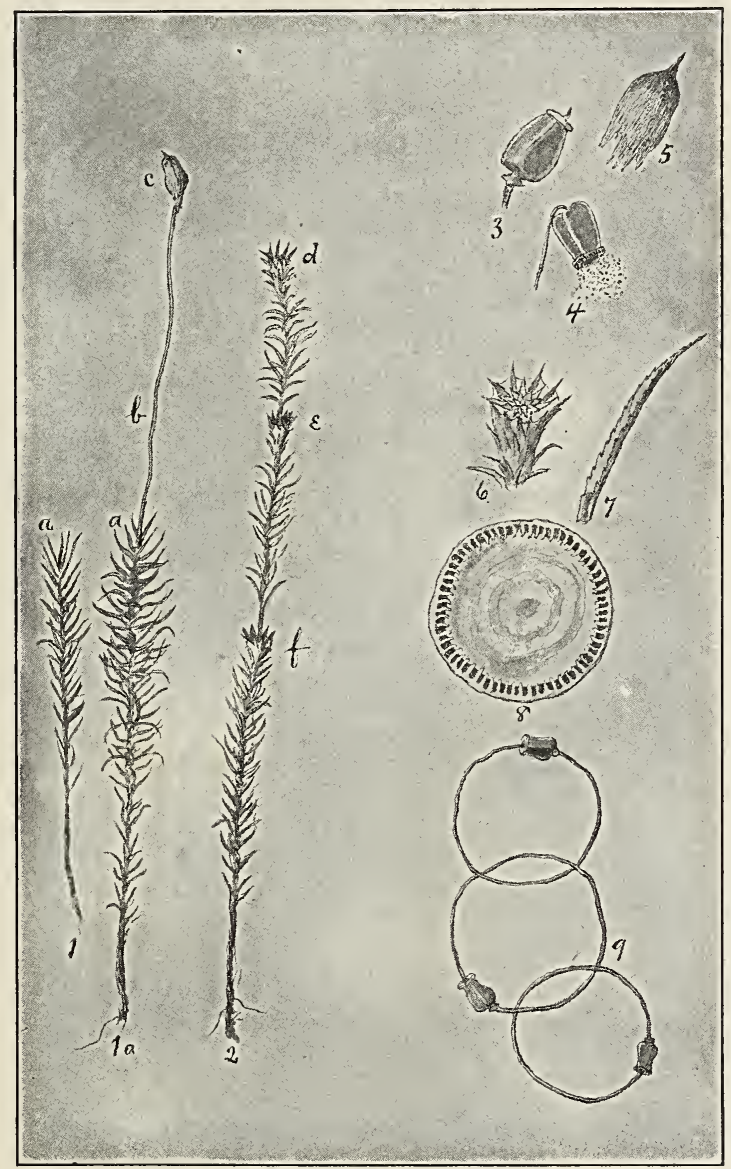

\section{Hair-cap moss.}

1 , fruit-bearing moss stem before fertilization; $1 a$, the same stem after fruit is developed; $a$, where the ovule was before fertilization; $b$, fruit stcm; $c$, sporc-capsule wi.h cap or veil upon jt. 2 , stem showing the starlike cups; $d$, the cup in which was developed the pollen which fertilized the ovule at $a$, this year; $e$, last year's cup; $f$, the cup of year before last; only the leaves from $e$ to $d$ are alive. 3, spore capsule with the cap removed, showing the lid. 5 , the cap or veil removed. 4 , spore capsule with lid off and shaking out the spores. 6, starlike cup in which the pollen is developed. 7, leaf of moss; 8 , the top of the spore capsule showing the teeth around the edge between which the spores sift out. 9, a part of a necklace chain made of the spore capsules and their stems. 
size of a grain of wheat. But it is safe to say that the pigeons and other birds enjoy our cwn kind of wheat better than this, which is attributed to them.

A study of one of these wheat grains reveals it as covered with a yellowish, mohair cap, ending in a golden brown peak at its tip, as if it were the original pattern of the toboggan cap; it closes loosely and downily around the stem below. This grain is the spore-capsule of the moss; the hairy cap pulls off easily when seized by its tip. This cap is present at the very beginning, even before the stem lengthens, to protect the delicate tissues of the growing spore-case; it is only through a lens that we can see it in all its silky softness. The capsule revealed by the removal of the cap is a beautiful green object, usually four-sided, set upon an elegant little pedestal where it joins the coral stem, and with a lid on its top like a sugar-bowl cover, with a point instead of a knob at its center. When the spores are ripe, this lid falls off, and then if we have a lens we may see another instance of moss mechanism. Looking at the uncovered end of the capsule, we see a row of tiny teeth around the margin, which seem to hold down an inner cover with a little raised rim. The botanists have counted these teeth and find there are 64 . The teeth themselves are not important, but the openings between them are, since only through these openings can the spores escape. In fact, the capsule is a pepper-box with a grating around its upper edge instead of holes in its cover; and when it is fully ripe, instead of standing right side up, it tips over so as to shake out its spores more easily. These teeth are like the moss leaves; they swell with moisture, and thus in rainy weather they, with the inner cover, swell so that not a single spore can be shaken out. If spores should come out during the rain, they would fall among the parent plants where there is no room for growth. But when they emerge in dry weather, the wind scatters them far and wide where there is room for development.

When seen with the naked eye, the spores seem to be simply fine dust, but each dust grain is able to produce moss plants. However, the spore does not grow up into a plant like a seed, it grows into fine, green, branching threads which push along the surface of damp soil; on these threads little buds appear, each of which grows up into a moss stem.

The spore-capsule is hardly the fruit of the moss plant. If we examine the moss, we find that some stems end in yellowish cups which look almost like blossoms; on closer examination, we find that there are several of these cups, one below the other, with the stem extending up through the middle. The upper cup matured this year, the one below it last year, and so on. These cups are star-pointed, and inside, at the bottom, is a starlike cluster of leaves. Among the leaves of this star-rosette are borne the moss anthers called antheridii, too small for us to see without a high power microscope. The pollen from these anthers is blown over to other plants, some of which produce ovules at their very tips, although the ovule has no leaf-rosette to show where it is. This ovule, after receiving the pollen, grows into the spore-capsule supported on its coral stem. These--stem, capsule and all-grow up out of the mother plant, the red stem is enlarged at its base, and fits into the moss stem like a flagstaff in the socket. After the star-shaped cup has shed its pollen, the stem grows up from its center for an inch or so in height and bears new leaves, and next year will bear another starry cup. 
The brown leaves on the lower part of the moss stem are dead, and only the green leaves on the upper part are living.

And this is the story of the moss cycle:

I. A plant with an ovule at its tip; another plant with a star-cup holding the moss pollen which is sifted by wind over to the waiting egg.

2. The egg or ovule as soon as fertilized develops into a spore-capsule, and is lifted up into the world on a beautiful shining stem and is protected by a silky cap.

3. The cap comes off; the lid of the spore-case falls off, the spores are shaken out and scattered by the wind.

4. Those spores that find fitting places grow into a net of green threads.

5. These green threads send up moss stems which repeat the story.

\section{LESSON CLXXVIII}

\section{The Hair-Cap Moss}

Leading thought-The mosses, like the butterfly and the fern, have several stages in their development. The butterfly stages are the egg, the caterpillar, the chrysalis, the butterfly. The moss stages are the egg (or ovule), the spores, the branching green threads, the moss plants with their green foliage. In June we can easily find all these stages, except perhaps the branching thread stage.

Method-The children should bring to the schoolroom a basin of moss in its fruiting stage; or still better, go with them to a knoll covered with moss. Incidentally tell them that this moss, when dried, is used by the Laplanders for stuffing their pillows, and that the bears use it for their beds. Once, a long time ago, people believed that a plant, by the shape of its leaf or flower, indicated its nature as a medicine, and as this moss looked like hair, the water in which it was steeped was used as a hair tonic.

Observation-r. Take a moss stem with a grain of pigeon wheat at the end. Examine the lower part of the stalk. How are the leaves arranged on it? Examine one of the little leaves through a lens and describe its shape, its edges, and the way it joins the stem. Are the lower leaves the same color as the upper ones? Why?

2. Describe the pretty shining stem of the fruit, which is called the pedicel. Is it the same color for its entire length? Can you pull it easily from the main plant? Describe how its base is embedded in the tip of the plant.

3. Note the silken cap on a grain of the pigeon wheat. This is called the veil. Is it all the same color? Is it grown fast to the plant at its lower margin? Take it by the tip, and pull it off. Is this done easily? Describe what it covers. This elegant little green vase is called a sporecapsule. How many sides has it? Describe its base which stands upon the stem. Describe the little lid. Pull off the lid; is there another lid below it? Can you see the tiny teeth around the edge which hold this lid in place? Ask your teacher, or read in the books, the purpose of this.

4. Do all the spore vases stand straight up, or do some bend over?

- 5. Do you think the silken cap falls off of itself after a while? Can you find any capsules where the cap or veil and the lid have fallen off? See if you can shake any dust out of such a spore vase. What do you 
think this dust is? Ask your teacher, or read in the books, about moss spores and what happens if they find a damp place in which to grow.

6. Hunt among the moss for some stems that have pretty, yellowish, starlike cups at their tips. How does the inside of one of these cups look? Ask the teacher to tell you what grows in this cup. Look down the stem and see if you can find last year's cup. The cup of two years ago? Measured by these cups how old do you think this moss stem is?

7. Select some stems of moss, both those that bear the fruit and those that bear the cups. After they are dried describe how the leaves look. Examine the plant with a lens and note how these leaves are folded and twisted. Do the leaves stand out from the stem or lie close to it? Is this action of the leaves of any use to the plant in keeping the water from evaporating? How do the star-cups look when dry?

8. Place these dried stems in a glass of water and describe what happens to the cup. Examine some of the dried moss and the wet moss with a lens, and describe the difference. Of what use to the moss is this power of changing form when damp?

Reference-First Lessons in Plant Life, Atkinson.

\section{MUSHROOMS AND OTHER FUNGI}

\section{Teacher's Story}

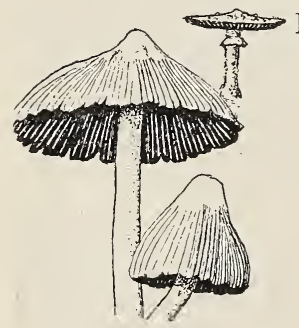

HERE is something uncanny about plants which have no green parts; they seem like people without blood. It is; therefore, no wonder that many superstitions cluster about toadstools. In times of old, not only did the toads sit on them, but fairies danced upon them and used them for umbrellas. The poisonous qualities of some species made them also a natural ingredient of the witch's cauldron. But science, in these days, brings revelations concerning these mysterious plants which are far more wonderful than the web which superstition wove about them in days of yore.

When we find plants with no green parts which grow and thrive, though unable to manufacture theirown organic food through the alchemy of chlorophyl, sunlight and air, we may safely infer that in one way or another they gain the products of this alchemy at second hand. Such plants are either parasites or saprophytes; if parasites, they steal the food from the cells of living plants; if saprophytes, they live on such of this food material as remains in dead wood, withered leaves, or soils enriched by their remains.

Thus, we find mushrooms and other fungus fruiting bodies, pallid, brown-olive, yellow or red in color, but with no signs of the living green of other plants; and this fact reveals their history. Some of them are parasites, as certain species of bracket fungi which are the deadly enemies of living trees; but most of the fungus species that we ordinarily see are saprophytes, and live on dead vegetation. Fungi, as a whole, are a zreat boon to the world. Without them our forests would be choked 
out with dead wood. Decay is simply the process by which fungi and other organisms break down dead material, so that the major part of it returns to the air in gaseous form, and the remainder, now mostly humus, mingles with the soil.

As a table delicacy, mushrooms are highly prized. A very large number of species are edible. But every year the newspapers report deaths resulting from eating the poisonous kinds-the price of an ignorance which comes from a lack of the powers of observation developed in nature-study. It would be very unwise for any teacher to give rules to guide her pupils in separating edible from poisonous mushrooms, since the most careful directions may be disregarded or misunderstood. She should emphasize the danger incurred by mistaking a poisonous for an edible species. One small button of the deadly kind, if eaten, may cause death. A few warning rules may be given, which if firmly impressed on the pupils, may result in saving human life.

First and most important, avoid all mushrooms that are covered with scales, or that have the base of the stem included in a sac, for two of the poisonous species, often mistaken for the common edible mushroom, have these distinguishing characters. Care should be taken that every specimen be collected in a way to show the base of the stem, since in some poisonous species this sac is hidden beneath the soil.

Second, avoid the young, or button, stages, since they are similar in appearance in species that are edible and in those that are poisonous.

Third, avoid those that have milky juices; unless the juices are reddish in color, the mushrooms should not be eaten.

Fourth, avoid those with shiny, thin, or brightly colored caps, and those with whitish or clay-colored spores.

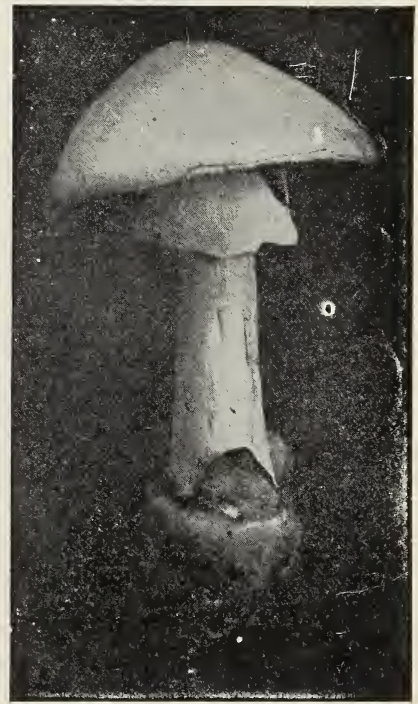

White form of the deadly Amanita (A. phalloides). Note the form of the ring and the cup at base of stem. Photo by G. F. Atkinson.

Fifth, no mushroom or puffball should be eaten after its meat has begun to turn brown or has become infested with fly larvæ.

\section{How Mushrooms Look and How They Live}

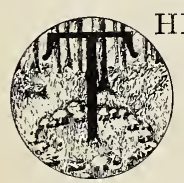

HERE are many kinds of mushrooms varying greatly in form, color and size, but wherever they appear it means that sometime previous the mushroom spores have been planted there. There they threw out threads which have penetrated the food substance and gained a successful growth, which finally resulted in sending up into the world the fruiting organs. In general shape these consist of a stem with a cap upon it, making it usually somewhat umbrella-shaped. Attached to the 
cap, and usually under it, are plate-like growths called gills, or a fleshy surface which is full of pores. In the case of the gills, each side of each
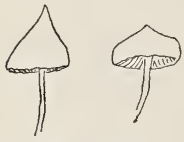

Cone. Bellshaped. shaped.

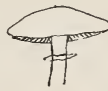

Convex.

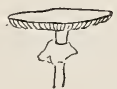

Plane.

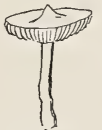

Raised at center.

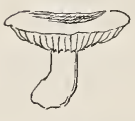

Depressed

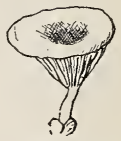

Funnel form.

plate develops spores. These, as fine as dust, are capable of producing other mushrooms.

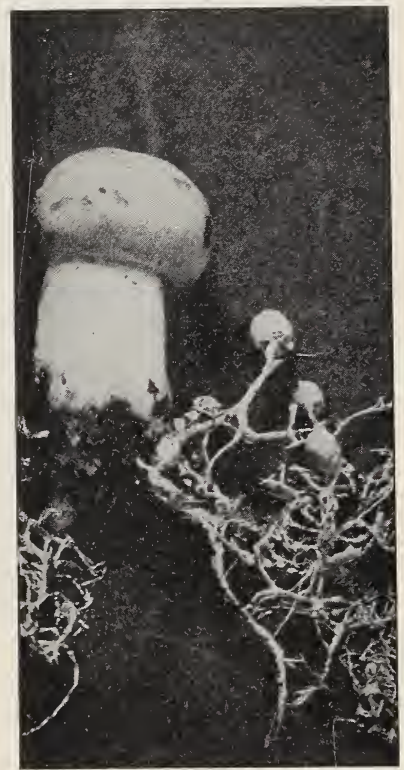

The common edible mushroom, in button stages, mycelium or spawn also shown.

Photo by G. F. Atkinson.
In the common edible species of mushroom (Agaricus campestris), the stem is white and almost cylindrical, tapering slightly toward the base; it is solid although the core is not so firm as the outside. When it first pushes above the ground, it is in what is called the "button stage" and consists of a little, rounded cap covered with a membrane which is attached to the stem. Later the cap spreads wide, for it is naturally umbrella-shaped, and it tears loose this membrane, leaving a piece of it attached to the stem; this remnant is called the ring or collar. The collar is very noticeable in many species, but in the common mushroom it soon shrivels and disappears. The cap is at first rounded and then convex; its surface is at first smooth, looking soft and silky; but as the plant becomes old, it is often broken up into triangular scales which are often dark brown; although the color of the cap is usually white or pale brown. The gills beneath the cap are at first white, but later, as the spores mature, they become brownish black because of the ripened spores.

References-Mushrooms, a most excellent and practical book with many beautiful pictures, written and illustrated by Professor George F. Atkinson; Henry Holt \& Co., N. Y., \$3.00; The Mushroom Book, Marshall, fully illustrated, \$4.0o, Doubleday, Page \& Co.; One Thousand American Fungi, Mcllvaine, illustrated, Bowen-Merrill Co., \$5.00; Our Edible Toadstools and Mushrooms, W. H. Gibson, very fully illustrated, Harper and Bros., $\$ 3 \cdot 5 \circ$. 


\section{LESSON CLXXIX}

\section{Mushrooms}

Leading thought-Mushrooms are the fruiting organs of the fungi which grow in the form of threads, spreading in every direction through the food material. The dust which falls from ripe mushrooms is made up of spores which are not true seeds, but which will start a new growth of the fungus.

Method-The ideal method would be to study the mushrooms in the field and forest, making an excursion for the purpose of collecting as many

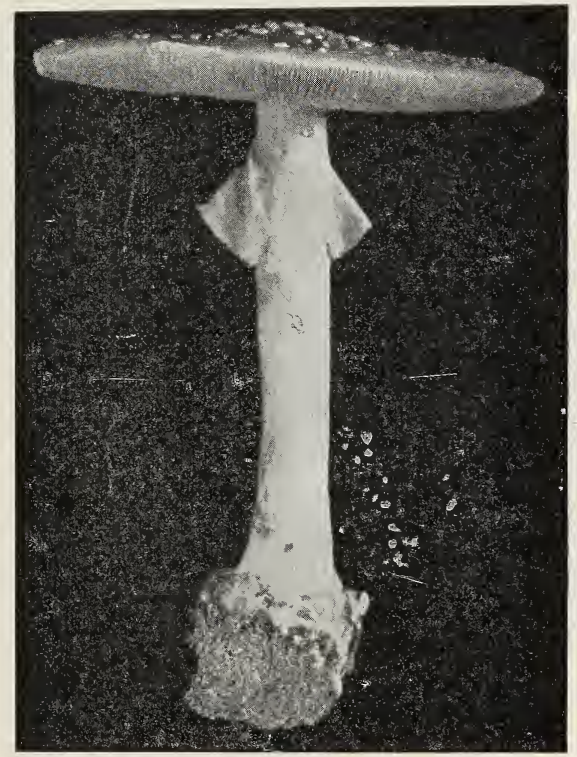

Dark form of the Amanita (A. phalloides). Compare with white form on page 707 .

Photo by George F. Atkinson.

species as possible. But the lesson may be given from specimens brought into the schoolroom by pupils, care being taken to bring with them the soil, dead wood or leaves on which they were found growing. After studying one species thus, encourage the pupils to bring in as many others as possible. There are a few terms which the pupils should learn to use, and the best method of teaching them is to place the diagrams shown on pages 708, 7 II, 7 I2, on the blackboard, and leave them there for a time.

Since mushrooms are especially good subjects for water-color and pencil studies, it would add much to the interest of the work if each pupil, or the school as a whole, should make a portfolio of sketches of all the species found. With each drawing there should be made on a supplementary sheet a spore-print of the species. White paper should be covered 
very thinly with white of egg or mucilage, so as to hold fast the discharged spores when making these prints for portfolio or herbarium.

Observations-I. Where was the mushroom found? If on the ground, was the soil wet or dry? Was it in open fields or in woods? Or was it found on rotten wood, fallen leaves, old trees or stumps, or roots? Were there many or few specimens?

2. Is the cap cone-shaped, bell-shaped, convex, plane, concave, or funnel-form? Has it a raised point at the center? How wide is it?

3. What is the color of the upper surface of the cap when young? When old? Has it any spots of different colors on it? Has it any striate markings, dots or fine grains on its surface? Is its texture smooth or scaly? Is its surface dull, or polished, or slimy? Break the cap and note the color of the juice. Is it milky?

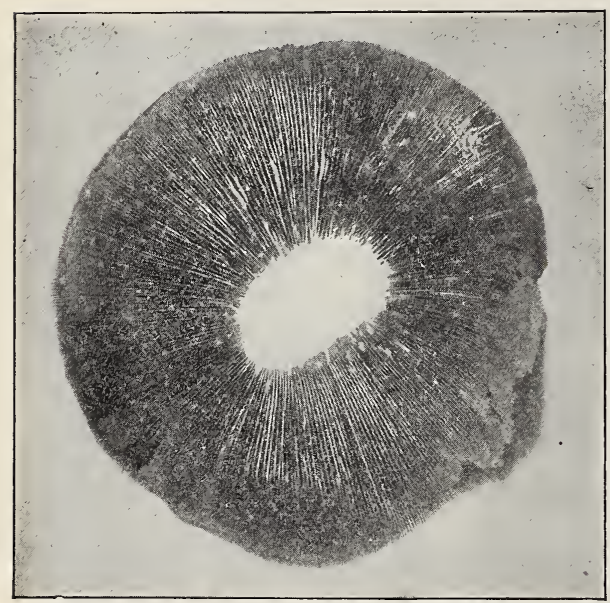

A spore print from the common edible mushroom. Photo by George F. Atkinson.

4. Look beneath the cap. Is the under surface divided into plates like the leaves of a book, or is it porous?

5. The plates which may be compared to the leaves of a book are called gills, although they are not for the purpose of breathing, as are the gills of a fish. Are there more gills near the edge of the cap than near the stem? How does this occur? What are the colors of the gills? Are the gills the same color when young as when old? Are the lower edges of the gills sharp, blunt or saw-toothed?

6. Break off a cap and note the relation of the gills to the stem. If they do not join the stem at all they are termed "free." If they end by being joined to the stem, they are called "adnate" or "adnexed." If thcy extend down the stem they are called "decurrent."

7. Take a freshly opened mushroom, cut off the stem, even with the cap, and set the cap, gills down, on white paper; cover with a tumbler, or other dish to exclude draught; leave it for twenty-four hours and then remove the cover, lift the cap carefully and examine the paper. What color is the imprint? What is its shape? Touch it gently with a pencil and see what makes the imprint. Can you tell by the pattern where this fine dust came from? Examine the dust with a lens. This dust is made up of mushroom spores, which are not true seeds, but which do for mushrooms what seeds do for plants. How do you think the spores are scattered? Do you lnow that one little grain of this spore dust would start a new growth of mushrooms? 


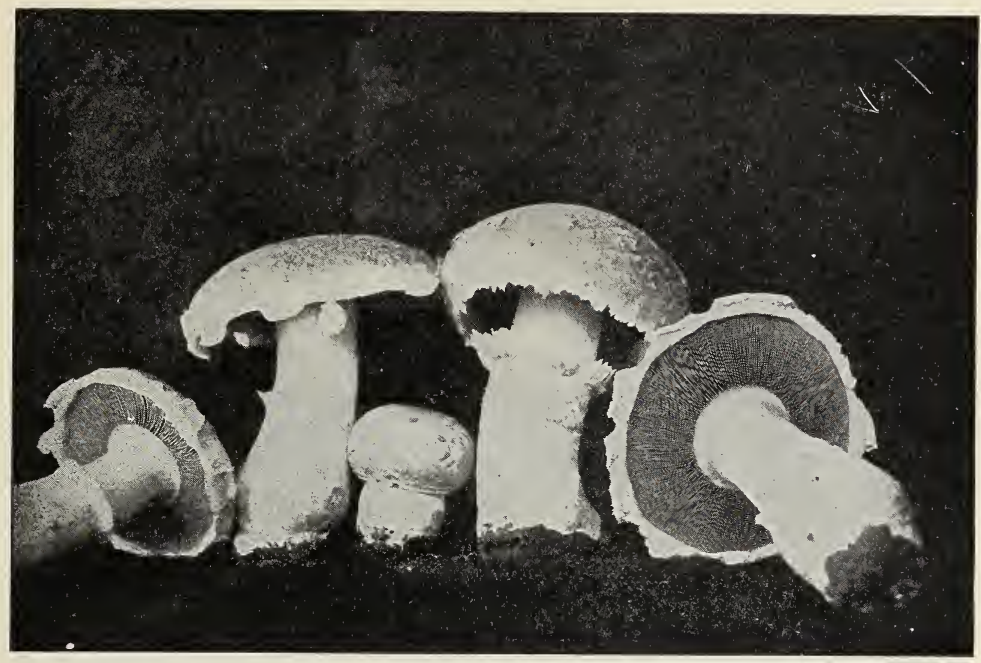

The common edible mushroom (Agaricus campestris), showing button stage, vanishing ring and gills.

Photo by George F. Atkinson.

8. Look at the stem. What is its length? Its color? Is it slender or stocky? Is its surface shiny, smooth, scaly, striate or dotted? Has it a collar or ring around it near the top? What is the appearance of this ring? Is it fastened to the stem, or will it slide up and down? Is the stem solid or hollow? Is it swollen at its base? Is its base set in a sac or cup, or is it covered with a membrane which scales off? Do you know that the most poisonous of mushrooms have the sac or the scaly covering at the base of the stem?

9. Examine with a lens the material on which the mushroom was growing; do you see any threads in it that look like mold? Find if you can what these threads do for the mushroom? If you were to go into the mushroom business what would you buy to start your beds? What is mushroom "spawn?"

Io. If you can find where the common edible mushrooms grow plentifully, or if you know of any place where they are grown for the market, get some of the young mushrooms when they are not larger than a pea and others that are larger and older. These young mushrooms are called "buttons." Find by your own investigation the relation be-

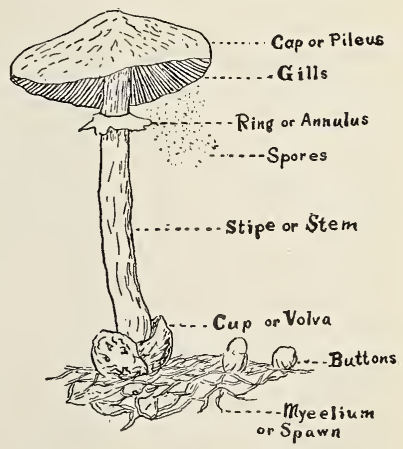

Mushroom with parts named. tween the buttons and the threads. Can you see the gills in the button? 

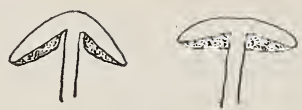

Gills free.
Gills adnexed.

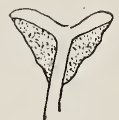

Gills decurrent.

Why? What becomes of the veil over the gills as the mushrooms grow large?

I I. Do you know the difference between mushrooms and toadstools? Do you know the common edible mushroom when you see it? What characters separate this from the poisonous species? What is the "death cup," as it is called, which covers the base of the stem of the most common poisonous species?

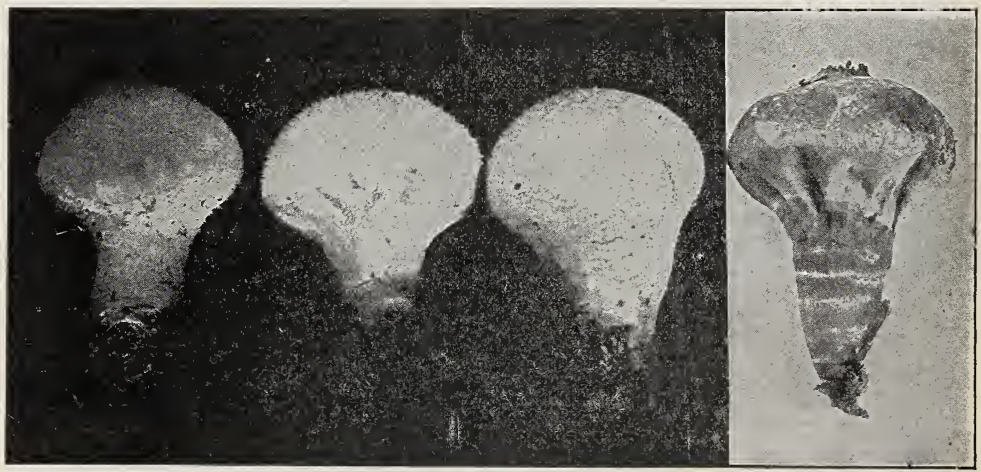

A common species of puffball, the three at the left showing early stages, the one at the right ripe and discharging spores.

Photo by G. F. Atkinson.

\section{PUFFBALLS \\ Teacher's Story}

The puffballs are always interesting to children, because of the "smoke" which issues from them in clouds when they are pressed between thumb and finger. The common species are white or creamy when young; and some of the species are warty or roughened, so that as children we called them "little lambs." They grow on the ground usually, some in wet. shady places, and others, as the giant species, in grassy fields in late summer. This giant puffball always excites interest, when found. It is a smoothish, white, rounded mass, apparently resting on the grass as if thrown there; when lifted it is seen that it has a connection below at its center, through its mycelium threads, which form a network in the soil. It is often a foot in diameter, and specimens four feet through have been recorded. When its meat is solid and white to the very center, it makes very good food. The skin should be pared off, the meat sliced and sprinkled with salt and pepper and fried in hot fat until browned. All the puffballs are edible, but ignorant persons might mistake the button stages of some of the poisonous mushrooms for little puffballs, and it is not well to encourage the use of small puffballs for the table. 
A common species- "the beaker puffball"-is pear-shaped, with its small end made fast to the ground, which is permeated with its vegetative threads.

The interior of a puffball, "the meat," is made up of the threads and spores. As they ripen, the threads break up so that with the spores they make the "smoke," as can be seen if the dust is examined through a microscope. The outer wall may become dry and brittle and break open to allow the spores to escape, or one or more openings may appear in it as spore doors. The spores of puffballs were used extensively in pioneer days to stop the bleeding of wounds and especially for nosebleed.

In one genus of the puffball family, the outer coat splits off in points on maturing, like an orange peel cut

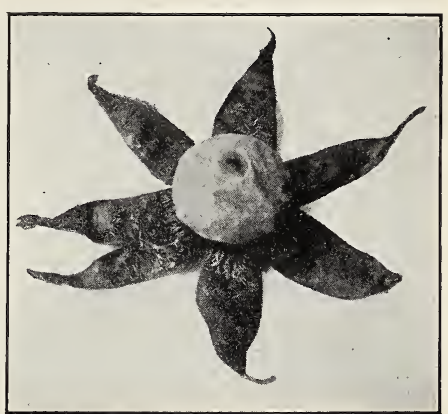

An earth-star.

Photo by Verne Morton. length wise in six or seven sections but still remaining attached to the base. There is an inner coat that remains as a protection to the spores, so that these little balls are set each in a little star-shaped saucer. These star points straighten out flat or even curl under in dry weather, but when damp they lift up and again envelop the ball to a greater or less extent.

\section{LESSON CLXXX}

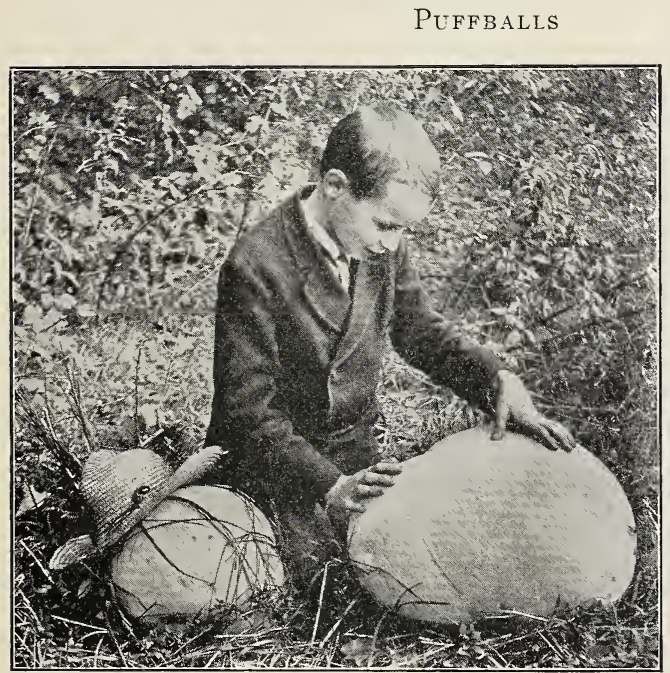

A big puffball.
Photo by Verne Morton.
Leading thoughtThe puffballs are fungi that grow from the threads, or mycelium, which permeate the ground or other matter on which the puffballs grow. The puffballs are the fruiting organs, and "smoke" which issues from th e $\mathrm{m}$ is largely made up of spores, which are carried off by the wind and sown and planted.

Method-Ask the pupils to bring to school any of the globular or pearshaped fungi in the early stages when 
they are white, taking pains to bring them on the soil or wood on which they are growing.

Observations-I. Where did you find the puffball? On what was it growing? Were there many growing in company? Remove the puffball, and examine the place where it stood with a lens to find the matted and crisscrossed fungus threads.

2. What is the size and shape of the puffball? Is its surface smooth or warty? What is its color inside and outside?

3. Have you ever found the giant puffball, which may become four inches to four feet through? Where was it growing? Have you evet eaten this puffball sliced and fried? Do you know by the looks of the meat when it is fit to eat?

4. If the puffball is ripe, what is its color outside and in? What is the color of its "smoke?" Does the smoke come out through the broken covering of the puffball, or are there one or more special openings to allow it to escape?

5. Puff some of the "smoke" on white paper and examine it with a lens. What do you think this dust is? Of what use is it to the puffball?

6. Have you ever found what are called earth-stars, which look like little puffballs set in star-shaped cups? If you find these note the following things:

a. Of what is the star-shaped base made? Was it always there?

b. Let this star saucer become very dry; how does it act?

c. Wet it; and how does it behave then?

d. Where and how does the spore dust escape from the earth-stars?

7. For what medicinal purpose is the "smoke" of the puffball sometimes used?

\section{THE BRACKET FUNGI Teacher's Story}

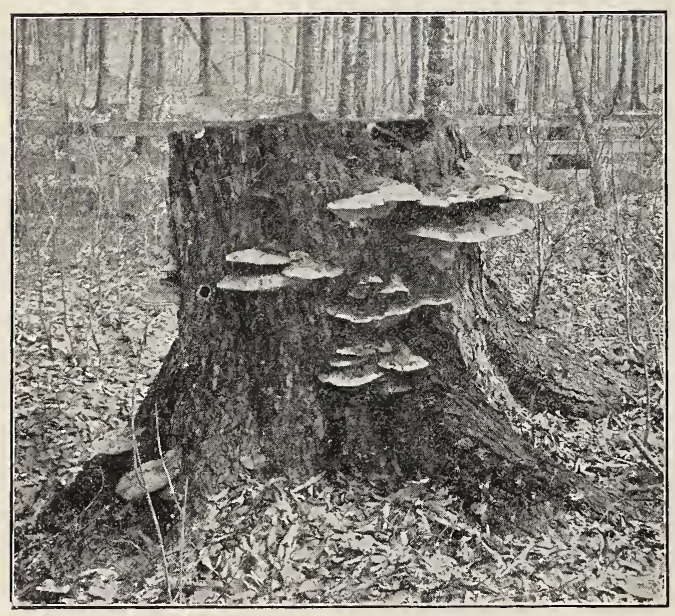

$A$ bracket fungus.
There are some naturalists whothink that one kind of life is as good as another and therefore call all things good. Perhaps this is the only true attitude for the nature lover. To such the bracketlike fungi which appear upon the sides of our forest and shade trees are simply an additional beauty, a bountiful ornamentation. But some of us have become special pleaders in our attitude toward life, and those of us who have come to 
feel the grandeur of tree life can but look with sorrow upon these fungus outgrowths, for they mean that the doom of the tree is sealed.

There are many species of bracket fungi. Three of these are very common. The gray bracket, gray above and with creamy surface below (Polyporous applanatus) is a favorite for amateur etchers, who with a sharp point make interesting sketches upon this naturally prepared plate; this species often grows tc great size and is frequently very old. Another species $(P$. lucidus $)$ is in color a beautiful mahogany, or coral-red above and has a peculiar stem from which it depends; the stem and upper surface are polished as if burnished and the lower surface is yellowish white. Another species ( $P$. sulphurens) is sulphur yellow above and below: usually many of these yellow brackets are grouped together, their fanshaped caps overlapping. Many of the shelf fungi live only on dead wood, and those are an aid in reducing dead branches and stumps until they crumble and become again a part of the soil. However, several of the species attack living trees and do great damage. They can gain access to the living tree only through an injured place in the bark, a break caused perhaps by the wind, by a bruise from a falling tree, or more often from the hack of the careless wood-chopper; often they gain entrance through an unhealed knot-hole. To one who understands trees and loves them, their patient striving to heal these wounds inflicted by forces they cannot withstand is truly pathetic. After the wound is made and before the healing is accomplished, the wind may sift into the wound the almost omnipresent spores of these fungi and the work of destruction begins. From the spores grows the mycelium, the fungus threads which push into the heart of the wood getting nourishment from it as they go. When we see wood thus diseased we say that it is rotting, but rotting merely means the yielding up of the body substance of the tree to these voracious fungus threads. They push in radially and then grow upward and downward, weakening the tree where it most needs strength to withstand the onslaught of the wind. Later these parasitic threads may reach the cambium layer, the living ring of the tree trunk, and kill the tree entirely; but many a tree has lived long with the fungus attacking its heartwood. A bracket fungus found by Professor Atkinson was eighty years old; however, this may have shortened the life of the tree a century or more.

After these fungus threads are thoroughly established in the tree, they again seek a wound in the protecting bark where they may push out and build the fruiting organ, which we call the bracket. This may be at the same place where the fatal entry was made, or it may be far from it. The bracket is at first very small and is composed of a layer of honeycomb cells, closed and hard above and opening below-celis so small that we can see the cell openings only with a lens. These cells are not hexagonal like the honeycomb, but are tubes packed together. Spores are developed in each tube. Next year another layer of cells grows beneath this first bracket and extends out beyond it; each year it is thus added to, making it thicker and marking its upper surface with concentric rings around the point of attachment. The creamy surface of the great bracket fungus on which etchings are made, is composed of a layer of these minute sporebearing tubes. Not all bracket fungi show their age by these annual growths, for some species form new shelves every year, which decay after the spores are ripened and shed. 
When once the mycelium of such fungus becomes established, the tret is doomed and its lumber made worthless even though, as sometimes happens, the tree heals its wounds so that the fungus is imprisoned and can never send out fruiting brackets. Thus it is most important to teach the pupils how to protect trees from the attacks of these enemies, which are devastating our forests and which sometimes attack our orchards and shade trees.

As soon as a tree is bruised, the wound should be painted or covered with a coat of tar. If the wind breaks a branch, the splinters left hanging should be sawed off, leaving a smooth stump, and this be painted. While ordinary paint if renewed each year will suffice, experiment has shown that the coat of tar is better and should be used.

Especially should teachers impress on pupils the harm done by careless hacking with axe or hatchet. We shall do an invaluable service in the protection of our forests, if we teach the rising generation the respectful treatment of trees-which is due living organisms whose span of life may cover centuries.

\section{LESSON CLXXXI}

\section{Bracket Fungi}

Leading thought-The fungi which we see growing shelflike from trees, are deadly enemies to the trees. Their spores germinate and penetrate at some open wound and the growing fungus weakens the wood.

Method-It is desirable that a tree on which shelf fungus grows should be studied by the class, for this is a lesson on the care of trees. After this lesson the fungus itself may be studied at leisure in the schoolroom.

Observations-r. On what kind of a tree is the bracket fungus growing? Is it alive or dead? If living, does it look vigorous or is it decaying?

2. Is the fungus bracket growing against the side of the tree, or does it stand out on a stem?

3. Look at the place where the bracket joined the tree. Does it seem to be a part of the wood?

4. What color is the fungus on its upper surface? How large is it? How thick near the tree? How thick at the edge? Can you detect concentric layers or rings? If it is the large species used for etching, cut down through it with a knife or hatchet and count the layers; this should show its age.

5. Look at the lower surface. How does it appear to the naked eye? If you scratch it with a pin or knife does the bruise show? Examine the surface with a lens and describe what you see. Cut or break the fungus and note that each of these holes is an opening to a little tube. In each of these tubes spores are borne.

6. Have you ever seen toadstools that, instead of having the leaflike gills, have beneath the cap a porous surface like a little honeycomb or like the under side of the shelf fungi?

7. How many kinds of shelf fungi can you find? Which of them is on living trees, and which on stumps or dead wood?

8. If the fungus is on a living tree, then the tree is ruined, for the fungus threads have worked through it and weakened it so that it will break easily and is of no use as lumber. There must have been an open wound in the tree where the fungus entered; see whether you can find this 
wound. There must also have been a wound where the shelf grew out; see whether you can detect it. If the tree should heal all its wounds after the fungus entered, what would become of the fungus?

9. What does the shelf fungus feed on? What part of it corresponds to the roots and leaves of other plants? What part may be compared to the flowering and fruiting parts of plants?

Io. What treatment must we give trees to keep them free from this enemy?

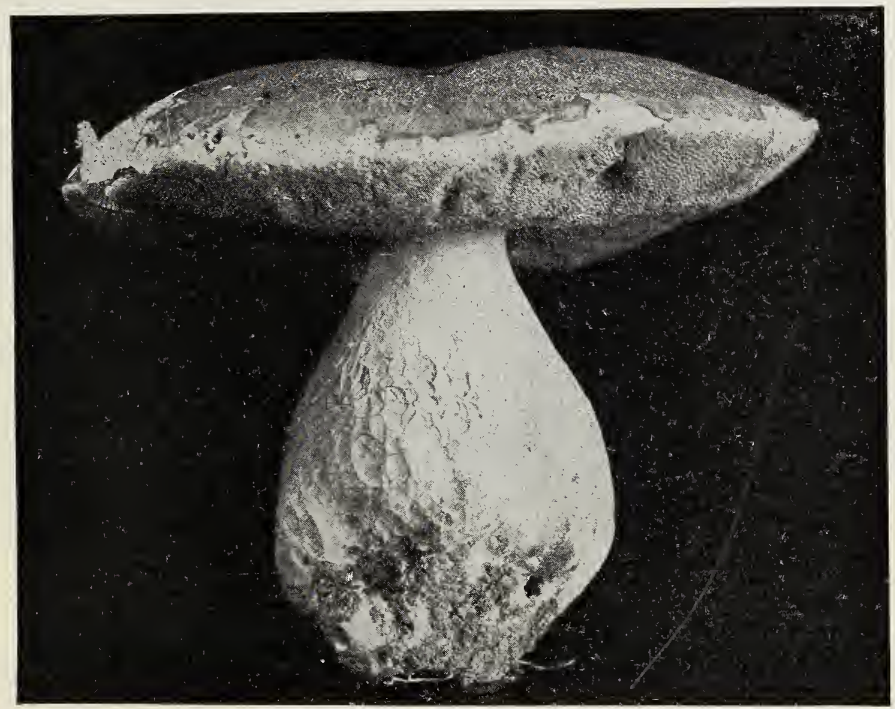

The edible Boletus (B. edulis). This has tubes below the cap instead of gills. The spores are developed within the tubes, as in the bracket fungi. Photo by G. F. Atkinson.

\section{LESSON CLXXXII \\ Hedgehog Fungi}

There is something mysterious about all fungi, but perhaps none of these wonderful organi ms so strangely impresses the observer as the fountainlike masses $c$ creamy white or the branching white coral that we see growing on a dead tree trunk. The writer remembers as a child that the finding of these woodland treasures made her feel as if she were in the presence of the supernatural, as if she had discovered a fairy grotto or a kobold cave. The prosaic name of hedgehog fungi has been applied to these exquisite growths. Their life story is simple enough. The spores falling upon dead wood start threads which ramify within it and feed on its substance, until strong enough to send out a fruiting organ. This consists of a stem, dividing into ascending branches; from these branches, depending like the stalactites in a cave, are masses of drooping spines, the surface of each bearing the spores. And it is so natural for these spines to hang earthward that they are invariably so placed when the tree is in the posi- 


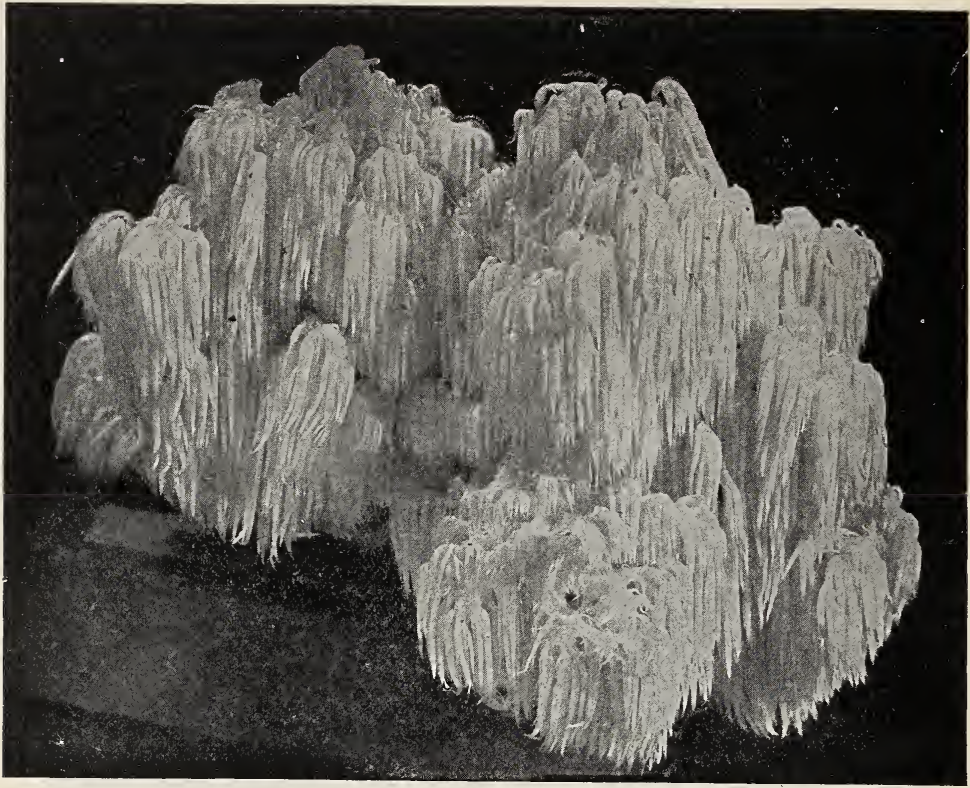

The bear's head fungus.

Photo by George F. Atkinson.

tion in which they grew. There is one species called the "satyr's beard," sometimes found on living trees, which is a mere bunch of downwardhanging spines; the corallike species is called Hydnum coraloides, and the one that looks like an exquisite white frozen fountain, and may be seen in late summer or early autumn growing from dead limbs or branches, is the bear's head fungus; it is often eight inches across.

Observations- 1 . These fungi come from a stem which extends into the wood.

2. This stem divides into many branchlets.

3. From these branchlets there hang long fleshy fringes like miniature icicles.

4. These fringes always hang downward when tire fungus is in natural position.

5. These fringes bear the spores.

\section{LESSON CLXXXIII}

The Scarlet Saucer (Sarcocypha coccinea)

The heart of the child, searching the woods for hepaticas-woods where snow banks still hold their ground on north slopes-is filled with delight at finding these exquisite saucerlike fungi. They are more often found on fallen rotting branches which are more or less buried in leaves, and there are likely to be several of different sizes on the same stick. 
When they grow unhindered and while they are young, they are very perfectly saucer-shaped and range from the size of a pea to an inch or two across. But the larger they are the more likely are they to be distorted, either by environment or by the bulging of rapid growth. The under side of the saucer is beautifully fleshlike in color and feeling and is attached at

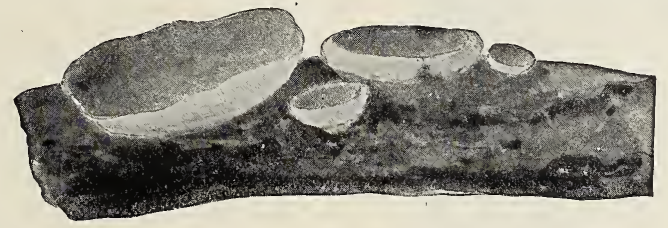

Scarlet saucer.

the middle to the stick. The inside of the saucer is the most exquisite scarlet shading to crimson. This crimson lining bears the spores in little sacs all over its surface.

Observations - - . Where did you find the fungus?

2. What is the shape of the saucer? How large is it? Is it regular and beautiful or irregular and distorted?

3. What is the color inside?

4. What is the color outside?

5. Turn the one you bring in bottom side up-that is, scarlet side down-on a piece of white paper, and see whether you can get a spore harvest.

\section{LESSON CLXXXIV}

\section{The Morels}

In May or June in open, damp places, as orchards or the moist fence corners of meadows, the morels may be found. This mushroom family contains no member that is poisonous, and the members are very unlike any other family in appearance. They are very pretty with their creamy white, thick, swollen stems and a cap more or less conical, made up of the deep-celled meshes of an unequal network. The outside edges of the network are yellowish or brownish when the morel is young and edible, but later turn dark as the spores develop. In some species the stems are comparatively smooth and in others their surface is more or less wrinkled. The spores are borne in the depressions of the network. These mushrooms should not be eaten after the cells change from creamy white to brownish.

Observations- $\mathrm{I}$. Where did you find the morels?

2. Describe the stem. Is it solid or hollow? Is it smooth or rough?

3. What is the shape of the cap? How does it look? What color is the outer edge of the net-

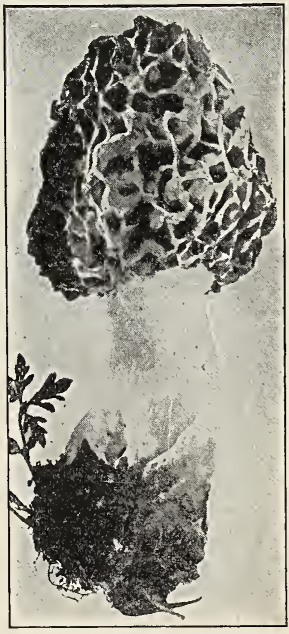

An edible morel (Morchella esculents).

Photo by George F. Atkinson. 


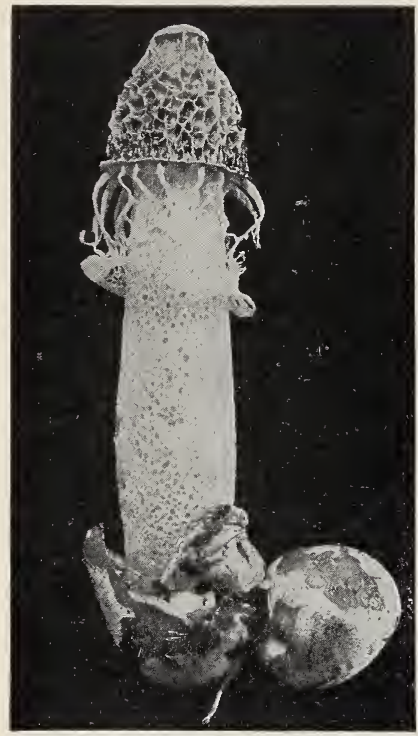

A stinkhorn.

Photo by George F. At kinson.

work? What is the color within the meshes?

4. Take one of these fung1, lay it on a sheet of white paper, and note the rolor of the spores.

\section{LESSON CLXXXV}

\section{THE STINKHORNS}

To give a nature-study lesson on the stinkhorn is quite out of the question, for the odor of these strange growths is so nauseating that even to come near to one of them in the garden is a disagreeable experience. The reason for mentioning them at all is because of the impression made by them that most mushrooms are ill smelling, which is a slander.

It is a pity that these fungi are so offensive that we do not care to come near enough to them to admire them, for they are most interesting in appearance. The scientific name of our commonest genus when translated means "the net bearers," and it is a most appropriate name. The stout, white stem is composed of network without and within. The outer covering of the stem seems to tear loose from the lower portion as the stem elongates, and is lifted so that it hangs as a veil around the bottom of the bell-shaped cap, which is always covered with a pitted network. The mycelium, or spawn, of the stinkhorn consists of strands which push their way through the ground or through the decaying vegetable matter on which they feed. On these strands are produced the stinkhorns, which at first look like eggs; but later the top of the egg is broken, and the strange horn-shaped fungus pushes up through it. The spores are borne in the chambers of the cap, and when ripe the substance of these chambers dissolves into a thick liquid in which the spores float. The flies are attracted by the fetid odor and come to feast upon these fungi and to lay their eggs within them, and incidentally they carry the spores away on their brushy feet, and thus help to spread the species.

\section{MOLDS \\ Teacher's Story}

It is lucky for our peace of mind that our eyes are not provided with microscopic lenses, for then we should know that the dust, which seems to foregather upon our furniture from nowhere, is composed of all sorts of germs, many of them of the deadly kind. The spores of mold are very 
minute objects, the spore-cases being the little white globes, not larger than the head of a small pin which we see upon mold, yet each of these spore-cases breaks and lets out into the world tho11sands of spores, each one ready and anxious to start a growth of mold and perfectly able to do it under the right conditions; almost any substance which we use for food, if placed in a damp and rather dark place, will prove a favorable situation for the development of the spore which swells, bursts its wall and sends out a short thread. This gains nourishment, grows longer and branches, sending out many threads, some of which go down into the nutritive material and are called the mycelium. While these threads, in a way, act like roots, they are not true roots. Presently the tip ends of the threads, which are spread out in the air above the bread or other material, begin to enlarge, forming little globules; the substance (protoplasm) within them breaks up into little round bodies, and each develops a cell wall and thus becomes a spore. When these are unripe they are white but later, they become almost black. In the blue mold the spores are borne in clusters of chains, and resemble tiny tassels instead of growing within little globular sacs.

Molds, mildews, blights, rusts and smuts are all flowerless plants and, with the mushrooms, belong to the great group of fungi. Molds and mildews will grow upon almost any organic substance, if the right conditions of moisture are present, and the temperature is not too cold.

Molds of several kinds may appear upon the bread used in the experiments for this lesson. Those most likely to appear are the bread moldconsisting of long, white threads tipped with white, globular spore-cases, and the green cheese-mold-which looks like thick patches of blue-green powder. Two others may appear, one a smaller white mold with smaller spore-cases, and a black mold. However, the bread mold is the one most desirable for this lesson, because of its comparatively large size. When examined with a lens, it is a most exquisite plant. The long threads are fringed at the sides, and they pass over and through each other, making a web fit for fairies - a web all beset with the sporecases, like fairy pearls. However, as the spores ripen, these spore-cases turn black, and after a time so many of them are developed and ripened that the whole mass of mold is black. The time required for the development of mold varies with the temperature. For two or three

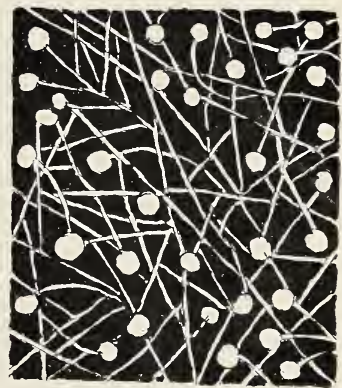

Bread mold, enlarged. days nothing may seem to be happening upon the moist bread; then a queer, soft whiteness appears in patches. In a few hours or perhaps during the night, these white patches send up white fuzz which is soon dotted with tiny pearl-like spore-cases. At first there is no odor when the glass is lifted from the saucer, but after the spores ripen, the odor is quite disagreeable.

The special point to teach the children in this lesson is that dryness and sunlight are unfavorable to the development of mold; and it might be well to take one of the luxuriant growths of mold developed in the dark, uncover it and place it in the sunlight, and see how soon it withers. The 
lesson should also impress upon them that dust is composed, in part, of living germs waiting for a chance to grow.

\section{LESSON CLXXXVI}

\section{MOLDS}

Leading thought-The spores of mold are everywhere and help to make what we call dust. These spores will grow on any substance which gives them nourishment, if the temperature is warm, the air moist and the sunlight is excluded.

Method-Take bread in slices two inches square, and also the juice of apple sauce or other stewed fruit. Have each pupil, or the one who does the work for the class, provided with tumblers and saucers. Use four pieces of bread cut in about two-inch squares, each placed on a saucer; moisten two and leave the other two dry. With a feather or the finger take some dust from the woodwork of the room or the furniture and with it lightly touch each piece of bread. Cover each with a tumbler. Set one of the moistened pieces in a warm, dark place and the other in a dry, sunny place. Place a dry piece in similar situations. Let the pupils examine these every two or three days.

Put fruit juice in a saucer, scatter a little dust over it and set it in a warm, dark place. Take some of the same, do not scatter any dust upon it, cover it safely with a tumbler and put it in the same place as the other. A lens is necessary for this lesson, and it is much more interesting for the pupils if they can see the mold under a microscope with a three-fourths objective.

Observations-I. When does the mold begin to appear? Which piece of bread showed it first? Describe the first changes you noticed. What is the color of the mold at first? Is there any odor to it?

2. At what date did the little branching mold-threads with round dots appear? Is there an odor when these appear? What are the colors of the dots, or spore-cases, at first? When do these begin to change color? How does the bread smell then? What caused the musty odor?

3. Did the mold fail to appear on any of the pieces of bread? If so, where were these placed? Were they moist? Were they exposed to the sunlight?

4. Did more than one kind of mold appear on the bread? If so, how do you know that they are different kinds? Are there any pink or yellow patches on the bread? If so, these are made by bacteria and not by mold.

5. From the results of the experiments, describe in what temperature mold grows best. In what conditions of dryness or moisture? Does it flourish in the sunlight or in the dark?

6. Where does the mold come from? What harm does it do? What should we do to prevent the growth of mold? Name all of the things on which you have seen mold or mildew growing.

7. Examine the mold through a microscope or a lens. Describe the threads. Describe the little round spore-cases. Look at some of the threads that have grown down into the fruit juice. Are they like the ones which grow in the air?

8. If you have a microscope cut a bit of the mold off, place it in a drop of water on a glass slide, put on a cover-glass. Examine it with a three-fourths objective, and describe the spores and spore-cases. 


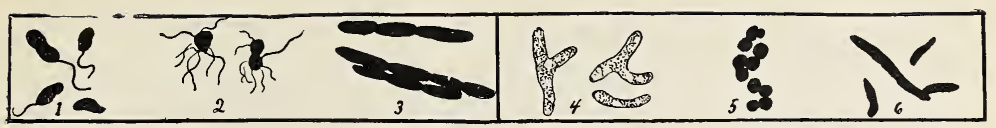

I. Cholera bacillus.

2. Typhoid bacillus.

3. A bacillus found in sewage.

These are all enlarged 2000 times.
4. Bacteria from tubercle on white sweet clover, much enlarged.

5 and 6. Bacteria of lactic acid ferments in ripening of cheese, much enlarged.

\section{BACTERIA}

\section{Teacher's Story}

The yellow, pink or purple spots developed upon the moist and moldy bread are caused by bacteria and yeast. Bacteria are one-celled organisms now classed as plants; they are the smallest known living beings, and can only be seen through a high power microscope.

Bacteria grow almost everywhere-in the soil, on all foods and fruits, in the water of ponds, streams and wells, in the mouths and stomachs of human beings, and in fact in almost all possible places, and occur in the air. Most of them are harmless, some of them are useful, and some produce disease in both plants and animals, including man.

What bacteria do would require many large volumes to enumerate. Some of them develop colors or pigments; some produce gases, often illsmelling; some are phosphorescent; some take nitrogen from the air and fix it in the soil; some produce putrefaction; and some produce disease. Nearly all of the "catching diseases" are produced by bacteria. Diphtheria, scarlet fever, typhoid fever, consumption, influenza, grippe, colds, cholera, lockjaw, leprosy, blood poisoning and many other diseases are the result of bacteria. On the other hand, many of the bacteria are beneficial to man. Some forms ripen the cream before churning, others give flavor to butter; while some are an absolute necessity in making cheese. The making of cider into vinegar is the work of bacteria; some clear the pollution from ponds and streams; some help to decompose the dead bodies of animals, so that they return to the dust whence they came.

We have in our blood little cells whose business it is to destroy the harmful bacteria which get into the blood. These little fighting cells move everywhere with our blood, and if we keep healthy and vigorous by right living, right food and exercise, these cells may prove strong enough to kill the disease germs before they harm us. Direct sunlight also kills some of the bacteria. Seven or eight minutes exposure to bright sunlight is said to kill the germs of tuberculosis. Exposure to the air is also a help in subduing disease germs. Bichloride of mercury, carbolic acid, formaldehyde and burning sulphur also kill germs, and may be applied to clothing or to rooms in which patients suffering from these germ diseases have been. We can do much to protect ourselves from harmful bacteria by being very clean in our persons and in our homes, by bathing frequently and washing our hands with soap often. We should eat only pure and freshly cooked food, we should get plenty of sleep and admit the sunlight to our homes; we should spend all the time possible in the open air and be careful to drink pure water. If we are not sure that the water is pure, it should be boiled for twenty minutes and then cooled for drinking.

In Experiment $\mathrm{A}$ the milk vials and the corks are all boiled, so that we may be sure that no other bacteria than the ones we chose are present, 
since boiling kills these germs. As soon as the milk becomes discolored we know that it is full of bacteria.

Experiment B shows that bacteria can be transplanted to gelatin. which is a material favorable for its growth. But the point of this experiment is to show the child that a soiled finger will have upon it germs which, by growing, cloud the gelatin. They should thus learn the value of washing their hands often or of keeping their fingers out of their mouths.

Experiment $\mathrm{C}$ shows the way the destructive bacteria attack the potato. The discolored spots show where the decay begins, and the odor is suggestive of decay. If a potato thus attacked is put in the bright sunlight the bacteria are destroyed, and this should enforce the moral of the value of sunshine.

References-The Story of the Bacteria; Dust and its Dangers, M. T. Prudden, Putnam's. Bacteria in Relation to Country Life, Lipman.

\section{LESSON CLXXXVII}

\section{BACTERIA}

Leading thought-Bacteria are such small plants that we cannot see them without the aid of a microscope, but they can be planted and will grow. The object of this lesson is to enforce cleanliness.

Method-Experiment A-The bread used for the mold experiment is likely to develop spots of yellow, red or purple upon it, and cultures from these spots may be used in this lesson as follows: Take some vials, boil them and their corks, and nearly fill them with milk that has been boiled. Take the head of a pin or hairpin, sterilize the point by holding in a flame, let it cool, touch one of the yellow spots on the bread with the point, being careful to touch nothing else, and thrust the point with the bacteria on it in to the milk; then cork the vials.

Experiment B-Prepare gelatin as for the table but do not sweeten. Pour some of this gelatin on clean plates or saucers. After it has cooled let one of the children touch lightly the gelatin in one saucer for a few seconds with his soiled finger. Note the place. Ask him to wash his hands thoroughly with soap and then apply a finger to the surface of the gelatin in the other plate. Cover both plates to keep out the dust and leave them for two or three days in a dark place. The plates touched by the soiled finger will show a clouded growth in the gelatin; the other plate will show a few irregular, scattered growths or none.

Experiment $C$ - Take a slice of boiled potato, place in a saucer, leave it uncovered for a time or blow dust upon it, label with date, then cover with a tumbler to keep from drying and place in a cool, somewhat dark place.

The pupils should examine all these cultures every day and make the following notes:

Experiment $A-$ How soon did you observe a change in the color of the milk? How can you tell when the milk is full of the bacteria? How do you know that the bacteria in the milk was transplanted by the pin?

Experiment B-Can you see that the gelatin is becoming clouded where the soiled finger touched it? This is a growth of the bacteria which were on the soiled finger.

Experiment C-What change has taken place in the appearance of the slice of potato? Are there any spots growing upon it? What is the odor? 
What makes the spots? Describe the shape of the spots. The color. Are any of them pimple-shaped? Make a drawing of the slice of potato showing the bacteria spots. What are the bacteria doing to the potato? Take a part of the slice of potato with the bacteria spots upon it, and put it in the sunshine. What happens? Compare this with the part kept in the dark.

After this lesson the children should be asked the following questions.

I. Why should the hands always be washed before eating?

2. Why should the finger nails be kept clean?

3. Why should we never bite the finger nails nor put the fingers in the mouth?

4. Why should we never put coins in the mouth?

5. Why should wounds be carefully cleansed and dressed at once?

6. Why should clothing, furniture and the house be kept free from dust? dust?

7. Why should sweeping be done as far as possible without raising

8. Why are hardwood floors more healthful than carpets? dust?

9. Why is a damp cloth better than a feather duster for removing

Io. Why should the prohibition against spitting in public places be strictly enforced?

Ir. Why should the dishes, clothes and other articles used bysick persons be kept distinctly separate from those used by well members of the family?

I 2. Why should food not be exposed for sale on the street?

I3. Why, during an epidemic, should water be boiled before drinking?

"This habit of looking first at what we call the beauty of objects is closely associated with the old conceit that everything is made to please man: man is only demanding his own. It is true that everything is man's because he may use it or enjoy it, but not because it was designed and 'made' for ' $\mathrm{him}$ ' in the beginning. This notion that ail things were made for man's special pleasure is colossal self-assurance. It has none of the humility of the psalmist, who exclaimed, 'What is man, that thou art mindful of him?"

" 'What were these things made for, then?' asked my friend. Just for themselves! Each thing lives for itself and its kind, and to live is worth the effort of living for man or bug. But there are more homely reasons for believing that things were not made for man alone. There was logic in the farmer's retort to the good man who told him that roses were made to make man happy. 'No, they wa'n't', said the farmer, 'or they wouldn't a had prickers.' A teacher asked me what snakes are 'good for.' Of course there is but one answer: they are good to be snakes."

—“The Nature Study Idea", L. H. Bailey. 


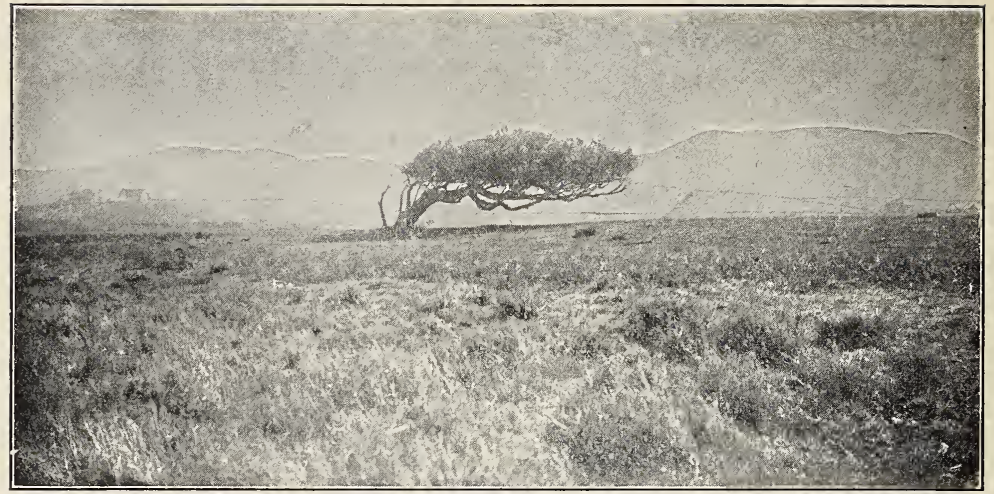

A Pacific Coast live oak showing the effects of constant, strong winds from one direction. Photo by G. K. Gilbert. Courtesy of U. S. Geological Survey.

\section{TREE STUDY \\ Teacher's Story}

"I wonder if they like it-being trees?

I suppose they do.

It must feel so good to have the ground so flat, And feel yourself stand straight up like that.

So stiff in the middle; and then branch at ease,

Big boughs that arch, small ones that bend and blow,

And all those fringy leaves that flutter so.

You'd think they'd break off at the lower end

When the wind fills them, and their great heads bend.

But when you think of all the roots they drop,

As much at bottom as there is on top,

$A$ double tree, widespread in earth and air,

Like a reflection in the water there."

- "Tree Feelings" By Charlotte Perkins Stetson

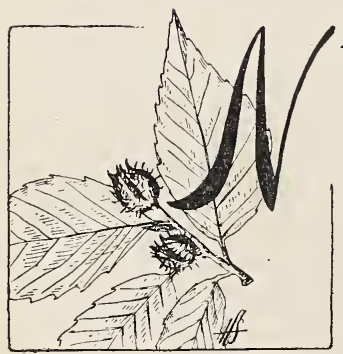

ATURAL is our love for trees! A tree is a living being, with a life comparable to our own. In one way it differs from us greatly: it is stationary, and it has roots and trunk instead of legs and body; it is obliged to wait to have what it needs come to it, instead of being able to search the wide world over to satisfy its wants.

\section{THE PARTS OF THE TREE}

The head, or crown, is composed of the branches as a whole, which in turn are composed of the larger and smaller branches and twigs. The spray is the term given to the outer twigs, the finest divisions of the trunk, which bear the leaves and fruit. The branches are divisions of the bole, or trunk, which is the body, or stem, of the tree. The bole, at the base, 
divides into roots, and the roots into rootlets, which are covered with roothairs. It is important to understand what each of the parts of a tree's anatomy does to help carry on the life of the tree.

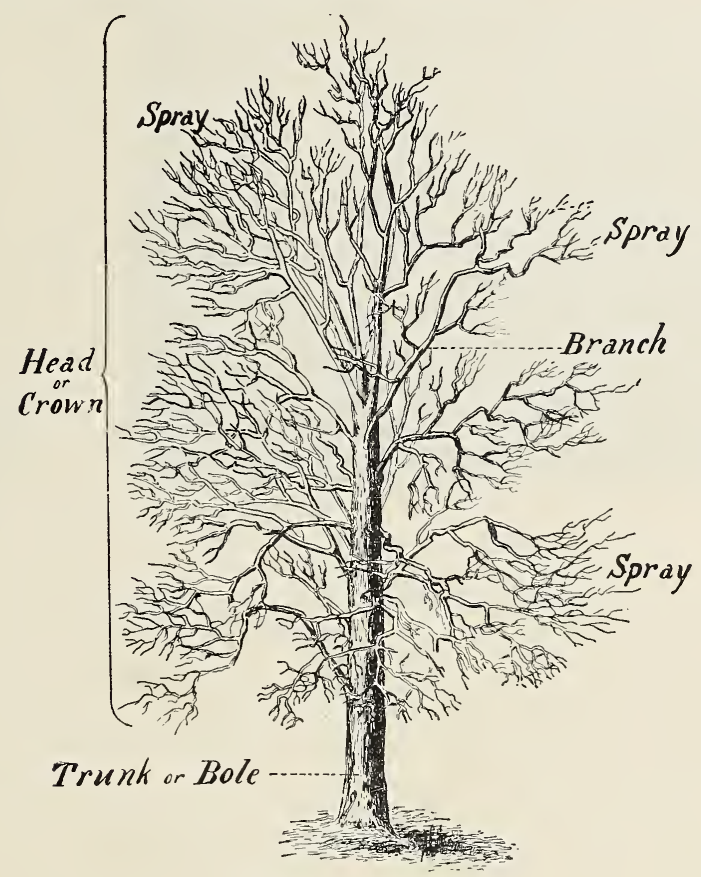

A tree with parts named.

The roots, which extend out in every direction beneath the surface of the ground, have two quite different offices to perform: First, they absorb the water which contains the tree food dissolved from the soil; second, they hold the tree in place against the onslaught of the winds. If we could see a tree standing on its head with its roots spread in the air in the same manner as they are in the ground, we could then better understand that there is as much of the tree hidden below ground as there is in sight above ground, although of quite different shape, being flatter and in a more dense mass. The roots seem to know in which direction to grow to reach water; thus, the larger number of the roots of a tree are often found to extend out toward a stream flowing perhaps some distance from the tree; when they find plenty of food and water the rootlets interlace forming a solid mat. On the Cornell Campus are certain elms which, every six or seven years, completely fill and clog the nearby sewers; these trees send most of their roots in the direction of the sewer pipe. The fine rootlets upon the tree-roots are covered with root-hairs, which really form the mouths by which the liquid food is taken into the tree. 
To understand how firm a base the roots form to hold up the tall trunk, we need to see an uprooted tree. The great roots seem to be molded to take

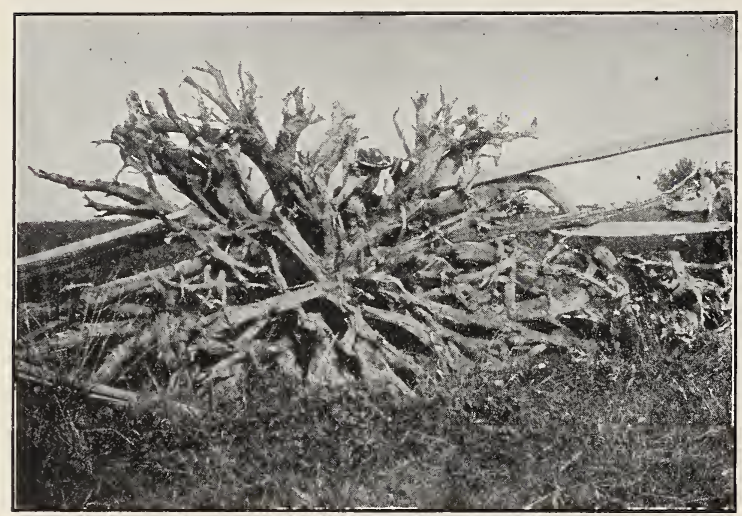

The upturned roots of a white pine; a part of a stump fence a century old. firm grasp upon the soil. It is interesting to study some of the "stump fences" which were made by our forefathers, who uprooted the white pines when the land was cleared of the primeval forest, and made fences of their widespreading but rather shallow extending roots. Many of these fences stand to-day with branching, out-reaching roots, white and weather-worn, but still staunch and massive as if in memory of their strong grasp upon the soil of the wilderness.

The trunk, or bole, or stem of the tree has also two chief offices: It holds the branches aloft, rising to a sufficient height in the forest so that its head shall push through the leaf canopy and expose the leaves to the sunlight. It also is a channel by which the water containing the food surges from root to leaf and back again through each growing part. The branches are divisions of the trunk, and have the same work to do.

In cross-section, the tree trunk shows on the outside the layer of protective bark; next to this comes the cambium layer, which is the vital part of the trunk; it builds on its outside a layer of bark, and on its inside a layer of wood around the trunk. Just within the cambium layer is a lighter colored portion of the trunk, which is called the sap-wood because it is filled with sap which moves up and down its cells in a mysterious manner; the sap-wood consists of the more recent annual rings of growth. Within the sap-wood are concentric rings to the very center or pith; this portion is usually darker in color and is called the heartwood; it no longer has anything to do with the life of the tree, but simply gives to it strength and staunchness. The larger branches, if cut across, show the same structure as the trunk, - the bark on the outside, the cambium layer next, and within this the rings of annual growth. Even the smaller branches and twigs show similar structure, but they are young and have not attained many annual rings.

The leaves are borne on the outermost parts of the tree. A leaf cannot grow, and if it could would be of no use, unless it can be reached by the sunlight. Therefore the trunk lifts the branches aloft, and the branches hold the twigs far out, and the twigs divide into the fine spray, so as to spread the leaves and hold them out into the sunshine. 
In structure, the leaf is made up of the stem, or petiole, and the blade, or widened portion of the leaf, which is sustained usually with a framework of many ribs or veins. The petioles and the veins are sap channels like the branches and twigs.

\section{WOOD-GRAIN}

This is the way that the sap-river ran

From the root to the top of the tree

Silent and dark,

Under the bark,

Working a wonderful plan

That the leaves never know,

And the branches that grow

On the brink of the tide never see.

-ЈонN B. ТАвв.

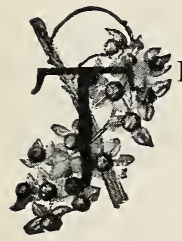

\section{THE WAY A TREE GROWS}

HE places of growth on a tree may be found at the tips of the twigs and the tips of the rootlets; each year through this growth the tree pushes up higher, down deeper and out farther at the sides. But in addition to all of these growing tips, there is a layer of growth over the entire treeover every root, over the trunk, over the limbs and over each least twig, just as if a thick coat of paint had been put over the complete tree. Ii is a coat of growth instead, and these coats of growth make the concentric rings which we see when the trunks or branches are cut across. Such growth as this cannot be made without food; but the tree can take only liquid food from the soil; the root-hairs take up the water in which the "fertilizer" is dissolved, and it is carried up through the larger roots, up through the sap-wood of the trunk, out through the branches to the leaves, where in the leaf-factories the water and free oxygen is given off to the air, and the nourishing elements retained and mixed with certain chemical elements of the air, thus becoming tree food. The leaf is a factory; the green pulp in the leaf cells is part of the machinery; the machinery is set in motion by sunshine power; the raw materials are taken from the air and from the sap containing food from the soil; the finished product is largely starch. Thus, it is well, when we begin the study of the tree, to notice that the leaves are so arranged as to gain all the sunlight possible, for without sunlight the starch factories would be obliged to "shut down." It has been estimated that on a mature maple of vigorous growth there is exposed to the sun nearly a half acre of leaf surface. Our tree appears to us in a new phase when we think of it as a starch factory covering half an acre.

Starch is plant food in a convenient form for storage, and it is stored in sap-wood of the limbs, the branches and trunk, to be used for the growth of the next year's leaves. But starch cannot be assimilated by plants in this form, it must be changed to sugar before it may be used to build up the plant tissues. So the leaves are obliged to perform the office of stomach and digest the food they have made for the tree's use. In the mysterious laboratory of the leaf-cells, the starch is changed to sugar; and nitrogen, sulphur, phosphorus and other substances are taken from the sap and starch added to them, and thus are made the proteids which form another part of 
the tree's diet. It is interesting to note that while the starch factories can operate only in the sunlight, the leaves can digest the food and it can be transported and used in the growing tissues in the dark. The leaves are also an aid to the tree in breathing, but they are not especially the lungs of the tree. The tree breathes in certain respects aswe do; it takes in oxygen

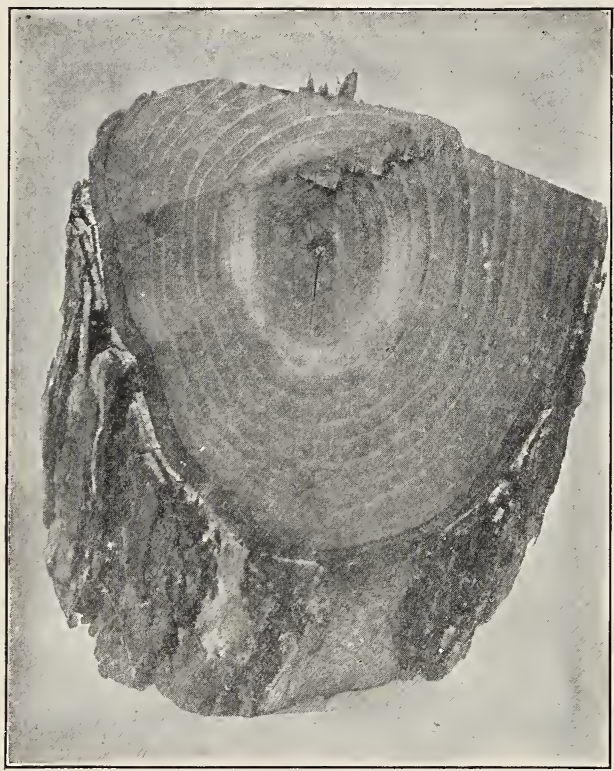

A stump showing rings of growth. and gives off carbondioxid; but the air containing the oxygen is taken in through the numerous pores in the leaves called stomata, and also through lenticels in the bark; so the tree really breathes all over its active surface.

The tree is a rapid worker and achieves most of its growth and does most of its work by midsummer. The autumn leaf which is so beautiful has completed its work. The green starch-machinery or chlorophyl, the living protoplasm in the leaf cells, has been withdrawn and is safely secluded in the woody part of the tree. The autumn leaf which glows gold or red, has in it only the material which the tree can no longer use. It is a mistake to believe that the frost causes the brilliant colors of autumn foliage; they are caused by the natural old age and death of the leaves-and where is there to be found old age and death more beautiful? When the leaf assumes its bright colors, it is making ready to depart from the tree; a thin, corky layer is being developed between its petiole and the twig, and when this is perfected, the leaf drops from its own weight or the touch of the slightest breeze.

A tree, growing in open ground, records in its shape, the direction of the prevailing winds. It grows more luxuriantly on the leeward side. It touches the heart of the one who loves trees to note their sturdy endurance of the onslaughts of this, their most ancient enemy.

Reference Books for Tree Study-The Tree Book, Julia Rogers; Our Native Trees, Harriet Keeler; Our Northern Shrubs, Harriet Keeler; The Trees of the Northern States, Romayne Hough. The Trees, N. L. Britton; Getting Acquainted with the Trees, J. Horace McFarland; Familiar Trees and their Leaves, Schuyler Mathews; Our Trees and How to Know Them, Clarence Moores Weed; A Guide to the Trees, Alice Lounsberry; The First Book of Forestry, Filibert Roth; Practical Forestry, John Gifford; Trees in Prose and Poetry, Stone \& Fickett; The Primers of Forestry, Pinchot. 


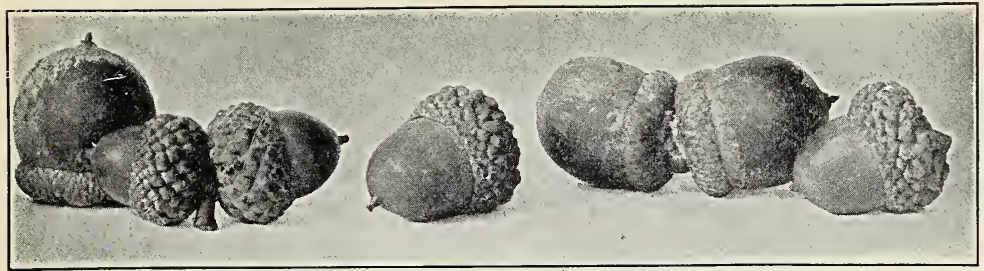

Acorns of the red and the scarlet oaks. Photo by O. L. Foster.

\section{HOW TO BEGIN TREE STUDY Teacher's Story}

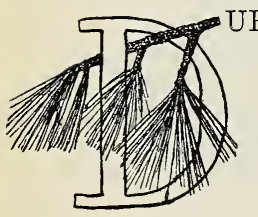

URING autumn the attention of the children should be attracted to the leaves by their gorgeous colors. It is well to use this interest to cultivate their knowledge of the forms of leaves of trees; but the teaching of the tree species to the young child should be done quite incidentally and guardedly. If the teacher says to the child bringing a leaf, "This is a white oak leaf," the child will soon quite unconsciously learn that leaf by name. Thus, tree study may be begun in the kindergarten or the primary grades.

r. Let the pupils use their leaves as a color lesson by classifying them according to color, and thus train the eye to discriminate tints and color values.

2. Let them classify the leaves according to form, selecting those which resemble each other.

3. Let each child select a leaf of his own choosing and draw it. This may be done by placing the leaf flat on paper and outlining it with pencil or with colored crayon.

4. Let the pupils select paper of a color similar to the chosen leaf and cut a paper leaf like it.

5. Let each pupil select four leaves which are similar and arrange them on a card in a symmetrical design. This may be done while the leaves are fresh, and the card with leaves may be pressed and thus preserved.

In the fourth grade, begin with the study of a tree which grows near the schoolhouse. In selecting this tree and in speaking of it, impress upon the children that it is a living being, with a life and with needs of its own. I believe so much in making this tree seem an individual, that I would if necessary name it Pocahontas or Martha Washington. First, try to ascertain the age of the tree. Tell an interesting story of who planted it and who were children and attended school in the schoolhouse when the tree was planted. To begin the pupils' work, let each have a little note-book in which shall be written, sketched or described all that happens to this particular tree for a year. The following words with their meaning should be given in the reading and spelling lessons: Head, bole, trunk, branches, twigs, spray, roots, bark, leaf, petiole, foliage, sap. 


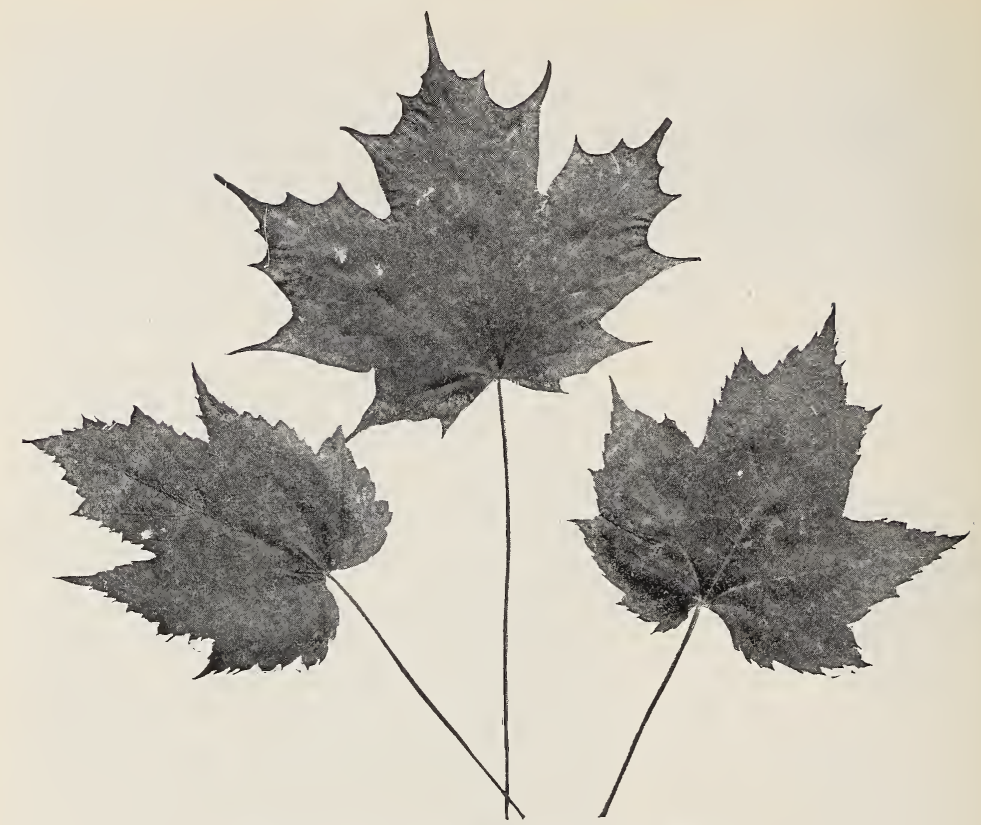

Mountain maple, sugar maple and red maple.

\section{LESSON CLXXXVIII}

\section{Tree Study}

Autumn Work-I. What is the color of the tree in its autumn foliage? Sketch it in water colors or crayons, showing the shape of the head, the relative proportions of head and trunk.

2. Describe what you can see of the tree's roots. How far do you suppose the roo's reach down? How far out at the sides? In how many ways are the roots useful to the tree? Do you suppose, if the tree were turned bottomside up, that it would show as many roots as it now shows branches?

3. How high on the trunk from the ground do the lower branches come off? How large around is the trunk three feet from the ground? If you know how large around it is, how can you get the distance through? What is the color of the bark? Is the bark smooth or rough? Are the ridges fine or coarse? Are the furrows between the ridges deep or shallow? Of what use is the bark to the tree?

4. Describe the leaf from your tree, paying special attention to its shape, its edges, its color above and below, its veins or ribs, and the relative length and thickness of its petiole. Are the leaves set opposite or alternate upon the twigs? As the leaves begin to fall, can you find two which are exactly the same in size and shape? Draw in your note-book the two leaves which differ most from each other of any that grew on your tree. At what date do the leaves begin to fall from your tree? At what date are they all off the tree? 
5. Do you find any fruit or seed upon your tree? If so describe and sketch it, and tell how you think it is scattered and planted.

Winter Study of the Tree-I. Make a sketch of the tree in your notebook, showing its shape as it stands bare. Does the trunk divide into branches, or does it extend through the center of the tree and the branches come off from its sides? Of what use are the branches to a tree? Is the spray, or the twigs at the end of the branches, coarse or fine? Does it lift up or droop? Is the bark on the branches like that on the trunk? Is the color of the spray the same as of the large branches? Why does the tree drop its leaves in winter? Does the tree grow during the winter? Do you think that it sleeps during the winter?

2. Study the cut end of a log or stump and also study a slab. Which is the heart-wood and which is the sap-wood? Can you see the rings of growth? Can you count these rings and tell how old was the tree from which this log came? Describe if you can, how a tree trunk grows larger each year. What is it makes the grain in the wood which we use for furniture? If we girdle a tree why does it die? If we place a nail in a tree three feet from the ground this winter, will it be any higher from the ground ten years from now? How does the tree grow tall?

3. Take a twig of a tree in February and look carefully at the buds. What is their color? Are they shiny, rough, sticky or downy? Are they arranged on the twigs opposite or alternate? Can you see the scar below the buds where the last year's leaf was borne? Place the twig in water and put in a light, warm place, and see what happens to the buds. As the leaves push out, what happens to the scales which protected the buds?

4. What birds do you find visiting your tree during winter? Tie some strips of beef fat upon its branches, and note all of the kinds of birds which come to feast upon it.

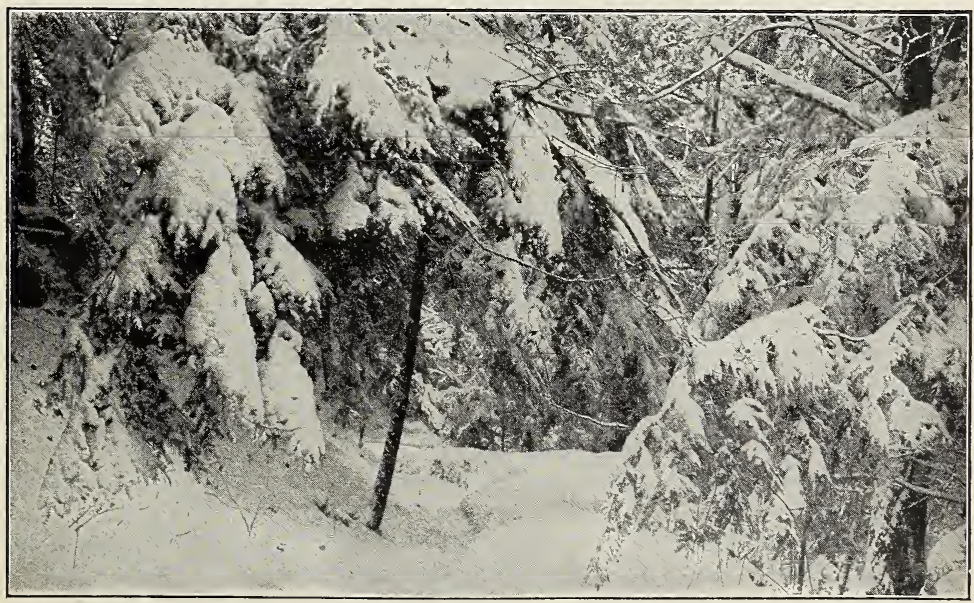

Trees in winter. 
Spring Work-I. At what date do the young leaves appear upon your tree? What color are they? Look carefully to see how each leaf was folded in the bud. Were all the leaves folded in the same way? Are the young leaves thin, downy and tender? Do they stand out straight as did the old leaves last autumn, or do they droop? Why? Will they change position and stand out as they grow stronger? Why do the leaves stand out from the twigs in order to get sunshine? What would happen to a tree if it lost all its leaves in spring and summer? Tell all of the things you know which the leaves do for the tree?

2. Are there any blossoms on your tree in the spring? If so, how do they look?: Are the blossoms which bear the fruit on different trees from those that bear the pollen, or are these flowers placed separately on the same tree? Or does the same flower which produces the pollen also produce the seed?. Do the insects carry the pollen from flower to flower, or does the wind do this for your tree? What sort of seeds are formed by these flowers? How are the seeds scattered and planted?

3. At what date does your tree stand in full leaf? What color is it now? What birds do you find visiting it? What insects? What animals seek its shade? Do the squirrels live in it?

4. Measure the height of your tree as follows: Choose a bright, sunny morning for this. Take a stick $3^{\mathrm{T}} / 2$ feet long and thrust it in the ground so that three feet will project above the soil. Immediately measure the length of its shadow and of the shadow which your tree makes from its base to the shadow of its topmost twigs. Supposing that the shadow from the stick is 4 feet long and the shadow from your tree is 8 o feet long, then your example will be: $4 \mathrm{ft} .: 3 \mathrm{ft} .:: 80 \mathrm{ft} .:$ ? Which will make the tree 60 feet high.

To measure the circumference of the tree, take the trunk three feet from the ground and measure it exactly with a tape measure. To find the thickness of the trunk, divide the circumference just found by 3.I 5 .

Supplementary Reading-Among Green Trees, Rogers; Chap. I in A Primer of Forestry, Pinchot; Part I in A First Book of Forestry, Roth; Chapter IV in Practical Forestry, Gifford.

\section{LESSON CLXXXIX}

\section{How to Make Leaf Prints}

A very practical help in interesting children in trees, is to encourage them to make portfolios of leaf-prints of all the trees of the region. Although the process is mechanical, yet the fact that every print must be correctly labeled makes for useful knowledge. One of my treasured possessions is such a portfolio made by the lads of St. Andrews School of Richmond, Va., who were guided and inspired in this work by their teacher, Professor W. W. Gillette. The impressions were made in green ink and the results are as beautiful as works of art. Professor Gillette gave me my first lesson in making leaf prints.

Material-I. A smooth slate, or better, a thick plate of glass, about I $2 \times 15$ inches.

2. A tube of printer's ink, either green or black, and costing 50 cents; one tube contains a sufficient supply of ink for making several hundred prints. - Or a small quantity of printer's ink may be purchased at any printing office. 
3. Two six-inch rubber rollers, such as photographers use in mounting prints, which cost I 5 cents each. A letter-press may be used instead of one roller.

4. A small bottle of kerosene to dilute the ink, and a bottle of benzine for cleaning the outfit after using, care being taken to store them safe from fire.

5. Sheets of paper $81 / 2 \times$ II inches. The paper should be of good quality, with smooth surface in order that it may take and hold a clear out-

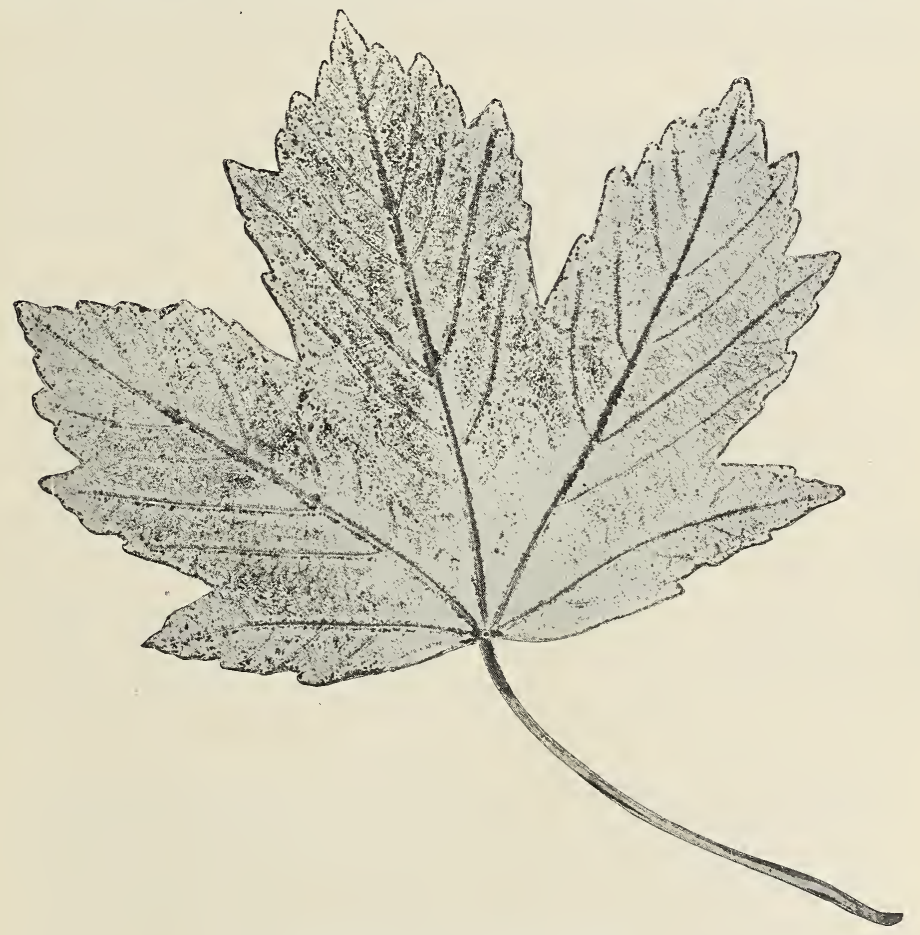

Leaf print of a sycamore maple.

line. The ordinary paper used in printers' offices for printing newspapers works fairly well. I have used with success the paper from blank notebooks which cost five cents a piece.

To make a print, place a few drops of ink upon the glass or slate, and spread it about with the roller until there is a thin coat of ink upon the roller and a smooth patch in the center of the glass or slate. It should never be so liquid as to "run," for then the outlines will be blurred. Ink the leaf by placing it on the inky surface of the glase and passing the inked roller over it once or twice until the veins show that they are smoothly filled. Now place the inked leaf between two sheets of paper and roll once with the clean 
roller, bearing on with all the strength possible; a second passage of the roller blurs the print. Two prints are made at each rolling, one of the upper, and one of the under side of the leaf. Dry and wrinkled leaves may be made pliant by soaking in water, drying between blotters before they are inked.

Prints may also be made a number at a time by pressing them under weights, being careful to put the sheets of paper with the leaves between the pages of old magazines or folded newspapers, in order that the impression of one set of leaves may not mar the others. If a letter-press is available for this purpose, it does the work quickly and well.

SAP

Strong as the sea and silent as the grave, It flows and ebbs unseen,

Flooding the earth, a fragrant tidal wave, With mists of deepening green.

- Јон B. ТАвв.

\section{THE MAPLES}

\section{Teacher's Story}

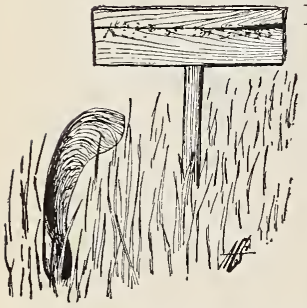

HE sugar maple, combining beauty with many kinds of utility, is dear to the American heart. Its habits of growth are very accommodating; when planted where it has plenty of room, it shows a short trunk and oval head, which, like a dark green period, prettily punctuates the summer landscape; but when it occurs in the forest, its noble bole, a pillar of granite gray, rises to uphold the arches of the forest canopy; and it attains there the height of roo feet. It grows rapidly and is a favorite shade tree, twenty years being long enough to make it thus useful. The foliage is deep green in the summer, the leaf being a glossy, dark green above and paler beneath. It has five main lobes, the two nearest the stem being smaller; the curved edges between the lobes are marked with a few, smoothly cut, large teeth; the main veins extend directly from the petiole to the sharp tips of the lobes; the petiole is long, slender, and occasionally red. The leaves are placed opposite. The shade made by the foliage of the maple is so dense that it shades down the plants beneath it, even grass growing but sparsely there. If a shade tree stands in an exposed position, it grows luxuriously to the leeward of the prevailing winds, and thus makes a one-sided record of their general direction.

It is its autumn transfiguration which has made people observant of the maple's beauty; yellow, orange, crimson and scarlet foliage make these trees gorgeous when October comes. Nor do the trees get their color uniformly; even in September, the maple will show a scarlet branch in the midst of its green foliage. I believe this is a hectic flush and a premonition of death to the branch which, less vigorous than its neighbors, is being pruned out by Nature's slow but sure method. After the vivid color is on the maple, it begins to shed its leaves. This is by no means the sad act which the poets would have us believe; the brilliant colors are an evidence 
that the trees have withdrawn from the leaves the green life-substance, the protoplasm-machinery for making the starch, and have stored it snugly in trunk and branch for winter keeping. Thus, only the mineral substances are left in theleaf, and they give the vivid hues. It is a mistake to think that frost causes this brilliance; it is caused by the natural, beautiful, old age of the leaf. When the leaves finally fall, they form a mulch-carpet for the tree that bore them, and add their substance to the humus from which the tree draws new powers for growth.

After every leaf has fallen, the maple shows why its shade is dense. It has many branches set close and at sharp angles to the trunk, dividing into fine, erect spray, giving the tree a resemblance to a giant whisk-broom. Its dark, deepfurrowed bark smoothes out and becomes light gray on the larger limbs, while the spray is purplish, a color given it by the winter buds. These buds are sharp-pointed and long. In February, their covering of scales shows premonitions of spring by enlarging, and as if due to the soft influence, they become downy, and take on a sunshine color before they are pushed off by the leaves. The leaves and the blossoms appear together. The leaves are at first, yellowish, downy and drooping, thus shunning the

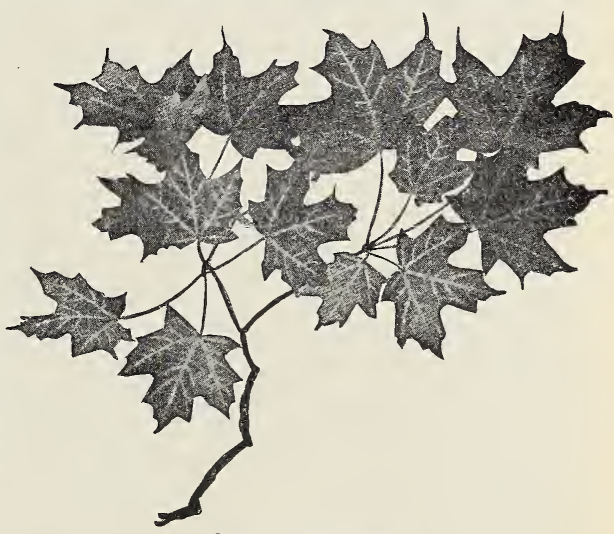

Sugar maple leaves. too hot sun and the violent pelting rains and fierce spring winds. The flowers appear in tassellike clusters, each downy drooping thread of the tassel bearing at its tip a five-lobed calyx, which may hold seven or eight long,

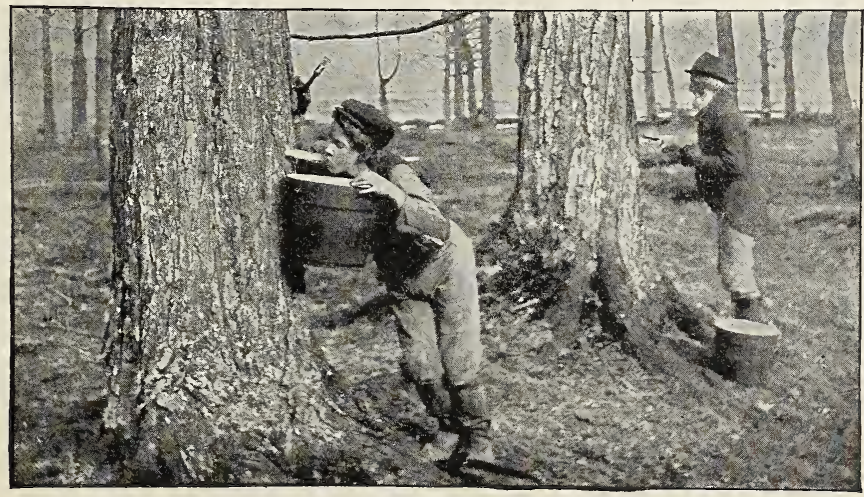

A foretaste.

Photo by Verne Morton 
drooping stamens or a pistil with long, double stigmas. The flowers are greenish yellow, and those that bear pollen and those that bear the seeds may be borne on separate trees or on the same tree, but they are always in different clusters. If on the same tree, the seed-bearing tassels are at the tips of the twigs, and those bearing pollen are along the sides.

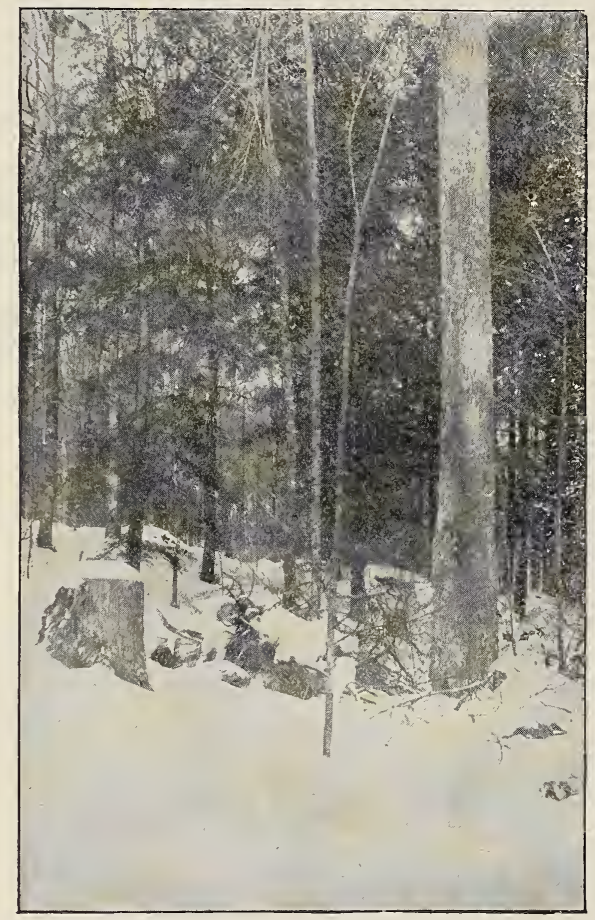

The trunk of sugar maple in forest.

The ovary is two-celled, but there is usually only one seed developed in the pair which forms a "key;" to observe this, however, we have to dissect the seeds; they have the appearance of two seeds joined together, each provided with a thin, closely veined wing and the two attached to the tree by a single long, drooping stem. This twin-winged form is well fitted to be whirled off by the autumn winds, for the seeds ripen in September. I have seen seedlings growing thickly for rods to the leeward of their parent tree, which stood in an open field. The maples bear blossoms and seeds every year. There are six species of native maples which are readily distinguishable. The silver and the red maples and the box elder are rather large trees; the mountain and the striped (or goosefoot) maples are scarcely more than shrubs, and mostly grow in woods along streams. The Norway and the sycamore maples have been introduced from Europe for ornamental planting. The cut-leaf silver maple comes from Japan.

The maple wood is hard, heavy, strong, tough and fine-grained; it is cream-color, the heart-wood showing shades of brown; it takes a fine polish and is used as a finishing timber for houses and furniture. It is used in construction of ships, cars, piano action and tool handles; its fine-grained quality makes it good for wood-carving; it is an excellent fuel and has many other uses.

\section{MAPLE-SUGAR MAKING}

Although we have tapped the trees in America for many hundred years, we do not as yet understand perfectly the mysteries of the sap flow. In I903, the scientists at the Vermont Experiment Station did some very 
remarkable work in clearing up the mysteries of sap movement. Their results were published in their Bulletins 103 and 105, which are very interesting and instructive.

The starch which is changed to sugar in the sap of early spring was made the previous season and stored within the tree. If the foliage of the tree is injured by caterpillars one year, very little sugar can be made from that tree the next spring, because it has been unable to store enough starch in its sapwood and in the outer ray-cells of its smaller branches to make a good supply of sugar. During the latter part of winter, the stored starch disappears, being converted into tree-food in the sap, and then begins that wonderful surging up and down of the sap tide During the first part of a typical sugar season, more sap comes from above down than from below up; toward the end of the season, during poor sap days, there is more sap coming up from below than down from above. The ideal sugar weather consists of warm days and freezing nights. This change of temperature between day and night acts as a pump. During the day when the branches of the tree are warmed, the pressure forces into the hole bored into the trunk all the sap located in the adjacent cells of the wood. Then the suction which follows a freezing night drives more sap into those cells, which is in turn

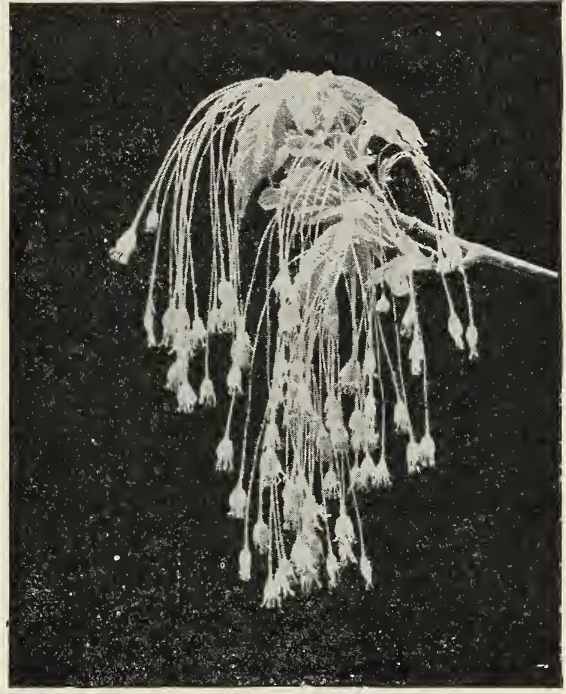

Sugar maple blossoms.

forced out when the top of the tree is again warmed. The tree is usually tapped on the south side, because the action of the sun and the consequent temperature-pump more readily affects that side.

"Tapping the sugar bush" are magical words to the country boy and gi:-1. Well do we older folk remember those days in March when the south wind settled the snow into hard, marblelike drifts, and the father would say, "We will get the sap-buckets down from the stable loft and wash them, for we shall tap the sugar-bush soon." In those days the buckets were made of staves and were by no means so easily washed as are the metal buckets of to-day. Well do we recall the sickish smell of musty sap that greeted our nostrils, when we poured in the boiling water to clean those old brown buckets. Previously during the winter evenings, we all had helped fashion sap-spiles from stems of sumac. With buckets and spiles ready when the momentous day came, the large, iron caldron kettle was loaded on a stoneboat together with a sap-cask, log-chain, ax and various other utensils, and as many children as could find standing room; then the oxen were hitched on and the procession started across the rough pasture to the 
woods, where it eventually arrived after numerous stops for reloading almost everything but the kettle.

Wwen we came to the boiling place, we lifted the kettle into position and flanked it with two great logs against which the fire was to be kindled. Meanwhile the oxen and stoneboat returned to the house for a load of buckets. The oxen blinking, with bowed heads, or with noses lifted aloft to keep the underbrush from striking their faces, "gee'd and haw'd" up hill and down dale through the woods, stopping here and there while the men with augers bored holes in certain trees near other holes which had bled sweet juices in years gone by. When the auger was withdrawn, the sap followed it, and enthusiastic young tongues met it half way, though they received more chips than sweetness therefrom; then the spiles were driven in with a wooden mallet.

The next day after "tapping," those of us large enough to wear the neckyoke donned cheerfully this badge of servitude and with its help brought

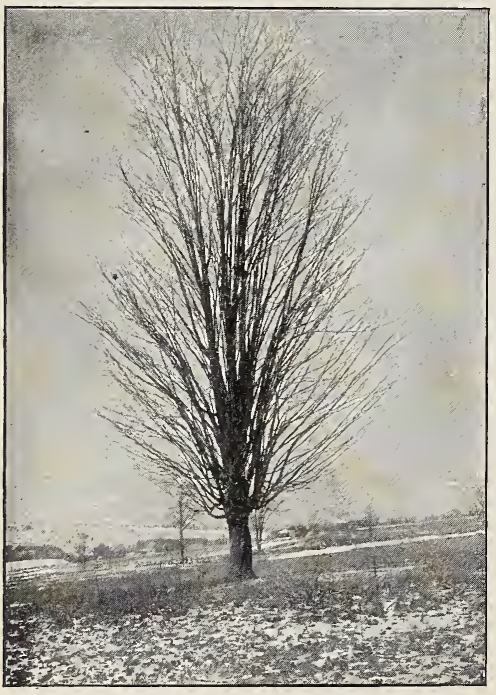

Sugar maple growing in the open. pails of sap to the kettle, and the "boiling" began. As the evening shades gathered, how delicious was the odor of the sap steam, permeating the woods farther than the shafts of firelight pierced the gloom! How weird and delightful was this night experience in the woods! And how cheerfully we swallowed the smoke which the contrary wind seemed ever to turn toward us! We poked the fire to send the sparks upward, and now and then added more sap from a barrel, and removed the scum from the boiling liquid with a skimmer thrust into the cleft of a long stick for a handle. As the evening wore on, we drew closer to each other as we told stories of the Indians, bears, panthers and wolves which had roamed these woods when our father was a little boy; and came to each of us a disquieting suspicion that perhaps they were not all gone yet, for everything seemed possible in those night-shrouded woods; and our hearts suddenly "jumped into our throats" when near by there sounded the tremulous, blood-curdling cry of the screech owl.

After about three days of gathering and boiling sap, came the "siruping down." During all that afternoon we added no more sap and we watched carefully the tawny, steaming mass in the kettle; when it threatened to boil over, we threw in a thin slice of fat pork which seemed to have some mysterious calming influence. The odor grew more and more delicious and presently the sirup was pronounced sufficiently thick. The kettle was swung off the logs and the sirup dipped through a cloth strainer into a carrying-pail. Oh, the blackness of the residue left on that strainer! But 
it was clean woods-dirt and never destroyed our faith in the maple-sugar, any more than did the belief that our friends were made of dirt destroy our friendship for them. The next day our interests were transferred to the house where we "sugared off." There we boiled the sirup to sugar on the stove and pouring it thick and hot upon snow made that most delicious of all sweetsthe maple-wax; or we stirred it until it "grained," before we poured it into the tins to make the "cakes" of maplesugar.

Now the old stave bucket and the sumac spile are gone; in their place the patent galvanized spile not only conducts the sap but holds in place a tin bucket carefully covered. The old caldron kettle is broken, or lies rusting in the shed. In its place, in the newfangled sugar-houses, are evaporating vats, set over furnaces with chimneys. But we may as well confess that the maple-sirup of to-day seems to us a pale and anaemic liquid, lacking the delicious flavor of the rich, dark nectar which we, with the help of cinders,

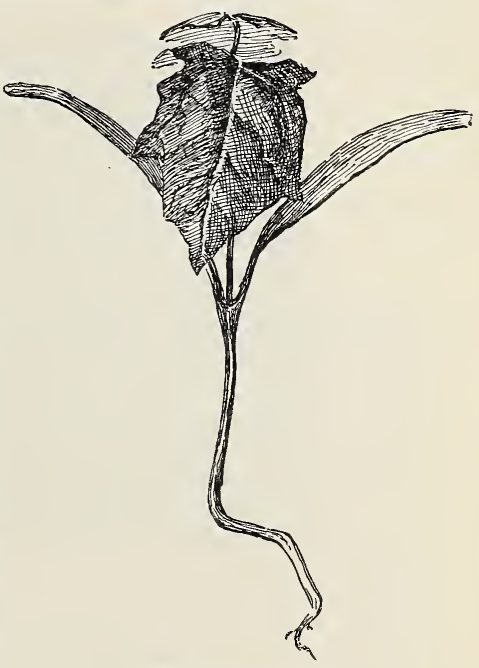

Maple seedling. smoke and various other things, brewed of yore in the open woods.

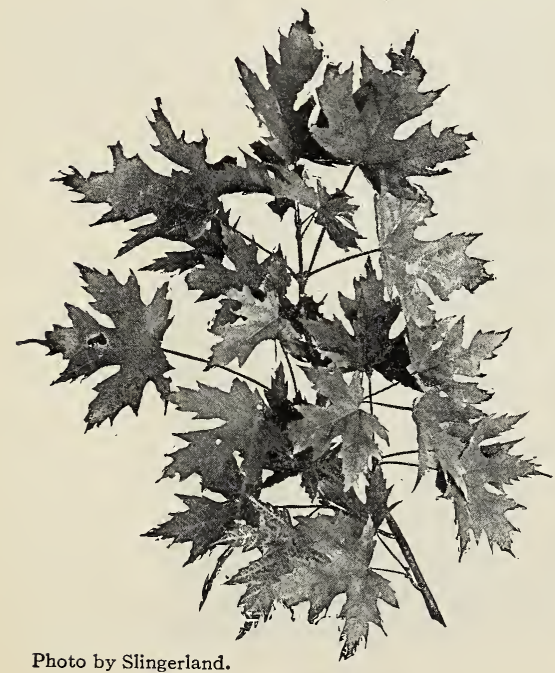

Leaves of silver maple.

LESSON CXC

The Sugar Maple

Leading thought-The sugar maple grows very rapidly, and is therefore a useful shade tree. Its wood is used for many purposes, and from its sap is made a delicious sugar.

Method-This study of the maple should be done by the pupils out of doors, with a tree to answer the questions. The study of the leaves, blossoms and fruit may be made in the schoolroom. The maple is an excellent subject for Lesson CLXXXVIII. The observations should begin in the fall and continue at intervals until June.

Observations. Fall WorkI. Where is the maple you are studying? Is it near other 
trees? What is the shape of the head? What is the height of the trunk below the branches? What is the height of the tree? How large around

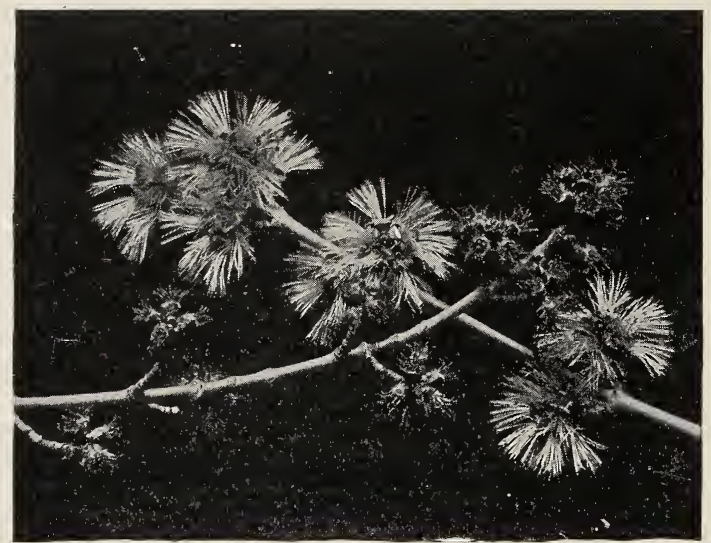

Blossoms of the silver maple.

Photo by Ralph Curtis.

is the trunk three feet from the ground? Can you find when the tree was planted? Can you tell by the shape of the tree from which direction the wind blows most often?

2. Can you find seeds on your tree? Each pair of seeds is called a key. Sketch a key, showing the way the seeds are joined and the direction of the wings. Sketch the stem which holds the key to the twig. Are both seeds of the key good or is one empty? How are the seeds scattered and planted?

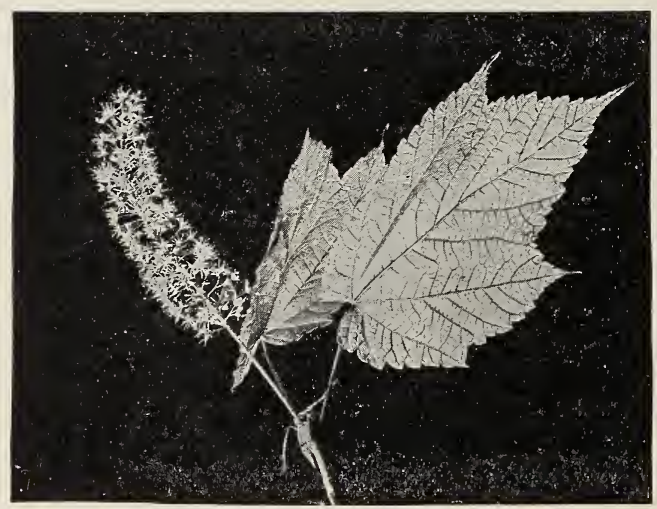

Blossoms of mountain maple.

Photo by Ralph Curtis. 
How far will a maple key fly on its wings? Plant a maple seed where you can watch it grow next year.

3. Make leaf prints and describe a leaf of the maple, showing its shape, its veins and petiole. Are the leaves arranged opposite or alternate on the twig? Make leaf-prints or sketches of the leaves of all the other kinds of maples which you can find. How can you tell the different kinds of maples by their leaves?

4. If your tree stands alone, measure the ground covered by its shadow from morning until evening. Mark the space by stakes. What grows beneath the tree? Do grass and other plants grow thriftily beneath the tree? Do the same plants grow there as in the open field?

5. Does your maple get its autumn colors all at once, or on one or two branches first? At what time do you see the first autumn colors on your tree? When is it completely clothed in its autumn dress? Is it all red or all yellow, or mixed? If it is yellow this year do you think it will be red next year? Watch and see. Sketch your maple in water-colors.

6. At what time do the leaves begin to fall? Do those branches which first colored brightly shed their leaves before the others? At what date does your tree stand bare?

7. Find a maple tree in the forest and compare it with one that grows as a shade tree in a field. Why this difference?

Winter Work-8. Make a sketch of your maple with the leaves off. What sort of

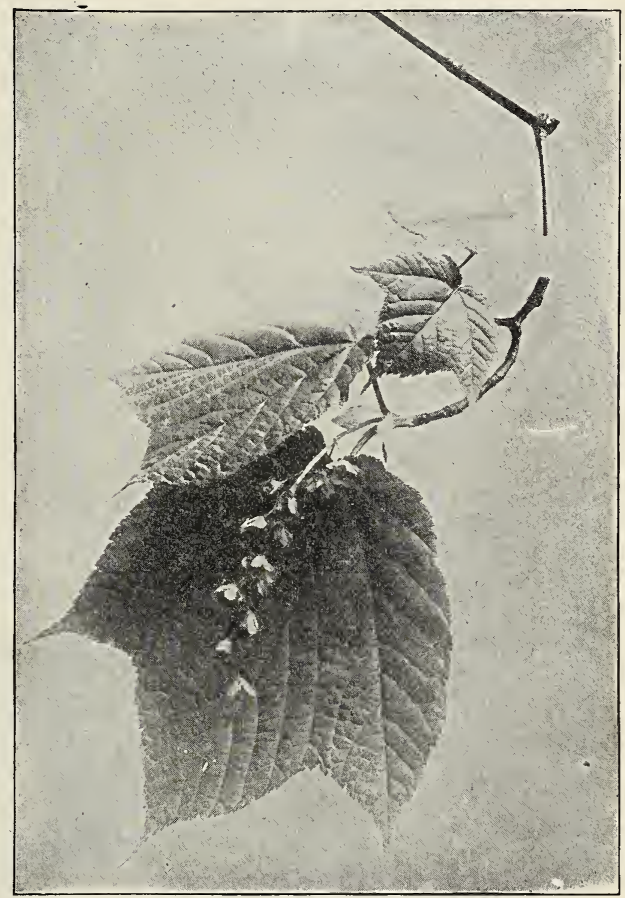

Blossom of striped maple.

Photo by Ralph Curtis.

bark has it? Is the bark on the branches like that on the trunk? Are the main branches large? At what angle do they come off the trunk? Does the trunk extend up through the entire tree? Is the spray fine or coarse? Is it straight or crooked?

9. Study the winter buds. Are they alternate or opposite on the twigs? Are they shining or dull? 
Spring Study - io. At what time do we tap maple trees for sap? On which side of the tree do we make the hole? If we tapped the tree earlier

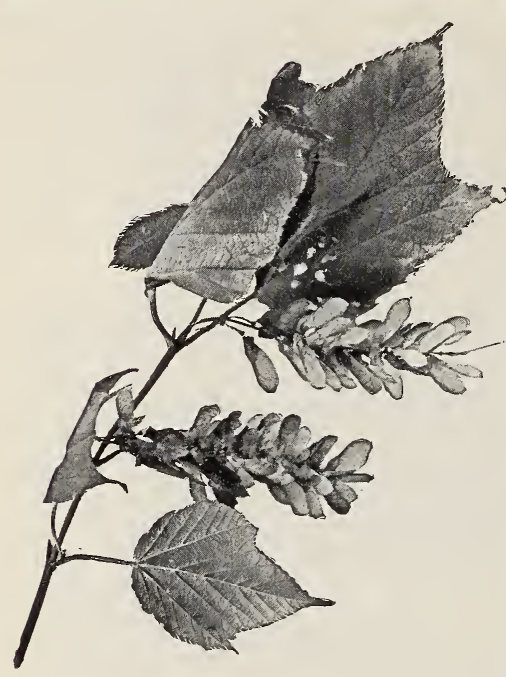

Leav's and fruit of striped maple. Photo by Ralph Curtis. would we get any sap? What kind of weather is the best for causing sap flow? Do you suppose that it is the sap going up from the root to the tree and the branches, or that coming down from the branches to the root which flows into the bucket? Why do we not make maplesugar all summer? Do you suppose the sap ceases to run because there is no more sap in the tree?

I I. Write a story telling all you can find in books or that you know from your own experience about the making of maple-sugar.

I2. When do the leaves of your maple first appear? How do they then look? Do they stand out or droop?

I3. Do the blossoms appear with the leaves or after them? How do the blossoms look? Can you tell the blossoms with stamens from those with pistils? Do you find them in the same cluster? Do you find them on the same tree?

I4. What uses do we find for maple wood? What is the character of the wood?

Supplementary reading-Trees in Prose and Poetry pp. 25-4I.

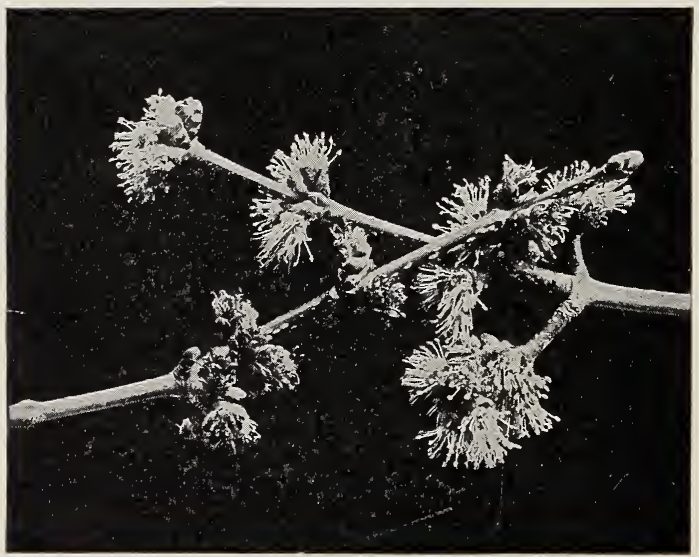

Blossoms of red maple.

Photo by Ralph Curtis. 


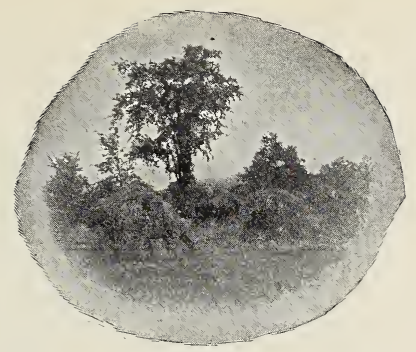

\section{THE AMERICAN ELM}

\section{Teacher's Story}

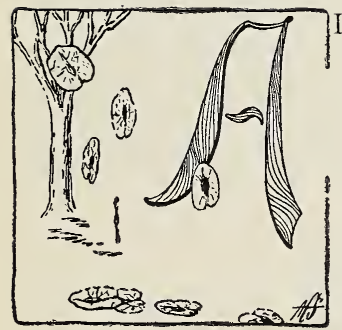

LTHOUGH the American elm loves moist woods, it is one of those trees that enjoys gadding; and without knowing just how it has managed to do it, we can see plainly that it has planted its seeds along fence corners, and many elms now grace our fields on sites of fences long ago laid low. Because of its beautiful form and its rapid growth, the elm has been from earliest times a favorite shade tree in the Eastern and Middle States. Thirty years after being planted, the elms on the Cornell Campus clasped branches across

the avenues; and the beauty of many a village and city is due chiefly to these graceful trees of bounteous shade. Moreover the elm is at no time more beautiful than when it traces its flowing lines against the background of snow and gray horizon. Whether the tree be shaped like a vase or a fountain, the trunk divides into great uplifting branches, which in turn divide into spray that oftentimes droops gracefully, as if it were made purposely to sustain from its fine tips the woven pocket-nest of the oriole. No wonder this bird so often chooses the elm for its rooftree!

In winter, the dark, coarselyridged bark and the peculiar, wiry, thick spray, as well as the characteristic shape of the tree reveal to us its identity; it also

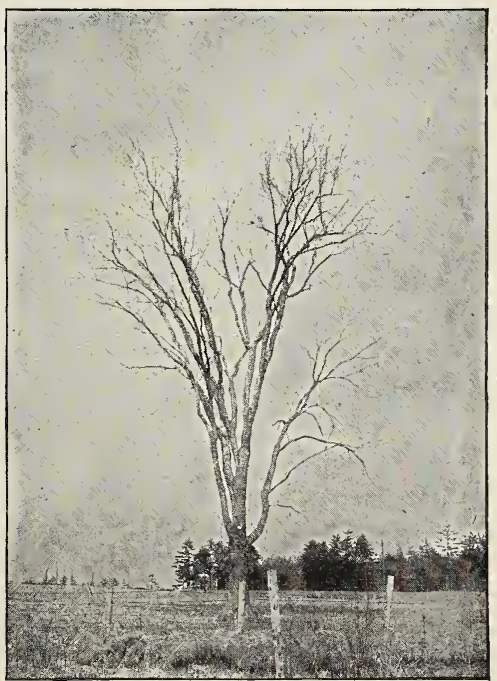

The elm in winter. 
has a peculiar habit of growing its short branches all the way down its trunk, making it look as if it were entwined with a vine. The elm leaf, although its ribs are straight and simple, shows a little quirk of its own in the uneven sides of its base where it joins the petiole? it is dark green and rough above, light green and somewhat rough below; but this leaf is rough only when stroked in certain directions, while the leaf of the slippery elm is rough whichever way it may be stroked. The leaf has the edges sawtoothed; which are in turn toothed; the petiole is short. The leaf comes out of the bud in the spring folded like a little fan; but before the fans are opened to the spring breezes, the elm twigs are furry with reddish green blossoms. The blossom consists of a calyx with an irregular number of lobes, and for every lobe, a stamen which consists of a threadlike filament from which hangs a bright red anther; at the center is a twocelled pistil with two light green styles. These blossoms appear in March or early April, before the leaves.

When full-grown the fruit hangs like beaded fringe from the twigs. The seed is flat and has a wide, much veined margin or wing, notched at the tip and edged with a white silken fringe; the seed is at the center, wrinkled and flat. Each seed shows at its base the old calyx and is attached by a slender threadlike stem to the twig at the axils of last year's leaves. A little later the lusty breezes of spring break the frail threads and release the seeds, although few of them find places fit for growth.

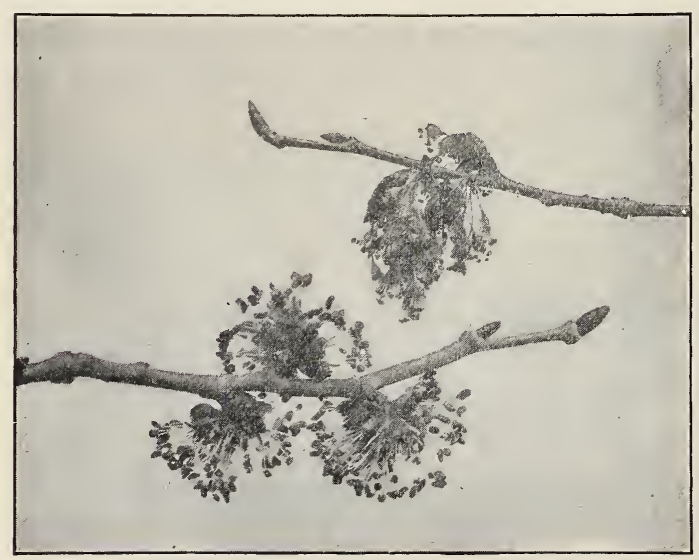

Elm blossoms.

Photo by Ralph Curtis.

The elm roots are water hunters and extend deep into the earth; they will grow towards water, seeming to know the way. The elm heart-wood is reddish, the sapwood being broad andwhitish in color; the wood is very tough because of theinterlaced fibers, and therefore very hard to split. It is used for cooperage, wheel hubs, saddlery, and is now used more extensively for furniture; its grain is most ornamental. It is

fairly durable as posts, but perhaps the greatest use of all for the tree is for shade. The slippery elm is much like the white elm, except that its inner bark is very mucilaginous, and children love to chew it. The cork elm has a peculiar corky growth on its branches, giving it a very unkempt look. The wahoo, or winged elm, is a small tree, and its twigs are ornamented on each side by a corky layer. The English elm has a solid, round head, very different from that of our graceful 
species. The elms are long-lived, some living for centuries. The Washington elm in Cambridge, and the William Penn elm in Philadelphia, which now has a monument to mark its place, were famous trees.

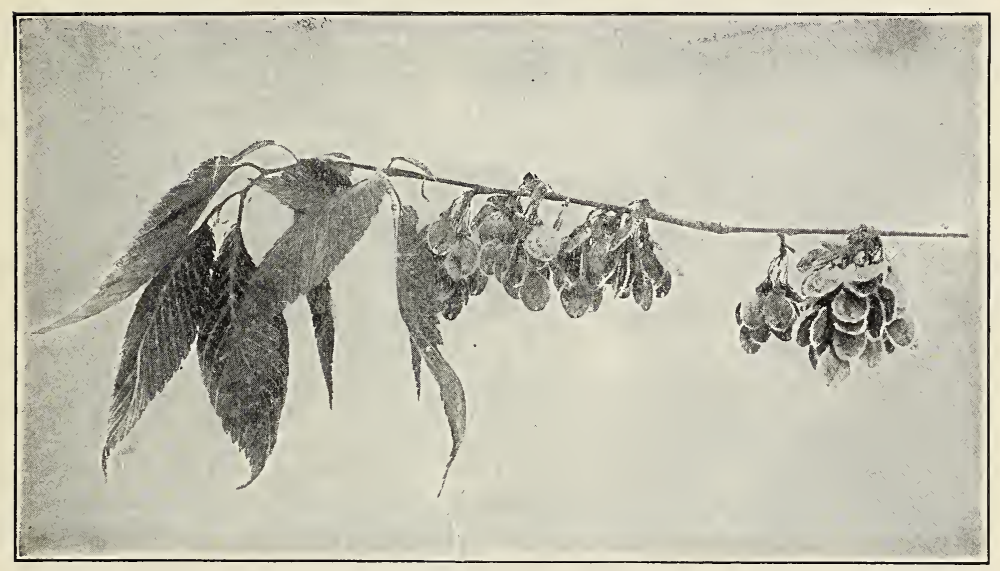

Elm seed.

Photo „y Morgan.

\section{LESSON CXCI}

The ElM

Leading thought-The elm has a peculiarly graceful form, which makes it of value as a shade tree. It grows best in moist locations. Its wood is very tough.

Method-This work should be begun in the fall with the study of the shape of the tree and its foliage. Sketches should be made when the tree is clothed in autumn tints, and later it should be sketched again when its branches are naked. Its blossoms should be studied in March and April and its seeds in May.

Observations-I. Where does the elm grow? Does it thrive where there is little water? What is the usual shape of the elm? How does the trunk divide into branches to make this shape possible? What is the shape of the larger elms? Describe the spray. Describe the elm bark. How can you tell the elm from other trees in winter?

2. Study the elm leaf. What is its form? What kind of edges has it? How large is it? What is the difference in appearance and feeling between the upper and lower sides? Are the leaves rough above whichever way you stroke them? If a leaf is folded lengthwise are the two halves exactly alike? How are the leaves arranged on the twig? What is their color above and below? Describe the leafy growth along the trunk.

3. What is the color of the elm tree in autumn? Make a sketch of the elm tree you are studying.

4. What sort of roots has the elm? Do they grow deep into the earth? What is the character of its wood? Is it easy to split? Why? What are the chief uses of the elm? 
5. Do you know what distinguishes the slippery elm, the cork elm, the winged elm, or wahoo, and the English elm from the common American or white elm which you have been studying?

6. Write an essay on two famous American elms.

7. What birds love to build in the elm trees?

\section{Spring Study of the Elm}

8. Which appear first, the blossoms or the leaves? Describe the elm blossom. How long before the seeds ripen? How are the seeds attached to the twig? Describe an elm seed. How are the seeds scattered? How are the young leaves folded as they come out of the bud?

Supplementary reading-Trees in Prose and Poetry, pp. 81-02.

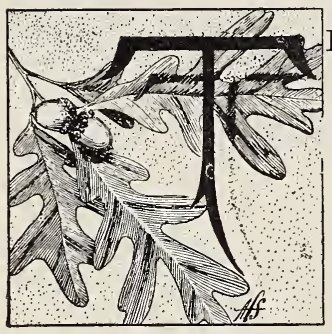

\section{THE OAK}

\section{Teacher's Story}

$\mathrm{HE}$ symbol of rugged strength since man first gazed upon its noble proportions, the oak more than other trees has been entangled in human myth, legend and imagination. It was regarded as the special tree of Zeus by the Greeks. Virgil sang of it thus:

"Full in the midst of his own strength he stands Stretching his brawny arms and leafy hands, His shade protects the plains, his head the hills commands."

While in primitive England the strange worship of the Druids centered around it.

Although the oak is a tree of grandeur when its broad branches are covered with leafage, yet it is only in winter when it stands stripped like an athlete that we realize wherein its supremacy lies. Then only can we appreciate the massive trunk and the strong limbs bent and gnarled with combating the blasts of centuries. But there are oaks and oaks, and each species fights time and tempest in his own peculiar armor and in his own way. Many of the oaks achieve the height of eighty to one hundred feet. The great branches come off the sturdy trunk at wide angles, branches that may be crooked or gnarled but are ever long and strong; the smaller branches also come off at wide angles, and in turn bear angular individual spray-all of
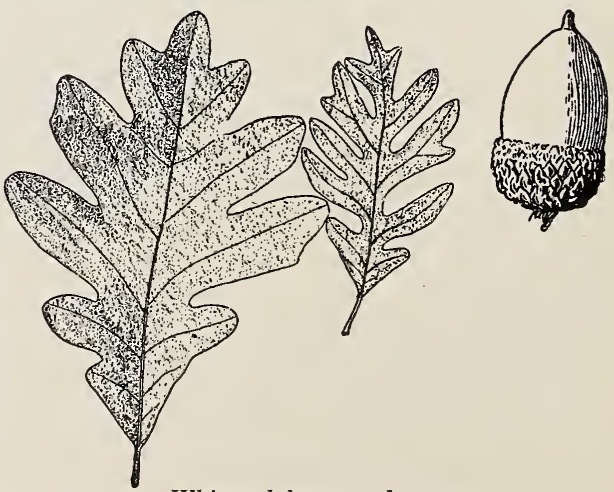

White oak leaves and acorn. 
which, when covered with leaves, make the broad, rounded head which characterizes this tree. The oaks are divided into two classes which the children soon learn to distinguish, as follows:

A. The white oak group, the leaves of which have rounded lobes and are rough and light-colored below; the wood is light-colored, the acorns have

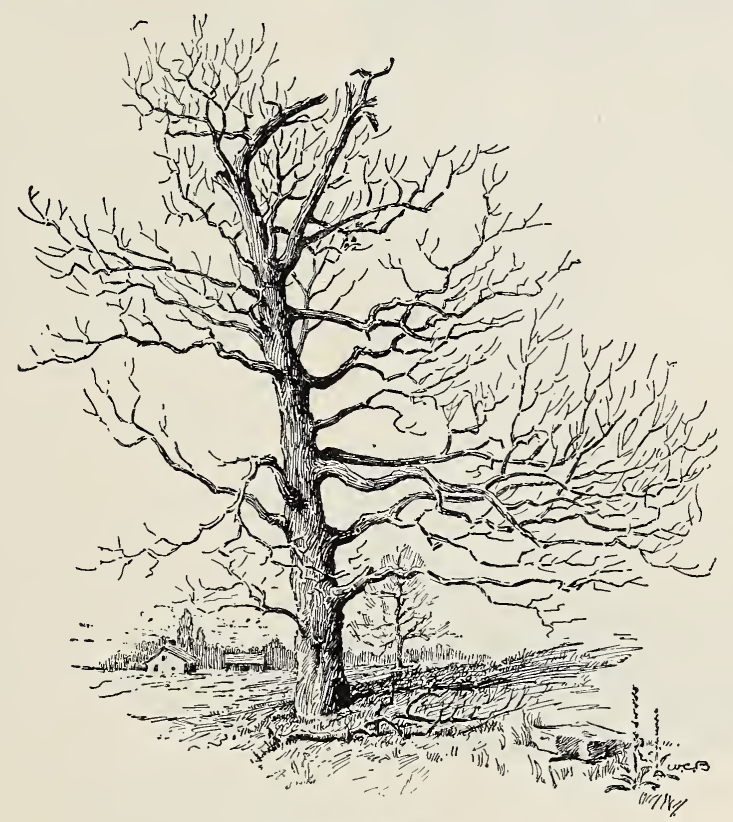

White oak in winter.

Drawing by W. C. Baker.

sweet kernels and mature in one year, so that there are no acorns on the branches in winter. To this class belong the white, chestnut, bur, and post oaks.

AA. The black oak group, the leaves of which are nearly as smooth below as above, and have angular lobes ending in sharp points. The bark is dark in color, the acorns have bitter kernels and require two years for maturing, so that they may be seen on the branches in winter. To this group belong the red, scarlet, Spanish, pin, scrub, black-jack, laurel and willow oaks.

There is a great variation in the shape of the leaves on the same tree, and while the black, the red and the scarlet caks are well-marked species, it is possible to find leaves on these three different trees which are similar in shape. Oaks also hybridize, and thus their leaves are a puzzle to the botanist; but in general, the species can be determined by any of the tree books, and the pupils should learn to distinguish them.

The acorns and their scaly saucers are varied in shape, and are a delight to children as well as to pigs. The great acorns of the red oak are made 


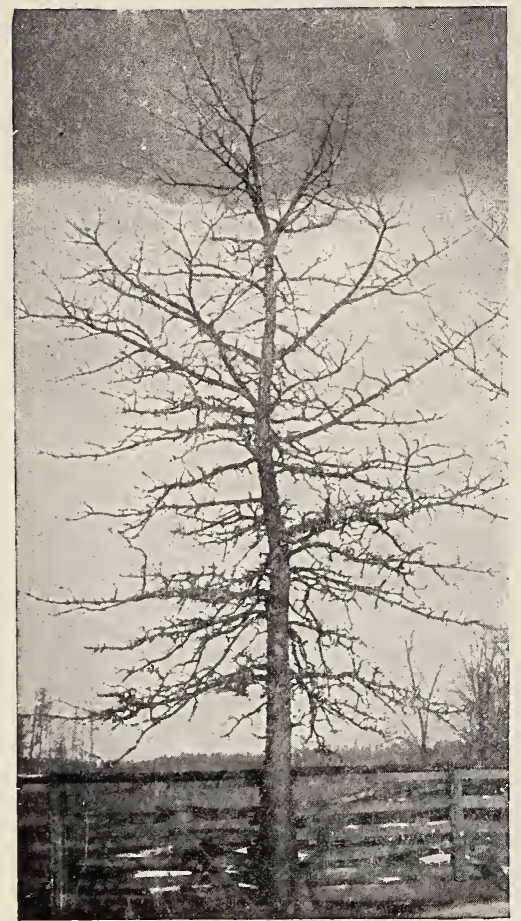

Swamp white oak in winter. into cups and saucers by the girls, and those of the scarlet oak into tops by the boys. The white oaks turn a rich wine-color in the autumn, while the bur and the chestnut are yellow. The red oak is a dark, wine-red; the black oak russet, and the scarlet a deep and brilliant red. When the oak leaves first come from the buds in the spring, they are soft and downy and drooping, those of the red and scarlet being reddish, and those of the white, pale green with red tints. Thoreau says of them, "They hang loosely, flacidly down at the mercy of the wind, like a new-born butterfly or dragonfly."

The pollen-bearing flowers are like beads on a string, several strings hanging down from the same point on the twig, making a fringe, and they are attractive to the eye that sees. The pistillate flowers are inconspicuous, at the axils of the leaves, and have irregular or curved stigmas; they are on the same branch as the pollen-bearing flowers.

The oak is long-lived; it does not produce acorns until about twenty years of age and requires

a century to mature. Although from two to three hundred years is the average age of most oaks, yet a scarlet oak of my acquaintance is about f o $\mathrm{ur}$ hundred years old, and there are oaks still living in England which were there when William, th e Conquerer came. The famous Wadsworth Oak at Geneseo, N.Y. had a circumferenceof twenty

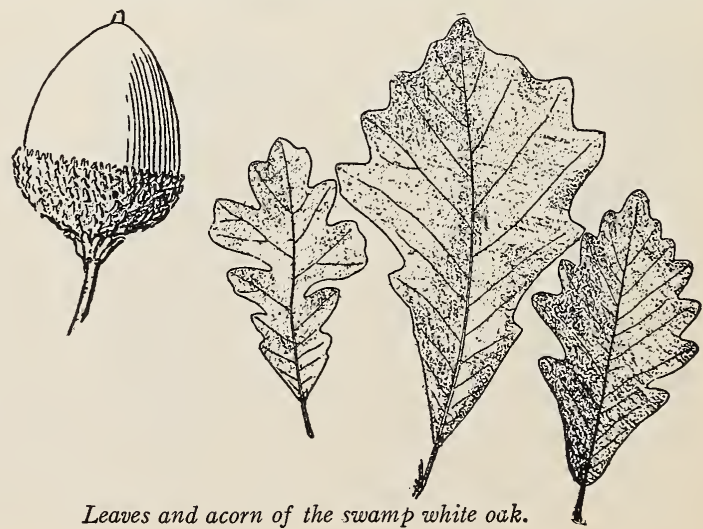


seven feet. This was a swamp white oak. One reason for their attaining great age is long, strong, tap-roots which plant them deep, also the great number of roots near the surface which act as braces, and their large and luxurious heads.

Oak wood is usually heavy, very strong, tough and coarse. The heart is brown, the sapwood whitish. It is used for many purposes-ships, furniture, wagons, cars, cooperage, farm implements, piles, wharves, railway ties, etc. The white and live oaks give the best wood. Oak bark is used extensively for tanning.

\section{LESSON CXCII}

\section{The OAKs}

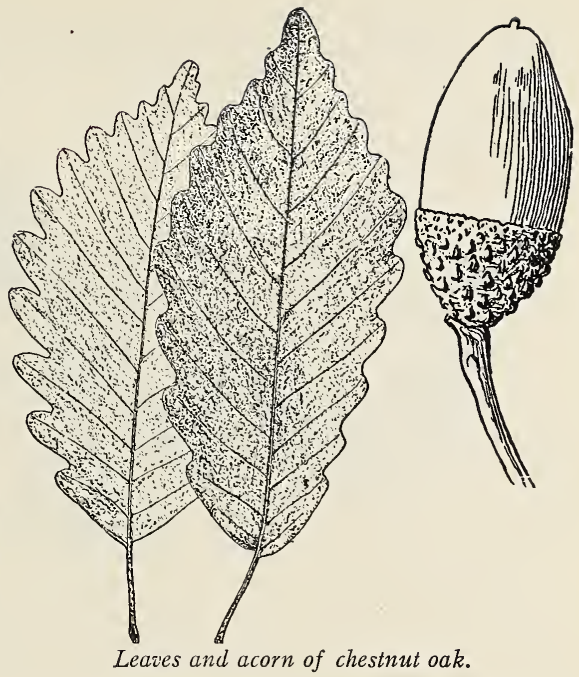

Leading thought-The oak tree is the symbol of strength and loyalty. Let us study it and see what qualities in it have thus distinguished it.

Method-Any oak tree may be used for this lesson; but whatever species is used, the lesson should lead to the knowledge of all the species of oaks in the neighborhood. The tree should be sketched, essays concerning the connection of the oak with human history should be written, while the

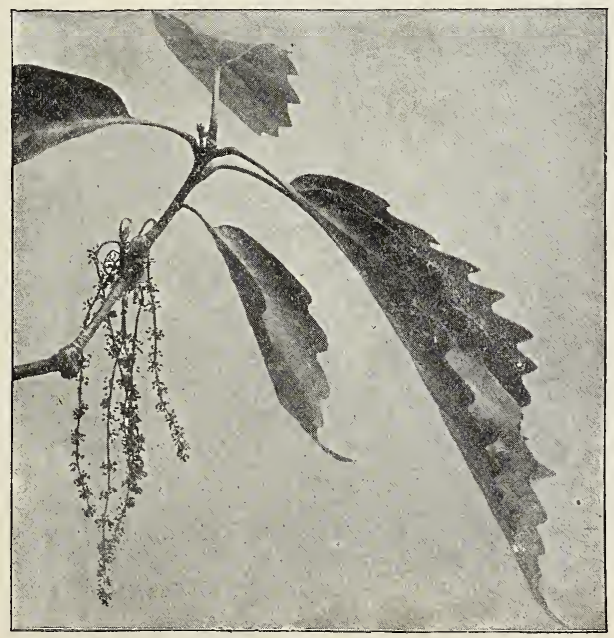

Blossoms of chestnut oa?. 
leaves and acorns may be brought into the schoolroom for study. Use Lesson CLXXXIX for a study of leaves of all the oaks of the neighborhood.

Observations- - . Describe the oak tree which you are studying. Where is it growing? What shape is its head? How high in proportion to the head is the trunk? What is the color and character of its bark? Describe its roots as far as you can see. Are the branches straight or crooked? Delicate or strong? Is the spray graceful or angular?

2. What is the name of your oak tree? What is the color of its foliage

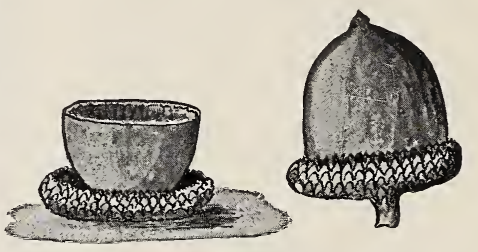

Cup and saucer made from the acorns of red oak in autumn? Find three leaves from your tree which differ most widely in form, and sketch them or make leaf prints of them for your note-book. Does the leaf have the lobes rounded, or angular and tipped with sharp points? Is the leaf smooth on the lower side or rough? Is there much difference in color between the upper and the lower side?

3. Describe the acorns which grow on your oak. Has the acorn a stem, or is it set directly on the twig. How much of the acorn does the cup cover? Are the scales on the cup fine or coarse? Is the cup rounded inwards at its rim? What is the length of the acorn including the cup? The diameter? Are there acorns on your oak in winter? If so, why? Is the kernel of the acorn sweet or bitter? Plant an acorn and watch it sprout.

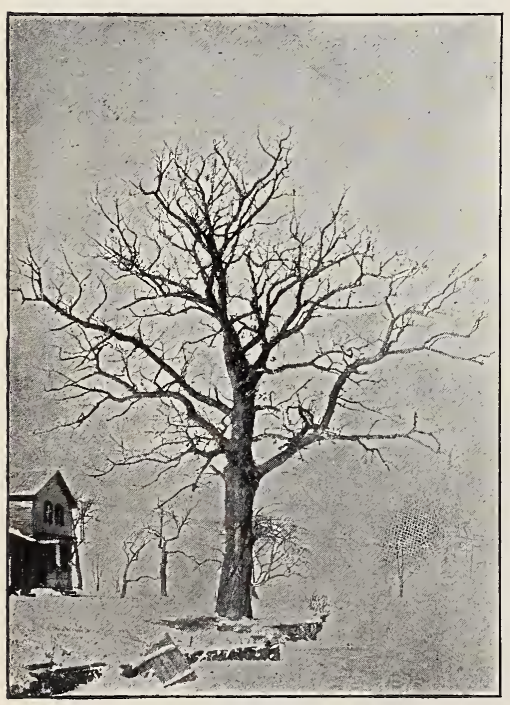

The red oak in winter.

Photo by Ralph Curtis.
4. Read all the stories you can find about oak trees, and write them in your note-book.

5. How great an age does the oak attain? Describe how the country round about looked when the oak tree you are studying was planted.

6. How many kinds of oaks do you know? What is the difference in leaves between the white and the black oak groups? What is the difference in the length of time required for the acorns to mature in these two groups? The difference in taste of the acorns? The difference in the general color of the bark? Why is the chestnut oak an exception to this latter rule?

7. How do the oak leaves look when they first come out of the bud in spring? What is the color of the tree covered with new leaves? When does your oak blossom? Find the pollen-bearing blossoms which are hung in 
long, fuzzy, beady strings. Find the pistillate flower which is to form the acorn. Where is it situated in relation to the pollen-bearing flower?

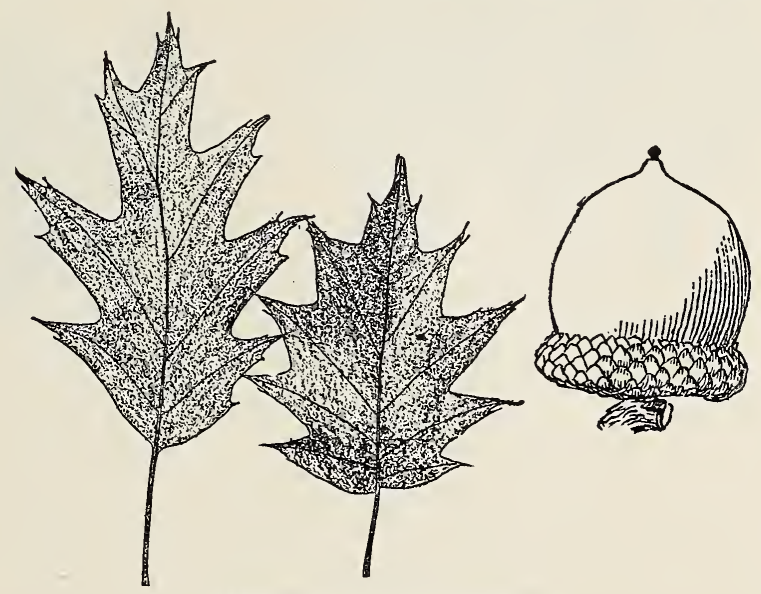

The leaves and acorn of red oa $\dot{k}$.

8. Make a sketch of your oak tree in the fall, and another in the winter. Write the autobiography of some old oak tree in your neighborhood.

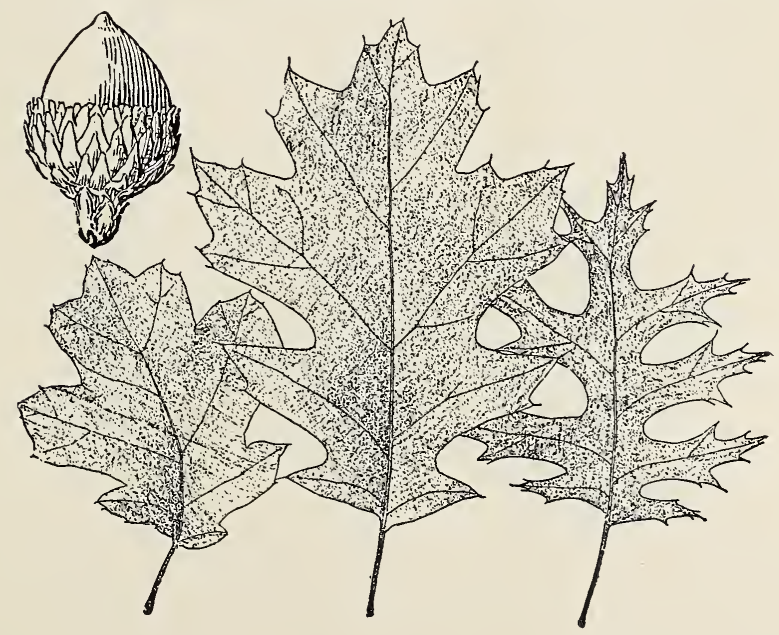

Leaves and acorn of black oak. 

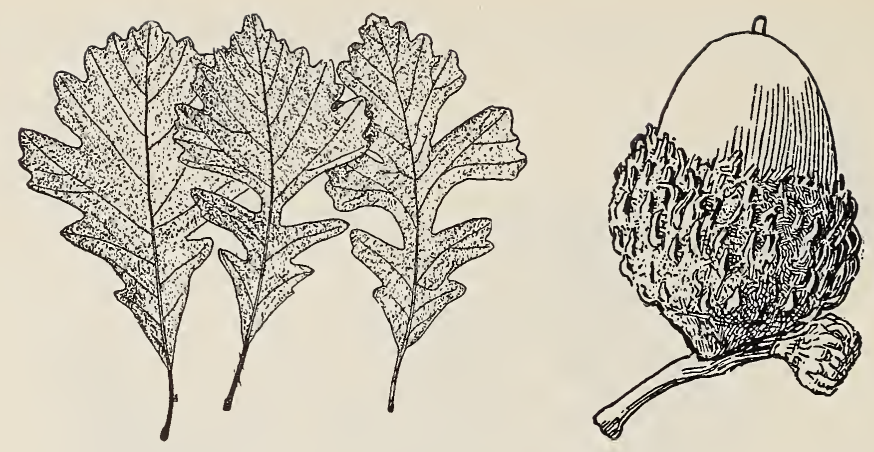

Leaves and acorn of bur oak.

9. For what is the oak wood used? How is the bark used?

Supplementary reading - Trees in Prose and Poetry, FP. I I I-I 29.

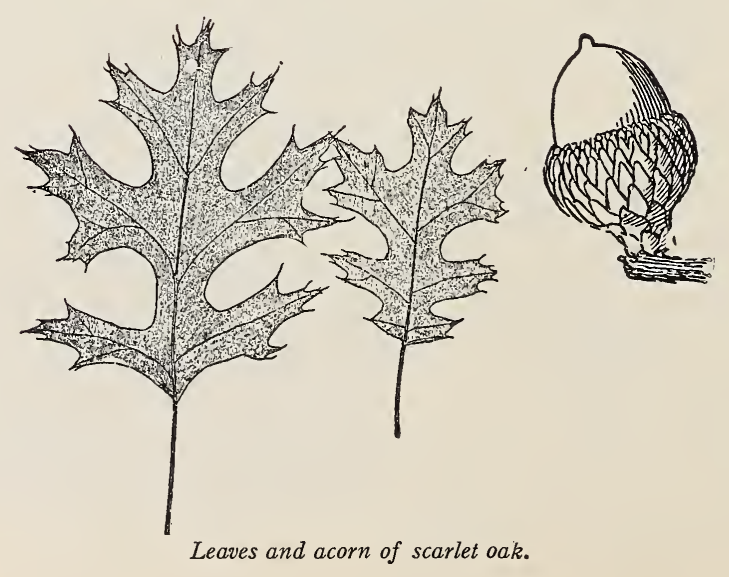




\section{THE SHAGBARK HICKORY}

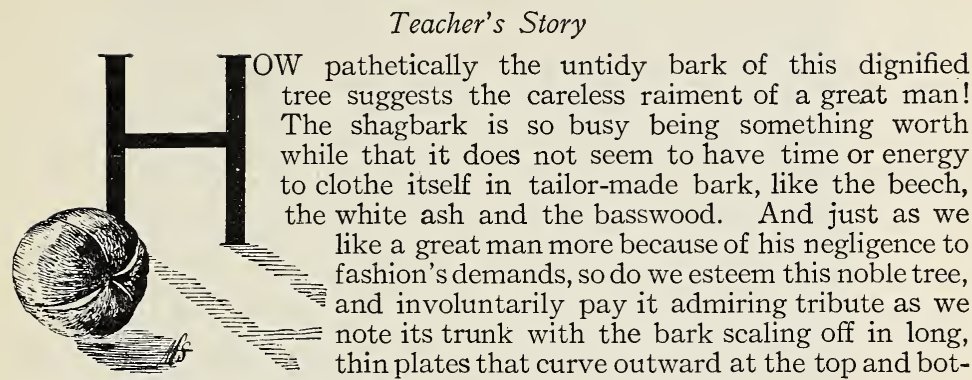
tom and seem to be only slightly attached at the middle.

In general shape, the shagbark resembles the oak; the lower branches are large and, although rising as they leave the bole, their tips are deflected; and, for their whole length, they are gnarled and knotted as if to show their strength. The bark on the larger branches may be scaly toward their bases but above is remarkably smooth. The spray is angular and extends in almost every direction. The leaves, like those of other hickories, are compound. There are generally five leaflets, but sometimes only three and sometimes seven. The basal pair is smaller than the others. The hickory leaves are borne alternately on the twig, and from this character the hickory may be distinguished from the ashes, which have leaves of similar type, but which are placed opposite on the twigs. The shagbark usually has an unsymmetrical oblong head; the lower branches are usually shorter than the upper ones, and the latter are irregularly placed, causing gaps in the foliage.

The nut is large, with a thick, smooth, outer husk channeled at the seams and separating readily into sections; the inner shell is sharply angled and pointed and slightly flattened at the sides; the kernel is sweet. The winter buds of the shagbark are large, light brown, egg-shaped and downy; they swell greatly before they expand. There are from eight to ten bud-scales; the inner ones, which are red, increase to two or three inches in length before the leaves unfold, after which they fall away. The young branches are smooth, soft, delicate in color, and with conspicuous leaf scars.

The hickory bears its staminate and pistillate flowers on the same tree. The pollen-bearing flowers grow at the base of the season's shoots in slender, pendulous, green catkins, which occur usually in clusters of three swinging from a conmon stem. The pistillate flowers grow at the tips of the season's shoots singly or perhaps two or three on a common stem. In the shagbark the middle lobe of the staminate calyx is nearly twice as long as the other two, and is tipped with long bristles; it usually has four stamens with yellow anthers; its pistillate calyx is four-toothed and hairy, and has two large, fringed stigmas.

Tha big shagbark, or king nut, is similar to the shagbark in height, manner of growth, and bark. However, its leaves have from seven to nine leaflets, which are more oblong and wedgelike than are those of the shagbark; they are also more downy when young and remain slightly downy beneath. The nut is very large, thick-shelled, oblong, angled, and pointed at both ends. The kernel is large and sweet but inferior in flavor to the smaller shagbark. The big shagbark has larger buds than has the other. 
Their fringy, reddish purple, inner scales grow so large that they appear tuliplike before they fall away at the unfolding of the leaves.

Hicko y wood ranks high in value; it is light-colored, close-grained, heavy, and very durable when not exposed to moisture. It is capable of resisting immense strain, and, therefore, it is used for the handles of spades, plows and other tools, and also for spokes and thills in carriage-making. As a fuel, it is superior to most woods, making a glowing, hot, and quite lasting fire.

\section{LESSON CXCIII}

\section{The Shagbark}

Leading thought-The hickories are important trees commercially. They have compound leaves which are set alternately upon the twig. The shagbark can be told from the other hickories by its ragged, scaling bark.

Method-This lesson may be begun in the winter when the tree can be studied carefully as to its shape and method of branching. Later, the unfolding of the leaves from the large buds should be watched, as this is a most interesting process; and a little later the blossoms may be studied. The work should be taken up again in the fall, when the fruit is ripe.

Observations Winter study-r. What is the general shape of the whole tree? Are the lower branches very large? At what angle do the branches, in general, grow from the trunk? Are there many large branches?

2. Where is the spray borne? What is its character-that is, is it fine and smooth, or knotted and angled? What is its color?

3. Describe the bark. Is the bark on the limbs like that on the trunk?

4. What is the size and shape of the buds? Are the buds greenishyellow, yellowish brown, or do they have a reddish tinge?

5. Count the bud-scales. Are they downy or smooth?

Spring study -6. Describe how the hickory leaf unfolds from its bud. How is each leaflet folded within the bud?

7. Describe the long greenish catkins which bear the pollen. On what part of the twigs do they grow? Do they grow singly or in clusters?

8. Take one of the tiny, pollen-bearing flowers and hold it under a lens on the point of a pin. How many lobes has the calyx? Count the stamens, and note the color of the anthers.

9. Upon what part of the twigs do the pistillate flowers grow? How many points or lobes has the pistillate calyx? Describe the growth of the nut from the flower.

Autumn study-io. Does the hickory you are studying grow in open field or wood?

I r. Are the trunk and branches slender and lofty, or sturdy and wide spreading?

I2. Note the number and shape of the leaflets. Are they slim and tapering, or do they swell to the width of half their length? Are they set directly upon or are they attached by tiny stems to the mid-stem? Are they smooth or downy on the under side? Are the leaves set upon the twigs alternately or opposite each other? How are the leaflets set upon the mid-stem?

I3. Describe the outer husk of the nut. Into how many sections does it open? Does it cling to the nut and fall with it to the ground? Is the nut angled and pointed, or is it roundish and without angles? Is the kernel sweet or bitter? 


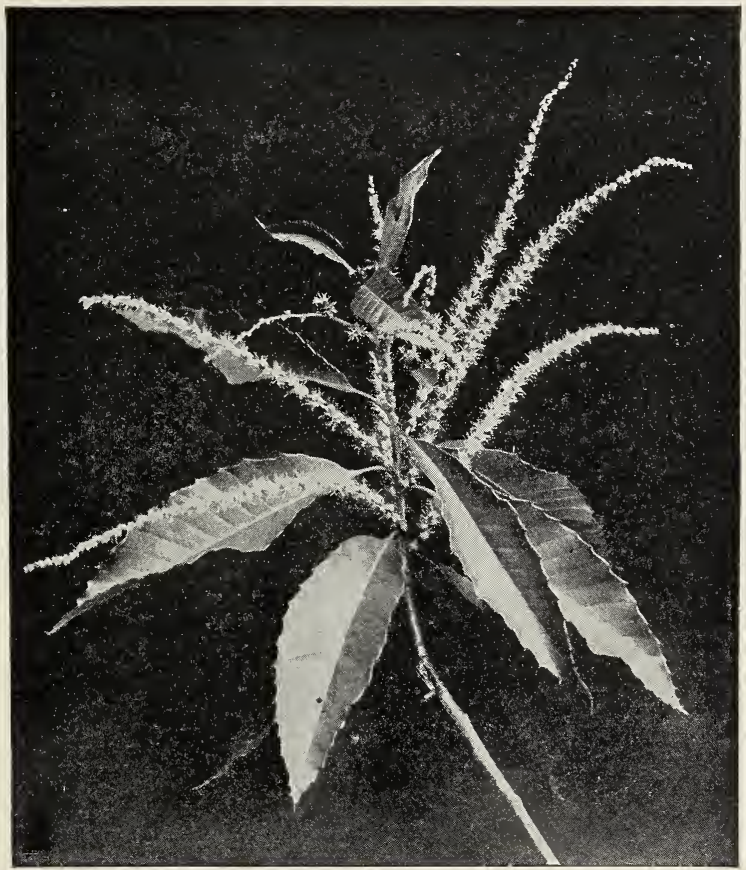

Chestnut blossoms.

Photo by Verne Morton.

Note the two pistillate flowers above the staminate catkins.

\section{THE CHESTNUT}

\section{Teacher's Story}

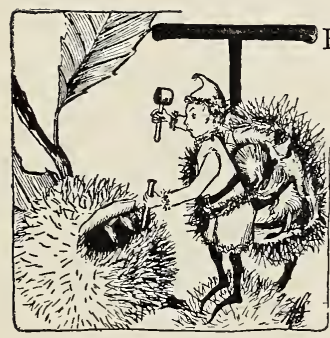

HIS splendid tree, sometimes reaching the height of one hundred feet, seldom receives the admiration due to it, simply because humanity is so much more interested in food than in beauty. The fact that the chestnuts are sought so eagerly has taken away from interest in the appearance of the tree. The chestnut has a great round head set firmly on a handsome bole, which is covered with grayish brown bark divided into rather broad, flat, irregular ridges. The foliage is superb; the long, slender, graceful leaves, tapering at both ends, are glossy, brilliant green above and paler below; and they are placed near the ends of the twigs, those of the fruiting twigs seeming to be arranged in rosettes to make a background for blossom or fruit. The leaves are placed alternately and have deeply notched edges, the veins extending straight and unbroken from midrib to margin; the petiole is short. The leaf is like that of the beech, 
except that it is much longer and more pointed; it resembles in general shape the leaf of the chestnut oak, except that the edges of the latter have rounded scallops instead of being sharply toothed. The burs appear at the axils of the leaves near the end of the twig. Thoreau has given us a most admirable description of the chestnut fruit:

"What a perfect chest the chestnut is packed in! With such wonderful care Nature has secluded and defended these nuts as if they were her most precious fruits, while diamonds are left to take care of themselves. First, it bristles all over with sharp, green prickles, some nearly a half inch long, like a hedgehog rolled into a ball; these rest on a thick, stiff, barklike rind onesixteenth to one-eighth of an inch thick, which again is most daintily lined with a kind of silvery fur or velvet plush one-sixteenth of an inch thick, even rising into a ridge between the nuts, like the lining of a casket in which the most precious commodities are kept. At last frost comes to unlock this chest; it alone holds the true key; and then Nature drops to the rustling leaves a 'done' nut, prepared to begin a chestnut's course again. Within itself again each individual nut is lined with a reddish velvet, as if to preserve the seed from jar and injury in falling, and perchance from sudden damp and cold; and within that a thin, white skin envelops the germ. Thus, it has lining within lining and unwearied care, not to count closely, six coverings at least before you reach the contents."

The red squirrels, as if to show thcir spite because of the protection of this treasure chest, have the reprehensible habit of cutting off the young burs and thus robbing themselves of a rich later harvest-which serves them right. There are usually two nuts in each bur, set with flat sides together; but sometimes there are three and then the middle one is squeezed so that it has two flat sides. Occasionally there is only one nut developed in a bur -an only child, so well cared for that it grows to be almost globular. The color we call chestnut is derivcd from the beautiful red-brown of the polished shell of the nut, polished except where the base joins the bur, and the apex which is gray and downy.

The chestnut is always a beautiful tree, whether green in summer or glowing golden yellow in autumn; but.it is most beautiful during late June and July, when covered with constellations of pale yellow stars. Each of these stars is a rosette of the pollen-bearing blossoms; each ray consists of a

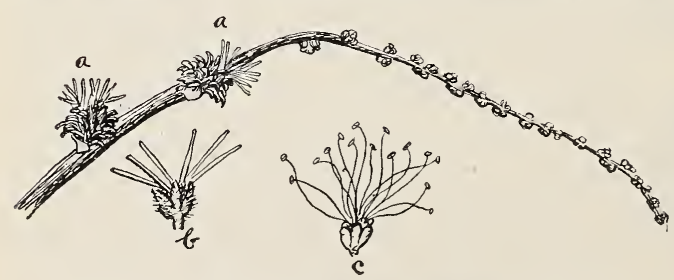

Detail of a chestnut blossom.

a. $a$. pistillate flowers set in a base of scales; $b$, pistillate flower enlarged; $c$, staminate flower enlarged. catkin often six or eight inches in length, looking like a thread of yellowish chenille fringe, clothing this thread in tufts for its whole length are the stamens, standing out like minute threads tipped with tiny anther balls. If we observe the blossom

early enough, we can see these stamens curled up as they come forth from the tiny, pale yellow, six-lobed calyx. One calyx, although scarcely one-sixteenth of an inch across, develops from ten to twenty of these stamens: these tiny flowers are arranged in knots along 


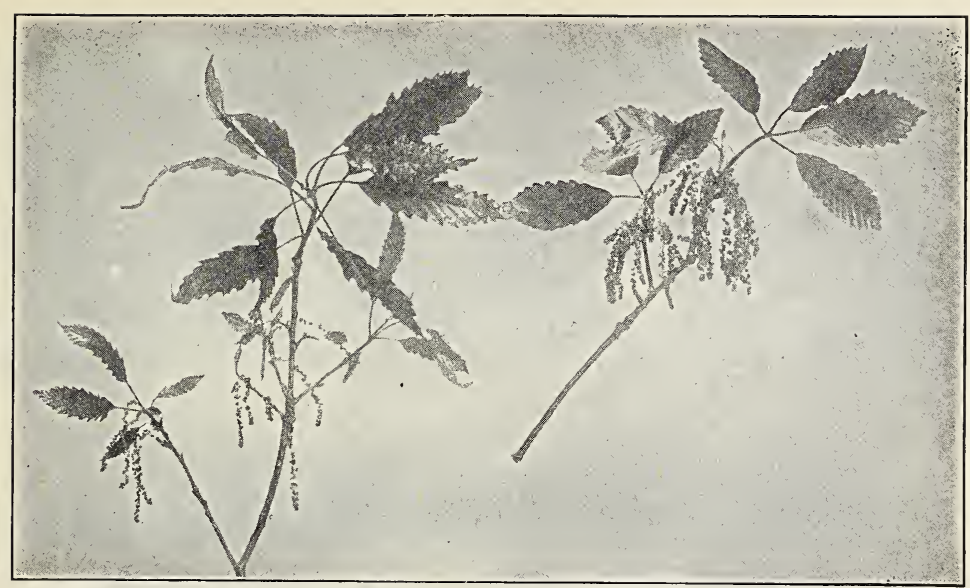

Leaves and flowers of chesinut and chestnut oak showing the differences. Photo by G. F. Morgan.

the central thread of the catkin. No wonder it looks like chenille! There are often as many as thirty of these catkin rays in the star rosette; the lower ones come from the axils of the leaves; but toward the tips of the twig, the leaves are ignored and the catkins have possession. In one catkin I estimated that there were approximately 2,500 stamens developed, each anther packed with pollen. When we think that there may be thirty of the catkins in a blossom-star, we get a glimmering of the amount of pollen produced.

And rhat is all this pollen for? Can it be simply to fertilize the three or four inconspicuous flowers at the tip of the twig beyond and at the center of the star? These pistillate flowers are little bunches of green scales with some short, white threads projecting from their centers; and beyond them a skimpy continuation of the stem with more little green bunches scattered along it, which are undeveloped pistillate blossoms. The one or two flowers at the base of the stem get all the nourishment and the others do not develop. If we examine one of these nests of green scales, we find that there are six threads belonging to one tiny, green flower with a six-lobed calyx; the six threads are the stigmas, each one reaching out and asking for no more than one grain of the rich shower of pollen.

Chestnut, wood is light, rather soft, stiff, coarse and not strong. It is used in cabinet work, cooperage, for telegraph poles and railway ties. When burned as fuel, it snaps and crackles almost equal to hemlock.

\section{LESSON CXCIV}

\section{The Chestnut}

Leading thought-The chestnut is one of our most beautiful trees. We should learn to appreciate it by observing the beauty of its blossoms and of its foliage when green and when brilliant yellow in autumn. Until the chestnut fruit is ripe, it is well protected by its spiny bur. 
Method-This study may be begun in the fall when chestnuts are ripe. Ask the boys to describe the trees from which they get this longed-for harvest. The leaves, burs and nuts may be studied in the schoolroom.

Observations - I. Where do chestnut trees grow? What is the general form of the head of the tree? How high is the trunk below the branches? Do the branches divide into fine twigs or spray at the tips?

2. Sketch and describe a chestnut leaf, showing the veins, edges and petiole. Are the leaves placed opposite or alternate? What is their color above and below? How do the chestnut leaves differ from those of the beech and of the chestnut oak? What is the color of the chestnut foliage in autumn?

3. Where on the branch is the bur borne? How does the green chestnut bur look? Why is this prickly exterior beneficial to the fruit? Does the

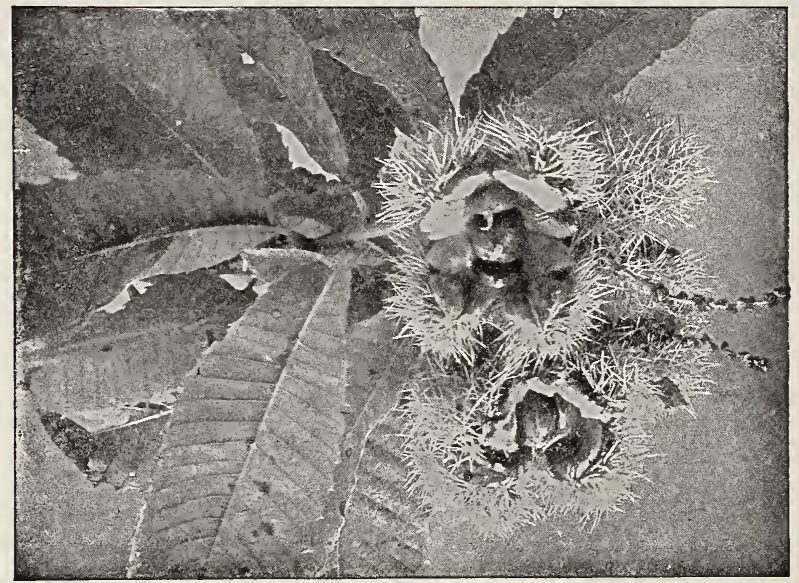

Chestnuts in burs.

Photo by Verne Morton

bur open easily when green? What causes the chestnut bur to open? Into how many lobes does it open? Describe an open bur outside and in.

4. Where in the bur are the chestnuts set? How many in one bur? How can you tell by the shape of the chestnut whether it grew as a twin or single in a bur. Are there ever three in a bur? If so, what shape is the middel one? Do the burs fall when the chestnuts are ripe?

5. Take a single chestnut. Describe its shape and color. What is the mark on its large end? Describe the coloring and covering of the tip. Open the shell and note the lining. Describe how the meat is finally protected. Can you see where the germ is? Plant a chestnut and watch it grow.

6. Study the chestnut blossom in late June or July. What kind of blossoms are those which look like yellow stars all over the tree? Study one of the catkins which makes a ray of the star, and describe it. Can you see the anthers and the pollen? How many of these pollen-bearing flowers are 


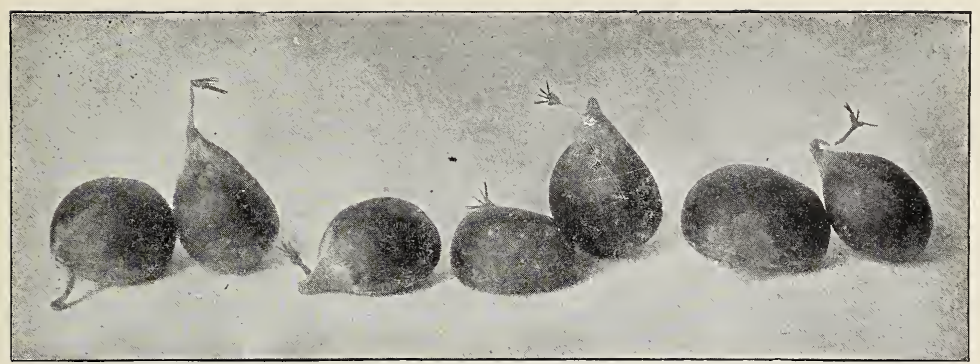

Chestnuts.

Photo by O. L. Foster.

on one stem? Where are the pistillace flowers which will grow into young chestnuts? Describe them.

7. How much are chestnuts worth per bushel? To what uses is chestnut timber put? What is the character of the wood?

\section{THE HORSE-CHESTNUT}

\section{Teacher's Story}

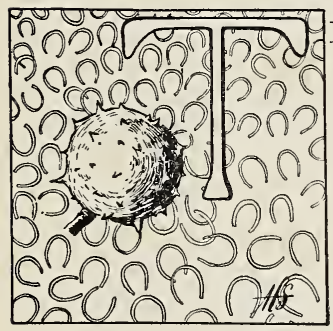

HE wealth of children is, after all, the truest wealth in this world; and the horse-chestnuts, brown and smooth, looking so appetizing and so belying their looks, have been used from time immemorial by boys as legal tender-a fit use, for these handsome nuts seem coined purposely for boys' pockets.

The horse-chestnut is a native of Asia Minor. It has also a home in the high mountains of Greece. In America, it is essentially a shade tree. Its head is a broad cone, its dark green foliage is dense and, when in blossom, the

flower clusters stand out like little white pyramids against the rich back-ground in a most striking fashion. "A pyramid of green supporting a thousand pyramids of white" is a clever description of this tree's blossoming. The brown bark of the trunk has a tendency to break into plates, and the trunk is just high enough to make a fitting base for the handsome head.

The blossom panicle is at the tip end of the twig and stops its growth at that point; the side buds continue to grow thus making a forking branch. Each blossom panicle stands erect like a candle

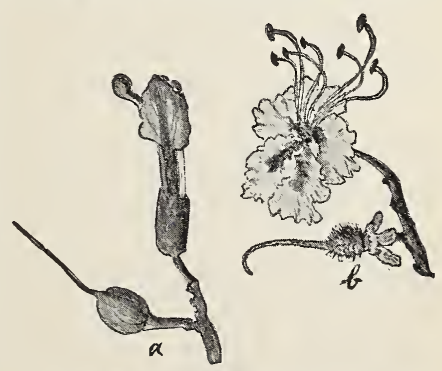

a, blossom of the sweet buck-eye and. young fruit; $\mathrm{b}$, blossom and young fruit of horse-chestnut. 


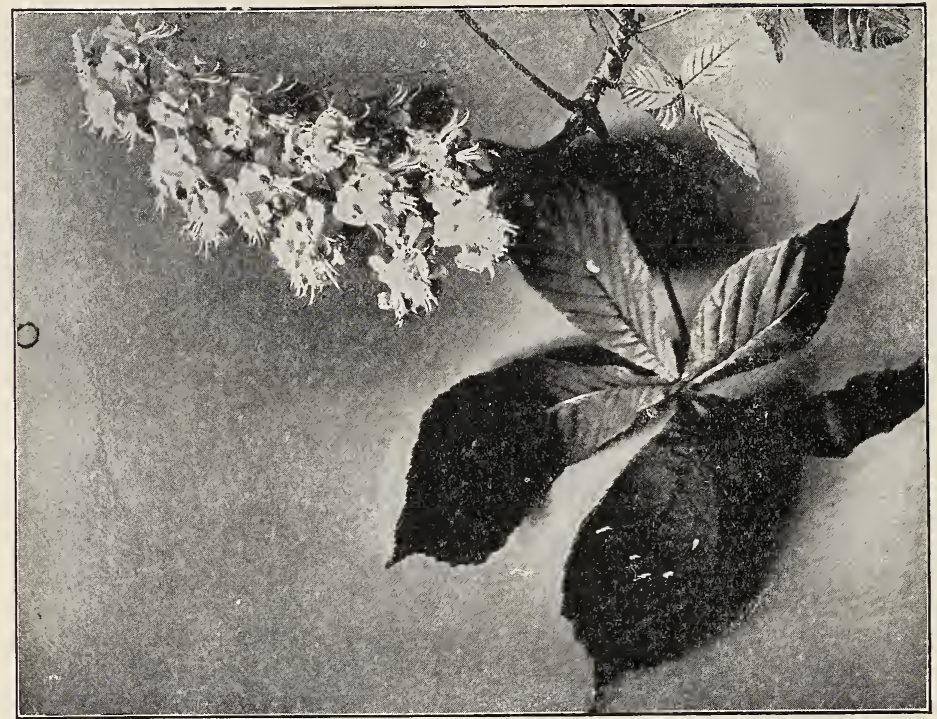

Horse-chestnut blossoms.

Photo by Verne Morton.

flame, and the flowers are arranged spirally around the central stem, each pedicel carrying from four to six flowers. The calyx has five unequal lobes, and it and the stem are downy. Five spreading and unequal petals with ruffled margins are raised on short claws, to form the corolla; seven stamens with orange colored anthers are thrust far out and up from the flower. The blossoms are creamy or pinkish white and have purple or yellow blotches in their throats. Not all the flowers have perfect pistils. The stigmas ripen before the pollen, and are often thrust forth from the unopened flower. The flowers are fragrant and are eagerly visited by bumblebees, honey-bees and wasps.

Very soon after the blossom falls, there may be seen one or two green, prickly balls which are all the fruits one flower cluster could afford to mature. By October the green, spherical husk breaks open in three parts, showing its white satin lining and the roundish, shining, smooth nut at its center. At first there were six little nuts in this husk, but all except one gave up to the burly occupant. The great, round, pale scar on the nut is where it joined the husk. Very few American animals will eat the nut; the squirrels scorn it and horses surely disown it.

In winter, the horse-chestnut twig has at its tip a large bud and looks like a knobbed antenna thrust forth to test the safety of the neighborhood. There are, besides the great varnished buds at the ends of the twigs, smaller buds opposite to each other along the sides of the twig, standing out stiffly. On each side of the end bud, and below each of the others, is a horseshoeshaped scar left by the falling leaf of last year. The "nails" in this horseshoe are formed by the leafy fibres which joined the petiole to the twig. 
The great terminal buds hold both leaves and flowers. The buds in winter are brown and shining as if varnished; when they begin to swell, they open, displaying the silky gray floss which swaddles the tiny leaves. The leaves unfold rapidly and lift up their green leaflets, looking like partly opened umbrellas, and giving the tree a very downy appearance, which Lowell so well describes:

"And gray hoss-chestnut's leetle hands unfold

Softer'n a baby's be at three days old."

The leaf, when fully developed, has seven leaflets, of which the central ones are the larger. They are all attached around the tip of the petiole. The number of leaflets may vary from three to nine, but is usually seven. The leaflets are oval in shape, being attached to the petiole at the smaller end; their edges are irregularly toothed. The veins are large, straight and lighter in color; the upper surface is smooth and dark green, the under side is lighter in color and slightly rough. The petiole is long and shining and enlarges at both ends; when cut across, it shows a woody outer part encasing a bundle of fibres, one fiber to each leaflet. The places where these fibers were attached to the twig make the nails in the horseshoe scar. The leaves are placed opposite on the twigs.

Very different from that of the horse-chestnut is the flower of the yellow or sweet, buckeye; the calyx is tubular, long and five-lobed; the two side petals are on long stalks and are closed like spoons over the stamens and anthers; the two upper petals are also on long stalks, lifting themselves up and showing on their inner surfaces a bit of color to tell the wandering bee that here is a tube to be explored. The flowers are greenish yellow. The flowers of the Ohio buckeye show a stage between the sweet buckeye and the horse-chestnut. The Ohio buckeye is our most common native relative of the horse-chestnut. Its leaves have five leaflets instead of seven. The Sweet buckeye is also an American species and grows in the Alleghany mountains.

\section{LESSON CXCV \\ The Horse-Chestnut}

Leading thought-The horse-chestnut has been introduced into America as a shade tree from Asia Minor and southern Europe. Its foliage and its flowers are both beautiful.

Method-This tree is almost always at hand for the village teacher, as it is so often used as a shade'tree. Watching the leaves develop from the buds is one of the most common of the nature-study lessons. The study of the buds, leaves and fruits may be made in school; but the children should observe the tree where it grows and pay special attention to its insect visitors when it is in bloom.

Observations-r. Describe the horse-chestnut tree when in blossom. At what time does this occur? What is there in its shape and foliage and flowers which make it a favorite shade tree? Where did it grow naturally? What relatives of the horse-chestnut are native to America?

2. Study the blossom cluster; are the flowers borne on the ends or on the sides of the twig? Describe the shape of the cluster. How are the flowers arranged on the main flower stalk to produce this form? Do the flowers open all at once from top to bottom of the cluster? Are all the flowers in the cluster the same color? Are they fragrant? What insects visit them? 


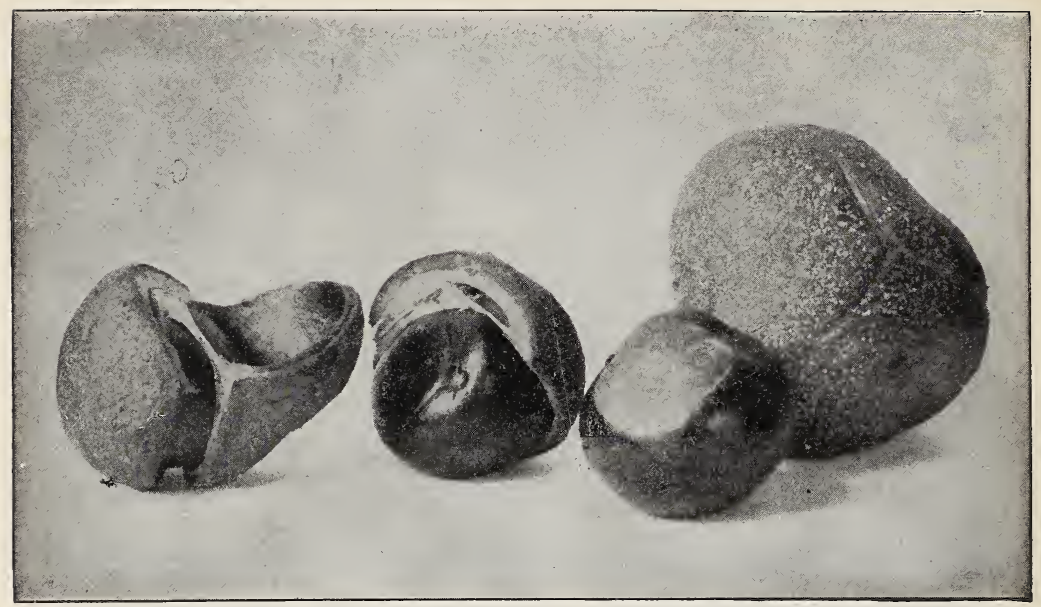

Horse-chestnuts, the coin of the small boy.

Photo by O. L. Foster.

3. Take a single flower; describe the form of the calyx. Is it smooth or downy? Are the lobes all the same size? Are the petals all alike in size and shape? What gives them the appearance of Japanese paper? Are any connected together? Are they all splashed with color alike?

4. How many stamens are there? Where do you see them? What color are the anthers? Search the center of a flower for a pistil with its green style. Do you find one in every flower? Could a bee reach the nectar at the base of the blossom without touching the stigma? Could she withdraw without dusting herself with pollen?

5. How long after the blossom does the young fruit appear? How does it look? How many nuts are developed from each cluster of blossoms? What is the shape of the bur? Into how many parts does it open? Describe the outside; the inside. Describe the shape of the nuts, their color and markings. Which make the best "conquerers," those which grow single in the bur or as twins? Open a nut. Can you find any division in the kernel? Is it good to eat?

Horse-chestnut Twigs and Leaves in Spring-6. Are the buds on the twigs nearly all the same size? Where are the larger ones situated? What is the color of the buds? How are the scales arranged on them? Are they shiny or dull? What do the scales enfold? Can you tell without opening them which buds contain flowers and which ones leaves?

7. Describe the scars below the buds. What caused them? What marks are on them? What made the "nails" in the horseshoe? Has the twig other scars? How do the ring-marks show the age of the twig? Do you see the little, light colored dots scattered over the bark of the twig? What are they?

8. Describe how the leaf unfolds from the bud. What is the shape of the leaf? Do all the leaves have the same number of leaflets? Do any of 
them have an even number? How are the leaflets set upon the petiole? Describe the leaflets, including shape, veins, edges, color above and below. Is the petiole pliant, or stiff and strong? Is it the same shape and size throughout its length? Break a petiole, is it green throughout? What can you see at its center? Are the leaves opposite or alternate? When they fall, do they drop entire or do the leaflets fall apart from the stem?

9. Sketch the horse-chestnut tree.

Io. How do the flowers and leaves of the horse-chestnut differ from those of the sweet buckeye and of the Ohio buckeye?

Supplementary reading-Trees in Prose and Poetry, p. I7.

\section{THE WILLOWS}

\section{Teacher's Story}

They shall spring up among the grass, as willows by the water courses. -ISAIAH.

"When I cross opposite the end of Willow Row the sun comes out and the trees are very handsome, like a rosette, pale, tawny or fawn color at base and red-yellow or orange-yellow for the upper three or four feet. This is, methinks, the brighlest object in the landscape these days. Nothing so betrays the spring sun. I am aware that the sun has come out of the cloud just by seeing it light up the osiers."-THOREAU.

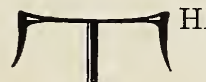

willow, Thoreau noted, is the golden osier, a colonial dame, a descendent from the white willow of Europe. It is the most common tree planted along streams to confine them to their channels, and affords an excellent subject for a nature-study lesson. The golden osier has a short though magnificent trunk, giving off tremendous branches, which in turn branch and uphold a mass of golden terminal shoots. But there are many willows besides this, and the one who tries to determine all the species and hybrids must conclude that of making willows there is no end. The species beloved by children is the pussy willow which is often a shrub, rarely reaching twenty feet in height. It loves moist localities, and on its branches in early spring are developed the silky, furry pussies. These are favorite objects for a nature-study lesson, and yet how little have the teachers or pupils known about these flowers!

The willow pussies are the pollen-bearing flowers; they are covered in winter by a brown, varnished, double, tentlike bract. The pussy in full bloom shows beneath each fur-bordered scale two stamens with long filaments and plump anthers; but there are no pistils in this blossom. The flowers which produce seed are borne on another tree entirely and in similar greenish gray catkins, but not so soft and furry. In the pistillate catkin each fringed scale has at its base a pistil which thrusts out a Y-shaped stigma. The question of how the pollen from one gets to

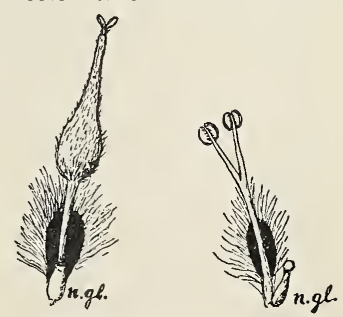

Enlarged willow blossoms.

Pistillate blossom showing nectar, gland, (n.gl.)

Staminate flower showing the nectar, gland (n.gl.) 


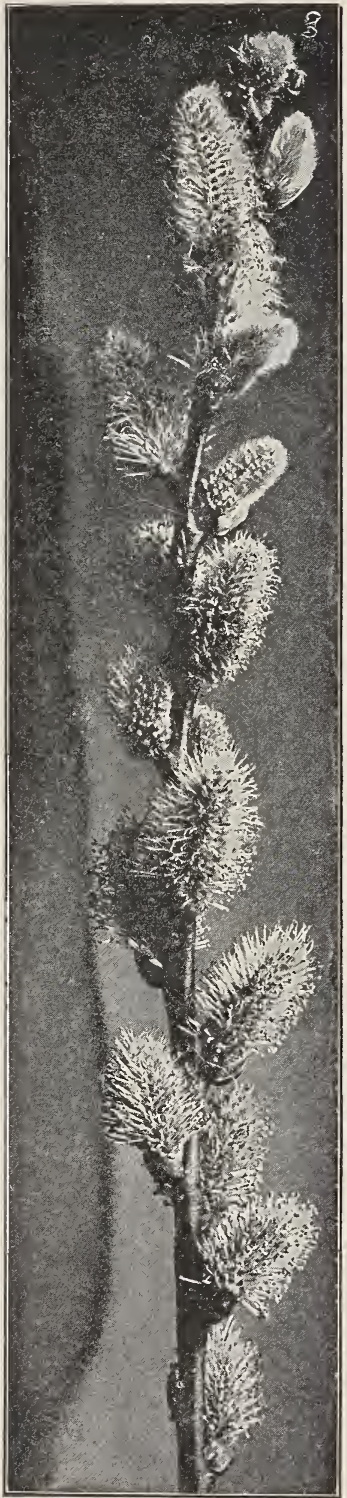

The willow pussies. The staminate blossoms of the willow. Photo by Verne Morton. the pistils of another is a story which the bees can best tell. The willow flowers give the bees almost their earliest spring feast and, when they are in blossom, the happy hum of the bees working in them can be heard for some distance from the trees. The pollen gives them bee bread for their early brood, and they get their honey supply from the nectar which is produced in little jug-shaped glands, at the base of each pollen-bearing flower on the "pussy" catkin, and in a long pocket at the base of each flower on the pistillate catkin. So they pass back and forth, carrying their pollen loads to fertilize the stigmas on trees where there is no pollen. It has been asserted that the pussies, or pollen-bearing flowers, yield no nectar but give only pollen, so that the bee is obliged to seek both trees in order to secure a dict of "balanced ration;" but the person who made this statement had never taken the pains to look at the tiny jugs over-flowing with nectar found at their bases.

In June the willow seed is ripe. The catkin then is made up of tiny pods, which open like milkweed pods and are filled with seed equipped with balloons. When these fuzzy seeds are being set free people say that the willows "shed cotton."

Although the seed of the willow is produced in abundance, it is hardly needed for preserving the species. Twigs which we place in water to develop flowers will also put forth roots; even if the twigs are placed in water wrong side up, rootlets will form. A twig lying flat on moist soil will push out rootlets along its entire length as though it were a root; and shoots will grow from the buds on its upper side. This habit of the willows and the fact that the roots are long, strong and fibrous make these trees of great use as soil binders. There is nothing better than a thick hedge of willows to hold streams to their proper channels during floods; the roots reach out in all directions, interlacing themselves in great masses, and thus hold the soil of the banks in place. The twigs of several of the species, notably the crack and sand-bar willows, are broken off easily by the wind and carried off down stream, and where they lodge, they take root; thus, many streams are bordered by selfplanted willow hedges.

The willow foliage is fine and makes a beautiful, soft mass. with delicate shadows. The leaf is long, narrow, pointed and slender, 
with finely toothed edges and short petiole; the exact shape of the leaf, of course, depends upon the species, but all of them are much lighter in color below than above. The willows are, as a whole, water lovers and quick growers.

Although willow wood is soft and exceedingly light, it is very tough when seasoned and is used for many things. The wooden shoes of the European peasant, artificial limbs, willowware, and charcoal of the finest grain used in the manufacture of gunpowder, are all made from the willow wood. The toughness and flexibility of the willow twigs have given rise to many industries; baskets, hampers, carriage bodies and furniture are made of them. To get these twigs the willow trees are pollarded, or cut back every year between the fall of the leaves and the flow of the sap in the spring. This pruning results in many twigs. The use of willow twigs in basketry is ancient. The Britons fought the Roman soldiers from behind shields of basket work; and the wattled huts in which they lived were woven of willow saplings smeared with clay. Salicylic acid, used widely in medicine, is made from willow bark, which produces also tannin and some unfading dyes.

There are many insect inhabitants of the willow, but perhaps the most interesting is the little chap which makes a conelike object on the twig of certain species of willow growing along our streams. This cone is naturally considered a fruit by the ignorant, but we know that the willow seeds are grown in catkins instead of cones. This willow cone is made by a small gnat which lays its egg in the tip of the twig; as soon as the little grub hatches, it begins to gnaw the twig, and this irritation for some reason stops the growth. The leaves instead of developing along the stem are dwarfed

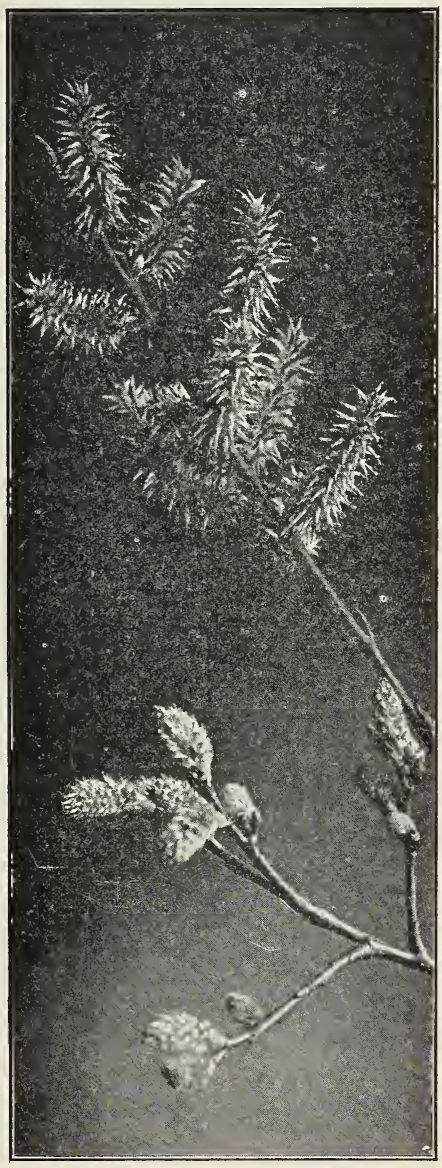

The pistillate blossoms of the willow. Photo by Verne Morton. and overlap each other. Just in the center of the cone at the tip of the twig the little larva lives its whole life surrounded by food and protected from enemies; it remains in the cone all winter, in the spring changes to a pupa. and after a time comes forth-a very delicate little fly. The larva in this gall is very hospitable. It has its own little apartment at the center but does not object to having a tenant in its outer chambers, a fact which is taken 
advantage of by another gall-gnat which breeds there in large numbers. It is well to gather these cones in winter; examine one by cutting it open to find the larva, and place others in a fruit jar with a cover so as to see the little flies when they shall issue in the spring. (See p. 362). For supplementary reading see "Outdoor Studies," page 24.

There is another interesting winter tenant of willow leaves, but it is rather difficult to find. On the lower branches may be discovered, during winter and spring, leaves rolled lengthwise and fastened, making elongated cups. Each little cup is very full of a caterpillar which just fits it, the caterpillar's head forming the plug of the opening. This is the partially grown larva of the viceroy butterfly. It eats off the tip of the leaf each side of the midrib for about half its length, fastens the petiole fast to the twig with silk, then ro:ls the base of the leaf into a cup, lines it with silk and backs into it, there to remain until fresh leaves on the willow in spring afford it new food.

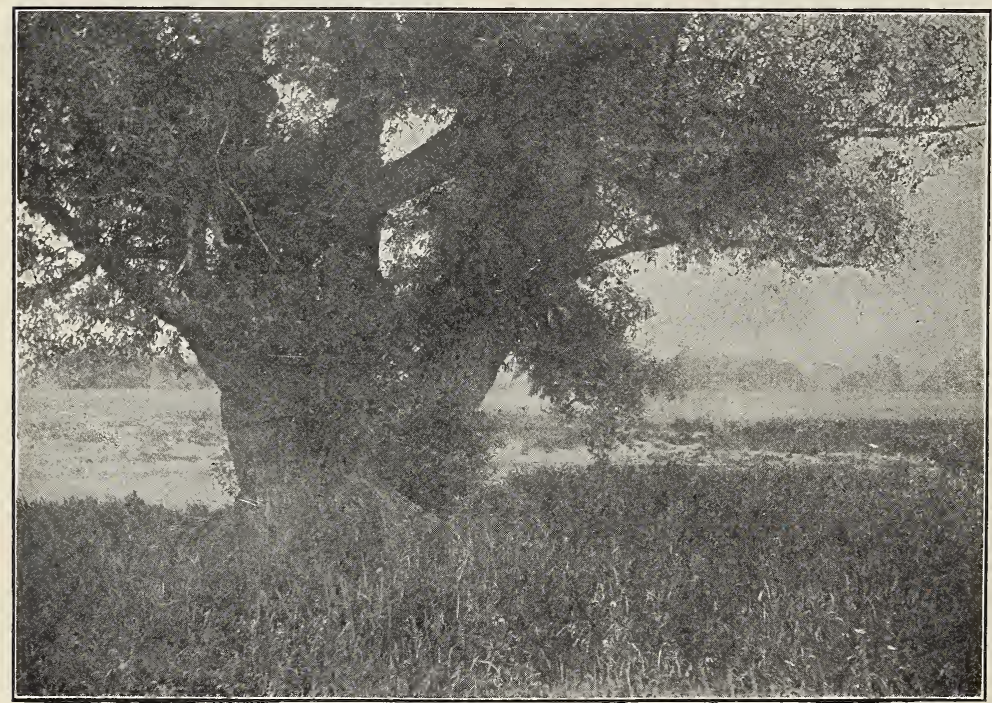

"My willow-tent."

Photo by W. C. Baker.

\section{LESSON CXCVI}

\section{The Willows}

Leading thought-The willows have their pollen-bearing flowers and their seed-bearing flowers on separate trees; the bees carry the pollen from one to the other. The willow pussies are the pollen-bearing flowers.

Method-As early in March as is practicable, have the pupils gather twigs of as many different kinds of willows as can be found; these should be put in jars of water and placed in a warm, sunny window. The catkins will soon begin to push out from the bud-scales, and the whole process of flowering may be watched. 
Observations-r. How can you tell the common willow tree from afar? In what localities do these trees grow? What is the general shape of the big willow? How high is the trunk, or bole? What sort of bark has it? Are the main branches large or small? Do they stand out at a wide angle or lift up sharply? What color are the terminal shoots, or spray?

2. Are the buds opposite or alternate on the twigs? Is there a bud at exactly the end of any twig? How many bracts are there covering the bud?

3. Which appear first, the leaves or the blossoms? Study the pussies on your twigs and see if they are all alike. Is one kind more soft and furry than the other? Are they of different colors?

4. Take one of the furry pussies. Describe the little bract, which is like a protecting hood at its base. What color is the fur? After a few days, what color is the pussy? Why does it change from silver color to yellow? Pick one of the catkins apart and see how the fur protects the stamens.

5. Take one of the pussies which is not so furry. Can you see the little pistils with the Y-shaped stigmas set in it? Is each little pistil set at the base of a little scale with fringed edges?

6. Since the pollen-bearing catkins are on one tree and the seed-bearing catkins are on the other, and since the seeds cannot be developed without the pollen, how is the pollen carried to the pistils? For this answer, visit the willows when the pussies are all in bloom and listen. Tell what you hear. What insects do you see working on the willow blossoms? What are they after?

7. What sort of seed has the willow?

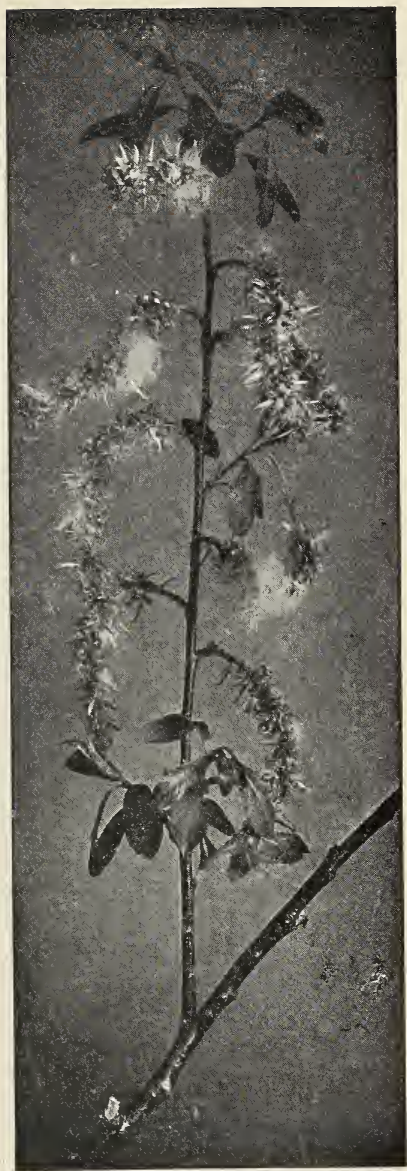

Seeds of willow.

Photo by Verne Morton. How is it scattered? Do you think the wind or water has most to do with planting willow seed?

Work for May or September - 8. Describe willow foliage and leaves. How can you tell willow foliage at a distance?

9. What sort of roots has the willow? Why are the willows planted along the banks of streams? If you wished to plant some willow trees how would you do it? Would you plant seeds or twigs?

I0. For what purposes is willow wood used? How are the twigs used? Why are they specially fitted for this use? What is pollarding a tree? What medicine do we get from willow bark? 
I I. Do you find willow cones on your willows? Cut one of these cones through and see if you can find any seeds? What is in the middle of it? What do you think made the scales of the cone? Do you think this little insect remains in here all winter?

I2. In winter, hunt the lower branches of willows for leaves rolled lengthwise making a winter cradle for the young caterpillars of the viceroy.

Supplementary reading-Trees in Prose and Poetry, p. I37.

\section{THE COTTONWOOD, OR CAROLINA POPLAR Teacher's Story}

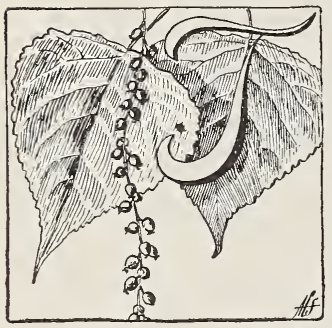

$\mathrm{HE}$ sojourner on our western plains where streams are few and sluggish, disappearing entirely in summer, soon learns to love the cottonwoods, for they will grow and cast their shade for men and cattle where no other tree could endure. The cottonwood may be unkempt and ragged, but it is a tree, and we are grateful to it for its ability to grow in unfavorable situations. In the Middle West it attains its perfection, although in New York we have some superb specimens-trees which are more than one hundred feet in height and with majestic trunks, perhaps five or six feet through. The deep-furrowed, pale gray bark makes a handsome covering. The trunk divides into great out-swinging, widely spaced branches, which bear a fine spray on their drooping ends. Sargent declares that at its best the cottonwood is one of the statliest inhabitants of our eastern forests. The variety we plant in cities we call the Carolina poplar, but it is a cottonwood. It is a rapid grower, and therefore a great help to the "boom towns" of the West and to the boom suburbs in the East; although for a city tree its weak branches break too readily in wind storms in old age. However, it keeps its foliage clean, the varnished leaves shedding the dust and smoke; because of this latter quality it is of special use in towns that burn soft coal.

The cottonwood twigs which we gather for study in the spring are yellowish or reddish, those of last year's growth being smooth and round, while those showing previous growth are angular. The buds are red-brown and shining, and covered with resin which the bees like to collect for their glue. The leaf buds are slender and sharp-pointed; the flower buds are wider and plumper.

The two sexes of the flowers are borne on separate trees. The trees bearing pollen catkins are so completely covered with them that they take on a very furry, purplish appearance when in blossom. These catkins are from three to five inches long and half an inch thick, looking fat and pendulous; each fringed scale of the catkin has at its base a disc looking like a white bracket, from which hang the reddish purple anthers; these catkins fall after the pollen is shed and look like red caterpillars upon the gruund.

The seed-bearing flowers are very different; they look like a string of little, greenish beads loosely strung. Each pistil is globular and set in a tiny cup, and it has three or four stigmas which are widened or lobed; as 


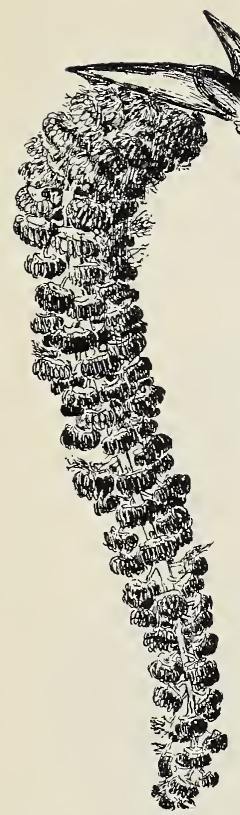

Staminate catkin of cottonwood.

Drawn by Anna Stryke.

it matures, it becomes larger and darker green, and the string elongates to six or even ten inches. The little pointed pods open into two or more valves and set free the seeds, which are provided with a fluff of pappus to sail them off on the breeze; so many of the seeds develop that every object in the neighborhood is covered with their fuzz, and thus the tree has gained its name "cottonwood."

The foliage of the cottonwood is like that of other poplars, trembling with the breeze. The heavy, subcircular leaf is supported on the sidewise flattened petiole, so that the slightest breath of air sets it quaking; a gentle breeze sets the whole tree twinkling and gives the eye a fascinating impression as of leaves beckoning. The leaf is in itself pretty. It is from three to five inches long, broad, slightly angular at the base and has a long, tapering, pointed tip. The edge is saw-toothed, and also slightly ruffled except near the stem where it is smooth; it is thick and shining green above and paler beneath. The long, slender petiole is red or yellowish, and the leaves are placed alternate on the twigs.

In the autumn the leaves are brilliant yellow. The wood is soft, weak, fine-grained, whitish or yellowish, and has a satiny luster; it is not durable. It is used somewhat for building and for furniture, in some kinds of cooperage, and also for crates and woodenware; but its greatest use is for making the pulp for paper. Many newspapers and books are printed on cottonwood paper. It is common from the Middle States to the Rocky Mountains and from Manitoba to Texas.

\section{LESSON CXCVII}

\section{The Cottonwood}

Leading thought-The cottonwood is a poplar. It grows rapidly and flourishes on the dry western plains where other trees fail to gain a foothold. It grows well in the dusty city, its shining leaves shedding the smoke and dirt.

Method-Begin this study in spring before the cottonwoods bloom. Bring in twigs in February, give them water and warmth, and watch the development of the catkins. Afterwards watch the unfolding of the leaves and study the tree.

Observations-r. What is the color of the bark on the cottonwoud? Is it ridged deeply? What is the color of the twigs? Are they round or angular, or both? Describe the winter buds and bud-scales. Can you tell which bud will produce leaves and which flowers?

2. Describe the catkin as it comes out. Has this catkin anthers and pollen, or will it produce seed? Do you think the seeds are produced on the same trees as the pollen? 


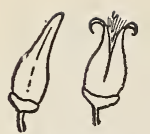

Seed-pod of poplar, shut and open.

3. Find a pollen-bearing catkin. Describe the stamens. Can you see anything but the anthers? On what are they set? What color are they? What color do they give to the tree when they are in blossom? What happens to the catkins after their pollen is shed?

4. Find a seed-bearing catkin. How long is it? Do you see why this tree is called the necklace poplar? Describe the pistils which make the beads on the necklace.

5. When do the seeds ripen? If you have been near the tree, how do you know when they are ripe? How long is the catkin with the ripened

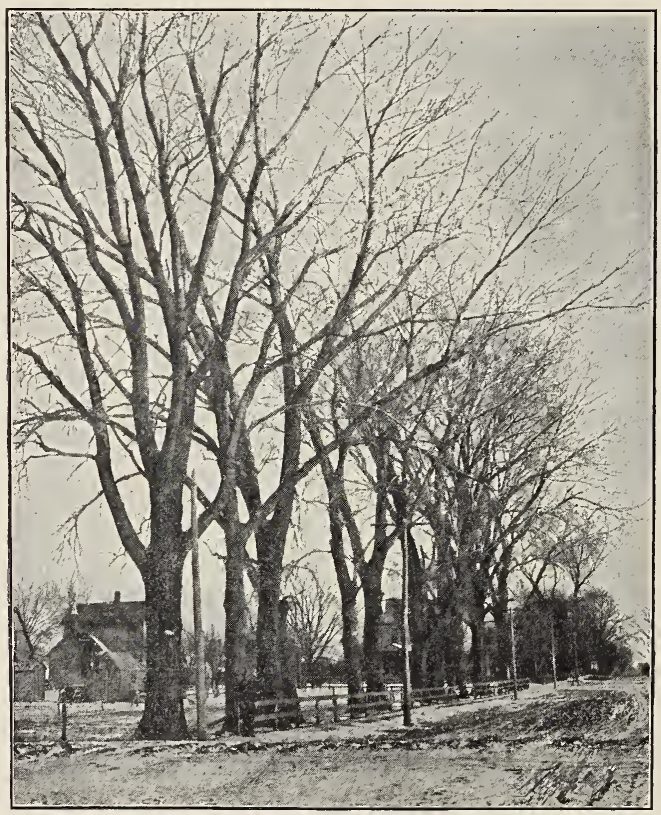

Cottonwoods.

Courtesy of U. S. Forest Service.

seeds? How many balls on the necklace now? What is the color? How many seeds conie out of each little pod? How are the seeds floated on the air? Why do we call this tree "cottonwood?"

6. How large is the largest cottonwood that you know? Sketch it to show the shape of the tree. Are the main branches large? Do they droop at the tips?

7. How does the foliage of the cottonwood look? Does it twinkle with the wind? Examine the leaves upon a branch and see why they twinkle. Are the petioles round or flat? Are they flattened sidewise or up and down? Are they stiff or slender? Describe the leaves, giving their shape, 
veins, edges, color and texture above and below. Are the edges ruffled as well as toothed? Is the leaf heavy? If a breeze comes along how would it affect such a heavy, broad leaf on such a slender, thin petiole? Blow against the leaves and see how they move? Do you understand, now, why they twinkle? Can you see why the leaves shed smoke and dust, when used for shading city streets?

8. Why is the cottonwood used as a shade tree? Do you think it makes a beautiful shade tree? How long does it take it to grow? What kind of wood does it produce? For what is it used?

Supplementary reading - Trees in Prose and Poetry, pp. I39-I49.

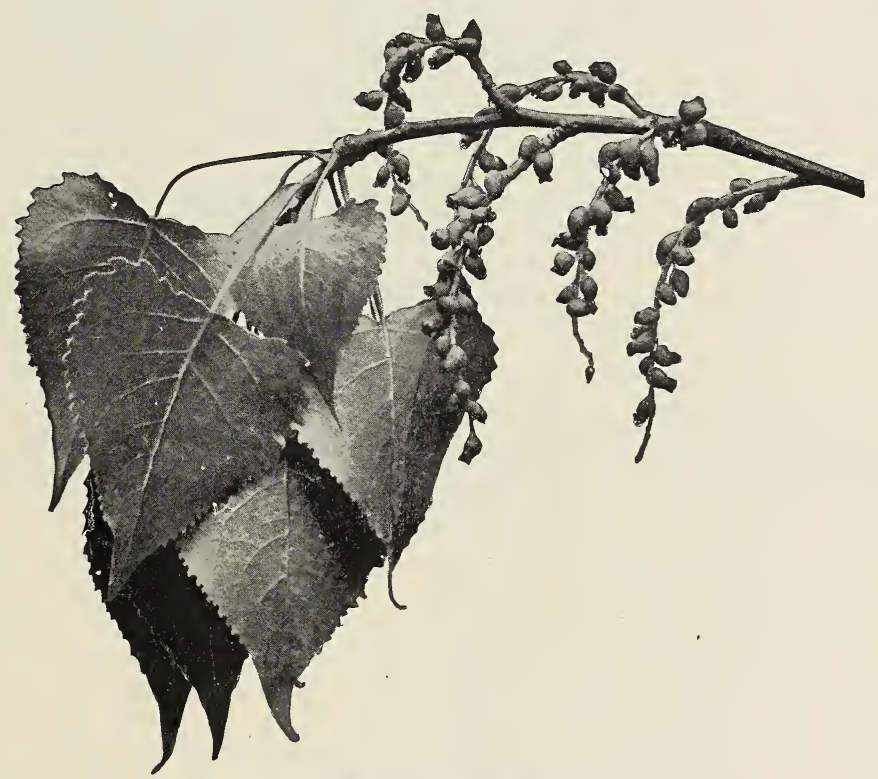

The growing fruit of the cottonwood.

Photo by Cyrus Crosby 


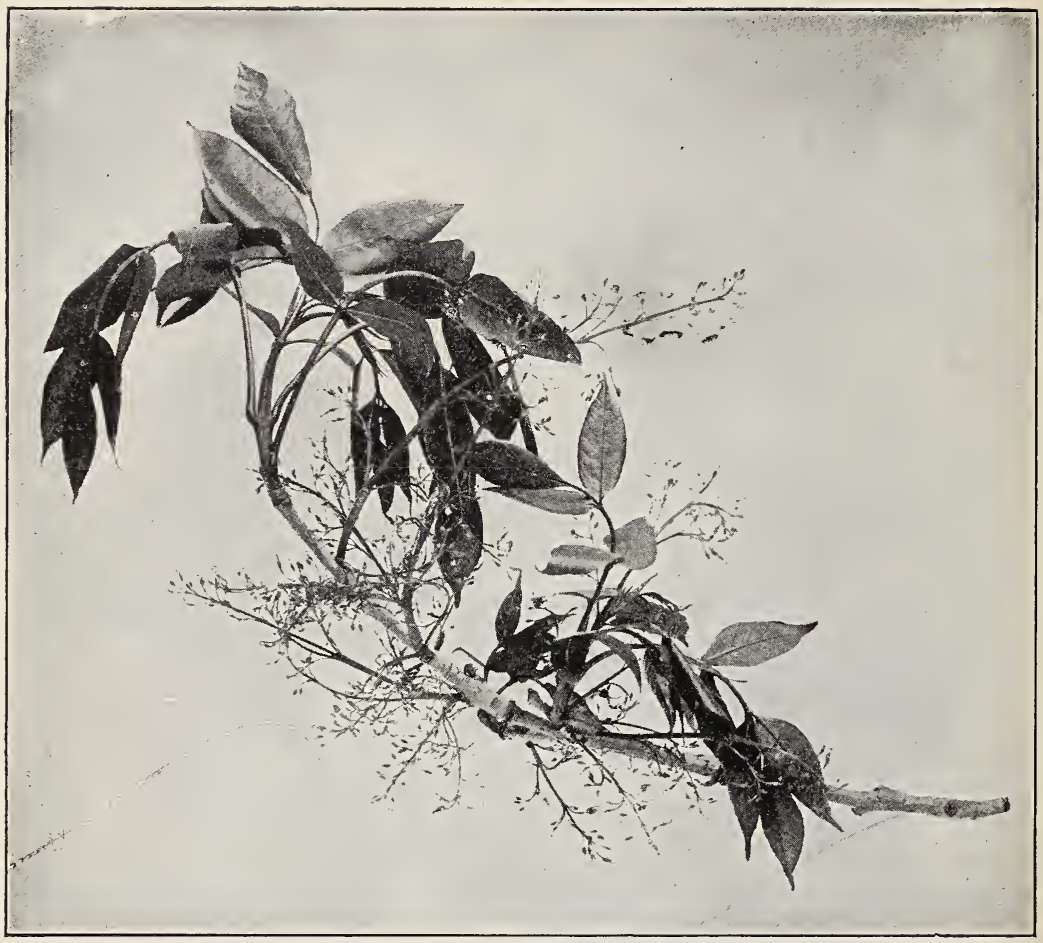

Pisilllate blossoms of white ash.

Photo by G. F. Morgan.

\section{THE WHITE ASH}

\section{Teacher's Story}

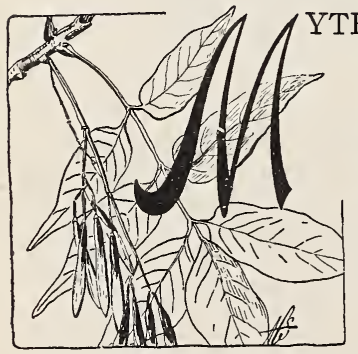

$S$ and legends cluster about the ash tree. It was, in the Norse mythology, the tree "Igdrasil," the tree of the universe, which was the origin of all things. It is a pity that it was not the Tree of Life in the Garden of Eden, for if another myth is true, no snake will go near it or cross its branches. There is a widespread belief that it draws lightning, just as the beech repels the thunderbolts. "As straight as a white ash tree" was the highest compliment that could be paid to the young pioneer; so straight is its fiber and so strong its quality, that the American Indians made their canoe paddles from it.

The ashes have the most beautiful bark in the world. It is divided into fine, vertical ridges, giving the trunks the look of being shaded with pencil 
ines; the bark smooths out on the lower branches. But even more characteristic than the bark, are the ash branches and twigs; the latter are sparse, coarse and clumsy, those of the white ash being pale orange or gray and seemingly warped into curves at the ends; they are covered with whitish gray dots, which reveal themselves under the lens to be breathingpores.

The white ash loves to grow in rich woods or in rich soil anywhere, even though it be shallow; at its best, it reaches the height of I3o feet, with a trunk six feet through. Its foliage is peculiarly graceful; the leaves are from eight to twelve inches long and are composed of from five to nine leaflets. The leaflets have little petioles connecting them with the middle stem; in shape they are ovate with edges obscurely toothed or entire; the two basal leaflets are smaller than the others and the end one largest; in texture, they are satiny, dark green above, whitish beneath, with featherlike veins, often hairy on the lower side. The petioles are swollen at the base. The leaves are set opposite upon the twig; except the horsechestnut, the ashes are our only trees with compound leaves which have the leaves opposite. This character alone readily distinguishes the ashes from the hickories. The autumn foliage has a very peculiar color; the leaves are dull purple above and pale yellow below; this brings the sunshine color into the shadowy parts of the tree, and gives a curious effect of no perspective. Notwithstanding this, the autumn coloring is a joy to the artistic eye and is very characteristic.

The seeds of the ash are borne in crowded clusters; the delicate stem, from three to five inches long, is branched into smaller stems to which are joined two or three keys, and often several of these main stems come from the same bud at the tip of last year's wood so that they seem crowded. The seed is winged, the wing being almost twice as long as the seed set at its base. Thoreau says: "The keys of the white ash cover the trees profusely, a sort of mulberry brown, an inch and a half long, and handsome." The seeds (ling persistently to the tree, and I have often observed them being blown over the surface of the snow as if they were skating to a planting place.

The flowers appear in April or May, before the leaves. The pistillate flowers make an untidy fringe, curling in every direction around the twigs. The chief flower stem is three to four inches long, quite stout, pale green, and from this arise short, fringed stems, each carrying along its sides the knobs on little stemswhich are the pistillate flowers. Each tiny flower seems to be bristling with individuality,stand-

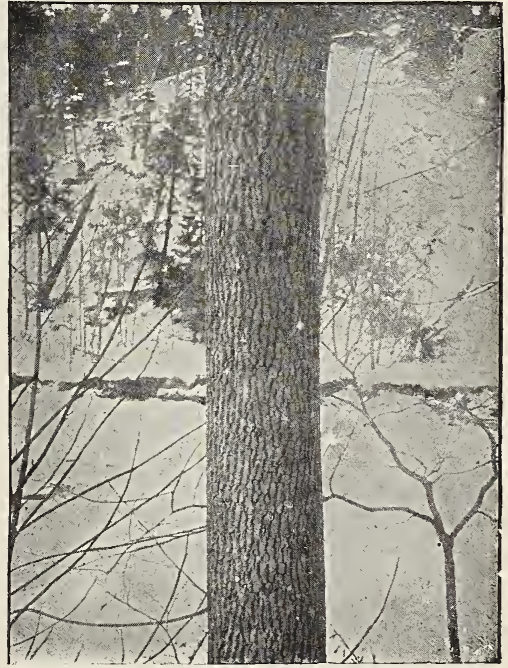

Bole of white ash showing the beautiful bark. Photo by Ralph Curtis. 
ing off at its own angle to get its own pollen. The flower has the calyx four-lobed; the style is long and slender and is divided into a V-shaped purple stigma.

The staminate flowers appear early in the spring, and look like knobs on the tips of the coarse, sparse twigs; they consist of masses of thick, green anthers with very short, stout filaments; each calyx is four-lobed.

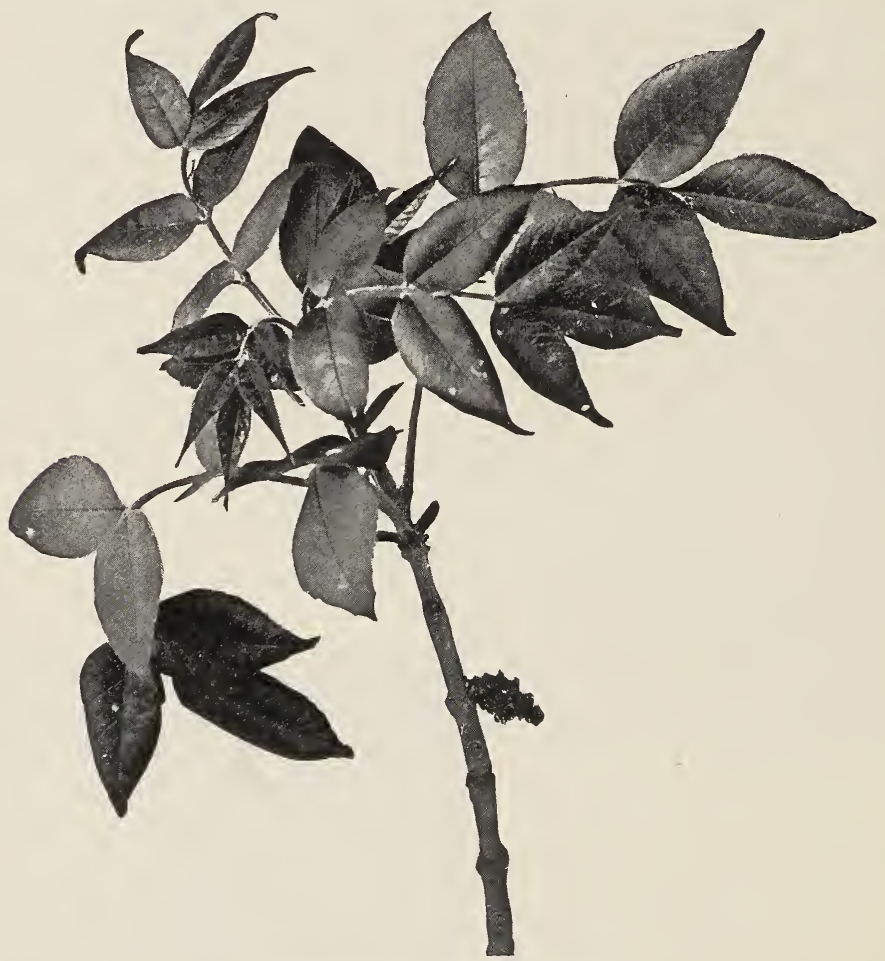

Staminate blossoms of white ash.

Photo by G. F. Morgan.

These flowers are attached to a five-branching stem; but the stem and its branches cannot be seen unless the anthers are plucked off, because they hang in such a crowded mass. Later the leaves come out beyond them.

The leaf buds in winter are very pretty; they are white, bluntly pointed, with a pale gray half-circle below, on which was set last year's leaf. Another one of nature's miracles is the bouquet of leaves coming from one of the big four-parted terminal buds, which is made up of four scales, two of which are longer and narrower than the others. Within the bud each little compound leaflet is folded like a sheet of paper lengthwise, and folded with the other leaflets like the leaves of a book; and when they first appear they look like tiny, scrawny, birds' claws. But it is 
not merely one pair of leaves that comes from this bud, but many, each pair being set on a twig opposite and at right angles to the next pair on either side. Even as many as five pairs of these splendid compound leaves come from this one prolific bud. As they push out, the green stem of the new wood grows, thus spacing the pairs properly for the making of beautiful foliage.

\section{LESSON CXCVIII}

\section{Ash TreEs}

Leading thought-The ashes are our most valuable timber trees; the white ash is one of the most beautiful and useful of them all. It does not make forests, but it grows in them, and its wood is of great value for many things.

Method-The pupils should all see the tree where it grows. The questions should be given to them for their field note-books. The lesson should begin in the fall and be continued in the spring.

Observations-I. What is there about the bark of the ash tree which distinguishes it from other trees? Where does the white ash grow? What is the height and thickness of the ash tree you are studying?

2. The ash leaf is a compound leaf; of how many leaflets is it composed? What is the texture and shape of the leaflets? Describe the veins. Do the leaflets have petioles (petiolules)? Are the edges of the leaflets toothed? Which of the leaflets is largest? Which smallest? Is the petiole swollen at the base? How are the leaves arranged on the twigs? How does this distinguish the ashes from all other of our trees having compound leaves? How do the hickories have their leaves arranged? What color is the ash foliage in autumn?

3. Describe the seeds of the ash and the way they are arranged on their stems. Where are they placed on the tree? How long do they cling? How does the snow help to scatter them?

4. When does the white ash blossom? Are the pistillate and staminate flowers together or separate? Find and describe them.

5. What are our uses for ash timber? For what are the saplings used? How did the Indians use the white ash? Write a theme on all the interesting things you can find about the ash trees.

6. How many species of the ash trees do you know?

Supplementary reading-Trees in Prose and Poetry, p p. 60-7I.

"I care not how men trace their ancestry, To ape or Adam; let them please their whim;

But I in June am midway to believe

A tree among my far progenitors,

Such sympathy is mine with all the race,

Such mutual recognition vaguely sweet

There is between us. Surely there are times

When they consent to own me of their kin, And condescend to me and call me cousin,-

Murmuring faint lullabies of eldest time, Forgotten, and yet dumbly felt with thrills Moving the lips, though fruitless of the words."

-From "Under the Willows," LowelL. 


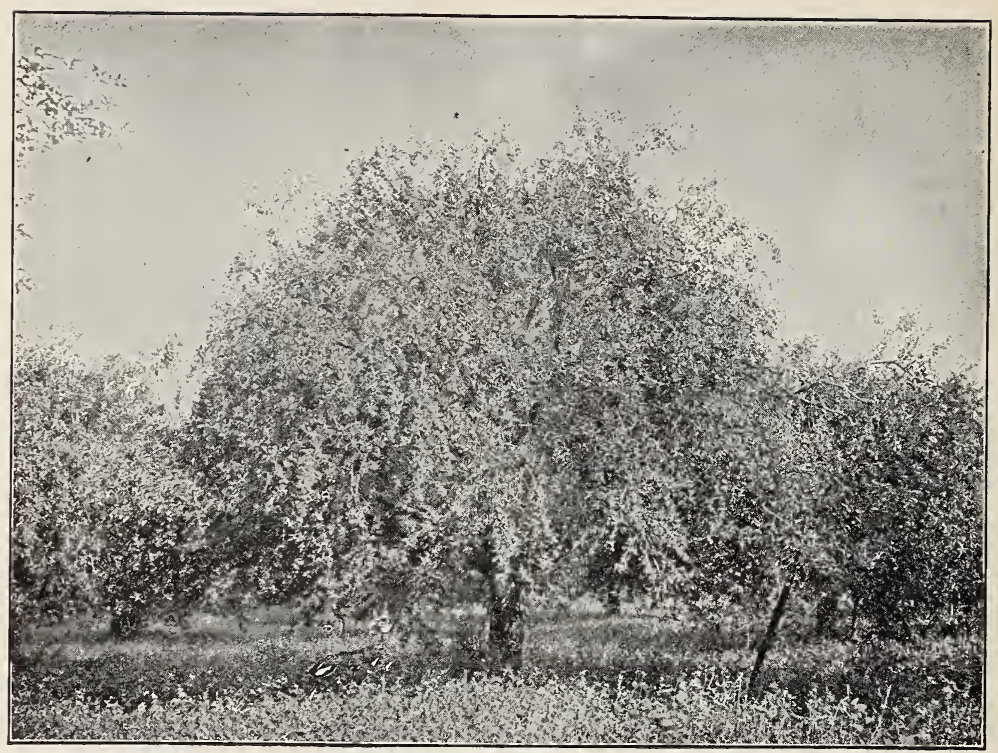

A baldwin apple tree.

\section{THE APPLE TREE \\ Teacher's Story}

As the apple tree among the trees of the wood, so is my beloved among the sons. I sat down under his shadow with great delight, and his fruit was sweet to my taste.

-The Song of Solomon.

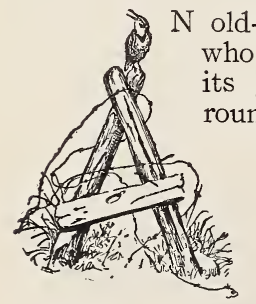

old-fashioned orchard is always a delight to those of us who love the picturesque. The venerable apple tree with its great twisted and gnarled branches, rearing aloft its rounded head, and casting its shadow on the green turf below, is a picture well worthy of the artist's brush. And that is the kind of orchard I should always have, because it suits me, just as it does bluebirds, downies and chickadees, as a place to live in. However, if I wished to make money by selling apples, I should need to have an orchard of comparatively young trees, which should be straight and well pruned, and the ground beneath them well cultivated; for there is no plant that responds more generously to cultivation than does the apple tree. In such an orchard, a few annual crops might be grown while the trees were young, and each year there should be planted in August or September the seed of crimson clover or of some other good cover-crop. This would grow so as to protect the ground from washing during the heavy rains and thaws of fall and winter, and in the spring it would be plowed under to add more humus to the soil. 
The apple originally came from southwestern Asia and the neighboring parts of Europe, but it has been cultivated so long that we have no accounts of how it began. The prehistoric lake-dwellers of Switzerland ate this fruit. In this country the apple thrives best on clay loam, although it grows on a great variety of soils; where wheat and corn grow, there will the apple also grow. In general, the shape of the apple tree head is rounded or broadly pyramidal; however, this differs somewhat with varieties. The trunk is short and rather stocky, the bark is a beautiful soft gray and is decidedly scaly, flaking off in pieces which are more or less quadrangular. The wood is very fine-grained and heavy. On this account for many years it was used for wood-engraving and is also a favorite wood for woodcarving; it makes a most excellent fuel. The spray is fine, and while at the tips of the limbs it may be drooping or horizontal, it often grows erect along the upper sides of the limbs, each shoot looking as if it were determined to be a tree in itself. The leaves are oval, with toothed edges and long petioles. When the leaves first appear each has two stipules at its base. The shape of the apple leaves depends to some extent upon the variety of the apple.

It has long been the practice not to depend upon the seeds for reproducing a variety; for, since the bees do such a large work in pollenating the apple flowers, it would be quite difficult to be sure that a seed would not be a result of a cross between two varieties. Therefore, the matter is made certain by the process of grafting or budding. There are several modes of grafting, but perhaps the one in most common use is the cleft-graft. A

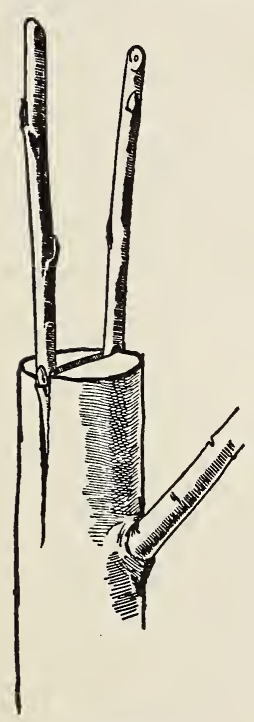

Cleft-graft.

One-half natural size.

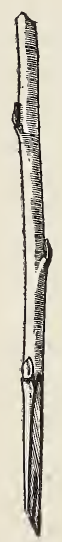

Scion for cleftgrafting.

One-half natural size.

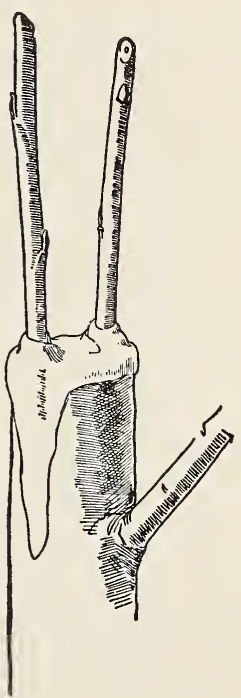

The graft waxed. 
scion which is a twig bearing several buds, is cut from a tree of the desired variety, and its lower end is cut wedge-shaped. The branch of the tree to be grafted is cut off across and split down through the end to the depth of about two inches; the wedge-shaped end of the scion is pressed into this cleft, so that its bark will come in contact with the inner edge of the bark on one side of the cleft branch. The reason for this is that the growing part of the tree is the cambium layer, which is just inside of the bark, and if the cambium of the scion does not come in contact with the cambium of the branch they will not grow together. After the graft becomes well-established, the other branches of the tree are cut off and the tree produces apples only from that part of it which grows from the graft. After the scion has been set in the stock, all of the wounded parts are covered with grafting wax, which keeps in the moisture and keeps out disease germs.

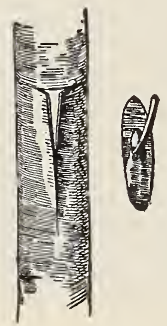

Shield-budding.

The T-shaped slit and the bud. One-half natural size.

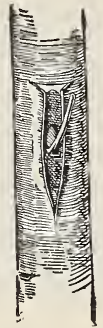

The bud set in the slit.

One-half natural

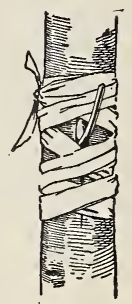

The bud tied.

Budding is done on a similar principle, but in a different fashion. A seedling apple tree about a year and a half old has a T-shaped slit cut into its bark; into this suture a bud, cut from a tree of the desired variety is inserted, and is bound in with yarn. The next spring this tree is cut back to just above the place where the bud was set in, and this bud-shoot grows several feet; the next year the tree may be sold to the orchardist. Budding is done on a large scale in the nurseries, for it is by this method that the different varieties are placed on the market.

Most varieties of apple trees should be set forty feet apart each way. It is possible, if done judiciously, to raise some small crops on the land with the young orchard, but care should be taken that they do not rob the trees of their rightful food. The dwarf varieties begin to bear much sooner than the others, but an orchard does not come into full bearing until after it has been planted fifteen or twenty years. The present practice is to prune a tree so that the trunk shall be very short. This makes the picking of the fruit much easier and also exposes the tree less to wind and sun-scald.

There are certain underlying principles of pruning that every child should know: The pruning of the root cuts down the amount of food which the tree is able to get from the soil. The pruning of the top throws the food into the branches which are left and makes them more vigorous. If the buds at the tips of the twigs are pruned off, the food is forced into the side buds and into the fruit, which make greater growth. Thinning the 
branches allows more light to reach down into the tree, and gives greater vigor to the branches which are left. A limb should be pruned off smoothly where it joins the larger limb, and there should be no stump projecting; the wound should be painted so as not to allow fungus spores to enter.

We should not forget that we have a native apple, which we know as the thornapple. Its low, broad head in winter makes a picturesque point along the fences; its fine, thick spray, spread herizontally, makes a fit framework for the bridal bouquet which will grow upon it in June; and it is scarcely less beautiful in autumn, when covered with the little, red apples called "haws." Though we may refrain from eating these native apples, which consist of a bit of sweet pulp around large seeds, the codling-moth finds them most acceptable

\section{LESSON CXCIX \\ The Apple Tree}

Leading thought-The tree of each variety of apple has its own characteristic shape, although all apple trees belong to one general type. The variety of the apple grown upon the tree is not determined by the kind of seed which is planted to produce the tree, but by the process of grafting or budding the young tree.

Method-A visit to a large, well-grown orchard in spring or autumn will aid in making this work interesting. Any apple tree near at hand may be used for the lesson.

Observations- $-\mathrm{x}$. How tall is the largest apple tree you know? What variety is it? How old is it? How can you distinguish old apple trees from young ones at a glance?

2. Choose a tree for study: How thick is its trunk? What is the shape of its head? Does the trunk divide into large branches or does it extend up through the center of the head?

3. What sort of bark has it? What is the color of the bark?

4. Does the spray stand erect or is it gnaried and querly? Does the spray grow simply at the ends of the branches or along the sides of the branches?

5. Are the leaves borne at the tip of the spray? Are the leaves opposite or alternate? Describe or sketch an apple leaf. Does it have stipules at its base when it first appears?

6. What is the character of apple-tree wood? What is it used for?

7. Did this tree come from a seed borne in an apple of the same variety which it produces? What is the purpose of grafting a tree? What is a scion? How and why do we choose a scion? How do we prepare a branch to receive the scion? If you should place the scion at the center of the branch would it grow? Where must it be placed in order to grow? How do we protect the cut-end of the branch after it is grafted? Why?

8. What is meant by the term "budding?" What is the difference between grafting and budding? Describe the process of budding.

9. Where is budding done on a large scale? How do nurserymen know what special varieties of apples their nursery stock will bear? How old is a tree when it is budded? How old when it is sold to the orchardist?

ro. Why should the soil around apple trees be tilled? Is this the practice in the best-paying orchards?

II. What is often used as a cover crop in orchards? When is this planted? For what purpose? 
I2. How far apart should apple trees be set? How may the land be utilized while the trees are growing? How old must the apple tree be to come into bearing?

I3. Is the practice now to allow an apple tree to grow tall? Why is an apple tree with a short trunk better?

I4. What does it do to a tree to prune its roots? What does it do to a tree to prune its branches?

15. How does it affect a tree to prune the buds at the tips of the twigs?

r6. How does it affect a tree to thin the branches? Describe how a limb should be pruned and how the wound thus made should be treated. Why?

\section{HOW AN APPLE GROWS Teacher's Story}

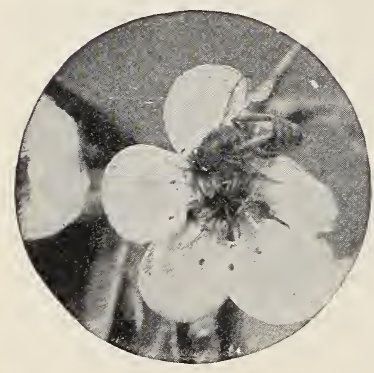

An apple tree in full blossom is a beautiful sight. If we try to analyze its beauty we find that on the tip of each twig there is a cluster of blossoms, and set around them, as in a conventional bouquet, are the pale, soft, downy leaves. These leaves and blossoms come from the terminal winter buds, which are protected during winter by little scales which are more or less downy. With the bursting of the bud, these scales fall off, each one leaving its mark crosswise on the twig, marking the end of the year's growth; these little ridges close together and in groups mark the winters which the twig has experienced, and thus reveal its age.

There is a difference in varieties of apples and in the season as to whether the blossoms or the leaves push out first. The white, downy leaves at first have two narrow stipules at the base of their petioles. They are soft, whitish and fuzzy, as are also the flower stem and the calyx, which holds fast in its slender, pointed lobes the globular flower bud. We speak of the lobes of the calyx because they are joined at the base, and are not entirely separate as are sepals. The basal part of the calyx is cup-shaped, and upon its rim are set the large, oval petals, each narrowing to a slender stem at its base. The petals are set between the sepals or lobes of the calyx, the latter appearing as a beautiful, pale green, five-pointed star at the bottom of the flower. The petals are pink on the outside and white on the inside, and are veined from base to edge like a leaf; they are crumpled more than are the cherry petals.

The many pale, greenish white stamens of different lengths and heights stand up like a column at the center of the flower. They are tipped with pale yellow anthers, and are attached to the rim of the calyx-cup. They are really attached in ten different groups but this is not easy to see.

The five pale green styles are very silky and downy and are tipped with green stigmas. The pistils all unite at their bases making a five-lobed, compound ovary. The upper part of this ovary may be seen above the calyx-cup, but the lower portion is grown fast to it and is hidden within it. The calyx-cup is what develops into the pulp of the apple, and each of these 
pistils becomes one of the five cells in the apple core. If one of the stigmas does not receive pollen, its ovary will develop no seed; this often makes the apple lop-sided. When the petals first fall, the calyx-lobes are spread wide apart; later they close in toward the center, making a tube. To note exactly the time of this change is important; since the time of spraying for the codling moth is before the calyx-lobes close. These lobes may be seen in any ripe apple as five little, wrinkled scales at the blossom end; within them may be seen the dried and wrinkled stamens, and within the circle of stamens, the sere and blackened styles.

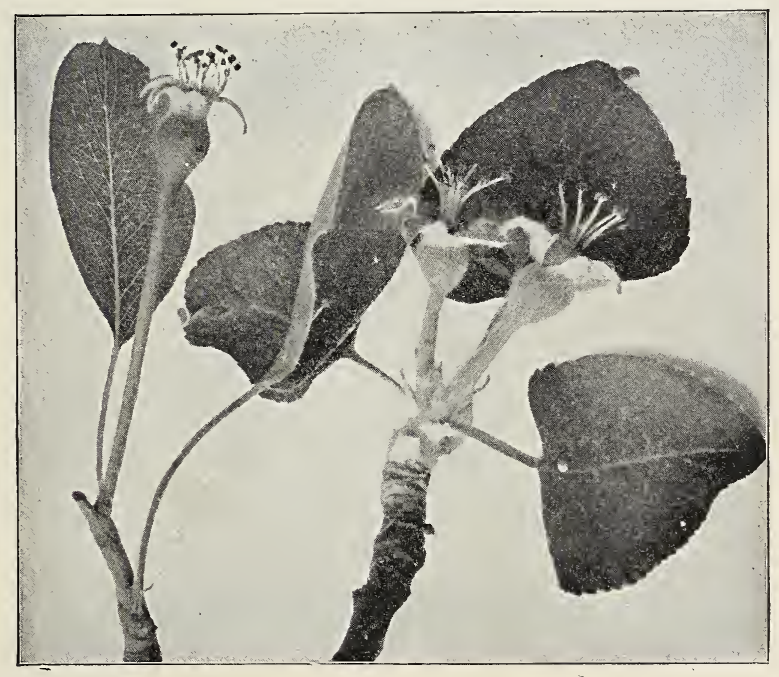

Just ready to spray. A pear and two apples from which the petals have recently fallen and with calyx lobes widely spread.

Photo by M. V. Slingerland.

There may be five or six, or even more blossoms developed from one winter bud, and there may be as many leaves encircling them, forming a bouquet at the tip of the twig. However, rarely more than two of these blossoms develop into fruit, and the fruit is much better when only one blossom of the bouquet produces an apple; if a tree bears too many apples it cannot perfect them.

The blossoms and fruit are always at the end of the twigs and spurs of the apple tree, and do not grow along the sides of the branches as do the cherry and the peach. However, there are many buds which produce only leaves; and just at the side and below the spur, where the apple is borne, a bud is developed, which pushes on and continues the growth of the twig, and will in turn be a spur and bear blossoms the following year. 


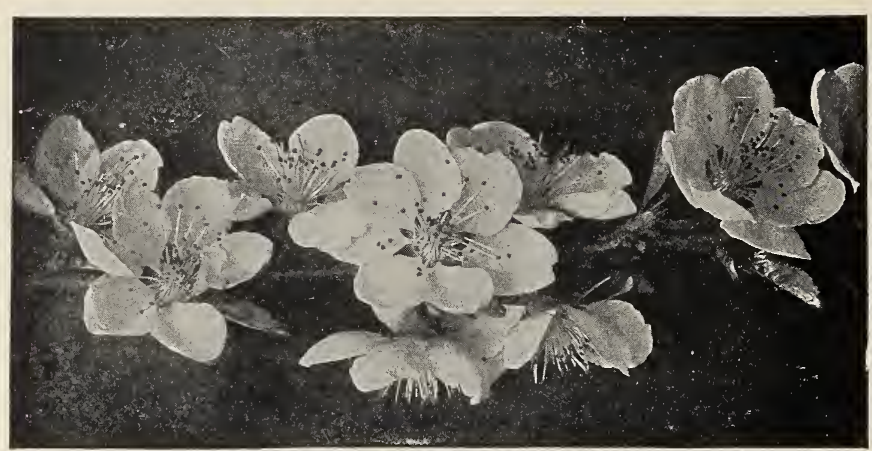

Apple blossoms.

Photo by Verne Morton.

\section{LESSON CC}

\section{How an Apple Grows}

Leading thought-The purpose of the apple blossom is to produce apples which shall contain seeds to grow into more apple trees.

Method-This lesson should begin with the apple blossoms in the spring and should continue, with occasional observations, until the apples are well grown. If this is not possible, the blossom may be studied, anci directly afterward, the apple may be observed carefully, noting its relation to the blossom.

\section{The Apple Blossom}

Observations-I. How are the apple buds protected in the winter? As the buds open what becomes of the protecting scales? Can you see the scars left by the scales after they have fallen. How does this help us to tell the age of a twig or branch?

2. As the winter buds open, which appear first-the flowers or the leaves? Do they both come from the same bud? Do all the buds produce both flowers and leaves?

3. Study the bud of the apple blossom. Describe its stem; its stipules; its calyx. What is the shape and position of the lobes, or sepals, of the calyx? Why do we usually call them the "lobes of the calyx" instead of sepals?

4. Sketch or describe an open apple blossom. How many petals? What is their shape and arrangement? Can you see the calyx-lobes between the petals as you look down into the blossom? What sort of a figure do they make? Are the petals usually cup-shaped? What is their color outside and inside? Why do the buds seem so pink and the blossoms so white?

5. How many stamens are there? Are they all of the same length? What is the color of the filaments and anthers? On what are they set?

6. How many pistils do you see? How many stigmas are there? Are the ovaries united? Are they attached to the calyx? 
7. Describe the young leaves as they appear around the blossoms. What is their color? Have they any stipules? Why do they make the flowers look like a bouquet?

8. After the petals fall, what of the blossom remains? What part develops into the apple? Does this part enclose the ovaries of the pistils? How can you tell in the ripe apple if any stigma failed to receive pollen?

9. What is the position of the calyx-lobes directly after the petals fall? Do they change later? How does this affect spraying for the codling moth?

ro. Watch an apple develop; look at it once a week and tell what parts of the blossom remain with the apple.

II. How many blossoms come from one winter bud? How many leaves? Do the blossoms ever appear along the sides of the branches, as in the cherries? How many blossoms from a single bud develop into apples?

I2. Since the apple is developed on the tip of the twig how does the twig keep on growing?

I3. Compare the apple with the pear, the plum, the cherry and the peach in the following particulars; position on the twigs; number of petals; number and color of stamens; number of pistils; whether the pistils are attached to the calyx-cup at the base.

\section{THE APPLE \\ Teacher's Story}

"Man fell with apples and with apples rose,

If this be true; for we must deem the mode

In which Sir Isaac Newton could disclose,

Through the then unpaved stars, the turnpike road,

A thing to counterbalance human woes."-BYron.

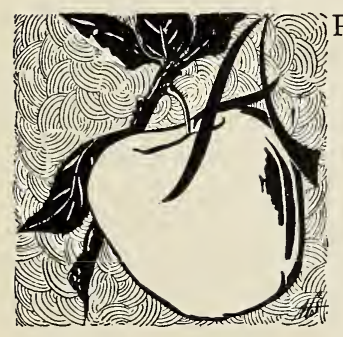

PPLES seem to have played a very important part in human history, and from the first had much effect upon human destiny, judging from the trouble that ensued both to Adam and to Helen of Troy from meddling, even though indirectly, with this much esteemed fruit. It is surely no more than just to humanity-shut out from the Garden of Eden-that the apple should have led Sir Isaac Newton to discover the law which holds us in the universe; and that, in these later centuries, apples have been developed, so beautiful and so luscious as almost to reconcile us to the closing of the gates of Paradise.

While it is true that no two apples were ever exactly alike, any more than any two leaves, yet their shapes are often very characteristic of the varieties. From the big, round Baldwin to the cone-shaped gillyflower, each has its own peculiar form, and also its own colors and markings and its own texture and flavor. Some have tough skins, others bruise readily even with careful handling; but to all kinds, the skin is an armor against those everpresent foes, the fungus spores, myriads of which are floating in the air 
ready to enter the smallest breach, and by their growth bring about decay. Even the tip of a branch or twig swayed by the wind, may bruise an apple and cause it to rot; windfalls are always bruised and will not keep. Greater care in packing, wrapping, picking and storing, so as to avoid contact with other apples, is a paying investment of labor to the apple grower.

The cavities at the stem and basin-ends of the fruit are also likely to have, in the same variety, a likeness in their depth or shallowness, and thus prove a help in identifying an apple. At the blossom, or basin, end of the fruit may be seen five scales, which are all that remain of the calyx-lobes which enclosed the blossom; and within them are the withered and shrunken stamens and styles.

When the fruit is cut, we see that the inner parts differ as much in the different varieties as do the outer parts. Some have large cores, others
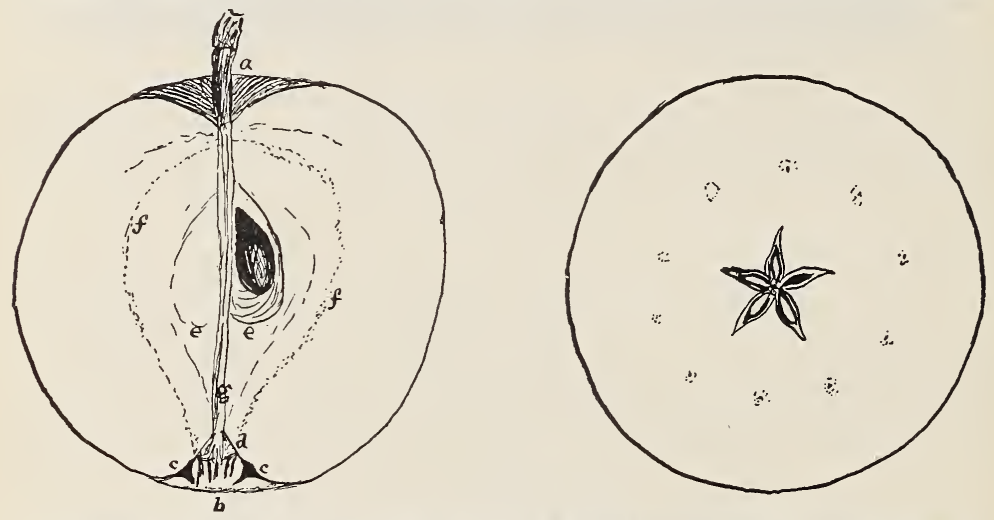

a, cavity; b, basin; c, calyx lobes; d, calyx tube with the withered stamens attached; e, carpels; f, outer core-lines, terminating at a point where stamens are attached; $\mathrm{g}$, fibres extending from stem to basin. Transverse section of apple showing the five carpels and the ten outer core-lines.

small. The carpels, or seed-cells, are five in number, and when the fruit is cut across through the center these carpels show as a pretty, five-pointed star; in them the seeds lie, all pointing toward the stem. Some apples have both seeds and carpels smooth and shining, while in others they are tufted with a soft, fuzzy outgrowth. The number of seeds in each cell varies; the usual number is two. In case a carpel is empty, the apple is often lopsided, and this signifies that the stigma of that ovary received no pollen. The apple seed is oval, plump and pointed, with an outer shell, and a delicate inner skin covering the white meat; this separates readily into two parts, between which, at the point, may be seen the germ. The entire core, with the pulp immediately surrounding the seed cells, is marked off from the rest of the pulp by the core-lines, faint in some varieties but distinct in others. In our native crab-apples this separation is so complete that, when the fruit is ripe, the core may be plucked out leaving a globular cavity at the center of the apple.

Extending from the stem to the basin, through the center of the apple, is a bundle of fibers, five in number, each attached to the inner edge of a 
carpel, or seed-box. Other bundles of fibers pass through the flesh about half way between the core and the skin. Delicate as they are, so that no one observes them in eating the fruit, they show clearly as a second coreline, and each terminates at a point in the calyx-tube where the stamens were attached-as can be easily seen by dissecting an apple. In transverse section, these show as ten faint dots placed opposite each outer point and inner angle of the star at the center formed by the carpels. Sometimes the seed-cells are very close to the stem, and the apple is said to have a sessile core; if at the center of the fruit, it has a medium core; if nearest to the blossom end, it has a distant core. This position of the core marks different varieties.

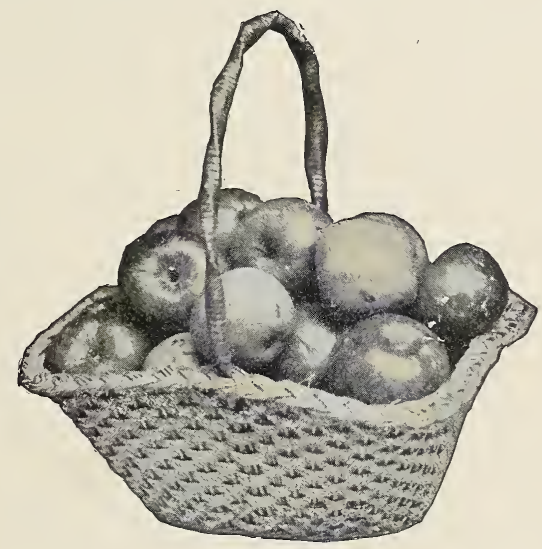

Basket of apples.

Apples even of the same variety, differ much in yield and quality according to the soil and climate in which they grow. The snow apple grows best in the St. Lawrence Valley, and New York State is noted for the fine flavor of the Esopus spitzenburg, the northern spy, and the Newtown p:ppin, all of which originated and grow best within its boundaries. Thus, each locality has its favorite variety.

Too often in passing through the country, we see neglected and unprofitable orchards, with soil untilled, the trees unpruned and scale-infested, yie'ding scanty fruit, fit only for the cider mill and the vinegar barrel. This kind of orchard must pass away and give place to the new horticulture.

References-Popular Apple Growing, Green; The American Apple Orchard, Waugh; The Apple and How to Grow It, Farmers' Bulletin I I3, U.S. Department of Agriculture.

\section{LESSON CCI}

The Apple

Leading thought-The apple is a nutritious fruit, wholesome and easily digested. The varieties of apple differ in shape, size, color, texture and flavor. A perfect apple has, no bruise upon it and no worm-holes in it. 
Method-Typical blossoms of different varieties of apples should be brought into the schoolroom, where the pupils may closely observe and make notes about their appearance. Each pupil should have one or two apples that may be cut in vertical and transverse sections, so that the pulp, corelines, carpels and seeds may be observed. After this lesson there should be an apple exhibit, and the pupils should be taught how to score the apples according to size, shape, color, flavor and texture.

Observations-I. Sketch the shape of your apple. Is it almost spheri$\mathrm{cal}$, or flattened, or long and egg-shaped, or with unequal tapering sides? How does the shape of the apple help in determining its variety?

2. What is the color of the skin? Is it varied by streaks, freckles or blotches? Has it one blushing cheek the rest being of a different color?

3 . Is the stem thick and fleshy, or short and knobby, or slender and woody and long? Does each variety have a characteristic stem?

4. Is the cavity or depression where the stem grew narrow and deep like a tunnel, or shallow like a saucer?

5. Examine the blossom end, or basin. What is its shape? Can you find within it the remnants of the calyx-lobes, the stamens and the pistils of the flower?

6. What is the texture of the skin of the apple? Is it thin, tough, waxy or oily? Has it a bloom that may be rubbed off? From what sort of injury does the skin protect the apple?

Experiment $I$. Take three apples of equal soundness and peel one of them; place them on a shelf. Place one of the unpeeled apples against the peeled one, and the other a little distance from it. Does the peeled apple begin to rot before the other two? Does the unpeeled apple touching the peeled one begin to decay first at the point of contact?

Experiment 2. Take an apple with a smooth, unblemished skin and vaccinate it with some juice from an apple that has begun to decay; perform the operation with a pin or meedle, pricking first the unsound fruit and then the sound one; this may be done in patterns around the apple or with the initials of the operator's name. Where does this apple begin to decay? What should these two experiments teach us as to the care and storage of fruit?

7. Cut an apple through its center from stem to blossom end. Describe the color, texture and taste of the pulp. Is it coarse or fine-grained? Crisp or smooth? Juicy, or dry and mealy? Sweet or sour? Does it exhale a fragrance or have a spicy flavor?

8. Is the flesh immediately surrounding the core separated from the rest of the pulp by a line more or less distinct? This is called the core-line and differs in size and outline in different varieties. Can you find any connection between the stem and blossom ends and the core? Can you see the fibrous threads which connect them?

9. Cut an apple transversely across the middle. In what shape are the seed-cells arranged in the center? Do the carpels, or seed-cells, vary in shape in different varieties? Are they closed, or do they all open into a common cavity? Can you see, between the core-lines and the skin, faint little dots? Count, and tell how they are arranged in relation to the star formed by the core.

Io. The stiff, parchment-like wails of the seed-cells are called carpels How many of these does the apple contain? Do all apples have the same number of carpels? Are the carpels of all varieties smooth and glossy, or 
velvety? How many seeds do you find in a carpel? Do they lie with the points toward the stem-end or the blossom-end of the apple? Where are they attached to the apple? Describe the apple seed-its outer and inner coat and its "meat." Can you find the germ within it which will, after the seed is planted, produce another apple tree?

I I. Is the core at the center of the apple, or is it nearer to the stem-end or to the blossom-end of the fruit? Are all apples alike in this particular?

I 2. Describe fully all the varieties of apples which you know, giving the average size, texture and color of the skin, the shape of the cavities at the stem and blossom ends, the color, texture and flavor of the pulp, and the position within the apple of the core.

Supplementary reading-Trees in Prose and Poetry, pp. 43-59.

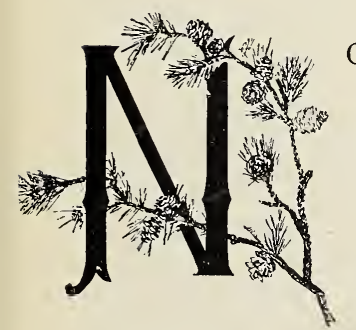

\section{THE PINE \\ Teacher's Story}

ONE other of our native trees is more beautiful than the pine. In the East, we have the white pine with its fine-tasselled foliage, growing often I 50 to 200 feet in height and reaching an age of from two to three hundred years. On the Pacific coast, the splendid sugar pine lifts its straight trunk from two to three hundred feet in height; and although the trunk may be from six to ten feet in diameter yet it looks slender, so tall is the tree. A sugar pine cone on my desk measures 22 inches in length and weighs almost one pound, although it is dried and emptied of seed.

There is something majestic about the pines, which even the most ignorant feel. Their dark foliage outlined against wintry skies appeals to the imagination, and well it may, for it represents an ancient tree-costume. The pines are among the most ancient of trees, and were the contemporaries of those plants which were put to sleep, during the Devonian age, in the coal beds. It is because the pines and the other evergreens belong essentially to earlier ages, when the climate was far different than it is to-day, that they do not shed their leaves like the more recent, deciduous trees. They stand among us, representatives of an ancient race, and wrap their green foliage about them as an Indian sachem does his blanket, in calm disregard of modern fashion of attire.

All cone-bearing trees have typically a central stem from which the branches come off in whorls, but so many things have happened to the old pine trees that the evidence of the whorls is not very plain; the young trees show this method of growth clearly, the white pine having five branches in each whorl.' Sometimes pines are seen which have two or three stems near the top; but this is a story of injury to the tree and its later victory.

The very tip of the central stem in the evergreens is called "the leader,' because it leads the growth of the tree upward; it stretches up from the center of the whorl of last year's young branches, and there at its tip are the buds which produce this year's branches. There is a little beetle which seems possessed of evil, for it likes best of all to lay its rascally eggs in the very tip of this leader; the grub, after hatching, feeds upon the bud and bor es down into the shoot, killing it. Then comes the question of which 


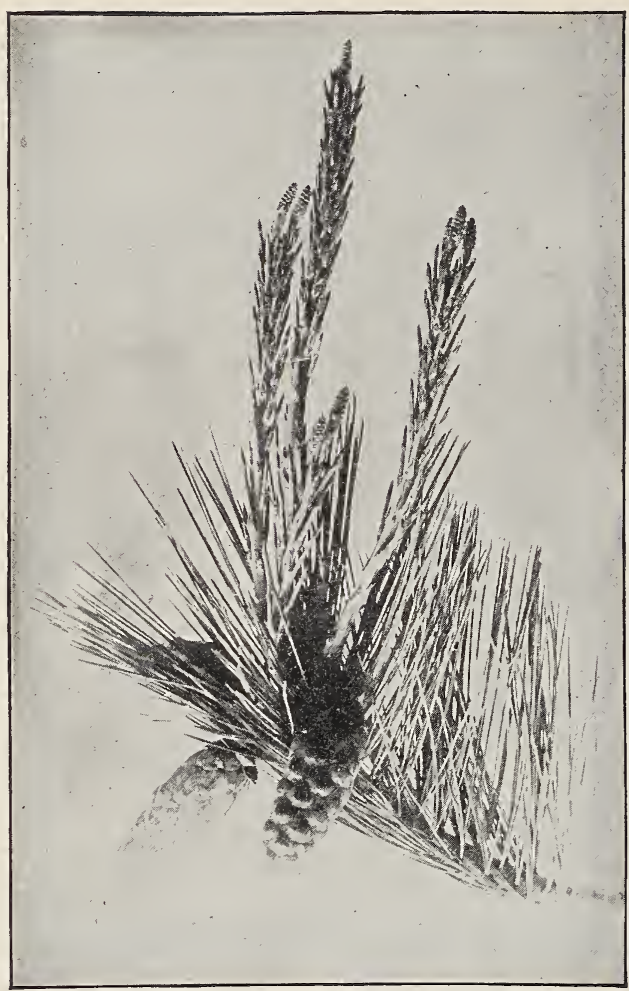

The young and the mature cones of white pine. Photo by Ralph Curtis. branch of the upper whorl shall be elected to rise up and take the place of the dead leader; but this is an election which we know less about than we do of those resulting from our blanket ballots. Whether the tree chooses, or whether the branches aspire, we may not know; but we do know that one branch of this upper whorl arises and continues the growth of the tree. Sometimes there are two candidates for this position, and they each make such a good struggle for the place that the tree grows on with two stems instead of one-and sometimes with even three. This evil insect injures the leaders of other conifers also, but these are less likely to allow two competitors to take the place of the dead leader.

The lower branches of many of the pines come off almost at right angles from the bole; the foliage is borne above the branches, which gives the pines a very different appearance from that of other trees. The foliage of most of the pines is dark green, looking almost black in winter; the pitch pine has the foliage yellowish green, and the white pine, bluish green; each species has its own peculiar shade. There is great variation in the color and form of the bark of different species. The white pine has nearly smooth bark on the young trees, but on the older ones it has ridges that are rather broad, flat and scaly, separated by shallow sutures, while the pitch pine has its bark in scales like the covering of a giant alligator.

The foliage of the pine consists of pine needles set in little bundles on raised points which look like little brackets along the twigs. When the pine needles are young, the bundle is enclosed in a sheath making the twig look as if it were covered with pin-feathers. In many of the species this sheath remains, encasing the base of the bundle of needles; but in the white pine it is shed early. The number of leaves in the bundle helps to determine the tree; the white pine has five needles in each bunch, the pitch pine has three, 
while the Austrian pine has two. There is a great difference in the length and the color of the needles of different species of pine. Those of the white pine are soft, delicate and pliable, and from three to four inches in length; the needles of the pitch pine are stiff and coarse and about the same length;

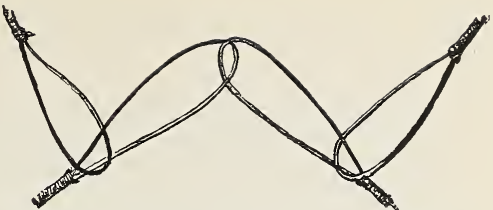

A part of a necklace of pitch pine needles. the white pine needles are triangular in section, and are set so as to form distinct tassels, while those of the Austrian pine simply clothe the ends of the twigs. The needles of the pine act like the strings of an aeolian harp; and the wind, in passing through the tree, sets them into vibration, making a sighing sound which seems to the listener like the voice of the tree. Therefore, the pine is the most companionable of all our trees and, to one who observes them closely, each tree has its own tones and whispers a different story.

The appearance of the unripe cone is another convincing evidence that mathematics is the basis of the beautiful. The pattern of the overlapping

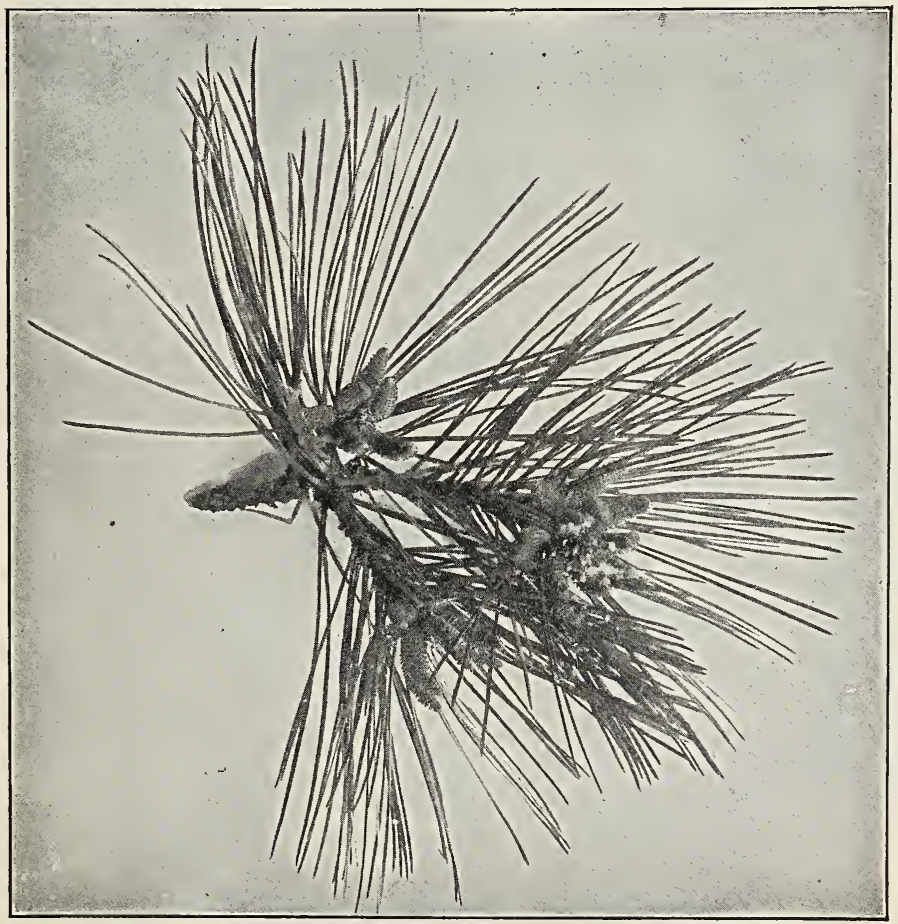

Austrian pine in blossom showing staminate flowers.

Photo by G. F. Morgan. 
scales is intricate and yet regular-to appreciate it one needs to try to sketch it. Beneath each scale, when it opens wide, we find nestled at its base two little seeds in twin boxes; each provided with a little wing so that it can sail off with the wind to find a place to grow. The shape of the scales of the cone is another distinguishing character of the pine, and sketching the outside of scales from several different species of pine cones will develop the pupils' powers of observation; the tip of the scale may be thickened or armed with a spine, and one wonders if these spines are for the purpose of discouraging the squirrels from stealing the green seeds.

The pine cone requires two years for maturing; the pistillate flower from which it is developed is a tiny cone with each scale spread wide and standing upright to catch the pollen for the tiny ovule nestled within it. The pistillate flower of the white pine grows near the tip of the new twig, and is pinkish in color. In the Austrian pine it is the merest pink dot at first, but after a little shows itself to be a true cone with pink-purple scales, which stand up very erect and makes a pretty object when viewed through a lens; each scale is pink at its three-pointed tip, with pink wings just below, the inner portions being pale green. The cone is set just beside the growing tip of the twig, is pointed upward, and its sheath-scales are turned back like chaff around its base.

In June when the new shoots of the pine twigs stand up like pale green candles on a Christmas tree, at their bases may be found the staminate catkins set in radiating whorls, making galaxies of golden stars against the

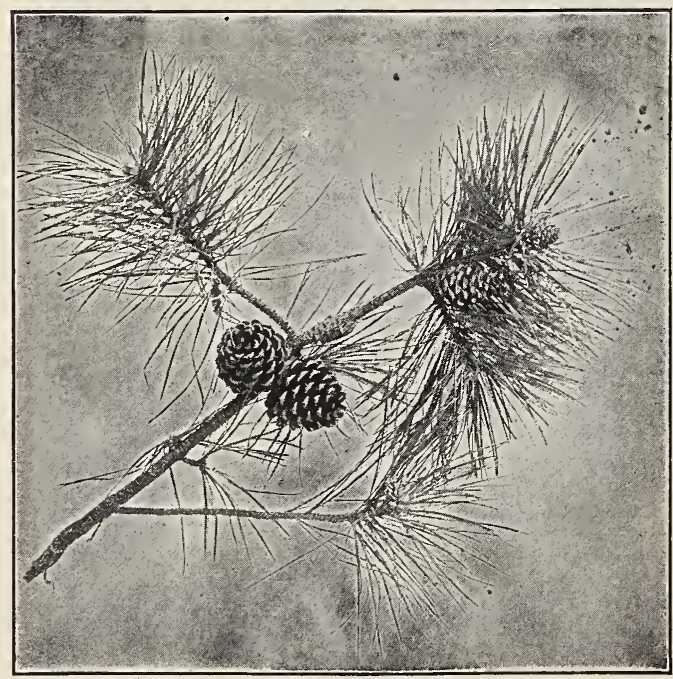

A ustrian pine, staminate blossoms and emply cones. Photo by Morgan. dark green background of foliage. In the Austrian pine, one of these pollen catkins may be an inch or two long and a half-inch in width; each little scale of this cone is an anther sac, filled to bursting with yellow pollen. From these starry pollen cones there descends a yellow shower every time a breeze passes; r the pine trees depend upon the wind to sift their pollen dust into the lifted cups of the cone scales, which will close upon the treasure soon. The pollen grains of pine are very beautiful when seen through a microscope; and it seems almost incredible that the masses of yellow dust sifted in showers from the pines when in blossom, should be composed of these beautiful 
structures. When the pine forests on the shores of the Great Lakes are in bloom, the pollen covers the waves for miles out from the shores.

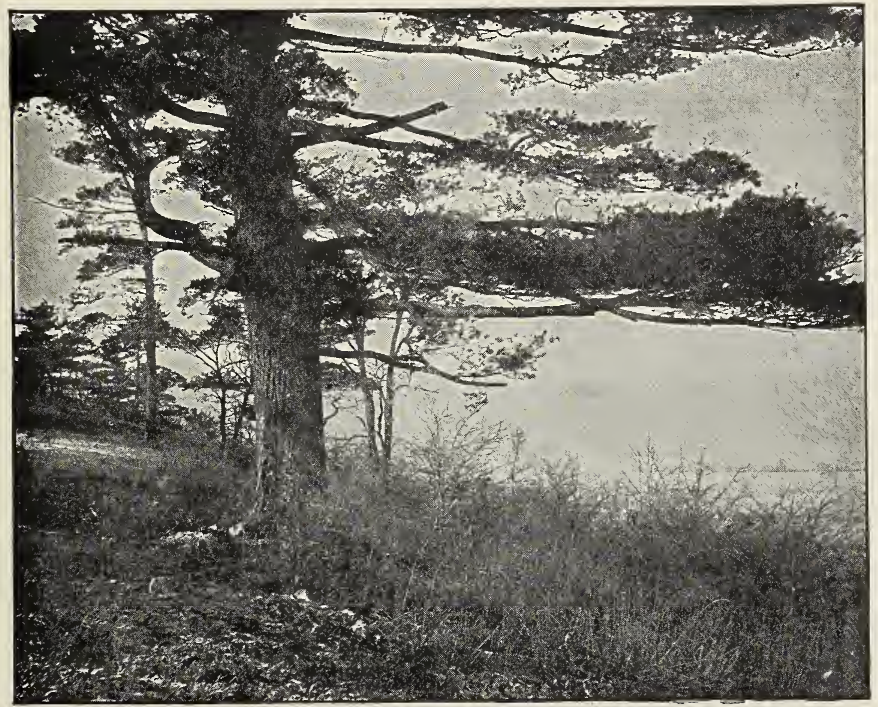

White pine.

If we examine the growing tips of the pine branches, we find the leaves look callow and pin-feathery. The entire leaf is wrapped in a smooth, shining, silken sheath, at the tip of which its green point protrudes. The sheath is tough like parchment and is cylindrical because the pine needles

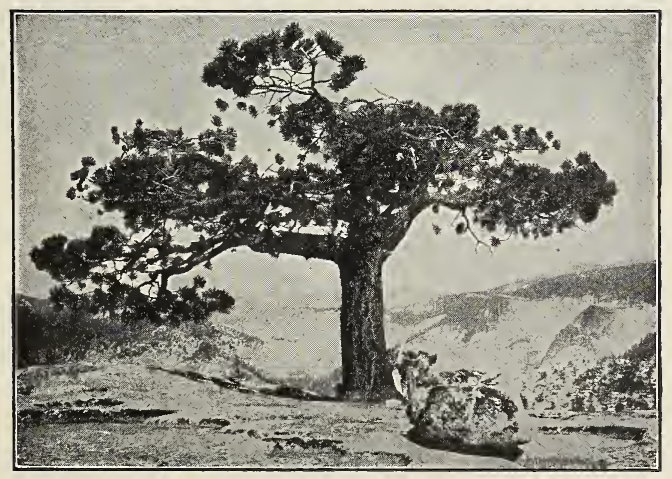

Yellow pine on the brink of the Litlle Yosemite Valley. Photo by G. K. Gilbert. Courtesy of U. S. Geological Survey. 
within it are perfectly adjusted one to another in cylindrical form. The sheath is made up of several layers, one over the other, and may be pulled apart. The new leaves are borne on the new, pale green wood.

The uses of pines are many. The lumber of many of the species, especially that of the white pine, is free from knots and is used for almost everything from house-building to masts for ships. In the Southern States, the long-leafed pines are tapped for resin, which is not the sap of the tree, as is generally supposed. Pine sap is like other sap; the resin is a product of certain glands of the tree, and is of great use to it in closing wounds and thus keeping out the spores of destructive fungi. It is this effort of the tree to heal its wounds that makes it pour resin into the cuts made by the turpentine gatherers. This resin is taken to a distillery, where the turpentine is given off as a vapor and condensed in a coiled tube which is kept cold. What is left is known as "rosin."

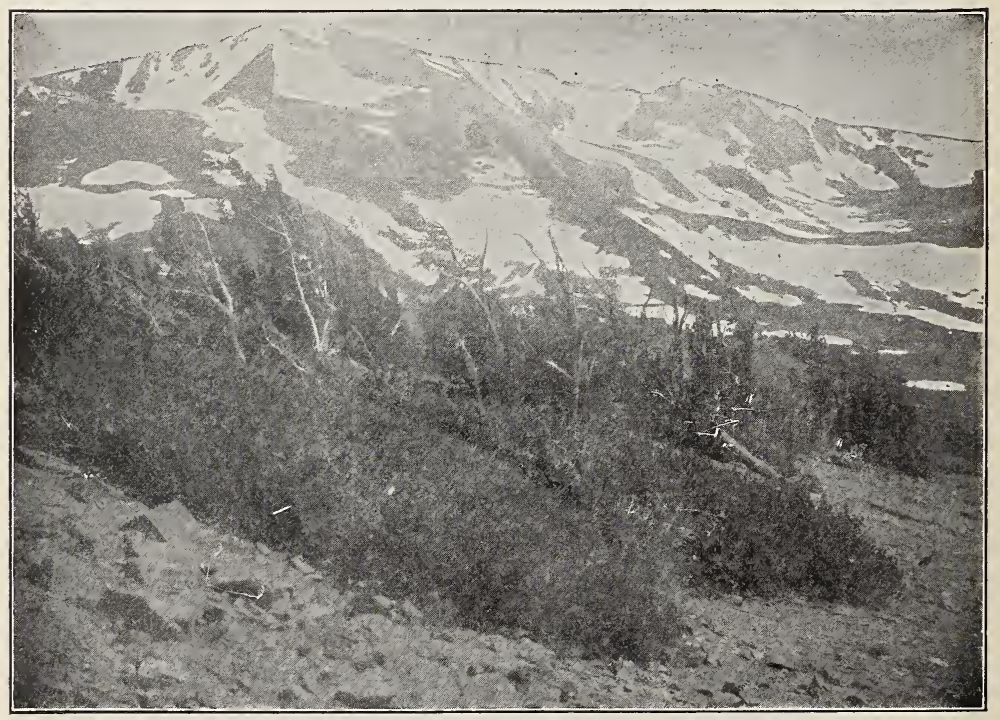

The mountain pine of the Sierras.

This species stands upright normally and is often over one hundred feet high; but on the mountain tops, exposed to wind and snow, its trunk reclines on the ground and its branches look like shrubs, as shown in the foreground. Trees of the same species, wind-beaten but standing are shown in the background.

Photo by G. K. Gilbert. Courtesy of the U. S. Geological Survey.

\section{LESSON CCII}

\section{The Pine}

Leading thought-The pines are among our most ancient trees. Their foliage is evergreen but is shed gradually. The pollen-bearing and the seed-bearing flowers are separate on the tree. The seeds are winged and are developed in cones. 
Method-At least one pine tree should be studied in the field. Any species will do but the white pine is the most interesting. The Austrian pine which is commonly planted in parks is a good subject. The leaves and cones may be studied in the schoolroom, each pupil having a specimen.

Observations-I. What is the general shape of the pine tree? Is there one central stem running straight up through the center of the tree to the top. Do you find any trees where this stem is divided into two or three near the top? Describe how the pine tree grows. What is the "leader?" What happens if the leader is injured? How do the topmost branches of the young pine look? Do they all come off from the same part of the stem? How many are there in a whorl?

2. What color is the bark? Is it ridged or in scales?

3. Do the branches come off the main stem at right angles or do they lift up or droop down? Where is the foliage borne on the branches? What is the color of the foliage? Is the pine foliage ever shed or does the pine leaf, when it comes, stay on as long as the tree lives?

4. Study the pine leaves. Why are they called needles? Note that they grow several together in what we call a bundle. How many in one bundle? Is the bundle enclosed in a little sheath at the base? Are the bundles grouped to make distinct tassels? Study one of the needles. How long is it? Is it straight or curved? Flexible or coarse and stiff? Cut it across and examine it with a lens. What is the outline in cross section? Why does the wind make a moaning sound in the pines?

5. Study a pine cone. Does it grow near the tip of the branch or along the sides? Does it hang down or stand out stiffly? What is its length? Sketch or describe its general shape. Note that it is made up of short, over-lapping scales. What pattern do the scales make as they are set together? Describe or sketch one scale; has it a thickened tip? Is there a spine at the tip of the scale?

6. Where in the cone are the seeds? Describe or sketch a pine seed. How long is its wing? How is it carried and planted? When the cone opens, how are the seeds scattered? What creatures feed upon the pine seed?

7. Study the pine when in blossom, which is likely to occur in June. This time is easily determined because the air around the tree is then filled with the yellow pollen dust. Study the pollen-bearing flower. Is it conelike in form? Does it produce a great deal of pollen? If you have a microscope, look at the pollen through a high objective and describe it. How many of the pollen catkins are clustered together? On what part of the twigs are they borne? Where are the pistillate flowers which are to form the young cones? How large are they and how do they look at the time the pollen is flying? Do they point upward or droop downward? Why? Look beneath

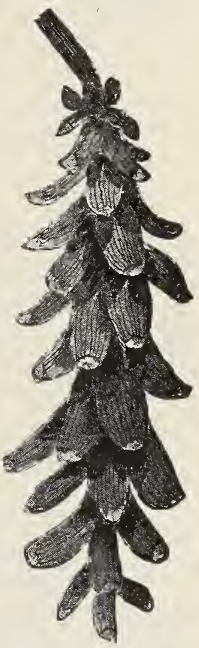

White pine cone. the scales of a little cone with a lens and see if you can find the flowers. What carries the pine pollen to the flowers in the cone?

8. Name all the uses for pine lumber that you know. Write an English theme on how turpentine is produced from pines and the effect of this industry upon pine forests. Where does resin appear on the pine? Of what use is it to the tree? Do you think it is pine sap? What is the difference between resin and rosin? 
9. How long do the pine trees live? Write a story of all that has happened to your neighborhood since the pine tree which you have been studying was planted.

Io. Make the following drawings: A bundle of pine needles showing the sheath and its attachment to the twig; the cone; the cone scale; the seed. Sketch a pine tree.

Supplementary reading-Trees in Prose and Poetry, pp. 32, I51, I52; The Spirit of the Pine, Bayard Taylor; To a Pine Tree, Lowell; Nature in Verse, pp. I $5,288$.

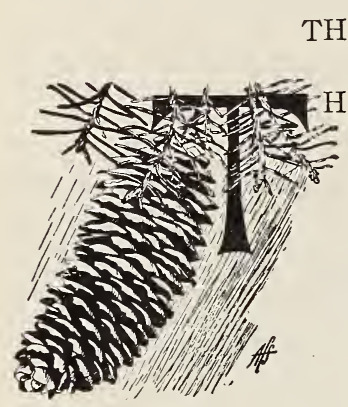

THE NORWAY SPRUCE

\section{Teacher's Story}

HE Norway spruce is a native of Europe, and we find it in America the most satisfactory of all spruces for ornamental planting; it lifts its slender cone from almost every park and private estate in our country, and is easily distinguished from all other evergreens by the drooping, pendant habit of its twigs, which seem to hang down from the straight, uplifted branches. We have spruces of our own-the black, the white and the red spruces; and it will add much to the interest of this lesson for the pupils to read in the tree and forestry books concerning these American species. Chewing gum and spruce beer are the products of the black and red spruce of our eastern forests. The Douglas spruce, which is a fir and not a spruce, is also commonly planted as an ornamental tree, but

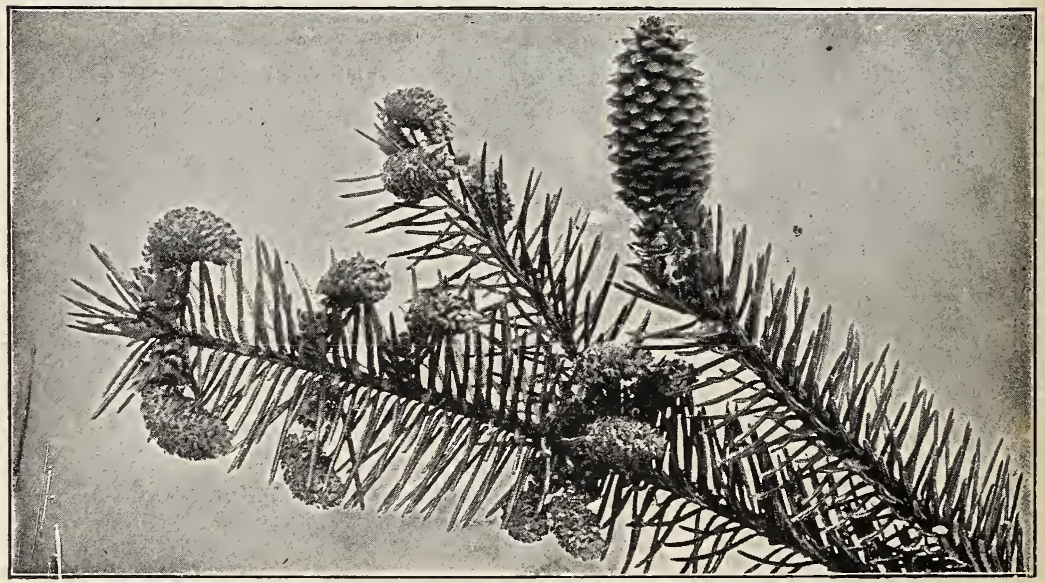

Slaminate blossoms and young cone of a Norway spruce Photo by G. F. Morgan. 
it is only at its best on the Pacific Coast, where it is one of the most magnificent of trees.

The Norway spruce tree is in form a beautiful cone, slanting from its slender tip to the ground, on which its lower drooping branches rest; the upper branches come off at a narrower angle from the sturdy central stem than do the widespreading lower branches. On the older trees, the twigs hang like pendulous fringes from the branches, enabling them to shed the snow more readily - a peculiarity which is of much use to the tree, because it is a native of the snowy northern countries of Europe and also grows successfully in the high altitudes of the Alps and other mountains. If we stroke a spruce branch toward the tip, the hand slides smoothly over it; but brusn backward from the tip, and the hand is pricked by hundreds of the sharp, bayonet-pointed leaves; this is another arrangement for letting the snow slide off.

If we examine a twig of the present year's growth, we can see on every side of its brown stem the pointed leaves, each growing from a short ridge; but the leaves on the lower side stretch out sidewise to get the light, and those above lift up angularly. Perhaps the twig of last year's growth has shed its leaves which grew on the under side and thus failed to reach the sun. The leaf of the spruce is curved, stiff, four-sided and ends in a sharp point. It is dark yellowish above and lighter beneath and is set stiffly on the twig. The winter buds for next year's growth may be seen at the tips of the twigs, covered with little, recurved, brown scales quite flowerlike in form. In the balsam fir, which is often planted with the Norway spruce, these buds are varnished.

The cones are borne on the tips of the branches and hang down. In color they are pale, wood-brown; they are from four to six inches long, and are very conspicuous. They are made up of broad scales that,are thin toward the notched tips; they are set around the central stem in spirals of five rows. If we follow one spiral around marking it with a winding string, it will prove to be the fifth row above the place where we started. These manifold spirals can be seen sometimes by looking into the tip end of a cone. The cone has much resin on it, and is a very safe box for seeds; but when it begins to open, squirrels impatiently tear it to pieces, harvesting the seeds and leaving a pile of cone-scales beneath the tree to tell of their piracy.

A Norway spruce in blossom is a beautiful sight; the little, wine-red pistillate cones are lifted upwards from the of tips of the twigs, while short, terminal branches are laden with the pollen-bearing catkins, which are soft and caterpillarish, growing on soft, white stems from the base of

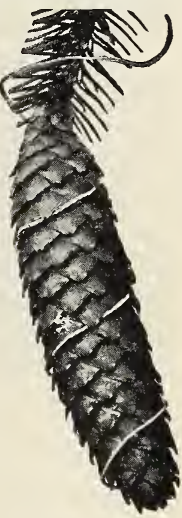

A cone of Norway spruce, showing that the spiral of the scales is in rows of five.

Photo by Cyrus Crosby. scales which enclosed and protected them during the winter; these catkins are filled with the yellow dust. The young cones continue to stand upright after the scales have closed on the pollen which has been sifted by the wind to the ovules which they guard; and for some time they remain most ornamentally purplish red. Before the cone is heavy enough to bend from its own weight, it turns deliberately around and downward, as if the act were a wilful deed, and then changes its color to green, ripening into brown in the fall. 
The Norway spruce grows on the Alps abundantly, and like the youth with the banner, "excelsior" is not only its motto but its scientific name, (Pi.ea excelsa). Here it grows to the height of one hundred to one hundred and fifiy feet. Its wood is valuable and its pitch is marketed. In this country, it is used chiefly for ornamental planting and for wind-breaks.

\section{LESSON CCIII}

\section{The Norway Spruce}

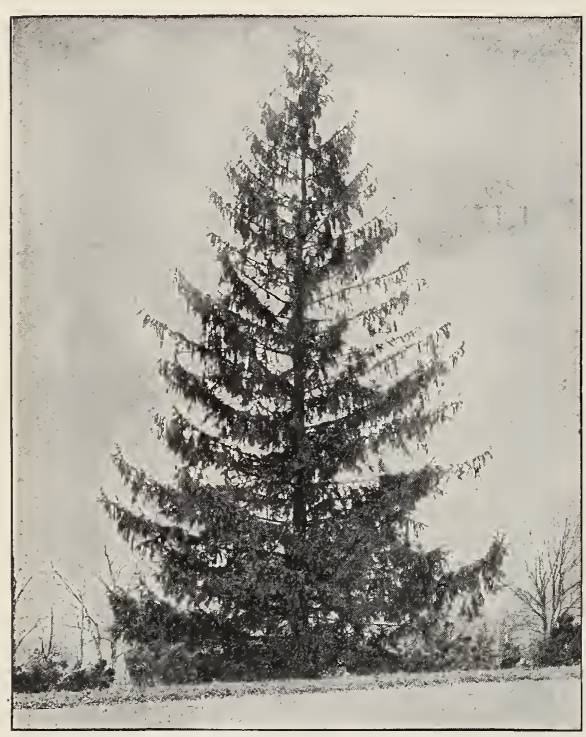

A Norway spruce.

Photo by Cyrus Crosby

Leading thought-The Norway spruce is one of the most valuable of the trees which have come to America from Europe. It grows naturally in high places and in northern countries where there is much snow; its drooping twigs cannot hold a great burden of snow, and thus it escapes being crushed.

Method-This lesson should begin in the autumn when the cones are ripe. The tree should be observed by all of the pupils, and they should bring in twigs and cones for study in the schoolroom. The lesson should be taken up again in May when the trees are in blossom.

Observations-I. What is the general shape of the tree? Do the lower branches come off at the same angle as the upper? If untrimmed, what can you see of the trunk? Do the lower branches rest upon the ground? What advantage would this be to the tree in winter? Do the twigs stand out, or droop from the branches? Of what advantage is this in case of heavy snow? What is the color of the foliage? Where did the Norway spruce come from?

2. What is the color of the twig? How are the leaves set upon it? Are there more leaves on the upper than on the under side of the twigs of this year's growth? Of last year's growth? Brush your hand along a branch toward the tip. Do the leaves prick? Brush from the tip backward. Is the result the same? Why is this angle of the leaves to the twig a benefit during snowstorms?

3. Take a single leaf. What is its shape? How many sides has it? Is it soft or stiff? Is it sharp at the tip? Describe the buds which are forming for next year's growth. Look along the twigs and see if you can discover the scales of the bud which produced last year's growth? 
4. Where are 1 he cones borne? How long does it take a cone to grow? Is jt heavy? Is there resin on it? Note that the scales are set in a spiral around the center of the cone. Wind a string around a cone following the same row of scales. How many rows between those marked with a string? Look into the tip of a cone and see the spiral arrangement. Sketch and describe a cone-scale, paying special attention to the shape of the tip. Try to tear a cone apart. Is this easily done? Hang a closed cone in a dry place and note what happens.

5. Describe the seed, i is wings and where it is placed at the base of the scale. How many seeds under each scale? When do the cones open of themselves to scatter the seed? Do you observe squirrels tearing these apart to get the seed?

6. The Norway spruce blossoms in May. Find the little flower which will produce the cone, and describe it. What color is it? Is it upright or hanging down? Do the scales turn toward the tip or backward? Why is this? Where are the pollen-catkins borne? How many of them arise from the same place on the twig?' Can you see the little scales at the base of each pistillate catkin? What are they? Are they very full of pollen? Do the insects carry the pollen for the Norway spruce, or does the wind sift it over the pistillate blossoms? After the pollen is shed, note if the scales of the young cones close up. How long before the cones begin to droop? Do you think it is their weight which causes them to droop?

7. What use do we make of the Norway spruce? What is it used for in Europe?

"All outward wisdom yields to that within,

Whereof nor creed nor canon holds the key;

We only feel that we have ever been

And evermore shall be.

And thus I know, by memories unfurled

In rarer moods, and many a nameless sign,

That once in Time, and somewhere in the world, $I$ was a towering pine.

Rooted upon a cape that overhung

The entrance to a mountain gorge; whereon

The wintry shade of a peak was flung,

Long after rise of sun.

There did I clutch the granite with firm feet, There shake my boughs above the roaring gulf,

When mountain whirlwinds through the passes beat, And howled the mountain wolf.

There did I louder sing than all the floods Whirled in white foam adown the precipice,

And the sharp sleet that stung the naked woods, Answer with sullen hiss.

I held the eagle till the mountain mist Rolled from the azure paths he came to soar, And like a hunter, on my gnarled wrist The dappled falcon bore." 


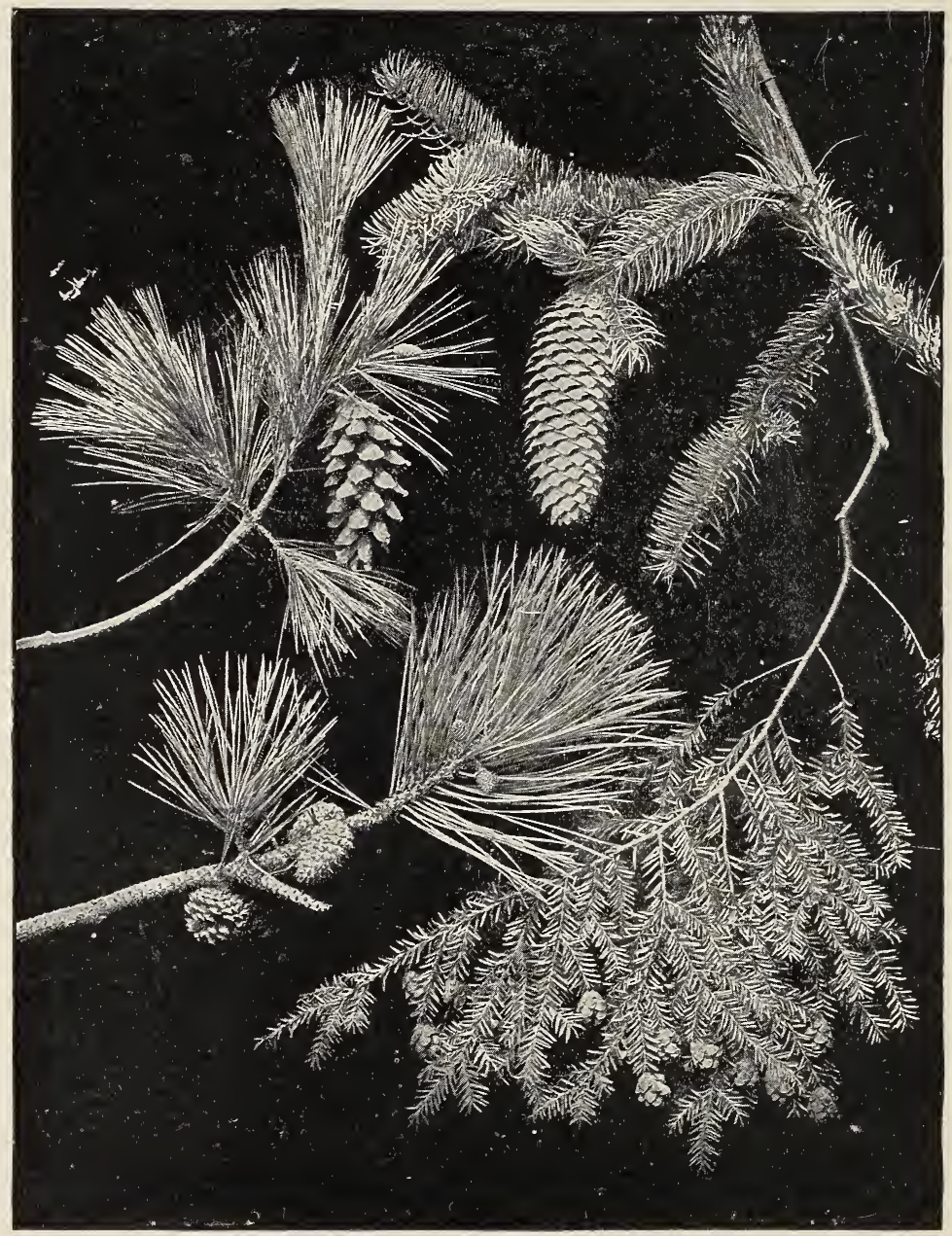

White pine.

Pitch pine

Norway spruce

Hemlock 


\section{THE HEMLOCK}

\section{Teacher's Story}

"O'er lonely lakes that wild and nameless lie, Black, shaggy, vast and still as Barca's sands $A$ hemlock forest stands. Oh forest like a palit Oh hemlock of the wild, Oh brother of my soul I love thy mantle black, thy shaggy bole, Thy form grotesque, thy spreading arms of steel."

-Pattee.

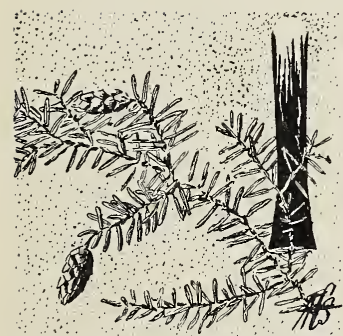

N ITS prime, the hemlock is a magnificent tree. It reaches the height of from sixty to one hundred feet, is cone-shaped, its fine, dense foliage and its drooping branches giving to its appearance exquisite delicacy; and I have yet to see elsewhere such graceful tree-spires as are the hemlocks of the Sierras, albeit they have bending tips. However, an old hemlock becomes very ragged and rugged in appearance; and dying, it rears its wind-broken branches against the sky, a gaunt figure of stark loneliness.

The hemlock branches are seldom broken by snow; they droop to let the burden slide off. The bark is reddish, or sometimes gray, and is furrowed into wide, scaly ridges. The foliage is a rich dark green, but whitish when seen from below. The leaves of the hemlock are really arranged in a spiral, but this is hard to demonstrate. They look as though they were arranged in double rows along each side of the little twig; but they are not in the same plane and there is usually a row of short leaves on the upper side of the twig. The leaf is blunt at the tip and has a little petiole of its own which distinguishes it from the leaves of any other species of conifer; it is dark, glossy green above, pale green beneath, marked with two white, lengthwise lines. In June, the tip of every twig grows and puts forth new leaves which are greenish yellow in color, making the tree very beautiful and giving it the appearance of blossoming. The leaves are shed during the third year. The hemlock cones are small and are borne on the tips of the twigs. The seeds are borne, two beneath each scale, and they have wings nearly as large as the scale itself. Squirrels are so fond of them that probably but few have an opportunity to try their wings. The cones mature in one year, and usually fall in the spring. The hemlock blossoms in May; the pistillate flowers are very difficult to observe as they are tiny and greenish and are placed at the tip of the twig. The pollen-bearing flowers are little, yellowish balls on delicate, short stems. borne along the sides of the twig.

Hemlock bark is rich in tannin and is used in great quantities for the tanning of leather. The timber, which is coarse-grained, is stiff and is used in framing buildings and for railroad ties; nails and spikes driven into it cling with great tenacity and the wood does not split in nailing. Oil distilled from the leaves of hemlock is used as an antiseptic.

The dense foliage of the hemlock offers a shelter to birds of all kinds in winter; even the partridges roost in the young trees. These young tree often have branches drooping to the ground, making an evergreen tent 
which forms a winter harbor for mice and other beasties. The seed-eating birds which remain with us during the winter, feed upon the seeds; and as the cones grow on the tips of the delicate twigs, the red squirrels display their utmost powers as acrobats when gathering this, their favorite food.

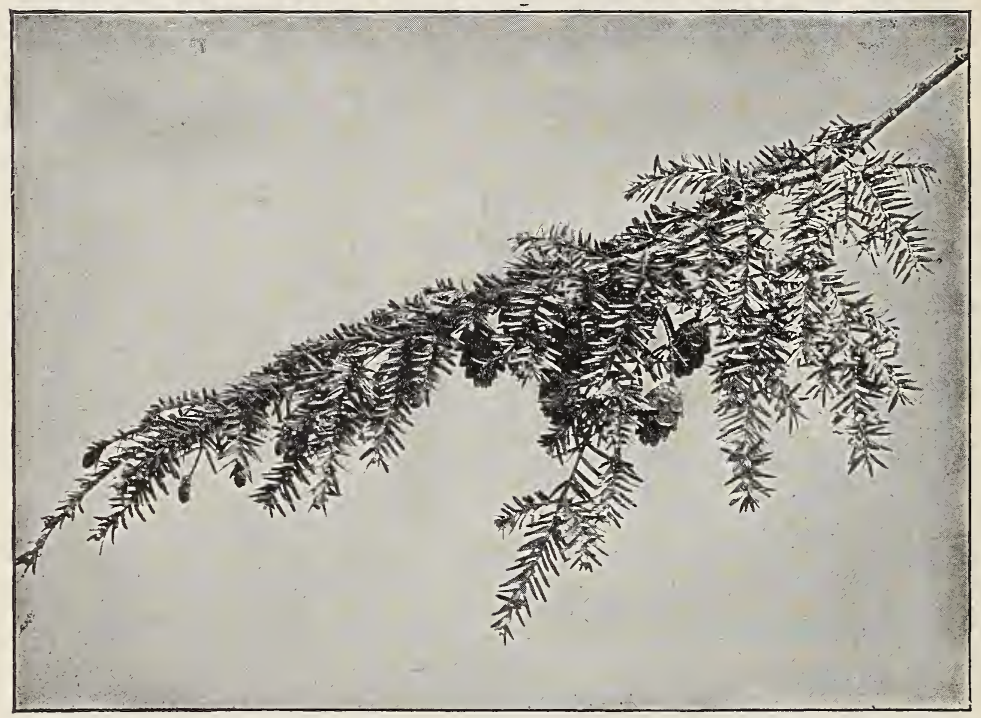

Hemlock branch showing young and mature cones.

\section{LESSON CCIV}

\section{The Hemlock}

Leading thought-This is one of the most common and useful and beautiful of our evergreen trees. Its fine foliage makes it an efficient winter shelter for birds

Method-Ask the children the questions and request them to make notes on the hemlock trees of the neighborhood. The study of the leaves and the cones may be made in the schoolroom.

Observations-I. Where does the hemlock tree grow in your neighborhood? What is the general shape of the tree? What sort of bark has it? How tall does it grow? How are its branches arranged to shed the snow?

2. What is the color of the foliage? How are the leaves arranged on the twigs? Are all the leaves of about the same size? What is the position of the smaller leaves?

3. Break off a leaf and describe its shape; its petiole. Does the leaf of any other evergreen have a petiole? What is the color and marking of the hemlock leaf above? Below? At what time of year are the new leaves developed? How does the hemlock tree look at this time? Does the hemlock ever shed its leaves? 
4. Are the hemlock cones borne on the tip of the twigs or along the s:de? How long does it take a cone to mature? When does it fall? How many scales has it? Where are the seeds borne? How many seeds beneath each scale? Describe and sketch a hemlock seed. How are the seeds scattered? Study the tree in May, and see if you can find the blossom?

5. Make drawings of the following: The hemlock twig, showing the arrangement of the leaves; single leaf, enlarged; cone; cone scale; seed.

6. What creatures feed upon the hemlock seed? What birds find protection in the hemlock foliage in winter?

7. For what purposes is hemlock bark used? What is the timber good for? Is a nail easily pulled out from a hemlock board?

\section{THE DOGWOOD \\ Teacher's Story}

Through cloud rifts the sunlight is streaming in floods to far depths of the wood, Retouching the velvet-leafed dogwood to crimson as vital as blood.

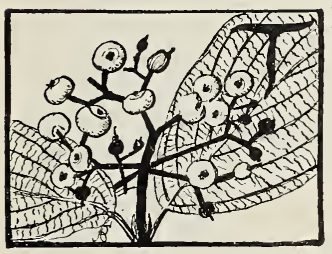

HERE is no prettier story among the flowers than that of the bracts of the dogwood, and it is a subject for investigation which any child can work out for himself. I shall never forget the thrill of triumph I experienced when I discovered for myself the cause of the mysterious dark notch at the tip of each great white bract, which I had for years idly noticed. One day my curiosity mastered my inertia, and I hunted a tree over for a flower bud, for it was rather late in the season; finally I was rewarded by finding the bracts in all stages of development.

The flowering dogwood forms its buds during the summer, and of course they must have winter protection; therefore, they are wrapped in four, close-clasping, purplish brown scales, one pair inside and one pair outside, both thick and well fitted to protect the bunch of tiny flower buds at their center. But when spring comes, these motherly bud-scales change their duties, and by rapid growth become four beautiful white or pinkish bracts calling aloud to all the insect world that here at their hearts is something sweet. For months they brood the flowers and then display them to an admiring world. The artistic eye loves the little notch at the tip of the bracts, even before it has read in it the story of winter protection, of which it is an evidence.

The study of the flowers at the center is more interesting if aided by a lens. Within each blossom can be seen its tube, set in the four-lobed calyx. It has four slender petals curled back, its four chubby, greenish yellow anthers set on filaments wh ch lift them up between the petals; and at the center of all is the tiny green pistil. There may be twenty, more or less, of these perfect flowers in this tiny, greenish yellow bunch at the center of the four great, flaring bracts. These flowers do not open simultaneously, and the yellow buds and open Blossom and bud of flowers are mingled together in the rosette. The calyx dogwoood, enlarged. 
shows better on the bud than on the open flower. It might be well to explain to the pupils that a bract is simply a leaf in some other business than that ordinarily performed by leaves.

The twigs have a beautiful, smooth bark, purplish brown above and greenish below. The flowers grow at the tips of the twigs; and the young leaves are just below the flowers and also at the tips of the twigs. These twigs are spread and bent in a peculiar way, so that each white flower-head may be seen by the admiring world and not be hidden behind any of its neighbors. This habit makes this tree a favorite for planting, since it forms a mass of white bloom.

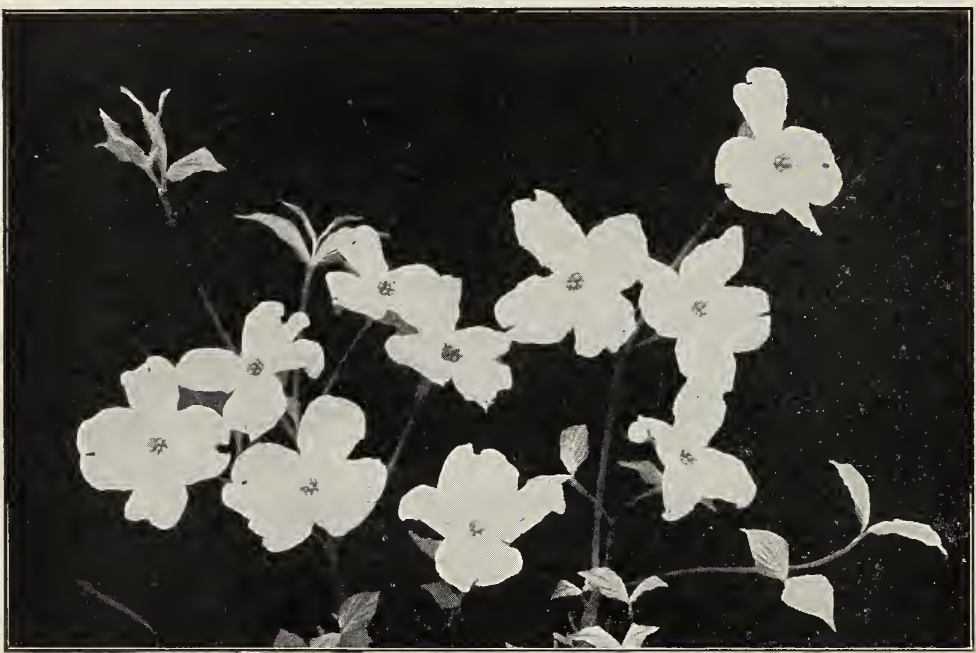

The flowers of dogwood.

Photo by Cyrus Crosby.

The dogwood banners unfurl before the flowers at their hearts open, and they remain after the last flower has received within itself the gracious, vital pollen which will enable it to mature into a beautiful berry. This long period of bloom is another quality which adds to the value of the dogwood as an ornamental tree. At the time the bracts fall, the curly petals also fall out leaving the little calyx-tubes standing with style and stigma projecting from their centers, making them look like a bunch of liliputian churns with dashers. In autumn, the foliage turns to a rich, purplish crimson-a most satisfying color.

During the winter, the flowering dogwood, which renders our forests so beautiful in early spring, may be readily recognized by its bark, which is broken up into small scales and mottled like the skin of a serpent; and on the tips of its branches are the beautiful clusters of red berries, or speaking more exactly, drupes. This fruit is oval, with a brilliant, shining, red, pulpy covering which must be attractive to birds. At its tip it has a little purple crown, in the center of which may be seen the remnant of the style, 
but this attractive outside covers a seed with a very thick, hard shell, which is quite indigestible and fully able to protect, even from the attack of the digestive juices of the bird's stomach, the tender white kernel within it, which includes the stored food and the embryo. There are in the North two other common species of dogwood which have dark blue fruit.

\section{LESSON CCV \\ The Dogwood}

Leading thought-The petals are not the only means of attracting insects to the flowers. Sometimes other parts of the plant are made into banners to show insects where the nectar is to be found.

Method-Bring in a branch of the dogwood when it is in flower. The branch should have upon it some flowers that are unopened. Study the flower first, and ask the pupils to discover for themselves why the great white bracts have a notch in the tip. A lens is a great help to the interest in studying these tiny flowers.

Observations-I. What is there at the center of the dogwood flower? How do the parts at the center look? Are they of the same shape? Are some opened and others not? Take a penknife and cut out one that is opened and describe it. Can you see how many petals this tiny flower has? Describe its calyx. How many stamens has it? Can you

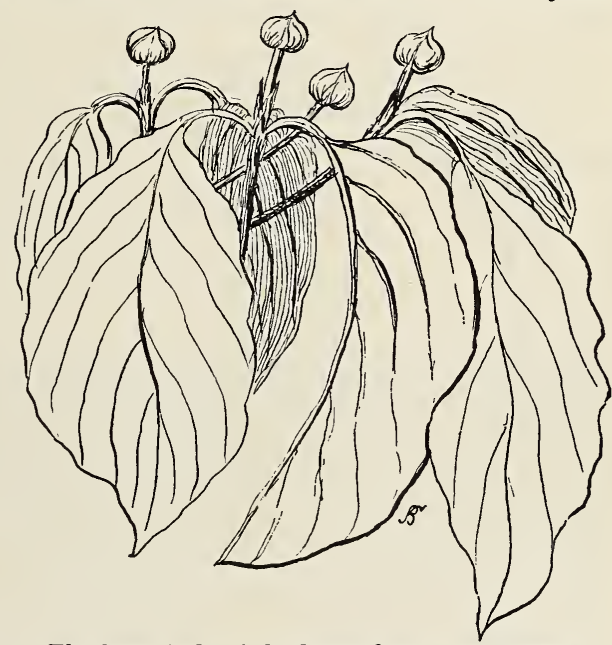

The flower buds of the dogwood are formed during the previous season.

see the pistil? If a flower has a calyx and stamens and a pistil, has it not all that a flower needs?

2. How many of these flowers are there at the center of the dogwood "blossom?" What color are they? Would they show off much if it were not for the great white banners around them? Do we not think of these great white bracts as the dogwood flower?

3. Study one of these banners. What is its shape? Are the four white bracts the same shape and size? Make a sketch of these four bracts with the bunch of flowers at the center. What is there peculiar about each one of these white bracts. Why should this notch be there? Find one of the flower-heads which is not yet opened and watch it develop, and then write a little story of the work done in the winter for the flowers by these bracts and the different work done by them in the spring, all for the sake of the precious blossoms. 
4. Sketch the bracts from below. Is one pair wider than the other? Is the wider pair inside or outside? Why is this so?

5. Where are the flowers of the dogwood borne? How are the twigs arranged so as to unfurl all the banners and not hide one behind another, so that the whole tree is a mass of white?

6. Whilestudying the flowers, study where the young leaves come from. Can you still see the scales which protected the leaf buds?

7. What kind of fruit develops from the dogwood blossoms? What colors are its leaves in autumn?

\section{THE VELVET, OR STAGHORN, SUMAC Teacher's Story}

The sumacs with flame leaves at half-mast, like wildfire spread over the glade; Above them, the crows on frayed pinions move northward in ragged parade.

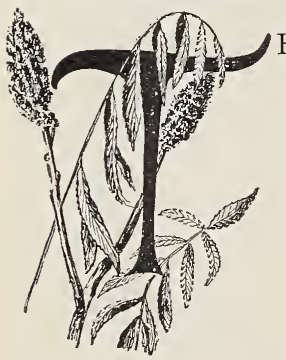

HE sumacs, in early autumn, form a "firing line" along the borders of woodlands and fences, before any other plant but the Virginia creeper has thought of taking on brighter colors. No other leaves can emulate the burning scarlet of their hues. The sumacs are a giory to our hills; and sometime, when Americans have time to cultivate a true artistic sense, these shrubs will play an important part in landscape gardening. They are beautiful in summer, when each crimson "bob" (a homely New England name for the fruit panicle) is set at the center of the bouquet of spreading, fernlike leaves. In winter nakedness they are most picturesque, with their broadly branching twigs bearing aloft the w.necolored pompons against the background of snow, and calling to the winter birds to come and partake of the pleasantly acid drupes. In spring, they put out their soft leaves in exquisite shades of pale pinkish green, and when in blossom their staminate panicles of greenish white cover them with loose pryamids of delicate bloom.

Well may it be called velvet sumac, for this year's growth of wood and the leaf stems are covered with fine hairs, pinkish at first, but soon white; if we slip our fingers down a branch, we can tell even without looking where last year's growth began and ended, because of the velvety feel. Th2 name staghorn sumac is just as fitting, for its upper branches spread widely like a stag's horns and, like them, the new growth is covered with velvet.

The leaves are borne on the new wood, and therefore at the ends of branches; they are alternate; the petiole broadens where it clasps the branch, making a perfect nursery for the little next-year's bud, which is nestled below it. The leaves are compound and the number of leaflets varies from eleven to thirty-one. Each leaflet is set close to the midrib, with a base that is not symmetrical; the leaflets have their edges toothed, and are long and narrow; they do not spread out on either side the midrib like a fern, but naturally droop somewhat, and thus conceal their undersides, which are much lighter in color. The leaflets are not always set exactly opposite; the basal ones are bent back toward the main stem, mak- 
ing a fold in the base of each. The end leaflets are not always three, symmetrically set, but sometimes are two and sometimes one, with two basal lobes.

The wine-colored "bob" is cone-shaped, but with a bunchy surface. Remove all the seeds from it and note its framework of tiny branches, and again pay admiring tribute to nature's way of doing up compact packages. Each seed is a drupe, as is also the cherry. A drupe is merely a seed within a fleshy layer, all being enclosed in a firmer outside covering; here, the outside case is covered with dark red fuzz, a clothing of furs for winter, the fur standing out in all directions. The fleshy part around the seed has a pleasantly acid taste, and one of my childhood diversions was to share these fruits in winter with the birds. I probably inadvertently ate also many a little six-footed brother hidden away for winter safe-keeping, for every sumac panicle is a crowded insect-tenement.

It is only in its'winter aspect that we can see the peculiar way of the sumac's branching, which is in picturesque zigzags, ending with coarse, wide-spreading twigs. As each terminal twig was a stem for the bouquet of blossom and fruit set about with graceful leaves, it needed room and this is reason enough for the coarse branching. The wood of the sumac has a pith, and is coarse in texture.

During late May the new growth starts near the end of last year's twig; the buds are yellowish and show off against the dark gray twigs. From the center of these buds comes the fuzzy new growth, which is usually reddish purple; the tiny leaves are folded, each leaflet creased at its midrib ard

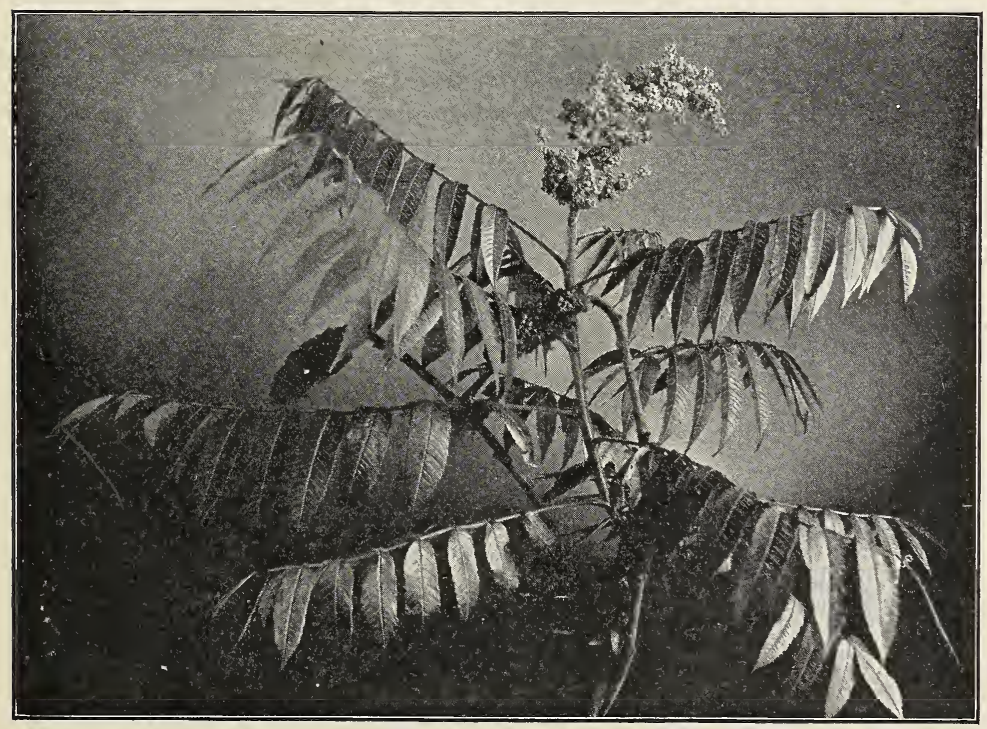

The stag-horn sumac.

Photo by Verne Morton. 
folded tightly against itself; as the leaves unfold, they are olive-green tinted with red, and look like tassels coming out around the old dark red "bob." When the sumacs are in blossom, we see in every group of them, two kinds; one with pyramids of white flowers, and the other with pinkish callow bobs. The structure of these two different flower-clusters is really the same, except that the white ones are looser and more widely spread. Each flower of the white panicle is staminate, and has five greenish, somewhat hairy sepals and five yellowish white petals, at the center of which are five large anthers. A flower from the bob is quite different; it has the five hairy sepals alternating with five narrow, yellowish white petals, both clasping the globular base, or ovary, which is now quite covered with pinkish plush, and bears at its tip the three styles flaring into stigmas.

The velvet sumac is larger than the smooth species (Rhus glabra), and is easily distinguished from it, since the new wood of the latter is smooth and covered with. bloom but is not at all velvety. The poison sumac, which is very dangerous to many people when handled, is a swamp species and its fruit is a loose, drooping panicle of whitish berries, very much like that of poison ivy; therefore, any sumac that has the red bob is not dangerous. The poison species has the edges of its leaflets entire and each leaflet has a distinct petiole of its own where it joins the midrib.

a, Pistillate flower from $a$ "bob." b, Staminate flower from the greenish panicle.

There is much tannin in sumac and it is used extensively to tan leather. The bobs are used for coloring a certain shade of brown. The famous Japanese lacquer is made from the juice of a species of sumac.

\section{LESSON CCVI}

\section{The Velvet, or Staghorn, Sumac}

Leading thought-The sumac is a beautiful shrub in summer because of its fern-like leaves; it is picturesque in winter, and its colors in autumn are most brilliant. Its dark red fruit clusters remain upon it during the entire winter. In June it shows two kinds of blossoms on different shrubs, one is whitish and bears the pollen, the other is reddish and is a pistillate flower, later developing into the seed on the "bob," or fruit cluster.

Method-Begin this study in October when the beautiful autumn color of the leaves attracts the eye. Observations to be made in the field should be outlined and should be answered in the field note-books. The study of the fruit and leaf may be made in the schoolroom, and an interest should be developed which will lead to the study of the interesting flowers the following spring. The sumacs in autumn make a beautiful subject for watercolor sketches, and their peculiar method of branching with their dark red seed clusters or bobs, make them excellent subjects for winter sketching.

Observations-I. Why is this called the velvet sumac? Why is it called the staghorn sumac? Look at the stems with a lens and describe the velvet. Can you tell this year's wood by the velvet? Is there any velvet on last year's wood? Is there any on the wood below? What is there peculiar in the appearance of last year's wood? What are the colors of the hairs that make the velvet on this year's growth? On last year's growth? What is the color of this year's growth under the velvet? Where are the leaves borne? 
2. Look at the leaves. How many come off the stem between two, one of which is above the other? Is the midrib velvety? What is its color at base and at tip? What is the shape of the petiole where it joins the stem? Remove the leaf. What do you find hidden and protected by its broad base?

3. How many leaflets are there on the longest leaf which you can find? How many on the shortest? Do the leaflets have little petioles, or are they set close to the midrib? How does the basal pair differ from the others? Are the leaflets the same color above as below? Are the pairs set exactly opposite each other? Look at the three leaflets at the tips of several leaves and see if they are all regular in form. Draw a leaflet showing its base, its veins and its margin. Draw an entire leaf, and color it as exactly as possible.

4. Study the fruit. Pick one of the bobs and note its general shape. Is it smooth or bunchy? Sketch it. Remove one of the little bunches and find out why it is of that shape. Remove all of the seeds from one of last. year's bobs and see how the fruit is borne. Sketch a part of such a bare stem.

5. Take a single seed; look at it through a lens and describe it. What are the colors? Cut or pare away the flesh, and describe the seed. What birds live on the sumac seeds in winter? How many kinds of insects can you find wintering in the bob? Find a seed free from insects and taste it.

Winter study of the Sumac-6. Study the sumac after the leaves have fallen and sketch it. What is there peculiar in its branching? Of what use to the plant is its method of branching? Break a branch and look at the end. Is there a pith? What color is the wood and pith?

May or June Study of the Sumac-7. Where on the branch does the new growth start? How are the tiny leaves folded? Look over a group of sumacs and see if their blossoms all look alike. Are the different kinds of blossoms found on the same tree or on different trees? Take one of the white pyramidal blossom clusters; look at one of these flowers with a lens and describe its sepals and petals. How many anthers has it and where are they? This is a pollen-bearing flower and has no pistil. How are its tiny staminate flowers arranged on the stem to give the beautiful pyramid shape? This kind of flower cluster is called a panicle.

8. Take one of the green bobs and see if it is made up of little round flowers. Through a lens study one of these. How many sepals? How many petals? Describe the middle of the flower around which the petals and sepals clasp. Is this the ovary, or seed box? Can you see the stigmas protruding beyond it? What insects visit these flowers?

9. How can you tell the velvet or staghorn sumac from the smooth sumac? How can you tell both of these from the poison sumac?

ro. To what uses are the sumacs put?

"I see the partridges feed quite extensively upon the sumach berries, at my old house. They come to them after every snow, making fresh tracks, and have now stripped many bushes quite bare."

-Thoreau's Journal, Feb. 4, 1856. 


\section{THE WITCH-HAZEL}

Teacher's Story

In the dusky, somber woodland, thwarting vistas dull and cold, Thrown in vivid constellations, gleam the hazel stars of gold, Gracious gift of wealth untold.

Hazel blossoms brightly glowing through the forests dark and drear, Work sweet miracles, bestowing gladness on the dying year,

Joy of life in woods grown sere.

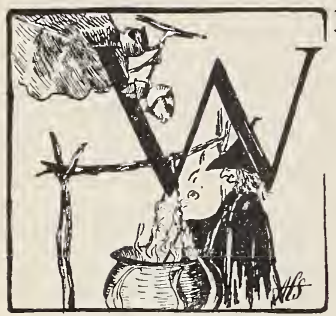

ITCH-HAZEL is not only a most interesting shrub in itself, but it has connected with it many legends. From its forked twigs were made the divining rods by which hidden springs of water or mines of precious metals were found, as it was firmly believed that the twig would turn in the hand when the one who held it passed over the spring or mine. At the present day, its fresh leaves and twigs are used in large quantities for the distilling of the healing extract so much in demand as a remedy for cuts and bruises and for chapped or sunburned skins. It is said that the Oneida Indians first taught the white people concerning its medicinal qualities.

The witch-hazel is a large shrub, usually from six to twelve feet high, although under very advantageous circumstances it has been known to take a tree-like form and attain a height of more than twenty feet. Its bark is very dark grayish brown, smooth, specked with little dots, which are the lenticels, or breathingpores. If the season's growth has been rapid, the new twigs are lighter in color, but when stunted by drouth or poor soil, the new growth has a tint similar to the old. The wood is white, very tough and fibrous, with a pith or heart-wood of softer substance and yellow in color. The leaves are alternate, and the leaf buds appear at the tips of the season's twigs, while the blossoms grow at the axils of the leaves.

The witch-hazel leaf is nearly as broad as it is long, bluntly pointed at its tip, with a stem generally less than one-half inch in length. The sides are unequal in size and shape, and the edges are roughly scalloped. The veins are straight, are depressed on the upper side but very prominent beneath, and they are lighter in color than the rest of the leaf. Witch-

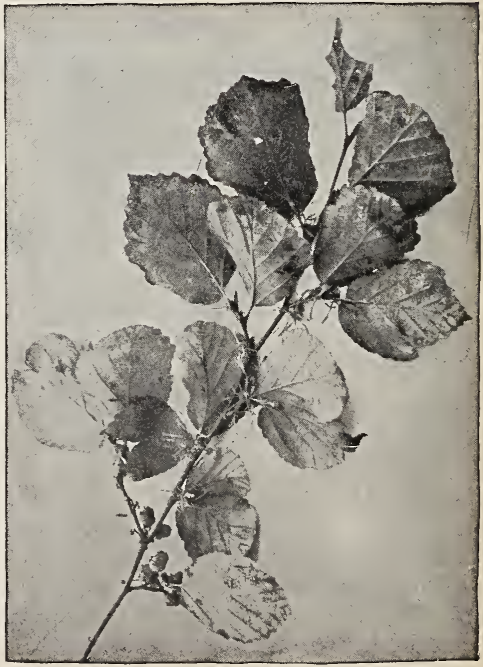

Witch-hazel. 
hazel leaves are likely to be apartment houses for insects, especially the insects that make galls. Of these there are many species, each making a diffesent shaped gall. One of the most common is a gall, shaped like a little horn or spur on the upper side of the leaf and having a tiny door opening on the under side of the leaf. If one of these snug little homes is torn open, it will be found occupied by a community of little aphids, or plant-lice.

The witch-hazel blossoms appear at the axil of a leaf or immediately above the scar from which a leaf has fallen, the season of bloom being so late that often the bush is bare of leaves and is clothed only with the yellow, fringe-like flowers. Usually the flowers are in c usters of three, but occasionally four or five can be found on the same very short stem. The calyx is four-lobed, the petals are four in number, shaped like tiny, yellow ribbons, about one-half inch long and not much wider than a coarse thread. In the bud, these petals are rolled inward in a close spiral, like a watchspring, and are coiled so tightly that each bud is a solid little ball no larger than a bird-shot. There are four stamens lying between the petals, and between each two of these stamens is a little scale just opposite the petal. The anthers are most interesting. Each has two little doors which fly open, as if by magic springs, and throw out the pollen which clings to them. The pistil has two stigmas, which are joined above the two-celled seed-box, or ovary. The blossoms sometimes open in late September, but the

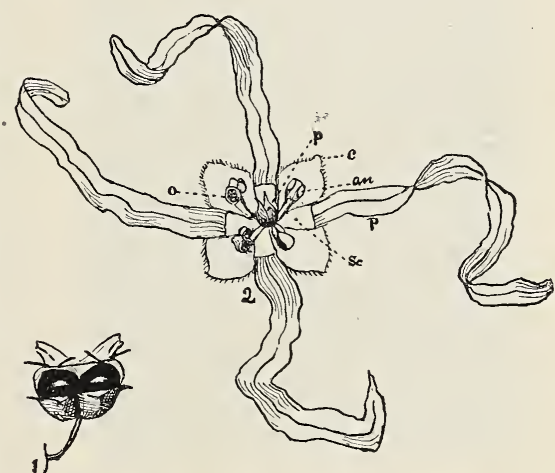
1, A queer little face-witch-hazelnut ready to shoot its seeds. 2, Enlarged flower of witchhazel showing the long petals; $\mathrm{p}$, with dotted line the pistil; an, anther; a, anther with doors open; c, lobes of calyx; sc, scale opposite the base of petal.

greater number appear in

October and November. They are more beautiful in November after the leaves have fallen, since these yellow, starry flowers seem to bring light and warmth into the landscape. After the petals fall, the calyx forms a beautiful little urn, holding the growing fruit.

The nuts seem to require a sharp frost to separate the closely joined parts; it requires a complete year to mature them. One of these nuts is about half an inch long and is covered with a velvety green outer husk, until the frost turns it brown; cutting through it discloses a yellowish white inner shell, which is as hard as bone; within this are the two brown seeds each ornamented with a white dot; note particularly that these seeds lie in close-fitting cells. The fruit, if looked at when the husk is opening, bears an odd resemblance to a grotesque monkey-like face with staring eyes. Frosty nights will open the husks, and the dry warmth of sunny days or of the heated schoolroom, will cause the edges of the cups which hold the seeds, to curve inward with such force as to send the seeds many feet away; ordinarily they are thrown from ten to twenty feet, but Hamilton Gibson 
records one actual measurement of forty-five feet. The children should note that the surface of the seeds is very polished and smooth, and the way they are discharged may be likened to that by which an orange seed is shot from between the fingers.

\section{LESSON CCVII}

\section{The Witch-HazeL}

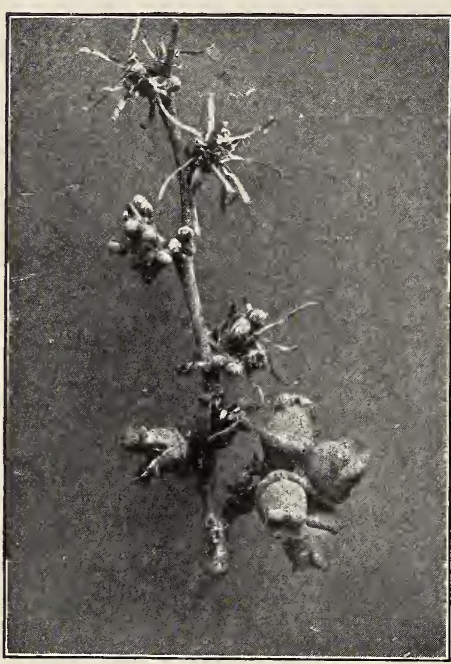

Flowers and fruit of wirch-hazel.

Photo by G. F. Morgan.

Leading thought-The witchhazel blossoms during the autumn, and thus adds beauty to the landscape. It has an interesting mechanism by which it can shoot its seeds for a distance of many feet.

Method-This lesson divides naturally into two parts; a study of the way the seeds are distributed is fitted for the primary grades, and a study of the flower for more advanced grades. For the primary grades the lesson should begin by the gathering of the twigs which bear the fruit. These should be brought to the schoolroomthere to await results. Soon the seeds will be popping all over the schoolroom, and then the question as to how this is done, and why, may be made the topic of the lesson. For the study of the flower and the shrub itself, the work should begin in October when the blossoms are still in bud. As they expand they may be studied, a lens being necessary for observing the interesting little doors to the anthers.

Observations-r. Is the witch-hazel a shrub or a tree?

2. What is the color of the bark? Is it thick or thin, rough or smooth, dark or light, or marked with dots or lines? Is there any differense in color between the older wood and the young twigs? Is the wood tough or brittle? Dark or light in color?

3. Do the leaves grow opposite each other or alternate? On what part of the plant do the leaf buds grow?

4. What is the general shape of the leaf? Is it more pointed at the base or at the tip? Are the leaves regular in form, or larger on one side than the other? Are the edges entire; tocthed or wavy? Are the petioles short or long? Are the veins straight or branching? Are they prominent? Are the leaves of the same color on both sides?

5. Are there many queer-shaped little swellings on the leaf above and below? See how many of these you can find? Tell what you think they are.

6. Do the flowers grow singly or in clusters? What is the shape and color of the petals, and how many of them are there in each blossom? 
Describe the calyx. If there are any flower buds just opening, observe and describe the way the petals are folded within them.

7. How many stamens? With a lens observe the way the two little doors to the anther fly open; how is the pollen thrown out? What is the shape of the pistil? How many stigmas?

8. Does each individual flower have a stem or is there a common stem for a cluster of blossoms? Do the flowers grow at the tips or along the sides of the twigs? When do the witch-hazel flowers appear and how long do they last?

9. Make a drawing of a witch-hazel nut before it opens. What is the color of the outer husk when ripe? Cut into a closed nut and observe the extreme hardness and strength of the inner shell.

Io. Where are the seeds situated? Can you see that the shell, when partially open, ready to throw out the seeds resembles a queer little face? Describe the color and marking of the seeds; are they rough or smooth? How far have you known the witch-hazel to throw its seeds? Study the nut and try to discover how it throws the seeds so far.

References-Tree Book, Rogers; Our Northern Shrubs, Keeler; Familiar Trees and Their Leaves, Mathews; Field, Forest and Wayside Botany, Gray.

\section{THE MOUNTAIN LAUREL}

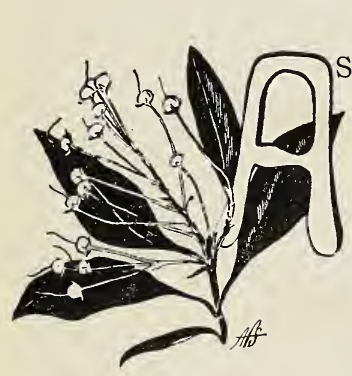

\section{Teacher's Story}

$S$ a child I never doubted that the laurel wreaths of Grecian heroes were made from mountain laurel, and I supposed, of course, that the flowers were used also. My vision was of a hero crowned with huge wreaths of laurel bouquets, which I thought so beautiful. It was a shock to exchange this sumptuous headgear of my dreams for a plain wreath of leaves from the green-bay tree.

However, the mountain laurel leaf is evergreen and beautiful enough to crown a victor; in color it is a rich, lustrous green above, with a yellow midrib, the lower side being of a much lighter color. In shape, the leaf is long, narrow, pointed at each end and smooth-edged, with a rather short petiole, The leaves each year grow on the new wood, which is greenish and rough, in contrast with the old wood, which is rich brownish red. The leaves are arranged below the flower cluster, so that they make a shining green base for this natural bouquet.

The flowers grow on the tips of the branching twigs, which are huddled together in a manner that brings into a mass many flowers. I have cnunted seventy-five of them in a single bunch; the youngest flowers grow nearest the tip of the twig. The blossom stems are pink, and afford a rich backgro'nd for the starry open flowers and knobby closed buds. The bud of the laurel blossom is very pretty and resembles a bit of rose-colored pottery; it has a five-sided, pyramidal top, and at the base of the pyramid are ten little buttresses which flare out from the calyx. The calyx is five-lobed, each lobe being green at the base and pink at the point. Each one of the 
ten little buttresses or ridges is a groove in which a stamen is growing, as we may see by looking into an opening flower; each anther is "headed" toward the pocket which ends the groove. The filament lengthens and shoves the anther into the pocket, and then keeps on growing until it forms a bow-shaped spring, like a sapling with the top bent to the ground. The opening flower is saucerlike, pinkish white, and in form is a five-pointed star. At the bottom of the saucer a ten-pointed star is outlined in crimson; and bowed above this crimson ring are the ten white filaments with their red-brown anthers stuffed cozily into the pockets, one pocket at the center of each lobe, and one half-way between; each pocket is marked with a

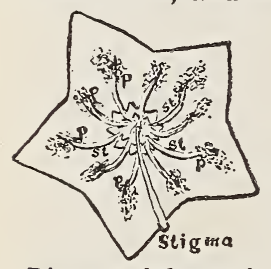

Diagram of flower of laurel.

p, pocket; st, stamen. splash of crimson with spotty edges. From the center of the flower projects the stigma, far from and above the pollen-pockets.

Each laurel flower is thus set with ten spring-traps all awaiting the visit of the unwary moth or bee which, when seeking the nectar at the center of the flower, is sure to touch one or all of these bent filaments. As soon as one is touched, up it springs and slings its pollen hard at the intruder. The pollen is not simply a shower of powder, but is in the form of a sticky string, as if the grains were strung on cobweb silk. When liberating these springs with a pencil point, I have seen the pollen thrown a distance of thirteen inches; thus, if the pollen ammunition does not strike the bee, it may fall upon some open flower in the neighborhood. The anthers spring back after this performance and the filaments curl over each other at the center of the flower below the pink stigma; but after a few hours they straighten out and each empty anther is suspended above its own pocket. The anthers open while in the pocket, each one is slit open at its tip so that it is like the leather pocket of a sling.

After the corollas fall, the long stigma still projects from the tip of the ripening ovary, and there it stays, until the capsule is ripe and open. The five-pointed calyx remains as an ornamental cup for the fruit. The capsule opens along five valves, and each section is stuffed with little, almost globular seeds.

The mountain laurel grows in woods and shows a preference for rocky mountain sides or sandy soil.

Another of the common species is the sheep laurel, which grows in swampy places, especially on hillsides. The flowers of this are smaller and pinker than the mountain laurel, and are set below the leaves on the twig. Another species called the pale, or swamp, laurel, has very small fiowers, not more than half an inch in breadth and its leaves have rolled-back edges and are whitish green beneath. This species is found only in cold peat-bogs and swamps

\section{LESSON CCVIII \\ The Mountain Laurel}

Leading thought-The laurel blossom is set with ten springs, and each spring acts as a sling in throwing pollen upon visiting insects, thus making sure that the visitor will carry pollen to other waiting flowers.

Method-Have the pupils bring to the schoolroom a branch of laurei which shows blossoms in all stages from the bud. Although this lesson is on the mountain laurel, any of the other species will do as well. 
Observations-I. How are the laurel leaves set about the blossom clusters to make them beautiful? What is the shape of the laurel leaf? What are its colors above and below? How do the leaves grow with reference to the flowers? Do they grow on last year's or this year's wood? How can you tell the new wood from the old?

2. Take a blossom bud. What is its shape? How many sides to the pyramid-like tip? How many little flaring ridges at the base of the pyramid? Describe the calyx.

3. What is the shape of the flower when open? How many lobes has it? What is its color? Where is it marked with red?

4. In the open blossom, what do you see of the ten ridges, or keels, which you noticed in the bud? How does each one of these grooves end? What does the laurel blossom keep in these ten pockets? Touch one of the ten filaments with a pencil and note what happens.

5. Take a bud scarcely open. Where are the stamens? Can you see the anthers? Take a blossom somewhat more open. Where are the anthers

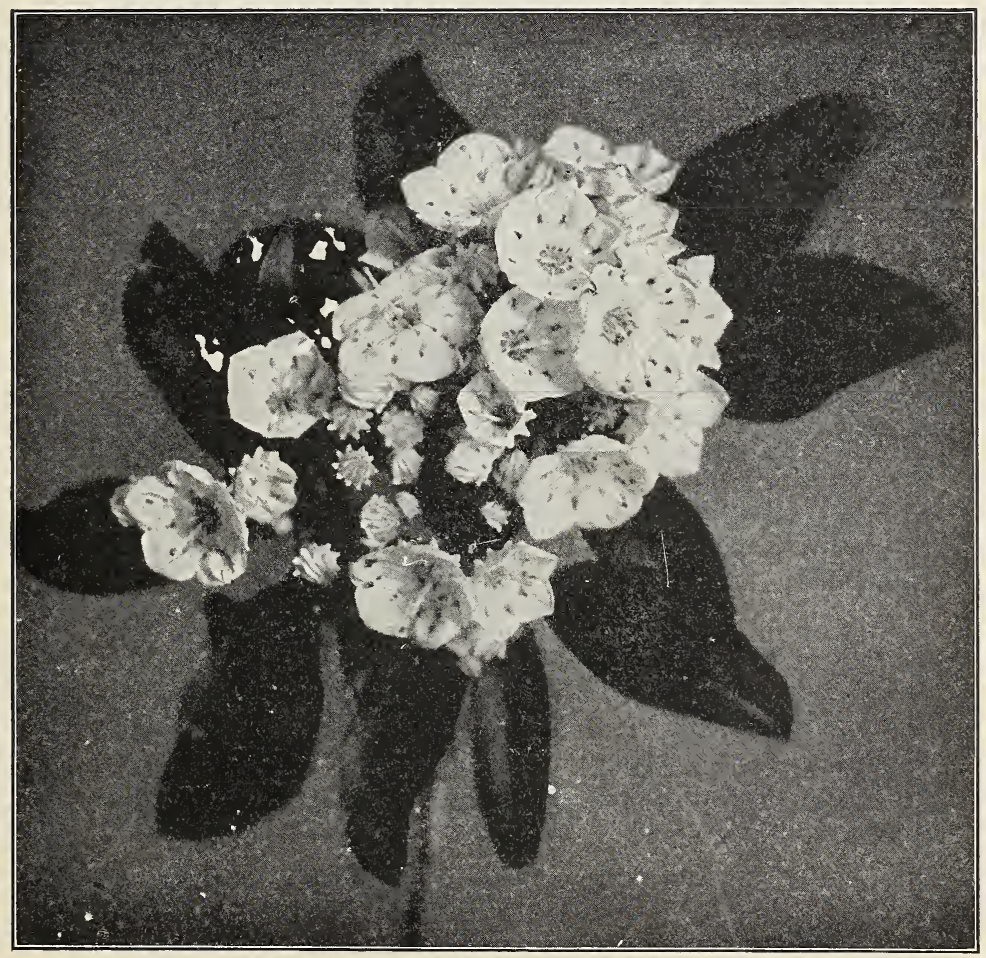

Mountain laurel.

Photo by Verne Morton. 
now? From these observations explain how the stamens place their anthers in the pockets. How do the filaments grow into bent springs?

6. Are the anthers open when they are still in the pocket? Look at an anther with a lens and tell how many slits it has. How do they open? Are the pollen grains loose when they are thrown from the anther? How are they fastened together? Does this pollen mass stick to whatever it touches?

7. What is the use to the flower of this arrangement for throwing pollen? What insects set free the stamen-springs? Where is the nectar which the bee or moth is after? Can it get this nectar without setting free the springs? Touch the filaments with a pencil and see how far they will sling the pollen.

8. Describe the pistil in the open flower. Is the stigma near the anthers? Would they be likely to throw their pollen on the stigma of their own flower? Could they throw it on the stigmas of neighboring flowers?

9. How does the fruit of the laurel look? Does the style still cling after the corolla falls? Describe the fruit-capsule. How does it open? How do the seeds look? Are there many of them?

ro. Where does the mountain laurel grow? What kind of soil does it like? Do you know any other species of laurel? If so, are they found in the same situations as the mountain laurel?

"A childish gladness stays my feet, As through the winter woods I go,

Behind some frozen ledge to meet A kalmia shining through the snow.

I see it, beauteous as it stood Ere autumn's glories paled and fled, And sigh no more in pensive mood, 'My leafy oreads are all dead.'

I hear its foliage move, like bells On rosaries strung, and listening there, Forget the icy wind that tells Of turfless fields, and forests bare.

All gently with th' inclement scene I feel its glossy verdure blend;-

I bless that lovely evergreen As heart in exile hails a friend.

Its boughs, by tempest scarcely stirred, Are tents beneath whose emerald fold

The rabbit and the snowbound bird Forget the world is white and cold.

And still, 'mid ruin undestroyed, Queen arbor with the fadeless crown,

Its brightness warms the frosty void, And softens winter's surliest frown."

-From "The Mountain Laurel" Theron Brown. 


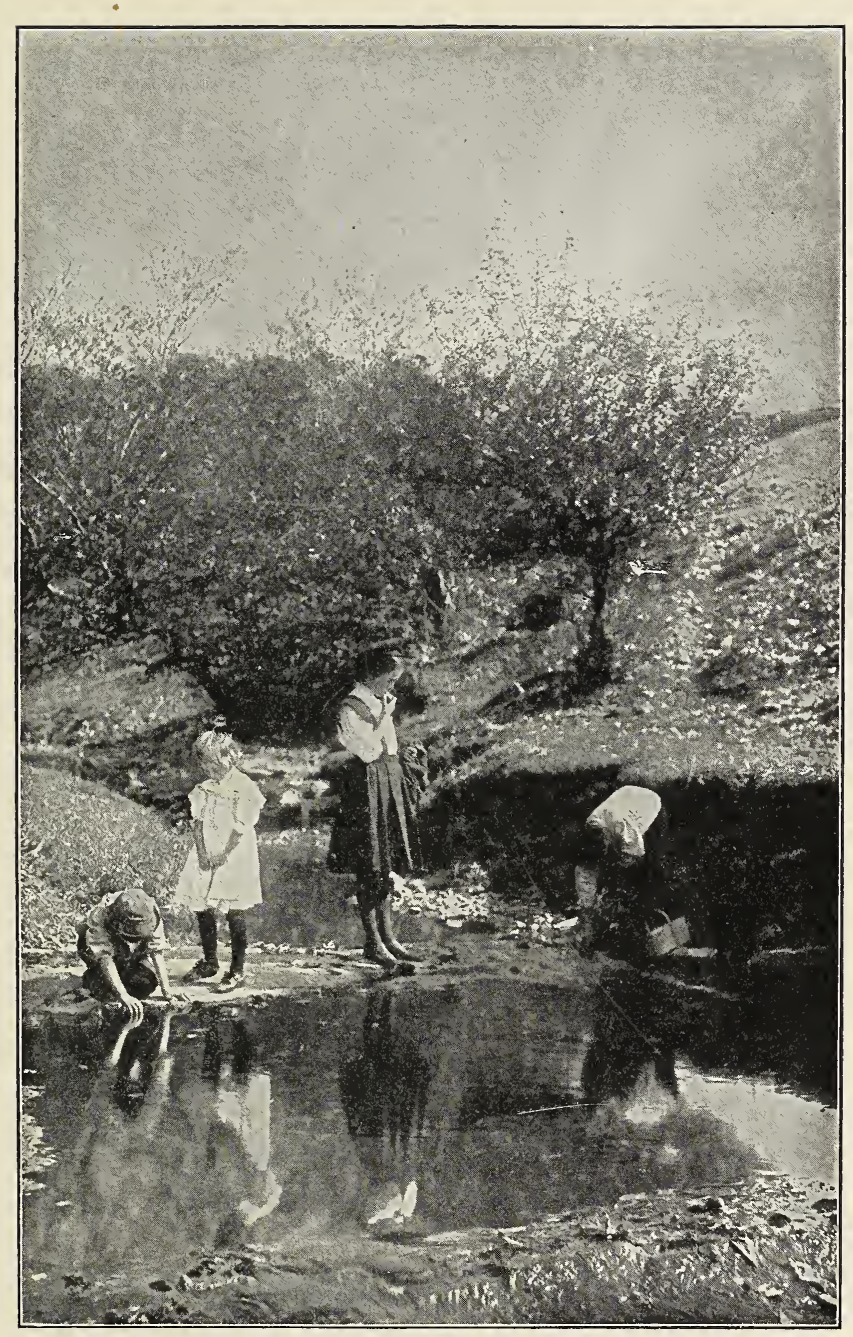

Brook study.

Photo by Verne Morton. 


\title{
PART IV
}

\section{EARTH AND SKY}

\author{
THE BROOK \\ Teacher's Story \\ "Little brook, sing a song of a leaf that sailed along, \\ Down the golden braided center of your current swift and strong." \\ -J. W. RILEY.
}

A brook is undoubtedly the most fascinating bit of geography which the child encounters; and yet how few children who happily play in the brookwading, making dams, drawing out the crayfish by his own grip from his lurking place under the log, or watching schools of tiny minnows-ever dream that they are dealing with real geography. The geography lesson on the brook should not be given for the purpose of making work out of play, but to conserve all of the natural interest in the brook, and add to it by revealing other and more interesting facts concerning it. A child who thus studies the brook will master some of the fundamental facts of physical geography, so that ever after he will know and understand all streams, whether they are brooks or rivers. An interesting time to study a brook is after a rain; and May or October give attractive surroundings for the study. However, the work should be continued now and then during the entire year, for each season gives it some new features of interest.

Each brook has its own history, which can be revealed only to the eyes of those that follow it from its beginning to where it empties its water into a larger stream or pond. At its source the brook usually is a small stream with narrow banks; not until it receives water from surrounding hills does it gain enough power to cut its bed deeper into the earth, thus making its banks higher. Where it flows with swift current down a hillside, it cuts its bed deeper, because swift-moving water has more power for cutting and carrying away the soil. However, if the hillside happens to be in the woods, the roots of trees or bushes will help to keep the soil from being washed away. Unless there are obstacles, the course of the brook is likely to be more direct in flowing down a hillside than when crossing level fields. The delightful way in which brooks meander crookedly across the level areas is due to the inequalities of the surface, which interfere more with water on a plain than on a hillside, since the gravity which pulls it forever down has less chance to act upon it forcibly in these situations. After a stream has thus started its crooked course, in time of flood the current strikes with more force against the curves, and cutting them deeper, makes the course still more crooked. The places on the banks where the soil is bare and exposed to the force of the current, are the points where the banks are cut most deeply at flood time.

But the brook is not simply an object to look at and admire; it is a very busy worker, its chief labor being that of a digger and carrier. When it is not carrying anything-that is, when its waters are perfectly clear-the 
stream is doing the least work. The poets, as well as common people, speak of the playing of the brook when its limpid waters catch the sunbeams on their dimpling surface; but when the waters are roily the brook is working very hard. This usually occurs after a rain, which adds much more water to the volume of the brook; the action of gravity upon this larger and heavier body forces it to flow more swiftly and every drop in the stream that touches the bank or bottom, snatches up a tiny load of earth and carries it along. And every drop thus laden, when it strikes against a corner of the bank, tears more soil loose through the impact, and other drops snatch it up and carry it on down the stream. And after a time there are so many drops carrying loads and bumping along, knocking loose more earth, that the whole brook, which is made up of drops, looks muddy. In its work as a digger, every drop of water that touches the soil at the bottom or on the banks of the brook uses its own little load of earth or gravel as a crowbar or pickaxe to pry up other bits of dirt and gravel; and all of the drops hastening on, working hard together, dig the channel of the brook wider and deeper In some steep places, so many of the drops are working together that they are able to pick up pebbles or stones, with which they batter and tear down larger pieces of the bank and scrape out greater holes in the bottom of the stream. On and on the brook flows, a gang of workmen each of which is using its own load as a tool, all in close procession and working double quick. But as soon as the brook reaches a plain or level, its activity ceases; the drops act tired and seem to have no amb:tion to pick up more soil, and each lets fall its own load as soon as possible, dropping the larger pieces of gravel and rock first, carrying the finer soil farther, but finally letting that down also. If we examine the sediment of a flooded brook, we find that the gravel is always dropped first, and that the fine mud is carried farthest before it is deposited.

The roar of a flooded stream is very different from the murmur of its waters when they are low. It is not to be wondered at, when we once think of all that is going on in the brook during periods of flood. There are some $\mathrm{s}$ mple experiments to show what the force of water can do when turned against the soil. Pour water from a pitcher into a bed of soft soil, and note how quickly a hole will be made; if the pitcher is held near the soil, less of a hole will be formed than if the pitcher is held high up, which shows that the farther the water falls, the greater is its force. This explains why the banks of streams are undermined when a strong current is driven against them. The swift current, of course, breaks away more earth at bends and curves than when it is flowing in a straight line; for ordinarily, when flowing straight, the current is swiftest in the bed of the stream, and is therefore only digging at the bottom; but when it flows around curves, it is directed against the banks, and therefore has much more surface to work upon. Thus it is that bends are cut deeper and deeper. If the bare arm is thrust into a flooded brook, we find that many pieces of gravel strike against it; and if we reach the bottom, we can feel the pebbles being moved along over the brook bed.

\section{LESSON CCIX}

\section{THE BROOK}

Leading thought-The water from the little brook near our schoolhouse is flowing toward the ocean, and is meanwhile digging out and carrying along with it the soil through which it flows. 


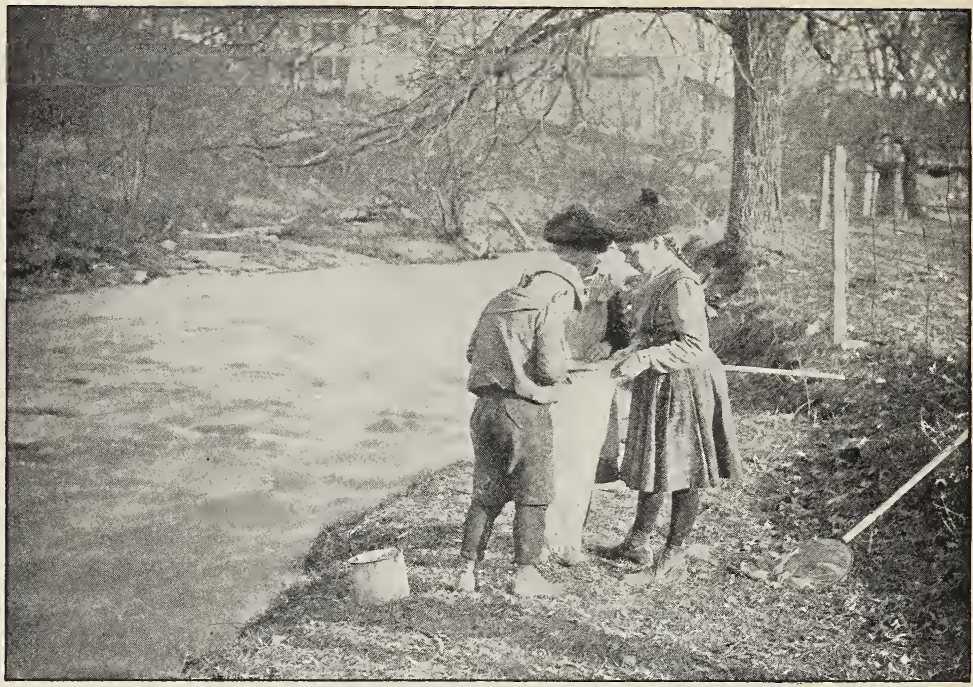

What the children find living in the brook.

Method - The best time to study a brook is after a rain, and October or May is an interesting time for beginning this lesson. The work should be continued during the entire year. It may be done at noon or recess, if the brook is near at hand; or there may be excursions after school, if the brook is at some distance. The observations should be made by the class as a whole.

Observations-I. Does the brook have its source in a spring or a swamp, or does it receive its water as drainage from surrounding hills? Follow it back to its very beginning. Do you find this in open fields or woods? Is the land about it level or hilly?

2. Are its banks deeper at the beginning, or is the brook at first almost on a level with the surrounding fields? Do the banks become deeper farther from the source? Are the banks higher where the brook flows down hill, or where it is on a level?

3. Is the course of the brook more crooked on a hillside or when flowing through a level area? Are the banks more worn away and steep where the brook flows through woods or bushes than through the open fields?

4. Can you find the places where the water is cutting the banks most, when the brook is flooded? Why does it cut the banks at these particular points?

5. Into what stream, pond or lake does the brook flow? If you should launch a toy boat upon the waters of this brook, and it should keep afloat, through what streams would it pass to reach the ocean? Through what townships, counties, states or countries wouid it pass?

6. When is the brook working and when is it playing? What is the difference between the color of the water ordinarily and when the brook is flooded? What causes this difference? 
7. Make the following experiment to show what the brook is carrying after a storm when the water is roily. Dip from the swift portion of the stream a glass fruit jar full of water. Place it on a window-sill and do not disturb it until the water is clear. How much sediment has settled at the bottom of the jar? Where was this sediment when you dipped up the water? If this quart of water could carry so much soil or sediment, how much, do you think, would the whole brook carry?

8. Where did the brook get the soil to make the water roily? Study its banks in order to answer this question. Do you think the soil in the water came from the banks that are covered by vegetation or from those which are bare?

9. How did the brook pick up the soil that it carried when it was flooded? Do you think that one of the tools that the brook digs with is the current? Try to find a place where the swift current strikes the bank, and note if the latter is being worn away.

ro. Does the swift current take more soil where it is flowing straight, or where there are sharp bends? How are the bends in the brook or creek made?

II. Thrust your bare hand or arm into the swift current of the brook when it is flooded. Do you feel the gravel strike against your arm or hand? Wadein the water. Do you feel the pebbles strike against the feet or legs, as they are being rolled along the bed of the stream?

I2. Does the water, loaded with soil and pebbles, dig into the banks more vigorously than just the water alone could do? Which washes away more earth and carries it down stream-a fast or a slow current?

13. Does the water of the brook flow fastest when its waters are low or high? When the brook is at its highest flood, do you think it is working the hardest? If so, explain why? When it is working the hardest and carrying most soil and gravel, does it make a different sound than when it is flowing slowly and its waters are clear?

I4. How does the brook look when it is doing the least amount of work possible?

I5 Make a map of your brook showing every pool, indicating the places where the current is swiftest and showing the bends in its course. To test the rapidity of the current, put something afloat on it and measure how far it will go in a minute.

r6. How many kinds of trees, bushes and plants grow along the banks of your brook? How many kinds of fish and insects do you find living in it? How many, kinds of birds do you see frequently near it?

A brook puzzle for pupils to solve-When we have a load to carry we go slowly because we are obliged to; and the heavier the load, the slower we go. On the other hand, when we wish to run very swiftly we drop the load so as not to be weighted down; when college or high school boys run races in athletic games, they do not wear even their ordinary clothing, but dress as lightly as possible in trunks and tights; they also train severely so that they do not have to carry any more flesh on their bones than is necessary. How is it that in the case of a brook just opposite is true? The faster the brook runs, the more it can carry; and the heavier it becomes the faster it runs; and the faster it runs the more work it can do. 


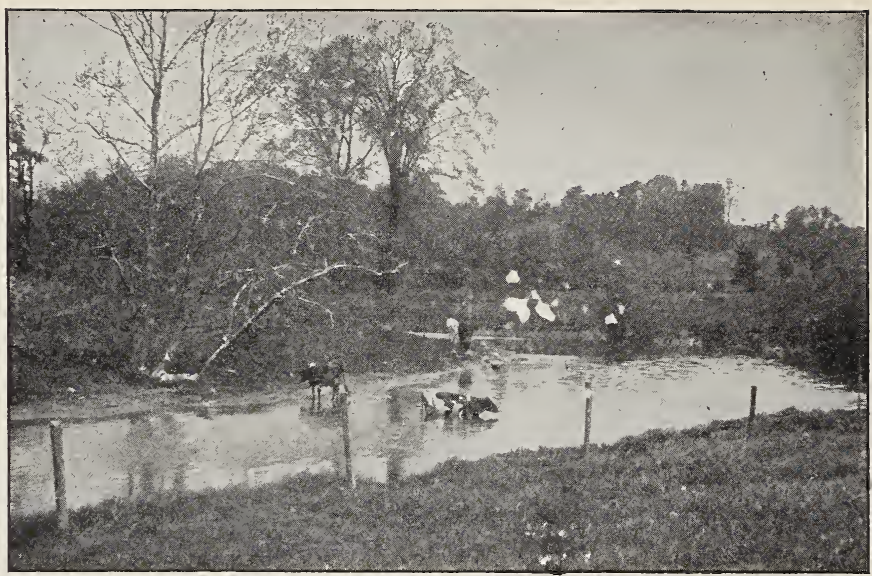

Where the stream drops its load.

\section{HOW A BROOK DROPS ITS LOAD}

\section{Teacher's Story}

The brook is most discriminating in the way it takes up its burdens, and also in the way it lays them down. It, with quite superhuman wisdom, selects the lightest material first, leaving the heaviest to the last; and when depositing the load, it promptly drops the heaviest part first. And thus the flowing waters of the earth are eternally lifting, selecting, and sifting the soils on its surface.

The action of rain upon the surface of the ground is in itself an excellent lesson in erosion. If there is on a hillside a bit of bare ground which has been recently cultivated or graded, we can plainly see, after a heavy rain, where the finer material has been sorted out and carried away, leaving the larger gravel and stones. And if we examine the pools in the brook, we shall find deltas as well as many examples of the way the soil is sifted as it is dropped. The water of a rill flowing through pasture and meadow is clear, even after a hard rain. This is owing, not so much to the fact that the roots hold the banks of the brook firmly, as that the grass on the surface of the ground acts as a mulch and protects the soil from the erosive impact of the raindrops. On the other hand, and for a reverse reason, a rill through plowed ground is muddy. On a hillside, therefore, contour plowing is practiced - that is, plowing crosswise the hillside instead of up and down. When the furrow is carried crosswise, the water after showers can not dash away, carrying off in it all the finer and more fertile portions of the soil. There are many instances in our Southern States where this difference in the direction of plowing has saved or destroyed the fertility of hillside farms.

The little experiment suggested at the beginning of the following lesson, should show the pupils clearly the following points: It is through motion that water takes up soil and holds it in suspension. The tendency of still 
water is to drop all the load which it is carrying and it drops the heaviest part first. We find the pebbles at the bottom of the jar, the sand and gravel next, and the fine mud on top. The water may become perfectly clear in the jar and yet, when stirred a little, it will become roily again because of the movement. Every child who wades in a brook, knows that the edges and the still pools are more comfortable for the feet than is the center of the stream under the swift current. This is because, where the water is less swift at the sides, it deposits its mud and makes a soft bottom; while under the swifter part of the current, mud is washed away leaving the larger stones bare. For the same reason, the bottom of a stream crossing a level field is soft, because the silt, washed down from the hills by the swift current, is dropped when the waters come to a more quiet place. If, across a stony brook, the pupils can build a dam that will hold for two or three months in the fall or spring when the brook is flooded, they will be able to note that the stones will soon be more or less covered with soft mud; for the dam, stopping the current, causes the water to drop its load of silt. It would have to be a very recently made pool in a stream, which would not have a soft mud bottom. The water at times of flood is forced to the side of the streams in eddies, and its current is thus checked, and its load of mud dropped.

It should be noted that at points where the brook is narrowest the current is swiftest, and where the current is swiftest the bottom is more stony. Also, where there is a bend in the stream the brook digs deeper into the bank where it strikes the curve, and much of the soil thus washed out is removed to the other side of the stream where the current is very slow, and there is dropped. (See Introduction to Physical Geography, Gilbert and Brigham, pp. $5^{I}$ and $5^{2}$.) If possible, note that where a muddy stream empties into a pond or lake, the waters of the latter are made roily for some distance out, but beyond this the water remains clear. The pupils should be made to see that the swift current of the brook is checked when its waters empty into a pond or lake, and because of this they drop their load. This happens year after year, and a point extending out into the lake or pond is thus built up. In this manner the great river deltas are formed.

References-The Brook Book, Mary Rogers Miller; Brooks and Brook Basins, Frye; Up and Down the Brooks, Bamford; Physical Geography, Tarr; Introduction to Physical Geography, Gilbert and Brigham.

\section{LESSON CCX}

\section{How a Brook Drops Its LoAd}

Leading thought-The brook carries its load only when it is flowing rapidly. As soon as the current is checked, it drops the larger stones and gravel first and then the finer sediment. It is thus that deltas are built up where streams empty into lakes and ponds.

Method-Study the rills made in freshly graded soil directly after a heavy rain. Ask the pupils individually to make observations on the flooded brook.

Experiment-Take a glass fruit jar nearly full of water from the brook, add gravel and smail stones from the bed of the brook, sand from its borders and mud from its quiet pools. Have it brought into the schoolroom, and shake it thoroughly. Then place in a window and ask the pupils to observe the following things: 
(a) Does the mud begin to settle while the water is in motion; that is, while it is being shaken?

(b) As soon as it is quiet, does the settling process begin?

(c) Which settles first- the pebbles, the sand or the mud? Which settles on top-that is, which settles last?

(d) Notice that as long as the water is in the least roily, it means that the soil in it has not all settled; if the water is disturbed even a little it becomes roily again, which means that as soon as the water is in motion it takes up its load.

Observations-I. Where is the current swiftest, in the middle or at the side of the stream?

2. What is the difference, in the bottom of the brook, between the place below the swift current and the edges? That is, if you were wading in the brook, where would it be more comfortable for your feet-at the sides or in the swiftest part of the current? Why?

3. Does the brook have a more stony bed where it flows down a hillside than where flowing through a level place?

4. Place a dam across your brook where the bottom is stony, and note how soon it will have a soft mud bottom. Why is this?

5. Can you find a still pool in your brook that has not a soft, muddy bottom? Why is this?

6. Does the brook flow more swiftly in the steep and narrow places than in the wide portions and where it is dammed?

7. Do you think if water, flowing swiftly and carrying a load of mud, were to come to a wider or more level place, like a pool or millpond dam, that it would drop some of its load? Why?

8. If the water flows less swiftly along the edges than in the middle, would this make the bottom below softer and more comfortable to the feet than where the current is swiftest? If so, why?

9. If you can see the place where a brook empties into a pond or lake, how does it make the waters of the latter look after a storm? What is the water of the brook doing to give this appearance, and why?

ro. What becomes of the soil dropped by the brook as it enters a pond or lake? Do you know of any points of land extending out into a lake or pond where the stream enters it? What is a stream delta?

"In the bottom of the valley is a brook that saunters between oozing banks. It falls over stones and dips under fences. It marks an open place on the face of the earth, and the trees and soft herbs bend their branches into the sunlight. The hangbird swings her nest over it. Mossy logs are crumbling into it. There are still pools where the minnows play. The brook runs away and away into the forest. As a boy I explored it but never found its source. It came somewhere from the Beyond and its name was Mystery.

The mystery of this brook was its changing moods. It had its own way of recording the passing of the weeks and months. I remember never to have seen it twice in the same mood, nor to have got the same lesson from it on two successive days: yet, with all its variety, it always left that same feeling of mystery and that same vague longing to follow to its source and to know the great world that $I$ was sure must lie beyond. I felt that the brook was greater and wiser than I. It became my teacher. I wondered how it knew when March came, anả why its round of life recurred so regularly with the returning seasons. I remember that $I$ was anxious for the spring to come, that I might see it again. I longed for the earthy smell when the snow settled away and left bare brown margins along its banks. I watched for the suckers that came up from the river to spawn. I made a note when the first frog peeped. I waited for the unfolding spray to soften the bare trunks. I watched the greening of the banks and looked eagerly for the bluebird when I heard his curling note somewhere high in the air." 


\section{CRYSTAL GROWTH}

\section{Teacher's Story}

To watch the growth of a crystal is to witness a miracle; involuntarily we stand in awe before it, as a proof that of all truths mathematics is the most divine and inherent in the universe. The teacher will fail to make the best use of this lesson if she does not reveal to the child through it something of the marvel of crystal growth.

That a substance which has been dissolved in water should, when the water evaporates, assemble its particles in solid form of a certain shape, with its plane surfaces set exactly at certain angles one to another, always the same whether the crystal be large or small, is quite beyond our

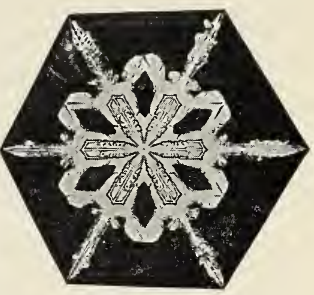

A snow crystal.

Photomicrograph by W. A. Bentley. understanding Perhaps it is no more miraculous than the growth of living beings, but it seems so. The fact that when an imperfect crystal, unfinished or broken, is placed in water which is saturated with the same substance, it will be built out and made perfect, shows a law of growth so exquisitely exemplified as to again make us glad to be a part of a universe so perfectly governed. Moreover, when crystals show a variation in numbers of angles and planes it is merely a matter of division or multiplication. A snow crystal is a six-rayed star, yet sometimes it has three rays.

The window-sill of a schoolroom may be a place for the working of greater wonders than those claimed by the astrologists of old, when they transmuted baser metals to gold and worthless stones to diamonds. It may be a place where strings of gems are made before the wondering eyes of the children; gems fit to make necklaces for any naiad of the brook or oread of the caves.

It adds much to the interest of this lesson if different colored substances are used for the forming of the crystals. Blue vitriol, potassium bichromate, and alum give beautiful crystals, contrasting in shape as well as in colors.

Copper sulphate and blue vitriol are two names for one substance; it is a poison when taken internally and, therefore, it is best for the teacher to carry on the experiment before the pupils instead of trusting the substance to them indiscriminately. Blue vitriol forms an exquisitely beautiful blue crystal, which is lozenge-shaped with oblique edges. Often, as purchased from the drug store, we find it in the form of rather large, broken, or imperfect crystals. One of the pretty experiments is to place some of these broken crystals in a saucer containing a saturated solution of the vitriol, and note that they straightway assert crystal nature by building out the broken places, and growing into perfect crystals. Blue vitriol is used much in the dying and in the printing of cotton and linen cloths. It has quite wonderful preservative qualities; if either animal or vegetable tissues are permeated by it they will remain dry and unchanged.

Potassium bichromate is also a poison and, therefore, the teacher should make the solution in the presence of the class. It forms orange-red crystals, more or less needle-shaped. It crystallizes so readily that if one drop of the so ution be placed on a saucer the pupils may see the formation of the crystals by watching it for a few moments through a lens. 
The common alum we buy in crystal form, however, it is very much broken. Its crystals are eight-sided and pretty. Alum is widely used in dyes, in medicines, and in many other ways. It is very astringent, as every child knows who has tried to eat it, and has found the lips and tongue much puckered thereby

Although we are more familiar with crystals formed from substances dissolved in water, yet there are some minerals, like iron which crystallize only when they are melted by heat; and there are other crystals, like the snow, which are formed from vapor. Thus, substances must be molten hot, or dissolved in a liquid, or in form of gas, in order to grow into crystals.

\section{LESSON CCXI}

\section{Crystal Growth}

Leading thought-Different substances when dissolved in water wil ${ }^{1}$ re-form as crystals; each substance forms crystals of its own peculiar color and shape.

Method-Take three test tubes, long vials or clear bottles. Fill one with a solution made by dissolving one part of blue vitriol in three parts of water; fill another by dissolving one part of bichromate of potash with twenty-five parts of water; fill another 'with one part of alum in three parts of water. Suspend from the mouth of each test tube or vial, a piece of white twine, the upper end tied to a tooth pick, which is placed across the mouth of the vial; the other end should reach the bottom of the vial. If necessary, tie a pebble to the lower end so that it will hang straight. Place the bottles on the window sill of the schoolroom, where the children may observe what is happening. Allow them to stand for a time, until the string in each case is encrusted with crystals; then pull out the string and the crystals. Dry them with a blotter, and let the children observe them closely. Care should be taken to prevent the children from trying to eat these beautiful crystals, by telling them that the red and blue crystals are poisonous.

Observations-r. In which bottle did the crystals form first? Which string is the heaviest with the crystals?

2. What was the color of the water in which the blue vitriol was dissolved? Is it as brilliant in color now as it was when it was first made? Do you think that the growth of the crystals took away from the blue material of the water? Look at the blue vitriol crystals with a lens, and describe their shape. Are the shapes of the large crystals of the vitriol the same as those of the small ones?

3. What is the shape of the crystals of the potassium bichromate? What is the color? Are these crystals as large as those of the blue vitriol or of the alum?

4. What shapes do you find among the crystals of alum?

5. Do you think that vitriol and potassium bichromate and alum will, under favorable circumstances, always form each its own shape of crystal wherever it occurs in the world? Do you think crystals could be formed without the aid of water?

6. How many kinds of crystals do you know? What is rock candy? Do you think you could make a string of rock candy if you dissolved sugar in water and placed a string in it? 


\section{SALT}

\section{Teacher's Story}

A "saturated solution" is an uninspiring term to one not chemically trained; and yet it merely means water which holds as much as it can take of the dissolved substance; if the water is hot, it disso ves more of most substances. To make a saturated solution of salt we need two parts of salt or a little more, for good measure, to five parts of water; the water should be stirred until it will take up

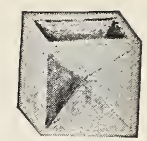

Form of a salt crystal no more salt.

A siip of paper placed in a saucer of this solution will prove a resting place for the crystals as they form. In about two days the miracle will be working, and the pupils should now and then observe its progress. Those saucers set in a draft or in a warm place will show crystals sooner than others, but the crystals will be smaller; for the faster a crystal grows, the smaller is its stature. If the water evaporates rapidly, the crystals are smaller, because so many crystals are started which do not have material for large growth. When the water is evaporated, to appreciate the beauty of the crystals we should look at them with a lens or microscope. Each crystal is a beautiful little cube, often with a pyramid-shaped depression in each face or side. After the pupils have seen these crystals, the story of where salt is found should be told them.

Salt is obtained by two methods: by mining large deposits of rock salt, and by evaporating water containing a strong solution of salt. The oldest salt works in this country are in Syracuse, New York, where the salt comes from salt springs which were famous among the American Indians. At Ithaca, N. Y., the salt deposits are about 2000 feet below the surface of the earth. Water is forced down into the stratum of rock, which was evidently once the bottom of a briny sea; the water dissolves the salt, and it is then pumped up to the surface and evaporated, leaving the salt in crystals. In Michigan and Louisiana thcre are other large salt works of a similar character. The largest salt mines in the world are those in Poland, which have been used for hundreds of years. In these mines there are fifty miles of corridors, and the salt has been carved into beautiful chambers with statues and other decorations, all cut from the solid salt. One of these chambers represents a chapel beautifully ornamented.

When the United States was first settled, salt was brought over from England; but this was so expensive that people could not afford it and they soon began to make their own salt by evaporating sea water in kettles on the beach. In those countries where it is scarce, salt is said to be literally worth its weight in gold. The necessity for salt to preserve the health of both people and animals has tempted the governments of some countries to place a special tax upon it; in Italy, especially, the poor people suffer greatly on account of the high price of salt from this cause.

Salt lakes are found in natural basins of arid lands, and are always withsut outlets. The water which runs in escapes by evaporation, but the salt it brings cannot escape, and accumulates. A salt lick is a place where salt is found on the surface of the earth, usually near a salt spring. Animals will travel a long distance to visit a salt lick which gained its name through their attentions. 


\section{LESSON CCXII}

SALT

Leading thought-Salt dissolves in water, and as the water evaporates the salt appears in beautiful crystals.

Method-Let each pupil, if possible, have a cup and saucer, a square of paper small enough to go into the saucer, some salt and water. Let each pupil take five teaspoonfuls of water and add to this two spoonfuls of salt, stirring the mixture until dissolved. When the water will take no more salt let each pupil write his name and the date on the square of paper, lay it in the saucer, pressing it down beneath the surface. Let some place their saucers in a warm place, others where they may be kept cool, and others in a draft. If it is impossible for each pupil to have a saucer, two or three pupils may be selected to perform the experiments.

Observations-r. When you pour the salt into the water, what becomes of it? How do you know when the water will hold no more salt?

2. After a saucer, filled with the salt water, stands exposed to the air for several days, what becomes of the water? From which saucers did the water evaporate fastest-those in the warm places, or those in the cold? In which did the crystals form first?

3. Which saucers contained the largest crystals- those from which the water evaporated first, or those from which it evaporated more slowly?

4. Could you see how the crystals began? What is the shape of the perfect salt crystal? Do the smallest crystals have the same shape as the largest ones?

5. What happens to people who cannot get salt to eat?

6. How is dairy salt and table salt obtained? What is rock salt? What are salt licks? Where are the salt mines found? Why is the ocean called "the briny deep?"

7. Name and locate the salt lakes. Why are lakes salt?

\section{LESSON CCXIII \\ How to Study Mineral}

Many children are naturally interested in stones. I once knew two childrer, aged seven and five, who could invariably select the boulders and pebbles of metamorphic rock in the region about Ithaca. They also could tell, when the pebbles were broken, which parts were quartz and which mica. They had incidentally asked about one of these stones, and I had told them the story of the glacial period and how these stones were torn away from the mountains in Canada and brought down by ice and dropped in Ithaca. It was a story they liked, and their interest in these granite voyagers was always a delightful element of our walks in the field.

For the pupils in the elementary grades it seems best to limit the study of minerals to those which make up our granite and common rocks. In order to teach about these minerals well, the teacher should have at least one set of labelled specimens. Such a collection may be obtained from Edward E. Howell, 6 I 2 I 7 th St., N. W., Washington, D. C., and also from 
Ward's Natural Science Establishment, College Avenue Rochester, N. Y. These collections vary in number of specimens and price from one to two dollars and are excellent. The teacher should have one or two perfect crystals of quartz, feldspar and calcite. An excellent practice for a boy is to copy these crystals in wood for the use of the teacher. follows:

The physical characteristics used in 1dentifying minerals are briefly as

I. Form. This may be crystalline, which shows the shape of the crystals definitely; granular, like marble, the grains having the internal structure, but not the external form, of crystals; compact, which is without crystalline form, as limestone or flint.

2. Color.

3. Luster or shine, which may be glassy like quartz, pearly like the inside of a shell; silky like asbestos; dull; or metallic like gold.

4. Hardness or resistance to scratching, thus: Easily scratched with the finger nail; cannot be scratched by the finger nail; easily scratched with steel; with difficulty scratched with steel; not to be scratched by steel. A pocket knife is usually the implement used for scratching.
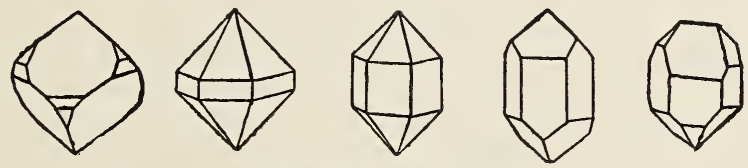

- Forms of quartz crystals.

\section{QUARTZ \\ Teacher's Story}

There is in the Cornell University Museum a great quartz crystal, a sixsided prism several inches in thickness. One-half of it is muddy and the other half clear, transparent and beautiful. The professor in charge, who has the imagination necessary to the expert crystallographer, said to his class: "This crystal was begun under conditions which made it cloudy; then something happened, perhaps some cataclysm that changed all the conditions around the half-grown crystal, and it may have lain a hundred or a thousand years unfinished, when, some other change occurring, there came about conditions which permitted it to resume growth, and the work began again exactly where it was left off, the shaft being perfected even to its six-sided pyramidal tip." And ever afterwards that crystal, half clouded and half clear, remained in the minds of his pupils as a witness of the eternal endurance of the laws which govern the growth of crystals.

Quartz is the least destructible and is one of the most abundant materials in the crust of the earth as we know it. It is made up of two elements chemically united-the solid silicon and the gas oxygen. It is the chief material of sand and sandstones, and it occurs, mixed with grains of other minerals, in granite, gneiss, and many lavas; it also occurs in thick masses or sheets, and sometimes in crystals ornamenting the walls of cavities in the rocks. Subterranean waters often contain a small amount of silica, the substance of quartz, in solution; from such solutions it may be deposited in 
fissures or cracks in the rock, thus forming bodies called "veins." Other materials are often deposited at the same time, and in this way the ores of the precious metals came to be associated with quartz. Sometimes quartz is deposited from hot springs or geysers, forming a spongy substance called sinter. In this case, some of the water is combined with the quartz, making what is called opal. Quartz crystal will cut glass.

Quartz occurs in many varieties: (a) In crystals like glass. If colorless and transparent it is called rock crystal; if smoky brown, it is called smoky quartz; if purple, amethyst. (b) In crystals, glassy but not transparent. If white, it is milky quartz; if pink, rose quartz. (c) As a compact crystalline structure without luster, waxy or dull, opaque or translucent, when polished. If bright red, it is carnelian; if brownish red, sard; if in various colors in bands, agate; if in horizontal layers, onyx; if dull red or brown, jasper; if green with red spots, bloodstone; if smoky or gray, breaking with small, shell-like or conchoidal fractures, flint.

Rock crystals are used in jewelry and especially are made to imitate diamonds. The amethyst is much prized as a semi-precious stone. Carnelian, bloodstone and agate are also used in jewelry; agate is used also in making many ornamental objects, and to make little mortars and pestles for grinding hard substances.

One of the marvels of the world is the petrified forest of Arizona, now set aside by the government as a national reserve. Great trees have been changed to agate and flint, the silica being substituted for the tissues of the wood so that the texture is preserved though the material is changed.

When our country was first settled, flint was used to start fires by striking it with steel and letting the sparks fly into dry, fine material, called tinder. It was also used in guns before the invention of cartridges, and the guns were called flintlocks. The Indians used flint to make hatchets and for tips to their arrows. The making of flint implements dates far back into prehistoric times; it was probably one of the first steps upward which man achieved in his long, hard climb from a level with the brute creation to the heights attained by our present civilization.

Quartz sand is used in making glass. It is melted with soda or potash or lead, and the glass varies in hardness according to the minerals added. Quartz is also used for sandpaper and glass paper; and ground to a fine powder, it is combined with Japans and oils and used as a finish for wood surfaces. Mineral wool is made from the slag refuse of furnaces where glass is made, and is used for rat-proof and fireproof padding for the walls of houses. Quartz combined with sodium or potassium and water, forms a liquid called water-glass, which is used for waterproof surfaces; it is also fireproof to a certain degree. Water-glass is the best substance in which to preserve eggs; one part of commercial water-glass to ten parts of water makes a proper solution for this purpose.

\section{LESSON CCXIV}

\section{QUARTZ}

Leading thought-Quartz is one of the most common of minerals. It occurs in many forms. As a crystal it is six-sided, and the ends terminate in a six-sided pyramid. It is very hard and will scratch and cut glass. When broken, it has a glassy luster and it does not break smoothly but shows an uneven surface. 
Method-The pupils should have before them as many varieties of quartz as possible; at least they should have rock crystal, amethyst, rose and smoky quartz and flint.

Observations- $\mathrm{I}$. What is the shape of quartz crystals? Are the sides all of the same size? Has the pyramid-shaped end the same number of plane surfaces as the sides?

2. What is the luster of quartz? Is this luster the same in all the different colored kinds of quartz?

3. Can you scratch quartz with the point of a knife? Can you scratch glass with a corner or piece of the quartz? Can you cut glass with quartz?

4. Describe the following kinds of quartz and their uses: amethyst, agate, flint.

5. How many varieties of quartz do you know? What has quartz to do with the petrified forests of Arizona?

\section{FELDSPAR \\ Teacher's Story}

We most commonly see feldspar as the pinkish portion of granite. This does not mean that feldspar is always pink, for it may be the lime-soda form known as labradorite, which is dark gray, brown or greenish brown, or white; or it may be the soda-lime feldspar called oligoclase, which is grayish green, grayish white, or white; but the most common feldspar of all is the potash feldspar-orthoclasewhich may be white, nearly transparent, or pinkish. Orthoclase is different from other feldspars in that, when it splits, its plane surfaces form right angles. Feldspar
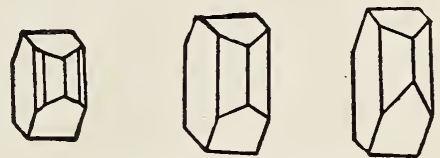

Forms of feldspar crystals. is next in the scale of hardness to quartz, and will with effort and perseverance scratch glass but will not cut it; it can be scratched with a steel point. Its luster is glassy and often somewhat pearly.

Maine leads all other states in the production of feldspar. It is quarried and crushed and ground to powder, as fine as flour, to make the clay from which china and all kinds of pottery are made. Our clayey soils are made chiefly from the potash feldspar which is weathered to fine dust. Kaolin, which has been used so extensively in making the finest porcelain, is the purest of all clays, and is formed of weathered feldspar; floor tiling and sewer pipes are also made from ground feldspar. Moonstone is clean, sodalime feldspar, whitish in color and with a reflection something like an opal.

\section{LESSON CCXV}

\section{FELDSPAR}

Leading thought-Feldspar is about five times as common as quartz. The crystal is obliquely brick-shaped, and when broken splits in two directions at right angles to each other. It is next in hardness to quartz, and will scratch glass but will not cut it.

Method-If possible, have the common feldspar (orthoclase), the sodalime feldspar (oligoclase) and the lime-soda feldspar (labradorite). 
Observations-I. What is the shape of the feldspar crystal?

2. What colors are your specimens of feldspar? How many kinds have you?

3. What is the luster of feldspar?

4. Can you scratch feldspar with the point of a knife? Can you scratch it with quartz? Can you scratch glass with it?

5. When you scratch feldspar with steel what is the color of the streak left upon it?

6. If feldspar is broken, does it break along certain lines, leaving smooth faces? At what angles do these smooth faces stand to each other?

7. How can you tell feldspar from quartz? Write a comparison of feldspar and quartz, giving clearly the characteristics of both.

8. Hunt over the pebbles found in a sand-bank. Which ones are quartz? Do you find any of feldspar?

9. When there is so much more feldspar than quartz in the earth's crust, why is there so much more quartz than feldspar in sand?

\section{MICA \\ Teacher's Story}

The mica crystal when perfect is a flat crystal with six straight edges. These crystals separate in thin layers parallel with the base. In color mica varies through shades of brown, from a pale smoked pearl to black. Its luster is pearly, and it can be scratched with the thumb nail. Its distinguishing characteristic is that the thin layers into which it splits bend without breaking and endure great heat.

Mica was used in antiquity for windows. Because it is transparent and not affected by heat, it is used in the doors of stoves and furnaces and for lamp chimneys. Its strength makes it of use for automobile goggles. Diamond dust is powdered mica, as is also the artificial snow scattered over cotton batting for the decoration of Christmas trees. When ground finely, it is used as an absorbent for nitroglycerine in the manufacture of dynamite

Mica mines are scarce in this country. There is an interesting one in North Carolina which had evidently been worked centuries before the advent of the white man in America. There are other mica mines in New Hampshire and Canada. The entire production of this mineral in the United States for the year I 908 , was valued at a little more than a quarter of a million dollars. Nearly all of this output was used in the electrical industries, since mica is one of the best insulating materials known.

\section{LESSON CCXVI}

\section{MicA}

Leading thought-Mica is a crystal which flakes off in thin scales parallel with the base of the crystal. We rarely see a complete mica crystal but simply the thin plates which have split off. The ordinary mica is light colored, but there is a black form.

Method-If it is not possible to obtain a mica crystal, get a thick piece of mica which the pupils may split off into layers. 
Observations-I. Describe your piece of mica. Pull off a lay'er with the point of your knife. See if you can separate this layer into two layers or more.

2. Can you see through mica? Can you bend it? Does it break easily? What is the color of your specimen? What is its luster? Can you cut it with a knife? Can you scratch it with the thumb nail? What color is the streak left by scratching it with steel?

3. What are some of the uses of mica? How is it especially fitted for some uses?

4. Write a theme on how and where mica is obtained.

\section{GRANITE}

\section{Teacher's Story}

In granite, the quartz may be detected by its fracture which is always conchoidal and never flat; that is, it has no cleavage planes. It is usually white or smoky, and is glassy in luster. It cannot be scratched with a knife. The feldspar is usually whitish or fleshcolored and the smooth surface of its cleavage planes shines brilliantly as the light strikes upon it; it can be scratched with a knife but this requires effort. The mica is in pearly scales, sometimes whitish and sometimes black. The scales of these mica particles may be lifted off with a knife, and it may thus be distinguished. If there are black particles in the granite which do not separate, like the mica, into thin layers, they probably consist of hornblende.

Granite is used extensively for building purposes and for monuments. It is a very durable stone but in the northeastern United States where there is much rain and cold weather, the stone decays. Mica is the

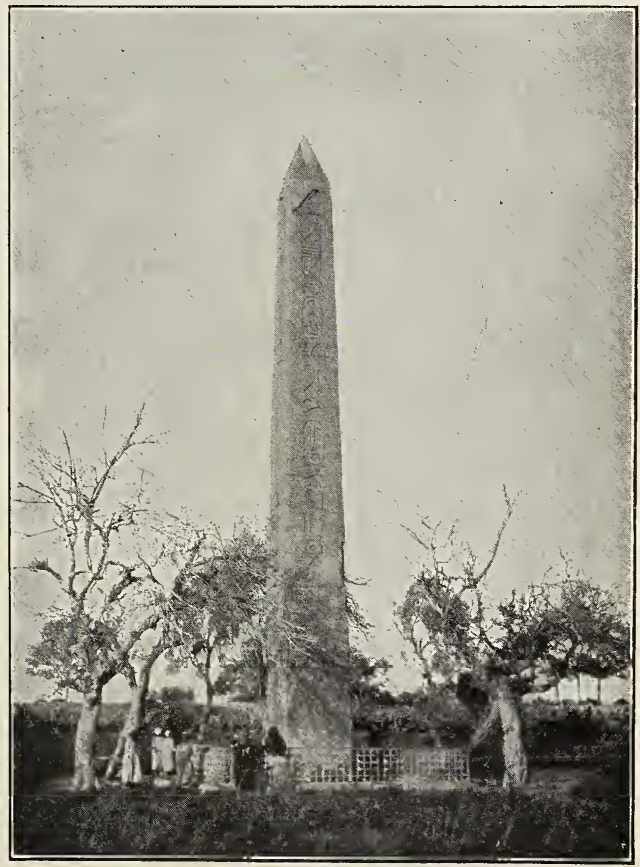

The granite obelisk still standing on the site of the anrient city of On.

Photo by J. H. Comstock. 
weakest, hornblende next, and feldspar is next to quartz, the strongest constituent of granite. Water permeates the mica, hornblende, feldspar and sometimes the quartz, and by its expansion in freezing causes the stone to crumble. The reason why polished granite endures better than the rough finished, is that the smooth surface gives less opportunity for the water to lodge and freeze. When the weathered granite is cut up into small particles by the waters of streams, they are sifted and all the parts which are soluble are carried off, leaving a sand composed of quartz and mica, which are insoluble. This sand is washed by streams into lakes, and then is dropped to the bottom; if enough is thus carried and dropped, it forms sandstone rock. All of our sandstones used for building purposes were thus laid down.

Cleopatra's Needle, which stood for thousands of years in the dry climate of Egypt, soon commenced to weather and crumble when placed in Central Park, N. Y. This shaft has a most interesting history. It was quarried near Assuan, in the most famous of all granite quarries of ancient Egypt. It was cut as a solid shaft in the quarry and carried down the Nile River for 500 miles-an engineering feat which would be hard to accomplish to-day, with all our modern appliances. It was one of the obelisks that graced the ancient city of On, later called Heliopolis, situated on a plateau near the present city of Cairo; On was the city where Moses was born and reared. There is still standing where it was first placed as a part of a magnificent temple, the temple a part of a magnificent city, one of these obelisks. It now stands alone in the m.ddle of a great fertile plain, which is vividly green with growing crops; a road shaded by tamarisk and lebbakh trees leads to it; nearby is a sakiah, creaking as the blindfolded bullock walks around and around, turning the wheel that lifts the chain of buckets from the well to irrigate the crops; and a hooded crow, whose ancestors were contemporaries of its erection, caws hoarsely as it alights on the beautiful apex of this ancient shaft, which has stood there nearly four thousand years and has seen a great city go down to dust to fertilize a grassy plain.

\section{LESSON CCXVII}

\section{Granite}

Leading thought-Granite is composed of feldspar, quartz and mica, and often contains hornblende.

Method-Specimens of coarse granite and a pocket knife are needed.

Observations-r. What minerals do you find in granite? How can you tell what these minerals are? Look at the granite with a lens. How can you tell the quartz from feldspar? Take a knife and scratch the two. Can you tell them apart in that way? How can you tell the mica? How can you tell the hornblende?

2. What buildings have you seen made of granite? What monuments have you seen made from it?

3. Which mineral in granite is especially affected by water? Which remains unharmed the longest?

4. What is weathering? Mention some of the characteristics of weathering. Why does the rough-finished granite weather sooner than that which is polished? 
5. Examine some sand with a lens. What mineral do you find present in it in the greatest quantity? York City.

5. Write the story of the Cleopatra's Needle in Central Park, New

\section{CALCITE, MARBLE AND LIMESTONE}

\section{Teacher's Story}

Calc spar, or calcium carbonate, is a mineral and is the material of which marble, limestone and chalk are made. The faces of the calcite crystal are always arranged in groups of three or multiples of three-athree-sided pyramid or two pyramids joined base to base. The pyramids may be obtuse or acute. When acute and formed of three pairs of faces, the crystals are called dog-tooth spar. The crystals appear in a great variety of forms, but they all have the common quality of splitting readily in three directions, the fragments resembling cubes which are oblique instead of rectangular. When these cleaved, or split pieces, are transparent, they are called Iceland spar. When an object is viewed through Iceland spar at least one-quarter inch thick, it appears double. The calcite crystal is often transparent with a clight yellowish tinge, but it also shows other colors; and it has a slightly cloudy or slightly pearly or almost glassy luster like feldspar. It is easily scratched with a knife and will not scratch glass. If a drop of strong vinegar or weak hydrochloric acid falls upon it, it will effervesce.

Limestone-so called because it is burned to make quicklime-was formed on the bottoms of oceans; its substance came chiefly from the skeletons of corals and the shells of other sea
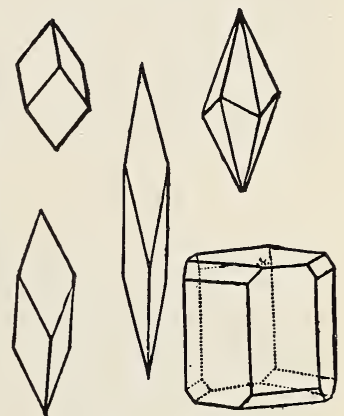

Forms of calcite crystals. creatures, since sea-shells and coral stems are pure calcium carbonate in composition. In the water, the shells and corals were broken down, and then deposited in layers on the bottom of the sea. So wherever we find limestone, we know that there was once the bottom of a great sea. Such layers of limestone are now being deposited off the shores of Florida, where corals grow in great abundance. Limestone is used extensively for building purposes, and in most climates is very durable. The great pyramids of Egypt are of limestone. It is not a good material for making roads, since it is so soft that it wears out readily, making a fine easily-blown dust. It is slowly dissolved in water, especially if the water be acid; thus, in limestone regions, there are caves where the water has dissolved out the rock; and attached to their roofs and piled upon their floors may be large icicle-shaped stalactites and stalagmites, which were made by the lime-bearing water dripping down and evaporating, leaving its burden in crystals behind it. When the roof of a cave falls in, the cavity thus made is called a sink hole and is often dangerous. The famous Natural Bridge in Virginia is all that is left of what was once the roof of such a cavern. The water in limestone regions is always hard, because of the lime which it holds in solution; and in such regions the streams usually have no 
silt, but have clean bottoms; moreover, the springs are likely to become contaminated because the water has run through long caves instead of filtering through sand.

Chalk is similar in origin to limestone; it is made up of the shells of minute sea creatures, so small that we can only see them with the aid of a microscope. Try and think how many years it must have required for the shells of such tiny beings to build up the beds which make the great chalk cliffs of England!

Marble is formed inside of the earth from limestone, under the influence of heat and pressure; it differs from limestone chiefly in that the grains are of crystalline structure, and are larger; it is usually white or gray in color, and sometimes is found in differing colors. At Cadiz in California, marble is found showing twenty or more quite different colors. The most famous marbles are the Carrara of Italy, the Parian from the Island of Paros, and the Pentelican from the mountain of that name near Athens. The reason why these marbles are so famous is that in ancient times sculptors carved beautiful statues from them, and the architects used them for building magnificent temples. The principal marble deposits in the United States are in Vermont, Georgia, Tennessee and California. Marble deteriorates when it is exposed to air which is filled with smoke and gases. It is also used to make lime. When either marble or limestone is heated very hot, it separates into two parts, one of which is lime, and the other carbonic acid gas-the same that is used for charging soda-water fountains.

\section{LESSON CCXVIII}

\section{Calcite, Marble and Limestone}

Leading thought-Calcite or calc spar is formed more than half of lime. The best known forms of its crystals are cubelike, but instead of having twelve right-angled edges, the sides are lozenge-shaped, and are set together with six obtuse angles and six acute. Dog-tooth spar is one form of calcite crystal. Limestone is a solid form of calcite. Marble is granular limestone which shows the broken crystals of calcite. Chalk is very fine, pulverized calcite.

Method-Specimens of dog-tooth spar, limestone, marble, shells of oysters or other sea creatures and coral should be provided for this lesson; also a bottle of dilute hydrochloric acid, and a piece of glass tubing about six inches long with which to drop the acid on the stones. Some strong vinegar will do instead of the acid.

Observations- $\mathrm{r}$. What is the form of the calcite crystal? What is the luster of the crystal? Is it the same as the inside of sea-shells? Will calcite scratch glass? Can you scratch it with a knife? What happens to calcite if you put a drop of weak hydrochloric acid upon it?

2. Is marble made up of crystals? Examine it with a lens to see. What is its color? Have you seen marble of other colors than white? Do you know the reason why marble is sometimes clouded and streaked?

3. Put a drop of weak hydrochloric acid on the marble. What happens?

4. What are the uses of marble? What have you ever seen made from marble? Why is it used for sculpture? What famous statues have you seen which were made of marble? Name some of the famous ancient marble buildings. 
5. Test a piece of limestone for hardness. Can you scratch it with a knife? Is it as soft as marble? Put on it a drop of acid. Does it effervesce? If there are any fossils in your piece of limestone, test them with acid and see if they will effervesce. Any other mineral that you have which will effervesce when touched with acid, is probably some form of calcite.

6. Are there any buildings in your town made of limestone? How do you know the stone is limestone? Where was it obtained? Is it affected by the weather?

7. Is limestone a good material for making or mending roads? Give a reason.

8. Why is water in limestone regions hard? Why are limestone regions likely to have caves within the rocks? How are stalactites and stalagmites formed in caves? What are sink holes? How are they formed? In what county of your state is limestone found?

9. How is the lime which is used for plastering houses made?

Io. Write a theme on how the chalk rocks are made?

II. Test a shell with acid; test a piece of coral with acid. How does it happen that these, which were once a part of living creatures, are now limestone? Of what are our own bones made?

"A great chapter in the history of the world is written in the chalk. Few passages in the history of man can be supported by such an overwhelming mass of direct and indirect evidence as that which testifies to the truth of the fragment of the history of the globe, which $I$ hope to enable you to read, with your own eyes, to-night. Let me add, that ferw chapters of human history have a more profound significance for ourselves. I weigh my words well when I assert, that the man who should know the true history of the bit of chalk which every carpenter carries about in his breeches-pocket, though ignorant of all other history, is likely, if he will think his knowledge out to its ultimate results, to have a truer, and therefore a better, conception of this wonderful universe, and of man's relation to it, than the most learned student who is deep-read in the records of humanity and ignorant of those of Nature."

"During the chalk period, or 'cretaceous epoch,' not one of the present great physical features of the globe was in existence. Our great mountain ranges, Pyrenees, Alps, Himaiayas, Andes, have all been upheaved since the chalk was deposited, and the cretaceous sea flowed over the sites of Sinai and Ararat. All this is certain, because rocks of cretaceous or still later date, have shared in the elevatory movements which give rise to these mountain chains; , and may be found perched up, in some cases, many thousand feet high upon their flanks."

-Thomas Huxley. 


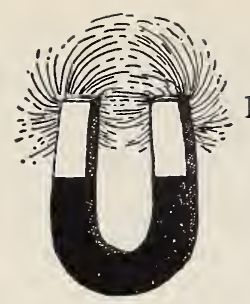

\section{THE MAGNET}

\section{Teacher's Story}

NTIL comparatively recent times, the power of the magnet was so inexplicable that it was regarded as the working of magic. The tale of the Great Black Mountain Island magnet described in the "Arabian Nights Entertainments" - the story of the island that pulled the nails from passing ships and thus wrecked themwas believed by the mariners of the Middle Ages. Professor George L. Burr assures me that this mountain of lodestone and the fear which ic inspired were potent factors in the development of Medieval navigation. Even yet, with all our scientific knowledge, the magnet is a mystery. We know what it does, but we do not know what it is. That a force unseen by us is flowing off the ends of a bar magnet, the force flowing from one end attracted to the force flowing from the other and repellent to a force similar to itself, we perceive clearly. We also know that there is less of this force at a point in the magnet half-way between the poles; and we know that the force of the magnet acts more strongly if we offer it more surface to act upon, as is shown in the experiment in drawing a needle to a magnet by trying to attract it first at its point and then along its length. That this force extends out beyond the ends of the magnet, the child likes to demonstrate by seeing across how wide a space the magnet, without touching the objects, can draw to it iron filings or tacks. That the magnet can impart this force to iron objects is demonstrated with curious interest, as the child takes up a chain of tacks at the end of the magnet; and yet the tacks when removed from the magnet have no such power of cohesion. That some magnets are stronger than others is shown in the favorite game of "stealing tacks," the stronger magnet taking them away from the weaker; it can also be demonstrated by a competition between magnets, noting how many tacks each will hold.

One of the most interesting things about a magnet is that like poles repel and opposite poles attract each other. How hard must we pull to separate two magnets that have the south pole of one against the north pole of the other! Even more interesting is the repellent power of two similar poles, which is shown by approaching a suspended magnetized needle with a magnet. These attractive and repellent forces are most interestingly demonstrated by the experiment in question $I_{3}$ of the lesson. These needles floating on cork join the magnet or flee from it, according to which pole is presented to them.

Not only does this power reside in the magnet, but it can be imparted to other objects of iron and steel. By rubbing one pole of the magnet over a needle several times, always in the same direction, the needle becomes a magnet. If we suspend such a needle by a bit of thread from its center, and the needle is not affected by the nearness of a magnet, it will soon arrange itself nearly north and south. It is well to thrust the needle through a cork, so it will hang horizontally, and then suspend the cork by a thread. The magnetized needle will not point exactly north, for the magnet poles of the earth do not quite coincide with the poles of the earth's axis.

The direction assumed by the magnetized needle may be explained by the fact that the earth is a great magnet, but the south pole of the great 
earth magnet lies near the North Pole of the earth. Thus, a magnet on the earth's surface, if allowed to move freely, will turn its north pole toward the south pole of the great earth magnet. Then, we might ask, why not call the earth's magnetic pole that lies nearest our North Pole its north magnetic pole? That is merely a matter of convenience for us. We see that the compass needle prints north and south, and the arm of the needle which points north we conveniently call its north pole.

The above experiment with a suspended needle shows how the mariner's compass is made. This most useful instrument is said to have been invented by the Chinese, at least I 400 B. C., and perhaps even longer ago. It was used by them to guide armies over the great plains, and the needle was made of lodestone. The compass was introduced into Europe about I $300 \mathrm{~A}$. D., and has been used by mariners ever since. To "box the compass" is to tell all the points on the compass dial, and is an exercise which the children will enjoy.

We are able to tell the direction of the lines of force flowing from a magnet, by placing fine iron filings on a pane of glass or a sheet of paper and holding close beneath one or both poles of a magnet; instantly the filings assume certain lines. If the two ends of a horseshoe magnet are used, we can see the direction of the lines of force that flow from one pole to the other. It is supposed that these lines of magnetic force streaming from the ends of the great earth magnet cause the Northern Lights, or Aurora Borealis.

Lodestone is a form of iron with a special chemical composition, and it is a natural magnet. Most interesting stories are told of the way the ancients discovered this apparently bewitched material, because it clung to the iron ends of their staffs or pulled the iron nails from their shoes. In the Ward's collection of minerals sent out to schools, which costs only one dollar, there is included a piece of lodestone, which is of perennial interest to the children.

Magnets made from lodestone are called natural magnets. A bar magnet or a horseshoe magnet has received its magnetism from some other magnet or from electrical sources. An electro magnet is of soft iron, and is only a magnet when under the influence of a coil of wire charged with electricity. As soon as the current is shut off the iron immediately ceases to be a magnet.

\section{LESSON CCXIX}

\section{The Magnet}

Leading thought-Any substance that will attract iron is called a magnet, and the force which enables it to attract iron is called magnetism. This force resides chiefly at the ends of magnets, called the poles. The forces residing at the opposite ends of a magnet act in opposite directions; in two magnets the like poles repel and the unlike poles attract each other. The needle of the mariner's compass points north and south, because the earth is a great magnet which has its south pole as a magnet at the North Pole of the world.

Method-Cheap toy horseshoe magnets are sufficiently good for this lesson, but the teacher should have a bar magnet, also a cheap toy compass, and a specimen of lodestone, which can be procured from any dealer in minerals. In addition, there should be nails, iron filings and tacks of both iron and brass, pins, darning needles or knitting needles, pens, etc. Each 
child, during play time, should have a chance to test the action of the magnets on these objects, and thus be able to answer for himself the questions which should be given a few at a time.

Observations - $\mathrm{I}$. How do we know that an object is a magnet? How many kinds of magnets do you know? Of what substance are the objects made which the magnets can pick up? Does a magnet pick up as many iron filings at its middle as at its ends? What does this show?

2. How far away from a needle must one end of the magnet be before the needle leaps toward it? Does it make any difference in this respect, if the magnet approaches the needle toward the point or along its length? Does this show that the magnetic force extends out beyond the magnet? Does it show that the magnetic force works more strongly where it has more surface to act upon?

3. Take a tack and see if it will pick up iron filings or another tack. Place a tack on one end of the magnet, does it pick up iron filings now? What do you think is the reason for this difference in the powers of the tack?

4. Are some magnets stronger than others? Will some magnets pull the iron filings off from others? In the game of "stealing tacks," which can be played with two magnets, does each end of the magnet work equally well in pulling the tacks away from the other magnet?

5. Pick up a tack with a magnet. Hang another tack to this one end to end. How many tacks will it thus hold? Can you hang more tacks to some magnets than to others? Will the last tack picked up attract iron filings as strongly as the first next to the magnet? Why? Pull off the tack which is next to the magnet. Do the other tacks continue to hold together? Why? Instead of placing the tacks end to end, pick up one tack with the magnet and place others around it. Will it hold more tacks in this way? Why? If a magnet is covered with iron filings will it hold as many tacks without dropping the filings?

6. Take two horseshoe magnets and bring their ends together. Then turn one over and again bring the ends together. Will they cling to each other more or less strongly than before? Bring two ends of two bar magnets together; do they hold fast to each other? Change ends with one, now do the two magnets cling more or less closely than before? Does this show that the force in the two ends of a magnet is different in character?

7. Magnetize a knitting needle or a long sewing needle by rubbing one end of a magnet along its length twelve times, always in the same direction, and not back and forth. Does a needle thus treated pick up iron filings? Why?

8. Suspend this magnetized needle by a thread from some object where it can swing clear. When it finally rests does it point north and south or east and west?

9. Bring one end of a bar magnet or of a horseshoe magnet near to the north end of the suspended needle; what happens? Bring the other end of the magnet near the north end of the needle; what happens?

ro. Magnetize two needles so that their eyes point in the same direction when they are suspended. Then bring the point of one of these needles toward the eye of the other, what happens? Bring the eye of one toward the eye of the other, what happens? When a needle is thus magnetized the end which turns toward the north is called the north pole, and the end pointing south is called the south pole. 
I I. Try this same experiment by thrusting the needles through the top of a cork and float them on a pan of water. Do the north poles of these needles attract or repel each other? Do the south poles of these needles attract or repel each other? If you place the north pole of one needle at the south pole of the other do they join and make one long magnet pointing north and south?

I2. Take a pocket compass; place the north end of one of the magnetized needles near the north arm of the compass needle; what happens? Place the south pole of the needle near the north arm of the compass needle, what happens? Can you tell by the action of your magnet upon the compass needle which end of your magnet is the north pole and which the south pole?

I3. Magnetize several long sewing needles by rubbing some of them toward the eye with the magnet and some from the eye toward the point. Take some small corks, cut them in cross sections about one-fourth inch thick, thrust a needle down through the center of each leaving only the eye above the cork. Then set them afloat on a pan of water. How do they act toward each other? Try them with a bar magnet first with one end and then with the other, how do they act?

I4. Describe how the needle in the mariner's compass is used in navigation.

I 5. Place fine iron filings on a pane of glass or on a stiff paper. Pass a magnet underneath; what forms do the filings assume? Do they make a picture of the direction of the lines of force which come from the magnet? Describe or sketch the direction of these lines of force, when the poles of a horseshoe magnet are placed below the filings. Place two similar poles of a bar magnet beneath the filings; what form do they take now?

r6. What is lodestone? Why is it so called?

r 7. What is the difference between lodestone and a bar magnet? What is an electro magnet?

I8. Write an English theme on "The Discovery and Early Use of the Mariner's Compass."

Supplementarv reading-Electrical Experiments, Bonney; The Wonder Book of Magnetism, Houston; "The Third Royal Calendar" from Arabian Nights Entertainments.

\footnotetext{
"Now, chief of all, the magnet's power I sing, And from what laws the attractive functions spring;

The magnet's name the observing Grecians drew

From the magnetic regions where it grew;

Its viewless potent virtues men surprise,

Its strange effects they view with wondering eyes,

When, without aid of hinges, links, or springs,

$A$ pendant chain we hold of steely rings

Dropt from the stone-the stone the binding source,-

Ring cleaves to ring, and owes magnetic force:

Those held superior, those below maintain,

Circle 'neath circle downward draws in vain,

Whilst free in air disports the oscillating chain."
}

- "De Rerum Naturae," Lucretius, 93-52 B. C. 


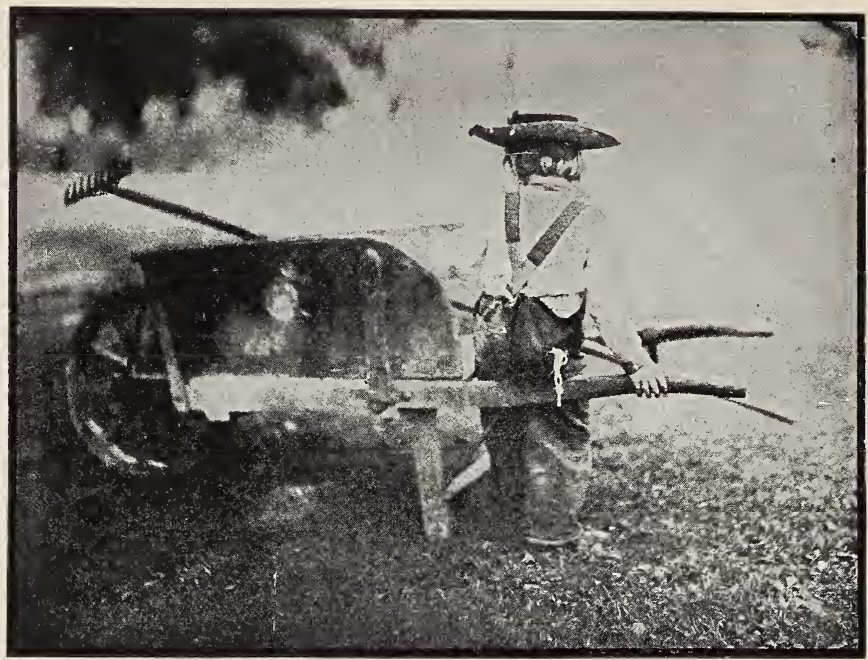

A tiller of the soil.

\section{THE SOIL}

\section{Teacher's Story}

The soil is the sepulcher and the resurrection of all life in the past. The greater the sepulcher the greater the resurrection. The greater the resurrection the greater the growth. The life of yesterday seeks the earth to-day that new life may come from it tomorrow. The soil is composed of stone flour and organic matter (humus) mixed; the greater the store of organic matter the greater the fertility.-JoHn WaLton SPENCER.

Because the child, after making mud pies, is told that his face is dirty, he naturally concludes that all soil is dirt. But it is only when out of place that it is dirt; for, in place, it is the home of miracles-the matrix from which comes that wonderful force which we call life. After the study of the brook, the crystals, the minerals and the rocks, the pupils are ready for a more careful study of the soil. However, most of the study in soils belongs to agriculture rather than to nature-study.

\section{The Soil Makers}

If we could go back to the very beginning, we should find that the soil consisted solely of broken off particles of rock-particles so finely ground by nature's forces that we might properly call them "rock flour." In our study of the brook, we noted that those stones with sharp corners were just beginning their experience in the brook mill, and those that were rounded out, forming pebbles, had their corners ground off in the making of the soil grist. And in the work of the brook we saw how this grinding was done, and how the soil grist is sifted, sorted, carried and dropped. 
But there are other agencies besides water that help in grinding the stone flour. If we visit some rocky cliff, we are sure to find at its base a heap of stones, gravel and soil, which the geologists call talvs. In our eastern country we know that these pebbles and soil were pried loose by Jack Frost with his ice wedges. The water filters into all the cracks and crevices of the rock, and since water, when freezing, is obliged to expand, the particles of rock were thereby torn loose and forced off and fell to the bottom of the cliff. Moreover, rocks expand when hot, and are often thus broken without the aid of water and frost. In the rocks of the desert, the changes in temperature pry off the rock particles, which the winds carry away to make up the sands of the desert. The winds hurl these sands against other rocks which are still standing, and hurl them with such force that more particles are torn off, making more sand. In fact, the wind, in some regions, grinds the rocks into stone flour as effectually as does the water in other

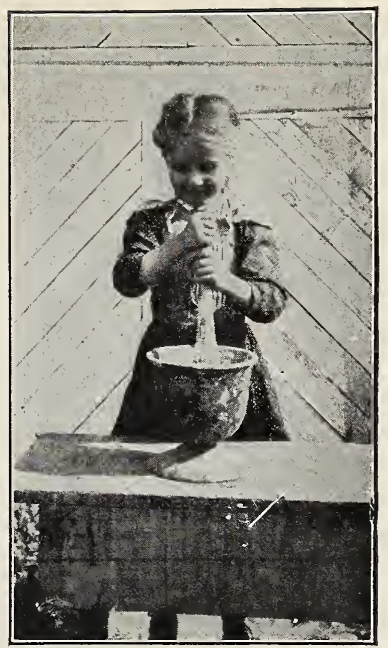

One of Uncle John's nieces making stone flour.

places. Then, too, the gases of the air also cause rocks to decay. We know how iron rusts and falls to pieces through contact with the gases of the air. Some rocks decompose in a similar way. We often see that the inscriptions on old headstones have been almost obliterated, because the gases in the air have so decomposed the marble.

In addition to the other soil makers, there are the little plants which we call lichens. The spores of these plants are so minute that we cannot see them, and they drift about in the air until they find resting place upon some rock. Here they begin to grow, and as they grow they become strongly acid; they are thus enabled to eat a foothold into the rock, softening its

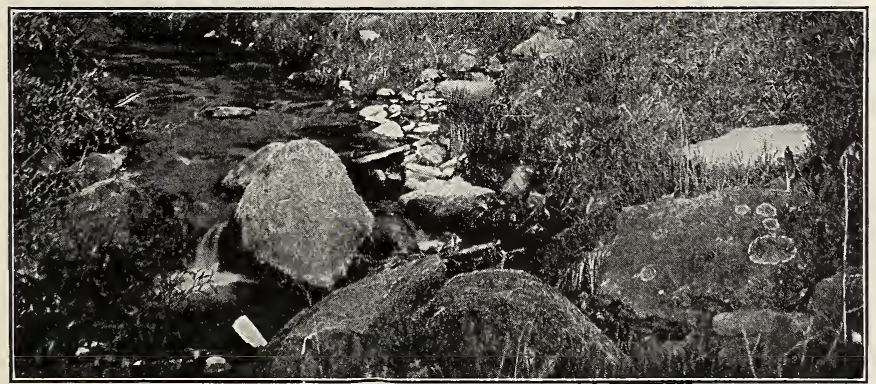

Lichens growing on rocks.

Photo by Verne Morton, 
surface and powdering it into stone flour. And in these situations other plants grow later, sending their roots down into every crack and orevice and thus prying off more of the rock.

\section{The Soil Carriers}

In the study of the brook we have seen how the water lifts, carries and deposits the soils; and since, at one time or another, the entire surface of the earth has been under water, we can see that water has been the most important of the soil carriers and has done the greatest work. The wind carries much soil, especially in the arid regions; the movements of the sand dunes in the deserts and on the seashores bear witness to what the wind can do as a soil carrier. But in the northern United States, from New England to the Dakotas, much of our soil has been carried by a great ice river that once upon a time flowed down upon our lands from the North. This great, slow-moving river, perhaps a mile or more high, plowed up the soil and stones, and freezing them fast carried and shoved them along under its great weight. After a time the ice melted and cropped its burden. Many of the stones were of granite taken up from the old mountains of northern Canada and ground off and rounded during their journey. We call these stones which were brought down to us from the North, "boulders;" and the soils which were brought along on the bottoms of glaciers and dropped and pressed down by the tremendous ice weight and thus made compact although unsorted, we call "hardpan."

\section{The Kinds of Soil}

By the work of these soil makers and soil carriers, the rock flour was made. But if we should take some of it and plant our seeds in it, we should find that they would not grow thriftily, even though we watered them and gave them every care. The reason for this is that most rock flour does not have in it the substances which the plants most need for their growth. But if we should go to the woods and get some of the black woods-earth and mix it with rock flour, we should find that our plants would thrive. This rich, earth mold in the forest is almost wholly made up of matter once alive, but which is now decayed, and which we call "humus." The more humus that we have in the rock flour, the richer it is in plant food, and the more plant. growth it will support.

In general, soils may be divided into clay, sand, gravel, loam and humus.

Clay in its purest state is kaolinite, the result of weathering of feldspar, or mica. It is finely powdered and is used for pottery, while the less pure clays are used for brickmaking. Clayey soil is sticky and slippery when wet, and bakes hard and cracks when dry. It is hard to cultivate, but it absorbs moisture from the air and holds fast to its fertility, and is especially good for permanent pastures and meadorvs.

Sand, in a pure state, is made up mostly of finely broken particles of quartz and feldspar, and is used for the making of glass. A sandy soil is light and open and easy to work. It absorbs little water from the air and has little power for holding plant food, since the water washes it out. It is especially valuable for truck gardening, because it is a warm soil. It is warm because water does not evaporate from its surface rapidly. 
Humus is composed of decayed animal and vegetable matter. It is very rich in plant food. Wherever there is humus in the soil it is likely to be darker in color than the stone flour.

Loam is a mixture of clay, sand and humus. For many crops it is the most desirable soil.

\section{LESSON CCXX}

\section{THe Soll}

Leading thought-The soil is composed of rock flour and humus. Soil, to support life, must be porous, so that the roots of the plants may receive through it both water and air.

Method-The children should bring in specimens of soils from various localities near the school. Parts of each specimen should be wet to see if they are clayey, that quality showing quickly in the puttylike adhesiveness 'when rubbed between the fingers. It would be well to get some pure blue zlay, and let the children make marbles of it to impress upon them this quality of clay. They should try and make marbles of other soils to show the lack of adhesiveness in them. They should examine sand through a lens and should examine humus in a similar way. After they are familiar with these three kinds of soils, they are ready for the lesson.

Observations-I. Look at any kind of soil with a lens, and tell why you think it is made up of small pieces of stone and rock.

2. Take a piece of rock and pound it fine. What does it look like? Do you think that your plants will grow weil if you plant them in the rock flour which you have just made? Try the experiment and describe the results.

3. How does the water grind off the stones and make soil? How does the wind do it?

4. How do water and frost pry off pieces of rock. Is there a cliff in your neighborhood that has at its foot a heap of soil and stones? Where did these comes from?

5. How do the lichens and other plants pry off the outside of rocks? Have you ever found lichens growing on stones?

6. Have you ever noticed old headstones in the cemetery that were falling to pieces? What causes them to decay?

7. Write an English theme or the great glacier that formerly covered the northeastern portion of the United States.

8. Go to the woods, scrape off the leaves and get some of the black earth beneath them. Of what is this soil composed? Is it rock flour? What makes it so black? Why do you call this soil rich? What does it do if you add it to the soil in the pots where your flowers are growing?

9. Find a railroad cut or some other place where the earth is exposed for some distance up and down. Is there solid rock at the bottom? How deep is the soil above the rock? Is the soil the same color at the surface as it is below?. Why is this?

Io. Experiment 1: To show which kinds of soil hold most water-Take three lamp chimneys, or bottles from which the bottoms have been broken. Place in one loam in another clay, in another fine-grained sand, using in each case the same amount. Tie cheesecloth over the bottom, so that the soil will not fall out; make the soil compact by jarring down. Place each over a tumbler. From a cup of water, held as near as possible to the soil, pour water into one of the bottles slowly, so as to keep the surface of the soi] 
covered. Consult a watch and note how long before the water begins dripping below. Do the same with the other two. Compare the results. Which soil takes the water most rapidly? Which lets it through first? Which lets through the most? How would rain affect fields of clayey soil? Of sandy soil? Of loam?

Hints for teacher on Experiment No. I-Through sand the water passes very rapidly - in less than a minute if the sand is coarse. It takes several minutes (I $4 \mathrm{~min}$.) to go through loam, but requires some hours to appear below the clay. It requires more water to saturate clay. Care should be taken to use the same amount of water on the three kinds of soil. More than one application will be required for clay, since the amount of water

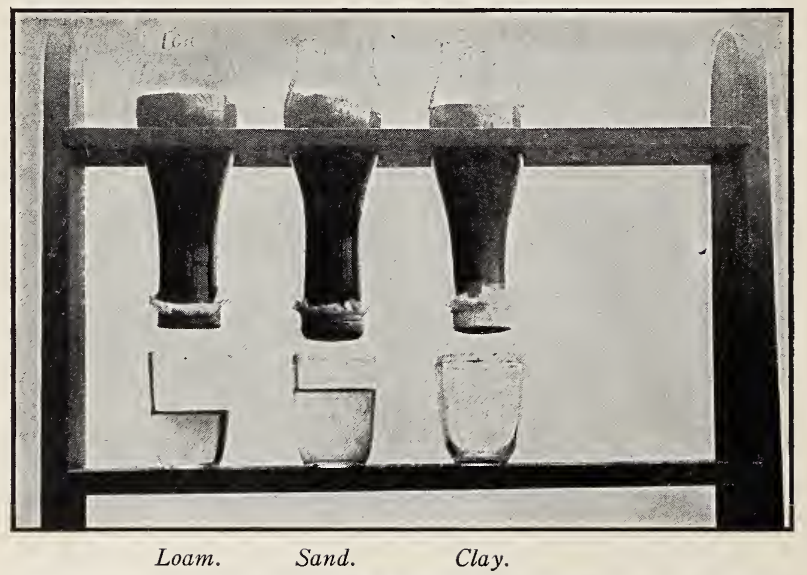

Note that the sand has allowed the most water to drip through it, the loam next, while no water has passed through the clay.

accommodated in the chimney above the soil will not be sufficient to saturate clay.

More water will be found to have percolated through sand than through loam or clay. The latter are more retentive of moisture than is sand, although absorbing rain less readily than sand. The mixture of sand and clay in loam is most ideal for cultivated fields, absorbing moisture more readily than clay and retaining it better than sand.

Experiment 2-Fill a glass tumbler with very small marbles or buckshot. Pour water over them to fill the glass. Placing cheesecloth over the top of the tumbler pour off all the water that easily drains away. Remove the cheesecloth, and immediately examine the marbles for the film of water which surrounds each one and can clearly be seen where one marble comes in contact with another marble or the side of the glass.

Hints for teacher on Experiment 2-It is sucn a film of water as remains on the marbles that on each particle of soil supplies the plant with water and food. The water between the marbles has been drained off. This water corresponds to that carried out of the soil by drainage; it is injurious to the plant, keeping "its feet too wet," and should be removed. 
Experiment 3-To show that soil lifts water up from below-Use the same soils arranged in the same way as for Experiment I, but instead of pouring water in at the top, place the three lamp chimneys in a pan which has water in it about an inch deep. In which soil does the water rise most rapidly? In which does it rise the highest? After the water has been taken up, let the soil stand in the lamp chimneys for several days. Which soil dries out the soonest? If we had three fields, one of loam, one of clay, and one of sand, in which would the most water be lifted from below for the use of the plants? Which would retain the water longest?

Hints for teacher on Experiment 3 -Water rises through the sand in a short time; if rather fine sand is used it requires less than half an hour. To rise through loam it will require three or four times as long, and may

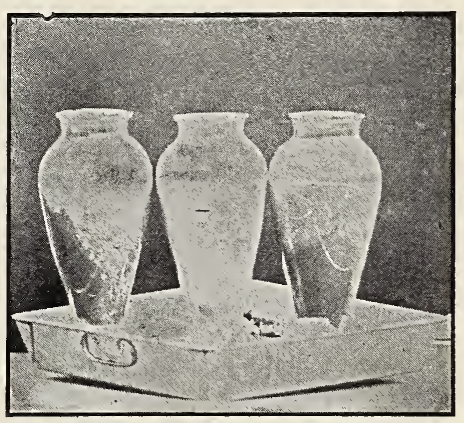

Sand. Clay. Loum.

The water has nearly reached the upper surface of the sand and is halfway up the loam; in the clay it has climbed but a short distance. not reach the top of the clay for several days. If the glass tubes were three or four feet long and allowed to stand for several days, we would find that although the water climbs very slowly through the clay it will climb to a greater height in clay than

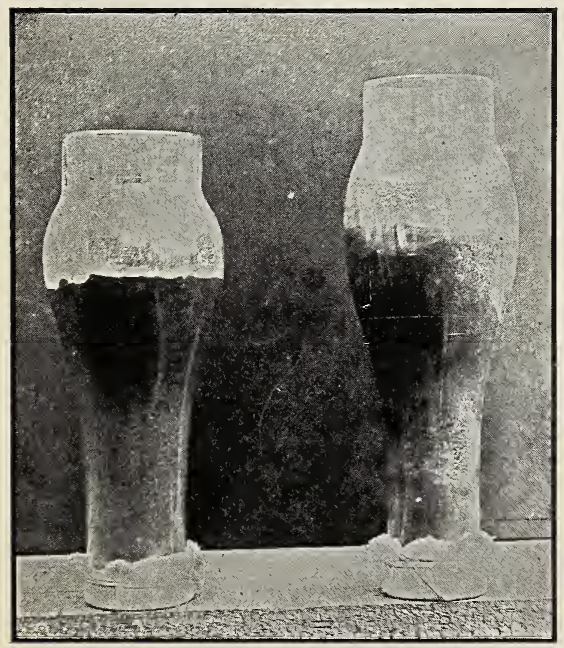

The unmulched loam in the chimney at the left dried out in four days. The loam covered with a dust mulch in the other chimney retained moisture for a month. in loam or sand. Under field conditions clay will retain moisture for a longer time than sand or loam.

Experiment 4-To show that mulch keeps the water from evaporating from soils-Take two of the lamp chimneys filled half full with loam. Pour in the same amount of water in each until the soil is thoroughly wet. Cover the top of one with an inch deep of dry, loose earth. Which dries out first? What does the loosening and pulverizing of the soil in our fields by harrowing do for our planted crops? What is a mulch?

Hints for teacher on Experiment 4-The soil covered with a layer of dry soila dust mulch - will retain moisture much longer than the unmulched soil. Hence, the farmer or gardener loosens 
and pulverizes the top soil by harrowing, hoeing or raking in order to retain moisture for plant roots. A mulch may also be of straw, boards, leaves or stones. Fallen leaves form a natural mulch in the woods. There, at any time, under this covering, may be found moist earth. A mulch is a soil cover which breaks the capillary connection, so that water will not rise to the surface to be evaporated. To be efficient a mulch must be $d r y$. After rain the "dust blanket" on the garden bed should be renewed by cultivation.

Experiment 5-Fill several vials with different soils from fields in the neighborhood. If the soil in any of the vials is dry, moisten it. Take a piece of blue litmus paper and press down into the soil in each vial. Does the litmus paper turn red as it becomes dampened by the soil in any of the vials? If so, this soil is acid. Add a little lime and mix it in thoroughly with the soil in the vial that shows the acid soil. Test it again with the litmus paper. Does the paper remain blue or turn red? Does alfalfa and clover grow on acid soils? Why should we add lime to such soils?

Hints for teacher on Experiment 5-A slightly acid soil may show no reaction with litmus paper. It may be well to have a prepared soil wiih a few drops of vinegar or other acid added, which will show the reaction. The addition of lime will correct the acid condition. Soils for alfalfa or

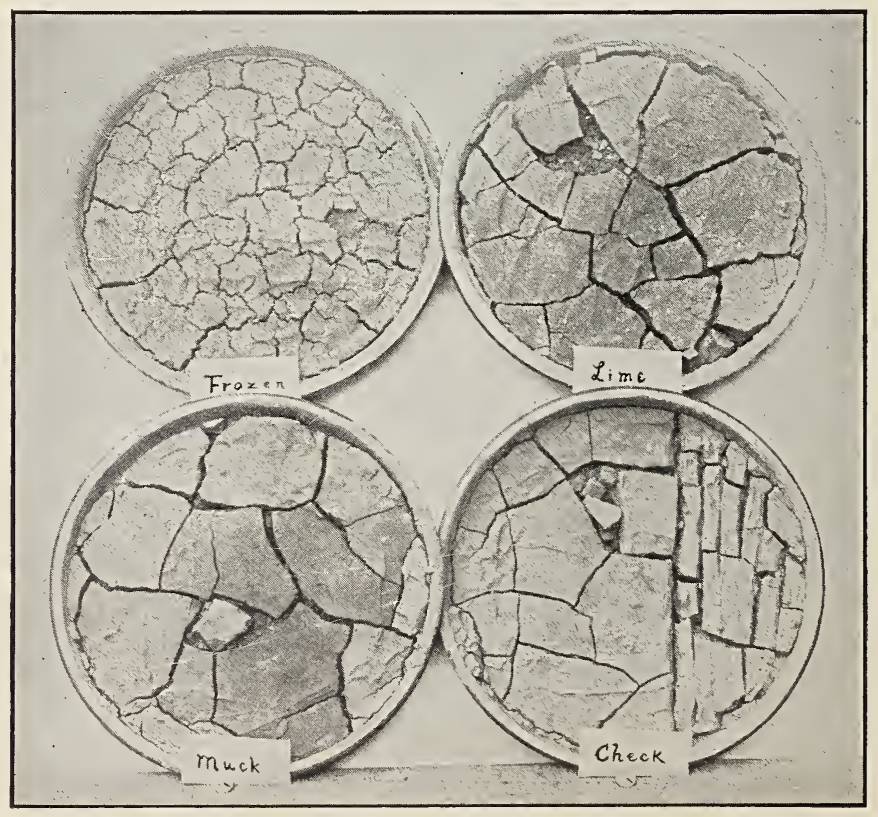

Experiment to show the proper treatment of clay soil. 
clover should never be acid. They are usually well limed before an attempt is made to grow these legumes.

Experiment 6, which indicates the proper treatment of clay soils-Fill four pie tins with clay which has been wet and smoothly puddled. In one mix with the clay a small portion of lime; in another add a larger portion of muck; leave two with pure clay, and place one of these out-of-doors where it will freeze hard. Then place the four tins on a shelf and allow to dry. In which of these is the clay most friable? In which is it the hardest?

Hints to the teacher on Experiment 6-This experiment shows that freezing the clay rendered it finer, so that it may be broken easily into particles small enough to set closely about the plant's roots. The clay mixed with lime is much more friable than the one mixed with muck, showing that clay needs lime more than organic matter to make it of greatest use. The pure clay which is dried without freezing hardens into large, flat pieces,, each being almost as hard as stone.

Supplementary reading-Ch. I, II, III in The Great World's Farm, Gaye: Cr. IV. in Practical Forestry, Gifford.

Beside the moist clods the slender flags arise filled with the sweetness of the earth. Out of the darkness-under that darkness: whi'h knows no day save when the ploughsiare opens its chinks-they have come to the light. To the light they have brought a colour which will autract the sunbeams from now till ha:vest.-RICHARD JEFFERIES.

"Here is a problem, a wonder for all to see.

Look at this marirelous thing I hold in my hand!

This is a magic surprising, a mystery

Strange as a miracle, harder to understand.

What is it? Only ir handful of dust: to your touch A dry, rough pouder you trample beneath your feet,

Dark and lifeless; but think for a moment, how much It hides and holds that is beautiful, bitter, or sweet.

Think of the glory of colorl The red of the rose, Green of the myriad leaves and the fields of grass,

vellow as bright as the sun where the daffodil blows, orple where viol ts nod as the breezes pass.

Strang, that this lifeless thing gives vine, flower, tree, Color and shape and character, fraçance too;

That the timber that builds the house, the ship for the sea, Out of this powder its strength and its toughness drew!"

-From "Dust," Celia Thaxter.

Some years ago there was receis:d at Cornell University a letter from a boy working upon a farm in Canada. In this letter 2 e said:

'I have read your leaflet entitled, 'The Soil, What It Is,' and as I trudged up and down the furrows every stone, every lump f earth, every shady knoll, every sod hollow had for me a new interest. "The day passed, the work was done, and I at least had had a rich experience." 


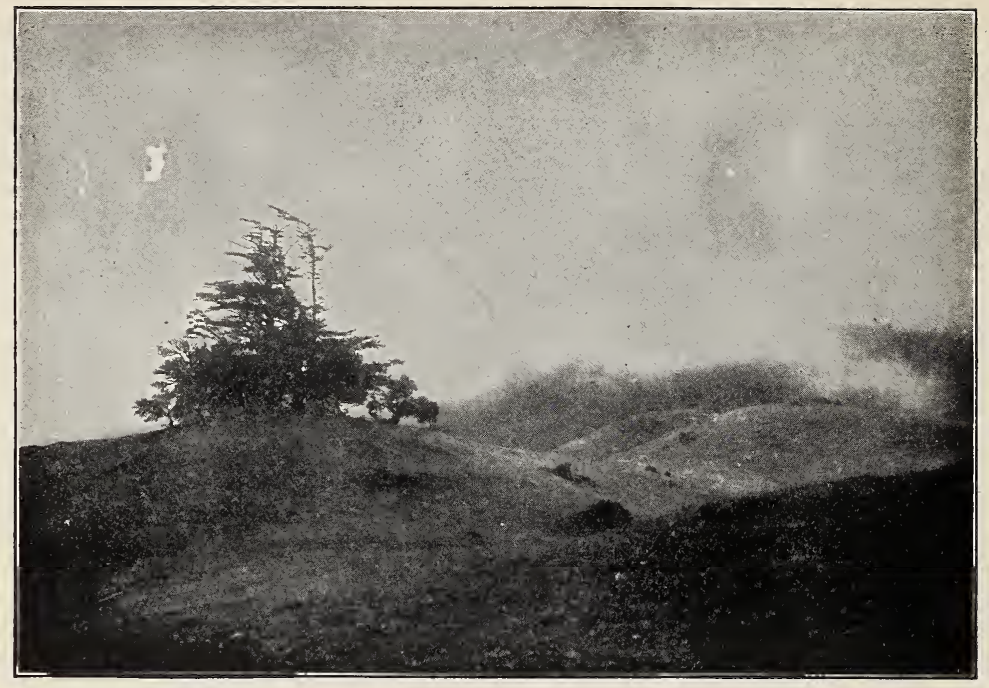

Fog on Mount Tamalpais, California.

Photo by G. K. Gilbert.

WATER FORMS

\section{Teacher's Story}

Water, in its various changing forms, is an example of another overworked miracle - so common that we fail to see the miraculous in it. We cultivate the imagination of our children by tales of the Prince who became invisible when he put on his cap of darkness, and who made far journeys through the air on his magic carpet. And yet no cap of darkness ever wrought more astonishing disappearances than occur when this most common of our earth's elements disappears from under our very eyes, dissolving into thin air. We cloak the miracle by saying "water evaporates," but think once of the travels of one of these drops of water in its invisible cap! It may be a drop caught and clogged in a towel hung on the line after washing, but as soon as it dons its magic cap, it flies off in the atmosphere invisible to our eyes; and the next time any of its parts are evident to our senses, they may occur as a portion of the white masses of cloud sailing across the blue sky, the cloud which Shelley impersonates:

"I am the daughter of Earth and Water, And the nursling of the Sky;

I pass through the pores of the ocean and shores:

I change, but I cannot die."

We have, however, learned the mysterious key-word which brings back the vapor spirit to our sight and touch. This word is "cold." For if our drop of water, in its cap of darkness, meets in its travels an object which is 
cold, straightway the cap falls off and it becomes visible. If it be a stratum of cold air that meets the invisible wanderer, it becomes visible as a cloud, or as mist, or as rain. If the cold object be an ice pitcher, then it appears as drops on its surface, captured from the air and chained as "flo'ving tears" upon its cold surface. And again, if it be the cooling surface of tri' earth at night that captures the wanderer, it appears as dew.

But the story of the water magic is only half told. The cold brings back the invisible water vapor, forming it into visible drops; but if it is cold enough to freeze, then we behold another miracle, for the drops are changed to crystals. The cool window-pane at evening may be dimmed with mist caught from the air of the room; if we examine the mist with a lens we find it composed of tiny drops of water. But if the night be very cold, we find next morning upon the window-pane exquisite ferns, or stars, or trees, all formed of the crystals grown from the mist which was there the night before. Moreover, the drops of mist have been drawn together by crystal magic, leaving portions of the glass dry and clear.

If we examine the grass during a cool evening of October we find it pearled with dew, wrung from the atmosphere by the permeating coolness of the surface of the ground. If the following night be freezing cold, the next morning we find the grass blades covered with the beautiful crystals of hoar frost.

If a raincloud encounters a stratum of air cold enough to freeze, then what would have been rain or mist comes down to us as sleet, hail or snowflakes, and of all the forms of water crystals, that of snow in its perfection is the most beautiful; it is, indeed, the most beautiful of all crystals that we know. Why should water freezing freely in the air so demonstrate geometry by forming, as it does, a star with six rays, each set to another, at an angle of 60 degrees? And as if to prove geometry divine beyond cavil, sometimes the rays are only three in number - a factor of six-and include angles of twice 60 degrees. Moreover, the rays are decorated, making thousands of intricate and beautiful forms; but if one ray of the six is ornamented with additional crystals the other five are decorated likewise. Those snow crystals formed in the higher clouds and, therefore, in cooler regions may be more solid in form, the spaces in the angles being built out to the tips of the rays including air spaces set in symmetrical patterns: and some of the crystals may be columnar in form, the column being six-sided. While those snow crystals formed in the lower currents of air, and therefore in warmer regions, show their six rays marvellously ornamented. The reason why the snow crystals are so much more beautiful ard perfect than the crystals of hoar frost or ice, is because they are formed from water vapor, and grow freely in the regions of

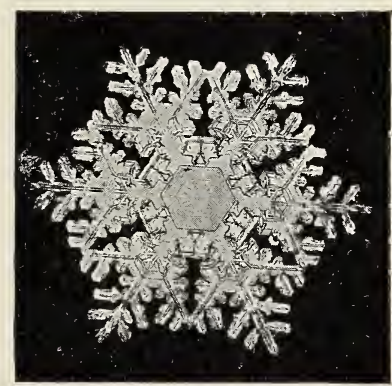

Composite snow crystal formed in high and medium clouds.

Photomicrograph by W. A. Bentley. the upper air. Mr. W. A. Bentley, who has spent many years photographing the snow crystals, has found more than I 300 distinct types. 


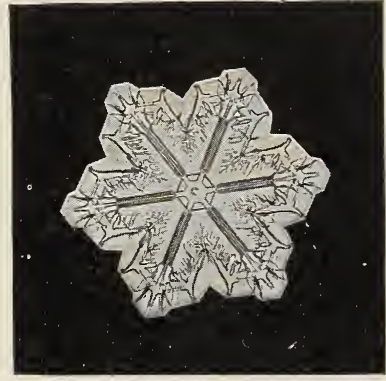

Snow crystal formed in high clouds.

Photomicrograph by W. A. Bentley.

The high clouds are composed of ice crystals formed from the cloud mists; such ice clouds form a halo when veiling the sun or the moon.

When the water changes to vapor and is absorbed into the atmosphere, we call the process evaporation. The water left in an open saucer will evaporate more rapidly than that in a covered saucer, because it comes in contact with more air. The clothes which are hung on the line wet, dry more rapidly if the air is dry and not damp; for if the air is damp, it means that it already has almost as much water in it as it can hold. The clothes will dry more rapidly when the air is hot,

because hot air takes up moisture more readily and holds more of it than does cold air. The clothes will dry more rapidly on a windy day, because more air moves over them and comes in contact with them than on a still day.

If we observe a boiling teakettle, we can see a clear space of perhaps an inch or less in front of the spout. This space is filled with steam, which is hot air saturated with hot water vapor. But what we call "steam" from a kettle, is this same water vapor condensed back into thin drops of water or mist by coming into contact with the cooler air of the room. When the atmosphere is dry, water will boil away much more rapidly than when the air is damp.

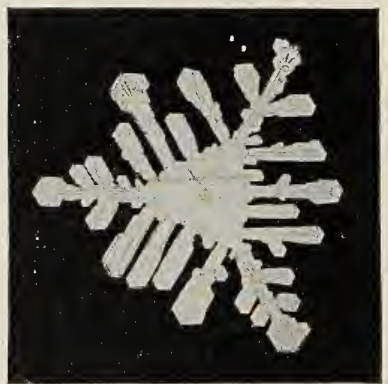

Blizzard type of snow crystal formed in low cloud.

Photomicrograph by W. A. Bentley.

The breath of a horse, or our own breath, is invisible during a warm day; but during a cold day, it is condensed to mist as soon as it is expelled from the nostrils and comes in contact with the cold air. The one who wears spectacles finds them unclouded during warm days; but in winter the glasses become cold out of doors, and as soon as they are brought into contact with the warmer, damp atmosphere of a room, they are covered with a mist. In a like manner, the window-pane in winter, cooled by the outside temperature, condenses on its inner surface the mist from the damp air of the room.

The water vapor in the atmosphere is invisible, and it moves with the air currents until it is wrung out by coming into contact with the cold. The air thus filled with water vapor may be entirely clear near the surface of the earth; but, as it rises, it comes in contact with cooler air and discharges its vapor in the form of mist, which we call clouds; and if there is enough vapor in the air when it meets a cold current, it is discharged as rain and falls back to the earth. Thus, when it is very cloudy, we think it will rain, because clouds consist of mist or fog; and if they are subjected to a colder temperature, the mist is condensed to rain. Thus, often in moun- 
tainous regions, the fog may be seen streaming and boiling over a mountain peak, and yet always disappears at a certain distance below it. This is because the temperature around the peak is cold and condenses the water vapor as fast as the wind bringsit along, but the mist passes over and soon meets a warm current below and, presto, it disappears! It is then taken back into the atmosphere. The level base of a cumt1lus cloud has a stratum of warmer air below it, and marks the level of condensation.

At the end of the day, the surface of the ground cools more quickly than the air above it. If it becomes sufficiently cold and the air is damp, then the water from it is condensed and dew is formed during the night. However, all dew is not always condensed from the atmosphere, since some of it is moisture pumped up by the plants, which could not evaporate in the cold night air. On windy nights, the stratum of air cooled by the surface of the earth is moved along and more air takes its place, and it therefore does not become cold enough to be obliged to yield up its water vapor as dew. If the weather during a dewy night becomes very cold, the dew becomes crystallized into hoar frost. The crystals of hoar frost are often very beautiful and are well worth our study.

The ice on the surface of a still pond begins to form usually around the edges first, and fine, lancelike needles of ice are sent out across the surface. It is a very interesting experience to watch the ice crystals form on a shallow pond of water. This may easily be seen during cold winter weather. It is equally interesting to watch the formation of the ice crystals in a glass bottle or jar. Water, in crystallizing, expands, and requires more room than it does as a fluid; therefore, as the water changes to ice it must have more room, and
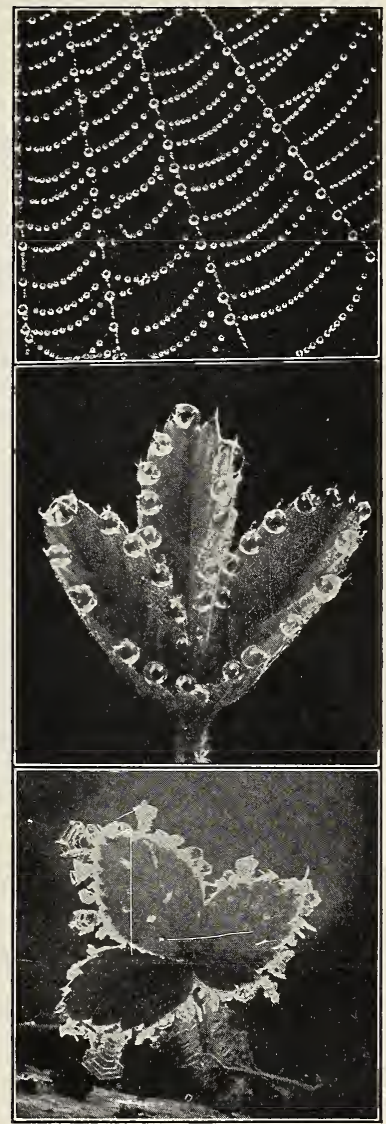

Dew on spider's web; Dewdrops on strawberry leaf; Hoar frost on strawberry leaf.

Photographs by W. A. Bentley. often presses so hard against the sides of the bottle as to breakit. The ice in the surface soil of the wheat fields expands and buckles, holding fast in its grip the leaves of the young wheat and tearing them loose from their roots; this "heaving" is one cause for the winter-killing of wheat. Sleet consists of rain crystallized in the form of sharp needles. Hail consists of ice and snow compacted together, making the hard, more or less globular hailstones. 


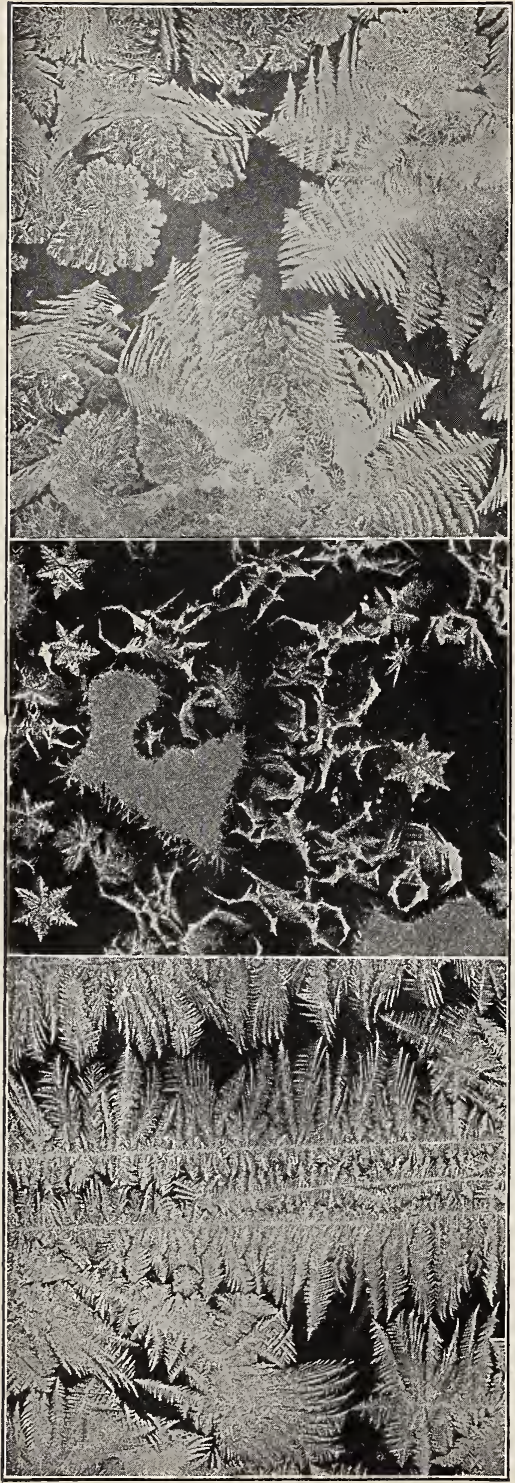

Frost crystals on window-pane.

Photo by W. A. Bentley.

\section{LESSON CCXXI \\ WATER FORMS}

Leading thought-Water occurs as an invisible vapor in the air and also as mist and rain; and when subjected to freezing, it crystallizes into ice and frost and snow.

Method-The answers to the questions of this lesson should, as far as possible, be given in the form of a demonstration. All of the experiments suggested should be tried, and the pupils should think the matter out for themselves. In the study of the snow crystals a compound microscope is a great help, but a hand lens will do. This part of the work must be done out of doors. The most advantageous time for studying the perfect snow crystals is when the snow is falling in small, hard flakes; since, when the snow is soft, there are many crystals massed together into great fleecy flakes, and they have lost their original form. The lessons on frost or dew may be given best in the autumn or spring.

Observations-I. Place a saucer filled with water near a stove or radiator; do not cover it nor disturb it. Place another saucer filled with water near this but cover it with a tight box. From which saucer does the water evaporate most rapidly? Why?

2. We hang the clothes, after they are washed, out of doors to dry; what becomes of the water that was in them? Will they dry more rapidly during a clear or during a damp day? Why? Will they dry more rapidly during a still or during a windy day? Why? Will they dry more rapidly during hot or cold weather? Why?

3. Watch a teakettle of 
water as it is boiling. Notice that near its spout there is no mist, but what we call steam is formed beyond this. Why is this so? What is steam? Why does water boil away? Do kettles boil dry sooner on some days than on others? Why?

4. If the water disappears in the atmosphere where does it go? Why do we say "the weather is damp"? What force is it that wrings the water out of the atmosphere?

5. Why does the breath of a horse show as a mist on a cold day? Why do persons who wear spectacles find their glasses covered with mist

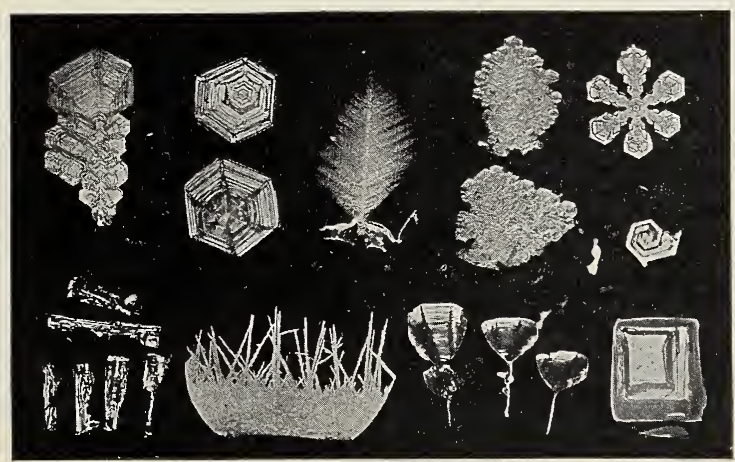

Forms of hoar frost.

Photo by W. A. Bentley.

as soon as they enter a warm room after having been out in the cold? Why do the window-panes become covered with mist during cold weather? Is the mist on the outside or on the inside? Why does steam show as a white mist? Why does the ice pitcher, on a warm day, become covered on the outside with drops of water? Would this happen on a cold day? Why not?

6. Why, when the water is invisible in the atmosphere, does it become visible as clouds? What causes the lower edges of cumulus clouds to be so level? What is fog? Why do clouds occur on mountain peaks? What causes rain?

7. What causes dew to form? When the grass is covered with dew, are the leaves of the higher trees likewise covered? Why not? What kind of weather must we have in order to have dewy nights? What must be the atmosphere of the air in relation to that of the ground in order to condense the dew? Does dew form on windy nights? Why not? Does all dew come from the air, or does some of it come from the ground through the plants? Why is not this water, pumped up by the plants, evaporated?

8. What happens to the dew if the weather becomes freezing during the night? What is hoar frost? Why should water change form when it is frozen? How many forms of frost crystals can you find on the grass on a frosty morning? 
9. When a pond begins freezing over, what part of it freezes first? Describe how the first layer of ice is formed over the surface.

Io. Place a bottle of water out of doors in freezing weather. How does the ice appear in it at first? What happens later? Why does the bottle break? How is it that water which has filled the crevices of rocks scales off pieces of the rock in cold weather? Why does winter wheat "winter-kill" on wet soil?

II. Why does frost form on a window-pane? How many different figures can you trace on a frosted pane? Are there any long, needlelike forms? Are there star forms? Can you find forms that resemble ferns and trees? Do you sometimes see, on boards or on the pavement, frost in forms like those on the window-pane?

12. When there is a fine, dry snow falling, take a piece of dark flannel and catch some flakes upon it. Examine them with a lens, being careful not to breathe upon them. How many forms of snow crystals can you find? How many rays are there in the star-shaped snow crystals? Do you find any solid crystals? Can you find any crystals that are triangular? When the snow is falling in large, feathery flakes, can you find the crystals? Why not?

I3. What is the difference between a hailstone and a snow crystal? What is sleet?

Supplementary reading-Water Wonders, Thompson; Forms of Water, Tyndall.

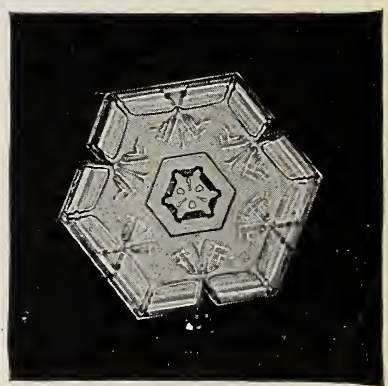

High cloud snow crystal. Photomicrograph by W. A. Bentley.

\footnotetext{
"When in the night we wake and hear the rain Which on the white bloom of the orchard falls, And on the young, green wheat-blades, where thought recalls How in the furrow stands the rusting plow, Then fancy pictures what the day will seeThe ducklings paddling in the puddled lane, Sheep grazing slowly up the emerald slope, Clear bird-notes ringing, and the droning bee Among the lilac's bloom-enchanting hopeHow fair the fading dreams we entertain, When in the night we wake and hear the rain!"
} -ROBERT Burns WiLson.

"The thin snow now driving from the north and lodging on my coat consists of those beautiful star crystals, not cottony and chubby spokes, but thin and partly transparent crystals. They are about a tenth of an inch in diameter, perfect little wheels with six spokes without a tire, or rather with six perfect little leaflets, fern-like, with a distinct straight and slender midrib, raying from the center. On each side of each midrib there is a transparent thin blade with a crenate edge. How full of creative genius is the air in which these are generated! I should hardly admire more if real stars fell and lodged on my coat. Nature is full of genius, full of divinity. Nothing is cheap and coarse, neither dewdrops nor snowflakes."

"A divinity must have stirred within them before the crystals did thus shoot and set. Wheels of storm-chariots. The same law that shapes the earth-star shapes the snow-stars. As surely as the petals of a flower are fixed, each of these countless snow-stars comes whirling to earth, pronouncing thus, with emphasis, the number six."-THOREAU's JOURNAL. 


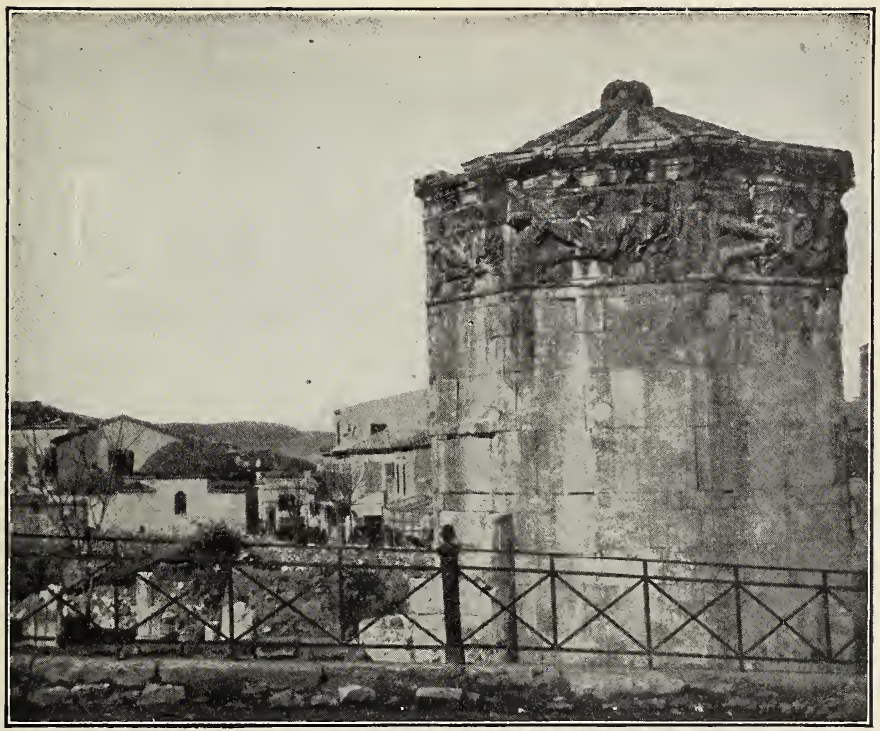

Temple of the winds at Athens.

Photo by J. H. Comstock.

\section{THE WEATHER}

\section{By Wilford M. Wilson}

Section Director, U. S. Weather Bureau, and Professor of Meteorology

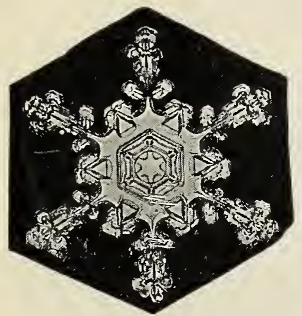

Composite snow crystal; the center formed in a high cloud and the margins in a lower cloud.

Photomicrograph by W. A. Bentley.

The atmosphere, at the bottom of which we live, may be compared to a great ocean of air, about two hundred miles deep, resting upon the earth. The changes and movements that take place in this ocean of air, the storms that invade it, the clouds that float in it, the sunshine, the rain, the dew, the sleet, the frost, the snow, and the hail are termed "weather." We live in it; we partake of its moods; we reflect its sunshine and shadows; it invades the everyday affairs of life, influences every business and social activity, and molds the character of nations; and yet nearly everything we know about the weather has been learned within the lifetime of the present generation. Not that the weather did not interest men of early times, but the problem appeared to be so complicated and so complex that it baffled their utmost endeavors. 


\section{The Temple of the Winds at Athens}

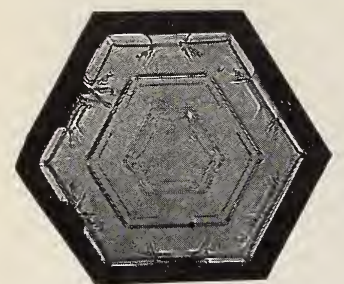

Snow crystal.

Photomicrograph by W. A. Bentley.

The Temple of the Winds, erected probably about five hundred years B. C., indicates the knowledge $f$ the weather possessed by the ancient Greeks. This temple is a little octagon tower, the eight sides of which face the eight principal winds. On each of its eight sides is a human figure cut in the marble, symbolizing the kind of weather the wind from that particular direction brought to Athens.

Boreas, the cold north wind, is represented by the figure of an old man wearing a thick mantle, high buskins (boots) and blowing on a "weathered horn." The northeast wind, which brought, and still brings to Athens, cold, snow, sleet and hail, is symbolized by a man with a severe countenance who is rattling slingstones in a shield, thus expressing the noise made by the falling hail and sleet.

The east wind, which brought weather favorable to the growth of vegetation, is shown by the figure of a beautiful youth bearing fruit and flowers in his tucked-up mantle.

Natos, the warm south wind, brought rain, and he is about to pour the water over the earth from the jar which he carries.

Lips, the southwest wind, beloved of the Greek sailors, drives a ship before him, while Zephros, the gentle west wind, is represented by a youth lightly clad, scattering flowers as he goes.

' The northwest wind, which brought dry and sometimes hot weather to Athens, is symbolized in the figure of a man holding a vessel of charcoal in his hands. Thus, the character of the weather brought by each separate wind is fixed in stone, and from this record we learn that, even with the lapse of twenty centuries, there has come no material change.

\section{HistoRICAL}

There is no record of any rational progress having been made in the study of the weather until about the middle of the seventeenth century, when Torricelli discovered the principles of the barometer. This was a most important discovery and marks the beginning of the modern science of meteorology. Soon after Torricelli's discovery of the barometer his great teacher, Galileo, discovered the thermometer, and thus made possible the collection of data upon which all meteorological investigations are based. About one hundred years after the discovery of the barometer, Benjamin Franklin made a discovery of equal importance. He demonstrated that storms were eddies in the atmosphere, and that they progressed or moved as a whole, along the surface of the earth.

It might be interesting to learn how Franklin made this discovery. Franklin, being interested at that time in astronomy, had arranged with a 
friend in Boston to take observations of a lunar eclipse at the same time that he, himself, was to take observations at Philadelphia. On the night of the eclipse a terrific northeast wind and rain storm set in at Philadelphia, and Franklin was unable to make any observations. He reasoned, that as the wind blew from the northeast, the storm must have been experienced in Boston before it reached Philadelphia. But imagine his surprise, when he heard from his friend in Boston that the night had been clear and favorable for observation, but that a fierce wind and rain storm set in on the following morning. Franklin determined to investigate. He sent out letters of inquiry to all surrounding mail stations, asking for the time of the beginning and ending of the storm, the direction and strength of the wind, etc. When the information contained in the replies was charted on a map it showed that, at all places to the southwest of Philadelphia, the beginning of the storm was earlier than at Philadelphia, while at all places to the northeast of Philadelphia the beginning of the storm was later than at Philadelphia. Likewise, the ending was earlier to the southwest and later to the northeast of Philadelphia than at Philadelphia. He also found that the winds in every instance passed through a regular sequence, setting in from some easterly point and veering to the south as the storm progressed, then to the southeast and finally to the west or northwest as the storm passed away and the weather cleared.

A further study of these facts convinced Franklin that the storm was an eddy in the atmosphere, and that the eddy moved as a whole from the southwest toward the northeast, and that the winds blew from all directions toward the center of the eddy, impelled by what he termed suction.

Franklin was so far in advance of his time that his ideas about storms made little impression on his contemporaries, and so it remained for Redfield, Espy, Loomis, Henry and Maury and other American meteorologists, a hundred years later, to show that Franklin had gained the first essentially correct and adequate conception of the structure and movement of storms.

During the first half of the nineteenth century, considerable progress was made in the study of storms, principally by American meteorologists, among whom was William Redfield of New York, who first demonstrated that storms had both a rotary and progressive movement. James Espy followed Redfield in the construction of weather maps, although he had already published much on meteorological subjects before the latter entered the field.

Professor Joseph Henry, Secretary of the Smithsonian Institution at Washington, was the first to prepare a daily weather map from observations collected by telegraph. He made no attempt to make forecasts, but used his weather map to demonstrate to members of Congress the feasibility of a national weather service.

An incident occurred during the Crimean War that gave meteorology a great impetus, especially in Europe. On November Ioth, I854, while the French fleet was at anchor in the Black Sea, a storm of great intensity occurred which practically destroyed its effectiveness against the enemy. The investigation that followed showed that the storm came from western Europe, and had there been adequate means of communication and its character and direction of progress been known, it would have been possible to have warned the fleet of its approach and thus afforded an opportunity for its protection. 
This report created a profound impression among scientific men and active measures were taken at once that resulted in the organization of weather services in the principal countries of Europe between I855 and I860.

The work of Professor Henry, Abbe, and others in this country would, doubtless, have resulted in such an organization in the United States in the early 6o's, had not the Civil War intervened, absorbing public attention to the exclusion of other matters. It was not until i 870 , that Dr. Increase A. Lapham of Milwaukee, in conjunction with Representative Paine of that city, was able so to present the claims for a national weather service that the act was finally passed that gave birth to the present meteorological bureau in the United States. Dr. Lapham issued from Chicago on November Io, I87 I, the first official forecast of the weather made in this country.

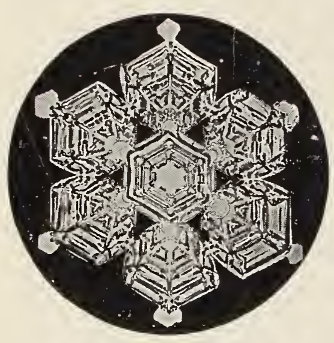

Snow crystal.

Photomicrograph by W. A. Bentley.

\section{The Atmosphere}

What is known about the atmosphere of our earth has been learned from the exploration of a comparatively thin layer at the bottom. There is reason to believe that the atmosphere extends upwards about two hundred miles from the surface of the earth. We have a great mass of observations made at the surface, some on mountains, but few in the free air more than a few miles above the surface. Our knowledge of the upper atmosphere is, therefore, in the nature of conclusions drawn from such observations as are at hand, and is subject to changes and modifications as the facts become known by actual observation.

During the past few years a concerted effort has been made in various parts of the world to explore the upper atmosphere by means of kites and balloons, carrying meteorological instruments that automatically record the temperature, pressure, humidity, velocity and direction of the wind, etc. In this country this work has been carried on principally at the Mount Weather Observatory, which is located in Loudon County, Virginia, and is under the direction of the United States Weather Bureau and at Blue Hill Observatory, a private institution located near Boston and supported by Professor Lawrence Rotch. From observations thus obtained much has been learned about the upper atmosphere that was not even suspected before. Some theories have been confirmed and some destroyed, but this line of research is gradually bringing us nearer the truth.

\section{Air as a Gas}

Air is not a simple substance, as was once supposed, but is composed of a number of gases, each one of which tends to form an atmosphere of its own, just as it would if none of the other gases were present. The different gases of the atmosphere are not chemically combined but are very thoroughly mixed, as one might mix sugar and salt. Samples of air collected from all parts of the world show that the relative proportion of the gases forming the atmosphere is practically uniform. 


\section{The Composition of Air}

Dry air is composed chiefly of oxygen and nitrogen. There are, however, small quantities of carbon dioxide, argon, helium, krepton, neon, hydrogen and xenon, and probably other gases yet to be discovered.

The approximate proportion, by volume is as follows: Nitrogen 78 parts, oxygen 2 I parts, argon I part, carbon-dioxide .03 parts, and krepton helium and xenon a trace. Pure dry air does not exist in nature, so there is always present in natural air a variable amount of water vapor, depending upon the temperature and the source of supply. Besides these, which may be termed the permanent constituents of the atmosphere, many other substances are occasionally met with. Lightning produces minute quantities of ammonia, nitrous acid and ozone. Dust comes from the earth, salt from the sea, while innumerable micro-organisms, most of which are harmless, besides the pollen and spores of plants, are frequently found floating in the atmosphere. Recent investigations in atmospheric electricity lead to the conclusion that electric ions are also present, and perform important functions, especially with respect to precipitation.

\section{Oxygen}

Oxygen is one of the most common substances. It exists in the atmosphere as a transparent, odorless, tasteless gas. It combines with hydrogen to form the water of the oceans, and with various other substances to form much of the solid crust of the earth. Chemically, it is a very active gas, and because of its tendency to unite with other substances to form chemical compounds, it is believed that the volume of oxygen now in the atmosphere, is less than during the early history of the earth. It supports combustion by combining with carbon and other substances, producing light and heat. It combines with some of the organic constituents of the blood, through the function of respiration, which is in itself a slow process of combustion, and thus supports life and maintains the bodily heat.

\section{Nitrogen}

Nitrogen forms the largest proportion of the atmosphere, but unlike oxygen it is a very inert substance, uniting with no element at ordinary temperatures, and at high temperatures with only a few; and when so united the bonds that hold it are easily broken and the gas set free. For this reason, it is utilized in the manufacture of explosives, such as gunpowder, guncotton, nitroglycerine, dynamite, etc. Its office in the atmosphere appears to be to give the air greater weight and to dilute the oxygen, for in an atmosphere of pure oxygen a fire once started could not be controlled. Although nitrogen does not contribute directly to animal life, in that it is not absorbed and assimilated from the air direct as oxygen is, nevertheless, it is a very important element of food both for animals and plants, and in combination with other substances forms a large proportion of animal and vegetable tissues.

\section{Carbon Dioxide}

Carbonic acid gas, known chemically as $\mathrm{CO}_{2}$ is a product of combustion. It results from the burning of fuel and is exhaled by the breathing of animals. It also results from certain chemical reactions. The amount in the atmosphere varies slightly, being somewhat greater at night than by day 
and during cloudy weather than during clear weather. Air containing more than $0.06 \%$ of carbon dioxide is not fit to breathe, not because air loaded with carbon dioxide is poisonous, but because it excludes the oxygen and thus produces death by suffocation. It is considerably heavier than air, and in certain localities, where it is emitted from the ground, accumulates in low places in such quantities as to suffocate animals. Death's Gulch, a deep ravine in Yellowstone Park, and Dog's Grotto near Naples, are examples. At the latter place, the gas, on account of being heavier than air, lies so close to the ground that a man, standing erect, will have no difficulty in breathing, while a dog will die of suffocation. It also accumulates in unused wells, cisterns and mines, and can usually be detected by lowering a lighted candle. If carbon dioxide is present in large quantities, the candle will be extinguished because of the lack of oxygen to support combustion.

Although carbon dioxide forms but a small proportion of the atmosphere, it is a very important element in plant life. Animals consume oxygen and exhale carbon dioxide, while plants take in carbon dioxide and give off oxygen; thus, the amount of these gases in the atmosphere is maintained at an equilibrium. Plants, through their leaves, absorb the carbon dioxide, which is decomposed by the sunlight, returning the oxygen free into the air, while the carbon is used to build up plant tissue.

\section{Dther Gases}

Argon, on account of its resemblance to nitrogen, was not discovered until 1894 , having been included with the nitrogen in all previous analyses of air. It constitutes about $\mathrm{I} \%$ of air by volume. Krepton, neon and xenon exist in minute quantities and have some interest chemically, but little for the meteorologists. Helium and hydrogen probably exist at great elevations in the atmosphere.

\section{Water Vapor}

The vapor of water in the atmosphere varies from about one per cent for arid regions to about five per cent. of the weight of the air for warm, humid regions. It is a little over one-half as heavy as air and moist air is, therefore, lighter than dry air; but the increase of moisture near the center of cyclones has only a slight effect in reducing the pressure. The amount of vapor decreases very rapidly with elevation, and probably disappears at an elevation of five or six miles above the surface. The amount of water in the form of vapor that can exist in the atmosphere increases with the temperature, being .54 grains Troy per cubic foot at zero temperature and I 4.8I at $90^{\circ} .1$ When the air has taken up all the moisture it can contain at a given temperature it is said to be saturated.

The dewpoint is the temperature at which saturation occurs. If the air is saturated, the temperature of the air and the dewpoint will be the same, but if the air is not saturated the dewpoint will be below that of the air.

Relative humidity is expressed in percentages of the amount necessary to saturate. If the air contains one-half enough vapor to saturate it, the relative humidity will be $50 \%$; if one-fourth, enough to saturate, $25 \%$; if saturated 100\% etc.

The absolute humidity is the actual amount of water in the form of vapor in the air, and is usually expressed by weight in grains per cubic foot 
or in inches of mercury, the weight of which would counterbalance the weight of the vapor in the air. The conditions present in a volume of. saturated air at a temperature of $32^{\circ}$ may be expressed as follows: Relative humidity $100 \%$; dewpoint $32^{\circ}$; absolute humidity 2. II grains per cu. ft. or.I 8 inch.

\section{Pressure of Atmosphere}

Although the atmosphere is composed of these various gases, it acts in all respects like a simple, single gas. It is very elastic, easily compressed, expands when heated and contracts when cooled. It is acted upon by gravity and, therefore, has weight and exerts pressure, which at sea level amount to about I 4.7 pounds on each square inch of the surface. Because it is compressible and has veight, it is more dense at the surface than at any elevation above the surface, and as we ascend in the atmosphere the weight or pressure decreases in proportion to the weight of that part of the atmosphere left below. The weight or pressure of the atmosphere is measured by means of a barometer and is expressed in terms of inches of mercury. The normal atmosphere at sea level will sustain a column of mercury about thirty inches high, and we therefore say that the normal pressure of the atmosphere is thirty inches. (See Lessons on air pressure and the barometer.)

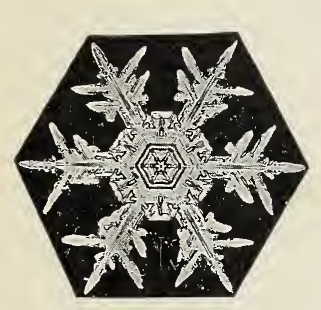

Snow crystal.

Photomicrograph by W. A. Bentley.

\section{The Height of the Atmosphere}

The air that surrounds the earth is called its atmosphere, but it is a rather curious fact that the earth has really ten atmospheres and may have others not yet discovered.

The air near the surface is a mixture of eight different gases, and each individual gas arranges itself so as to form an atmosphere just as it would if no other gases were present. Thus, the earth is surrounded by an atmosphere of oxygen, an atmosphere of nitrogen, one of carbon dioxide, one of water vapor, one each of argon, krypton, neon, and xenon, while hydrogen and helium are believed to exist at great elevations above the earth's surface.

These gases are kept from flying off into space by the force of gravity, just as a piece of iron, stone, or a building is held fast to the earth by the same force. Gravity acts with greater force on some things than on others. For example, a piece of iron is pulled down by gravity with greater force than is a piece of wood of the same size; likewise, a piece of lead is pulled down with greater force than a piece of iron. We, therefore, say that iron is heavier than woud and that lead is heavier than iron, simply because gravity acts with greater force on the one than on the other. The weight of gases differ just as the weight of different solids, such as lead, wood or iron differ. For instance, nitrogen is I 4 and oxygen I 6 times heavier than hydrogen.

Gases having the least weight extend upward the farthest, because the lighter the gas the greater its expansive force. Every boy who rides a bicycle takes advantage of the expansive force of air when he pumps his tires. The air is compressed by the pump into the tube and the expansive force exerted by the air in trying to expand makes the tire "stand up." If it requires Io pounds pressure to compress the gas into the tube, the expansive force will be just ten pounds. 
There are two forces in constant operation on each gas that surrounds the earth, viz., expansive force and gravity. Expansive force pushes the gas up and gravity pulls it down, but the force of gravity decreases as the distance from the center of the earth increases, so there is a point at a certain distance above the earth where the two forces just balance each other, and each gas will expand upward to that point but will not rise beyond it. Therefore, if we know the expansive force of a gas and the rate at which gravity decreases, it is possible to calculate the height to which the different gases that compose the air will rise.

In this way it has been determined that carbon dioxide, which is one of the heavier gases, extends upward about ten miles, water vapor about I 2 miles, oxygen about 30 miles and nitrogen about 35 miles while hydrogen and helium, the lightest gases known, do not appear at the surface at all, but probably exist at a height of from 30 miles to possibly 200 miles.

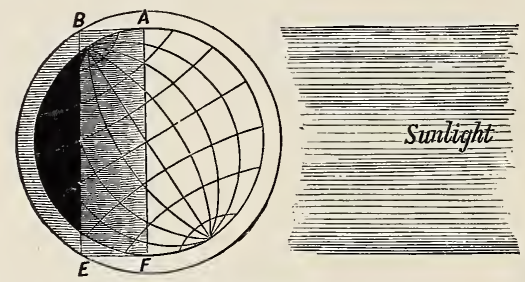

The zone of twilight in midwinter.

From Todd's New Astronomy.

There are other ways in which we are able to gain some idea of the approximate height at which there is an appreciable atmosphere. When the rays of light from the sun enter our atmosphere they are broken up or scattered-diffracted-so that the atmosphere is partially lighted for some time before sunrise and after sunset. This is called twilight. If there were no atmosphere, there would be no twilight, and darkness would fall the instant the sun passed below the horizon. Twilight, which is caused by the sun shining on the upper atmosphere, is perceptible until the sun is about $16^{\circ}$ below the horizon.' 'From this it is calculated that the atmosphere has sufficient density at a height of 40 miles to scatter, or diffract, sunlight.

Observations of meteors, commonly called shooting stars, indicate that there is an appreciable atmosphere at a height of nearly 200 miles. Meteors are solid bodies flying with great velocity through space. Occasionally they enter our atmosphere. Their velocity is so great that the slight resistance offered by the air generates enough heat by friction, or by the compression of the air in the path of the meteor, to make it red hot or to burn it up before it reaches the bottom of the atmosphere. Only the largest meteors reach the earth.

When a meteor is observed by two or more persons at a known distance from each other, and the angle which the line of vision makes with the horizon is noted by each, it is a simple matter to calculate the distance from the earth where the lines of vision intersect, and thus determine the height of the meteor. In this way, reliable observations have given the height at which there is sufficient density in the atmosphere to render meteors luminous as 188 miles. 


\section{Temperature of the Atmosphere}

The condition of the atmosphere with respect to its temperature is determined by means of the thermometer. This instrument is in such common use that a detailed description is not necessary. It might be interesting to note that the instrument invented by Galileo was very different from those now in use. Galileo's original thermometer was what is known as an air thermometer, and its operation when subjected to different degrees of heat or cold depended upon the expansion and contraction of air instead of mercury or alcohol. It had one serious defect, viz., the length of a column of air is affected by pressure as well as by temperature and it was, therefore, necessary, when using this thermometer, to obtain the pressure of the atmosphere by means of the barometer before the temperature could be determined. This is obviated in the modern thermometer by the use of mercury or alcohol in a vacuum tube. Mercury is not used when it is expected to register very low temperatures, because it congeals at about 45 degrees below zero Fahr.

\section{Thermometer Scales in Use}

There are three systems in common use for marking the degrees on the scale, viz., Fahrenheit, Centigrade and Reaumur.

The Fahrenheit scale was the invention of a German by that name, but it is worthy of note that this scale is used principally by English speaking nations and is not in common use in Germany. Fahrenheit found that by mixing snow and salt he was able to obtain a very low temperature, and Delieving that the temperature thus obtained was the lowest possible he started his scale at that point, which he called zero. He then fixed the freezing temperature of water 32 degrees above this zero, and the boiling point of water at 2 I 2 degrees. There are, therefore, I 80 divisions or degrees between the freezing and boiling point of water on the Fahrenheit scale.

The Centigrade scale starts with zero at the freezing point of water and makes the boiling point Ioo. Thus I 80 degrees on the Fahrenheit scale equal roo degrees on the Centigrade. The Fahrenheit degree is, therefore, only a little more than half as large, to be exact five-ninths of a degree, as a degree on the Centigrade scale. The Centigrade scale is in common use in France and is used almost exclusively in all scientific work throughout the world.

The Reaumur scale is used generally in Russia and quite commonly in some parts of Europe, especially in Germany. On this scale the zero is placed at the freezing point of water and the boiling point at 80 degrees. The divisions are, therefore, larger than those of the Centigrade scale and more than twice as large as the Fahrenheit. The general use of these different scales has led to endless confusion and made the comparison of records difficult, so that even at the present time when making a temperature record it is necessary to indicate the scale in use.

\section{Distribution of the Temperature and Pressure}

The heat received on the earth from the sun is the controlling factor in all weather conditions. If the earth were composed of all land or all water, and the amount of heat received were everywhere the same throughout the year, there would be no winds, no storms and probably no clouds and no 
rain, because the force of gravity, which acts on everything on the earth's surface and on the air as well, would soon settle all differences and the atmosphere would become perfectly still. But the earth is composed of land and water and the land heats up more rapidly under sunshine than the water and also gives off- "radiates" its heal more rapidly than water. As a result, the air over the land is warmer in summer than the air over the water. During the winter this is reversed, and the air over the oceans is warmer than the air over the land. The great ocean currents, by carrying the heat from the equatorial regions toward the poles, and by bringing the cold from the polar regions toward the equator, assist in maintaining a constant difference in temperature between the continents and the adjacent oceans.

Furthermore, the fact that the path of the earth about the sun is not a circle but an ellipse, and that the axis of the earth is not perpendicular to the plane of its orbit, result in an unequal distribution of heat over the surface. It is always warmer near the equator than at the poles, and warmer in summer than in winter. All these differences in temperature cause corresponding differences in density, which, in turn, cause differences in weight or pressure over various parts of the earth's surface. These changes are, in no way, the result of chance but are determined by the operation of fixed natural laws, and with this in mind we may now take up the study of the winds of the world.

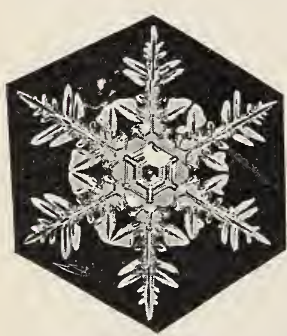

Snow crystal.

Photomicrograph by W. A. Bentley.

The Winds OF THE WorLd

The general circulation of the atmosphere may be best studied by disregarding those smaller differences of temperature and pressure that result from local causes and by viewing the earth and its atmosphere as a whole, considering only those larger differences which are in constant operation. In the great oceans of the world we find the water constantly moving in a very systematic manner, and we call this system of movements ocean currents. The Gulf Stream, the Equatorial Current, the Japan Current and others may be likened to great rivers of water moving systematically on their courses in the ocean.

There are greater rivers of air in the atmosphere than any in the oceans, and they move on their courses with equally systematic precision and in obedience to fixed laws, which we may in a measure understand.

The river, at the bottom of which we live, is broad and deep, extending in width from Florida northward nearly to the north pole. It flows from west to east circling the globe and its name is The Prevailing Westerlies. The other river in this hemisphere extends southward from latitude about $35^{\circ}$ nearly to the equator. Its name is The Northeast Trade Winds.

In the southern hemisphere are two similar rivers, one extending southward from latitude about $30^{\circ}$ nearly to the south pole with its current, like its counterpart in the northern hemisphere, flowing from west to east, circling the globe. It is also called The Prevailing Westerlies. The other river in the southern hemisphere extends from about latitude $30^{\circ}$ northward nearly to the equator and flows from the southeast 
toward the northwest, hence the name Southeast Trade Winds. The dividing line, or bank, between the rivers in each hemisphere belts the earth at about $35^{\circ}$ north and $30^{\circ}$ south of the equator. Why does the air move and why does it move in such a regular, systematic manner? To answer these questions we will rely upon gravity, the heat from the sun and the effect of the rotation of the earth on moving wind currents.

Everyone knows that water flows down hill because of the force of gravity. Gravity is nature's great peacemaker. It is always trying to settle disturbances, even things up, smooth them over. If there were no winds to bring rain to the land or to stir up the ocean, gravity would

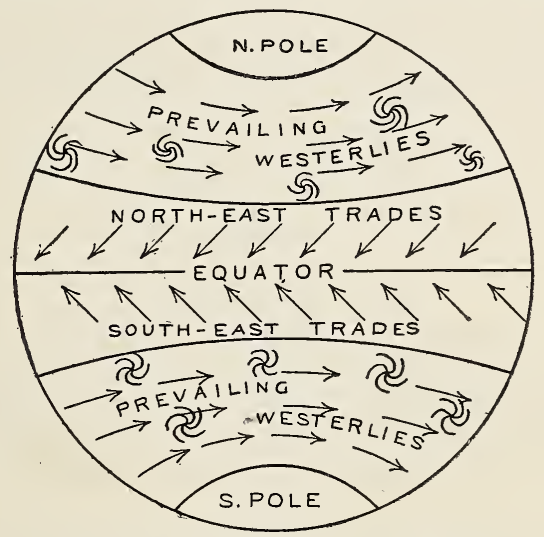

WINDS OF THE WORLD

soon run all the water into the lakes and the seas, and then smooth them out like sheets of glass; and if there were nothing to stir up the winds, gravity would soon settleall differences in the atmosphere and the air would become perfectly quiet. So gravity is kept busy trying to smooth out the water which the wind stirs up, at the same time trying to quiet the winds which are stirred up by the heat of the sun.

Tyndall says that heat is a mode of motion, that when heat is imparted to a substance the molecules of which it is composed are set into very rapid vibration. They are continually trying to get away from each other and usually succeed in getting more space, and thus increase the size or volume of the substance, or, in other words, expand it. Iron, brass, copper, water and many other substances expand under heat. Air is a gas and expands very rapidly when heated. One cubic foot of cold air becomes two cubic feet when heated. Now gravity pulls things down toward the center of the earth in accordance with their weight-density, and a cubic foot of cold air, being more dense and thus heavier than an equal volume of warm air, is pulled down with greater force. We, therefore, say that warm air is lighter than cold air, and if lighter it will rise. What it actually does is to press equally in all directions and when a place is found where there is less 
resistance than elsewhere it moves in that direction. So when heat causes air to expand and become lighter than the surrounding cool air, it moves, and air in motion is wind.

This diagram represents a section of the atmosphere over a broad, level plain with the air at rest and pressing down equally on every part of the surface. The dotted line $\mathrm{H}$ represents the top of the quiet atmosphere. Such a condition occurs frequently at night after the heat from the sun is withdrawn and gravity has settled the atmosphere. When the rays of the sun fall upon the earth upon which this quiet air rests they warm the earth first, then the layer of air immediately in contact with the surface, so the atmosphere is heated from the bottom upward. We will assume that the layer of air between the earth and the dotted line, G, is thus heated to a higher temperature than the air above it. It will, therefore, expand. It cannot expand downward because of the earth. It cannot expand much laterally because it is pressed upon by air that is also seeking more space. It, therefore, expands upward as represented by the line A B C. Now in expanding

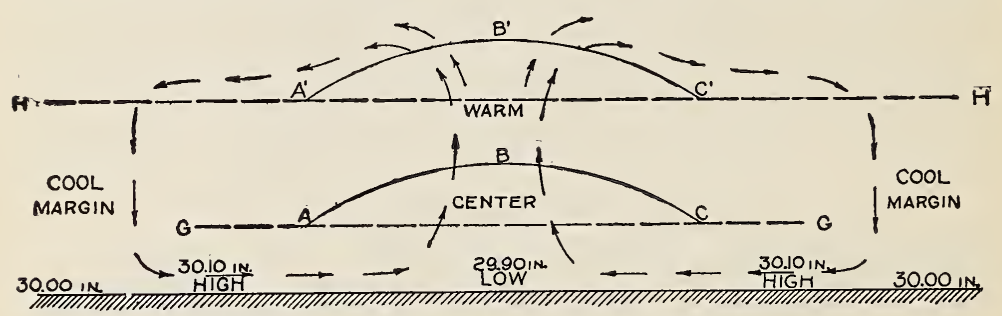

Fig. I. Diagram showing air currents set up by sun's heat.

upward it lifts all the air above it and the line $\mathrm{H}$, representing the top of the atmosphere, will become bowed upward also as indicated by the line $\mathrm{A}^{\prime} \mathrm{B}^{\prime} \mathrm{C}^{\prime}$. As a result, the air at the top of the atmosphere over the warm center slides down the slopes on either side toward the cool margins. As soon as the flow of air away from the warm center begins, just that instant the pressure upon the heated layer at the surface is relieved and the warm air rushes upward (is pushed upward) and the whole circulation, as indicated by the arrows, begins. It must be remembered that gravity is the really active force in maintaining this movement, because it pulls down the denser, heavier air at the cool margins with greater force than the warm, expanded, light air at the warm center. The descent of the cool air actually lifts the warm air.

The normal pressure, or weight, of the atmosphere at sea level is about I4.7 pounds on each square inch of surface. It is customary, however, to express the weight of the atmosphere in terms of inches of mercury instead of in pounds and ounces. A column of air one inch square from sea level to the top of the atmosphere will just counterbalance a column of mercury 30.00 inches high in a barometer tube of the same size. We, therefore, say that the normal pressure of the atmosphere at sea level is abcat 30.00 inches. If, for any reason, the atmosphere becomes heavier than normal, it will raise the column of mercury above the 30 inch mark, and we say that the pressure is "high." If the atmosphere becomes lighter than normal, we 
say that the pressure is "low." So high pressure means a heavy atmosphere and low pressure a light atmosphere.

At the beginning we assumed that the atmosphere over the broad, level plain was quiet and that it pressed down equally on every part of the surface. We will now assume that the pressure was normal, or 30.00 inches, and note the changes in pressure that result from the interchange of air between the warm center and the cool margins. So long as none of the air raised by the expanding layer at the surface, moved away toward the cool margins, no change in pressure occurred; but the instant the air began to glide down the slopes away from the warm center, then the pressure at the surface decreased, because, some air having moved away, there was less to press down than before. The pressure at the warm center, therefore, became less than 30.00 inches, or in other words, low. Likewise, the air as it moved away from the warm center, having lost much of its heat during its ascent, was gradually pulled down by gravity because of its greater density, thus increasing the pressure over the cool margins. We, therefore, have low pressure at the warm center, 29.90 inches and high pressure, 30.10 inches, at the cool margins. From this illustration we obtain the six principles of convectional circulation, viz.:

I. Low pressure at warm center.

2. High pressure at cool margins.

3. Ascending currents at warm center.

4. Descending currents at cool margins.

5. Surface winds from high pressure to low pressure.

6. Upper currents from low pressure to high pressure.

Now, we all know that the temperature of air is much higher at the equator than at the poles and we may, therefore, let Fig. I represent a sec-

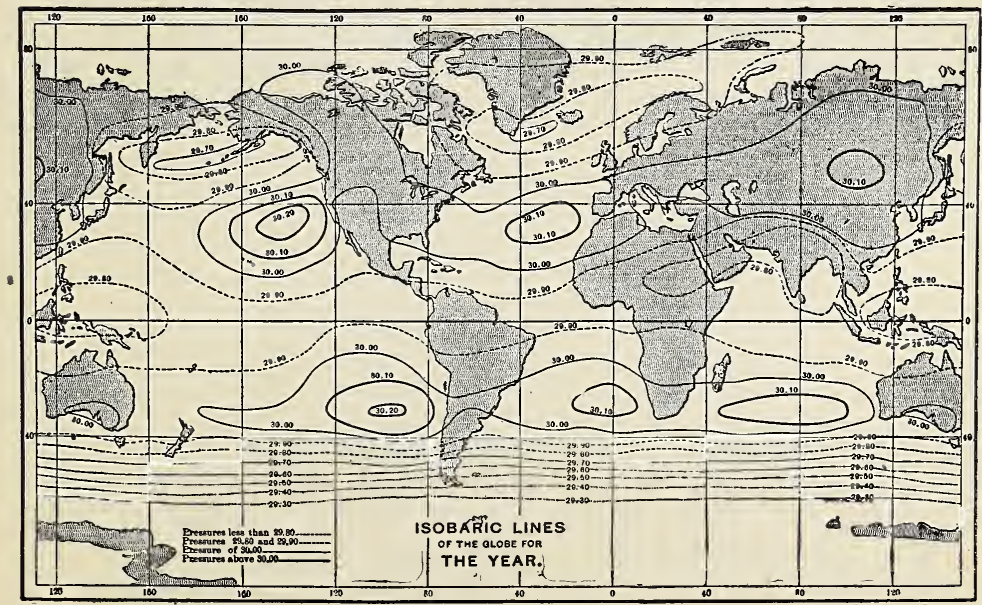

Fig. 2. Isobars of the world. 
tion of the atmosphere along any meridian from the north to the south pole. The equator would then become the warm center and the poles the cool marg:ns. We would then expect to find a belt of low pressure around the world near the equator because of the high temperature, and high pressure at the poles because of the low temperature. We would, also, expect to find ascending currents at the equator; upper currents flowing from the equator toward the poles; descending currents at the poles, and surface winds blowing from the poles toward the equator. Let us now test our. theory by actual facts and see how far they are in accord.

The chart, Fig. 2, represents the normal, or average, pressure at sea level for the world, and if our theory is in accord with the facts, we should find a belt of low pressure all around the world near the equator, with areas of high pressure at the poles. Let us examine the chart. Beginning at the equator, and bearing in mind that the normal pressure is about 30.00 inches,

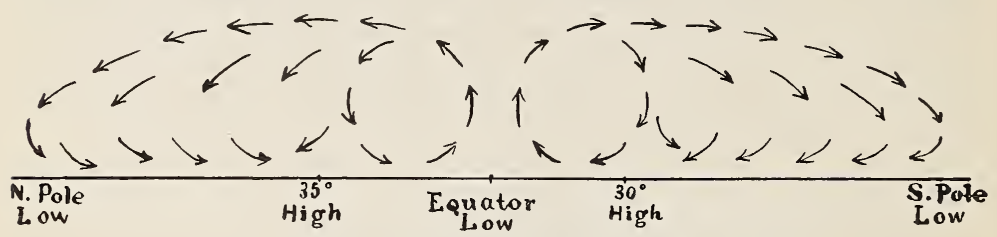

Fig. 3. Diagram showing air currents along any meridian.

we find irregular lines, representing pressures of 29.90 inches-slightly below normal-around the world on both sides of the equator. Between these lines we find pressure as low as 29.80. It is, therefore, evident that there is a belt of low pressure around the world near the equator, as anticipated. Let us look for the high pressure at the poles. We have comparatively few observations near the poles, but the line nearest the south pole is marked 29.30 inches, a surprisingly low pressure, much lower even than the low belt at the equator, and just the reverse of what we expected to find. When we look at the north pole we find that the pressure is not so low as at the south pole, but still below normal and about as low as at the equator. Going north and south from the equator we find that the pressure increases gradually up to about latitude $35^{\circ}$ in the northern hemisphere and to about latitude $30^{\circ}$ in the southern, after which it decreases toward the poles. So there are two well marked belts of high pressure circling the globe; the one about $35^{\circ}$ north, and the other about $30^{\circ}$, south of the equator. May it not be significant that these belts of high pressure coincide so nearly with the margins, or banks, of the air rivers mentioned on page 867 ?

Thus far our theory does not accord very well with the facts. True, we found the low pressure at the equator as anticipated; but we also found low pressure at the poles, where the reverse was expected; and the high pressire that we anticipated at the poles, we found not far north and south of the equator. We will, therefore, have to discard our theory, or reconstruct it to accord with the facts. Let us reconstruct Fig. I, and mark the pressure on the line representing the earth's surface along any meridian to accord with the facts as they appear on Fig. 2.

The above diagram now represents the true pressure along any meridian, as determined by actual observations, and we cannot escape the conviction that the requirements as to temperature and pressure at the warm center 
are fulfilled by the high temperature and low pressure found at the equator. Furthermore, the temperature decreases north and south from the equator, and thus the belts of high pressure near the tropics may be taken to represent the conditions at the cool margins. The first and second principles of a convectional circulation, viz., low pressure at the warm center and a high pressure at the cool margins, are thus fulfilled. To satisfy the remaining conditions, we should find ascending currents near the equator, upper currents flowing from the equator toward the tropical belts of high pressure, descending currents at the tropics, and surface winds blowing from the tropics toward the equator. Let us now examine the surface winds of the world as illustrated by the diagram on page 867 .

On either side of the equator and blowing toward it, we find the famous trade winds - the most constant and steady winds of the world. Their northern and southern margins coincide with the tropical belts of high pressure. They blow from high pressure to low pressure and we cannot doubt that they act in obedience to the fifth principle of convectional circulation. From observation of the lofty, cirrus clouds in the trade wind belts, we have abundant evidence of upper currents, flowing away from the equator toward the tropical belts of high pressure; thus the sixth principle is satisfied. The torrential rains and violent thunderstorms, characteristic of the equatorial regions, bear evidence to the rapid cooling of the ascending currents near the equator; while the clear, cool weather and light winds of the Horse Latitudes clearly indicate the presence of descending currents at the tropics. Thus, the six principles of a convectional circulation are satisfied, and the evidence is conclusive that the trade winds form a part of a convectional circulation between the tropical belts of high pressure and the equatorial belt of low pressure.

You have doubtless observed that the trade winds do not blow directly toward the equator but are turned to the west so that they blow from the northeast in the northern hemisphere, and from the southeast in the southern. This peculiarity is not in strict accord with our ideas of a simple convectional circulation and suggests, at least, the presence of some outside influence. If we turn to Ferre's treatise on the winds, we find a demonstration of the following principle: a free moving body, such as air, in moving over the surface of a rotating globe, such as the earth, describes a path on the surface that turns to the right of the direction of motion in the northern hemisphere and to the left in the southern. The curvature of the path increases with the latitude, being zero at the equator and greatest at the poles, and is independent of direction. With this in mind, if we take position at the northern limit of the trade winds in the northern hemisphere and face the equator, (see p. 867), we find that the winds moving toward the equator turn to our right; likewise, if we face the equator from the southern limit of the southeast trades, we find them turning to our left. Observations of upper clouds in the trade wind belts show that the upper currents also turn to the right in the northern hemisphere, and to the left in the southern. It is, therefore, clear that the systematic turning of the trade winds from the meridian is due to the rotation of the earth. The value of a force at various latitudes and for various velocities that would cause a body to turn away from a straight line, is purely a problem in mathematics, and for the benefit of those versed in the science the formula is given. The amount of such a force is expressed by $2 \mathrm{MVW} \sin \mathrm{D}$, where $\mathrm{M}$ is the mass, $\mathrm{V}$ the velocity, $\mathrm{W}$ the angular rotation of the earth, and $\mathrm{D}$ the latitude. 
Not all of us may be able to solve the problem, but we may understand something of the effect of the rotation of the earth on moving wind currents. It is a well-known principle of physics that if a body be given a motion in any direction, it will continue to move in a straight line by reason of its inertia, without reference to north, south, east or west. A personal experience of this principle may be gained in a street car while it is rounding a curve.

In this diagram, we have a view of the northern hemisphere. The direction of the rotation is indicated by the curved arrows outside the circle representing the equator. Suppose that a wind starts from the equator, moving along the meridian A directly toward the north pole. It is clear that it cannot continue to move along the meridian, because the direction of the meridian with reference to space, is continually changing, and the inertia of the wind compels it to move in a straight line without reference to the points of the compass. So when the meridian A has been moved to B by

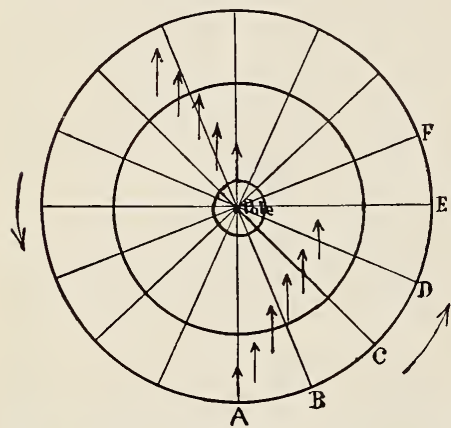

Diagram showing effect of earth's rotation on the atmosphere. the rotation of the earth, the wind, although it maintains its original direction, no longer points toward the pole but to the right of the pole. Likewise, a wind starting from the pole toward the equator also turns to the right of the meridians and becomes a northeast wind as it approaches the equator. A wind moving east or west, also turns to the right of the parallels for the same reason. So a wind starting out from the equator with the best possible intention of hitting the pole, and all the while continuing in the same straight line, will miss the pole by many miles, and always on the right side in the northern and on the left side in the southern hemisphere. Thus, the oblique movement of both the trade winds and the prevailing westerlies is accounted for.

It now remains to consider the cause of the unexpected low pressure found at the poles, and the reason for the belts of high pressure at the tropics. If we refer to Fig. 2, it is evident that not all the air that ascends at the equator descends at the tropics, else there would be an absence of air at the higher latitudes, which is manifestly not the case. On the other hand, it is equally impossible that all the air ascending at the equator should move to the poles, because the space it could occupy decreases rapidly from a maximum at the equator to zero at the poles. Only a part of the air that ascends at the equator is, therefore, involved in the trade wind circulation and a part passes over the tropics and moves on toward the low pressure at the poles. Furthermore, some of the air that descends at the tropics moves along the surface toward the poles, obeying the law that impels air to move from high pressure to low pressure. Now every particle of air that passes over the tropics, every particle that moves northward along the surface, turns to the right in the northern and to the left in the southern hemisphere. All, therefore, miss the poles-on the right side in the northern and on the left side in the southern hemisphere. The result 
is that two great whirlpools develop in the atmosphere; one whirling about the north and the other whirling about the south pole. The outer margins of these whirlpools coincide with the tropical belts of high pressure.

As an example of a whirlpool we may take a sasin having a vent at the center of the bottom. If the basin is filled with water, the plug withdrawn and the water given a slight rotary motion, its velocity will increase as it approaches the center and the rapid whirling will develop sufficient centrifugal force to open an empty core. Those who have visited the great whirlpool at Niagara, undoubtedly noticed that the whirling waters are held away from the center and piled up around the margins by the centrifugal force developed. ' Let us suppose that air starting from the equator, moves without friction or other resistances toward the pole. Its velocity must increase as its radius shortens, because the law of the conservation of

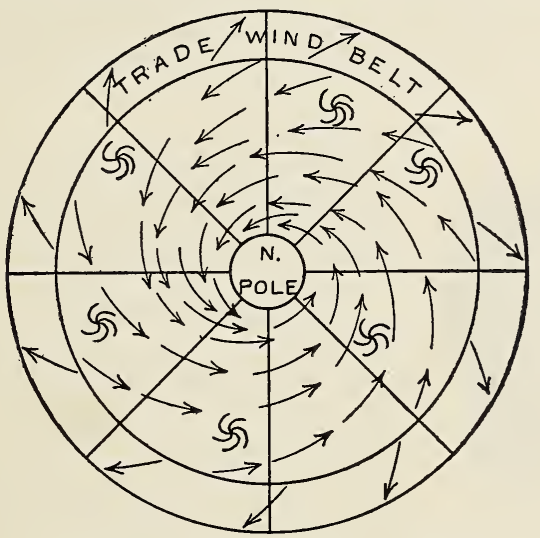

CIRCUMPOLAR WHIRL

areas requires that the radius must always sweep over equal areas in a given unit of time. (See law of conservation of areas.) At the equator, the air has an easterly motion equal to the eastward motion of the earth, which is I,000 miles per hour. At latitude $60^{\circ}$ the radius will have decreased onehalf and the velocity, therefore, doubled; but at latitude $60^{\circ}$ the eastward motion of the earth is only 500 miles per hour, so the air would be moving I 500 miles per hour faster than the earth. At a distance of 40 miles from the pole the wind would attain an easterly velocity of 100,000 miles per hour, and moving on so short a radius would develop sufficient centrifugal force to hold all the air away from the pole and thus form a vacuum. That the supposed case of no friction is far from the truth is evidenced by the fact that the pressure at the north pole is but little less than at the equator; but the centrifugal force developed by the gyration winds, in thus withdrawing the air from the poles and piling it up at the tropics, may be fairly taken as sufficient cause for the low pressure found at the poles and the belts of high pressure at the tropics.

The questions that remain to be considered are: (I) the low pressure at the south pole as compared with the pressure at the north pole and (2) the 
unequal distance of the tropical belts of high pressure from the equator. These questions may be considered together.

It is to be remembered that the southern hemisphere is the water hemisphere, and that the prevailing westerlies, in gliding over the smooth water surface, are but little retarded by friction and, therefore, attain a higher velocity than the corresponding winds of the northern hemisphere, where the rougher surface materially retards their movement. As a consequence, the circumpolar whirl of the southern hemisphere is stronger, and develops a greater centrifugal force, thus holding a larger quantity of air away from the south pole and reducing the pressure to a greater degree than is brought about by the weaker winds of the northern hemisphere.

Since the circumpolar whirl of the southern hemisphere is the stronger of the two, it withdraws the air to a greater distance from the pole than does its weaker counterpart of the northern hemisphere, and piles it up in the tropical belt of high pressure about five degrees nearer the equator than does the weaker forces of the northern hemisphere.

\section{STORMS}

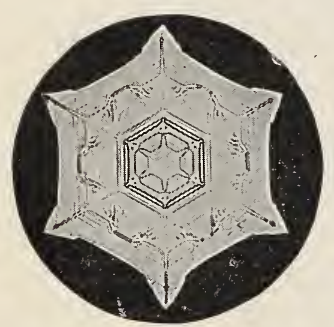

Snow crystal.

Photomicrograph by W. A. Bentley.

Having gained a comprehensive view of the general, planetary wind system, we may now undertake the study of local disturbances that arise within the general circulation and are known as "storms."

Storms are simply eddies in the atmosphere. They may be compared to the eddies that are often seen floating along with the current of a river or creek. In these eddies the water is seen to move rapidly around a central vertex, developing sufficient centrifugal force to hold some of the water away from the center, thus forming a well marked depression, frequently of considerable depth. The whole circulation of the eddy is quite independent of the current of the stream which carries it along its course, and while its general direction and velocity of movement coincide with that of the current, there are times when it will be seen to move quickly from side to side and again when it will remain nearly stationary for a time or take on a rapid movement.

The eddies or storms in the atmosphere act in much the same way. They are carried along by the general currents of the river of air in which they exist. Their general direction coincides with the direction of the current in which they are floating, and their rate of movement conforms in a general way to its velocity; but like the eddies in the river, they do not always move in straight lines nor at a uniform rate of speed.

There is one important respect in which the eddies in the air differ from eddies in water. The water eddy may revolve in either direction, depending upon the direction in which the initial force was applied, but the storm eddies in the atmosphere always revolve counter-clockwise in the northern hemisphere, and clockwise in the southern.

This is due to the deflecting force of the earth's rotation, which is fully explained on page 872 . 


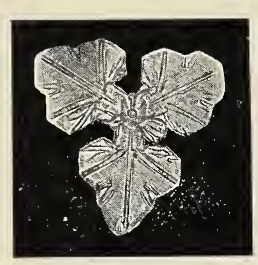

Snow crystal.

Photomicrograph by W. A. Bentley.

\section{Weather Maps}

A weather map is a sort of flashlight photograph of a section of the bottom of one or more of these great rivers of air. It brings into view the whole meteorological situation over a large territory at a given instant of time; and, while a single map conveys no indication of the movements continually taking place in the atmosphere, a series of maps, like a moving picture, shows not only the whirling eddies, the hurrying clouds and the fast-moving winds, but the ceaseless on-flow of the great river of air in which they float. Our present knowledge of the movements of the atmosphere has been gained chiefly from a study of weather maps; they form the basis of the modern system of weather forecasting, and their careful study is essential to any adequate understanding of the problems presented by the atmosphere. (See pages $884-885$.)

\section{The Principles of Weather Forecasting}

The forecasting of the weather has been made possible by the electric telegraph. It is based upon a perfectly simple, rational process constantly employed in everyday affairs. We go to a railway station and ask the operator about a certain train. He tells us that it will arrive in. an hour. We accept his statement without question, because we are confident that he knows the speed at which the train is approaching, a few clicks of his telegraph instrument has told him just where it is and the time it will arrive, barring acciaents, is a simple calculation. Information of coming weather changes are obtained in a similar manner. Although storms do net run on steel rails like a train,

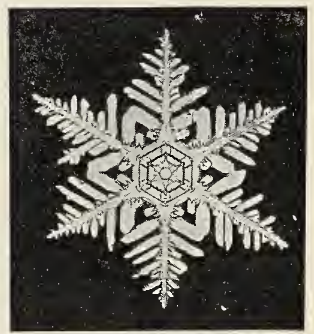

Snow crystal. Photomicrograph by
W. A. Bentley. nevertheless their movements may be foreseen with a reasonable degree of accuracy, depending chiefly upon the size of the territory from which telegraphic reports are received and the experience and skill of the forecaster. As a rule, the larger the territory brought under observation, especially in its longitudinal extent (the general currents carry storms of the middle latitudes eastward around the world and those of the tropics westward), the earlier advancing changes may be recognized and the more accurately their movements foreseen.

\section{Forecasts Based on Weather Maps}

The forecasts issued by the United States Weather Bureau are based on weather maps, prepared from observations taken at $8 \mathrm{a} . \mathrm{m}$. and $8 \mathrm{p} . \mathrm{m}$. at about 200 observatories. In addition to the reports received by telegraph by the Central Office at Washington, the several forecast centers and other designated stations from observatories or stations in the United States, a system of interchange with Canada, Mexico, the West Indies and other island outposts in the Atlantic and Pacific gives to the forecaster two daily photographs of the weather conditions over a territory embracing nearly 
the whole of the inhabited part of the western hemisphere north of the equator. Any sort of disturbance within this vast region is photographed at once upon the weather map. If it be a West Indies hurricane or other destructive storm, its character is recognized instantly, its rate and direction determined and information of the probable time of its arrival sent to those places that lie in its path. The method is perfectly simple. Anyone with a weather map and a little experience can forecast the weather with some degree of accuracy, or, at least, gain an intelligent understanding of the conditions upon which the forecasts that accompany the map are based.

\section{Maps, Where Published and How Obtained}

Weather maps are published in many daily papers, and in somewhat larger form and more in detail, at many Weather Bureau stations. They may usually be obtained for school use by applying to the nearest Weather Bureau station or to the Chief of the Weather Bureau at Washington, D. C.

The forecasts that accompany the maps are simply an expression on the part of the official forecaster as to the weather changes he expects to occur in various parts of the country within the time specified, usually within 36 to 48 hours. His opinion is based upon the conditions shown by the map. $\mathrm{He}$ has no secret source of information. You may accept his conclusions, or, if in your opinion they are not justified, you have all the information necessary to make a forecast for yourself. Weather maps are published so extensively with a view to thus stimulating an intelligent interest in the problem of weather forecasting, and also that one may see at a glance what the temperature, rainfall, wind and weather is in any part of the country in which he may be interested. The friends of the weather service are those who best understand its work.

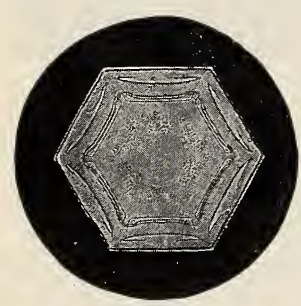

Snow crystal.

Photomicrograph by W. A. Bentley.

\section{The Value of the Weather Service}

No one knows so well as the forecaster that the changes that appear most certain to come sometimes fail, or come too late; but taking all in all, about 85 out of Ioo forecasts are correct. Of those that fail, probably not more than three of four per cent. fail because the changes come unannounced. Most forecasters predict too much, and their forecasts fail because the expected changes come after the time specified or not at all. It is fortunate that this is so; for it is better to be prepared for the change though it be late in coming than to have it come without warning.

The value of the weather service to the agriculture and commerce of the United States cannot be questioned seriously. That the appropriations for its support have been increased year by year from $\$ 1,500$ in I87I to nearly $\$ \mathrm{I}, 500,000$ in I 9 IO is evidence of its value and efficiency. A conservative estimate places the value of property saved by the warnings issued by the Weather Bureau at $\$ 30,000,000$ annually. 


\section{LESSON CCXXII}

\section{Experiments to Show Air Pressure}

Leading thought-The air presses equally in all directions.

Experiment I-To show that air presses upward-Fill a tumbler which has an unbroken edge as full of water as possible. Take a piece of writing paper and cover the tumbler, pressing the paper down firmly upon the edge of the glass. Turn the glass bottom side up and ask why the water does not flow out. Allow a little air to enter; what happens? Why? Turn the glass filled with water and covered with paper sidewise; does the water flow out? If not, why?

Experiment 2-To show that air passes downward-Ask some of the boys of the class to make what they call a sucker. This is a piece of leather a few inches

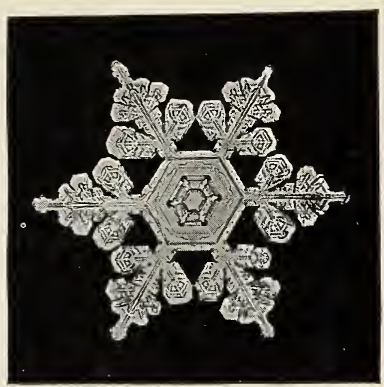

Composite crystal; high cloud at center and medium high cloud at the border.

Photomicrograph by W. A. Bentley. across. Through its center a string is drawn which fits very closely into the leather and is held in place by a very flat knot on the lower side. Dampen the leather and press it against any flat surface, and try to pull it off. If possible, place the sucker on a flat stone and see how heavy a stone can be lifted by the sucker. Ask why a sucker clings so to the flat surface. If a little air is allowed to get between the sucker and the stone, what happens? Why?

Hints to the teacher regarding the Experiments-The water is kept in the tumbler in Experiment I by the pressure of the atmosphere against the paper. If the tumbler is tipped to one side the water still remains in the glass, which shows that the air is pressing against the paper from the side with sufficient force to restrain the water, and if the tumbler is tipped bottom side up it shows the air is pressing upward with sufficient force to keep the water within the glass.

In the case of Experiment 2, we know that the leather pressing upon the floor or on the stone is not in itself adhesive, but it is made wet simply so that it shall press against the smooth surface more closely. The reason why we cannot pull it off is that the air is pressing down upon it with the force of about fifteen pounds to the square inch. If the experiment is performed at sea level, we should be able to lift by the string of the sucker a stone weighing fifteen pounds. The reason why the water falls out of the tumbler after a little air is let beneath the paper, is that then the air is pressing on both sides of the paper; and the reason why the sucker will not hold if there is any air between it and the stone, is because the air is pressing in both directions upon it.

Supplementary reading - The Wonderbook of the Atmosphere, Houston, Chapters III, IV, V. 


\section{LESSON CCXXIII}

\section{The Barometer}

Leading thought-The weight of our

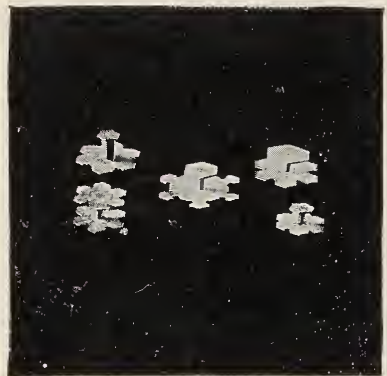

Compound snow crystals.

Photo by W. A. Bentley. atmosphere balances a column of mercury about thirty inches high, and is equal to about fifteen pounds to the square inch. This pressure varies from day to day, and becomes less as the height of the place increases. The barometer is an instrument for measuring the atmospheric pressure. It is used in finding the height of mountains, and, to a certain extent, it indicates changes of the weather.

Method-A glass tube about 36 inches long, closed at one end; a little glass funnel about an inch in diameter at the top; a small cup-a bird's bathtub is a good size since it allows plenty of room for the fingers; mercury enough to fill the tube and have the mercury an inch or more deep in the cup. Be careful not to spill the mercury in the following process, or you will be as badly off as old Sisyphus with his rolling stone.

Set the closed end of the tube in the cup so that any spilled mercury will not be lost; with the help of the funnel slowly and carefully fill the tube clear to the top with the mercury; empty the rest of the mercury into the cup; place the end of one of the fingers of the left hand tightly over the open end of the tube and keep it there; with the right hand invert the tube, keeping the end closed with the finger, and place the hand, finger and all, beneath the mercury in the cup then remove the finger, keeping the open end of the tube all the time below the surface of the mercury. When the mercury has ceased to fall measure the distance from the surface in the cup to the top of the mercury in the tube.

Observations-I. How high is the column of mercury in the tube?

2. What keeps the mercury in the tube? Place the cup and the tube on a table in the corner of the room, place behind the tube a yardstick, and note whether the column of mercury is the same height day after day. If it varies, why?

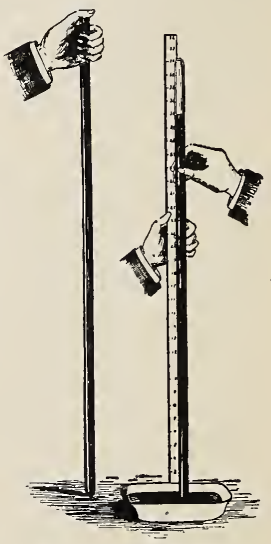

$A$ barometer made by pupils.

3. Would the mercury column be as high in the tube if it were placed on top of a mountain as it would at the foot? Why?

Supplementary reading-Chap. II in The Wonderbook of the Atmos. phere, Houston. 


\section{HOW TO READ WEATHER MAPS \\ Teacher's Story}

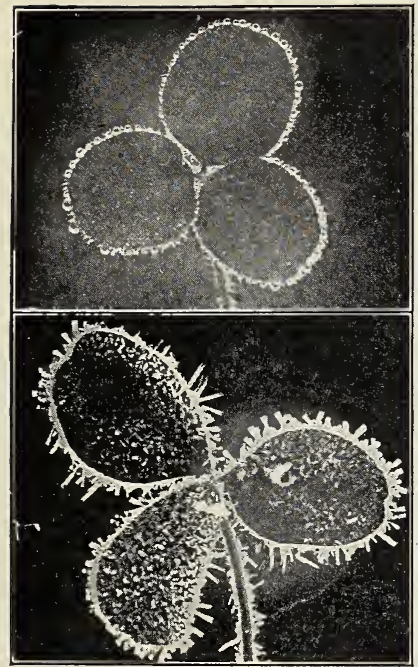

Dew on clover leaf. Hoar frost on clover leaf.

Photo by W. A. Bentley.

Weather maps may be obtained by writing to the nearest Weather Station, or by writing to the Chief of the Weather Bureau, Dr. Willis L. Moore, Washington, D. C., stating that you wish to post the maps in a public place. A supply of maps for three successive days for use in these lessons may be obtained at 20 cents per hundred. Sometimes they are sent free, if it is stated that they are to be used for school purposes.

The words isobar and isotherm have been bogies which have frightened many a teacher from undertaking to teach about weather maps, and yet how simple are the meaning of these two words. Isobar is made up of two Greek words, isos meaning equal and baros meaning weight. Thercfore, an isobar means equal weight, and on a map one of these continuous lines means that, wherever it passes, the atmosphere there has equal weight and the barometer stands at equal height. The isobar of 30 means that the mercury in the barometcr stands 30 inches in height in all the regions where that line passes.

"Isotherm" comes from the two Greek words, isos meaning equal aná therme meaning heat. Therefore, on the map the dotted lines show the region where the temperature is the same. If at the end of the dotted line you find 60 it means that, wherever that line passes, the thermometer stands at 60 degrees.

Many of the "highe" and "lows" enter the United States from the Pacific Ocean about the latitude of Washington State or southwest British Columbia. They follow one another alternately, crossing the continent in the general direction of west to east in a path which curves somewhat to the north, and they leave the United States in the latitude of Maine or Ncw Brunswick. If they enter by way of lower California, they pass over to the Atlantic Ocean farther south. The time for the passage of a high or low across the continent averages about three and one-half days, sometimes a little more. These areas are usually more marked in winter, and wind storms are more marked and more regular.

A low area is called a cyclone and a high area an anti-cyclone. The destructive winds, popularly called cyclones, which occur in certain regions, should be called tornadoes instead, although in fact they are simply small and violent cyclones. But a cyclone, when used in a meteorological sense, extends over thousands of square miles and is not violent; while a tornado may be only a few rods in diameter and be very destructivc. The little whirlwinds which lift the dust in the roads are rotary winds also, but merely the eddies of a gentle wind. 
In a cyclone or "low," and also in a tornado, the air blows from all sides spirally inward toward the center where there is a column of ascending air.

In an anti-cyclone or "high" the air blows outward in every direction in curved lines from a column of descending air.

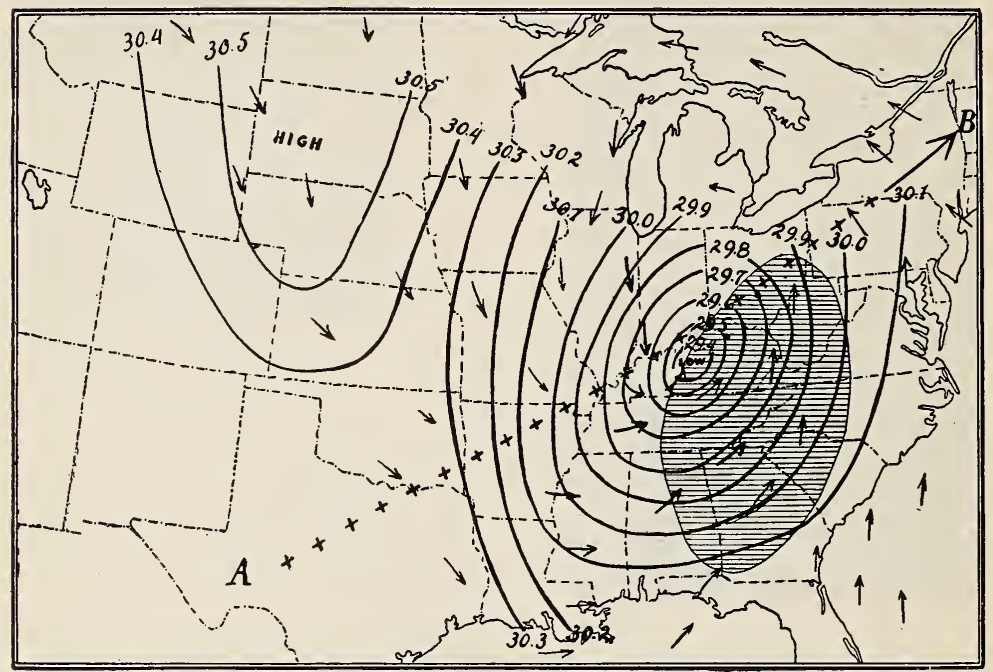

Map of a storm.

In the above map, the curved lines are isobars; the line of crosses from $\mathrm{A}$ to $\mathrm{B}$ indicates the course of the storm; the arrows indicate the direction of the wind, note that it is moving counter-clockwise around the area of low pressure; the shaded area indicates the region where it is raining or snowing; note that this is the area where the warm, moist air from the Gulf and the Ocean meets the colder air of the North.

The weather conditions during the passage of a cyclone are briefly as follows: Small, changing wisps of cirrus clouds appear about 24 hours before rain; these gradually become larger and cover the whole sky, making a nimbus cloud. The wind changes from northeast to east or southeast to south. The barometer falls; the thermometer rises, that is, air pressure is less to the square inch, and the temperature of the atmosphere is warmer. Rain begins and falls for a time, varying from an hour to a day or more. After the rain there appear breaks in the great nimbus clouds and finally the blue sky conquers until there are only a few or no clouds. The wind changes to southwest and west; the barometer rises, the temperature falls. The rain ceases, the sun shines out brightly. The low has passed and the high is approaching to last about three days. 


\section{U.S. DEPARTMENT OF AGRICULTURE, WEATHER BUREAU}

\section{EXPLANATION OF WEATHER SIGNALS}

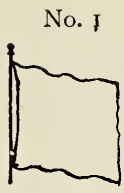

Fair Weather
No. 2

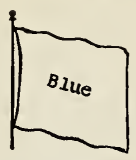

Rain or Snow
No. 3

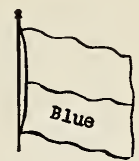

Local Rain or Snow

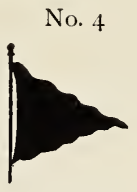

Temperature
No. 5

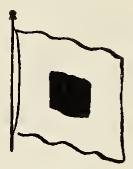

Cold Wave

\section{INTERPRETATION OF DISPLAYS}

No. I, alone, indicates fair weather, stationary temperature.

No. 2, alone, indicates rain or snow, stationary temperature.

No. 3, alone, indicates local rain or snow, stationary temperature.

No. I, with No. 4 above it, indicates fair weather, warmer.

No. I, with No. 4 below it, indicates fair weather, colder.

No. 2, with No. 4 above it, indicates rain or snow, warmer.

No. 2, with No. 4 below it, indicates rain or snow, colder.

No. 3, with No. 4 above it, indicates local rain or snow, warmer.

No. 3, with No. 4 below it, indicates local rain or snow colder.

WILLIS L. MOORE,

Chief U.S. Weather Bureau.

\section{EXPLANATION OF WHISTLE SIGNALS}

A warning blast of fifteen to twenty seconds duration is sounded to attract attention. After this warning the longer blasts (of four to six seconds duration) refer to weather, and shorter blasts (of one to three seconds duration) refer to temperature; those for weather are sounded first.

\section{Blasts}

One long

Two long ............ Rain or snow.

Three long $\ldots \ldots \ldots \ldots \ldots \ldots$ Local rain or snow.
Blasts.

Indicate.

One short . ............. Lower temperature.

Two short ............... Higher temperature. Three short ................... Cold wave.

By repeating each combination a few times, with intervals of ten seconds, liability to error in reading the signals may be avoided.

\section{STORM AND HURRICANE WARNINGS}

Storm warnings.

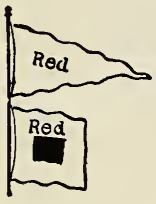

NE. winds

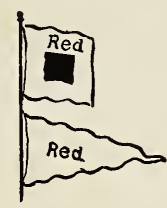

SE. winds.

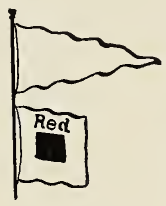

NW. winds.
Hurricane warning.
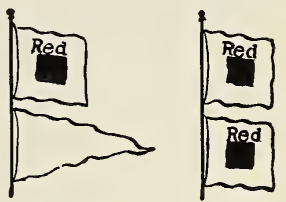

SW. winds.

\section{Explanation of Storm and Hurricane Signals}

Storm warning-A red flag with a black center indicates that a storm of marked violence is expected.

The pennants displayed with the flags indicate the direction of the wind; red, easterly (from northeast to south); white (westerly from southwest to north). The pennant above the flag indicates that the wind is expected to blow from the northerly quadrants; below from the southerly quadrants.

By night a red light indicates easterly winds and a white light below a red light westerly winds.

Hurricane warning - Two red flags with black centers displayed one above the other indicates the expected approach of a tropical hurricane or one of those extremely severe and dangerous storms which occasionally move across the Lakes and northern Atlantic coast.

No night hurricane warnings are displayed. 

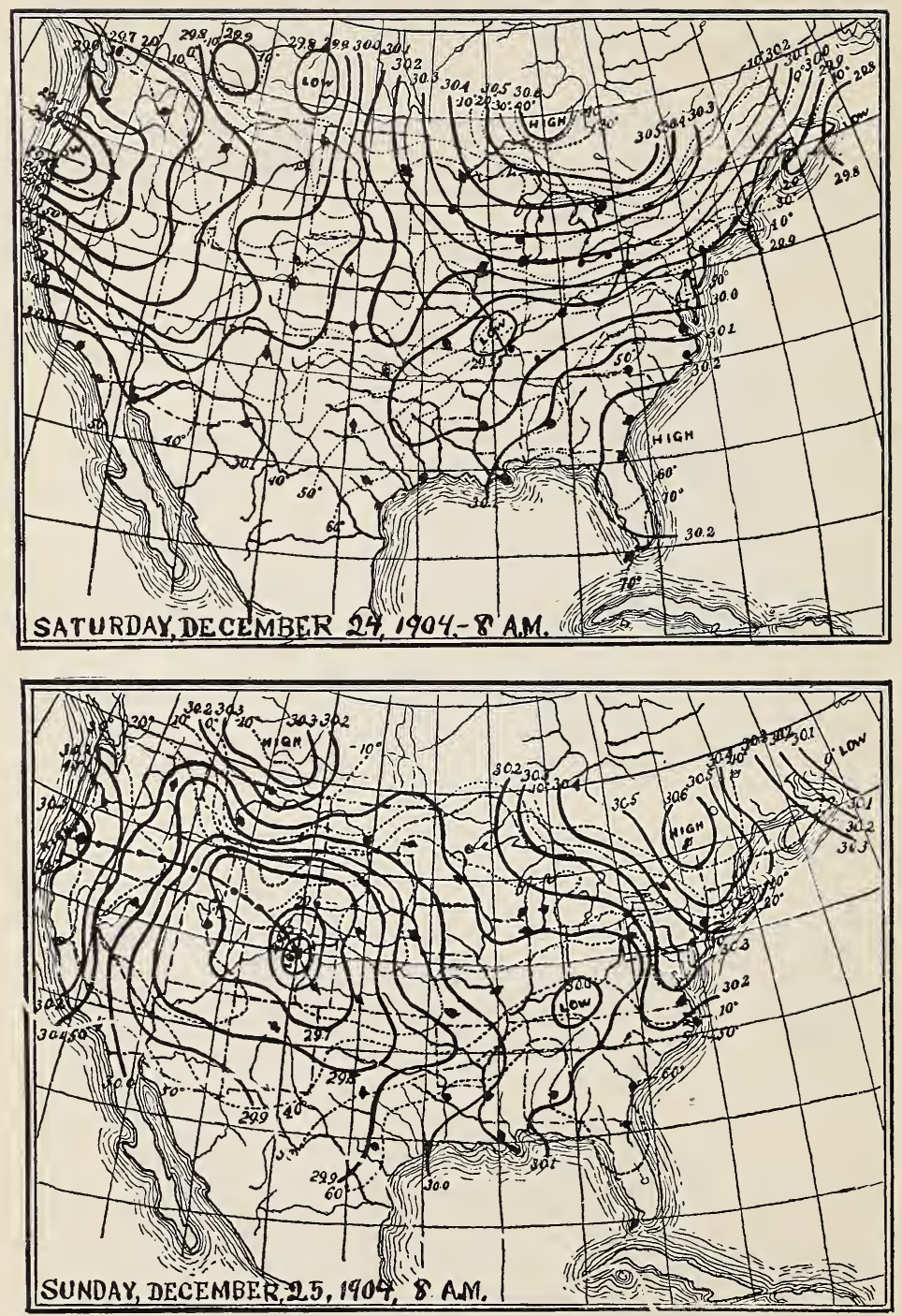

$U . S$. weather maps, showing the e.rstward progress Nivte the course of the low that was on the Pacific Coast Dec. $24^{\circ}$ this 

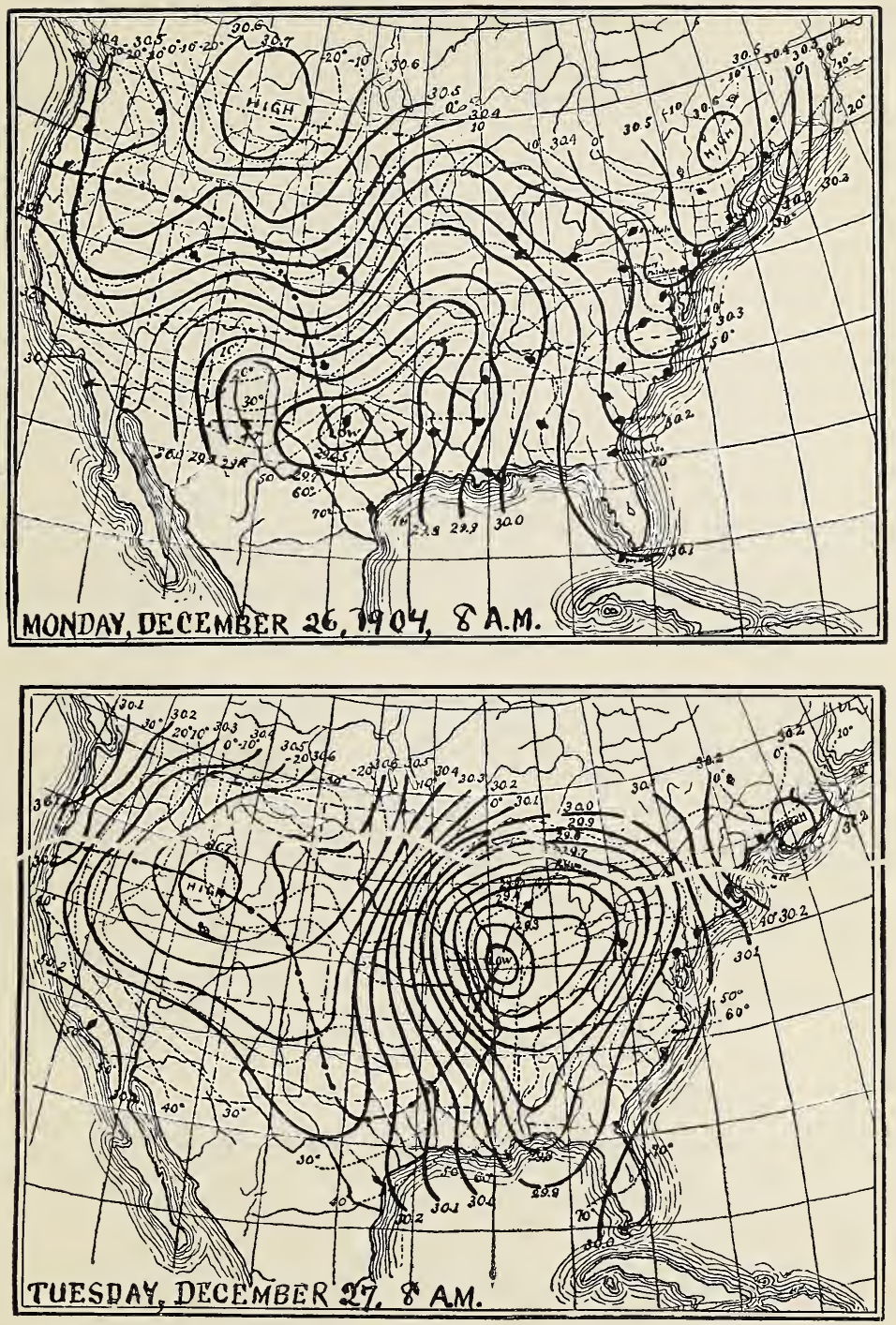

of an area of low pressure for four consecutive days.

is indicated by the line of dots and dashes on the later maps. 


\section{LESSON CCXXIV}

\section{How to Read Weather Maps}

Leading thought-Weather maps are made with great care by the Weather Bureau experts. Each map is the result of many telegraphic communications from all parts of the country. Every intelligent person should be able to understand the weather maps.

Method-Get several weather maps of the nearest Weather Bureau Station. They should be maps for successive days, and there should be enough so that each pupil can have three maps, showing the weather conditions for three successive days.

Observations-I. Take the map of the earliest date of the three. Where was your map used? What is its date? How many kinds of lines are there on your map? Are there explanatory notes on the lower left-hand corner of your map? Explain what the continuous lines mean. Find an isobar of 30 ; to what does this figure refer? Find all the towns on your map where the barometer stands at 30 inches. Is there more than one isobar on your map where the barometer stands at 30 ?

2. Where is the greatest air pressure on your map? How high does the barometer stand there? How are the isobars arranged with reference to this region? What word is printed in the center of this series of isobars?

3. What do the arrows indicate? What do the circles attached to the arrows indicate?

4. In general, what is the direction of the winds with reference to this high center?

5. Is the air rising or sinking at the center of this area? If the wind is blowing in all directions from a center marked high, what sort of weather must the places just east of the high be having? Do the arrows with their circles indicate this?

6. Find a center marked low. How high does the barometer stand there? Does the air pressure increase or diminish away from the center marked low, as indicated by the isobars? Do the winds blow toward this center or away from it?

7. What must the weather in the region just east of the low be? Why? Do the arrows and circles indicate this?

8. Is there a shaded area on your map? If so, what does this show?

9. Compare the map of the next date with the one you have just studied. Are the highs and lows in just the same position that they were the day before? Where are the centers high and low now? In what directions have they moved?

Io. Look at the third map and compare the three maps. Where do the high and low centers seem to have originated? How long does it take a high or low to cross the United States? How far north and south does a high or low, with all its isobars, extend?

II. What do the dotted lines on your map mean? Do they follow exactly the isobars?

I2. What is the greatest isotherm on your map? Through or near what towns does it pass?

I3. Do the regions of high air pressure have the highest temperature or the lowest? Do high temperatures accompany low pressures? Why?

I 4. What is the condition of the sky just east of a low center? What, is its condition just west of low? 
I5. If the isobars are near together in a low, it means that the wind is moving rather fast and that there will be a well marked storm. Look at the column giving wind velocity. Was the wind blowing toward the center of the low on the map? If so, does that mean it is coming fast or slow? How does this fact correspond with the indications shown by the distance between the isobars?

I6. Describe the weather accompanying the approach and passage of a low in the region where your town is situated? What sort of clouds would you have, what winds, what change of the barometer and thermometer?

\section{How to Find the General Direction and Average Rate of Motion of Highs and Lows}

Observations-I. On the first map of the series of three given, put an $\mathrm{X}$ in red pencil or crayon at the center of the high and a blue one at the center of the low; or if you do not have the colored pencils, use some other distinguishing marks for the two. If there are two highs and two lows use a different mark for each one.

2. Mark the position of each center on this map for the following day with the same mark that you first used for that area. Do this for each of the highs and lows until it leaves the map or until your maps have been used. All the marks of one kind can be joined by a line, using a red line for the red marks and a blue line for the blue marks.

3. What do you find to be the general direction of the movement of the highs and lows?

4. Examine the scale marked statute miles at the bottom of the map. How many miles are represented by one inch on the scale?

5. With your ruler find out how many miles one area of high or low has moved in twenty-four hours; in three days. Divide the distance which the area has moved in three days by three and this will give the average velocity for one day.

6. In the same way find the average veolcity of each of the areas on your map for three days and write down all your answers. From all your results find the average weekly velocity; that is, how many miles per hour and the general direction which has characterized the movement of the high and low areas.

Supplementary reading-The Wonderbook of the Atmosphere, Houston, Chapters XIV-XXIII.

\section{How to Keep a Daily Weather Map}

The pupils should keep a daily weather map record for at least six months. The observations should be made twice each day and always at the same hours. While it would be better if these records could be made at $8 o^{\prime}$ clock in the morning and again at 8 o'clock in the evening, this is hardly practicable and they should, therefore, be made at 9 o'clock and at 4 . The accompanying chart may be drawn enlarged. Sheets of manila paper are often used, so that one chart may cover the observations for a month.

Few schools are able to have a working barometer, but observations of temperature and sky should be made in every school. Almost any boy can make a weather vane, which should be placed on a high building or tree where the wind will not be deflected from its true direction when striking it. A thermometer should be placed on the north side of a post and on a level 
with the eyes; it should not be hung to a building, as the temperature of the building might affect it.

The direction of the wind and the cloudiness of the day may be indicated on the chart, as it is on the weather maps, by a circle attached to an arrow which points in the direction in which the wind is blowing.

References-Elementary Meteorology, Waldo, American Book Co., \$r.50; Elementary Meteorology, Davis, Ginn and Co., \$2.50; Bulletins from the United States Weather Bureau, Washington, D. C.

Chart for School Weather-Records.

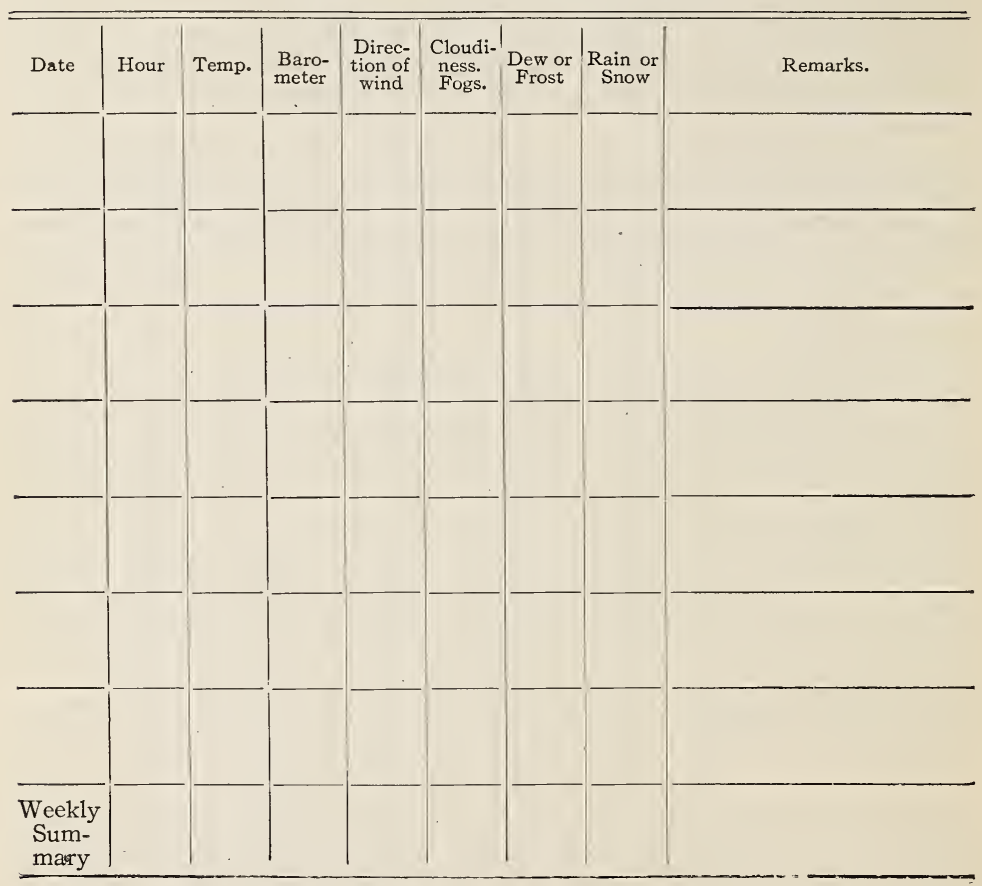




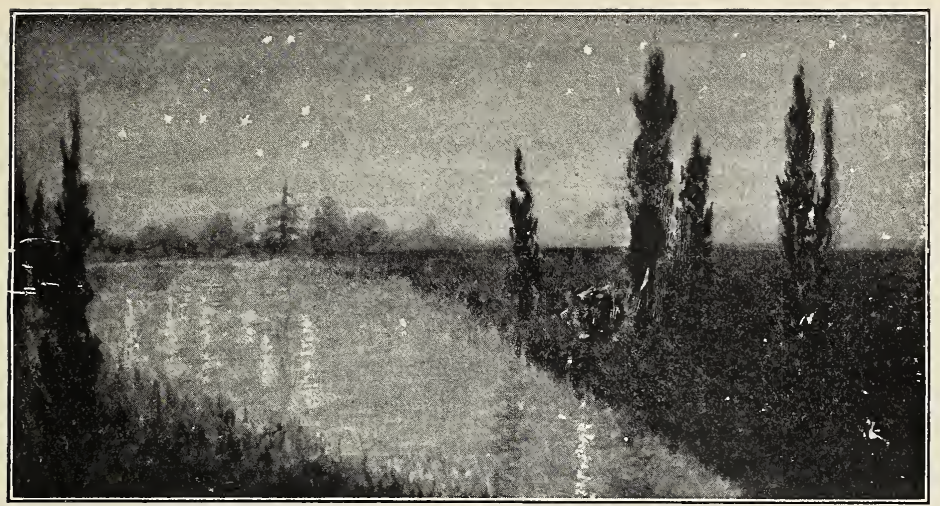

"Though I know not what you are, twinkle, twinkle little star."

\section{THE STORY OF THE STARS Teacher's Story}

"Why did not somebody teach me the constellations and make me at home in the starry heavens, which are always overhead, and which I don't half know to this day."

-Thomas Carlyle.

For many reasons aside from the mere knowledge acquired, children should be taught to know something of the stars. It is an investment for future years; the stars are a constant reminder to us of the thousands of worlds outside our own, and looking at them intelligently, lifts us out of ourselves in wonder and admiration for the infinity of the universe, and serves to make our own cares and trials seem trivial. The author has not a wide knowledge of the stars; a dozen constellations were taught to her as a little child by her mother, who loved the sky as well as the earth; but perhaps nothing she has ever learned has been to her such a constant source of satisfaction and pleasure as this ability to call a few stars by the names they have borne since the men of ancient times first mapped the heavens. It has given her a sense of friendliness with the night sky, that can only be undcrstood by those who have had a similar experience.

There are three ways in which the mysteries of the skics are made plain to us: First, by the telescope; second, by geometry, trigonometry and calculations - a proof that mathematics is even more of a heavenly than an earthly scicnce; and third, by the use of the spcctroscope, which can only be understood after we study physics. It is an instrument which tells us, by analyzing the light of the stars, what chemical elements compose them; and also, by the means of the light, it estimates the rate at which the stars are moving and the direction of their motion toward or away from us.

'Thus, we have lcarned many things about the stars; we know that every shining star is a great blazing sun, and there is no reason to doubt that many of thcse suns have worlds, like the earth, spinning around them although, of course, so far away as to be invisible to us; for our world could not be seen at all from even the nearest star. We also know that many of 
the stars which seem single to us are really double-made up of two vast suns swinging around a common center; and although they may be millions of miles apart, they are so far away that they seem to us as one star. The telescope reveals many of these double stars and shows that they circle around their orbits in various periods of time, the most rapid makirig the circle in five years, another in sixteen years, another in forty-six years; while there is at least one lazy pair which seems to require fully sixteen hundred years to complete their circle. And the spectroscope has revealed to us that many of the stars which seem single through the largest telescope are really double, and some of these great suns race around each other in the period of a few hours, which is a rate of speed we could hardly imagine.

Astronomers have been able to measure the distance from us to many of the stars, but when this distance is expressed in miles it is too much for us to grasp. Thus, they have come to measure heavenly distance in terms of the rate at which light travels, which is 186,400 miles per second or about six trillions of miles per year; this distance is called a light-year. Light reaches us from the sun in about eight minutes, but it takes more than four years for a ray to reach us from the nearest star. It adds new interest to the Polestar to know that the light which reaches our eyes left that star almost half a century ago, and that the light we get from the Pleiades may have started on its journey before America was discovered. Most of the stars are so far away that we cannot measure the distance.

Although stars seem stationary, they are all moving through space just as our own sun is doing; but the stars are so far away that even if one moved a million miles a day, it would require years of observation to detect that it moved at all, unless it was moving toward or away from us. We know the rate of movement of some stars but have no idea of their goal, nor do we know where our sun is dragging us at the rate of nearly 800 miles a minute; all we know is that each star is going somewhere and attending strictly to its own business.

The spectroscope reveals the life cycle of stars; when young they are composed of thin gases shining red and are giant stars; when older and more condensed they shine yellow, when still more condensed they shine white and blue, which marks middle life. With old age they contract and begin to cool; after this they shine white, then yellow, then red, and then become dark, cold, dead stars. Red is a sign of infancy and of old age; but the young red stars are giants and the old red stars are dwarfs. The spectroscope reveals many dark stars in our skies; but they are not all dead suns for some of them may still be unborn. If one of these dark stars should approach another star, the force developed would shatter it into glowing, gaseous atoms and it would finally become a shining star.

Scattered through the skies are masses of misty light called nebulae, meaning "clouds." They are vast gaseous bodies of different shapes, and are classified as irregular, globular, ringed and spiral. While some are dark, many are made up of glowing gases, largely hydrogen and helium, and each nebula keeps its own place in the heavens like a star, and moves through space like a star. The spiral nebulae are at least ıо,,oo lightyears distant and are moving away at the rate of 800 miles a second; many believe that the spiral nebulae are star galaxies like our Milky Way. Many astronomers believe that nebulae have to do with the formation of stars, but this much only do they know by observation: they have seen stars change to nebulae but never the reverse. 
Nebulae are practically beyond our unaided vision; the telescope reveals about eight thousand irregular nebulae and photography shows numberless others. It is thought that radiation from the stars sets up the activity in nebulae that gives off light. The ring nebulae are mere dots compared with the spiral forms yet some idea of their size is given by Ball who says of the ring nebula of Lyra, which we cannot see with the: naked eye, if a railroad train started to cross its middle, at the rate of a mile a minute, one thousand years would not complete the journey.

The number of stars that may be seen with the unaided eye, if one were to travel from the southern to the northern polar region, would be between six and seven thousand; but it would require very keen eyes to see two thousand at one time. With the help of the telescope, about eight hundred thousand stars have been discovered, classified and catalogued, while photography of the skies reveals millions. It is thought that the new international photographic chart, which shall cover all the space seen from our globe may show thirty millions of stars. The Milky Way or Galaxy, that great, white band across the heavens, is made up of stars which are so far away that we cannot see them, but see only their diffused light. It is well called a "River of Stars" flowing in a circle around our whole solar system; and, except during the spring months, one-half of it may be seen directly above us while the other half is hidden below us. The place of the Milky Way in the heavens seems fixed and eternal; any star within its borders is always seen at the same point. Wher the Northern Cross lifts itself toward the zenith we are able to see that, near that constellation, the star river divides into three streams with long, blue islands between.

Reference books-There are a large number of excellent text-books and popular books on astronomy. The following are a few which I have used most often: Astronomy for Everybody, Newcomb; Todd's New Astronomy; The Friendly Stars, Martin; Starland, Ball; The Stars Through an Opera Glass, Serviss; Other Suns than Ours, Proctor; Other Worlds than Ours, Proctor.

For children-Earth and Sky, Holden; Stories of Starland, Proctor; The Children's Book of Stars, G. E. Mitton; Storyland of the Stars, Pratt; Stars in Song and Legend, Porter; The Planisphere, Thos. Whittaker.

\section{HOW TO BEGIN STAR STUDY \\ The Pole-star and the Dippers \\ Teacher's Story}

The way to begin star study is to learn to know the Big Dipper, and through its pointers to distinguish the Pole-star; for whenever we try to find any star we have to find the Big Dipper and Pole-star first so as to have some fixed point to start from. There are four stars in the bowl of the Big Dipper and three in the curved handle. A line drawn through the outer two stars of the bowl, if extended, will touch the North Star, or Pole-star. It is very important for us to know the Pole-star, because the northern end of the earth's axis is directed toward it, and it is therefore situated in the heavens almost directly above our North Pole. For those of us who live in the northern Hemisphere, the North Star never sets, but is always in our sky. Of course, the North Star has nothing to do with the axis of our earth 
any more than the figure on the blackboard has to do with the pointer; it simply happens to lie in the direction toward which the northern end of the earth's axis points. In the southern skies, there is no convenient star which lies directly above the South Pole, so there is no South Pole-star. It is also a coincidence that the needle of the mariner's compass points toward the North Star; the earth being a large magnet exercises its influence on all substances which can be magnetized, and since the poles of our great earthmagnet are nearly in line with the poles of the earth's axis, the magnetic needle naturally points approximately north and south in many regions, and the North Star chances to be nearly in the direction toward which the northern end of the compass needle points.

The Pole-star cannot be seen from the southern hemisphere; but if we should start from Florida, on a journey toward Baffin's Bay, we should discover that each night this star would seem higher in the sky. And if we should succeed in reaching the North Pole, we would find the Polestar directly over our heads, and what a wonderful sight the stars would be from this point! For none of the stars which we could see would rise or set, but would move around us in circles parallel to the horizon.

The Big Dipper shows to us the Pole-star, and to us seems to revolve around it every twenty-four hours but, of course, this appearance is caused by the fact that we ourselves are revolving from west to east. Therefore, the stars seems to revolve from west to east under the Pole-star and from east to west above it, or in exactly the opposite direction in which the hands of a clock turn. Owing to the movement of the earth in its orbit, the Big Dipper and all the other stars arrive at a certain point in our sky four minutes earlier each day or about two hours earlier each month; thus, the Big Dipper is east of the Pole-star with handle down in the evenings of January, while at the same time of night in July, it is west of the Pole-star with the handle up. But the time of year that a certain star reaches a certain point is so invariable, that if we know star time, or sidereal time as it is called, we can tell just what hour of the night it is when a star passes this point. Thus, the Big Dipper and the other polar constellations are the night clock of the sailors of the northern hemisphere; for though this great polar clock has its hands moving around the wrong way, it gains time

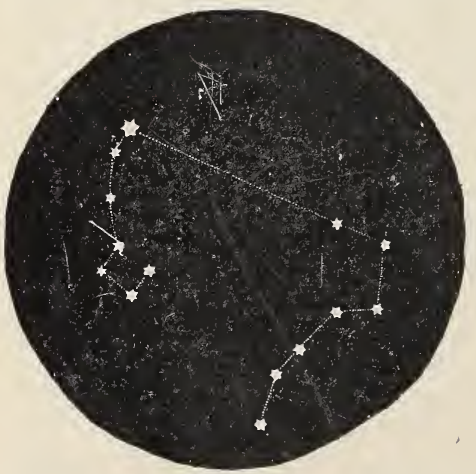

The Pole-star and the Big and Little Dippers. with such regularity that anyone who understands is able to compute exact time by it.

The Little Dipperliesmuchnearer the Pole-star than does the Big Dipper; in fact, the Pole-star itself is the end if the handle of the Little Dipper. Besides the Pole-star, there are two more stars in the handle of the Little Dipper, and of the four stars which make the bowl, the two that form the outer edge are much the brighter. The bowl of the Little Dipper is above or below the Polestar according to the hour of the evening, or the night of the year, for it apparently revolves about the Pole-star as does the Big Dipper. 
The two Dippers open toward each other, and some one said "they pour into each other."

The Big Dipper is a part of a constellation called Ursa Major, the Great Bear; and the Little Dipper is the Little Bear, the handlc of the dipper being the bear's tail.

There is an ancient myth tclling the story of the Big and Little Bears: A beautiful mother called Callisto had a little son whom she named Arcas. Callisto was so beautiful that she awakened the anger of Juno, who changed her to a bear; and when her son grew up he became a hunter, and one day would have killed his transformed mother; but Jupiter seeing the danger of this crimc caught the two up into the heavens, and set them there as shining stars. But Juno was still vindictive, so she wrought a spell which never allowed these stars to rise and set like other stars, but kept them always moving around and around.

References-The Friendly Stars by Martin is a most delightful book and at the same time gives explicit directions for finding the stars and much interesting information concerning them. The planisphere is a little chart with a mechanical device which enables us to find what stars are in sight every night of the year, or at any time of night. It is published by Thos. Whittaker, Bible House, New York, and costs seventy-five cents.

\section{LESSON CCXXV}

\section{The Two Dippers}

Leading thought-The North Star or Pole-star may always be found by the stars known as the pointers in the Big Dipper; the stars of the Big Dipper seem to revolve around the Pole-star once in twenty-four hours.

Method-The time to bcgin these observations is when the moon is in its last quarter, so that the moonlight will not make pale the stars in early evening. Draw upon the blackboard, from the chart shown on page 890 , the Big Dipper and the Pole-star, with a line extending through the pointers. Say to the pupils that this Big Dipper is above or below or at one side of the Pole-star, and that you wish them to observe for themselves where it. is and tell you about it the next day. After they surely know the Big Dipper, ask the following questions:

Observations-I. Can you find the Big Dipper among the stars

2. Is it in the north, south, east or west?

3. Which stars are the "pointers" in the dipper, and why are they called so?

4. Make a drawing showing how you can always find the Pole-star, if you can see the Big Dipper.

5. How many stars make the bowl of the Dipper?

6. How many stars in the handle?

7. Is the handle straight or is it curved?

8. Does the Big Dipper open toward the Pole-star, or away from it?

9. Is it above or below the Pole-star at eight o'clock in the evening, or at the right or the left of it?

Io. Does the Big Dipper remain in the same direction from the Polestar all night? Look at it at seven o'clock and again at nine o'clock and see if it has changed position?

I I. Do you think it moves around the Pole-star once every twenty-four hours? In which direction? How could you tell the time of night by the Big Dipper and the Pole-star? 
I 2. Does the Big Dipper ever rise and set?

I3. The Big Dipper is also called the Great Bear. Can you find the stars which make the bear's head and front legs?

After the pupils surely know the Big Dipper and Pole-star draw the complete diagram upon the board to show the Little Dipper and where it may be found, and call attention to the fact that the end of the Little Dipper's handle is the Pole-star itself and that its bowl is not flaring, like that of the Big Dipper and that the two pour into each other. Let the pupils find the Little Dipper in the sky for themselves and ask the following questions:

Observations-I4. Is the Little Dipper nearer or farther from the Polestar than the Big Dipper?

I 5. How many stars in the handle of the Little Dipper?

I6. How many stars make the bowl of the Little Dipper? Which of these stars are the brightest? Is the bowl of the Little Dipper above or below the Pole-star?

I 7. Does the Little Dipper extend in the same direction in relation to the Pole-star all night?

I8. Make observations on the relation to each other of the two dippers at eight o'clock in the evening of January, February, March and April.

After the above lessons are well learned, give the following questions, and try to have the pupils answer by thinking:

Questions about Polaris (the North Star) for the pupils to think about and answer:

I9. How many names has the Pole-star? Can the Pole-star be seen from the southern hemisphere? If not, why not?

20. If you should start from southern Florida and travel straight north, how would the Pole-star seem to change position each succeeding night?

$2 \mathrm{I}$. If you could stand at the North Pole, where would the Pole-star seem to be?

22. If you were at the North Pole, would any of the stars rise and set? In what direction would the stars seem to move and why? why?

23. How does the North Star help the sailors to navigate the seas and

24. How do astronomers reckon distances between us and the stars? What is a light-year?

Topics for English lesson-(a) What a star is. (b) What a constellation is. (c) How the stars and constellations received their names in ancient times. In ancient times the Big and Little Dippers were named the Big and Little Bears, and that is their Latin name to this day. Write a story about what the ancient Greeks told about these Bears and how they came to be in the sky.

Supplementary reading-Stories of Starland, Proctor, pp. I I 7-I 2 I: Storyland of the Stars, Pratt, p. 75; Child's Study of the Classics, p. 33 . 


\section{CASSIOPEIA'S CHAIR, CEPHEUS, AND THE DRAGON \\ Teacher's Story}

There are other constellations besides the two Dippers, which never rise and set in this latitude, because they are so near to the Pole-star that, when revolving around it, they do not fall below the horizon. There is one very brilliant star, called Capella, which almost belongs to the polar constella-

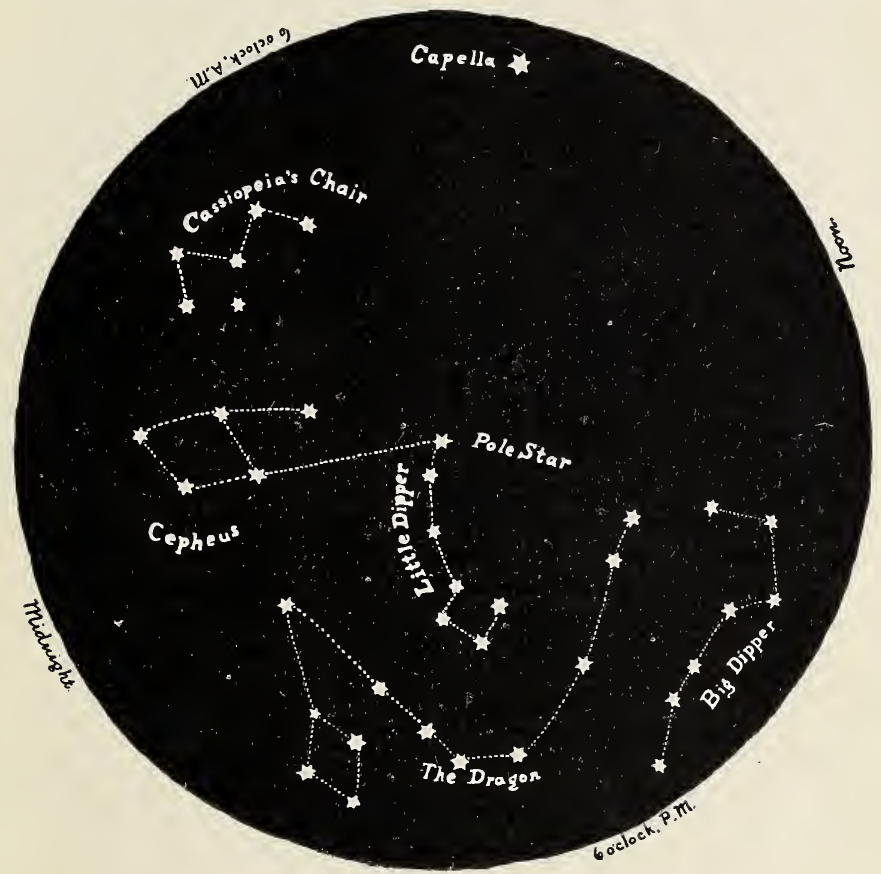

The polar constellations as they appear at about $80^{\prime}$ clock January 20 , the Dragon being south of the Pole-star. By revolving this chart as indicated, the positions of the stars is shown for 6 p. m., midnight, 6 a.m. and noon of January 20 th.

tions but not quite, for it is far enough away from Polaris to dip below the horizon for four hours of the twenty-four.

Queen Cassiopeia's Chair is on the opposite side of the Pole-star from the Big Dipper and at about equal distance from it. It consists of five brilliant stars that form a W with the top toward Polaris, one-half of the W being wider than the other. There is a less brilliant sixth star which finishes out half of the $\mathrm{W}$ into a chair seat, making of the figure a very uneasy looking throne for a poor queen to sit upon.

King Cepheus is Queen Cassiopeia's husband, and he sits with one foot on the Pole-star quite near to his royal spouse. His constellation is marked 
by five stars, four of which form a lozenge, and a line connecting the two stars on the side of the lozenge farthest from Cassiopeia, if extended, will reach the Pole-star as surely as a line from the Big Dipper pointers. Cepheus is not such a shining light in the heavens as is his wife, for his stars are not so brilliant. Perhaps this is because he was only incidentally put in the skies. He was merely the consort of Queen Cassiopeia, who being a vain and jealous lady boasted that she and her daughter, Andromeda, were far more beautiful than any other goddesses that ever were, and thus incurred the wrath of Juno and Jupiter who set the whole family "sky high" and quite out of the way, a punishment which must have had its compensations since they are where the world of men may look at and admire them for all ages.

Lying between the Big and Little Dippers and extending beyond the latter is a straggling line of stars, which, if connected by a line, make a very satisfactory dragon. Nine stars form his body, three his head, the two brighter ones being the eyes.

\section{LESSON CCXXVI \\ Cassiopeia's Chair, Cepheus, and the Dragon}

Leading thought-To learn to know and to map the constellations which are so near the Pole-star that they never rise or set in our latitude, but seem to swing around the North Star once in twenty-four hours.

Method-Place on the blackboard the diagram given showing the Polestar, Big and Little Dippers and Cassiopeia's Chair, and ask for ubservations and sketches showing their position in the skies the following evening. After the pupils have observed the Chair and know it, add to your diagram, first Cepheus and then the Dragon. After you are sure the pupils know these constellations, give the following lesson. The observations should be made early and late in the same evening and at different times of the month, so that pupils will in every case note the apparent movement of these stars around Polaris.

Observations - I. How many stars form Cassiopeia's Chair? Make a drawing showing them and their relation to the Pole-star.

2. Is the Queen's Chair on the same side of the Pole-star as the Big Dipper? Is the top or the bottom of the "W" which forms Cassiopeia's Chair turned toward the Pole-star?

3. Does Cassiopeia's Chair move around the Pole-star, like the Big Dipper?

4. How many stars mark the constellation of Cepheus?

5. Make a sketch of these stars and show the two which are pointers toward the North Star.

6. Does Cepheus also move around the Pole-star, and in which direc. tion?

7. Describe where the Dragon lies, and where are his tail and his head in relation to the two Dippers. Make a sketch of the Dragon.

8. Why do all the poplar constellations seem to move around the Polestar every twenty-four hours, and why do they seem to go in a direction opposite the movement of the hands of a clock? What do we mean by "Polar constellations"?

Topics for English Themes-The Story of Queen Cassiopeia, King Cepheus and their daughter, Andromeda; the story of the Dragon.

Supplementary reading-Storyland of the Stars, Frati. 


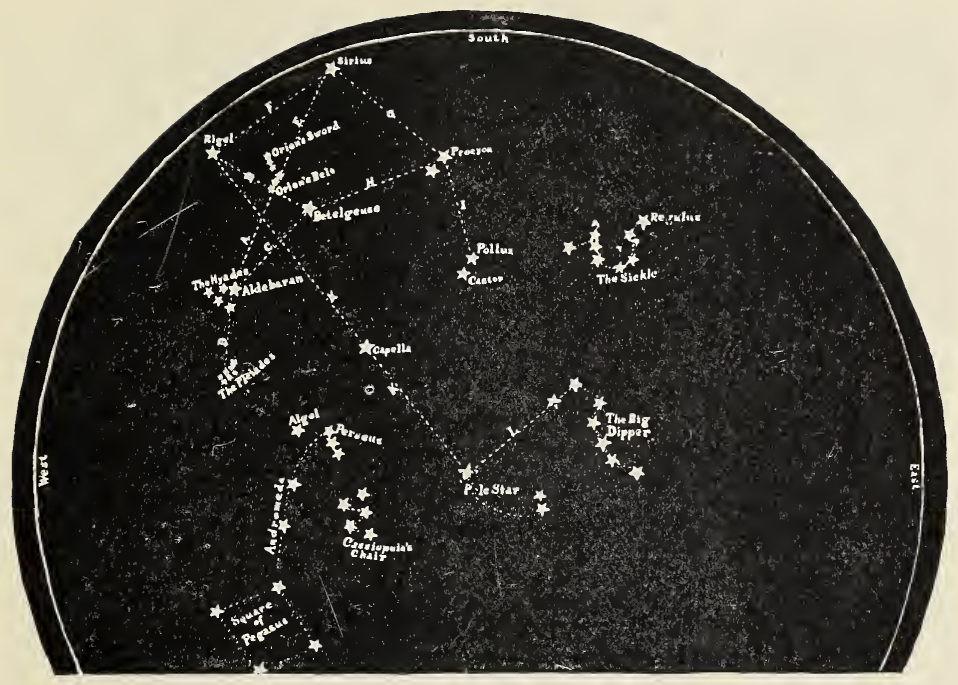

A diagram of the principal stars of winter as seen in early evening late in February.

To use the chart take it in the hands, face the Pole-star and hold the chart above the head so that the side marked east will extend eastward.

\section{THE WINTER STARS}

\section{Teacher's Story}

The natural time for beginning star study is in the autumn when the days are shortening and the early evenings give us opportunity for observation. After the polar constellations are learned, we are then ready for further study in the still earlier evenings of winter, when the clear atmosphere and beautiful blue of the heavens make the stars seem more alive, more sparkling, and more beautiful than at any other period of the year. One of the first lessons should be to instruct the pupils how to draw an imaginary straight line from one star to another, and to perceive the angles which such lines make when they meet at a given star. A rule, or what is just as effective, a postal card or some other piece of stiff paper which shows right-angled corners, is very useful in this work. It should be held between the eyes and the stars which we wish to connect, and thus make us certain of a straight line and a right angle.

\section{ORION (o-ri'on)}

During the evenings of January, February and March the splendid constellation of Orion takes possession of the southern half of the heavens; and so striking is it that we find other stars by referring to it instead of to the Pole-star. Orion is a constellation which almost everyone knows; three stars in a row outline his belt, and a curving line of stars, set obliquely below the belt, outline the sword. Above the belt in the evening sky we can 


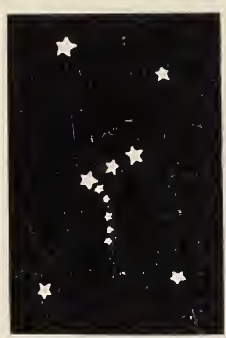

Orion, the three large stars in a line forming the belt, the curved line of smaller stars below forming the sword, Betelgeuse above, Rigel below.

see the splendid red star Betelgeuse (bet-el-gerz), and below the belt, at about an equal distance, is the white star Rigel $(r e-j e l)$. West of the red star above, and east of the white star below, are two fainter stars, and if these four stars are connected by lines, an irregular foursided figure results, which includes the belt and the sword. In this constellation the ancients saw Orion, the great hunter, with his belt and his sword; Betelgeuse was set like a glowing ruby on his shoulder, and the white star Rigel was set like a spur on his heel. Thus, stood the great hunter in the sky, with his club raised to keep off the plunging bull whose eye is the red Aldebaran $\left(a l-d e b^{\prime} a-r a n\right)$. And beyond him follows the Great Dog with the bright blue star Sirius (sir'i-us) in his mouth, and the Little Dog branded by the white star Procyon (pro'si-on). However, our New England ancestors did not see this grand figure in the sky; they called the constellation the Yard-ell or the Ell-yard.

The three beautiful stars which make Orion's belt are all double stars; the belt is just three degrees long and is a good unit for sky measurement. The sword is not merely the three stars which we ordinarily see, but is really a curved line of five stars; and what seems to be the third star from the tip of the sword and which looks hazy, is in fact a great nebula. Through the telescope this nebula seems a splash of light with six beautiful stars within it. The first star in Orion to appear above the horizon is red Betelgeuse, a blushing young giant just starting on its career as a star; it is composed of a gas much thinner than our air. Its diameter is $215,000,000$ miles, which is millions more than that of the Earth's orbit. It is one hundred and sixty light-years away from us and it is receding from us all the time. About fifteen minutes after Betelgeuse rises, and after the belt and sword are in sight, a white sparkling star appears at the southwest of the belt. This is Rigel, and its distance is too great to measure.

\section{LESSON CCXXVII OrION}

Leading thought-Orion is one of the most beautiful constellations in the heavens. It is especially marked by the three stars which form Orion's belt, and the line of stars below the belt which form the sword.

Method-Place on the blackboard the outline of Orion as given in the diagram. Ask the pupils to make the following observations in the evening and give their report the next day.

Observations-I. Where is Orion in relation to the Pole-star?

2. How many stars in the belt of Orion? How many stars in the sword? Can you see plainly the third star from the bottom of the sword?

3. Notice above the belt, about three times its length, a bright star; this is Betelgeuse. What is the color of this star? What do we know about the age of a star if it is red?

4. Look below the belt and observe another bright star at about the same distance below that Betelgeuse is above. What is the color of this star? What does its color signify? The name of this star is Rigel. 
5. Note that west of the red star above and east of the white star below are two fainter stars. If we connect these four stars by lines we shall make an irregular four-sided figure, fencing in the belt and sword. Sketch this figure with the belt and sword, and write on your diagram the name of the red star above and the white star below and also the name of the constellation.

6. Which star of the constellation rises first in the evening? Which last?

7. Write an English theme on the story of Orion, the great hunter.

Supplementary reading-Stories of Starland, Proctor; The Stars in Song and Legend, Porter; Storyland of the Stars, Pratt.

\section{ALDEBARAN AND THE PLEIADES Teacher's Story}

Almost in a line with the.belt of Orion, up in the skies northwest from it, is the rosy star Aldebaran. This star, which is also a ruddy young giant, marks the end of the lower arm of a $\mathrm{V}$-shaped constellation composed of this and four other stars. This constellation is the Hyades $\left(h i^{\prime} a-d e z\right)$. The Hyades is a part of the constellation called by the ancients Taurus, the bull, and is the head of the infuriated animal. Aldebaran is a comparatively near neighbor of ours, since it takes light only thirty-twoAldebaran in the $V$ years to pass from it to us. It gives off about fortyfive times as much light as does our sun; it lies in the path traversed by the moon as it crosses the sky, and is often thus hidden from our view.

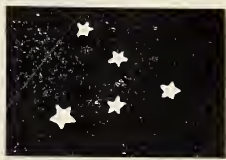

shaped constellation called the Hyades.

This is a part of the constellation, Taurus.

Although we are attracted by many bright stars in the winter sky, yet there is a little misty group of stars, which has ever held the human attention enthralled, and of which the poets of all the ages have sung. These stars are called the Pleiades (ple'ya-dees); most eyes can count only six stars in the constellation. There are nine stars large enough to be seen through the telescope, and which have been given names; but sky photography has revealed to us that there are more than three thousand stars in this little group. Perhaps no stars in the heavens give us such a feeling of the infinity of the universe as do the Pleiades; for astronomers believe that they form a great star system, known as one of the globular nebulae. The reason for this belief is that these stars

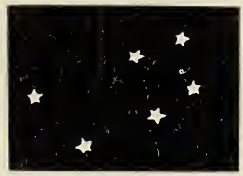

The Pleiades, a group of six small stars sur. rounded by a misty light. in the Pleiades to another. The Pleiades are so far from us that only recently have astronomers estimated that it takes light six hundred years to reach us from them. There is a mythical sometimes seems to be looped from one to another; and, too, the stars are all in the same stage of development and have the same chemical composition, and they are all moving together in the same direction. These stars which look so close together to us are so far apart really that our own sun and all its planets could roll in between them and never be noticed. It would require several years for light to travel from one of these stars seem to be surrounded by a brilliant mist which 
story found in literature, that once the unaided eye could see seven instead of six stars in the Pleiades, and much poetic imagining has been developed to account for the "lost Pleiad."

\section{LESSON CCXXVIII}

\section{Aldebaran and the Pleiades}

Leading thought-The Pleiades seem to be a little misty group of six stars, but instead there are in it three thousand stars. Half way between the Pleiades and Orion's belt is Aldebaran, an ageing ruddy star.

Method-Draw the diagram (p. 895) on the blackboard showing Orion, Aldebaran and the Pleiades, and the lines B, C, D. Give an outline of the observations to be made by the pupils, and let them work out the answers when they have opportunity. Each pupil should prepare a chart of these constellations.

Observations-I. Imagine a line drawn from Rigel to Betelgeuse and then another line just as long extending to the west of the latter at a little less than a right angle, and it will end in a bright, rosy star, not so red as Betelgeuse.

2. What is the name of this star? Write it on your chart.

3. Can you see the figure $V$ formed by Aldebaran and four fainter stars? Sketch the V and show where in it Aldebaran belongs. This V-shaped constellation is called the Hyades.

4. Imagine a line drawn from Orion's belt to Aldebaran and extend it to not quite an equal length beyond it, and it will end near a "fuzzy little bunch" of stars which are called the Pleiades. Place the Pleiades on your chart.

5. How many stars can you see in the Pleiades?

6. Why are they called the seven sisters?

7. How many stars in the Pleiades which are named, and how many does photography show that there really are in the group?

8. How far apart from each other are the nearest neighbors of the Pleiades?

9. What do the astronomers think about the Pleiades and why do they think this?

\section{THE TWO DOG STARS, SIRIUS AND PROCYON Teacher's Story}

If a line from Aldebaran pass through the belt of Orion and is extended about as far on the other side, it will reach the Great Dog Star, following at Orion's heels. This is Sirius, (Sir'-e-us) the most brilliant of all the stars in our skies, glinting with ever changing colors, sometimes blue, at others rosy or white. It must have been of this star that Browning wrote:

\footnotetext{
"All that I know

Of, a certain star

Is, it can throw

(Like the angled spar)

Now a dart of red,

Now a dart of blue."
} 
Sirius has reached the bluewhite stage of star development. Although it is larger than our sun, its superior brilliance is due to its nearness to us; it is only eight and one-half light-years away from us and is the most celebrated star in literature. The ancients knew it, the Egyptians worshipped it, Homer sang of it, and it has had its place in the poetry of all ages.

Procyon, (pro'-se-on) the Little Dog Star, was so-called perhaps because it trots up the eastern skies a little ahead of the magnificent Great Dog

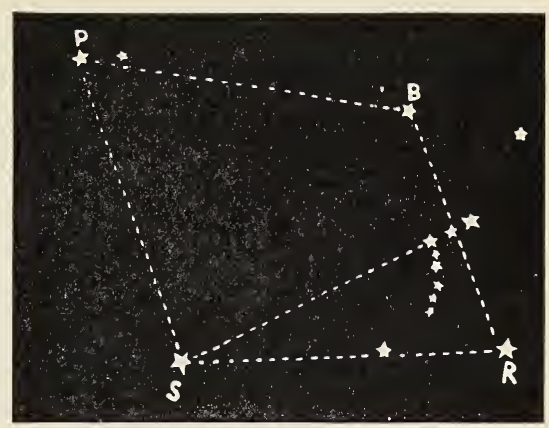

Orion and the Dog Stars.

B, Betelgeuse; R, Rigel; S, Sirius, the Great Dog Star; P, Procyon, the Little Dog Star. Star; it gives out eight times as much light as our sun, and is only ten light-years away from us. It has a fainter companion about three or four degrees to the northwest of it.

\section{LESSON CCXXIX \\ The Two Dog Stars}

Leading thought-The Great Dog Star, Sirius, is the most famous of all stars in the literature of the ages. The Two Dog Stars were supposed by the ancients to be following the great hunter, Orion.

Method-Draw upon the board from the chart shown on this page, the constellation of Orion with Sirius and Procyon. Ask the pupils to note that after Orion is well up in the sky a straight line drawn through Orion's belt and dropping down toward the eastern horizon ends in a beautiful white star, which is Sirius. And that if we draw a line from Betelgeuse to Rigel from Rigel to Sirius and then draw lines to complete a quadrangle, we shall find our lines meet at a bright star just a little too far away to make the figure a square, but making it somewhat kite-shaped instead. This is the Little Dog Star, Procyon, and it has a twin star near it. After giving these directions let the children make the following observations:

r. How do you find Sirius? Which rises first, Orion or Sirius?

2. What color is Sirius? Judging from its color what stage of development do you think it is in?

3. Try and find out how large Sirius is compared with our sun and how near it is to us.

4. Why is Sirius called the Great Dog Star? Is the Little Dog Star nearer to the North Star than Sirius? Which is the brighter, the Great Dog Star or the Little Dog Star? Can you see any fainter star near Procyon?

5. Why is Procyon called the Little Dog Star?

6. Make a chart showing Orion and the two Dog Stars. 


\section{CAPELLA AND THE HEAVENLY TWINS}

\section{Teacher's Story}

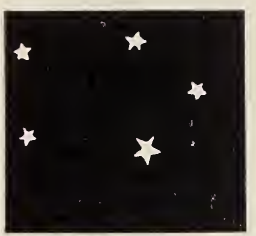

Capella in the constellation Auriga.

Capella is nearer to the North Star than any other of the bright stars and it comes very near belonging to the strictly polar constellations, since it falls below the horizon only four hours out of twenty-four. In composition it much resembles our sun, as do all the bright yellow stars; but it is much larger; it gives off one hundred and twenty times as much light as our sun, and it is forty light-years away from us. Capella is always a beautiful feature of the northern skies, being almost in the zenith during the evenings of January and February. It is in a brilliant shield . shaped constellation known as Auriga. Capella is a double star.

During the winter evenings we see two stars set like glowing eyes almost in the zenith, and in a region of the sky where there are no other bright stars. These twin stars are set just a little closer together than are the pointers of the Big Dipper. To this brilliant pair the ancients gave the names of Castor and Pollux. Pollux is the brighter of the two and is the more southward in situation. Pollux and Castor were two beautiful twin boys who loved each other so much that, after they were dead, they were placed in the skies where they could always be near each other. The twin stars are supposed to exert a benign influence on oceans and seas and are, therefore, beloved by sailors. Although they seem to us so near together, they are separated by a space so great that we cannot conceive of it and they are going in opposite directions.

Pollux is a yellow star, and supposed to be in the same stage of development as our sun, while Castor is white and according to star ages is young. When a boy says "By Jimminy," he does not realize that he is using an ancient expletive "By Gemini," which is the Latin name of these twin stars and was a favorite ancient oath, especially of sailors.

\section{LESSON CCXXX}

\section{Capella and the Heavenly Twins}

Leading thought-There are, during the evenings of January and February, three brilliant stars almost directly overhead. One of these is Capella, the other two are the Heavenly Twins.

Method-Place on the board the part of the chart (p. 895) showing the Big Dipper, Pole-star, Capella and the Twins. Draw a line, L, from the pointers of the Big Dipper, and extend it to the Pole-star. Draw another line, $\mathrm{K}$, from the Pole-star at right angles to the line L, and on the side away from the Big Dipper's handle, and it will pass through a large, brilliant, yellow star which is Capella. Ask the pupils to imagine similar lines drawn across the sky, when they are making their observations and thus find these stars, and to place them on their charts, making the following observations:

I. What color is Capella, and how does its color compare with that of our sun? 
2. Is Capella as near to the Pole-star as the Big Dipper? Is it near enough so that it never sets?

3. Can you see the shield-like constellation of which Capella is a part? Do you know the name of this constellation?

4. How do you find the Heavenly Twins after you have found Capella?

5. Why are these stars called the Heavenly Twins? What is their Latin name? What are the names of the two stars? Are these twins set nearer together than the pointers of the Big Dipper?

6. How can you tell the Heavenly Twins from the Little Dog Star and its companion?

7. Read in the books all that you can find about the Heavenly Twins. Try and find if they are the same age, if they are as near together as they seem, and if they are going in the same direction. What did the ancient sailors think of these twin stars?

\section{THE STARS OF SUMMER}

To us, who dwell in a world of change, the stars give the comfort of abidingness; they remain ever the same to our eyes and the teacher should make much of this. When we once come to know a star, we know exactly where to find it in the heavens, wherever we may be. A star which a person knows during childhood will, in later life and in other lands, seem a staunch friend and a bond, drawing him back to his early home and associations.

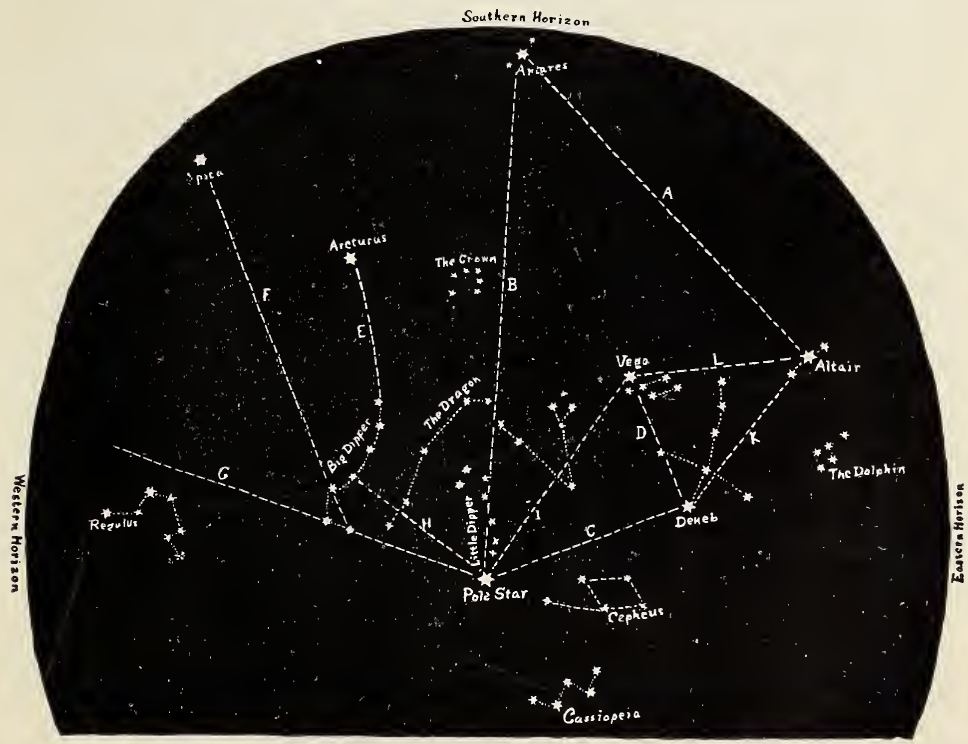

$A$ chart of the brightest stars of summer, showing their positions in early evenings of June. To find the stars hold the chart above the head and face the north. 
The summer is an enticing season for making the acquaintance of eight of the fifteen brightest stars visible in northern latitudes. Few midsummer entertainments rival that of lying on one's back on the grass of some open space which commands a wide view of the heavens, and there with a planisphere and an intermittently lighted candle with which to consult it, learn by sight, by name and by heart those brilliant stars which will ever after meet with friendly greeting our uplifted eyes. To teach the children in a true informing way about the stars, the teacher should know them, and nowhere in nature's realm is there a more thought-awakening lesson.

\section{LESSON CCXXXI}

\section{The Bright Stars of Summer}

Leading thought-The stars which we see shining during summer evenings are not the same ones that we see during the winter evenings, except those in the polar constellations. There are eight of the brilliant summer stars, which we should be able to distinguish and call by name.

Method-Begin by the middle of May when the Big Dipper is well above the Pole-star in the early evening, and when, therefore, Regulus, Spica, Arcturus and the Crown are high in the sky. The others may be learned in June, although July is the best month for observing them. In teaching the pupils how to find the stars, again instruct them how to draw an imaginary straight line from one star to another and to observe the angles made by such lines connecting three or four stars.

Place upon the blackboard the figures from the chart (page 90I), as indicated, leaving each one there until the pupils have observed and learned it. Then erase and place another figure. In each case try to get the pupils interested in what we know about each star, a brief summary of which is given. Note that the observations given in the lessons are for early in the evenings of the last of May, of June, and of early July.

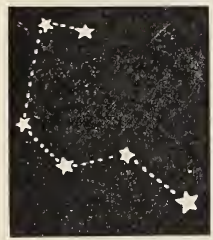

Regulus, the large star in the handle of the sickle.

\section{Regulus (reg'-u-lus)}

Draw upon the blackboard from the chart (p. 9or) the Pole-star, the Big Dipper, the line G and the Sickle shown just below the outer end of the line. Extend the line that passes through the pointers of the Big Dipper to the North Star backward into the western skies; just west of this line lies a constellation called the Sickle, and the stars that form it outline this implement. The Sickle has a jewel at the end of the handle, which is a white and diamond-glittering star called Regulus. It is a great sun giving out one thousand times as much light as our own sun, and this light reaches us in about one hundred and sixty years. The Sickle is part of a constellation called the Lion, and from which comes the shower of meteors which we see on the evening of November 13th. Regulus is seen best in Spring.

\section{Arcturus (ark-tu'rus)}

Place on the blackboard the Big Dipper, the Pole-star and the line E, Arcturus and the Crown. Extend the handle of the Big Dipper fol- 
lowing its own curve for about twice its length and it will end in a beautiful, yellow star, the only very bright one in that region. It is a thousand times brighter than our own sun, but its light does not reach us for a hundred years after it is given off. Arcturus

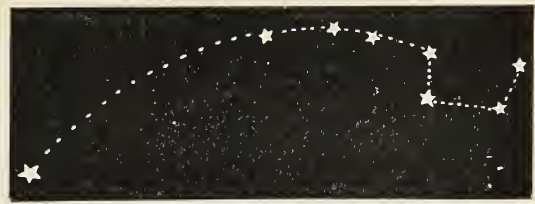

Arcturus and the Big Dipper. is supposed to be one of the largest of all the suns, having a diameter of twenty-one million miles. During the latter part of June and July it is almost overhead in the early evening.

\section{The Crown}

Between Arcturus and Vega, but much nearer the former,

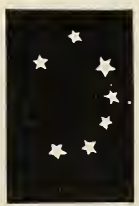

The Northern Crown. is a circle of smaller stars that is called the Northern Crown, and which because of its form is quite noticeable.

$$
\text { Spica }\left(s p i^{\prime}-k a\right)
$$

Place on the blackboard the Big Dipper, the Pole-star, the line $\mathrm{F}$ and Spica. To find Spica draw a line through the star on the outer edge of the top of the bowl of the Big Dipper, through the star at the bottom of the bowl next the handle, and extend this line far over to the southwest, during the evenings of June and July. (See page 9or) In August, this star sets at ten o'clock. Spica is a white star, and is the only bright one in that part of the sky. It is so far away from us that the distance has never been measured. Spica is in the constellation called the Virgin.

$$
\text { Vega }\left(v e e^{\prime}-g a\right)
$$

Place on the blackboard the Pole-star, the Big Dipper, the lines $\mathrm{H}$ and $\mathrm{I}$ and Vega with her five attendant stars, as shown in the chart. Teach that these stars are the chief ones in the constellation called The Lyre. To find Vega, draw a line from the Pole-star to the star in the Big Dipper which joins the bowl to the handle. Then draw a line at right angles to this (see chart lines $\mathrm{H}, \mathrm{I}$ ) and extend the line I a little farther from the North-star than is the end star of the Dipper handle; this line will reach a bright star, bluish in color, which can always be identified by four smaller attendant stars which lie near it and outline a parallelogram with slanting ends. Vega is the most brilliant summer star that we see in the northern hemisphere. It is a very large sun, giving out ninety times as much light as our sun; it is so far away that it requires

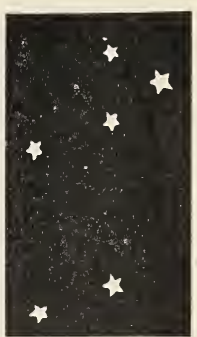

Vega and her train of five stars.

twenty-nine years for a ray of light to reach us from it. Vega's chief interest for us, aside from its beauty, is that toward it our sun and all its planets, including our earth, are moving at the rate of thirteen miles per second. 


\section{Antares (an-ta'-rees)}

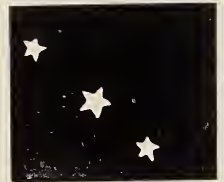

Antares, a brilliant star in the southern skies

Add to the last diagram on the blackboard the line E, Arcturus, the line B and Antares. To find this star, draw a line half way between Arcturus and Vega from the Pole-star straight across the sky to the south, and just above the southern horizon it will point to the glowing star, Antares, in the constellation of the Scorpion. Also a line drawn at right angles to the line connecting Altair with its companions and extending toward the south will reach Antares. Late June and July about ten o'clock in the evening is the best for viewing this beautiful star. An interesting thing about Antares is that it is the greatest of the young giant-stars yet measured; it has a diameter of $400,000,000$ miles.

\section{Deneb, or Arided (den'-eb; $a^{\prime}$-ri-ded)}

Erase from the last diagram Antares and the line B. Add to it the lines C and D making a right angle at Deneb; and the Cross - the head of which is Deneb, the foot ending near the letter on line L. This star is at the head of the Northern Cross, which is a very shaky looking cross and appears upside down in the eastern skies during the evenings of June and July. Deneb is white in color and is a very large sun, because it seems to us a bright star although it is so far away from us that the distance has never been surely measured; but it has been estimated that a ray of light would need at least three hundred and twenty-five years to reach us from Deneb. It and the cross are a part of the constellation of Cygnus, or the Swan.

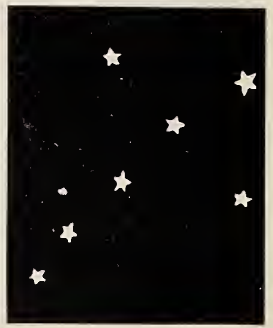

The Northern Cross, in the constellation of the Swan.

\section{Altair}

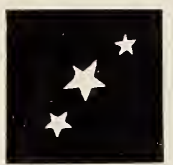

Altair in the constellation of the Eagle.

Add to the last diagram on the board the lines $\mathrm{L}, \mathrm{K}$, Altair and its two attendant stars and the Dolphin. Emphasize the fact that Altair marks the constellation of Aquila, or the Eagle. This beautiful star is easily distinguished because of its small companions, one on each side, all three in a line. The three belong to a constellation called the Eagle, and may be seen in early evening from June to December. Altair, Deneb and Vega form a triangle with the most acute angle at Altair. (See chart L, K.) Just northeast of Altair is a little diamond-shaped cluster of stars called the Dolphin, which is a good name for it, since it looks like a Dolphin, the fifth star forming the tail. It is also called Job's Coffin, but the reason for this is uncertain, unless Job's trials extended to a coffin which could not possibly fit him. If the line $\mathrm{C}$ on the chart drawn from the Pole-star to

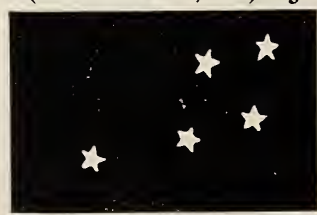

The Dolphin or Job's Coffin. Deneb be extended, it will touch the Dolphin. Altair is always low in the sky; it is a great sun giving off nearly ten times as much light as our own sun; light reaches us from it in fifteen years. 


\section{THE SUN}

\section{Teacher's Story}

To be retold to pupils.

If, only once in a century, there came to us from our great sun, light and heat, bringing the power to awaken dormant life, to lift the plant from the seed and clothe the earth with verdure, then it would indeed be a miracle. But the sun by shining every day cheapens its miracles in the eyes of the thoughtless. While it hardly comes within the province of the naturestudy teacher to make a careful study of the sun, yet she may surely stimulate in her pupils a desire to know something of this great luminous center of our system.

Our sun is a great shining globe about one hundred and ten times as thick through as the earth, and more than a million times as large. If we look at the sun in a clear sky, it is so brilliant that it hurts our eyes. Thus, it is better to look at it through a smoked glass, or when the atmosphere is very hazy. If we should see the sun through a telescope, we should find that its surface is not one great glare of light but is mottled, looking like a plate of rice soup, and at times there are dark spots to be seen upon its surface. Some of these spots are so large that during very "smoky weather" we can see them with the naked eye. In September, 1908, a sun-spot was plainly visible; it was ten thousand miles across, and our whole world could have been dropped into it with a thousand miles to spare all around it. We do not, know the cause of these sun-spots, but we know they appear in greater numbers in certain regions of the sun, above and below the equator. And since each sun-spot retains its place on the surface of the sun, just as a hole dug in the surface of our earth would retain its place, we have been able to tell by the apparent movement of these spots how rapidly and in which direction the sun is turning on its axis; it revolves once in about twenty-six days and, since the sun is so much larger than our earth, a spot on the equator travels at a rate of more than a mile a second. There is a queer thing about the outside surface of the sun-the equator rotates more rapidly than the parts lying nearer the poles; this shows that the sun is a gaseous or liquid body, for if it were solid, like our earth, all its parts would have to rotate at the same rate. At periods of eleven years the greatest number of spots appear upon the sun.

Another interesting feature of the sun is the tremendous explosion of hydrogen gas mixed with the vapors of calcium and magnesium, which shoot out flames from twenty-five thousand to three hundred thousand miles high, at a rate of speed two hundred times as swift as a rifle bullet travels.i Think what fireworks one might see from the sun's surface all the time! One would not need to wait until the Fourth of July for fireworks there. These great, explosive flames can be seen by the telescope when the moon eclipses the sun, and they have been analyzed by means of the spectroscope. Besides these magnificent explosions, there is surrounding the sun a glow which is brighter near the sun's surface and paler at the edges; it is a magnificent solar halo, some of its streamers being millions of miles long. This halo is called the Corona, and is visible during total eclipses. By means of the spectroscope we know that there are about fifty chemical elements in the sun, which are the same as those we find upon our earth.

The sun weighs 330,000 times as much as the earth; the force of gravity upon its surface is twenty-seven and two-thirds times as much as it 
is here. A letter which weighs an ounce here would weigh almost a pound and three quarters on the sun; and a man of ordinary size in this world would weigh more than two tons there, and would be crushed to death by his own weight. Find how much your watch, your book, your pencil, your baseball, your football would weigh on the sun.

\section{Our Sun and its Family}

First of all we shall have to acknowledge that our great, blazing sun is simply a medium-sized star, not nearly so large as Vega, nor even as large as the Pole-star; but it happens to be our own particular star and so is of the greatest importance to us. The sun has several other worlds, more or less like our own, revolving around it on almost the same level or plane in which our world revolves, but some of these worlds are much nearer the sun and others much farther away than ours. Nearest of all is Mercury, but it is not half so thick through as our earth, and it is so close to the sun that it circles around in 88 days; that is, its year is only 88 days long. Next comes Venus, almost as large as the earth, with a year 225 days long; next comes our earth, which completes its year in 365 days; next beyond us is Mars, a little more than half as thick as the earth and with a year 687 days long; beyond Mars is a group of small planets which are not large enough to be seen with the telescope, but we know that one of the largest of the group is only 490 miles through; beyond this mysterious swarm of little worlds is great Jupiter almost ten times as thick through as the earth, and it is so far away that it does not circle about the sun but once in I I years; beyond great Jupiter comes Saturn, not quite ten times the diameter of the earth and so far from the sun that it takes $291 / 2$ years for it to move around its orbit; beyond Saturn is Uranus, only about four times as thick through as our world, and it has a year 84 years long; but the outermost of all our sun's planets is Neptune, little larger than Uranus, but so far from the sun that ${ }^{6} 65$ years are required for it to complete its circle. Just think of a spring or a winter $4 \mathrm{I}$ years long! If Methuselah had lived on Neptune, he would have died before he was five and one-half years old.

Almost all of the Earth's sister planets are better off for moons than she; neither Venus nor Mercury has any moons. Mars has two moons, Jupiter nine and Saturn has nine besides some splendid rings; strangely, two of Jupiter's and one of Saturn's moons revolve in an opposite direction from the others. Uranus has four moons, while Neptune is not any better off than we are, unless there are some we have not been able to discover because they are so far away.

One peculiar thing about all of the planets of the sun's family and all of their moons is that they all shine by reflecting the light of the sun, and none of them are hot enough to give off light independently; but these sister worlds of ours are so near us that they often seem larger and brighter than the stars, which are true suns and give off much more light than our own sun. After a little experience the young astronomer learns to distinguish the planets from the true stars; the planets always follow closely the path of the sun and moon through the sky; they often seem larger and brighter than the true stars and do not twinkle so much. The so-called morning and evening stars are other planets of our sun's family and are not stars at all.

Dr. Simon Newcomb in his delightful book, "Astronomy for Everybody," gives the best illustration to make us understand the place of our 
sun and its planets and its relation to the stars in space. He explains that if here in the Atlantic States we should make a model of our solar system by putting an apple down in a field to represent the sun; then our earth could be represented by a mustard seed forty feet away revolving around the apple; and Neptune, our outermost planet, could be represented as a small pea circling around the apple at the distance of a quarter of a mile. Thus, our whole solar system could be modeled in a field one-half mile square, except for comets which might extend out in their long orbits for several miles. But to find the star nearest to our earth, the star that is only four and one-half light-years away from us, we should have to travel from this field across the whole of North America to California, and then take steamer and go out into the Pacific Ocean before we should reach our nearest star neighbor, which would be another sun like our own and be represented by another apple.

\section{Comets}

Besides planets and stars there are in space other bodies spinning around our great sun, and following paths shaped quite differently than those followed by our earth and its sister planets. We move around the sun nearly in a circle with the sun at the center, but these other heavenly bodies move in narrow oval orbits, the sun being near one end of the ellipse and the other end being out in space beyond our farthest planet. These bodies do not revolve around the sun in the same plane as our world and the other planets; indeed they often move in quite the opposite direction. The most noticeable of these bodies whose race-track around the sun is long instead of circular are the comets, and we know that some of these almost brush the sun when turning at the end of their course. The astronomers have been able to measure the length of the race-tracks of some of the comets and thus tell when they will come back. Encke's comet, named after the German astronomer, makes its course in three and one-half years and this is the shortest period of any we know. There are five hundred comets whose courses have been thus measured; the longest period belongs to Halley's comet, which makes such a long trip that it comes back only once in seventy-six years; but there are other comets which astronomers are sure travel such long routes that they come back only once in hundreds or even thousands of years. About twelve hundred comets have been discovered, many of them so small that they can only be seen through the aid of the telescope; and it has been found that in one instance, at least, three comets are racing around the sun on the same track.

A comet is a beautiful object, usually having a head which is a point of brilliant light and a long, flaring tail of fainter light, which always extends out from it on the side opposite the sun. The head of a comet must be nearly twice as thick through as the earth in order to be large enough for our telescopes to discover it. Some of the comet heads have been measured, and one was thirty-one times, and another one hundred and fifty times, as wide as our earth. If the heads are this large, imagine how long the tails must be! Some of them are far longer than the distance from our earth to the sun. The comet head decreases as it approaches the sun.

The head of a comet is supposed to be a swarm of meteors with some gas, glowing partly by reflected light and partly by the sun's radiation. In fact, this gas has so little weight that light can push it; one would never believe that light could push anything, because we cannot feel it 
strike against us; but the physicists have found that it does push, and by pushing against the particles of the gas of comets it sends them out into a streamer away from the sun, just as the heat pushes out a flaring cloud of steam from the spout of a teakettle.

Comets have played an important part in history; they were formerly considered signs of the approval or wrath of God. The comet appearing in I066 struck terror to the Saxons and presaged the Norman conquest of England. The comet of I8I I was thought to warn us of the war of I 8 I 2 and Napoleon of his coming defeat. This was a wonderful comet illuminating our skies for a year and a half; its rosy head was veiled in a gaseous sphere one hundred and twenty miles across and its tail was one hundred and thirty million miles long. Some comets that have failed to appear when expected have their orbits marked by swarms of meteors.

Since comets are moving around the sun in every direction, it is possible that the earth may sometime meet one; and if this proves to be a "head on collision" there are those who prophesy that there will be no people left to tell the story; but the tails of comets are so thin and ethereal that our earth actually passed through one once, and no one but the astronomers knew anything about it.

\section{Shooting StaRs}

When we look up during an evening walk and see a star falling through space, sometimes leaving a track of light behind it, we wonder which of the beautiful stars of the heavens has fallen. But astronomers tell us that no real star ever fell, but that what we saw was a lump of the matter of which worlds and comets are made; and it was following its own swift path around the sun, when by chance it crossed our earth's path, and there was a collision. Luckily for us we were the larger of the two colliding bodies, and luckier still for us is the fact that our earth is surrounded by some miles of air, else we should be helpless under this meteoric bombardment. Although this shooting star was just a dark, cold lump of metal, too small for us to see, yet it was moving so swiftly along its path around the sun that the friction caused by its passing through our air, lighted it and burned it up, just as a match scratched on sandpaper lights and burns; as soon as it blazed we saw it and said, "There is a shooting star!" Sometimes the lump is so big that it does not have time to burn up while passing through the hundred miles or more of our atmosphere, and what is left of it strikes the earth usually with such force as to bury itself deep in the soil. Such lumps are called "meteoroids" before they fall and "meteors" while plunging white-hot through the air, but when they reach our earth we call what is left of them "meteorites." There are, in museums, many meteorites of this so-called stone, which is largely iron. Chemists find no new metals or elements in these strangers from space, but they do find new kinds of chemical partnerships and combinations. Some of these meteorites weigh hundreds of pounds, one in the Yale Museum weighing I635 pounds. If it were not for the air that wraps our globe, like a great, kindly blanket, and by its friction sets fire to the meteors and destroys them, no one could live on this earth because we all should be pelted to death. Prof. Newton estimated that every twenty-four hours our world meets seven millions of these shooting stars, some of them no larger than shot and others weighing tons. 


\section{The Relation Between Comets and Meteors}

It has been discovered that many of the shooting stars are gathered in great flocks and move about the sun in elongated paths, like the comets. We have learned the times of year when the path our earth follows comes close to these flocks of meteors which are flying around the sun like birds. One of these flocks is straggling, and we begin to meet it about the end of July and reach the center of the crowd on August Ioth, and then continue to take stragglers until the last of August. We can see the point where we meet this flock of meteors, if we look for it in the direction of the constellation Perseus (see planisphere). On November 13 th, we meet another flock which we find in the direction of the constellation Leo, of which the great star Regulus is the heart (see chart); but this flock is usually all in a bunch and we pass it in two days. Once there was a splendid flock which our world met every thirty-three years, and we took so many stragglers from it that our skies were filled with shooting stars, and ignorant people were greatly frightened; but for some reason, this flock has changed its path and we looked in vain for the great display of fireworks which was due to occur in 1899 .

While we know from observation that the flocks of shooting stars, which make our star showers, are just broken pieces of comets which once traveled the same path, yet it does not follow that all our shooting stars are comet fragments. Prof. Elkins has shown by photographing meteors that some of them must be wanderers in the vast spaces which lie between the stars.

\section{* THE RELATION BETWEEN THE TROPIC OF CANCER AND THE PLANTING OF THE GARDEN \\ By John W. SPENCER \\ A story to be read to the pupils}

In years gone by, many farmers had a favorite phase of the moon when they planted certain crops, usually spoken of as the "dark" or the "light" of the moon. I once knew a woman who picked her geese by the "sign of the moon." Hogs were butchered in the "light" of the moon, and then the pork would not "fry away" so much in the skillet. It is true some pork from some hogs wastes faster than that of others, but the difference is due to the kind of food given the hogs. Many farmers hold to those old superstitions yet, but the number is much less now than twenty-five years ago. I wish I might impress on you young agriculturists that the moon has no influence on plant life, or pork, or geese, but the position of the sun most decidedly has. We have some plants that had best be planted when the sun's rays strike the state of New York slantingly, which means in early spring or late fall. We have other plants that should not be put in the open ground until the rays of the sun strike the state more direct blows, which means the hotter weather of summer. If I were in close touch with you pupils, I should be glad to tell some things that happen to three young friends of mine, hoping that thereby my statement might give the boys and girls an interest in three geographical lines concerning the tropics, and lead them to find their location on the map, particularly when later they learn what happens to my

\footnotetext{
*A portion of a letter to apprentice gardeners from Uncle John, published as a supplement to tha
Home Nature-Study Course Leaflet, for April-May, 1907.
} 
three young friends, whom we will call by the following names: There is one in Quito, Ecuador, of whom we will speak as Equator Shem; the one on the Island of Cuba is named Tropic of Cancer Ham; and the other in San Paulo, Brazil, answers to the name of Tropic of Capricorn Japhet.

What happens to these three boys, Shem, Ham and Japhet, is this. At certain times of the year they have no shadow when they go home for dinner at noon. This state of affairs is no fault of theirs. It is not because they are too thin to make shadows. It is due to the position of the sun. 'If the boys should look for that luminary at noon, they would find it as directly over their heads as a plumb line. It is a case of direct or straight blows from rays of the sun, and, oh, how hot-hotter than any Fourth of July the oldest inhabitant can remember! These three boys are not hit squarely on the head on one and the same day. Each is hit three months after the other. The first boy to be hit this year in the above manner will be the Equator Shem. The time will be during the last half of March. Can any of my young friends in this grade tell me the exact day of March that Equator Shem has no shadow? If no one of you can answer that question at this time, you had best talk it over with your friends, and bring your answers tomorrow. It happens at a time when our days are of about equal length.

Another thing about this particular day is that our almanacs call it the first day of spring. All because no boy or anything else has a shadow on the equator at noon time. People and bluebirds and robins in the state of New York will see squalls of snow about that time, and there will be some freezing nights. But after the first day of spring the cold storms do not last so long, as was the case during December, January, and early February, when the sun's rays hit us with very glancing blows. Watch to see how much faster the sun melts the snow on the last days of March than it did at Christmas time. The light is also stronger and brighter, and plants in greenhouses and our homes have more life, and are not so shiftless, so to speak. Even the hens feel the influence, for they begin to lay more eggs and cackle, and down goes the price of eggs. Do not forget to learn what day in March spring begins, when the Equator boy finds it so hot that he would like to take off his flesh, and sit in his bones. After a few days, Equator Shem will find he again has a shadow at noon. A short one it is true, but it will get longer andlonger each day. Now his shadow will be on the south side of him. Is this a queer thing to happen? On which side of you is your noon-time shadow? I will give every one of you a red apple that finds it anywhere but on the north side of him at twelve o'clock. Every time the sun shines at noon, watch to find your old uncle in the wrong, and thereby get the apple. Each day that the shadow of Equator Shem becomes longer and longer, the noon-day shadow of Tropic of Cancer Ham, living on the Island of Cuba, will be getting shorter and shorter, until at last there comes a day during the last of June that he, too, will have no shadow, and the almanac says that that day is the beginning of summer.

Now it will be the turn of the Tropic of Cancer Ham, on the Island of Cuba, to say the weather is hotter than two Fourths of July beat into one, and he too will wish that he could take off his flesh, and sit in his bones. Everybody in the state of New York will say that the first summer day is the longest day of the year. It is on this day that Equator Shem will have as long a shadow as he ever had in his life. No United States boy will ever be without a shadow at noon so long as he remains in his own country. When the eight o'clock curfew bell says it is time for boys and girls to go to 
bed, it will yet be light enough to read the papers. The sun not only sets late on that first summer day, but it appears early next morning. What a beautiful spectacle a sunrise in June is! Men of wealth will pay thousands of dollars for pictures showing its glory, yet I suppose that not one boy in five hundred ever saw the beauty of the birth of a new day in the sixth month of the year, and with no price of admission at that.

For only one day do the sun's rays fall directly on top of the head of Tropic of Cancer Ham, who lives on the Island of Cuba-just for one day, after which the up and down rays travel back towards the Equator Shem. On the twenty-first of September Shem again has no shadow at noon, and the almanac makers say that is the last day of summer, and tomorrow will be the first day of autumn. Again it is very hot where Shem lives, but the alligators and monkeys and the parrots do not seem to mind it. Where do the up and down rays of the sun go next? They keep going south, hunting for the boy named Tropic of Capricorn Japhet, to warm him up, as was the case with the boys in Cuba and at the Equator. The up and down rays do not find the top of the head of the lad in the City of San Paulo, Brazil until the last part of December, just four days before Christmas, and then the almanac says this is the beginning of winter, and the shorter days of the year, when we in the state of New York light the lamp at five o'clock in the afternoon. Now, my boys and girls, do you understand why we have a change of seasons? Do you understand that the sun changes his manner of pitching his rays at us? That in winter, when he is over the head of the Tropic of Capricorn Japhet in San Paulo, and making summer on that part of the earth, to us people in the north, in the State of New York, he pitche : only slanting rays that do not hit us hard, and have but little power? Thus you will see that the rays of the sun that strike the earth direct blows, swing: back and forth like a pendulum, year after year, and century after century, coming north as far as Tropic of Cancer Shem, but no farther, and then swinging south as far as the boy named Tropic of Capricorn Japhet, and no farther, just stopping and swinging back again towards the north.

\section{THE ZODIAC AND ITS SIGNS}

Teacher's Story

To be retold to pupils.

The mysterious symbols of the Zodiac on the first pages of almanacs are always a source of wonder and awe to children, and remain a life-long mystery to most people except fortune tellers; and yet the Zodiac is the simplest thing in the world to understand. However, the lesson should not be given until after the children have had their lessons on the sun and the shadow-stick, and also the lessons on the stars.

The ancients who believed the earth stood still and the sun moved around it, noticed inevitably that the path through the heavens pursued by the sun reached in summer a point farther north and higher up than in the winter, and they naturally wished to map this path, so as to fix it in their minds and writings. Nothing could be easier, for there in the skies were the eternal stars always following the same fixed path through the heavens and never wobbling up and down like the sun. So they chose the constellation which marked the highest point in the sun's path for each month, and these constellations might be likened to a stairway with six steps down toward the 
south and six steps up toward the north, the highest stair being reached by the sun in June, for then the sun is highest in the heavens and the farthest north. So beginning in June with Cancer, (the Crab), which is high in the heavens, it steps down to Leo, (the Lion) in July, takes another step lower to the Virgin in August, another down to the Scorpion in September, and comes to the lowest step of all, Sagittarius, (the Archer), in November; for at the last of November, the sun's path reaches its lowest point farthest south in the heavens and then the days are shortest. But in December it begins to climb and takes a short step up to Capricornus, (the Goat), in January it rises to Aquarius, (the Water Carrier), and in February rises another step to Pisces, (the Fishes). In March it reaches up to Aries, (the Ram), in April attains Taurus, (the Bull), and in May reaches Gemini, (the Twins), which step is almost as high and as near to the North Star as was the Cancer, where the journey began the June before.

It may be difficult for the pupils to learn to know all these constellations, as some of them are not very well marked; however, if they wish to learn them they can do so by the use of the planisphere. Some of the Zodiac constellations are marked by brilliant stars which havealready been learned. Regulus is the heart of Leo, the Lion; Spica which means "ear" is the ear of wheat which the Virgin is holding in the constellation Virgo. Red Antares lies in the Scorpion; and the Milk Dipper, which is shaped like the Big Dipper, but smaller, marks Sagittarius. Red Aldebaran is the fiery eye of Taurus, the Bull, while the Gemini, or Twins, are the most conspicuous of the stars in the evening skies of February and March. It should be noted, however, that at the present day, owing to the peculiar movement of our earth, the path of the sun in climbing up and down these constellation steps is not quite the same as it seemed to the ancients.

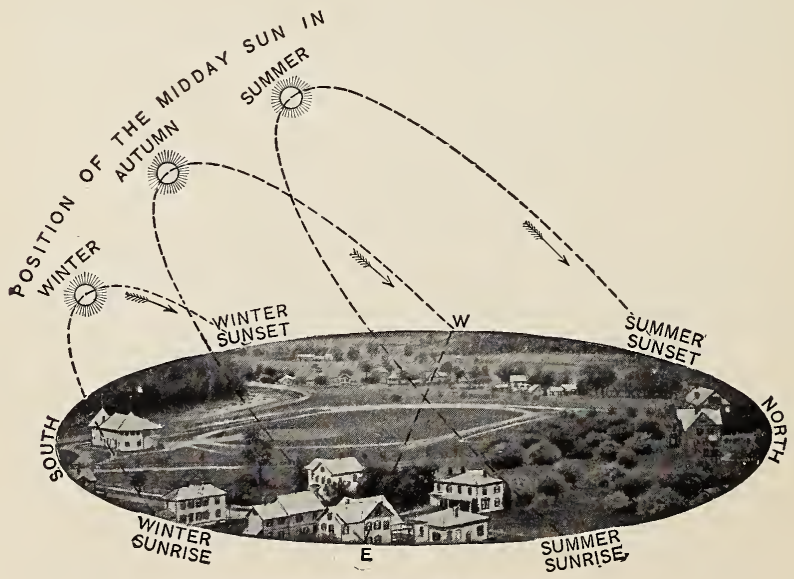

From Todd's New Astronomy. 


\section{THE RELATIONS OF THE SUN TO THE EARTH \\ Teacher's Story \\ "Whether we look or whether we listen, We hear life murmur or see it glisten."}

-LOWELL.

All this murmuring and glistening life on our earth planet has its source in the great sun which swings through our skies daily, sending to us through the friendly ether his messages of light and warmth - messages that kindle life in the seed and perfect the existence of every living organism, whether it be the weed in the field or the king on his throne.

At sunrise this heat which the sun sends out equally at all times of day and night, is tempered when it reaches us because it passes obliquely through our atmosphere-blanket, and thus traverses a greater distance in the cooling air. The same is true at sunset; but at noon, when the sun is most directly over our heads its rays pass through the least possible distance of the atmosphere-blanket and, therefore, lose less heat on the way. It is true that often about three o'clock in the afternoon is the hottest period of the day, but this is because the air-blanket has become thoroughly heated; but we receive the most heat directly from the sun at noon.

The variations in the time of the rising and the setting of the sun may be made a most interesting investigation on the part of the pupils. They should keep a record for a month in the winter; and with this as a basis, use the almanac to complete the lesson. Thus, each one may learn for himself which is the shortest and which the longest day of the year. There is a slight variation in different years; the shortest day of the year when this lesson was written, as computed from a current almanac, was the $22 \mathrm{~d}$ of December; it was nine hours and fourteen minutes long. The longest day of the year was the $22 \mathrm{~d}$ of June, and it was fifteen hours and six minutes in duration. " On the longest day of the year the sun reaches its farthest point north and is, therefore, most nearly above us at mid-day. On the shortest day of the year, the sun reaches its farthest point south and is, therefore, farther from the point directly above us at mid-day than during any other day of the year.

Also the movement of the sun north and south is an interesting subject for personal investigation, as suggested in the lesson. Through quite involuntary observation, I have become so accustomed to the arc traversed by the points of sunrive as seen from my home, that I can tell what month of the year it is, by simply noting the place where the sun rises. When it first peeps at us over a certain pine tree far to the south, it is December;' when it rises over the reservoir it is February or October; and when it rises over Beebe pond it is July. Only at the equinox of spring and fall does it rise exactly in the east and set directly in the west. Equinox means equal nights, that is, the length of the night is equal to that of the day.

So vast is the weight of the sun that the force of gravity upon its surface is so great that even if it were not for the white-hot fireworks there so constantly active, we could not live upon it, for our own weight would crush us to death.: But this multiplying the weight of common objects by twentyseven and two-thirds to find how much they would weigh on the sun is an interesting diversion for the pupils, and incidentally teaches them how to weigh objects, and something about that mysterious force called gravity; and it is also an excellent lesson in fractions. 


\section{LESSON CCXXXII}

\section{The Relation of the Sun to the Earth.}

Leading thought-The sun which is the source of all our light and heat and, therefore, of all life on our globe travels a path that is higher across the sky in June than the path which it follows in December, and hence we experience changes of seasons. The lesson should be given to the pupils of the upper grades and should be correlated with reading, arithmetic and thinking.

Observations- - I. What does the sun do for us?

2. At what time of the day after the sun rises do we get the least heat from it? What hour of the day do we get the most heat from it?

3. Is the sun equally hot all day? Why does it seem hotter to us at one time of the day than at another?

4. At what hour does the sun rise and set on the first of the following months; February, March, Arpil, May and June?

5. Which is the shortest day of the year, and how long is it?

6. Which is the longest day of the year, and how many hours and minutes are there in it?

7. What day of the year is the sun nearest a point directly over our heads at mid-day?

8. Which day of the year is the sun at mid-day farthest from the point directly above our heads? Explain why this is so.

9. Standing in a certain place, mark by some building, tree or other object just where the sun rises in the east and sets in the west on the first of February. Observe the rising and setting of the sun from the same place on the first day of March and again on the first of April. Does it rise and set in the same place always or does it move northward or southward?

Io. Is the sun farthest south on the shortest day of the year? If so, is it farthest north on the longest day of the year?

II. At what time of the year does the sun rise due east and set due west?

12. The sun is so much larger than the earth that its force of gravity is twenty-seven and two-thirds times that of the earth. How much would your watch weigh if you were living on the sun? How much would you yourself weigh if you were there?

13. Experiment. A shadow stick--Place a peg two or three inches high upright in a board and place the board lengthwise on the sill of a south

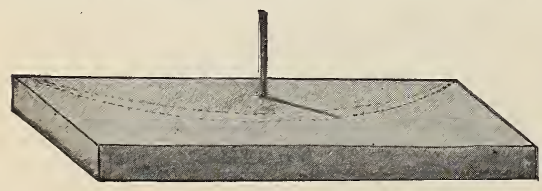

A shadow-stick. window or where it will get the south light. Note the length cast by the shadow of the peg during a sunny day and draw a line with pencil or chalk outlining the tip of the shadow of the stick from 9 a.m. to 4 p. m. Make a similar outline a month later and again a month later and note whether the shadow traces the same line during each of these days of observation. Note especially the length of the shadow at noon. 
Another excellent observation lesson for teaching the fact that the sun travels farther south in the winter, is to measure the shadow of a tree on the school grounds at noonday once a month during the school year. The length of the tree shadow can be measured from the base of the tree trunk, a memorandum being made of it.

I4. When does the stick or tree cast its longest shadow at noon-in December or February? February or April? April or June? Why?

Topics for English themes - The size and distance of the sun. The heat of the sun and its effect upon the earth. What we know about the sun spots. Our path around the sun.

Supplementary reading-Starland, Ball; The Earth and Sky, Holden.

\section{LESSON CCXXXIII}

\section{How to Make a Sundial}

Method-The diagram for the dial is a lesson in mechanical drawing. Each pupil should construct a gnomon (no-mon) of cardboard, and should make a drawing of the face of the dial upon paper. Then the sundial may be constructed by the help of the more skillful in the class. It should be made and set up by the pupils. A sundial in the school grounds may be made a center of interest and an object of beauty as well.

Materials-For the gnomon a piece of board a half inch thick and six inches square is required. It should be given several coats of white paint so that it will not warp. For the dial, take a board

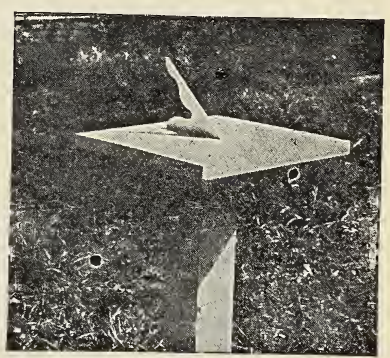

A sundial made by pupils. about I4 inches square and an inch or more thick. The lower edge may be bevelled if desired. This should be given three coats of white paint, so that it will not warp and check.

To make the gnomon-The word gnomon is from a Greek word meaning

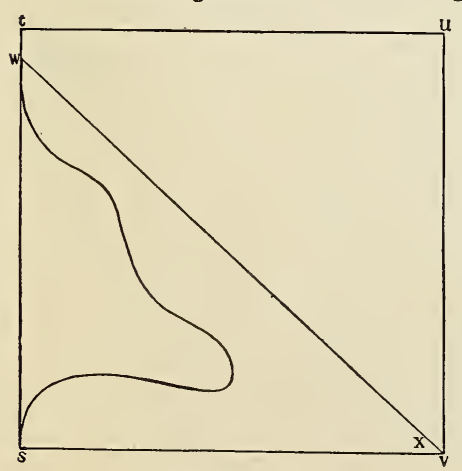

The gnomon. "one who knows." It is the hand of the sundial, which throws its shadow on the face of the dial, indicating the hour. Take a piece of board six inches square, and be very sure its angles are right angles. Let $\mathrm{s}, \mathrm{t}, \mathrm{u}, \mathrm{v}$ represent the four angles; drc, w on it a quarter of a circle from $\mathrm{s}$ to $\mathrm{u}$ with a radius equal to the line vs. Then with a cardboard protractor, costing fifteen cents, or by working it out without any help except knowing that a right angle is $90^{\circ}$, draw the line vw making the angle at $x$ the same as the degree of latitude where the sundial is to be placed. At Ithaca the latitude is $42^{\circ}, 27^{\prime}$ and the angle at $x$ 
measures $42^{\circ} 27^{\prime}$. Then the board should be cut off at the line vw, and later the edge sw may be cut in some ornamental pattern.

To make the dial-Take the painted board $\mathrm{I} 4$ inches square and find its exact center, y. Draw on it with a pencil the line $\mathrm{A} \mathrm{A}^{\prime \prime}$ a foot long and onefourth inch at the left of the center. Then draw the line B B" exactly parallel to the line $\mathrm{A} \mathrm{A}^{\prime \prime}$ and a half inch to the right of it. These lines should be one-half inch apart-which is just the thickness of the gnomon. If the gnomon were only one-fourth inch thick, then these lines should be onefourth inch apart, etc.

With a compass, or a pencil fastened to a string, draw the half-circle $\mathrm{A} \mathrm{A}^{\prime} \mathrm{A}^{\prime \prime}$ with a radius of six inches with the point $C$ for its center. Draw a similar half-circle $\mathrm{B} \mathrm{B}^{\prime} \mathrm{B}^{\prime \prime}$ opposite with $\mathrm{c}^{\prime}$ for its center. Then draw the half-circle from $\mathrm{D}, \mathrm{D}^{\prime}, \mathrm{D}^{\prime \prime}$, from $\mathrm{c}$ with a radius of five and three-quarter inches. Then draw similarly from $\mathrm{c}^{\prime}$ the half-circle $\mathrm{E}, \mathrm{E}^{\prime}, \mathrm{E}^{\prime \prime}$. Then draw from $\mathrm{c}$ the half-circle $\mathrm{F}, \mathrm{F}^{\prime}, \mathrm{F}^{\prime \prime}$ with a radius of five inches and a similar halfcircle $G, G^{\prime}, G^{\prime \prime}$ from $c^{\prime}$ as a center.

Find the points $M, M^{\prime}$ just six inches from the points $F, G$; draw the line $\mathrm{J}, \mathrm{K}$ through $\mathrm{M}, \mathrm{M}^{\prime}$ exactly at right angles to the line $\mathrm{A}, \mathrm{A}^{\prime}$. This will

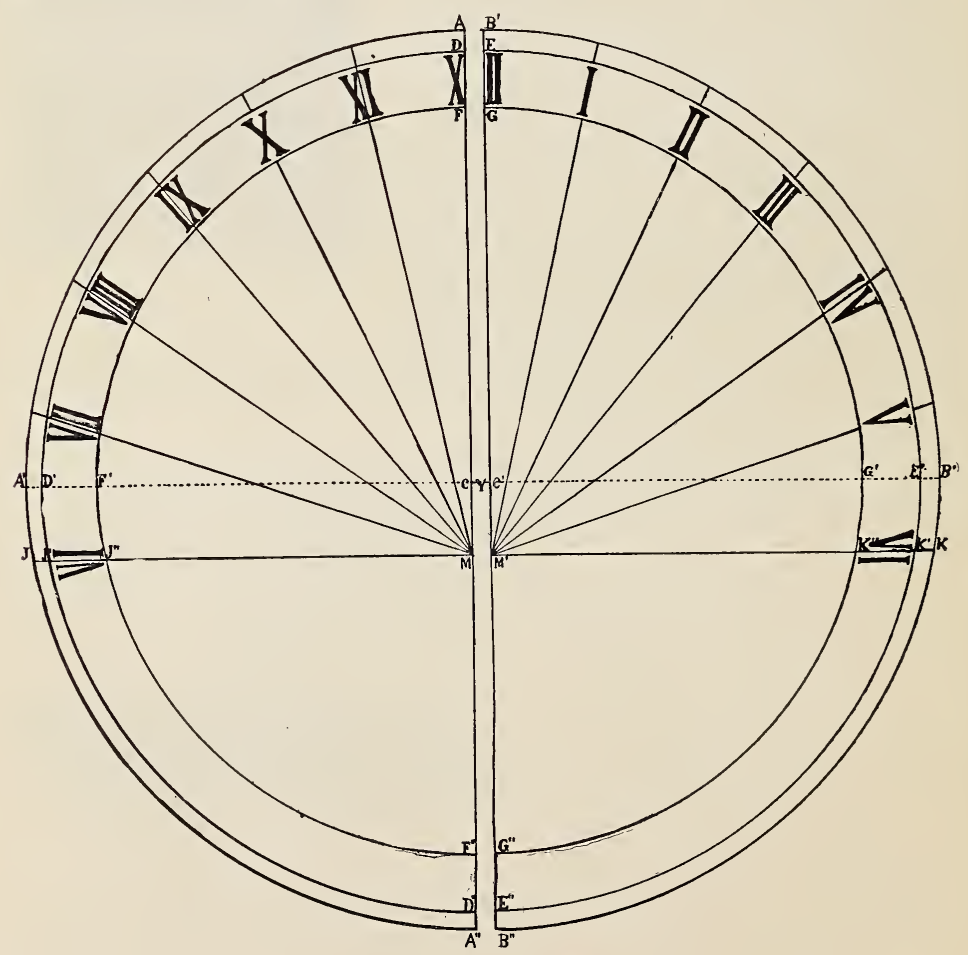

The face of the sundial. 
mark the six o'clock point so the figures VI may be placed on it in the space between the two inner circles. The noon mark XII should be placed as indicated (the "X" at D, F, the "II" at E, G). With black paint outline all the semi-circles and figures.

To set up the sundial-Fasten the base of the gnomon by screws or brads to the dial with the point $\mathrm{s}$ of the gnomon at $\mathrm{F}, \mathrm{G}$, and the point $\mathrm{v}$ of the gnomon at $M, M^{\prime}$, so that the point $W$ is up in the air. Set the dial on some perfectly level standard with the line A, $\mathrm{A}^{\prime \prime}$ extending exactly north and south. If no compass is available, wait until noon and set the dial so that the shadow from $W$ will fall exactly between the points $A, B$, and this will mean that the dial is set exactly right. Then with a good watch note the points on the arc $\mathrm{E}, \mathrm{K}^{\prime}$, on which the shadow falls at one, two, three, four, and five o'clock: and in the morning the points on the arc $\mathrm{J}^{\prime} \mathrm{D}$ on which the shadow falls at seven, eight, nine, ten and eleven o'clock. Draw lines from $M$ to these points, and lines from $\mathrm{M}^{\prime}$ to the points on the $\operatorname{arc} \mathrm{E} \mathrm{K}^{\prime}$. Then place the figures on the dial as indicated in the spaces between the two inner circles. The space between the two outer circles may be marked with lines indicating the half and quarter hours. The figures should be outlined in pencil and then painted with black paint, or carved in the wood and then painted.

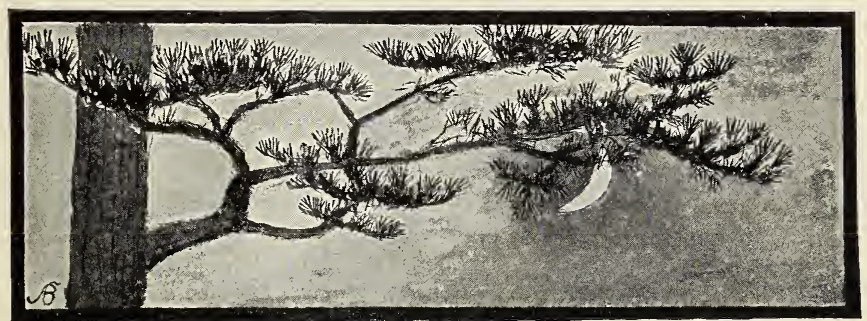

Twilight, twilight of the west,

Sky-lines fading into rest, Cloud-bars lying far and slight,

Shadows sinking into night, -

$O$ moon, ye moon, so faint and still,

Hanging, hanging as ye will

Low along the western sky,

Far and far and yet so nigh

A finger's breadth within the sheen

And silent shoreless vasts between-

Thy aching heart is long ages lost.

And clear and calm as film of frost,

$Y e$ know no longer strain or stress,

All passionless and passionless.

-From "The New IMoon," L. H. BaIley. 


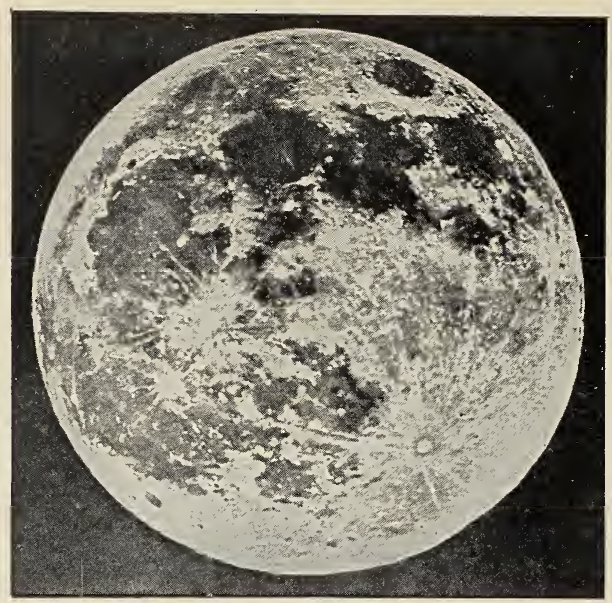

A photograph of the moon.

\section{THE MOON \\ Teacher's Story}

The moon is in more senses than one an illuminating object for both the earth and the skies. As a beginning for earth study it is an object lesson, illustrating what air and water do for our world and incidentally for us; while as the beginning of the study of astronomy, it is the largest and brightest object seen in the sky at night; and since it lies nearest us, it is the first natural step from our world to outer space.

The moon is a little dead world that circles around our earth with one face always towards us, just as a hat-pin thrust into an apple would keep the same side of its head always toward the apple no matter how rapidly the apple was twirled. As we study the face of the moon, thus always turned toward us, we see that it is dark in some places and shining in others, and some ignorant people have thought that the dark places are oceans and the light places, land. But the dark portions are simply areas of darker rocks, while the lighter portions are yellowish or whitish rocks. The dark portions are of such a form that people have imagined them to represent the eyes, nose and mouth of a man's face; but a far prettier picture is that of a woman's uplifted face in profile. The author has a personal feeling on this point, for as a child she saw the man's face always and thought it very ugly and, moreover, concluded that he chewed tobacco; but after she had been taught to find the face of the lady, the moon was always a beautiful object to her.

The moon is a member of our sun's family, his granddaughter we might call her if the earth be his daughter; and since the moon has no fires or light of its own, it shines by light reflected from the sun and, therefore, one-half of it is always in shadow. When we see the whole surface of the lighted half we say the moon is full; but when we see only half of the 
lighted side turned toward us, we say the moon is in its quarter, because all we can see is onehalf of one-half which is onequarter; and when the lighted side is almost entirely turned away from us we say it is a crescent moon; and when the lighted side is entirely turned away from us we say there is no moon, although it is always there just the same. Thus, we can understand that, although we can never see the other side of the moon, the sun shines on all sides of it. Our earth, like the moon, shines always by reflected light and is almost four times as wide as

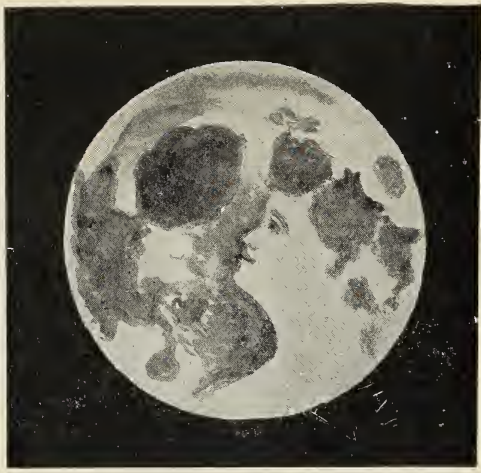

The lady in the moon. the moon. Think what a splendid moon our earth must seem to the lady in the moon! When we see the old moon in the new moon's arms, the dark outline of the moon within the bright crescent is visible because of the earthshine reflected from it. Sometimes pupils confuse this appearance of the moon with a partial eclipse; but the former is the new or old moon, which is one edge of the moon shining in the sunlight, the remainder faintly illumined by earth light, while an eclipse must always occur at the full of the moon when the earth passes between the sun and the moon, hiding the latter in its shadow.

It is approximately a month from one new moon to the next, since it takes twenty-nine and one-half days for the moon to complete its cycle around the earth and thus turn once around in the sunshine. Therefore, each moon day is fourteen and three-quarter days long and the night is the same length. The moon always rises in the east and sets in the west, following pretty nearly the sun's summer path. The full moon rises at sunset and sets at sunrise, but owing to the movement of the earth around the sun the moon rises about fifty minutes later each evening; however, this time varies with the different phases of the moon and at different times of the year. This difference in the time of rising is so shortened in August, that we have several nights when the full moon lengthens the day; and it is called the "harvest moon," because in England it adds to the hours devoted to harvesting the grain.

\section{A Visit to the Moon}

If we could be shot out from a Jules Verne cannon and make a visit to the moon, it would be a strange experience. First, we should find on this ittle world, which is only as thick through as the distance from Boston to Salt Lake City, mountains rising from its surface more than thirty thousand feet high, which is twice as high as Mt. Blanc and a thousand feet higher than the tallest peak of the Himalayas; and these moon mountains are so steep that no one could climb them. Besides ranges of these tremendous mountains, there are great craters or circular spaces enclosed with steep rock walls many thousand feet high. Sometimes at the center of the crater there is a peak lifting itself up thousands of feet, and sometimes the space 
within the crater circle is level. Thirty-three thousand of these craters have been discovered. And, too, on the moon, there are great plains and chasms; and all these features of the moon have been mapped, measured and photographed by people on our earth. For a boy studying geometry, the measuring of the height of the mountains of the moon is an interesting story.

But we could never in our present bodies visit the moon, because of one terrible fact-the moon has no air surrounding it. No air! What does that mean to a world? First of all, as we know life, no living thing-animal or plant-could exist there, for living beings must have air. Neither is there water on the moon; for if there were water there would have to be air. And without water no green thing can be grown, and the surface of the moon is simply naked, barren rock. If we were on the moon, we could not turn our eyes toward the sun, for with no air to veil it, its fierce light would blind us; and the sky is as black at midday as at midnight, since there is no atmosphere to sift out the other rays of light, leaving the beautiful blue in the sky; nor is there a glow at sunset because there is no air prism to separate the rays of light and no clouds to reflect or refract them. The stars could be seen in the black skies of midday as well as in the black skies of night, and they would be simply points of light and could not twinkle, since there is no air to diffuse the sun's light and thus curtain the stars by day and cause them to twinkle at night. The shadows on the moon are, for the same reason, as black as midnight and as sharply defined; and if we should step into the shadow of a rock at midday we should be hidden although some light reflected from the rocks around us might reach us. Hiding in such a shadow would be like putting on the invisible cloak of fairy lore.

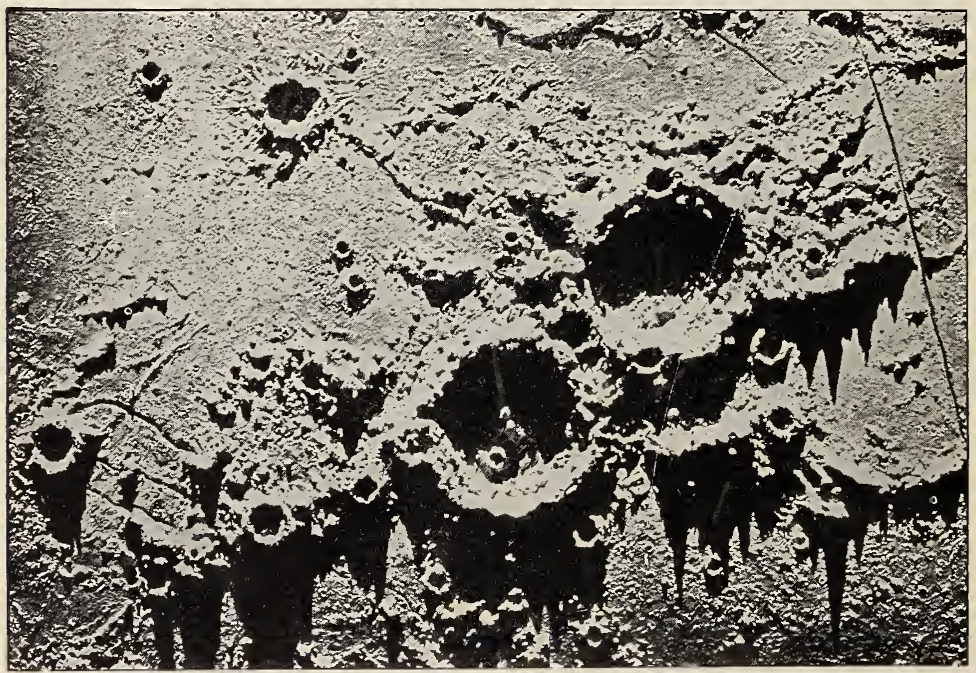

The moon's surface seen through a ielescope, showing the craters Mercator and Campanus. Note that the shadows give some idoa of their height. 
And because of no layers of air to make an aerial perspective, a mountain a hundred miles away would seem as close to us as one a mile away.

Since there is no atmosphere on the moon to act as a buffer between the cold of outer space, which is estimated to be $250^{\circ}$ below zero, and the heat of the sun, which is $500^{\circ}$ above zero, the temperature of the moon reaches above boiling point at noon and absolute zero at midnight, because there is no air to carry the heat over into the shadow or to blanket the moon at night. But this great change of temperature between sunlight and darkness is the only force on the moon to change the shape of its rocks, for the expansion under heat and contraction under cold must break and crumble even the firmest rock more or less. Our rocks are broken by the freezing of water that creeps into every crevice, but there is no water to act on the moon's mountains in this fashion or to wear them away by dashing over their surface. However, the rocks and mountains of the moon may be changed in shape by the battering of meteorites, which pelt into the moon by the million, since the moon has no air to set them afire and make them into harmless shooting stars, burning up before they strike. But though a meteorite weighing thousands of tons should crash into a moon mountain and shatter it to atoms there would be no sound, since sound is carried only by the atmosphere.

Imagine this barren, dead world, chained to our earth by links forged from unbreakable gravity, with never a breath of air, a drop of rain or flake of snow, with no streams, nor seas, nor graced by any green thing - not even a blade of grass - a tree, nor by the presence of any living creature! Out there in space it whirls its dreary round, with its stupendous mountains cutting the black skies with their jagged peaks above, and casting their inky shadows below; heated by the sun's rays until hotter than the flame of a blast furnace, then suddenly immersed into cold that would freeze our air into solid ice, its only companion the terrific rain of meteoric stones driven against it with a force far beyond that of cannon balls, and yet with never a sound as loud as a whisper to break the terrible stillness which envelops it.

\section{LESSON CCXXXIV}

The Moon

Leading thought-The moon always has the same side turned toward us so we do not know what is on the other side. The moon shines by reflected light from the sun, and is always half in light and half in shadow. The moon has neither air nor water on its surface and what we call the moon phases depend on how much of the lighted surface we see.

Method-Have the pupils observe the moon as often as possible for a month, beginning with the full moon. After the suggested experiment, the questions which follow may be given a few at a time.

Experiment for recess-Darken the room as much as possible; use a lighted lamp or gas jet or electric light for the sun, which is, of course, stationary. Take a large apple to represent the earth and a small one to represent the moon. Thrust a hat pin through the big apple to represent the axis of the earth and also the axis about which the moon revolves. Tie a string about a foot long to the stem of the moon apple and make fast the other end to the hat pin just above the earth apple. Hold the hat pin in one hand and revolve the apple representing the moon slowly with the other 
hand letting the children see that if they were living on the earth apple the following things would be true:

I. Moving from right to left when the moon is between the earth and the sun it reflects no light.

2. Moving a little to the left a crescent appears.

3. Moving a quarter around shows the first quarter.

4. When just opposite the lamp, it shows its whole face lighted turnerl toward the earth.

5. Another quarter around shows a half disc, which is the third quarter:

6. When almost between the sun and the earth the crescent of the old moon appears.

7. Note that the moon always keeps one face toward the earth.

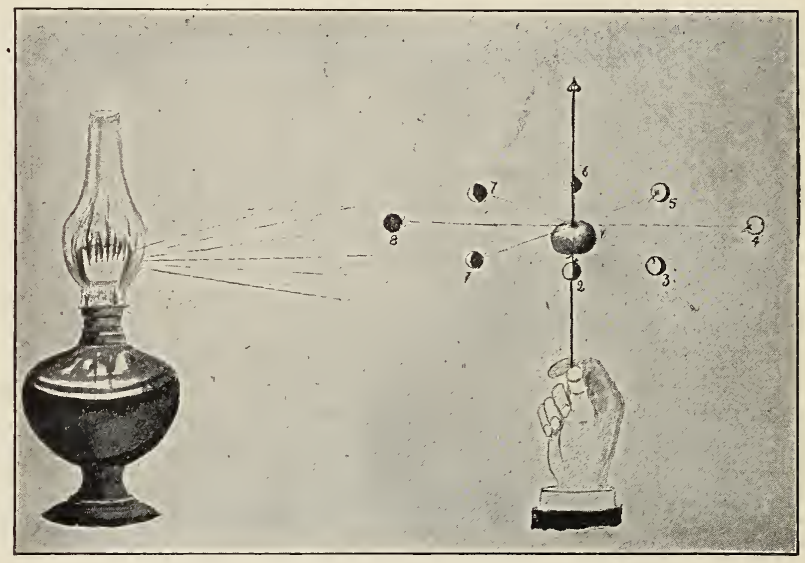

Experiment for illustrating the phases of the moon.

8. Note that the new moon crescent is the lighted edge of one side of the moon, while the old moon crescent is the lighted edge of the opposite side.

9. Make an eclipse of the moon by letting the shadow of the earth fall upon it, and an eclipse of the sun by revolving the moon apple between the sun and the earth. The earth's orbit and the moon's orbit are such that this relative position of the two bodies occurs but seldom.

Observations-I. Describe how the moon looks when it is full.

2. What do you think you see in the moon?

3. Describe the difference in appearance between the new moon and the full moon, and explain this difference.

4. Where does the new moon rise and where does it set?

5. When does it rise and when does it set?

6. Where and when does the full moon rise and where and when does it set?

7. How does the old moon look?

8. Could the crescent moon which is seen in early evening be the old moon instead of the new; and, if not, why not? 
9. When and where do we ordinarily see the old moon when it is crescent shaped?

Io. Does the moon rise earlier or later on succeeding nights? What is approximately the difference in time of moonrise on two successive nights?

I I. Do you think we always look at the same side of the moon? If so, why?

I2. Is more than one side of the moon luminous? Why?

I3. How many days from one new moon until the next?

I4. How long is the day on the moon and how long the night?

I5. How many times does the moon go around the earth in a year?

I6. What is the difference between the disappearance of the old moon and an eclipse of the moon? In both cases the moon is hidden from us.

\section{The Physical Geography of the Moon}

Questions for the pupils to think about and answer if they can-I7. Since it has been proved that there is no air or water on the moon, could there be any life there?

I 8 . Supposing you could do without air or water and should be able to visit the moon, what would you find to be the color of the sky there?

I9. Would there be a red glow before sunrise or beautiful colors at sunset?

2o. Would the sun appear to have rays? Could you look at the sun without being blinded?

2 I. Would the stars appear to twinkle? Could you see the stars in the. daytime?

22. How would the shadows look? If you could step into the shadow of a rock at midday, could you be seen?

23. Could you tell by luoking at it whether a mountain was far or near?

24. It is estimated that the temperature of outer space is 250 degrees below zero, and the sun's direct heat is 500 degrees above zero. If this be correct, how hot would it be in the sunshine on the moon? How cold would it be at midnight?

25. Why is it so much hotter and colder on the moon than upon the earth?

26. If you could shout on the moon, how would it sound? If one hundred cannons should be fired at once on the moon, how would it sound?

27. Is there any rain or snow on tha moon? Are there any clouds there? If there are no air and water on the moon, would the intense heat and the powerful cold affect the soils or rocks, as freezing and thawing affect our rocks?

28. Professor Newton estimated that the earth meets seven million meteorites (shooting stars) every twenty-four hours. Why do we not see more of these? What happens when a meteorite strikes the moon?

29. The moon is so small that the force of gravity on its surface is onesixth that on the earth's surface. If a man can carry seventy-five pounds on his back here, how much could he carry on the moon? If a boy can throw a ball one hundred yards here, how many yards could he throw on the moon? If a boy can kick a football one hundred and thirty-five feet in the air here, how far could he kick it on the moon? 


\section{BOOKS OF REFERENCE}

The following list of nature books is by no means complete. It simply includes books which the author has consulted in her work as a teacher, and to which she naturally referred in the lessons. The list is given with the publishers for the convenience of those who may use this volume.

\section{BIRD STUDY}

American Birds-Wm. L Finley-Scribners.

Birdcraft-Wright-MacMillan.

Bird Life-Chapman-Appleton.

Bird Neighbors-Blanchan-Doubleday, $\mathrm{Pa}$ ye \& Co.

Birds that Iunt and are Hunted-Blanchan-Doubleday, Page \& Co.

Bird Honies-Dugmore-Doubleday, Page \& Co.

Birds and Bees-John Burroughs-Houghton, Mifflin \& Co.

Birds of New York-Eaton and Fuertes-University of State of New York Press.

Birds of the United States-Apgar-American Book Co.

Birds of Song and Story-Grinnell-Mumford, Chicago.

Birds in their Relation to Man-Weed \& Dearborn-Lippincott.

Birds of Village and Field-Merriam-Houghton, Mifflin \& Co.

Birds through an Opera Glass-Merriam-Houghton, Mifflin \& Co.

Bob: The Story of a Mockingbird-Lanier-Scribner.

Citizen Bird-Wright-MacMillan.

Everyday Birds-Torrey-Houghton, Mifflin \& Co.

Field Book of Wild Birds and their Music-Mathews-Putnams.

First and Second Book of Birds-Miller-Houghton, Mifflin \& Co.

Guide to the Birds-Hoffman,-Houghton, Mifflin \& Co.

Handbook of Birds of Eastern N. America-Chapman-Appletons.

How to Attract the Birds-Blanchan-Doubleday, Page \& Co.

Leaflets of National Association of Audubon Societies-I4I Broadway, N. Y.

Mother Nature's Children-Gould-Ginn \& Co.

Nestlings of Forest and Marsh-Wheelock-A. C. McClurg \& Co.

Neighbors with Wings and Fins-Johonnot-American Book Co.

Notes on New England Birds---H. D. Thoreau-Houghton, Mifflin \& Co.

Our Birds and their Nestlings-Walker-American Book Co.

Sharp Eyes-John Burroughs-Houghton, Mifflin \& Co.

Story of the Birds-Baskett-Appletons.

Stories About Birds-Kirby-Educational Publishing Co.

The Bird: Its Form and Function-Beebe-Henry Holt \& Co.

The Sird Book-Eckstorm-D. C. Heath \& Co.

The Song of the Cardinal-Porter-Bobbs, Merrill \& Co.

The Woodpeckers-Eckstorm-Houghton, Mifflin \& Co.

True Bird Stories-Miller-Houghton, Mifflin \& Co.

Useful Birds and Their Protection-Forbush-Mass. Board of Agri.

\section{FISH STUDY}

American Food and Game Fishes-Jordan \& Everman-Doubleday, Page \& Co

Fish Stories-Holder \& Jordan-Henry Holt \& Co.

Fisherman's Luck-Van Dyke-Scribners.

Guide to the Study of the Fishes-Jordan-Henry Holt \& Co.

Neighbors with Wings and Fins-Johonnot-American Book Co.

Science Sketches-Jordan-McClurg.

The Complete Angler-Isaac Walton-Little Brown \& Co.

The Freshwater Aquarium-Eggeling \& Ehrenberg-Henry Holt \& Co.

The Home Aquarium-Eugene Smith-E. P. Dutton \& Co.

The Story of the Fishes-Baskett-Appletons.

\section{BATRACHIAN AND REPTILE STUDY}

American Natural History-Hornaday-Scribner.

Elementary Zoology-Kellogg-Henry Holt \& Co.

Familiar Life of Field and'Forest-Mathews-Appletons. 
The Frog Book-Dickerson-Doubleday, Page \& Co.

The Reptile Book-Ditmars-Doubleday, Page \& Co.

Serpents of Pennsylvania-Surface-State College, Penn.

\section{MAMMAL STUDY}

American Animals-Stone \& Cram-Doubleday, Page \& Co.

Animals of the World-Knight \& Jenks-Frederick Stokes Co.

Animal Heroes-Thompson-Seton-Scribners.

A Country Reader-Buchanan-MacMillan.

A Wat her in the Woods-Dallas Lore Sharp-Century Co.

Black Beauty-Sewell-Lothrop.

Bob, Son of Battle-Olliphant-McClure, Phillips \& Co.

Campfires of a Naturalist-Edwards-Appletons.

Camp Life in the Woods-Gibson-Harpers.

Concerning Cats-Winslow-Lothrop.

Domestic Animals-Burkett-Ginn \& Co.

Domesticated Animals-Shaler-Scribners.

Dog of Flanders-Ouida-.

Familiar Life of Field and Forest-Mathews-Appletons.

Familiar Wild Animals-Lottridge-Henry Holt \& Co.

Forest Neighbors-Hurlbert-McClure, Phillips \& Co.

Half Hours with Mammals-Holder-American Book Co.

In Praise of the Dog-Bicknell-E. P. Dutton \& Co.

Jack of the Bush Veldt-Fitz Patrick-Longmans, Green \& Co

Jungle Books, First and Second-Kipling-Century Co.

Kindred of the Wild-Roberts-L. C. Page \& Co.

Life of Animals-Ingersoll-MacMilian.

Lives of the Hunted-Thompson-Seton-Scribners.

Little Beasts of Field and Wood-Cram-Small, Maynard \& Co.

Little Brother of the Bear-Long-Ginn \& Co.

Little People of the Sycamore-Roberts-L. C. Page \& Co.

Mack, His Book-Florence Leigh-Frederick Stokes Co.

Neighbors of Field, Wood and Stream-Grinnell-Frederick Stokes.

Neighbors with Claws and Hoofs-Johonnot-American Book Co.

Nights with Uncle Remus-Harris-McClure, Phillips \& Co.

$\mathrm{Rab}$ and his Friends-Dr. John Brown-Houghton, Mifflin \& Co.

Red Fox-Roberts-L. C. Page \& Co.

Roof and Meadow-Dallas Lore Sharp-Century Co.

Secrets of the Woods-Wm. J. Long-Ginn \& Co.

Squirrels and other Fur-bearers-Burroughs-Houghton, Mifflin \& Co.

Stickeen-John Muir-Houghton, Mifflin \& Co.

The Animals and Man-Kellogg-Henry Holt \& Co.

The Horse-I. P. Roberts-Mac Millans.

The Fir eside Sphinx-Repplier-Houghton, Mifflin \& Co.

The Face of the Fields-D. Lore Sharp-Houghton, Mifflin \& Co.

The Case for the Goat-Various Authors-E. P. Dutton.

The Silver Fox-Seton-Century Co.

Two Little Savages-Seton-Doubleday, Page \& Co.

True Tales of Birds and Beasts- Jordan-

Ways of Wood Folk-Wm. J. Long-Ginn \& Co.

Wild Animals I Have Known-Seton-Scribners.

Wild Life Near Home-Dallar - re Sharp-Century Co.

Wild Life in Orchard and Fip ${ }^{3}$-Ingersoll-Harpers.

Wild Neighbors-Ingersoll- cMillan.

Wild Mammals of North America-Merriam-Henry Holt \& Co.

\section{ITS AND OTHER INVERTEBRATES}

American Insects-Kell - Jenry Holt \& Cu.

A. B. C. of Bee Culture- Root-A. I. Root Co., Merlina, O.

Ant Communities-McCook-Harpeis.

Ants. W. LV. Wheeler-Columbia University Press.

Caterpillars and their Moths-Elliot \& Soule-Century Co.

Common Spiders-Emerton-Ginn \& Co. 
Earthworms-Darwin-Appletons.

Economic Entomology-Smith-Lippincotts.

Everyday Butterflies-Scudder-Houghton, Mifflin \& Co.

Grasshopper Land-Morley-A. C. McClurg \& Co.

Home Studies in Nature-Treat-American Book Co.

How to Keep Bees-Comstock-Doubleday, Page \& Co.

How to Know the Butterflies-Comstock-Appletons.

Insect Book-Howard-Doubleday, Page \& Co.

Insect Life-Comstock-Appletons.

Insect Stories-Kellogg-Henry Holt \& Co.

Life Histories of American Insects-Weed-MacMillan.

Life of the Honey Bee-Ticknor Edwards-Methuen \& Co.

Manual for the Study of Insects-Comstock-Comstock Pub. Co.

Mosquito Life-Mitchell-Putnams.

Moths and Butterflies-Ballard-Putnams.

Moths and Butterflies-Dickerson-Ginn \& Co.

Nature Biographies-Weed-Doubleday, Page \& Co.

Nature's Craftsmen-McCook-Harpers.

Outdoor Studies-Needham-American Book Co.

The Bee People-Morley-A. C. McClurg \& Co.

The House Fly-Howard-Frederick S. Stokes Co.

The Natural History of Some Common Animals-Latter-Cambridge Press.

The Spider Book-Comstock-Doubleday, Page \& Co.

Wasps and their Ways-Morley-A. C. McClurg \& Co.

Wasps, Social and Solitary-Peckham-Houghton, Mifflin \& Co.

Ways of the Six-footed-Comstock-Ginn \& Co.

\section{PLANT LIFE-FLOWERS}

Beginner's Botany-Bailey-MacMillan.

Blossom Hosts and Insect Guests-Gibson-Newson \& Co.

Botany Reader-Newell-Ginn \& Co.

Botany; Elementary Textbook-Bailey-MacMillan.

Childs Own Book of Wild Flowers-Comstock-American Book Co.

Field Book of American Wild Flowers-Mathews-Putnams.

Field, Forest and Garden Botany-Gray-American Book Co.

Field, Forest and Wayside Flowers-Going-Baker, Taylor Co.

First Lessons in Plant Iife-Atkinson-Ginn \& Co.

First Lessons with Plants-Bailey-MacMillan.

Flowers and their Friends-Morley-Ginn \& Co.

Flowers of Field, Hill and Swamp-Creevy-Harpers.

Flowers of Northeastern United States-Miller \& Whitney-Putnams.

Guide to the Wild Flowers-Lounsberry-Frederick S. Stokes Co.

How Plants Behave-Gray-Amerizan Book Co.

How Plants Grow-Gray-American Book Co.

How to Know the Wild Flowers-Dana-Scribners.

Manual of Botany-Gray-American Book Co.

Our Garden Flowers-Keeler-Scribners.

Plants and their Children Dana-American Book Co.

Plant Life-Coulter-Appletons.

Procession of the Flowers-Higginson-Houghton, Mifflin \& Co.

Recreations in Botany-Creevy-Harpers.

Who's Who Among the Wild Flowers-Beecroft-Moffatt Yard \& Co.

\section{FLOWERLESS PLANTS}

Bacteria in Relation to Country Life-Lipman-Macmillan.

Dust and its Dangers-Prudden-Putnams.

Ferns-Waters-Henry Holt \& Co.

Fern Allies of North America-Clute-Frederick Stokes.

Fungi: Their Nature and Uses-Mc Cook-Appletons.

How to Know the Ferns-Parsons-Scribners.

Mosses with a Hand Lens-A. J. Grout-O. T. Lewis Co., N. Y.

Moulds, Mildews and Mushrooms-Underwood-Henry Hoit \& Ca

Mushrooms-Atkinson-Henry Holt \& Co. 
New England Ferns-Eastman-Houghton, Mifflin \& Co.

Our Edible Toadstools and Mushrooms-Gibson-Harpers.

Our Ferns in their Haunts-Clute-Frederick Stokes.

One Thousand American Fungi-McIlvaine-Bobbs, Merrill \& Co.

Story of the Bacteria-Prudden-Putnam.

\section{PLANT LIFE-GARDENING AND AGRICULTURE}

Agriculture for Beginners-Burkett, Stevens \& Hill-Ginn \& Co.

Agricultural Botany-Percival-Henry Holt \& Co.

All the Year in the Garden-Matson-Crowell.

Among School Gardens-Greene-Sage Foundation.

An Island Garden-Thaxter-Houghton, Mifflin \& Co.

Book of Corn-Myrick-Orange, Judd Co.

Bulbs and How to Grow them-Doubleday, Page \& Co.

Common Weeds of Field and Garden-Long-Smith, Elder \& Co.

Corn Plants-Sargent-Houghton, Mifflin \& Co.

Elements of Agriculture-Warren-MacMillan.

Encyclopedia of Horticulture-Bailey-MacMillan.

Farm Grasses of United States-Spillman-Orange, Judd Co.

First Principles of Agriculture-Goff \& Mayne-American Bonk Cc.

First Book of Farming-Goodrich-Doubleday, Page \& Co.

Four Seasons in a Garden-Rexford-Lippincott.

Handy Book of Agriculture-Hayes-E. P. Dutton \& Co.

Indoor Gardening-Rexford-Lippincotts.

Living Plant, the-Knight-Hutchinson \& Co.

Mary's Garden and How it Grew-Duncan-Century Co.

Manual of Gardening-Bailey-MacMillan.

School Garden Book-Weed \& Emerson-Scribners.

Seed Dispersal-Beal-Ginn \& Co.

Spraying of Plants-Lodeman-MacMillan.

Story of a Grain of Wheat-Edgar-Appletons.

Survival of the Unlike-Bailey-MacMillan.

The Amateur's Practical Garden-Book-Hunn and Bailey-Mac Millan.

\section{TREE STUDY}

A Guide to the Trees-Lounsherry-Stokes.

A First Book of Forestry-Roth-Ginn \& Co.

Among Green Trees-Rogers-Mumford-Chicago.

Familiar Trees and their Leaves-Mathews-Appletons.

Forestry in Nature-Study-Jackson-Office of Expt. Sta., Washington, D. C.

Getting Acquainted with the Trees-McFarland-Outlook Co.

Handbook of the Trees-Romeyn Hough-Harpers.

Manual of Trees of N. America-Sargent-Houghton, Mifflin \& Co.

North American Trees-N. L. Britton-Henry Holt \& Co.

North American Forests and Forestry-Bruncken-Putnams.

Our Native Trees-Keeler-Scribners.

Our Northern Shrubs-Kceler-Scribners.

Our Trees and How to Know Them-Emerson \& Weed-Lippincott.

Practical Forestry-Gifford-Appletons.

Primer of Forestry-Pinchot-Bureau of Forestry, Washington, D. C.

Studies of Trees-Mosher, 3 vols-C. W. Bardeen.

Studies of Trees in Winter-Huntingdon-Knight \& Mellet.

The Tree Book-Rogers-Doubleday, Page \& Co.

Trees of Northern United States-Apgar-American Book Co.

Trees, Shrubs and Vines-Parkhurst-Scribners.

Trees in Prose and Poetry-Stone \& Pickett-Ginn \& Co.

With the Trees-Going-Baker Taylor \& Co.

\section{ASTRONOMY-GEOLOGY-METEOROLOGY}

Astronomy for Everybody-Newcomb-McClure, Phillips \& Co.

Astronomy Through an Opera-Glass-Serviss-Appletons.

Children's Book of Stars-Milton-Adam, Black \& Co.

Earth and Sky-Holden-Appletons.

Fieldbook of the Stars-Olcutt-Putnams. 
Friendly Stars-Martin-Harpers.

New Astronomy-Todd-American Book Co.

Other Suns than Ours-Proctor-Longman, Green \& Co.

Other Worlds than Ours-Proctor-Longman, Green \& Co.

The Planisphere-Thos. Whittaker.

Starland-Ball-Ginn \& Co.

Stars in Song and Legend-Porter-Ginn \& Co.

Storyland of Stars-Pratt-Educational Publishing Co.

Stories of Star Land-Miss Proctor-Potter \& Putnam Co.

Study of the Sky-Howe-Flood \& Vincent.

The Moon-Nasmyth \& Carpenter-Murray, London.

The Stars in their Seasons-Proctor-Longmans Green \& Co.

Brooks and Brook Basins-Frye-Ginn \& Co.

Brook Book-Miller-Doubleday, Page \& Co.

Geological Story Briefly Told-Dana-American Book Co.

Great World's Farm-Gaye-MacMillan.

Introduction to Physical Geography-Gilbert \& Brigham-Appletons

Physical Geography-Tarr-MacMillan.

Soils-King-MacMillan.

Soils-Fletcher-Doubleday, Page \& Co.

Story of our Continent-Shaler-Appletons.

Up and Down the Brooks-Bamford-Houghton, Mifflin \& Co.

Water Wonders-Thompson-Doubleday, Page \& Co.

Wonder Book of the Atmosphere-Houston-Stokes.

Wonder Book of Magnetism-Houston-Stokes.

\section{NATURE-STUDY-MANUALS AND LITERATURE}

Education through Nature-Munson-E. L. Kellogg \& Co.

Field Work in Nature-Study-Jackman-Flanagan.

Handbook of Nature-Study-Lange-MacMillan.

How Nature-Study Should be Taught-Bigelow-Hinds \& Noble.

How to Study Nature-J. D. Wilson-Bardeen.

Lessons in Nature-Study-Jenkins \& Kellogg-Whittaker \& Ray, San Francisco。

Nature-Study Idea-L. H. Bailey-MacMillan.

Nature-Study and Life-Hodge-Ginn \& Co.

Nature-Study and the Child-Scott-D. C. Heath \& Co.

Nature-Study in the Common Schools-Jackman-Henry Holt \& Co.

Nature-Study for Grammar Grades-Jackman-MacMillan.

Nature-Study-Holtz-Scribner's.

Nature-Study in the Lower-Grades-Cummings-American Book Co.

Nature-Study in Elementary Schools-L. L. Wilson-MacMillan.

Nature-Study Lessons-Various Authors-Hinds, Noble \& Co.

Nature-Study-Overton \& Hill-American Book Co.

Nature Teaching-Watts \& Freeman-E. P. Dutton \& Co.

Outlines in Nature-study-Engel-Silver, Burdett \& Co.

Outlook to Nature-L. H. Bailey-MacMillan.

Practical Nature-Study-Coulter \& Patterson-Appletons.

Study of Nature-Schmucker-Lippincott.

Writings of H. D. Thoreau-Houghton, Mifflin \& Co.

Works of John Burroughs-Houghton, Mifflin \& Co.

The Land of Little Rain-Mary Austin-Houghton, Mifflin \& Co.

The Flock-Mary Austin-Houghton, Mifflin \& Co.

Songs of Nature, edited by John Burroughs-McClure, Phillips \& Co.

Golden Numbers, edited by Wiggin \& Smith-McClure, Phillips \& Co.

The Posy Ring, edited by Wiggin \& Smith-Doubleday, Page \& Co.

Among Flowers and Trees with the Poets, edited by Wait \& Leonard-Lee \& Shepard.

Nature in Verse, comp. by Mary I. Lovejoy-Silver, Burdett Co.

Poetry of the Seasons, comp. by Mary I. Lovejoy-Silver, Burdett Co.

Nature Pictures by American Poets, Annie R. Marble-MacMillan Co.

Trees in Prose and Poetry-Stone \& Fickett-Ginn \& Co.

Stars in Song and Legend-Jermain G. Porter-Ginn \& Co.

Sharp Eyes, by Hamilton Gibson-Harpers.

Pageant of Summer-by Richard Jefferies-Mosher, Portland, Me.

“Ye Gardeyne Boke," J. D. Haines-Paul Elder \& Co., San Francisco. 


\section{INDEX}

Page

Abbe, Prot. Henry. . . . . . . . . . . . 860

Abdomen (of insect).......... 3 I2-3 I4

Acid Soils................. . 848

Acorns .................. 731

Acorn-cup and saucer . . . . . . . 752

of Burr Oak .............. . 754

of Chestnut Oak . . . . . . . . . 751

of Red Oak. . . . . . . . . . . . . 753

of Scarlet Oak . . . . . . . . . . . 754

of Swamp White Oak... . . . . . 750

Acorn plum-gall . . . . . . . . . . . . 360

Adder's Tongue or Dogtooth Violet $499,500,501,502$

Adult Stage or Imago (of insects) .... 3 I I Agaricus Campestris ....... 708, 710,711 Agate .................... 830

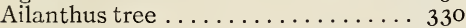

Air, as a gas ... . . . . . . . . . . . 860

Composition of .......... 86I

Akers, Elizabeth...... . 4 475, 477, 509

Allcn, A. A. . . . . . . . I I 5, I I 7, I 22, I 23

Aldebaran .......... 896, 897, 898, 9 I 2

Aldrich, Thomas Bailey....... 62, 598

Allen, James Lane. . . . . . . . . . . . . . I I33

Altair . . . . . . . . . . . . . . . . 904

Alfalfa ..............654, 653, 654

Altenburger Cheese .......... 278

Alum...................... 826

A manita phalloides . . . . . . . . . . 707, 709

Ames, Mary Clcmmer . . . . . . . . . 557

Amethyst ................ 830

Animal Life . . . . . . . . . . . . . 25

Anopheles.................. 402

Antares.................. 904,90I

Ants ........4 19, 420,425, 426, 422 agriculturaj .............

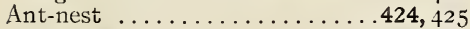

Antennae ................ 312,314 of male mosquito............ 402

Antenna-comb on ant's $1 \mathrm{c} . \ldots \ldots \ldots .426$ on wasp ................ 434

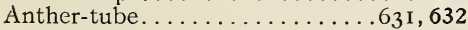

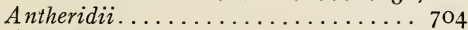

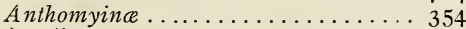

Ant-lion . . . . . . . . . . . . . 395, 396

Anti-cyclone . . . . . . . . . . . . 879,880

Aphids . . . . . . . . . 392, 393, 394, 42 I

Aphid stable ............... 421

Aphis-lion . . . . . . . . . 397, 398, 399

Apple ........ 73, 779, 785, 787, 789

Apple The .............................

Apples-basket of . . . . . . . . . 787

Apple-blossoms............... . 783

the core-lincs . . . . . . . . . . . 787

just ready to spray ....... 350,783

too late to spray............. 351

the tree. . . . . . . . . . 778-78I

Aquarium, tadpole ............ I85

Aquarium, how to make...........

for insects............. 380
Aquarius (the Water Carrier) . . . . . 912

Arcturus.............902, 903, 904

Argon .................... . 862

Arided ................... 904

Aries (the Ram) . . . . . . . . . 912

Arnold, Edwin. . . . . . . . . . . . 595

Ash, white . . . . . . . . 774, 775, 776

Asters..............558, 559, 560

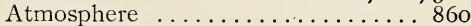
height of . . . ........... 863 temperature of ............. 865

Atmosphere pressure . . . . . . . . 860, 863 High . . . . . . . . . . 868, 869, 879 Low . . . . . . . . . . . . 869, 879, 885

Atkinson, Prof. Gto. F . . . . . . . . . $496,697,708,7$ I 5, 7 I 7, 7 I 8, 7 I9, 720

Aurora Borealis............. 839 Austin, Mary................ 28I

Averill-Anna Boynton... . . . . . 550

Babcock Milk Tester ........... 300

Bachelor's Button............. 636

Bacteria ................. 723

Bailey Prof. L. H. ...38, I 80, I 89, 246, $495,496,539,602,610,640,642,725,824$ Bailey, Vernon .............. 255 Baker, W. C. . . . . . . . . . . 565, 768 Baker, Ida . . . . . . . . . . . . . 372,652 Ball, Sir Robert. . . . . . . . . . . . . 889 Ballard, Julia P 3 I 7, 323, 328, 334, 338, 343

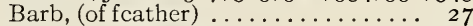
Barbels, (of feather) ...........27, I 54 Barker, Eugcne. . . . . . . . . . . . 170, 526 Barometer ................. 878

Baskett, J. N. . . . . . . . 64, I49, I67 Batrachian Study . . . . . . . . . I 8 I

Bat ................... 245

Bear, Great (Ursa Major) . . . . . .890,89 I Little (Ursa Minor) ... . . . . . . . 89I

Bee .............. I8, 20, 54I, 679 Bumble.

$2 \mathrm{I}, 442,444,579,580,624,626,655$ Carpenter............ 439,440 Carpenter nest of . . . . . . . . . 441 drone . . . . 445, 445, 447, 448, 449, 450 Honey . . . . . . . . . . . . . . 445, 449 queen $\ldots \ldots \ldots+45,416,447,448,450$ Leaf-cutter. . . . . . . . I I , 436, 438,437 Mining . . . . . . . . . . . . . . . 526 worker . . . . . 445, 446, 447, 448, 449

Beecher, H. W. . . . . . . . . . . 635

Bee larkspur . . . . . . . . 623, 624, 625

Beetle.............6. 61, 64, 3 I0

Ground .................. 92

Colorado Potato . . . . . . 409, 410,411

Beet leaf-miners ............. 88

Belgian Hares . . . . . . . . . . . . . . . 216

Benefits of Nature-Study to Child... I to Teachers .............. 
Bentley, W. J. .825, 828, 85I, 852, 853 , $854,855,856,857,858,860,863$, $866,874,875,876,877,878,879$ Big Dipper...........889, 890, 89 I, $892,893,894,900,901,902,903$

Big and Little Dippers . . . . . . . . . . . . 894

Bindweed...............535, 536

Birch.................. 73

Birds ................... 25

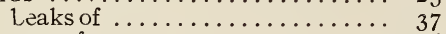

ears of .......................... 36

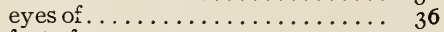

feet of ................. 39

nostrils of $\ldots \ldots \ldots \ldots \ldots \ldots \ldots \ldots \ldots . \ldots \ldots$

Birds-Flight of . . . . . . . . . 33

Bird houses . . . . . . . . . . . . . 47 , 60

Birds' Nests.................. I 47

Bird, parts named............... I 47

Bird Study................. 25

Birthroot .................. 506,508

Blackbirds ................. I 30

red-winged............. 122, 123

Blade (of leaf) . . . . . . . . . . .493, 687

Blanchan, Neltje........... I 3 I, I 42, I 46

Bleeding Heart . . . . . . . . . 611, 6I2, 6I3

Blights .................. . . . . . I

Bloodroot. . . . . . . . 503, 504, 505, 506

Bloodstone .................. 830

Bluebird ..................6.6. 61

Bluets. . . . . . . . . . . . . . . . 523, 524

Blue Hill Observatory........... 860

Blue Vitriol . . . . . . . . . . 825,826

Bole or Trunk of Tree. . . . . . . 726, 727

Boreas .................... 858

Box Elder. . . . . . . . . . . . . . 738

Boulders. . . . . . . . . . . . . . . . 844

Bracken... . . . . . . . . . . . . . 689

Branch . . . . . . . . . . . . . . . 727

Bread mold, enlarged ........... 721

Breathing pores of insect........ 314

Brook Study . . . . . . . . . . . . 817

Brook, the........... 8 i 8,8 iq, 844 Brown, Theron.......585, 59 I, 657, 8 I6 Browning Robert . . . . . . . . . 5 I5, 898

Bryant, W. C. . . . . . . . . . . . . . 49 I

Buchanan, H. B. M. . . . . . . . 294, 306

Buckeye, sweet, blossom .......... 761

Budding ................. 780

Bufialo .................... I8, 295

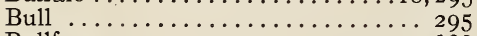

Bullfrog ..................... 193

Bullhead............... 154, 155, I 56

Burdock ......566, 567, 568, 569, 594, 633

Burkett, W. B..............280

Burroughs, John........ 72, 74, 76, 79

Burr, Prof. Geo. L. . . . . . . . . . . . 838

Butter-and-eggs . . . . . . . . . . . . 594

Buttercup ............. 528,529,530

Butterfly-Black swallow-tail....315, 3 I 8 changing to chrysalis ........ 317 scales on wing of ...................... 321 Cabbage................... 317 Monarch ............................ 324
Page

Butterfly-Papilio troilus ........ 579

Viceroy ...........321, 322, 768

Byron ................. 785

Caddis-fly ..........387, 388, 389, 390

Caddis-worms cases of . . 387, 389, 390, 391 spiral ribbon . . . . . . . . 390, 39I with a grating of silk .......... 389

Cage, bird ................... 8

breeding $\ldots \ldots \ldots \ldots \ldots \ldots \ldots$

for crickets................. 375

Calcite, marble and limestone. . . 835, 836

Calla lily................. 5 I 2

Callisto .................. 89

Calves, dehorned............. 30I

Camel $\ldots \ldots \ldots \ldots \ldots \ldots \ldots \ldots \ldots$ r 8

Campanus ................... 920

Canada thistles .............. 566

Canary .................. 49

Cancer (the crab) . . . . . . . . . . 912

Tropic of .............

Canker-worms............... 92

Capella ...................... 90 I and the Heavenly Twins ....... 900

Capricorn, Tropic of. . . . . . . . . . . 9 I I

Capricornus, (the Goat) ......... 9 I 2

Carapace (of turtle) ........... 208 of crayfish .............. 466

Caraway worms .............. 319

Carbon dioxide . . . . . . . . . 861, 862, 864

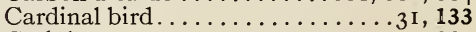

Carlyle . . . . . . . . . . . . . . . . 887

Carolina locusts. . . . . . . . . . . . 367 poplar ............... 770

Carpenter, Edward............. 39 I

Carpenter bee . . . . . . . . 439, 440, 44I

Carrot, wild . . . . . . . . . . 5 590, 591, 592

Cassiopeias Chair, Cepheus and the Dragon ..............893,894

Castor. . . . . . . . . . . . . . . . 900

Catastomus commersoni . . . . . . . . I I 59

Cat-tail.......... $8, \mathbf{5} 5 \mathbf{1}, \mathbf{5 5 2}, \mathbf{5} 53,554$

Cat, the $\ldots \ldots \ldots \ldots \ldots \ldots 56,6$ I, 268, 272

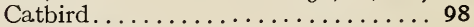

Caterpillars ............ Cabbage.................. 88

Cecropia ................... 331

cotton-boll .................... 96

external anatomy of ...................... 314

Forest tent. . . . . . . . . . 308

Milkweed or Monarch.......322, 324

Myron sphinx . . . . . . . . . 343

Myron sphinx parisitized........ 345

pro-legs, prop legs and true legs of 314

Promethea ............... 337

shedding skin. . . . . . . . . . 308

skin of ................ 309

Caterpillars, swallow-tail........... 316

Viceroy in winter home ....... 323

Woolly bear ................ 327

Catkins.................766, 767

Cattle . . . . . . . . . . . . . 295, 298

Original American wild ........ 295 
Cayuga basin .............. I70

Cayuga Lake.................. I 58

Cecropia, caterpillar, molting . . . . . 331 weaving cocoon........... 332 cocoon, cut open ........... 333 moth ..............330, 334

Cedars ................... I9

Celandine, silver leaf, ladies' eardrop. $\mathbf{5 8 0}$

Carnelian ................. 830

Chalk ................... 836

Chapman Frank . . . . . . . . . 5 I

Charles, Prof. Fred S. . . . . . 254, 256, 260

Charts, use of ............... Io

Chart, of bright stars of summer. . . 901 of Polar Constellations. . . . . . . . 893 of Winter Stars . . . . . . . . . . . . . . 895

Cheese, Altenburger............... 278 Roquefort ............. 278 Schweitzer . . . . . . . . . . . . . . 278

Chestnut. . . . . . 757, 758, 759, 760, 761

Chickadee ................6, 60

Chickaree ............233,234,236

Chick, the .............. 4I

Chicken ways $\ldots \ldots \ldots \ldots \ldots \ldots \ldots \ldots . . \ldots 1$

Chickweed ................. 594

Chinch bug ............... 82

Chipmunk ............240, 241,242

Chlorophyll ................. 729

Chrysalis ................. 309

of Monarch . . . . . . . . . . . . 322

Chrysanthemum ........... 56 I

Chub.................... I63

Circumpolar whirl. . . . . . . . . 873,874

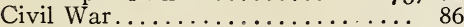

Claws of Cat ............... 269 (of insects) ............. 313

Clay .............844,845,846,847

Cleopatra's Needle . . . . . . . . . . . 834

Clisodon terminalis . . . . . . . . . . 627

Clitellum, (of earthworm) ......... 463

Clouds ..........85i, 852,855,87 I

Clovers, the ...........652,653, 655 Alfalfa ................ 654

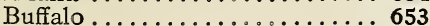

Crimson ............. 652,778

Rabbit-foot or pussy..........653

Red ..................654

Spotted medic . . . . . . . . . . 655

Sweet .........654 655, 656, 657

White ..............658,659

Yellow or Hop............... 653

Clute Prof. W. N. . . . . . . 684, 680 , 690

Cob-webs................475, $470^{\circ}$

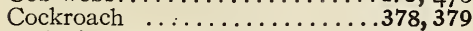
laying case of eggs.......... . 379

Cocoon .................... 309

of Cecropia................ 333

of Luna.................. 309

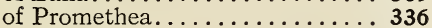

of woolly bear .............. 327

Codling Moth . . . . . . . . . . . 347, 349 larva of ................ 348

Collections of birds or insects...... 8
Page

Colorado Potato Beetle. .409, 410, 411,412 larva of ..............4 410

Colt.................... 289

Comet. ................997,908

Compass, Mariner's . . . . . . . . . . . 839, 84 I plant ............... 570

Compositae ............554, 631, 633

Composite snow crystal, formed in high and medium clouds. . . . . . . 851

Composite flower .............. . 554

Comstock, Prof. J. H.... .45, 319, 833, 857

Cone-bearing trees ............ 789

Constellations, of the Chair. . . . . . 893

The Archer. . . . . . . . . . . 912

The Bull. . . . . . . . . . . 897, 912

The Crown ............... 903

Cygnus .................. 904

Orion ................ 896

Pleiades ................ 897

Dippers ................. 890

The Virgin . . . . . . . . . . . 912

Coolbrith, Ina . . . . . . . . . . . 83

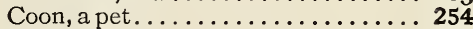

tracks ............... 250

Copper sulphate ............ 825

Coral. ................... 837

Corm (of crocus) ............. 596 of Jack-in-pulpit . . . . . . . . . 512

Corn .............85, I3 I, 660, 665

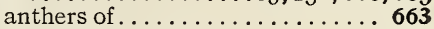
an ear of $\ldots \ldots \ldots \ldots \ldots \ldots \ldots 62,665$ ears with braided husks....... 663 husking for braiding by Seneca Indian women ............660 pollen-bearing flower of ........662 growth of . ..........663,665 in the shock ............... 664

Corn-cracker, the red ........... 133

Cornwall Barry .............. 515

Corona (of daffodils) ... . . . . . . . 599 (of the sun) ............... 905

Correlation of Nature Study with : Arithmetic ............. I9 Drawing . . . . . . . . . . . $\ldots \ldots$ I7 English................ I6 Geography.............. I8 History .............. I8 Language work. . . . . . . . . . I6

Cotton ....... $666, \mathbf{6 6 7}, \mathbf{6} 6 \dot{6}, \mathbf{6} 69,670$

Cotton-gin ................. 668

Cotton-tail rabbit. . . . . . . . 213, 216

Cottonwood tree .....770, 771, 772, 773

Cotyledons or seed-leaves . . . . . . . 496

Country Life in America........ 6r

Coverts (of feathers) ... . . . . . . . . 44

Cow ..........295,296, 298, 300, 30I care of milch ............ 300

Cows as draft animals . . . . . . . . . . 298

Cow's stomach . . . . . . . . . . 296

Cow-peas ................... 654

Coxa (of insect) . . . . . . . . . . . 314

Coyote pet ................... 256 
Cray-fish ...........466, 468, 470 where it lurks. . . . . . . . . . 465

Crickets .............. 3 I I 5 373, 375 Black male and female.....372, 374 front leg of ............. 373 Snowy Tree . . . . . . . . . 377, 378 wing covers of . . . . . . . . . 374

Crocus ..............596, 597, 598

Crosby, Prof. Cyrus . . . I I90, 523, 538, 570, $594,623,629,636,773,797,798$ Crosiers (of ferns) . . . . . . . . . . 692

Cross, Northern . . . . . . . . . . 889, 904

Croton bug. . . . . . . . . . . . . . . 378

Crow the..........43,46, 56, 129, I3 I

Crown, Northern . . . . . . . . 902,903 of bird................ 44 of daffodil . . . . . . . . . . . . 599

Crystal, growth of ............ 825

Crystals ................. 825,85I

Alum................. 826

Calcite ................ 835

Feldspar .............831

Frost ................854

Quartz ................. 829

Rock ................ 830

Salt ................. 827

Cultivated-Plant Study . . . . . . . . 596

Curculio of Plum............ 347

Curtis, Ralph . .742, 743, 744, 746, 752, 775

Cutworm .............56, 82, 85, 92

Cyclone .................. 879

Cygnus ................... 904

Cynthia Moth................ 337

Dace

I6I

"Daddy Longlegs", . . . . . . . . . . .472, 474

Daffodils. . . . . . . . . . . . . 599, 600,601

Daisy .............. I 8, 560, 561 Yellow ............... 562

Damsel-flies ........... 382, 383, 384

Dandelion ....... I9, 57 $2,573,574,575$

Dandridge, Danske............. 503

Davie, Oliver................ 98

Dawson, Dr . . . . . . . . . . . . I33

Day, longest................ 9I 3

shortest................ 9I3

Definition of Nature-Study . . . . . . . I

Deland, Mrs. Margaret . . . . . . . . 530

Deneb ... . . . . . . . . . . . . . . . 904

Design for embroidery . . . . . . . 498, 502

Devil's darning needle .......... 382

Dew ......479, 851, 853, 855,862, 879

Dickinson, Emily . . . . . . . . 200, 204

Dicksonia (fern) . . . . . . . . . . 695

Dippers, Big and Little . .889, 890, 89I, 901

Disk-flowers

$554,557,558,560,562,564,567,577,632$

Dodder .................. 538

Dogs . . . . . . . . . . . . . . 261, 267

Dog Stars, Great . . . . . . . . . 8 898, 899

Dogtooth Spar. . . . . . . . . . 835, 836

Dogwood ...............803, 804, 805

Dolphin, or Job's Coffin . . . . . . . . . 904
Dorr, Julia C $\ldots \ldots \ldots \ldots \ldots \ldots \ldots$

Double Stars .................. 8888

Dragon-flies.............. 31 I, 382, 386

Drake, J. R................ 97

Drawing and Nature-Study......... I 3

Dryden, John . . . . . . . . . . . . . 48

Duck, Rouen .................. $31,37,39$

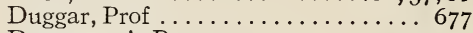

Dugmore, A. R ................ I40 I 47

Dutchman's breeches .........509, 511

Eagle, the constellation of . . . . . . 904

Ears (of insects) . . . . . . 3 14, 365, 369, 373

Earth and Sky .............. 818

Earthworms........20, 56, 462, 464

Eft or newt. . . . . . . . 197, 198, 199

Egg-shell Experiment farm . . . . . . . 4 495

Egyptian lotus flower ........... 546

Elkins, Prof ................ 909

Elm, American or White....745, 746, 747

Electro-magnet . . . . . . . . . . . 839

Ell-yard, the .............. 896

Emerson, R. W. . . . . . . . . 442

Eohippus ................... 286

Equatorial Current............. 866

Equipment for teaching Nature-Study 8

Eschcholtzia californica........... 616

Everlasting, early or Pussy-toes ..... 578 Pearly............576, 577, 633

Evening Primrose . . . . . . . . 530, 531

Excursions, field . ............. I5

Eyelid,film ............... 36

Eyes, insects, compound........312, 314 simple ..................

Feathers, as clothing.......... 27 as ornament $\ldots \ldots \ldots \ldots \ldots \ldots .30$ form of $\ldots \ldots \ldots \ldots \ldots \ldots \ldots, 27$ wing, coverts ........... 44 wing, primaries $\ldots \ldots \ldots \ldots \ldots 33,44$ wings, secondaries..........33, 44

Feelers-insects ................ 312

Feldspar..........831, 833,834, 844

Femur, insect. . . . . . . . 312, 3 I 3, 3 I 4

Ferns..................6. 684-698

bladder ............6.697,698

boulder ..............695,697

bracken or brake. . .689, 690, 691, 697

chain ...............695, 697 Christmas........6.684, 685, 688, 694 cinnamon . . . . . . . . . . . . . 697 Dicksonia .................. 695

fiddle-heads or crosiers. . . . . . . . 691 flowering . ..............695, 697 frond of ................. 687 fruiting of . . . . . . . . . . 693, 694 indusia or spore-cases of........

$686,694,695,697$ interrupted..............6 697 leaf-print of, with parts named... 687 Maiden-hair ............... 697 Osmunda ..................... 695 Ostrich ................... 697 

rachis of ............. 687

Sensitive...........695, 696, 698 sori of ................ 687,694 Spleenwort .............. 697 sporangia of . . . . . . . 686, 694, 697 stipe or stem of ............ 687 unfolding of ...........691, 692 Walking ............... 693 Woodsia ................... 697

Festina Lente............... 196

Fielde, Miss Adele.............. 420 Ant-nest ................ 424

Field lessons................ I5

Field note-book $\ldots \ldots \ldots \ldots \ldots \ldots \ldots$ I 3

Firefly...................

Fish Study . . . . . . . . . . I 492

Fish bream............. I6

Brook-trout . . . . . . . . . . . 164

Bullhead.................154, 155

Catostomus commersoni. . . . . . . I 159

Chub..................... 163

Dace..................... 163

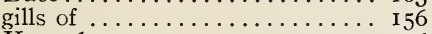

Horned pout . . . . . . . . . . . 156

Johnny darter . . . . . . . . . . 177

Minnows .................. 163

Shiner .................

Stickleback ..............168, 170

Sucker common.............158, 160

Sunfish or Pumpkin seed .172, 173, 174

Fiske Geo............ 78, 1 I 8, I I9, 250 John, Prof.....................

Fleur-de-lis.................6. 626,629

Flower head .............. 554

Flower and insect partners. . . . . . . . . 4944 wild................. with parts named ............ 492

Flowerless Plant Study. . . . . . . . . 684

Fly, House. . . . . . . . 405, 406, 407

Fog .................. 850, 852, 853, 855

Forestry, Practical . . . . . . . . . . . 849

Forest Service ............... 555,771

Forsyth, Mary Isabella . . . . . . . . . . $\quad 84$

Foster, O. L . . . . . . 5 509, 73 1, 761, 764

Fox ............257, 259, 260, 267

Franklin................. 858, 859

Frog ......................... tree, or Pickering's Hyla. . . . . 190,191

Frost................ 853, 854, 855

Fudge, C. F ................ 592

Fuertes, Louis A. $45,70,73,75,80,81,94$

Fungi $\ldots \ldots \ldots \ldots \ldots \ldots \ldots \ldots 706-725$

Fungus, bears head ............. 718

Bracket .................. 714

Earth star.................... 713

Hedgehog................... 717

Sarcocypha coccinea or scarlet saucer .............. 7 18, 719 Shelf .................. 714

Page

stink-horn ........... 720

Furry ........................ 238

Gage, Prof. S. H.......... 187, 192

Gage, Mrs. S. H.............. 198

Galaxy the, (of stars) . . . . . . . . 889

Galileo ......................... 858,865

Gallager, W...$\ldots \ldots \ldots \ldots \ldots \ldots \ldots \ldots \ldots \ldots \ldots$

Gall-dwellers . .360, 361, 362, 363, 364, 768

Galls ..................360, 364, 767

Garden, window ............. 8

Gardening and Nature-Study ...... 20

Geese ....................136-142 Canada or wild.............139, 140

Gelechia pinifoliella............... 353

Gemini, (the Heavenly Twins) . . 900, 912

Geography I 8, 299, 545, 548, 552, 81 8, 822

Geranium...........643, 644, 645, 646

Gilbert,Grove Karl, $142,726,793,794,850$

Glass ..................... 830

Glow-worms................ 4 17

Gnomon, the $\ldots \ldots \ldots \ldots \ldots \ldots$ 91 5

Goat, The.....275, 276, 277, 278, 279

Goldfinch, or Thistle bird......3 I, 49, 50

Goldfish with parts named.......... I 50

Golden Osier .................. 765

Goldenrod . . . . . . . . . . . 555, 556, 557

Goodale, Elaine .............. 525

Grades, bird study in primary ...... 25

Grafting, cleft ................... 779

Grandfather Greybeard ........472, 473

Granite ................. 833 Obelisk .............. 833

Grasshoppers........ 18, 6I, 82, 85, $92,311,312,365,366,367,368,369$

Grasshopper, with external parts named ................... 365

Short-horned ............ 367-369

Gravel................... 844

Green Bay-tree .............. 8 I 3

Greene, Robert ............... $3^{2}$

Grosbeak, the Cardinal ........... I 33

Ground-hog ..............229, 230

Gulf Stream.................. 866

Hail $\ldots \ldots \ldots \ldots \ldots \ldots \ldots \ldots . \ldots 83$

Hardpan $\ldots \ldots \ldots \ldots \ldots \ldots \ldots \ldots . .644$

Hardy, Irene . . . . . . . . . . 243, 619

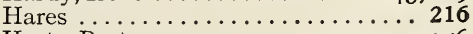

Harte, Bret ...................... 224, 256

Hawks............... 43, 46, 108, 109

Hay, John .................... ${ }^{\mathbf{1} 32}$

Helium ................862,864

Hemlock...............

Hen. . . 25, 27, 30, 33, 36, 37, 39, 41, 42, 43

Henry, Prof. Joseph .............8 859

Hepatica..............496, 497, 498

Herford, Oliver............213, 419

Hickory, the shagbark ............ 755

H. H. .............. 558, 622, 652

Higginson, Ella .............. 659

Hill, Mary E ................. I 7

Hives-observation.........453, 455 
Page

Hoar-frost. . . . . . . . . 851, 853, 855, 879

Hog, the . . . . . . . . . . 304, 305, 306

Homer. . . . . . . . . . . . . . . . . . . 899

Honey, honeycomb. . . . . . . 451, 452, 453

Hornblende . . . . . . . . . . . . . 383

Horne, R. H. . . . . . . . . . . . 325

Horse-chestnut . . . . . . 761, 762, 763, 764

Horse, the . 286, 287, 288, 289, 290, 291, 292

Horsetail or Equisetum. . . . . . 699, 700

Howells, W. D. . . . . . . . . . . . . I 25

Howitt, Mary ............... I03

How an apple grows . . . . . . . . . 782

a brook drops its load ... . . . . . 822

to begin study of plants and flowers 489

to begin study of stars. . . . . . . . 889

to make an aquarium ............ 380

to make a sun-dial. . . . . . . . . . 9 I5

to read weather maps ......... 879

to keep daily weather maps ...... 883

to find the general direction and

average rate of motion of high

and low areas ............ 883

to make leaf prints . . . . . . . . 734

to make plants comfortable . . . . . 490

to produce good milk . . . . . . . 299

to study minerals . . . . . . . . . . 828

to teach names of parts of plants

and flowers.............. 492

Humidity, absolute and relative .... 862

Hummingbird ............... I 20

Huxley, Thomas . . . . . . . . . . . 837

Hyades .................. 897

Ice . . . . . . . . . . . . 853, 854, 856

Iceland spar $\ldots \ldots \ldots \ldots \ldots \ldots \ldots \ldots . \ldots \ldots 35$

Imago, or adult stage of insect. . . . . . 3 Io

Imagination, training of . . . . . . . . I

Impatiens or Touch-me-not. . . . . . . 578

Indians, North American503, 660, 676. 810

Indian turnip............. 5 I 2

Indusia of ferns. . . 686, 687, 694, 695, 697

Insect Study . . . . . . . . . . 308

Insects, breathing of . . . . . . . . 3 I 3

biting and sucking ........... 3 I 3

brownies .............. 3I I

eggs of ................... 308

Ingersoll, Ernest . . . . . . . . . . . . . . . 249

Invertebrate-Animal Study . . . . . . . . $45^{8}$

Iris, or blue flag . . . . . .626, 627, 628, 629

Irvine, J. P. . . . . . . . . . . . I I I

Isaiah . . . . . . . . . . . . . 765

Isobar . . . . . . . . . . . 8 870, 879

Isotherm. . . . . . . . . . . . . . 879

Jack-in-the-pulpit. . . . . . . . 512, 513, 514

Japan Current . . . . . . . . . . . . 866

Jasper $\ldots \ldots \ldots \ldots \ldots \ldots \ldots \ldots \ldots \ldots 830$

Javelins (hogs) . . . . . . . . . . . . . 304

Jeffries, Richard . . . . . . . . . . 593, 849

Jewelweed or touch-me-not . . . . . . . 578

Jimson or Jamestown weed . . . . . . . 640

Job's Coffin . . . . . . . . . . . . . . . . 904

Johnny darter . . . . . . . . . . 177, 178

Jonquils . . . . . . . . . . . . 599, 602
Page

Jordan, David Starr. . . . . . . . . I49, I57, I66, I67, I68, I 76, I 77, I79, 2 I 7 Jug-building wasp............ 43I Junior Naturalist Clubs . . . . . . . . 23 Jupiter ................. 906

Kaolin.................. 831, 844

Katydid ................... 369, 370, 371

Keats, John ..............53, I63,648

Kentucky Cardinal............... I33

King, Harriet. . . . . . . . . . . . . 598

Kingfisher, Belted............... 101

Labium.................. 3I3, 3I4

Labrum $\ldots \ldots \ldots \ldots \ldots \ldots \ldots \ldots \ldots$ 3I 3 , 3I 4

Labradorite .................. 83I

Lace-wing . . . . . . . . . . . . . . 397, 398

Ladybird ...........413,414,415

Lady in the Moon . . . . . . . . . . . . 919

Lady's Slipper . . . . . . . . . . . . . . . 525, 526

Lanier, Sydney . . . . . . . . . . . . . 96

Lapham, Dr. Increase. . . . . . . . . . . . 860

Larcom, Lucy . . . . . . . . . . . . . 90, 93, 582

Larkspur. . . . . . . . . . . 623, 624, 625

Laurel. . . . . . . . . . . . 813, 814, 81.5

Laurence, Ray .......524, 540, 578, 620

Larvae ..................308, 3 I I

Leaf, with parts named. . . . . . . . . . 493

Leaf-factories. . . . . . . . . . . . . . . 1, 729, 730

Leaf-miners . . . . . . . . . . . 352, 353, 354

Leaf-print, how to make . . . . . . . . 734 of fern with parts named........ 687

Leaf-rollers . . . . . . . . . . . 357, 358, 359

Leaves, their use . . . . . . . . . 491, 728

Leigh, Florence . . . . . . . . . . . . . . 267

Lens $\ldots \ldots \ldots \ldots \ldots \ldots \ldots \ldots \ldots$

Leo, (the Lion). . . . . . . . . . . 902. 909, 912

Lesson, the nature-study ......... I0 always new.................. 7

length of $\ldots \ldots \ldots \ldots \ldots \ldots \ldots \ldots$

time for................. 6

object lesson method......... 7

Lichens, growing on rocks . . . . . . 843

Lily, calla ................ 5 I2 pond or water, white..... $545,546,547$

Lime . . . . . . . . . . . 835, 836,837, 849

Light-year . . . . . . . . . . . . 888

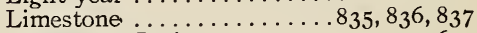

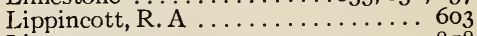

Lips .................. $85^{8}$

Little Dipper . . . . . . . . . . . . . . 892

Dog Star. . . . . . . . . . . . 896, 899

Living material in schoolroom ....... 8

Loam. . . . . . . . . . . 844, 845, 846, 847

Lodestone. . . . . . . . . . . . . . . 838,84 I

Longfellow, Henry W....... 2, 493, 626

Lowell, James Russell. 7, I 28, 153, I96, $382,418,503,572,763,777$

Lloyd, J. T . . . . I I 4, 2 I I , 387, 388, 389, 390

Lubbock, Sir John . . . . . . . . . 423, 433

Lyra .................. 889, 903

Maggots ................. 308 
Magnets.............. 838, 839, 840 Maize or Indian corn $660,661,662,663,664$ Mammal Study..............2 2 2 Mandibles-insects... . . . . . . 313, 314

Mandrake or May apple.......519, 520

Maple, the............732, 735, 736 Mountain ............732,742 Norway . . . . . . . . . . . . . . . . . . . . . . 738 Red................7332,744 seedlings ............. 74 I Silver ..........738, 741, 742 Striped or goosefoot . . . . 738, 743, 744 Sugar or hard . . . . 732, 739, 740, 741 Sycamore ............. 735, 738

Maple-sugar, making . . . . . . . . 738

Marble .................. 835

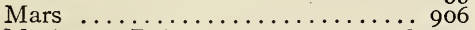

Matheson, Robert........... 82, 98

Maxillae, insect............. 313 , 3 I4

May beetle.............. I3 I, 4I 8

Meadow lark...........77, 80, 81, 82

Mercator ............... 920

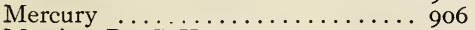

Merriam Dr. C. Hart . . . . . . . . . 248

Mesothorax ..............3 3, 3 I4

Metathorax .................

Meteorites ..............908,92 I

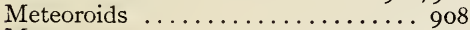

Meteors . . . . . . . . . . . . 864, 908

Mica . . . . . . . . . 832, 833,834, 844

Mice ............. 224, 225, 226, 227

Mildews .................. 72 I

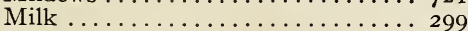

Milk-dipper, the ............ 912

Milky Way, the. . . . . . . . . . . . 889

Milkweed ............540, 541, 543

Minnows ................. I63

Mist . . . . . . . . . . . . ${ }^{2}$

Mitchell, Evelyn. . .401, 402, 498, 502, 5 I4

Metamorphosis, insect. ........ 3 I I, 367

Moccasin flower or Lady's Slipper 525, 527

Mockingbird ................ 94

Molds . . . . . . . . . . . . . . . 720,721

Molting insects ..............308, 309

Montgomery . . . . . . . . . . . . . . 635

Moon, the.......... $64,918,919,920$

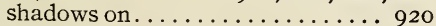

Moonstone ................. . . . . . . . .

Moore, Dr. Willis L. . . . . . . . . . . . . . 879

Morgan, G. F. . . . . . . 652, 747, 759, $774,776,79 \mathrm{I}, 792,796,8 \mathrm{I} 2$

Morton, Verne-Photos by-Frontispiece, I $64,230,242,247,27 \mathrm{I}, 274,501,505$, $506,508,5$ I 5,5 I6, 5 I 7, 520, 525, 529, $533,545,55 \mathrm{I}, 553,560,56 \mathrm{I}, 562,563$, $566,576,577,583,586,588,590,609$, $6 \mathrm{II}, 627,664,672,676,678,68 \mathrm{I}, 682$, $685,686,689,692,694,698,702,713$, $714,737,757,760,762,766,767,769$, $784,807,8$ I 5,8 I 7,843

Mosquito........309, $400,401,402,403$
Moss, hair cap or pigeon wheat. .702, 703

Moth, Cecropia. . . 330, 331, 332, 333, 334 Codling ....................... 349

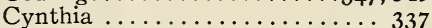

Isabella tiger . . . . . . . . 326, 327, 328

Luna. . . . . . . . . . . . . 309, 310, 330

Promethea ......330, 336, 337, 338

Polyphemus ............ 330 Sphinx

$313,340,341,342,343,344,345,346$ Mouse, dcer, cr whitefooted.....223,226 house...............224, 225

Mulch . . . . . . . . . . . . 847

Mullein . . . . . . . . I $8,582,583,584$

Mulock, Miss. . . . . . . . . . . . . 602 Muskrat. . . . . . . . . 218, 220, 221

Museum specimens............. 8

Mushrooms 706,707,708, 709, 710, 7i1, 712

Nape, (of bird) . . . . . . . . . . . . 44

Narcissus . . . . . . . . . . . . . 599, 601

Nasturtium ..............620, 621

Natos .................. $85^{8}$

Natural Bridge in Virginia. . . . . . . . . 835

Nature-study clubs............ 22

Naylor. . . . . . . . . . . . . . I I 34

Nebula . . . . . . . . . . . . . . . 888

Needham, Dr. James G., $382,383,384,385,626,627,64 \mathrm{I}$

Neptune ....................... 906

Newcomb, Dr. Simon ............ 906

Newt, red-spotted. . ....... I97, 198, 199

Nitrogen. . . . . . . . . . . 653, 861, 864

North pole . . . . . . . . 839,889, 890

Northern Lights . . . . . . . . . . . . . 839

North Star $889,890,891,892,893,894,902$

Nuthatch, white-breasted......63, 64

Nymph .................. 3I I of damsel-fly $\ldots \ldots \ldots \ldots \ldots \ldots 384,385$ of dragon-fly . . . . . . . . . . 384 of red-legged grasshopper....... 366

Oaks, the .................. 748 Black ............... $\ldots \ldots \ldots 49,753$

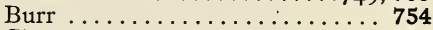

Chestnut ............. 751

Live. . . . . . . . . . . . . . . . . . . 726

Red . . . . . . . . . . . 752, 753

Scarlet .................. 754

White .............748, 749750

Oak-apple................... 36 I

Ocelli (of insects) . . . . . . . . . 312, 314

Oligoclase .............. 83

Onyx .................. 830

Oriole, Baltimore........ 125, 126, 127

Ovipositor (of insect) . . . . . . . . 3I4

Owl, screech.................... I04

Oxen ........................ 298

Oxygen . . . . . . . . . . . . 730, 86i, 864

Orion. . . . . . . . $888,895,896,897,899$

Palpi, insect .............313,314 
Pansies ..............607, 608, 609

Partridge .................. 30,4 I

Pattee ................ 80 I

Peacock ................ 30, 31, 32

Pears and apples, ready to spray.... 350

Peccaries ................... 304

Pelargonium ................. 643

Perianth ................. 599

Perseus ................... 909

Petrified forest of Arizona . . . . . . . 830

Pets .................. I5

Petunia.................640, 641

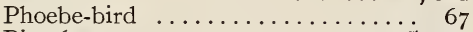

Pig, the................... $303,305,306$

Pigeons . . . . . . . . . . . 45, 46, 47

Pigeon houses . . . . . . . . . . .45, 47

Pigeon-grass or pigeon wheat. . .702, 703

Pine, the . . . . . . . . . . . . 73, 789

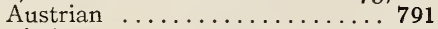
Pitch ................... 79 I, 800 White...... I9, 790, 792, 793, 795, 800 Yellow ................... 793 Mountain, of Sierras........... . 794 upturned roots ............ 728

Pisces (the Fishes) . . . . . . . . . . 9 I2

Planisphere ................ 89I

Plant-lice............ 92, 392, 393, 421

Plant Life. . . . . . . . . . . . . . . 489

Plant Physiology . . . . . . . . . . 20,49I

Pleiad, the lost................. . 898

Pleiades, the........... 888, 889, 897

Polaris-Pole-star......888, 890, 89I, $892,893,894,895,901,902,904,906$

Pollen ...................... 494

Pollux ................... 900

Pond-weed.................. . . . . . 548,549

Poplar Carolina . . . . . . . . 7770, 771, 772

Poppy, the ..............613,614 California.............. . 616, 617

Potassium bichromate . . . . . . . . . 825

Potash, bichromate of . . . . . . . . . 825

Prickly Lettuce . . . . . . . . . . . . . . 570

Procyon . . . . . . . . . . . . . . . 898

Pruning, principles of ........... 780

Pumpkin, the $675,676,677,678,679,680,681$ seed (sunfish) ............ I 72

Pupae .............................. 3 I I of caddis fly ............... 388 of Codling Moth . . . . . . . . . . 349 of firefly $\ldots \ldots \ldots \ldots \ldots \ldots \ldots \ldots \ldots . \ldots \ldots$. 34 of Potato beetle............ 4 II of Ladybird . . . . . . . . . . . 4 I 5 of Mosquito . ................. 402 (jug handle) Tomato sphinx... 342

Purslane ................. 594

Quail ................... 4 I

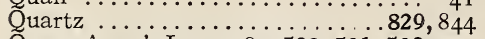

Queen Anne's Lace. 589, 590, 591, 592, 593

Rabbit . . . . . . . . . 213, 215, 216

Raccoon .............250, 253,254

Page

Rain .............. 852, 874. 880

Rattlesnake, The............ 203

Redbird .................. . I33

Red-winged blackbird. . . . . . . 122, 123

Regulus .............902, 909, 91 2

Reighard, Professor ........... I74, I 75

Reptile Study .............. 200

Resin.................... . 794

Rexford, Eben ........... 6 I

Rice, Prof. J. E . . . . . . . . . . . 33

Rich, John ................ 295

Rigel .................. 896

Riley, James Whitcomb. .70, 201, 52 I, 8 I 8

Robin ............. 54, 55, 57

Root, A. I. Co ............. 456

Root tubercles................ . 653

Rosin ................... 794

Rossetti, Christina ............. 326

Rotch, Prof. Laurence . . . . . . . . . . 860

Rowe, Mrs. F. W . . . . . . . . . . . 95

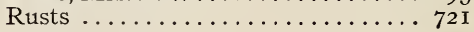

Saggittarius (the Archer) ........ 912 Salamander ............197, 198, 199

Salt . . . . . . . . . . . . . 827,828

Salvia or Scarlet Sage..........637, 638

Sand . . . . . . . . . 834, 844, 845,847

Sand-stones . . . . . . . . . . . . . 834

Sap movements of . . . . . . . . . . 739

poem ................ 736

Saturn. . . . . . . . . . . . 906

Scales, on butterfly's wing ......... 42 I

Screech Owl.................. I04

Seed germination . . . . . . . . . . . . . . 495

Seed-leaves (cotyledons) . . . . . . . . . 496

Shakespeare ............ 5 I5, 6I I

Shadow-stick, $\ddot{A} \ldots \ldots \ldots \ldots \ldots \ldots \ldots$. . . . . 9 I 4

Sheep .......... 281, 283, 284, 285

Sheldon, S. L . . . . . . . . . . . . . . . . 644

Shelley ................... 850

Shepherd, a Sicilian............ 28I

Shiner ................. 161,162

Sickle, the (constellation) . . . . . . . . 902

Silk-worm................ 312

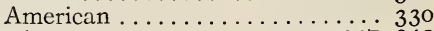

Skunk . . . . . . . . . . . $43,247,248$

Sleet . . . . . . . . . . . . . . . . 853

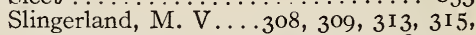
$316,317,318,322,323,327,328,330$, $33 \mathrm{I}, 332,33.3,334,3.36,337,338,340$, $34 \mathrm{I}, 342,343,344,345,346,348,349$, $350,35 \mathrm{I}, 362,374,379,392,4 \mathrm{IO}, 4 \mathrm{I} \mathrm{I}$, $4 \mathrm{I} 8,42 \mathrm{I}, 429,430,438,443,457,489$,

Slingerland, M.V.....488, 737, 741, 783

Smuts ................... 72 I

Snake . . . . . . . . . . . . . . . . . . . I94

Garden ................20 I, 20 $\tilde{z}$

Garter ....................

Milk .................... 204

Rattle ................. 203

Spotted Adder. . . . . . . . . . . . . 204

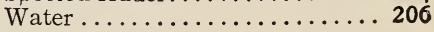


Snail, garden ............... . . 488,459

Snow ................ 85 I

Snow-crystals . . . . 825, 828, 851 852,856 $858,860,863,866,874,875,876$

Soil, the ................. 842

Solar System . . . . . . . . . . . . 906

Song of Solomon . . . . . . . . . . 778

Spadix ...............512, 513

Sparrow-chipping . . . . . . . 88, 89 English ..........54, 6I, 84 Song ................. 91

Spathe...............512, 513

Spectroscope . . . . . . . . . . . 887, 888

Spencer, John W. . . . . . I I6, 23, 842, 909

Spiders ................. 475 Ballooning ............. 484

White Crab . . . . . . . . . . . . . 485 care of eggs. . . . . . . . . . 487, 488

Spider-webs, cobwebs... . . . . . . 475 Filmy Dome. . . . . . . . . .482, 483 funnel . . . . . . . . . . . . . . . 477 Orb . . . . . . . . . 478, 479, 481

Spiracles, (of insects) .......... 3I3, 3 I 4 Spores 686, 693, 699, 704, 708, 7 I 3, 7 I 5,72 I Spore-prints, (of mushrooms) ...... 7 I0 Spray of tree ............ 727,728

Spruce, Douglas . . . . . . . . . . . .796 Norway . . . . . . . . . .796, 797, 798

Squash ..................6680 Squirrel. . . . . . . . . . 56 6 , 233, 234, 236 Squirrel corn ..........509, 511, 6I I Stalactites . . . . . . . . . . . 835, 837

Stalagmites . . . . . . . . . . . . . 835

Starch ...............491,729

Star Study . . . . . . . . . . . . . . 887

Stars, "the Friendly" . . . . . . . . . . 89 the Story of $\ldots \ldots \ldots \ldots \ldots \ldots \ldots 89$ of Summer . . . . . . . . . . . . . 90 go of Winter . . . . . . . . . . . . . 895 shooting .............. 898

Stetson, Charlotte Perkins......286, 726

Stickleback . . . . . . . . . . . . . . 168

Stigma . . . . . . . . . . . . . . . . . 492

Storms .................. 874

Storm and Hurricane warnings ... . . 88

Strawberry . . . . . . 672, 673, 674, 675

Street. A. B. . . . . . . . . . . . 585

Stryke, Anna-Drawings by ... . I , 2, 3, 4, $5,6,7,8,9$, IO, I I, I 5 I6, I 7,24 , I 36 , I6I, I8I, I90, I93, I97, I99, 200, 204, $223,233,247,250,255,26 \mathrm{I}, 288,3$ I 5 , $320,326,336,340,347,352,357,360$, $365,370,373,377,378,387,392,395$, $397,400,405,409,4 \mathrm{I} 3,4 \mathrm{I} 6,429,430$, $432,436,439,442,45 \mathrm{I}, 453,45^{8}, 462$, $468,472,475,483,484,485,487,494$, $495,535,540,607,6$ I 3,6 I 4,6 I 6, 6 I 7 , $630,640,684,707,727,736,745,748$, $755,757,76 \mathrm{I}, 765,770,77 \mathrm{I}, 774,785$, $789,796,8$ o , 806, 8I $0,8 \mathrm{I} 3$

Sucker, common ............158, 160 Sumac, velvet or Staghorn . . . 806, 807, 808
Sumac, smooth ............... 808

Poison ................ 808

Sun, the ................. 905

Sun-spots . . . . . . . . . . . . 905

Sundial. . . . . . . . . . . . . 915,916

Sunfish . . . . . . . . . . . I 72, 173, 174

Sunflower....................... 654, 632

Swallows, the............... 112

Swan the (constellation. . . . . . . . . . 904

Sweet Peas. . . . . . . . . . . . . 648, 649, 650

Swett, S. H............... . 476

Swift, chimney .............. 112

Tabb, John B........29, 545, 729, 736

Tadpoles............. I 82, I 83, I 86 of frog ................. I94 of toad .................... 187

of tree-frog. ............. 191

aquarium for ............ 185

Talus.................... 843

Tanager, scarlet............. 3 I

Taurus, (the Bull) ........... 897, 912

Taylor, Bayard . . . . . . . . . . 376, 799

Teasel .............586, 587, 588

Telescope ................ 887

Temple of Winds at Athens. . . . . 857, 858

Tennyson ................. 659

Thaxter, Celia........... I32, I42, 849

Thermometer scales in use. . . . . . . 865

Thistles..........563, 564, 566, 633

Thomas, Edith. ............... I00

Thompson Maurice... . . 63, 95, I 33, 279

Thoreau, H. D. . . . . . . . . . 9I , I 29 I $61,205,207,232,249,75^{8}, 765,85^{6}$

Thornapples................. 78 I

Thrush family . . . . . . . . . . . 57,60

Titmouse, black-capped. . . . . . . 66, 67, 68

Toad, common . . . . . . . I 8I , 182, 183, 187 development of a season. . . . . . . I 87 eggs of .............. 82, I 86 tree ................ I90, I91

Todd, Professor. . . . . . . . . . 864, 91 2

Tornado ................... 880

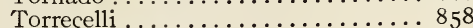

Treadwell, Prof .............. 56

Tree Study . . . . . . . . . . . . . . 726 how to begin .............. 73 I

Tree anatomy of ............ 727 how it grows ............. 733 head or crown of . . . . . . 777, 789 to measure . . . . . . . . . . . . . . 734

Tree-stump, showing rings of growth. 730

Tree-trunk or bole............ 727

Trilliums, The . ......... 506, 507, 508

Trowbridge, J. T.............. 47 I

Trout ................... 164, I67

Tulips..............603, 604, 605

Turkey, the ................ I, 143

Turtles ...............208, 209, 211

Tyndall, Prof. John . . . . . . . 837, 867

"Uncle John" . . . . I 6, 23, 490, 842, 843, 909 
Page

U. S. Dept. of Agriculture. . . . . . . . I 85,22 I , 276, 278, 279, 3O I, 352, 4 I I

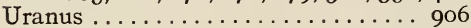

Ursa Major ................ 89

Valley of Cashmere............ 279

Vampires ................... 244

Van Dyke, Henry . . . . . . . . . . . 8o, 9I

Vapor, water . . . . . . 852, 853,862, 864

Vega ................903, 904, 906

Velvet Plant, American . . . . . . . . 584

Venus ...................... 906

Vetches, the................. 654

Violet, The .............. 5 5 I5

Canada white............. 5 I 7

Common blue. . . . . . . . . . . 5 I6

Long-spurred . . . . . . . . . . . . . 5 I5

Virgil................... 48,748

Virgin, the (constellation) . . . . . . 912

Vitriol, blue ............825,826

Wadsworth ............267,750

Wait, M. C................67

Wake-robin . . . . . . . . 506, 508,509

Walton, Isaac . . . . . . . . . . . . I49, I 54

Wasp.................. .429, 437 Jug-builder and nest. . . . . . . . . 431 Mud-dauber. . . . . . . . . . . 429,430 Yellow Jacket . . . . . . . . . . 432,434

Wasp-nest, with side removed . . . . . 457 nest of carpenter. . . . . . . . . 440 nest of mud-dauber. . . . . . . . . 429 Yellow-jackets.......... . 432, 435

Water, crystallizing of ......... 853 forms of ............ 850,854

Water-glass .................... 830

Water-lily . . . . . . . . . . 545, 546,547

Water-vapor........852, 853, 862, 864

Weasel .................. 43

Weather, the ............... 857 U.S. Bureau . . . . . . . . . 875 value of service............ 876

Weather-maps: How to read ....... 879 where published and how obtained

$\ldots \ldots \ldots \ldots \ldots \ldots \ldots \ldots 75,876$

Weather-maps, forecasts based on... 875 showing eastward progress . . . . . 884

Weather-forecasting, principles of... 875

Weather signals, explanation of . . . . . 88 I

Weeds ..................... 594 outline for study of . . . . . . . 595
Wheat ............. $\begin{array}{r}\text { Page } \\ 85\end{array}$

cause of winter-killing ............. 855

White, Gilbert. . . . . . . . . . . 48

Whitman, Walt. . . . . . . . . . . . . 484

Whittier, J. G . . . . . . . . . . I64, 683

Whitney, Eli .............. 667

Wildflower Study . . . . . . . . . . 496

Willow .........765, 766767 768, 769 cone-gall ............ 362, 767

Wilson, Wilford M . . . . . . . . . 857

Wilson, Robert B. . . . . . . . . . . . . 856

Winds of the World. . . . . . . . . 866, 867

Trade ............... 87 I

Trade northeast. . . . . . . . . . . 866

Temple of, at Athens. . . . . . 857, $85^{8}$

Window-pane in winter. . . .85 I, 852, 854

Winter Rosettes, evening primrose. . 533 Mullein ............... 584 Teasel . . . . . . . . . . . . . . 588

Wister, Owen. . . . . . . . . . . . 277

Witch-hazel .....356 810, 811812,8 I 3

Wolf, gray . . . . . . . . . . . 255

Woodchuck or groundhog . . . . . 229, 230

Wood grain . . . . . . . . . . . . 729, 730

Woodpeckers, carpenter. . . . . . . . . 75 Downy . . . . . . . . . . . 69, 70

Hairy . . . . . . . . . . . . . . 69

Flicker, yellow hammer or goldenshafted ............77, 80

Red-headed .............. 75

Sapsucker................. 73

Woolly-bear. . . . . . . . . . . 326, 327, 328

Wordsworth..... 329, 5 I 5, 602, 647, 659

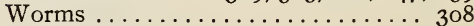

Army ............... 82

Canker ................ 92

Caraway ................... 319

Cut ...............82,92

Earth ................. 462

Glow .................. 417

Wire ............. 82,417

Xenon ................. 862

Yard-ell ...................896

Yellow bird $\ldots \ldots \ldots \ldots \ldots \ldots \ldots \ldots \ldots .4249$
Yellow-jacket $\ldots \ldots \ldots \ldots \ldots \ldots .432,433$

Zephros................. 858

Zodiac and its signs..........9I I, 912

Zone of twilight in mid-winter. . . . . 864 




\section{Date Due}

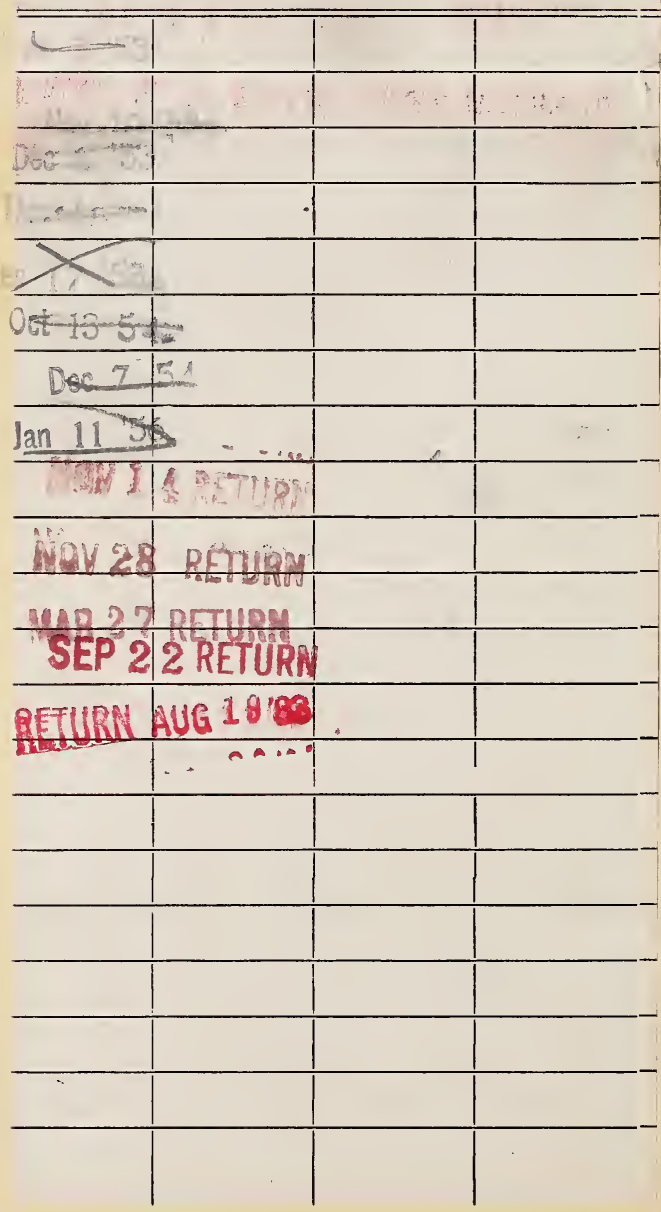


OH 53 . C73 $\mathrm{C}=2$

COMSTOCK ANNA BOTSFORD

$1854=1930$

HANDBOOK OF NATURE-STUDY FOR

39447930 CURR HIST

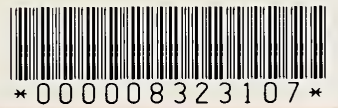

$$
\begin{aligned}
& \text { QH } 53 \text { C73 C. } 2 \\
& \text { Comstock, Anna Botsford, 1854-1930 } \\
& \text { Handbook of natura-study for } \\
& \text { teachers and perents; } \\
& - \text { J } 39447930 \text { CURR } \\
& \text { C. }
\end{aligned}
$$

CURRICULUR

HISTORICAL

COLLOA 
